\title{
Christian Utz
}

Musical Composition in the Context of Clobalization

New Perspectives on Music History of the 20th and 21st Century 
Christian Utz

Musical Composition in the Context of Globalization

Music and Sound Culture | Volume 43 
Christian Utz is Professor of Music Theory and Analysis at the University of Music and Performing Arts Graz and an associate professor at the University of Vienna. He directed the FWF-funded research projects "A Context-Sensitive Theory of Post-tonal Sound Organization" (2012-2014) and "Performing, Experiencing and Theorizing Augmented Listening" (2017-2020). 
Christian Utz

\section{Musical Composition in the Context of Globalization}

New Perspectives on Music History in the 20th and 21st Century

translated by Laurence Sinclair Willis

[transcript] 
Translation, copy-editing, and open access publication of this book are kindly supported by the Austrian Science Fund FWF and the University of Music and Performing Arts Graz

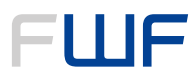

Der Wissenschaftsfonds.

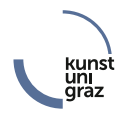

Revised and expanded edition

Original edition:

Christian Utz, Komponieren im Kontext der Globalisierung. Perspektiven für eine Musikgeschichte des 20. und 21. Jahrhunderts, Bielefeld, transcript, 2014

Bibliographic information published by the Deutsche Nationalbibliothek

The Deutsche Nationalbibliothek lists this publication in the Deutsche Nationalbibliografie; detailed bibliographic data are available in the Internet at http://dnb.d-nb.de

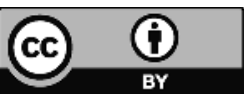

This work is licensed under the Creative Commons Attribution 4.0 (BY) license, which means that the text may be be remixed, transformed and built upon and be copied and redistributed in any medium or format even commercially, provided credit is given to the author. For details go to http://creativecommons.org/licenses/by/4.0/

Creative Commons license terms for re-use do not apply to any content (such as graphs, figures, photos, excerpts, etc.) not original to the Open Access publication and further permission may be required from the rights holder. The obligation to research and clear permission lies solely with the party re-using the material.

\section{First published in 2021 by transcript Verlag, Bielefeld (c) Christian Utz}

Cover concept: Kordula Röckenhaus, Bielefeld

Cover illustration: Kazuko Takada plays a reconstructed five-string ancient Chinese zither in Yūji Takahashi's Unebiyama (1992) (photo: Takashi Kijima). Reproduced in Toshirō Kido, Reconstructed Music Instruments of Ancient East Asia, edited by the National Theatre of Japan. Tokyo: Japan Arts Council/Ongaku no tomo sha 1994. The rights to the cover image could not be clarified beyond doubt, despite our efforts. We request that the publisher be notified if necessary.

Copy-editing by Wieland Hoban

Typeset by Jan Gerlach

Printed by Majuskel Medienproduktion $\mathrm{GmbH}$, Wetzlar

Print-ISBN 978-3-8376-5095-2

PDF-ISBN 978-3-8394-5095-6

https://doi.org/10.14361/9783839450956

Printed on permanent acid-free text paper. 


\section{Table of Contents}

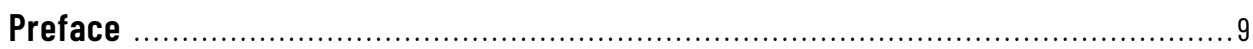

Preface to the Revised and Expanded English Edition ...................................... 11

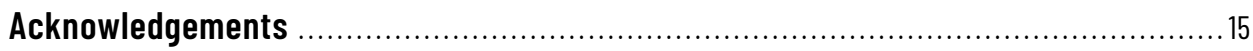

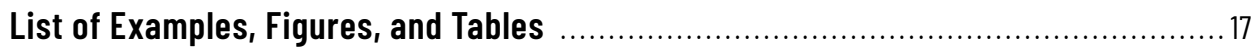

I. Introduction: Art Music, Identity, and Reflexive Globalization ......................... 25

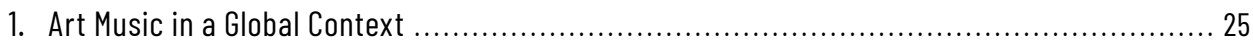

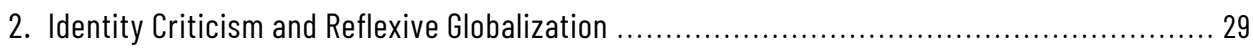

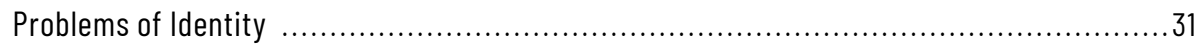

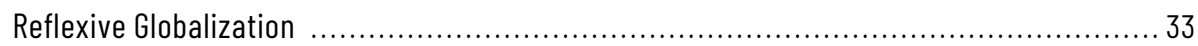

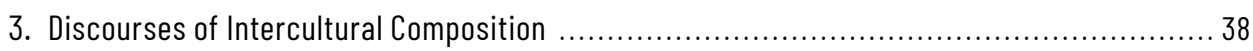

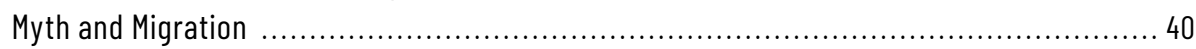

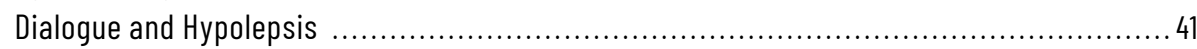

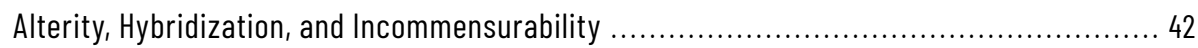

II. Toward an Entangled History of Twentieth-Century Music in a Global Context ...... 47

1. Preliminaries of an Intercultural Music Historiography ............................................. 47

Models of Music Historiography and the Critique of Universal History .............................. 50

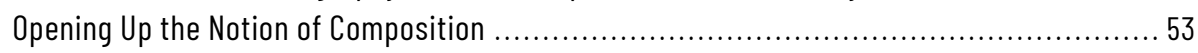

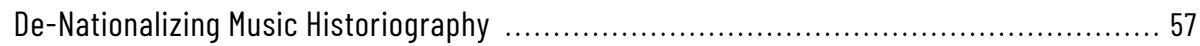

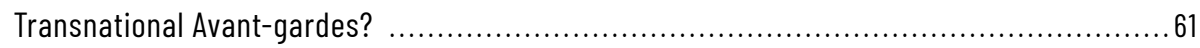

2. Internationalism and Universalism: Repercussions of Political and Cultural History ............6 63

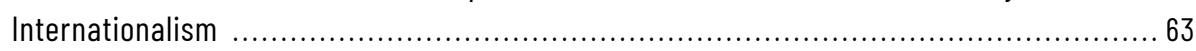

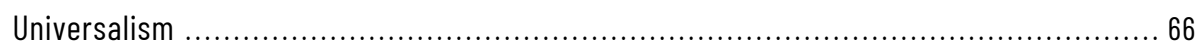

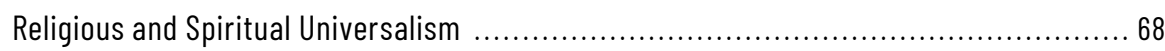

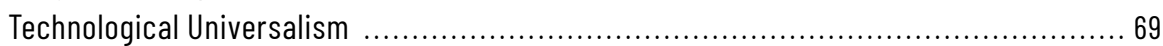

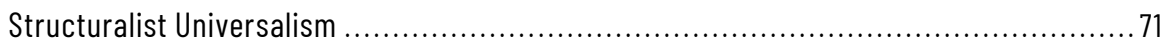

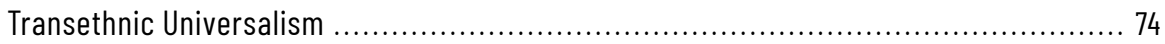


3. The Ambivalence of the Local in Twentieth-Century Music 75

Stravinsky and Bartók: Construction and Criticism of National Music

in the Tension Fields Between Composition and Ethnography ................................. 75

Localism in Chinese New Music Since the 1980s ............................................ 78

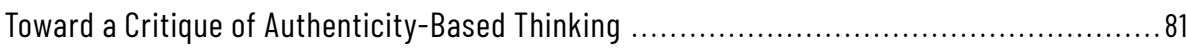

4. Modernist Reception of Japanese and Indian Traditional Music

between 1910 and 1945: Delage, Cowell, Mitsukuri, and Hayasaka ................................ 82

Maurice Delage: Close Listening to Asian Traditions

and the Emancipation from Exoticism ................................................. 83

Henry Cowell: Toward Cultural Hybridity ................................................... 93

Shūkichi Mitsukuri and Fumio Hayasaka: Between Modernity and Nationalism .................. 101

5. Re-Reading the Impact of the "Cultural Cold War" on Music History:

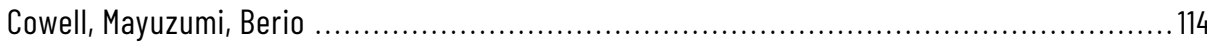

Postwar Music History and the "Cultural Cold War" ............................................ 114

Henry Cowell, Toshirō Mayuzumi, Luciano Berio

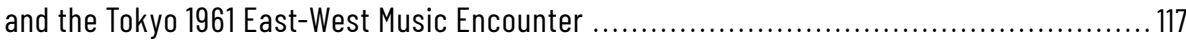

Henry Cowell and the Project of Hybridization ..................................... 122

Toshirō Mayuzumi: Reception of Modernism and Neo-Nationalism ....................... 126

Luciano Berio: Collage Technique with "Suppressed Political Overtones"? ................. 129

6. Categories of Intercultural Reception in Western Composition ............................... 135

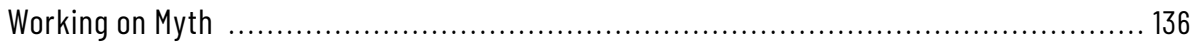

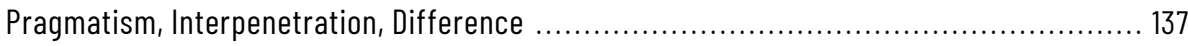

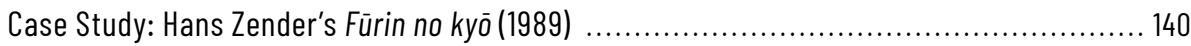

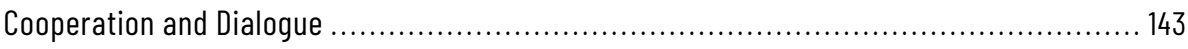

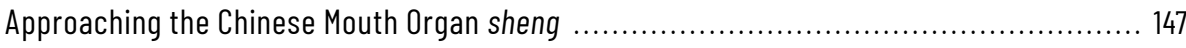

III.Studies on the History and Analysis of New East Asian Music .......................... 155

1. The Reception of Western Modernism in the Music

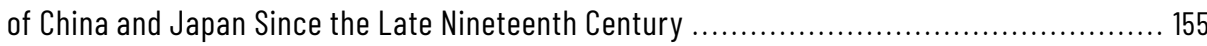

2. Triggering Musical Modernism in China:

The Work of Wolfgang Fraenkel in Shanghai Exile .............................................. 167

Wolfgang Fraenkel's Development as a Composer and Path to Exile ............................ 168

Fraenkel's Activities as Musician, Pedagogue, and Composer in Shanghai ..................... 172

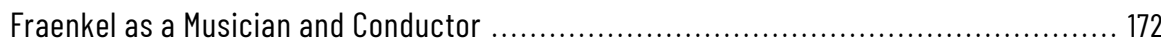

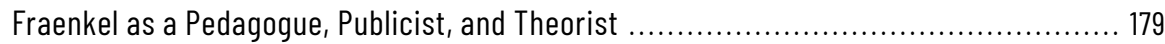

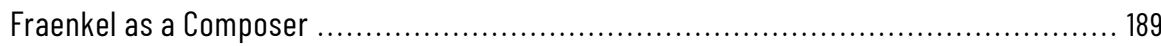

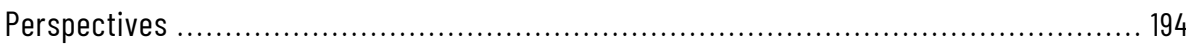

3. The Travels of a Jasmine Flower: A Chinese Folk Song, Its Prehistory

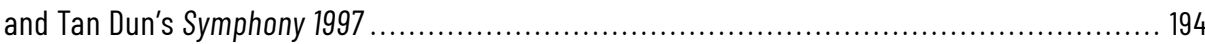

4. Probing the Compositional Relevance of Cultural Difference:

Key Tendencies of East Asian New Music Since the 1950s ....................................... 206

Culturalist Polarization in Isang Yun's Music ............................................ 207 
November Steps (1967), Distance (1972), and Tōru Takemitsu's Enactment of Alterity .......... 212

José Maceda's Sound Masses and the Search for an Anti-Causal Logic ........................ 215

Ge Ganru's Yi Feng (1983) and the Liberation from Culturalist Categories .......................223

Yūji Takahashi: Attentive Listening and Social Interaction .................................... 225

Discussion ........................................................................... 233

5. Intercultural Narrativity in East Asian Art Music since the 1990s ................................235

New Chinese Music Between Essentialism and Cultural Conflict ...............................2236

Polarizing Essentialism: Tan Dun .............................................................. 237

Pluralistic Essentialism: Qin Wenchen and Guo Wenjing ....................................238

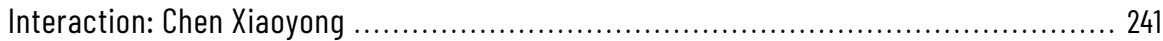

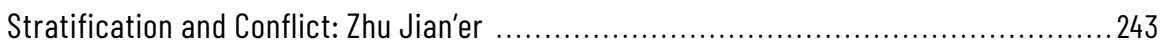

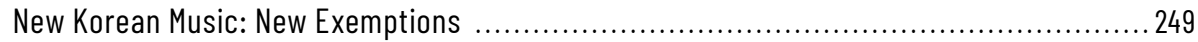

Sublation of Traditional Practice: Eun-Hye Kim, Jin-Hi Kim ............................... 251

Liberation from Culturalism: Bonu Koo, Kunsu Shim ........................................ 254

Tendencies in Japanese Music Around the Millenium:

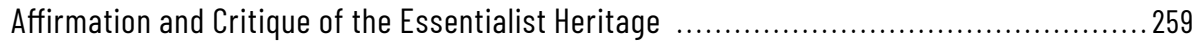

Conclusion: The Limitations of Musical Narrative in an Intercultural Context ...................262

6. The Impact of Traditional Music on Composition

in Taiwan since the Postwar Period .263

The General Conditions of Contemporary Music in Taiwan and the Implications

of its Historical Development since 1950

Problems of Taiwanese Cultural Identity and the Two-Pronged Discourse

of Traditional and Contemporary Music 268

Taiwan's Small Avant-Garde During the 1970s and After -

The Works of Lee Tai-Hsiang, Hsu Po-Yun, and Pan Hwang-Long ................................269

Conservatism and Reinvention of Traditions since the 1980s ................................ 281

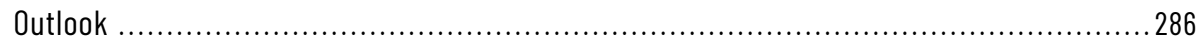

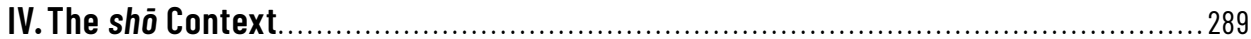

1. Transformation and Myth Criticism in Works for the Japanese Mouth Organ .....................289

The Japanese Mouth Organ in the Traditional Context ........................................ 289

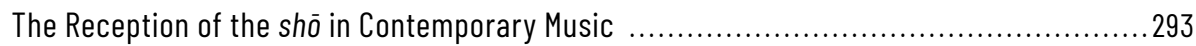

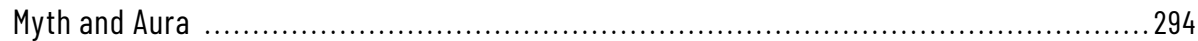

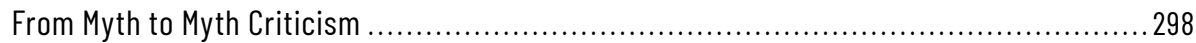

2. The shō as a Medium of Alterity and Self-Referentiality

in Helmut Lachenmann's Music ............................................................ 308

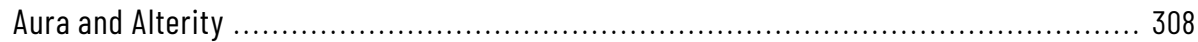

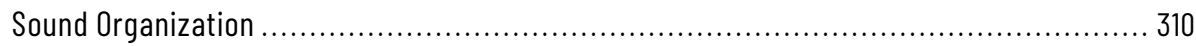

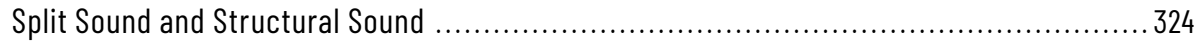

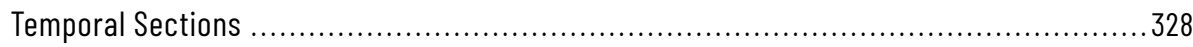

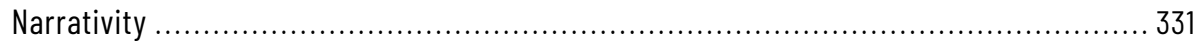

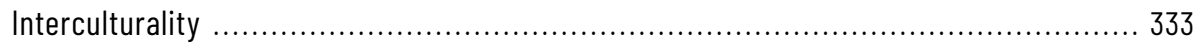


1. The Rediscovery of Presence: Intercultural Passages Through Vocal Spaces Between Speech and Song...... .337

The Voice in Twentieth- and Twenty-First Century Music .337

Articulation and Codification of the Voice:

Thresholds and Interactions Between Speech and Song ...... .342

Fragmentation and Montage (gidayū-bushi, Tan Dun, Schoenberg) ...............................346

Incantation, Prosody, Ritual (Shimoyama, Takahashi, Peri, Sciarrino) ........................... 353

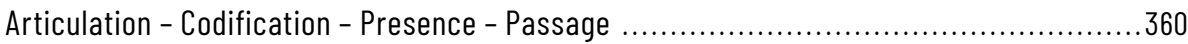

2. Space-Time Movements in György Ligeti's Piano Concerto:

Polymeter and Conflicting Meter in Historical and Intercultural Perspective ................... 363

György Ligeti's "Space-Time" and the "Generalized Hemiola" ...................................... 363

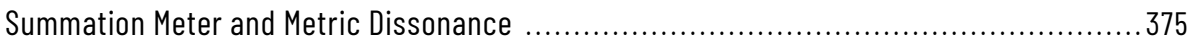

Toward an Intercultural Theory of Musical Time and Its Historiographic Implications .........382

3. Intercultural Tension in Music by Chaya Czernowin and Isabel Mundry:

Variations on Identity and Musical Meaning

Chaya Czernowin's Excavated Dialogues - Fragments:

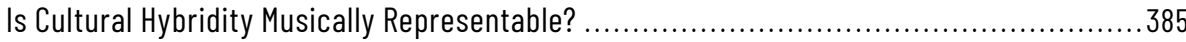

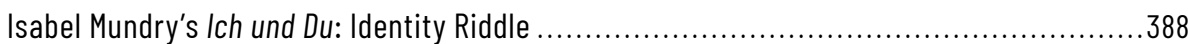

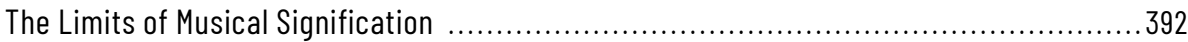

VI. Reflections on My Own Composing as a Search for Traces in the In-Between.......393

1. Layered Fabric, Intertextuality, and Cultural Context:

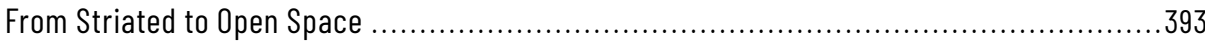

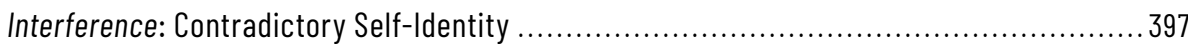

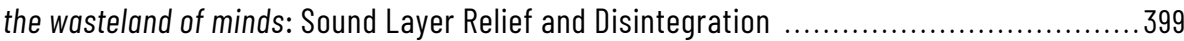

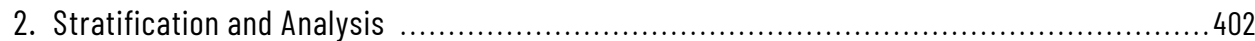

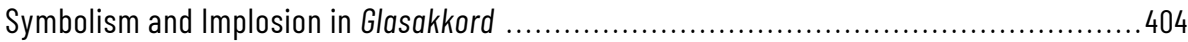

together//apart: Reconstruction, Recomposition, and Irritation ................................408

3. Intercultural and Multilingual Trajectories of the Human Voice ....................................... 411

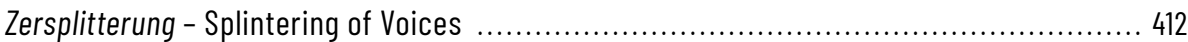

Exploration of Tone Spaces and Political Narrativity in telinga - mulut ........................... 417

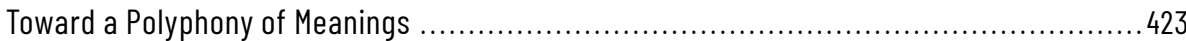

4. Composition as Polyphony: Creating, Performing,

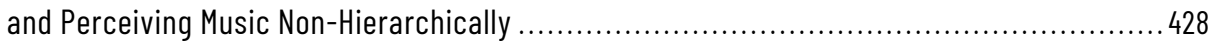

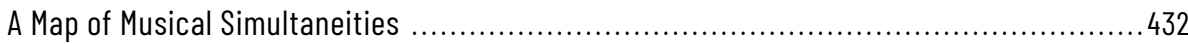

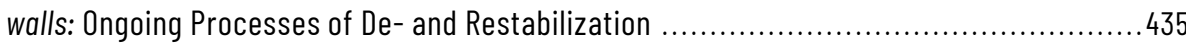

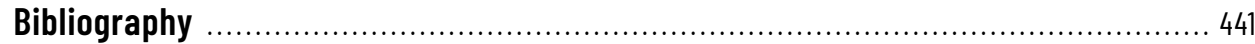

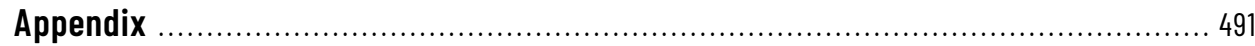

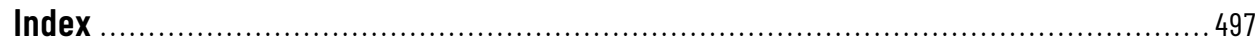




\section{Preface}

In the public debate, the relevance of the topics of musical interculturality and musical globalization seems to have faded in many places, to be replaced by a technology-centered media discourse that shows little interest in conventional notions of culture and emphasizes the permeability, performativity, and mutability of interconnected concepts of identity. In this context the idea of globalization, influenced by the model of popular musics, which have always been "global" in their orientation and increasingly determine musicological discourses, has all too often been restricted to the economic spectrum of meanings that once spawned it; what is of interest here is less a play with or problematizing of established cultural identities, whose significance is fairly marginal in the mainstream, or the worldwide dissemination of particular idioms or genres of pop, which is often taken for granted, than a grown market of consumers that was opened up by the new distribution possibilities of the internet - a situation that seems to fundamentally change the general reception of music far beyond these popular genres.

Against this background, insisting not only on a concept of interculturality but also on an art music discourse must therefore appear doubly quixotic, a clinging to long-questionable, paling categories, especially if this shows a tendency to presuppose the critical - "culture-critical" - impulse of art that was allegedly only brought forth by the "special path" of Western aesthetic modernity. But, one could respond, is it even necessary to emphasize that the concern cannot be to transfer a "purely Western" concept of art (assuming this can be constructed in the first place) to other cultural and geographical contexts, or must we do away with the misconception that the concept of "interculturality" is predicated on an obsolete, isolationist "container model" of cultures? Such questions, which certainly demand more than simple answers, are examined in detail in Chapter 1 of this book.

A desire to point not only to such "false dichotomies," but also to impulses in a musicological field that - with a few exceptions - can still be considered a blind spot in musicology and music theory, but also compositional practice, was sufficient motivation to undertake the studies presented here, written over the last twelve years following the publication of my 2000 dissertation under the title Neue Musik und Interkulturalität. Von John Cage zu Tan Dun in 2002. These studies have been brought together in a thoroughly revised, refocused, and reconsidered state. Most texts could, in the widest sense, be understood as excursuses on the previous book: they were meant to close certain gaps inevitably left by the earlier study, despite its considerable length, and also to expand the range of historical-analytical research methodologically and, to a limited extent, geographically. The relationship between East Asia (China, Taiwan, Japan, and Korea) and the West (Europe and North America) continues to play a central part, as 
in Neue Musik und Interkulturalität, but is augmented through the inclusion of several other local contexts (Africa, the Philippines, Indonesia, and the Arab world).

Many of the compositional trends discussed in this book are characterized by a growing reflexivity vis-à-vis compositional methods and aesthetic positions toward the two opposing tendencies in cultural globalization: on the one hand, owing to an often hasty reception of European music in Asia, Africa, or Latin America, there are unmistakably clear tendencies toward a worldwide standardization of compositional practice according to Western criteria, seemingly continuing the effects of colonial power structures to the present day. On the other hand, the composition of art music and the discourses awakened by it often act as important triggers for movements of self-determination and liberation in non-Western countries - though equally as tools of pure nationalism, oppression, and exclusion. In the six chapters, I attempt to interpret such "paradoxes" of producing music in the globalized tension field against the background of contemporary historical developments, culture-political and culturesociological situations in their many layers of meaning. The argumentation also attempts to open up perspectives on the problem of a consistently globally conceived music historiography $\rightarrow$ II.1) and compositional practice, but can perhaps also offer individual suggestions for answering the question of how cultural techniques and processes of globalization can, beyond the realm of music, fundamentally be understood and interpreted more precisely. In this context, the attempt to incorporate music-analytical, culture-scientific, and sociohistorical approaches serves the purpose of breaking through the methodologically one-sided application of these research paradigms found all too often in musicological disciplines. An additional expansion of methodology comes from the fact that essays on the author's own "culturally fluctuating" compositional projects are included in the final chapter, albeit understood as a supplement and an art-specific, in many ways irreducible extension of the argumentation, not as the artistic "realization" of a theoretical model.

Needless to say, the present study does not purport to offer any concise historiography or universalist historical conception. "Perspectives" on music history are meant in the sense of selected, disparate snapshots of the tightly interwoven music histories of the West and East Asia, and certainly not a comprehensive consideration thereof. Thus, in contrast to the broadly conceived overview chapters in Neue Musik und Interkulturalität, I have refrained here from attempting to show any form of representative selection of compositional conceptions with the greatest possible stylistic range from a bird's eye view, as it were; rather, I attempt to thematize exemplary sonic thought in which the fault lines of cultural, historical, or aesthetic discourses become audible and appreciable. The studies presented give particular weight to the prehistory and early history of intercultural musical reflection $\rightarrow$ II.3-4, III.2-3) as well as to recent developments of the last two to three decades ( $\rightarrow$ II.6, III.5, IV-VI). 


\section{Preface to the Revised and Expanded English Edition}

Musical interculturality and intercultural composition have been addressed as concepts somewhat more often in music studies in recent years. Many of these scholarly activities emerge from the globalizing and transnational dynamics whose preconditions and musical consequences form the core of this book. A motivation shared by scholars working in this area is surely what Tobias Janz and Yang Chien-Chang have termed "Decentering Musical Modernity" in their volume of collected essays, edited by transcript in 2019, which reconsiders more recent concepts of historical analysis such as "multiple modernities" and "entangled histories" for musicology, concepts which have also been influential for the newly added and revised parts of the present book. ${ }^{1}$ Although we have been now aware for some time that gender, racial, social, historical, and cultural biases surround research and teaching of music history and music theory in multiple ways, the actual musical repertory tackled in research projects, publications, and theory and history classes often remains restricted to works of the Western, white, and classical canon. Recently, in a plenary talk first given in 2019 at the Plenary Session of the Annual Conference of the Society for Music Theory (SMT), Yayoi Uno Everett distinguished two main issues to be addressed in what she describes as "counter-framing the East-West binary": "a greater inclusion of this [non-Western] repertory into the canon and [...] diversifying methods of analysis." Indeed, against the backdrop of political upheavals in the USA, recent activities within the SMT have prompted a group of theorists to publish an "Open Letter on Antiracist Actions Within SMT" which criticized "the structural force of white supremacy in our discipline." According to the letter, "we all need to ask ourselves: What have I done as an individual to perpetuate existing white supremacist systems of power and inequity in our field?" The situation is further reflected by the 2020 publication of Philip A. Ewell's article "Music Theory and the White Racial Frame" in Music Theory Online, also first presented as a plenary talk at the 2019 Plenary Session of the Annual Conference of the SMT, an article that broadly reflects on the deep and long-established cultural, social, and racial processes of exclusion in our disciplines. ${ }^{4}$

Some of the original impulses that sparked my interest in what is presented in this book had been similar observations, although they might have appeared somewhat less pressing or violent in the European context twenty years ago. On the one hand, the narrowness of reper-

1 Janz and Yang, Decentering Musical Modernity.

2 Everett, "From Exoticism to Interculturalism."

3 "Open Letter on Antiracist Actions Within SMT,"

https://docs.google.com/document/d/1pneo6DbjDt-ume06]Mtc5fljpbLDkMZgw3mRFOrRepE.

4 Ewell, "Music Theory and the White Racial Frame." 
toire studied at music academies and during musicology programs at universities was all too obvious during the late 1990s and early 2000s, when even the impulses of Anglophone critical musicologies could hardly be felt. The continuous isolation of ethnomusicological and historical branches of musicology contributed (and arguably still contributes to some degree) to this unsatisfactory situation. Well into the new millennium, intercultural composition was denounced in German-language music journalism as an escape into "distant illusory worlds" or an arrangement of "stolen ideas and objects."

This made it increasingly obvious to me that the very reality of interculturality in musical life, past and present, was something that gnawed at some hidden point as a critical voice in the ear of the purely academically Western-trained and oriented composer, music theorist, or music historian. The tendency toward global standardization of compositional idioms based on models of a "historical avant-garde" legitimized by Western musical history ultimately contradicts this aesthetic reality, as does the geographically ubiquitous commercialization and banalization of traditional music genres.

While culture and identity have been acknowledged as key areas of popular music studies for some time, an intensified examination of the consequences, aporiai, and potential of cultural globalization in the historical and analytical interpretation of new art music not only seems to be urgent, but has become the only conceivable standard for a present in which "cultures" are in an unprecedented process of transformation, mixing, and overlap - but also (still) in confrontation with one another. Recent writings on intercultural composition and the historical processes it involved and involves have taken up this challenge hands-on during the seven years since the original edition of this book appeared, showing how transnational meetings and associations such as the Darmstadt International Summer Course (since 1946), ${ }^{6}$ the Asian Composers League (founded in 1973), ${ }^{7}$ or the Dutch Musicultura Meetings (since 1974) ${ }^{8}$ increased the interconnectedness and awareness of globalized forms of music-making in the context of the Cold War. However, as Hilary Vanessa Finchum-Sung explains, "insider/outsider dichotomies have remained foundational to the reception and interpretation of compositions by non-European, non-U.S.-American composers into the new millennium." ${ }^{\prime \prime}$ The conclusion drawn from this, as formulated by Yang Chien-Chang, namely "to avoid the East-West binary opposition, so that a more entangled web of the history can be revealed,"10 is shared by the studies presented here. They also demonstrate that the earlier focus of many composers and scholars on the musical materialization and reception of cultural difference has given way to increasingly complex forms of ambiguity, ${ }^{11}$ not least in relation to new processes of migration and cultural multiplicity that feed into a continuous decentering, readjusting, and sometimes reaffirming of identity concepts in and through music.

Although the present book attempts neither a history nor a theory of intercultural music in the twentieth and twenty-first centuries in an all-encompassing sense, the revised and expanded edition strives to demonstrate the potential of entangled historical perspectives more

\footnotetext{
5 Boehmer, "Clobalisierung als heimischer Fetisch," 44 ("in ferne Scheinwelten [...] fliehen," "Arrangeur geklauter Ideen und Objekte").

6 See Caitano, "Intercultural Perspectives in the International Summer Courses for New Music."

7 See Yang, "Technologies of Tradition in Post-War Musical Avant-Gardism."

8 See Langenkamp, "Close Encounters of Another Kind."

9 Finchum-Sung, "Foreword: Aesthetics of Interculturality in East Asian Contemporary Music," 8.

10 Yang, "Technologies of Tradition in Post-War Musical Avant-Cardism," 43.

11 See Lee, "Postcolonial Affect" and Lee "Introduction: From Difference to Ambiguity."
} 
comprehensively than the original German edition, especially in the newly added Chapters II.2, II.4, and II.5. While many of the added parts include a broader approach combining institutional, sociocultural, and analytical perspectives, the core methodology pursued in most chapters may be described as a "bottom-up" focus on what has been called "artistic agency," including reflections on performance, perception, and reception. Many intercultural musical processes discussed in this book emerged from grassroots projects without much institutional support, sustained by the composers' and the performers' shared enthusiasm for the area. The observation that a "re-negotiation of new cultural spaces" in intercultural composition is often based on "intimate artist-to-artist, musician-to-musician collaborations"13 and requires a community of dedicated listeners describes unstable preconditions that cannot be taken for granted today or in the future. This makes it obvious that within the often socially and institutionally marginalized sphere of contemporary music, intercultural composition may easily be considered an ephemeral and peripheral phenomenon. It is implied in this book's multiple narratives that, on the contrary, composers who have continuously scrutinized the cultural and historical prejudices of our listening provide models of musical interculturality that should be valued as key elements of a globalized music-historical process. Certainly, the book's most important aim is to suggest a change in focus by bringing these new geographies, new protagonists, and new ideas to the center of historiographical attention. Installing these composers as key figures of a grand "world music history," however, would likely fail to grasp the fragmented, fluctuating, and decentered musical cultures of the past century, as outlined in Chapter II. A more moderate implication of the research presented here, then, might be that all music is in a fundamental sense intercultural, and that the hybrid or composite character of the historical constructs of "Western" or "non-Western" music today and their long history continuously demand new perspectives in music research as well as in composition, performance, and listening, perspectives that challenge and discard long-held stereotypes and canonized thinking.

Vienna, 17 September 2020

12 Finchum-Sung, "Foreword: Aesthetics of Interculturality in East Asian Contemporary Music," 16.

13 Ibid. 



\section{Acknowledgements}

In total, 41 different publications laid the groundwork for the present book, with the main articles forming the background of the original German edition of 2014 supplemented by six more recent ones. The Appendix offers a list of these publications. At this point, I would like to express my sincere thanks to all colleagues and friends who have helped me to pursue my research, and who have inspired me and provoked my imagination and scholarly as well as artistic activity. Significant discussions emerged during the long processes of translation by Laurence Willis and copy-editing by Wieland Hoban (who also made important contributions to the translation at an earlier point), and I extend my deepest gratitude for their long and continuous efforts to manage the considerable amount of text to be interpreted (and, in that process, reconsidered and updated). I am also grateful for additional research material and comments on chapters of the revised edition provided by Yayoi Uno Everett, Sophie Fetthauer, John Winzenburg, Lin-Ni Liao, and Nancy Yunhwa Rao. In addition, three anonymous reviewers made valuable comments and suggestions on how to improve the content and scope of the book.

Major research contexts, conferences, collaborations, and valuable discussions that have found their way into the book involved a large number of scholars including Hermann Gottschewski (University of Tokyo), Frederick Lau (The Chinese University of Hong Kong), John Winzenburg (Hong Kong Baptist University), Kam Lap-Kwan and Tung Chao-Ming (National Chiao-Tung University Hsinchu, Taiwan), Pan Hwang-Long (Taipei National University of the Arts), Lo Kii-Ming (National Taiwan Normal University), Wang Yingfen and Yang Chien-Chang (National Taipei University), Hee-Sook Oh (Seoul National University), Jia Daqun and Yang Yandi (Conservatory of Music Shanghai), Jörn Peter Hiekel (Hochschule für Musik Dresden), Tobias Janz (University of Bonn), Claudius Torp (University of Kassel), Sophie Fetthauer (University of Hamburg), Minari Bochmann (University of Leipzig), Barbara Mittler and Dorothea Redepenning (University of Heidelberg), Walter-Wolfgang Sparrer (Berlin), Albrecht Riethmüller (Free University of Berlin), Federico Celestini (University of Innsbruck), Nina Polaschegg (Vienna), Yayoi Uno Everett (University of Illinois at Chicago), Sandeep Bhagwati (Concordia University), Nancy Yunhwa Rao (Rutgers University), Martin Scherzinger (NYU Steinhardt), Philip V. Bohlman (University of Chicago), Anna Maria Busse Berger (University of California Davis), Nicholas Cook (University of Cambridge), Jonathan Stock (University College Cork), Luciana Galliano (Universitá Ca' Foscari di Venezia) as well as Lin-Ni Liao, Jean-Yves Bosseur (Paris), and François Picard (Université Paris-Sorbonne, Paris IV). Also, many important conversations with colleagues at the University of Music and Performing Arts Graz including Peter Revers, Gerd Grupe, Christa Brüstle, André Doehring, Deniz Peters, and Andreas Dorschel, as well as many students in the music theory and $\mathrm{PhD}$ programs, sparked new ideas and perspectives. 
I am equally deeply indebted to all colleagues, musicians, ensembles, and organizers who helped me to develop, create, and realize my own musical ideas, including Chai Found Music Workshop (Caifeng Yuefang) Taipei, the Contemporary Music Ensemble Korea, PHACE (formerly ensemble on_line, Vienna), Simeon Pironkoff (Vienna), Lars Mlekusch (Zurich), Martin Lindsay (Cologne), Kō Ishikawa (Tokyo), Qin Wenchen (Central Conservatory of Music Beijing), Wu Wei (Berlin), Yeh Jiuan-Reng (Taipei), Hong Wen-Tsien (Vienna), Jong-Ah Yoon (Singapore), Dirk Rothbrust (Cologne), Xenia Xienyue Groh-Hu (Berlin), William Lane (Hong Kong), the late Jack Body and Michael Norris (New Zealand School of Music/Victoria University of Wellington), Tony Prabowo (Jakarta), Matthias Osterwold (Berliner Festspiele), the late Reinhard Oehlschlägel (Deutschlandfunk Cologne), Giselher Smekal (Austrian Broadcasting Corporation Vienna) as well as Gerhard Stäbler and Kunsu Shim (EarPort, Duisburg/Düsseldorf).

I am grateful to transcript for taking on the revised English translation of this book after producing the original German edition so beautifully. In addition, I must thank the Austrian Science Fund (FWF) for its generous financial support of the translation and open access publication, as well as the Graz University of Music and Performing Arts for additional funding. Oren Vinogradov kindly assisted in the formatting and proofreading of the lengthy bibliography and the footnotes, Dimitrios Katharopoulos offered his help in reformatting the musical examples, and Dieter Kleinrath again provided his assistance in putting together the index. Last but not least, I am deeply grateful for all the love and support I have received from my family and close friends over the years.

A few closing remarks: Asian names are rendered in the order first name, family name for Japanese and Korean names (Tōru Takemitsu, Isang Yun), but in the more common reverse order for Chinese and Taiwanese names (Tan Dun, Pan Hwang-Long). Exceptions are made where a common order differs from this system, as in the case of the Korean poet Ko Un. In the bibliography, all names are of course ordered alphabetically according to family names. The date of last access to internet links in footnotes and bibliography has not been specified for each link for reasons of readability. All weblinks have been checked and updated as of 2 February 2021. 


\section{List of Examples, Figures, and Tables}

Example 2.1: Guo Wenjing, She Huo, rehearsal number 6

Example 2.2: Guo Wenjing, She Huo, rehearsal number 26

Table 2.1: Chronology 1875-1965 of the institutions, works, and articles discussed in this chapter

Example 2.3: Maurice Delage, Ragamalika (version for voice and piano, 1914), final section

Example 2.4: Maurice Delage, Sept Haï-kaïs (1923/24), no. 5: "La lune d'automne...," piano version

Example 2.5: Maurice Delage, Sept Haï-kaïs (1923/24), no. 5: "La lune d'automne...," orchestral version, final part

Example 2.6: Henry Cowell, Atlantis, first movement, mm. 1-14

Example 2.7: Shūkichi Mitsukuri, Bashō kikōshū (1930/31), no. 2: "Uma ni nete" (I slept on my horse)

Example 2.8: Shūkichi Mitsukuri, Bashō kikōshū (1930/31), no. 6: "Shizukasa ya" (The stillness)

Example 2.9: Fumio Hayasaka, Piano Pieces (Piano shōhin shū), no. 11

Example 2.10: Fumio Hayasaka, Four Unaccompanied Songs to Poems by Haruo (Haruo no shi ni yoru yottsu no mubansō kakyoku) (1943/44), no. 1: "Uguisu"

Table 2.2: $\quad$ East West Music Encounter Conference, Tokyo 17-22 April 1961, Program and List of Participants

Example 2.11: Henry Cowell, Ongaku, first movement - pitch structures

Example 2.12: Toshirō Mayuzumi, Bugaku, part 1, mm. 1-5 (vln. 2)

Example 2.13: Luciano Berio, Sinfonia, rehearsal number AA

Example 2.14: Hans Zender, ChiefJoseph, Act I, Scene 2b

Table 2.3: Hans Zender, Fürin no kyō; four versions of the Ikkyū poem Fūrin in Japanese, English, German, and Chinese (standardized transliteration: Modified Hepburn and Hanyu Pinyin)

Example 2.15: Hans Zender, Fürin no kyō, mm. 182-193, soprano part and schematic representation of the language structure of the first stanza

Example 2.16: Hans Zender, Fürin no kyō, mm. 194-196

Example 2.17: Jorge Sánchez-Chiong, Teatro Shanghai-Bühnenmusik, second movement: Descarga for sheng and Chinese ensemble, mm. 911-913

Example 2.18: Sandeep Bhagwati, Illusies van harder en zacht for viola and sheng, I, mm. 13-23

Example 2.19: Simeon Pironkoff, Fall/Wende for sheng and accordion, I, mm. 1-5; III, mm. 40-42

Example 2.20: Wolfgang Suppan, Studie II for sheng and live-electronics, section 1 
Example 3.1: He Luting, Buffalo Boy's Flute (Mutong duandi), mm. 1-11

Example 3.2: Zhu Jian'er, Second Symphony op. 28, rehearsal number 16+3-6: main theme with the underlying words weishenme, weishenme zheyang, weishenme zheyang dou ("Why? Why so? Why is it such a struggle?")

Figure 3.1: $\quad$ Letter from Wolfgang Fraenkel to Arnold Schoenberg, 14 September 1949

Figure 3.2: Fraenkel's portrait in the newspaper preview of the Shanghai Songsters' concerts, 18 and 20/2/1941 (The Shanghai Sunday Times, 2/2/1941)

Figure 3.3: Program booklet for the concert at the Lyceum Theater Shanghai, 01/03/1946; Fraenkel conducted the China Symphonic Orchestra

Table 3.1: Concerts 1939-1946, in which Wolfgang Fraenkel participated; lit. est., ANA 496, Sch. 5, "Programme" and "Zeitungsartikel und Kritiken"

Table 3.2: Wolfgang Fraenkel's students in China

Example 3.3: Sang Tong, Yejing for violin and piano, p. 1

Example 3.4: Sang Tong, Zai na yaoyuan de difang for piano, p. 1

Example 3.5: Wolfgang Fraenkel, Drei zweistimmige Praeludien, p. 1

Figure 3.4: Wolfgang Fraenkel, calligraphy from the appendix to the Drei Orchesterlieder; the poem "Spring Night" (Chun xiao) by Su Dong-Bo (Su Shi) is shown, which is set in the first movement; left: the English translation of each individual character is placed on the Chinese characters using transparent paper; right: calligraphy without transparent paper

Example 3.6: Wolfgang Fraenkel, row analysis in the appendix of the score of Drei Orchesterlieder: first line: prime twelve-tone row; below: row forms and variants used in the movements 1 to 3

Example 3.7: Wolfgang Fraenkel, Drei Orchesterlieder, no. 2 "Am frühen Frühlingstage," score, mm. 25-27

Table 3.3: $\quad$ Molihua, overview of sources, transcriptions, and editions

Example 3.8: Nine Versions of Molihua, a. Kambra 1795 (based on Hüttner's transcription 1793/94), b. Barrow 1804 (Hüttner's transcription 1793/94), c. Ambros 1862 (source: Irwin 1797; *: A4 instead of B4 in third edition 1887, also in Irwin 1797), d. van Aalst 1884; e. Fassini-Camossi's music box (1920; recorded in the 1970s); f. Puccini, Turandot (1920-24), Act I, rehearsal number 19 (boys choir); g. gong chepu transcription (Chinese solmisation notation) from 1821 (after Qian, Zhong guo jingdian minge jianshang zhinan, vol. 1, 103), h. modern transcription of the folk song from Jiangsu province (after ibid., 101), i. Tan Dun, Symphony 1997, I. Heaven, mm. 129-143 (children's choir)

Example 3.9: Molihua - "imperial" version: harmonizations by Puccini (Turandot, Act I, rehearsal number 48) and Tan Dun (Symphony 1997, I. Heaven, mm. 115-119)

Table 3.4: Molihua, different versions of the song text (pinyin transliteration)

Table 3.5: $\quad$ Polarization of Korean and European music in Isang Yun's radio program "Musik und Instrumente des alten Korea" (1963)

Example 3.10: Tōru Takemitsu, Distance for oboe and shō, p. 5-6

Example 3.11: Iannis Xenakis, Pithoprakta for string orchestra, two trombones, and percussion, p. 10

Example 3.12: José Maceda, Pagsamba for 241 performers, II. "Gloria / Luwalhati," Opening Example 3.13: José Maceda, Udlot-Udlot for 6, 60, 600 or more performers

Example 3.14: José Maceda, Suling, Suling, mm. 266-269 
Example 3.15: Ge Ganru, Yi Feng for Violoncello solo; newly edited version of the handwritten score from 1983, p. 1-2

Example 3.16: Yūji Takahashi, Koto nado asobi; "koto," model A

Example 3.17: Yūji Takahashi, Koto nado asobi; “-- nado asobi” for any instruments; models

Example 3.18: Yūji Takahashi, Tori mo tsukai ka, orchestra model 1

Example 3.19: Yüji Takahashi, The Song of the Blue Sword, Section Di

Example 3.20: Yūji Takahashi, Sangen sanju for shamisen, beginning

Example 3.21: Qin Wenchen, $\mathrm{He}-\mathrm{Yi}$, rehearsal number 5

Example 3.22: Guo Wenjing, Ye Yan, Scene 1, entrance aria of Hong Zhu (soprano), accompanied by the pipa

Example 3.23: Chen Xiaoyong, Invisible Landscapes for zheng, piano, percussion and ensemble, m. 42

Example 3.24: Chen Xiaoyong, Speechlessness, Clearness and Ease, mm. 32-39

Example 3.25: Zhu Jian'er, Sixth Symphony, third movement, left: after rehearsal number 15; right: before rehearsal number 19; Tape I: upper system: song of the Yi girls; lower system: Naxi song (above: women, below: men)

Example 3.26: Eun-Hye Kim, Kayagum, III, mm. 14-19

Example 3.27: Jin-Hi Kim, Nong Rock for kŏmun'go and string quartet, I. Nong, mm. 1-5

Example 3.28: Bonu Koo, nah/fern for kayagŭm (upper system) and string trio, mm. 1-14

Example 3.29: Bonu Koo, nah/fern for kayagŭm (upper system) and string trio, mm. 154-160

Example 3.30: Kunsu Shim, cello/hören (I), excerpt

Example 3.31: Kunsu Shim, Luftrand for string trio, violin part, part A, no. 16-24

Example 3.32: Toshio Hosokawa, Koto-Uta for singer and koto, rehearsal number 4

Example 3.33: Yūji Takahashi, Nasuno kasane, excerpt

Table 3.5: Three generation groups of Taiwanese composers

Example 3.34: Lee Tai-Hsiang, Yunxing sanbian, III, staff systems 1-2

Example 3.35: Lee Tai-Hsiang, Yunxing sanbian, I, staff system 6

Example 3.36: Lee Tai-Hsiang, Da Shenji, II, Chengren li (Initiation Ritual), mm. 37-45

Example 3.37: Lee Tai-Hsiang, Da Shenji, III, Qi ge (Worship), voices, mm. 55-63

Example 3.38: Hsu Po-Yun, Zhongguo xiqu mingxiang, p. 27

Example 3.39: Hsu Po-Yun, Han Shi, p. 2

Example 3.40: Pan Hwang-Long, String Quartet no. 3, IV, mm. 144-147

Example 3.41: Pan Hwang-Long, Wujing, qingjing, yijing, mm. 27-29

Example 3.42: Lee Tzyy-Sheng, Wang guo shi I, mm. 80-83

Example 3.43: Tung Chao-Ming, Formosa, II. Wudao, m. 63

Example 3.44: Tung Chao-Ming, Formosa, I. Fangwu luocheng ge, p. 6

Example 3.45: Tung Chao-Ming, Die Gesichter des Buddha, p. 20

Example 4.1: Pitches playable on the shō; the diamond noteheads indicate the pitches that are only available on the modern instrument and are not used in traditional music.

Example 4.2: Schematic presentation of the eleven aitake chords of the shō in traditional tōgaku repertoire

Example 4.3: The beginning of the shō part in the famous piece Etenraku (in the mode hyōjo) from the togaku repertoire with the characteristic position changes known as te-utsuri (Miki, Nihon gakki hō, 79)

Example 4.4: Fingering table of the 17-pitched shō (Kō Ishikawa) 
Example 4.5: Toshio Hosokawa, "Wie ein Atem im Lichte" for shō solo, opening

Example 4.6: Toshio Hosokawa, Landscape $V$ for shō and string quartet, harmonic reduction and pitch-class set analysis

Example 4.7: Klaus Huber, black plaint for shō and percussion, p. 8

Example 4.8: Gerhard Stäbler, ]LIFE[ for shō, hichiriki and glass chimes, III, ending

Example 4.9: Chaya Czernowin, Die Kreuzung for $\bar{u}$, alto saxophone, and double bass, beginning of section $\mathrm{C}$

Example 4.10: Yüji Takahashi, Mimi no ho, score pages shō (left) and viola (right); under the instructions for the viola player (section C) one finds the final sho glissandi with which the piece ends

Example 4.11: Yūji Takahashi, Sōjō rinzetsu for one or two shō, part 2; right: transcription in Western notation by the composer

Example 4.12: Above: beginning of the shō part of Etenraku (in the hyōjō mode; transcription after Miki, Nihon gakki hō, 79); below: Helmut Lachenmann, Das Mädchen mit den Schwefelhölzern, scene 23: Shō, shō part, mm. 544-556

Example 4.13: Above: chord progression otsu-bō-jü-ge-otsu from Etenraku; below: Lachenmann, Das Mädchen mit den Schwefelhölzern, scene 23: Shō, shō chords, mm. 516-518, 540 , each with a graphic representation of the fingerings and fingering changes

Example 4.14: Helmut Lachenmann, Das Mädchen mit den Schwefelhölzern, scene 23: Shō, analysis of the $s h \bar{o}$-sound fields; upper line: chord progression (gray highlights: quartal/quintal structures); lower line: analysis of the sounds according to pitch-class sets (white noteheads: whole tone segments)

Example 4.15: Helmut Lachenmann, Das Mädchen mit den Schwefelhölzern, scene 23: Shō, simplified score reduction (without dynamics and articulations), mm. 508-539

Example 4.16: Helmut Lachenmann, Das Mädchen mit den Schwefelhölzern, scene 23: Shō, simplified score reduction, mm. 540-582

Example 4.17: Helmut Lachenmann, Das Mädchen mit den Schwefelhölzern, scene 23: Shō, simplified score reduction, $\mathrm{mm}$. 583-646

Example 4.18: Helmut Lachenmann, Concertini: analysis of the central sounds in the final section; first row: pitch sum with interval structure in semitones; second row: sequence of entries (below in brackets: included triads or four-note chords); third row: pitch content (pitch-class sets); fourth row: fifth/fourth structures

Example 4.19: Helmut Lachenmann, Concertini, mm. 697-701

Example 4.20: Helmut Lachenmann, Concertini, mm. 697-701, reduction of instrumental groups

Example 4.21: Spectral analysis of the traditional shō chord $b \bar{o}$, ordered according to loudness of the spectral components (duration of the sound: 5.532 seconds; source: CD of Miki, Nihon gakki hō); values above the notes denote the loudness in sone (average over the entire duration of the sound)

Example 4.22: Spectral analysis of the final chord of Lachenmann's Concertini (m. 699), comparison of the recordings by Ensemble Modern (2006, above) and Klangforum Wien (2009, below)

Table 4.1: $\quad$ Helmut Lachenmann, Das Mädchen mit den Schwefelhölzern, scene 23: Shō, analysis of temporal divisions

Table 4.2: Helmut Lachenmann, Concertini, final section, analysis of temporal divisions 
Table 5.1: Gradation of the areas between spoken voice and singing by George List with placement of the examples discussed by List

Table 5.2: Gradations between speech and song in the four most important vocal genres of traditional Japanese music using Hirano's classification of ginshō, rōshō, and eishō

Example 5.1: The three vocal delivery techniques shirakoe, kudoki, and sanjü in transcriptions of the heikyoku piece Suzuki (performer: Tsutomu Imai; transcription:

Komoda, Heike no ongaku, 404-417)

Example 5.2: Hanji Chikamatsu, Imoseyama onna teikin (Mount Imo and Mount Se. A Parable of Female Virtue). Section from the scene Yama no dan (Mountain Scene), based on a performance by Sumitayū Takemoto, recitation, and Kizaemon Nozawa, futozao shamisen

Example 5.3: Tan Dun, Silk Road for soprano and percussion, 3, systems 1+2

Example 5.4: Tan Dun, Marco Polo. An Opera within an Opera, Scene Sea; Part "Water," mm. 35-70

Example 5.5: Different instructions for voice articulation in Arnold Schoenberg's Pierrot lunaire op. 21, no. 3: Der Dandy, mm. 6-11, 15-20, 30-31

Example 5.6: Hifumi Shimoyama, Monolog for shamisen and vocal soloist, p. 4, systems 1-3

Example 5.7: Hifumi Shimoyama, Breath for three voices, two percussionists, and piano, five vocal articulations (a-e) from pages 3, 13, 11, 2, 7 of the score

Example 5.8: Yūji Takahashi, Unebiyama for five-string zither and incantation, p. 1

Example 5.9: Salvatore Sciarrino, Luci mie traditrici, variants of the "sillabazione scivolata": [a]-[c] scene 1, Il Malaspina (baritone), mm. 15, 17, 29-30; [d], [e] scene 8, La Malaspina (soprano)/Il Malaspina (baritone), mm. 67-69, 83

Example 5.10: György Ligeti, Concerto for Piano and Orchestra, third movement, mm. 1-9

Example 5.11: György Ligeti, Concerto for Piano and Orchestra, third movement, mm. 83-85, layers

Example 5.12: György Ligeti, Concerto for Piano and Orchestra, third movement, mm. 71-76, piano solo/xylophone

Table 5.3: $\quad$ György Ligeti, Concerto for Piano and Orchestra, third movement, mm. 71-76: pulse layers, data in sixteenth note values ( ${ }^{*}=$ offset), ostinato pulses marked in bold

Example 5.13: György Ligeti, Concerto for Piano and Orchestra, third movement, mm. 71-76, accent layers in three registers A, B and C; wedges: common accents piano and xylophone; circles: accents xylophone (without piano)

Table 5.4: György Ligeti, Concerto for Piano and Orchestra, third movement, mm. 71-76, accent layers in three registers A, B and C, represented on the basis of an adapted Time-Unit Box System (TUBS), developed by Philip Harland

Example 5.14: György Ligeti, Concerto for Piano and Orchestra, third movement, mm. 71-76, resulting rhythms of layers $\mathrm{A}$ (left) and C/B (right); accents: common accents piano/xylophone; circles: impulses xylophone

Example 5.15: E Juba - beginning of a popular song from South Sudan (transcription: Gerhard Kubik; Kubik, "Musikgestaltung in Afrika," 36)

Example 5.16: Tan'b'oloko se? - song from a fairy tale of the Yoruba, West Africa (transcription: Gerhard Kubik; Kubik, "Musikgestaltung in Afrika," 37)

Table 5.5: Representation of Example 5.15 in the Time-Unit Box System (TUBS); metric periodicities of the patterns are marked by changing gray levels 
Table 5.6: $\quad$ Pulse speeds and metric patterns in Example 5.15

Table 5.7: Representation of Example 5.16 in the Time-Unit Box System (TUBS); metric periodicities of the patterns are marked by changing gray levels

Table 5.8: $\quad$ Pulse speeds and metric patterns in Example 5.16

Table 5.9: $\quad$ Categories of metric dissonance in Classical-Romantic music

Example 5.17: Chaya Czernowin, Excavated Dialogues - Fragments, second movement, a. mm. 1-3 (string instruments); b. mm. 7-19 (bangdi/oboe);

c. mm. 37-42 (tutti)

Example 6.1: Christian Utz, Interference, first movement: chord structure of the sheng

Example 6.2: Christian Utz, Interference, third movement, p. 26

Figure 6.1: Structural grid of rhythmic periods for Christian Utz, the wasteland of minds, mm. 1-20

Example 6.3: Christian Utz, the wasteland of minds, tuning of the zheng. The accidentals marked with an arrow indicate a retuning of the pitch by 30 cents (higher/ lower). In the score (see Ex. 6.5), the other parts with the same notation show a quartertone offset (+/- 50 cents).

Example 6.4: Christian Utz, the wasteland of minds, compositional sketches of the harmony

Example 6.5: Christian Utz, the wasteland of minds, mm. 43-45 (end of the first section)

Example 6.6: Christian Utz, Glasakkord, mm. 1-17, shō part; chord progression: 7-2-2 pitches

Example 6.7: Christian Utz, Glasakkord; "glass chords" of the strings obtained by spectral analysis of glass sounds

Example 6.8: Christian Utz, Glasakkord; "glass chords" of the strings: realization in the score, mm. 1-7

Example 6.9: Christian Utz, Glasakkord, mm. 151-155

Example 6.10: Sangnyŏngsan from the Yŏngsan hoesang suite (Korean court music): first verse, $k \bar{k} k$ 2+3 (Anthology of Korean Traditional Music, vol. 5, edited by National Classical Music Institute, Seoul, n. d.)

Example 6.11: Christian Utz, together//apart, mm. 4-6

Example 6.12: Christian Utz, together//apart, mm. 84-87

Example 6.13: Christian Utz, Zersplitterung, first interlude (p. 5), reference of Saeya, saeya (whistled by the pianist)

Example 6.14: Transcription of pyŏng sijo by Chang Sa-hun, "Art Song." In Survey of Korean Arts - Traditional Music, Seoul 1973, 194 (quoted in Reese, "Gattungen des Kunstliedes," 106)

Example 6.15: Christian Utz, Zersplitterung, beginning of the second part (p. 6)

Example 6.16: Christian Utz, Zersplitterung, second interlude; breakage of the glass plate (p. 11).

Table 6.1: Christian Utz, Zersplitterung (2002), Libretto

Table 6.2: $\quad$ Christian Utz, telinga - mulut (ears - mouth) (2009)

Example 6.17: Christian Utz, telinga-mulut, tone systems

Table 6.3: Christian Utz, telinga-mulut, synopsis. Line numbers for the poem refer to the English translation (see Table 6.2), although the verse structure differs from that of the Indonesian original in some instances.

Example 6.18: Christian Utz, telinga-mulut, beginnings of sections A1 (mm. 1-6), A2 (mm. 72-79), A3 (mm. 186-192), A4 (mm. 238-243)

Example 6.19: Christian Utz, telinga-mulut, section B2, mm. 177-185 
Example 6.20: Christian Utz, telinga - mulut, section A4.2, mm. 275-282

Figure 6.2: Christian Utz, the wasteland of minds, mm. 1-8, sonagram and rudimentary transcription; the graphic elements suggest four different modes of listening: "analytical" (small gray boxes and dotted lines), "holistic" (large black box around the entire sonagram excerpt), "cue-oriented" (arrows and vertical lines), and "presentist" (mid-size gray boxes)

Figure 6.3: A map of musical simultaneities

Example 6.21: Anton Webern, Symphonie op. 21, second movement, variation V; the structural model explored in Utz, walls for ensemble and electronics

Example 6.22: Christian Utz, walls for ensemble and electronics, opening, mm. 1-9

Example 6.23: Christian Utz, walls for ensemble and electronics, beginning of the closing section, mm. 144-151 



\section{Introduction: Art Music, Identity, and Reflexive Globalization}

\section{Art Music in a Global Context}

Simon Rattle's assessment that the future of "classical music" lies in China, made on the occasion of the Berlin Philharmonic's China tour in 2005 that Rattle conducted, ${ }^{1}$ may be taken as a jumping-off-point for the re-examination of the now over one-hundred-year history of the reception of Western music in Japan, China, and Korea from new perspectives that can help answer obvious questions: how did this seemingly high esteem for European art music in East Asia come about? Against which historical, political, and social dynamics did this development take place? And can it really be assumed after critical examination that, in fifty or one hundred years, East Asian artists will dominate "classical music" globally?

Of course, the unquestioning reference to the concept of "classical music" already makes one suspicious: "The categories of autonomously oriented art have no applicability to the contemporary reception of music; not even for that of serious music, domesticated under the barbarous name of classical so as to enable one to turn away from it again in comfort."2 It is probably not wholly unnecessary to point out the ongoing relevance of this statement from 1938 by Theodor W. Adorno. The trend to use the music industry label "Classical Music" as a seemingly neutral technical term in several recent music-sociological publications correlates with an unwillingness to allow for multifaceted interpretations of musical works, or to grant them the potential of provoking independent meaning. ${ }^{3}$ The codification of a canon of European and North American symphonic, opera, vocal, chamber, and solo repertoire (roughly from Bach to Mahler) is thus accepted without reservation, along with the exclusion of large parts of twentieth-century

1 Rattle expressed this at a press conference in China as part of the tour. See Spahn, "Der lange Marsch zu Beethoven."

2 Adorno, "On the Fetish-Character in Music and the Regression of Listening," 289. ("Die Kategorien der autonom intendierten Kunst sind für die gegenwärtige Rezeption von Musik außer Celtung: weithin auch für die der ernsten, die man unter dem barbarischen Namen des Klassischen umgänglich gemacht hat, um sich ihr weiter bequem entziehen zu können." Adorno, "Über den Fetischcharakter in der Musik," 15.)

3 See especially the review of the book Jungmann, Sozialgeschichte der klassischen Musik, in Zehentreiter, "Anatomie des Bildungsbürgertums." Michael Custodis gives a comprehensive history of the concept and its definitions. Yet, he also uses it over broad passages in a way that is (too) little differentiated. In particular, it is not sufficiently clarified that "classical music" has long been one of those "common buzzwords" that are based on "market strategies of the recorded music industry," which is how Custodis characterizes the term "crossover" (Custodis, Klassische Musik heute, 19). A nuanced discussion of the concept is presented in Kramer, Why Classical Music Still Matters. 
art music. ${ }^{4}$ Even when more recent composers are considered for admission to this "Classical" canon, this inevitably happens within the relatively narrow framework of value criteria and listener expectations dominated by the canon. Music that deliberately challenges the conventions of such a canonized listening (or, in Helmut Lachenmann's terminology, breaks away from the flow of habit-oriented "listening" [Zuhören] to an existential "hearing-in" [Hinhören] $)^{5}(\rightarrow$ IV.2) has no real place in this concept of musical future - even if such a fragility of listening may undoubtedly turn itself into an object of canonization, and thus be aesthetically tamed.

The discussion about the process of canonization for Classical-Romantic music and its effects on the present has indeed hardly been addressed at length by representatives and theorists of new music. Undoubtedly, there is also a tendency within new music discourse toward the canonization of certain composers or works arising from the desire to identify structures in the "new obscurity," while at the same time - in all areas of contemporary music - we are confronted with an ever widening and intensifying fragmentation or diversification. ${ }^{6}$ If the deconstructive perspective of globalization is added to this complex situation, the implied problem of "canonicity" becomes particularly acute: Jim Samson aptly argues that "the authority of the canon as a measurement of quality in some absolute sense has proved increasingly difficult to sustain," since "any notion of a single culture, of which the canon might be regarded as the finest expression, is no longer viable."7 The sense of insecurity created by this situation has lately led to numerous attempts at re-canonization, including in the field of contemporary repertoires. Such attempts, however, are usually confined to Western protagonists. Consider, for example, the list of the "100 Classics of Modern Music" (100 Klassiker der modernen Musik) in which the editors of the German weekly Die Zeit did not rank a single Asian, African, or Latin American artist. ${ }^{8}$ Not only does the term "classical music" tend to exclude critical forms of new music, its use is usually implicitly ethnocentric and a priori prevents a substantial expansion and alteration of the repertoire through intercultural hybridization or elementary compositional interventions in tonal system, pitch structure, and musical syntax. That a concept of "classical music" or "classical style" also exists in other musical cultures is certainly not an ar-

4 On the genesis, theory, and critique of the Classical-Romantic musical canon, see, among others, Pietschmann and Wald-Fuhrmann, Der Kanon der Musik, Bergeron and Bohlman, Disciplining Music, Weber, "The History of Musical Canon," Dorschel, "Über Kanonisierung."

5 "Hearing means, in contrast to co-enacting listening: to radically reorient oneself, to have to find new bearings; it means opening up hidden spaces within oneself in tackling unfamiliar structures." (Lachenmann, "Accanto," 169, "Hören heißt im Gegensatz zum mitvollziehenden Zuhören: sich radikal umorientieren, sich neu zurechtfinden müssen, heißt, im Ertasten ungewohnter Strukturen verborgene Räume in sich erschließen.") See also Hamilton, Aesthetics and Music, 95-111.

6 Michael Custodis places this term at the center of his investigation (Custodis, Klassische Musik heute, 9-22).

7 Samson, "Canon [iii]."

8 This is stated laconically in episode 96 of the series: "95 musical classics have already been presented in this series but, as the series is coming to an end, no African (or Asian, New Zealand, Australian) recording has been included. Globalization has not yet led to a truly global view of the cultures of the world." (Groß, "Aus dem Schrein." "95 Musikklassiker wurden in dieser Rubrik bereits vorgestellt, die Serie geht auf ihr Ende zu, doch eine afrikanische [wahlweise auch: asiatische, neuseeländische, australische] Aufnahme war bislang nicht dabei. Die Globalisierung hat eben doch noch zu keinem wirklich globalen Blick auf die Kulturen der Welt geführt.") Related examples abound, such as in Dietrich Schwanitz's successful publication Alles, was man wissen muß (1999), which exclusively contains chapters on European history and art forms, or Dubal, The Essential Canon of Classical Music (2003), in which merely one Asian composer (Tōru Takemitsu) is featured. See Citron, Gender and the Musical Canon for an exclusion of female composers from the musical canon of Classical and Romantic music. 
gument against the unambiguously ethnocentric idea of a "future of classical music in China." There is no doubt here that the "classical" is considered exclusively European in the sense defined above. In addition, it would first be necessary to examine on a case-by-case basis whether designations such as "classical Indian music" or "classical Persian music" actually describe original concepts of canonization in the respective musical cultures or are, rather, premature transfers of (Western-oriented) research. Although there are certainly tendencies in the canonization of certain pieces of music or interpretive schools in virtually all art music traditions, they are usually associated with forms of cultural transmission that fundamentally differ from the Western process of canonization (in the Japanese context, for example, they can be described by the ambiguous binary dentō/denshōo).

Even more problematic in the context of Simon Rattle's account of the future of "classical music" in China or Asia is the implied thesis that - if more is meant than just a new consumer market - future Asian performers will cultivate and maintain the core repertoire in more or less the same way as Western performers have in the past 200 years. Indeed, among contemporary Asian performers of (Western) art music, significant deviations from established paradigms of interpretation seem extremely rare. There are exceptions of course, such as Yüji Takahashi's second recording of the Bach "Goldberg Variations" (2004). While the pianist here applies his decades-long compositional and practical experience with the performance practice of Japanese instruments ( $\rightarrow$ IV.4) to create an exceptionally free and flexible rhythmic representation of Bach's work, such a recording is given little attention at the international level and is certainly too unspectacular on the surface to survive on the "Classical market." ${ }^{10}$ The global concert audience, both in the West and in Asia, is usually fed by far more harmless varieties of a vaguely assumed "Asian identity," such as those featuring star pianist Lang Lang adorned with the stereotype of virtuoso dexterity - in a duo with his father, who played the Chinese two-stringed fiddle erhu, as an encore in his solo recitals. ${ }^{11}$ From a compositional perspective, the Chinese-American composer Tan Dun hits the bull's eye of this new pseudo-traditional Asian future music when, in his piano concerto for Lang Lang (with the additional title The Fire, 2008), he vaguely references the archaic Chinese philosophy of the five elements (wu xing). The composer makes use of simplified Chinese folk tunes cast in the style of Liszt's Liebesträume and Bartók-esque motoric passages as central elements of the composition. In this way, he consciously accepts the association of these features with exotic clichés of Asian sensuality

9 See Ackermann, "Japan," 110. Both terms vaguely signify what is meant by the term "tradition" in Western languages; while dentō implies the concepts of heritage, continuation, and handing-down, denshō additionally connotes the acts of receiving and inheriting traditions. As Ackermann explains, the terms can also be associated with a strong tendency in Japan's traditional culture to preserve (musical) traditions down to the tiniest details in small groups of specialists, which, however, can also imply adapting them to changing circumstances or necessities.

10 Avex AVCL-25026, 2004. Like Glenn Could, Takahashi has recorded the work twice, for the first time in 1976 (newly edited as Denon COCQ-84162, 2006). The aforementioned "Asian" characteristics are much more radical in the second recording than in the first, and are a document of a decades-long examination of the body, instrumental practice, hearing, and sound aesthetics in an intercultural context. See, among others, Takahashi, "Bach as a Failure," and Takahashi, "Two Statements on Music." Takahashi also criticized both of Could's recordings as "an auto-repressive stoicism of North American intellectuals before the Vietnam War" and as "a projection of the Eastern American Puritanism" on Bach's music (review, On-Stage Shinbun, 27/01/1995, translated by Junichi Miyazawa, http://glenngould.org/f_minor/msgo1925.html).

11 See https://www.youtube.com/watch?v=fyJemfohwkU. This is a duo adaption of Huang Haihuai's (1935-1967) virtuoso erhu solo saima (Horse Race, 1964). On the development of the erhu solo repertoire, see Stock "Contemporary Recital Solos for the Chinese Two-Stringed Fiddle erhu." 
or primitiveness. Otherwise, however, the Western genre type of the virtuoso solo concerto is not questioned for one second.

In this book, by considering this contemporary background and interpreting historical developments at the intersection between Asia and the West, I will address the question of what an alternative future of global art music might look like if less blatantly dominated by economic constraints. I consciously replace the concept of "classical music" with that of "art music." In using this term, it must first be asked whether this implies a (too) strong tendency to exclusion, particularly toward forms of popular music. Indeed, it is often said that the future of "classical music" must open up more to contemporary popular music, and popular culture more generally. ${ }^{12}$ Linked to this is an adoption of new forms of presentation and dissemination, allegedly pragmatically embodied in the YouTube Symphony Orchestra (for which Tan Dun composed a five-minute "Eroica" Symphony from Beethoven quotations). ${ }^{13}$ Even if one rejects too close a rapprochement of the "Classical" to popular culture, or believes that such an approach is already more than sufficiently well-established in many places (Beethoven's construction as a star of popular culture is as old as the Beethoven myth itself ${ }^{14}$ ), the question of which concept of art one uses in the formulation "art music" is by no means trivial. For the time being, it may perhaps be stated that a basic conception of "music as an art form" does not a priori make a cultural confinement to a specific concept of art (such as the European one), nor does it necessarily require certain types of transmission (such as written notation) or presentation (such as the "concert"). The first two chapters of this book interrogate these issues ( $\rightarrow$ I.3, II.1).

So, what could an art music of the future look like in which Asian (or other non-Western) performers and composers are not merely vicarious agents of an unquestionable European art and music concept? Where they are not consumers of a museum-like "Classical" market, but where - from diverse perspectives (theories, concepts, or ways of making music as an art form) - traces of a reflexive globalization (more on this concept below) can be recognized? Countless composers from Asia, Oceania, the Arabic world, Africa, Latin America, but also North America and Europe have been seeking answers to such questions for more than a hundred years, though each has faced radically different sociopolitical conditions that have had a lasting effect on the answers.

12 This demand is based on the 2009 study by the TNS Emnid Institute commissioned by the Bertelsmann Foundation: "Asked what needs to change so that more people are interested in classical music, nearly three-quarters of people respond that they want lower ticket prices for concerts and opera performances (72\%), closely followed by a wish for more events that combine classical and pop (71\%)." ("Danach gefragt, was sich ändern müsse, damit sich mehr Menschen für klassische Musikinteressierten, antworten nahezu drei Viertel der Menschen, sie halten niedrige Eintrittspreise für Konzert- und Opernabende für wünschenswert (72 Prozent), dicht gefolgt (mit 71 Prozent) von mehr Veranstaltungsangeboten, die Klassik und Pop verbinden." https://www.bertels mann-stiftung.de/de/presse/pressemitteilungen/pressemitteilung/pid/klassik-und-oper-sind-unverzichtbar)

13 http://www.youtube.com/user/symphony. The debut of the orchestra, which was put together through a selection process via video broadcasts, took place on 15 April 2009 at Carnegie Hall. Tan Dun's Internet Symphony Eroica (http://www.youtube.com/watch?v=w47v5NI5g7Q) was the first composition for this project and served as one of the two compulsory pieces in the selection process. The symphony was recorded in advance on 6 October 2008 by the London Symphony Orchestra conducted by the composer on video and released on 20 November 2008 on YouTube (http://www.youtube.com/watch?v=Tqiro1kdRlw). Thousands of video submissions to the orchestra were later made into a "mash-up" version of the symphony ("The Internet Symphony' Clobal Mash Up," http://www.youtube.com/watch?v=oC4FAyg64OI).

14 For an overview, see the articles "Mythos Beethoven," "Popmusik," and "Rezeption und Wirkung," in Loesch and Raab, Beethoven-Lexikon. 


\section{Identity Criticism and Reflexive Globalization}

An identity developed from artistic positions, despite all cultural "turns" in research, seems the unquestioned foundation for a variety of texts about new art music. They proceed from the basic assumption that the works of individual composers articulate a "distinctive" and "authentic" position. The principle, which references Enlightenment philosophy, of "speaking with one's own voice" - understood since the late eighteenth century as the obligation imposed on each of us "to live up to our originality"15 - is omnipresent in the discourse on contemporary music. It also generally remains the decisive criterion in the education of composers today, which aims for novelty and uniqueness. The crisis of the modern subject asserted by Theodor W. Adorno, Michel Foucault and others, ${ }^{16}$ the poststructuralist critique of the authorial principle and monologic authority, and attempts to highlight the "mixed identities" or "semantic chameleon"17 hidden in musical works of art barely seem to play a part in such a perpetuation of the aesthetics of genius. ${ }^{18}$ With a mixture of obstinacy and helplessness, this adherence to composer-centered hermeneutics opposes their obvious marginalization in favor of performers and events that takes place in the commercialized "classical music" scene.

Musicology and music criticism play a key part in this process of ascription. Writing and speaking about music as well as documenting the processes of its creation and performance ultimately cannot avoid providing or "writing over" sound and musical text with identities of the most varied kinds. The increasingly strong orientation toward cultural studies in music research has sensitized us to the subtexts of such music-related identity discourses: the basic idea that composers, performers, and listeners are acting as part of a "cultural practice"19 implies that their conception of musical sounds and structures is inextricably linked to culturally specific ideas about music. Viewed in a broad historical context, such concepts emerge from a "cultural memory" as described by Aleida and Jan Assmann. The "connective structure" of cultural memory is based on a continued evocation of canonical motifs and ideas within an "extended situation." ${ }^{20}$ It is bound to specific institutions and ritualized forms of public and private presentation and reception as well as the interactions between production, transmission, and reception. ${ }^{21}$ Even if many of these processes of cultural practice are disintegrating in the age of digitalization and globalization, we should not underestimate their ongoing presence in cultural discourse and their tendency to reactivate cultural essentialism.

The conception of music as a "cultural practice" has led many authors to reconsider the particular local context in which musical concepts, ways of thinking, works, or performances are formulated and realized. Thus Annegret Fauser describes the compositional results of Claude Debussy's fascination with West Javanese gamelan saléndro and the Vietnamese music theater form hát bội at the 1889 Paris World's Fair as "a form of appropriation firmly inscribed in the tradition of French music of the 1890s" while emphasizing that Debussy's "structural appropriation" eventually paved the way for many similar reinventions of gamelan in twentieth-century

15 Taylor, Sources of the Self, 37.

16 See Wellmer, "Über Musik und Sprache. Variationen und Ergänzungen," 23-37.

17 Kramer, "Hercules' Hautboys," 149.

18 An extensive critique of this situation is found in Utz, "Musik von einem fremden Planeten?"

19 See Kramer, Music as Cultural Practice, 1800-1900.

20 Jan Assmann, Cultural Memory and Early Civilization, 2-4, 7-8.

21 See Aleida Assmann, Cultural Memory and Western Civilization and Jan Assmann, Cultural Memory and Early Civilization. 
music on a global scale. ${ }^{22}$ Fauser's study sharpens our understanding of the specific cultural and historical context of Debussy's reception of gamelan, but also makes clear that his particular approach points beyond the framework of a historical contextualization limited by, or to, local or national contexts.

The changing "faces" of Debussy indeed demonstrate very clearly how identities in musical discourse are not simply "given" but continuously reshaped and reinvented. Famously, Debussy idealized "Javanese music" as a refined form of polyphony following "a counterpoint that makes Palestrina's seem like child's play," ${ }^{23}$ a form of music that "contained all the nuances [...] where tonic and dominant became naught but vain ghosts for the use of unruly children."24 These statements express serious doubts about what many of Debussy's contemporaries perceived as the unchallenged superiority of Western musical culture over non-Western cultures - whereas Debussy's formulations also transferred elements of the exoticist "noble savage" topos to the context of modernity. ${ }^{25}$ These hints at a culture-critical skepticism did not prevent Debussy from subsequently becoming a key representative of French national music in the run-up to the First World War. Debussy and his increasingly explicit nationalist sentiments played a crucial part in this process, as documented in detail by Barbara L. Kelly. ${ }^{26}$ In this way, while the earlier Debussy decided of his own accord to identify with a counterculture, partly constituted of the culture-pessimistic discourse that characterized the ennui of an entire generation in late nineteenth-century Europe, ${ }^{27}$ Debussy later contributed equally explicitly to the reinvention of an affirmative, essentialist French national style in the early twentieth century. One could name many other cases around 1900 that demonstrate a shift from an ambivalent internationalist to an affirmatively nationalist idiom - or vice versa - including those of Bartók, Stravinsky $(\rightarrow$ II.3), and Sibelius.

Such examples show clearly that on the one hand, identity is the result of a deliberate, considered, and at times strategic choice between several options, while on the other hand, it is closely tied to complex sociological and political entanglements that may make it seem "inevitable" in many cases. In Debussy's case, such entanglements were his close connection to widespread tendencies of cultural pessimism and orientalism as well as the overall trend of re-ethnicization and a nationalist form of pre- and post-World War I cultural essentialism that ultimately led to the extreme polarizations and ideological conflicts of the 1930 s and 40 s.

22 Fauser, Musical Encounters at the 1889 Paris World's Fair, 205.

23 "Yet Javanese music is based on a type of counterpoint compared to which that of Palestrina is child's play." ("Cependant, la musique javanaise observe un contrepoint auprès du quel celui de Palestrina n'est qu'un jeu d'enfant." Debussy, Monsieur Croche et autres écrits, 223. This characterization was published in a retrospective in 1913 in the Revue S.I.M.)

24 Letter to Pierre Louÿs, 22/1/1895, translation quoted after Fauser, Musical Encounters at the 1889 Paris World's Fair, 198.

25 See Locke, Musical Exoticism, 228-238.

26 Kelly, French Music, Culture, and National Identity, 1870-1939, 58-76.

27 See Charle, "Debussy in Fin-de-Siècle Paris." 


\section{Problems of Identity}

So, what are the problems with the affirmative concept of identity that is still invoked so often in today's discourse on recent music? In his seminal text "The Question of Cultural Identity," Stuart Hall names five factors that lastingly decentered the image of a stable self-identity in modernity, ${ }^{28}$ all based on a close intertwining of subject identity and collective identity:

1. Post-Marxist thinkers have abandoned the idea of an "essence" of the modern subject;

2. Freud's and Lacan's psychoanalysis made it unambiguously clear that identity is not a fixed state, but rather a dynamic and never-ending process;

3. poststructuralist linguistics and philosophy indicated that "structured" identities such as those expressed through language always include uncontrollable supplementary meanings;

4. Michel Foucault described the paradoxical relationship between the isolation of the subject and its collective disciplining in the modern era, with particular reference to the repressive character of discourses on identity;

5. theories and social movements of feminism have created a lasting awareness of the gendered layers of the modern subject.

At first glance, the concepts of personal and collective identity, already lastingly destabilized, have been completely abandoned by postcolonial criticism. To state any form of affirmative connection between identity, culture, and ethnicity would raise suspicion of complicity with inherently colonial thought. Viewed against this background, the types of identity offered by strengthened neo-nationalist or pan-national religious, even fundamentalist, "isms" are only seemingly anachronistic: they both react to the same tendencies toward grassroots globalization, ${ }^{29}$ in which local and global processes interact and new communities beyond established nations and cultures are formed. The increasing fragmentation of modern societies, termed "super-diversity"30 by Stephen Vertovec, has in many places sparked the desire for re-territorialization and (re-)ethnicization of identity, extending to a "proliferation and reification of [geographical and mental] boundaries." ${ }^{\text {11 }}$ Today, the traditions that Eric Hobsbawm terms "invented" play a key role in this process, as they have in the construction of national identities for 200 years, as well as in the field of music. ${ }^{32}$

Arif Dirlik shows that it is highly questionable to understand migrants - as paradigmatic as they seem at the present - as the key metaphor of the contemporary world: "The great majority of humankind [continues to] lead settled lives unless pulled or pushed into mobility." ${ }^{33}$ Indeed, it is doubtful whether a convincing connection can be made between the social phenomenon of migration and issues of identity in recent arts discourse. Slavoj Žižek incisively shows that the models of the academic or artist, who is always equipped with an appropriate visa, and the migrant, for whom "hybridity" is a traumatic experience, are incompatible $\rightarrow$ I.3). ${ }^{34}$ Helmut

28 Hall, "The Question of Cultural Identity," 285-291.

29 Appadurai, "Crassroots Clobalization."

30 Vertovec, "Super-Diversity and Its Implications."

31 Dirlik, "Transnationalism in Theory and Practice."

32 Hobsbawm, "Introduction: Inventing Traditions." For an application of this concept to the music history of China see Lau, "Forever Red."

33 Dirlik, "Transnationalism in Theory and Practice."

34 See Žižek, Ein Plädoyer für die Intoleranz, 80-81. 
Lachenmann has pointed out that the composer - embarking on intercultural encounters with a valid return ticket in their pocket - is unable to understand the kind of "security" that the music of other cultures might constitute in its own local setting $\rightarrow$ I.3; IV.2). ${ }^{35}$ In addition, the tendencies of polycultural mixture and hybridity in art and pop culture seem equally toothless: "Obviously, these diverse impulses can be absorbed without remotely threatening the respective societies with descent into an identity crisis. But above all, such a pluralizing and increasingly colorful cultural scene has never threatened, at least not so far, the core of political culture."36 So, in new art music too, one can speak of what Dieter Senghaas calls "globalization deluxe", ${ }^{37} \mathrm{a}$ privileged mode in which the advantages of globalization outshine its problematic side-effects.

Can one, however, conclude from this, as Harry Lehmann suggests, that new music since the postwar period has not known "identity problems" because "otherness" is virtually its basic prerequisite ${ }^{38}$ This would mean overlooking the fact that there is a complex intertwining of music-historical, aesthetic, and compositional discourses that certainly do limit the possibilities to articulate such otherness in specific contexts. One should first of all mention the sustained tendency to suppress the "cultural" element in much new music, which is primarily the legacy of the global political situation after 1945. The institutions for new music in Germany were supported by the allied occupying powers not least with the ulterior motive of installing a supposedly ideology-free area of artistic development as a symbol of political freedom from which no new ideological dangers could result $\rightarrow$ II.5) ${ }^{39}$ In fact, in postwar serialism a special compositional logic was developed that sought to remove any "culturally" encoded language from music. Such techniques were guided by the search for an alternative model to the misuse of the language-like communication of messages in totalitarian political systems. The same sociohistorical background can be seen as informing John Cage's conception of music as "free from likes and dislikes," which can be understood as the result of a basic skepticism toward the values of European schools of thought among American intellectuals in the aftermath of the Second World War ( $\rightarrow$ II.6). Admittedly, Igor Stravinsky's neoclassicism had already been based on a departure from a narrowly defined ethno-national character of the musical language of the Russian nationalist school and his own neo-national works prior to 1917/21. Meanwhile, Béla Bartók ad hered to his concept of hybridity of folk and art music, even if its original neonational components were heavily ruptured by historical events and his overall conception became increasingly universalistically accentuated from the 1930 s on $\left(\rightarrow\right.$ II.3). ${ }^{40}$ Specifically,

35 Helmut Lachenmann in conversation with Rolf Elberfeld and Toshio Hosokawa (Haus der Kulturen der Welt, Berlin, 12/5/2005), quoted in Utz, "Zwischen Mythos und Kooperation," 28, 31. Probably both Žižek's and Lachenmann's arguments can be traced back to Herbert Marcuse's much-disputed 1965 critique of "repressive tolerance" (see Marcuse, "Repressive Tolerance").

36 "[O]ffensichtlich lassen sich diese vielfältigen Impulse absorbieren, ohne daß die betroffenen Gesellschaften auch nur anfänglich in Identitätskrisen zu verfallen drohen. Vor allem: eine sich dergestalt pluralisierende, bunter werdende Kulturszene bedroht nicht, zumindest nicht bis heute, den Kernbestand der politischen Kultur." (Senghaas, "Moderne und Antimoderne angesichts kultureller Clobalisierung," 329.)

37 Ibid., 328-329.

38 Lehmann, "Entfremdung -Verfremdung."

39 See Beal, "Negotiating Cultural Allies."

40 See Brown, "Bartók, the Cypsies, and Hybridity in Music." 
Bartók's approach had a formative effect on decisive developments in art music in Turkey (during the 1920s) and China (during the 1980s). ${ }^{41}$

Of course, the practical implementation of the claim of universalism and self-referentialism in the early 1950 s left much to be desired. Even a superficial look at German-French polarities dating back to the beginning of the century shows this clearly: if the Schoenberg-Debussy relationship was "uptight" in every respect due to complications of historical tendencies ${ }^{42}$ it is also scarcely possible to find commonalities between Pierre Boulez's reception of Antonin Artaud in a work such as the Second Piano Sonata $(1946-48)^{43}$ and the structuralist mysticism of Karlheinz Stockhausen's Kreuzspiel (1951) as supposed "founding moments" of serial thought. And Wolfgang Rihm's neo-expressionist chamber opera Jakob Lenz (1977-78), like the neo-organicist sound-time processes in Gérard Grisey's Les Espaces Acoustiques (1974-85), can hardly be understood outside of their respective nationally specific traditions of expression, time, language, and sound (though neither work can, of course, be reduced to these traditions). These "cultural" dimensions of modern music in Europe, which are closely connected to their institutional establishment, ${ }^{44}$ were barely discussed in European publications until recently. Against such a background, the position that new art music is independent of any "culture," as stated a number of times during the symposium Musik-Kulturen at the Darmstadt Summer Course in 2006, is certainly untenable. "Identity problems" indeed hardly seem to exist in many areas of today's composing - but not least because a firm (re)focusing on specific local European forms of thought, language, and sound is taking place. Since the 1980s, this new cultural isolationism can be interpreted not least as echoing the failure of the explicit cultural universalism of the 1960s, which had been articulated in such works as Stockhausen's Telemusik (1966) or Hymnen $(1965-67)\left(\rightarrow\right.$ II.2). ${ }^{45}$ The unhesitating approach to the "resources" of a diffuse "world music" in these works highlights the fact that a critical compositional reflection on cultural difference must first of all overcome the "self-awareness and sense of mission of the (Western) composer. ${ }^{, 46}$ Until now, however, few have been prepared to take this step with its full implications.

\section{Reflexive Globalization}

Pointing out the diversification of contemporary music has become commonplace in music journalism. There is now an increasing awareness that general patterns of cultural globalization can be identified equally in the social, political, and structural dimensions of an art music whose production and reception take place almost everywhere in the world today. One of these patterns lies in the interdependence of cultural homogenization and cultural particularization: ${ }^{47}$ on the one hand, cultural norms and idioms are subject to a process of standardization largely synonymous with Westernization - expressed in striking buzzwords of globalization

41 See Gertich and Greve, "Neue Musik im postkolonialen Zeitalter," 52-55, Kouwenhoven, "Mainland China's New Music (III)," 85-86, and Wong, "Bartók's Influence on Chinese New Music in the Post-Cultural Revolution Era."

42 See Haselböck, "Debussy und die Wiener Schule."

43 See Zenck, "Artaud-Boulez-Rihm."

44 See Born, Rationalizing Culture.

45 See Utz, Neue Musik und Interkulturalität, 136-171.

46 Wilson, "Die Ahnen des Kolumbus," 18 ("Selbst- und Sendungsbewusstsein[s] des [westlichen] Komponisten.")

47 See Hall, "The Question of Cultural Identity," 273-316. 
theory such as "McDonaldization" ${ }^{\text {"48 }}$ or "Coca-Colonization.."49 In the realm of contemporary art music, this trend is closely linked to an enduring monopoly on professional music education exerted by Western musical institutions as well as the problems posed by the institutionalization of an independent art in non-Western societies. One can observe a leveling-out process: it is often hard or impossible to determine whether a new work has been created by a composer from Cologne, Paris, Milan, Beijing, San Francisco, or Johannesburg. At this point, no concept initially seems more questionable in the music of today than that of a specific local or regional identity, let alone "ethnicity." This skepticism toward the "idiomatic" must undoubtedly be viewed as the legacy of the aforementioned radical critique of music's likeness to language after 1945 .

This situation, however, triggers an understandable compensatory backlash: a search for lasting and emphatic forms of cultural difference that cannot be leveled out by this process of standardization $\rightarrow$ III.4). At the same time, however, it is important to realize that simply opposing homogenizing Westernization and a naïve "back to the origins" movement cannot do justice to the complexity of the situation. Several studies of non-Western contemporary music have emphasized that music which defies the stereotypical patterns of local identity can been seen in the social contexts of Africa, Asia, and Latin America as a resistance against those ubiquitous styles that flatten traditional practices for commercial or political purposes. ${ }^{50} \mathrm{Such}$ ways of accentuating cultural difference in the new art musics of Africa, Asia, and South America are suggestive for an intercultural music history $(\rightarrow$ II.1), but also demand a more precise definition of what cultural difference, alterity, or incommensurability can mean $(\rightarrow$ I.3, II.4).

This seems all the more urgent because ethnomusicology has abandoned its formerly strict concept of authenticity. Now ethnomusicologists often sympathize with forms of popular music that adopt elements from traditional musical practice. Standardizing tendencies inherent in such forms of pop music (defined as "ethnic") are rarely criticized. This is despite their homogenized phrases and regular beats often eliminating precisely the subtle melodic or rhythmic blurring that forms one of the "irritating" layers of cultural difference, and is therefore unsuited to representative or economic purposes. ${ }^{51}$ Overall, forms of standardizing mediation have particularly far-reaching effects in the age of digitalization, including in non-Western practices. Thus, the media-assisted production and dissemination of certain traditional genres can result in a loss of religious or ritual functions, as shown by Gerd Grupe in the case of qawwali music in India and Pakistan. In addition, one can observe a transregional standardization in certain styles of performance that leads to a loss of diversity in regional practices, for example in the karawitan compositions of Javanese gamelan music. ${ }^{52}$

Taking all this into account, then, one should begin by noting that with regard to the dynamics of globalization, global standardization processes and local identity conflicts interact in manifold ways - as Roland Robertson already tried to express in 1995 with the term "glocalization. ${ }^{.53}$ Applied to musical discourses, these dynamics mean first of all that very specific local practices (that cannot be learned or understood without personal, long-term contact) mingle

\footnotetext{
48 Ritzer, The McDonaldization of Society.

49 Kooijman, "Fabricating the Absolute Fake," 34-35, Wagnleitner, Coca-Colonisation und Kalter Krieg.

50 See Scherzinger, "Art Music in a Cross-Cultural Context," 610-611.

51 See the discussion in Dorschel, "Interkulturelle Begegnung als existentielles Risiko," 104-108.

52 Grupe, "Wachswalzen und CDs," 206.

53 Robertson, "Clocalization: Time-Space and Homogeneity-Heterogeneity."
} 
in various ways with the appropriation of "international" practices. This inevitably leads to a process of fragmentation and progressive differentiation.

Naturally, such fragmentation is already implicit in the European concept of modernity, which initiated an increasingly critical form of self-reflection expressed in the concept of a "Second Modernity" or "reflexive modernity." These terms emphasize the irreversibility of globalization processes and urgently thematize the resulting social and societal problems such as mass unemployment, environmental damage, and so forth. ${ }^{54}$ Following on from this at the end of the 1990s, Ulrich Beck described the concept of "reflexive globalization" as a situation in which the current problematic, conflict-laden (environmental or social - but also cultural) effects of globalization can be "reflected upon" and incorporated into new cultural practices.$^{55} \mathrm{He}$ thus rejected, as in the previously mentioned theories of Appadurai, Vertovec, and Dirlik, the basic model of "container theory," in which a dynamic acting from "outside" a clearly delineated territory influences it locally. Instead, reflexive globalization also refers to the formation of new groupings and communities across established (national, cultural, political, or religious) identity boundaries.

Since at least the early twentieth century, such reflexivity has been absolutely essential for understanding musical cultures outside Europe. They have evolved in close, reflexive, and often fractious interaction with European modernity. Thus, during the notorious symposium "Overcoming Modernity" (Kindai no chōkoku) in July 1942 in Kyoto, the Japanese composer Saburō Moroi (1903-1977) ${ }^{56}$ stated that only music that expressed Japanese "spirit" using the means of Western compositional techniques and instrumentation was capable of "overcoming modernity. ${ }^{157}$ This was the slogan of the symposium for the construction of an alternative Japanese modernity that was not meant to be synonymous with "Westernization." Its jingoistic undertones in the context of Japanese military aggression led to sustained criticism of the symposium in postwar Japan. ${ }^{58}$ While those that repeatedly praise the title and content of this symposium have mostly been nationalist Japanese authors, ${ }^{59}$ the realization has spread in the last two decades that a discussion of modernity will remain inadequate without an acceptance of several different, competing "modernities" $" \rightarrow$ II.1).

Moroi's distinction between spirit and technique was a master pattern for the adoption of Western culture in Japan and China as early as the mid-nineteenth century $(\rightarrow$ III.1). It has been incorporated, in a milder form, as part of the cultural essentialism in the aesthetics of many composers in Asia since the 1930s. In the 1960s, Isang Yun, José Maceda, Chou Wen-Chung, and Tōru Takemitsu established - each with their own points of emphasis - a discourse on the "characteristics" of Asian music that specifically aimed to "overcome" the dominance of Western aesthetics $(\rightarrow$ III.4). Such aesthetics had become particularly questionable, not least because of the Second World War. But these composers also sought to integrate key elements

\footnotetext{
54 Beck, "Das Zeitalter der Nebenfolgen und die Politisierung der Moderne."

55 Beck and Zolo, "What Is Clobalization?”; see also Beck, Die Erfindung des Politischen.

56 On Moroi see Galliano, Yōgaku, 73-76, 88.

57 See Minamoto, "The Symposium on 'Overcoming Modernity."

58 This criticism also concerned the philosophers of the Kyoto school participating in the symposium, namely Keiji Nishitani and Shigetaka Suzuki, see ibid.

59 See Hijiya-Kirschnereit, "Leuchtet Japan?"

60 See Eisenstadt, Multiple Modernities and Elberfeld, "Moderne interkulturell."
} 
of Western thought. ${ }^{61}$ Yun and Chou, as migrant composers, faced the challenge of leading this discourse in direct confrontation with Western aesthetic trends.

While their writings and statements showed clear tendencies toward essentialism, ${ }^{62}$ their works, by contrast, often dealt with very specific traditions. Chou's works The Willows are New (1957) and Yü Ko (1965), for example, attempt - with somewhat limited success - to apply performance principles of the ancient Chinese zither qin to Western instruments. ${ }^{63}$ Yun's Réak (1966) transfers the continuous pitch inflections and interwoven lines of Korean court music into sound textures of the Western orchestra. ${ }^{64}$ If such concepts often emphasize alterity in relation to Western musical aesthetic discourse, it should not be forgotten how strongly they were also influenced by Arnold Schoenberg's, Edgard Varèse's, Iannis Xenakis's, and Karlheinz Stockhausen's critiques of tradition and identity in Western modernity.

The brief outline I have thus far presented already suggests that jettisoning the concept of identity entirely on account of the crisis of identity is far too crudely reductive. It has been asserted on various occasions that the music of non-Western contemporary composers ought not only to be discussed against the backdrop of debates of cultural identity, but rather primarily understood and respected as a manifestation of "individual" artistic positions:

New Chinese Music ought to be considered on an international stage, not as a music both exotic and Other, but as a music in its own right, [...] as a music of international import, by individuals, independent of their national descent. [...] the Chineseness of Chinese music need not be considered a matter of course but of individual choice and development. Each of these composers writes his or her own personal music, creating something beyond the traditions (Chinese or otherwise) that are being used. ${ }^{65}$

What is required is to illuminate these international, simply musical aspects rather than persisting in the search - naturally an important one, but no longer indispensable - for Chinese or Asian identity, self-assertion or national style in this music, which, to put it in extreme terms, amounts more to a discrimination against Asian composers and their music. [...] the Asian composer must be able and allowed to define themselves not as an Asian composer, but as an Asian composer. ${ }^{66}$

In fact, this has long been a reality in the music scene. Younger composers such as Unsuk Chin, Dai Fujikura, or Ying Wang pursue exceptionally successful careers, mainly in Western cultural centers. Their international, virtuosic idiom is a guarantee of success, and it seems that if they were to address themes of intercultural rupture and hybridity more explicitly, this success would be hindered rather than assisted. But is it really possible for "cultural" discourse - re-

61 See Utz, Neue Musik und Interkulturalität, 222-311.

62 See for example Chou, "Asian Esthetics and World Music" and Yun, "Über meine Musik."

63 See Utz, Neue Musik und Interkulturalität, 270-277.

64 See Choi, "Réak (1966)."

65 Mittler, "Against National Style."

66 Mittler, "Wider den 'nationalen Stil," 607. ("Diese internationalen, einfach musikalischen Aspekte gilt es zu beleuchten, nicht mehr zu verharren in der [natürlich wichtigen, aber nicht mehr unerlässlichen] Suche nach chinesischer oder asiatischer Identität, nach Selbstbehauptung, nach nationalem Stil in dieser Musik, die, um es extrem auszudrücken, eher einer Diskriminierung asiatischer Komponisten und ihrer Musik gleichkommt. [...]: Der asiatische Komponist muss sich neu definieren können und dürfen, nicht als asiatischer Komponist, sondern als asiatischer Komponist.") 
gardless of a composer's origin and tradition - to be simply ignored in favor of an "individual" perspective? Is it not necessary, rather, to place renewed emphasis on the sociocultural conditions of recent composition and its incorporation into a network of sociocultural transfer of meaning (in the sense of abandoning the music-historical paradigm of "techno-essentialism $\left.{ }^{167}\right)$ ? ( $\rightarrow$ II.1) In this sense, Samson Young makes it clear that the possibility of "culture-free" listening is limited while "cultural identities" continue to be deliberately evoked by composers and their performers alike through appropriately charged signifiers:

If we embrace the view that ethnic identities are constructs, then to what extent are we interested in how cultural signifiers function to reinforce these imaginary categories? [...] Instead of focusing on the degrees to which a signifier is "traditional" or "contemporary," could one not ask why ethnicity is performed when it is not always necessary, and potentially even distracts attention from the music itself? In the case of contemporary Chinese music, if sound can indeed be heard free of cultural contexts [...], then why do composers and analysts continue to invoke culture? ${ }^{68}$

Young has also emphasized that it is precisely the demand for a continuous opposition to cultural essentialism and a culturalist stereotyping of artistic positions that necessitates thematizing questions of "race, ethnicity, culture and politics" time and again:

I don't think of myself as Chinese in some way, but I probably don't believe in, and certainly do not want to play any part in, reaffirming the notion of a singular, unproblematic "China proper": the communist China, the China that sits behind firewalls, the China that suppresses freedom of speech and individual liberty. Artists do not operate in vacuums. Works of art circulate, generating real cultural, social and political consequences. It is my belief that an artist as a free agent ought to reflect upon the values she/he abides by in all acts of creativity [...]. The age [of] globalization demands an intensified level of communicative nuance. In times of conflicts, turbulence and confusion, we need to say more, not less, about issues of race, ethnicity, culture and politics. ${ }^{69}$

Frederick Lau ultimately went so far as to say that the protean (and in parts rather successful) adoption of culturalist identity models by Chinese composers of the "new wave" generation in the USA, since the 1980s, can be considered a symptom of identity construction as a career strategy, much like the pop industry's "superstar syndrome":

In advocating a style that makes use of Chinese elements, the new wave composers are participating in a codified and globalized market in which they are being perceived through their music and the use of Chinese elements. They are clearly capitalizing on Orientalism as expressed in their music and in their own words in order to transgress the boundaries of Western Orientalist discourse with its emphases on difference, othering, and the exotic. Musical exoticism, according to Jonathan Bellman, suggests the strangeness of a specifically alien culture or ethos. The new wave composers are utilizing such a strategy under the aegis of multiculturalism. ${ }^{70}$

67 See Williams, "Of Canons and Context." See also Cook and Pople, "Introduction: Trajectories of TwentiethCentury Music," 4.

68 Young, "Reconsidering Cultural Politics in the Analysis of Contemporary Chinese Music," 607.

69 Young, "Reading Contemporary Chinese Music," 89-90.

70 Lau, "Fusion or Fission," citing Bellman, The Exotic in Western Music, xii. See also Melvin and Cai, Rhapsody in Red, 332-333. 
Positively put, when art music's "identity problems" become genuinely perceptible, reflexive globalization becomes truly relevant. Only then can a new framing and definition of perspective regarding established concepts of identity affect both the - admittedly hegemonic - European discourses on aesthetics and the culture-essentialist and neo-nationalist models in and outside of the West. In the process, the resulting musical situations can produce "cluster identities," "patchwork identities," or "multiple identities," in detail. Thus they can ultimately claim contemporary social relevance after all, albeit from a deluxe position. Against the backdrop of twentieth-century musical and political history, and the overwhelming economization of present times, this reflexivity appears not merely to be the best of many options, but rather a necessity for advanced art music's survival.

\section{Discourses of Intercultural Composition}

The term "intercultural" is intended here to refer to the interaction of two or more cultural discourses - a form of interaction that must inevitably critically question the lines separating "cultural entities." One way to accentuate the processual aspect of intercultural action is developed in this chapter. Further below, I will apply Jan Assmann's concept of "hypolepsis" - understood as the transformative continuation of texts within the configuration of (inter)cultural memories - to musical contexts.

In analyzing musical interculturality, it would seem that we are obliged to problematize fundamental preconditions of the European concept of art if we are to avoid the frequent accusation of merely integrating elements from non-Western cultures into a "Eurological"72 discourse. That integration inevitably places the Other in an asymmetrical power structure, appropriates it in a postcolonial fashion, and thus distorts it without giving its elements a chance to articulate their cultural difference. However accurate this critique may be in the cases of some allegedly intercultural, but in fact monocultural, compositional approaches, its problem lies in its culture-essentialist precondition, which remains trapped in the very dualism of "self" and "other," of "cultural self" and "cultural other," that it purports to reject. Wolfgang Welsch addresses this with his concept of "transculturality," and accuses theories of multiculturality and interculturality of clinging to the traditional concept of culture attributed to Johann Gottfried Herder's "sphere premise." ${ }^{73}$ This means that they propagate (at least implicitly) a homogeneous concept of culture and thus lay the foundation for culture-based separation and isolation, extending to "cultural racism," ${ }^{\text {"4 }}$ whereas multiculturality retains a basic polarity in the model of coexistence of cultural entities, Welsch argues, and produces "parallel cultures." The basic model of dialogue presupposed in interculturality does not solve the basic problem, since its insistence on the singularity of cultures involves the exclusion of others. Rather, Welsch highlights the hybrid, permeable, and transformative constitution of all present cultures and emphasizes, in the context of globalization, the internal transculturality of individuals, which is clear in the fact that "we all possess 'multiple attachments and identities."'75 This is taken a step further by Byung-Chul Han

71 See Elberfeld, "'Das Ich ist kein Ding, sondern ein Ort."

72 Lewis, "Improvised Music after 1950." See Bhagwati, "Imagining the Other's Voice."

73 See Löchte, Johann Cottfried Herder: Kulturtheorie und Humanitätsidee, 128-139, Zimmermann, "Clobale Entwürfe," 227-231, and Welsch, "Transculturality: The Puzzling Form of Cultures Today."

74 Welsch, "Transculturality: The Puzzling Form of Cultures Today," 195.

75 Ibid., 198. 
with his concept of "hyperculturality," which assumes a free-floating mass of "defactized" objects no longer tied to the here and now. ${ }^{76}$ These are available to the "hypercultural tourist" with virtually no preconditions, without requiring the effort of crossing boundaries or "wandering." 77 The model of a hyperculture, however, is unconvincing because of its definitional imprecision: it is by no means true that the methods, idioms, and grammars of "all cultures" are - for today's creative artists, for example - equally learnable and available. In addition, any remotely substantial acquisition of such an idiom demands a great deal of time and patience. Paradoxically, the idea of "defactized" cultural objects contradicts the very desire to overcome established cultural concepts that guides Welsch's and Han's thought. It is precisely when assuming a dynamic, transformative concept of culture that one thing must become clear: any decontextualization of "cultural objects" risks descending into a stereotypical representation of (national) cultures. Indeed, the notion of a removal of such contexts is an illusion. In addition, the idea of hyperculture overlooks that artistic production to this day is integrated into a global power discourse in which Western and non-Western artists can by no means always act with the same preconditions. What makes both concepts problematic is their idealizing tendency: "parallel cultures" are as much an indisputable reality in today's societies as the necessity of a continuous intercultural dialogue. Here one can argue against Welsch that the dialogical model is limited in its ability to transcend cultural essentialism (see below).

At any rate, the constantly changing constitution of cultures has long been recognized by the constructivism of postcolonial cultural theory. Since at least the 1970s, cultures have been understood as resulting from a construction of historical "narratives," and no longer as essential, given a priori. ${ }^{78}$ The process of constant reinvention and redefinition has been demonstrated especially through the history of nationalism. ${ }^{79}$ Against the background of increasingly multiethnic societies, the cultural theory of the 1990s developed such concepts as "mixed identities" or "strange multiplicity." ${ }^{\prime 0}$ Edward Said saw the achievement of such theoretical formulations as questioning the "binary oppositions dear to the nationalist and imperialist enterprise"si and replacing them with more complex models. On the contrary, there is no doubt that the dichotomy of "us" and "them" continues, and has at times even been intensified in the public consciousness - as can be experienced daily in post-9/11 societies. Here it is important to recognize that this dichotomy not only served the foundation of the (former) colonizers' identity, but also provided crucial building blocks for a self-definition of the (formerly) colonized cultures. ${ }^{82}$

The resulting web of entangled intercultural influences, demarcations, and connections makes an "aseptic" definition of cultures (at the expense of their inner complexity) seem reductionist and simplistic. It fails to recognize the long history of their mutual dependence. Such a reduction of complexity is especially characteristic of the authoritarian construction of national cultural identity for political or propaganda purposes. The wealth of examples in the West, East Asia, and elsewhere is well-known. In global music history, they include the simplification of Asian musical models in European exoticism - and in the early style of composed East Asian

76 Han, Hyperkulturalität, 13.

77 Ibid., 20, 56-60.

78 See Hobsbawm and Ranger, The Invention of Tradition, Said, Culture and Imperialism, and Benhabib, The Claims of Culture.

79 See Gellner, Nations and Nationalism and Anderson, Imagined Communities.

80 See Tully, Strange Multiplicity.

81 Said, Culture and Imperialism, xxviii.

82 See Utz, Neue Musik und Interkulturalität, 22-23. 
music $\left(\rightarrow\right.$ III.1) that Barbara Mittler terms "pentatonic romanticism." ${ }^{83}$ She uses this term to describe the dominant compositional style in twentieth-century East Asia, which is usually based on crudely simplified scales, models, and melodies from East Asian tradition cloaked in Western late Romantic harmonies. This style was in turn inseparable from the high degree of politicization in East Asian contemporary music and in some areas has remained this way to the present day.

In the following section, I will connect culture-theoretical discussion to questions of compositional aesthetics and methodology. We can initially assume that the tiny (in the global context) area of an emphatically or critically conceived "art music" seems most suited to provide a space for concrete utopias of musical interculturality. Here, admittedly, composers are faced with a seemingly chaotic "field of possibilities" in the dynamics between individualist and collectivist conceptions of culture, and also between an affirmation and a problematization, or even (potential) negation, of cultural self and cultural Other.

\section{Myth and Migration}

It is not always possible to distinguish clearly between mythologizing processes of reception and creative engagement with myth, ritual, and spiritual experience as an open space of encounters between cultures. In the most diverse contexts, composers keep referring back to existential, structural, and spiritual dimensions of archaic-mythological cultural layers. In this, they are often motivated by the intention of pointing beyond a simple East-West (or North-South) cultural dualism, or culturalist thought in general $\rightarrow$ II.6). Admittedly, the less philologically or analytically founded this approach to an allegedly precultural area of myth, the greater the tendency to construct "modern myths" of cultures. These find frequent corroboration in the media's propagation of culturalist stereotypes that portray such phenomena as "mythical India" or "mysterious China" (often for representational purposes) through supposedly "timeless" and "inviolable" attributes and paint a static, collectivist picture of culture as a whole. This culturally essentialist discourse may be accentuated both from the Western side (often for commercial purposes such as tourism) and the non-Western side (often with a nationalist - but also commercial - agenda), frequently buttressed by politically dominant groups. Contrasting practices are found in those forms of myth reception that allow for spaces of intuitive connection or encounter while distancing themselves from essentialist stereotypes.

A direct contrast to mythologization is found in the "migration" discourse, which focuses on the hybridity and complexity of contemporary cultural situations (for example, in urban centers). That discourse rejects a monistic concept of culture and confronts the seemingly "depoliticized" myth discourse with "harsh" political reality. Although migration discourse has rarely been connected to art music, it resonates with Helmut Lachenmann's aforementioned demand to engage compositionally and existentially with intercultural processes, rather than merely "strolling" comfortably through non-European worlds, safe in the knowledge of always having a "return ticket" "in one's pocket":

For me as a European, I think that this aspect of resistance is somehow necessary to avoid simply consuming []apanese shō music] as "fresh non-European meat" (as I called it on one occasion) for the broken, weary European world, or strolling about in it as a tourist - and as long as you still have your return ticket in your pocket so that you can listen to Beethoven again at home, it's

83 Mittler, Dangerous Tunes, 33. 
alright. But actually exposing oneself to a world in which that music gives people security, that's an existential challenge. ${ }^{84}$

Lachenmann does not, admittedly, specify what the compositional consequences of entering the other "lock, stock, and barrel" might be, nor whether it has had concrete effects on his own music ( $\rightarrow$ IV.2). Lachenmann's polarization, as explained, echoes Slavoj Žižek's criticism of academic theories that celebrate hybridity without dealing with the existential, often traumatic experience of hybridity among political migrants. ${ }^{85} \mathrm{~A}$ potential way out of this dilemma would be the existential commitment (formulated by Hans Zender and others) to the multidimensionality of musical cultures in the form of personal, unguarded, even hazardous encounters with actual musicians, ensembles, genres, texts, or through spiritual experiences. ${ }^{86}$ In this context, Charles Taylor has emphasized that a key to overcoming polarized essentialist thought lies in the act of solidarity: in the fact "that we have been transformed by the study of the other, so that we are not simply judging by our original familiar standards. ${ }^{87}$ Here, at last, the step has been taken from concepts emphasizing the collective to concepts emphasizing the individual experiences of culture. These concepts, especially in a time when collective "cultural values" are still demanded by some in today's societies, take on ever greater significance and undoubtedly show a tendency toward a fragmentation and individualization of (inter)cultural experience (which is also emphasized by Welsch).

\section{Dialogue and Hypolepsis}

We can use the terms "dialogue" and "hypolepsis" to refer to two models that seek to explain how individuals might articulate themselves within the dynamics of myth and migration. While the "dialogue" model presupposes fundamental differences between (usually two) partners in dialogue that are meant to be bridged, or at least contained, the model of hypólepsis, a concept from ancient rhetoric taken up by Jan Assmann, ${ }^{88}$ refers to a configuration of cultural memory in which, unlike the discourses of "myth" and "canon," contradictions and critique are preserved:

Mythical discourse is [...] pacified in so far as it is not confronted by any visible contradiction, and all of its statements and images stand on an equal footing beside one another. Canonical discourse is also appeased because it simply does not allow any contradiction. But hypoleptic discourse is riddled with contradictions, and indeed its whole basis is a sharpened perception of contradictions, that is, of criticism that at the same time preserves the positions that it criticizes. ${ }^{89}$

84 Helmut Lachenmann in conversation with Rolf Elberfeld and Toshio Hosokawa (see footnote 35); see also Hiekel, "Interkulturalität als existentielle Erfahrung," 64.

85 Žižek, Ein Plädoyer für die Intoleranz, 80-81.

86 See Hans Zender's statement in Dorschel, “Interkulturelle Begegnung als existentielles Risiko," 106-107.

87 Taylor, "The Politics of Recognition," 70.

88 Jan Assmann, Cultural Memory and Early Civilization, 255-267. The term hypólepsis was coined by Aristotle in his late treatise De anima (see Theobald, "Spuren des Mythos in der Aristotelischen Theorie der Erkenntnis"). Assmann, however, mainly refers to the usage in antique treatises on rhetoric (Jan Assmann, Cultural Memory and Early Civilization, 257-258) where the term signifies a connection to what a preceding speaker has said.

89 Jan Assmann, Cultural Memory and Early Civilization, 262 ("Der mythische Diskurs ist insofern beruhigt, als er keinen Widerspruch sichtbar werden und alle Aussagen und Bilder gleichberechtigt nebeneinander stehen lässt. 
In classical rhetoric, "hypolepsis" meant taking over from the words of the previous speaker and continuing them freely. Assmann expands the concept to include commentary on and further development of texts within the configuration of cultural memories:

[...] the hypoleptic process is one of engaging in approximations. It draws its momentum from the awareness that knowledge is never complete, and there is always more to be had. You can only come closer to the truth [...] by freeing yourself from the delusion that you can keep starting afresh, by recognizing that you have been born into an ongoing process, by seeing which way things go, and by consciously, understandingly, but also critically learning what your predecessors have already said..$^{00}$

In contrast to the "dialogue" model, which may ultimately result in understanding partners merely for the sake of understanding (and may thus block creative and altering processes), hypolepsis leaves space for free, transformative, critical variation. The concept can only be transferred to intercultural musical situations if one assumes that composers today can operate in a theoretically unlimited meta-cultural space in which a globalized cultural memory continually reconfigures itself. Differences are not eliminated in this space, but neither are they posited as absolutes. The hypoleptic discourse only becomes visible, however, through the highly specific competencies that enable a substantial identification - whether philological or intuitive - of these differences, and possibly also their points of contact. ${ }^{91}$ Thus a globalized cultural memory is by no means a license for the consumerist attitude implicit in the concept of the "hypercultural tourist."

\section{Alterity, Hybridization, and Incommensurability}

One can identify a key problem connected to musical interculturality in supposed explanations of the question of cultural alterity: "alterity" can basically be defined as the form of being-different that cannot be directly decoded as a sociocultural phenomenon that is ideological, or shaped by power discourses, and hence historically conditioned. Rather, it requires "essential" justifications, however one chooses to define them. In this definition, the concept of "alterity" has become an important instrument in identity-creating liberation discourses that are critical of authority. In addition, the tendency of those who use alterity toward essentialism exposes them to the critique of constructivist theories of identity summarized above.

In his thoughts on recognition, Paul Ricœur stresses that the foundations of the concept of "alterity" contain an originary asymmetry ("the other remains inaccessible in his or her alterity as such"; "the one is not the other") and a reciprocity that retains a middle position between

Der kanonische Diskurs ist beruhigt, weil er keinen Widerspruch duldet. Der hypoleptische Diskurs ist demgegenüber eine Kultur des Widerspruchs. Er beruht auf einer verschärften Wahrnehmung von Widersprüchen, d. h. Kritik, bei gleichzeitiger Bewahrung der kritisierten Positionen." Jan Assmann, Das kulturelle Cedächtnis, 288).

90 Ibid., 261 ("Der hypoleptische Prozess ist ein Prozess der Annäherung. Aus dem Bewusstsein der nie ganz vollständigen, immer vorausliegenden Erkenntnis bezieht er seine kinetische Energie. Der Wahrheit kann man nur näher kommen [...], wenn man erkennt, dass man immer schon in einen laufenden Diskurs hineingeboren ist, sieht, wie die Richtungen verlaufen, und lernt, sich bewusst, verstehend und kritisch auf das zu beziehen, was die Vorredner gesagt haben." Jan Assmann, Das kulturelle Gedächtnis, 287).

91 See Utz, Neue Musikund Interkulturalität, 483. 
nearness and respect in equal measure, and thus avoids the "pitfalls of a fusional union." ${ }^{92}$ At the same time, alterity is a key agent of conflict, such that "recognition" can be replaced by Hegel's model of a "struggle for recognition" implying an "involvement of misrecognition in recognition." ${ }^{\prime 93}$ In other words, every attempt at mutual recognition must seek a balance between the abandonment of a "narcissism of minor differences" and the acceptance of originary asymmetries. What Freud called the "narcissism of minor differences," namely "a comfortable and relatively harmless gratification of the inclination to aggression, through which cohesion is made easier for the members of the community," ${ }^{\prime 4}$ ultimately tends toward a stance that is often less harmless than Freud claims. It potentially extends to discriminatory culturalism and essentialism. By contrast, "forgetting" originary asymmetries can result precisely in cementing open or hidden hierarchies.

Ricœur's emphasis on the "intermediate" finally appears as a common factor with the deconstructivist cultural theory of Homi K. Bhabha, revealing links with the Japanese cultural philosopher Tetsurō Watsuji (Bhabha: "in-between,"Watsuji: "intervening” [aidagara] ${ }^{95}$ ). According to Bhabha, the "in-between" breaks up the "politics of polarity," advancing into a "Third Space" of articulations in which cultural hybridity becomes possible:

the split-space of enunciation may open the way to conceptualizing an international culture, based not on the exoticism of multiculturalism or the diversity of cultures, but on the inscription and articulation of culture's hybridity. To that end we should remember that it is the "inter" - the cutting edge of translation and negotiation, the in-between space - that carries the burden of the meaning of culture. [...] And by exploring this Third Space, we may elude the politics of polarity and emerge as the others of our selves. ${ }^{96}$

Martin Stokes, on the other hand, has argued that the concept of hybridity implicitly perpetuates the authenticity discourse so that "authenticity and hybridity are, from a discursive point of view, more complexly entangled concepts. Popular world music discourse reveals the links between the two terms and betrays their ideological dimensions. ${ }^{97}$ In addition, Peter Burke has criticized the supposedly neutral-objective observer position associated with hybridityoriented thought, partly following the same argumentation as Žižek. It is from this position that opposites merge almost of their own accord: the concept of "hybridity," Burke argues, rules out all action and evokes "the outside observer that studies culture as if it were nature, and the products of individuals and groups as if they were botanical specimens. ${ }^{n 8}$ So, in the concept of

92 Ricœur, The Course of Recognition, 259-260, 263.

93 Ibid., 259. This might be further highlighted by the thin line that Ricœur perceives between the French words mépris (contempt) and méprise (mistake) (ibid., 258). While mistakes turn out to be constitutive components in the search for the truth, contempt is inseparably linked to the "struggle for recognition" and thus ultimately inherent to all forms of recognition.

94 Freud, Civilization and Its Discontents, 88. ("Narzißmus der kleinen Differenzen, [...] eine bequeme und relativ harmlose Befriedigung der Aggressionsneigung, durch die den Mitgliedern einer Cemeinschaft das Zusammenhalten erleichtert wird." Freud, Das Unbehagen in der Kultur, 79.)

95 See Pörtner and Heise, Die Philosophie Japans, 366 and Nagami, "The Ontological Foundation in Tetsuro Watsuji's Philosophy."

96 Bhabha, The Location of Culture, 38-39.

97 Stokes, "Music and the Clobal Order," 59.

98 Burke, Cultural Hybridity, 54-55. 
hybridity, one can also identify those idealizing traces criticized above in the figures of transand hyperculturality. Certainly, we should remain aware that the hybrid substance of cultures describes a fundamental constitution of all cultures that has simply become increasingly visible as we have approached the present day - and can thus claim considerable empirical evidence for itself. Yet hybridity should not be understood as an insubstantial game with cultural articulations, but rather as a complement to fundamental differences between these articulations. These differences - often enough in trivialized forms - like hybridity, continue to define large parts of globalized societies.

Viewed in the broader context of the history of ideas, cultural alterity can also be connected to the idea of "incommensurability." This is a central topic of discussion in the philosophy of language, political aesthetics, and the philosophy of science, as well as a basic model for understanding the modern and postmodern arts. Though a detailed treatment of this discourse is not possible here, it certainly is a relevant concept for the discussion of musical interculturality.

Incommensurability became a key concept in the philosophy of science as a result of Paul Feyerabend's writings after the late 1950s, and especially Thomas Kuhn's influential study The Structure of Scientific Revolutions (1962/69). ${ }^{99}$ The central focus of Kuhn's theory is the methodological and conceptual incompatibility between historically successive scientific paradigms, as well as "translation errors" between scientific theories belonging to different paradigms. ${ }^{100}$ Similarly, Feyerabend had earlier described the irreconcilability of successive ontological theories: they are incompatible and cannot be reduced to or derived from one another. ${ }^{101}$ Although they developed their respective theories of incommensurability on different foundations, Kuhn and Feyerabend were both influenced by the gestalt-theoretical postulate that basic theoretical concepts have a lasting effect on the process of observation in the (natural) sciences. Hence, they both followed

the basic idea [...] that because the meanings, even of observational terms, are determined by the theories to which they belong, when there is theory change, there are meaning changes that can result in a new conception of reality. As a consequence, logical relations cannot correctly characterize the relationship between certain pairs of successive scientific theories..$^{102}$

In French poststructuralism in particular, "incommensurability" became a decisive part of the discourse, albeit in a sharper form that constituted a "general attack on rationalism that still triggers defensive reactions to this day." ${ }^{103}$ Michel Foucault's concept of the "archaeology of knowledge," for example, highlights the discontinuous development of the forms in which knowledge is represented in "heterotopias" without offering a (rational) reason for such an abrupt breaking-away of the episteme. ${ }^{104}$ Meanwhile Jean-François Lyotard, following on from Ludwig Wittgenstein's theory of language games, uses the term "incommensurability" to address the irreconcilable and untranslatable nature of language systems. ${ }^{105} \mathrm{He}$ points out, in Wittgenstein's sense, the fundamental irreconcilability of saying and showing, and thus ulti-

\footnotetext{
99 See Oberheim, "On the Historical Origins of the Contemporary Notion of Incommensurability."

100 Kuhn, The Structure of Scientific Revolutions.

101 Feyerabend, "Explanation, Reduction and Empiricism," 74, 90.

102 Oberheim, "On the Historical Origins of the Contemporary Notion of Incommensurability," 386.

103 Abitor, "Metapher als Antwort auf Inkommensurabilität," 124 ("Ceneralangriff auf den Rationalismus [...], der bis heute Abwehrreaktionen hervorruft").

104 Foucault, The Order of Things.

105 Lyotard, The Differend, 128-137.
} 
mately the irreducibility of linguistic materiality. ${ }^{106}$ Lyotard connects such models to the aesthetics of artistic avant-gardes in the twentieth century and their tendency to make "an allusion to the unpresentable by means of visible presentations" and thus deny themselves "the solace of good forms." 107

Those researching music-historical reception and intertextuality have often contented themselves with showing traditions and anxieties of "influence," without addressing the question of cultural (un)translatability. Yet this has long been discussed in depth by ethnomusicologists and literary scholars ${ }^{108}$ - very often explicating language-inherent power discourses in the process. ${ }^{109}$ It is clear that even (or especially) in the age of digitalization and the increasing availability of cultural "objects," the possibility of misunderstanding and talking at cross purposes is omnipresent. Admittedly, "productive misunderstandings" are always welcome in the artistic context, and "communication disturbances" are a popular topic in avant-garde artistic production (projects based on the Theater of the Absurd, for example). In situations of productive misunderstanding, the idea of incommensurability can indeed become fruitful without having to withdraw to the position of a rigorous untranslatability. ${ }^{110}$

It is also important to recognize that comparable discourses on the incommensurable exist in many cultures, and are also taken up by non-Western composers, often in a very explicit political sense $\rightarrow$ III.4-6). Here one could point to the reception of Daoist philosophy or references to the archaic verses of the exiled poet $\mathrm{Qu}$ Yuan (340-278 BCE) in Chinese music of the $1980 \mathrm{~s}$. Instances of this reception refer to anti-authoritarian and regime-critical elements of these traditions - a type of coded political statement that forms a tradition of its own in Chinese intellectual history. ${ }^{11}$

In this context, therefore, what is required is no less than a critical discussion of the limits and exclusion mechanisms of the European concept of art already mentioned above, as well as an engagement with the cultural preconditions of composition $(\rightarrow$ II.1). We should be aware of the inadequacy of Helmut Lachenmann's cultural categorizations. That is, his attempt to associate the European concept of art with structuring, rupture, self-reflection, and self-perception, while associating non-European music - with reference to a concert given by Ravi Shankar at the 1957 Darmstadt Summer Course - all too one-sidedly with religious, ritual and magical intentions, and a "paradise of content intactness." ${ }^{\text {"12 }}(\rightarrow$ IV.2)

In these introductory "circlings," I have attempted to place contemporary composition in the context of wider discourses, specifically those of canonicity, identity critique, reflexive globalization, and interculturality. Against the backdrop of a continuous dominance of Western

106 See Mersch, "Ceschieht es?"

107 Lyotard, "Answering the Question: What is Postmodernism?," 129, 131.

108 See the late writings of Edward Evan Evans-Pritchard as well as Chan and Noble, Sounds in Translation; see also the overview in Pym, Exploring Translation Theories.

109 See for example Asad, "The Concept of Cultural Translation."

110 For an updated and general review of musicology-related translation concepts see Lessmann, "Übersetzungein Thema der Musikforschung?"

111 See Utz, Neue Musik und Interkulturalität, 355-357, 403-423 (Qu Yuan) and 444 (Daoism). See also Mittler, Dangerous Tunes, 116-125.

112 Lachenmann, “East meets West?," 90-91. 
cultural centers in global cultural politics, ${ }^{113}$ as well as the inescapable ethnocentrism of canonforming discourses $(\rightarrow$ I.1), it is clear that a central challenge of intercultural composition - and a historiography contextualizing and reflecting it - is to respect "originary asymmetries" and seek out areas of the "in-between," without falling into the trap of a "narcissism of minor differences." Most of all, however, the task is to contextualize such musical works and their social embeddedness without subsuming these asymmetries under a pseudo-universalist but ultimately ethnocentric conception of global culture. This means that the methodology of a global, or more modestly a "globally informed," historiography and analysis of music would first have to meet four requirements:

1. It must be shown how musical articulations position themselves in the field of reflexive globalization and what positions they adopt in relation to the figures of alterity or incommensurability.

2. Compositional approaches must be discussed in the context of the dynamic between an intercultural competency (which ultimately lies in a critique of established forms of cultural essentialism and cultural stereotyping, represented here by the figure of "hypolepsis") and the inevitably continued effects of and changes to the cultural essentialism it critiques.

3. An awareness that the recognition of cultural alterity (that can imply or presuppose a "struggle for recognition" involving conflict and aggression) necessitates a profound skepticism toward any form of "synthesis" or "fusional union" - it should not, however, rule out the possibility of reciprocity. Music is destined for such reciprocity to the extent that it can sonically create dialogicity or isolation among different levels of material or coded structures - especially with the help of the compositional techniques developed in musical modernism. Designing suitable historiographical and music-analytical categories for such structures, however, is undoubtedly a great challenge.

4. Not least, the complex situation in which intercultural composition occurs in the twentieth and twenty-first centuries must be approached by considering its divergent but interrelated political and cultural preconditions. These comprise the institutions, media, individuals, performers, writers, and listeners that help to create music as a historical and social event and negotiate its meanings. The next chapter addresses this challenge head-on, favoring decentered, transnational, entangled perspectives in which "asymmetries" and "non-simultaneities" are highlighted without denying real and potential phenomena of historical convergence and coincidence. 


\section{Toward an Entangled History of Twentieth-Century Music in a Global Context}

\section{Preliminaries of an Intercultural Music Historiography}

The methodological reflections in the first chapter result in two understandings: first, the necessity of recognizing the aesthetic, cultural, local, and individual particularity of specific artistic positions. Second, the need to develop categories for comparing forms of music that come about under different sociocultural and culture-historical conditions without smoothing over their differences or presupposing any speculative claims of "shared roots" - but also with the aim of moving beyond a mere statement of multiplicity. In the light of recent (and not so recent) developments in music research, it is a given that this cannot take the form of an "either/ or" of aesthetics or history, of work history or social history, or of analytical or socioethnological methodology. ${ }^{1}$ Admittedly, as heated discussions of the work concept ${ }^{2}$ or historiographical methodology ${ }^{3}$ have shown, many of these polarities are still alive and well. For example, we still debate how music historiography, despite all postmodern objections, can continue to be conceived of as a "grand narrative" following "mainstreams,"4 or whether we should rather allow competing descriptions to exist alongside one another and increasingly seek out alternative sites, foregrounding once-neglected areas through a "micrology" of pétit récits. ${ }^{5}$ Naturally such

1 See the polemic in Taruskin, "Introduction: The History of What?, XXVII-XXVIII against the polarities established in Dahlhaus, Grundlagen der Musikgeschichte. This is discussed in Christensen, "Dahlhaus in Amerika," 135-136.

2 See Strohm, "Looking Back at Ourselves: The Problem with the Musical Work-Concept" and Goehr, "On the Problems of Dating' or 'Looking Backward and Forward with Strohm,'” referring back to Coehr, The Imaginary Museum ofMusical Works.

3 See Taruskin, "Speed Bumps," Cook, "Alternative Realities." See also Janz, "Musikhistoriographie und Moderne" and Danielczyk et al., Konstruktivität von Musikgeschichtsschreibung.

4 " $\mathrm{CH}_{2} \mathrm{O}$ degenerates before our eyes into a Babel of squabbling mainstreams, all clamoring for supremacy. That well exemplifies a salient feature of twentieth-century musical life, to be sure; but what a history of twentiethcentury music ought to attempt is a realistic contextualization of it, and an explanation." (Taruskin, "Speed Bumps," 205.) "[...] the trouble is the way in which, as the difference between 'streams' and 'mainstreams' illustrates, that kind of approach tends to prioritize the historian's interpretation at the expense of communicating the experiences of historical subjects." (Cook, "Alternative Realities," 207.)

5 See Lyotard, La condition postmoderne, 107. "[...] it will be evident to all readers that this book devotes as much attention to a congeries of 'petits récits' - individual accounts of this and that - as it does to the epic sketched in the foregoing paragraphs. But the overarching trajectory of musical literacy is nevertheless part of all the stories, and a particularly revealing one." (Taruskin, "Introduction: The History of What?," XXIII.) See also Kogler, "Von der großen Erzählung zur Mikrologie?" 
supposedly antagonistic positions need not remain mutually exclusive. A specifically intercultural historiography, however, would have to investigate the existing tensions between such opposing positions intensively. Especially when - as would seem almost indispensable for the actual repertoire and when reflecting on material, perceptual, and performative turns in musical scholarship - music breaks with the criterion of scripturality, or an exclusive orientation toward the text paradigm. It is clear that such a history can ultimately only be described, as Jürgen Osterhammel has done in his recent history of the nineteenth century, ${ }^{6}$ as a "polylogue of different narratives, themes and theories" through a "consistent decentering of perspective [...] no longer from Europe as the center, but from an ensemble of different centers." ${ }^{77}$ Music historiography has, at best, only taken tentative steps in this direction. ${ }^{8}$

First of all, then, the analyses presented here presuppose a basic comparability of musical works from different cultural and historical contexts, though this by no means suggests a purely functionalist notion of structure (in the sense that "all music" is ultimately no more than a structured, and hence analyzable, organization of sounds). Rather, attempting to act with methodological rationality demands that we seek to avoid the pitfalls of both a rigorous culturalist relativism (that would rule out any possibility of comparability) and an emphatic, covertly ethnocentric universalism (that would view all individual phenomena as manifestations of a single reference concept). ${ }^{9}$ Furthermore, it seems no less self-evident that one should assume a continued interplay of immanent and contextual factors in the production of musical "meaning" through composition, notation, interpretation and reception, and increasingly understand how these areas correlate and interweave. When combining individual "voices" in the complex of what "music" can mean in an interculturally expanded domain, however, we must be content to dispense with evolutionary or teleological models. Inevitably, we must respect discontinuity as a basic principle present even in the smallest cells of the individual articulations being examined: a fundamental "polyphony."

At the least, dispensing with the "grand narratives" must be a precondition when they refer to the orthodoxy of "techno-essentialism,"10 a naïve concept of progress that reduces musichistorical dynamics to an increase in structural complexity or gives absolute precedence to the structural paradigm as a whole:

This orthodoxy, offering a headline story around which a range of more conservative or simply different traditions can be clustered, not only construes history as a quasi-evolutionary process

6 Osterhammel, Die Verwandlung der Welt.

7 Janz, "Musikhistoriographie und Moderne," 313-314 ("konsequente Dezentrierung der Perspektive [...] nicht mehr vom Zentrum Europa, sondern von einem Ensemble unterschiedlicher Zentren aus erzählt").

8 See Gertich and Greve, "Neue Musik im postkolonialen Zeitalter," Utz, Neue Musik und Interkulturalität, Danuser, Musikalische Lyrik, vol. 2: Vom 19. Jahrhundert bis zur Cegenwart-außereuropäische Perspektiven, Cook and Pople, The Cambridge History of Twentieth-Century Music.

9 Such a method is in many respects akin to Michael Tenzer's approach to an "analysis and theory of musics of the world," though I do not share Tenzer's optimism that we are indeed heading toward a "world music theory" (Tenzer, "Introduction: Analysis, Categorization, and Theory of Musics of the World," 32-35). What I share is Tenzer's insight that "comparison across any boundary requires reconsidering basic assumptions so that clear descriptive language can emerge and lead not only to new categories of learning, but beyond them to new experiences and construals of music" (Tenzer, "Temporal Transformations in Cross-Cultural Perspective," 517). The universalistic project of a "Clobal Music Theory" in which, among others, scale systems are introduced as "qualified musical universals" (Hijleh, Towards a Clobal Music Theory, 9) must surely evoke considerable doubts.

10 See Williams, "Of Canons and Context." 
but also locates that process in compositional technique: it is the same kind of approach that you might use in writing the history of, say, the internal combustion engine [...]. ${ }^{11}$

Nicholas Cook's and Anthony Pople's attempt to oppose this orthodoxy through the broad focus of the Cambridge History of Twentieth-Century Music, however, proves problematic in some respects. While it seems fair that the chapter on serial music does not take up more space than that on the "moderate mainstream 1945-75," one of many things that remains unclear is why there is a chapter on art music in Africa, but none on art music in Asia or Latin America. In a strangely timid gesture, the explanation provided for this takes back the de-restriction aimed for directly beforehand:

The rationale, in short, is that non-Western musics fall within the book's scope to the extent that they can be seen as integral to the historical development of Western music, "our" music. That can't to any great extent be said of Beijing opera between the wars, but it becomes more generally the case as the century progresses, with globalization replacing a pattern of sporadic encounters by one of sustained interaction. Indeed there is a sense in which, by the time you get to the end of the century, it is in principle impossible to justify leaving any music, anywhere, out of the book. [...] "Western" music, clearly located around 1900 in the urban centers of Europe and North America, has become a global currency in the same way as the hamburger, and one sometimes has the impression that the "art" tradition flourishes more in East Asia, Israel, and parts of South America than in its former heartlands. It is not so much that there has been a relocation from the center to the periphery as that the distinction between center and periphery has become increasingly fuzzy [...]. And so it is appropriate that the accumulating emphasis, as the book proceeds, on increasingly globalized and hybridized popular musics leads [...] to a kind of reverse discourse: issues of musical modernism and autonomy, increasingly sidelined in the First World, ironically take on a new cultural significance when relocated to the Third. ${ }^{12}$

However instructive the insight may be that the discourses of Western music have to change in a globalized context and take on new qualities, I find that the seemingly helpless, albeit ironically understated, retention of the focus on "our' music" is rather questionable. Björn Heile is therefore right in his criticism that "the consequences of the global and globalized nature of new music haven't been fully thought through or conceptualized. [...] behind the ostensible cosmopolitanism of the new music scene, the old thinking in terms of 'self' and 'other,' 'center' and 'periphery' seems to go on unabated."13 Admittedly, Cook himself did not stop at this unsatisfactory perspective; since 2002 , he has worked continuously on a concept of "relational musicology,"14 referring, among other things, to an approach outlined by Regula Burckhardt Qureshi, ${ }^{15}$ a concept further pursued by Georgina Born. ${ }^{16}$ Cook bases this perspective not only on an integration of music analysis, music historiography, and ethnomusicology, but also on a fundamentally relational understanding of musical "meaning":

11 Cook and Pople, "Introduction: Trajectories of Twentieth-Century Music," 4.

12 Ibid., 8-9.

13 Heile, "Weltmusik and the Clobalization of New Music," 101-102.

14 See Cook's essays “'One Size Fits All'?, "We Are All (Ethno)musicologists Now," "Intercultural Analysis as Relational Musicology," and "Anatomy of the Encounter."

15 Qureshi, "Other Musicologies."

16 Born, "For a Relational Musicology." 
I think of meaning as something that emerges through the interaction between different texts or practices (between works and performances, between different media), and that is accordingly negotiated at the point of reception. In other words meaning is not intrinsic but arises from relationships, and that's why I speak of relational musicology. ${ }^{17}$

\section{Models of Music Historiography and the Critique of Universal History}

From the age of colonialism and historicism onward, a persistent dichotomy was established between the history ascribed to Western music, and how Asian, African or Latin American musical cultures have only been credited with musical traditions but no music-historical continuity. Such a dichotomy exists not least because scripturality has usually only played a secondary part in those cultures: in traditional music historiography, a basic model of continuity closely relates to scripturality. This view, stemming from the theories of history developed by Friedrich Schlegel and Georg Wilhelm Friedrich Hegel in the early nineteenth century, and the accompanying selectionist value judgments, have retained their influence to this day. In Taruskin's compendium, explicitly termed a history of Western music, the criterion of scripturality becomes the decisive key to an overarching narrative:

it is the basic claim of this multivolumed narrative - its number-one postulate - that the literate tradition of Western music is coherent at least insofar as it has a completed shape. Its beginnings are known and explicable, and its end is now foreseeable (and also explicable). And just as the early chapters are dominated by the interplay of literate and preliterate modes of thinking and transmission (and the middle chapters try to cite enough examples to keep the interplay of literate and nonliterate alive in the reader's consciousness), so the concluding chapters are dominated by the interplay of literate and postliterate modes, which have been discernable at least since the middle of the twentieth century, and which sent the literate tradition (in the form of a backlash) into its culminating phase..$^{18}$

In Taruskin's case, this delimitation of pre- and postliterate epochal boundaries has an undertone of cultural pessimism that foregrounds the prevalence of cursory, fragmented listening in the media age. His attitude connects with Jerrold Levinson's phenomenological theory of merely stringing together isolated events while listening to music - concatenationism. ${ }^{19}$ In addition, Taruskin defends the restriction to the Western world (Europe and North America) with a clearly contestable argument: "The sheer abundance and the generic heterogeneity of the music so disseminated in 'the West' is a truly distinguishing feature - perhaps the West's signal musical distinction. It is deserving of critical study." ${ }^{20}$ But this unique "abundance of the most varied styles and expressive forms"21 in Western music, often celebrated even by "critical" voices, hardly stands up to objections from postcolonial theory or ethnomusicology, and could surely be claimed for traditions such as Indian or Korean art music with equal justification.

17 Cook, "Intercultural Analysis as Relational Musicology."

18 Taruskin, "Introduction: The History of What?," XXIII.

19 Taruskin, Music in the Late Twentieth Century, 510-514. See Levinson, Music in the Moment.

20 Taruskin, "Introduction: The History of What?," XXIII.

21 Helmut Lachenmann in Spahn, "Gegen die Vormacht der Oberflächlichkeit" ("Keine [andere Musiktradition außer der europäischen] hat sich so rasant fortentwickelt und einen solchen Reichtum an unterschiedlichsten Stilen und Ausdrucksformen hervorgebracht.") 
Alternative approaches to music historiography have repeatedly been outlined, but rarely put into practice. A teleological principle of progress was already questioned in rudimentary manner during the 1920s, for example in the model of metamorphosis and fluctuation in Paul Bekker's Musikgeschichte als Geschichte der musikalischen Formwandlungen (Music History as the History of Changes in Musical Form, 1926), ${ }^{22}$ in the cyclical model of Alfred Lorenz's Abendländische Musikgeschichte im Rhythmus der Generationen (Occidental Music History in the Rhythm of Generations, 1928), ${ }^{23}$ and in sociohistorical approaches first pursued systematically since the 1920s. ${ }^{24}$ To be sure, every one of these studies was limited to European music ${ }^{25}$ and, in Lorenz's case, was even shaped by a deep cultural pessimism of a decaying "occidental" (or more specifically German) culture threatened by non-European cultural "forces" as outlined in proto-fascist writings such as Oswald Spengler's Der Untergang des Abendlandes (The Decline of the West, 1918/22, first translated into English in 1926), of which the second volume in its subtitle claimed to provide "Perspectives of World History."

While it is still the prevailing view that "everything presented as a line of development is simply an abstraction from progressions and regressions," and that "development has many threads and moves in several directions simultaneously," ${ }^{27}$ there is hardly a music-historical overview that has truly drawn out the necessary conclusions from this insight. A systematic discussion of methods would have to draw on something like Dahlhaus's "problem history of composition" against the backdrop of a combination of compositional history, history of ideas, and social history, ${ }^{28}$ as well as its critique or refinement in the context of New Musicology. ${ }^{29}$ Such a discussion would have to reflect especially on developments in other disciplines, for example the idea of an intercultural history of philosophy. ${ }^{30}$ Ultimately, the models of "multiple modernities" and "entangled history," explored further below in this chapter, pursue the aim of weaving together at least some of these requirements.

First, however, steps toward an engagement with the tradition of universal-historical and culturally comparative research approaches will be sketched in contrast to two well-known studies, Walter Wiora's Die vier Weltalter der Musik (The Four Ages of Music, 1961) and John Blacking's How Musical Is Man? (1973). Despite Wiora's efforts to distance himself from Eurocentrism,

22 See Bekker, Musikgeschichte als Ceschichte der musikalischen Formwandlungen, 5-15.

23 See Lorenz, Abendländische Musikgeschichte im Rhythmus der Generationen.

24 See Potter, Most German of the Arts.

25 Very few exceptions such as Jacques Handschin's essay “Réflexions dangereuses sur le renouveau de la musique ancienne" [Dangerous Reflections on the Revival of Early Music] (1938) were labeling non-European (here: Japanese) music consistently as "exotic," crediting it with a lack of immediacy. Handschin though questions the universal validity claim of music historiography based on these reflections. See Maier, Jacques Handschins "Toncharakter", 50-59.

26 See Spengler, Der Untergang des Abendlandes. Lorenz later became an enthusiastic supporter of the Nazi regime; see among others Kinderman, "Das Institut für Musikwissenschaft in der NS-Zeit."

27 Rienäcker and Rösing, "Epochendefinition und Geschichtsschreibung," 411 ("[...] alles, was als Entwicklungslinie dargestellt wird, [ist] nichts anderes als Abstraktion von Progressionen und Regressionen"; "Entwicklung ist [...] vielsträngig und geht gleichzeitig in verschiedene Richtungen [...].")

28 Dahlhaus, Grundlagen der Musikgeschichte, 182-187, Dahlhaus, "Zur Problemgeschichte des Komponierens."

29 See Treitler, Music and the Historical Imagination, Tomlinson, Music in Renaissance Magic, Cook and Pople, The Cambridge History of Twentieth-Century Music, and Taruskin, The Oxford History of Western Music.

30 See for example Wimmer, Interkulturelle Philosophie, 89-117 and Kimmerle, Interkulturelle Philosophie zur Einführung. 
his outline stands in the tradition of colonialist universal-historical concepts. He presupposes a "natural" foundation of music that he only believes to have been fully developed in "occidental music," and whose "naturalness" - as opposed to power-political factors, for example - is the chief cause for the global dissemination of Western musical forms:

It was easy for occidental music to be appropriated by tribal cultures and basic classes of the Orient because its folk forms offered very simple, striking and therefore convincing shapes. One such simple shape is the straight eight-bar tune in a major key with a constant alternation between the tonic and dominant. This was encountered in all cultures by structures of varying kinship, and was thus easily assimilated, for example in national anthems. The "second primitivity" of rhythmically straight song types is in keeping with the original primitivity. The typical structure of marches or popular songs has a "striking" effect. ${ }^{31}$

In 1939, in a review of the volume Zur Tonalität des deutschen Volksliedes (On the Tonality of the German Folk Song), edited by Guido Waldmann and published in 1938 by the Nazi organization Reich Youth Leadership (Reichsjugendführung), Wiora had listed basic aims of folk music research, including calls to reconstruct what he considered a natural development of folk music toward tonality and emphasizing the ability of German folk song to assimilate foreign influences. ${ }^{32}$ It is not difficult to recognize, then, how a blatantly nationalist and xenophobic emphasis can be reworked, without any changes to the substance of the argumentation, as a universal-historical concept. That concept, then, attempts to prove with great enthusiasm the special status of Western music in purely technical, seemingly non-ideological terms.

One could say that Blacking's study starts from a diametrically opposed position, namely the thesis that "all music is structurally, as well as functionally, folk music." ${ }^{33}$ Hence his study attempts to examine all forms of music from a culture-sociological position through analyses "that explain how a musical system is part of other systems of relationships within a culture."34 From this perspective one can understand Blacking's critique of world-historical approaches, especially when they have an evolutionist focus: "Musical styles cannot be heard as stages in the evolution of music, as judged in terms of one particular civilization's concepts of music." 35 Blacking calls for a precise examination of the sociocultural situation from which music emerges, the "cultural agreement" 36 through which alone it can communicate meaning, and the "sonic order" ${ }^{\prime 37}$ that, as a music-specific principle of organization, enables this communication. Blacking's approach flattens out the differences between cultures as he tries to apply the same basic

31 Wiora, Die vier Weltalter der Musik, 146 ("Musik des Abendlandes konnte in Stammeskulturen und Grundschichten des Orients darum leicht angeeignet werden, weil sie in ihren volkstümlichen Formen überaus einfache, prägnante und darum einleuchtende Gestalten darbot. Eine solche einfache Gestalt ist der glatte Acht-Takter in Dur mit ständigem Wechsel von Tonika und Dominante. Er traf bei allen Völkern auf mehr oder weniger verwandte Strukturen und konnte sich leicht einbürgern, so in Nationalhymnen. Die 'zweite Primitivität' rhythmisch glatter Liedtypen kommt der ursprünglichen Primitivität entgegen. Die durchschnittliche Struktur von Märschen oder Schlagern hat 'schlagende' Wirkung.").

32 Wiora, "Die Tonarten im deutschen Volkslied." See also Potter, Most German of the Arts.

33 Blacking, How Musical is Man?, xi.

34 Ibid., 25.

35 Ibid., 56.

36 Ibid., 9-10.

37 Ibid., 11. 
socioanalytical approach to all kinds of music - a goal that he barely achieves when, in contrast to structuralist analyses of the music of the South African Venda, in discussing works by Benjamin Britten or Gustav Mahler, he follows his own subjective feelings and strongly emphasizes that he has not drawn on any analyses by other authors. ${ }^{38}$

Blacking's approach has nonetheless been continued intensively in Anglo-American research in particular, one example of which is Stephen Blum's notable article "Composition" in The New Grove. ${ }^{39}$ Blum defines composition primarily by the postulate of self-identity (music that remains identifiably the same in different performances can be termed "composition") and begins his account paradigmatically with examples of African and Latin American ritual music whose self-identity - as in many genres of European music - lies primarily in core models that can be augmented in a given performance with varyingly extensive variations. Indeed, as the following section shows, opening up the notion of composition is a preliminary when intercultural contexts of music history are approached, as narrow conceptualizations of this term would leave major gaps in the repertoire to be discussed in such a history. This implies that scripturality can by no means be the sole criterion to delineate what music should be included in an intercultural music history, but also that distinguishing between the connection to written and non-written components of the compositional process can assist in laying out the criteria for comparison sought here. What must also be found is a convincing combination of textual and contextual analysis that unifies hermeneutical, structural, music-aesthetic, and sociohistorical factors in order to grasp the fabric-like, network-like basic structures woven between compositional act, composer, society, politics, and historical "encyclopedia."

\section{Opening Up the Notion of Composition}

The sociohistorical preconditions for artistic, and hence compositional, acts in the globalized context are undoubtedly closely linked to the problems accompanying the global dominance of the Western musical discourse (in the Foucauldian sense). So when one speaks of "new composed music," for example (or also "composed new music"), it is certainly worth questioning first of all how culturally-conditioned these concepts, or the historical processes to which they refer, in fact are.

If we direct our attention toward "new composed music" in East Asia, for example, we are confronted with a common two-phase model. The phase before the intensive encounter with Western culture through imperialism and colonialism since the nineteenth century essentially featured nothing analogous to the Western concept of "musical composition," which consequently appears as a "special path" of the West. After this confrontation with the West, however, the concept of composition experienced a gradual reception and assimilation in East Asia. The spectrum of this assimilation meanwhile extends from the imitation or flawless mastery of Western styles or compositional tendencies toward the rupturing of the cultural-aesthetic foundations underlying the concept of "composition." Leaving aside the problematic postcolonial perspective that presents music-historical movements as solely dependent on Western influence, this also denigrates (traditional) forms of composition in East Asia without further discussion by denying them the dignity of being considered "composition." Thus, in the article "Komposition" (1996) from the encyclopedia Die Musik in Geschichte und Gegenwart, non-Western contexts are consistently ignored, implying that their forms of musical creativity do not meet

38 Ibid., 60.

39 See Blum, "Composition." 
the standard laid out, namely producing a "construct with artistic ambition (which is thus characterized by a particular quality of forms, expressive capacity, depth of meaning etc.)."40

In opposition to this rather dualistic view of Western composed music and non-Western traditionally (predominantly aurally and orally) transmitted music, I would like to propose a more complex model. My model will not dispute the cultural autonomy and largely independent historical development of both forms of musical creativity before the nineteenth century while adopting a less essentialist position. For now, let us continue to assess the concept of "musical composition" in the Western context. ${ }^{41}$ No matter which point of time or period one chooses as the time of its birth - 1025, 1474, or $1537^{42}$ - the criteria that justify "viewing composition as specific to the European cultural tradition" ${ }^{\prime 43}$ and hence placing it in opposition to musical creativity in other cultures are far from self-evident.$^{44}$ Certainly there was a new development between the Notre Dame period and the Franco-Flemish school toward the separation and autonomy of the fixed text in relation to various practices of improvisation and extemporized performance, leading to the introduction of a functional and exact music notation. Together with a new hierarchy led by the creative poeticus musicus, ${ }^{45}$ this situation laid the foundation for a new form of musical autonomy, reaching a first peak in the compositional procedures of the late fourteenth-century ars subtilior. These properties of musical composition remained crucial in Western music up to the twentieth century, in a complexity that only became possible through scripturality. The "New Complexity" associated with Brian Ferneyhough, for example, is only conceivable as the radicalized autonomy of written formulation in relation to musical practice, which it certainly enriches creatively at the same time, but without being limited by the possibilities of any established res facta (which may freely signify here both the means of standard notational practice as well as limitations of traditional musical perfor-

40 Sachs et al., "Komposition" ("ein Gebilde mit Kunstanspruch [das sich somit durch besondere Cestaltqualität, Ausdrucksfähigkeit, Sinntiefe u. ä. ausweist]”).

41 See Cahn, "Zur Vorgeschichte des 'Opus perfectum et absolutum," Kaden, Des Lebens wilder Kreis, 64-103, Loesch, Der Werkbegriffin der protestantischen Musiktheorie des 16. und 17. Jahrhunderts, Strohm, "Opus: An Aspect of the Early History of the Musical Work-Concept," Strohm, "Der musikalische Werkbegriff: Dahlhaus und die Nachwelt," Flotzinger, "Clossen zum frühen abendländischen 'Kompositions'-Begriff," and Bandur, "Composition/Komposition," Sachs et al., "Komposition," Blum, "Composition," Möller, "Komposition."

42 One might understand this concept to have arisen in the early appearance of the term "componere" in Guido of Arezzo's Micrologus de musica (Chapter 15, 1025), indicating a significant paradigm shift toward a "reflective, thoroughly considered form of musical invention." (Kaden, Des Lebens wilder Kreis, 69; "reflektierte[], mehrfach überdachte[] Form musikalischen Erfindens.") Equally one might view the term res facta of Johannes Tinctoris (Terminorum Musicae Diffinitorium, 1472-74) or the definition of the opus perfectum et absolutum (and the opus consumatum et effectum) in Chapter I of Nikolaus Listenius's Musica (1537), that is to say, the Cerman musica poetica of the Reformation, as a decisive step toward the establishment of the concept in Western music history.

43 Kaden, Des Lebens wilder Kreis, 65 ("Komposition als ein Spezifikum europäischer Kulturtradition zu erachten”).

44 See Blum, "Composition."

45 See Cahn, "Zur Vorgeschichte des 'Opus perfectum et absolutum'” and the critical arguments in Loesch, Der Werkbegriffin der protestantischen Musiktheorie des 16. und 17. Jahrhunderts, rejected by Strohm, "Der musikalische Werkbegriff: Dahlhaus und die Nachwelt," 272: "Der Begriff des musikalischen opus [...] war lange vor Listenius und der Wittenberger Schulreform im internationalen humanistischen Sprachgebrauch verbreitet und stellte bereits dieselben normativen Ansprüche wie derjenige des 19. Jahrhunderts, wenn er auch die Musikpraxis noch nicht in derselben Breite abdeckte wie in späteren Jahrhunderten." "The concept of a musical opus [...] was common long before Listenius and the Wittenberg educational reform in international humanistic usage and already placed the same normative demands as those of the nineteenth century, although it did not yet cover music practice to the same extent as in later centuries.") 
mance). Yet Debussy's polemical comment, quoted in Chapter 1, that characterized Javanese gamelan music as "a counterpoint that makes Palestrina's seem like child's play ${ }^{\text {"46 }}$ shall remind us that complexity is by no means linearly dependent on scripturality. (This will be exemplified, among many other examples, by those African genres that served as György Ligeti's models in creating hyper-complex rhythmic-metrical structures in his later works, $\rightarrow$ V.2.)

Such practices as Ferneyhough's are undoubtedly deeply indebted to a specific feature in the Western conception of composition that emerged in the early phases of modernity around 1800: the "objectified spirit" of the musical work, in which the notated appears as a (culturally encoded) text. ${ }^{47}$ The culture-sociological circumstances involving this topos were the emancipation of music from social functions, the development of concert and opera life, and above all a corresponding repertoire that enabled the intertwining of antiquity and modernity in which the paradoxical postulate of "originality" could be realized. This paradox is illustrated most clearly by the expectation that the "original genius" (Originalgenie) will keep creating new things while still respecting the limits of certain conventions. ${ }^{48}$ In other words, the new and advanced was (or is) only acceptable if it could (or can) be related to the existing repertoire, even if only by slowly "seeping into" that repertoire through its repeated performance and gradual ascent to canonic status.

This kind of self-reflexivity of music has been singled out as the decisive criterion for the definition of musical modernity by Tobias Janz ${ }^{49}$ who also stresses the extent to which progress-driven European modernity remained dependent on an anti-modernist "discomfort of modernity." 50 Examples of such a paradoxical linking of modernist and anti-modernist layers are the juxtaposition of authoritarian pre-modern art religion and high-modernist dramaturgy of sound in Richard Wagner' Parsifal (1877-82), ${ }^{51}$ or the ambivalence between colonialist and postcolonialist readings in Charles Koechlin's and Percy Grainger's adaptations of Rudyard Kipling's Jungle Book, where the non-European Other as an idealized "counter model" of Western modernity is at once integrated and ostracized..$^{52}$

The question still remains whether general autonomy from musical practice, involving the strong focus on scripturality, is sufficient to qualify composition as specific to Western culture. In recent musical performance studies, this assumption has been thoroughly challenged and countered by minimizing the impact of written musical notation to a mere "script," a secondary aid for the primary experience of musical performance or "musicking,"53 positing a work concept which is inwardly based on "sounded writing" - the "work as performance. ${ }^{54}$ Probably the most important intervention in this field has been Carolyn Abbate's essay "Music - Drastic or Gnostic?," which adopted Vladimir Jankélévitch's music philosophy for a much-discussed challenge of the long-lasting discourse of "great works as unperformed abstractions,"

46 Debussy, Monsieur Croche et autres écrits, 223 (see Chapter 1, footnote 23).

47 Dahlhaus, “Der Werkbegriff als Paradigma," 94-95. See also Bürger, Theory of the Avant-Carde, 47-54.

48 Dahlhaus, "Der Werkbegriff als Paradigma," 97-98.

49 Janz, Cenealogie der musikalischen Moderne, 239-265.

50 Ibid., 513 ("Unbehagen an der Moderne" - a formulation which alludes to the title of the German translation of Charles Taylor's book The Malaise of Modernity, 1991)

51 Ibid., 448-456.

52 Ibid., 457-514.

53 See Small, Musicking.

54 See Cook, Beyond the Score, 237-248.

55 Abbate, "Music-Drastic or Cnostic?," 505. 
stead demanding a new focus of musicology on "music not as a work but as an event" "material presence and carnality." ${ }^{17}$ It has been noted by several commentators that Abbate's intervention (via sources from Jankélévitch that extend back to the 1920s) can be traced to early twentieth-century vitalism, but also to music-specific approaches of prioritizing sounding performance as introduced by Paul Bekker or Alfred Schütz. ${ }^{58}$ This substantiates the observation, made by many scholars today, that a critique of modernity is deeply ingrained in the process of modernity itself, a process which prominently and necessarily involves the decentering dynamics of globalization processes and intercultural conflict zones.

Even if this tradition of turns toward "material" or "performance" in music scholarship tends to retain a dualism of written and sounding dimensions of music, thus remaining indebted to a basic polarization they claim to transcend, each offers a highly necessary extension of focus when approaching the definition of composition in an intercultural context: not only is composition dependent on performative reproduction and aural perception, composition and listening can themselves be understood as performative acts and thus described as incommensurable and idiosyncratic. ${ }^{59}$ This idea will become obvious in numerous analyses presented in the following chapters. There we will see how an interaction between composers, performers, and audiences may become completely reconceived and "reinvented," often on the basis of specific cultural preconditions. This concept will perhaps become clearest in the partly politically motivated ideas of José Maceda and Yüji Takahashi $(\rightarrow$ III.4).

Of course, the idea that non-Western cultures would be based primarily (or even entirely) on performative and "material" (aural/oral) practices is equally one-dimensional. It should be acknowledged that non-Western musical cultures also have writing practices that emancipate themselves from musical realization and add speculative and autonomous dimensions to the functionality of musical notation. ${ }^{60}$ Even in early phases, one can detect a creative self-awareness in this context - for example, in the scores of $c i$ songs by the Chinese scholar Jiang Kui (1155-1221) from the southern Song Dynasty (1127-1279). Jiang not only termed these songs his "own compositions" (ziduqu), but also added prefaces to his scores explaining in detail how he had developed the text and music in close parallel. ${ }^{61}$

Therefore, it seems cogent to define the concept of "composition" in a "global" manner from the outset, as Stephen Blum has done. ${ }^{62}$ Understanding the invention, notation, performance, and reception of music as sociocultural acts lets "composing" appear as the definition of an (inter)cultural position and thus offers insight into the composer's (and performer's or listener's) stance toward cultural, social, and societal conditions and realities. According to Theodor W. Adorno, we can trace these conditions to the tiniest details of a score, ${ }^{63}$ even if the composer remains unaware of such connections. The complexity of thus defining a sociocultural position

56 Ibid., 533.

57 Ibid., 529.

58 See Bork, "Text versus Performance - zu einem Dualismus der Musikgeschichtsschreibung," 383, Jost, "Der 'performative turn' in der Musikforschung," 292, and Kabisch, "Verschwindendes Erscheinen' als Prinzip einer Musik der Moderne," 39, summarized in Utz, "Carolyn Abbate. Music - Drastic or Cnostic?"

59 See Kramer, "From the Other to the Abject," 65-66 and Utz, "Vom adäquaten zum performativen Hören" for a theory of "performative listening."

60 See for example Liang, Music of the Billion, 186-202.

61 Lam, "Writing Music Biographies of Historical East Asian Musicians."

62 Blum, "Composition."

63 Adorno, "Zur gesellschaftlichen Lage der Musik," 731. 
undoubtedly increases with the two opposing tendencies in cultural globalization: homogenization and diversification. Through this binary, one can understand the compositional process as the conceptual linking of historical location, social context, cultural context, and the composer's biographical "constellation" to the specific processing of problems immanent in tradition, genre, œuvre, and the individual work. In an interculturally accentuated approach to composition, the interplay between these factors becomes clear. As soon as composers operate between different cultural contexts, their historical location and the immediately relevant musical traditions begin to oscillate. Such oscillations should be the focus of an intercultural music historiography.

\section{De-Nationalizing Music Historiography}

Broadening our idea of musical composition, integrating dimensions of performed and perceived sound, and deconstructing the idea of authenticity are merely preliminary steps in an attempt at decentering and denationalizing the writing of music history. In order to outline a more comprehensive view of this challenge, the following chapters (II.2-II.6) develop ideas put forward by recent theories in historical studies such as "entangled history"64 and "multiple" or "alternative modernities." ${ }^{15}$ The focus is on "non-simultaneous" processes in music history of different nations or regions of the world during the first and the second half of the twentieth century, alluding to the notions of "relationality" and "synchronicity" as discussed in recent historical scholarship: ${ }^{66}$ Whereas relationality signifies that in modernity no region or nation is the sole agent of its history, that the emergence of modern societies is deeply connected to an interactive process among regions, nations, or cultures, ${ }^{67}$ synchronicity stresses the fact that "synchronous" (largely synonymous with "simultaneous") global processes in modern history have often engendered interdependent changes in different areas of the world. ${ }^{68}$ While these approaches suggest a more emphatic perspective on the project of a "world history" by bringing local developments together into a common framework, my approach aims to confront this framework with those "non-synchronous" or "non-simultaneous" aspects of pre- and postwar (music) history of the twentieth century that resist the project of a unified "world (music) history." The precondition and challenge, therefore, is to understand any local, national, or regional music-historical processes not in isolation from global processes but as (frequently unconscious and/or unconsidered) consequences of inter- or transnational dynamics, including (but not limited to) political and social contexts such as political ideologies and postcolonial power structures, images, and mentalities. Local or national dynamics and processes that do not match an overarching historical narrative must still be acknowledged.

Reflecting these tensions and the divergent preconditions of art music composition in the different areas of the world since 1900, the notion of a "non-simultaneity of the simultaneous" [Ungleichzeitigkeit des Gleichzeitigen] as coined by art historian Wilhelm Pinder during the 1920 and made famous by Ernst Bloch's in-depth Marxist analysis of rising fascism in the

64 See Werner and Zimmermann, "Beyond Comparison."

65 See Eisenstadt, Multiple Modernities, Gaonkar, Alternative Modernities, Conrad and Eckert, "Globalgeschichte, Clobalisierung, multiple Modernen," and Janz, "Multiple Musical Modernities?" This concept is discussed more thoroughly toward the end of Chapter II.4.

66 See the summaries in Conrad, What is Global History?, 65-66, 150-156.

67 See Goody, The East in the West.

68 See Harvey, The Condition of Postmodernity. 
1930s springs to mind.$^{69}$ In Bloch's social theory, the "non-simultaneous" designated the "different times, the different 'nows" of European societies during the first decades of the twentieth century, which Bloch determined "using the coordinates of age, class, and geography": ${ }^{70}$ the unemployed youth, the peasantry, and the rising urban middle class all lived in different "nows" but shared a common impulse to reject the modernist present, making them susceptible to extremist ideas and movements. A literal transfer of this theory to music history is surely not viable and is not my principal aim. Rather, I am curious about how the "radical polyphony" of twentieth-century new music as described by Andreas Meyer ${ }^{71}$ can be understood against the background of Bloch's theoretical framework. The challenge thus is not to resort to the common stereotype of a simple "stylistic pluralism" in music since 1945 or to the trope of non-Western areas experiencing an "asynchronous delay" to Western centers, connected to an implicit or explicit pressure to "catch up" with Western standards (though this was a common, if often shortsighted demand articulated by many non-Western reformers in early postcolonial periods $\mathrm{s}^{72}$ ). Rather, the repeated emphasis on "non-simultaneity" points to the fact that twentieth-century music is much less subject to one linear historical narrative than has often been supposed.

That music history can only be adequately understood and written from an inter- or transnational perspective is neither a new nor, probably, a particularly provocative insight. Concert and opera companies of the seventeenth to nineteenth centuries were characterized by continuous processes of migration and exchange, and their protagonists - composers, virtuosos, singers, impresarios - usually had correspondingly polyglot life stories. ${ }^{73}$ Styles typically blended ingredients from diverse local, supra-regional, and "foreign" traditions, even and paradoxically where they claimed to produce "national styles." ${ }^{74}$ Even in the nineteenth century, fueled by the "poison of nationalism," public recognition could only be gained on the basis of international success, and the musical biographies of Chopin, Liszt, Wagner, or Mahler are unimaginable without transnational journeys - in part forced by economic pressures.

In its turn, music historiography from Johann Nikolaus Forkel, François-Joseph Fétis, and August Wilhelm Ambros to Hugo Riemann has followed the model of a universal history, dating back to the Enlightenment - with the well-known problems associated with this concept in the context of a world marked by colonialism, imperialism, and militarism. In these universal music histories, international or intercontinental relations were by no means presented neutrally, but - since the mid-nineteenth century mostly under Hegelian influence - increasingly shaped teleologically or evolutionarily toward recent European art music as a kind of "optimized" state of global development. This viewpoint downgraded music of other cultures and earlier times to mere early or pre-history, if it was attributed a "historical capacity" at all. Even after 1900, when such Eurocentrism was criticized by comparative musicology, which aimed

69 Pinder, Das Problem der Generation in der Kunstgeschichte Europas and Bloch, Erbschaft dieser Zeit; see Schwartz, "Ernst Bloch and Wilhelm Pinder."

70 Schwartz, "Ernst Bloch and Wilhelm Pinder," 58.

71 "The music history of the twentieth century is radically polyphonic. It disintegrates into different cultures, and no zeitgeist can mediate between them." (Meyer, "Volkstümlich - primitiv - populär," 27. "Die Musikgeschichte des 20. Jahrhunderts ist radikal vielstimmig. Sie zerfällt in verschiedene Kulturen, die kein Zeitgeist miteinander vermittelt.")

72 Mishra, From the Ruins of the Empire, 7.

73 See, Calella, "Migration, Transfer und Gattungswandel."

74 See, among others, Bohlman, Focus: Music, Nationalism, and the Making of the New Europe and La Motte-Haber, Nationaler Stil und europäische Dimension in der Musik der Jahrhundertwende. 
at a more context-sensitive understanding of musical cultures, little changed. Hugo Riemann, for example, reacting to early studies of non-Western tone and tuning systems in the foreword to the first volume of his Handbuch der Musikgeschichte (1904) insisted on the universal validity of the "division of the octave into twelve semitones" and declared this a "historical fact that a few poorly drilled pipes from Polynesia or questionable singing performances of colored females cannot upset." ${ }^{75}$ In his late work Folkloristische Tonalitätstudien (1916), Riemann attempted to substantiate the alleged universality of the European major and minor scales by means of a developmental narrative of melodies and modes in various musical cultures. At that point, the influential nineteenth-century concept of a continuous evolution of cultures had already been challenged by new ideas of a relativity, equality, and multiplicity of cultures as put forward most prominently by Alexander Ellis's epochal comparative study on the "Musical Scales of Various Nations" (1885) and in writings by German-American anthropologist Franz Boas. ${ }^{76}$ This cultural relativism, however, was not yet a well-established concept in early comparative musicology, as testified by Erich Moritz von Hornbostel's and Carl Stumpf's but also by Charles Seeger's basically evolutionary concepts of cultural history, which generally accredited low developmental stages to "primitive" non-Western musics. ${ }^{77}$

Despite the blatant isolationism brought about by totalitarian systems, especially in the first half of the twentieth century, and despite many neo-nationalist tendencies extending into the immediate present, the extent of the transnational network of interrelationships in both art and popular music grew in the twentieth century. At least toward the end of the century, these changing relationships made the need to revise the established music-historical methodologies increasingly clear. It can be said that, as a result of exile and extensive migratory movements, an increased transnational orientation in the arts has been a simple historical fact since the beginning of the twentieth century. This orientation also decisively influenced the aesthetics and reception of prominent émigré artists such as Edgard Varèse, Arnold Schoenberg, Igor Stravinsky, Béla Bartók, Isang Yun, or Tan Dun. The awareness of addressing a global audience shaped compositional aesthetic concepts on a particularly broad scale after 1945, even though initially only few composers defended an explicitly inter- or transculturally oriented universalism $(\rightarrow$ II.2).

Yet even today, a critique of the national bias of music historiography is by no means obsolete. Certainly, Richard Taruskin has been accused of, in volume 5 of his Oxford History of Western Music, which deals with music since 1945, overemphasizing American tendencies ${ }^{78}$ (and among them neotonal currents) and constructing a teleological music-historical narrative from the geopolitical tensions of the Cold War based on the supposed decline of the avantgarde. Taruskin unequivocally defends his narrative in the preface to the paperback edition of the volume:

75 Riemann, Handbuch der Musikgeschichte, vol. 1, V-VI. ("Teilung der Oktave in zwölf Halbtöne," "historisches Faktum, das man mit ein paar mangelhaft gebohrten Pfeifen aus Polynesien oder mit fragwürdigen Gesangsleistungen farbiger Weiber nicht über den Haufen rennt.")

76 Ellis, "On the Musical Scales of Various Nations" and Boas, The Mind of Primitive Man. See Taylor, Beyond Exoticism, 107-108.

77 See Stumpf, Die Anfänge der Musik and Hornbostel, "Die Probleme der vergleichenden Musikwissenschaft." On Seeger see Sharif, Speech about Music.

78 See among others the critique of Taruskin's "xenophobic essentialism" (Cook, "Alternative Realities," 208) and his "erstaunlichen Akt des Ethnozentrismus" ("amazing act of ethnocentrism") (Cox, "Richard Taruskins The Oxford History of Western Music," 103). 
The United States unquestionably inherited musical leadership during this period from Europe - at first by default, as a gift from Adolf Hitler, thanks to whom Schoenberg, Stravinsky, Bartók, Hindemith, Krenek, Korngold, Milhaud, and many others had, by 1945, joined Rachmaninoff, Varese, and Bloch in America, many of them remaining and becoming citizens. The conditions that stimulated the rise of the postwar European avant-garde were largely created by the Office of Military Government, United States (OMCUS), the American occupying force that, for one particularly telling example, financed and at first administered the Darmstädter Ferienkurse, at which total serialism, European-style, was born - in far more direct response to Soviet arts policy than has ever been publicly admitted. Thereafter, it was the music of the American avant-garde, chiefly represented by John Cage and Morton Feldman, and enthusiastically propagated by lavishly subsidized West German radio stations [...], that set the tone for European experimentation. ${ }^{79}$

Despite all legitimate criticism and an unmistakable onesidedness, it can be conceded that Taruskin's arguments not only fulfill a general and basic requirement of cultural-scientific methodology by combining the ideological and institutional historical with aesthetic dimensions of recent music history, but in particular, his text places a finger on sore points and unresolved problems of historiographical methodology (it is no coincidence that Taruskin sees it as the historian's primary task "to disenchant auras and demystify discourses" ${ }^{80}$ ). What could a less polemically charged concretion of such a method look like that also ties in with recent considerations of a global music history as outlined above? The case studies in the following chapters (II.2-II.6) address this challenge by revisiting the situation of an increasingly interconnected world against the backdrop of music-historical situations in Europe, the USA, and East Asia. The focus will be placed on applying the model of entangled history, which, in contrast to models of national history, attempts to "systematically draw attention to the interlocking of the levels of investigation and their mutual conditionality." ${ }^{11}$ This approach aims to explore "social, cultural, and political formation, generally at the national level, that are assumed to be one-toone," ${ }^{82}$ with internationalized art production as a prime example of "areas of contact that are transformed through their mutual interaction." ${ }^{83}$

Transferred to the field of music, interdependencies between compositional decisions, conventions and innovations, institutional developments, and (cultural) political conditions can be considered at the transnational level. In the current subject discourse of musicology, such a model seems to encounter problems, above all, because the division of labor between subdisciplines of musicology is very advanced and sometimes seems irreversible: a "World Music" explored by ethnomusicology, encompassing traditional and popular music, is juxtaposed with globalized "Western Music," for which historical musicology is deemed responsible. ${ }^{84} \mathrm{~A}$ high degree of differentiation and, certainly, the institutional separation of these two disciplines, seem to make linking them perennially difficult.

79 Taruskin, "Preface," XIX-XX.

80 Taruskin, "Afterword: Nicht blutbefleckt?," 280.

81 Werner and Zimmermann, "Vergleich, Transfer, Verflechtung," 630 ("die Aufmerksamkeit systematisch auf die Verschränkung der Untersuchungsebenen und auf ihre wechselseitige Bedingtheit [lenken]"). For the historical classification of this approach see among others Haupt, "Historische Komparatistik in der internationalen Ceschichtsschreibung."

82 Werner and Zimmermann, "Beyond Comparison," 31.

83 lbid., 35 .

84 See Janz, “'Gibt es eine Weltgeschichte der Musik?'” 148. 
New music before and after 1945, however, is at odds with this division simply because in its development, the turn to forms of traditional (often non-European) musical practice, which were increasingly marginalized in the course of musical and social modernization, played a key part - at least since Bartók's and Stravinsky's doubly reflected and broken folklorism ( $\rightarrow$ II.3). What Andreas Meyer refers to as "musical anthropology"85 sheds light on a specific area of tension in twentieth-century art music: between the integration of the marginalized, the "Other," into public discourse and the shift toward the allegedly "non-cultural," "pure" structures as they appear especially in the aesthetics of serial music after 1950, numerous facets of new music emerge in which modernist and anti-modernist motifs are interwoven. In other words, for new music - especially in the 1950 s and 60 s - there is a paradox that exists between a basic cultural relativism - an essentialism insisting on the uniqueness and incommensurability of local traditions - and an advanced structuralist universalism. Such aesthetic transformations cannot be adequately understood without the geopolitical context of the twentieth century.

\section{Transnational Avant-gardes?}

Understanding musical composition, performance, and reception as results of "non-simultaneous" entangled networks, does not, of course, imply the existence of a "transcultural avantgarde." As discussed earlier, a single person may always be conceived or conceive themselves as "transcultural," as not indebted to a specific national or regional cultural essence - perhaps, following Welsch or Han, transcending or even eliminating the very notion of clearly distinct, separate cultures $(\rightarrow$ I.3). However, such an idealized definition of transculturality is ill-fitting with a historical analysis of the decades around 1900 and later periods in which cultural essentialism blossomed in both its hegemonic and its emancipatory forms. Of course, this polarity between authoritarian and relativist cultural essentialism did not stop at the frontiers of musical composition. The way in which composers (mis-)represented and appropriated non-Western musics in musical exoticism and orientalism is a well-studied area of postcolonial musicology. However, we can arguably detect traces of relativist thought in the ideas of some composers who turned to non-Western musical traditions with more dedication and enthusiasm. In such cases, the context of musical modernity, its rejection of established musical modes and practices, helped to overcome prejudice against an assumed low evolutionary stage of non-Western traditions.

One of the questions we have to solve here is whether such modernist approaches toward non-Western musics resulted in a transnational proliferation of compositional techniques and aesthetic ideas that were indeed shared by a "transcultural avant-garde." Even if we, as a first step, attempt here to replace "transcultural" with the more neutral term "transnational," and thus challenge the idea that composers actually created a hybrid aesthetic area beyond the spheres of distinct cultures, the question remains whether these composers formed transnational groups connected either by real networks or at least by shared ideas. My basic argument here will be that such transnational connections were quite loose, especially before the 1950s, but even during later periods.

Adopting Bloch's concept of the "non-simultaneity of the simultaneous" to music historiography may enable us to understand how composers and musicians developed similar ideas and approaches against radically different social backgrounds, and motivated by hardly comparable social and aesthetic agendas ( $\rightarrow$ II.4, II.5). Whether we highlight the entanglement (relationality, simultaneity) of these ideas (guided by the principle of an entangled history) or rather

85 Meyer, "Volkstümlich-primitiv-populär," 34-40. 
their social, geographical, or conceptual distinction and independence (isolation, non-simultaneity; guided by the principle of multiple modernities) might not least be a question of our trust or skepticism toward the idea of a global music history in an emphatic sense. Though my focus on the "non-simultaneity of the simultaneous" may seem to place me in the camp of the skeptics, I must emphasize that I endorse the concept of global music historiography precisely because it makes us aware of such "non-simultaneities" or non-relations.

The other, even more complex issue to be tackled here is the definition of a musical avantgarde. One might argue that we must somehow live with the problem of "musical avant-garde" as an ill-defined term which turns out to be either too narrowly or too broadly defined. The key point for the discussion of a transnational avant-garde is, of course, that it compels us to redefine the notion of "musical avant-garde" in the context of a global dimension of (art) music making. But let us first remind ourselves that the definition of the term avant-garde, even within a Western discourse of new music, is far from evident. Recently, Pietro Cavallotti has insisted that Peter Bürger's standard definition of the term, which takes its cue from early twentiethcentury avant-garde movements in visual arts and literature, is in many ways ill-fitting with twentieth-century music history. ${ }^{86}$ In this sense, Gianmario Borio suggested earlier that an aesthetics of continuously surpassing the features of musical modernity must be considered a key concern of the musical avant-garde (without necessarily calling such procedures "progress" in a narrow sense). ${ }^{87}$ Applying this definition consistently, however, provokes the paradoxical conclusion that the avant-garde concept must be opened up for large parts of twentieth-century music because innovation, the surpassing of previously "modern" musical features, the "remaking of the past," as Joseph N. Straus put it, ${ }^{88}$ is a broad concern of musical poetics from the early to the late twentieth century in and beyond the West.

I believe that this situation prompts us to doubt seriously the usage of the term "avantgarde(s)" in music-historical writing. On the one hand, anti-traditionalist innovation, the critique of unconsidered convention in a contemporary society, has been described as a key feature of modernity in general, so that "avant-garde" and modernity seem to be inclusive or at least closely entangled in the field of music. On the other hand, giving up the term avant-garde enables intercultural music historiography to stress how closely musical modernity and the awareness of non-Western traditions are intertwined:

The ethnographic fascination, from André Jolivet to Boulez, from Varèse to Ceorge Crumb, is not a relic of conventional exoticism. It marks a music that - under the condition of extreme self-alienation and a questionability of all established forms - is willing to discover expression and emotion in the encounter with the distinct Other of reason and conventional expression. ${ }^{89}$

The affection and solidarity which many composers of new music in the twentieth century developed toward non-Western "traditional music" arguably grew out of the observation that

86 Cavallotti, "Avantgarde," see Bürger, Theory of the Avant-Garde.

87 Borio, Musikalische Avantgarde um 1960.

88 See Straus, The Remaking of the Past.

89 Meyer, "Volkstümlich - primitiv - populär," 34. ("Die ethnographische Faszination, von André Jolivet bis Boulez, von Varèse bis George Crumb, ist kein Relikt des konventionellen Exotismus. Sie kennzeichnet eine Musik, die bereit ist, unter Bedingungen einer extremen Selbstentfremdung, einer Fraglichkeit aller überkommenen Formen, in der Begegnung mit dem ganz Anderen der Vernunft und des konventionellen Ausdrucks dennoch Ausdruck und Emotion wiederzufinden.") 
both globalizing art music in the Western tradition and traditional non-Western musics were marginalized by the processes of canonization, commerce, and the abounding genres of popular music established since the advent of the recording industry. For emerging non-Western composers, the situation was even more complex, as traditional musics underwent accelerated and often radical transformations, usually closely linked to nationalist, pro- or anti-Western agendas. It is thus vital to see a connection between the modernist readings of traditional nonWestern musics by Western-educated composers and these composers' social situation. I will therefore aim consistently to place emphasis on the social embeddedness of the musical works that serve as my case studies.

\section{Internationalism and Universalism: Repercussions of Political and Cultural History}

Both before and after 1945, "internationalism" and "universalism" have been the most prominent concepts of global entanglement; it therefore seems consistent to dedicate a closer reading to their changing meanings and implications in music-historical contexts. By attending to the controversial debates which arose from these ideas, this chapter demonstrates how the increasing awareness among composers (and, in turn, performers and audiences) of acting as "agents" in an international or global context substantially affected compositional technique and aesthetics. I also show how the "simultaneity" of such an increasingly globalized musical communication continued to imply many "non-simultaneities" between global and local, Western and non-Western music aesthetics or "realities." I suggest that these "non-simultaneities" in particular offer a key to understanding the music-historical dynamics of these periods. This will provide a framework for detailed case studies to follow in the subsequent chapters (II.3-6).

\section{Internationalism}

The dedication to internationalism in twentieth-century music predated the Cold War period by several decades, and resulted from both political-militarist confrontation and a certain social isolation of modernist music in European societies. The trend toward internationalization was in fact already a global characteristic of political movements in the second half of the nineteenth century, including the First International, founded by Karl Marx in 1864; the Second International, founded in Paris in 1889; the International Council of Women founded in Washington, D.C., in 1888; and international pacifism, emerging from the Universal Peace Congress in Paris (1889) and the Conventions of Geneva (1864) and The Hague $(1899,1907)$, as well as the first steps toward the establishment of international law. In general, the decades around 1900 saw a proliferation of international non-governmental organizations in many areas, particularly in the social and political domain, which became crucial sites of activity for the globalization process. ${ }^{90}$ Not least, this tendency accelerated a normalizing universalization of economic, communicative, and technical standards such as standardized measures and weights - but it also led to an increasing internationalization of cultural events as marked by the revitalized Olympic Games in $1896 .{ }^{91}$ World exhibitions in London (1851/62/86), Paris $(1855 / 67 / 78 / 89,1900)$, and elsewhere celebrated "world peace" and "social harmony" as

90 Osterhammel, Die Verwandlung der Welt, 723-735.

91 Ibid., 732. 
presumably brought about by Western civilization. ${ }^{92}$ Some had a profound impact on cultural and musical processes and innovations, ${ }^{93}$ suggesting a fine line between imperialist strategies of appropriation and modernity-skeptical cultural pessimism $\rightarrow$ II.1) ${ }^{94}$ In addition, the internationalization of the world did not exclude the (mis)use of international communication for nationalist agendas. ${ }^{95}$

The International Society for Contemporary Music (ISCM) was founded in 1922 to overcome the national isolation of musical scenes and institutions resulting from World War I and the largely nationally defined infrastructure of nineteenth-century musical institutions that had been deeply involved in musical "nation building." Inspired by the League of Nations founded in 1919, and the Club of Poets, Essayists, Novelists (PEN) founded in 1921, ${ }^{96}$ the ISCM intended to represent and support composers, performers, and amateurs of contemporary music "of all aesthetic directions and tendencies - irrespective of citizenship, race, religion, or political beliefs. ${ }^{197}$ Although nationalist and aesthetic conflicts arose within the ISCM early on, the organization remained a platform for a relatively non-ideological, though clearly Western-oriented, international exchange - Soviet and communist countries never applied or were considered for membership. ${ }^{98}$ Indeed, the "Prague manifesto," approved by the Second International Congress of Composers and Music Critics in May 1948, envisioned the foundation of a counter organization. ${ }^{99}$ The countries under Soviet control during the decades until 1991 were dominated by the powerful Union of Soviet Composers under the general secretary Tikhon Khrennikov, although the repression of Western-oriented aesthetics varied considerably, with Poland and later former Yugoslavia and East Germany establishing particularly close ties of musical exchange with the West.

In the immediate postwar period, the word "internationalism" usually had positive connotations when used by Soviet-oriented writers, based on the idea of solidarity among nations fighting for a common cause against capitalist exploitation. ${ }^{100}$ Most notably, this "internationalism" was based on the preservation of national identities and characteristics, in declared contrast to Western capitalist "cosmopolitanism," which was considered to erode these characteristics. The word "cosmopolitan" was also used as a propagandist invective during the concealed Stalinist anti-Semitic campaigns and pogroms between 1949 and $1953 .{ }^{101}$ In the Prague manifesto, formulated by Hanns Eisler, these terms were connected with the diagnosis of a "serious crisis" of contemporary music, contributing to a much-repeated trope of postwar musicrelated discourse and, indeed, of the modernist discourse in general. ${ }^{102}$ In both popular and art

92 Ibid., 41-42.

93 See Fauser, Musical Encounters at the 1889 Paris World's Fair.

94 See Born and Hesmondhalgh, Western Music and Its Others.

95 Osterhammel, Die Verwandlung der Welt, 733.

96 Nonnenmann, "Institutionen/Organisationen," 284-286.

97 Haefeli, ICNM: Die Internationale Gesellschaft für Neue Musik, 53 ("gegründet zur Förderung zeitgenössischer Musik aller ästhetischen Richtungen und Tendenzen - ohne Rücksicht auf Staatsangehörigkeit, Rasse, Religion oder politische Ansicht ihrer Mitglieder").

98 Russia has been a member of the ISCM since 2005, China since 2012. Japan joined the ISCM in 1935, South Korea in 1957, Hong Kong (Hong Kong Composers' Guild) in 1983, Taiwan in 1989.

99 Kovácz, "Die Institution - Entstehung und Struktur," 118.

100 The following information is predominantly based on ibid., 116-139.

101 See Azadovskii and Egorov, "From Anti-Westernism to Anti-Semitism."

102 See Meyer, "Volkstümlich - primitiv - populär," 39-40. 
music, the reason for this "crisis" was believed to lie in the "individualism" and "subjectivism" of the Western composer and performer.

Leftist artists living in the West usually defended the freedom of individual expression. They included Hermann Scherchen and most prominently René Leibowitz, whose book L'artiste et sa conscience (1950) features a critique of his former student Serge Nigg's inclination toward the program of the Prague manifesto. ${ }^{103}$ Some were more explicit in their support for Eisler's program, such as the prominent scholar and critic Hans Mayer, one of the most influential speakers during the first five years of the Darmstadt Summer Course (1946-50). Mayer sought to reconcile socialist realism with musical modernism, including his positive assessment of Schoenberg and the Viennese School attuned to the rhetoric of a "crisis" of bourgeois culture attributed to an increasing gap between art and "reality." For Eisler and Mayer, the origins of modernity's crisis were to be seen in the "emancipation from the religious-cultic to the cultural-civil" and the implied processes of individualization and anti-collectivism. In contrast to the official Zhdanov doctrine, however, Mayer was skeptical about a preservation of "national characteristics" and associated "formalism" with Stravinsky's and Hindemith's neoclassicism rather than with atonality and dissonance. The audience and press reception of the early Darmstadt Summer Course demonstrates how such "moderate" positions during the years around 1950 increasingly gave way to a more polarized rhetoric. Such polarization is especially documented in East German press reviews that idealized nationalist and folkloristic styles, of which Béla Bartók was considered exemplary, while denouncing "international" and "formalist" tendencies, particularly associated with American composers such as Edgard Varèse - whose lifelong fight against "formalist" aesthetics in this context evidently remained unnoticed. Thus in Soviet-influenced rhetoric, the term "international" had changed from positive to negative within a few years. Meanwhile, the Darmstadt course increasingly claimed to represent a true "international" platform, not least marked by the notable change of name from "Ferienkurse für internationale neue Musik" to "Internationale Ferienkurse für neue Musik" in 1948. In the following decade, the proportion of non-German participants increased from 4.3 percent in 1948 continuously to a peak of 70.4 percent in $1961 .{ }^{104}$

Musical trends and works from that period, which manifest elements of such new "internationalism," may be found most prominently in interwar, wartime, and postwar neoclassicism, which from the beginning had been declared an "international" trend with profound influences on pre- and postwar musical history in Russia, France, Eastern and Northern Europe, and Latin America. The awareness of writing for a broad international audience, however, informs many politically imbued works of the period that are not of the neoclassicist repertoire, such as Arnold Schoenberg's A Survivor from Warsaw (1948) - which instigated a particularly broad and controversial discussion on political music in postwar Europe, ${ }^{105}$ Karl Amadeus Hartmann's postwar Symphonies 3 to 8 (1945-62), ${ }^{106}$ and Hanns Eisler's paradigmatic Deutsche Symphonie (1935-57). ${ }^{107}$ In their idioms and programs as well their genesis and performance history, these pieces mirror particular concrete facets of wartime and postwar history, as do the well-known examples of Shostakovich's Symphonies 9 to 13 (1948-62) and Stravinsky's Sym-

103 See Carroll, Music and Ideology in Cold War Europe, 116-131 and Sprout,"The 1945 Stravinsky Debates."

104 Kovácz, "Die Institution - Entstehung und Struktur," 62.

105 Carroll, Music and Ideology in Cold War Europe, 116-131, Calico, Arnold Schoenberg's A Survivor from Warsaw in Postwar Europe, and Shreffler, "Cold War Dissonance," 53-54.

106 See Mosch, “'Freiheit war es immer, die er meinte.' Karl Amadeus Hartmann und die 'Stunde Null.”

107 See Wißmann, Hanns Eisler: Komponist, Weltbürger, Revolutionär, 107-126. 
phony in Three Movements (1943-45). Most composers (including the prominent cases introduced below, $\rightarrow$ II.5), even if they did not react to the political situation or the terrors of the recent past in similarly explicit terms, consequently tended to conceive of their potential audience as a "global" community, which, not least, in many cases may have helped to overcome local resistance to their innovations. This "global audience," naturally, turned out in some ways to be an imagined community, and was not dissimilar to the "humanity" Theodor W. Adorno had in mind when he termed Beethoven's symphonies "public addresses to humanity" ("Volksreden an die Menschheit"108). Against this background, postwar musical internationalism and universalism must arguably be viewed not only as reactions against the nationalist discourses of the recent past, but also as evidence of an increasing awareness of global interconnectedness - including the awareness that many trends in Cold War policies were threatening to push the world back into localist or regionalist isolationism. The two most influential music-historical tendencies in this context were the invention of serial music, with its structuralist universalist claims, and forms of ethnically accentuated multi- or transethnic universalism occurring later on.

\section{Universalism}

Whereas "internationalism" seems to signify a complex of global or transnational networks, often implying the wish to overcome restrictive nationalist thinking and agency, "universalism" clearly indicates a more emphatic and optimistic world-embracing concept aimed at transcending the limits of national or culture-specific discourse, heading toward "world music," "world literature," "world art," etc. ${ }^{109}$ Universalism in the European context is primarily a product of Enlightenment thought, in the area of music reflected in the well-known quote attributed to Joseph Haydn in which he assumes that his "language" can be understood throughout the whole world. This idea was criticized and met with skepticism in many areas of nineteenthcentury aesthetics. ${ }^{110}$ At the same time, universalism served as the founding ideology of nineteenth-century colonialism and imperialism. The concept is thus heavily involved in political history and ideology:

In the same period when most political philosophers began to defend the principles of universalism and equality, the same individuals still defended the legitimacy of colonialism and imperialism. One way of reconciling those apparently opposed principles was the argument known as the "civilizing mission," which suggested that a temporary period of political dependence or tutelage was necessary in order for "uncivilized" societies to advance to the point where they were capable of sustaining liberal institutions and self-government. ${ }^{111}$

In music historiography and comparative musicology, Eurocentric universalism dominated the early decades of the disciplines almost exclusively. Even though comparative musicology criticized Eurocentric music-theoretical and music-historical methodologies early on, the search for musical universals continued to shape (and confine) later studies in global music history,

108 Adorno, "Einleitung in die Musiksoziologie," 281.

109 See Utz, Neue Musik und Interkulturalität, 26-43, Heile, "Weltmusik and the Globalization of New Music," Huang, "Constellating World Literature," and Fillitz, "Anthropology and Discourses on Clobal Art."

110 Dahlhaus, "Historisches Bewußtsein und Ethnologie," 220; see Janz, "'Gibt es eine Weltgeschichte der Musik?," 147.

111 Kohn, "Colonialism." 
such as Walter Wiora's Die vier Weltalter der Musik $\rightarrow$ II.1). The idea of musical universals still figures in the (predominantly ethnomusicologically based) discourse on "world music," which tends toward a notion of "music" that encompasses all kinds and genres worldwide, seemingly without introducing hierarchies: ${ }^{112}$

Whether musical systems leak at the borders or not, languages are not all that coherent, being subject to constant change, and failing in the test of precise geographic borders. Whether there is something still to be said for the concept of music as the universal language of mankind, and whether enjoying the sounds of a foreign music is identical with understanding may be argued. The issue is not 'one' or 'many,' but in what ways the notion of music and musics provide insight. A history of world music should, if it does not come down on one side or the other, show how the two perspectives provide different interpretations of what happened. ${ }^{113}$

It is obvious (and has been explained by many authors) that universalism is dialectically opposed to the concepts of (cultural) essentialism, particularism, and relativism. The latter concepts tend to deny the possibility of universal forms of artistic (or political) articulation and to emphasize cultural uniqueness and the partial incompatibility or alterity of a "culture" or "nation" with other comparable entities. Relativism in particular seems to function essentially as a critical counterpart of universalism, exemplified by some approaches in postcolonial studies. Nonetheless, cultural and national essentialisms are deeply embedded in the history of modernity and act both as intrinsic components in the process of nation building and as the basis of most claims of cultural difference. ${ }^{114}$ At the same time, we can recognize that essentialism and universalism are not mutually exclusive but rather interdependent concepts: universalists often presuppose basic and essential differences - cultural, national, racial, political, aesthetic, stylistic - that are then emphatically "transcended" in an act of "synthesis" or "integration." The idea of essential entities is a shared assumption of both universalism and essentialism.

Therefore, a reasonable and careful discussion about whether different forms of music, art, religious ideas, or social structures, etc. are (partly) compatible or not might easily revert to ideological forms of opposition, or even become the basis for new kinds of radicalized thinking or political misuse, as for example in diverse forms of neo-nationalism. Such a reclamation of identities seems to recur in waves. The term "neo-nationalism," for example, has been used in describing European music history of the 1910 s and 1920s (pre- and post-World War I affirmations of national identities, as in Stravinsky's "Russian" ballets or in Bartók's idealization of peasant music; $\rightarrow$ II.3). This idea, however, can equally apply to dimensions of transnational history of the early 1990s (post-1989, post-Cold War reclamation of national identity especially in Eastern Europe, but also in East Germany, as well as a first wave of right-wing populist parties and politicians) and to the present period (the reaffirmation of national interest and xenophobic sentiments throughout Europe and in many Asian and American countries as an obvious counter-reaction to migration and economic changes resulting from globalized political and economic dynamics). In Asia, (neo-)nationalist tides have proved influential for music history, as can be identified in many areas of twentieth-century music in Japan, Korea, and China $(\rightarrow$ III).

\footnotetext{
112 See Janz, "'Gibt es eine Weltgeschichte der Musik?," 148.

113 Nettl, "On World Music as a Concept in the History of Music Scholarship," 25.

114 See, e.g., Zhou, "Essentialist Legacies and Shifting Identities."
} 
In European music from the 1940s to the 1970s, there are at least four basic forms of universalism, which I label "religious" or "spiritual universalism," "technological universalism," "structuralist universalism," and "transethnic" or "transcultural universalism," and I will characterize each below. These classifications are all indebted to Enlightenment ideas regarding "art" and music, particularly the notion of art as a universal phenomenon, understood as a "collective singular" with the composer acting as a kind of high priest of a "religion of art" with potentially global impact. My categories do not exclude one another, but rather interact in myriad ways. From this perspective, these different types of musical universalism potentially appear as a particularly apt exemplification of the "non-simultaneity of the simultaneous" in pre- and postwar music history, which will ultimately become evident in the case studies discussed below.

\section{Religious and Spiritual Universalism}

Religious thought mostly tends to be universal by definition. This universalism to some extent lets the political impact of Enlightenment universalism and the universalism of political theories and ideologies such as Marxism appear as necessary consequences of a critique of religion (eventually itself taking on many features of a religion). The "sacred" implications of musical performance and reception became particularly pertinent in nineteenth-century "religion of art," eventually motivating composers to conceive an all-encompassing reform of the modes of musical presentation and reception, the most prominent example being Richard Wagner. The decades around 1900 saw a wave of highly influential post- or pseudo-religious universalist theories such as Theosophy and Anthroposophy, many of which incorporated fragments of mystic Asian traditions. An important Russian-American-Italian trajectory in this respect leads from Alexander Scriabin and Ferruccio Busoni to Dane Rudhyar and Giacinto Scelsi. ${ }^{115}$ Olivier Messiaen's outline of a "theological" music was deeply informed by such individualized mystic universalism, as it was cultivated during the 1930s in the group La Jeune France by André Jolivet, among others, ${ }^{116}$ while the inspiration drawn from the Renouveau catholique movement also included considerable culturally conservative elements. ${ }^{117}$ Messiaen's Indianinspired rhythms, however, were not used to evoke Indian music (in contrast to the clearly audible evocation of gamelan music in the Turangalila Symphony, 1946-48, or of Japanese gagaku in the fourth movement of the Sept Haïkaï, 1964), but rather represented a "timeless," primordial theological world order, thus also connecting to the quadrivium tradition of religiously based numerical rationalism and symbolism. ${ }^{118}$

In the early 1950s, influenced by Messiaen's religiously based universalism, Karel Goeyvaerts and Karlheinz Stockhausen were strongly attracted to the idea of a "pure structure."119 Early on, Stockhausen grounded his activity on the idea of being sent on the compositional path by a divine message, ${ }^{120}$ claiming that his music merely "translated" divine vibrations. ${ }^{121}$

115 Reish, "The Transformation of Giacinto Scelsi's Musical Style and Aesthetic," Celestini, "Busoni und Scelsi," Utz, "Klang als Energie in der Musik seit 1900."

116 Gut, Le Groupe Jeune France, Borio, "Vom Ende des Exotismus."

117 Lindhorst, "Gedanken, Bilder und Schlüsselbegriffe des Renouveau catholique in den Texten von Olivier Messiaen."

118 Bruhn, Messiaens musikalische Sprache des Claubens.

119 Sabbe, Karlheinz Stockhausen. ... wie die Zeit verging ...

120 Blumröder, Die Grundlegung der Musik Karlheinz Stockhausens, 73.

121 lbid., 89. 
Stockhausen also proposed more explicitly culturally or ethnically defined universalist ideas. Inspired by a 1952 Paris concert with Balinese and Tibetan music, Stockhausen (retrospectively) claimed to have decided to "make a kind of music that relies on the tradition of music from the entire world."122 This claim acquired neo-imperialist undertones and thus aroused heated debate in a later formulation, in which Stockhausen proposed to write "not 'my own' music but a music of the whole earth, of all countries and races." ${ }^{123}$ The mystic tradition of religious intuition as a basis for the compositional process, with the composer acting as a "medium" between divine forces and sounding material in Stockhausen's case, can be linked to at least two major traditions of thought: Messiaen's "theological" aesthetics, in which mystic universalism had already been closely linked to the reception of non-Western musical traditions harking back to Debussy's, Roussel's, and Delage's "submerged exoticism"124 around $1900(\rightarrow$ II.4); and Catholic thought, which substantially influenced Stockhausen's conception of music, resulting in a characteristic simultaneity of rationalism and mysticism. ${ }^{125}$

\section{Technological Universalism}

The argument that technological innovation, usually considered a driving force of modernity if not its main constituting factor, has led to the "time-space-compression"126 typical of globalization processes $(\rightarrow$ I.2), is familiar from our immediate present where the high-speed internet, Google, and YouTube seem to contribute to a readily available and continuously expanding archive of "world cultures." The essentialist, materialist, and technocratic conviction that a musical recording has the capacity to "represent" a specific culture; the misconception that technology is a culture-independent force, transcending traditional forms of encultured communication and articulation; and the optimistic enthusiasm that saw new technologies as a symptom of a "new era" can all be detected clearly in many areas of European music of the 1950 s and 1960s. ${ }^{127}$ Marshall McLuhan's trope of the "global village" offers the best-known theorization of this overt technological optimism (McLuhan, The Gutenberg Galaxy, 1962, German translation 1968; Understanding Media, 1964; The Medium Is the Message, 1967; War and Peace in the Global Village, 1968 ${ }^{128}$ ). McLuhan's theory was sparked by sensational technological innovations during the 1960 s, culminating in the first satellite communication in $1969 .{ }^{129}$ Many of Stockhausen's statements suggest close ties to McLuhan's ideas, as he repeatedly invokes the metaphor of the "global village"; ${ }^{130}$ indeed, McLuhan is quoted once in Stockhausen's essay "Ein

122 Stockhausen, "Nr. 13: Momente für Sopran, 4 Chorgruppen und 13 Instrumentalisten," 133 ("es mir bewußt wurde, daß ich mich sogar in kleinsten Fragen der Klangmaterial-Auswahl entscheiden müßte, ob ich mich streng an unsere zentraleuropäische Tradition halte oder eine Musik mache, deren Tradition die Musik der ganzen Welt ist").

123 Stockhausen, "Telemusik," 75 ("nicht 'meine' Musik zu schreiben, sondern eine Musik der ganzen Erde, aller Länder und Rassen").

124 See Locke, Musical Exoticism, 214-244.

125 Gutknecht, "Das Geistliche im realen Kompositionsprozeß Stockhausens," Ulrich, "Spirituelle All-Einheit und das Subjekt des Komponisten," and Utz, Neue Musik und Interkulturalität, 141-144.

126 Hall, "The Question of Cultural Identity," 300-302.

127 Utz, Neue Musik und Interkulturalität, 147-148.

128 See Heile, "Weltmusik and the Clobalization of New Music," 105-106.

129 Siebert, Musik im Zeitalter der Clobalisierung, 86.

130 Stockhausen, "Interview über Telemusik," 81 ("Wir werden immer mehr der Tatsache bewußt, daß dieser ganze Globus ein einziges Dorf ist."). 
Mundstück" from 1969. ${ }^{131}$ In a 1968 interview on his electronic composition Telemusik, realized in the NHK studios Tokyo in 1966, Stockhausen offered clear examples of how this technological universalism may be put into compositional practice:

Overcoming time and space at such a speed that the time delay and the distance become almost zero has become possible only by applying these modern technical possibilities of communication. They make it possible for the first time for this world to become one world. And for us musicians, the tools for this are microphones and magnetic tapes. They may produce other tools that improve those first possibilities. This is the beginning of universalism; the integrating force is expressed in the technical devices we use. The possibility of my phoning to Africa to order a tape recording, whose parts I then combine with electronic sounds that I make in Tokyo, is an outrageous fact that enables us to connect things that were previously completely unconnected. In the past it was only possible to listen to music from Africa if you traveled there. And who had that opportunity? Today we can all listen to this music. [...]

You just shouldn't try to level things. I do not strive for a 'synthesis' in which everything merges into a huge mishmash, on the contrary: one still has to support the characteristic structures in a chosen context. I don't want to destroy anything, but I want to preserve the independence of the individual phenomena in the sense of the aforementioned polyphony. After all, individual aspects of a structure are related to other individual details. ${ }^{132}$

This skepticism toward synthesis, however, does not fit in with the affirmative synthetic universalism of Stockhausen's electronic composition Hymnen (1965-67), based on forty different national anthems, in which the fourth "region" of the work culminates in the anthem of the imaginary country of Hymunion (part of the cosmic Harmondie) led by Pluramon: ${ }^{133}$ the universalist claim, based on the technological availability of sound documents and their collage-like presentation, is filtered into an "original" composition, superseding pluralism and reinstalling the genius composer as a universalist, "global" agent empowered by technology. ${ }^{134}$

131 Stockhausen, "Ein Mundstück," 300.

132 Stockhausen, "Interview über Telemusik," 83 ("Zeit und Raum in dieser Geschwindigkeit überwinden, daß die Zeitverzögerung und der Abstand fast Null werden, können wir eben erst dadurch, daß wir diese modernen technischen Möglichkeiten der Kommunikation anwenden. Sie machen es erstmals möglich, daß diese Welt eine Welt wird. Und die Mittel hierzu sind bei uns Musikern Mikrophone und Magnetophonbänder. Aus ihnen werden vielleicht andere Mittel hervorgebracht, die jene Möglichkeiten noch verbessern. Das ist der Anfang des Universalismus. Die integrierende Kraft drückt sich aus in den technischen Mitteln, die wir verwenden. Die Möglichkeit, daß ich nach Afrika telephonieren kann, um eine Tonbandaufnahme zu bestellen, deren Teile ich dann mit elektronischen Klängen, die ich in Tokio herstelle, verbinde, ist eine unerhörte Tatsache, die es erlaubt, Dinge in Beziehung zu bringen, die bisher völlig unbezogen waren. Früher war es nur dann möglich, Musik aus Afrika zu hören, wenn man dorthin reiste. Und wer hatte diese Chance schon? Heute können wir alle diese Musik hören. [...] Man darf nur nicht versuchen, die Dinge zu nivellieren. Ich strebe nicht eine 'Synthese' an, bei der alles in einem riesigen Mischmasch aufgeht, im Gegenteil: Man muß die charakteristischen Cebilde noch unterstützen in einem gewählten Kontext. Ich will ja nichts zerstören, sondern im Sinne der genannten Polyphonie die Selbständigkeit der einzelnen Phänomene erhalten. Es werden ja einzelne Momente eines Cebildes zu anderen Einzelheiten in Beziehung gesetzt.").

133 See Siebert, Musik im Zeitalter der Clobalisierung, 88.

134 Revers, "Europäische Treibhausblüten," 192-196 and Utz, Neue Musik und Interkulturalität, 165-171. 
The implied position of the composer becomes even clearer in Stockhausen's Telemusik, in which - contrary to the composer's emphasis on a diversity of musical styles that should not be distorted by creating a "superstyle," but rather retain their diversity - Stockhausen's procedures do not give a prominent role to the articulation of cultural difference, but appear firmly rooted in the aesthetics and techniques of Western Europe's electronic music of the 1950 s and 1960 s. $^{135}$ The cultural difference of the recorded music is transformed and filtered into a musical context in which the uniqueness of the individual elements is almost completely erased - Telemusik employs both synthetically generated sounds from sine tone and triangle wave generators and recordings of traditional art and folk music from Japan, China, Vietnam, Bali, sub-Saharan Africa, indigenous Amazonian peoples, Spain, and Hungary. Stockhausen's Pluramon concept, which strives for a balanced relationship between pluralism and "monism," "136 is hardly put into practice here - the monism of Stockhausen's compositional style clearly predominates. When fragments of the traditional music recordings become audible, they are heard in a blurred, sometimes even grotesquely distorted manner that seems to mock the original performance style. Even if Stockhausen's reluctance to render the qualities of the traditional music genres used might have been rooted in the wish to respect their "original" form by not quoting them literally, the question remains why he actually decided to make use of them in the first place. The analyses show that the reasons for this decision do not stem from the specific musical qualities of the recorded music, nor from its acoustic properties; ${ }^{137}$ rather, Stockhausen's conventionally Western conception of a composer as universalist and "discoverer," based on nineteenth-century religion of art and Catholic faith, probably should be considered the main reason.

\section{Structuralist Universalism}

The cases of Messiaen and Stockhausen clarify how religious and structural universalism interrelate. The assumption of the universal, culture-free, or transcultural properties of serial structure is an oft-invoked topos, although it was employed in most cases with reservation and, more importantly, articulated in quite different ways by different composers and authors. In both the Cologne and Paris contexts, the impact of universalist linguistic theories should be noted (Saussurian and Lévi-Straussian structuralism in Paris and Meyer-Eppler's information-theoretical research into an artificial hyperlanguage in Cologne). Although the common understanding of a "global" structure in which "everything is contained," supposedly reflecting a "universal, planned order," 138 was rarely connected to explicit cultural or ethnic claims during the 1950s, the interpretation of serial technique as a "culturally neutral" basis of postwar musical language was emphasized retrospectively in Dieter Schnebel's 1972 essay "New World Music." This text was written for the catalogue of the Munich Olympic Games 1972, entitled World Cultures and Modern Art: The Encounter of Nineteenth-and Twentieth-Century European Art and Music with Asia, Africa, Oceania, Afro- and Indo-America:

135 See the analyses in Utz, Neue Musik und Interkulturalität, 153-165, Kohl, "Serial Composition, Serial Form, and Process in Karlheinz Stockhausen's Telemusik," Erbe, "Karlheinz Stockhausens 'Telemusik," and Hünermann, "Transkription und Intermodulation."

136 Cott, Stockhausen. Conversations with the Composer, 144 and Shimizu, "Was ist PluraMonismus?"

137 This is claimed by Maconie, The Works of Karlheinz Stockhausen, 207.

138 Stockhausen, "Zur Situation des Metiers," 46-47 ("universelle[], geplante[] Ordnung"; "Musikjeweils als Vorstellung jener umfassendsten 'globalen' Struktur zu verstehen, in die alles einbezogen ist”; emphasis original). 
The music produced after the Second World War, especially in Europe, marked a new beginning. The new music was distinguished from the old in that it lacked to a large extent both the traditional rules and regional coloring. We can almost talk of the birth of a futuristic world language. Although the new compositions stemmed from Western music, they did not necessarily demand a knowledge of it for their understanding. They were the creations of composers hailing from all the industrialized countries, without more than hidden regional reminiscences: the serial music of a Korean has as little of the oriental about it as that of a Swede has of the Nordic. This rather uncharacteristic and seemingly traditionless world music of a technological age at first avoided employing the customary apparatus of the bourgeois era. The usual operatic and concert forms were scorned and the compositions were written for unorthodox ensembles. ${ }^{139}$

Considering that the catalogue included both a "postcolonial" criticism of aesthetic (and political) universalism ${ }^{140}$ and seemingly "neutral" descriptions of how Western artists used "nonWestern material,"141 this period today appears as a transitional phase from a structurally to an ethnically rooted universalism while, at the same time, the deep problem inherent in musical universalism slowly came to be more openly disputed, especially in the wake of Stockhausen's essay "Weltmusik" from 1973, which can be considered a peak of his universalist aesthetics, summarizing ideas since the $1950 \mathrm{~s}^{142}$ and particularly building on a Darmstadt seminar on "meta-collage" from 1970. ${ }^{143}$ The postwar "ideology" of a nonpolitical role of art and music here takes on the increasingly esoteric and vague language Stockhausen developed since at least the late 1960s, denying any postcolonial impact in favor of a "process of inner renewal":

One often hears the argument today that Europeans had transformed their earlier land-colonization into cultural colonization. In other words, today, the tourists are the conquerors and exploiters in another form. But this argument overlooks the fact that under the surface mankind is moved by trends of development which crop up in all cultures. One cannot speak of separate problems of some island culture without taking into account the trends which bind this island culture to all others. The process of inner renewal in all cultures begins more or less at the same time $[. . .]^{144}$

139 Schnebel, "New World Music," 338.

140 Lissa, "Vom Wesen des Universalismus in der Musik."

141 Pelinski, "Oriental Colouring in the Music of the Nineteenth Century," Pelinski, "Musical Exoticism Around the Year 1900," Raab, "Difficulties in the Fusion of Jazz and Symphonic Music," Raab, "Negro Music in Latin America," Schnebel, "New World Music."

142 Siebert, Musikim Zeitalter der Clobalisierung, 41-92.

143 Ibid., 45. The essay was written by Stockhausen on 8 April 1973. Excerpts first appeared in the Frankfurter Allgemeine Zeitung on 17 November 1973. Printed unabridged in Musik und Bildung 6, no. 1 (1974) and in Universitas 31, no. 6 (1976). Published in Stockhausen's Texte zur Musik, Vol. 4 (see Stockhausen [1973] 1978).

144 Stockhausen, "World Music," 5-6 (Stockhausen, "Weltmusik," 470. "Man hört heute oft das Argument, die Europäer hätten ihren bisherigen Land-Kolonialismus umgewandelt in einen Kultur-Kolonialismus. Mit anderen Worten: die Touristen seien Eroberer und Ausbeuter in anderer Form. Man übersieht aber dabei, daß die Menschheit unter der Oberfläche durch Entwicklungsströme bewegt wird, die in allen Kulturen auftauchen. Man kann nicht über separate Probleme irgendeiner Inselkultur sprechen, ohne die Ströme zu berücksichtigen, die diese Inselkultur mit allen anderen verbinden. Der Prozeß der inneren Erneuerung in allen Kulturen setzt mehr oder weniger gleichzeitig ein [.....") 
It is surely characteristic that Stockhausen recognized some crucial features of the globalization process early on when he emphasized the interconnectedness and entanglement of global regions, while his belief in a deterministic convergence and "inner renewal" of decaying and perishing cultures shows clear traits of early twentieth-century cultural pessimism in the style of Dane Rudhyar's writings of the 1920s and 1930s, which were in turn influenced by politically proto-fascist writings such as Oswald Spengler's Der Untergang des Abendlandes (The Decline of the West): $:^{145}$

[...] at the same time, cultures are destroyed from within. They are over-ripe and in a state of decay, and therefore definitely destined to change into something new. The consequence of this rapid process of the disintegration of individual cultures is that they all lead into a more unified world culture. ${ }^{146}$

This decline sets the stage for the "savior-composer," labeled "earthling" (Erdling) by Stockhausen, who has abandoned the chimera of a "personal style"; ${ }^{147}$ he "literally embrace[s] the earth," and sets out to create "new forms [...] in which many aspects - stylistic qualities - are united." Only to this end is the "[p]reservation of the greatest possible number of musical forms of all cultures" deemed necessary. ${ }^{148}$

The complex interrelation between presumably declining cultures - both Western and nonWestern - serving as a justification for the individual genius composer's task of taking up the "invigorating" forces of global musical traditions, the call for a preservation of traditional musical cultures (to be freely used as material in new compositions), and the assignment of a key role to the composer, staged as a preserver of traditions and innovator transcending them at the same time, is a paradox that lies at the heart of globalized art music's universalist tendencies from the 1960s up to the 2000s. It recurs, for example, in Tan Dun's intermedia cello concerto The Map (2002), which integrates video footage of music from southwestern Chinese minorities into a conventional Western orchestra with a cello soloist. In this work, Tan Dun seems to be playing two roles simultaneously, each coming from a different ideological standpoint: that of the preserver of vanishing cultures, specifically as an ethnically Chinese artist, and that of the innovator of the modern Western orchestra, a citizen of the world and practitioner of Western art $\rightarrow$ III.5). ${ }^{149}$

\section{Transethnic Universalism}

Stockhausen's arrival at an explicit transethnic universalism was undoubtedly instigated by his increasingly international success as a composer, which included performances, commissions, and invitations from the United States (1958, 1961, 1965, 1966-67) and Japan (1966, 1970,

145 Ertan, Dane Rudhyar, 18-21; see Utz, "Klang als Energie in der Musik seit 1900."

146 Stockhausen, "World Music," 4 (Stockhausen, "Weltmusik," 469. "[...] gleichzeitig zerstören sich Kulturen von innen heraus selber. Sie sind überreif und im Zustand der Fäulnis, dazu bestimmt, sich in etwas Neues zu verwandeln. Die Konsequenz aus diesem schnellen Prozeß der Auflösung individueller Kulturen ist, daß sie alle in eine mehr einheitliche Erdkultur münden.")

147 Ibid., 9. (Stockhausen, "Weltmusik," 472. "persönliche[r] Stil.")

148 Ibid. (Stockhausen, "Weltmusik," 472-473. "buchstäblich die Erde umfassen”; "neue Cebilde [...], in denen eine große Zahl von Aspekten - stilistischen Qualitäten - vereinigt ist”; "Erhaltung möglichst vieler musikalischer Formen aller Kulturen.")

149 See Young, "The Voicing of the Voiceless in Tan Dun's The Map." 
1976-77), among others. The multiple mutual influences between Stockhausen and the American "Experimental Tradition" before, during, and after his professorship at the University of California (Davis) in 1966-67 remain a desideratum of future research. ${ }^{150}$ In contrast, the impact of Stockhausen's trips to Japan have been highlighted by both Stockhausen himself and several studies. ${ }^{151}$ Historically, the concept of transethnicism had developed in North American music in the early twentieth century with proponents such as Percy Grainger, Henry Eichheim, Dane Rudhyar, Henry Cowell (see below), Colin McPhee, Harry Partch, Lou Harrison, Alan Hovhaness, George Crumb, and John Cage ${ }^{152}$ - although Cage's universalism is arguably better described as a complex synthesis of structural and ethnic or cultural components.

Transethnic universalism in music was of course no new idea in the 1960s. It had been discussed controversially in the early twentieth century, sparked by the concept of a new "exoticist musical style," testified in the theory of Georg Capellen that was destined to overcome the "crisis" of modern music with its "rejuvenating" forces. ${ }^{153}$ Capellen's approach shows obvious parallels to Stockhausen's, suggesting that the idea of "stagnation" of both European and nonEuropean cultures - to be "revitalized" by the genius composer - and the idea of a necessary (static) "preservation" of non-Western cultures by documentation are archetypes of transnational modernity discourse, recurring in waves. ${ }^{154}$ Representatives of early comparative musicology were horrified by the "specter" and the "unrealistic utopia" of a "Universalmusik" to which one might listen "with the same excitement on Fifth Avenue as in the Kalahari," 155 a position expanded and intensified in critiques and polemics surrounding Stockhausen's "Weltmusik" concept amply documented and analyzed in earlier studies. ${ }^{156}$

The impact of an explicit, ethnically oriented universalist thought around 1970 in both US and European musical contexts can hardly be overestimated, with many approaches reacting directly or implicitly and often critically to Stockhausen's "Weltmusik" ideal. ${ }^{157}$ Mauricio Kagel, Peter Michael Hamel, Hans Zender, and Helmut Lachenmann in Germany, Giacinto Scelsi, Luciano Berio, Alvin Curran in Italy and the United States, Pierre Boulez, Jean-Claude Eloy, and Georges Aperghis in France, Benjamin Britten in Great Britain, and, largely neglected by research, Henri Pousseur in Belgium, ${ }^{158}$ as well as the aforementioned North American composers and a considerable number of Asian composers (including most prominently Pan-Asiat-

150 See Heile, "Weltmusik and the Clobalization of New Music," 106.

151 Gutknecht "Stockhausen und Japan," Shimizu, "Stockhausen und Japan," and Utz, Neue Musik und Interkulturalität, 148-153.

152 Nicholls, "Transethnicism and the American Experimental Tradition."

153 Capellen, Ein neuer exotischer Musikstil an Notenbeispielen nachgewiesen, Capellen, "Exotische Rhythmik," and Capellen, "Was können uns exotische Melodien lehren?” See Utz, "Musikalische 'Treibhausblüten'?”

154 Revers, "Europäische Treibhausblüten."

155 Hornbostel, "U.S.A. National Music," 67-68 ("Eine Universalmusik [...], die der tönende Ausdruck des 'Allgemein-Menschlichen' wäre und der man mit gleichem Entzücken in der Fifth Avenue und in der Kalahari lauschen würde, [...] wird immer eine wirklichkeitsfremde Utopie bleiben. Auch würde sie besser zum Schreckgespenst taugen als zum Ideal.").

156 Fritsch, "Zur Idee der Weltmusik," Utz, Neue Musikund Interkulturalität, 136-171, Heile, "Weltmusik and the Globalization of New Music," 109-115, and Siebert, Musik im Zeitalter der Globalisierung, 43-44.

157 Nicholls "Transethnicism and the American Experimental Tradition," Utz, Neue Musik und Interkulturalität, Heile, "Weltmusik and the Globalization of New Music," Borio, "Convergence Between West and East in 2oth-Century Music," and Borio, "Vom Ende des Exotismus."

158 Heile, "Weltmusik and the Globalization of New Music," 113. 
ic tendencies in works by Toshirō Mayuzumi, Akira Nishimura, Minoru Miki, José Maceda, and Isang Yun), all included intercultural ideas prominently in their compositional aesthetics during this period, sometimes in an explicitly universalist manner close to Stockhausen (e.g., Pousseur), sometimes with a decidedly opposing approach (Boulez, who, as a young man, wanted to study ethnology and was in close contact with the anthropologist André Schaeffner throughout the 1950 s to $1970 \mathrm{~s}^{159}$ ). The reason for this broad attempt at an identification with non-Western cultures, though frequently linked to a rigorous criticism of modernized nonWestern musical practices, might very well be found in the precarious social situation of new music, necessitating the creation of aesthetic and cultural alliances and solidarities that transcend the limitations of the immediate (local) "realities" and constraints. ${ }^{160}$

\section{The Ambivalence of the Local in Twentieth-Century Music}

A dynamic concept of culture must concede that a tendency toward essentializing cultural symbols, idioms, or stereotypical representations of (national) cultures in musical contexts is not simply a thing of the past. Not only do the local and the global stand in an ongoing relationship of interaction or feedback (as Robertson's concept of "glocalization" tried to explain $\rightarrow$ I.2), but local and national (or nationalist) discourses are also variously interwoven. The local challenge of nationalist generalization can itself turn into a questionable nationalism when aiming to escape from a hegemonic "internationalist" standardization: a resentment of the Other may be subsumed under the local, and in a generalized form - as an "invented tradition" - turn into a (neo-)nationalist symbol. In the following, I will investigate how such specific, locally focused concepts of musical culture can be understood within the tensions between national essentialism and global standardization. This question will be broached against the background of two prominent examples from the first half of the twentieth century that had "non-simultaneous" resonances during the century's second half.

\section{Stravinsky and Bartók: Construction and Criticism of National Music in the Tension Fields Between Composition and Ethnography}

The tendency toward suppressing "ethnic" categories in most new music was primarily a legacy of the post-1945 political-musical situation. In this period, serial music acted as a self-referential counter-model to the misuse of musical topicality by the totalitarian political systems of the immediate past, especially in National Socialism $\rightarrow$ I.2). But a phenomenon both aesthetically and socially contradictory to serialism, such as the neoclassicism of Igor Stravinsky (a declared sympathizer of Italian fascism ${ }^{161}$ with notoriously anti-Semitic attitudes), was also based on a renunciation of musical "language" in the narrower sense. In Stravinsky's case, this renunciation concerned above all the idiom of the national Russian school of the decades following the 1860 s and was preserved and transformed in the neo-national "Russian" sound of his works before the October Revolution in 1917. In his Autobiography of 1936, Stravinsky attacked the

159 Borio, "Vom Ende des Exotismus," 117-118 and Zenck, Pierre Boulez, 63-64.

160 Meyer, "Volkstümlich-primitiv-populär," 34.

161 In 1930, Stravinsky declared Mussolini "the savior [...] of Europe" (quoted in Taruskin, "The Dark Side of the Moon," 208). See Stenzl, Von Giacomo Puccini zu Luigi Nono, 29, Sachs, Music in Fascist Italy, Taruskin, "Notes on Svadebka," 450-453, and Taruskin, "The Dark Side of the Moon," 208-212. 
"naive but dangerous" and "sterile tendency" of nationally minded Russian and Spanish composers including his former teacher Nikolai Rimski-Korsakov "to remake an art that has already been created instinctively by the genius of the people" on an ethnographic basis. ${ }^{162}$ At the same time, he drastically downplayed the importance of Russian folk music as a source of his own works. Stravinsky's tendency to mask the ethnic contexts of his music continued in the influential, purely structuralist analyses of his music by Olivier Messiaen and Pierre Boulez after $1945 .{ }^{163}$

Recent investigations, namely the extensive studies of Richard Taruskin, ${ }^{164}$ show, on the contrary, how fundamental the confrontation with local music was for Stavinsky's three "Russian" ballets and other works before 1917. Much of the melodic material of The Rite of Spring (Le Sacre du Printemps 1911-13) was based on Lithuanian and Russian folk melodies, though considerably abstracted and transformed. ${ }^{165}$ Similarly, the sonorities in large parts of The Rite of Spring, Petrushka (1910-11), and The Firebird (1909-10) are based on the aural impression of characteristic Russian instruments, such as the shepherd shawms dudka and rozhók, the hurdygurdy lira or the psaltery gusli. ${ }^{166}$ Stravinsky used various folk song collections, but apparently also occasionally notated the music of his local environment. ${ }^{167}$ On the whole, it is noteworthy that Stravinsky emphasized ethnographic precision and critically assessed the reliability of the melodic transcription of his sources, even considering the sociocritical context of the melodies in the context of his ballet scenarios. ${ }^{168}$ Yet, in contrast to the "kuchkist" tradition of his precursors, "The Five" (Mogučaja kučka), he did not set these sources in their "original form," but rather exposed them to radical transformation processes that went as far as pre-serial methods (including, for example, the verticalization of folk melodies on the basis of serial practices). ${ }^{169}$ Against this background, Martin Zenck's interpretation of the music of The Rite in accordance with Sigmund Freud's analysis in Totem and Taboo (which appeared in 1913, the year of the premiere of The Rite) seems cogent. Such an analysis seems particularly apt for the final Danse Sacrale (which conspicuously no longer features folk melodies); the often analyzed Danse seems to formulate a critique of the sacrificial practice of the ritual and not an archaistically colored

162 Stravinsky, An Autobiography, 97. See Taruskin, "Russian Folk Melodies in The Rite of Spring," 503.

163 See Taruskin, "Russian Folk Melodies in The Rite of Spring," 505.

164 See ibid. and Taruskin, Stravinsky and the Russian Traditions, vol. 1, 891-950.

165 Stravinsky used at least four melodies from the collection Melodje ludowe litewskie [Lithuanian Folk Melodies], edited by the Polish priest Anton Juszkiewicz (1819-1880), in the composition of The Rite ofSpring. The collection contains 1,785 Lithuanian folk songs (especially wedding songs). See, for further details, ibid., 891-923.

166 See ibid., 730, 935. The title page of volume 1 of Taruskin's Stravinsky and the Russian Traditions features a sketch of a rozhók player in a costume by Nicholas Roerich for The Rite of Spring (Bakhrushin State Central Theatrical Museum, Moskau).

167 As seen in a frequently reproduced photograph, Stravinsky notated the hurdy-gurdy (líra) lyrical accompaniment of a song of a sightless lirnik (traveling musician) in his summer residence at Ustilug (c. 1910; see Danuser, Die Musik des 20. Jahrhunderts, 53, Taruskin, "Russian Folk Melodies in The Rite of Spring," 507). In his monograph (Stravinsky and the Russian Traditions, vol. 1, 870) Taruskin contradicts his own earlier interpretation of the photograph, in which he (as well as Danuser) took the photograph as evidence that Stravinsky had conducted ethnological studies "à la Bartok." Taruskin rather suggests that the photo does not allow conclusions to be drawn about Stravinsky's wider ethnomusicological activities, since it seems "posed" and that closer contact with local musicians would have contradicted Stravinsky's "class" consciousness.

168 Taruskin, Stravinsky and the Russian Traditions, vol. 1, 893, 911.

169 See Taruskin, "Russian Folk Melodies in The Rite of Spring," 541-543 and Vlad, "Reihenstrukturen im Sacre du Printemps." 
nostalgia for lost primitivity. ${ }^{170}$ Thus, Stravinsky's music clearly stood in opposition to Nicholas Roerich, who designed the scenario based strictly on ethnographic authenticity. The composer implicitly distanced himself from a neo-nationalist idealization of archaic Slavic rituals.

Today, Béla Bartók's attempt to establish new art music on the basis of Hungarian, Romanian, and Slavic folk music - which initially showed a far clearer neo-nationalist emphasis - may seem even more contradictory than Stravinsky's engagement with the sources of traditional folk music forms. Only since the mid-1990s has Bartók research subjected this approach to differentiated criticism, and thus also uncovered the reasons why this composer still occupies a position of primacy in the "official" history of new music - even if this position has been reaffirmed and in a broader sense surely appears beyond doubt. ${ }^{171}$ Julie Brown distinguishes two phases of Bartók's neo-national aesthetics, which are inextricably linked to turbulent contemporary history: ${ }^{172}$ Bartók turned to a "pure" and "authentic" form of Hungarian peasant music (also using the central orientalist trope of the "noble savage") as a point of departure until about $1931 .{ }^{173} \mathrm{He}$ clearly distinguished it from the hybrid and "contaminated" form of urban gypsy music and chose it as the sole legitimate source of this new art music. Under the influence of socialism, however, Bartók re-examined his assessment of gypsy music and gave it a more neutral interpretation, defining it as "Hungarian popular art music." ${ }^{174}$ At the same time, Bartók called the "purity" of peasant music into question. Through expanded ethnological studies, Bartók gained knowledge of the constant reciprocal influences that made it difficult to differentiate between "authentic" and "contaminated" forms of local music. However, this insight remained qualified by Bartók's demand that the ethnographic sources of new art music should be "pure, fresh and healthy." 175

The collapse of the Austro-Hungarian monarchy, the repressions of the proto-fascist Hungarian Horthy-regime, and upcoming Nazism and anti-Semitism transformed Bartók's nationalist project into an undertaking that aimed at universality, with the dream of creating a "brotherhood of people." Romanian, Slovakian, and Arab music - and essentially music from around the world - is now being presented as a possible source ("well assimilated foreign impulses offer possibilities of enrichment" ${ }^{\text {"176 }}$ ), and the Rákóczi March, which integrates extremely diverse cultural influences, is used as an example of the hybrid nature of Hungarian folk music. Nevertheless, Bartók remains tied to the concept of "national character": despite its inner hybridity, the march is labeled "incontestably Hungarian." 177 The contradiction between isolationist and diffusionist models of culture, which, based on Johann Gottfried Herder, has determined the discourse on culture and "race" since the nineteenth century, ${ }^{178}$ is evident in Bartók's models of thought. In that context, it is particularly interesting that Bartók ultimately did not consider philological authenticity to be relevant for art music at the highest level, but rather foregrounded the ability of a composer - such as Stravinsky - to reinterpret the versatility of folk

170 See Zenck, "Ritual or Imaginary Ethnography in Stravinsky’s Le Sacre du Printemps?"

171 See Taruskin, "Why You Cannot Leave Bartók Out."

172 Brown, "Bartók, the Cypsies, and Hybridity in Music."

173 Ibid., 128-129.

174 Bartók, "Gypsy Music or Hungarian Music?”; see Brown, "Bartók, the Gypsies, and Hybridity in Music," 130.

175 Letter to Octavian Beu, 11/01/1931. In Bartók, Weg und Werk, 261-263: 262.

176 Bartók, "Race Purity in Music," 31.

177 Ibid., 32.

178 See among others Young, Colonial Desire, 36-43 and Löchte, Johann Cottfried Herder: Kulturtheorie und Humanitätsidee, $128-139(\rightarrow \mathrm{I} .3)$. 
music through the transformative processes of art music. Bartók's and Stravinsky's use of local music thus did not rule out an unbroken commitment of their music to the Western art music tradition after Beethoven and its drive toward autonomy - Bartók consequently refrained from voicing any skepticism toward Stravinsky's statement that a composer could make use of all conceivable sources, and that the mere fact that he considers musical material suitable for influencing art music would make it his intellectual property. ${ }^{179}$

\section{Localism in Chinese New Music Since the 1980s}

The subliminal discourses of nation and race cast a problematic light on the compositionally certainly remarkable transformative processes in the music of Stravinsky and Bartók. That these dimensions of power and appropriation are more visible today than in the past cannot least be considered an important effect of the work of many composers outside the West. The discourse of cultural difference between Asian aesthetic and musical concepts and the mainstream of Western composition, founded on a broad basis by Chou Wen-Chung, Isang Yun, José Maceda, or Töru Takemitsu since the 1960s ( $\rightarrow$ I.3, III.4), played an important part in this process. This discourse should also be understood as a reaction to the increasing Westernization of Asia since the mid-nineteenth century and the tendency, often particularly marked in this context, toward cultural homogenization according to Western models $(\rightarrow$ III.1). The understanding of Asian musical "characteristics," which in the 1960 s were still conceived in a strongly culturally essentialist way - such as the constant change, variation, coloring of single tones, the great importance of silence, non-finalistic concepts of form, or anti-causal concepts of time - has become more differentiated and pluralistic since the 1980 s - a process that has ultimately led to a fundamental critique of cultural essentialism through pointed localist or pluralistic approaches $(\rightarrow$ III.4-5).

In Asia, localism has played an important part in music history, especially in China, starting from the political upheaval at the end of the Cultural Revolution (1966-76). Firstly, many young composers had been ordered to grow rice in the context of the large-scale relocation program (shangshan xiaxiang, "Up to the mountains, down to the villages") like many other "educated youth" (zhishi qingnian) since the late 1960 . ${ }^{180}$ Some of them had come to know local forms of music first-hand and usually with active participation over the years. In the composition classes at the newly opened conservatories of the late 1970s and early 1980s, a Western modernity - almost completely unknown and viewed as taboo for decades - was received enthusiastically, with Bartók's work playing a key role: Many composers of this generation, known as the xinchao (new

179 Bartók, "The Influence of Peasant Music on Modern Music," [1931], 343 ("Stravinsky [...] wants to demonstrate that it does not matter a jot whether a composer invents his own themes or uses themes from elsewhere. He has a right to use musical material taken from all sources. What he has judged suitable for his purpose has become through this very use his mental property. [...] The question of origins can only be interesting from the point of view of musical documentation. [...] This much is certain, that if among the thematic material of Stravinsky's there are some of his own invention (and who can doubt that there are?) these are the most faithful and clever imitations of folk songs.") See Taruskin, "Russian Folk Melodies in The Rite of Spring," 501-502. See also Bartók's similar statement referring to Stravinsky's neoclassicist period: "[...] when I once met Stravinsky in Paris, he told me that he thinks he has the right to incorporate into his music any material he believes to be fit or appropriate for his purposes. [...] Stravinsky uses this material in his own way, arranging and transforming it according to his own individual spirit, thus creating works of a new, individual style." (Bartók, "Harvard Lectures,"360.)

180 See Bernstein, Up to the Mountains and Down to the Villages and Mittler, Dangerous Tunes, 296. See also https:// chineseposters.net/themes/up-to-the-mountains.php. 
Example 2.1: Guo Wenjing, She Huo, rehearsal number 6

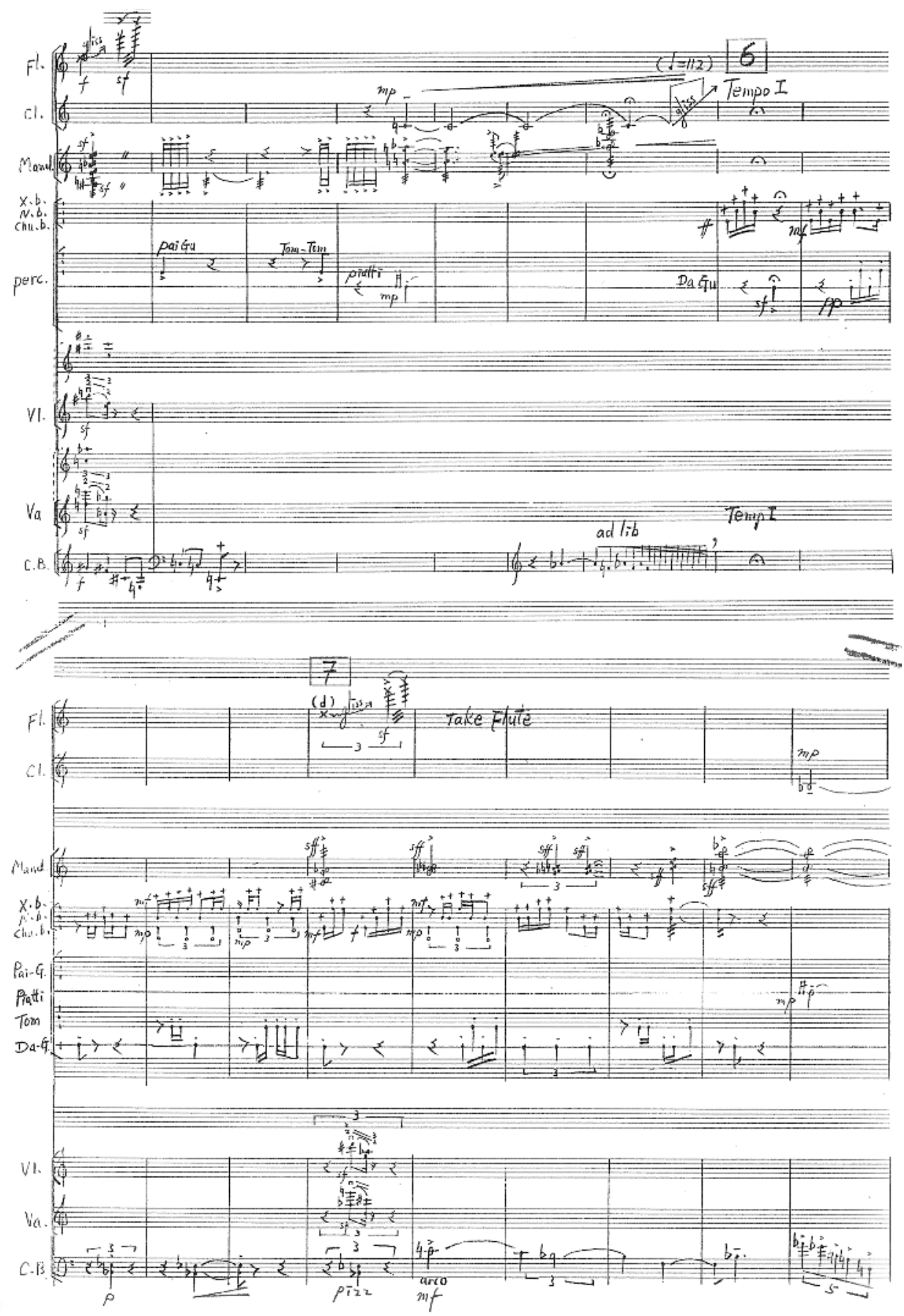


wave), initially referred explicitly to Bartók's concept of hybridity and attempted to amalgamate Chinese local traditions in an analogous way. ${ }^{181}$ It was, however, only after the Bartók model had been overcome that genuinely original concepts of cultural difference emerged through radicalization, hybridization, and abstraction of local traditions in works such as Qu Xiaosong's (b. 1951) Mong Dong for voice and chamber ensemble (1984), Tan Dun's (b. 1957) On Taoism for voice and orchestra (1985), or Guo Wenjing's (b. 1956) She Huo for chamber ensemble (1991). Guo's work for Western instrumental ensemble is not so much about the musical depiction of a harvest festival to which the title refers ${ }^{182}$ as a general atmospheric characterization of Chinese country life. In this work, the means of reinforcing, distorting, and intensifying the textures found in the models of Chinese rural music practice are more reminiscent of Stravinsky's technique than Bartók's, such as when the cross-rhythms of two cymbal players from the local Sichuan Opera (chuanju) are extended to three players (Ex. 2.1) and thereby condensed. Following the same principle, the blurring of the instrumental tuning of various local ensembles is "radicalized" by microtonally adjusted tunings of the stringed instruments and by using a violin with four A-strings (Ex. 2.2).

Similarly, Qu Xiaosong's known ensemble work Mong Dong for male voice and ensemble would be unthinkable without the complex experience of the xinchao generation. What is decisive for the quality of this work is not so much the nature-symbolic aspect, the attempt to summon a lost originality between man and nature, evident in the adoption of vocal techniques of shan'ge folk songs, the use of microtones, and the renunciation of a text setting. The reference to the local here also involves the integration of a new dimension of structural thinking. Possibly influenced by techniques of the older generation, such as Luo Zhongrong (b. 1924) ( $\rightarrow$ III.1), Qu refers to the $y u$-he-ba patterns of the shifan luogu percussion ensembles ${ }^{183}$ In a dialogic manner, short phrases of eight beats each are grouped in ever new proportions, for instance in measures $85-92$ as $7+1,5+3,3+5,1+7 \cdot{ }^{184}$

Perhaps the most spectacular result of the move toward localism in Chinese new music has been Tan Dun's "ritual opera" Nine Songs (1989). ${ }^{185}$ Tan Dun recombines fragments of the famous archaic poetry cycle Jiu ge (Nine Songs) by Qu Yuan (340-278 BCE), and has them articulated in an "imaginary dialect" of the archaic Chu culture (c. 800-223 BCE), using singing, screaming, and whispering, as well as ceramic instruments that were largely newly built for this project. Tan develops his imaginary archaist music from a very broad repertoire of vocal characters such as the shan'ge folk songs, simple rhythmic figures, and a largely monophonic melodic texture, determined by the goal to redesign the ritualist music conjured up in $\mathrm{Qu}$ Yuan's poetry. This conception refers to an attitude of the literary xungen ("root") movement in China during the 1980s, whose main representative Han Shaogong (b. 1952), as well as Tan Dun from Hunan Province, derives a fluid connection between local - rather than national - identity with an openness to international tendencies - but without the goal of "total Westernization" often demanded by China's early reformers $(\rightarrow$ III.1). Tan Dun also positioned himself with Nine Songs in a time of political upheaval in China: the premiere took place in New York on 12 May 1989, shortly before the massacre in Tiananmen Square on 4 June 1989.

181 See Kouwenhoven, "Mainland China's New Music (III)," 85-86 and Wong, "Bartók's Influence on Chinese New Music in the Post-Cultural Revolution Era."

182 Mittler, Neue Musikaus China, 14-15.

183 See Jones, Folk Music ofChina, 260-269.

184 See Kouwenhoven, "Mainland China's New Music (III) - The Age of Pluralism," 83-85, 93.

185 A detailed introduction to this work can be found in Utz, Neue Musik und Interkulturalität, 403-423. 
Example 2.2: Guo Wenjing, She Huo, rehearsal number 26

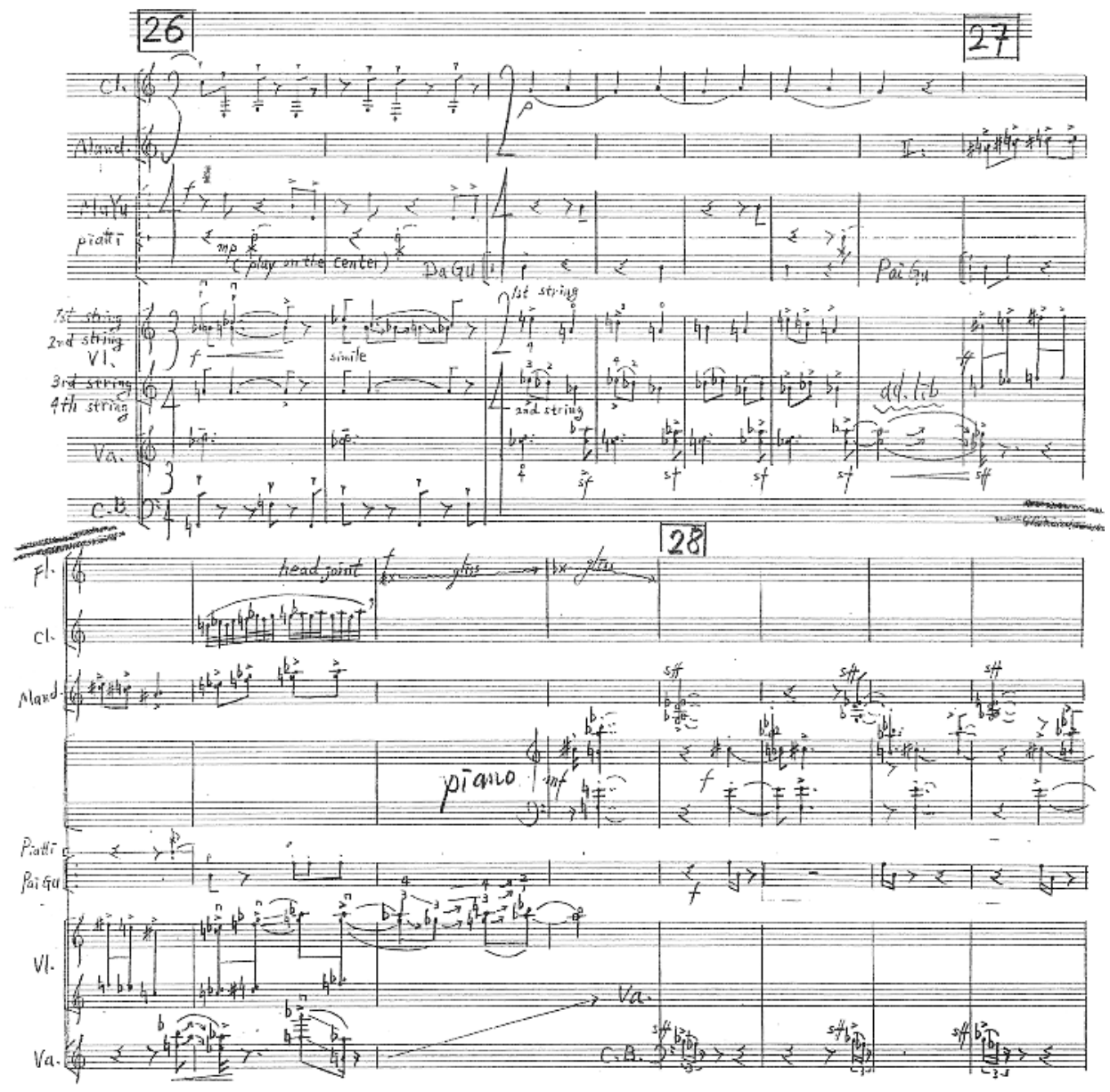

Copyright $\odot$ by Universal Music Publishing Ricordi; Milan, Italy

His concept would thus immediately become a criticism of Chinese nationalism as well as the homogenizing tendencies of Western cultures.

\section{Toward a Critique of Authenticity-Based Thinking}

The works of Guo, $\mathrm{Qu}$, and Tan remain ambivalent in their attitude. Their musical character sketches of rural Chinese atmospheres cannot only be considered a critique of nationalism. Rather, they may be heard also as a "paradoxical redemption" of Mao Zedong's anti-urban ideology, as an aftereffect of the idealization of rural life during the time of relocation. The ideological dimension of compositional localism is thus hardly less complex here than in Bartók or Stravinsky, as it always flirts with a mythically transfigured ethnological authenticity, which can then be "abstracted" almost arbitrarily in the process of appropriation. Here 
lies the basic problem of musical localism as a whole: on the one hand, composing as an act of cultural or intercultural positioning seems more plausible the more specific it becomes, and the more precisely art takes certain local traditions seriously, with all their implications, and draws comprehensive compositional conclusions from them. On the other hand, such a rigorous restriction of the musical-idiomatic "listening field" - as becomes very clear in Tan Dun's Nine Songs - risks approaching imitation, a culture-specific onesidedness and - in an international context - a flirtation with one's own exoticism: self-exoticization. ${ }^{186}$ In this context, however, it should be noted that since 1986, Tan Dun's works have been produced in the United States and are primarily aimed at Western audiences - even though they have been no less successful in China - and that Guo Wenjing's and Qu Xiaosong's larger works in the 1990 s have likewise been predominantly performed in Europe and the USA.

This paradox makes it clear once again that musical traditions - art music and local music genres - are in a constant process of transformation and do not produce immutable "authentic objects," so that any compositional action inevitably decontextualizes such traditions. Every musical or compositional act will therefore operate, consciously or unconsciously, within this tension field - whether concrete local traditions are explicitly addressed or not. Both extremes that can be deduced from this are problematic: the notion of an "absolute authenticity" of local music, which must not be touched by art music, as well as the image of a "hypercultural" supermarket that music creators can freely navigate. Only compositional designs that completely transform these extremes through variety and precision of compositional ideas and solutions can attempt to outstrip the ideological accents of the local - especially in view of the resurgent nationalism in Asia today, especially in China (and in parts of Europe and the Americas), and its demagogically leveling construction of national characteristics. Effectively rejecting nationalist or provincial discourses involves an artistically substantive reference to local identities as refracted, pluralistic, and critical. The final statement in Theodor W. Adorno's Philosophy of New Music is rather topical in this regard: "Perhaps that art alone would be authentic that would be liberated from the idea of authenticity, of being thus and not otherwise. ${ }^{1187}$

\section{Modernist Reception of Japanese and Indian Traditional Music between 1910 and 1945: Delage, Cowell, Mitsukuri, and Hayasaka}

Having reapplied Ernst Bloch's concept of the "non-simultaneity of the simultaneous" (Ungleichzeitigkeit des Gleichzeitigen) to music historiography in Chapter II.1 (section De-Nationalizing Music Historiography), I will now attempt to show, in Chapters II.4 and II.5, how composers and musicians during the pre- and postwar decades developed similar musical ideas and approaches against radically differing social backgrounds, motivated by distinct social and aesthetic agendas. Guided by the principle of an "entangled history" ( $\rightarrow$ II.1), the following case studies highlight the differing cultural and historical situations in which these protagonists acted, focusing on the degree to which their works exhibit affinities and entanglements.

The four composers introduced in this chapter represent three generations born in the decades around 1900, three countries or continents (France/Europe, the United States/America, and Japan/Asia), and different compositional schools and aesthetics. Maurice Delage (1879-1961),

186 On the subject of "self-exoticization" in the Japanese context see Hijiya-Kirschnereit, Das Ende der Exotik, 13-16.

187 Adorno, Philosophy of New Music, 158. ("Vielleicht wäre authentisch erst die Kunst, die der Idee von Authentizität selber, des so und nicht anders Seins, sich entledigt hätte." Adorno, Philosophie der neuen Musik, 196.) 
Henry Cowell (1897-1965), Shūkichi Mitsukuri (1895-1971), and Fumio Hayasaka (1914-1955) distinguish themselves from most of their contemporaries by their dedicated and systematic attempts to adopt, incorporate, and re-invent non-Western music traditions as a principal feature of their music (and not, as it was far more common at the time, as a subsidiary element). Moreover, all of them acted as nodes of local and international networks and music societies (see Table 2.1), embedding their artistic work in an internationalized social context. We may retrospectively consider their independent artists' groups as key institutions of modern music in their respective countries. These groups shared a pronounced internationalism, implemented through the performance of the most recent and advanced new music from other countries, while also sharing anti-establishment aesthetics. This context was undoubtedly crucial in provoking the composers' modernist reception of non-Western musics. The guiding idea behind these approaches emerged from a pessimistic view of contemporaneous Western music, a common stance in early twentieth-century discourse. Japanese and Chinese as well as Indonesian or Indian traditional music seemed to provide all those features that Western music of the early twentieth century supposedly lacked: intricate rhythm, refined melodic design, spontaneity, "feeling," timbral differentiation, complex layering, etc. ${ }^{188}$ This search for a decentering Otherness converged in an unsettling manner on tendencies of nationalist, essentialist, and isolationist thought in the wake of two world wars and major sociohistorical turns such as the Great Depression. The conflicts and paradoxical situations resulting from such "non-simultaneities" will be at the focus of the following analytical readings, which relate musical detail to historical context. Table 2.1 provides an overview of the institutions, musical works, and articles referred to throughout.

\section{Maurice Delage: Close Listening to Asian Traditions and the Emancipation from Exoticism}

Maurice Delage, born in 1879, was a leading member of the artists' collective Apaches, founded in 1902, and of the Société Musicale Indépendante (SMI), founded in 1909. Both groups were centered around Maurice Ravel (1875-1937), Delage's teacher and close friend. The Apaches considered themselves a rebellious group and were united by their enthusiasm for Claude Debussy's opera Pelléas et Mélisande (premiered in 1902), their substantial interest in Russian music, and their criticism of the nationalist and conservative impact of the academic musical establishment of the Schola Cantorum around Vincent d'Indy who also controlled the politics of the influential Société National de Musique (founded in 1871). The weekly gatherings of the Apaches, starting in 1904, took place in a pavilion in the Parisian quarter Auteuil which was rented by Maurice Delage (son of a wealthy entrepreneur) especially for that occasion. ${ }^{189}$ The largely selftaught Delage was an important figure in this group which his close friendship to Igor Stravinsky reflects. Stravinsky joined the group along with Manuel de Falla, Isaac Albeniz, and other international figures during the first decade of the twentieth century.

Delage was also involved in the foundation of the more official organization Société Musicale Indépendante in 1909 that formally marked the rejection of the ideas represented by the Société National. The immediate reason for its foundation was that the Sociéte National had declined to perform "Temples," the first of Charles Koechlin's two Etudes antiques (1908-10), and Delage's

188 See Pasler, "Race, Orientalism, and Distinction in the Wake of the Yellow Peril," 101-103.

189 Pasler, "Stravinsky and the Apaches," 403. 


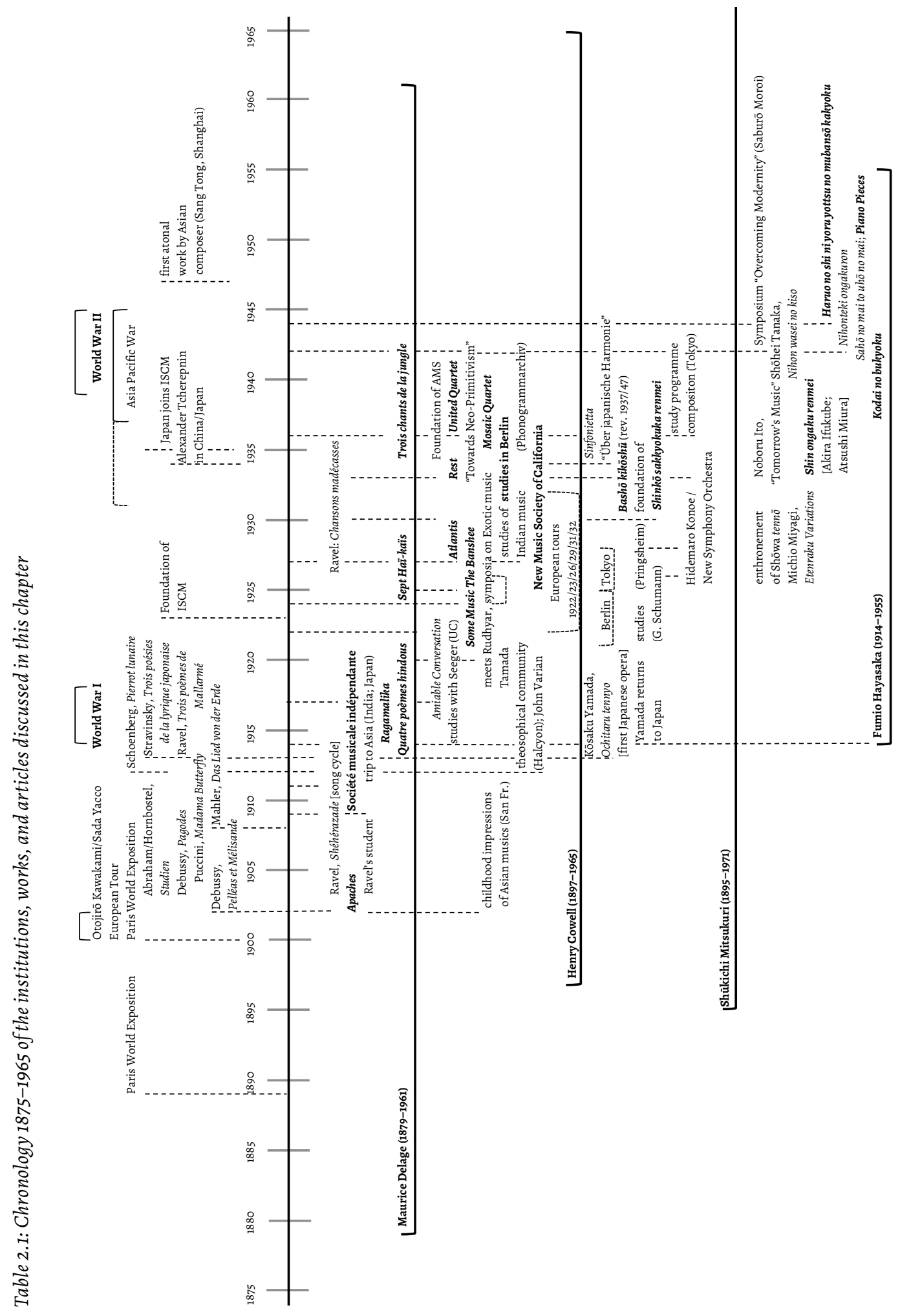


symphonic poem Conté par la mer (1908) due to their advanced style. ${ }^{190}$ The SMI from its beginnings successfully introduced the most recent musical trends from both its French members and international composers. Among other activities, it organized the French premieres of Arnold Schoenberg's Three Piano Pieces op. 11 (1909) in 1913 and Six Little Piano Pieces op. 19 (1911) in $1914 .{ }^{191}$ Stravinsky's enthusiasm for Schoenberg's Pierrot lunaire (1912) ${ }^{192}$ sparked the plan to organize the French premiere of this work in what Ravel imagined to be a "scandalous concert."193 Although the Pierrot premiere had to be canceled for practical reasons, ${ }^{194}$ the society's concert on 14 January 1914 featured the world premieres of two pieces that were at least indirectly influenced or triggered by the enthusiasm for Schoenberg's Pierrot: Stravinsky's Trois poésies de la lyrique japonaise (1912/13) and Ravel's Trois poèmes de Mallarmé (1913) - along with Delage's Quatre poèmes hindous for soprano and chamber ensemble (1913) which is closely intertwined with these two cycles. The rebellious tone is evident in a review of this concert by Apaches- and SMI-member Émile Vuillermoz: ${ }^{195}$

For a long time - since the heroic evenings of the old Nationale - musicians had not had the sensation of attending such an important event, so significant for the evolution of our art. The Salle Erard, where so many glorious pages of our musical history were already written, heard that day echo the energetic blows of the young demolishers who had been occupied for some time, to the great terror of the ignorant crowd, to tear down the walls, behind which they hope to discover the beautiful enchanted gardens of earthly paradise. [...]

There is no longer any security on the market of the sixteenth notes and new cataclysms are preparing. The SMI has just torn down a whole wall and, blinded by the cloud of sound dust that rose after the collapse of the wall, some listeners are already trying to discover, among the chunks, a road toward the obscure sensed delights. ${ }^{196}$

190 Duchesneau, “Maurice Ravel et la Société Musicale Indépendante," 257. Both pieces were performed in the first orchestral concert of the SMI on 9 June 1910 in Salle Gaveau with considerable success, see ibid., 261-262, 274.

191 op. 11: 28 May 1913, Salle de la Société des concerts (Ancien Conservatoire); op. 19: 9 February 1914, Salle Erard. See Duchesneau, "Maurice Ravel et la Société Musicale Indépendante," 278-280, Meyer, Ensemblelieder in der frühen Nachfolge (1912-17) von Arnold Schönbergs Pierrot lunaire, 141.

192 Stravinsky had attended the fourth performance of the work in Berlin on 8 December 1912; later Stravinsky claimed that he had been merely interested in the instrumental music of the Pierrot lunaire (Stravinsky, An Autobiography, 43-44; see Meyer, Ensemblelieder, 26-28).

193 "Projet mirifique d'un concert scandaleux [...]." Maurice Ravel, letter to Hélène Kahn-Casella (for the Comité de la SMI), 2/4/1913, quoted in Meyer, Ensemblelieder, 29.

194 See ibid., 32-33.

195 See ibid., 137.

196 Vuillermoz, "La musique au concert." (“Depuis bien longtemps - depuis les soirs heroiques de l'ancienne Nationale-les musiciens n'avaient pas eu la sensation d'assister à une manifestation aussi importante, aussi capitale pour l'évolution de notre art. La salle Erard, où s'écrivirent déjà tant de pages glorieuses de notre histoire musical, entendit ce jour-là résonner les énergiques coups de pic des jeunes démolisseurs occupés depuis quelque temps, au grand effroi de la foule ignorante, à abattre des murs derrière lesquelles ils espèrent découvrir les beaux jardins enchantés du paradis terrestre. [...] II n'y a plus aucune sécurité sur le marché de la double-croche et de nouveaux cataclysmes se préparent. La SMI vient d'abbatre tout un pan de mur et, aveuglé par le nuage de poussière sonore que souleva sa chute, certains auditeurs cherchent déjà à se frayer péniblement, parmi les plâtras, une route vers d'obscures délices pressenties.") 
This radicalized rhetoric initially seems unjustified in light of the fragile pieces performed during this concert, but it documents the struggles of the younger generation of Paris-based composers in the aftermath of the Sacre scandal of 29 May 1913.

Their drive to reach beyond the limitations of a narrowly defined nationalism made the Apaches and the Société Musicale Indépendante a fertile ground for openness toward non-Western music. Such interests were necessarily prefigured by the superficial appropriations of French orientalism and exoticism reaching back at least to Jean-Philippe Rameau's ballet opera Les Indes galantes (1735) and still present in Ravel's song cycle Shéhérazade from 1903, one of the first artistic achievements of the Apaches group (Tristan Klingsor, whose poems provided the lyrics for Ravel's cycle, was also a member). Debussy's simultaneous, refined efforts at incorporating Javanese gamelan structures into some of his piano pieces, most notably in Pagodes from 1903, ${ }^{197}$ gave way to attempts at a closer modeling of non-Western traditions as in Charles Koechlin's Deux pièces javanaises, which were based on transcriptions of Javanese gamelan pieces and were premiered in the second concert of the SMI on 4 May 1910. ${ }^{198}$ Furthermore, given that, during his studies with Ravel, Delage had been encouraged to accept the concept of stylistic imitation as a major technique in developing one's own style, ${ }^{199}$ it seems consistent that his approach to Asian traditions was based on detailed study, close listening, and reconstruction of these traditions' musical details in his scores. These features were elaborated to their furthest point in a series of works for soprano and piano or chamber ensemble, most notably in "Lahore," the second movement of Quatre poèmes hindous (1913), in Ragamalika (1914), as well as in Sept Hä̈-kaïs (1923/24).

The reception of Indian music by Maurice Delage has been documented and discussed in great detail by Jann Pasler and Andreas Meyer, and thus this aspect of Delage's work will only be briefly summarized here. ${ }^{200}$ The Quatre poèmes hindous were composed in the wake of the composer's five-month trip to India and Japan in 1911 and 1912. The exact dates of composition are not easy to determine. In the autograph and the printed edition of the piano score, the following dates are indicated at the end of the movements: I. Madras (Une Belle...) [Madras, Mars 1912]; II. Lahore (Un Sapin isolé...) [Lahore, Février 1912]; III. Bénarès (Naissance de Bouddha) [Bénarès, Janvier 1912]; IV. Jeypur (Si vous pensez...) [Jeypur, Janvier 1912]. ${ }^{201}$ Delage mentioned in a letter to Stra-

197 See, most recently, Tamagawa, Echoes from the East: The Javanese Gamelan and Its Influence on the Music of Claude Debussy.

198 Duchesneau, “Maurice Ravel et la Société Musicale Indépendante," 264. This work, catalogued by Orledge, Charles Koechlin (1867-1950): His Life and Works, 345, as the Suite Javanaise op. 44b, is an arrangement of two Javanese gamelan pieces "Gamelan palag" and "Camelan salandro" (transcribed by Louis Laloy) for eleven European instruments, and was composed in April 1910. Koechlin wanted to reconstruct the impression he had of this music during the World Exposition in 1889 based on the transcriptions by Laloy, see Koechlin, Écrits, vol. 1,88 .

199 See Meyer, Ensemblelieder, 152.

200 Pasler, "Reinterpreting Indian Music," Pasler, "Race, Orientalism, and Distinction," and Meyer, Ensemblelieder, 31-35, 149-153, 244-268.

201 Madras, modern-day Chennai, is the capital of the Tamil Nadu state in South-East India and was the center of the East India Company; Lahore, formerly part of Northern India, is the historical capital of the Punjab region (today the second largest city of Pakistan); Bénarès, now Varanasi, in the North Indian state of Uttar Pradesh, is considered the spiritual capital of India and attracts pilgrims who go there to bathe in the Canges; Jeypore (Jaipur) is the capital of the Northern Indian state of Rajasthan (close to New Delhi). Thus, it would seem that Delage's trip followed the route Jeypore (Jan. 1912) - Bénarès (Jan. 1912) - Lahore (Feb. 1912) - Madras (Mar. 1912). Delage's "Lettre de l'Inde" from Kandy (Ceylon, today Sri Lanka), published in the Revue musicale S.I.M. on 15 June 1912, is dated 4 March 1912 (see below). 
vinsky, however, that he completed these pieces only in the summer of 1913, so it seems likely that the dates indicated in the score signify the time of Delage's visit to the four cities during his trip rather than the dates of composition. ${ }^{202}$ This would mean that more than one year passed after the trip before Delage actually composed this work. The chamber ensemble version for 2 flutes ( 1 also piccolo), oboe (also English horn), 2 clarinets (in both A and B b, 1 also bass clarinet), harp, and string quartet, probably completed in November 1913, was of particular significance for Delage, as he indicated in a letter to Stravinsky eight days before the premiere: "I am restless about my small orchestra since I have searched for Hindu sonorities that send chills up my spine."203

Based on Delage's "Lettre de l'Inde," a short account of his Indian trip published in the journal Revue musicale S.I.M. on 15 June $1912^{204}$ and other sources, Jann Pasler has singled out those characteristics of Delage's approach to Indian music that differed from the common exoticism of his epoch: ${ }^{205}$ he followed Debussy's strategy in focusing on those features of Indian music that seemed to expose a culture-specific logic - deemed opaque to the Western listener - as well as the continuity of pitch, rich timbres, especially in vocal music, and their supposed spontaneity and emotional effect. Like many composers in the following decades, Delage was concerned about "contaminating" Western (phonograph, harmonium, violin) and particularly Muslim influences on "Hindu music." ${ }^{206}$ Like Dane Rudhyar about ten years after him, he held on to the image of a "pure" Hindu music. ${ }^{207}$ Delage was in personal contact with several distinguished soloists from different Indian music traditions and bought several recordings of Indian music, which served as his main source for the adaptations elaborated in his scores after he had returned to France.

Pasler has identified the beginning of Lahore (a song based on the French translation of a poem by Heinrich Heine ${ }^{208}$ ) as a transcription of a surbahā $r^{209}$ performance of Jaunpuri Todika

202 "Heureusement que j'ai fait quatre poèmes Hindous cet été. Ravel pretend que c'est bien." Maurice Delage, letter to Igor Stravinsky, 9/12/1913 (Collection Igor Stravinsky, Paul Sacher Foundation Basel), quoted in Meyer, Ensemblelieder, 31.

203 "Je suis inquiet pour mon petit orchestre, car j'ai cherché des sonorités Hindoues qui me donnent froid dans le dos." Maurice Delage, letter to Igor Stravinsky, 6/1/1914 (Collection Igor Stravinsky, Paul Sacher Foundation Basel), quoted in Meyer, Ensemblelieder, 32.

204 Delage, "Lettre de l'Inde."

205 Pasler, "Race, Orientalism, and Distinction," 100-103.

206 Ibid., 101.

207 See Rudhyar, "A Call to Indian Musicians."

208 Delage obviously relied on the French translation of this poem by Gérard de Nerval, first published in 1848 (although no source is provided in the two printed editions of the work): "Un sapin isolé se dresse sur une montagne / Aride du Nord. II sommeille. / La glace et la neige l'environnent / D'un manteau blanc. / II rêve d'un palmier qui là-bas / Dans l'Orient lointain se désole, / Solitaire et taciturne, / Sur la pente de son rocher brûlant." German original: "Ein Fichtenbaum steht einsam / Im Norden auf kahler Höh. / Ihn schläfert; mit weißer Decke / Umhüllen ihn Eis und Schnee. / Er träumt von einer Palme, / Die, fern im Morgenland, / Einsam und schweigend trauert / Auf brennender Felsenwand." (Heinrich Heine, "Lyrisches Intermezzo" [1822/23], no. 33. In: Sämtliche Gedichte, Stuttgart, 1997, 94, quoted in Meyer, Ensemblelieder, 244.) Pasler notes that Delage had already set a poem by Heine in French translation three years earlier (Intermezzo no. 1 of the Trois mélodies op. 2, composed in January 1910, a setting of Heine's famous "Auf Flügeln des Cesanges"). This poem already invokes dreamy images of India in the lines "Fort nach den Fluren des Ganges, / Dort weiß ich den schönsten Ort;" and "Dort wollen wir niedersinken / Unter dem Palmenbaum, / Und Liebe und Ruhe trinken, / Und träumen seligen Traum." See Pasler, "Reinterpreting Indian Music," 136.

209 Large plucked long-necked lute in North Indian music, belonging to the same family of instruments as the sitar and usually tuned a fourth or fifth lower. 
Alap by Imdad Khan (1848-1920), probably recorded in 1905, the slow, unmeasured introduction (alap) to an improvisation on the rāga jaunpuri (upward: C D F G Ab Bb C; downward: C $\mathrm{B} b \mathrm{Ab}$ G F Eb D C). ${ }^{210}$ Delage closely reconstructs surbahār playing techniques in the cello part including slides between adjacent pitches with the same finger. The ensemble slowly establishes a drone on the fifth $\mathrm{B}-\mathrm{F} \#$ in different registers, recalling another key principle of Indian music practice. The sparse harmonic structure is based on modal and plagal progressions and tends to avoid conventional triadic harmony. The timbres, however, repeatedly evoke topics of musical orientalism, namely in the harp's arpeggiation and the two flutes' soloistic figures that accompany the line "Il rêve d'un palmier qui là-bas dans l'Orient lointain se désole" [It dreams of a palm-tree which grieves far away in the distant East]. Conventional orientalist "coloring" is thus "quoted" in the context of a much more refined approach to Indian music, clearly marking the difference between these two forms of composition based on non-Western material.

The most remarkable feature of this song is surely the partly unaccompanied concluding vocalise, which systematically changes between open and closed mouth articulation, a feature of Indian vocal music that Delage had described in his "Lettre de l'Inde."211 In contrast to the famous vocalise from Léo Délibes's opera Lakmé (1883), one of the most representative works of late nineteenth-century exoticism, the refined rhythmic structure in Delage's song again suggests close modeling on a recorded performance. ${ }^{212}$ In the final part of this vocalise, the ensemble joins in a highly complex heterophony. A 1914 review of the edited score highlights the end of "Lahore" as a particular successful part of the work after quoting a sentence from Delage's "Lettre de l'Inde" that clearly evokes orientalist stereotypes:

"Strange impression of horizons where vehement or very soft tears pass by, tender sites and awakenings in beautiful light." I do not know any other such exquisite newness for our European ears than the vocalise that terminates the melody synthesized in Lahore; a vocalise sung with a closed mouth on strange nasal sonorities, hot breath, cries and caresses! ${ }^{213}$

The complexity of the musical structure is even increased in Delage's Ragamalika from May 1914, composed a few months after the successful premiere of the Quatre poèmes hindous. The piece is a detailed transcription of a recording of the devadasi singer Coimbatore Thayi (1872-1917), who was based in Madras ${ }^{214}$ and whom Delage had met during his trip in India while visiting the temples at Mahabalipuram. ${ }^{215}$ Coimbatore Thayi made about 300 recordings after the

210 Pasler, "Race, Orientalism, and Distinction,"103-104, 117. The recording can be found on the $78 \mathrm{rpm}$ disc Gramo C.C. 17364. Without knowledge of this source Meyer (Ensemblelieder, 254), has tried to identify the rāga as darbari-kanada ("midnight rāga"; upward: C D Eb F C Ab Bb C/ downward: C Ab B b G F G Eb D C). Pasler ("Reinterpreting Indian Music," 138) specifies that the switch from jaunpuri to darbari in the final part of the cello solo marks an intentional departure from the recorded model.

211 Delage, “Lettre de l'Inde," 74.

212 See Pasler, "Race, Orientalism, and Distinction," 105, Meyer, Ensemblelieder, 260-262.

213 "'Curieuse impression d'horizons où passent des sanglots véhéments ou très doux, des sites tendres et des réveils dans la belle lumière.' Je ne connais rien de plus exquisément nouveau pour nos oreilles européennes que la vocalise qui termine la mélodie qui synthétise Lahore; vocalise à bouche fermée sur d'étranges sonorités nasales, souffle chaud, cris et caresses!" Gabriel Grovlez, "La musique dans les partitions," Musica 1/7/1914, 141; quotation from Delage, "Lettre de l'Inde," 73.

214 See Badrinathan, "Interplay of the devadasi and the Composer" and Sampath, "Coimbatore Thayi."

215 Pasler, "Race, Orientalism, and Distinction," 106, 117. Mamallapuram (Mahabalipuram), located south of Chennai (Madras), is a town with important archeological sites from the Pallavian Period (seventh to ninth century). 
British Gramophone Company had started to record Indian music in $1904 .{ }^{216}$ The recorded piece Rāgamālika, Ramalinga swamis arulpa was probably recorded in 1909. ${ }^{217}$ Devadasi dancers and singers were temple courtesans who were sold to temples at a young age and learned classical Indian styles of music and dance. Arulpa is a genre of devotional song with the highly melismatic and sliding line of the voice accompanied by tabla drums and a tanpura drone; rāgamālika means "garland of rāgas," signifying a continuous change between different rāgas during the same piece. ${ }^{218}$ The text of this specific arulpa is attributed to Ramalinga Swamigal (Swamy, 1823-1874), a Tamil Shivait saint and poet. In Carnatic vocal tradition, a "vocalist usually sings a Sanskrit, Tamil, or Telugu poem toward the end of a concert by improvising in a rāgamālik $\bar{a}$ 'garland of ragas.' This is nonmetered improvisation similar to ālāpana, in which the performer uses the text freely to bring out the essence of the raga and the meaning of the text." ${ }^{219}$ The common pitch center of the emerging rāgas in this piece, $\mathrm{B} b$, in Delage's adaption is optionally damped in the piano by placing a small piece of cardboard under the hammer of the piano's Bb2-string, imitating the buzzing sound of the tanpura. Delage here also makes an attempt to transliterate the Tamil lyrics of the piece, which praise the god Nadaradjâ (Shiva), ${ }^{220}$ indicating special pronunciation rules in a short note at the beginning. The final section recapitulates the beginning, creating a variation similar to the end of "Lahore" by continuously alternating between open- and closed-mouth sections (Ex. 2.3).

Delage's literal approach definitely shows deep respect for the musical tradition he was approaching - and the orientalist ideal of "purity" may have influenced his method, even though it was doubtless naïve considering the complex history of Indian music traditions and their continuous mutual influences and flux: "With its emphasis on self-criticism, sound for its own sake, and respect for traditions on their own terms, the modernist aesthetic prepared Delage to hear Indian music in its own terms."221

Ten years later, in the Sept Haï-kaïs of 1923/24, Delage's approach appears to have changed, now being less oriented toward ethnographic precision than the India-inspired works. Still, these seven short songs also markedly differ from the musical Japonisme in many French and other European works from the turn of the century. In contrast to Delage's trip to India, his stay in Japan appears to be largely undocumented. It is obvious, however, that Delage acquired a substantial knowledge of the Japanese language. ${ }^{222} \mathrm{He}$ probably assisted Stravinsky in selecting the poems for the latter's Trois poésies de la lyrique japonaise in 1912/13 and provided French translations. ${ }^{223}$ Five of the seven poems of Sept Haï-kaïs are taken from Kikou Yamata's anthology of translations of Japanese poetry from different periods (Sur les lèvres japonaises, Paris: Le Divan 1924);

216 Sampath, "Coimbatore Thayi."

217 Pasler, "Race, Orientalism, and Distinction," 106, 117. The recording is published on Cramo G.C. 8-13793.

218 Kassebaum, "Karnatak Raga," 99.

219 Ibid.

220 Gordon, “Discovering Maurice Delage," 302.

221 Pasler, "Race, Orientalism, and Distinction," 107.

222 Rodriguez, Maurice Delage ou La solitude de l'artisan, 38.

223 Funayama, "Three Japanese Lyrics and Japonisme," 279. It is known, however, that Stravinsky used the Russian translation of the poems during the compositional process. Stravinsky's enthusiasm for Japanese wood prints and their "two-dimensional" character seems to have developed independently of Delage (see ibid. and Taruskin, Stravinsky and the Russian Traditions, vol. 1, 822-848). 
Example 2.3: Maurice Delage, Ragamalika (version for voice and piano, 1914), final section
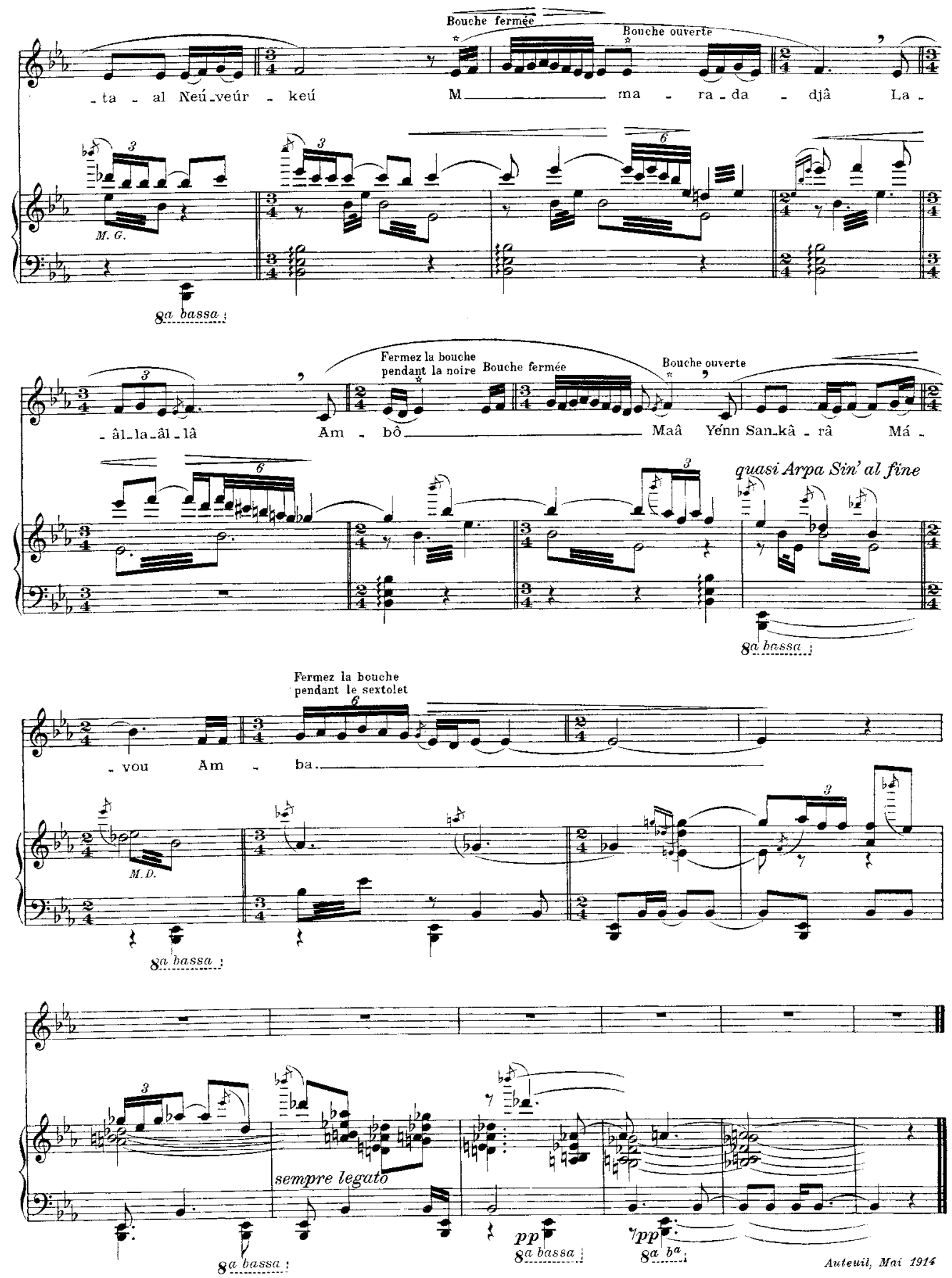

Copyright $\odot$ by Durand \& Cie 1915 
Example 2.4: Maurice Delage, Sept Haï-kaïs (1923/24), no. 5: "La lune d'automne... , piano version

V_ La lune d'automne...
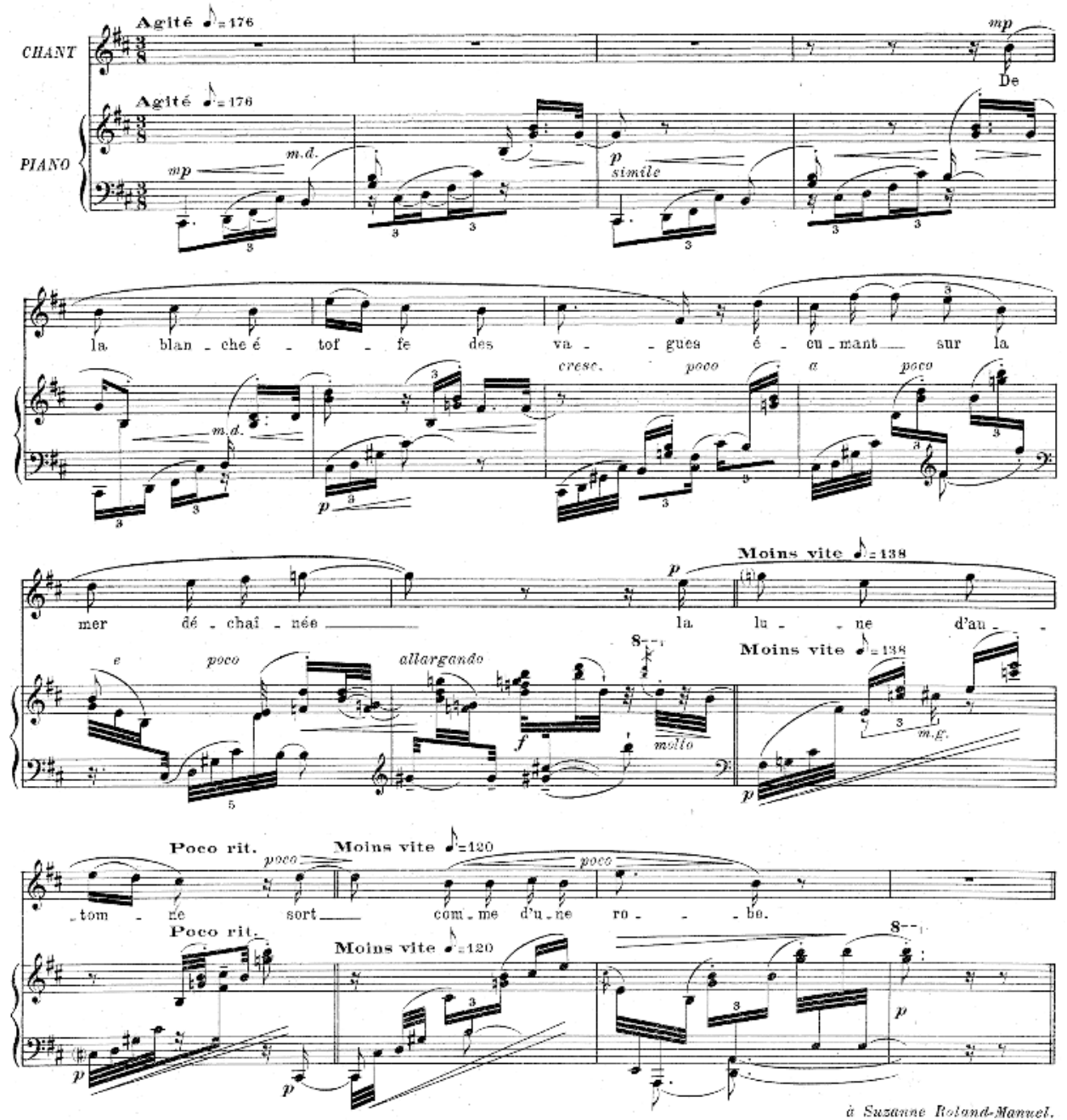

Copyright (c) by ]. Jaubert 1924

no. 6 was translated by Paul-Louis Couchoud, who in 1905 had published Au fil de l'eau, a collection of French haikai, and no. 3 was written by the French poet Georges Sabiron (1882-1918). ${ }^{224}$

224 Chipot, "Musique \& haiku." The haikai, a form of tanka poetry (following a verse scheme of 5-7-5-7-7 syllables) emerged in Japan during the fifteenth to seventeenth centuries. Yet among the seven poems selected by Delage, only two are examples of traditional haiku form - a reduced variant of the haikai model organized in 5-7-5 syllables (no. 6 by Onitsura Uejima, 1661-1738, and no. 7 by Bashō Matsuo, 1644-1694), while two poems have to be attributed to the medieval Heian-period waka genre (no. 1 by Ki no Tsurayuki, 872-945, and no. 2 by Sosei, c. 844910). The three remaining poems were written by contemporary poets in haiku or haikai form (no. 3, in French, by Georges Sabiron, 1882-1918, no. 4 by Hiroko Katayama, 1878-1957, and no. 5 by Akiko Yosano, 1878-1942). 
Both the piano and the ensemble version of the Sept Haï-kaïs were published by Jaubert in 1924. The cycle was premiered on 16 February 1925 in a SIM concert (soprano: Jane Bathorie, conductor: Darius Milhaud) and performed again at the ISCM festival in April 1929 in Geneva by Madeleine Grey and Ernest Ansermet. Around the same period, in 1925, Delage and Ravel organized a private concert with their Japanese friend Jirohachi Satsuma (1901-1976) of the Japanese shamisen player Kineya Sakichi IV (1884-1945) in the apartment of the pianist Henri GilMarchex, who had toured Japan for the first time the same year. ${ }^{225}$ Delage dedicated another (yet unpublished) short song, based on a haiku by Bashō Matsuo, to Satsuma on 20 December 1924 after completing the Sept Haï-kaïs. ${ }^{226}$

The Sept Haï-kaïs, created more than ten years after Stravinsky's Three Japanese Lyrics, are hardly related to Stravinsky's musical style. Neither is there any clear indication of an adaption of Japanese scales or modes - although the harmonic structure, based on stacked fourths and fifths, may well be derived from a polymodal arrangement of pentatonic or heptatonic pitch collections. Repeatedly, Delage employs drone-like structures in these songs. The first song ("Préface de Kokinshiou") after a free prelude establishes a drone on $\mathrm{E} b$ and $\mathrm{B} b$ with major and minor thirds $(G / G b)$ repeatedly colliding in a setting that rather closely resembles that of Ragamalika. A calmer variant of the same harmonic principle is taken up in the second half of no. 6 (“Alors...”), prolonged into the final song (no. 7: "Lété..."), establishing a harmonic frame for the cycle. The third song ("Le coq...") introduces a similar structure raised by a semitone to $\mathrm{E} q-\mathrm{B}$ ฤ and the conflicting thirds $G$ Ł and $G \sharp$, providing the frame for a musical pictorialism that evokes the coq's cackling by short appoggiaturas in the style of Ravel's Histoires naturelles (1906). ${ }^{227}$ The second ("Les herbes de l'oubli...") and the fourth song ("La petite tortue...") as well as the first half of no. 6 , in contrast, situate the drone-like structures on major seconds ( $D \#-E \#$ in no. 2 , $\mathrm{F} \#-G \sharp$ in no. $4, \mathrm{C}-\mathrm{D} / \mathrm{C}$ - $-\mathrm{D}$ b in no. 6). While no. 2 is characterized by melodic lines moving in parallel fourths, no. 4 adopts the appoggiaturas from no. 3, possibly now pointing to the clunky movements of the tortoise.

A reference to Japanese modes is perhaps intended in no. 5 ("La lune d'automne..."), which starts with an ostinato figure comprising the pitch-classes $C \sharp-D-F \#-G-B$ (Ex. 2.4), reminiscent of the miyakobushi-mode, popular in adaptations of Japanese melodies and modes around 1900. ${ }^{228}$ However, a modal ambivalence is established when the voice takes $\mathrm{B}$ as its pitch center and adds $E$ to the pitch collection ( $F \#-B-C \#-E-F \#)$ while the ensemble/piano now again (as in the preceding movements) continuously switches between $G \sharp$ and $G \sharp$. The ambivalence remains unresolved until the end: a tendency toward $\mathrm{E}$ minor in the final two bars of the instrumental part, supported by the B-E-B contour in the voice, is undermined by the bass that superimposes the progression $\mathrm{A}-\mathrm{D}$ below the $\mathrm{E}$ minor harmony, resulting in a polymodal arrangement of a complete pentatonic scale (D-E-G-A-B).

225 Funayama, "Three Japanese Lyrics and Japonisme," 278-279. Kineya Sakichi IV was a reformer of Japanese traditional music and developed larger types of shamisen such as the sero shamisen (cello shamisen) and the teion shamisen ("lower range shamisen") (Wade, Composing Japanese Musical Modernity, 250). Henri Gil-Marchex (18941970) toured Japan four times, in 1925, 1931, 1932, and 1937. The Japanese composer Yoritsune Matsudaira (19072001) was impressed by Gil-Marchex's performances and took piano lessons with him while the pianist was in Japan (Galliano, Yōgaku, 83-84). In 1936 Gil-Marchex composed Quatre [Deux] images du vieux ]apon for piano.

226 Funayama, "Three Japanese Lyrics and Japonisme," 279-281.

227 Rodriguez, Maurice Delage ou La solitude de l'artisan, 83.

228 Pacun, "Nationalism and Musical Style in Interwar Yōgaku," 11-22 (see below). 
Example 2.5: Maurice Delage, Sept Haï-kaïs (1923/24), no. 5: "La lune d'automne... ," orchestral version, final part

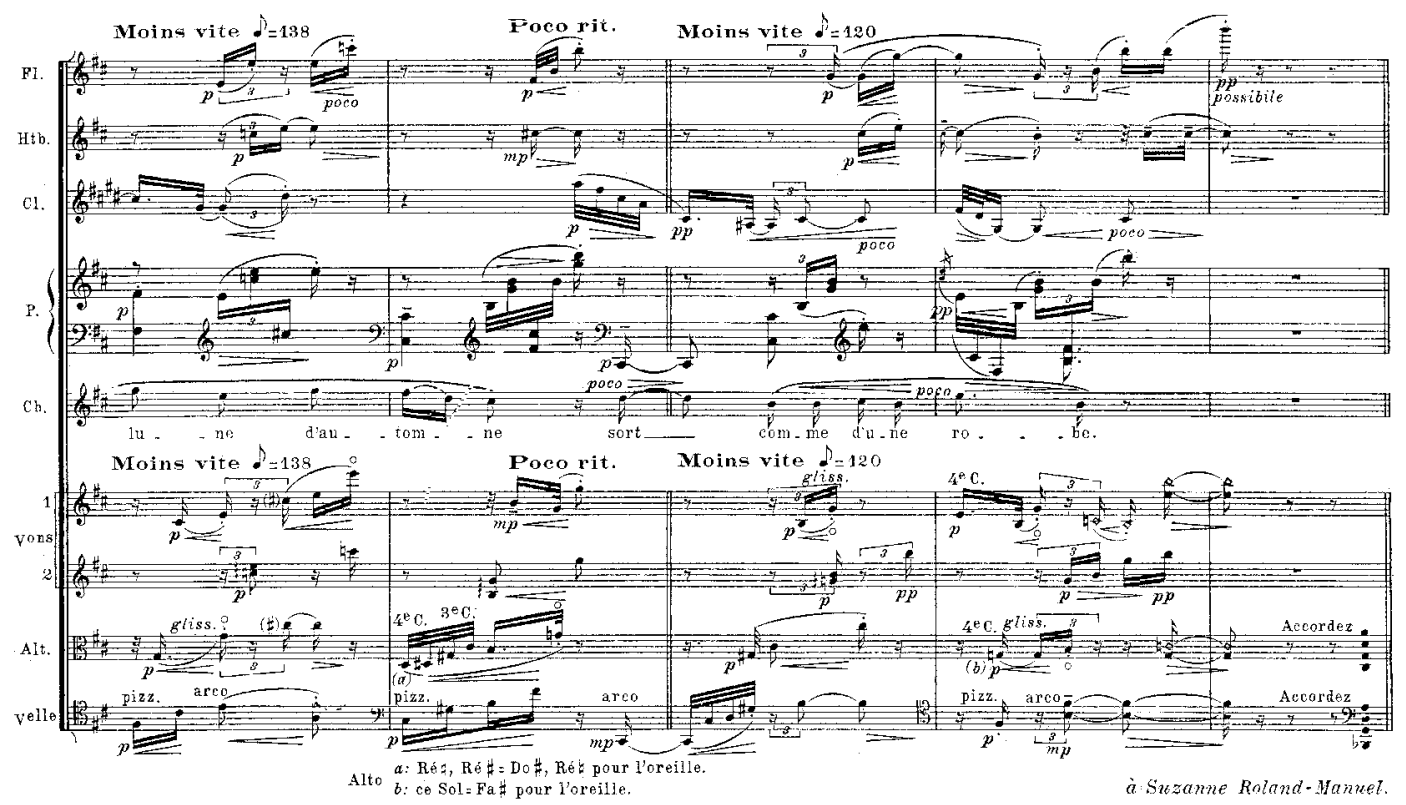

Copyright $\odot 1924$ by Jaubert

The rich sonorities of the ensemble version considerably expand these restrained harmonic structures into veritable flashes of color. This may be exemplified by the fifth song again (Ex. 2.5). The quick tempo here lets the highly perforated orchestration, comprising fluttertonguing in the flute and glissandi in the strings, turn into a dissonant and bewildering sonorous field. The composer's great attention to detail, evident from the score, thus gives way to a "sound composition" reaching far beyond established orientalist musical concepts. Although the current state of research does not allow a reliable conclusion as to the actual impact of Japanese traditional music for Delage's compositional conception, it is apt to say that in comparison to the earlier literal approach in "Lahore" or Ragamalika, the Sept Haï-kaïs establish a far more abstract and concealed way of communicating with the non-Western tradition - most importantly through a radicalized aphoristic form and a highly refined (poly)modal harmony.

\section{Henry Cowell: Toward Cultural Hybridity}

If the Société Musicale Indépendante stood for a new internationalism and new approaches toward the music of non-Western cultures, those preconditions reappeared in a more rigorous and resolute manner in the context of Henry Cowell's New Music Society of California, established in Los Angeles in 1925, continued in San Francisco from 1927 to 1936, and later in New York. According to Cowell's first flyer, the society was dedicated to the performance of the "most discussed composers of so-called ultramodern tendencies, such as Strawinsky [sic], Schoenberg, Ruggles, Rudhyar, etc." ${ }^{229}$ and it had a decidedly international perspective (works 
by 36 European, six Latin-American, and 30 American composers were performed in the society's concerts between 1925 and $1936^{230}$ ). At least one of the society's events (a concert on 1 April 1935) also included performances of traditional Japanese music. ${ }^{231}$

By 1925, at the age of 28 , Cowell had already become an international celebrity. He had been on tour to Europe several times since 1923 as a "scandalous" pianist performing clusters and playing on the piano strings, and had made his debut at Carnegie Hall on 4 February 1924. In Europe he met a number of leading modernist composers and musicians. His Berlin recital in 1923 had been funded by Hermann Scherchen's Neue Musikgesellschaft. ${ }^{232}$ Similarly to Ravel's and Delage's societies, Cowell's New Music Society of California was conceived in opposition to the nationalist aesthetics of composers assembled in the League of Composers, founded in 1923. ${ }^{233}$ An anti-nationalist stance was a precondition especially for many composers who had emigrated to the US during the First World War, such as Edgard Varèse or Dane Rudhyar, ${ }^{234} \mathrm{a}$ close friend and ally of Cowell. Rudhyar wrote in 1922:

Nationalism breeds hatred of the foreigner. Wherever such hatred exists [and] the fundamental interhuman quality is killed, music ceases to express the essential life of Man, his ideal, his fervor, his aspirations - colored as they may be by racial idiosyncrasies - it expresses only the superficial complex of fashions, of peculiar brain-activities, which constitutes the outer make-up of a nation, not truly a Race in the spiritually human sense of the word. [...]

We insist on this point because it is an essential one today. America should be considered as the new soil (culturally speaking) which will be the home of the next civilization when Europe has fallen in the state of slumber and medievalism which she is fast approaching. It is nationalism which killed Europe. The various European states could not and cannot realize their fundamental identity, unite and constitute the United States of Europe which alone could have given birth to a true European culture. Now the American civilization which is being born is inherently an heir to the European civilization. Will it inherit its nationalistic attitude, or will it repudiate it at the outset, and begin to think in terms of interhuman unity? [...] If these [European] seeds are permeated by the virus of nationalistic separativeness, the future will repeat the past, and various schools will war within the borders of America instead of cooperating together in a true synthetic culture. Such a glorious synthetic culture can only manifest if America responds to the spiritual note of artistic internationalism, which is not indifference to race but humanism as a fundamental, and racial differences as overtones. ${ }^{235}$

230 Ibid., 454 .

231 Ibid., 454, 461.

232 Ibid., 449.

233 An explicitly international perspective had also been envisioned by Edgard Varèse and Carlos Salzédo when they had founded the International Composer's Guild (ICG) in 1921. Among other activities, the ICG was organizing the US premiere of Pierrot lunaire on 4 February 1923. The League of Composers segregated from the ICC in 1923. In 1928 Varèse and Cowell united to form the Pan American Association of Composers (PAAC), supporting composers from both North and Latin America (ibid., 453; see also Oja, Making Music Modern, 177-200 and Nonnenmann, "Institutionen/Organisationen," 285).

234 Varèse arrived in the US on 29 December 1915, Rudhyar (then still under the name Daniel Chennevière) on 13 November 1916.

235 Rudhyar, "Edgard Varèse and the New Music of America." 
Cowell's international activities between 1923 and 1936 show great efforts and also a certain restlessness, increasingly leading to frustrations in the wake of the Great Depression and the ensuing financial limitations. The Pan American Association of Composers (PAAC), founded by Varèse and Cowell in 1928, for example, involved, among others, a close contact to the Havana Society for Contemporary Music in 1930 and the collaboration with the Commission for International Exchange Concerts, founded in Vienna also in 1930. ${ }^{236}$

Both Rudhyar and Cowell were deeply influenced by non-Western musical traditions early on. Rudhyar had immigrated to the United States from France in 1916, and by 1918 had established ties to theosophical communities through Scriabin's student Djane Lavoie-Herz (18891982), whom Rudhyar met in New York in $1918 .{ }^{237}$ Rudhyar and Cowell first met in 1920 in the Californian theosophical community Halcyon, ${ }^{238}$ led by John Varian (1863-1931), an Irish-American poet and amateur musician. Cowell had already joined the community as a teenager in 1912 and many of his early pianist practices, such as cluster and string piano techniques, as well as music-theoretical ideas, namely microtonal and polyrhythmic concepts, ${ }^{239}$ can be attributed to theosophical influences, as Gregor Herzfeld has demonstrated. ${ }^{240}$ The clusters, for example, were to represent the oneness of humans and nature, ${ }^{241}$ and the string piano techniques (sound created by playing directly on the piano strings) evolved in the context of the idea of a giant harp conceived as the universe's body of resonance (a reference to the antique concept of the "Aeolian harp" as first described by Athanasius Kircher), an idea adopted by Varian in his "cosmic play" The Harp of Life (1916), for which Cowell wrote the music. ${ }^{242}$ A transcultural dimension was implicit in theosophical thought. Influenced by Indian myths of origin preserved in the Vedas, Helena Blavatsky conceived of music as "cosmic energy" and as a principle characterized by continuous movement and dynamic motion ${ }^{243}$ - features that abound in Cowell's early work. In a more explicit move toward cultural and racial hybridity, John Varian considered the theosophical community the "germic embryonic seed of future majesties of growth," of a "new civilization now starting round the Pacific" prominently including "oriental races."244

236 Sachs, Henry Cowell, 182-183, 198-199. Already by 1929 Cowell, returning from a tour to the Soviet Union, had suggested to Erich Moritz von Hornbostel and Carl Stumpf in Berlin the "creation of an international network to exchange and disseminate information through centers in Moscow, Leningrad, Berlin, Paris, New York, and Stanford." (ibid., 187.) After the same idea was presented to a circle of New York scholars and composers, the New York Musicological Society was founded, reorganized as the American Musicological Society (AMS) in Philadelphia in 1934. Both international and intercultural focuses were abandoned during this process, so Cowell did not remain involved (ibid.; see also Rao, "American Compositional Theory in the 1930s," 596-608).

237 Ertan, Dane Rudhyar, 30-32.

238 Oja, Making Music Modern, 128-129.

239 In Halcyon, Cowell was probably drawn to "Hindu rhythms" by the community's music director Edgard Cheetham as early as 1916 (Sachs, Henry Cowell, 188). The most substantial influence on the rhythmic system explored in Cowell's treatise New Musical Resources (1916-19), however, resulted from the correspondence with John Varian's son Russell (Herzfeld, Zeit als Prozess und Epiphanie, 136-137).

240 Herzfeld, Zeit als Prozess und Epiphanie, 122-151.

241 lbid., 126.

242 Ibid., 132-133.

243 See Oja, Making Music Modern, 101-106, Reish, "The Transformation of Giacinto Scelsi's Musical Style," 68-76, and Baatz, "Resonanz des 'weißen Unbewegten," 36.

244 "There is a new race birthing here in the West [...]. In the ages coming, it will be a large factor in a new civilization now starting round the Pacific - of a quite different nature from that of the Atlantic. Oriental races will be in it 
In his childhood days in San Francisco where he spent the first nine years of his life, Cowell came into close contact with music traditions of China (Cantonese Opera), Japan (koto music), and India ("Indian virtuosi" who allowed Cowell to listen from a corner in their room), ${ }^{245}$ - an experience that, according to the composer, explains his open-mindedness toward musics of the world: "No one [in these early years] [...] ever told him that Western music was supposed to be superior." ${ }^{246}$ In his short piano encore Amiable Conversation from 1917, Cowell modeled the (largely pentatonic) melodies in the left hand (black keys) and right hand (white keys) on the speech melodies in a conversation between two Cantonese in a Chinese laundry. ${ }^{247}$

During the 1920s, Cowell repeatedly established contacts with Asian musicians and studied the foundations of Asian music practices. He organized two "Symposia on Exotic Music" in 1924 and 1926 in the Manhattan church St. Mark's-in-the-Bouwerie, featuring performances of traditional music from Japan (shamisen, shakuhachi), India (sitar, esraj), and China in $1924,{ }^{248}$ and performers from Japanese, Chinese, Hindu, and Arab music traditions in 1926. The first symposium also included a talk on "the peculiarities of Oriental Music illustrated by Instrumentalists." 249 This might have been "the first public presentation of extra-European music in the United States" for a "white audience." ${ }^{\text {250 }}$ Anti-immigrant and racist discourse generally confined musical activities of Asian musicians to their local urban communities such as Chinatown and lend Cowell's efforts a pioneering character.

In 1927, Cowell's possible conversations with Béla Bartók and his trip to a Moravian mountain village in 1926 were referred to in two articles. ${ }^{251}$ In the same year, he began a study of the North Indian rāga and tāla systems with Sarat Lahiri (a performer in the Symposium on Exotic Music in 1924) and Arab music; he obviously also studied African drumming in $1928 .{ }^{252}$ After he was appointed music teacher at the New York School for Social Research, he lectured on "Newly Discovered Oriental Principles" in spring 1930, organized twelve weekly lecture recitals on

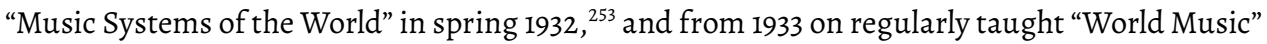
classes at the New School and from 1934 on at the University of California at Berkeley and Stanford University, henceforth using the title "Music of the Peoples of the World."254 In the autumn

[...]. We are germic embryonic seed of future majesties of growth." (]ohn Varian, foreword to Tirawa [San Diego: Troubadour, 1930], quoted in Johnson, "Henry Cowell, John Varian, and Halcyon," 16.)

245 Sachs, Henry Cowell, 21-26 and Rao, "Henry Cowell and His Chinese Music Heritage," 120-122.

246 Sachs, Henry Cowell, 25.

247 Ibid., 86. A similar setting is taken up in Ruth Crawford-Seeger's short song Chinaman Laundryman (1931) under the direct influence of Cowell's approach to sliding tones in Chinese speech and Chinese opera (Rao, "Henry Cowell and His Chinese Music Heritage," 124-125, 244). In this song, Crawford-Seeger introduces two roles, "a boss who verbally assaults his employee, and the laundryman himself who delivers a recitation describing the harsh working conditions he endures and spurring his fellow men to work for a better world" (https://en.wikipedia.org/wiki/Chinaman,_Laundryman).

248 Sachs, Henry Cowell, 129, 527n20 identifies the performers at the 28/12/1924 concert as Yoshi, shamisen; Yoshica, shakuhachi; Arjun Govind, sitar; Sarat Lahiri, esraj; Wang Kang Hou, wu con (at ibid., 188, 533n11 the second concert on 20/2/1926 is mentioned).

249 Ibid., 129.

250 lbid.

251 Cowell, "Moravian Music" and Cowell, "How Young Hungary Expresses Individuality."

252 Sachs, Henry Cowell, 188.

253 This series included live performances of Arab, Balkan, Chinese, Indian, Irish, Japanese, Javanese, Mexican, Russian, Scottish, Native American, and Hebrew music (ibid., 195).

254 Ibid., 208-209. 
and winter of 1931, and from the summer to the winter of 1932, Cowell was living in Berlin on a Guggenheim Foundation grant. ${ }^{255}$ In Berlin, he was studying audio recordings in Erich Moritz von Hornbostel's Phonogramm-Archiv systematically as well as receiving intense instructions in the performance and theory of Javanese music by Raden Mas Jodjana, in Balinese music by the dancer-musician A. F. Roemahlaiselan, and in Indian music by Pichu Sambamoorthy (1903-73) from the University of Madras. ${ }^{256}$ During his Berlin years he met Arnold Schoenberg, Alban Berg, and Anton Webern, who at one point was supposed to conduct a concert with American composers in Vienna. ${ }^{257}$

Perhaps the most significant aspect of Cowell's approach toward non-Western music is his anti-essentialist position, based on the close observation of the musical traditions he studied. Criticizing the focus of comparative musicology on acoustics and tone psychology, Cowell deplored that such an approach would exclude cultural exchange and hybridity: "There is very little music in the world of which one may say with certainty that it is completely indigenous to the region in which it may be found. And when, through integration, does a hybrid form cease to be hybrid? It is hard to say. Opinions differ." 258 This eventually led to Cowell's provocative idea that "the single tone with a given pitch is not the basis of musical sound" but that such a basis rather is to be found in the sliding tone, represented by a curve. ${ }^{259}$ In reaction to systematic scale theories in American music theory during the early 1930 s, ${ }^{260}$ this idea was eventually worked out in the 1937 treatise The Nature of Melody, in which sliding tones occupy a prominent position because

[Sliding tones] are differentiated so as to express the finest shades of meaning in the cultivated Oriental systems of music. In our vocal music, they are a sort of skeleton in the closet. It is physically impossible for the human voice to proceed from one pitch to another, legato, without sliding. [...] The reason that slides have been banned is doubtless because they were so badly used, and that was because so little was known of their functions. In all vocal music, and on all stringed and other instruments capable of sliding, they are used often according to certain conventions [.... ${ }^{261}$

The idea that it is not fixed tones but rather continuous movements between tones or pitches that act as the basis of music clearly emerged from the close study of Indian, Chinese, and Japanese music traditions, as well as theosophical ideas of a continuous, dynamic, energetic flow of sound as manifest in Cowell's string piano compositions.

As Nancy Yunhwa Rao has demonstrated, expanded sliding structures form the basis of the unpublished score of Atlantis (1926) for three vocalists and orchestra. The premiere of the piece, written for a dance performance of the choreographer Doris Humphrey, was canceled, possibly due to the experimental setting of the score. ${ }^{262}$ The first movement shows a systematic layering

255 Cowell's stays in Berlin (including frequent trips to other places in Europe) covered the periods 1/10/193123/12/1931 and 31/7/1932-22/12/1932. The Guggenheim grant was granted for one year but Cowell was allowed to split his stay in Berlin into two halves to be able to teach at the New School in spring semester 1932 (ibid., 189).

256 Ibid., 190.

257 Ibid., 192-193.

258 Cowell, "Hybrid Music" (unpublished Ms.), quoted in Sachs, Henry Cowell, 197-198.

259 Sachs, Henry Cowell, 198.

260 See Rao, "American Compositional Theory in the 1930s" and Rao, "Henry Cowell and His Chinese Music Heritage," 129-130.

261 Cowell, The Nature of Melody, 76, quoted in Rao, "Henry Cowell and His Chinese Music Heritage," 130.

262 Rao, "Henry Cowell and His Chinese Music Heritage," 125. 
of glissandi with and without a change of direction (Ex. 2.6). The immediate inspiration for this approach may have been a vocal ensemble using extended vocal techniques that Cowell heard in a concert in Prague in April 1926, probably led by Emil František Burian. ${ }^{263}$ Atlantis thus demonstrates impressively how principles derived from non-Western practices and the latest techniques of contemporary music may merge into specific and innovative musical structures. Perhaps even more remarkable is Cowell's adoption of the slide principle in his early orchestral score Some Music, published as early as 1922. The orchestral structure exemplifies the principle of continuous movement, realized by alternating scalar movements within semi- and wholetone-clusters of different ranges. The score seems to anticipate certain sound compositions by Iannis Xenakis and Krzysztof Penderecki of the 1950 s and 60s, and clearly represents the idea of indistinct, steadily inflected pitches and the theosophical "oneness of sound."

Sliding pitches are used more consistently in works from Cowell's later periods, as in Symphonies 11 to 15 (1953-60). In the works of the 1930s, sliding tone techniques are not dominant; the restricted use of sliding lines for the purpose of word-painting in the song Rest (1933) and the secondary role of continuous slides in the third movement of the Mosaic Quartet of 1935, where three higher strings provide a background of continuously sliding pitches for the cello's cantilena, do not define sliding tones as core structural elements. ${ }^{264}$

Cowell's United Quartet (String Quartet no. 4) of 1936 marks the composer's first explicit attempt at musical polystylism, flexibly adapting a variety of "the world's music systems," a feature which would become characteristic of Cowell's later style, although usually only one particular tradition per piece is evoked. ${ }^{265}$ Cowell declared the United Quartet "an attempt toward a more universal musical style"266 and a preface to the score explicitly addresses a multicultural listenership across all social classes ("Americans, Europeans, Orientals, or higher primitives; anybody from a coal miner to a bank president"). ${ }^{267}$

263 Sachs, Henry Cowell, 139. It is most likely that Cowell heard Emil František Burian's (1904-1959) Voiceband, which, however, was only officially formed in 1927. Cowell described Burian's practices in 1930 in his article "Vocal Innovators of Europe."

264 See Rao, "Henry Cowell and His Chinese Music Heritage," 126, 136.

265 Among others, the following works by Cowell refer to specific musical traditions: Indonesia: Ostinato Pianissimo for percussion ensemble (1934); Ireland: Celtic Set for Concert Band (1938); Iran: Persian Set for chamber orchestra (1956-57); India: Pulse for percussion ensemble (1939), Symphony no. 13 "Madras" (1956-58); Japan: Ongaku for orchestra (1957, $\rightarrow$ II.5.). Besides the United Quartet, the explicitly "multi-ethnic" pieces include Four Assorted Movements for flute, oboe, clarinet, bass clarinet, bassoon, horn, and piano (ad lib.) (1938) [first movement: Hoedown; second movement: Taxim; third movement: Tala; fourth movement: Chorale] and American Melting Pot for chamber orchestra (1940).

266 "[...] the United Quartet is an attempt toward a more universal musical style. [...] Primitive music is represented, not by imitating it, nor by taking a specific melody or rhythm from some tribe, but by using a three-tone scale, and exhausting all the different ways the three tones can appear, which is a procedure of some primitive music." (Henry Cowell, note to String Quartet no. 4, United Quartet, New York: C. F. Peters, 1966, quoted in Taylor, Beyond Exoticism, 109.)

267 "The Quartet should not only be easy to understand, without following any known pathway, but it should be understood equally well by Americans, Europeans, Orientals, or higher primitives; by anybody from a coal miner to a bank president. The main purpose of it, of course, is not in its technique, but in the message, which, of course, is not suitable for expression in words. It may be said that it concerns human and social relationships. The technique is for the purpose of conveying the message to the widely differentiated groups who need to be united in these relationships." (Cowell, "Introduction," quoted in Nicholls, "Henry Cowell's United Quartet," 199.) 
Example 2.6: Henry Cowell, Atlantis, first movement, mm. 1-14
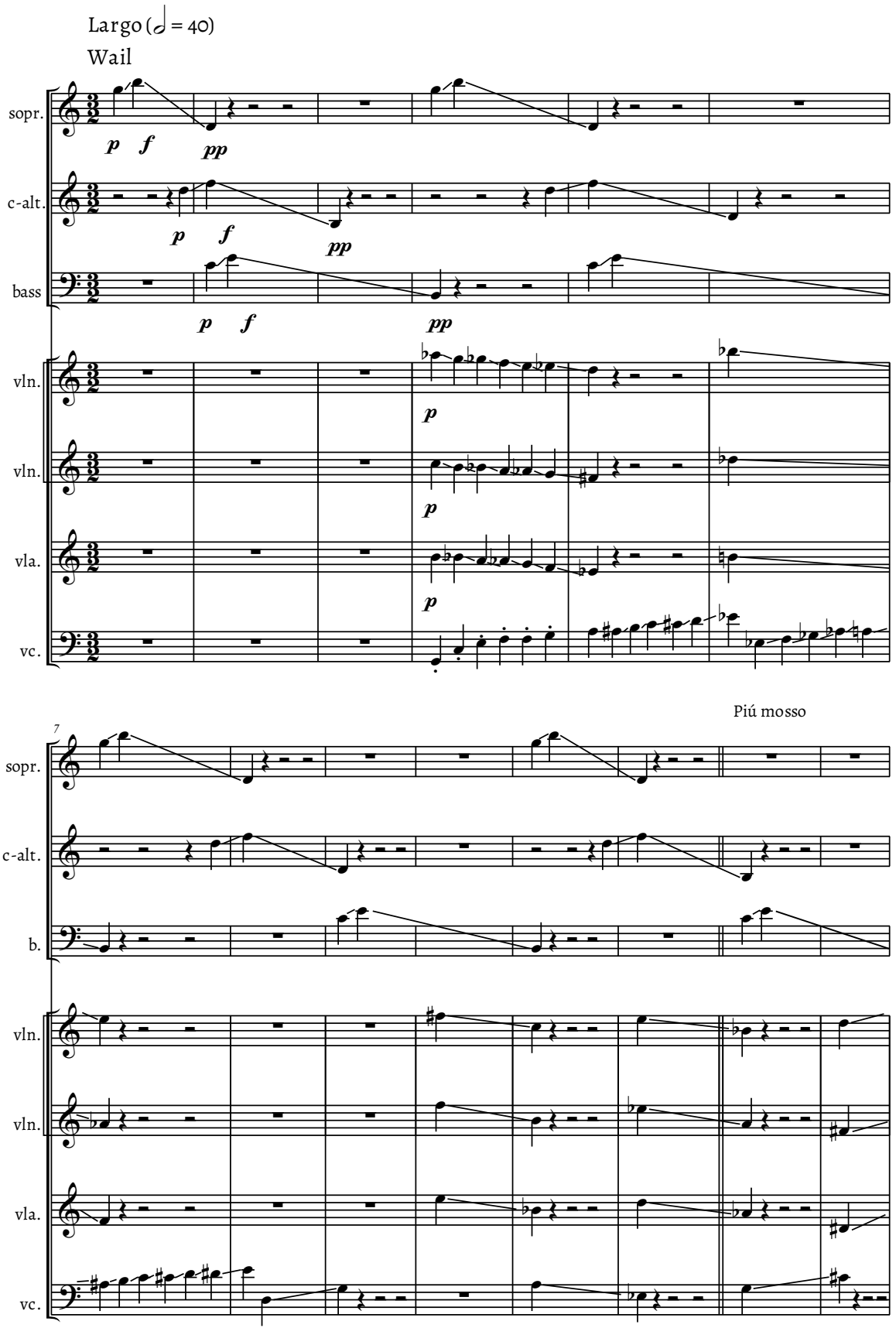

Reproduced by permission of the David and Sylvia Teitelbaum Fund, Inc., as successors to Henry and Sidney Cowell 
Timothy Taylor has interpreted this as evidence of Cowell's relativist approach to musical cultures, in tune with Boas's cultural theory $\left(\rightarrow\right.$ II.1). ${ }^{268}$ However, Cowell here makes a clear distinction between "primitive music" ("represented [...] by using a three-tone scale, and exhausting all the different ways the three tones can appear, which is a procedure of some primitive music"), "Oriental music" ("represented by modes which are constructed as Oriental modes are constructed, without being actual modes used in particular cultures"), and "the modern" ("The modern is represented by the use of unresolved discords, by free intervals in two-part counterpoint, and by the fact that the whole result is something new, - and all that is new is modern!"). ${ }^{269}$ It becomes clear from this distinction that both Cowell's cultural relativism as well as his aesthetic universalism are based on those essentialist concepts he had felt at odds with during his days in the Berlin Phonogramm-Archiv. The fourth movement presenting its three simple layers as "principal melody, countermelody plus drone, and percussive accompaniment"270 makes the unspecific ethnic background problematic and tends toward a stereotypical "neo-primitivism." In 1933 Cowell had conceived of this style theoretically in order to set his approach clearly apart from French and American neoclassicism. Characteristically, Cowell here navigates between sweeping generalizations and anti-essentialist arguments:

Now the time has come for a strong new counter-movement, full-blooded and vital. The tendency already exists, and shows signs of steady growth. It reacts against the over-complexity of the earlier modern music but not against experiment; against the sentimentality and pomp of later romantic music but not against feeling; against the supercilious formalism of a return to the particular style of some past century but not against the use of primary musical elements. [...] It is not an attempt to imitate primitive music, but rather to draw on those materials common to the music of all the peoples of the world, to build a new music particularly related to our own century. [...] Many of the customary generalizations can no longer be made in the face of this wider knowledge. There is, of course, no aboriginal music to be found anywhere which corresponds to the common conception of an uncontrolled expression of wild, unbridled, savage feeling. Nor can primitive music be lumped into one group. The music of various tribes is as different as the music of the various cultivated nations. [...]

However there are some general characteristics which nearly all primitive music shares. Most of it is sung to the accompaniment of percussion; melody and rhythm are thus the main elements. Where several different voices sing together they are either in unison or heterophonic, making a free polyphony in which each part is quite independent except that it must come out with the others at the end. Further, nearly all primitive music has rapid rhythmical changes, syncopations, polyrhythms and cross-rhythms. In the melody there may be a wide range of different sorts of pitch curves as well as straight lines of sound. The tones either wabble back and forth or slide up or down - not carelessly, but as a vital part of the musical scheme. ${ }^{271}$

Cowell detailed his perspectives on the relationship between traditional and contemporary music in many further essays and statements that have been scrutinized in the dissertation by Ethan Lechner from 2008. Lechner confirms that Cowell's approach to non-Western mu-

268 Taylor, Beyond Exoticism, 106-108.

269 All quotations from Cowell, note to String Quartet no. 4 (see footnote 266).

270 Nicholls, "Transethnicism and the American Experimental Tradition," 573.

271 Cowell, "Towards Neo-Primitivism," 150-151. 
sics was still shaped by an evolutionary concept distinguishing between "primitive cultures" and "civilizations," and between different stages of "development" achieved in different cultures. ${ }^{272}$ Notably, this concept did not conceive of Western culture or music as the fulfillment of an evolutionary process because Western music, according to Cowell, particularly lacked rhythmic and melodic refinement. Still, it was substantiated by a positivistic compositional and scholarly concept of music consisting of discrete, analyzable "elements" that might be turned into "resources" for composers. The composer as a quasi-scientific experimenter was free to use and combine these resources into a new universalist model of a "music of many cultures." Such naïve openness and the straightforward goal of its audience-friendly compositional realization would become increasingly explicit in Cowell's output from the 1930s on, eventually making him the ideal composer for the American cultural politics of transcultural universalism during the Cold War period ( $\rightarrow$ II.5).

\section{Shūkichi Mitsukuri and Fumio Hayasaka: Between Modernity and Nationalism}

Switching the geographical and sociocultural context to 1920s and 1930s Japan, the differences are obvious. By the early 1930s, Western-oriented musical institutions and musical life in Japan had reached considerable standards, an outcome of roughly sixty years of radical and all-encompassing modernization and Westernization programs since the Meiji restauration in $1868 \rightarrow$ III.1). Westernization was not only prevalent in yōgaku, Western-oriented chamber and orchestral music written by Japanese composers, but also in hōgaku, traditional Japanese music. While these two segments of Japanese music were largely isolated from each other until the late 1920s, attempts at convergence arose in the early 1930s, not least in a response to Michio Miyagi's Etenraku Variations with an orchestral arrangement by Hidemaro and Naomaro Konoe, an adaptation of the most famous piece from gagaku court music, performed during the enthronement ceremonies of the new Showa emperor in 1928. ${ }^{273}$

This rapprochement should also be viewed in the context of an increasingly obvious nationalist tide in Japanese politics, escalating in the occupation of the Manchuria peninsula in 1931. Although composers' groups of the early 1930s, such as the Shinkō sakkyokuka renmei (Federation of Innovative Composers), founded in Tokyo in 1930, and the Shin ongaku renmei (New Music Federation), founded in Sapporo in 1934, did not pursue explicit political agendas, their common objective was to qualitatively change the integration of Japanese musical traditions into contemporary music. As Stefan Menzel has demonstrated, the compositional scene had been monopolized far into the 1920s by Kōsaku Yamada (1885-1963), who, at the age of 29, had returned to Japan in 1914 after four years of study in Berlin $\rightarrow$ III.1). ${ }^{274}$ Oriented toward Richard Strauss's style, Yamada wrote the first Japanese opera (Ochitaru tennyo, 1913, premiered in 1929), the first Japanese symphony (Symphony in F major "Peace and War," 1912, premiered in 1914), and the first Japanese symphonic poem (Kurai to, 1913; premiered in 1918). Relying on generous funding from the Mitsubishi corporation, Yamada was central in the founding and development of musical institutions, namely the Philharmonic Society Tokyo (founded in 1910), the Japanese Symphony Orchestra (1923), and particularly the New Symphony Orchestra (Shin $k \bar{k} k y \bar{o}$ gakudan) together with the influential conductor Hidemaro Konoe in 1926. The New Symphony Orchestra was crucial in performing new orchestral works by Japanese composers over

272 Lechner, "Composers as Ethnographers," 110-176.

273 Menzel, Hōgaku, 117-119.

274 Ibid., 104-108. 
the decades that followed. ${ }^{275}$ At the same time, Yamada composed a large number of songs (his total output amounts to over 1,100), the favorite genre of Japanese composers up to the 1940 s. $^{276}$ By the early 1920s, certain topoi of a "Japanese harmony" had developed, particularly in folk song settings by Yamada and other composers such as Kiyomi Fujii (1899-1944), including the prominent use of the half-diminished seventh chord in connection to the miyakobushi scale and harmonies based on stacked fourths and fifths, emerging from pentatonic scales, as well as a frequent evocation of French music by Debussy, Ravel, and their contemporaries. ${ }^{277}$

The Shinkō sakkyokuka renmei, founded by sixteen young music artists aged between 23 and 34 (eleven composers, four musicians, and one critic ${ }^{278}$ ) from differing backgrounds, aimed to reach beyond such conventional limitations, adopting the term shinkō (lit. "rising," "innovative") which in the late 1920 s had replaced bunmei ("civilization") as a guiding principle in Japanese cultural discourse. ${ }^{279}$ One of the foremost concerns of the group was to establish an "antithesis" to the dominant German-style composition of the time, mainly represented by Yamada. In addition, it seems that the association was conceived in opposition to the Dainihon sakkyokuka kyōkai (Great Japanese Association of Composers), founded in 1925, in which composers of popular and children's songs assembled (as elsewhere in the world, popular music reached an initial peak in Japan during the 1920 s due to the advent of the recording industry). ${ }^{280}$ In its beginnings, Shinkō sakkyokuka renmei was associated with the concept of "avant-garde" that was concurrently imported into culture-related discourse, translated as zen'ei or transliterated as avantgyardo. ${ }^{281}$ Although all composers of the group were oriented toward recent musical developments in Europe, it was only Noboru Ito (1903-1993) who actually employed such features as quartertones and polytonality by the early 1930s; in 1933 he wrote an article entitled "Tomorrow's Music" on recent European trends, including dodecaphony. ${ }^{282}$

Musical innovation was such an important objective of Shinkō sakkyokuka renmei that it was even codified in four guidelines of the association that urged the members to (1) use scales and modes from (Japanese) traditional music, (2) develop tonal systems oriented toward the quartal

275 Ibid., 105.

276 See Cottschewski, “'Poesie und Musik," 380.

277 Pacun, "Nationalism and Musical Style in Interwar Yōgaku," 24-25.

278 Lehtonen, "'March from the Age of Imitation to the Age of Creation," 38-39. The founding members were Kunihiko Hashimoto (1904-1949), Yuzuru Ike (1902-1990), Gorō Ishii (1909-1990), Noboru Ito (1903-1993), Yasuji Kiyose (1900-1981), Heigorō Komatsu (1897-1953), Kiyoshi Komatsu (1899-1975), Yoritsune Matsudaira (19072001), Shūkichi Mitsukuri (1895-1971), Meirō Sugawara (1897-1988), and Naotada Yamamoto (1904-1965); the critic Kamesuke Shioiri (1900-1938); the pianists Hakujirō Kondō (1900-1932) and Kōkichi Oida (1902-1964); the cellist and conductor Hideo Saitō (1902-1974); and the cellist Fumio Suzuki (1900-1945). "The division into composers and performers was, however, originally not that strict; although listed as musicians here, Oida, Saitō, and Suzuki composed some works at the early stages of their careers. And vice versa: practically all composers were also musicians or conductors." (Ibid., 39.)

279 Galliano, Yōgaku, 66-73, 79-82.

280 Menzel, Hōgaku, 115-116.

281 Galliano, Yōgaku, 88.

282 Ibid., 78. In 1934, Noboru Ito and Gorō Ishii founded the Shin ongaku ha (New Music Group), evidently because the support for their "avant-gardist" ideas within Shinkō sakkyokuka renmei was limited. Another group founded during that period was Prometeo, started in 1937 by Shirō Fukai (1907-1959, like Ito a student of Meiro Sugawara), focusing on the reception of recent European music, mainly French neoclassicism. Fukai criticized nationalist tendencies in Japan and argued that "Japanese composers should immerse themselves completely and unreservedly in the European tradition" (ibid., 79). 
harmonies of the mouth organ (shō) in gagaku, (3) develop heterophonic textures inspired by the traditional chamber music genres sankyoku and jiuta, and (4) make creative use of instrumental "colors." ${ }^{283}$ Apart from the remarkable fact that a heterogeneous group of composers was willing to agree on such a detailed compositional program, ${ }^{284}$ the four guidelines can also be read as a criticism of the limited means deployed in the music of established composers like Yamada, Kōsuke Komatsu (1884-1966), and Shinpei Nakayama (1887-1952) - although Yamada soon shared the group's aims and became a member in $1932 .{ }^{285}$ It is likely that Shūkichi Mitsukuri (1895-1971), as the oldest founding member, had a considerable influence on formulating these guidelines; his works of the same period, in particular his song cycle Bashō kikosh $\bar{u}$ from 1930/31, can be considered a compositional exemplification of most of these guidelines (see below). ${ }^{286}$

In 1935 the society renamed itself Nihon gendai sakkyokuka renmei (Federation of Contemporary Japanese Composers) and expanded considerably; thanks to the efforts of Mitsukuri and Saburō Moroi (1903-1977), it joined the International Society for Contemporary Music in the same year, ${ }^{287}$ representing Japan at the ISCM festivals in 1937 in Paris and in 1939 in Warsaw and Krakow. This considerably increased international awareness of composers from Japan. ${ }^{288}$

While the ISCM membership made Japanese composers part of an international community, the federation's invitation of international composers to Japan before 1935 was arguably even more important for stylistic developments within Japan: while Alexandre Tansman's (1897-1986) visit to Japan in March 1933 probably only had a limited effect (as on the young Yoritsune Matsudaira, 1907-2001, who obviously adopted the principle of tritone-related harmonies from Tansman ${ }^{289}$ ), the impact of Alexander Tcherepnin's (1899-1977) frequent visits in the mid-1930s (1934/35) was substantial and long-lasting, like his impact in China during the same period $\leftrightarrow$ III.1). Akira Ifukube (1914-2006) and Yasuji Kiyose (1900-1981) took composition lessons with Tcherepnin, who motivated them to remain independent from European music and supported their "moderately" modernizing approach toward folkloristic material. In 1935 Tcherepnin an-

283 Herd, "The Cultural Politics of Japan's Modern Music," 44.

284 Indeed, recent research has doubted that these guidelines were actually agreed upon by all members (Lehtonen, "March from the Age of Imitation to the Age of Creation," 40).

285 Ibid., 38.

286 In 1934 the federation changed its name to Kindai Nippon sakkyokuka renmei (Modern Composers' Federation of Japan) as the term shinko had come to be associated with communist activities that were increasingly subject to governmental repressions (ibid., 42). In 1935 the federation declared its objective to "work together to promote the progress of tomorrow's music." (Galliano, Yōgaku, 82.)

287 Lehtonen, "'March from the Age of Imitation to the Age of Creation," 42.

288 Ibid. and Galliano, Yōgaku, 82. In November 1940, all music societies were forced to unite in the Alliance to Promote the New Order in the Musical World (Gakudan shintaisei sokushin dōmei), replaced in 1941 by the Association for Japanese Music Culture (Nihon ongaku bunka kyōkai), operating until the end of the war (Lehtonen, "'March from the Age of Imitation to the Age of Creation," 43). After the war, the ISCM-branch of Japan was re-founded in 1946 as Japan Society for Contemporary Music (JSCM; Nihon gendai ongaku kyōkai) with Mitsukuri assuming the position of its first chair (ibid.). Until its enforced dissolution in 1940 the federation had organized 39 concerts and several radio broadcasts, mostly featuring works by the federation's members, the number of which by 1939 had reached its peak with 116 composers (ibid., 42), but also at least once introducing new works by German composers (ibid., 40-41). The foundation of the new journal Ongaku hyōron (Music Review) in 1934 by Mitsukuri and other members also contributed to an increasing awareness of the group in Japanese musical life (ibid., 41). The founders of this journal apart from Mitsukuri were Heigorō Komatsu, Kiyoshi Komatsu, Saburō Moroi, Masao Ōki (1901-1971), Naotada Yamamoto, and Ginji Yamane (1906-1982) (ibid., 71).

289 Galliano, Yōgaku, 83. 
nounced a composition prize and works by Ifukube and Matsudaira were selected. ${ }^{290}$ Tcherepnin published the winning scores in his own publishing series and, back in Europe, introduced works by young Japanese and Chinese composers in his piano recitals. ${ }^{291}$

Both composers' federations adopted optimistic language at their outset. In the context of the foundation of the Shin ongaku renmei (New Music Federation) in 1934 in remote Sapporo, Fumio Hayasaka said: "Absolutely the only path that is open to us younger composers is to combine new methods and techniques with the venerable heritage of our traditional culture."292 Aged 20, Hayasaka (1914-55) and his colleague Akira Ifukube had founded the federation two years after meeting in Sapporo, which was rather isolated from Tokyo-centered Japanese musical life during that period. Notwithstanding, the two young composers and the music critic Atsushi Miura (1913-1997), who had already been corresponding with European and American musicians and composers for about two years, started their activities. ${ }^{293}$ On 30 September 1934, they staged a one-day festival under the French name Le festival de musique contemporaine in Sapporo's Imai Memorial Hall. ${ }^{294}$ The festival featured Japanese premieres of works by Satie, Ravel, Stravinsky, de Falla, Casella, Erwin Schulhoff, and other European composers, including a version of de Falla's ballet music El amor brujo (1915/16) arranged for sextet by Hayasaka and Ifukube. The group clearly also regarded itself as an opposition (nozai) to Tokyo's academic establishment. ${ }^{295}$ This position was expressed not least in the group's dedicated internationalism and the composers' more rigorous and direct approach toward Japanese traditional and folk musics. Ifukube's orchestral piece Japanese Rhapsody (Nihon kyōshi kyoku) from 1935, awarded the Tcherepnin Price of the same year, became the foremost model of a neo-folklorist style dubbed kokumin-shikyoku (national tone poems) by $1938^{296}$ - adopting the national style of European composers around 1900 and painting an idealized picture of a pre-Westernized rural Japan. However, Hayasaka's more refined approach to the court music genre tōgaku, based on detailed structural modeling as realized in his 1937 orchestral work Ancient Dance (Kodai no bukyoku), was probably closer to the approach originally envisaged by Mitsukuri and his colleagues in 1930, when they formulated the guidelines for the Shinkō sakkyokuka renmei.

Mitsukuri and Hayasaka were both participants in the controversial discussion on "Japanese harmony" (Nihonteki waseiron) that spanned the entire 1930s and continued into the 1940s.

290 First prize: Ifukube, Japanese Rhapsody (Nihon kyōshi kyoku) for orchestra (1935); second prize: Matsudaira, Pastorale (1935) for orchestra; the jury of the competition in Paris included Jacques lbert, Albert Roussel, Arthur Honegger, Alexandre Tansman, Tibor Harsányi, Pierre-Octave Ferroud, Henri Cil-Marchex, and Henri Prunières (Homenick, "Biography," III). In Shanghai, where he lived during the period 1934-37 as an advisor of the Chinese-Japanese admnistration, Tcherepnin had also organized a competition in 1934, in which the piano piece Buffalo Boy's Flute by He Luting won the first prize $(\rightarrow$ III.1). During a concert tour with the Vienna Philharmonic in 1937, its conductor Felix Weingartner (1863-1942) also awarded a composition prize; the prize winners in 1939 were Mitsukuri (first prize for Sinfonietta [Shōkōkyōkyoku], 1934), Fumio Hayasaka (Ancient Dance, 1937), and Masao Oki (Yoru no meisō [Evening Meditation]) (Galliano, Yōgaku, 92-93). According to Lehtonen ("March from the Age of Imitation to the Age of Creation," 71), Mitsukuri's Sinfonietta was also awarded the prize of the Ongaku konkuuru (Music Competition) in 1934; this competition had been established in 1932.

291 Lehtonen, "'March from the Age of Imitation to the Age of Creation," 42, 72, 98.

292 Quoted in Galliano, Yōgaku, 81 (no original source provided).

293 Ibid., 79-81.

294 Homenick, "Biography."

295 Menzel, Hōgaku, 116.

296 Ibid., 144-163 (here Menzel also provides close readings of Ifukube's and Hayasaka's folkloristic symphonic poems). 
In 1929 and 1930, Mitsukuri first introduced a system of symmetrically ordered fifths, developed from Japanese scales and grounded in Hugo Riemann's dualism. The system was explicated again in some detail in an article in three languages (Japanese, French, German) in 1934, thereby addressing an international readership. ${ }^{297}$ In this system, the arrangement of fifths, a model of gagaku tuning and chord-building, results in two different six- (or seven-)note scales, one ascending (positive) and one descending (negative), which are largely identical to the Japanese ryo- and ritsu-scales of the gagaku system (positive: A-B-C\#-[D\#]-E-F\#-G\#-[A]; negative: $\mathrm{E}-\mathrm{D}-\mathrm{C} \mathrm{q}-[\mathrm{B} b]-\mathrm{A}-\mathrm{G}-\mathrm{F} \sharp-[\mathrm{E}]) .{ }^{298}$ Mitsukuri highlights the option to switch between the two systems that might be interconnected by either $\mathrm{F}$ and $\mathrm{F} \sharp$ or $\mathrm{B} b$ and $\mathrm{B} \sharp$. Assuming a Pythagorean tuning system, Mitsukuri argues that in Japanese music the major second would be considered more consonant than the (major or minor) thirds. In a system based on $\mathrm{A}$, for example, the trichord A-B-E should be considered consonant. ${ }^{299}$ Also, the tritone should be applied consistently, as it occurs in both basic scales. ${ }^{300}$ Mitsukuri's song cycle Bashō kikōshū (Bashō's Travelogue) after ten haiku by Matsuo Bashō (1644-1694) from 1930/31 for voice and piano (arranged for voice and chamber orchestra in 1937) exemplifies the theory's potential. Here, minor and major seconds significantly enrich the harmonic language based on fourths and fifths. ${ }^{301}$ Indeed, seconds here repeatedly seem to have the status of resolution sonorities. ${ }^{302}$

Following Lasse Lehtonen's analysis of this cycle, we can see that Mitsukuri did not apply his system mechanically. Indeed, it seems that he took the basic idea of switching between the pitches $F$ and $F \#$ as well as between $B \sharp$ and $B b$ as a starting point for a rather free alteration of the basic modes; moreover, the frequent switching between related modes creates a constant harmonic flux. Song no. 2 "Uma ni nete" (I slept on my horse; Ex. 2.7 ) $^{303}$ clearly establishes E as a pitch center throughout (it acts as the root in all measures except for 3 and 6-7 - built on A - and measure 9 - built on D - which here can be interpreted as a cadential major second below the tonic: E-D-E). The pitch content of the first three measures is E-F-A-B-D(-E), a fivenote variant of the miyakobushi scale, which cannot be derived from Mitsukuri's modal system. The mode E-negative would be E-F-G-A-Bb-C-D, so $G$ and $C$ are missing entirely and $B b$ is raised to $\mathrm{B} \sharp$, resulting in a combination of a miyakobushi-trichord (E-F-A) and a min'yo-trichord ( $\mathrm{B}$ $\mathrm{D}-\mathrm{E}) .^{304}$ Measures 4 and 5.1 now replace the $\mathrm{B}$ by $\mathrm{B} b$, resulting in a full five-note miyakobushiscale (E-F-A- Bb-D-[E]). In measure 5.2 the $\mathrm{B}$ a again replaces $\mathrm{Bb}$ and in the next measure the $\mathrm{F} \nvdash$ is raised to $F \#$, resulting in a simple tetrachord in measures $6-7$ : A-B-E-F\# which could be interpreted as a subset of the mode A-positive (the dualist relative of E-negative) in Mitsukuri's

297 Mitsukuri, “Über japanische Harmonie.”

298 Ibid., 2.

299 Lehtonen, "'March from the Age of Imitation to the Age of Creation," 74.

300 See ibid., 75 .

301 This cycle has received considerable attention in the literature; see Miyuki, "Basho kikoshu to Mitsukuri Shūkichi," Galliano, Yōgaku, 68-70, Herd, "The Cultural Politics of Japan's Modern Music," 50-51, Pacun, "Nationalism and Musical Style in Interwar Yōgaku," 28-31, and Lehtonen, "March from the Age of Imitation to the Age of Creation,"' 108-119.

302 Corresponding sonorities in Japanese koto music had often been reduced to single notes in European arrangements of Japanese music around 1900 (see Revers, Das Fremde und das Vertraute, 65, 78, 85).

303 Uma ni nete / Zanmu tsuki tōshi / Cha no kemuri; I slept on my horse / lingering dream - the moon far away / steam from tea (translation after Lehtonen, "March from the Age of Imitation to the Age of Creation," 109).

304 See Komoda and Nogawa, "Theory and Notation in Japan" for the theory of trichords and tetrachords in Japanese music theory, developed by Fumio Koizumi. 
system. In measures 8-10 the original pitch content E-F-A-B-D-(E) is restored, focusing on the major second D-E (both as a "leading tone" in the bass and in creating tension between the final melody pitches in the voice (D5) and the piano (E5), as well as at the end of the concluding piano arpeggio). In general, the harmonic structure of this song suggests that Mitsukuri was concerned with deploying alterations to the standard miyakobushi scale rather than the consistent application of his own system. ${ }^{305}$

The situation is considerably more complex in no. 6 "Shizukasa ya" (The stillness; Ex. 2.8), ${ }^{306}$ a song that Mitsukuri claimed not to be able to understand fully himself. ${ }^{307}$ A continuous minor second ostinato in the right hand of the piano renders the chirping of cicadas, evoked in the final part of the haiku. This ostinato clearly alludes to the E negative scale (or varied miyakobushi) used in no. 2 and other songs of the cycle. Despite such an allusion, the left hand in measures 2-3 brings pitches $\mathrm{E}-\mathrm{F} \mathrm{h}-\mathrm{A}-\mathrm{B} b-\mathrm{B} \mathrm{h}-\mathrm{C}-\mathrm{D} b$, thus expanding and altering the $\mathrm{E}$ negative scale chromatically, as had already occurred in nos. 3 and 5. Then $E$ is replaced by $E b$ in measure 4, when the voice enters, and the passage starting in measure 5 clearly establishes $F$ as a recurring pitch center in the bass. Later $A b$ replaces $A \sharp$ (m. 6) and $G b$ (m. 7) appears, temporarily raised to $G \sharp$ (m. 9) but returning to $\mathrm{Gb}$ later (m. 10); thus the reference scale for this passage appears to be "F-negative" F-Gb-Ab-Bb-C-Db-Eb(-F) (with the fifth scale degree $\mathrm{Cb}$ raised to $\mathrm{C} \downarrow$, analogous to no. 2). We can thus understand this song as a scalar extension of the two ostinato pitches $E$ and F: while the first melodic segment in the piano (mm. 2-3) still appears to establish an E tonic, the remaining part of the song establishes the F center. ${ }^{308}$ The centrality of the pitch $\mathrm{F}$ is even more apparent in the adaptation of this song in the second movement of Mitsukuri's Sonata for Violin and Piano from 1935, where the violin's melodic line always returns to F (or F-C) toward the end of the phrases.

Mitsukuri had to defend his system and an originary Japanese approach to harmony in general against Klaus Pringsheim (1883-1972), who taught from 1931 to 1937 at the Tokyo Music School and demanded of his students a "submission to the fundamental law of our functional harmony" and to the "strict regulation of imitative-contrapuntal structure." ${ }^{309}$ In this debate, Mitsukuri pointed to a critique of Pringsheim's arguments that had been raised by Shōhei Tanaka (1862-1945), a former student of Hermann von Helmholtz and a leading musicologist in Japan during the 1930s. Tanaka's 1940 treatise Nihon wasei no kiso (Foundations of Japanese Harmony) proposed a group of 70 sonorities that were considered adequate for Japanese harmony, based on two heptatonic scales, stacked thirds, and the principle of just intonation. ${ }^{310}$

305 Lehtonen's analysis (following the composer's own account) seems too theoretical in assuming three different modes in five different sections ("March from the Age of Imitation to the Age of Creation," 108-112). Particularly the interpretation of measures $4-5.1$ as A negative seems hardly to make sense, considering that $E$ is clearly established as a tonic in the bass here, as in measures 1-2.

306 Shizukasa ya / iwa ni shimiiru / semi no koe / The stillness / seeping into the rocks / cicadas' screech (translation after ibid., 116).

307 See ibid.

308 My analysis here again differs from that of Lehtonen, who interprets measures 2-9 as based on C negative (ibid., 116-118).

309 Quoted in Suchy “Deutschsprachige Musiker in Japan vor 1945," 84, 131 (“Unterwerfung unter das Grundgesetz unserer funktionellen Harmonie"; "strikte Regulativ der imitatorisch-kontrapunktischen Satzweise"). See also ibid., 84-90 and Galliano, Yōgkau, 41-43.

310 Tanaka, Nihon wasei no kiso; see Service, "Harmony Outside the Iron Cage." 

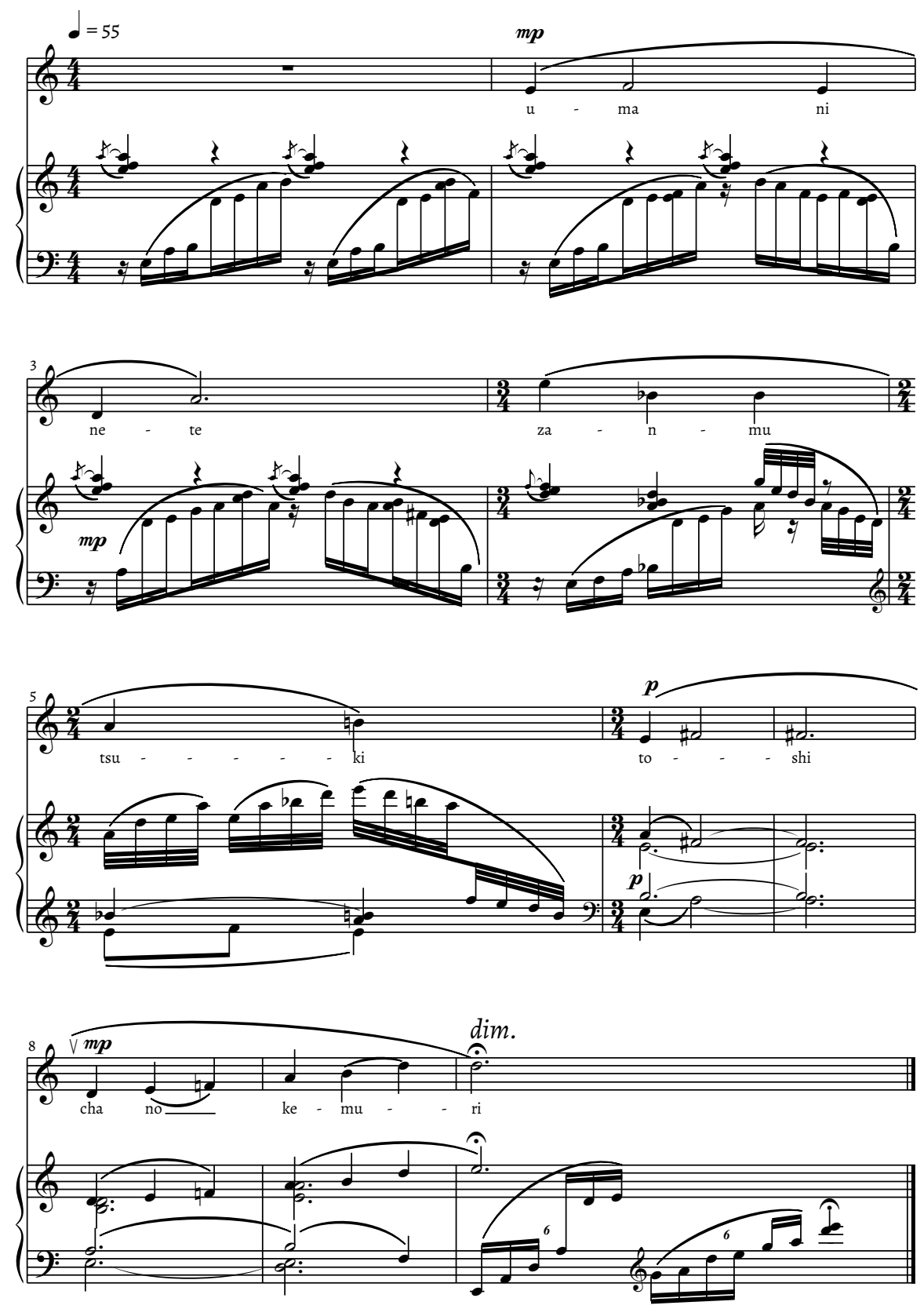

Copyright @ Shūkichi Mitsukuri / Tokyo: Zen-On Music 1971 
Example 2.8: Shūkichi Mitsukuri, Bashō kikōshū (1930/31), no. 6: "Shizukasa ya" (The stillness)
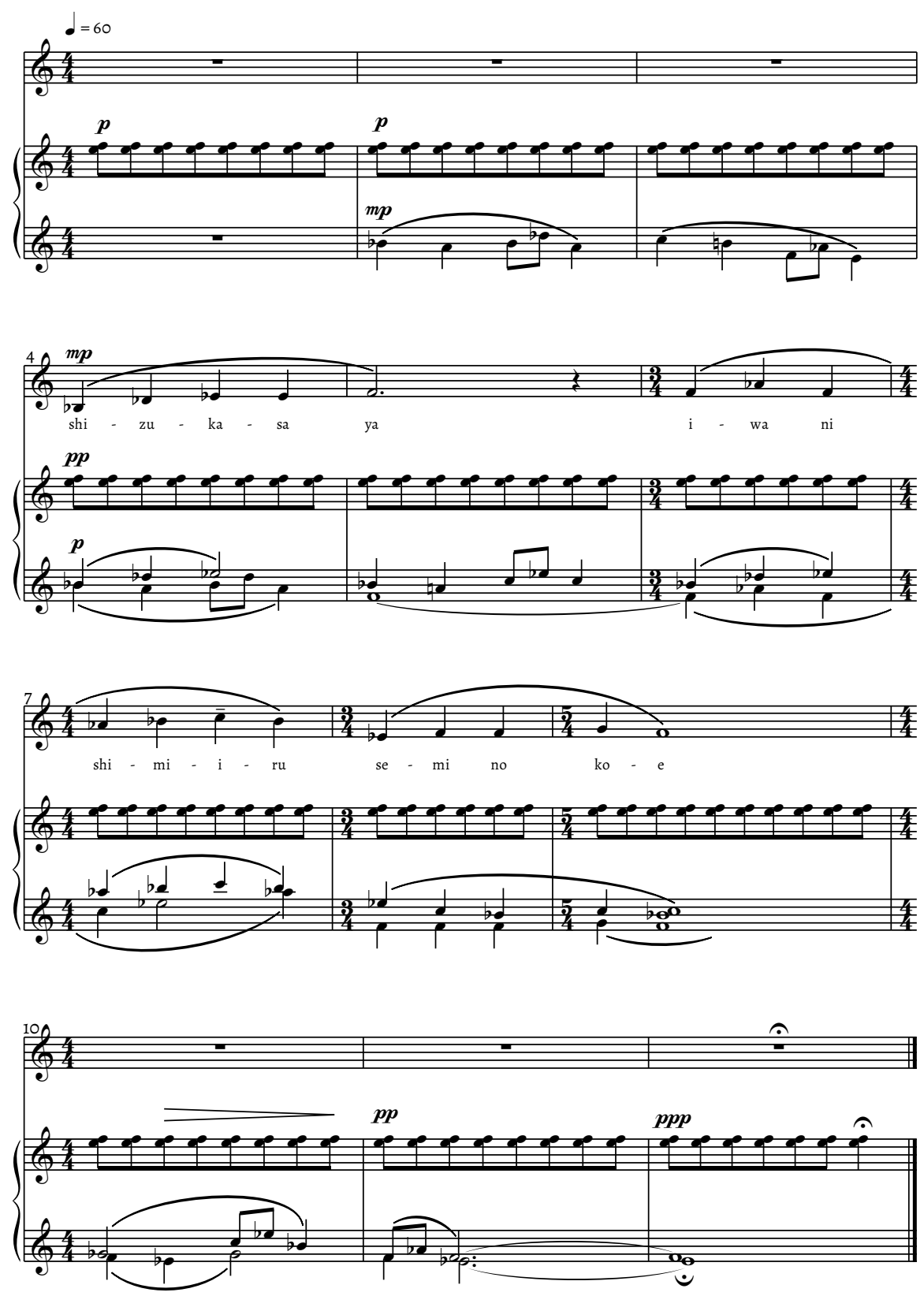

Copyright @ Shūkichi Mitsukuri / Tokyo: Zen-On Music 1971 
Example 2.9: Fumio Hayasaka, Piano Pieces (Piano shōhin shū), no. 11

Andante aussi calma que possible, delicatamente, vago
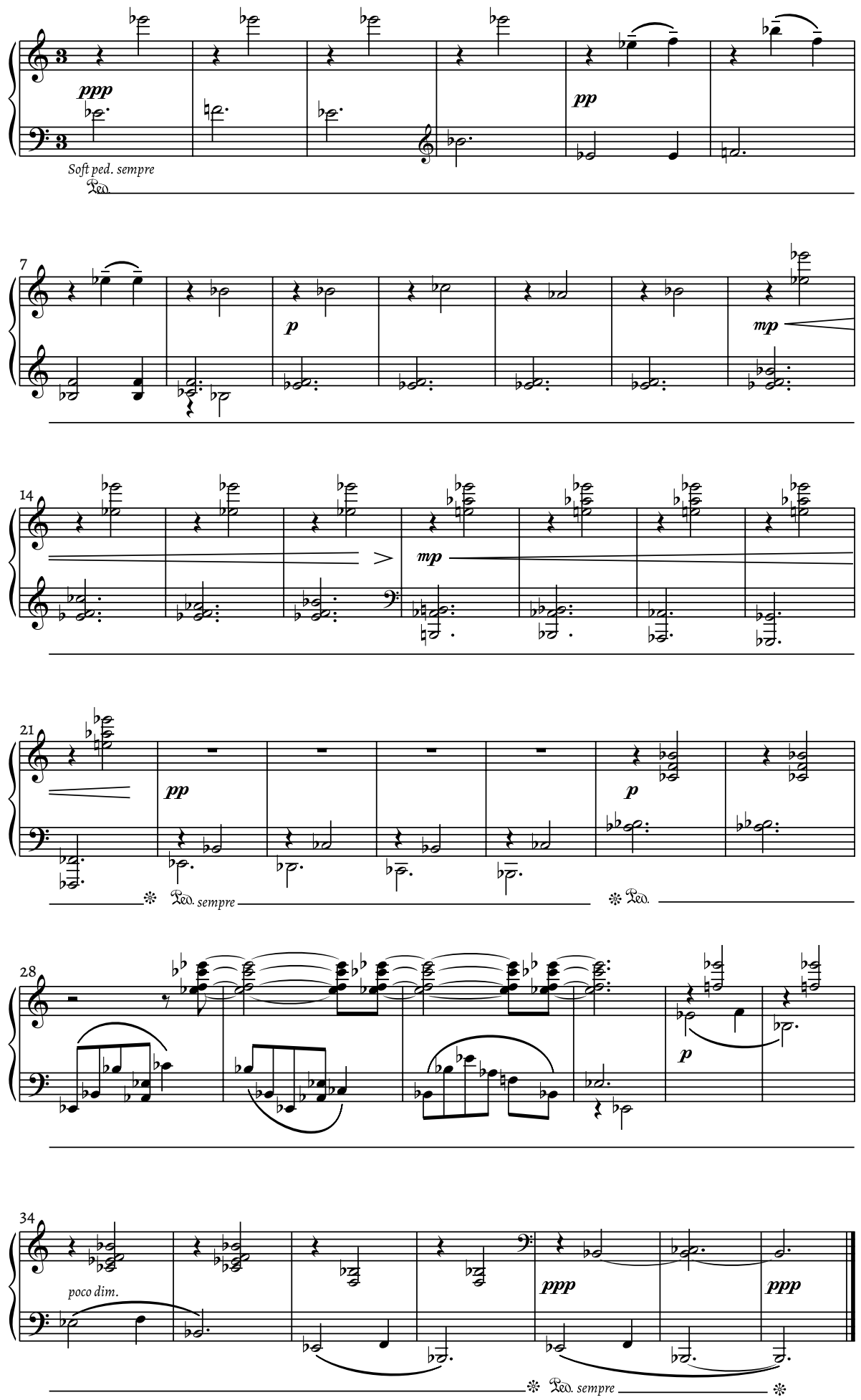
Such a systematic construction of Japanese harmony sparked criticism from Hayasaka who refuted a number of the sonorities introduced by Tanaka in an article from 1941 and in his 1942 treatise Nihonteki ongakuron (Treatise of Japanese Music). Hayasaka's complaint rested on Tanaka's reliance on stacked thirds, and in turn appended a number of Tanaka's chords by adding second- and fourth-intervals as well as excluding several chords entirely from the system of "Japanese harmony." 311

Hayasaka's 17 short Piano Pieces (Piano shōhin shū, 1941) demonstrate this "modernist" approach to Japanese harmony while remaining indebted to traditional scalar and melodic structures $^{312}$ - an approach which provided the point of departure for the young Tōru Takemitsu after 1945, who considered Hayasaka his most important mentor. No. 11 from this cycle (Ex. 2.9) clearly demonstrates what can be described as the main feature of Hayasaka's "corrections" of Tanaka's chord progressions: he always prolongs pitches of the first chord into the second "resolution" chord, resulting in major seconds (in few cases also minor seconds) and fourths. In the piano piece the pitch content is slowly expanded from $\mathrm{E} b-\mathrm{F}-\mathrm{B} b$ in measures 1 to 7 first by adding $\mathrm{Cb}$ and $\mathrm{Ab}$, clearly establishing $\mathrm{E} b$ (mostly combined with the simultaneous upper-second $\mathrm{F}$ ) as a pitch center of a ritsu-type scale without a third scale degree ( $\mathrm{E} b-\mathrm{F}-\mathrm{A} b-\mathrm{B} b-\mathrm{C} b)$. From measure 17 alterations are introduced, namely $\mathrm{E} \sharp$ and $\mathrm{B}$ ฤ as well as $\mathrm{Gb}$ and $\mathrm{Fb}$ (mm. 20-21), resulting in dissonant sonorities like $\mathrm{E} \sharp-\mathrm{Ab}-\mathrm{Eb}$ (mm. 17-21) that can be understood as "verticalizations" of the miyakobushi trichord $\mathrm{Eb}-\mathrm{Fb}(\mathrm{E})-\mathrm{A} b$ which is concurrently introduced in the bass line. A similar approach is applied to the miyakobushi tetrachord on $\mathrm{B} b$ during the next section (mm. 22-27), resulting in a transposition of the dissonant sonority to $\mathrm{C} b-\mathrm{F}-\mathrm{B} b$. The remaining two sections restabilize the simple modal situation of the beginning, the pitch content is restricted to $\mathrm{Eb}-\mathrm{F}$ $\mathrm{A} b-\mathrm{B} b-\mathrm{C} b$ but now dissonant chords are added (mm. 28-31: Eb-F-Cb-Eb; mm. 34-35 Cb-Eb-F-B b) that again are verticalizations of the mode's pitch content. The minor second $\mathrm{B} b-\mathrm{C} b$ in the penultimate measure, resolving into $\mathrm{B} b$ in the very last measure, makes this principle of simultaneous modal pitches evident.

The intimate writing style of Hayasaka's Piano Pieces marks a first step into the composer's "inner emigration" during the war years. The most impressive document of this period is the cycle Four Unaccompanied Songs to Poems by Haruo (Haruo no shi ni yoru yottsu no mubansō kakyoku) for solo voice, composed in 1943/44 on poems by Haruo Satō (1892-1964) and alluding to ancient unaccompanied vocal music genres of the court music gagaku such as rōei. Although no sliding by glissando is indicated, the constantly used fast figures result in slide- or portamento-like vocal articulations. Again, a mode-based writing with continuously altered scale degrees is evident. The first song (Ex. 2.10), evoking the unique singing of the Japanese Bush Warbler (uguisu), a bird repeatedly described in classical Japanese poetry of the Man'yōsh $\bar{u}$ (compiled c. 759), is based on B with the second, fifth, and sixth scale degrees repeatedly switching between two variants ( $C / C \#, F / F \#, G / G \sharp)$. Hayasaka's and Mitsukuri's techniques of harmonic writing are therefore much closer related than one might expect on first hearing.

Wartime Japanese nationalism, as David Pacun has demonstrated, influenced the discussions on "Japanese harmony" in multiple ways, turning the debates on harmonic details into "ideo-

311 Hayasaka, "Tanaka hakushi no Nihon wasei no kiso ni oite no shiken," Hayasaka, Nihonteki ongakuron; see Galliano,

Yōgkau, 69-72, 87.

312 See Pacun, "Nationalism and Musical Style in Interwar Yōgaku," 33-36. 
Example 2.10: Fumio Hayasaka, Four Unaccompanied Songs to Poems by Haruo (Haruo no shi ni yoru yottsu no mubansō kakyoku) (1943/44), No. 1: "Uguisu"
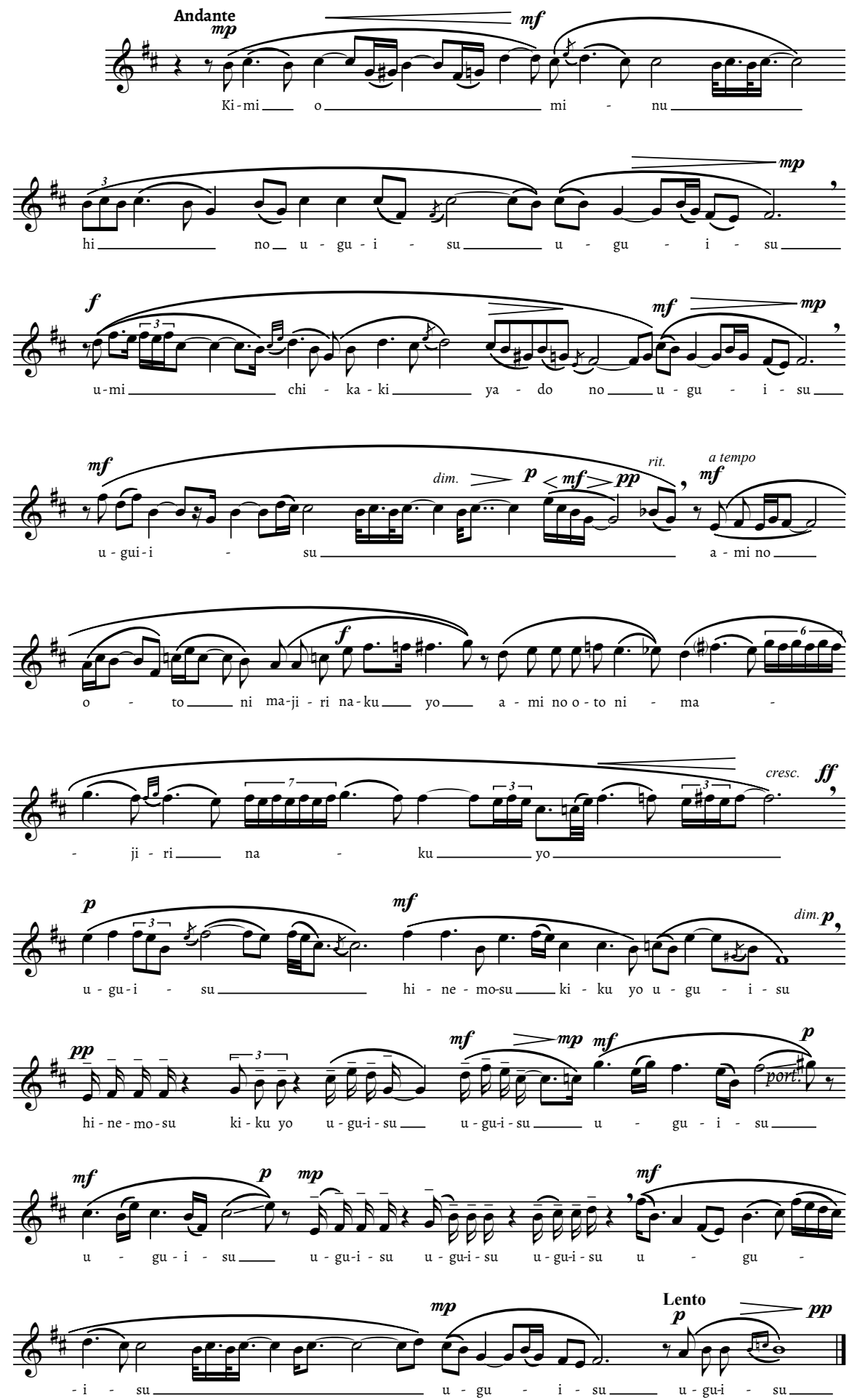

Copyright $\odot 1958$ by Ongaku no tomo sha, Tokyo 
logical hair splitting." ${ }^{313}$ Within a few years' time, Mitsukuri's or Hayasaka's refined harmonic elaborations were turned into tools of propaganda, culminating at the conference "Overcoming Modernity" in July 1942 ( $\rightarrow$ I.2, Reflexive Globalization). At the same time, Delage turned away from the enthusiasm of his earlier periods and into "inner emigration" during the war, allegedly - similarly to Anton Webern - sympathizing with the German Nazi occupiers. ${ }^{314}$

Delage, Cowell, Mitsukuri, and Hayasaka considerably invigorated the internationalization and globalization of music in their respective countries of France, the United States, and Japan. A personal encounter between these composers is not documented. Delage and Cowell may have met at a private concert that Cowell gave in Paris in 1923 and for which Béla Bartók allegedly had assembled Ravel, de Falla, Honegger, Milhaud, Prunières, and Roussel as an exclusive audience. ${ }^{315}$ Cowell and Mitsukuri may have crossed paths at an ISCM festival in the postwar period or during Cowell's stays in Japan in 1955 and $1961(\rightarrow$ II.5). The focus of my argument, of course, has not been the personal interaction or influences between these composers but the question of how their works may exemplify the "non-simultaneity of the simultaneous" in global music history.

Starting by summarizing the commonalities, we can highlight that all four composers were proactive founding members of composers' societies that were conceived in direct opposition to dominant conservative composers of older generations. These groups thus all reflected critically on a hierarchical, paternalistic social system in the arts with strong nationalist tendencies and showed the necessity for the younger generation to establish itself by setting up their own institutional and artistic infrastructure: musicians, ensembles, concert halls, organization, and funding (in all societies, the founding composers also frequently acted as performers and, of course, as organizers, usually without receiving any payment). Naturally, this process had quite different implications in 1909 Paris, in 1924 California, in 1930 Tokyo, and in 1934 Sapporo.

While internationalism was employed in all these cases as a main counterdiscourse against the aesthetics of the dominating repertoire in concert life and compositional production, tropes of national style were not at all absent from the group's discourses. In 1930s Japan, a refined approach toward Japanese music was indeed the precondition for an emancipation from six decades of massive European influence on musical production, resulting in a type of modernity-related cultural confusion that had been described as early as 1912 as "complicated and intricate" (fukuzatsu hansa) by the writer Sakutarō Hagiwara (1886-1942). ${ }^{316}$ Similar to preWorld-War-I nationalism in France and the Great Depression in the United States during the early 1930s, the increasingly fierce political nationalism in Japan since the late 1930s inevitably puts the Japanese composers' activities during that period in a politically charged context. Moreover, the Parisian, Californian, and Tokyo societies had lost their vanguard status after a few years and turned into nationwide organizations, necessarily losing the initial rigor of their aesthetic programs. We can therefore say that the institutional context in which these four composers operated, and which was evidently crucial for the development of their aesthetic ideas, was deeply shaped and influenced by local politics and society. The world wars that followed interrupted the optimistic internationalism of the enthusiastic early periods.

As discussed earlier ( $\rightarrow$ II.I), the model of a "non-simultaneity of the simultaneous" might be expanded in two directions, either highlighting the entanglement of aesthetic ideas in a

313 Pacun, "Nationalism and Musical Style in Interwar Yōgaku," 26.

314 Gordon, "Discovering Maurice Delage," 298-299.

315 Sachs, Henry Cowell, 122.

316 Menzel, Hōgaku, 47-49. 
global context, thus suggesting an "entangled history," or rather their distinction and independence, thus suggesting Eisenstadt's "multiple modernities." Tobias Janz has recently discussed the option of multiple musical modernities as a music-historiographical model at length, choosing Japan as a case study. ${ }^{317}$ He outlines the difficulty of reconciling, on the one hand the close interaction between Japanese and Western music since the Meiji era and, on the other, the particular situation and "uniqueness" of Japanese music history, with its yōgaku-hoggaku separation and interaction. Adopting a skeptical position toward Japanese peculiarity such as that of philosopher Masao Maruyama ( $\rightarrow$ III.4), Janz arrives at the careful conclusion that "the imagination of an autochthonous, incommensurable musical culture of Japan gave way to a polyphony of completely different interests in Japanese musical modernity," sitive historiographical framework that can account for cultural difference without negating the highly entangled manner in which Western and Japanese modernities are cross-related. It seems therefore, that the "entangled history" model is ultimately a more useful approach, especially for a conclusion to the materials presented in this chapter: that Delage and Mitsukuri chose to set traditional Japanese poems (haikai resp. haiku) in extremely short pieces, with a harmony based on drone and ostinato structures and multiply chromaticized modes, might be considered a particularly evident case of entanglement. Of course, these two works have to be considered in broader contexts, such as the anti-Romanticist turn to aphoristic forms around 1910 shared by composers worldwide. ${ }^{319}$ More specifically, both Delage and Mitsukuri were indebted to Debussy's and Ravel's harmonic innovations as well as their experiences of Japanese hōgaku, aiming to reach beyond orientalist clichés. Despite such similarities, a quasiethnographical approach as documented in Delage's Indian-inspired works clearly contrasts with Cowell's attempt in the United Quartet to extract commonalities from diverse "primitive musics," necessarily eradicating distinguishing features of individual traditions. Still, these approaches are "entangled" by their intention, also shared by Mitsukuri and Hayasaka, to reconceive non-Western musics as a counterdiscourse to a European Classical-Romantic tradition that seemed to provide inappropriate tools for responding to the social and aesthetic problems of music-making in a globalizing modernity.

In the works of these four composers, we can therefore find surprising convergences that hint at the tentative beginnings of a transnational musical modernity. But the divergences, which can be attributed primarily to the institutional, social, and political contexts of their work, make it necessary to conclude that it was impossible for this transnational musical modernity to blossom and to develop before 1945. As the following chapter will demonstrate, even after 1945, institutional and political restrictions considerably obstructed balanced forms of transnational music-aesthetic exchange.

317 Janz, "Multiple Musical Modernities?"

318 Ibid., 301.

319 See Obert, Musikalische Kürze. 


\section{Re-Reading the Impact of the "Cultural Cold War" on Music History: Cowell, Mayuzumi, Berio}

\section{Postwar Music History and the "Cultural Cold War"}

The relevance of the Cold War for the music history of the decades after 1945, which serves as a master narrative for Richard Taruskin, remains controversial. ${ }^{320}$ First, it is certainly obvious that the lasting influence of (cultural) politics on music in Soviet-dependent countries on the one hand, and those under the influence of the United States on the other hand, can hardly be doubted. Second, there is no denying that the music-semantic complexity of the music of composers like Igor Stravinsky, Pierre Boulez, Dmitri Shostakovich, or Hanns Eisler cannot be grasped with reference to contemporary or political discourses alone - and this claim can be made without having to assume an "aseptic" sphere of aesthetic difference divorced from the sociopolitical. Certainly, Taruskin is right to say unequivocally that there is no such thing as "apolitical music"321 and, in particular, that there is a connection between the aesthetics of serial music in postwar Western Europe and the Cold War mentalities of the same period (often considered "apolitical" in the past - or conversely decidedly political). ${ }^{322}$ In addition, Anne C. Shreffler has shown clearly that addressing the issues of control and freedom in the discussion of serial and aleatoric music cannot be understood as detached from the political ideologies of the time, in which these issues arose from battles between ideological camps. ${ }^{323}$

Ultimately, we must develop a perspective that can do justice to the complex relationships between music and society in the postwar era. In this respect, Martin Zenck suggests that Taruskin puts forward a "rather blunt equation of 'Cold War' and the strict and stringent organization of serial music, which is referred to as 'cold,' constructed and inhumane." ${ }^{324}$ Zenck rightly criticizes Taruskin's simplifying and distorting equation of the polemical aesthetic writings of René Leibowitz with Goebbels's propaganda and of Boulez's rhetoric with the "Communist journalism of his day," as well as the diagnosis of alleged "Nazi resonances" in Herbert Eimert's writings. ${ }^{325}$ There is no question, however, that an authoritarian rhetoric that spoke of the "worthlessness" of contrary aesthetic attitudes, or the "eradication" or "extinction" of certain residues of past styles, is found everywhere in the writings of the 1950 s and 60 .

Artists were sometimes well aware of the historical burden of such rhetoric. In this situation, in the early 1950s, a young composer like Pierre Boulez tried to write music that was emphatically based on historical experience and knowledge, a music

which distances itself from the abuse of the body and its sensations in Nazi ideology and its relative, the Vichy regime in France, a music [...] that cannot be used for any political machinations.

320 See in summary, among others, Schmelz, "Introduction: Music in the Cold War" and Shreffler, "Cold War Dissonance." In German-language musicology, the Cold War has so far been addressed largely in reviews of East German music history after 1945/48; see Jungmann, Kalter Krieg in der Musik and Tischer, "Musik in der Ara des kalten Krieges."

321 See Taruskin, "Afterword: Nicht blutbefleckt?," 276-277.

322 Shreffler, "Cold War Dissonance," 54-56.

323 See Shreffler, "Ideologies of Serialism," 221-225.

324 Zenck, Pierre Boulez, 64 ("ziemlich plumpe[] Gleichsetzung von 'Kaltem Krieg' [...] und der strikten wie stringenten Organisation der seriellen Musik [...], die als 'kalt', konstruiert und als [...] inhuman bezeichnet wird").

325 See Taruskin, Music in the Late Twentieth Century, 18. 
In this sense, it is an eminently political music that, in its internal organization and expression, follows the concept of a "committed literature" in the sense of Jean-Paul Sartre, without being explicitly or crudely connected to any external political content. ${ }^{326}$

And that the anti-communist cultural policy of the American occupying forces sometimes also promoted performances and institutions of the musical avant-garde $\mathrm{e}^{327}$ - in the sense of a defense of artistic freedom, more nolens volens than with real conviction - does not make the resulting works simply "products" of the Cold War. ${ }^{328}$

Finally, following the observations of Ben Parsons ${ }^{329}$ and Zenck, the "changeability of the temporal core as inscribed in the musical work, which unfolds in its post-history," ${ }^{330}$ must be taken into account. This aspect is reflected above all in the performance history ${ }^{331}$ and changing public reception of serial music and other avant-garde music during the 1950 s and 60 . This history might arguably be interpreted as a fruitful public dispute and continued revision of positions, rather than ideological "blindness." 332

326 Zenck, Pierre Boulez, 66 ("[...] die sich vom Missbrauch des Körpers und seines Cefühls in der Nazi-Ideologie und dem mit ihr verwandten des Vichy-Systems in Frankreich distanziert, also eine Musik [...], die in keiner Weise politischen Machenschaften dienstbar gemacht werden kann. In diesem Sinne handelt es sich um eine eminent politische Musik, die von ihrer inneren Organisation und vom Ausdruck das Konzept einer 'engagierten Literatur' im Sinne Jean-Paul Sartres sucht, ohne mit einem externen politischen Außenhalt ausdrücklich und plakativ verbunden zu sein."). Of course, Sartre's position is exactly characterized by this "external political content," which Boulez declined. In addition, Sartre expressed in public discussion with René Leibowitz a stressed skepticism regarding the possibilities of a musique engagée. See also Carroll, Music and Ideology in Cold War Europe, 103-140 and Claser, "René Leibowitz und die Idee einer 'musique engagée."

327 The most thorough examination of this question can be found in Beal, New Music, New Allies. See also Beal, "Negotiating Cultural Allies" as well as Monod, Settling Scores. The share of funds of the US occupying power in the budget of the Darmstadt Summer Courses reached a maximum of about 20 percent only during three years (1949-51) (Beal, New Music, New Allies, 40). Skeptical positions on this question can also be found in Shreffler, "Cold War Dissonance," 58. Zenck states that "such support could never serve the political control of progressive composers such as Pierre Boulez, because they sought to realize their positions completely independently of political systems in order to finally escape the exploitation of music, as practiced previously by the Nazi ideology and the Vichy system." (Zenck, Pierre Boulez, 67 ["[...] dass entsprechende Unterstützungen nie der politischen Gängelung fortschrittlicher Komponisten wie Pierre Boulez dienen konnten, weil diese ihre Positionen vollkommen unabhängig von politischen Systemen zu verwirklichen suchten, um der Indienstnahme der Musik, wie sie durch die Nazi-Ideologie und die des Vichy-Systems zuvor gehandhabt wurde, endgültig zu entkommen."]). See also the nuanced treatment of these issues in Carrol, Music and Ideology in Cold War Europe, 91-102, Sprout, "The 1945 Stravinsky Debates," 120, and Wellens, Music on the Frontline, 121-126.

328 See Hiekel, "Angekommen im Hier und Jetzt?," 61.

329 Parsons, "Sets and the City."

330 Zenck, Pierre Boulez, 69-70 ("Veränderbarkeit des im jeweiligen Werk eingeschriebenen Zeitkerns, der sich in der Nachgeschichte entfaltet").

331 See Utz, "Zum performativem Hören serieller Musik."

332 Ofa "Cold War Blindness" Shreffler speaks in relation to the German-language music historiography of the $1970 \mathrm{~s}$ and 8os, especially in the work of Carl Dahlhaus: "One symptom of this 'blindness' was the implicit assumption that autonomous music was apolitical per se. The serial avant-garde was accordingly understood as the epitome of artistic autonomy. The fact that the political support for artistic autonomy was more covert than overt is one aspect of this 'blindness,' and in this sense inherent in the system. The efforts of Western governments to use cultural promotion as an instrument of international politics were largely unknown at the time, such as the support for the Darmstadt Summer Course by the US occupation or the activities of the CIA-sponsored Congress for Cultural Freedom (from which, among others, the journal Der Monat as well as the Berliner Festwochen 
Considering the historical situation after 1945, in which the entire continent of Europe was at the center of a global conflict between the new "superpowers," the United States and the Soviet Union, a tendency to view all manifestations of art or culture as having an implicitly global or international impact was particularly strong in Western Europe. The fact that the most influential trend in Western European postwar music, 1950s serialism, drew considerably on the idea of a "pure" (and therefore potentially "apolitical") structure is like the negative image of this all-encompassing public and political role often attributed to music and the arts in postwar societies. Indeed, the fact that music, and new music in particular, was part of this power struggle and was consciously conceived of as a medium or even "weapon" in the "Cultural Cold War" has been highlighted in a number of recent studies, ${ }^{333}$ though the extent to which this explicit political context shaped aesthetic and stylistic developments and decisions remains contested.

The dedicated attempts of influential institutions such as the Darmstadt Summer Course to avoid overt political topics or influences can clearly be seen as a counter-reaction to the politicized artistic doctrines of Soviet "socialist realism" reimplemented by Andrej Zhdanov in early 1948 and in the Prague Manifesto of the same year, adopted by the Second International Congress of Composers and Music Critics (20-29 May 1948), modifying but also affirming the Zhdanov doctrine $\left(\rightarrow\right.$ II.2). ${ }^{334}$ In both Western Europe and the United States, the sometimes naïve idealization of scientific thought - clearly exemplified by serial music theory - and the optimistic image and use of technology for experimental means were further indications of a close relationship between Western new music and capitalist modernism, eventually resulting in a re-academization of musical composition, most famously instigated by Milton Babbitt's efforts to install a $\mathrm{PhD}$ program in composition at Princeton University. ${ }^{335}$ And while technological progress had equally positive connotations in the Soviet-dominated sphere, the aesthetic appropriation of the social prestige attached to the sciences in art music during the postwar period was unique to the project of the Western avant-garde.

The general politicization in large parts of the musical world during the 1960 s and 1970s remained closely connected to world political events and developments, particularly in divided countries such as Germany ${ }^{336}$ and Korea. ${ }^{337}$ More generally, the tremendous effect of the Cold War in East Asia with the Maoist revolution in 1949, the withdrawal of the nationalist Chinese forces to Taiwan, the Korean War, and the division of Korea, suggests that from an Asian perspective, cultural or musical statements in this region were considered implicitly political, all the more since a concept of "musical autonomy" had not been established in Asian countries

emerged)." (Shreffler, "Dahlhaus und die 'höhere Kritik," 256 ["Ein Symptom dieser 'Blindheit' war die implizite Annahme, dass die autonome Musik per se unpolitisch sei. Die serielle Avantgarde wurde dementsprechend als Inbegriff der künstlerischen Autonomie verstanden. Dass die politische Unterstützung künstlerischer Autonomie eher im Verborgenen betrieben wurde, gehört mit zu dieser 'Blindheit' und ist insofern systemimmanent bedingt. So waren die Bestrebungen westlicher Regierungen, Kulturförderung als Instrument internationaler Politik einzusetzen, damals weitgehend unbekannt, wie zum Beispiel die Unterstützung der Darmstädter Ferienkurse durch die U.S.-Besatzung oder die Tätigkeiten des $\mathrm{CIA}$-geförderten Congress for Cultural Freedom (woraus unter anderem die Zeitschrift Der Monat sowie die Berliner Festwochen hervorgingen)."])

333 See Shreffler, "Ideologies of Serialism," 237.

334 Kovács, "Die Institution - Entstehung und Struktur," 118-119 and Carroll, Music and Ideology in Cold War Europe, 37-49.

335 Taruskin, Music in the Late Twentieth Century, 153-173.

336 See Noeske, Musikalische Dekonstruktion and Jungmann, Kalter Krieg in der Musik.

337 See Howard, Creating Korean Music and Killick, Hwang Byungki. 
on a broader basis before 1945. This does not mean that musical works in postwar East Asia were explicitly political in general; on the contrary, the majority of Western-oriented East Asian composers, like most of their Western colleagues well into the 1960s, tried to remain aloof from political engagement.

Although global politics was thus obviously a considerable factor of synchronization and interconnection in postwar music history, "Cold War ideologies" remain too crude and inflexible a framework for grasping the complex effects of musical works and performances on the diverse historical processes in different countries and regions of the world. Moreover, it seems inadequate and insensitive to the complexity of historical constellations and processes to place the aesthetic appropriation of scientific trends of the Cold War (even if they were based on or implied a certain authoritarian worldview) in (Western) serial music and the simultaneous control of composers and musicians in totalitarian regimes on the same level. In sum, "simultaneous" discourses or processes should not be simplified by attributing them to a common (in this case political-ideological) framework; rather, one must keep the "non-simultaneous" character of local music-related discourses in mind when trying to sketch the entanglements of global music-making in the postwar period. The following discussion will show that this is all the truer if one widens the perspective from the transatlantic situation to the global. For an appropriate music-historical account of the decades after 1945, nuance is required in order to avoid falling back into the polarizations that characterize this historical period.

\section{Henry Cowell, Toshirō Mayuzumi, Luciano Berio and the Tokyo 1961 East-West Music Encounter}

As demonstrated in Chapter II.2, both internationalism - as a form of composers', performers', and audiences' awareness of global interconnectedness and interdependence - and universalism - as the more or less open attempt to reach beyond the limitations of national or local musical confinements, guided by religious, technological, structural, or ethnic ideas and categories - may be understood as countermodels to the ubiquitous construction of composers as representatives of specific national or cultural identities by media, historians, and audiences. How, then, did the different facets of international and universal composition interact during the postwar period in such a way that simultaneous works and discourses reveal "non-simultaneous" preconditions and entangled histories? Three short case studies will address this question, focusing on the involvement of three prominent composers from different countries (United States, Japan, Italy) in a key event of the "Cultural Cold War."

The term "international" figured prominently in most activities and events hosted or supported by the Congress for Cultural Freedom (CCF), a CIA-sponsored organization that existed between 1950 and 1967 and played a crucial role in enhancing international relations in music and other arts during the 1950 s and 1960s, pursuing a decidedly anticommunist agenda. ${ }^{338}$

338 The secret financing of the CCF, founded in West Berlin in June 1950, by the CIA, which was mainly carried out through the shell organization Farfield Foundation, was disclosed in a series of articles in the New York Times in April 1966 and led initially to the renaming of the CCF as the International Association for Cultural Freedom (IACF), which was then funded by the Ford Foundation. In 1979, the organization dissolved. For basic information about the Congress for Cultural Freedom see among others Coleman, The Liberal Conspiracy, Hochgeschwender, Freiheit in der Offensive?, Stonor Saunders, The Cultural Cold War, Scott-Smith, The Politics of Apolitical Culture, and Wellens, Music on the Frontline. Musical institutions, works, and developments connected to the CCF are discussed, among others, in Stonor Saunders, The Cultural Cold War, Carroll, Music and Ideology in 
By funding large music festivals in Paris (1952), Rome (1954), Venice (1958), and Tokyo (1961), the CCF aimed to demonstrate the unlimited freedom of style and expression in contemporary music in the West as counterexample to the Soviet bloc's "controlled music" ("gegängelte Musik"). ${ }^{339}$ This is clearly documented in the introduction by the CCF's secretary general, the Russian-American composer Nicolas Nabokov, to the 1952 Paris festival:

During this coming arts festival, dedicated to l'CFuvre du XXe siècle, we will not hear any scores that do not owe their qualities, their very soul, to the fact that they are the music and the art of men who know the value of liberty. [...] And those who live today know this value of their times better because they have seen it. [...] If a music festival has a purpose and a virtue, it must be to combat hopelessness and discouragement. [...] Totalitarian ideologies [...] cannot diminish one inch the masterworks that speak for themselves - and for the civilization that gave them birth. ${ }^{340}$

A peak of the CCF's dedicated internationalism was the Tokyo East-West Music Encounter Festival and Conference in April 1961, co-funded by the Ford Foundation, purportedly aiming at closing the gap between the musical "East" and the musical "West." The festival and conference had been in planning since Nabokov's stay in Tokyo in 1955, but the realization had been delayed time and again due to political events and other factors. ${ }^{341}$ The CCF acted as the initiator and cofinancier, with funding mainly from the Rockefeller Foundation as well as the Japanese Society for International Cultural Exchange (KBK) and the Tokyo City Government. ${ }^{342}$ Both festival and conference attracted high-profile attendees from the United States, Europe, and East Asia (the conference program and a list of conference participants are provided in Table $2.2^{343}$ ). Elliott Carter, Colin McPhee, Lou Harrison, and Alan Hovhaness, among others, traveled from the USA alongside the 64-year-old Henry Cowell, while Luciano Berio, Iannis Xenakis, Bruno Maderna, and Boris Blacher, among others, came from Europe. Berio was in the process of moving his main residence from Italy to the United States, where he worked from 1962, initially at Mills College. In a concert on 5 May 1961 at the East-West Music Encounter Festival, Toshirō Mayuzumi's neoclassical orchestral work Bacchanale (1953) was performed under the direction of Seiji Ozawa by the New York Philharmonic; Cowell forwent the performance of his own work at the festival in Mayuzumi's favor (albeit not entirely voluntarily). ${ }^{344}$

Cold War Europe, Parsons, "Sets and the City," Shreffler, "Ideologies of Serialism," Beal, New Music, New Allies, Sheppard, "Continuity in Composing the American Cross-Cultural," and Giroud, Nicolas Nabokov.

339 Adorno's essay "Die gegängelte Musik" was written in 1948 in immediate response to Eisler's Prague Manifesto and was first published in 1953 in the Berlin journal Der Monat, which was supported by the CCF (other journals supported by the CCF included Encounter in London and Preuves in Paris) (Stonor Saunders, The Cultural Cold War, 26, 85-87, 138-158; see also footnote 332 above).

340 Nabokov, "Introduction à L'CEuvre du XXe siècle," 8, quoted in Parsons, "Sets and the City," 59.

341 Giroud, Nicolas Nabokov, 329. Initially the event had been scheduled for April 1959.

342 Ibid., 329-331.

343 The conference is discussed in Fukunaka, "Chinmoku suru 'seijin', chūshō ka sareta 'aika," Sheppard, "Continuity in Composing the American Cross-Cultural," 523-524, Borio, "Convergence Between West and East in 20th-Century Music," 109-110, Giroud, Nicolas Nabokov, 329-332, and Fukunaka, "World Music History and Interculturality."

344 Sachs, Henry Cowell, 473-474. 
Table 2.2: East West Music Encounter Conference, Tokyo 17-22 April 1961,

Program and List of Participants ${ }^{345}$

\section{Program (17-22 April 1961)}

17 April: Inaugural Session

18 April: The Difference in Musical Notions of the East and the West

The Eastern Musical Traditions

The Music of India

The Music of Indonesia

Music as a Liberal Art: Its Place in the Life of the Community

Religious Music (Liturgical and Religious Music)

Operatic and Ballet Music

Concert Music

19 April: Musical Interaction Between the East and the West

Western Studies of Eastern Music

Asian Music under the Impact of Western Culture

Problems of the Sino-Japanese Musical Tradition Today

Problems of the Indonesian Musical Tradition Today

Problems of the Indian Musical Tradition Today

Oriental Influence on Western Music

Western Music in the East

Western Music in Japan

Western Music in India

Western Music in the Philippines

The Composer in Japan Today

20 April: Music and the Listener. Panel Discussion;

Instruction in Music as Part of General Education

21 April: Expression and Technique in Contemporary Music:

Renewing the Musical Language

Extending the Classical Syntax

Electronic Composition

Stochastic Music

Refreshing the Auditory Perception

The Philosophy of Style

An Eastern View

Theme: Patronage of Music

Patronage of Music in the East

Patronage of Music in the West

Presenting the Eastern Tradition under Conditions of Mass Distribution

Situation of Creative Art in the Industrial Society

22 April: Critics' Forum 


\begin{tabular}{|l|l|}
\hline Conference Participants & \\
Arima, Daigoro & Moroi, Makoto \\
Arisaka, Yoshihiko & Murata, Takeo \\
Bekku, Sadao & Nomura, Koichi \\
Bhatia, Vanraj & Nomura, Yoshio \\
Carter, Elliott & Roy, R.L. \\
Cowell, Henry & Ruppel, Karl H. \\
Crossley-Holland, Peter & Sakka, Keisei \\
Cvetko, Dragotin & Schuh, Willi \\
Daniélou, Alain & Seefehlner, Egon \\
Draeger, Hans H. & Shiba, Sukehiro \\
Garfias, Robert & Singh, Thakur J. \\
Glock, William & Stuckenschmidt, Hans H. \\
Gostuški, Dragutin & Thomson, Virgil \\
Harewood, The Earl of & Toyama, Kazuyuki \\
Harrison, Lou & Tran Van Khe \\
Hirashima, Masao & Valenti-Ferro, Enzo \\
Hood, Mantle & Vatsyayan, Kapila \\
Kelemen, Milko & Viswanathan, T. \\
Kitazawa, Masakuni & Vlad, Roman \\
Maceda, José & Xenakis, lannis \\
McPhee, Colin & Yoshida, Hidekazu \\
Miyagi, Mamoru & Yuize, Shinichi \\
\hline selected festival participants not listed as conference speakers: \\
\hline Berio, Luciano & New York Philharmonic \\
Bernstein, Leonard & Japan Philharmonic Symphony Orchestra \\
Blacher, Boris & Gagaku Ensemble \\
Einem, Gottfried von & Gamelan-Ensemble (Bali) \\
Kontarsky, Aloys and Alfons & Royal Ballet (UK) \\
Maderna, Bruno & Royal Dancers of Thailand \\
Prey, Hermann & Kathakali Dance Group Kerala (India) \\
Stern, Isaac & \\
\hline
\end{tabular}

Though largely obscured by the propagation and endorsement of "freedom" in the arts, the hidden political motives of the CCF's activities, mainly its aim to "contain" leftist or more explicitly pro-Soviet tendencies, were obvious to many commentators and participants in Tokyo ${ }^{346}$ as well as at the earlier European events, although the CIA funding was revealed only in 1966. In addition, there was a general anti-American sentiment in Japan, with the previous year's ratification of the Ampo Pact (Treaty of Mutual Cooperation and Security between the United States and Japan, 19 June 1960), in which troop postings on Japanese territory were prolonged, provoking student protests.

Many of the composers participating in the Tokyo conference ostensibly shared Euroskeptic viewpoints, envisioning a new "universalist" musical idiom independent from dominating European trends such as serialism, while arguing for "preserving" non-Western traditions, sa-

346 Hayashi, "Two Opinions Over the Tokyo World Music Festival: II.” See Fukunaka, "Chinmoku suru ‘seijin', chūshō ka sareta 'aika."” 
ving them from the threat of a contaminating Western influence ${ }^{347}$ - not least in order to subject them to compositional appropriation. Cowell was particularly clear in this regard:

[...] composers would like to feel that they have the freedom to draw on worldwide musical resources, so we would like to do more of what Dr. Mantle Hood is doing in Los Angeles; that is in training groups of American people to play oriental instruments from all nations, to sing in oriental languages and styles and composers would like to draw on the tone quality of certain oriental instruments. We would like to include this and to have a worldwide and international field by drawing on the music which appeals to people all over the world. ${ }^{348}$

During the conference, ethnomusicologists and composers therefore unanimously demanded the preservation of "non-Western" traditional musical practices, which to them appeared under acute threat in the rapidly Westernizing Asian countries. ${ }^{349}$ This focus on the preservation of musical traditions did not occur "by coincidence," but was part of a larger trend in US foreign cultural policy at the time:

Especially at the time when the Vietnam War, civil rights movements, and revelations about covert $\mathrm{CIA}$ interventions in Africa, Asia and Latin America shattered faith in liberal universalism in favour of cultural relativism, [Ford Foundation] administrators considered investment in local heritages as a tactic of soothing those who criticised the American modernization programmes for being too one-sidedly focused on economic and political development at the expense of the indigenous traditions they sought to sustain. ${ }^{350}$

A memorandum written at the end of the conference outlined the project of an "International Institute for Comparative Music Studies." Two years later, in 1963, when Nabokov was invited by the Mayor of Berlin, Willy Brandt, to act as advisor to the city government on cultural matters, ${ }^{351}$ the Berlin International Institute of Comparative Music Studies and Documentation (iicmsd, in 1991 renamed International Institute for Traditional Music) was founded, financed through the Ford Foundation and directed by Alain Daniélou (the Institute was closed in 1996). ${ }^{352}$

Despite these connections, it would clearly miss the point to attribute the international or even universalist claims of both serial music and countertrends such as Henry Cowell's ethnically defined universalism exclusively to institutional and political history and denigrate these

347 See Cowell, "Oriental Influence on Western Music," Sheppard "Continuity in Composing the American CrossCultural," 523-524.

348 Henry Cowell in "Discussions. Music and the Listener," in: Executive Committee for 1961 Tokyo East-West Music Encounter, Music-East and West, 183-201: 197.

349 "Non-Western" within this conference denotes "Asian" exclusively, since African and Latin American music were conspicuously absent from the discussion.

350 Langenkamp, “(Dis)Connecting Cultures, Creating Dreamworlds," 221.

351 See Stonor Saunders, The Cultural Cold War, 295-296 and Ciroud, Nicolas Nabokov, 341-371.

352 "A Proposal by the Standing Committee of 1961 Tokyo East-West Music Encounter Conference," in: Executive Committee for 1961 Tokyo East-West Music Encounter, Music - East and West, 227-228. The Standing Committee included prominent names such as Yehudi Menuhin, Saburō Moroi, Alain Daniélou, and Hans H. Stuckenschmidt (see Giroud, Nicolas Nabokov, 332). The plan for such an institute went back to a meeting of Nabokov with Alain Daniélou in Madras in 1955 (ibid., 346) and was part of a comprehensive effort by the CCF to sustainably strengthen Berlin as the location of "free" culture, especially after the Berlin Wall had been built; the Berliner Festspiele also emerged from this process. See Stonor Saunders, The Cultural Cold War, 295-296. 
largely unpopular styles as corrupted by the ideologies of their day: "It is easy to dismiss the musical styles that we never liked anyway, if we can convince ourselves that they only existed as part of a CIA plot." ${ }^{353}$ However, such contexts reveal the important insight that "advanced music is not neutral (autonomous) or even necessarily critical, simply by virtue of its idiom. ${ }^{\text {"354 }}$ A closer look at three composers involved in the 1961 conference and festival will elaborate on this point, while hinting at their "non-synchronous" motives and presumptions: Henry Cowell (1897-1965), Toshirō Mayuzumi (1929-1997), and Luciano Berio (1925-2003) participated in (or can be at least associated with) the 1961 Tokyo Festival and Conference, with the sixty-four-year-old Cowell being promoted as a major figure by the American co-organizers. The personal participation of Mayuzumi in the conference at present cannot be confirmed, as he was on a six-month stay in the United States around that time, although, as mentioned above, a piece by him was performed during the festival. Far beyond the conference, the "entanglement" of all three composers with Cold-War-related institutions was significant for their careers and artistic development, despite their different ages, social status, and roles in their respective countries' musical scenes. Thus, their unlikely "encounter" at the Tokyo 1961 conference and festival provides an apt example of the "non-simultaneous" impact of simultaneous events in postwar music history.

\section{Henry Cowell and the Project of Hybridization}

Henry Cowell's compositional approach, aimed at hybridizing global musical traditions, was particularly conducive to the "cross-national" impulse of the East-West Music Encounter Conference. Cowell had been studying non-Western music cultures since the mid-1920s ( $\rightarrow$ II.4). His program of transethnic universalism developed in the early 1930s, and remained surprisingly consistent over more than three decades despite all the political changes during that period. Cowell increasingly regarded his approach as specifically American:

In my own music I believe I coordinate [...] musical means from all parts of the world, and from all ages of musical history. Into my inner creative needs I may feel the necessity of drawing on resources from any part of the world, folk or cultivated, and from any age, simple or complex. [...] In a way, I think of this as truly American, because America more than any other country, is made up of all the peoples of the world, and less than any other great composer-producing country does it have any one specific old tradition of musical composition. ${ }^{355}$

As shown in the previous chapter, Cowell systematically created works that deal with individual music cultures as well as culturally hybrid works. ${ }^{356} \mathrm{He}$ simultaneously tended toward a more conservative idiom contrasted with his early "ultramodernist" experiments, an idiom which was certainly better suited for representative political purposes than, for instance, John Cage's concurrent ascetic purism $\rightarrow$ II.6), despite the two composers' shared ideas and orientation toward universalism.

As early as the 1930s, Cowell had grown acquainted with Japanese music. Of particular importance was his encounter with the shakuhachi player Kitaro Tamada, who taught Cowell the

353 Shreffler, "Cold War Dissonance," 59.

354 lbid.

355 Cowell, statement Tokyo, 1 May 1961, quoted in Sheppard, "Continuity in Composing the American Cross-Cultural," 507.

356 See, among others, Nicholls, "Transethnicism and the American Experimental Tradition." 
instrument from 1937 during Cowell's imprisonment in San Quentin Prison (1936-40). ${ }^{357}$ In 1946, Cowell dedicated the solo work The Universal Flute for shakuhachi to Tamada. ${ }^{358}$ Crucial to the context of the Tokyo conference in 1961 was Cowell's year-long trip to Asia between August 1956 and September 1957, which was generously funded by the Rockefeller Foundation and the US Department of State. This trip took Cowell through Ireland, London, Turkey, Lebanon, Syria, Jordan, Egypt, Pakistan, India, Iran (for two months), Burma (Myanmar), Thailand, Indonesia, the Philippines, Hong Kong, Japan, and Korea. ${ }^{359}$ Comparable to the activities of the Congress for Cultural Freedom, the Rockefeller Foundation had been actively involved in the "Cultural Cold War" since 1955 and saw Asia as a key region, not least as a result of the Korean War. ${ }^{360}$

While still in Japan at the end of this journey, Cowell began composing the orchestral piece Ongaku in June 1957. The work, commissioned by the Louisville Orchestra, was inspired by the Japanese court music gagaku and the urban chamber music sankyoku. Cowell completed this work in September 1957 after his return to the US. ${ }^{361}$ Ongaku was directly influenced by the music Cowell heard during his stay in Tokyo; this included rehearsals by court musicians, gagaku court music, and shakuhachi music. Cowell was particularly impressed by the chord structures of the mouth organ shō in gagaku music $\left(\rightarrow\right.$ IV.). ${ }^{362}$

The work was a prelude to a series of works by Cowell inspired by Japanese instruments and musical genres, including two concertos for koto and orchestra. ${ }^{363}$ Cowell explicitly pursued an anti-European program, or, more specifically, a program directed against the contemporary serial avant-garde in Europe and the USA: "In 'drawing on resources' from nations such as Japan, Cowell's explicitly stated goal was to counter international serialism with a new musical universalism - on American terms." ${ }^{364}$ As part of the Tokyo conference, Cowell clarified that from his point of view, the interest in Asian music was primarily due to the diagnosis that Western music styles had already lost their "vitality" toward the end of the nineteenth century. ${ }^{365}$ Undoubtedly, Cowell's universalistic transethnicism benefited US diplomacy at the time:

His universalism and attempts to synthesize East and West in his music, however benign in motivation, worked hand-in-hand with U.S. Cold War efforts to form political bonds with Asian nations, particularly with Japan, much in the same way as state-sponsored radio broadcasts, lectures, and concerts of American music abroad [...]. [...] living "in the whole world of mu-

357 Sheppard, Continuity in Composing the American Cross-Cultural, 500-506. For a broader representation of the reception of Japanese traditional music in the twentieth-century USA see Sheppard, Extreme Exoticism.

358 Sheppard, Continuity in Composing the American Cross-Cultural, 505-506.

359 Sachs, Henry Cowell, 429-430. "For his 1957 tour, Cowell had been contacted by the U.S. Information Agency and asked to deliver lectures on contemporary American music with the explicit goal of promoting the image of the U.S. as a cultured nation to counter Soviet propaganda." (Sheppard, "Continuity in Composing the American Cross-Cultural," 507).

360 Sachs, Henry Cowell, 469-470.

361 Sheppard, "Continuity in Composing the American Cross-Cultural," 518.

362 Sachs, Henry Cowell, 453.

363 Concerto [no. 1] for koto and Orchestra (1962) and Concerto no. 2 for koto and Orchestra (1965). The Concerto for Harmonica (1962) was created at the same time and originally bore the title Haiku (Spirit of Japan), which was crossed out in the autograph (Sheppard, "Continuity in Composing the American Cross-Cultural," 518).

364 Ibid., 508.

365 Cowell, "Oriental Influence on Western Music," 72. 
sic" and subsuming all musics under an American label do involve a certain problematic egotism that resonates with U.S. covert imperialism of the past fifty years. ${ }^{366}$

Naturally one must treat such theses, which suggest a kind of "complicity" between artists and cultural politics or diplomacy, with a degree of caution. ${ }^{367}$ Even though the Head of the American Center in Japan, E.J. Findlay, thanked Cowell after a week-long lecture and concert tour in Japan after the East-West Music Encounter Festival "for all you did in Japan to win the cultural cold war," ${ }^{368}$ one must at least consider that Cowell's universalism was not an immediate result of the geopolitical situations of the Cold War, especially since it had developed from the $1920 \mathrm{~s}$ onwards. Certainly the Cold War provided additional motivation and encouragement for this perspective. Nevertheless, it is obvious that Cowell's approach, which, unlike John Cage's, gave up neither the concept of the work nor an essentialist concept of culture, was indeed suitable as a model for a diplomatic elite whose target group was a broad public.

How did Cowell's hybridized musical language actually materialize? In the introductory text to Ongaku, the composer wrote:

The foreign music strangest to Western ears is certainly that of the Far East: China, Korea and Japan. But the strangeness seems to be largely superficial: a matter of tone color and technique rather than structure. The basic relationship between music East and West is attested, I think, by the fact that Western orchestra performers will find nothing particularly surprising in their individual instrumental parts [in Ongaku] [...] in spite of the unfamiliar style in which the music is couched. [...] [the piece] is not an imitation of ]apanese music, but an integration of some of its usages with related aspects of Western music. [...] all the thematic material is my own; there are no actual Japanese themes in the work. The themes are extended by means of techniques for melodic variation that are common to both cultures. Western techniques for thematic development are not applied to the material. ${ }^{369}$

It is remarkable in this note that Cowell implicitly refers to his own work as "Japanese music" - from the perspective of American musicians and listeners - while emphasizing that he had not quoted any Japanese melodies. Autograph materials, meanwhile, have revealed a close connection between the first movement with the pitch structure and instrumentation of the tōgaku repertoire of gagaku Japanese court music. ${ }^{370}$ Cowell, however, chose the miyakobushi scale for the first movement. This scale had played a significant role in nationalist music theory and composition in the 1920 s to 40 s and had been conceptualized as specifically "Japanese" as described in Chapter II.4. It does not, however, appear in the togaku repertoire, but rather in certain koto and shamisen traditions of urban music during the Edo period (1600-1867) as in the pieces of sankyoku (trio setting originally of shamisen, koto, and the knee fiddle koky $\bar{u}$, increasingly replaced by the shakuhachi). In addition, Cowell's scale on the pitch G (G-Ab-(A)-C-

366 Sheppard, "Continuity in Composing the American Cross-Cultural," 507-508 and Sachs, Henry Cowell, $452-453$.

367 Cowell, like several other artists, was a consultant worker at the Office of War Information between the two world wars (OWI; United States War Information Office), where he was responsible for designing radio programs for US soldiers. See Cowell, "Shaping Music for Total War" and Beal, New Music, New Allies, 8-11.

368 Quoted in Sachs, Henry Cowell, 474.

369 Cowell, program note to Ongaku, quoted in Sheppard, "Continuity in Composing the American Cross-Cultural," 508 .

370 Sheppard, "Continuity in Composing the American Cross-Cultural," 510. 
$\mathrm{D}-\mathrm{E} b-\mathrm{G}$ ) includes the pitch $\mathrm{E} b$, which does not appear in the pitch system of tōgaku (Ex. 2.11). ${ }^{371}$ Likewise, the chords characterized by mild dissonances in high strings and woodwinds are not exact duplications or transpositions of the shö's aitake chords, which determine the harmony of togaku $\rightarrow$ IV.1). Thus, on the one hand, Cowell may have felt a special affinity for the "oriental" sounding miyakobushi due to his engagement with Persian and Arab music, while on the other hand, the references to Japanese traditions are possibly intentionally set in an imprecise manner in order to avoid the implication of "cultural imperialist" plagiarism. The combination of koto and gagaku traditions, which are strictly separated in the Japanese hogaku (traditional music) system, may also indicate a deliberate form of intra-Japanese hybridization, which is also suggested by the choice of the general title Ongaku ("Music" - in opposition to yōgaku, Western-oriented musical composition, and hōgaku, traditional Japanese music). ${ }^{372}$

Cowell was by no means the only composer fascinated by the musical traditions that Japan had institutionalized with great "success" since the Meiji restoration. Especially gagaku and the shō offered a point of attraction for many composers from both Japan and the West, including Iannis Xenakis, Olivier Messiaen, Benjamin Britten, Karlheinz Stockhausen, Tōru Takemitsu, Jean-Claude Eloy, and Toshio Hosokawa $(\rightarrow$ IV.). Except for the "scenic music" of Stockhausen with gagaku instruments from the late 1970s, ${ }^{373}$ the public in Japan responded favorably to these approaches of Western composers, as in Cowell's case. ${ }^{374}$ In all these cases, in the sense of

371 The modal system of gagaku has often been described in different ways and is characterized by some contradictions between theory and practice: "Gradually theory (even as rationalized in Japan) and evolving performance practice in gagaku diverged to a confusing degree" (McQueen Tokita and Hughes, "Context and Change in Japanese Music," 19). Fundamentally, one starts from a nine-note pitch repository, the pitches available on the mouth organ shō: $C-C \sharp-D-E-F \sharp-G-C \sharp-A-B b$ (i.e., without Eb, F , and B ) (Carfias, Music of a Thousand Autumns, 60). In the mode classes ryo (major third over the central tone) and ritsu (minor third over the central tone) categorized in today's practice, or three mode types on it (see ibid., 61-63), there are no formations that contain the typical miyakobushi trichord (C-Db-F). Although similar melodic formations sometimes occur in the context of the variable intonation of the leading reed hichiriki (see ibid., 133), Cowell, in the first movement of Ongaku, clearly uses the trichords C-Ab-C and G-Eb-D as a structural basis, not as intonational variants. Sheppard, in his account also referring to the compositional sketches, states that only the second movement of Ongaku was oriented to sankyoku, while the first movement was (exclusively) related to gagaku (Sheppard, "Continuity in Composing the American Cross-Cultural," 510). There is no doubt that the main models of both movements are unequivocal in terms of composition and instrumentation (in the second movement the gagaku model is retaken in measure 90 in a reminiscent form). It is, however, likely that Cowell, intentionally avoiding too close a reference to the original forms, consciously kept the modal system of the first movement "inauthentic," thus blending gagaku and sankyoku references in both movements.

372 This was also evident in the performance of the work in Japan: "some Japanese audience members were apparently disturbed by Cowell's juxtaposition of the sacred and ritualistic gagaku alongside the sankyoku genre of secular entertainment" (Sheppard, "Continuity in Composing the American Cross-Cultural," 511).

373 See Shimizu, "Stockhausen und Japan" and Utz, Neue Musik und Interkulturalität, 148-153. In the 1970s, Stockhausen developed the concept of "Szenische Musik," culminating in his music theater cycle Licht (1977-2003). Der Jahreslauf provides an early example of this approach. See Wirtz, Licht. Die szenische Musik von Karlheinz Stockhausen.

374 The koto soloist Kimio Eto (1924-2012), a student of the eminent koto reformer Michio Miyagi and soloist at the premiere of Cowell's first koto concerto, said of Cowell's Ongaku, "The degree of success with which Mr. Cowell has caught the flavor of Japanese music is illustrated by the reaction of a Japanese audience to [Ongaku] in 1959. It was enthusiastically received by older members of the audience. But some of the younger ones, whose musical leanings and experience are increasingly Western, were puzzled. 'Frankly, it's too Japanese for us,' said 
Example 2.11: Henry Cowell, Ongaku, first movement - pitch structures
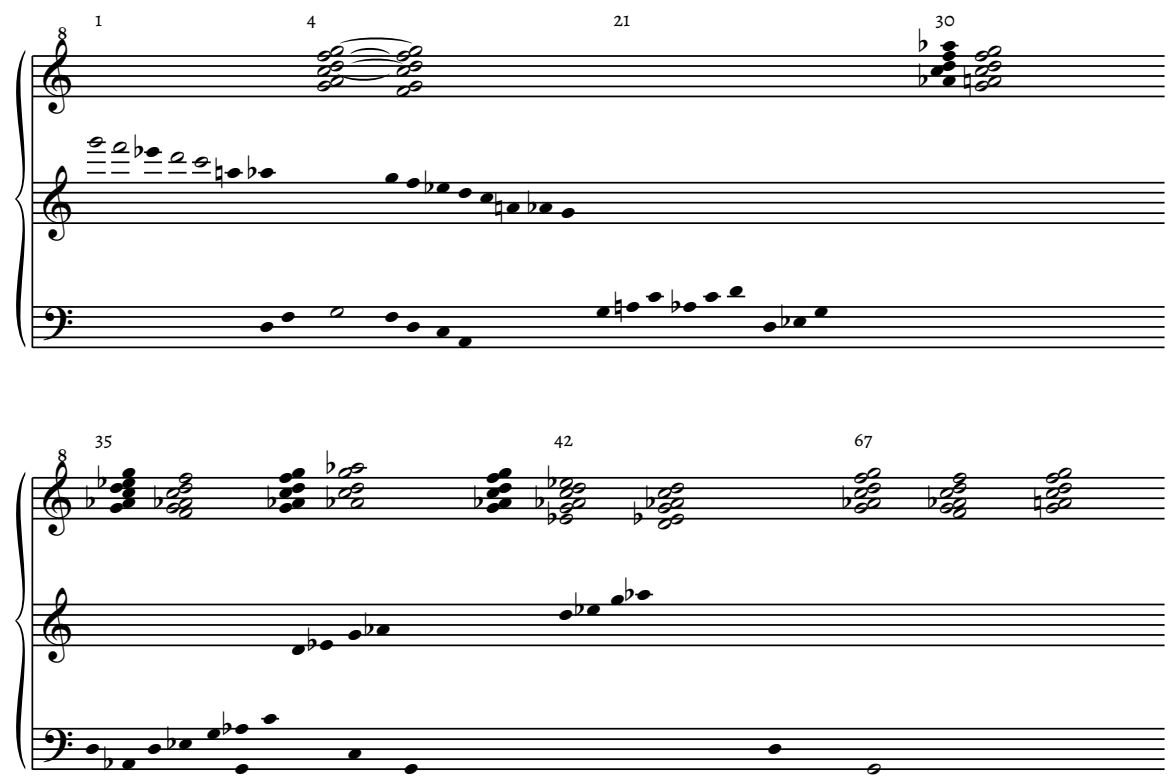

Andreas Meyer's "musical anthropology," 375 there is a tension between what is considered an "archaic," but in fact idealized, non-Western tradition (which, in the case of Japanese court music for example, was a construct of modern Japan) and the aesthetic demand after hybridizing such traditions under the conditions of musical modernity, where the forms of "synthesis" could by no means all be equivalent, but were subject to a controversial contemporaneous discourse.

\section{Toshirō Mayuzumi: Reception of Modernism and Neo-Nationalism}

In global music-political contexts, the polarization of "West" and "East" after 1945 made itself felt in a variety of ways, and also had a tremendous impact on postwar Japan. It may be too neutral to describe the development of Japanese music after 1945 as a "shared space" of European and Japanese musical culture (as Bonnie Wade does $^{376}$ ), as a common ground prepared by the systematic adaptation of European music since the Meiji restoration of 1868 . That such an adaptation had to be thoroughly reconceived after a period of fierce militarist aggression, war crimes, and the atomic catastrophe may be demonstrated by the example of Toshirō Mayuzumi, probably the most active and innovative Japanese composer during the 1950s. Mayuzumi presented a key work of a neo-national aesthetic in 1958 at the age of 29 with his Nirvana Symphony [Nehan kokyokyoku] for orchestra and male choir. The neo-national aesthetic, one that many artists in postwar Japan avoided or explicitly denounced, reminded many of the Japanese militarism in the Pacific War and its exploitation of traditional cultural symbols. Mayuzumi, born in 1929, was part of the composers' group San'nin no kai (Group of Three) founded

one, 'it's way over our heads." (Daniel Webster, "An Interview with Kimio Eto." Philadelphia Inquirer, 18/12/1964, quoted in Sheppard, "Continuity in Composing the American Cross-Cultural," 511).

375 See Meyer, "Volkstümlich - primitiv - populär." ( $\rightarrow$ II.1, II.2)

376 See Wade, Composing Japanese Musical Modernity, 39-95. 
in 1953, which also included Yasushi Akutagawa (1925-89) and Ikuma Dan (1924-2001). San'nin no kai was the only one of numerous groups to emerge during the 1950 s that attempted to connect to national or "pan-Asian" prewar trends. After a short period of study in Paris in 1951-52, Mayuzumi presented the earliest examples of musique concrète and electronic music in Japan, as well as orchestral and chamber works in different styles situated between neoclassicist and avant-garde idioms. ${ }^{377}$ Steven Nuss describes Mayuzumi's subsequent neo-nationalist turn as a "conscious decision in the late 1950 s and early 1960 s to reject or subjugate the considerable influence on him of contemporary Western (particularly French) compositional techniques and styles and to draw instead on his profound knowledge of Japan's traditional musical genres for musical inspiration" and thus as a "clear attempt to take what he saw as the West's insidious (musical) colonialism and flip it on its head."378

Mayuzumi tried to continue nationally-oriented prewar tendencies using new studio technologies: in a remarkable anticipation of spectral tendencies, he took spectral analyses of Japanese temple bells (bonshō), as the harmonic basis for moving "sound-masses" in movements 1, 3, and 5 (Campanology I-III) of the six-movement Nirvana Symphony. Characteristically, he wanted to make a trace of the "Japanese" in the bell spectrum via two pentatonic modes. ${ }^{379}$ The modes, however, are largely presented in a decidedly "modern," textural reading of the national element and integrated into a system of "verticalized" serial rows. ${ }^{380}$ The result is fundamentally different from Cowell's traditionalist hybrid style study designed just one year earlier. A modernity-driven critique of tradition is linked to a novel interpretation of the national element. The textural technique continues in some passages of movements 2,4 , and 6 (Śürangama; Mahāprajūāpāramitā; Finale). Here, the Buddhist recitation practices of various Japanese sects are taken up and dissolved into moving sound fields.

At the invitation of the Ford Foundation, Mayuzumi spent about six months in New York from the end of 1960, where he attended performances of his orchestral work Bacchanale (1953) by the New York Philharmonic under Leonard Bernstein at Carnegie Hall (13, 14, and 16 April 1961). He received a commission from the New York City Ballet and met with its director George Balanchine. Subsequently, he composed his two-movement orchestral work Bugaku (the score was completed on 23 March 1962 in Tokyo, and the world premiere was on 20 March 1963 in New York). ${ }^{381}$ Following on from his spectacular cello solo Bunraku (1960), Mayuzumi drew more and more explicitly on Japanese models - possibly also motivated by works such as Cowell's Ongaku, but maybe also by the Tokyo East-West Music Encounter Conference of $1961 .{ }^{382}$ In the context of

377 Galliano, Yōgaku, 166-168, 185-186.

378 Nuss, "Music from the Right," 86-87.

379 Mayuzumi, "Traditional Elements as a Creative Source for Composition."

380 Shimizu, "Mayuzumi Toshirō no kanpanoloji efekuto."

381 Mayuzumi, "Baranshin to barē 'Bugaku."

382 Other similarly oriented works by Mayuzumi from the same period include Sange (Scattering) for male choir (1959), the Mandala Symphony (1960), the symphonic poem Samsara (Reincarnation) (1962), and the cantata Ceka (Pratidesana) (Public Confession) (1963). "These compositions mirror his nationalist partiality through the use of Japanese elements and in some cases overtly nationalist messages" (Cook, "Venerable Traditions," 105). Yoritsune Matsudaira (1907-2001), 22 years older than Mayuzumi, had sought since the 1930s to integrate Japanese traditional material into Japanese new music, presenting an orchestral work of the same title, Bugaku, the previous year (1961). This work was awarded first prize at the competition of the annual festival of the International Society for Contemporary Music (ISCM) in Italy, and thus received widespread attention (Galliano, Yōgaku, 141). In contrast to Mayuzumi's increasingly explicit reference to Japanese models, Matsudaira tried to 
Example 2.12: Toshirō Mayuzumi, Bugaku, part 1, mm. 1-5 (vln. 2); the performance instruction written in the score reads: "Whole string should be played without vibrato through 11 . All glissandi marked - or are to be played in such a manner that starting note is left immediately, producing an even gliding sound until the following note is reached. Melodies played by solo string players are to be played in such a manner that each note is stopped by a single finger (preferably on index finger of left hand) without changing the finger even if the note is changed."

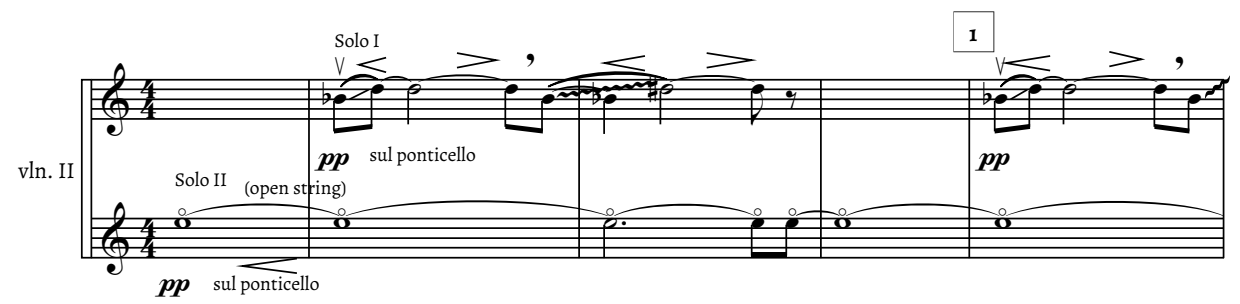

Copyright $\odot 1963$ by C. F. Peters Corporation, New York

the reference to the dance genre of the court music gagaku $u^{383}$ - a traditionalism characterized by the sliding notes of the beginning (Ex. 2.12) of the first movement transforming into a broad and affirmatively extended tutti - it seems clear how the tutti effect brutally overpowers the subtle study of the traditional style. In addition, it seems that besides a Western influence in the cyclic ostinato rhythms, we may also hear traits of gamelan structures, which had already provided a model for Mayuzumi since the early 1950 s. $^{384}$ In any case, the violent effect of the concluding tutti is symptomatic of Mayuzumi's neoconservative turn during this period, which - seemingly paradoxically - went hand in hand with a growing shift away from explicit references to the Japanese music tradition in the 1960s, although this process was not linear.

In Mayuzumi's works around 1960, one can retrospectively recognize an awareness of the need to strengthen the relevance of the national in order to counteract the questionable strategy of "catching up" with European developments, without - at that point - necessarily involving a "patriotic" or "narrow nationalist" outrage. ${ }^{385}$ Cultural essentialism, however, was thus foreshadowed as a central discourse that would strongly influence Japanese music at least until the 1980s, coinciding with a general increase in nationalist sentiments in Japanese society as mirrored in the nihonjinron (Japanese discourses). ${ }^{386}$

combine serial methods and tentative elements of aleatoricism, first used in Bugaku, with the Japanese pitch system.

383 In traditional bugaku, the "left dance" (sahō/samai; the dancer appears from the left side of the stage) is accompanied by tōgaku music in a solemnly sustained tempo, which can increase as the dance progresses, and is framed by two unmetered canonic sections (chōshi) (see Garfias, Music of a Thousand Autumns, 76-77), which corresponds to Mayuzumi's first movement. In the "right dance" (uhō/umai; the dancer appears from the right side), music from the komagaku tradition is played without any unmetered passages. The second movement of Mayzumi's work, which is characterized by ostinati, finally takes up the tutti material from the first movement to arrive at a "triumphant" finale. See Katayama, "Toshiro Mayuzumi," 21-22.

384 Galliano, Yōgaku, 185.

385 Cook, "Venerable Traditions," 125-126.

386 See Hijiya-Kirschnereit, Das Ende der Exotik. 
Mayuzumi's nationalism eventually became more politically explicit during the 1960s, conditioned by, among other factors, his encounter with the writer Yukio Mishima (1925-70), who had increasingly turned to nationalist ideas as a result of the protests against the Ampo Pact in 1960. As one of few Japanese composers, Mayuzumi combined the widespread cultural essentialism in the sense of minzoku shugi ("cultural tradition") with nationalist political ideology (kokumin shugi). ${ }^{387}$ Especially after Mishima's spectacular ritual suicide (following an "attempted coup") in 1970, Mayuzumi stepped up as a political activist and headed the nationalist organization Nihon wo mamoru kokumin kaigi (National Conference for the Defense of Japan; since 1997 Nippon kaigi, Japan Conference) from 1981-91. ${ }^{388}$ This group, which denied Japanese war crimes, set itself the goal of reviving the principles of the Japanese empire. During the same time, Mayuzumi's Showa tenpyōraku (1970) was the first work by a Japanese composer for traditional gagaku ensemble commissioned by the Tokyo National Theater, followed by many more. ${ }^{389}$

It is precarious to assert a direct connection between Mayuzumi's clearly positively accentuated reception of Western modernism and his political Japanese nationalism. It is as clear that both are closely related as it would be problematic simply to call Mayuzumi's highly virtuosic "synthesis" of European orchestral technique and substantial knowledge of Japanese pitch systems and practices "nationalist" - an approach that need not shy away from the comparison with Yoritsune Matsudaira or Tōru Takemitsu. Declaring Mayuzumi a musical nationalist tout court would ignore the tradition-critical impulse that found its way into Mayuzumi's scores along with his reception of modernity. It should also be considered that paradoxically, Mayuzumi, through the international context of the "Cultural Cold War," must generally have experienced support rather than obstruction for his neo-nationalist idiom, given that his specific combination of international postwar avant-garde and Japanese traditional idioms had resulted in a hybridity that coincided favorably with a politically motivated American cultural universalism. This was a universalism that Mayuzumi directly confronted during his stay in the USA (supported by the Ford Foundation) and at the 1961 Tokyo East-West Music Encounter.

\section{Luciano Berio: Collage Technique with "Suppressed Political Overtones"?}

The resistance to a culturally restrictive aesthetic approach in Europe, as represented especially by Karlheinz Stockhausen's works between 1958 and 1974 (not least triggered and reinforced by the composer's multiple trips to the United States and Japan, $\rightarrow$ II.2), was considerable from the beginning. This is reflected not least in the widespread lack of understanding among his fellow European composers (and in part audiences), who were presented in the early 1970s with the musical minimalism of Steve Reich or Terry Riley (which was also interculturally oriented). ${ }^{390}$ Less explored in this context is Luciano Berio's tendency toward transethnicism in the context of the musical collage technique for which his spectacular Sinfonia (1968, rev. 1969) has become famous. For these tendencies in Berio's work, the American influence must again be assigned a key role. Berio's acquaintance with John Cage, who had created Fontana Mix in Berio's Milanese RAI studio in 1958 and composed his Aria for Berio's American-born wife Cathy Berberian, was just one of the jigsaw pieces among Berio's many contacts with the United States. In her 2011 dissertation, Tiffany M. Kuo has compiled a precise chronology of Berio's US stays

387 See Cook, "Venerable Traditions," 100-101.

388 Havens, Radicals and Realists in the Japanese Nonverbal Arts, 258.

389 See Everett, "Mirrors of West and Mirrors of East," 182.

390 See Kleinrath, “Minimalismus/Minimal Music," 378. 
Example 2.13: Luciano Berio, Sinfonia, rehearsal number AA

Copyright $\odot 1972$ by Universal Edition (London) Ltd., London

and their (cultural-)political backgrounds. ${ }^{391}$ As early as 1952, Berio had been in the USA for the first time with the support of a Koussevitzky Foundation scholarship and participated in a composition course with Luigi Dallapiccola at the Berkshire Festival in Tanglewood, Massachusetts. From 1962 to 1974 Berio lived mainly in the USA, where he taught at the Juilliard School from 1965, among other activities such as numerous trips and concerts including a prolonged stay in Berlin from the end of 1964, funded by the Ford Foundation..$^{392}$

Berio's Folk Songs for mezzo-soprano and seven instruments from 1964 (arranged for mezzo-soprano and orchestra in 1973) can perhaps be seen as the composer's first approach to an emphatically multicultural concept that largely eschews any "structural" paradigm in favor of established "traditional" idioms. In the same period, Berio's experimental music theater works more strongly accentuated the political context of the time, in particular the "messa in scena" Passaggio (1961-62), based on texts by Edoardo Sanguineti, and Traces (1965) for two soloists, two actors, two choirs, and orchestra based on texts by Sanguineti and Susan Oyama, commissioned by the Koussevitzky Foundation (1961) and conceived for a premiere at the Library of Congress in 1965. The belated premiere in 1969 at the University of Iowa followed the rejection of the work by the head of the Music Division at the Library of Congress, Harold Spivacke. In response to the American Civil Rights Movement and President Lyndon B. Johnson's (1963-69) inaugural address (27 November 1963), with reference to J.F. Kennedy's testimony, which demanded that Americans "eliminate from this Nation every trace of discrimination and oppressions that is based upon race or color, ${ }^{393}$ Berio's work shows how traces of racial discrimination were still ubiquitous in everyday American life. ${ }^{394}$ Thus, Traces can be understood as a musical analogy to the critique of the reality of President Johnson's "Great Society" model that appeared in Herbert Marcuse's 1966 essay “The Individual in the Great Society."395 Berio's work was conceived exclusively for an African-American ensemble, with the exception of the mezzo-soprano, in which one of the opposing groups was to wear white masks. This confrontational dramaturgy was influenced by Jean Genet's play Les nègres (1957/58), which had become popular in the USA at the time through an off-Broadway production under the title The Blacks. ${ }^{396}$ In addition to the provocative libretto, this conception was found to be incompatible with the official line of "containment" and ultimately led to Spivacke's rejection. ${ }^{397}$ By contrast, Passaggio (which had caused massive public protests at the premiere in the Piccola Scala in Milan in May $1963^{398}$ ), a work committed to interaction and challenging the audience in the sense of Bertold Brecht's

391 Kuo, "Composing American Individualism."

392 Ibid., 13.

393 Quoted in ibid., 33.

394 The ratification of Kennedy's ]une 1963 Civil Rights Act, which banned racial discrimination and racial segregation, was delayed by Congress for almost a year and was not signed by Johnson until 2 July 1964.

395 Herbert Marcuse, "The Individual in the Great Society" [lecture at Syracuse University, 12/11/1965]. First published in Alternatives 1/1 (1966), 14-16/20 and 1/2 (1966), 29-35. See Kuo, "Composing American Individualism," 102-104.

396 See Kuo, "Composing American Individualism," 37-38.

397 Ibid., 36-39.

398 Ibid., 36; see also Ehrmann-Herfort, "Teatro per gli orecchi," 73-75. 
AA
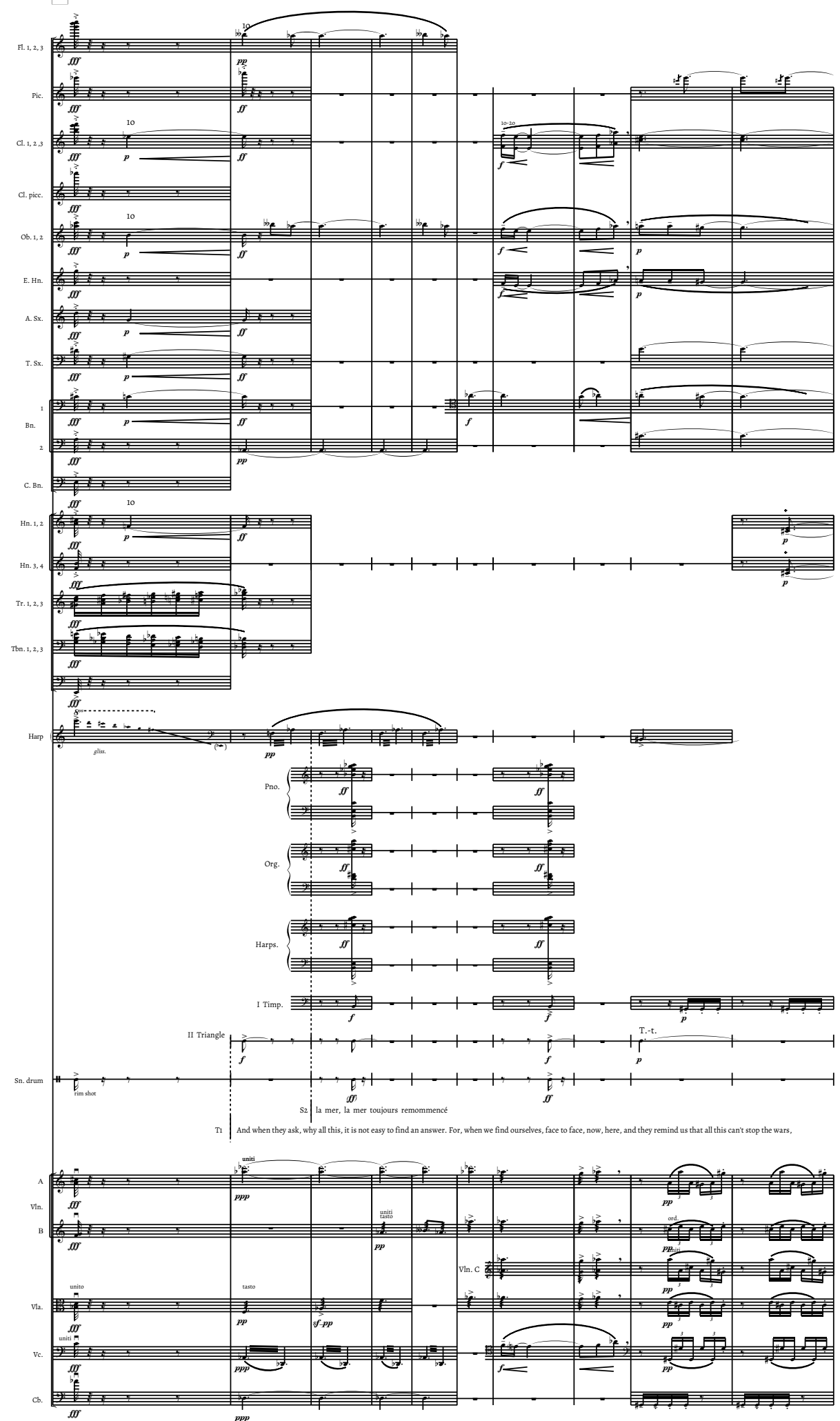
epic theater and Erwin Piscator's political theater, largely benefitted from a distinguished pub$\operatorname{lic}^{399}$ at the 1967 US premiere at the Juilliard School and Harvard University, supported by the Rockefeller Foundation. In this work, the problem of discrimination was treated in a more generalized social sense, ${ }^{400}$ less directly confronting contemporary US politics.

Later works by Berio such as Sinfonia and Coro (1975-76) reacted to these conflicting encounters with Realpolitik insofar as they radically expanded the plurality of cultural associations and stylistic levels already laid down in the two aforementioned music theater works into a comprehensive collage, ironically undermining overt political statements. In the third movement of Sinfonia, Berio paraphrases a sentence from a separate essay published in the same year (1968) - interrupting the flow of a textual layer from Samuel Beckett's The Unnamable - shortly after the recapitulation of Gustav Mahler's Scherzo from the Second Symphony, which serves as a structural basis for the movement (rehearsal number AA, Tenor I, Ex. 2.13): "[...] all this can't stop the war, can't make the old younger, or lower the price of bread"401 (in the essay, there was talk of "music" at this point, which is replaced by "all this" in the score, that is to say, it points self-referentially to the previously heard "music"402). The context and the simultaneous layers of additional musical and textual quotations here create a clear distance from any form of political activism: there are quotations from Debussy's La mer and Schoenberg's Orchestral Piece op. 16, no. 1, alongside a quotation (evoking the sea) from Paul Valéry's poem "La cimitière marin." The distancing from the political content of Berio's own statement is even more explicit in its second appearance in varied form - at the request "Say it again, louder!" (three measures after rehearsal number BB, Alto I); here the movement becomes involved in an "absurd" chain of associations, "desparate[ly]" spoken by Tenor I (five measures after rehearsal number BB):

it can't stop the wars, can't make the old younger or lower the price of bread, can't erase solitude or dull the tread outside the door, we can only nod, yes, it's true, but no need to remind, to point, for it is all with us, always, except, perhaps at certain moments, here among these rows of balconies, in a crowd or out of it, perhaps waiting to enter, watching. ${ }^{403}$

In addition, the two textual self-citations are separated by the intervening climactic chord ( $\mathrm{B}$ minor over the bass note $C$ ) from Mahler's Scherzo, abstracting the content of the spoken statements further as part of a formal music-speech dramaturgy.

In his article "Meditation on a Twelve-tone Horse," from the same year (1968), Berio adds to the sentence quoted in Sinfonia the idea that "[n]ever before [...] have responsible composers felt so compelled to challenge the meaning of and reasons for their work in relation to the world

399 Kuo, "Composing American Individualism," 106-109.

400 See Ehrmann-Herfort, "Teatro per gli orecchi," 73-75.

401 "And when they ask, why all this, it is not easy to find an answer. For, when we find ourselves, face to face, now, here, and they remind us that all this can't stop the wars, can't make the old younger or lower the price of bread" (Berio, Sinfonia, 87-88, rehearsal number AA). Foundational research on Berio' groundbreaking work is provided in Altmann, Sinfonia von Luciano Berio, Osmond-Smith, Playing on Words, and Bandur, "I prefer a wake," among others.

402 "We all know that music can't lower the cost of bread, is incapable of stopping (or starting, for that matter) wars, cannot eradicate slums and injustice." (Berio, "The Composer on His Work.") See Kuo, "Composing American Individualism," 135-137.

403 Berio, Sinfonia, 89-91. 


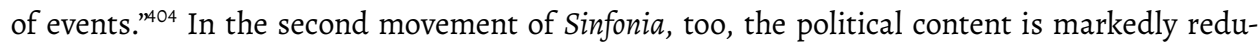
ced in comparison to the overtly political music of Traces: the textual material of this homage to Martin Luther King consists exclusively of the sounds of the name of the civil rights activist murdered during the composition of the work (4 April 1968; the second movement had already been composed in 1967). On this basis, Kuo diagnosed in Sinfonia "suppressed political overtones that would jeopardize a harmonious image of American freedom and democracy. [...] I argue that Berio acceded to George Kennan's 1965 exhortation to artists to 'forbear' rather than to criticize directly America's failings. ${ }^{405}$ The historian and diplomat George F. Kennan, the inventor of containment policy, in a White House speech in 1965 called for such "tolerance" of American artists toward the government, in exchange for the unlimited freedom that he afforded them at the same time - in deliberate contrast to the concept of "art as a weapon," which was attributed to Soviet cultural policy. ${ }^{406}$ The concept of freedom underlying this attitude was emphasized several times by the generally art-friendly administration of the Johnson presidency. On the one hand, freedom was understood as a "negative" freedom from restrictions (freedom of speech, religion, and assembly), but on the other hand as a "positive" freedom for the responsibility of the artist in society, with the goal of peace and "strengthening the nation," as formulated by president Johnson in $1965 .{ }^{407}$ Kuo makes it clear how this specifically American concept of freedom, as represented by the Congress for Cultural Freedom, found paradigmatic expression in Berio's Sinfonia: the work individualizes the listening experience of each recipient, especially since the strategies of perception in relation to the complexity of this text-music collage are heavily dependent on listening background, level of education, age, political attitude, etc. ${ }^{408}$ In this respect, the work realizes a maximum of "negative" freedom on the reception level. By contrast, examining Sinfonia and the evidence of past and present listeners' reactions to the work ${ }^{409}$ make the relationship between the art world and reality particularly explicit - albeit with almost no direct reference to daily politics - thus also honoring the aim of "positive" freedom.

Was Berio really a "model composer for America's cultural Cold War battle," as Kuo put it? Does the following conclusion not fall short? - "As an Italian-born American resident who garnered financial resources in academia, from private foundations, and from performing arts organizations, Berio reciprocated his gratitude with a sanitized and apolitical text in the second movement of Sinfonia to prove his allegiance. ${ }^{, 410}$ Berio undoubtedly showed a considerable understanding of the precarious political situation in his adopted American home, and Sinfonia (for example, via the involvement of the Swingle Singers, long known in popular culture before the world premiere of Berio's work) may even be something like a "designed success" (Morton Subotnick ${ }^{411}$ ). Even so, we can clearly see that Sinfonia is by no means the result of a politically corrupted aesthetic, but draws on the achievements of serial music - the autonomy of the individual in the context of a still-related whole, as well as the treatment of the various text sources - in the tradition of the late 1950 s and 1960s Sprachkomposition - the emancipation

404 Berio, "The Composer on His Work." See Kuo, "Composing American Individualism," 137.

405 Kuo, "Composing American Individualism," 31.

406 George F. Kennan, "The Arts and American Society," White House Speech 15/6/1965, quoted in Kuo, "Composing American Individualism," 150-151.

407 Quoted in Kuo, “Composing American Individualism," 183-184.

408 Ibid., 169-180.

409 See ibid., 158-169.

410 Ibid.

411 Quoted in ibid., 163. 
of the sound of language from the context of meaning. Therefore, the work participates in an essential development in compositional history. It was not until Coro - that is, after his return to Europe - that Berio resorted to an explicitly intercultural concept (music from Peru, Central Africa, and medieval and Romantic Europe are all incorporated into a pronounced structuralism $^{412}$ ), pursuing the aim to find "relations between very distant points. ${ }^{, 413}$ Still, a comparable universalistic model in the sense of a concert music "world theater" had already been developed in a mature form in Sinfonia. That Berio in these works avoided unambiguous political statements - as Bernd Alois Zimmerman does at the same time in his Requiem für einen jungen Dichter (1967-69), which is comparatively nuanced in its political message ${ }^{414}$ - without giving up the connection to the present, should be considered a particular quality. The cultural and political present in this work is tangible for every listener and signifies a quality that cannot be adequately interpreted according to any model based on the polarizations of the Cold War, no matter how much these were undoubtedly involved in Berio's concept.

In sum, the three case studies discussed in this chapter offer important historical insights: during the 1950s and 1960s, many composers consciously conceived of composing in a global political context; this awareness of "international" relations provided fertile ground for universalist concepts, even if they sometimes appeared in a "neo-nationalist" guise, as in Mayuzumi's case. However, Cowell's Ongaku, Mayuzumi's Bugaku, and Berio's Sinfonia respond to this situation with strikingly different and individual approaches that cannot be subsumed under any shared historical label. Cowell's American model of a "hybrid music," an idealized model of transethnicism; Mayuzumi's Japanese neo-nationalism, optimizing traditionalist structures by Western means; and Berio's politically abstracted form of universalist montage, to which we might add Stockhausen's emphatic "world music" ideas ( $\rightarrow$ II.2), occurred "simultaneously" on the historical stage but testify to radically different local, individual, political, and aesthetic preconditions of compositional craftsmanship, structural and timbral organization, performance, and reception. At the same time, all three composers were inclined to understand their music as particularly "public," linking their compositions to many of the other works mentioned earlier in this chapter, to which one might add idiosyncratic pieces like Luigi Nono's Intolleranza 1960 (1960), Tōru Takemitsu's November Steps (1967), Bernd Alois Zimmermann's Requiem für einen jungen Dichter (1967-69), or Alfred Schnittke's First Symphony (1972). Despite the evident political impact of all these works, it seems a clear underestimation of their semiotic ambiguity to reduce them to mere (if partly unconscious) reactions to (or results of) political discourses. By continuously reframing and reconsidering established concepts of identity, all these composers ultimately contributed to challenging the global hegemony of established Western concepts of music. Despite the various non-synchronous processes involved in the political and musical layers of their musical aesthetics, the anti-traditionalist impulse of

412 On the reference in Berio's Coro to the music of the Central African Banda Linda in Simha Arom's transcription, see Scherzinger, "Luciano Berio's Coro" and Dreyer, "Theorie aus der Ferne," 53-56. In Sequenza XIV for Violoncello (2002) Berio worked with information from the soloist at the premiere, Rohan de Saram, about traditional rhythmic models from Sri Lanka (de Saram's native country).

413 Berio, Two Interviews, 23.

414 For a comprehensive interpretation of this major work see Hiekel, Bernd Alois Zimmermanns Requiem für einen jungen Dichter. 
the Western postwar avant-garde and its paradoxical allegiance to so-called "traditional" musics reveal a basic ambiguity in postwar music history that, in its best moments, provided impressive proof of a general public relevance of art music. Considering the worldwide marginalization of art music's role in later periods and in today's commercialized and digitalized societies, one cannot help but see this public impact as the primary quality that distinguishes the globalized music of the postwar decades from that of the present.

\section{Categories of Intercultural Reception in Western Composition}

This concluding chapter of part II attempts to draw a broader picture of intercultural composition in the West than the admittedly narrow focuses of the three preceding chapters. The intention here is to follow the development of basic aesthetic and technical paradigms from the immediate postwar period to the more recent decades of the late twentieth and early twentyfirst centuries. Although "transnational" perspectives certainly predominate in the following, the exclusive attention given to Western composers may appear at odds with the "entangled" perspectives developed in the preceding chapters. Of course, we must acknowledge that many compositional processes, decisions, and innovations since the postwar period were and are still deeply dependent on specific processes that Western music history has created. The impact of John Cage, explored at the beginning of this chapter, is surely a case in point. Also, as the final part of this chapter on compositions for the Chinese mouth organ sheng demonstrates, the migration of performers and composers tends to make a neat definition of the "West" increasingly arbitrary from the final period of the twentieth century onward - even though cultural essentialism (as we will see) was doubtless still relevant and influential for musical thought and compositional agency.

The self-referentiality of postwar serial "logic" and John Cage's conception of a music "free of likes and dislikes" shared a suppression of ethnic layers: it is no coincidence that Cage's transfer of the model of "unimpededness and interpenetration" (wu ai yuan rong), derived from Huayan Buddhism, to an intentionless continuum of sounds and silences ${ }^{415}$ emerged in close dialogue with Pierre Boulez's early serial techniques. ${ }^{416}$ Both concepts can be equally understood as attempts to free music from any form of established grammar or idiom. Postserial Sprachkomposition of the late 1950 s and $1960 \mathrm{~s}^{417}$ whose tradition is still alive today, continued to flirt with a rigorous elimination of semantic components of language(s), as in György Ligeti's Aventures (1962), which (like Mauricio Kagel's Anagrama, 1957-58) was based on a meticulously organized system of asemantic sounds free from the rules of existing languages. At the same time, Sprachkomposition instigated a dynamics compensating for such a negation of language: Dieter Schnebel's Glossolalie 61 (1961-65), distinguished by the inclusion of an abundance of language and articulation systems, and Karlheinz Stockhausen's universalism of the 1960s, which culminated in the controversial electronic works Telemusik (1966) and Hymnen (1965-67) $(\rightarrow$ II.2), can be perceived as globally expanded attempts to recapture the ability of music to "speak" in different idioms and

415 See Pritchett, The Music of John Cage, 74-78, Klein, "Cegenseitige Durchdringung und Nicht-Behinderung," and Utz, Neue Musik und Interkulturalität, 78-84.

416 See Nattiez and Piencikowski, Pierre Boulez-John Cage. Correspondance et documents.

417 See Klüppelholz, Sprache als Musik for an introduction into the key works of German Sprachkomposition, and Utz and Lau, Vocal Music and Contemporary Identities for a broader few on intercultural tendencies in twentiethcentury vocal music. 
colors. A negative of these ethnicized attempts at a "universal language" appeared in Kagel's ironic deconstruction of intercultural music-making in Exotica (1971-72). ${ }^{418}$

Such an explicit universalism, based on a confrontation, connection, or (in Stockhausen's case) "intermodulation" ${ }^{\text {"419 }}$ between cultural idioms, and the proclaimed "universal" meaning of post-1945 concepts of language criticism in serial music, are only two sides of the same coin. Ultimately, both can only be understood in the light of specific movements in Western cultural and music history during the twentieth century. In this way, they are recognizable as a form of Western exceptionalism. Such universalism proves especially dependent on local discourses: the appropriation of cultural idioms, usually referred to as "foreign" or even "exotic," takes place solely within the specific logic of a single work, œuvre, or culture. The failure of these approaches, which has intensified criticism of appropriation strategies in the New Age movement and commercial world music since the 1970s ( $\rightarrow$ II.2), has turned the emphatic skepticism of culturally encoded musical idiomatics in European music after 1945 into a music-aesthetic mainstream - admittedly with significant exceptions and a new awareness of global interdependencies since the 1990s. In the following, a sketch-like representation of the essential paradigms of Western composers' in tercultural reception since the postwar period is intended to break up and differentiate the "false polarity" between a compositional self-reflexivity and the dissolution of culturalist paradigms.

\section{Working on Myth}

One way to distinguish intercultural musical composition is to look at precompositional stages and critically examine the written and oral sources used. Of course, it is often easy enough to dismiss such sources as inadequate and thus call into question the creative process as a whole. The vaguer the sources are, the more seemingly obvious the tendency to construct the Other as a myth in the tradition of musical exoticism, possibly with reference to archaic traditions that are treated ahistorically, without criticism of their interpretive tradition. This might involve a tendency to refer to conceptual aesthetic or philosophical positions rather than musical idioms or practices. John Cage's reception of Zen Buddhism on the basis of Daisetz T. Suzuki's writings and lectures and other sources ${ }^{420}$ was criticized even by an otherwise well-meaning interpreter like Umberto Eco as a "mythological surrogate for a critical consciousness." ${ }^{\text {"21 }}$ In fact, the ambivalent institutional and political context of Zen in Japan was largely ignored both by its intercultural mediators and the American artists of the 1930s to '50s. "The irrationality and spontaneity" of Zen was "highlighted and played off against the prevailing conventions and rationalist forms of knowledge of industrial society." ${ }^{342}$ In a nuanced form, a similar criticism could also be made of the intensifying reception of the philosophy of the Kyoto school (the same circle from which Suzuki's interpretation of Zen emerged) in the early 2000 s by Helmut Lachenmann, Hans Zen-

418 A comprehensive analysis of Stockhausen's universalism and Kagel's ironic reaction, along with detailed analyses of Telemusik and Exotica, is provided in Utz, Neue Musik und Interkulturalität, 136-171 and 172-186 respectively.

419 "Intermodulation" was the term Stockhausen devised for superimposing audio material from diverse musical cultures in Telemusik and Hymnen. See Hünermann, "Transkription und Intermodulation."

420 See Patterson, "Cage and Asia" and Utz, Neue Musik und Interkulturalität, 71-116.

421 Eco, Das offene Kunstwerk, 236 ("mythologisches Surrogat für ein kritisches Bewusstsein").

422 Baier, "Offenes Kunstwerk versus Kunst der Offenheit," 48 ("Das Irrationale und Spontane wird hervorgekehrt und gegen die herrschenden Konventionen sowie die rationalistischen Wissensformen der Industriegesellschaft ausgespielt.") See also Pepper, "John Cage und der Jargon des Nichts" and Pepper, "From the 'Aesthetics of Indifference' to 'Negative Aesthetics." 
der, and Toshio Hosokawa. In this context, nationalist and culturally essentialist aspects, especially in Keiji Nishitani's thinking, have hardly been discussed up to now $\left(\rightarrow\right.$ IV.2). ${ }^{423}$

Nonetheless, John Cage succeeded, through his undoubtedly selective reception of Zen and other Asian philosophies, in an eminently important music-historical emancipation from a dominant European aesthetic discourse, and in a comprehensive liberation of aural perception whose effect continues to this day. We can characterize his appropriation of Asian sources according to three factors: pragmatism (direct applicability, for example, by adopting only the "technical" tools but not the interpretive tradition of the ancient Chinese oracle book Yijing); radicality (heightening the received fragments within the scope of certain "intra-cultural" aesthetic objectives); and utopianism (for example, in the generalization of certain aspects of Zen and of Huayan Buddhism to construct an "infinite" continuum of sound and silence). ${ }^{424}$

A very important facet becomes clear: intercultural composition always serves to establish an intracultural position that clearly determines the handling and interpretation of the received elements. Criticism in the context of postcolonial perspectives on a falsely mythologizing or post-exotic projection of "sacral desires" ${ }^{\prime 425}$ is certainly necessary. On the contrary, as already explained $(\rightarrow \mathrm{I} .3$ ), a distinction must be made between unreflexively mythologizing reception processes and a creative examination of myth, ritual, and spiritual experience as an open meeting space of cultures.

\section{Pragmatism, Interpenetration, Difference}

The example of Cage shows that mythologizing and pragmatic components of intercultural reception cannot always be clearly separated. The postcolonial critique aims at both components anyway: the mythologizing simplification of complex cultural systems as well as the instrumentalization of the Other for one's own purposes. A prototypical example of the latter tendency might be found in Steve Reich's quotes from the early 1970s:

Non-Western music in general and African, Indonesian, and Indian music in particular will serve as new structural models for Western musicians. Not as new models of sound. (That's the old exoticism trip.) $)^{426}$

[O]ne can create a music with one's own sound that is constructed in the light of one's knowledge of non-Western structure. [...] One can study the rhythmic structure of non-Western music [...], while continuing to use the instruments, scales, and any other sound one has grown up with. ${ }^{427}$

423 Lachenmann's reception of the Kyoto school is discussed in detail by Hiekel, "Interkulturalität als existentielle Erfahrung," 77-82. A central source for Lachenmann (like Zender) in dealing with East Asian philosophy is Elberfeld, Phänomenologie der Zeit im Buddhismus. For work on the historical role of Zen and the Kyoto school in Japanese wartime nationalism, see Heisig and Maraldo, Rude Awakenings. A nuanced critical view of the frequently used sources on "Japanese aesthetics" from the perspective of cultural and political nationalism would, on the whole, be a necessary supplement to the discussion; this concerns, for example, a critique of writings such as Kikkawa, Vom Charakter der japanischen Musik, Tanizaki, In Praise ofShadows, or Ōhashi, Kire: Das "Schöne" in Japan. As a counterpoint to essentialist Japanese aesthetics, see Maruyama, Studies in Intellectual History of Tokugawa Japan.

424 See further Utz, Neue Musik und Interkulturalität, 112-116.

425 See Wilson, "Sakrale Sehnsüchte."

426 Reich, "Some Optimistic Predictions (1970) About the Future of Music," 51.

427 Reich, "Postscript to a Brief Study of Balinese and African Music," 71. 
Reich's separation of his own elements (sound, scales, instruments) and foreign ones (rhythm) may certainly appear categorical and simplistic, and his appropriation of non-Western idioms utilitarian - an aspect that may (among others) initially have contributed to the difficult reception his music encountered in Europe during the early 1970s. ${ }^{428}$ At the same time, the change of perspective accomplished through Reich's ethnological-critical and active learning engagement with West African drum music, Balinese Gamelan, and Jewish cantillation, is remarkable. ${ }^{429}$ The reception of North Indian art music in key works by La Monte Young, Terry Riley, and Philip Glass was equally based on comparatively detailed ethnological and practical knowledge, albeit with entirely different compositional and stylistic consequences. ${ }^{430}$

In Europe, in contrast to Reich's sober pragmatism, intercultural reception processes are usually integrated into comprehensive aesthetic conceptions, which can be conceived in the tradition of modernism as "heteroglossia,", process, a reception model of interpenetration is developed, in part even with explicit reference to Goethe's concept of a "world literature. ${ }^{1432}$ The focus of composers tending toward this model is different, of course: György Ligeti's compositional method is in many ways akin to Reich's pragmatic approach. But his conceptual thinking is far more pluralistic: the reception of African genres - including the ongo [horn] ensembles of the Central African Banda Linda, songs of the Aka pygmies, and the amadinda [xylophone] music of Uganda $(\rightarrow$ V.2) - forms only one link in an eclectic chain of associations between chaos theory, fractal geometry, Romantic piano music, Debussy, late fourteenth-century ars subtilior, and much more besides. Similarly, Hans Zender's pluralistic aesthetic cosmos, which like Reich's or Ligeti's includes the close reading of philological forms of intercultural reception, is associative and transformative, albeit focused on other areas:

Cultures are emerging as competing systems and the laws of aesthetic consciousness are intimately bound up with the different semiotic systems of the respective cultures. As world cultures began to take note of one an other, the idea of the absolute truth of their own semiotic systems was undermined. In the age of the interpenetration of all cultures that we are entering, these ideas disappear more and more. ${ }^{433}$

428 The well-known controversy between Reich and Clytus Cottwald in 1975, documented in the journal Melos and comprehensively interpreted by Beate Kutschke against the background of different traditions of thought in Europe and the USA, is one example. See Kutschke, Neue Linke - neue Musik, 260-287, and Kleinrath, "Minimalismus/Minimal Music."

429 With regard to Reich's reception of African music, see, among others, Reich's essays "Cahu-A Dance of the Ewe Tribe in Chana," "Drumming," "Postscript to a Brief Study of Balinese and African Music," and "Non-Western Music and the Western Composer." A thorough source-based discussion of Reich's reception of African music is provided in Klein, Alexander Zemlinsky-Steve Reich: Alternative Moderne(n), 107-153. See also Scherzinger, "Cyörgy Ligeti and the Aka Pygmies Project."

430 Welch, "Meeting Along the Edge."

431 Bakhtin, The Dialogic Imagination.

432 Zender "Weltmusik," 234-235.

433 Zender, "Über das Hören," 179 ("Kulturen bilden sich als konkurrierende Systeme aus, und die Gesetzmäßigkeiten im ästhetischen Bewusstsein sind aufs engste verbunden mit den anderen Zeichensystemen der jeweiligen Kultur. In dem Maße, als die Weltkulturen begannen, voneinander Notiz zu nehmen, wurde die Vorstellung einer absoluten Wahrheit des jeweils eigenen Zeichensystems untergraben; im Zeitalter der Durchdringung aller Kulturen, in das wir gerade eintreten, verschwinden diese Vorstellungen mehr und mehr.") 
Example 2.14: Hans Zender, ChiefJoseph, Act I, Scene $2 b$

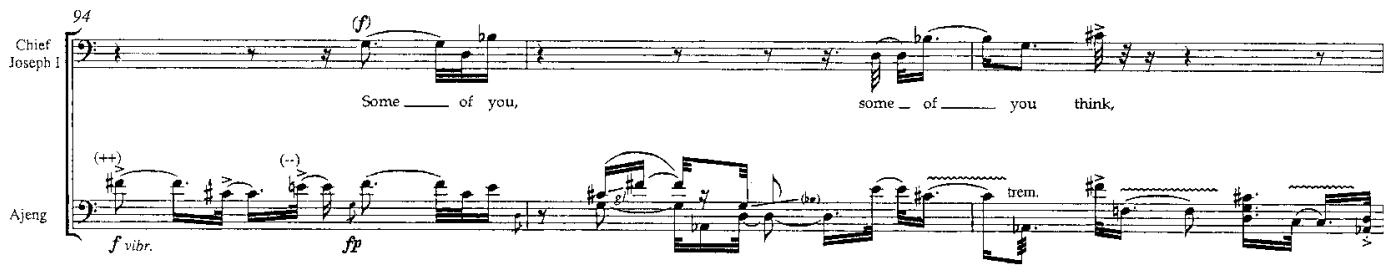

Copyright $(2004$ by Breitkopf \& Härtel, Wiesbaden

At the heart of Zender's music since the late 1990s (with first attempts in this direction since the 1970s) is a 72-tone system of a "harmony of opposing tensions" (gegenstrebige Harmonik) based on archaic Chinese and Pythagorean tuning theories. This falls firmly within the tradition of speculative music theory. ${ }^{434}$ In addition, one must mention his engagement with the Buddhist concept of time since the early 1970s, primarily with reference to Japanese philosophy and the tradition of $n \bar{o}$ theater, which, along with the pitch system, is bound up in inexorably oscillating intercultural references. ${ }^{435}$ Both dimensions, alternative concepts of tunings and of time, are explored extensively in Zender's last music theater work Chief Joseph (2003), which deals explicitly with the tension in (colonial and postcolonial) intercultural encounters. ${ }^{436}$

In ChiefJoseph, as well as in Helmut Lachenmann's Das Mädchen mit den Schwefelhölzern (The Little Match Girl, 1990-96, $\rightarrow$ IV.2), an East Asian instrument assumes the function of the extraterritorial, the incommensurate. In Lachenmann's "music with images" this is the Japanese shō in the penultimate scene (no. 23). Its extraterritorial character is manifest above all in the fact that, following the example of the traditional shō instrumental technique of the tōgaku repertoire of Japanese court music, it forms a continuum of interlocking chords or Lachenmannian "cadential sounds." These contrast strongly with the non-linear "sound structure" of previous scenes, marking the shō's sonic exclusivity through its cultural alterity. In Zender's Chief Joseph, the struck Korean zither ajaeng accompanies the lamenting chants of the main character (Ex. 2.14). Here, no reference is made to the accompaniment of shamanistic dances or folk songs by the sanjo ajaeng in the Korean context. Rather, as with Lachenmann, the instrument essentially serves as a "symbol of the Other" that consistently resists integration. ${ }^{437}$ If, on the one hand, a conception becomes visible here that attempts to emphasize the difference between music traditions, affording a respectful space for the aural effects of the Asian instruments, on the other hand, it is precisely this distillation of aura that can be seen as a continuity in the tradition of mythologizing forms of cultural representation.

434 See Zender, "Gegenstrebige Harmonik." A number of studies have already been published on Zender's harmonic system. See, among others, Hasegawa, "Cegenstrebige Harmonik' in the Music of Hans Zender" and Gerhardt "'Gegenstrebige Harmonik."

435 See, among others, Hiekel, "Erstaunen und Widersprüchlichkeit," Gruhn, "Das andere Denken der Ohren," Utz, Neue Musik und Interkulturalität, 190-195, Revers, "Hans Zender: Furin no kyo," and Hiekel, "Vielstimmig in sich."

436 See Zender, "Das Eigene und das Fremde" and Schmidt, "Wegkarte für Orpheus?"

437 Personal communication with Hans Zender, Berlin, 24 March 2006. 


\section{Case Study: Hans Zender's Fūrin no kyō (1989)}

It is worth taking a closer look at a key work by Zender at this point. It seems characteristic of the nuanced, but at its core still culturally essentialist handling of difference among many European composers during the 1980 s and '90s. As with Stockhausen ( $\rightarrow$ II.2), Zender's longstanding and intensive engagement with Asian cultures was triggered by a stay in Japan (in the early 1970s) that called into question a seemingly self-evident primacy of European culture. ${ }^{438}$ Yet Zender by no means retained this culture-pessimistic approach unchanged, but, as outlined above, instead embarked on a pluralistic universalism that cannot be attributed merely to the influence of postmodern philosophies. Zender claimed from the late 1980s on that all sound media, sounds, and the music of all eras could now be considered material for the creation of music. In approaching these sounds, he adopts Cage's principle that every sound should be respected in its individuality and peculiarity. For Zender, however, the musical forms that are transmitted through different cultures are not equivalent and interchangeable objects. Rather they are media that convey fundamentally different, often contradictory, messages. ${ }^{439}$

Zender has most forcefully implemented these ideas in Fürin no kyō for soprano, clarinet, and ensemble (1989). ${ }^{440}$ Possibly the most notable feature of this work is the idea of opposing cultural "codes" in the multilingual arrangement of the underlying text, a poem by the iconoclastic Zen monk Sōjun Ikkyū (1394-1481). This text appears in sections I, II, and IV in the (Sino-)Japanese original, as well as in English and German translations, while the conclud-ing section $\mathrm{V}$ introduces a phonetic hybrid of these three versions and a Chinese version (section III is conceived as an instrumental interlude). Table 2.3 shows the four versions of the text, including the Chinese symbols and transliteration. ${ }^{441}$

438 "The piece [Muji no kyō] is certainly inconceivable without the deep impression of ancient Japanese culture I received on my first trip to Japan. European intellectualism, technology, the hustle and noise of today's existence: all this seemed more questionable than ever." (Zender, "Muji no kyō." "Das Stück [Muji no kyō] ist sicherlich nicht denkbar ohne den tiefen Eindruck, den ich auf meiner ersten Japanreise von der alten japanischen Kultur empfing. Der Intellektualismus Europas, Technologie, die Hektik und Lärmentfaltung des heutigen Daseins: All das erschien mir so fragwürdig wie nie.")

439 See Zender, "Über das Hören" and Zender, "Was kann Musik heute sein?"

440 The following remarks appear alongside my analytical sketch of this work in Utz, Neue Musik und Interkulturalität, 192-195. See also the analyses in Revers, "Hans Zender: Fūrin no kyō" and Hiekel, "Erstaunen und Widersprüchlichkeit," 90-91.

441 The words in bold in the table differ from the spelling in Zender's score, which is indicated in square brackets. While the missing "i"s at the end of the first and third lines are presumably typographical errors (the "i" in "mei" can be found in the autograph score, but not in the typeset score published by Breitkopf \& Härtel; in both scores there is no "i" in "sui"), the reading of "kan" for the work "monk" seems to be a clear mistake (with thanks to Ingrid Fritsch, Cologne, for linguistic information on the pronunciation of the Sino-Japanese text; in some cases a Sino-Japanese character may indeed be pronounced in various ways, but at this point the reading sō is clearly correct). The deviations for the pinyin transliteration in the Chinese version are probably due to Zender's desire to find a way of writing that is as intuitive as possible for Western vocal performers. The spellings $z u$ for zhou and hei for he, however, are rather misleading. Thus the available recordings with Julie Moffat (Durian 1995, Kairos 2001) and Nancy Shade (col legno 1991) have several mistakes in the pronunciation of the Chinese text. The characters reproduced in this table follow the edition of the poem in Ichikawa, Iriya, and Yanagida, Chūsei Zenka no shisō, 306. The title of the poem is only given as Fürin in this edition, and is the first of a pair of poems (the second does not appear in Zender's work). The two poems appear as no. 110 and no. 111 in Ikkyū's famous poetry collection Kyōunshū (Chinese: Kuang Yun Ji, "Crazy Cloud"). While working on Fūrin no kyō, Zender consulted Covell and Yamada, Unraveling Zen's Red Thread. 
Table 2.3: Hans Zender, Fürin no kyō; four versions of the Ikkyū poem Fürin in Japanese, English, German, and Chinese (standardized transliteration: Modified Hepburn and Hanyu Pinyin)

Ikkyū Sōjun 一休宗純

Fürin [no kyō] 風鈴[の響]

jō ji mu kyō dō ji mei

rin yū sei ya fū yū sei

kyō ki rō sō [kan] haku chū sui

ka shu [su] nichi go da san kō
靜時無響動時鳴、

鈴有聲耶風有聲?

驚起老僧白畫睡、

何須日午打三更 ?

in stillness mute in motion sound

is it the bell, is it the wind that has the voice?

the old monk, terrified, wakes up from his day-time nap

what need to sound the midnight watch at noon?

Stille Zeit: Nichtklang. Bewegte Zeit: Schall.

Ist es die Stimme der Glocke - Ist es die Kraft des Windes?

Erschreckt fährt er auf - der alte Mönch aus seinem Mittagsschlaf.

Da! Was ist das? Jetzt zur Mittagszeit die Mitternachtsglocke?

jing shí wú xiăng dòng shí míng

líng yŏu shēng yē fēng yŏu shēng

jīng qĭ lăo sēng bái zhòu $[z u]$ shuì

hé xũ [hei chü] rì wŭ dă sān gēng [keng]
靜時無響動時鳴,

鈴有聲耶風有聲?

驚起老僧白畫睡,

何須日午打三更?

In the fifth section of the work (mm. 182-250) the vocal soloist, as explained above, constantly jumps between four linguistic levels. The sounds of the different languages are associatively linked by means of alliterations and assonances (Ex. 2.15). Here, as in the preceding sections I, II, and IV, each language is assigned its own basic vocal technique: noisy inflections in the Japanese; dramatic, high-contrast vocals in the English; articulated Sprechgesang in the German; and pitched speech glissandi and syllabic extensions in the Chinese. Of course, this setting is deliberately related to traditional vocal and instrumental techniques of the four "cultures" and also corresponds to different temporal models that Zender assigned to the five sections. ${ }^{442}$ For example, the emphasis on the consonants, inclusion of breath sounds, and constant inflection 
of the pitch in the setting of the Japanese texts refer to the vocal delivery techniques of nō theater, ${ }^{443}$ the breathy sound ideal of shakuhachi music, and the vocal quality of the narrative genre gidayu bushi, which may be grasped via the concept of ibushi (oxidation) $(\rightarrow$ V.1). The four language layers in Fürin no kyō should therefore remain clearly distinguishable, even where they follow in close succession. An interpenetration of the four language systems conceived as an approximation and combination of their phonetic differences - but not as its synthesis, merging, or leveling - thus becomes the productive microstructural impulse in the vocal part.

Example 2.15: Hans Zender, Fürin no kyō, mm. 182-193, soprano part (Copyright (c) 2003 by Breitkopf $\mathcal{E}$ Härtel, Wiesbaden) and schematic representation of the language structure of the first stanza

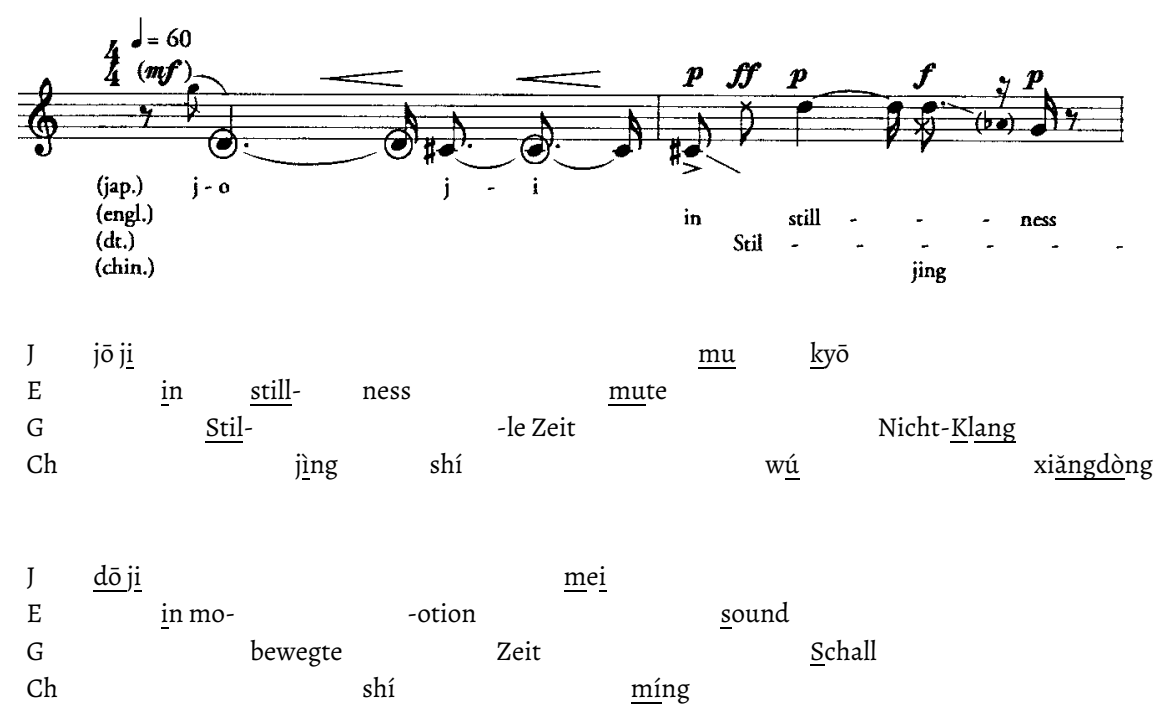

These montages of musical languages, presented largely unaccompanied, become further gesturally interwoven and transformed into simultaneous textures in short instrumental interludes (first in mm. 194-197, Ex. 2.16). In this way, the speech gestures are "translated" into instrumental gestures: the "Japanese" idiom is found in noisy harmonics (violins) and drum sounds; the "English" in "dramatic" figures (e.g., solo clarinet, piano), the "German" in staccato figures (brass); the "Chinese" in glissando-like scales (violoncello, trombone, oboe), so that the hybrid language of the song produces a miniature "song without words."

Zender's clear intention to preserve cultural difference even where a tendency toward impenetrable mixture runs counter to that intention, undoubtedly comes up against conceptual, as well as psychological and perceptual, limits. While, in the vocal part of section V, the dramatic "European" articulation tends to mask the quieter and more subtle "East Asian" articulations, these differences disappear completely in the rather conventional polyphonic structures of the instrumental "reinterpretations." Zender's meticulous approach to cultural difference is certainly a significant step in the history of intercultural composition, but, in the end, remains trapped in a certain schematism of strongly culturally essentialist thought. 


\section{Cooperation and Dialogue}

Among composers as diverse as Giacinto Scelsi, Jean-Claude Eloy, or Heiner Goebbels, we find a different weighting of elements from the previously discussed categories of intercultural composition. Their music contrasts with that discussed above, since non-Western sonic materiality and/or performers had a decisive impact on the compositional results in some of their work, and thus, at least temporarily, these composers allowed for drastic processes of stylistic transformation. ${ }^{44}$ In this context, one must also mention Klaus Huber's engagement with Arab music and music theory, initially politically motivated by the Gulf War of 1990/91. This engagement resulted in the project Die Erde bewegt sich auf den Hörnern eines Stiers [Ochsen] [The Earth Moves on the Horns of a Bull (Ox), 1992-94], an "assemblage" for four Arab and two European musicians and fixed media. In this work, the composer not only put aside his authorial control in favor of elements of traditional improvisation practice, but also invited the European musicians to engage with the Arab modes and melodic formulas (maqāmāt) and rhythmic cycles (auzān). Basically, Huber's reception of Arab scales and rhythms, with the exception of this assemblage, does not seem to establish a strong sonic relationship with Arab music. Huber uses the maqāmāt in his works from the 1990s on almost exclusively as an abstract repository of pitches largely detached from melodic-rhythmic models (these models are essential for the distinction between maqāmāt in Arab musical practice). ${ }^{445}$ Insofar as the origin of the superimposed scales and modes remains largely concealed in the substructure of Huber's music, no maqām "effect" arises in the final score. Of course, this point would need to be discussed separately and possibly examined empirically, especially since there is by no means an ethnomusicological or music-theoretical consensus on the theory and practice of maquamāt. ${ }^{446}$ In any case, consideration should be given to how maqām tones deployed freely in pitch space, as in the first movement of Huber's Miserere Hominibus (2006), ${ }^{447}$ can still be understood as a meaningful reference to Arab music - even when detached from their scalar structure and placed in the context of complex harmony. ${ }^{448}$

444 See Utz, Neue Musikund Interkulturalität, 188-190 (Scelsi), 195-200 (Eloy), Goebbels, Komposition als Inszenierung. Scelsi's intercultural aesthetics have been discussed repeatedly; see, among others, Reish, "The Transformation of Giacinto Scelsi's Musical Style and Aesthetic," 59-114, Baatz, "Resonanz des 'weißen Unbewegten," and Utz, "Klang als Energie in der Musik seit 1900."

445 See Zidarić Györek, "Transformation und Polyphonie in Klaus Hubers Die Seele muss vom Reittiersteigen."

446 See Maraqa, "Auf der Suche nach den Anfängen der 'modernen' arabischen Musiktheorie."

447 See Utz, "Morphologie und Bedeutung der Klänge in Klaus Hubers Miserere Hominibus."

448 In an unpublished 2008 manuscript, the Jordanian composer Saed Haddad takes a decidedly critical position on Huber's reception of Arab music on the basis of his 2005 dissertation "The Abstraction of Arabic Musical Vocabulary, Spiritual and Cultural Values into Contemporary Western Music." A comprehensive and independent presentation of this problem is still pending (and will hopefully form a part of Petra Zidarić Györek's dissertation project at the Graz University of Music and Performing Arts, to be finalized in 2021). Admittedly, Günter Kleinen's contribution "Ausweitung harmonischer Räume durch arabische Tonarten" attempts to take a position independent of the composer's self-interpretation, but an analogical relationship between compositional intention and perception is arguably still ubiquitous in this article. To a large extent, Huber's own positions are referred to and elaborated in the articles Keller, "Impulse aus dem Orient auf Klaus Hubers musikalisches Schaffen" (as well as various previous publications by the same author) and Mahnkopf, "Polykulturalität als Polyphonietypus." By contrast, Knipper, "Tonsysteme im kompositorischen Schaffen von Klaus Huber" offers a far more nuanced discussion of the topic. 
144 Musical Composition in the Context of Globalization

Example 2.16: Hans Zender, Fürin no kyō, mm. 194-196
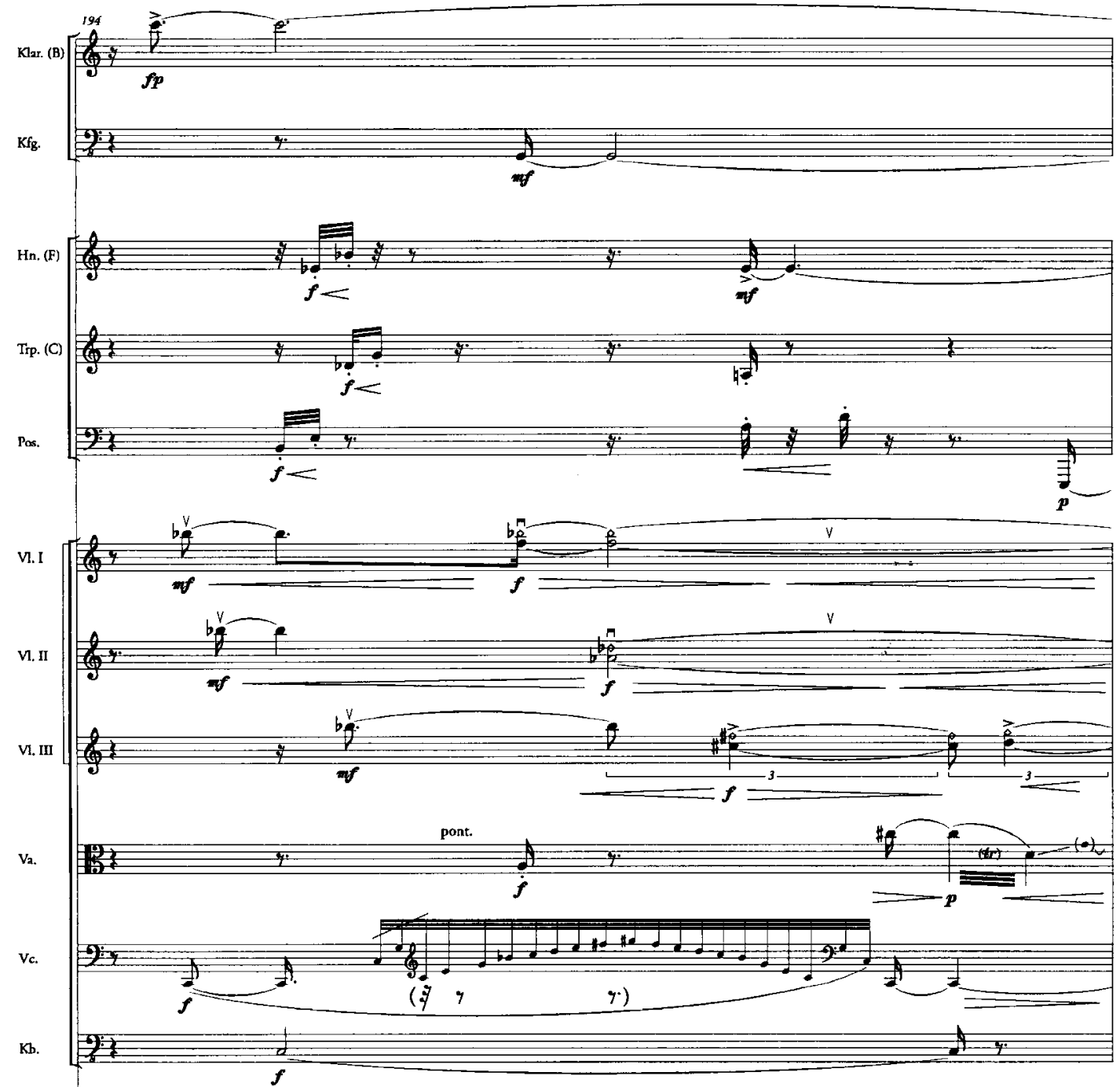

Klav.

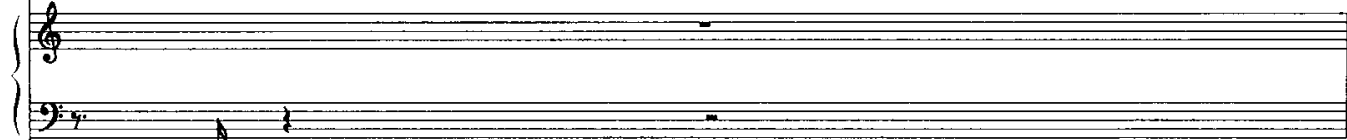

9a

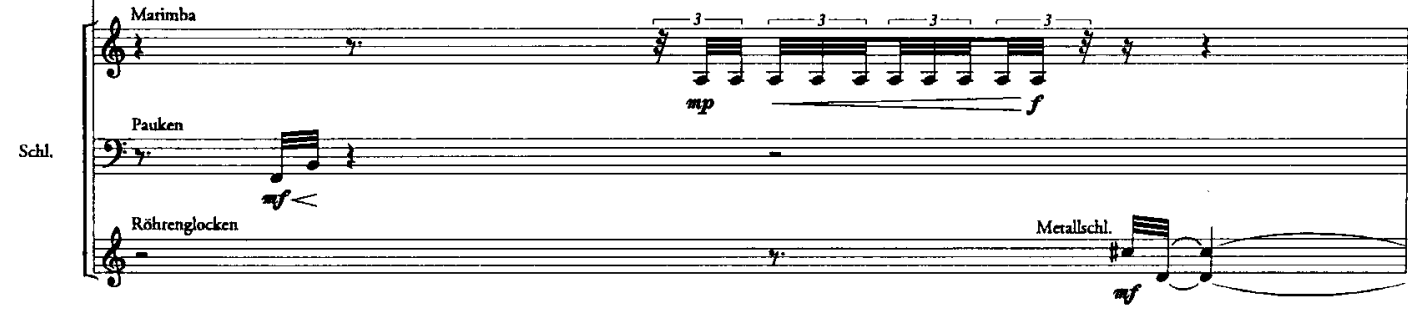

Copyright $\odot 2003$ by Breitkopf \& Härtel, Wiesbaden 

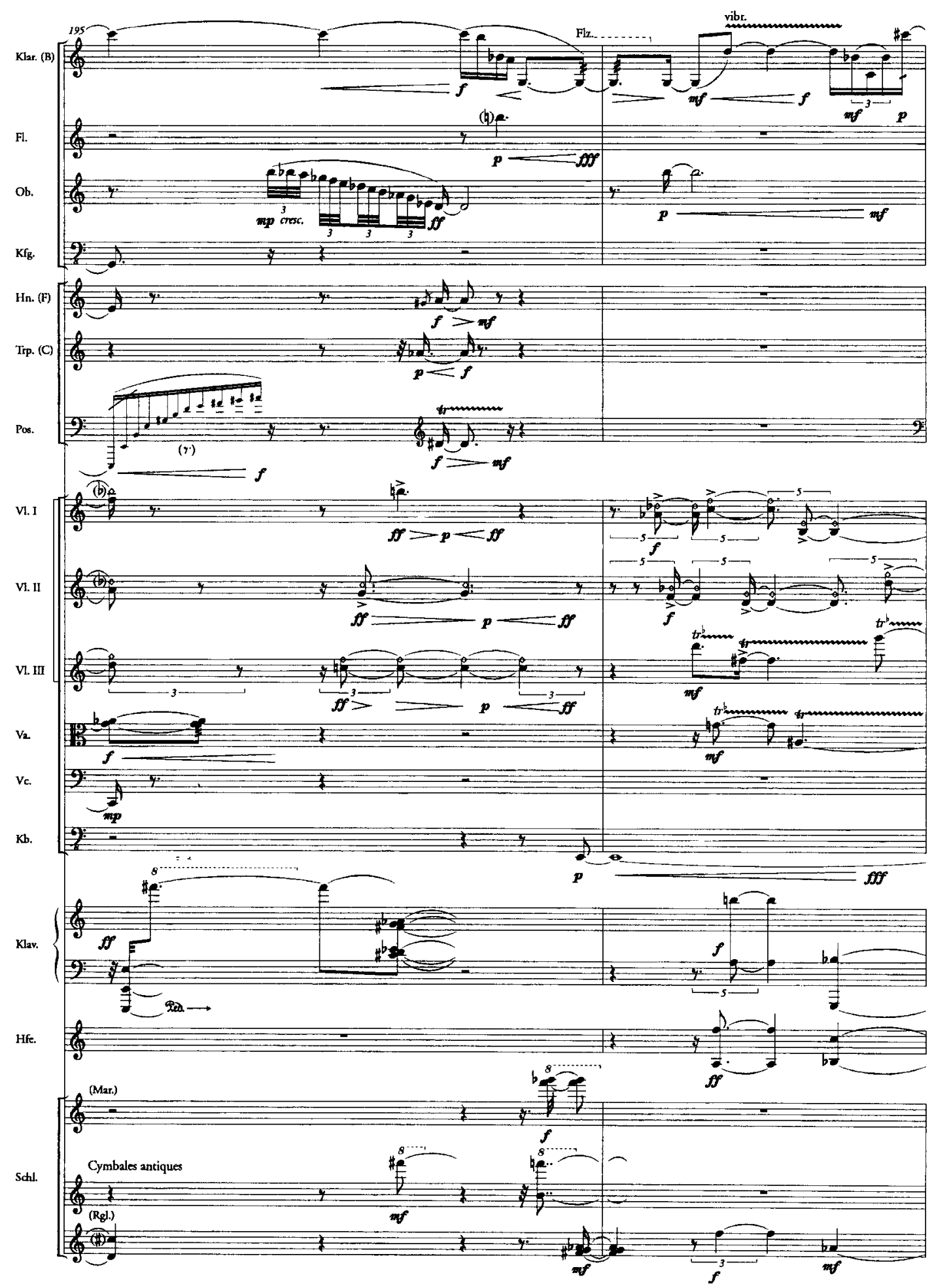
We can certainly consider Die Erde bewegt sich auf den Hörnern eines Stiers a precursor of more recent tendencies, in which representatives of Western and non-Western instrumental and/or vocal practitioners and composers enter into direct dialogue. In East Asia, there have been strong initiatives from traditional instrumentalists to work with composers since the 1980 s (in Japan, such tendencies date back to the gendai hoggaku [Traditional Japanese Music of the Present] movement of the 1950 s and 1960 s and earlier periods $\rightarrow$ II.4, III.1). For example, the shō soloist Mayumi Miyata encouraged numerous composers to write new works for her instrument $(\rightarrow$ IV.1). Recent initiatives are so numerous that only the most important can be cursorily named here: Joël Bons's Atlas Ensemble (since 2002), Sandeep Bhagwati's "contemporary Xchange" and "Rasalîla" projects with Ensemble Modern and musicians or theorists of traditional Indian music (2001-06), and more recently Bhagwati's ensemble ckstьaktə (featuring musicians from China, Germany, India, Korea, Bulgaria, Syria, and the USA), Dieter Mack's projects with Indonesian composers and gamelan ensembles, "Crossings," initiated by AsianCultureLink with Klangforum Wien and China (Chai) Found Music Workshop Taipei (2003-04, $\rightarrow$ III.6), commissions by the Berlin Isang Yun Society for ensembles mixing Korean and Western instruments, Istanbul's Hezarfen Ensemble, or the Berlin Asian Art Ensemble, directed by the composer-percussionist Il-Ryun Chung (since 2007/09). ${ }^{449}$ These initiatives seek dialogic forms of musical interculturality - frequently facing common practical and financial obstacles - that encourage mutual learning and study of musical practices and theories. In this way they bring together the critical awareness and self-reflexivity of art music traditions in and outside Europe, the potential for processual collaboration, and precise compositional thinking. ${ }^{450}$

The paradigms of intercultural reception discussed here offer a chance - in favorable conditions - to exist alongside one another without premature evaluation and, at the same time, to be exposed to a discourse that allows for new forms of "competence" among all participants. In this way, the traditional dominance of the composer's role can both be circumvented and revitalized. Like all substantive forms of dialogue, this process requires one thing above all else: an open way of listening that takes into account our own assumptions and prejudices; a listening that always leaves open the possibility to revise our understanding of contexts through new experiences and insights.

449 In 2017, the Berlin festival and conference Turbulences. New Roots for New Music brought together a selected number of ensembles with cross-cultural instrumentation including the Omnibus Ensemble Tashkent (https:// turbulenzen.wordpress.com).

450 The potential and the difficulties of such problems are critically and practically reflected in Bhagwati, "Meistern, Warten, Vergessen, Finden" and Utz, "Interkulturalität in der neuen Musik." 


\section{Approaching the Chinese Mouth Organ sheng}

I will now outline some of the results of such collaborations, using new works for the Chinese mouth organ sheng as case studies. Because of their unusual and multi-faceted sound and their archaic-mythological connotations, as well as the initiatives of virtuoso performers, a compositional examination of the East Asian mouth organs sheng $(\rightarrow$ VI.I), shō $\rightarrow$ IV, VI.2), and saengwang ( $\rightarrow$ VI.2) has taken place on a relatively broad scale over the past four decades. The activities of the Shanghai-trained virtuoso Wu Wei (b. 1970), who has lived in Berlin since 1995, have played a crucial role in the compositional exploration of the sheng by Western composers. Wu, in addition to his work with composed scores, regularly participates in (semi-) improvisational contexts, including performances with the zheng player Xu Fengxia ( $\rightarrow$ III.5), the Berlin-based ensemble ekstьaktə, and the Elision Ensemble, and thus opened up the sheng to entirely new possibilities that go far beyond its roles in traditional music. The sheng is one of the oldest Chinese instruments and dates back to the Shang Dynasty (1766-1122 BCE) $(\rightarrow$ IV.1). Throughout Chinese history, the sheng has developed a wide variety of forms and constructions, including chromatically tuned instruments, though the use of these was presumably restricted to Confucian ritual music. ${ }^{451}$ Traditional instruments are used today in rural forms of ceremonial music, in kunqu opera, and sizhu (silk and bamboo) ensembles ( $\rightarrow$ III.1, III.3). These instruments resemble the Japanese shō insofar as they are largely tuned to diatonic scales and not all of the usually 17 bamboo pipes are equipped with reeds (some pipes remain "silent" - usually only 14, 13, or fewer pipes sound). As in other cases, sheng instruments, their organology, and their repertoire underwent significant changes in the course of modernization in the twentieth century $(\rightarrow$ III.1). Several modern varieties of the instruments were developed, among them the fully chromatic sheng with 36 or 37 pipes, partly extended by means of metal attachments for dynamic reinforcement. The modern sheng is connected not least with a heavily Westernized repertoire of "conservatory style" ( $\rightarrow$ III.1), in which a highly virtuosic soloistic playing meets a simplistic appropriation of conventional Western major-minor harmonies.

Just as the largely "traditional" architecture of the sho stimulated the compositional imagination through its limitations, the extended possibilities of the modern sheng were heightened to the utmost complexity (see below as well as VI.1). In contrast to these radicalized attempts to "modernize" the instrument, a form of simplicity associated with the archaic was sought by the Swiss composer Heinz Reber (1952-2007) in his Music for Sheng (2003-04) for Chinese and Western instruments. This work was conceived with the sheng soloist Huang Lung-Yi from Taipei, who in this piece plays on a traditional 17-pipe instrument, acting as the central figure and a conductor of sorts in the ensemble. During a lengthy collaboration with Huang, Reber notated traditional chord progressions (presumably from the accompaniment of Confucian shrine music, Jikong dianli, which in Taiwan is performed only once a year). In his score, Reber carefully extended the traditional chords and allowed them to "fray out" in ensemble textures, where they mingle with a ubiquitous timpani tremolo. The piece ends with a juxtaposition of all individual layers presented during the approximately 13 preceding minutes: the timpani roll, a respiratory flow of constantly animated stacked fifths in the leading sheng, repetitions of simple patterns of the four strings, improvisational, jazz-phrased piano gestures, and freely chosen quotations of traditional playing styles of the Chinese two-stringed knee fiddle (erhu) all sound simultaneously. Only the points of entrance and exit of the parts are notated, with no exact synchronization indicated. This montage-like intensification lasts a little less than two 
Example 2.17: Jorge Sánchez-Chiong, Teatro Shanghai-Bühnenmusik, second movement:

Descarga for sheng and Chinese ensemble, $\mathrm{mm}$. 911-913

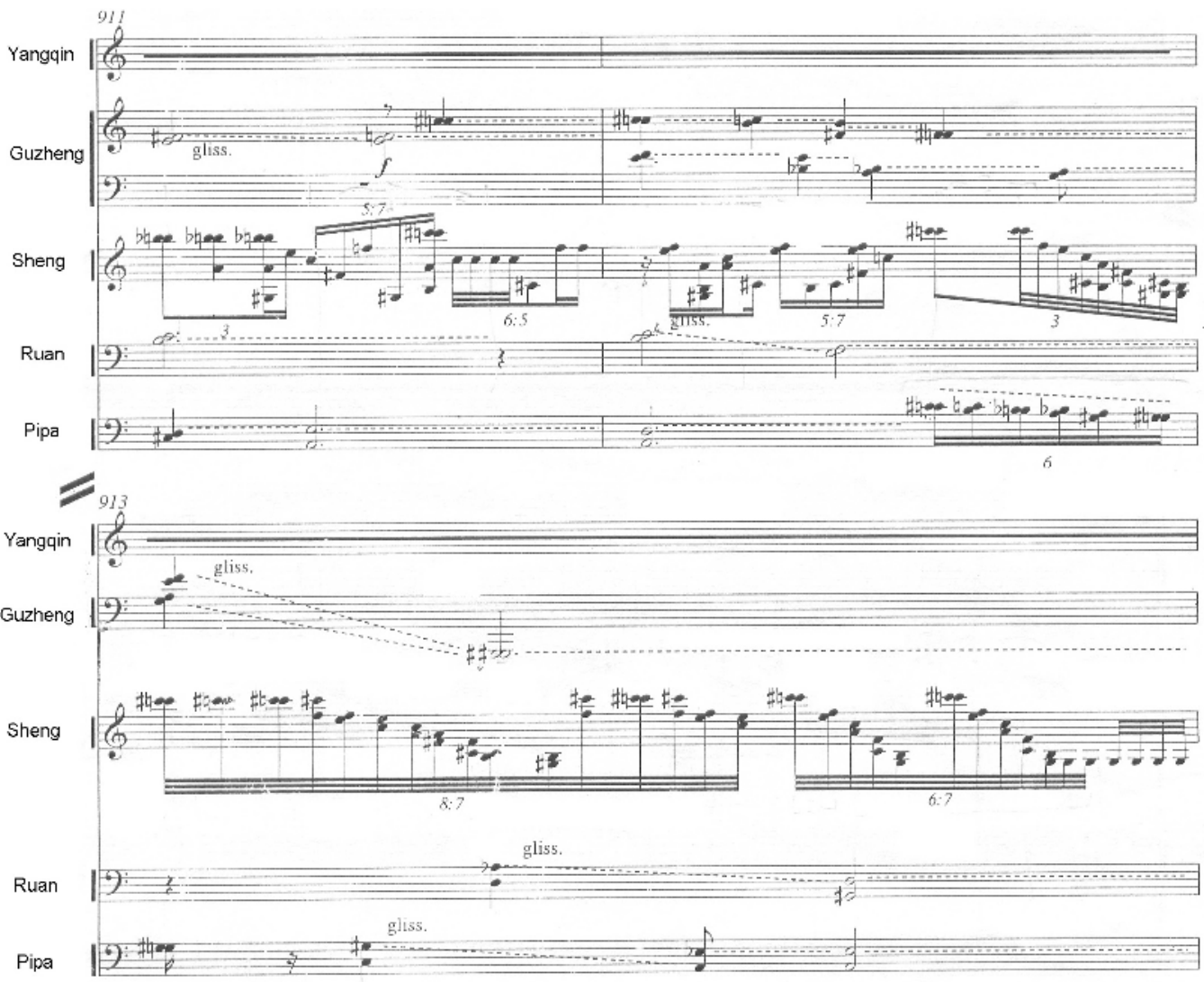

Copyright $\odot 2000$ by Jorge Sánchez-Chiong, Vienna

minutes before the sheng and, finally, only the timpani remain. By this setting, Reber tried to provide space for all the instruments in which they can "interpenetrate unimpededly." The abandonment of a clearly stated compositional structure in the Buddhist-inspired tradition seeks a Cage-like "immediacy of the now. Someone thinks, but he does not think. Someone sings, but he does not sing a melody. Someone is playing and his playing is based on nothing., ${ }^{2452}$

Surely one of most virtuoso sheng parts to this day offers the utmost contrast to Reber's approach: Teatro Shanghai - Bühnenmusik (2000) for seven Chinese instruments and percussion, written by the Vienna-based composer Jorge Sánchez-Chiong (b. 1969), born in Venezuela to a Cuban-Chinese family. This part was also realized by Huang Lung-Yi, now on a modernized, 36-pipe instrument. The second movement, Descarga für sheng und chinesisches Ensemble, is derived from the energetic rhythms of the Cuban improvisatory genre descarga (discharge) and places the highest of technical demands on all instruments involved. Sánchez-Chiong's goal aims beyond a simple transfer of a Cuban model to Chinese instruments or tracing of

452 Reber, "Music for Sheng" ("die Unmittelbarkeit des Jetzt. Jemand denkt, aber er denkt keine Gedanken. Jemand singt, aber er singt keine Melodie. Jemand spielt und sein Spiel ist auf Nichts bezogen.") 
autobiographical hybridity. The composer instead intends to create a surreal atmosphere, inspired by the character of a theater director intoxicated by drugs as described in the novel $D e$ donde son los cantantes? (Where do the singers come from?) by the Cuban author Severo Sarduy (1937-1989): "We do not hear the music played by the instrumentalists, but what has already been digested by a 'subjective ear': a distorted music, as perceived by the director under the influence of drugs; his music, his own Descarga. An alienation that enters a new musical character and takes on a life of its own."453

After a dense tutti of the other six instruments of the Silk-and-Bamboo ensemble (erhu, yangqin, zheng, ruan, pipa, and dizi) driven by irregular beats and accents, the sheng first establishes a ten-note chord, which is enhanced by various vibrato techniques in a "very nervous" manner leading to a first culmination. Following a heterophonic passage without exact synchronization, the concluding section is filled with virtuoso gestures in highly complex rhythms (Ex. 2.17) that increasingly cover and "neutralize" the energetic pitch pulsations of the other instruments.

Sánchez-Chiong certainly does little to evoke an atmosphere of authenticity or archaic mythology. It is obvious in many cases that those composers who have experienced merging, hybridity, and anti-purism as a daily reality of life rebel against any thought of cultural "authenticity" in a most pronounced manner. Among them is the Indian-born Sandeep Bhagwati (b. 1963), who was educated and trained in Germany and now teaches in Canada. He developed pioneering concepts of intercultural composition, especially in the area of tension between Indian vocal and instrumental practice. ${ }^{454}$ In his duo Illusies van harder en zacht (Illusions of Noise and Silence, 2003) for viola and sheng after a poem by Cees Nooteboom, dialogues of exciting rhythmic intensity oscillate between quasi-improvisational gestures and moments of sudden synchronization (Ex. 2.18). ${ }^{455}$ Here too, however, the boundaries of "established" playing technique are deliberately exceeded time and again, albeit not to the same extent as by Sánchez-Chiong.

An even increased density and complexity, compared to Sánchez-Chiong, is designed in Simeon Pironkoff's (b. 1966) duo Fall/Wende (2005-06) for the organologically related instruments sheng and accordion $(\rightarrow$ IV.1). In this work, the mythological associations that both instruments carry are deliberately "deconstructed" by developing a model of permanent transition - perhaps in the sense of Mathias Spahlinger's well-known orchestral work passage/ paysage (2001). The traditionalist contemplative model of the sheng is situated in areas of "limited" predictability, during which the two instruments approach each other in several cycles before repelling each other. As Example 2.19, from the beginning of the first movement (top), demonstrates, it is clear how minutely conceived the sonic transitions are, ${ }^{456}$ while the excerpt from the third movement (bottom) indicates a moment of maximum approximation in which, however, the instruments seem to be permanently "shifted" against each other. The quarter-

453 Sánchez-Chiong, "Teatro Shanghai - Bühnenmusik." ("Wir hören nicht die vom Instrumentalisten gespielte Musik, sondern was bereits durch ein 'subjektives Ohr' verdaut wurde: Eine verzerrte Musik, so wie sie vom Direktor unter Drogenwirkung wahrgenommen wird; seine Musik, seine eigene Descarga. Eine Verfremdung, die sich einem neuen Duktus einfügt und verselbständigt.")

454 See Bhagwati's essays "Meistern, Warten, Vergessen, Finden," "Sein Zuhause komponieren," and "Imagining the Other's Voice."

455 Bhagwati composed further works with Chinese instruments, including Wörterbuch der Winde (2002) for Chinese-Western ensemble and two conductors, further versions of Illusies van harder en zacht including a quartet for sheng, zheng, viola, and cello (2004-06) as well as Traces and Shadows for sheng solo (2006).

456 In both instruments, the decay phases are indicated in a tablature-like notation. 
Example 2.18: Sandeep Bhagwati, Illusies van harder en zacht for viola and sheng, I, mm. 13-23
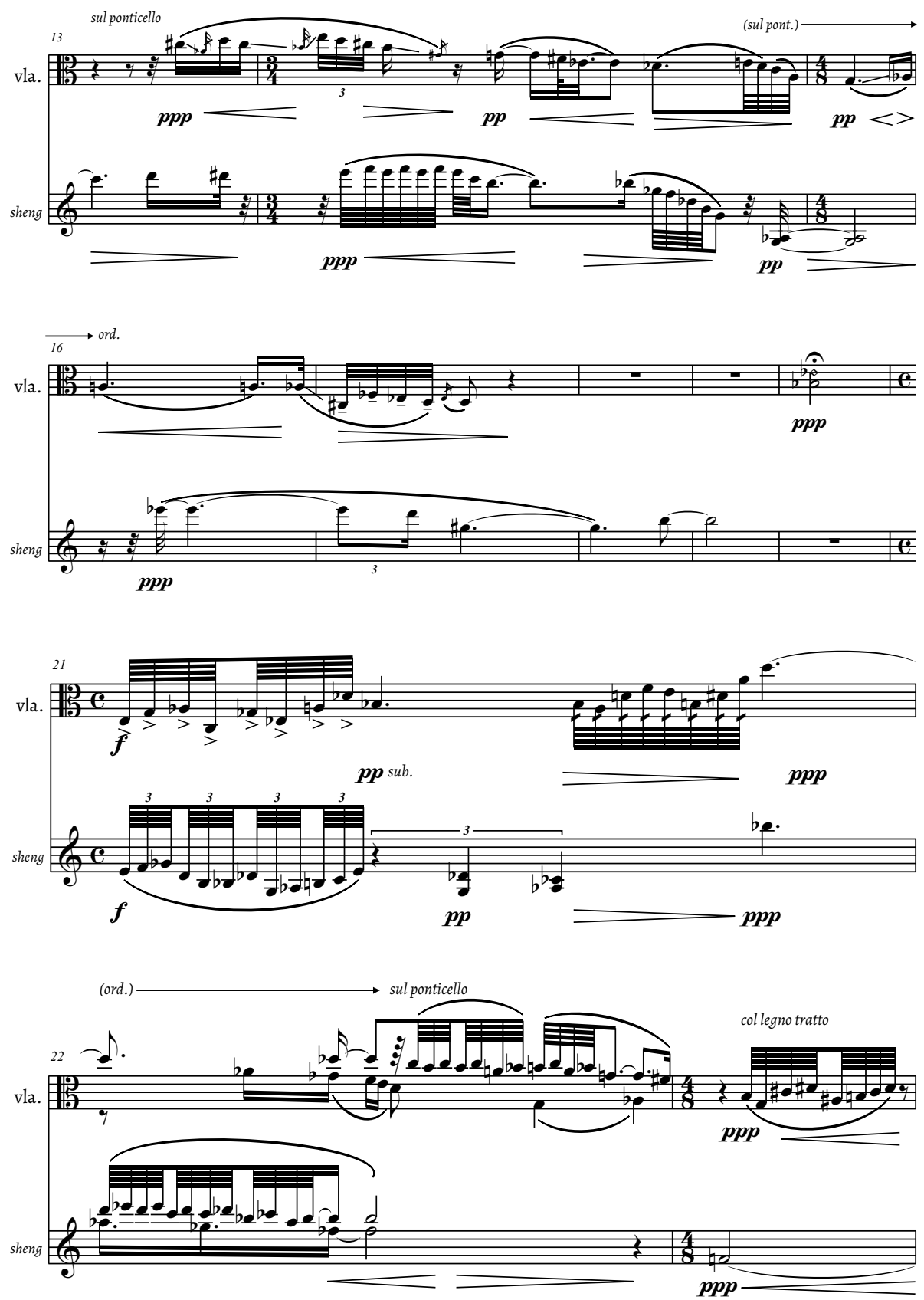
Example 2.19: Simeon Pironkoff, Fall/Wende for sheng and accordion, I, mm. 1-5; III, mm. 40-42
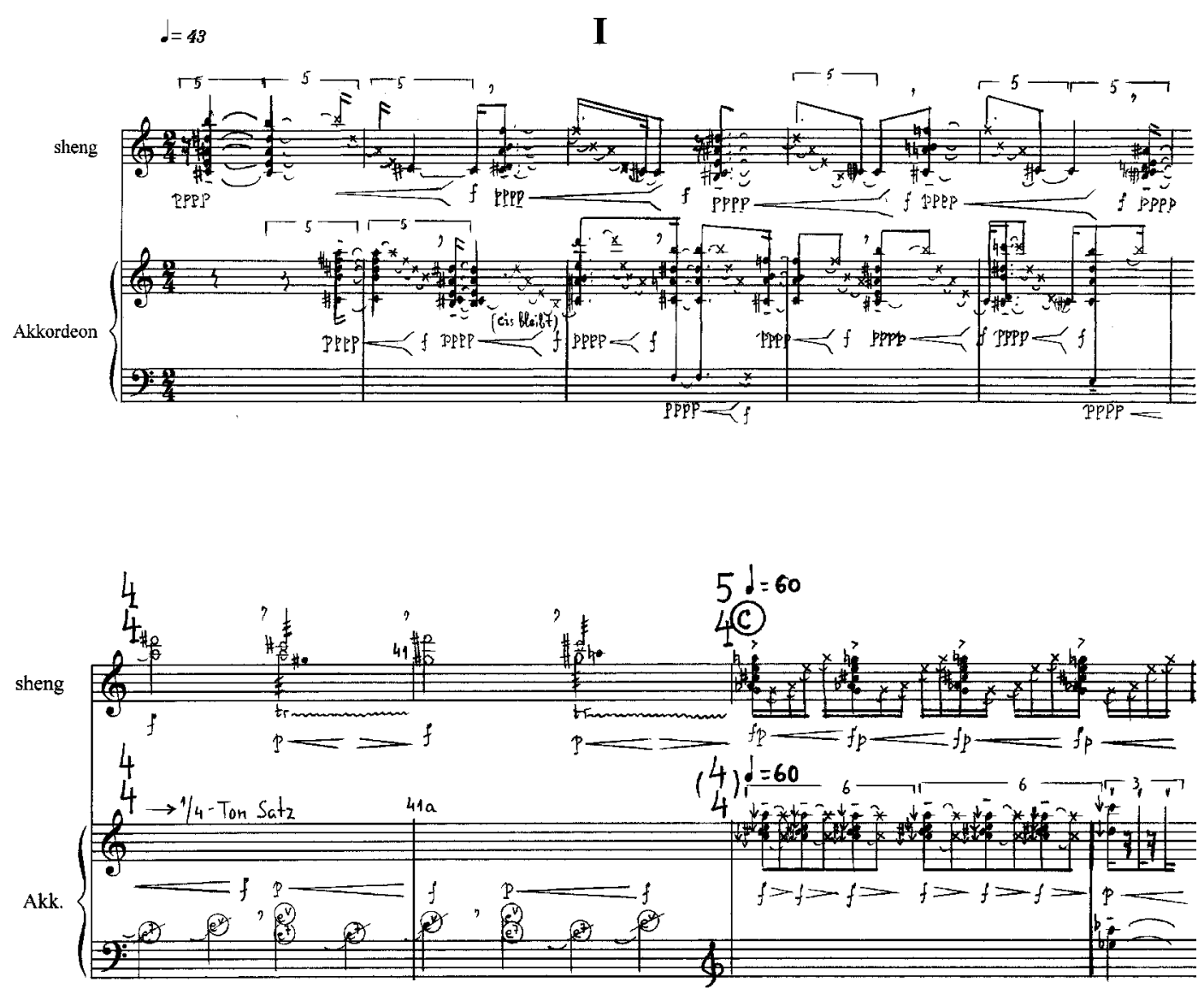

(D)

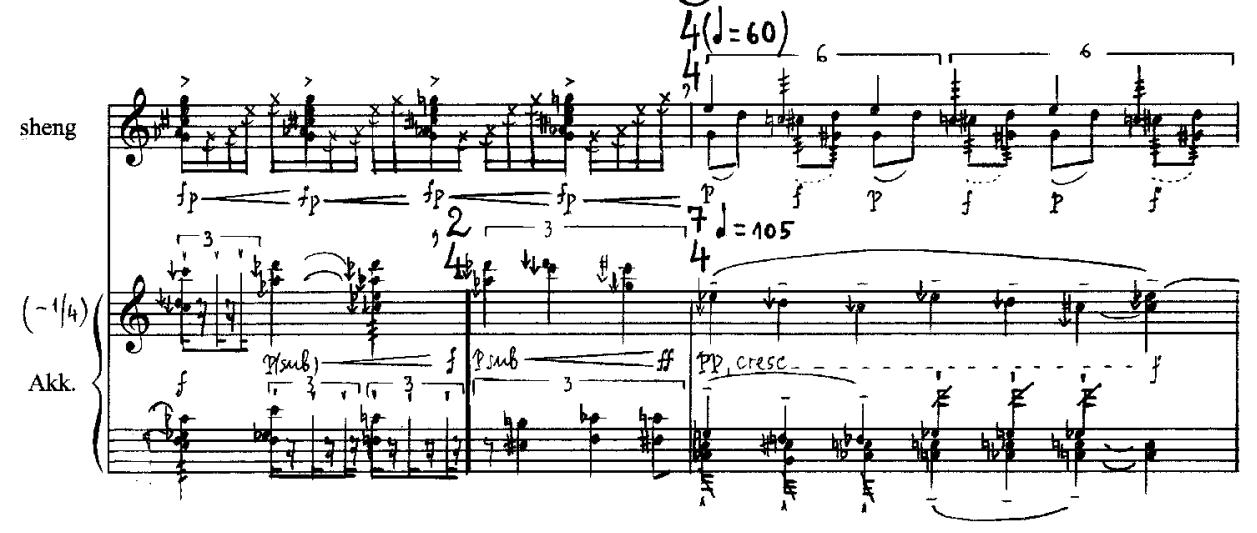

Copyright (c) 2006 by Simeon Pironkoff, Vienna 
Example 2.20: Wolfgang Suppan, Studie II for sheng and live-electronics, section I
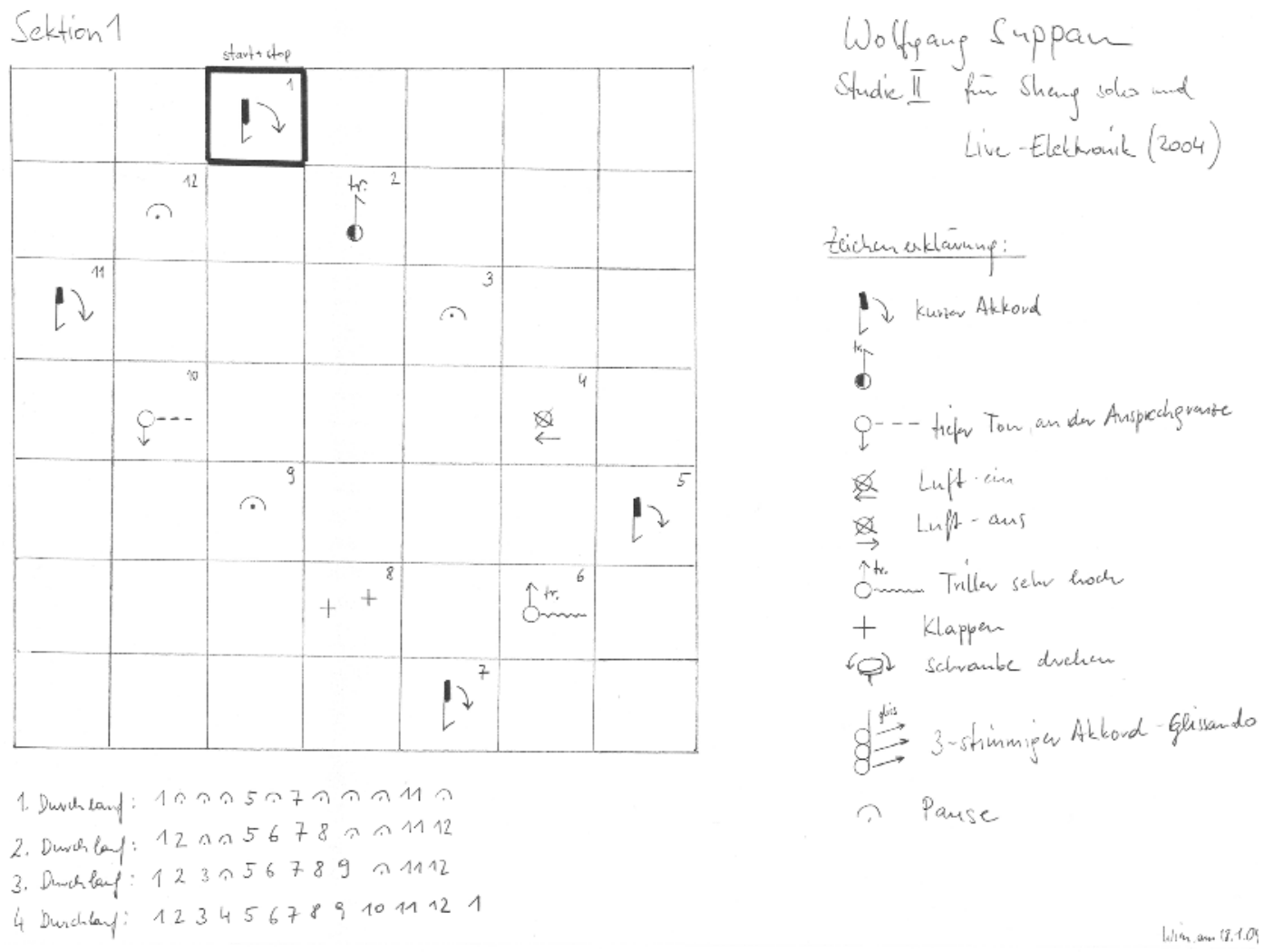

Copyright $\odot 2004$ by Wolfgang Suppan, Vienna

tone tuning of the wrest plank of the accordion used here (developed by the soloist, Krassimir Sterev) contributes to establishing a fundamental "alterity" between the two instruments.

Wolfgang Suppan's (b. 1966) more cautious and delicate approach achieves, of course, no less startling sounding results in his Studie II (2004) for sheng and live electronics (controlled by the software SuperCollider). In close collaboration with Wu Wei, Suppan developed a catalogue of short sound impulses with and without pitch bends. These include advanced techniques of haptic exploration of the instrument and its construction (turning screws, blowing air over the pipes) or techniques that are characteristic of Wu Wei's playing style, such as polyphonic chord glissandos. During the rehearsal process, Wu Wei experimented with the highly responsive comb filter effect provided by the live electronics, for example by continuously varying the distance from the microphone. These experiments eventually culminated in a threephase formal process that gradually turns the initially isolated sound impulses into a continuous sound stream before returning to impulses. In the first section, the performer reads a semi-graphic score four times (Ex. 2.20), with more sound events made audible each time until all twelve sound events are performed in succession. The third section reverses this process so that the sounds are increasingly reduced to noisy impulses and "clicks" while previously, in the 
second section, the continuity achieved at the end of the first section is sustained by an uninterrupted series of 49 sound events.

Similar to some works for sho, which are based on a tendency to explore the fingerings, organology, and sound possibilities of the instrument systematically ( $\rightarrow$ IV.1, VI.2), Reber and Suppan derive their structures from an inventory of playing and sound possibilities of the instrument. The flexibility and openness of their approach allows the sheng soloist to act as a kind of co-composer. Of course, the more "prescriptively" conceived works of Sánchez-Chiong, Bhagwati, and Pironkoff are also inseparable from the almost "unlimited" performative possibilities of soloists like Huang or $\mathrm{Wu}$, who have grown out of the much maligned "conservatory style." This leaves room for an independent interpretation by the performers at the seams of the tightly woven structure. The obvious objection that this approach grafts a "Western," "unidiomatic" model of virtuosity onto a "traditional" instrument must be countered. The recent history of East Asia demonstrates $(\rightarrow$ III) how a self-confident appropriation of advanced "technicity" has long since given rise to a multitude of independent "hybrid formations," to which the works presented here merely add further facets. In these works' refusal to appeal to simple culturalist and essentialist oppositions, they take particularities, aspects of alterity, and incommensurability seriously. By implementing these elements in a compositionally nuanced way, these works incorporate the basic prerequisites of a deeper study and the acquisition of intercultural competencies in order to reach beyond established models of a purely technically or purely ideologically imprinted appropriation of cultural "Otherness." 



\section{Studies on the History and Analysis of New East Asian Music}

\section{The Reception of Western Modernism in the Music of China and Japan Since the Late Nineteenth Century}

From the mid-nineteenth century, the history of East Asian music is inextricably linked to the influence and spread of Western music in East Asia, though by no means reducible to this as the sole factor $(\rightarrow$ II.1). Although the Japanese model of a coexistence of Japanese and Western music and the Chinese model of a reform of Chinese music and instruments by Western standards have been identified as two opposing and rather momentous paradigms in the response to Western influence, there were also revealing parallels in the reception of Western music in Japan and China. It is remarkable, for example, that even at the height of anti-Western tendencies - in Japan during the Second World War, in China during the Cultural Revolution - musicians unflinchingly clung to European instruments and the European symphony orchestra as the essential medium of sound.

The distinction made by Saburō Moroi at the "Overcoming Modernity" symposium during the Second World War between Japanese spirit and Western technique $(\rightarrow$ I.2) revisited a model in the appropriation of Western culture in Japan and China since the mid-nineteenth century. This can be traced in neo-Confucian slogans distributed from the 1850s, first in Japan and shortly afterward in China, "Japanese Spirit and Western Technology" (wakon yōsai), ${ }^{1}$ or "Chinese thinking [Confucian ethics] as substance, Western thinking [administration and technology] as means of use" (zhongxue wei ti, xixue wei yong). ${ }^{2}$ Military music, school songs (Japanese shōka, these in turn serving partly as a template for the Chinese xuetangge ${ }^{3}$ ), and political songs were often created by following Western models note for note. Early nationalist symphonic works were usually based on the constructions and inventions of national identity in late nine-

1 The slogan was coined by Tadayasu Yoshikawa (1824-1884) in his Kaika sakuron (Questions and Themes on Progress, 1867) (http://en.wikipedia.org/wiki/Yamato-damashii). Similar slogans had preceded this formulation, such as Shōzan Sakuma's (1811-1864) "Eastern ethics, Western technical learning" (tōyō dōtoku, seiyō gakugei). Both were nineteenth-century re-phrasings of the Heian-period slogan wakon kansai ("Japanese spirit, Chinese technique"), credited to Sugawara no Michizane (845-903). See Josephson, The Invention of Religion in Japan, 108.

2 Geist, Die Modernisierung der chinesischen Kultur, 12-20. This formula was first formulated in 1898 by the moderate reformer Zhang Zhidong (1837-1909) and was provocatively turned over by the reformers of the 1980s in xi ti zhong yong, "Western as substance, Chinese as means of use" (ibid., 13).

3 See Cottschewski, "Eine Musikkultur auf dem Scheidewege," Galliano, Yōgaku, 27-63, Gild, "Early 2oth Century 'Reforms' in Chinese Music," Liang, "Western Influence on Chinese Music in the Early Twentieth Century," 139144, Liu, A Critical History of New Music in China, 23-78, and Utz, Neue Musik und Interkulturalität, 206-221. 
teenth-century European "national schools," and combined this largely stylistically consistent idiom with Japanese or Chinese titles, texts, and paratexts. Indeed, the interaction between Japanese and Chinese tendencies of modernization was so complex that the whole epoch around 1900 can only be adequately understood as a "triangular relationship between Europe, Japan, and China.".

A concept of modernism as a progressive breach of the norm that finds itself in a tense and non-affirmative relation to societal processes may generally be of limited use with regard to East Asian countries in the twentieth century, as argued in Eisenstadt's theory of "multiple modernities" ( $\rightarrow$ II.1 De-Nationalizing Music Historiography). In China, the starting point for the reception of Western music was utilitarianism characterized by colonial constellations, which can be traced back to both the Opium Wars of 1839-42 and 1851-60 and the subsequent Westernization and Self-Strengthening Movement (Yangwu ziqiang yundong). In the musical realm, the aspects of Western tradition first received were basic materials that were always assigned clearly defined social functions: the arming of the military involved the adoption of Western military brass music, modernized school education involved the introduction of Westernoriented school songs, and - most prominently - the strengthening of national self-esteem involved creating songs, and soon also symphonic works, with nationalistically accentuated texts, titles, or melodies. ${ }^{5}$

In various Chinese reform movements of the 1920 s and 1930s, a stronger focus on local traditions under the guiding idea of a mutual complementation of Chinese and Western cultures (yi zhong bu xi) was opposed by a radicalized demand for "total Westernization" as (a temporary) means of modernization. ${ }^{6}$ One of the most important reformers of this time in the field of music was Liu Tianhua (1895-1932), who founded the Society for the Improvement of National Music (Guoyue gaijinshe) in 1927 along with Xiao Youmei (1884-1940), which received strong impulses from the Western-oriented Xin wenhua yundong (New Culture Movement, 1915-22, better known as the May Fourth Movement), which had been instigated by writers and intellectuals such as Qu Qiubai (1899-1935), Chen Duxin (1879-1942), Hu Shi (1891-1962), and Chen Xujing (1903-1967). With his ten posthumously published studies for the two-stringed knee fiddle erhu (1918-32), Liu contributed significantly to the establishment of a modern solo repertoire for Chinese instruments. ${ }^{7}$ Tuning, pitch, tonal system, notation (the cipher notation jianzipu ${ }^{8}$ ), meter and rhythm (triple meter, march rhythm), and instrumental technique (bowing techniques, up- and down-bow, etc.) were standardized according to principles of Western music, while, at the same time, elements of Chinese instrumental practice and aesthetics, especial-

4 Cottschewski, "Zur Rezeption chinesischer Musik in Japan um 1900," 616 (“Dreiecksbeziehung Europa-Japan-China").

5 See among others Wong, "Ceming Gequ," Mittler, Dangerous Tunes, 21-32, Melvin and Cai, Rhapsody in Red, $159-224$.

6 The slogan of "total Westernization" (quanpai xifanghua) was coined in 1933 by the sociologist Chen Xujing (19031967). In the wake of the May Fourth Movement until the 1930s, this demand was also advocated by Hu Shi (18911962), and in the democracy movement of the 1980s by Fang Lizhi (1936-2012) and Liu Xiaobo (1955-2017) (Geist, Die Moderniserung der chinesischen Kultur, 14). While in the 1920 s social changes were still almost entirely equated with "Westernization" (xihua), from the beginning of the 1930s the more neutral term "modernization" (xiandaihua) became prevalent (ibid., 13-14).

7 Stock, "Contemporary Recital Solos for the Chinese Two-Stringed Fiddle erhu," 60-66. See also Stock, "An Ethnomusicological Perspective on Musical Style" and Liang, Music of the Billion, 148-150.

8 This simple type of notation, in which scale steps are rendered by numbers (1-7) and octave registers are indicated by dots placed below or above the numbers, was introduced to China by French missionaries in the early twentieth century and can be traced back to Jean-Jacques Rousseau. See Picard, "Oralité et notations, de Chine en Europe." 
ly with reference to northern Chinese traditions, were maintained: sectional form, programmatic titles, iconographic musical figures (for example, for imitating birdsong), and erhu fingering patterns. The decisive factor was that the studies were conceived and published in fixed notation and, in contrast to the flexibility of traditional music practice, assumed a largely exact rendering of this musical text in performance.

Eric Hobsbawm's concept of "invented tradition" ( $\rightarrow$ I.3, II.3) has been applied to the development of the new repertoire of that period, in particular to the solo literature of the Chinese bamboo flute dizi after 1949. It is characteristic that there was originally no clear distinction in the practice of local Chinese genres between solo and ensemble repertoire. In the context of the Maoist "subversion" (fanshen) of the feudal class structure after 1949, the rickshaw driver Lu Chunling and the simple farmer Feng Zicun were able to rise to celebrated dizi soloists and were commissioned to create short characteristic solo pieces, which they derived from the dizi part of traditional ensembles and which were distributed to the masses via cassette recordings. ${ }^{9}$

With the emergence of the Chinese symphony orchestra from the 1930s, a development had already begun that made the problems of the separation of spirit and technique increasingly visible: while Liu's solo works, following the idea of a "national essence,"10 still testify to an appreciation of the aesthetics of traditional instrumental playing, the repertoire of the newly developed orchestras of Chinese instruments was commonly based on a naïve imitation of popular Western orchestral music. This made it abundantly clear that, in contrast to solos and ensembles, an independent Chinese tradition could not be used for orchestral settings. The development of the Chinese symphony orchestra, usually referred to as the "Modern Chinese Folk Orchestra," took decisive steps during the Second World War, the Chinese Civil War (1947-49), and the early Maoist period, and is thus intimately connected with the systematic invention of a national musical idiom. ${ }^{11}$ To be able to equip a symphony orchestra with exclusively Chinese instruments, many instruments had to be rebuilt, especially instruments in the bass register. The number of instrument types was systematically expanded until the 1960s. Liu Tianhua had already introduced the standardized procedure, unusual in traditional practice, of notating all parts of a heterophonic ensemble structure. This practice was now transferred to the symphony orchestra, and the use of precisely notated parts and a conductor were adopted largely unchanged from the Western model.

Of course, the translation of Eastern models to the Western orchestra created the acute question of harmony, since polyphonic models could hardly be derived from traditional heterophonic practice. While earlier pieces usually - in analogy to earlier European harmonization of East Asian melodies ( $\rightarrow$ III.3) - added simple major-minor tonal harmonies to Chinese melodies, a new method was developed in the 1950 s by Wang Zhenya and Li Yinghai as Hanzu diaoshi hesheng (Han Chinese Musical Modes and Harmonies). In 1959 Li Yinghai presented a book with a similar title, ${ }^{12}$ based on Wang Zhenya's earlier Wusheng yinjie ji qi hesheng (The Pentatonic Scale

\footnotetext{
9 Lau, "Forever Red." See Hobsbawm, "Introduction: Inventing Traditions."

10 The idea of a "national essence" (guocui, Japanese kokosui), taken from the Japanese discourse, had already triggered an intense debate on cultural identity in the framework of the May Fourth Movement (Geist, Die Modernisierung der chinesischen Kultur, 14).

11 See Jedeck, "Different Interpretations of Musical Modernity?" for a detailed discussion, and Tsui, "The Modern Chinese Folk Orchestra" and Tsui, "Ensembles: The Modern Chinese Orchestra" for a historical overview of the Chinese symphony orchestra.
}

12 Li, Hanzu diaoshiji qi hesheng (Han Modality and Its Harmony). 
and Its Harmonies) from 1949. ${ }^{13}$ In this system, the harmonies are composed almost entirely of the notes of the pentatonic mode that form the corresponding melody. The system has also been widely used in works by Chinese composers for Western instruments and is still employed in music for the Chinese symphonic orchestra to the present day, although chromatic alterations have been increasingly introduced since the 1980 s. $^{14}$ Only a few experimental works took advantage of the unique sound of the new orchestral apparatus, such as Lam Doming's (b. 1926) well-known sonorist piece Insect World (1979). In the dominant standard repertoire of the Chinese symphony orchestra, the problem remains unmistakable that with the alleged "modernization" and standardization of the instrumental playing, the very same subtle deviations, inflections, and variations that constitute a style like the South Chinese "silk-and-bamboo music" (sizhuyue) $\rightarrow$ III.3) in the first place were suppressed..$^{15}$ Formally, too, the flow of the melodic line that is essential for such forms is undermined by the effectively optimized dramaturgies of suspension and contrast in most works and arrangements for the Chinese symphony orchestra.

The combination of Asian and European instruments was not yet provided for in the musical concepts of the reformers, and, considering the institutional separation of Western and Asian musical practice, it would hardly have been feasible. The earliest step in this direction was probably the inclusion of Asian solo instruments in the context of Western-oriented orchestral settings, although some of these, as in the case of Xian Xinghai's (1905-1945) Yellow River Cantata (Huanghe dahechang, 1939), written in the structurally weak retreat of the Communist Party in Yan'an (Shaanxi), may have been merely material makeshift solutions. ${ }^{16}$ In a different context, Japanese instruments in Kōsaku [Kósçak] Yamada’s (1886-1965) "grande opéra" Yoake - Kuro Fune (The Black Ships, 1929-39) merely contributed to a kind of "self-exoticizing" locality, that hardly found its way into the substance of the music. Finally, the combination of Western and Chinese instruments in the "model works" (yangbanxi) during the Chinese Cultural Revolution coincided with related pragmatic and political omens: the singing style of Beijing Opera was "tempered" and stylistically leveled due to a musical style based on Westernized Romantic orchestral textures. ${ }^{17}$

In creating musical identifications recognized by the masses, communist and nationalist-republican idioms differed primarily on the textual level. Xian Xinghai, who had studied with Vincent d'Indy and Paul Dukas in Paris from 1930 to 1935, produced perhaps the best-known piece of this genre in 1939, the Yellow River Cantata (Huanghe dahechang). In contrast to Liu Tianhua's works, Xian's style shows no signs of an intensive examination of Chinese music traditions. The harmony of the opening movement, built according to the traditional antiphonal pattern of Chinese rowing songs, characteristically combines pentatonic melody formation with simple diatonic harmonies reminiscent of the Italian (operatic) tradition in their repetitive and sequential patterns.

It is not insignificant that Xian's Cantata was characterized as late as 1984 - notably in an academic study in English - as follows:

13 Wang, Wusheng yinjie ji qi hesheng (The Pentatonic Scale and Its Harmony). A detailed explanation of this system is provided by Cheong and Ding, "Sposobin Remains," 62-68. See also Kouwenhoven, "Mainland China's New Music (II)," 59-60.

14 See Cheong, "Reading Schoenberg, Hindemith, and Kurth in Sang Tong."

15 See among others Thrasher, "Bianzou - Performance Variation in Jiangnan sizhu" and Witzleben, "Silk and Bamboo" Music in Shanghai.

16 See Kraus, Pianos \& Politics in China, 56-59.

17 See Clark, "Model Theatrical Works," Mittler, "Cultural Revolution Model Works," Melvin and Cai, Rhapsody in Red, 225-264, and Liu, A Critical History of New Music in China, 377-482. 
It is by far the most convincing synthesis of Western and Chinese musical idioms. In a single work it unites such diverse techniques and elements as, for example, the Chinese folk antiphonal singing style called duikou chang, the Chinese fisherman's work song called haozi, traditional Chinese percussive patterns and instrumentation, Hugo Wolf's declamatory recitative style (adapted to the Chinese language), the traditional Western contrapuntal technique of choral writing, and, finally, the atmospheric orchestral effects of the French Impressionistic school. ${ }^{18}$

One could draw a clear line from Xian's cantata to works of the 1950 s and 1960 s as represented by Ding Shande's (1911-1995) Long March Symphony (Changzheng jiaoxiangqu, 1959-62). National identity and authenticity are suggested here through the use of folk songs, which geographically trace the approximately 6,000-kilometer route of the long march of the fleeing communist troops from 1934 to $1935^{19}$ from southern Jiangxi to northern Yan'an. That folk songs of the Yao people and other minorities are also included here points to the claim of national music as an all-encompassing idea of a "Great China," especially in the second movement, where this claim is even made explicit in the title: "The Red Army, Loved by Many Peoples" (Hongjun, ge zu renmin de qinren).

It seems evident that in the contexts mentioned so far, the reception of aesthetic modernity in the narrower sense hardly caught the attention of musical protagonists. And so, from today's perspective, it is crucial to emphasize those developments in East Asia that did not fit into this ostensibly seamless lineage of deliberate and naïve iconographic appropriation of Western (programmatic) music. Decisive for this "alternative" lineage of East Asian music of the twentieth century is, on the one hand, the temporary residence and emigration of European musicians in the 1930s and 1940s, primarily in Shanghai, the center of encounter between Western and Chinese trends, and, on the other hand, independent dynamics within the East Asian composer scenes.

The Russian composer and pianist Alexander Tcherepnin (1899-1977) served as an advisor to the Chinese ministry of culture from 1934 to 1937 in Shanghai and Beijing as well as Japan, developing models for the integration of East Asian elements into a moderately modern style $\left(\rightarrow\right.$ II.4).${ }^{20} \mathrm{He}$ focused primarily on the modernist folklorism of Bartók and Russian composers, which was also reflected in the music of the most important Chinese composers he mentored, including He Luting (1903-1999) and Jiang Wenye (1910-1983). Tcherepnin cites He Luting's piano piece Buffalo Boy's Flute (Mutong duandi, 1934, Ex. 3.1) as a possible model of a new Chinese music in his 1935 article "Music in Modern China." ${ }^{21}$ While in this piece a tonal-harmonic ambiguity is initially maintained by the consistent use of the pentatonic scale, the second part analogous to examples cited above - is characterized by a pentatonic melodic line in the right hand and a diatonic accompaniment in the left. Contrary to Tcherepnin's appraisal, a serious reception of Chinese traditions or modern Western currents is hardly recognizable here.

18 Wong, "Ceming Gequ," 125.

19 See Moise, Modern China, 78-82.

20 See Chang, "Alexander Tcherepnin, his Influence on Modern Chinese Music," Melvin and Cai, Rhapsody in Red, 110-126, Winzenburg, "From 'Folk Cure' to Catharsis: Alexander Tcherepnin and New Chinese Piano Music."

21 Tcherepnine, "Music in Modern China," 398-400. On this piece see also Kouwenhoven, "Mainland China's New Music (II)," 57-59. 
Example 3.1: He Luting, Buffalo Boy's Flute (Mutong duandi), mm. 1-11

(Kouwenhoven, "Mainland China's New Music (II)," 57)
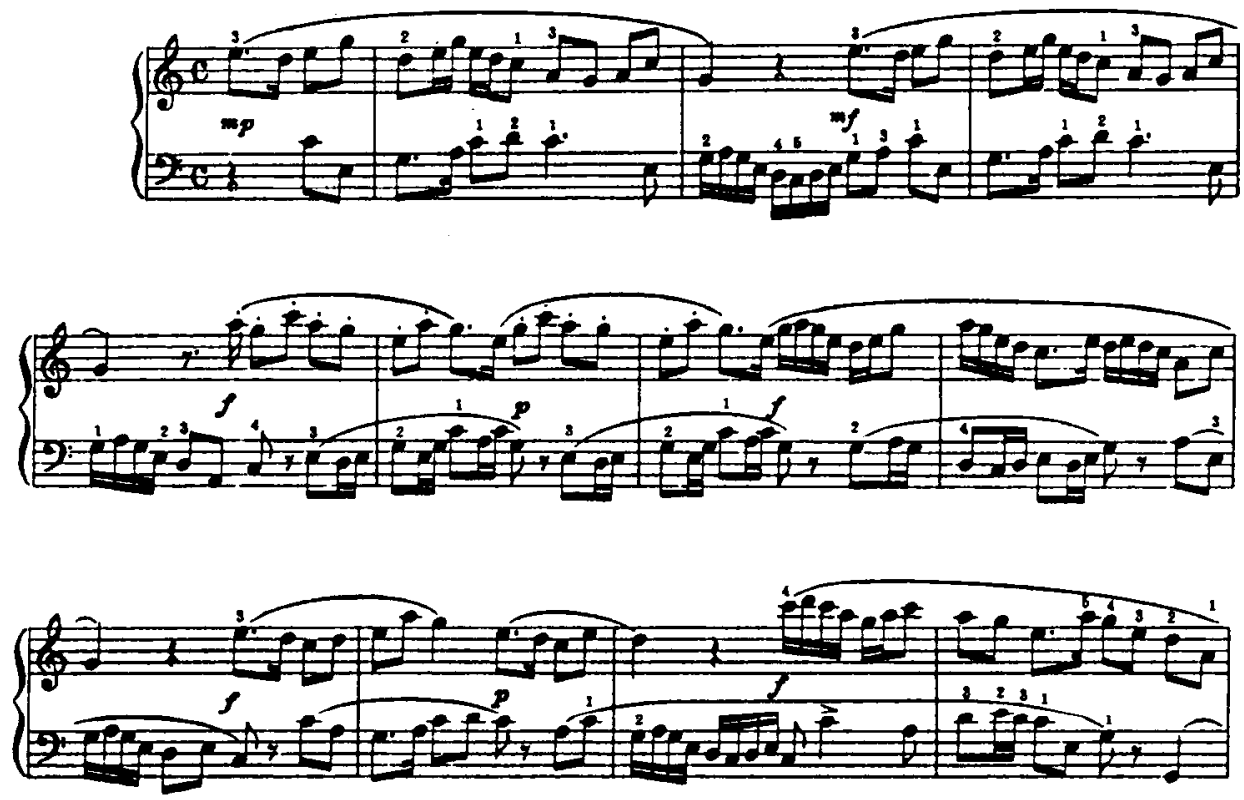

What is noteworthy is Tcherepnin's demand that the training of Chinese musicians should begin with the adaptation of Chinese melodies to a "modern style," oriented toward European music of the early twentieth century (Debussy, Stravinsky), not toward Classical or Romantic music. ${ }^{22}$ In Tcherepnin's argumentation, there is an implicit optimism based on the traditional non-reliance of Chinese musicians on Western tradition, as well as an enthusiasm about the potential of the most populous nation for a future independent Chinese music.

Like Tcherepnin, the composer, music theorist, violist, and lawyer Wolfgang Fraenkel (1897-1983), who lived in exile in Shanghai from 1939 to 1947 after fleeing from the National Socialists, saw the future of Chinese music in a combination of Western modernism with autochthonous Chinese music traditions, though his conception of modernism was shaped differently. Influenced by the Schoenberg school, Fraenkel conceived of new music as fundamentally different from the Classical-Romantic tradition in a specific music-linguistic sense, and in his text "Music Development?" he recommended that his Chinese colleagues develop just such an alterity: Chinese composers should absorb the "technical and sensory qualities of Western art," which would, however, only serve as a basis for making connections with traditional Chinese music without destroying its particularities. In the pronounced distance from a classical musical language, Fraenkel saw a possible connection between pre-Classical and modern European music and Chinese music $(\rightarrow$ III.2).

Fraenkel and Tcherepnin brought a fresh perspective to the ongoing discussion on the future of Chinese music, as the basis for the controversy over the roles of Western music up to the 1930 s had implicitly always referred to the nineteenth century as the source of tonaldiatonic musical language. Fraenkel's most important student at the Shanghai Conservatory,

22 Tcherepnine, "Music in Modern China," 398. 
Sang Tong (1923-2011), wrote Yejing (Night Scenery, 1947, published in 1981) for violin and piano - the first Asian composition incorporating atonal and dodecaphonic structures ${ }^{23}$ - and Zai na yaoyuan de difang (In the Land, Far, Far Away, 1947) for piano. These works represent impressive outlines of what a new Chinese music might have looked like later if this development had not been abruptly ended by political and social upheavals such as the Civil War 1947-49 and the takeover by the Communist Party in 1949 ( $\rightarrow$ III.2). Dodecaphonic works did not appear until the late 1970s, with Luo Zhongrong's (b. 1924) Shejiang cai furong (Picking Lotus Flowers at the Riverside, 1979) for voice and piano playing a pioneering role. In a similar fashion to Sang Tong's early works, Luo synthesized pentatonic melody with twelve-tone technique. ${ }^{24}$ The changing political atmosphere in post-Mao China is expressed in the assessment of the musicologist Wang Ningyi, who wrote in 1981 that “Comrade Luo's courageous move into the prohibited zone of twelve-tone music should be looked upon as a meaningful exploration."25

Aaron Avshalomov (1894-1956) has been another important figure in the musical life of Shanghai during the 1930 s and has received some attention in research recently. Avshalomov was born in Nikolayevsk-on-Amur close to the Chinese-Russian border. During his stay in China from 1918 to 1947 (Tianjin, 1918-31, Shanghai, 1931-47) and after a period of field research on Chinese folk music he became a much-respected composer and music teacher, sharing his Chinese colleague's search for new Chinese musical identities. His works exhibit a type of cultural "fusion" that in many respects seems to predate compositional concepts of both Cultural Revolution "model works" (yangbanxi) and the young avant-garde of the 1980s. Most notably, his "music drama" The Great Wall (Meng Jiang Nü, 1943-45) ${ }^{26}$ and his Piano Concerto (1935) $)^{27}$ exhibit the composer's conscious reaction to a sensitive, politicized environment. Labeling his Great Wall, premiered in November 1945 in a production requiring considerable resources and effort, a "Chinese Music Drama" (Yinyue gewuju) avoided obvious connections to a much-debated reform of Beijing Opera (jingju). Emerging from the concept of a monodrama, the musical idiom to a text spoken and sung in Mandarin Chinese is characterized by an "eclectic mixture of late-Romantic, impressionist, and early modernist styles to depict changes in the dramatic action and emotion from moment to moment." ${ }^{28}$ While the blending of genres and styles in The Great Wall to some extent anticipated the yangbanxi aesthetic, Avshalomov's Piano Concerto in $\mathrm{G}$ major paved the way for the veritable sub-genre of the "fusion concerto," of which

23 See Cheong, "Reading Schoenberg, Hindemith, and Kurth in Sang Tong," who notes that although Sang's work "is not based on any twelve-tone row, the twelve chromatic notes obviously constitute a main resource" (96). After the opening of Chinese culture in 1976/78 Zheng Yinglie and the composer himself published two analyses of this piece in 1983 and 1991 respectively (Zheng, "Sang Tong de Yejing shishi" [A Preliminary Analysis of Sang Tong's Night Scenery]; Sang, "Yejing zhong de wudiaoxing shoufa ji qita" [Atonal and Other Techniques in Night Scenery]). Both analyses emphasized the use of traditional Chinese scales and modes in this work.

24 See Zheng, "Letter from China: The Use of Twelve Tone Technique in Chinese Musical Composition," Kouwenhoven, "Mainland China's New Music (III)," 81, Zhang, Akkulturationsphänomene in der gegenwärtigen Musikkultur Chinas, 104-107, Mittler, Dangerous Tunes, 154, Utz, Neue Musik und Interkulturalität, 360-361, Rao, "Hearing Pentatonicism Through Serialism," and Cheong, "Reading Schoenberg, Hindemith, and Kurth in Sang Tong," 91-92.

25 Wang Ningyi, “Farenshensi de tansuo: Ping Luo Zhongrong de 'Shejiang cai furong'” [A Thought-Provoking Experiment: A Critique of Luo Zhongrong's Picking Lotus Flowers at the Riverside], 45, translation quoted after Cheong, "Reading Schoenberg, Hindemith, and Kurth in Sang Tong," 92.

26 See Winzenburg, "Aaron Avshalomov and New Chinese Music in Shanghai, 1931-1947," Winzenburg, "MusicalDramatic Experimentation in the Yangbanxi," and Winzenburg, "Partnering with the Shanghai Arts Community."

27 See Winzenburg, "A New Multivoiced World."

28 Winzenburg, "Musical-Dramatic Experimentation in the Yangbanxi," 193. 
John Winzenburg has currently assembled more than 400 representative examples. ${ }^{29}$ The second movement of this concerto, an adagio carefully incorporating a kunqu opera tune, hints at Chinese performance techniques such as sliding pitch lines. The movement was arranged by the composer for an ensemble of 14 Chinese instruments that enter into a dialogue with the solo piano. This arrangement was performed separately from the three-movement work at the premiere on 19 January 1936 in Shanghai, ${ }^{30}$ and, according to the composer, the confrontation between the two performances and settings was intended to demonstrate the key role of timbre for the understanding of musical identity:

Working on the modernizing of Chinese music, i.e., trying to bring it up to a standard acceptable to the present generation, one is confronted with the problem of losing, in the process, very much of what is typically and characteristically Chinese. Since it must be recognized that the Chinese instruments, in spite of the charm of their ton-colour [sic], cannot be yet efficiently employed to perform on them symphonic music on account of technical shortcomings, the only way out (the composer sees it for the present and until that time when the mechanical and technical possibilities will be improved) is to use the western orchestra trying the [sic] preserve only the spirit of Chinese music as expressed in the thematic material, not taking into much account the loss of that peculiar colour which could not be obtained by using Chinese instruments. The present experiment [...] is not a comparison: it is a desire to explain through actual music that although (as in the case of this "Adagio") the two versions are entirely identical as regard instrumentation, harmonization, form, and thematic material, the western orchestra does not - (perhaps cannot?) - sound as what is ordinarily called "Chinese music." Or does it?? ... This the composer leaves for the audience. ${ }^{31}$

During the same period, some - equally implicitly political - comparable approaches emerged in Japan, most notably in the orchestral works Akebono (1931) by Kunihiko Hashimoto ${ }^{32}$ (19041949) and the Nagauta Symphony "Tsurukame" (1934) by Kōsaku (Kósçak) Yamada. ${ }^{33}$ In both works, a choral nagauta shamisen ensemble (an ensemble consisting of shamisen-accompanying singers in unison) and a Western symphony orchestra are connected in a variety of ways. These works emerged in a politicized context of increasing nationalism that had spread in the wake of Japan's occupation of the Manchurian peninsula in 1931/32. Hashimoto's 30-minute Akebono

29 Winzenburg, "A New Multivoiced World," 222-223; see also Winzenburg, "Heteroglossia and Traditional Vocal Genres."

30 Winzenburg, "A New Multivoiced World," 224.

31 Aaron Avshalomov, "Notes upon the Orchestral Works," in The Shanghai Municipal Orchestra at the Lyceum, Fifteenth Sunday Concert Symphonic Programme (19 January 1936), 4-5, quoted after Winzenburg, "A New Multivoiced World," 231.

32 From 1934 to 1937, Hashimoto studied in Vienna with Egon Wellesz. On returning to Japan, with a stopover in Los Angeles, he met with Schoenberg (Galliano, Yōgaku, 205). Akebono was performed again in 2005 at the Tokyo University of the Arts (Tokyo Ceijutsu Daigaku) under the direction of Hiroshi Wakasugi to great acclaim. The text is by Tatsuyuki Takano (1876-1947), the underlying shamisen music was composed by Kosaburo Yoshizumi (1876-1972) and Rokeshiro Kineya (1904-1987).

33 Yamada was the most internationally respected composer in Japan in the first half of the twentieth century. He had, among other teachers, studied in Berlin with Max Bruch and Karl Wolf (1910-12), and contributed significantly to the development of Japanese music life. During the Pacific War, Yamada offered his services to the militarist regime, leading to fierce controversies in the immediate postwar period (Galliano, Yōgaku, 130-131). Some further information on Yamada has been provided in Chapter II.4. 
(Sunrise), written for a huge ensemble, caused a scandal at its premiere on 14 November 1931, followed by harsh and politically charged press reviews that insisted on the basic incompatibility of the intimate character of Japanese music and the representational character of Western orchestral styles. ${ }^{34}$ The composer himself published an extensive list of harmonic strategies and ensemble combinations used in his work, concluding that he had "failed to achieve a synthesis, to combine these techniques into a single procedure." 35 Yamada's Nagauta Symphony "Tsurukame," by contrast, was much better received, although it pursued an agenda similar to Hashimoto's, namely “the urgently needed overcoming of the opposition between Japanese and Western music with the aim of creating a Japanese national music. ${ }^{36}$ It is evident that Yamada's success was not least due to the allusions to nationalist tropes and symbols in the quoted nagauta material, and not merely to the astonishing inventiveness of how this material is technically interwoven, through considerable effort, with harmonic and contrapuntal structures. ${ }^{37}$

In both works, the melodies of the shamisen ensemble are integrated into the idiom of the orchestra by coloring and developing them with the means of major-minor tonality. At the same time, the composers claimed to have left the traditional idiom of the shamisen ensemble largely untouched. In this formalized dialogue, the juxtaposed ensembles describe a kind of coexistence of Japanese and European music that had been characteristic of the Japanese modernization model since the Meiji era (1868-1911) as a whole. While Hashimoto, a member of Shinkō sakkyokuka renmei (Federation of Innovative Composers, founded in 1930, $\rightarrow$ II.4), was the only composer of his generation to have studied both European and Japanese music, Yamada's music had initially been strongly influenced by Richard Strauss, but increasingly turned toward an integration of traditional Japanese instruments and genres. Already in Yamada's symphony "Inno Meiji" (1921) a hichiriki is used, which, however, - like the Japanese instruments in the opera Yoake - Kuro Fune (see above) - does not play a major role. The Nagauta Symphony is based on the play Tsurukame ("Crane and Tortoise," a story documenting imperial worship), adapted from the no theater for kabuki. In sum, both symphonies reflect increasingly nationalist tendencies of Japanese music of the 1920s and 1930s, with Yamada's work expressing a more explicit political undertone.

After early attempts to make structural use of the modes and timbres of Japanese traditional genres during the 1930s in the context of the Shinkō sakkyokuka renmei, Yoritsune Matsudaira (1907-2001) extensively linked current European developments from neoclassicism to dodecaphony, serialism, and aleatoricism with structural and tonal aspects of gagaku, during the postwar period. ${ }^{38}$ Matsudaira's Theme and Variations for Piano and Orchestra (1952) on the fa-

34 See Menzel, Hōgaku, 125-133.

35 Hashimoto, "Nagauta shinkyoku 'Akebono," 45, quoted after Menzel, Hōgaku, 127 ("Obwohl ich danach trachtete, die oben beschriebenen Techniken in Synthese zu bringen, zu einer einzigen Verfahrensweise zu verbinden, [...] muss ich leider bekennen, dass mit dieser entscheidende Schritt nicht gelungen ist.").

36 Tsuyuki, "Nihon ongaku to yōgaku to no kōryū," 36, quoted after Menzel, Hōgaku, 134 ("[Tsurukame] [...] versteht sich als Schritt in Richtung der dringend nötigen Überwindung der Opposition von japanischer und westlicher Musik, mit dem Ziel, eine japanische Nationalmusik zu schaffen.").

37 See Menzel, Hōgaku, 134-141.

38 Yoritsune Matsudaira was one of Japan's most influential and internationally active composers; he became known in the West already during the 1930 s after being awarded the Tcherepnin composition prize in 1935. He attended the 1957 and 1958 Darmstadt Summer Course (Caitano, "Intercultural Perspectives in the International Summer Courses for New Music," 336-342). In 1958 his orchestral work U-Mai (1957-58) was premiered in Darmstadt. Among his later works, the Drei Arien nach Gedichten aus der "Ceschichte vom Prinzen Genji" (1990) for soprano, shō, flute, and koto, a preliminary work toward his late opera Genji Monogatari (1991-97), made use of 
mous gagaku piece Etenraku (in the mode banshikicho) was awarded a prize at the ISCM festival 1952 and afterward conducted by Herbert von Karajan in Vienna (1952) and Tokyo (1954). In 1930, Matsudaira had been the youngest founding member of the Shinkō sakkyokuka renmei, which encouraged "the development of Japanese tonal systems suitable for primarily pentatonic and modal melodies, structured after the type of 'quartal harmonies' derived from the vertical tone clusters of the sho in gagaku"39 in the second of its four guidelines $\rightarrow$ II.4). As outlined in Chapter II.4, this demand was met in particular by Fumio Hayasaka (1914-1955) in works such as Kodai no bukyoku (Ancient Dance, 1937) along with the second movement of Matsudaira's Sonatine for Flute and Piano (1936) that uses a gagaku melody in a predominantly neoclassicist context, "alienating it from its origins. ${ }^{140}$ As discussed in detail in Chapter II.4, in the 1930s, Japan's tendency toward cultural renewal, known as shinkō, had sparked an intense debate over "Japanese harmony," in which Shūkichi Mitsukuri, Shōhei Tanaka, and Klaus Pringsheim participated alongside Hayasaka. ${ }^{41}$ Hayasaka's and Matsudaira's works of the postwar period conveyed these principles to the younger generation. In his works of the 1950s, Matsudaira continued to explore specific concepts of Japanese harmony, such as in his adaptation of the mouth organ shö's aitake chords in his central work Saibara ni yoru Metamorfözu (Metamorphoses on Saibara, 1953/58). ${ }^{42}$

Reforms in traditional music were far less radical in Japan than in China. A central figure was the koto player Michio Miyagi ${ }^{43}$ (1894-1956), who became the protagonist of Shin Nihon ongaku (New Japanese Music), a movement that sought to gently integrate Western elements into traditional Japanese instrumental structures. ${ }^{44}$ The movement aimed to expand the performance techniques of traditional instruments, but also experimented with modifications (usually enlargements) of the instruments. Already before Miyagi, the koto genre shinkyoku (New Pieces) had been created during the Meiji Period (1868-1911) in Osaka, in which elements of Western music were included. Noboru Tateyama (1876-1926) played a significant role in the formation of that repertoire. ${ }^{45}$ After the Second World War, a broader trend toward the confluence of Japanese and European musical traditions was not re-established until the 1960s, primarily by musicians who, following Miyagi (who died in 1956) adopted the term gendai hoggaku (Traditional Japanese Music of the Present). This notable group of distinguished soloists was able to arouse a new interest in traditional instruments among Westerneducated composers. ${ }^{46}$ Most prominently, the "Group of four for traditional Japanese music"

Japanese instruments for the first time. On Matsudaira see, among others, Sawabe, Neue Musik in Japan von 1950 bis 1960, 48-51, Sawabe, "Der lange Weg zur 'Ceschichte vom Prinzen Genji," Galliano, Yōgaku, 82-85, 137-144, 259-260, as well as the essays in Benítez and Kondō, Gagaku and Serialism. Some further information on Matsudaira is provided in Chapter II.4.

39 Quoted in Herd, "The Cultural Politics of Japan's Modern Music," 44 ( $\rightarrow$ II.4).

40 Lehtonen, "'March from the Age of Imitation to the Age of Creation," 181. Lehtonen (ibid., 167-185) provides a close reading of this movement and other prewar works by Matsudaira.

41 Galliano, Yōgaku, 66-73, 79-82.

42 Ibid., 138-141.

43 The blind koto player Michio Miyagi was one of the most important reformers of traditional Japanese music in the twentieth century. At the age of 18 , he reached the highest rank (kengyo) with the traditional Japanese musician system. See Galliano, Yōgaku, 52-55.

44 See especially Menzel, Hōgaku, 66-82.

45 See Flavin, "Meiji shinkyoku" and Menzel, Hōgaku, 55-65.

46 See Galliano, Yōgaku, 238-254. 
(Hōgaku yonin no kai) and the koto player Kayoko Suzuki developed the rapprochement. In this context, Yoshirō Irino (1921-1980) wrote Music for Two Kotos (1957), the first dodecaphonic work for traditional Japanese instruments, ${ }^{47}$ and ten years later Tōru Takemitsu composed his seminal works for traditional instruments Eclipse (1966) and November Steps (1967) $\rightarrow$ III.4).

In China, Shi Yongkang's (b. 1929) concerto Huanghe de gushi (The Story of the Yellow Crane, 1955) represents an early example of a "fusion concerto" with a Chinese solo instrument, reversing Avshalomov's setting twenty years earlier. The solo instrument is the Chinese bamboo flute dizi, but the piece almost entirely conforms to the conventions of the Western Romantic virtuoso concerto tradition. ${ }^{48}$ An appropriation of Western virtuosity has generally acted as a determining factor in the repertoire of almost all Chinese instruments since the 1930s. The resulting style is marked by an integration of Chinese sound resources into an almost entirely European nineteenth-century idiom. This goes hand in hand with a considerable reduction in complexity at all musical levels and is generally summarized as "conservatory style" since it is closely linked with the establishment of academic music education institutions since 1927: ${ }^{49}$

\begin{abstract}
Many virtuosos in the conservatories or professional state-supported urban troupes come from the background of hereditary village "folk artist" families, but they have largely abandoned the traditional ethos in favour of a modernized, virtuoso and partly Westernized style, using a tempered scale, abbreviating pieces considerably and exaggerating dynamics and gestures for stage performance. This "conservatory style" is more accessible but of less complexity than the traditional rural music-making. ${ }^{50}$
\end{abstract}

The use of Chinese solo instruments in orchestral contexts became significantly more sophisticated after the end of the Cultural Revolution in the 1980s and 90s. For example, the dizi in Zhu Jian'er's (1922-2017) Fourth Symphony (1990) represents a structurally looser principle, acting within a stylistically complex amalgamation of dodecaphony, sound masses, and Chinese percussion ensemble rhythms. This situation is similar to the role of the musical saw in Zhu's Second Symphony (1987). An obvious narrative interpretation is one that that understands the solo instruments in these two works as depicting the articulation of the individual in a repressive and coercively constrained society, thus processing the traumas of the Cultural Revolution, which were the explicit theme of the First Symphony (1977-86). ${ }^{51}$

Zhu Jian'er's ten symphonies were written between 1986 and 1999, and can be seen as an almost systematic undertaking to find a music differing in significant ways from the Western symphonic tradition by means of different experimental arrangements while upholding the emphatic aesthetic claims of the symphonic tradition $\rightarrow$ III.5). ${ }^{52}$ At the age of 50, Zhu, who

47 Sawabe, Neue Musik in Japan von 1950 bis 1960, 47.

48 The score of this work is extensively discussed and fully reproduced in Mittler, Dangerous Tunes, 321-323, 440-457.

49 In 1927, the Shanghai Conservatory was opened. See Schimmelpenninck and Kouwenhoven, "The Shanghai Conservatory of Music" and Yang, "The Shanghai Conservatory, Chinese Musical Life, and the Russian Diaspora, 1927-1949."

50 Jones, "China §ાV. Living Traditions."

51 See in particular Barbara Mittler's interpretation of Zhu's First Symphony in Dangerous Tunes, 97-105. On the continued importance of post-Cultural Revolution "scar music" for Chinese composers until the 1990s see Mittler, "Sound Patterns of Cultural Memory."

52 The scores of Zhu's ten symphonies and his sinfonietta were released, along with CD recordings, in 2002 in an elaborate three-volume edition of the Shanghai Music Publishing House. See also Sun, "Zhu Jian'er's Symphonies." 
had mostly composed unnoticed before and during the Cultural Revolution, attended composition classes at the Shanghai Conservatory with Chen Mingzhi (1925-2009) and Yang Liqing (1942-2013) to explore and appropriate new techniques, including the twelve-tone method in particular. ${ }^{53}$ While the First Symphony, in its long formation and methodological eclecticism, aptly documents the difficulties of finding a new musical language in the years following the Cultural Revolution, the Second Symphony compresses the traumatic experiences into an extreme density. The two halves of the twelve-tone row (C-A-G\#-F-E-C\#-D\#-F\#-G-A\#$\mathrm{B}-\mathrm{D}$; all trichords being members of the same set class 014), similar in structure to Anton Webern's dodecaphonic symmetries, appear in the main theme permuted and simultaneously sharply accentuated by a whole tone $\left(\mathrm{T}_{2}\right)$ transposition, which articulates the Chinese speech rhythm of the question "Why?" (Ex. 3.2). ${ }^{54}$

Example 3.2: Zhu Jian'er, Second Symphony op. 28, rehearsal number 16+3-6: main theme with the underlying words "weishenme, weishenme zheyang, weishenme zheyang dou" ("Why? Why so? Why is it such a struggle?") ${ }^{55}$

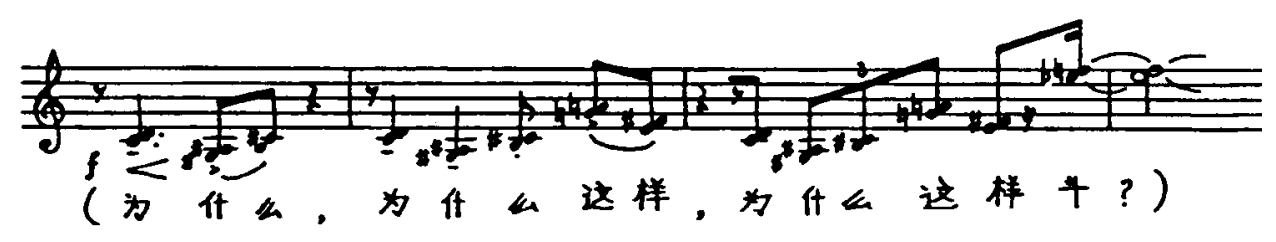

In the broad introduction to the first movement, the fragile sounds of the musical saw continue in extensive solo fields of other instruments but are repeatedly cut off harshly by rolling tutti sounds. These spread out considerably in the second part of the work until, at the end, after a painful polytonal "apparent triumph" of the brass, an echo of the saw becomes audible - which can easily be understood as the barely audible, yet sustainably articulated voice of the individual.

In completely different social and historical terms, the treatment of the Japanese solo instruments shakuhachi and (satsuma-) biwa in Takemitsu's November Steps (1967) is also characterized by a much greater flexibility of tempo, synchronization, and articulation when compared to the orchestral structures, resulting not least from the mostly unmetered, partly ambiguous notation for the solo instruments ( $\rightarrow$ III.4). Owing to the differences in tone and technique, the Asian instruments for $\mathrm{Zhu}$ and Takemitsu become carriers of an individualization process, and produce an autonomous music that disengages from the determinism of compositional ideas and penetrates open spaces removed from large-scale formal processes.

Reform, imitation, coexistence, integration, and individualization: these historical concepts in dealing with East Asian sounds, instruments, and genres make it particularly clear how closely composition in East Asia was, and still is, linked to broader sociocultural developments, but also how differently the responses to the challenges of aesthetic and political modernity could be conceived. In these conceptual constellations, a realm of absolute alterity (Hashimoto's and Yamada's dualistic orchestral settings, Zhu's and Takemitsu's contrasting time strata), rationalized mediation (Liu's and Miyagi's reforms), and stylistic leveling and appropriation (the Chinese symphony orchestra, Shi's virtuoso concerto, the conservatoire style) -

53 Mittler, Dangerous Tunes, 151.

54 Kouwenhoven, "Mainland China's New Music (II)," 65 and Sun, "Zhu Jian'er's Symphonies."

55 Kouwenhoven, "Mainland China's New Music (II)," 65. 
was staked out along with substantial attempts at a re-invention of an independent Asian modernity filtered through the ethics and aesthetics of recent musical modernism (Avshalomov, Tcherepnin, Fraenkel). The potential for intercultural mediation and transformation in East Asian music history emerging from these fundamental concepts will now be further explored by the case studies in this chapter.

\section{Triggering Musical Modernism in China: The Work of Wolfgang Fraenkel in Shanghai Exile}

The history of early musical modernism in East Asia has not yet been written with an adequate multiplicity of perspectives. Initial studies that have approached this topic ${ }^{56}$ confirm that European composers and musicians sometimes played important roles in the formation of a modern musical identity in East Asian countries. These European figures' roles, however, often remained ambivalent in a colonial, semi-colonial, or postcolonial situation due to the obvious tension between a sometimes obvious contempt for Asian musicians and a sensitive empathy for local circumstances and traditions. The Shanghai of the first half of the twentieth century offers a wealth of examples. The interactions, collaborations, and conflicts between Russian and Western European and Chinese inhabitants as well as colonial (Western and Japanese) administrators in Shanghai's internationalized music scene in the late 1930 s and early 1940s were intensified by the presence of a significant number of Jewish musicians fleeing Nazi Germany and Austria. Only three of them may count among representatives of Western musical modernism: Alban Berg's German student and assistant Julius Schloß (1902-1972); the pianist Karl Steiner (1912-2001), also from Schoenberg's Viennese circle; and the Berlin composer, musician, and judge Wolfgang Fraenkel (1897-1983). All three arrived in Shanghai in 1939 as refugees from Nazism after being detained for a few months in concentration camps. The lives and artistic work of Schloß and Steiner have been documented as part of research on the history of the Schoenberg school ${ }^{57}$ and Fraenkel's case has only been studied since 2003 . The following overview summarizes his work in Shanghai as a musician, teacher, and composer while attempting to identify essential starting points for research on Fraenkel. ${ }^{58}$

56 See Sawabe, Neue Musik in Japan von 1950 bis 1960, 15-33, Mittler, Dangerous Tunes, 21-32, Galliano, Yōgaku, 27-123, Utz, Neue Musik und Interkulturalität, 206-222, Melvin and Cai, Rhapsody in Red, and Liu, A Critical History of New Music in China, 23-286.

57 On Schloß see Krones, "Es waere die Erfuellung eines meiner ernstesten Wuensche und Pflichten, die LULU zu vollenden," Krones, "Julius Schloß," Fricke, "Ein saarländischer Vertreter der Zweiten Wiener Schule," and Fricke, "Julius Schloß." On Steiner, see Krones, "Karl Steiner - ein später Pianist der 'Wiener Schule," Gaub, "Karl Steiner," Baier, "50 Jahre danach: Julius Schloss, Karl Steiner, Jenö Takács," Steiner, "50 nian zhi hou," and Steiner, "Report About My Years in Shanghai, 1939-1949." In 2003 I published the first of several articles on Fraenkel, on which this part of the chapter is based (see Appendix).

58 The documents of the Fraenkel estate cited below are part of the musical estate of Wolfgang Fraenkel, Bavarian State Library, Music Department, Mus.ms. 19557-19828 (here cited as mus. est.), and the literary estate Wolfgang Fraenkel, Bavarian State Library, Department of Manuscripts and Rare Books, ANA 496, Sch[achteln] (boxes) 1-6 (here cited as lit. est.). So far, only two studies have dealt with Fraenkel's estate: Kellermann, "Kellermann-Verzeichnis der Werke von Wolfgang Fraenkel" and Fraenkel, Afunktionelle Musik (edited and with a commentary by Markus Köhler). Fraenkel's musical works are identified below using the Kellermann catalogue of Fraenkel's works (Kel.V.). There is also a rudimentary overview of the Fraenkel estate in McCredie, "Komponisten, die in den westpazifischen Raum und nach Ozeanien emigrierten" and McCredie, "Die emigrierten euro- 


\section{Wolfgang Fraenkel's Development as a Composer and Path to Exile}

Wolfgang Fraenkel was born in Berlin on 10 October 1897, the son of the respected lawyer Philipp and Agnes Fraenkel (née Krenz), and married Rosa Fraenkel (née Nebenzahl) in 1929. As a child and as young man, Fraenkel took violin lessons with Max Heinecke, a member of the Waldemar Meyer String Quartet, and Issay Barmas (1872-1946), and later violin and viola lessons with P. Saager, the principal viola player of the Berlin State Opera. He studied piano and music theory at the Klindworth-Scharwenka Conservatory ${ }^{59}$ and later, after being forced out of his position as a district court counselor (Amts- and Landgerichtsrat), conducting with Julius Prüwer of the Berlin Philharmonic Orchestra. On graduation from high school, he studied law at Berlin University until the beginning of World War I, during which he served in the German army. After the war, Fraenkel completed his studies in law in 1923 and from 1929 worked as district court counselor until April 1933, when, as a consequence of Hitler's seizure of power, all Jews were removed from public office. From 1933 until November 1938, now "Landgerichtsrat a.D." (retired district court counselor), he worked as a freelance musician, composer, and conductor, taking part in a number of performances organized by the Kulturbund Deutscher Juden (Jewish Cultural League), which was a central instrument for the isolation and control of Jewish artists by the "culture officer" (Kulturreferent) Hans Hinkel and existed from June 1933 to 11 September $1941 .^{60}$ An example of these activities is Fraenkel's direction of a series of performances of Stravinsky's L'Histoire du Soldat (1918), which he conducted in 1936 and $1937 .{ }^{61}$

jüdischen Komponisten im ostasiatischen Raum." Additional information is drawn from the Archives of the Far Eastern Jewish Central Information Bureau (DALJEWCIB) Harbin-Shanghai at The Central Archives for the History of the Jewish People (PBC), The Hebrew University of Jerusalem, DAL 1119 Fraenkel, Wolfgang (microfilmed for the United States Holocaust Memorial Museum 2007) (here quoted as DAL 1119). All material is quoted and reproduced here with kind permission of the libraries and archives. For basic information on the life and work of Jewish exiles in Shanghai in the field of music during and after World War II, see, among others, Cheung, "Divide and Connections in Chinese Musical Modernity," Fetthauer, "Das Far Eastern Jewish Central Information Bureau in Harbin und Shanghai," Eory, "Zur Rolle der Musik für zentraleuropäische jüdische Flüchtlinge in der Diaspora Shanghai," Xu, "Youtai yinyuejia zai Shanghai," Xu, "Nacui tudao xia de toushengzhe," Xu, "The Influence of]ewish Refugees on the Musical and Intellectual Life of Shanghai," Xu, "Jews and the Musical Life of Shanghai," Xu, Xunfang Youtairen, Tang, "Musical Life in the Jewish Refugee Community in Shanghai," Tang, "Reconstructing the Vanished Musical Life of the Shanghai Jewish Diaspora," Tang, Shanghai Youtai shequ de yinyue shenghuo, Melvin and Cai, Rhapsody in Red, 100-106, and Rosenson, "Jewish Musicians in Shanghai."

59 The Klindworth-Scharwenka Conservatory was founded in 1893 out of an amalgamation of Karl Klindworth's (1830-1916) and Xaver Scharwenka's (1850-1924) piano conservatories. Under the direction of Xaver's brother Philipp (until his death in 1917) and Antonín Dvořák's student Robert Robitschek (until 1937), the conservatory played an important role in Berlin's musical life.

60 See Geisel and Broder, Der Jüdische Kulturbund 1933-1941.

61 Programs of these concerts can be found in the lit. est., ANA 496, Sch. 5, "Programme." The outstanding quality of Fraenkel's conducting of this work in Berlin and Breslau is also mentioned in a letter of recommendation from 10/09/1938 by Oscar Guttmann (DAL 1119). In a late letter to Hans Moldenhauer, Fraenkel reports on these Stravinsky performances in a way that does not reflect well on the Kulturbund: "[...] die Leitung des Kulturbundes hat uns aber so viele Steine in den Weg gelegt, dass wir es nur zu einer Wiederholung in Berlin und zu einer Aufführung in Breslau brachten - wenn Sie über den geliebten Kulturbund weiteres wissen wollen, bin ich gerne bereit zu berichten, muss aber betonen, dass der Kbund sich ausserordentlich gut benahm, als ich im KZ. war und für meine baldige Entlassung wirklich viel getan hat!!" (Letter Wolfgang Fraenkel to Hans Moldenhauer, Los Angeles, 17/01/1973, lit. est., ANA 496, Sch. 5, "Korrespondenz." "[...] the administrators of the Kulturbund have put so many obstacles in our way that we accomplished only one repeat performance in Berlin and one performance 
In November 1938, Fraenkel was imprisoned at Sachsenhausen concentration camp in Oranienburg, near Berlin, as probably one of 6,000 Jewish males who were deported to Sachsenhausen following the "Reichskristallnacht" pogrom on 9 November. As his mother was considered to be "Aryan" and he promised to leave the country immediately, he was released from Sachsenhausen with the help of the Kulturbund after one or two months, probably in late 1938 or early 1939. In 1939, 12,089 German and Austrian refugees reached Shanghai as a "port of last resort," since the international city was the only remaining place worldwide that did not require visa or even a passport for immigration. ${ }^{62}$ Among the roughly 18,000 German and Austrian refugees who reached Shanghai in this period, a considerable number -450 (2.5\%) - were musicians. ${ }^{63}$

Fraenkel left for Shanghai on the Conte Rosso, a famous Italian Lloyd-Triestino liner, on 12 April 1939 and arrived in Shanghai on 7 May $1939 .{ }^{64}$ Deprived of most of their personal belongings and only allowed personal funds of 10 Reichsmark (4 US \$), the refugees arrived in Shanghai after a long and exhausting journey, mostly in poor material condition and without any preparation for living in a Chinese - albeit very international - city. The situation of the Jewish refugees was partly relieved by the activities of several self-founded Jewish assistance organizations, such as the Speelman committee (Committee for Assistance of European Refugees in Shanghai) of the Dutch businessman Michel Speelman, which provided housing and a monthly stipend for a certain period to the victims of the Nazi regime, and the Far Eastern Jewish Central Information Bureau in Harbin und Shanghai, which established contacts to local employers and provided advice.

During the eight years he spent in Shanghai, Wolfgang Fraenkel had at least six different addresses: in November 1939 he was registered at 372 Bourgeat (Pushi lu, today named Changle $l u$ ) in the French Concession (the part of the city where most Russian as well as Western European immigrants lived). ${ }^{65}$ Around 1941 he lived in Chengdu lu and by early 1943 in the "Cosmopolitan Centre" (Shijie Xin Cun) in Tianping lu. ${ }^{66}$ On 18 February 1943 the Japanese government announced that all "stateless refugees" (designating all Jewish refugees who had arrived in Shanghai from 1937 onward) were to move to a marked-off area in Hongkou (a northern district of Shanghai) within three months. Fraenkel relocated to this Jewish Ghetto in Hongkou where, according to his former student Qin Xixuan, he first lived in Zhabei $l u .{ }^{67}$ In the "List of Foreigners in Dee Lay Jao Police District" from 24 August 1944, he is registered as "Dolf-

in Breslau -ifyou would like to know more about the beloved Kulturbund I am happy to report but I have to stress that the K[ultur]bund behaved exceptionally well when I was in concentration camp and really did a lot for my early release!!")

62 See Ristiano, Port of Last Resort and Messmer, Jewish Wayfarers in Modern China.

63 Fetthauer, "Das Far Eastern Jewish Central Information Bureau in Harbin und Shanghai," 52.

64 Letter from the Hilfsverein der Juden in Deutschland (Aid Association of German Jews) to the Far Eastern Jewish Central Information Bureau (DALJEWCIB) Harbin 14/03/1939 and Fraenkel's letter to DALJEWCIB from 25/05/1939 (DAL 1119). On the Hilfsverein, which had been founded in 1901 and closed down by the Nazis in 1939, see AdlerRudel, "Jüdische Selbsthilfe unter dem Naziregime 1933-1939."

65 Emigranten Adressbuch für Shanghai. Mit einem Anhang: Branchen-Register, Facsimile reprint of the original edition (Shanghai: The New Star Company 1939), Hong Kong, 1995. Fraenkel announced his activities as a private teacher of music theory, harmony, counterpoint, composition, and instrumental practice in the North-China Daily News between December 1939 and October 1940 under the address 1434 Avenue Road, Room 25 (today Beijing Road) (information provided by Sophie Fetthauer).

66 Personal communication from Fraenkel's former student Sang Tong, Shanghai, November 2002.

67 Personal communication from Fraenkel's former student Qin Xixuan, Beijing, December 2002. 
gang [sic] Fraenkel, Musician," age 48, together with his wife, Rosa Fraenkel, age 46, in 343/53 Zangyang lu (most likely an incorrect transcription of Changyang lu, formerly Ward Road/ Huade lu, one of the main streets in the Hongkou Ghetto). ${ }^{68}$ He probably moved again in 1946, to Yuyuan lu no. 1000 in the French Concession, where he was still registered in $1947 .^{69}$

Fraenkel's artistic development before 1939 reflects different trends of the early twentieth century, namely neoclassicism, free atonality, and twelve-tone technique. His most important works of this period include the opera Der brennende Dornbusch (The Burning Bush, 1926-28, Kel.V. 190) after Oskar Kokoschka and the cantata Die 82. Sure des Koran (1936, Kel.V. 112). The cantata was premiered on 9 November 1937 under the direction of Fraenkel by the Haarlem Orchestra Association and the alto Paula Lindberg in Haarlem (Netherlands). ${ }^{70}$ In addition, he composed two string quartets (1923-24, Kel.V. 19 and 20), Musik mit konzertanter Flöte (Music with Concertante Flute, 1930, Kel.V. 13), the cantata Der Wegweiser (also listed as Musik mit obligater Oboe, 1931, Kel.V. 110), as well as a violin sonata and a cello sonata (1935, Kel.V. 29 and 34).

The works from the mid-1930s onward in particular show a self-confident atonal style in the tradition of the early Schoenberg, largely without systematic use of the twelve-tone method, which Fraenkel had probably known since the early 1930s. Fraenkel's personal contact with Schoenberg during the latter's professorship at the Akademie der Künste (1926-33) or with Schoenberg's Berlin circle cannot currently be proven, however, and it seems likely that Fraenkel cannot be considered part of Schoenberg's "Berlin School" in the narrower sense. Nevertheless, his further development makes it clear that Schoenberg's music and compositional aesthetics played a central role for him, but he could synthesize them from a distance, in a very original way, with other influences from Paul Hindemith to Ernst Kurth, as documented in his theoretical main work Afunktionelle Musik (Afunctional Music, 1937-43, see below).

Like numerous other exiles from Shanghai, Fraenkel left Shanghai when the Chinese Civil War broke out and moved to Los Angeles in August $1947 .{ }^{71}$ In the remaining 36 years he was able to celebrate some successes as a composer despite his slightly advanced age, and his work was beginning to be noticed in Europe. Three of his works were awarded European composition prizes, and on 21 October 1966 Bruno Maderna conducted the premiere of his Symphonische Aphorismen (1959), a work oriented toward Webern, at La Scala in Milan. At the age of 60, Fraenkel followed the latest developments in European music, writings by Karlheinz Stockhausen and Pierre Boulez can be found in his estate with notes and (sometimes critical) comments. In Los Angeles, Fraenkel also met Arnold Schoenberg and, on the latter's $75^{\text {th }}$ birthday on 13 September 1949, directed a performance of the Ode to Napoleon Buonaparte (1942) op. 41 in the version for string quartet, piano, and reciter. For this birthday he also dedicated his (freely atonal, not dodecaphonic) Music for String Quartet (1948-49, Kel.V. 21; Fig. 3.1) to Schoenberg.

68 The listis published on CD-ROMin Armbrüster, Kohlstruckand Mühlberger, Exil Shanghai1938-1947. Unfortunately the facsimile of the page on which Fraenkel is listed (page 65) cannot be found on the CD-ROM (page 85 is wrongly provided instead).

69 Personal communication from Fraenkel's former students Qin Xixuan and Zhou Guangren, Beijing, December 2002. This address is also listed in the Shi sheng tongxun lu (Record of Teachers and Students) of the National Conservatory of Music Shanghai, July 1947, 2.

70 Program in lit. est., ANA 496, Sch. 5, "Programme"; newspaper reviews in lit. est., ANA 496, Sch. 5, "Zeitungsartikel und Kritiken."

71 Fraenkel's journey from Shanghai to Los Angeles can be reconstructed from the autograph score of Musik für großes Orchester (1946-48, Kel.V. 8), on which the following place names are indicated: Shanghai (p. 1), Nanjing (p. 35), Kobe (p. 36), Yokohama (p. 39), Honolulu (p. 51), San Francisco (p. 53), Los Angeles (p. 55). See footnote 133. 
Figure 3.1: Letter from Wolfgang Fraenkel to Arnold Schoenberg, 14 September 1949

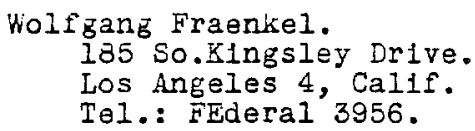

14. September 1349.

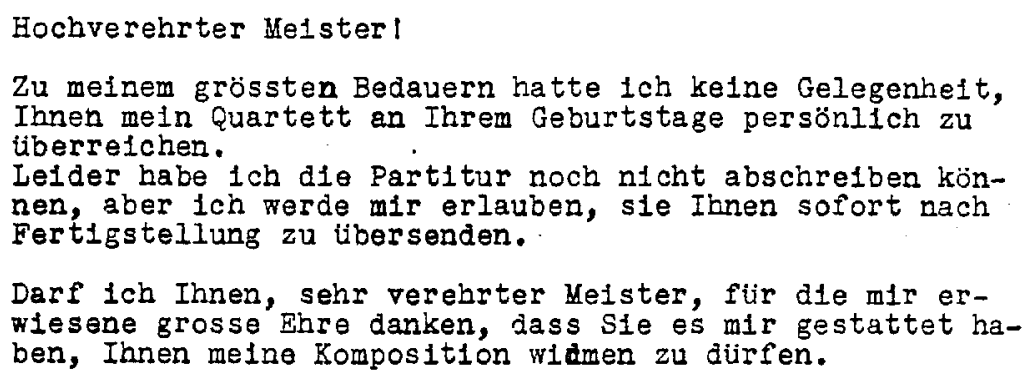

Ich verbleibe

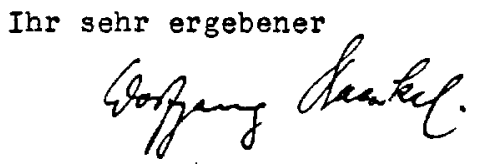

Copyright ( ) by Arnold Schönberg Center Vienna

Wolfgang Fraenkel died in 1983 at the age of 85 . He left behind 193 works, 19 of which remained unfinished. Most of the scores have survived in Fraenkel's hand-written manuscript; only a few were published during his lifetime. ${ }^{72}$

72 Most notably, the published scores include 3 Impromptus for Pianoforte, Ries \& Erler, Berlin c. 1921 (R 9175 E), Die 82. Sure des Koran for alto voice, string orchestra, and timpani, Universal Edition, Vienna c. 1948 (UE 11880), and Variationen und Fantasien über ein Thema von Arnold Schönberg for piano, Universal Edition, Vienna 1959 (UE 12549) (the theme on which the latter work is based is no. 3 from Schoenberg's Six little Piano Pieces op. 19, 1911). 


\section{Fraenkel's Activities as Musician, Pedagogue, and Composer in Shanghai}

\section{Fraenkel as a Musician and Conductor}

In a letter to the Far Eastern Jewish Central Information Bureau written about two weeks after his arrival, Fraenkel stated that in Shanghai there would be "no prospects at all to earn money even to the most modest extent.. ${ }^{73} \mathrm{He}$ was therefore prepared to move on to Harbin or other East Asian cities. Due to its large Russian population, Harbin was still viewed by many immigrants (possibly including Fraenkel) as a city characterized by a "European" cultural life. Russian immigration to Harbin (Russian: Charbin), the "St. Petersburg of the East," a city founded by Russia after occupying Northern Manchuria in 1898, had started in the early twentieth century with economic migrants and Jewish refugees fleeing poor living conditions and antiSemitic persecution..$^{74}$ Another wave of Russian immigrants fled to Harbin after the October Revolution in 1917. Russians contributed significantly to musical life in Harbin including a symphony orchestra, a music academy, and a string quartet..$^{75}$ After Japan occupied Manchuria in 1931, a large number of Russian immigrants moved to Shanghai, which soon became the new center of internationalized cultural life, continuing despite the escalating Second Sino-Japanese War (1937-45), including the battle of Shanghai in 1937, and the Pacific War (1941-45).

The reply from the Bureau's manager Meir (Meyer Eliash) Birman ${ }^{76}$ to Fraenkel states that in Harbin too, "the opportunities for serious musicians have now begun to be very restricted." Birman recommends to Fraenkel to orient himself toward Tianjin (Tientsin), and regrets that Fraenkel had "come to Shanghai so late." ${ }^{77}$ In a letter to Fraenkel from 28 July 1939, however, the Bureau still offers to organize a position for Fraenkel at the Harbin Symphony Orchestra in autumn $1939 .^{78}$

Wolfgang Fraenkel stayed on in Shanghai, however, and began work as a musician immediately after his arrival (Tab. 3.1). Two arrangements written in Shanghai, both for viola and piano, already date from June 1939 (G.F. Handel, Passacaglia in G minor HWV 432/6, Kel.V. 197; J.S. Bach, Gavotte and Musette from the English Suite in G minor BWV 808, Kel.V. 198) and were possibly performed at the first concert in which Fraenkel is documented the have participated on 15(?) June 1939. The next chamber concert in which Fraenkel is listed as the violinist of a piano trio is documented on 25 October $1939 .{ }^{79}$ Possibly on the recommendation of Otto Klemperer and Hidemaro Konoe, and maybe also due to the strong support by Fritz Segall of the Berlin Künstlerhilfe der Jüdischen Gemeinde (Association for the Support of Artists of the Jewish Community), ${ }^{80}$ Fraenkel became a member of the Shanghai Municipal Orchestra (SMO) in early

73 Fraenkel's letter to the Far Eastern Jewish Central Information Bureau, Shanghai 25/05/1939 (DAL 1119).

74 Melvin and Cai, Rhapsody in Red, 100-101

75 Ibid., 101.

76 On Birman see Messmer, Jewish Wayfarers in Modern China, 27-28. The Bureau had its office in Harbin and only in autumn 1939 moved its office to Shanghai (Fetthauer, "Das Far Eastern Jewish Central Information Bureau in Harbin und Shanghai," 60).

77 Letter of the Far Eastern Jewish Central Information Bureau to Fraenkel 12/06/1939 (DAL 1119).

78 Letter of the Far Eastern Jewish Central Information Bureau to Fraenkel 28/07/1939 (DAL 1119).

79 Lit. est., ANA 496, Sch. 5, "Programme."

80 Otto Klemperer (1885-1973), who had emigrated to the USA in April 1933, recommended Fraenkel, primarily as a violist, in a letter to the influential Japanese conductor Hidemaro Konoe $(\rightarrow$ III.1): "an Viscount Konoye. Lieber Herr Kollege! Darf ich Ihnen Herr [sic] Wolfgang Fränkel aus Berlin nachdrücklichst empfehlen. Er ist ein ausgezeichneter Musiker, der in vieler Hinsicht (vor allem als Bratschist) zu verwenden ist. Herzliche collegiale Grüsse 
1940, which since 1919 had developed into a professional ensemble under the direction of Mario Paci (1878-1946; head of SMO 1919-42). ${ }^{81}$ The SMO gave weekly concerts every Sunday at the Lyceum in the French Concession. ${ }^{82}$ In the orchestra, Fraenkel usually played the viola, although there is evidence that he occasionally played both first and second violin as well. ${ }^{83}$ Fraenkel also arranged repertoire for the SMO (Table 3.1). Due to the Pacific War, the SMO officially declared its dissolution on 1 May 1942 and on 31 May gave a "farewell concert" in which Fraenkel participated. The orchestra, however, continued to give regular concerts under the name of the Shanghai Philharmonic Society from 1942 to 1945, controlled by Japanese military authorities, and officially resumed work on 18 November 1945, now mostly designated as the Shanghai Municipal Symphony Orchestra. ${ }^{84}$ Fraenkel's estate contains sixteen programs that document

Ihr Klemperer, Jan 24. 39" (lit. est., ANA 496, Sch. 5, "Korrespondenz"). Klemperer wrote a similar short recommendation to Joseph Rosenstock (1895-1985), who at that time was principal conductor of the New Symphony Orchestra (which became the NHK Orchestra in 1951) (before his emigration, Rosenstock had been director of the Berlin orchestra of the Kulturbund deutscher]uden from 1933 to 1936). Fraenkel had definitely considered the option of immigrating to Japan (Xu, Xunfang Youtairen, 75-76), and was likely also aware of the considerable influence of Japanese musicians in Harbin, Shanghai, and other Chinese cities. Konoe (1898-1973), who was probably in Berlin at the time of Fraenkel's departure, may have paved the way for Fraenkel into the musical life of the city in the Japanese-administered Shanghai. Konoe was the brother of Fumimaro Konoe (1891-1945, Japanese Prime Minister 1937-39 and 1940-41). Hidemaro Konoe, a conductor, pianist and composer and an important figure in Japanese Mahler reception, had studied with Erich Kleiber in Berlin and was in close contact with well-known conductors of the time such as Furtwängler, Stokowski and Klemperer; he conducted the Berlin Philharmonic several times during the 1930s. Together with the Japanese composer Kunihiko Hashimoto, Konoe had helped Manfred Gurlitt (1890-1972) emigrate to Japan in the same period (early 1939) (see Suchy, "Deutschsprachige Musiker in Japan vor 1945," 196). The strong support from the Künstlerhilfe is documented in a letter by Segall to the Hilfsverein der Juden in Deutschland (26/01/1939) and to the Far Eastern Jewish Central Information Bureau (10/03/1939) (DAL 1119).

81 On the SMO, see Yang, "From Colonial Modernity to Global Identity," Tang, Diguo feishan bianzouqu, Bickers, "The Createst Cultural Asset East of Suez," and Melvin and Cai, Rhapsody in Red, 17-44. On Paci see also ibid., 117-124, 147-154. Melvin and Cai emphasize the positive effects of Paci's work and his support for Chinese musicians (ibid., 322-323), while he is represented in some Chinese and Western studies as a representative of Western imperialism and cultural colonialism. Yang also paints a positive image of Paci by emphasizing the broad and modern repertoire introduced by the Italian conductor (Yang, "From Colonial Modernity to Clobal Identity," 52-53). The orchestra had adopted the name "Shanghai Municipal Orchestra" in 1922; before, it was known as the Shanghai Public Band (emerging from a town band for British settlers in the Shanghai International Settlement founded in 1879), and is known today as the Shanghai Symphony Orchestra (SSO) (ibid., 49-50). Chinese audiences were admitted to the SMO's concerts only from 1925 (ibid.). About ten musicians from the GermanAustrian refugee community became members of the SMO or played with the orchestra occasionally; besides Fraenkel and Ferdinand Adler (violinist from Vienna, see footnote 119), this group included the violinist Otto Joachim (1910-2010) and his brother, the cellist Walter Joachim (1912-2001) as well as the violinist and pianist Alfred Wittenberg (1880-1952), a student of Joseph Joachim. See Xu, "Jews and the Musical Life of Shanghai" and Rosenson, "Jewish Musicians in Shanghai." Other emigrants who were musicians of the orchestra included Eugen Winkler (violoncello), Helmut Spittel (clarinet), Adolf Steiner (violin), Alexander Spoliansky (violoncello), Joe Glash (double bass), and Henry Margolinsky (conducting).

82 The SMO's concerts had taken place at the municipal town hall up to 1930 but after the town hall was sold to a private owner, concerts were held in several theater halls with the Lyceum becoming the orchestra's permanent performance venue in 1934 (ibid., 51).

83 See the concert on 21 January 1940 (Tab. 3.1) and Xu, "Youtai yinyuejia zai Shanghai," part 2, 1-2.

84 Tang, "Japanese Musicians and the Shanghai Municipal Orchestra (1942-45)" provides a detailed history of the concert activities during this three-year period. The conductors of the orchestra during this period were Arrigo Foa, Alexander Sloutsky, and Henry Margolinsky. 
Figure 3.2: Fraenkel's portrait in the newspaper preview of the Shanghai Songsters' concerts, 18 and 20/2/1941 (The Shanghai Sunday Times, 2/2/1941)

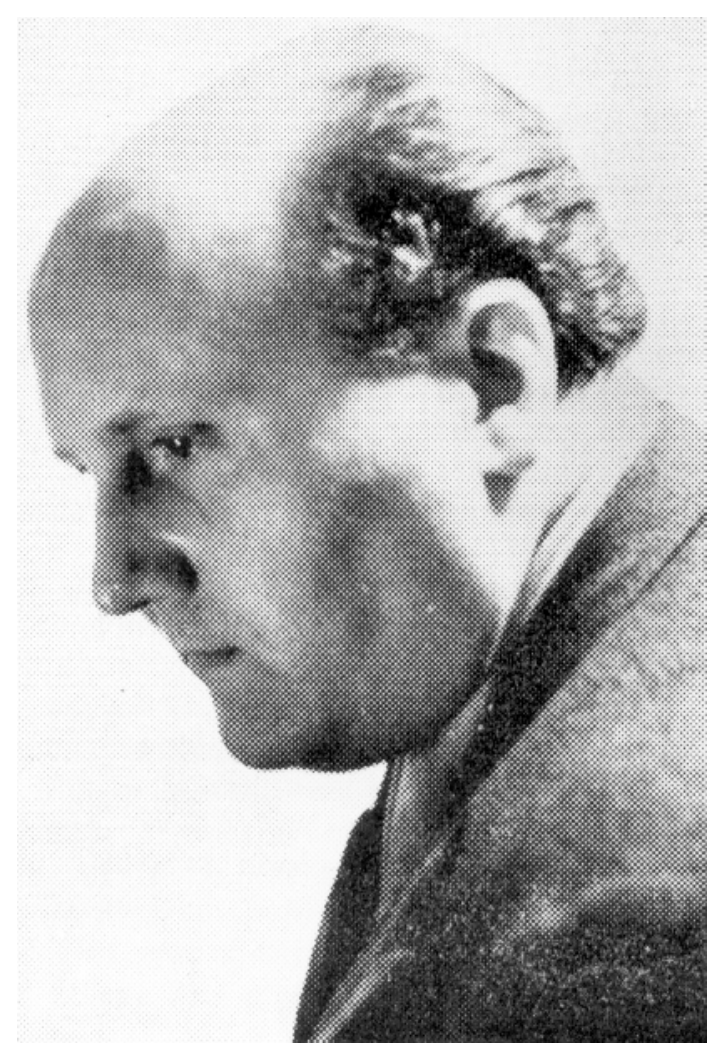

Bavarian State Library, Abteilung Handschriften and Seltene Drucke, ANA 496 his activities as a musician (Table 3.1), but it can be assumed that he participated in many more concerts, especially in his role as a member of the SMO.

How did Fraenkel act and react in the Shanghai environment that was deeply affected by diverse and often contradictory political, economic, and cultural interests? Even if no documents have yet come to light that reveal his emotional reactions or his more personal considerations, the sociohistorical context suggests that the daily struggle for existence that characterized the life of most Shanghai refugees ${ }^{85}$ was an immediate challenge for him too, at least in the beginning. In this situation, a mixture of determination, foresight, clearly defined goals, and a certain pragmatism (which does not mean opportunism) surely helped him to survive, while his multi-faceted musical talent allowed him to find a broad range of music-related occupations. Within a relatively short time, Fraenkel worked as a violinist, violist, pianist, orchestral and choral conductor (Fig. 3.2, 3.3), teacher of music theory and composition, writer of theoretical essays, and arranger and composer for dance and film productions. Even though he knew how to settle in the European enclave of Shanghai and certainly had to come to terms with Japanese rulers or Chinese collaborators - although he undoubtedly tried to stay out of political entanglements ${ }^{86}-$ he never did so at the expense of Chinese or European colleagues or students. On the contrary, his high level of commitment clearly went beyond what was necessary.

In 1939, Fraenkel encountered a situation in which a musical practice based on European tradition that went beyond mere colonial culture was still in its early stages, but had already been an object of heated discussion. It was not until 1938 that the SMO began to regularly

85 See among others Armbrüster, Kohlstruck, and Mühlberger, Exil Shanghai 1938-1947.

86 Activities related to Japan such as the arrangement of Japanese dances for Western orchestra (for a dance evening on April 18, 1940; lit. est., ANA 496, Sch. 5 "Programme") or film music for a Japanese sound film (1942; note in Shanghai Jewish Chronicle 9/8/1942; lit. est., ANA 496, Sch. 5, "Zeitungsartikel und Kritiken") may have been concessions to the situation, which were difficult to avoid from an economic and political point of view. 
appoint Chinese orchestral members. ${ }^{87}$ The music created by Chinese composers during that period mostly remained in the context of a simple tonal style accentuated by pentatonic scales at a low level $(\rightarrow$ III.1). Still, the SMO supported works by Chinese composers; the first work by a Chinese composer, Huang Zi's overture In Memoriam (1929), was performed on 23 November $1930 .{ }^{88}$ After 1929, the SMO also began to feature Chinese soloists regularly. ${ }^{89}$

Under these circumstances, and in view of the difficult material and political situation during the war years, it was remarkable that Fraenkel was involved in building a youth orchestra (Zhongguo Qingnian Jiaoxiang Yuetuan) during and after the war, founded by his students Li Delun ${ }^{90}$ (1917-2001), who later became one of China's leading conductors, and his later wife, the violinist Li Jue (1924-2013). The China Symphonic Orchestra (Zhongguo Jiaoxiang Yuetuan), which Fraenkel conducted several times in 1945 and 1946 with very demanding programs, emerged from the same context (Li Delun and Li Jue also played here). A concert on 1 March 1946 with Fraenkel conducting Mendelssohn's Violin Concerto and Beethoven's Pastoral Symphony among other works (Fig. 3.3) was praised by the German critic Alfred Dreifuß (19021993), who informed his readers that the orchestra had been founded during the war years "under difficult circumstances," adding the observation that Fraenkel, a "pedagogue wellknown in Shanghai's musical life," had made a "cultural effort [...] that can hardly be overstated." ${ }^{91}$ The orchestra may have been closely linked to the conservatory, since Li Weining, the president of the conservatory, is listed on the program booklet as the orchestra's "advisor."

87 Rosenson, "Jewish Musicians in Shanghai," 241 and Yang, "From Colonial Modernity to Global Identity," 58. An exception was Tan Shuzhen (1907-2002), who had been violinist of the SMO from 1927 to 1929. Tan Shuzhen later became the head of the violin department at the Shanghai Conservatory and played a prominent role in the well-known documentary From Mao to Mozart (1979, directed by Murray Lerner). See also the extensive depiction of Tan's impact in Melvin and Cai, Rhapsody in Red.

88 Yang, "From Colonial Modernity to Global Identity," 53.

89 Ibid., 54-57.

90 See Melvin and Cai, Rhapsody in Red, 154-158 and Kraus, Pianos \& Politics in China, 212-213. Li Delun was the principal conductor of the Central Philharmonic Orchestra (Zhongyang Yuetuan) in Beijing for many years and was one of the few musicians in China to play a key role in Chinese musical life before, during, and after the Cultural Revolution. With his orchestra he contributed to the musical realization of the model works (yangbanxi, $\rightarrow$ III.1) during the Cultural Revolution and after the Cultural Revolution he conducted the first performance after more than ten years by a Chinese orchestra of a European orchestral work (Beethoven's Fifth Symphony) on 26 March 1977 (in September 1973 the Philadelphia Orchestra under Eugene Ormandy had performed Beethoven's Fifth and Sixth Symphonies for the first time in China since 1963, during guest appearances in Beijing and Shanghai; see Melvin and Cai, Rhapsody in Red, 268-279). Li Delun became internationally known through the film From Mao to Mozart (1979, see footnote 87), in 1999 he conducted a "reunion" concert with Isaac Stern in Shanghai to celebrate the film's 2oth anniversary (see ibid., 288-289, 296).

91 A[lfred] Dreifuss, "Wolfgang Fraenkel dirigierte!" In The Shanghai Herald. Cerman Supplement 1946, no. 2, 03/06/1946: 8, lit. est., ANA 496, Sch. 5, “Zeitungsartikel und Kritiken.” (“Das 'China Symphonic Orchestra,' [...] unter schwierigen Umstaenden schon waehrend des Krieges gebildet und arbeitend [...]. [...] Der im Schanghaier Musikleben wohlbekannte Paedagoge Professor Wolfgang Fraenkel hat mit der Heranbildung und Erziehung dieses Klangkoerpers eine Kulturarbeit geleistet, die gar nicht hoch genug bewertet werden kann."). On Dreifuß see Fetthauer, "Alfred Dreifuß." 
Figure 3.3: Program booklet for the concert at the Lyceum Theater Shanghai, 01/03/1946;

Fraenkel conducted the China Symphonic Orchestra

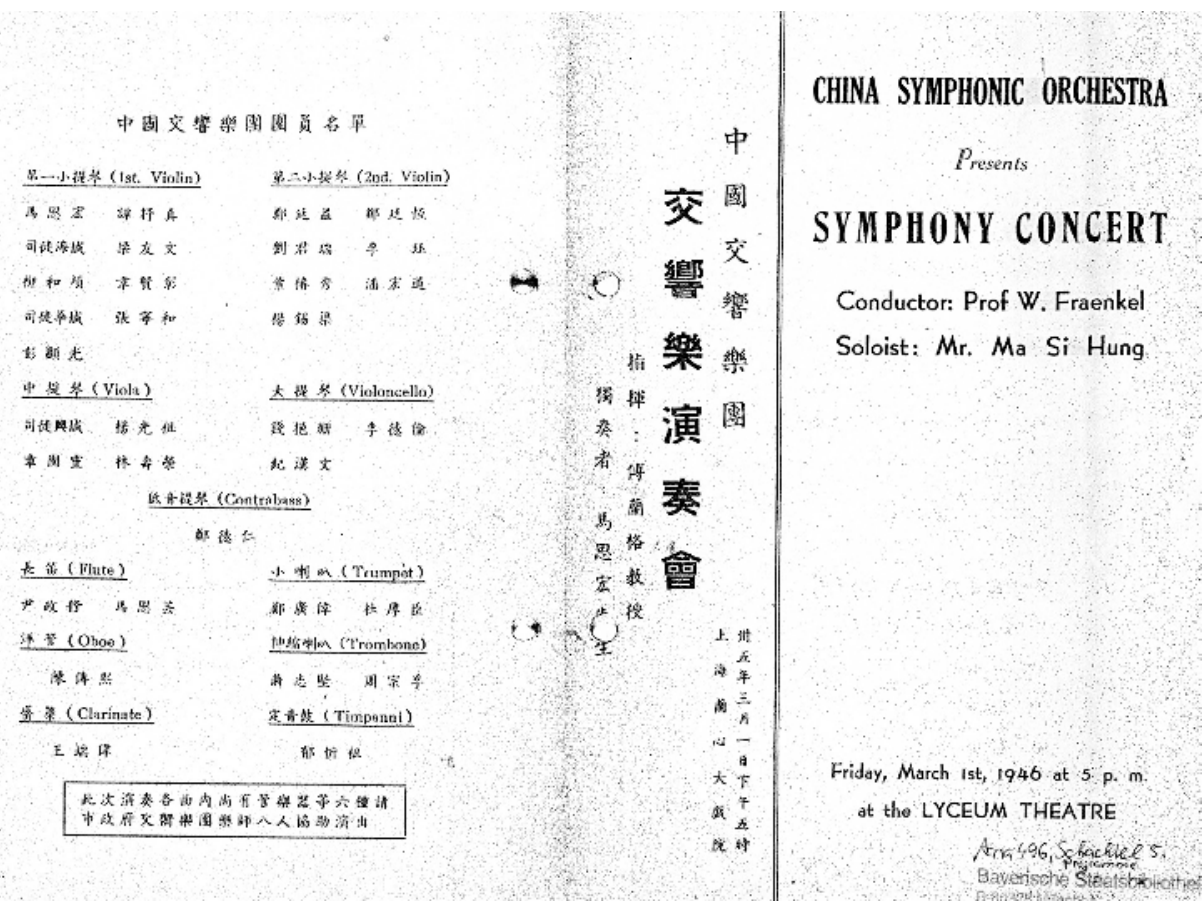

Table 3.1: Concerts 1939-1946, in which Wolfgang Fraenkel participated; lit. est., ANA 496, Sch. 5, "Programme" and "Zeitungsartikel und Kritiken"

\begin{tabular}{|l|l|l|l|l|}
\hline Date & Venue & Performers & Program & Sources/Comments \\
\hline 15(?)/06/1939 & $\begin{array}{l}\text { Young Women's } \\
\text { Christian Asso- } \\
\text { ciation (YWCA), } \\
\text { 999 Bubbling } \\
\text { Well Road }\end{array}$ & $\begin{array}{l}\text { Irene Seidel-Margolinski, } \\
\text { soprano; Max Warschauer; } \\
\text { Wolfgang Fraenkel; Henry } \\
\text { Margolinski }\end{array}$ & & $\begin{array}{l}\text { The North-China Daily News, } \\
16 / 06 / 1939,3\end{array}$ \\
\hline $25 / 10 / 1939$ & $\begin{array}{l}\text { American } \\
\text { Women's Club }\end{array}$ & $\begin{array}{l}\text { Chamber music concert. } \\
\text { piano trio with Fraenkel as } \\
\text { a violinist }\end{array}$ & $\begin{array}{l}\text { Beethoven, Ravel, } \\
\text { Dvořák }\end{array}$ & $\begin{array}{l}\text { Program, four announcements } \\
\text { in North-China Daily News, } \\
\text { 22/10/1939 among others, concert } \\
\text { review in Le Journal de Shanghai, } \\
\text { 29/10/1939 (Ch[arles] Grosbois) }\end{array}$ \\
\hline 21/01/1940 & $\begin{array}{l}\text { Lyceum Theatre } \\
\text { (Lanxin daxi } \\
\text { yuan) }\end{array}$ & $\begin{array}{l}\text { Shanghai Municipal Orches- } \\
\text { tra (Shanghai gongbuju } \\
\text { guanxian yuedui); conductor: } \\
\text { Mario Paci }\end{array}$ & $\begin{array}{l}\text { Scriabin, Gretchani- } \\
\text { nov, Vasily Kalinnikov, } \\
\text { Dvoŕák, Richard } \\
\text { Strauss }\end{array}$ & $\begin{array}{l}\text { Concert review in North-China } \\
\text { Daily News, 23/01/1940 (Fraenkel } \\
\text { played the first violin and } \\
\text { arranged two songs by Alexander } \\
\text { Gretchaninov for orchestra) }\end{array}$ \\
\hline
\end{tabular}




\begin{tabular}{|c|c|c|c|c|}
\hline 18/04/1940 & Lyceum Theatre & $\begin{array}{l}\text { Dance performance with } \\
\text { Slavina-Brown and Indira } \\
\text { Devi; Aaron Avshalomov, } \\
\text { conductor }\end{array}$ & $\begin{array}{l}\text { Arrangements of } \\
\text { traditional Indian and } \\
\text { Japanese dances, in- } \\
\text { cluding two Japanese } \\
\text { dances arranged by } \\
\text { Fraenkel: Ombacha } \\
\text { and Three Masks } \\
\text { (Improvisation on a } \\
\text { Japanese Theme) }\end{array}$ & Program booklet \\
\hline 09/01/1941 & $\begin{array}{l}\text { XCDN Radio } \\
\text { broadcast }\end{array}$ & $\begin{array}{l}\text { Sabine Rapp, mezzo- } \\
\text { soprano; Fraenkel, piano }\end{array}$ & $\begin{array}{l}\text { Songs by Dowland, } \\
\text { Purcell, Schubert }\end{array}$ & $\begin{array}{l}\text { Newspaper announcement in The } \\
\text { China Press, 08/01/1941 }\end{array}$ \\
\hline $\begin{array}{l}18 \& \\
20 / 02 / 1941\end{array}$ & Lyceum Theatre & $\begin{array}{l}\text { Shanghai Songsters and } \\
\text { Shanghai Cantonese Union } \\
\text { Church Orchestra conducted } \\
\text { by Fraenkel }\end{array}$ & Bach, Purcell, Mozart & $\begin{array}{l}\text { Program booklet. Fraenkel's } \\
\text { name is reproduced here as } \\
\text { Fa Lunke and he is incorrectly } \\
\text { presented as "Maestro Wolfgang } \\
\text { Fraenkel, formerly of Vienna and } \\
\text { now of the Shanghai Municipal } \\
\text { Orchestra." Several newspaper } \\
\text { announcements, including one } \\
\text { with a photo of Fraenkel; concert } \\
\text { review in Le Journal de Shanghai, } \\
23 / 02 / 1941\end{array}$ \\
\hline $04 / 05 / 1941$ & Lyceum Theatre & $\begin{array}{l}\text { Shanghai Municipal Orches- } \\
\text { tra chamber music program. } \\
\text { Fraenkel played a viola part } \\
\text { in a Brahms String Sextet. }\end{array}$ & $\begin{array}{l}\text { Brahms: String } \\
\text { Sextett, Franck: } \\
\text { Violin Sonata (Arrigo } \\
\text { Foa, vl.; Boris } \\
\text { Zakharoff, pno.) }\end{array}$ & Program booklet \\
\hline 28/03/1942 & $\begin{array}{l}\text { Jewish Club } \\
\text { Shanghai }\end{array}$ & $\begin{array}{l}\text { EJAS (European Jewish } \\
\text { Artists Society); Henry } \\
\text { Margolinski, Ferdinand Adler, } \\
\text { vl.; Fraenkel, vla.; John } \\
\text { Kraus, vc.; B. L. Usiskin, pno. }\end{array}$ & $\begin{array}{l}\text { Schubert: } \\
\text { Trout Quintet }\end{array}$ & Program booklet \\
\hline $04 / 04 / 1942$ & $\begin{array}{l}\text { Chinese YMCA, } \\
\text { Auditorium }\end{array}$ & $\begin{array}{l}\text { Song recital by Sabine Rapp, } \\
\text { mezzo-soprano; Fraenkel } \\
\text { and Li Weining, pno. }\end{array}$ & $\begin{array}{l}\text { songs by Wolf, } \\
\text { Wagner, Brahms, De- } \\
\text { bussy, Bizet (Fraenkel, } \\
\text { pno.), Li Weining, } \\
\text { Schubert (Li, pno.) }\end{array}$ & $\begin{array}{l}\text { Program book, concert reviews } \\
\text { in Shanghai Jewish Chronicle } \\
09 / 04 / 1942 \text { (Erwin Felber) and in } \\
\text { Le Journal de Shanghai 12/4/1942 } \\
\text { (Ch[arles] Grosbois) }\end{array}$ \\
\hline $31 / 05 / 1942$ & Lyceum Theatre & $\begin{array}{l}\text { Shanghai Municipal } \\
\text { Orchestra }\end{array}$ & Farewell Concert & Program booklet* \\
\hline $15 / 06 / 1944$ & $\begin{array}{l}\text { Jewish Club } \\
\text { Shanghai }\end{array}$ & Fraenkel, vl. & $\begin{array}{l}\text { Beethoven: Romance } \\
\text { no. } 2 \text { F major op. 50; } \\
\text { Henri Vieuxtemps, } \\
\text { Ballade et Polonaise } \\
\text { G major op. } 38\end{array}$ & Program booklet \\
\hline $02 / 04 / 1945$ & Ximen Road & $\begin{array}{l}\text { First Private Concert of the } \\
\text { Chinese Youth Orches- } \\
\text { tra (Zhongguo Qingnian } \\
\text { Yuetuan) }\end{array}$ & $\begin{array}{l}\text { J. S. Bach: Chromatic } \\
\text { fantasy and fugue } \\
\text { (arranged for } \\
\text { orchestra by } \\
\text { Fraenkel), Branden- } \\
\text { burg concerto no. } 5\end{array}$ & $\begin{array}{l}\text { Program booklet; Chinese } \\
\text { newspaper report }\end{array}$ \\
\hline
\end{tabular}




\begin{tabular}{|c|c|c|c|c|}
\hline $03 / 06 / 1945$ & $\begin{array}{l}\text { Da Hua Yingxi } \\
\text { Yuan (Great } \\
\text { Chinese Shadow- } \\
\text { play-Theatre) }\end{array}$ & $\begin{array}{l}\text { Fraenkel conducting the } \\
\text { Chinese Youth Orchestra. }\end{array}$ & $\begin{array}{l}\text { Beethoven: } \\
\text { Symphony no. } 1\end{array}$ & Program booklet \\
\hline $17 / 07 / 1945$ & Lyceum Theatre & $\begin{array}{l}\text { Fraenkel conducting the } \\
\text { China Symphonic Orchestra } \\
\text { (Zhongguo Jiaoxiang Yue- } \\
\text { tuan); Leonora Valesby, vl.; } \\
\text { William Hsu, vla. }\end{array}$ & $\begin{array}{l}\text { Mozart, Otto Nicolai, } \\
\text { Weber/Berlioz, } \\
\text { Johann Strauß }\end{array}$ & $\begin{array}{l}\text { Program booklet; concert review } \\
\text { in North China Daily News } \\
\text { 04/08/1945 (Erwin Felber); the } \\
\text { orchestra consisted exclusively } \\
\text { of Chinese musicians. }\end{array}$ \\
\hline 01/08/1945 & Lyceum Theatre & $\begin{array}{l}\text { Fraenkel conducting the } \\
\text { China Symphonic Orchestra; } \\
\text { Leonora Valesby, vl.; William } \\
\text { Hsu, vla. }\end{array}$ & $\begin{array}{l}\text { Mozart, Rossini, We- } \\
\text { ber/Berlioz, Johann } \\
\text { Strauß }\end{array}$ & $\begin{array}{l}\text { Program booklet; Concert review } \\
\text { in North China Daily News } \\
04 / 08 / 1945\end{array}$ \\
\hline $\begin{array}{l}\text { 28/02/1946 } \\
\text { (?) }\end{array}$ & Lyceum Theatre & $\begin{array}{l}\text { Fraenkel conducting the } \\
\text { China Symphonic Orchestra }\end{array}$ & $\begin{array}{l}\text { Mozart, Beethoven, } \\
\text { Rossini, Johann } \\
\text { Strauß }\end{array}$ & Program booklet \\
\hline 01/03/1946 & Lyceum Theatre & $\begin{array}{l}\text { Fraenkel conducting the } \\
\text { China Symphonic Orchestra, } \\
\text { Ma Si-Hong, vl. }\end{array}$ & $\begin{array}{l}\text { Mozart, Mendelssohn, } \\
\text { Beethoven }\end{array}$ & $\begin{array}{l}\text { Program booklet, concert } \\
\text { review in China Press Shanghai, } \\
\text { 05/03/1946, The Shanghai Herald, } \\
\text { 03/06/1946 (German review, } \\
\text { Dr. A. Dreifuss) and 05/03/1946. } \\
\text { The violinist Ma Si-Hon (Ma } \\
\text { Sihong) was celebrated by the } \\
\text { press. }\end{array}$ \\
\hline
\end{tabular}

(* This program is listed in the catalogue of lit. est., ANA 496, Sch. 6, but could not be found in the box; it is cited by Bickers, "The Greatest Cultural Asset East of Suez," from the Shanghai Municipal Archives W-1-997)

The high esteem Fraenkel enjoyed among the Shanghai music community and the cultural conflicts of this musical life are documented in a handwritten letter in English addressed to Fraenkel, dealing with a young female pianist referred to as "Kwong Kwong." The writer clearly means Tung Kwong-Kwong (Dong Guang-Guang, 1927-2013), a Chinese pianist who left China for the USA in 1947 and was married to Ma Si-Hon (Ma Sihong, 1925-2009), brother of the wellknown composer and violinist Ma Sicong (1912-1987). ${ }^{92} \mathrm{Ma}$ Si-Hon was the violinist who performed Mendelssohn's Violin Concerto under Fraenkel's direction at the concert on 1 March 1946. Although the signature of this letter is difficult to decipher, the writer can be identified as Mario Paci, who directed the SMO from 1919 to 1942 and was also a sought-after piano teacher (his pupils included the young Fou Tsung ${ }^{93}$ [Fu Cong, b. 1934] - the most prominent Chinese pianist during the 1960 s and 70s). The letter was presumably written in 1943, since the writer refers to a period of " 24 years" in which he has been working in China. Fraenkel apparently planned to perform a piano concerto with Tung Kwong-Kwong as a soloist with one of his orchestras, a project Paci seems skeptical of for reasons that are not entirely obvious:

92 Tung Kwong-Kwong studied with Artur Schnabel in New York and, together with her husband, continued her career as a pianist and teacher in the USA. Ma Sicong was "the first Chinese soloist to play with the SMO" on 22 December 1929 (Yang, "From Colonial Modernity to Clobal Identity," 55).

93 See Kraus, Pianos \& Politics in China, 70-99. 
My dear Fraenkel,

I am terribly sorry that circumstances (the "circumstances" in which they (the Chinese) have put me) oblige me to deney [sic] my permission to Kwong Kwong to play with your orchestra.

We have always been good friends, and I have always expressed my sincere appreciation and esteem for you as a very fine musician. I have always said to everyone that there is only one musician in Shanghai and that is you. And this I repeat now. -

I don't want therefore that you may think that in denying to play to Kwong Kwong [...] should be considered as anything against you. Personally - on the contrary - if I have something against somebody is not against you, but against the Chinese musicians who have failed to express a little appreciation to me who for 24 years I have given so much of my Art for them.-

They want Kwong Kwong. Why? Because [she] is the only good Chinese pianiste [sic]. - Why they don't come to me (they - not you) to ask me her collaboration which of course will make a success of their concert?-

If they ask me to present her, and conduct her accompaniment, I will do it free of charge and with pleasure. You can [do (?)] better, you should conduct the whole programme. I don't want to do it. I will be the accompanist. - But Kwong Kwong is the only thing left to me of my long years of work in China and I don't give it willingly to them. - If you don't see the point, try to come and see $\mathrm{me}^{94}$ and I will explain still clearer.-

$$
\text { Your[s] M.[ario] Paci }{ }^{95}
$$

It was not possible to reconstruct the outcome of this episode. The pianist Zhou Guangren (also Paci's student and Tung's colleague around 1946) pointed out to me that Tung had played Edvard Grieg's Piano Concerto in public before immigrating to the USA in 1947, but she was not sure whether this concert was conducted by Fraenkel.

\section{Fraenkel as a Pedagogue, Publicist, and Theorist}

Fraenkel was soon able to establish contacts with the conservatory, probably through the SMO, which had been founded in 1927 by Cai Yuanpei and Xiao Youmei as the first music academy in Asia based on the Russian model and successfully expanded in the following years $\rightarrow$ III.1). ${ }^{96}$ In the years of the Japanese occupation, the conservatory, which was then known as the "National Vocational School for Music" (Guoli yinyue zhuanke xuexiao), was in a very difficult situation. After war broke out between Japan and China in August 1937, the conservatory moved from its location in Jiangwan in the Northern part of the city to Xujiahui Street in the Southwest, and had to move again several times due to the exigencies of the war before it could

94 Fraenkel noted down the address "Kings App. House 345 / Room 7" on the first page of the letter; as this was indeed Paci's address (see Paci Zaharoff, "The Daughter of the Maestro," 286), this indicates that Fraenkel actually met Paci for a face-to-face meeting.

95 Lit. est., ANA 496, Sch. 5, "Korrespondenz."

96 See Schimmelpenninck and Kouwenhoven, "The Shanghai Conservatory of Music" and Melvin and Cai, Rhapsody in Red, 106-117. 
return to its original location in the Jiangwan district in 1946. In order to avoid any obvious connection with the Chinese government, the conservatory was even referred to as Sili Shanghai yinyue yuan (Shanghai Private Music School) for a period during the war. ${ }^{97}$

Fraenkel was appointed as a teacher of music theory and composition in the summer of 1941 by Li Weining, who had studied in Paris and Vienna in the 1930s. Li had headed the theory and composition department since 1937, had been a member of the SMO committee since 1939, ${ }^{98}$ and became president of the conservatory in 1940 after the founding president Xiao Youmei passed away (1884-1940). Li was dismissed from his position in 1946 as a "collaborator" (Li had already collaborated with the Japanese before the conservatory was officially placed under Japanese administration). After the end of the war, Fraenkel was also appointed to the National Music School Nanjing (Nanjing guoli yinyue yuan) on the suggestion of his student Ding Shande (1911-95). Ding himself was supposed to teach piano in Nanjing, but lessons only started in early 1947 owing to the destruction of the building. Therefore, Fraenkel only taught in Nanjing for two shortened semesters from January to July $1947,{ }^{99}$ while at the same time continuing to fulfill his teaching obligation in Shanghai. In addition to his work at the conservatory, Fraenkel gave private lessons, which he sought to expand, since here he could charge a higher fee. ${ }^{100}$

Contrary to Fraenkel's strikingly progressive artistic stance, demonstrated by his affinity for the Schoenberg School, his music theory and composition lessons seem to have remained largely conventional, albeit at a high level. He began teaching harmony in September 1941, according to the curriculum, but subsequently also taught strict and free counterpoint, analysis, form, instrumentation, and composition..$^{101}$

I have identified 24 Chinese students and one emigré student ${ }^{102}$ by name (Table 3.2), including leading representatives of their generation such as Ding Shande (1911-1995), Sang Tong (1923-2011), and Zhang Hao (1910-2003), as well as the renowned popular songwriter Chen Gexin (1914-1961). ${ }^{103}$ Three accounts by Fraenkel's former students Ding Shande, Sang Tong, and Qin Xixuan give detailed descriptions of his teaching methods and the content of the theory and composition lessons. ${ }^{104}$ Fraenkel's estate contains extensive teaching materials from the Shanghai era, including several hundred pages of manuscripts on counterpoint, harmony, orchestration, and musical analyses of Bach, Beethoven, Schubert, Chopin, Brahms, Richard Strauss, Reger, Hindemith, and Schoenberg. ${ }^{105}$ In fact, Fraenkel used both Schoenberg's Harmonielehre (1911, $\left.{ }^{3} 1922\right)$ and Kurth's Grundlagen des linearen Kontrapunkts: Bachs melodische Polyphonie (1917, $\left.{ }^{2} 1922,{ }^{3} 1927\right)$ as teaching materials. ${ }^{106}$ For pre-Baroque counterpoint he mainly referred to examples by Girolamo Frescobaldi, rather than to Palestrina. ${ }^{107}$ Fraenkel's appreciation of

97 Schimmelpenninck and Kouwenhoven, "The Shanghai Conservatory of Music," 68.

98 Bickers, "'The Greatest Cultural Asset East of Suez," 862-863.

99 Personal communication with Wang Zhengya, Beijing, December 2002.

100 See "Ding Shande Festival," in: CHIME 5 (1992), 144.

101 Sang, "Jinian Fulanke'er yu Xu Luoshi," 10.

102 On Andreas Barban see King and Silk, "Barban, Andreas."

103 See Xu, Xunfang youtairen, 79.

104 Dai, "Ding Shande yinyue nianpu chang bian," Sang, "Jinian Fulanke'er yu Xu Luoshi," and Qin, "Huiyi Woerfugang Fulanke'er."

105 Lit. est., ANA 496, Sch. 2.

106 Sang, "Jinian Fulanke'er yu Xu Luoshi," 10. See Schönberg, Harmonielehre, Kurth, Grundlagen des linearen Kontrapunkts.

107 Sang, "Jinian Fulanke'er yu Xu Luoshi," 10. 
Frescobaldi is also documented in Afunktionelle Musik (1937-43) $)^{108}$ and in his arrangement of Frescobaldi's Five Organ Pieces (1957-58, Kel.V. 199).

Table 3.2: Wolfgang Fraenkel's students in China

\begin{tabular}{|c|c|c|c|c|c|}
\hline name & pinyin transliteration & birth-death & studied with Fraenkel from-to & place of study & major \\
\hline 丁善德 & Ding Shande & $1911-1995$ & $1941-1946$ & Shanghai & composition \\
\hline 鄧爾敬 & Deng Erjing & $1918-1996$ & $1941-1943$ & Shanghai & composition \\
\hline 桑桐 & Sang Tong & 1923-2011 & $1941-1943,1945-1947$ & Shanghai & composition \\
\hline 湯正方 & Tang Zhengfang & & $1941-1945$ & Shanghai & composition \\
\hline 張寧和 & Zhang Ninghe & $1926-2004$ & $1941-?$ & Shanghai & composition \\
\hline 楊永 & Yang Yong & & 1941-? & Shanghai & composition \\
\hline 管蔭深 & Guan Yinshen & & 1941-? & Shanghai & composition \\
\hline 李乃聰 & Li Naicong & & 1941-? & Shanghai & composition \\
\hline 龐憲聘 & Pang Xianpin & & 1941-? & Shanghai & composition \\
\hline 薛岩 & Xue Yan & 1920- & $1943-?$ & Shanghai & composition \\
\hline 朱建 & Zhu Jian & $1924-2008$ & $1943-1945$ & Shanghai & composition \\
\hline 矍希賢 & Qu Xixian & $1919-2008$ & 1944-1945 & Shanghai & composition \\
\hline 秦西炫 & Qin Xixuan & $1922-2012$ & $1944-1947$ & Shanghai & composition \\
\hline 張昊 & Zhang Hao & $1910-2003$ & $1944 ?-1947$ & Shanghai & composition \\
\hline 陳歌辛 & Chen Gexin & 1914-1961 & $?$ & Shanghai & composition \\
\hline \multirow[t]{2}{*}{ 楊與石 } & Yang Yushi & & $?-1947$ & Shanghai & composition \\
\hline & Andreas Barban & $1914-1993$ & $?$ & Shanghai & composition \\
\hline 董光光 & Dong Guang-Guang & $1927-2013$ & $1943-1947 ?$ & Shanghai & piano \\
\hline 周廣仁 & Zhou Guangren & $1928-$ & 1946-1947 & Shanghai & piano \\
\hline 李德倫 & Li Delun & $1917-2001$ & ?-1945 & Shanghai & violoncello \\
\hline 郭乃安 & Guo Nai'an & 1920- & 1947 & Nanjing & composition \\
\hline 文顏 & Wen Yan & $1922-$ & 1947 & Nanjing & composition \\
\hline 王整亞 & Wang Zhengya & 1923- & 1947 & Nanjing & composition \\
\hline 段平泰 & Duan Pingtai & $1926-$ & 1947 & Nanjing & composition \\
\hline 黎英海 & Li Yinghai & $1927-2007$ & 1947 & Nanjing & composition \\
\hline
\end{tabular}

In the memoirs of his students, Fraenkel appears as a precise and competent educator, as well as an unconventional and non-conformist spirit. Zhou Guangren, who later became one of the leading pianists in China, reports that Fraenkel asked her to determine the best harmonic progression using a coin toss instead of following conventional harmony rules. ${ }^{109}$

108 See Fraenkel, Afunktionelle Musik, 262.

109 Personal communication, Beijing, 4/12/2002. 
Fraenkel's most important student, Sang Tong, began working with him in 1941, studying pieces by Claude Debussy, Igor Stravinsky, Ralph Vaughan Williams, Zoltán Kodály, Béla Bartók, and Alexander Scriabin - and, last but not least, by Gustav Mahler, whom Fraenkel described as "our great Master." 110 It seems, however, that Fraenkel only introduced the twelve-tone technique to a small group of his students (Sang Tong and Yang Yushi) between 1945 and 1947, presumably using his own Drei zweistimmige Praeludien for piano (1945, Kel.V. 80-82). ${ }^{111}$ Sang Tong's first composition experimenting with atonal and twelve-tone technique - and thus probably the first atonal work by an Asian composer - is Yejing (Night Scenery, 1947) for violin and piano $\left(\rightarrow\right.$ III.1), completed in February 1947 under Fraenkel's guidance (Ex. 3.3). ${ }^{112}$ Sang's next piece Zai na yaoyuan de difang (In the Land, Far, Far Away) for piano, completed later in 1947, was already written under the direction of Julius Schloß, Fraenkel's successor. ${ }^{113}$ Due to their original and technically sophisticated combination of Western and Chinese materials (the piano piece is based on a highly abstracted version of the folk song mentioned in the title), both compositions - far from naive folklorism - can be considered key works of Chinese musical modernity, even if political turmoil and Maoist cultural policy meant that they only slowly had an impact after 1978. They were premiered in 1948 at the United States Information Service in Shanghai by Karl Steiner as pianist and the violinist Zhang Guoling, who died shortly thereafter.

As outlined in the previous part of this chapter, a modernist-driven compositional treatment of folk song material based on the model of Béla Bartók, French, and Russian composers had been widespread in China and Japan since the influence of Alexander Tcherepnin in the mid-1930s ( $\rightarrow$ III.1). Sang Tong's Zai na yaoyuan de difang takes this concept to a new level through the inclusion of atonal harmony and "prose rhythms" analogous to Schoenberg's early piano pieces. The heptatonic folk song from the northwest Chinese province of Qinghai alluded to in the title is treated in five variations, to which Sang Tong assigs "longing states" ("deep," "sincere," "passionate," "intimate," and "excited" longing). It is striking that the central chords at the beginning are based on tritones and sevenths (Ex. 3.4) and are increasingly replaced by octaves from the third variation up to double octaves in the fifth, in which the folk song now appears clearly in apotheotic form. Despite this anticipation of the ubiquitous pathos of Chinese political music from 1950 to 1978, Sang's work gives an impressive outline of what new Chinese music could have looked like if this development had not been curtailed by political and social upheavals - the civil war from 1947 to 1949 and the takeover of the Communist Party in 1949. It was only after 1978 that a new generation of composers, the "New Wave" (xinchao), could resume this "short summer" of China's musical modernity $\rightarrow$ III.4).

110 Sang, "Jinian Fulanke'er yu Xu Luoshi," 10. According to Sang Tong, Fraenkel even brought a Mahler "autograph" with him to Shanghai, which he showed to his master student (ibid., 11). However, it seems unlikely that Fraenkel indeed owned a Mahler manuscript.

111 Ibid., 10 and personal communication 29/11/2002.

112 Detailed analyses of this work can be found in Zheng, "Sang Tong de Yejing shishi" and especially in Cheong, "Reading Schoenberg, Hindemith, and Kurth in Sang Tong," 95-97. See III.1, footnote 23, for further details.

113 For a discussion of this piece, see Kouwenhoven, "Mainland China's New Music (I)," 85, Mittler, Dangerous Tunes, 350-351, and Cheong, "Reading Schoenberg, Hindemith, and Kurth in Sang Tong," 88-93. During his one year at the conservatory, Julius Schloß (who left Shanghai one year after Fraenkel in 1948) wrote two Chinesische Rhapsodien for Violin and Orchestra (1947/48 and 1948/49) after he had to stop composing between 1935 and 1947 due to persecution, detention (Dachau Concentration Camp), and the hard life in Shanghai exile (Fricke, "Julius Schloß"). 
Example 3.3: Sang Tong, Yejing for violin and piano, p. 1
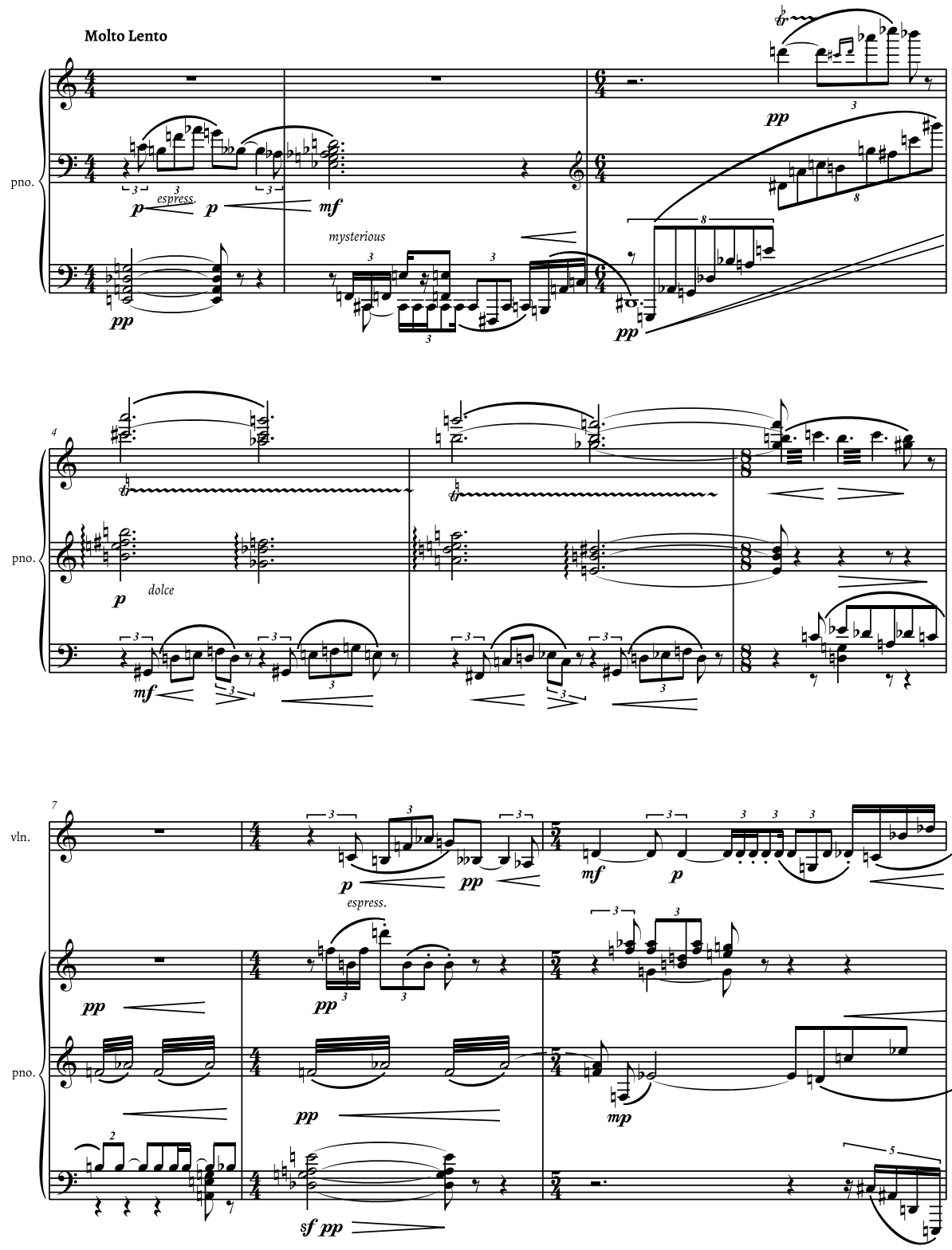

Copyright $\odot 1947$ by Sang Tong, Shanghai

From this perspective, although Fraenkel's contribution to musical modernity in China may appear rather marginal, one must take into account how his modernist-informed view of early - European and Asian - musics had a lasting impact on the musical thinking of an entire generation. In fact, many former students agree that of all the teachers and artists, Fraen- 
Example 3.4: Sang Tong, Zai na yaoyuan de difang for piano, p. I
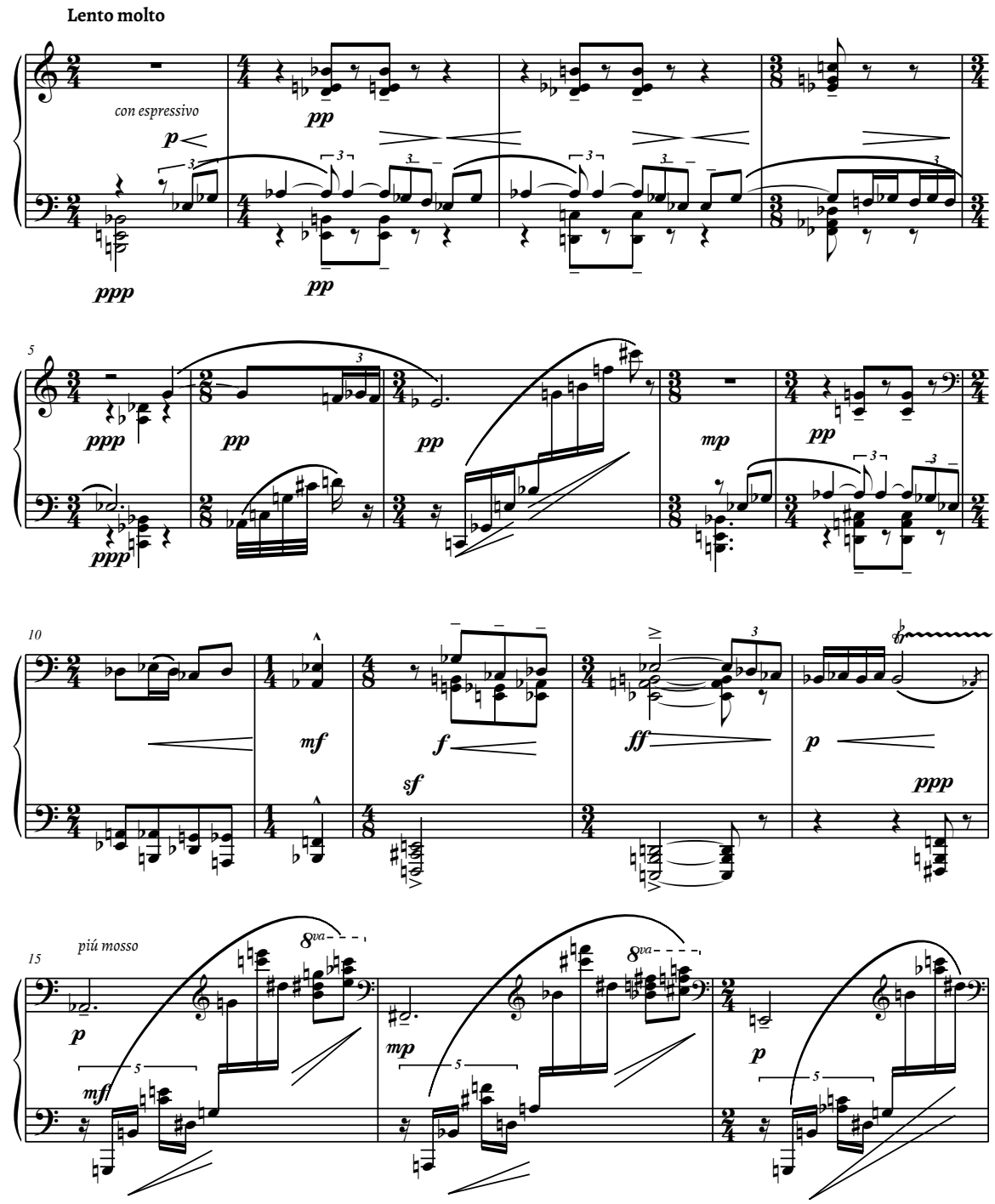

Copyright $\odot 1947$ by Sang Tong, Shanghai/2005 by Shanghai Yinyue Chubanshe

kel had the greatest influence on their view of music. ${ }^{114}$ This appreciation seems completely plausible, not least with reference to Fraenkel's demand for an independent and self-assured development of Chinese musical modernity: Fraenkel's manuscript "Music-Development?," apparently edited and translated by his student Zhu Jian (1924-2008) in October 1945 under the title Weilai de Zhongguo yinyue (The Future of Chinese Music) in the first edition of Music Weekly,

114 Personal communication with the Fraenkel students Sang Tong, Zhou Guangren, Wang Zhengya, and Duan Pingtai, Shanghai and Beijing, 29/11 to 05/12/2002. 
a short-lived weekly paper produced by the Guanghua Daily, ${ }^{115}$ proves that Fraenkel reflected in a forward-looking way on the current situation of Chinese music and took a very unusual view for a European at the time. He argued that the European musical tradition should not be adopted uncritically by Chinese artists, and that the main task for the formation of a meaningful synthesis fell to the Chinese musicians themselves, not the Europeans (Fraenkel's sometimes unidiomatic English and orthography have not been modified):

One of the most important problems regarding the future music-life in China is the relationship between chinese and western music. Combination of these both divergent branches of musicart seems advisable on account of the fundamental character of western music: to conceive and write concerted music.

The western musician cannot shape a new development of chinese music, he only can prepare the way, perhaps try to exert some kind of influence; the completion must be carried out by chinese composers. It will be up to them, first to absorb the technical and sensational items of western art, and then to find out ways to form connexions to the existing (old) chinese music without disturbing it's characteristic pecularities.

To judge the prospects of a development of such kind is rather difficult, as there are not made even beginnings yet. I am convinced that it will be of no use for chinese musicians to create typical western music: such work means neither development nor progress; maybe it is remarkable and noteworthy, but it remains to be some kind of copy, as the innermost feeling is heterogeneous. The essential knowledge of western music should be the basis only, which it is necessary to advance from, an advance which may in fact hold out incalculable prospects.

To my mind the technical starting-point for attempts of such kind is not the music of the classic period of western music. The newest development in Europe demonstrated that the classic period is some terminated unit which hardly can produce new offsprings of real value. The modern western music, which is developed since about 40 years, found it's point of contact in the events of the preclassic music and counterpoint which give more freedom and quite other possibilities of evolution. Here seems to be the way to insert the fundamental princip of concerted music to a system which is inwardly not connected with the western music-ideas. ${ }^{116}$

This perspective, which added new elements to the discourse on new Chinese music established by figures like Avshalomov and Tcherepnin, did not see the future of "concertante" Chinese music in connection to the Classical-Romantic European tradition. This tradition, however, was the mainstream practice of Chinese composers during the 1930s and 1940s, and, despite many attempts at reform, it was largely retained until the end of the Cultural Revolution. Fraenkel's perspective, in contrast to this common practice, recommended that composers claim an alterity to this Classical-Romantic tradition in analogy to European new music, pos-

115 Email communication with Zhang Yi, Shanghai, 31/05/2003, who interviewed Zhu Jian on his teacher Fraenkel. The first and only edition of Music Weekly also included articles by Fu Cong and Shen Zhibai.

116 Two-page typescript dated "October 1945" in lit. est., ANA 496, Sch. 3; handwritten drafts in German and English under the sketches for the opera Hölle, Weg, Erde (mus. est., Mus.ms. 19605, supplement: unnumbered sheet and Mus.ms. 19605, 96 verso). Since Fraenkel counted the words in the handwritten version, one can assume that the text was intended for publication. 
sibly also in combination with pre-Classical European music forms, but certainly with a sustained orientation toward the Chinese music tradition.

As shown in part 1 of this chapter, several efforts had been made by Chinese reformers and researchers since the 1910s - like Wang Guangqi (1892-1936), Liu Tianhua or Yang Yinliu (1899-1984), who criticized the spreading influence of Western music in China - to reflect on a synthesis of Chinese and European music in the wake of the May Fourth Movement ( $\rightarrow$ III.I). Criticism of Western music, however, usually had a nationalist angle and was commonly directed exclusively against the Classical-Romantic music tradition, not against Western modernism. In the same period, during his work on the influential Zhongguo gudai yinyue shi gang (A Draft History of Ancient Chinese Music, 1944), Yang Yinliu wrote in his article "Guoyue qiantu jiqi yanjiu" (The Future of National Music and Its Study), published in three installments from 1942 to 1944:

Western music has already had an affect [sic] on Chinese culture, and we have encountered problems here which we have never met with before [...]. Consequently, the development of Western music - unproblematic in its own context - is highly problematic in China, which has its own history, life customs, and national background. [...] Part of this problem with regard to Western music and national music in China emerges from their mutual relationship; its future resolution must also be present in their interrelationship: the proper course of development of each, very probably, will be a common one [...]. National music has so far followed its own path, but to develop further, Western music, rather than being swallowed whole in China must be properly and naturally digested. ${ }^{117}$

Fraenkel's perspective under these conditions must therefore have seemed new and fresh to his readers, although most probably only a few had a very vague idea of the "newest development in Europe" or of "modern Western music" that he outlined as a model. Especially by suggesting the synthesis of traditional Chinese and modern Western music, Fraenkel was putting forward a vision whose time would only come in the 1980s ( $\rightarrow$ III.5), despite Avshalomov's pioneering works of the 1930s. Fraenkel thus implicitly criticized the era-defining style of (politically coded) pentatonic Romanticism, as represented by the works of He Luting, Huang Zi, Xian Xinghai, or Ma Sicong, a style which has remained a principal musical code for neo-bourgeois audiences throughout East Asia - even under changing and diverse political conditions.

In a broader context, it is evident that Fraenkel's ideas were part of a dedicated movement toward a balanced confluence of Chinese and Western music that had been advocated by Avshalomov since the early 1930s ( $\rightarrow$ III.1) and had been supported by Paci and the SMO who in 1933 even introduced a "special grand Chinese evening" featuring Chinese ensemble music performed by Datong Yuehui (Union Music Club) and a pipa solo performance by Wei Zhongle, along with orchestral works by Avshalomov. ${ }^{118}$ Avshalomov's son, the composer Jacob Avshalomov (1919-2013), has documented a letter in which his father expressed sincere appreciation for Fraenkel, shortly after the latter's arrival in Shanghai:

117 Yang, "Guoyue qiantu jiqi yanjiu" (The Future of National Music and Its Study), quoted in Shen, "Ethnomusicology in China," 14.

118 Winzenburg, "Aaron Avshalomov and New Chinese Music in Shanghai, 1931-1947," 60-61 and Yang, "From CoIonial Modernity to Clobal Identity," 54. 
There is no stimulus for work here, although there is much musical activity in Shanghai today (mainly of inferior quality). Many refugees from Austria and Cermany. Of the numerous musicians two are outstanding. One a violinist, Adler by name. The other is a composer, Frankel, who is first class. A follower of Schoenberg, with many compositions, a very erudite man, skillful orchestrator and theoretician. Nice fellow, too, the only person except Crisha with whom it is possible to talk music with understanding. ${ }^{119}$

It is also documented that Fraenkel had an artistic exchange with the influential baritone and choral conductor Chao Mei-Pa (Zhao Meibo, 1905-1999), who had studied in Belgium and lived in the USA before returning to China in 1936 and serving as head of the conservatory's vocal music department. ${ }^{120}$ In 1937, Chao had published an article "The Trend of Modern Chinese Music" in which he had to some extent refuted the enthusiasm about Tcherepnin's impact, claiming an enhanced independence from Western ideas - in words clearly driven by a nationalist undertone (as well as by a skeptical position toward modernist Western tendencies):

Tcherepnine soon [...] cursed the danger of Western influence. [...] In his lectures he declared that Chinese do not have to learn from Bach, Handel, or Beethoven; and if Chinese do adopt Western music they should go directly to the impressionistic composers, such as Debussy or Stravinsky. [...] But whether Mr. Tcherepnine's principle is workable or not still remains an open question, for after all Tcherepnine is a European himself.

In the field of composition, suppose we should follow Tcherepnine's idea, shall we be satisfied with a harmony based upon the pentatonic scale with modulations? Should we invent a harmony and a science of orchestration by ourselves? [...] It is interesting to know that Chinese are inclined to counterpoint. But will counterpoint without harmony satisfy us? Mr. Tcherepnine was right in one way when he recognized the capacity of Chinese in counterpoint, and he did not agree with our blind acceptance of Western ideas; but how far can his study help? [...]

If there is anything China is taking from the West, it is only for temporary use. In the long run, China will always be Chinese, in style and in expression, and not less so in her music. ${ }^{121}$

Fraenkel's position also agreed with that of Tan Xiaolin (1912-1948), who returned to China from studying with Paul Hindemith at Yale University in 1946, as Sang Tong testifies: "Like Tan Xiaolin, he supported the idea of a synthesis from the spirit of [Chinese] folk music and the new compositional techniques and saw this as an influential means of musical creation." ${ }^{\text {122 }}$ It can be

119 Letter from Aaron Avshalomov from 24/04/1940 (Avshalomov and Avshalomov, Avshalomov's Winding Way, 162). By "Grisha," Avshalomov means the Russian pianist Gregory (Grisha) Singer. The violinist Ferdinand Adler emigrated from Vienna to Shanghai in 1939 after being imprisoned at Dachau concentration camp. He became a member and concertmaster of the SMO in 1939, and Professor of Violin at the conservatory in 1941. See, Fetthauer, "Ferdinand Adler."

120 Since 1937, Chao had been involved in conducting mass choral singing at rallies during Chiang Kai-Shek's New Life Movement (Xin shenghuoyundong) aiming at China's unification, started in 1934, and partly oriented toward National Socialist propaganda (Jones, Yellow Music, 49).

121 Chao, "The Trend of Modern Chinese Music," 283, 286. See Winzenburg, "From 'Folk Cure' to Catharsis: Alexander Tcherepnin and New Chinese Piano Music."

122 Sang, "Jinian Fulanke'er yu Xu Luoshi," 11 (translated by the author). 
assumed that Fraenkel was in contact with Tan, who on his return became head of the theory and composition departments at the conservatory. Similarly, Fraenkel may have exchanged views with Fritz Kuttner (1903-1991), who probably arrived in Shanghai as a refugee shortly after Fraenkel in May 1939 and worked as a music journalist (1948-49 for China Press) and teacher of music history and theory at St. John's University (from 1944). After moving to the United States in 1949, he continued to research ancient Chinese instruments and tuning systems. ${ }^{123}$

In his "Music-Development?" Fraenkel outlined the idea of a fundamental contradiction between new and classical (European) music, an argument which he had already proposed a few years earlier, based on the analogy of music and language and its limits, in his article "Grundprobleme der Neuen Musik: Der neue Tonsprachkreis und seine Begriffsbestimmung," published in Shanghai in 1941. The first part of this article was published in the sole issue of the journal Der Kreis in December 1941, while the second part, announced at the end of this article, has probably never been published. ${ }^{124}$ As in his main theoretical work Afunktionelle Musik ("Afunctional Music"), which Fraenkel continued to work on in Shanghai, this article makes it clear that Fraenkel saw language and music as related means of "presenting imagination and ideas"125 - as evidenced by the focus on the concept of "Gedanke," certainly shaped by the Schoenberg School. In the realm of music, however, the close coupling of the musical idea to the underlying "tonal language" makes this idea untranslatable, as it were: "Ideas and tonal language are so closely related that one must almost speak of interpenetration, of outer events rubbing off on inner events." ${ }^{26}$ For Fraenkel, classical and new music are both "musical languages" in this emphatic sense.

Fraenkel's comprehensive theoretical-aesthetic knowledge and interests were gathered together in his extensive theoretical work Afunktionelle Musik, written in 1937/38 and revised in Shanghai in 1942/43. ${ }^{127}$ This book-length study attempts to apply Ernst Kurth's music theory to the analysis of "afunctional" (atonal or post-tonal) music. Afunktionelle Musik can be understood as a nuanced examination of trends in new European music from 1910 to 1935 (with a focus on the Schoenberg School and Hindemith), and the theoretical discussion deals with a wide range of music theory writings, including those by Hugo Riemann and Joseph Yasser, but most prominently Ernst Kurth and his concept of musical "energetics." As other surviving documents show, Fraenkel engaged intensively with Kurth's writings. ${ }^{128}$ Fraenkel's term "afunctional music" implies a profound skepticism toward the nineteenth-century idea of musical "functionalism" as reflected primarily in Riemann's influential theory of tonal functions in

123 Fetthauer, "Fritz A. Kuttner," Rosenson, "Jewish Musicians in Shanghai," 243-245, and Schimmelpenninck and Kouwenhoven, "The Shanghai Conservatory of Music," 71-72. Kuttner's research into ancient Chinese music is documented in Kuttner, The Archaeology of Music in Ancient China.

124 Wolfgang Fraenkel, "Grundprobleme der neuen Musik. Der neue Tonsprachkreis und seine Begriffsbestimmung," Der Kreis (December 1941), 13-18 (lit. est., ANA 496, Sch. 3).

125 Ibid., 16 ("Darlegung von Vorstellungen und Gedanken").

126 Ibid., 18. ("Cedanke und Tonsprache [sind] miteinander so eng verbunden, dass geradezu von einer gegenseitigen Durchdringung, einem Abfärben des äusseren Geschehens auf das innere gesprochen werden muss.")

127 An edition with a commentary on this work, based on the complete manuscript and notes from Fraenkel's estate, has been completed as an academic thesis by Markus Köhler in 1989 (Fraenkel, Afunktionelle Musik).

128 Fraenkel had studied Kurth's four major publications in great detail, as revealed by his notes collected in the 71page file "Kritische Notizen über musikwissenschaftliche Veröffentlichungen" (March to October, 1937), which contains commentaries on Kurth's books Grundlagen des linearen Kontrapunkts, Romantische Harmonik und ihre Krise in Wagners Tristan, Bruckner, and Musikpsychologie. 
harmony. Discarding the idea of functions, Fraenkel conceives of music as "kinetic energy" in Kurth's sense. In his introductory chapter, there are a number of inserts that show the influence of his exile experience. Writing about general musical principles, for example, he limits the concept of "music as a demonstration of musical ideas" to the "occidental musical area" and criticizes those who think that Chinese or Arab musical traditions cannot be labeled "music."129 In such passages (as in the adherence to this voluminous theoretical project as a whole), it becomes clear how Fraenkel consolidated his identity as a representative of musical modernism in exile, but also palpably incorporated his exile experience.

\section{Fraenkel as a Composer}

Even if no performance of Fraenkel's works is documented during the time in Shanghai, the papers in his estate prove that he was unusually active in composition during these years. His compositional activity only seems to have included "applied music" (arrangements for orchestra [see above], arrangements of traditional Chinese and Japanese music [see below], film music ${ }^{130}$ ) in a few cases, an area in which most other exiled musicians worked. In at least one case, Fraenkel's compositional activity shows a very interesting reaction to his exile environment: Drei Orchesterlieder (Three Orchestral Songs, Kel.V. 113-115), after Chinese poems from Tang and Song Dynasties, translated into German by Vinzenz Hundhausen (1878-1955). ${ }^{131}$ Composed between 9 May and 24 September 1941, it is the only major work that Fraenkel was able to complete during his time in Shanghai. In addition, only the aforementioned Drei zweistimmige Praeludien (Three Two-part Preludes, Kel.V. 80-82, 1945) for piano were completed, which were to be part of a planned cycle of twelve-tone inventions and preludes and were probably written along the lines of Bach as both compositional and pianistic studies (only one of the inventions was composed after the time in Shanghai, in $1951^{132}$ ). The Praeludien combine a relatively simple form of dodecaphonic technique with an imitative counterpoint based on Hindemith (Ex. 3.5). It was not until 1964 that Fraenkel collected the three completed preludes (without the invention) for a volume of his collected piano works to create the preserved three-movement series.

In addition to the orchestral songs and the Praeludien, Fraenkel worked on the following pieces in Shanghai: the Third Symphony (Kel.V. 3), begun on 4 December 1937 in Berlin, interrupted on 23 March 1940; the Fourth Symphony (Kel.V. 4), begun on 10 May 1942, interrupted on 6 May 1944; the opera fragment Hölle - Weg-Erde (Hell - Path - Earth, Kel.V. 191) after Georg Kaiser, begun on 19 September 1944, and Musik für großes Orchester (Music for Large Orchestra, Kel.V. 8), begun on 2 November 1946, interrupted on 12 September $1948 .{ }^{133}$ None of these unfinished works were completed later.

129 Fraenkel, Afunktionelle Musik, 16 ("Darlegung musikalischer Cedanken"; "abendländischen Musikkreis"), 18-19.

130 A Cerman-language newspaper note in the Shanghai Jewish Chronicle (09/08/1942) mentions that Fraenkel was rehearsing the music for a Japanese film with the Shanghai Philharmonic Society (ANA 496, Sch. 5, "Zeitungsartikel und Kritiken").

131 See Walravens, Vincenz Hundhausen (1878-1955).

132 See Kellermann, "Kellermann-Verzeichnis der Werke von Wolfgang Fraenkel," 92.

133 The Musik für großes Orchester breaks off in measure 208 of the second movement. As mentioned in footnote 71, entries in the score show Fraenkel's route from Shanghai to Los Angeles. 
Example 3.5: Wolfgang Fraenkel, Drei zweistimmige Praeludien, p. I
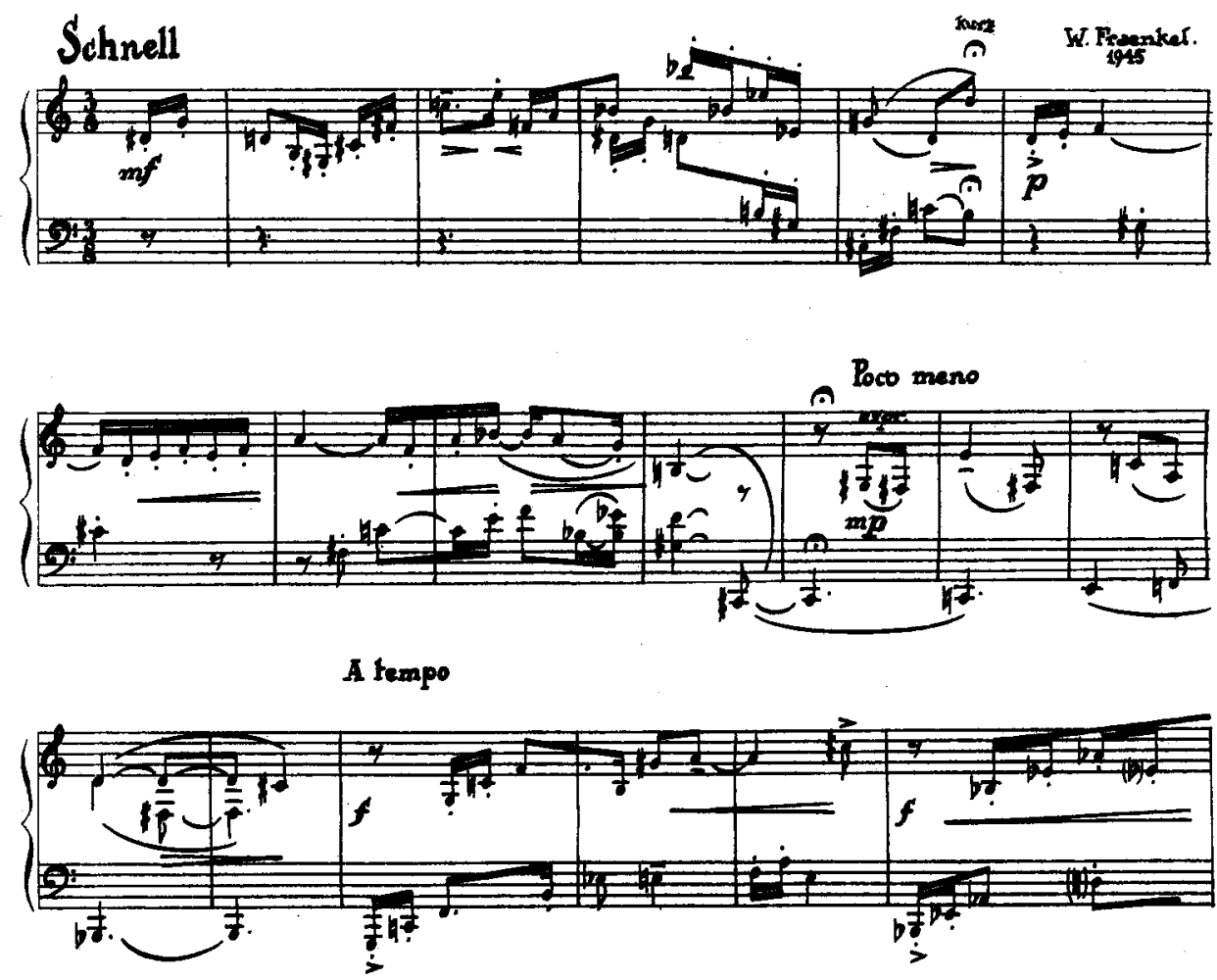

Bayerische Staatsbibliothek, Musikabteilung, Mus.ms. 19804

The three poems that Fraenkel set in Drei Orchesterlieder likely came from Hundhausen's publication Chinesische Dichter in deutscher Sprache, mit 2 Bildern nach Originalen des Wang Ting-Dsche (Beijing/Leipzig 1926). All three poems evoke spring in their titles:

- No. I "Frühlingsnacht" (Spring Night, Chun xiao) by Su Dong-Bo (Su Shi, 1036-1101);

- No. 2 "Am frühen Frühlingstage" (On an Early Spring Day, Chun xiao) by Meng Haoran (689-740);

- No. 3 "Ein Flötenlied in Lau-Yang" (A Flute Song in Lau-Yang, Chunye Luoyang xin di) by Li Tai-Bo (699-762).

Hundhausen's German Nachdichtungen (free adaptations) of classical Chinese poems were generally based on word-for-word translations by his Chinese friends and students. Interestingly, this approach to the Chinese is shown in the appendix to Fraenkel's score. The Chinese characters are written on the score sheet and an English word-for-word translation is provided on an overlaid sheet of transparent paper (Fig. 3.4). This analogy to Hundhausen's work could indicate Fraenkel's personal contact with the Beijing-based poet and literature professor. It also proves that Fraenkel endeavored to gain an adequate understanding of the original versions of the texts set to music. 
Figure 3.4: Wolfgang Fraenkel, calligraphy from the appendix to the Drei Orchesterlieder; the poem "Spring Night" (Chun xiao) by Su Dong-Bo (Su Shi) is shown, which is set in the first movement; ${ }^{134}$ left: the English translation of each individual character is placed on the Chinese characters using transparent paper; right: calligraphy without transparent paper
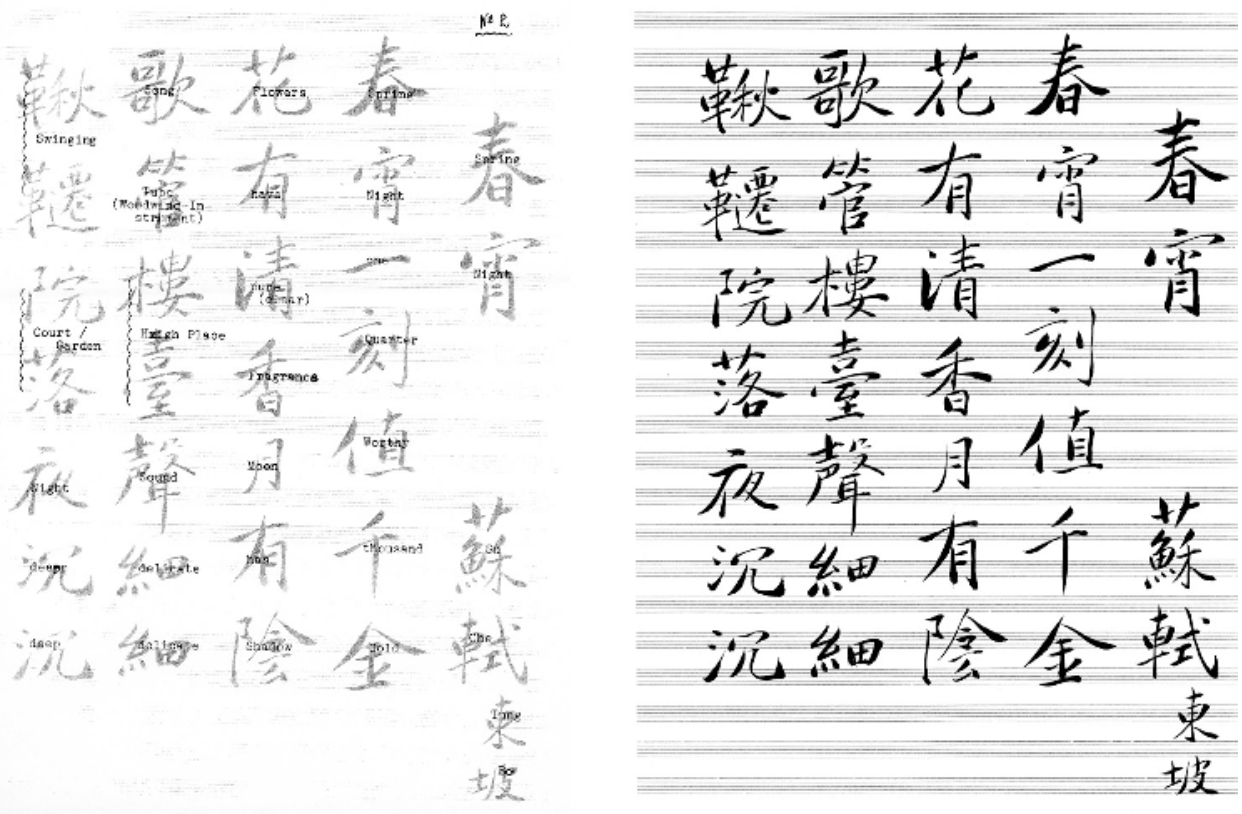

Bayerische Staatsbibliothek, Musikabteilung, Mus.ms. 19654, p. $50 a$

All three orchestral songs are based on the same twelve-tone row, which Fraenkel provides in the appendix to the score (Ex. 3.6). Fraenkel designed a quasi-symmetrical structure: songs I and III use only the four basic forms of the series (P, I, R, RI) as well as transpositions one fourth higher (I) and lower (III), while the second movement uses the tritone transposition and two related rows. While this systematic application of the dodecaphonic technique points to an intensified examination of the twelve-tone method in the context of his extensive theoretical writing in Afunctional Music (1937-43), the deliberate, sometimes almost "impressionistic" use of orchestral colors (e.g., no. 2 "Am frühen Frühlingstage," score, mm. 23-27, Ex. 3.7) certainly comes from an attempt to interpret the atmosphere of the Chinese poems musically in a (post-) exoticist manner. Despite such coloristic experiments, the quality of the work can be seen in that Fraenkel largely refrains from any kind of plain exoticism and instead tries to render the atmosphere of the texts with his personal (Western) means. The work was not performed during his time in Shanghai, but it seems that a premiere may have taken place after Fraenkel moved to the US, since the score has notes obviously made during rehearsals. ${ }^{135}$

134 Fraenkel mistakenly identified this poem as no. 2 in the manuscript, but later corrected this mistake.

135 A recent performance of the work in Beijing (March 2019) has been co-organized by the Vienna organization exil.arte (e-mail-communication with Gerold Cruber, 25/05/2020). 
Example 3.6: Wolfgang Fraenkel, row analysis in the appendix of the score of Drei Orchesterlieder: first line: prime twelve-tone row; below: row forms and variants used in the movements 1 to 3

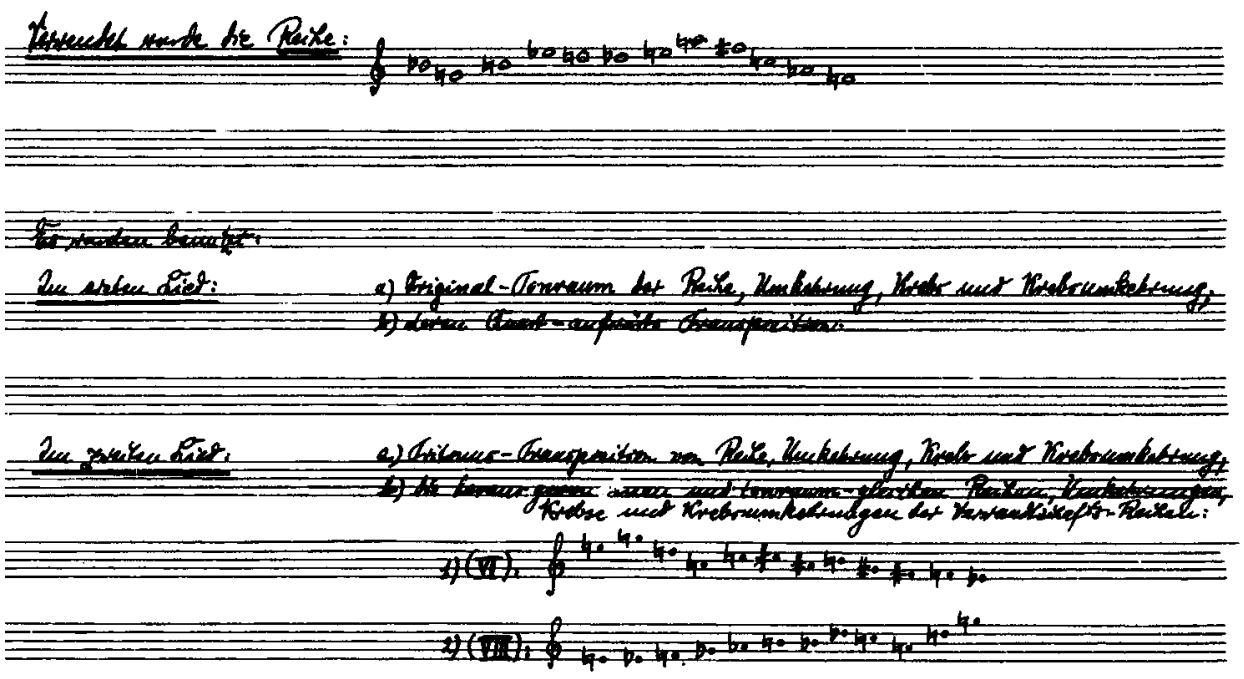

Extensive transcriptions of recorded music show that Fraenkel also tried to understand traditional Chinese and Japanese music. Yet the transcriptions of works by the Chinese instrument and repertoire reformer Liu Tianhua $\rightarrow$ III.1), recorded on the LP Chinese Classical Music (Lyrichord LP, LL 722, 1956), may have arisen only some time after the stay in Shanghai, probably around the end of the 1950s. They formed the basis for the sketched Chinese Song (Kel.V. 35, c. 1960) for alto flute and guitar, an attempt to find a "Chinese tone" in Liu's style.

The transcriptions of Japanese music, ${ }^{136}$ on the contrary, probably already largely originated in Shanghai in the context of a dance evening with Slavina-Brown and Indira Devi on 18 April 1940, where two arrangements by Fraenkel were performed under the direction of Aaron Avshalomov (see Tab. 3.1): Ombacha and Three Masks (Improvisation on a Japanese Theme). Both arrangements were most likely based on transcriptions of pieces recorded on the LP Om-bat-tha (Victor-Records no. 52282-a [3740]). A transcription of the famous Japanese gagaku classic Etenraku is also preserved in Fraenkel's estate; he very likely transcribed it from the record Music over the Sky (Victor-Records, no. 13487 [8745/46]), and notes in the transcription suggest that an arrangement for Western orchestra was considered. It is still unclear whether this arrangement was carried out or indeed performed. 
Example 3.7: Wolfgang Fraenkel, Drei Orchesterlieder, no. 2 "Am frühen Frühlingstage," score, $\mathrm{mm}$. 25-27

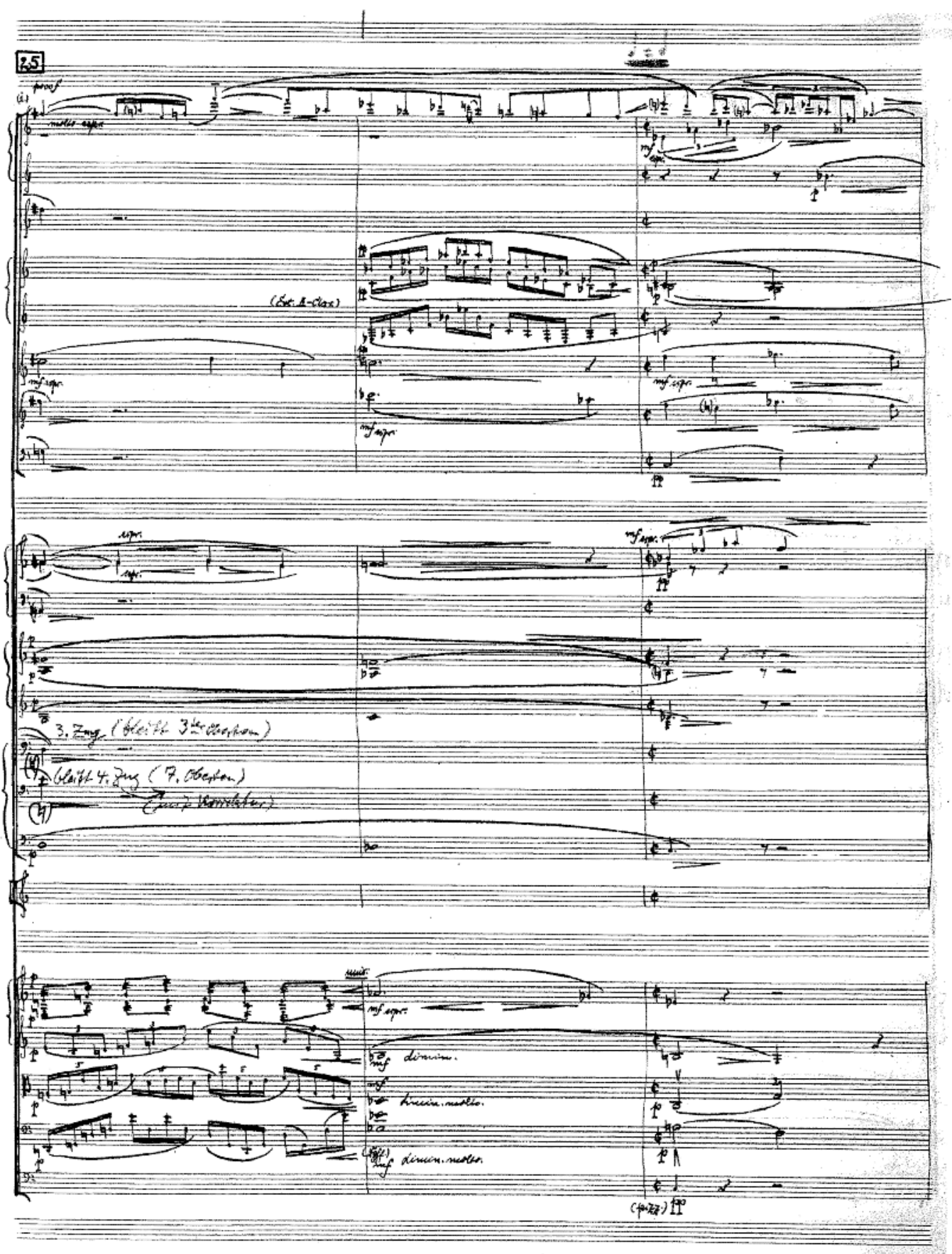

Bayerische Staatsbibliothek, Musikabteilung, Mus.ms. 19654, p. 21 


\section{Perspectives}

Aside from the aspects summarized here, it is not easy to reconstruct Fraenkel's time in Shanghai in great detail. In many respects, we still have to rely on assumptions, for example, when trying to reconstruct the exact circumstances of his release from Sachsenhausen and his trip to Shanghai, but, most importantly, also his artistic and cultural impact during the exile years: how did Fraenkel make contacts in Shanghai? How did he find a connection to the city's music scene so quickly, gaining a comparatively privileged position in the impoverished immigrant community, in contrast to Julius Schloß or Karl Steiner, who had to make ends meet in bars as accordion and piano players? ${ }^{137}$

Further studies of his estate, a more comprehensive consideration of the oral history, which was only cursorily included here, and, last but not least, more precise analyses of his musical works could certainly help to answer these and other questions that arise. For the time being, it remains remarkable how sensitively Fraenkel reacted to the state of music in China and how this was partly reflected in his writings and works.

From the perspective of Chinese music historiography, Fraenkel is a small but crucial building block. Without him, the early reception of musical modernism in China would probably not have taken place at all, and the sensational "second musical modernity" in China during the 1980 s and 1990s $\rightarrow$ III.5) would not have found any point of reference in its own past. Fraenkel's work as a pedagogue, conductor, musician, and composer deserves to be further examined in China as well as in the West. Publishing his writings and performing his highly original and innovative musical works would undoubtedly be worthwhile, and would help to rescue an important mediator between Europe and Asia from oblivion.

\section{The Travels of a Jasmine Flower: A Chinese Folk Song, Its Prehistory, and Tan Dun's Symphony 1997}

The history of the Chinese melody Molihua (Jasmine Flower, also known as Xianhua [Fresh Flower]), which became famous through Giacomo Puccini's opera Turandot (1920-24), offers a manifold impression of the intricate and recursive intercultural processes that provided the background for composition in East Asia in the twentieth century and persist to this day. That Tan Dun quotes - and above all, how he quotes - this melody in his politically charged Symphony 1997 requires us to look closer at this historic source of Chinese identities. We can compare its various versions here from a (music-)historical perspective. We can show how they have changed since the first written source for the melody in 1795 to the most recent contemporary version (summarized in Table 3.3; see also Examples 3.8, 3.9, and Table 3.4). It remains to be discussed in which ways these variations refer back to the changes in culture and environment that they record. From an ethno(musico)logical perspective, the different versions of the melody within the musical practice of China or Asia can be investigated and potential conclusions drawn about the transregional traditions of the melody. After all, through the musical analysis of the respective melodic figures and, if applicable, the harmonization, orchestration, or per-

137 The remark in the Fraenkel entry in Baker's Biographical Dictionary that Fraenkel had enjoyed the protection of Chiang Kai-Shek, who had asked him to coordinate the musical training in Shanghai and Nanjing, should be followed up in this context. To the extent suggested here, it seems rather unlikely, at least before 1945, given the political situation and the extensive control by the Japanese authorities. See Slonimsky, "Fraenkel." 
formance practice, cross-connections, affinities, or opposites of the different traditional and modern versions and their musical meaning can be worked out.

Table 3.3: Molihua, overview of sources, transcriptions, and editions

\begin{tabular}{|c|c|}
\hline Europe & China \\
\hline & $\begin{array}{l}\text { song text of the melody Shuang die cui } \\
\text { (Liu Xiaozu, Ci Luan, woodcut print 1566); } \\
\text { melody not presented }\end{array}$ \\
\hline & $\begin{array}{l}\text { Qing Dynasty (1644-1911) } \\
\text { The titles Xianhua and Molihua are widespread, also } \\
\text { occasionally referred to as Zhang xi Ying-Ying } \\
\text { (Zhang Sheng plays with Ying-Ying). The text refers } \\
\text { to the classic novel The West Chamber (Xi Xiang Ji; } \\
\text { Wang Shifu, around 1300) and the love story between } \\
\text { Zhang Sheng and Cui Ying-Ying described therein. }\end{array}$ \\
\hline & $\begin{array}{l}\text { song text in the libretto collection Zhui bai qiu } \\
\text { (1771, published in the reign of the emperor Oianlong, } \\
\text { 1736-95), Vol. 6, chapter Huagu, edited by Wang Xieru } \\
\text { and Qian Decang }\end{array}$ \\
\hline $\begin{array}{l}\text { Karl Kambra, Two Chinese Songs, London } 1795 \\
\text { (Moo-Lee-Chwa) } \\
\text { Eyles Irwin, "Chinese Musick," London } 1797 \text { (Tsin Fa) }\end{array}$ & \\
\hline \multicolumn{2}{|l|}{$\begin{array}{l}\text { John Barrow, Travels in China, London } 1804 \text { (Moo-Lee-Hwa) } \\
\text { Johann Christian Hüttner, Johann Barrow's Reise nach } \\
\text { China, Vol. 1, Weimar } 1804 \text { (Mu-Li-Chwa) }\end{array}$} \\
\hline & $\begin{array}{l}\text { Gongchepu (Chinese character score) in the } \\
\text { collection Xiao hui ji, } 1821 \text { (1838), edited by Xiao Liu }\end{array}$ \\
\hline \multicolumn{2}{|l|}{$\begin{array}{l}\text { August Wilhelm Ambros, Geschichte der Musik, } \\
\text { Vol. } 1\left(1862,{ }^{2} 1882,{ }^{1} 1887, \text { Tsin-fa = Irwin 1797) }\right. \\
\end{array}$} \\
\hline \multicolumn{2}{|l|}{$\begin{array}{l}\text { Jules A. van Aalst, Chinese Music, Shanghai } 1884 \\
\text { (Xianhua [The fresh beautiful flower]) }\end{array}$} \\
\hline \multicolumn{2}{|l|}{ Edoardo Fassini-Camossi, music box, 1920} \\
\hline \multicolumn{2}{|l|}{ Giacomo Puccini, Turandot, 1920-24 } \\
\hline & $\begin{array}{l}1942 \text { recording of the Jiangsu folk sung } \\
\text { by He Fang in the region Liuhe } \\
\text { (Jiangsu province) }\end{array}$ \\
\hline & 1957 altered text, setting for female choir \\
\hline & $\begin{array}{l}1959 \text { newly altered text, documented in the program } \\
\text { of the Seventh World Festival of the Youth and } \\
\text { Students in Vienna }\end{array}$ \\
\hline & $\begin{array}{l}\text { Modern transcriptions of the Jiangsu folk song: 1980, } \\
\text { 1982, 1993, 1998, 2002; versions of the song in Heilong- } \\
\text { jiang, Liaoning, Gansu, Shandong, Beijing, Shanxi, } \\
\text { Shaanxi, Hubei, Gansu, Ningxia, Sichuan, Hebei, Fujian, } \\
\text { Guangxi }\end{array}$ \\
\hline & Tan Dun, Symphony 1997 (1997) \\
\hline & Fish Leong, Molihua (Album Wings of Love, 2004) \\
\hline
\end{tabular}


The melody is first documented in Chinese in 1821 in a gongche solmization notation ${ }^{138}$ (Ex. 3.8g), although the text's origins, at least, possibly go back to the year 1566 (the substance mentioned in the text even refers back to the novel The West Chamber, which was written during the Yuan Dynasty around 1300). ${ }^{139}$ Today, versions of this tune are to be found in at least thirteen Chinese provinces and in Tibet, some of which differ greatly from one another and often reveal similarities only in the texts and titles. ${ }^{140}$ Within the category of xiaodiao (little melodies), the song belongs to the shidiao (free-[time] melodies), some of which are also performed by (semi-) professional musicians. These melodies are predominantly performed in urban centers and public spaces, often with instrumental accompaniment. The most famous version comes from the southern central Chinese province of Jiangsu and is documented in various modern transcriptions and recordings ${ }^{141}$ (Ex. 3.8h). This version can be clearly traced to the earliest written source of 1821. Of course, the transcription of the melody in the five-line system (and likewise in the Chinese cipher notation jianzipu) does not capture the crucial blurring in intonation, the fine vibrato, and inflections, as well as the heterophonic independence of the voice and instruments. These aspects of the music are associated with sizhuyue (silk and bamboo music), a main ensemble type of Jiangsu that is also used for the accompaniment of folk songs. ${ }^{142}$

Now, this intra-Chinese context is overlaid with an intercultural one. As part of the (ultimately unsuccessful) mission of the English diplomat Lord George Macartney to China in 1793 and $1794^{143}$ a melody entitled Molihua (spelled as Moo-Lee-Hwa and Mu-Li-Chwa) was recorded by the German teacher and writer Johann Christian Hüttner. ${ }^{144}$ Later, Hüttner acted as an important source of information for Goethe in London, where he was in contact with, among others, the renowned music historian Charles Burney. ${ }^{145}$ Although Hüttner does not mention

138 This source is reproduced in Huang, "Zhongguo minge 'Molihua' de xizhuang yu donggui," 9. Qiao, Zhongguo jingdian zhinan, Vol. 1,102 dates this source to 1838.

139 See Jiang, Hanzu minge gailun, 235-238 and Feng, Zhongguo tongzong minge, 18-30.

140 In an over 400-page monographic study, Chang Chi-Kuang meticulously researches the genealogy of the melody and systematically compares a variety of text and melody variants (Chang, Minge "Molihua" yanjiu). The standard work Zhongguo minjian gequ jicheng (Anthology of Chinese Folk Songs) lists variants of the tune in the provinces of Fujian, Gansu, Hebei, Heilongjiang, Hubei, Liaoning, Shaanxi, Shandong, Shanxi, Sichuan, in the autonomous regions of Guangxi and Ningxia, and in Beijing. See also Feng, Zhongguo tongzong minge.

141 Identical transcriptions of the Jiangsu folk song can be found in, among others, Zhongguo minjian gequ jicheng (Anthology of Chinese Folk Songs), Vol. Jiangsu, part 2, 726-727, Jiang, Hanzu minge gailun, 236, Qiao, Zhongguo jingdian minge jianshang zhinan, Vol. 1, 101, as well as in Schaffrath, Einhundert chinesische Volkslieder, 112-113.

142 A well-grounded introduction to sizhuyue is Witzleben, "Silk and Bamboo" Music in Shanghai. The interpretation of Molihua by Lu Qingshuang can be heard at http://www.youtube.com/watch?v=9Yn3nxeGn6c. On the playlist http://www.youtube.com/playlist?list=PLA43962352597C895 there are twelve more recordings of the song, including, in addition to several interpretations of the tune from Jiangsu, the versions from Hebei, Shaanxi, and from the Manchurian northeast of China, but mostly in much less "authentic" arrangements.

143 See among others Melvin and Cai, Rhapsody in Red, 78-82.

144 According to Barrow, the song was transcribed from the song of a musician accompanied on some kind of guitar (possibly a sanxian or a pipa; Barrow, John Barrow's Travels in China, 315). Unfortunately, neither Barrow nor Hüttner provide information on where they heard this tune while traveling between Beijing and Canton (Guangzhou).

145 See Proescholdt, "Johann Christian Hüttner." Hüttner was one of only a few Germans to participate in Macartney's diplomatic mission. He was the teacher of the son of Macartney's deputy Ceorge Leonhard Staunton. Hüttner subsequently became a journalist and translator in London, where he also advised Charles Burney on a dictionary entry on Chinese music (see Burney, "Chinese Music"). 
the melody in the very revealing paragraph on Chinese music of his travelogue Nachricht von der Britischen Gesandtschaftsreise nach China 1792-94, which appeared in 1797, ${ }^{146}$ his transcription had already been published in London in 1795 together with the Chinese rowing song Higho high-hau by the Saxon composer Karl Kambra, both in its supposedly "original" form (Ex. 3.8a) and in an arrangement for piano, where the melody is complemented by major-minor tonal harmonies. The edition advances the following remarkable explanation:

The following Chinese Songs were brought to England by a Gentleman of the late Embassy to China, who took them down upon the Spot. Their Originality, therefore, may be depended on, and Mr. KAMBRA, in offering them to the Public, with the addition of a Bass, flatters himself to have rendered them more agreeable to the English Ear. ${ }^{147}$

In 1804, John Barrow, secretary to Lord Macartney during the legate mission to China, published his Travels in China in London, which Hüttner translated and published in German the same year. Barrow reproduces a transcription of Molihua (Ex. 3.8b) that differs markedly in some details from Kambra's version. Barrow justifies his version - in reference to Kambra's piano writing with the astonishing reasoning that with the addition of an accompaniment, the music "ceases to be a specimen of the plain melody of China." ${ }^{148}$ A version slightly different from Barrow's, in turn, is reproduced in the first volume of August Wilhelm Ambros's Geschichte der Musik in 1862 (Ex. 3.8c), again with a tonal harmonization (in D minor); without making reference to his source, Ambros reproduces a version of the melody handed down by Eyles Irwin in $1797 .{ }^{149} \mathrm{An}$ -

146 Hüttner, Nachricht von der Britischen Cesandtschaftsreise nach China 1792-94, 179-183.

147 Karl Kambra, Two Original Chinese Songs, Moo-Lee-Chwa \& Higho Highau, for the Piano Forte or Harpsichord, London 1795, reprinted in Harrison, Time, Place, and Music, 213-219: 213. The same volume published the Chinese rowing song Higho highau and was reprinted in 1796 in the January issue of the Weimar Journal des Luxus und der Moden with a commentary by Hüttner: Johann Christian Hüttner, "Ein Ruderliedchen aus China mit Melodie." Journal des Luxus und der Moden 11, no. 1 (1796), 36-37. Hüttner's commentary in the Journal is reprinted in Harrison, Time, Place and Music, 188-189.

148 Barrow, John Barrow's Travels in China, 315. In his translation of Barrow's text, Hüttner contradicts Barrow in a footnote with this assessment: "But if he [Kambra] immediately made a bass, then nothing was added to the melody itself. The bass could not change the melody; it remains as plain and Chinese as before. [translator's comment]" ("Aber ob er [Kambra] gleich einen Baß dazu machte, so wurde doch zur Melodie selbst nichts hinzugefügt. Der Baß konnte die Melodie nicht ändern; sie bliebt so einfach und Chinesisch wie vorher. Uebers.") (Barrow, Johann Barrow's Reise durch China, 380.)

149 Ambros, Geschichte der Musik, Vol. 1, 34-36. Ambros's source was Irwin, "Chinese Musick," 343 (1797, here the tune is reproduced under the title $\mathrm{T} \sin \mathrm{Fa}$, along with another tune Cheu Teu; two further melodies were published by Irwin in Volume 2 of The Oriental Collections, London 1798, 148). Eyles Irwin was an Irish poet and colonial official working for the East India Company and spent the years between 1792 and 1794 in China. He was also involved in the Macartney mission, so it can be assumed that he had Hüttner's transcription of the song to work from. It cannot be ruled out that the differences in details between the versions of Barrow/Hüttner and Irwin/Ambros are due to copying errors (the title $T \sin \mathrm{Fa}$ - in other sources spelled Sinfa - indicates the Cantonese pronunciation of the alternative title Xianhua, which is also named by Barrow and Hüttner). In describing this melody, Ambros does not hesitate to voice his aversion to Chinese music as a whole. The melody "only too soon enters into the peculiar and grotesque, which is a family trait of all Chinese melodies" (Ambros, Geschichte der Musik, Vol. 1, 34 , "sie geräth nur allzubald in das Absonderliche und Fratzenhafte hinein, welches den Familienzug aller chinesischen Melodien bildet"). In a footnote, Ambros also refers to Barrow's version, which he considers "a little less barbaric" (ibid., 35, "etwas weniger barbarisch"). Other melodies introduced by Ambros served Ferruccio Busoni as an important source for his opera Turandot (1905/17), see Lo, Turandot aufder Opernbühne, 257-266. 
Example 3.8: Nine Versions of Molihua, a. Kambra 1795 (based on Hüttner's transcription 1793/94), b. Barrow 1804 (Hüttner's transcription 1793/94), c. Ambros 1862 (source: Irwin 1797; ": A4 instead of B4 in third edition 1887, also in Irwin 1797), d. van Aalst 1884; e. Fassini-Camossi's music box (1920; recorded in the 1970s); f. Puccini, Turandot (1920-24), Act I, rehearsal number 19 (boys choir); g. gongchepu transcription (Chinese solmisation notation) from 1821 (after Qian, Zhongguo jingdian minge jianshang zhinan, vol. 1, 103), h. modern transcription of the folk song from Jiangsu province (after ibid., 101), i. Tan Dun, Symphony 1997, I. Heaven, mm. 129-143 (children's choir)

other version was published by Jules A. van Aalst in 1884, a Belgian official who was acting in the service of the Chinese imperial customs authority, in his book Chinese Music (Ex. 3.8d). This version has the title Xianhua (Fresh Flower), which appears in very early Chinese sources as an alternative title for Molihua, as well as a Chinese gongche score reproduced by the author. Although this demonstrates that van Aalst had a Chinese source at his disposal, his version quite clearly differs from both the aforementioned 1821 gongche score and Barrow's and Ambros's versions. ${ }^{150}$

In August 1920, during a visit to Bagni di Lucca, Giacomo Puccini heard four Chinese tunes on a music box of his friend Baron Edoardo Fassini-Camossi (1871-1941), "a veteran of the 1900 campaign to suppress the Boxer Rebellion and of a military mission through China to Siberia at the end of the First World War in 1918-20 to reclaim Italian prisoners." ${ }^{151}$ The first of the four tunes was Molihua, in a polyphonic version whose main melody resembles that reproduced by Barrow and Ambros (Ex. 3.8e). ${ }^{152}$ Puccini made use of this version of the melody (along with two

150 Aalst, Chinese Music, 19. The relatively large deviations in the version reproduced by van Aalst may indicate that the author either made mistakes in transferring the original gongche characters into his book, or when transcribing these characters into Western notation. The gongche notation reproduced by van Aalst deviates fundamentally from the gongche source of 1821. Van Aalst's transcription oddly contains the fourth scale degree, which occurs in none of the other versions. Van Aalst may have mistaken the gongche sign 仩 (shang, the octave of the first scale step) for 凡 (fan, fourth scale step). Compare, for example, van Aalst's gongche depiction with a gongche source of Molihua in the Japanese collection Cekkin Gakufu, Tokyo 1877 (https://zh.wikipedia.org/wiki/ File:Molihua1877.jpg).

151 Sheppard, "Puccini and the Music Boxes," 71.

152 The melodies of Fassini-Camossi's music box are discussed in Ashbrook and Powers, Puccini's Turandot. The End of the Great Tradition, 94-96, Lo, Turandot aufder Opernbühne, 326-327, and, most recently and most comprehensively, in Sheppard, "Puccini and the Music Boxes." Sheppard has discovered that "Puccini had also turned to a music box for exotic inspiration some 18 years earlier, during the composition of Madama Butterfly" (ibid., 43). He points to the fact that music boxes with Asian melodies from around 1900 were produced in Switzerland and France rather than in Asia; therefore, they testify to orientalist conceptions of Asian music and cannot be considered "authentic" sources. "The box appears to have been manufactured in Switzerland and exported to China in the late nineteenth century. Baron Fassini returned with the box to Italy either after the Boxer War or in 1920 and brought the instrument to Bagni di Lucca, where Puccini encountered it in August 1920." (ibid., 76)

Puccini's encounter with the Fassini-Camossi music box had been documented early on in a newspaper article by Luigi Cualtiero Paolini in the Giornale d'Italia on 19 August 1920 (see ibid., 70). A further indication of Puccini's source was given by Giuseppe Adami, one of the two librettists of Turandot and Puccini's biographer (Adami, Puccini, 176). The Fassini-Camossi music box was discovered and recorded in 1965 by "Michael Rose and Hans Hammelmann in Rome at the home of Fassini's widow just in time for a BBC Third Programme radio broadcast about Turandot in the series 'Birth of an Opera'" (Sheppard, "Puccini and the Music Boxes," 72). William Weaver, who had joined Rose and Hammelmann, broadcast the music box tunes in a "Metropolitan Opera Intermission Broadcast" on 28 December 1974. I thank Jürgen Maehder for referring me to this broadcast and providing me with a copy of the program. The version of Molihua on the music box employs a simple counter- 


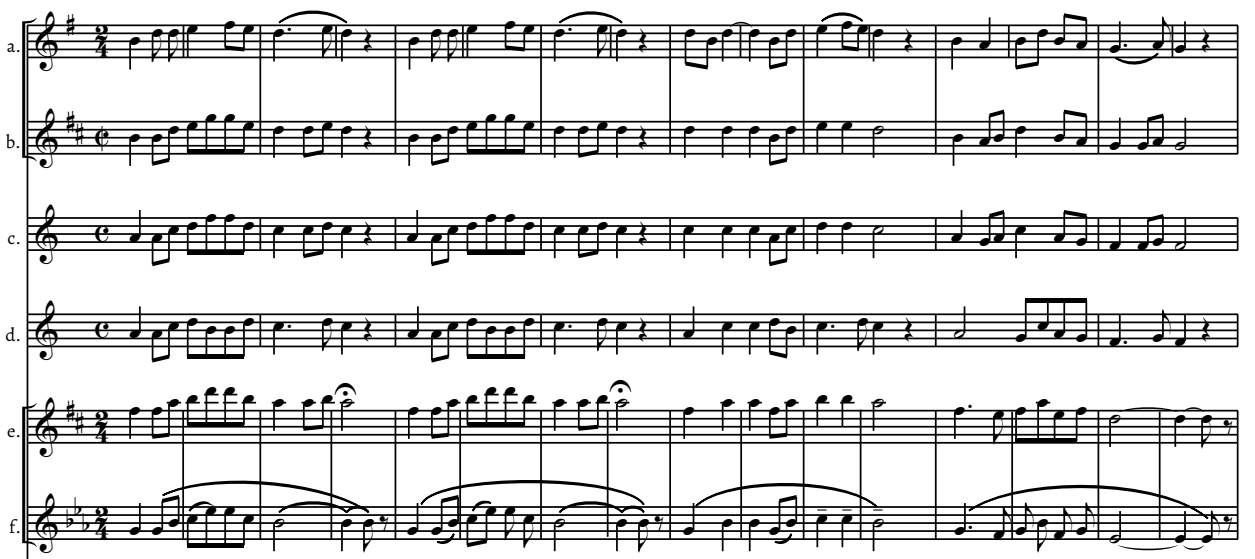

.

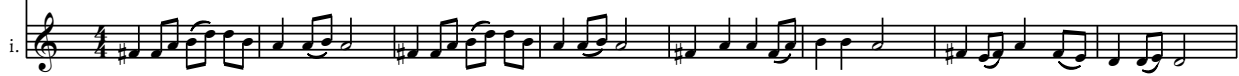

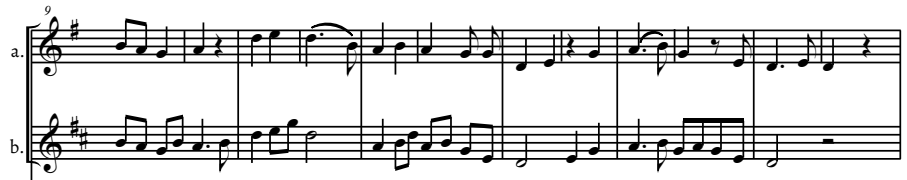

c. एव

d.

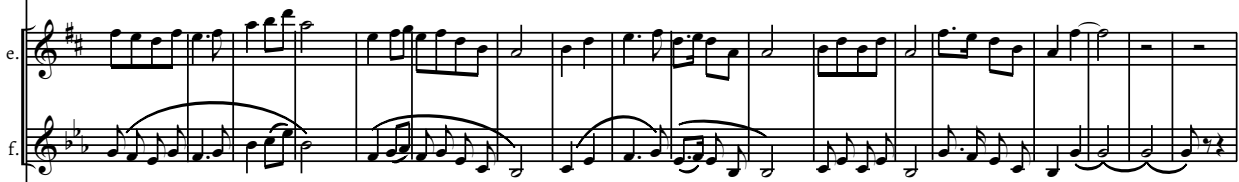

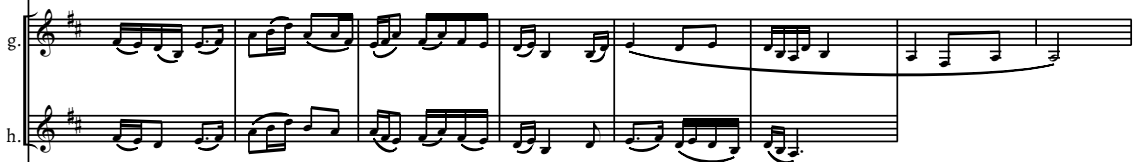

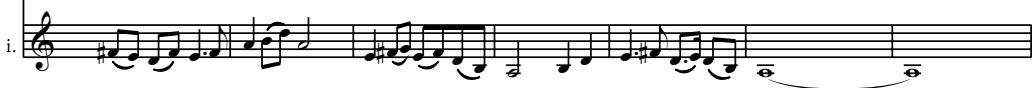

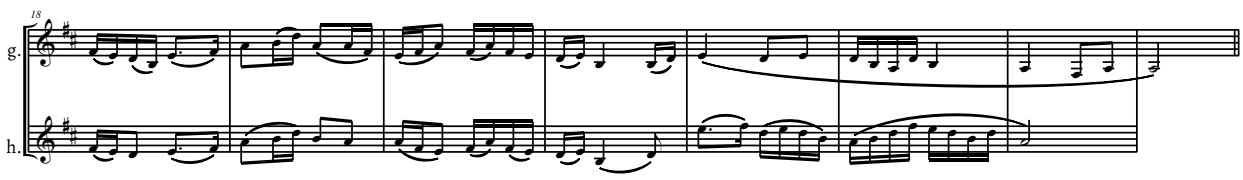


further melodies of Fassini-Camossi's music box) almost literally as a central motif in his opera Turandot, but re-designed the harmonic accompaniment and, of course, the tonal dimension in quite a different manner. At times he treats the melody as a symbol of child-like innocence (as in Act I, rehearsal number 19, boys choir, Ex. 3.8f, Act II, rehearsal number 42, Act III, five measures after rehearsal number 40), at times he introduces an imperially solemn, somewhat threatening, version of the melody (as in Act I, rehearsal number 48, Ex. 3.9; Act II, 16 measures before rehearsal number 63; Act III, two measures before rehearsal number 17). Puccini repeatedly alludes to the music box's specific timbre in his orchestration and the shaping of Turandot's "mechanical" character in the opera might equally have been enhanced by the rhythmically stiff version of the melody on the music box, thus perpetuating Orientalist stereotypes of the "mechanical" character of Asian people and their music. ${ }^{153}$

Both characteristics of Puccini's Molihua are explored by Tan Dun in his Symphony 1997: Heaven - Earth - Mankind (1997), composed for the return of Hong Kong to China on 1 July 1997: in the first movement, Heaven, the "imperial" version (mm. 115-122, Ex. 3.9) is heard first, and then the childlike innocent version (mixed children's choir, canonically complemented by solo violoncello, mm. 129-143, Ex. 3.8i). The references to and deviations from Puccini's version are informative: Tan Dun harmonizes the "imperial" version with slightly different chords, G$\mathrm{C}-\mathrm{D}-\mathrm{C}_{/ \mathrm{G}}-\mathrm{D}-\mathrm{C}_{/ \mathrm{G}}-\mathrm{D}-\mathrm{C}$ (I. Heaven, mm. 115-122), while Puccini (at the first appearance of the "imperial" version in Act I, rehearsal number 48, later always analogously) repeats the two-measure harmonic model $\mathrm{D}-\mathrm{C}-\mathrm{D}-\mathrm{a}^{7}$. The resulting harmonic color is similar owing to the ubiquitous sixte ajoutée, seventh, and ninth chords as well as the mixolydian minor seventh (Ex. 3.9), referring to late European exoticism, not least represented by the harmonies of Gustav Mahler's Das Lied von der Erde, where the added sixth is derived from pentatonic collections and plays a central role throughout the work.

Tan Dun's undeniable familiarity with a wide range of Chinese musical practice has often been instrumentalized as a central factor in his notable success in the Western music world. ${ }^{154}$ In fact, Tan comes from a generation that grew up after the Cultural Revolution in a climate that favored an enthusiastic reception of Western modernism, while Chinese symphonic writing from the 1930 s to the 1970s was regarded skeptically by the younger generation. The main feature of Chinese symphonic music before 1978 was Western-based "pentatonic

melody; in Example 3.8e, only the melody voice is reproduced (although Weaver's broadcast renders the tune in D major, I have reproduced it in Eb major here, since "the Metropolitan Opera broadcast lowered the pitch of these three tunes by a semitone" (ibid., 75). It is clear that Puccini made use of this Molihua version and not the version reproduced by van Aalst, although he took four other melodies from van Aalst's book that play an important part in Turandot (see Ashbrook and Powers, Puccini's Turandot. The End of the Great Tradition, 96-98 and Lo, Turandot aufder Opernbühne, 330-334). Most Chinese melodies reproduced by Swiss music boxes were probably based on transcriptions by the Swiss businessman Frederic 'Fritz' Bovet (1824-1914) (Sheppard, "Puccini and the Music Boxes," 83-88). The notation used for pinning Molihua on a Bovet music box is reproduced in Chapuis, History of the Musical Box and of Mechanical Music, 265.

153 See Wilson, "Modernism and the Machine Woman in Puccini's Turandot" and Sheppard, "Puccini and the Music Boxes," 88-89.

154 In the words of his publishing agent in the 1990s: "Perhaps no more authentic 'world' composer exists today than Tan Dun. For he grew up planting rice in China; lives now amidst the noisy diversity of downtown Manhattan; and constantly travels the world, eagerly absorbing its cultures, as part of a career that has placed him at the center of the international music scene." (http://www.schirmer.com/composers/tan_bio.html, January 2000) Later this text was replaced by another one. Today the official profile of Tan Dun is found at https://www. wisemusicclassical.com/composer/1561/Tan-Dun. 
Example 3.9: Molihua - "imperial" version: harmonizations by Puccini (Turandot, Act I, rehearsal number 48) and Tan Dun (Symphony 1997, I. Heaven, mm. 115-119)

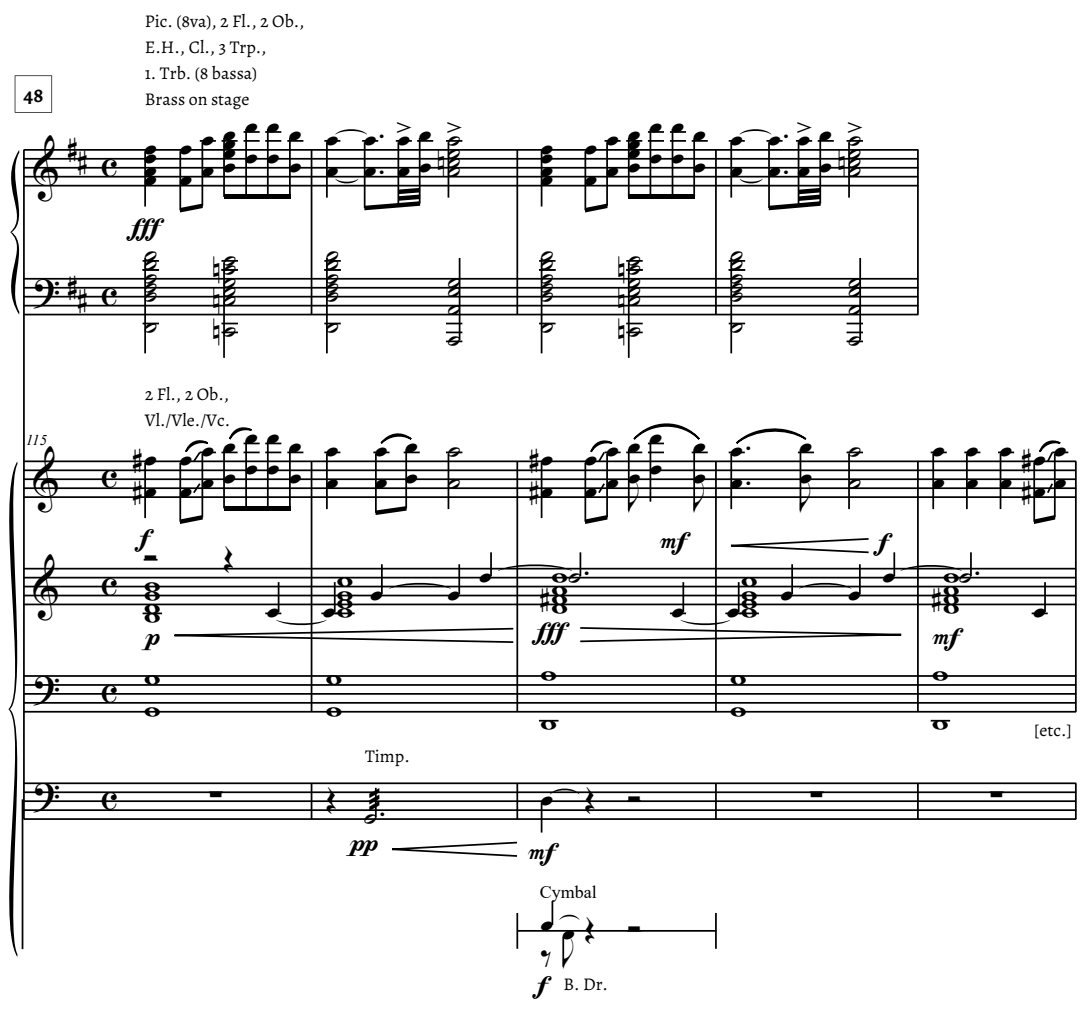

Romanticism," which confined itself to heavily simplified reminiscences of traditional Chinese music. In many respects this repertoire set out from the legacy of European exoticism and the "national schools" of the nineteenth century ( $\rightarrow$ III.1). Tan Dun and his colleagues in China's "new wave" (xinchao), on the contrary, expressed their new path not least by referring to materials of Chinese music that could not be captured with such simplifications. ${ }^{155}$ Tan Dun, like no one else, had to feel the precarious consequences of such an approach, when being accused of acting as a "running dog of capitalism"156 during the first "Anti-Spiritual Pollution Campaign" (Qingchujingshen wuran) from 1983 to 1984, and his music was banned from public performance for six months. ${ }^{157}$ Against this background, the connection to the formulas of exoticist power representation in the Symphony, which only arose thirteen years later, in the context of Tan Dun's glaring success story is all the more haunting. ${ }^{158}$

155 Tan, for example, was very fascinated by the music of the Yao minority that he had encountered in the southern Chinese Guangxi province, not least because of their unusual melodic formations in which tritone-like intervals play an important role, features that cannot be represented in the context of a pentatonic tone system; see Utz, Neue Musik und Interkulturalität, 351-352, 361.

156 Lu, "Ting Tan Dun xianyue sichongzou Feng - Ya - Song," quoted in Mittler, Dangerous Tunes, 99, 123.

157 See Mittler, Dangerous Tunes, 99, 123-124 and Utz, Neue Musik und Interkulturalität, 358.

158 CCP General Secretary Jiang Zemin is said to have smiled approvingly as he recognized the melody of Molihua during the premiere of Tan's Symphony, see Yu, "Two Practices Confused in One Composition," 58. 
Table 3.4: Molihua, different versions of the song text (pinyin transliteration)

\begin{tabular}{|c|c|c|c|c|}
\hline $\begin{array}{l}\text { Zhui bai qiu }{ }^{159} \\
\text { (Libretto collection 1771) }\end{array}$ & Barrow $1804^{160}$ & Xiao hui ji gongchepu $1821^{161}$ & Jiangsu folk song ${ }^{162}$ & Tan Dun Symphony $1997^{163}$ \\
\hline $\begin{array}{l}\text { hao yi duo molihua, } \\
\text { hao yi duo molihua, } \\
\text { man yuan de hua kai sai } \\
\text { bu guo le ta, } \\
\text { ॥: ben dai yao, cai yi duo dai, } \\
\text { you kongpa kan hua de } \\
\text { ma. :\| }\end{array}$ & $\begin{array}{l}\text { hao yi duo xianhua, } \\
\text { [hao yi duo xianhua,] } \\
\text { you chao yi ri luo zai wo jia } \\
\text { wo ben dai, bu chu men } \\
\text { dui zhe xianhua['er] le. } \\
\text { hao yi duo molihua } \\
\text { [hao yi duo molihua] } \\
\text { man yuan hua kai sai bu guo ta } \\
\text { wo ben dai cai yi duo } \\
\text { dai you kong kan } \\
\text { hua ren ma. }\end{array}$ & $\begin{array}{l}\text { hao yi duo xianhua, } \\
\text { hao yi duo xianhua, } \\
\text { piao lai piao qu luo zai wo de jia, } \\
\text { wo ben dai bu chu men } \\
\text { jiu ba na xianhua'er cai. } \\
\text { hao yi duo molihua, } \\
\text { hao yi duo molihua, } \\
\text { hua yuan hua kai zen ji de ta, } \\
\text { ॥: wo ben dai cai yi duo dai, } \\
\text { you kong na guan } \\
\text { hua ren lai ma. :॥ }\end{array}$ & $\begin{array}{l}\text { hao yi duo molihua, } \\
\text { hao yi duo molihua, } \\
\text { man yuan hua cao xiang } \\
\text { ye xiang bu guo ta; } \\
\text { Il: wo you xin cai yi duo dai, } \\
\text { kan hua de ren'er yao } \\
\text { jiang wo ma. :\| }\end{array}$ & $\begin{array}{l}\text { hao yi duo meili de molihua } \\
\text { hao yi duo meili de molihua } \\
\text { fenfang meili man zhiya you } \\
\text { xiang you bai ren ren kua } \\
\text { rang wo lai jiang ni zhai jia } \\
\text { song gei qingren jia } \\
\text { molihua, molihua }\end{array}$ \\
\hline
\end{tabular}

159 After Qiao, Zhongguojingdian minge jianshang zhinan, Vol. 1, 102.

160 Here rendered in pinyin transliteration (after ibid., 104; Qiao supplements or replaces individual syllables, which have been omitted here). Barrow's transliteration is probably based on Cantonese pronunciation: "I. Hau ye-to sien wha,/Yeu tchau yeu jie lo tsai go kia/Go pun tai, poo tchoo mun/Twee tcho sien wha ul lo./ II. Hau ye to Moo-lee wha/Man yuen wha kai soy poo quee ta/Go pun tai tsai ye ta/Tai you kung kan wha jin ma" (Travels in China, 316-317). Barrow translates: "I. How delightful this branch of fresh flowers/One morning one day it was dropped in my house/l the owner will wear it not out of doors/But I will hold the fresh flower and be happy./II. How delightful this branch of the Moo-lee flower/In the full plot of flowers blowing freely none excels it/l the owner will wear this gathered branch/Wear it yet fear, the flower seen, men will envy." (ibid., 317.) Hüttner translates as follows "I. Wie angenehm dieser Zweig frischer Blumen/Eines Morgens eines Tages wurde er in mein Haus geworfen,/Ich der Eigenthümer will ihn tragen nicht außer der Thür/Sondern ich will halten die frische Blume und glücklich seyn./II. Wie angenehm dieser Zweig der Muliblume/In dem vollen Beete der Blumen blühend frei keine übertrifft sie/lch der Eigenthümer will tragen diesen gebrochenen Zweig/Tragen ihn doch fürchten, die Blume gesehen, Menschen werden beneiden." (Barrow, Johann Barrow's Reise durch China, 382.)

161 After Qiao, Zhongguo jingdian minge jianshang zhinan, Vol. 1, 103.

162 After Zhongguo minjian gequ jicheng, Vol. Jaingsu, part 2, 726-727, Jiang, Hanzu minge gailun, 236, and Qiao, Zhongguo jingdian minge jianshang zhinan, Vol. 1, 101. The sources also record a second and a third stanza (with a text different from the first stanza quoted in Barrow 1804 and the gongche score 1821).

163 Tan Dun, Heaven Earth Mankind - Symphony 1997 (score), New York: Schirmer 1997, I. Heaven, mm. 129-143. Tan Dun does not use a pinyin transliteration, and spells the song text: "Hau yi do mei li di mo li Hua/Hau yi do mei li di mo li Hua/fen fang mei li Man zi ya/you shiang you bai ren ren kua/Rang wo lai Jiang ni zai shia/Sung gei ching ren jia/mo li hua mo li Hua." Except for one word in the penultimate line (bieren instead of Tan's qingren), this corresponds to the version reproduced on the Chinese Wikipedia page for Molihua: https://zh.wikipedia.org/ wiki/File:Jasmine_barrow.svg. Both this "modern" text and the traditional text version of the Jiangsu folk song are quoted, adding that the "modern" version has been spreading for "a few years" (https://zh.wikipedia.org/ wiki/茉莉花(民歌)). The internet encyclopedia BaiKe.ZiDianTong.Com identifies the Sino-Malaysian pop singer Fish Leong (Jasmine Leong, Liang Jingru, b. 1978) as the originator of these "modernized" variants of lyrics and melody (Fish Leong popularized the folk song by her pop song Molihua on the Album Wings of Love [Yangweidie, "Swallowtail"] 2004, music: Li Zhengfan, text: Yao Ruolong, based on the folk song) (https://baike.baidu.com/ item/茉莉花/3899330). The music of this pop ballad, however, evidently does not go back to the folk song, and even the text version should, as Tan's symphony from seven years earlier demonstrates, have long been prevalent. From the fifth line onwards, the lyrics of Fish Leong are fundamentally different from Tan's version (Fish Leong's text here reads: bu rang shei ba xin zhaixia/jiu deng neige ren ai ya/molihua ya molihua). 
It remains clear that Tan, despite some efforts to suggest Chinese idiomatic sounds - for example, with the sliding melody in the strings or occasional ornaments ${ }^{164}$ - clearly references Puccini or the Western appropriation of the melody and not one of the variants of Chinese folk music practice named above. The "innocent" version sung by the children's choir (I. Heaven; mm. 129-143, Ex. 3.8i) is imitated by the solo cello in canon, which points toward another intercultural context: as outlined earlier, the arrangement of folk songs based on Western principles and styles has played a pivotal role in Chinese music history since the end of the nineteenth century $(\rightarrow$ III.1).

Now, indeed, the version of Molihua reproduced by Tan Dun is known and popularized today as a "national" Chinese folk song, and its relationship to the variations of Jiangsu folk music introduced above has not yet been fully explained by music research. A comparison of the song text in the various sources reveals significant differences between the version used by Tan Dun and the remaining variants, which are related to the altered number of pitches and phrase structure (Table 3.4). Regarding the historical origin of this textual alteration, one may glean some hints from the sources: the Jiangsu folk song was transcribed by the (then only 14-yearold) singer He Fang in 1942 in the Liuhe region of Jiangsu province from the song of an old master. Then, in 1957, He Fang set the text for female choir, an arrangement that was recorded and distributed throughout China, and finally, in 1959, it appeared with a new text at the Seventh World Festival of Youth and Students in Vienna, thus playing a politically representative part. ${ }^{165}$ It can be assumed that in the course of the 1950s, Puccini's opera had already become known in China, at least among musicians, although the opera was officially banned there and was first performed at the Shanghai Opera House only in 1990. ${ }^{166}$ In any case, Puccini's version of the melody may still have had an impact on arrangements such as He Fang's, which were in turn widely used in China, in keeping with Mao Zedong's new slogan issued in the 1950s, gu wei jin yong, yang wei Zhong yong (Making the past useful to the present and the foreign useful for China), based on a similar slogan by the official Zhang Zhidong from the late nineteenth century $\rightarrow$ III.1). ${ }^{167}$ The focus was therefore less on the preservation of regional or cultural peculiarities, but rather on the utilitarian adoption of Western techniques for mass dissemination and identity formation - for which Puccini's simplistic version was no doubt more effective than the folk song from Jiangsu, with its basis in complex oral traditions and performance practice. Finally, it should be noted that for Chinese researchers and musicians, the difference between the "European" and the (local) Chinese versions is not as blatant as it was presented here. On the contrary, in Puccini's version, some of them see another more "regional" variant of an only imaginarily existing framework material, to which all the other roughly 15 different melodies in China also refer, and in which, due to the regional styles, there are also sometimes intriguing changes to the text and the melodic structure. ${ }^{168}$ This rather original argument seems to

164 Elsewhere, efforts are made by Tan to add a special quality distinguishing his rendition from Puccini's, as in the approach to the third bar of the melody (enhanced by dynamics, timpani tremolo, and cymbal accent) or by the "countermelody" in the ascending fifths $\mathrm{C}_{4}-\mathrm{C}_{4}-\mathrm{D} 5$. All this, of course, does not change Tan's basic reliance on Puccini's "representation" of the melody.

165 Zhongguo minjian gequ jicheng, 727. See also the quoted internet sources in footnote 163.

$166 \mathrm{He}$, "The Ambiguities of Chineseness," 551.

167 See Ceist, Die Modernisierung der chinesischen Kultur, 12-20. For the first time in 1898, Zhang formulated the slogan zhongxue wei ti, xixue wei yong: "Traditional (Chinese) learning [Confucian ethics] as substance, New (Western) learning [administration and technology] as application." ( $\rightarrow$ III.1)

168 Personal conversation with Jiang Mingdun, Shanghai, 28/11/2002. 
overlook that in both the Puccini and the Tan Dun China (or Chinese culture in the sense of the "myth paradigm," $\rightarrow$ I.3) is represented by this melody as an (imaginary) "entity," and the manner of its simplification by the Western musical context is conditional - something categorically different from transformations of a model owing to regional music practice.

It is not difficult to see in Tan Dun's Symphony an example of a postcolonial construction of cultural identity, which, incidentally, can be clearly demonstrated on various other levels of the work, and in concluding, I will briefly discuss two such levels: The set of imperial bells bianzhong, which plays a central role in Tan's work, was first unearthed in 1978 in the Suixian region of Hubei province and quickly became a new symbol of Chinese "national culture," as one of the oldest known Chinese instruments. Of its 64 bronze bells, 45 were used for the courtly ceremonial music and 19 added only for tuning reasons. The instrument comes from the estate of Duke Yi from the state of Zeng (722-221 BCE) during the ancient Zhou Dynasty. ${ }^{169}$ The bells were used in various genres of court music. In the context of Tan Dun's Symphony 1997, the archaic instrument seems like a foreign body that is difficult to integrate, due in particular to the combination of the equally-tempered, mostly even diatonic orchestral structures and the specific "microtonal" tuning of the bells. ${ }^{170}$ The 2400-year-old imperial bell set thus serves only as a splash of color, its specifically unequally-tempered tuning is leveled in a largely diatonic music. In his study of the Symphony, Yu Siu Wah also elaborates on the significance and, above all, the ambivalent cultural symbolism of the bell set. His positive conclusion, however, is difficult to agree with:

Tan tackled the problem [of connecting the non-equally tempered bells to the equally tempered Western symphony orchestra] by deliberately using the bells in solo for a long section; when used simultaneously with the orchestra, the bell-chimes are always scored as percussion instruments, and the clash in temperament with the orchestra is thus undermined. ${ }^{171}$

In contrast to Yu's thesis, in the transition to the "imperial" Molihua reference in the first movement Heaven (mm. 114-115), the discrepancy between the bell's harmony and the abruptly occurring $\mathrm{G}$ major tutti chord is very obvious.

The program of the Symphony, subtitled Heaven - Earth-Mankind, also refers to the archaic world of the Zhou Dynasty. A symbiotic, transparent, and fluid relationship between tiandi (heaven and earth, which symbolize the entire cosmos) and ren (humankind) indeed plays an essential part in the worldview of ancient Daoism as it unfolded during the Zhou Dynasty. This worldview informed, among others, numerous religious practices, such as the worship of the "officials" of heaven (tianguan), earth (diguan), water (shuiguan), and humanity (renguan). But the two lines by the philosopher Zhuangzi (c. 369-286 BCE) quoted by Tan Dun at the climax of his Song of Peace, a short movement that serves as both introduction and coda to his Symphony, considerably distort the original meaning of the text. ${ }^{172}$ In the context of the "heroic" D major, to evoke unequivocal associations with the setting of Schiller's Ode To Joy in Beethoven's

169 See Liang, Music of the Billion, 71-75.

170 The CD recording of Tan's work made use of the originally excavated bronze bell set Zenghouyi Bianzhong unearthed in 1978, which has otherwise been kept under lock and key at the Hubei Museum since the mid-1980s; for the premiere on 1 July 1997 and follow-up performances, a replica was used. See Yu, "Two Practices Confused in One Composition," 57, 65.

171 Ibid., 67.

172 See Gooi, "Making an Identity," Chapter 3.5. 
Ninth Symphony, the phrases "Heaven, Earth, and I are born together, the 10,000 things [that is, everything in existence] and I am one" confirm associations with an emphatic assertion of the unity of heaven, earth, and humanity. ${ }^{173}$ In Zhuangzi's chapter Qi wu lun (The Adjustment of Controversies), however, these two lines are followed by two questions and a brilliant paradoxical conclusion that totally challenges the first statement about unity or the very idea of unity:

Heaven, Earth, and I were produced together, and all things and I are one. Since they are one, can there be speech about them? But since they are spoken of as one, must there not be room for speech? One and Speech are two; two and one are three. Going on from this (in our enumeration), the most skilful reckoner cannot reach (the end of the necessary numbers), and how much less can ordinary people do so! Therefore from non-existence we proceed to existence till we arrive at three; proceeding from existence to existence, to how many should we reach? Let us abjure such procedure, and simply rest here. ${ }^{174}$

It is surely no coincidence that this passage does not find its way into Tan's representationalist music. The question of how to determine whether music represents cultural identity in an "essentialist" manner is answered in several ways by Tan's Symphony 1997. It characteristically abbreviates classical symbols of Chinese culture, neglecting their internal plurality, and this is a vivid example of an "affirmative" type of essentialism, which in this case also has strong political overtones. ${ }^{175}$ The "misunderstandings" of European exoticism and colonialism seem to be hardened in Tan's work, confirming its mésalliance with affirmative nationalist Chinese symphonic works of the twentieth century.

Tan Dun was not afraid to resort to the melody in a musical setting analogous to the Symphony in the music he arranged jointly with the People Liberation Army's composer Wang Hesheng for the 302 medal ceremonies at the Beijing Olympics 2008, ${ }^{176}$ and to characterize it as an "iconic piece," "almost a cultural symbol of China" and "a gift from the Chinese people to the world's athletes." 177 The story of the melody took a turn when it was played in a version for solo violin by the American-Chinese violinist Lynn Chang at the ceremony for the awarding of the Nobel Peace Prize to the imprisoned dissident Liu Xiaobo in Oslo on 10 December 2010, ${ }^{178}$ and especially shortly afterward, when, following the example of the anti-regime protests in Tunisia, there were also broad anti-government protests in China in February and March 2011 referred to as the "Jasmine Revolution" (molihua geming): the term "jasmine" came under internet censorship, and even trade in jasmine flowers was prohibited. ${ }^{179}$

173 See ibid., 161-171.

174 Zhuangzi, The Writings of Chuang Tzu.

175 On political-cultural symbolism in the symphony and the reception of works in Hongkong, see Yu, "Two Practices Confused in One Composition."

176 Cui, "Classical Piece Will Ring in Ears of Winners."

177 Ibid.

178 See The Nobel Peace Prize Award Ceremony 2010, http://www.nobelprize.org/mediaplayer/index.php?id=1405, 48:45.

179 Chou, "From Nation's Favourite to Populist Poison" and Sheppard, "Puccini and the Music Boxes," 91-92. 


\section{Probing the Compositional Relevance of Cultural Difference: Key Tendencies of East Asian New Music Since the 1950s}

The most obvious compositional articulation of culturally encoded forms of alterity is the immediate juxtaposition of idioms or structures that are clearly "culturally charged," accentuating their uniqueness, their fundamental difference, perhaps their incommensurability $(\rightarrow$ I.3). This model becomes particularly palpable if Western and non-Western instruments are placed in direct confrontation with one another - a tendency that has been mostly peripheral on a global scale since Tōru Takemitsu's November Steps for shakuhachi, satsuma-biwa, and orchestra (1967), but should be accentuated all the more in the studies presented here. Tan Dun's Ghost Opera (1994) for pipa and string quartet offers a relevant example of "composed-out" alterity, as do many works by composers such as Toshio Hosokawa or Toshi Ichiyanagi $(\rightarrow$ III.5, IV.1). As outlined already in Chapter II.6, there are two key works of modern European music theater in which an East Asian instrument assumes the extraterritorial function of the "Other": the Japanese shō mouth organ in Helmut Lachenmann's Das Mädchen mit den Schwefelhölzern (1990-96) and the Korean arched zither ajaeng in Hans Zender's ChiefJoseph (2003) $\rightarrow$ II.6). Thus, the staging of cultural alterity through the dramaturgical use of musical instruments can be found among composers of different nationalities and is not limited to the Asian context.

Meanwhile, within globalized art music, a clearly ambiguous discourse of cultural difference has become established. On the one hand, many authors sympathize with approaches that aim at independence from the aesthetic criteria of Western modernism, understanding cultural difference as a medium of incommensurability and thus adopting a substantial achievement of aesthetic modernity by working against its consolidation as a norm. On the other hand, this dynamic has been picked up by Western-dominated markets, such that concert promoters and the public often expect traces of cultural difference in works by Asian, African, or Latin American composers ( $\rightarrow$ I.3). Concurrently, the unspoken norms and formats of new music sometimes leave little room for deviation. This paradoxical situation is further confused by often polemically accentuated phrases in music journalism - especially in German-speaking countries - that sometimes still derogate cultural heterogeneity, ambivalence, and hybridity with epithets such as "dilution," "touristic appropriation," or "pastiche."180

This chapter sketches some of the historical and aesthetic conditions under which the compositional relevance of cultural difference in the Asian context has steadily increased since the 1950s. In particular, it can be shown how cultural difference has become a central aesthetic metaphor for composition in situations of cultural upheaval. But the following case studies also demonstrate that attempts to impose a simple dualism between cultural difference and cultural Westernization usually fail. On the contrary, in all cases an essential impulse emanates from the aesthetics and critical thought of Western modernism or postmodernism, although their basic sociocultural basic requirements obviously cannot be transplanted to other cultural contexts without friction. The most prominent Asian composers of the 1960 s and 70s, Isang Yun (1917-1995), José Maceda (1918-2004), Chou Wen-Chung (1923-2019), and Tōru Takemitsu (1930-1996), were explicitly aiming at a compositional expression or integration of the culturally different. Their works are unthinkable without the indissoluble entanglement of local or national discourses with the impression and influence of Western politics, art, and aesthetics. These played into detailed compositional decisions but also into the way these composers

180 Examples can be found in abundance; see, for example, Häusler, "Begegnungswege," Boehmer, "Clobalisierung als heimischer Fetisch," and Nyffeler, "Der Reiz des Fremdgehens." 
communicated their compositional ideas and techniques to both Western and non-Western audiences or readerships.

\section{Culturalist Polarization in Isang Yun's Music}

This rings particularly true when the situation of migration is considered. The problem of (nonWestern) national(ist) essentialism appears particularly troublesome when confronted with a (Western) cultural surrounding as the unsettling experience of otherness and alterity might be existentially perturbing or potentially traumatic. ${ }^{181}$ When considering this biographical context, it appears inevitable that Isang Yun (1917-1995), surely the most influential Korean composer worldwide to date, was concerned from the beginning of his stay in Europe (1956) with the problem of finding a compositional identity that can encompass both his Korean origin and past and his European/German present. The inescapable frame of reference of this search for identity can be found in the discourses of contemporary European music from the 1950 s to the 1990s, a frame of reference of the highest importance for Yun's self-conception as a composer, as has been repeatedly shown. ${ }^{182}$ The cultural frame of reference during Yun's first 40 years in Korea, including his studies in Japan (1933-36 in Osaka, 1938-41 in Tokyo with Tomojirō Ikenouchi), on the contrary, was significantly more fragmented and inseparably linked to the modernization of East Asian societies oriented toward Western models, as well as repressive Japanese colonial rule in Korea. Against this background, I will first explore the question of how Yun constructed, polarized, or negotiated a cultural "self" and cultural "other." The basis of my reflections is Yun's music before 1975, works in which references to Korean or East Asian traditions tend to play a more significant role than in later works, giving them immediate relevance to the discussion of interculturality.

How did Yun resolve the question of a cultural self and cultural other? First of all, it is noticeable that he always drew a very sharp contrast in his writings between "East" and "West." One of the numerous statements that point in this direction is the following: "The West is more work-related, Asia more intuition-driven, with all the little colors, melismas, and ornaments. The West accentuates the structure and the form, the East the underlying vitality of the music." ${ }^{183} \mathrm{~A}$ similar juxtaposition, here transferred to the more specific contrast between Korean and European music, can be found in the radio program "Musik und Instrumente des alten Korea"184 (Music and Instruments of Ancient Korea), which Yun made in 1963 for West German Radio in Cologne. Its main arguments are summarized in keywords in Table 3.5.

181 See, among others, Gratzer and Grosch, Musik und Migration.

182 See, among others, Eikemeier, "Ist Yun Isangs Musik koreanisch?," Howard, "Korean Tradition in Isang Yun's Composition Style," Sparrer, "Isang Yun und koreanische Tradition," Kim, "The Diasporic Composer," Utz, Neue Musik und Interkulturalität, 222-254, Yun, Zwischen zwei Musikwelten, Howard, Creating Korean Music, 129-135, 140-153, and Han, Interkulturalität in der neuen Musik Koreas.

183 Yun, “Über meine Musik," 305 (“Der Westen ist mehr werkbezogen, Asien mehr von der Intuition getragen, mit all den kleinen Färbungen, Melismen und Verzierungen. Der Westen akzentuiert die Struktur und die Form, der Osten die tragende Lebendigkeit der Musik.").

184 Yun, "Musik und Instrumente des alten Korea." 
Table 3.5: Polarization of Korean and European music in Isang Yun's radio program

"Musik und Instrumente des alten Korea" (1963)

\begin{tabular}{|l|l|l|}
\hline & Korean Music & European Music \\
\hline time & no beginning, no end & ends \\
& rests & hastening \\
& reaches completion in the moment & reaches completion over time \\
\hline individual tone & $\begin{array}{l}\text { infinitely long, vessel of vividly } \\
\text { flowing feeling } \\
\text { articulated in naive joy } \\
\text { stylized according to the rules of a } \\
\text { pronounced decorative sense of art } \\
\text { lively brush stroke of ink painting }\end{array}$ & $\begin{array}{l}\text { smoothing, abstraction } \\
\text { receives meaning from } \\
\text { the sense of the whole } \\
\text { abstract lines }\end{array}$ \\
\hline
\end{tabular}

The sweeping nature of this comparison catches the eye. The thesis, for example, that the tone in Western music is always "bound in functional contexts" follows the highly influential stereotype that for "all" European music at least since Beethoven, if not since Bach or earlier, a kind of musical discursivity can be assumed in which each tone has a clear and definite function in the hierarchy of the whole. This stereotype was not least established by the Hegel- and NeoKantian-influenced German-language music theory of the nineteenth century, which was often oriented almost exclusively toward Beethoven, and has most prominently resulted in the ideas of "harmonic functions" (Hugo Riemann) and "formal functions" (Arnold Schoenberg, Erwin Ratz). ${ }^{185}$ The fact that many works by Schubert, Schumann, Berlioz, or Debussy cannot be adequately described according to such a concept was already recognized in the early twentieth century, but this did little to impede the "success" of this idea until today. Yet Yun's tendency toward stereotyping is even clearer in the statement that the Korean tone is "articulated in naive joy." Is the single tone in Korean court music - Yun refers here in particular to the wellknown piece Sujech'on $n^{186}$ - not equally part of a structural framework, a network of heterophonic lines that have a considerable complexity? Without delving into this question here, we can say that Yun's words demonstrate a postcolonial pattern: his "native" non-Western tradition represents the "feeling," the "naive," the "decorative," while the Western, on the contrary, aims at the "sense of the whole" and at "abstraction," and therefore at rationality. It is a small step from this position to the sweeping comparisons of nineteenth-century orientalism, ${ }^{187}$ whose evaluations Yun reverses simply by positively defining attributes formerly considered deficient. Overall, it is obvious that Yun constructs a largely homogeneous "self" and "other."

185 A critique of the idea of musical "functions" is implicit in many energetic and phenomenological approaches to music theory and analysis that tend to highlight the qualia of perceived sound at least in part independently from their functionality within a larger form or context. It is relevant in this context that Yun received instructions, among others, from Josef Rufer, an influential former student of Schoenberg, in Berlin in 1957 whose book Die Komposition mit zwölfTönen (1952) he had studied in Japanese translation while still in Korea (Sparrer, "Isang Yun").

186 Yun, “Musik und Instrumente des alten Korea,"15.

187 See Wimmer, "Vom Umgang mit kulturellen Differenzen in der Philosophie." 
Of course, it would also be completely misleading to deny that certain fundamental differences exist between traditional Korean and modern European music, even if such differences might have lost some of their sharpness as a result of the extensive process of renewal in both traditional Korean and twentieth-century Western-oriented music. The decisive factor, however, is the observation that Yun's music does not make these differences audible in the sense of a polarized tension. His works appear to be - possibly in contrast to traditional Korean music - quite spontaneously comprehensible, and were well-received within a European frame of reference. This is often explained with the argument that Yun "integrated" these differences into his personal style in the process of composing. This argument is evident in the following assessment from the 1996 article "Korea" in the MGG encyclopedia:

In his music, Yun shows that Korean origin and identity can also become recognizable in the musical language of avant-garde sounds, not only superficially, by deploying traditional rhythms, scales, or ornaments, or by incorporating historical instruments, but rather by an aesthetic sensibility rooted in Eastern philosophies and intellectual contexts that lead to a distinctive style that is not Asian or European, but rather both at once. In this sense, Isang Yun became a teacher and role model for the following generation. ${ }^{188}$

On the face of it, this characterization seems plausible, yet I would like to draw attention to a point that strikes me as a key problem in the discussion of interculturality as a whole, namely the argument of a dualism between "surface" and "substance."189 The "surface" is supposedly "merely technical," here referring to elements from traditional Korean music or "historical" (meaning Korean) instruments. The "substance," meanwhile, lies in "aesthetic sensibility" and "intellectual contexts." In this simplistic separation of spirit and technique - a foundational discourse in the early reception of Western music in East Asia $\rightarrow$ III.1) - lies a core problem of intercultural reception generally. On closer examination, it quickly becomes clear that "surface" and "substance" in musical contexts are as difficult to separate as "mind" and "body" in the field of epistemology.

This becomes particularly obvious in light of traditional Korean instruments: instrumental "technique" cannot be separated from a particular mental attitude or condition with which the performers produce a sound; this becomes clear in aesthetic concepts such as mat ("delicateness") or mót ("taste"). ${ }^{190}$ But conversely, the instruments themselves already contain the full potential of the (music) culture that produced and produces them (and which was and is produced by them), as evidenced, for example, by the connection between the construction of the instruments and the structural elements of the traditional repertoire, such as the varied heterophony based on constant inflection. One could further specify this connection and ask how far the identity of Korean music can be communicated without its medium, the "historical instruments." Conversely, one might similarly pursue the question of how much of the "spirit"

188 Bühler and Chu, "Korea" ("In seiner Musik zeigt Yun, dass koreanische Herkunft und Identität auch in der Musiksprache avantgardistischer Klänge erkennbar werden kann, nicht nur vordergründig durch Verwendung traditioneller Rhythmen, Skalen oder Ornamente, oder durch Einbeziehung historischer Instrumente, sondern durch ein in östlichen Philosophien verwurzeltes ästhetisches Empfinden und geistige Inhalte, die zu einem unverwechselbar eigenen Stil führen, der nicht asiatisch ist oder europäisch, sondern beides zugleich. In diesem Sinne wurde Isang Yun Lehrer und Vorbild für die nachfolgende Ceneration.")

189 See, more specifically, Utz, Neue Musik und Interkulturalität, 43-49, 58-61.

190 See Howard, "Different Spheres: Perceptions of Traditional Music and Western Music in Korea." 
of Mozart's music is preserved in recordings of Eine kleine Nachtmusik by Japanese koto ensembles $?^{191}$ But this argument cannot be limited to the question of the instruments alone: fundamentally, one must question the possibility, often taken for granted, of being able to communicate cultural "substance" musically, without recourse to its structurally and timbrally defined idioms. Ultimately, this discussion points back to those polarizations between structure and sound, or form and sound, that are deeply ingrained in nineteenth- and twentieth-century music-aesthetic discourse $\left(\rightarrow\right.$ II.1). ${ }^{192}$

Yun's move to the allegedly "more substantial" level of reception of basic philosophical and aesthetic concepts, and his great reluctance about the use of concrete and recognizable Korean sources in his works in any case demonstrates, in a particularly clear way, that he operated within a European frame of reference. His view "back" on Korean and East Asian culture was prominently shaped by a "regionalist" European gaze. ${ }^{193}$ The unified image that he verbally painted of Asia and Europe ("We Asians," "in Europe," etc. ${ }^{194}$ ) corresponds to the vagueness of his compositional reception of Asian music and aesthetics from an ethnological perspective, which Keith Howard has discussed: ${ }^{195}$ the construction of basic aesthetic principles from archaic, Daoist, Buddhist, and shamanistic ideas as well as from different, scarcely compatible Korean music genres, yields on closer examination a complex of strongly divergent references that are only provisionally held together under the mantle of the "Asian."

This situation undoubtedly also means that ethnological authenticity was of secondary importance to Yun's composing, which of course was also a widespread attitude in his generation. With a stronger emphasis on authenticity in the details, a substantial counterdiscourse to the dominant Western concept of music might have developed - yet Yun avoided this possibility, not least through his insistence on the emphatic conception of the autonomous musical work, and perhaps also through the predominantly discursive macroformal design of his compositions. It was not until the 1980 s and 1990s that such a counterculture took on a distinct shape in some works by younger Korean and other East Asian composers $(\rightarrow$ III.5).

This is not the place for a detailed musical analysis of Yun's music, but on the basis of the previously discussed problems, some preconditions and objectives of such analyses may be suggested. First of all, it is obvious that only a small (though surely significant) part of the intercultural reception processes that preceded the writing of Yun's works are in fact deducible from his scores. A closer understanding of Yun's music therefore requires a research approach that connects source-oriented historical and ethnomusicological knowledge as equal poles of analysis. This of course requires a more extensive availability of written sources (translation of Korean writings by and about Yun, increased exchange of Western and Korean research,

191 See The New Koto Ensemble of Tokyo: Koto Mozart!, LP Angel S-37553 (1978, the LPalso includes one koto arrangement of the Symphony in C minor K. 550). Numerous similar productions have appeared, such as the CD Samurai Chamber Orchestra: Samurai Mozart (insideout 2007), which contains six arrangements of Eine kleine Nachtmusik, among others for koto ensemble, shamisen ensemble, and shakuhachi ensemble.

192 See, among others, Janz, Klangdramaturgie, 32-39, Stollberg, Ohr und Auge - Klang und Form, and Utz, "'Liberating' Sound and Perception," 21-30.

193 "Yun's Asian identity emerged in Europe, and was a reaction and accommodation to his migration into a new cultural environment." (Howard, "Korean Tradition in Isang Yun's Composition Style," 67.) See also Kim, "Migration im Wandel" and Kim, "European music' outside Europe?"

194 See, for example, Yun, “Über meine Musik," 298.

195 Howard, "Korean Tradition in Isang Yun's Composition Style," 83-84. 
collection and publication of Yun's writings and letter ${ }^{196}$ ) as well as the documentation of oral history (systematic interviews with contemporary witnesses, etc.). Finally, a precise presentation of the performance history and audience, press, and scholarly reception of Yun's music in Germany and Korea, and an explanation of how these performance and reception histories impacted Yun's work, would be required.

For a close reading of intercultural aspects in Yun's works, it seems necessary to put together a detailed chronology of Yun's encounter with Western and Korean or East Asian music and culture, in order to be able to establish his knowledge and perspectives regarding these areas during the composition of key works such as Réak (1966), Glissées (1970), Piri (1971), and Gagok (1972). ${ }^{197}$ It also seems imperative to reconstruct the creative processes of such key works through closer scrutiny. What were Yun's sources prior to, and during, these compositions? In what ways did information about Korean (or other Asian) musical genres flow into these works, and how did Yun bring this knowledge together with compositional techniques that he appropriated in Europe (serial technique, etc.)?

Similar issues could be proposed for research on other dominant Asian composers of Yun's generation who significantly contributed to the idea of intercultural compositions from the 1950 s and 60 s on, among them Chou Wen-Chung, Tōru Takemitsu, and José Maceda. While much has been written about their aesthetic approaches and, importantly, close analyses of their key works have been published, a precise philological account of their compositional processes that sheds light on the preconditions and dynamics of their intercultural reception process remains a profound challenge for a future global music historiography - especially since such a philological approach could substantially transform certain tropes and currently one-sided assessments of their work.

More than fifty years after Yun's Réak, numerous composers of various backgrounds still face the problem that the dominance of the Western cultural and aesthetic frame of reference in new music is difficult to escape, and that the potential for a thoroughgoing differentiation of musical "languages" in the context of cultural globalization is far from exhausted. This problem becomes pressing when composers aim to materialize aspects of fragmented or hybrid identities musically or - from the elementary experiential space of migration - feel the necessity or compulsion to address them $(\rightarrow$ I.2). Yun may have guessed much of this when he wrote:

We Asians stayed in our tradition for much longer because we were satisfied, and now we are approaching Europe's traditional music in a hurried and careless way. But should this continue, or can we not find something in our own musical cosmos with which we can enrich the world? ${ }^{198}$

196 First steps have been taken in the five volumes of the Ssi-ol Almanach of the Berlin Internationale Isang Yun Gesellschaft (https://yun-gesellschaft.de/die-gesellschaft/buecher) and in the scholarly works mentioned in footnote 182. A major step for an updated view on Yun's biography has recently been provided by Walter-Wolfgang Sparrer's trilingual monograph on Yun's “Life and Work in Pictures" (Sparrer, Isang Yun. Leben und Werk im Bild).

197 Currently, there are significant analyses of all these works, but, owing to a lack of documentary sources, they remain largely speculative with regard to the objectives raised here. See, most importantly, Kabisch, "Klang, Ton, Geräusch, Exkurs," Choi, “Réak (1966)," Kim, "Musical Syncretism in Isang Yun's Gasa," Howard, "P'iri: Isang Yun's composition and the Korean oboe," and Turner, "Performing Cultural Hybridity in Isang Yun's Glissées pour violoncelle seul (1970)."

198 Yun, “Über meine Musik," 300 ("Wir Asiaten sind viel länger in unserer Tradition geblieben, weil wir zufrieden waren, und jetzt nähern wir uns sehr eilig und unvorsichtig der europäischen traditionellen Musik. Ob das aber so weitergehen soll oder ob wir nicht doch in unserem musikalischen Kosmos etwas finden können, womit wir die Welt zu bereichern vermögen?"). 


\section{November Steps (1967), Distance (1972), and Tōru Takemitsu's Enactment of Alterity}

In East Asia, it became apparent already during the late 1950 s that, after almost a hundred years of permeation by Western models ( $\rightarrow$ III.1), it was no longer possible to construct a simple opposition between Western and East Asian discourses of musical aesthetics as two homogeneous systems. Takemitsu's most famous work, November Steps, demonstrates a special awareness of this situation. The composer was influenced over many years by the intercultural aesthetics of John Cage, which was of great importance for a number of Japanese composers following guest performances by Cage and David Tudor in Japan in 1962 - although research sometimes overemphasizes this influence. ${ }^{199}$ Cage's "tactic" was to erase the cultural meaning of musical material in the process of composition - that is, to alter it beyond recognition, completely "deidiomizing" it until a "culture-free space" is reached, outside of cultural dialects and attributions, a position Cage supported by adopting the Huayan Buddhist principle of "unimpededness and interpenetration" ( $\rightarrow$ II.6). This tactic made all epochs and cultures seemingly coexist on an unlimited continuum of sound and silence, which the composer ultimately only had to "capture" and depict in his music, as Cage rigorously attempted in his "silent work" 4'33" (1952).

We see the influence of Cage on the conception of November Steps above all in the goal of avoiding an overly obvious interaction between Western orchestra and Japanese solo instruments (satsuma-biwa and shakuhachi); the concern is for Japanese and Western sounds to coexist without a constructed relationship, without a compositionally "forced" association. The intention to enhance the difference between Western and Asian principles was key to many of Takemitsu's works from the 1960 s and 1970s, and his musical thinking thus shows clear traces of the systematic separation of both traditions since the Meiji era $(\rightarrow$ III.1). Takemitsu comments on his concept of cultural alterity:

We have to spend much time in understanding each culture. And it seems to take almost infinite time. Therefore, rather than resolving the contradiction I have in my mind, I would like to spend a long time making it greater, expanding it until it becomes my personal way of representation. ${ }^{200}$

And, with reference to November Steps, Takemitsu wrote:

A composer should not be occupied by such things as how one blends traditional Japanese instruments with an orchestra. Two worlds of sound: biwa-shakuhachi and the orchestra. Through juxtaposition, it is the difference between the two that should be emphasized. ${ }^{201}$

A detailed analysis of the score does indeed show the subtle and carefully planned connection of both cultural layers in timbre, melodic design, and energy, and how logically and "organically" they merge with or evolve from each other. ${ }^{202}$ The desired representation of difference thus

199 See Sawabe, Neue Musikin Japan, 103-128, Galliano, Yōgaku, 221-238, and especially the more detailed historical analysis in Fukunaka, "Re-situating Japan's Post-War Musical Avant-Garde through Re-situating Cage."

200 Takemitsu, "Music and Culture" (translation adapted by the author).

201 Takemitsu, "Notes on November Steps," 87.

202 For more detail, see Utz, Neue Musik und Interkulturalität, 296-299. For more comprehensive analyses of this work, see Burt, The Music of Tōru Takemitsu, 110-131, Langenkamp, "Close Encounters of Another Kind,"186-188, and Menzel, Hōgaku, 287-294. In total, Takemitsu composed seven pieces featuring Japanese instruments: Eclipse (1966) for shakuhachi and biwa, November Steps (1967) and Autumn (1973) for orchestra with shakuhachi and 
tends to lead to a balanced synthesis that was meant to be avoided. The difficulty of translating cultural difference into musical structures - as outlined earlier, for example, in Zender's Fürin no kyō - becomes apparent. To be sure, unlike the radical "de-idiomaticization" of Cage, Takemitsu's aim was not a complete "abstraction" of cultural dialects, but their preservation in coexistent juxtaposition. The compositional sophistication of sonic rapprochement and connection in his music, however, at least partially obliterates the layers of meaning - not least those of the original sociocultural context - that might essentially underline a claim of the materials' cultural difference.

Takemitsu's work Distance for oboe and shō (1972) also explicitly addresses cultural alterity by the juxtaposition of instruments. The work shows comparable problems to November Steps, though its entirely pioneering character is beyond any doubt (it is probably one of the earliest works to use the sho as a solo instrument, $\rightarrow 4.1$ ). That the composer gives the pragmatic option in the score's preface for the work to be performed without the shō part (i.e., as an oboe solo) makes it clear that the two instruments are not placed on the same compositional level. Whereas the European instrument is furnished with all the refinements of modern instrumental technique, thanks to the soloist and dedicatee Heinz Holliger, the sho is limited to an ebbing and flowing harmonic background. This seems to derive from the - simplistic and historically dubious $(\rightarrow$ IV.1) - traditional "background" function of the sho in the tōgaku repertoire of gagaku. The arrangement on stage also expresses this hierarchy: the sho soloist stands in the background, far from the oboist. ${ }^{203}$ Takemitsu's intention to use distinct Western and Asian categories by no means succeeds, as in November Steps. On the contrary, Asian and Western instruments are integrated into shared processes through clear relationships in pitch organization and Klangfarbenmelodie. For example, in the excerpt shown in Example 3.10, dissonant relationships (seconds and sevenths) between the pitches of oboe and shō (marked by arrows) predominate, creating musical tension that dissolves into unisons or octaves (marked by circles).

To what extent is cultural difference actually audible or comprehensible here? A critical analysis of interculturally conceived strata must, above all, problematize hidden hierarchies. The seemingly balanced coexistence of strata can prove to be a mere conceptual idea that is only fulfilled by the compositional design in a rudimentary way. As a composition, Distance may well be quite convincing on its own terms. As an intercultural situation, however, Takemitsu's polarization remains questionable, above all because of the culturalist reduction to which both instruments are subjected, and the consequent hierarchization of their interactions.

biwa, Distance (1972) for oboe and shō, Voyage (1973) for three biwas, In an Autumn Carden (1973/79) for gagaku, and Ceremonial (1991) for shō and orchestra.

203 See also corresponding stage arrangements in Toshio Hosokawa's Birds Fragments II (1990) for shō with percussion ad libitum, Birds Fragments III (1990) for shō and flute(s), and in Yūji Takahashi's Mimi no ho (1995) for shō, viola, and speaker ( $\rightarrow$ IV.1). We can assume, in all cases, a direct reference to Takemitsu. Yet the compositional conception of Hosokawa (which is also close to Takemitsu in terms of compositional aesthetics) and Takahashi (which starts from a fundamental critique of cultural essentialism) are to be regarded as clearly contradictory $(\rightarrow$ III.5, IV.1). 

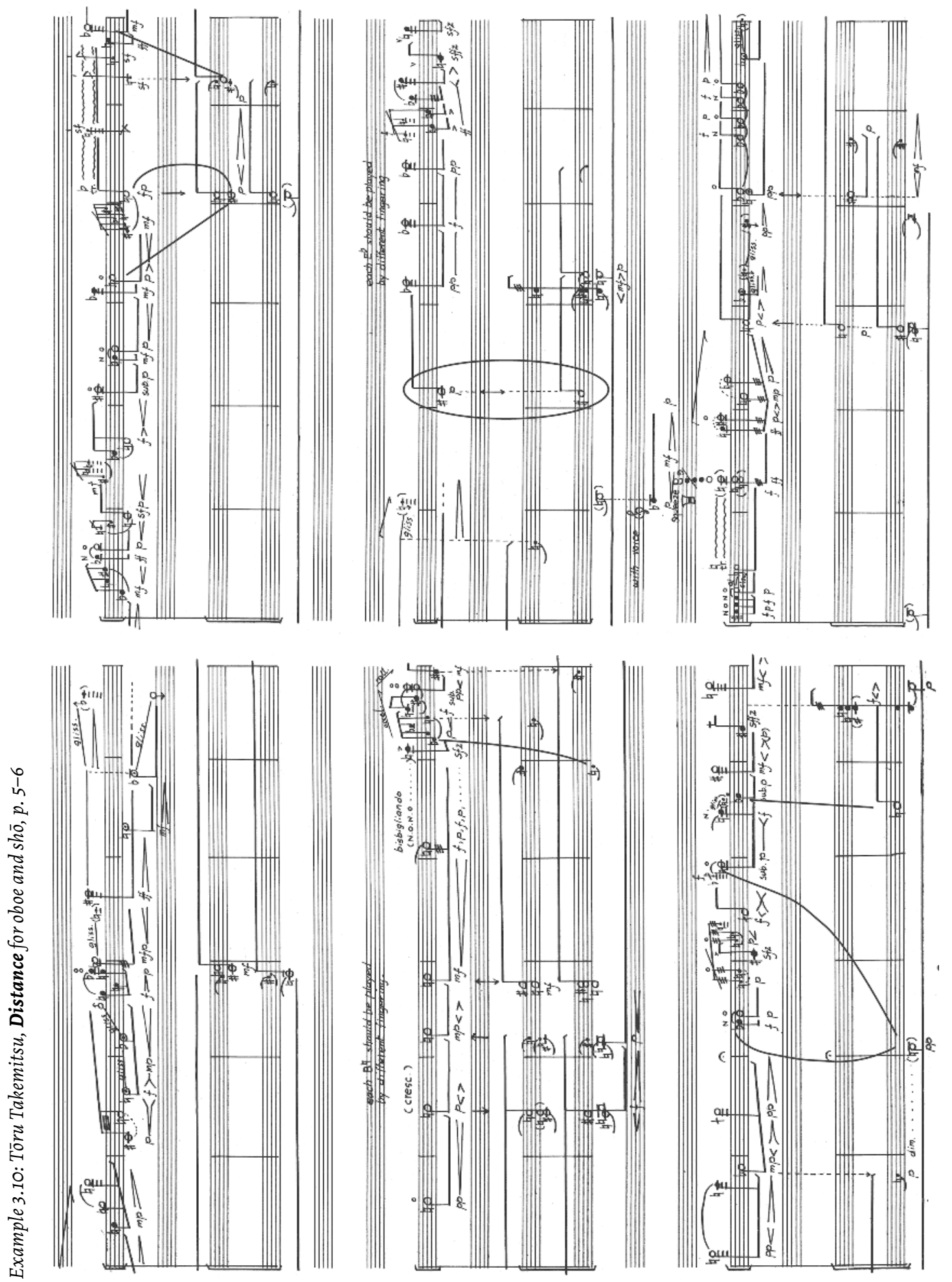

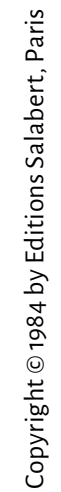




\section{José Maceda's Sound Masses and the Search for an Anti-Causal Logic}

The music of the Philippine composer José Maceda (1917-2004) creates unorthodox connections between aurality and written notation, a feature which evidences his double perspective as a composer-ethnomusicologist. ${ }^{204}$ Maceda's historical position might be considered even more anachronistic than Yun's or Takemitsu's, as he worked within a generation that was heavily involved in the formation of affirmative national music after independence in 1946, relying, as in almost all other Asian countries, on the vocabulary of Classical-Romantic symphonic music $(\rightarrow$ III.1). The Romantic idiom was enriched with folk melodies and rhythms, especially ones derived from the songs of the kundiman repertoire. ${ }^{205}$ Remarkably, Maceda's resort to pre-colonial forms of Philippine music did not lead to his claiming that it was "untouched" or "authentic." Rather, he tried to derive from these early practices general principles that he considered valid at least for Southeast Asian music, if not for Asian music as a whole. From these principles he sought to derive an anti-Aristotelian logic - as an explicit antithesis to cultural homogenization by Western standards, which was particularly noticeable in the Philippines after almost 400 years of colonial history. ${ }^{206}$ Maceda described the paradigms of this logic with the three key concepts of continuity, infinity, and indefiniteness. ${ }^{207}$

Maceda's turn - after training in Paris as a pianist - toward local forms of Philippine music was triggered by his discovery of the kubing jaw harp of the Hanunóo-Mangyan people on the West Philippine island of Mindoro during fieldwork in 1952. (Fourteen years later, in the composition Kubing [1966], this find was directly cast in a composition for five male voices, seven kubing, and other Philippine instruments.) As a result, Maceda studied the music of Southeast Asia in detail from 1957 to 1958 and from 1961 to 1963, graduating with a degree in ethnomusicology in the USA (PhD supervised by Mantle Hood at the University of California Los Angeles). ${ }^{208}$

Like several other non-Western and Western composers who turned to political and social issues in the 1970s, Maceda's work was initially based on social situations related to the fragmented experiences of cultural difference, as documented in the question he asked himself during a tour of his homeland as a pianist in 1947: "What has all of this got to do with coconuts and

204 The most important source for the understanding of Maceda's work, personality, and aesthetics is Tenzer, "José Maceda and the Paradoxes of Modern Composition in Southeast Asia," an article on which much of the following is based. Maceda's estate is catalogued by the UP Center for Ethnomusicology at the University of the Philippines, Quezon City (http://upethnom.com/jmcollection/index.php/josemaceda). In addition, the encyclopedia MCG Online published a new entry on Maceda in 2019 (Kartomi, “Maceda, José").

205 See Samson, Die zeitgenössische Kunstmusik der Philippinen and Santos, "Art Music of the Philippines in the Twentieth Century."

206 Magellan arrived in the archipelago in 1521, and Spanish colonial rule began in 1565, lasting 333 years until 1898. The Philippines was a US colony from 1898 to 1946.

207 See Maceda, "A Concept of Time in a Music of Southeast Asia."

208 A selection of the most important publications of José Maceda is listed here: "Chants from Sagada Mountain Province, Philippines," "Drone and Melody in Philippine Musical Instruments," "A Search for an Old and a New Music in Southeast Asia," "A Concept of Time in a Music of Southeast Asia (A Preliminary Account)," "In Search of a Source of Pentatonic Hemitonic and Anhemitonic Scales in Southeast Asia," "Acculturation and Internationalization: The Philippine Situation," "A Logic in Court Music of the Tang Dynasty," "Bipolarity and the Fifth Interval in Gamelan and Medieval European Music," "Counts of Four and the Fifth Interval," Congs and Bamboo. A Panorama of Philippine Musical Instruments, "Upland Peoples of the Philippines," as well as Maceda et al. "Philippines." Yūji Takahashi translated a selection of Maceda's articles into Japanese, published 1989 as Maceda, Dorōn to merodī / Drone and Melody. 
55

$\left\{\begin{array}{l}3.1 \\ 3\end{array}\right.$

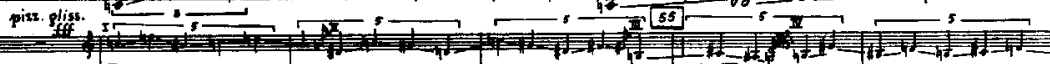
30,5 A.

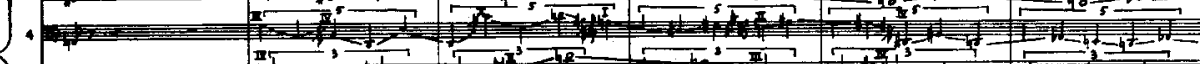
3 a

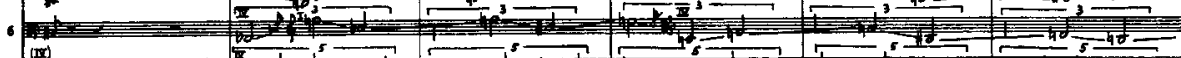

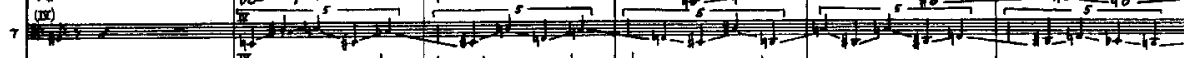

8 pixz.gliast (1)

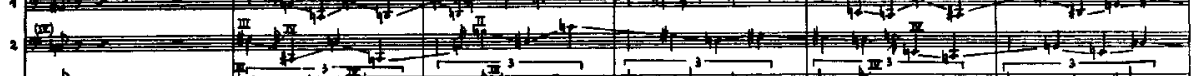
$3 \quad 20+3$ 4 (2)

v. 1 and

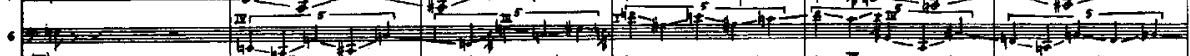
1 (1)

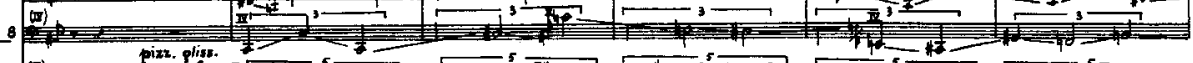

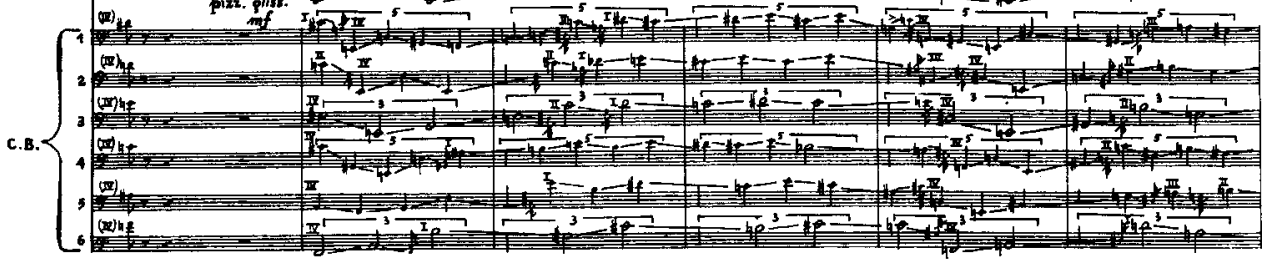


Example 3.11: Iannis Xenakis, Pithoprakta for string orchestra, two trombones, and percussion, $p .10$ Copyright $\odot 1967$ by Boosey \& Hawkes, London

rice?"209 The sociopolitical reality of the Philippines seemed incompatible with the emphatic aesthetics of the Classical-Romantic work of art. His compositional thinking was subsequently clarified through the examination of Edgard Varèse's and Iannis Xenakis's concept of sound masses, as well as through Parisian musique concrète, which he encountered in 1958. In the aesthetic designs of Varèse and Xenakis, Maceda saw, in contrast to parameter-oriented postwar serialism, a path that pointed beyond the narrow limits of European music. ${ }^{210}$

In Maceda's works of the 1960s and 1970s, his exploration of social and societal contexts and the resulting compositions with large groups of performers converged with his interest in the sound masses of Varèse and Xenakis. These works are more directly bound to specific performance contexts than Maceda's later, increasingly precisely formulated scores. These earlier works include, above all, the ritual music Pagsamba (Adoration, 1968) for 241 performers, Cassettes 100 (1971) for one hundred tape recorders and one hundred players, Ugnayan (Atmospheres, 1974) for 20 radio stations, Udlot - Udlot (Hesitations, 1975) for several hundred performers, and Ading (1978) for two hundred performers and public participation. ${ }^{211}$

Taking up an idea formulated by Michael Tenzer, ${ }^{212}$ it is constructive to compare three music examples to explore Maceda's music: the field recording of the Hanunóo Kalipay celebration made by Maceda in 1953 with Harold C. Conklin, the beginning of Iannis Xenakis' Pithoprakta for string orchestra, two trombones, and percussion (1955-56), and the beginning of the second part ("Gloria / Luwalhati") of Maceda's Pagsamba. In all three examples one can hear transformations between clearly separated "sound masses" or sound states: in the field recording of the Kalipay celebration, we can hear different sound qualities emerging successively from the regular basic rhythm: the gong agung played with wooden mallets, the small guitar-like kudyapi, and the three-string fiddles gitgit (possibly the highlighting of these instrumental parts might be due to the recording researchers moving in-between the groups of musicians). In Xenakis's large orchestral textures, one first hears a continuous agglomeration of low pizzicato sounds, and then an even transformation into short bowed glissandi with significant changes of register. This is followed by two more sound fields, first high pizzicato pitches in high density (Ex. 3.11), then sustained high harmonics, over which we hear Morse-code-like pulses of woodblocks and pizzicati. Maceda's Pagsamba, a Catholic mass set in the Philippine language Tagalog (originally a local language of the Manila area that later served as the basis for the official national language, Filipino), is scored for 241 performers. The "Gloria" (Ex. 3.12) opens with a small poly-

209 Quoted in Tenzer, "José Maceda and the Paradoxes of Modern Composition in Southeast Asia," 94.

210 See ibid., 97-99.

211 To the best of my knowledge, the most comprehensive catalogue of José Maceda's works can be found in the "Living Composers Project" by Dan Albertson at http://www.composers21.com/compdocs/macedaj.htm (updated 02/01/2017), see also "Werkverzeichnis José Maceda." MusikTexte no. 102 (2004), 75. It should be added that it is extremely difficult at present to consult Maceda's scores for study purposes, as they have not been edited by a music publisher and the administration of the estate is currently unable to perform such tasks. At this point, I would like to thank Ramon P. Santos and Jonas Baes for providing excerpts and copies from Maceda's works.

212 See Tenzer, "José Maceda and the Paradoxes of Modern Composition in Southeast Asia,"100-103. 
Example 3.12: José Maceda, Pagsamba for 241 performers, II. "Gloria / Luwalhati," Opening

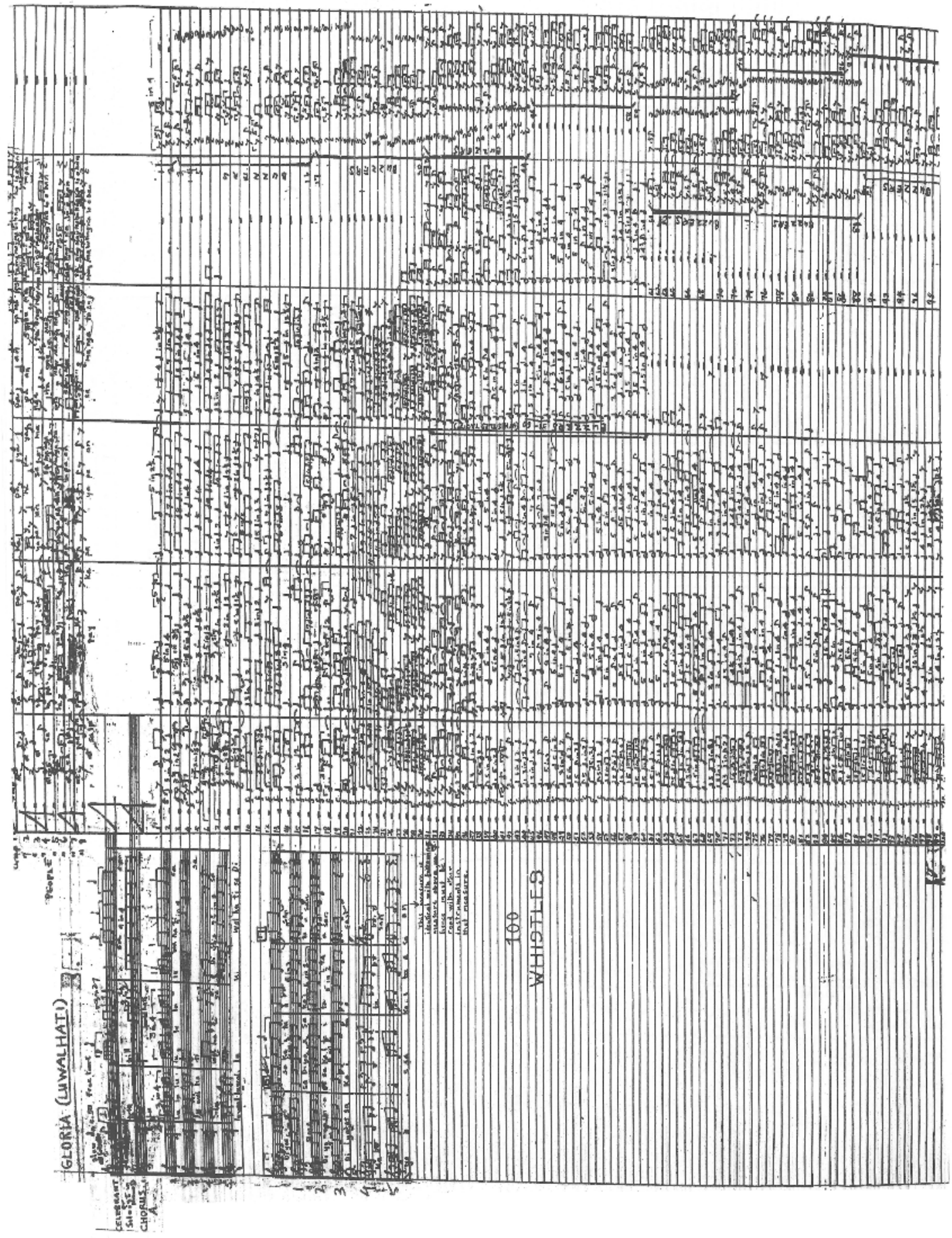

Copyright $\odot 1968$ by José Maceda, Manila 
phonic setting in male choirs ("Luwalhati sa Diyos so kaitaasan" / Glory to God in the highest), followed suddenly by a large tutti outburst ("At so lupa ay kapayapaan at sa anga taong may mabuting kalooban" / and on Earth peace, good will toward men), after which the duct flutes ongiyong (Huagao) and calling choir voices can be heard, then the buzzers balingbing (Kalinga, Luzon), passing into the rattles palakpak (Tagalog) and the wooden sticks bangibang (Huagao), with which the voices mingle again. At the end of the first section, the texture transforms into agung gongs (hanging nipple gongs, Maguindanao province) and gandingan (narrow-rimmed nipple gongs, also from Maguindanao) and back to the low male voices of the beginning. The sound masses are thus organized according to quasi-ethnomusicological classificatory principles. The performers are distributed in a circle around the audience, following an exact plan of the original performance space, the large circular building of the Catholic church Parish of the Holy Sacrifice in Quezon City. This aspect of the staging refers to the social component of Maceda's concept and thus to the ritual functions of pre-colonial music in the Philippines. The 241 performers are scattered around the auditorium according to a detailed floor plan ${ }^{213}$ and located in the midst of the audience. Each of the one hundred instrumentalists uses five different bamboo instruments: in addition to the aforementioned duct flutes, buzzers, rattles, and wooden sticks, these instruments also include tagutok (Maranao) bamboo scrapers. There are one hundred vocalists, five quintets of male voices, and two gong groups of eight agung and gandingan respectively.

In Maceda's work, cultural difference is conceptualized as having a dual function: on the one hand, the ethnomusicologist Maceda tries to find a new musical "grammar" through a comparative analysis of different local and superregional Asian genres, which is very deliberately opposed to a paradigmatic Western concept of art and at the expense of a certain essentializing tendency. On the other hand, the composer Maceda refers to the sound masses of Varèse and Xenakis, thus adopting a compositional technique of material organization that is decisively shaped by Western modernity and that must be understood, in the Philippine and Asian contexts, as a counterdiscourse to nationalist trends.

Maceda relates the participation of large groups of people to a special Javanese and Balinese concept of nature: "The participation of thousands of people in music-making in the open air is like their identification with nature, a concept manifest in Javanese and Balinese paintings, where men, plants, and animals are all treated as part of the jungle that envelops them." ${ }^{214}$ This perhaps naïve desire of Maceda's to include a harmonious interaction of man and nature in his music must surely be seen as the result of his ethnological research, which was accompanied by a critique of the often hasty and unreflecting form of Westernized cultural development in the region. On this basis, Maceda in 1984 formulated three basic principles of his ethnomusicological research, which can also be directly related to his compositional procedures: ${ }^{215}$

1. The variety of musical colors that results from the interplay of larger ensembles.

2. The primary significance of fundamental sounds or drone sounds, which include various ostinato variants, drones, or large-scale repetitions.

3. The importance of ethnomusicological classification of instrumental and vocal sounds as a source of ideas for connecting and organizing instrumental groups and sound events.

213 The floor plan appears on the cover of the CD José Maceda: Gongs and Bamboos, Tzadik TZ 7067 (2001).

214 Maceda, "A Search for an Old and a New Music," 167.

215 Maceda, "A Concept of Time in a Music of Southeast Asia." This text is based on Maceda's 1984 Charles Seeger Memorial Lecture for the Society for Ethnomusicology. 
Example 3.13: José Maceda, Udlot-Udlot for 6, 60, 600 or more performers

\section{UdLOT-UdLOT (HESITATIONS)}

for $6,60,600$ or more performers

José Maceda (1975)

\begin{tabular}{|c|c|c|c|c|c|c|}
\hline \multirow[b]{2}{*}{ DRONE } & \multirow{2}{*}{$\left|\begin{array}{c}\text { TIME } \\
\text { in } \\
\text { min. }\end{array}\right|$} & \multicolumn{3}{|c|}{ MIXED INSTRUMENTS } & \multirow{2}{*}{$\mid \begin{array}{c}\text { Time } \\
\text { in } \\
\text { min. }\end{array}$} & \multirow[b]{2}{*}{ VOICES } \\
\hline & & Group 1 & & Group 2 & & \\
\hline \multirow{5}{*}{$\begin{array}{l}\text { DRONE: Players beat } \\
\text { a pair of percussion } \\
\text { sticks continuousiy. } \\
\text { slowly untilt the end of } \\
\text { the music. They will } \\
\text { walk in stylized steps } \\
\text { around a big circle. }\end{array}$} & \begin{tabular}{|l|}
00 \\
01 \\
\end{tabular} & \multirow[t]{2}{*}{ ILLE } & \multicolumn{2}{|r|}{ SILENCE } & 00 & \multirow{2}{*}{ SILENCE } \\
\hline & \begin{tabular}{|l|}
02 \\
02 \\
\end{tabular} & & & \multirow{2}{*}{$688 \quad 689$} & 02 & \\
\hline & 03 & $587 \quad 589$ & & & 03 & \multirow{3}{*}{$\frac{7.515}{15}$} \\
\hline & 04 & : $789 \quad 5811 \quad 7 \& 11$ & & $6 \& 10 \quad 588 \quad 6 \& 11$ & 04 & \\
\hline & \begin{tabular}{|l|}
05 \\
06 \\
\end{tabular} & SILENCE & \multicolumn{2}{|r|}{ SILENCE } & \begin{tabular}{|l|}
05 \\
06 \\
\end{tabular} & \\
\hline \multirow{12}{*}{ 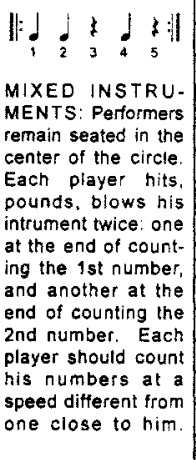 } & \begin{tabular}{|l|}
07 \\
09 \\
\end{tabular} & \multirow{2}{*}{$\begin{array}{ccc}283 & 284 \\
285 & 384 & 385\end{array}$} & \multirow{2}{*}{\multicolumn{2}{|c|}{ 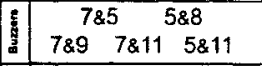 }} & \multirow{2}{*}{\begin{tabular}{|l|}
07 \\
08 \\
\end{tabular}} & \multirow{3}{*}{ SILENCE } \\
\hline & 08 & & & & & \\
\hline & \begin{tabular}{|l|}
09 \\
\end{tabular} & SILENCE & \multirow{2}{*}{\multicolumn{2}{|c|}{$2 \& 3 \quad 2 \& 4$}} & 09 & \\
\hline & 10 & $587 \quad 589$ & \multirow{2}{*}{\multicolumn{2}{|c|}{$285 \quad 3 \& 4 \quad 3 \& 5$}} & 10 & \multirow{3}{*}{ 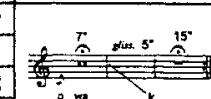 } \\
\hline & 11 & 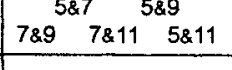 & & & 11 & \\
\hline & 12 & $2 \& 3 \quad 2 \& 4$ & \multicolumn{2}{|r|}{ SILENCE } & 12 & \\
\hline & \begin{tabular}{|l|}
13 \\
14 \\
\end{tabular} & $285 \quad 384 \quad 385$ & & $688 \quad 689$ & \begin{tabular}{|l|}
13 \\
14 \\
\end{tabular} & \\
\hline & 15 & SUENC & & $6 \& 11 \quad 6810 \quad 6812$ & 15 & SILE \\
\hline & 16 & GNLIN & & SILENCE & 16 & \\
\hline & \begin{tabular}{|l|}
17 \\
48 \\
\end{tabular} & & & & \begin{tabular}{|l|}
17 \\
19
\end{tabular} & \\
\hline & \begin{tabular}{|l|}
18 \\
19 \\
\end{tabular} & 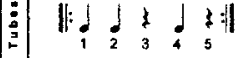 & 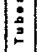 & 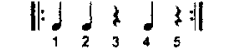 & \begin{tabular}{|l|}
18 \\
19
\end{tabular} & \\
\hline & 20 & & & & 20 & \\
\hline ers stand and sing to- & 21 & SILENCE & & & 21 & \\
\hline tor & 22 & & & SILENCE & 22 & SILENCE \\
\hline $\begin{array}{l}\text { During } \\
\text { silence. }\end{array}$ & 23 & & & & 23 & \\
\hline & 24 & 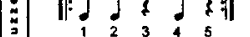 & i & 588 & 24 & \\
\hline $\begin{array}{l}\text { place } \\
\text { anoth }\end{array}$ & 25 & 12345 & 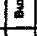 & $6810 \quad 7810 \quad 7812$ & 25 & \\
\hline & 26 & SILENCE & $\vdots$ & & 26 & m \\
\hline to sing. & 27 & 683 & & & 27 & \\
\hline $\begin{array}{l}\text { NO. OF PERFORM- } \\
\text { ERS: For } 6 \text { players - }\end{array}$ & $\frac{28}{29}$ & \begin{tabular}{l|lll} 
& 685 & 783 & 584
\end{tabular} & & 384 & $\frac{28}{20}$ & SILENCE \\
\hline $\begin{array}{l}\text { plays the Drone, } \\
\text { play Mixed in- }\end{array}$ & 30 & SILENCE & & SILENCE & 30 & \\
\hline $\begin{array}{l}\text { yone } \\
\text { Joice. }\end{array}$ & 31 & & & $586 \quad 584$ & 31 & \\
\hline For 60 performers - & 32 & 283 & & & 32 & \\
\hline $\begin{array}{l}10 \text { play the Dorne, } \\
40 \text { play the Mixed in- }\end{array}$ & \begin{tabular}{|l|}
33 \\
34 \\
\end{tabular} & $\begin{array}{|ll|}\vdots & 284 \\
\end{array}$ & & 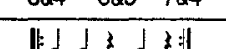 & $\mid \frac{33}{34}$ & \\
\hline to. The & \begin{tabular}{|l|}
55 \\
\end{tabular} & SILENCE & & +5 & 35 & SILENCE \\
\hline $\begin{array}{l}\text { ayed } \\
2^{\prime}\end{array}$ & $36 \mid$ & & & SILENCE & 36 & \\
\hline 10' & \begin{tabular}{|l|}
37 \\
38
\end{tabular} & 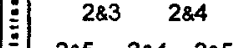 & & & $\frac{37}{38}$ & \\
\hline & 39 & 285 & & $483 \quad 485$ & 39 & \\
\hline
\end{tabular}

By emphasizing such general principles, Maceda sought to find a solution to the conflict between nationalism or localism and cultural Westernization. The confrontation with drone, ostinato, and a system in which timbres have more weight than pitch organization led to a compositional aesthetic concept that accentuates continuity, infinity, and indefiniteness. Maceda expands on this concept in his extensive article "A Concept of Time in a Music of Southeast Asia (A Preliminary Account)," in which the construction of a (Southeast) Asian concept of time and a (Southeast) Asian logic, clearly tending toward essentialism, derives a fundamentally postcolonial discourse from musical structures: 
[...] the music of Southeast Asia fills time along notions of continuity, infinity and indefiniteness in a non-secular metaphysical world, and hierarchy in a secular world. The musical techniques used in musical forms prefer melodic ambiguity, repetition and diffusion to identification and isolation of things as these are brought about by a system of logic known as causality. ${ }^{216}$

Maceda considers causal logic manifested in the hierarchy of major-minor tonality, ${ }^{217}$ though here he implies, perhaps subliminally, the overly functional and reductionist interpretation of tonality by (the earlier writings of) Hugo Riemann. ${ }^{218}$ In addition, Maceda also claims to recognize a causal logic based on polarities in postwar serialism ${ }^{219}$ - a certainly contestable interpretation, since parameter-based serialism is ultimately not based on polarities, but on gradations of all parameters. Overall, Maceda's juxtaposition of Western/causal and Asian/ anti-causal logic seems too dualistic and simplistic. His argumentation is more convincing elsewhere, when he applies principles of Southeast Asian traditions to his own music, which he ultimately describes as distilling a substance that he as an ethnologist cannot easily put into words and therefore intends to reflect in his music:

I have spoken of elements such as repetition, drone, nature, time, the universe, scales, shamanism, rituals, timbre as fundamental musical elements, and of a thinking of what music may beas these are present in the music cultures in the Philippines and Southeast Asia. These elements make up an imaginary world which is felt and understood by a village inhabitant, but they are too deep for words and therefore are unexplainable by himself, a village guru, an anthropologist or by an ethnomusicologist. This world may be captured in a sound structure or in music, just as an eighteenth-century enlightenment is crystallized in the music of Bach, and the clarity and discipline in Chinese thought are manifest in the music of a South Chinese ensemble. ${ }^{220}$

What do these principles imply for the creative process and the notation of Maceda's scores? In the 1970s, the principles of continuity, infinity, and indefiniteness could still be clearly derived from action scores, which describe sound constellations in a very precise manner, but ultimately leave the musical detail to the dynamic interaction between performers. In Udlot-Udlot (1975), more than 800 students performed three different ostinato patterns (Ex. 3.13, left column): percussionists repeat a five-part ostinato, to which they walk in rhythmic steps in a circle; the instrumentalists sitting in the center superimpose different timbres in the proportions 5:7, 5:9, 7:9, 7:11, etc. (middle columns); the chorus is set up in groups that sing long sustained notes followed by glissandi (right column).

In the 1980s, Maceda's notation became more precise. Rhythmic complexity became a necessity because it was the only way to realize the desired transcendence of a causal time structure in compositional terms, while microtonal melodic fluctuations are often left to the players. Whereas the open concept of Maceda's scores is obvious in the earlier works, his later attempts to treat the ensembles compositionally as a "body of sound" over longer periods seem to require

216 Ibid., 46.

217 Ibid., 47.

218 One might argue that recent neo-Riemannian theories of tonality have contributed to an increasingly complex image of tonality as an expansive network-like system, in which linear causality plays an increasingly subordinate role as the system transforms into late and post-tonal areas.

219 Maceda, "A Concept of Time in a Music of Southeast Asia," 47-48.

220 Maceda, "A Search for an Old and a New Music," 166-167. 


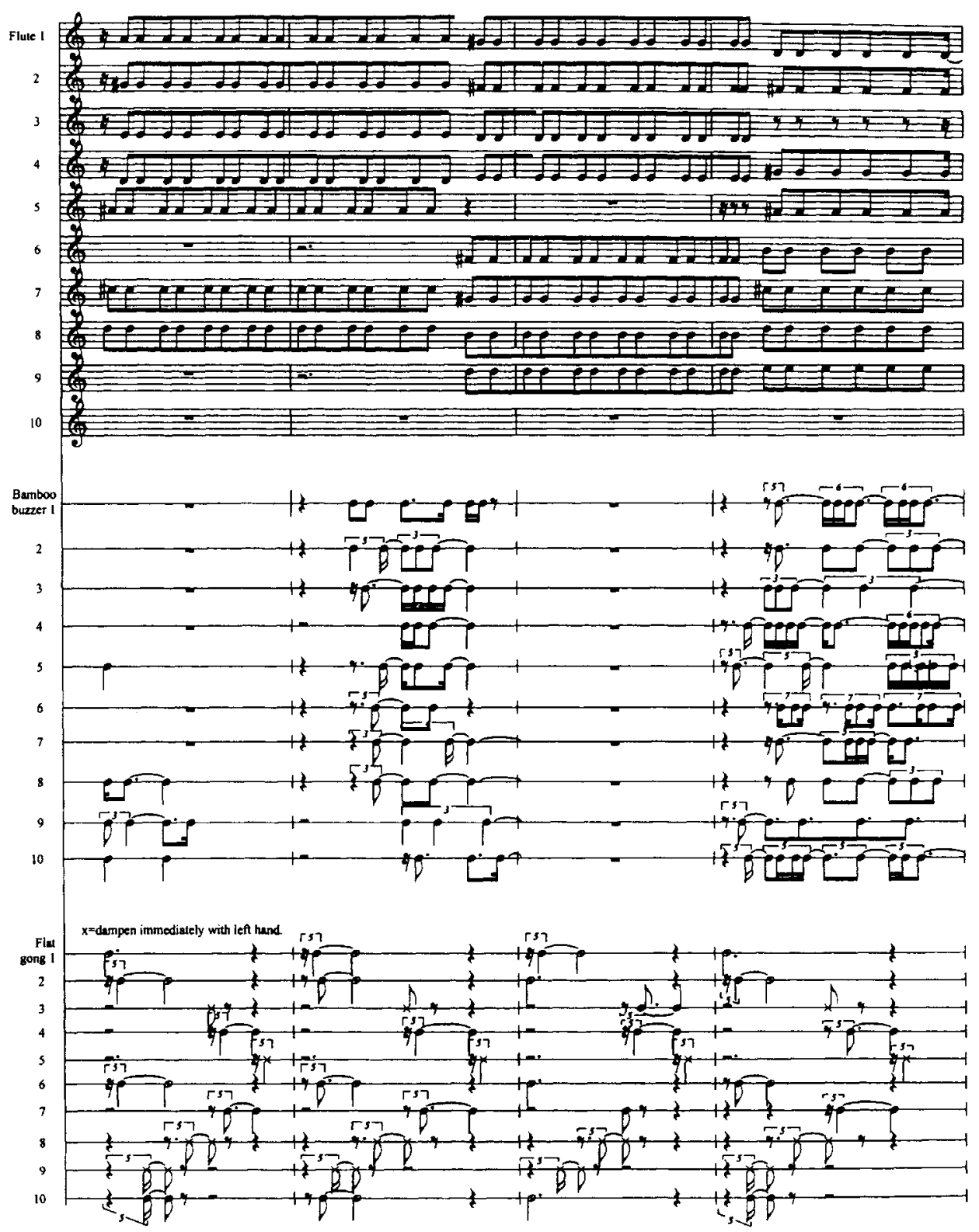

a more systematic and more prescriptive approach to notation. In Suling, Suling (1984) for ten suling bamboo flutes or ten (Western transverse) flutes, ten pakkung / balingbing buzzers or tagutok scrapers, and ten gangsa (flat gongs), the exact flute types and pitches of the gongs are left to the performers, but the rhythmic framework is precisely written out and can only be performed with a conductor (Ex. 3.14). A constant that connects these works with the earlier concepts is the organization of the music in sound surfaces or masses, as can easily be seen from the score example. 
The slow transformations of the 22-minute musical textures of Suling, Suling are not far removed from the ongoing transitional states developed by Morton Feldman and Giacinto Scelsi during the same period. Maceda's compositional discoveries have created a variety of "lessness" (see the section on Takahashi below) that, because of its complex ethno-philosophical background, is unique, but also converges with tendencies within the new music of the West that resulted from a liberation from the linear, teleological time frame formulated by different composers, often independently of each other, including Varèse, Xenakis, Feldman and Scelsi as well as Charles Ives, John Cage, György Ligeti, and Bernd Alois Zimmermann. ${ }^{21}$

Maceda's work ultimately shows that cultural difference need not be articulated as a conflict of materials within a composition. Rather, it may attain significance in far more fundamental layers of compositional methodology. Cultural difference influences the instruments and languages used, the highly qualified significance of writing, and the tendency to eliminate the separation between audience and performer.

\section{Ge Ganru's Yi Feng (1983) and the Liberation from Culturalist Categories}

In Maceda's case we can observe sharply that ideas derived from Western musical modernism serve as a principal means in re-inventing local practices, putting them into a new context, and thus countering simplified and affirmative notions of musical as well as political nationalism. The following example demonstrates perhaps even more clearly how a confrontation with Western modernism might cause massive conflicts as well as provoke liberation. Confrontation may lead in productive directions toward the articulation of the culturally different.

Ge Ganru (b. 1954) belongs to the xinchao generation of Chinese composers who were severely restricted in their development by the Cultural Revolution. Later, this group of composers developed very independently at breathtaking speed, under a lasting impression of Europe's early musical modernism $\left(\rightarrow\right.$ II.3). ${ }^{222}$ During the Cultural Revolution, Ge secretly learned to play the violin. Then he was sent to Chongming Island for agricultural labor from 1971 to 1974, where, despite the extreme living conditions, he founded an ensemble that played variants and excerpts from the "model works" (yangbanxi, $\rightarrow$ III.1). Already in 1974, he was admitted to the violin class of the Shanghai Conservatory and began studying composition there in 1977. After he had acquired Arnold Schoenberg's twelve-tone method, stimulated by the important guest seminar with Alexander Goehr in Beijing in 1980, Ge fell into a compositional crisis. He felt an unbridgeable gap between his fragmented musical biography and the coherence of twelve-tone music.

Ge's Yi Feng (Lost Style, 1983) for violoncello solo was a radical move toward liberation and transformed the characteristics of Chinese music in a most unusual way, such as by focusing on the timbral and microtonal shading of a single note and colorations of unpitched noise. The percussive performance techniques and free rhythms are based on traditional drum ensembles such as those from Chinese opera $(\rightarrow$ III.5). Yet Ge aimed for a purely imaginary archaic style (to which the title refers), a style intended to lie beyond clear culturalist identities. The instrument's strings are tuned in fourths and up to one octave lower than the original tuning ( $\# \# 1-B 1-E 2-A 2)$, thus also greatly expanding the possibilities of playing behind the bridge. The score is notated on six staves (Ex. 3.15). At the time of the composition, Ge hardly knew any works of Western new music after 1945, except for isolated pieces by John Cage, Tōru

221 See Utz, "Paradoxien musikalischer Temporalität in der neueren Musikgeschichte."

222 Mittler, Dangerous Tunes, 173-177, provides biographical details and an overview of Ge's works up to the early 1990s. See also Kouwenhoven, “Mainland China's New Music (III),"109-111. 

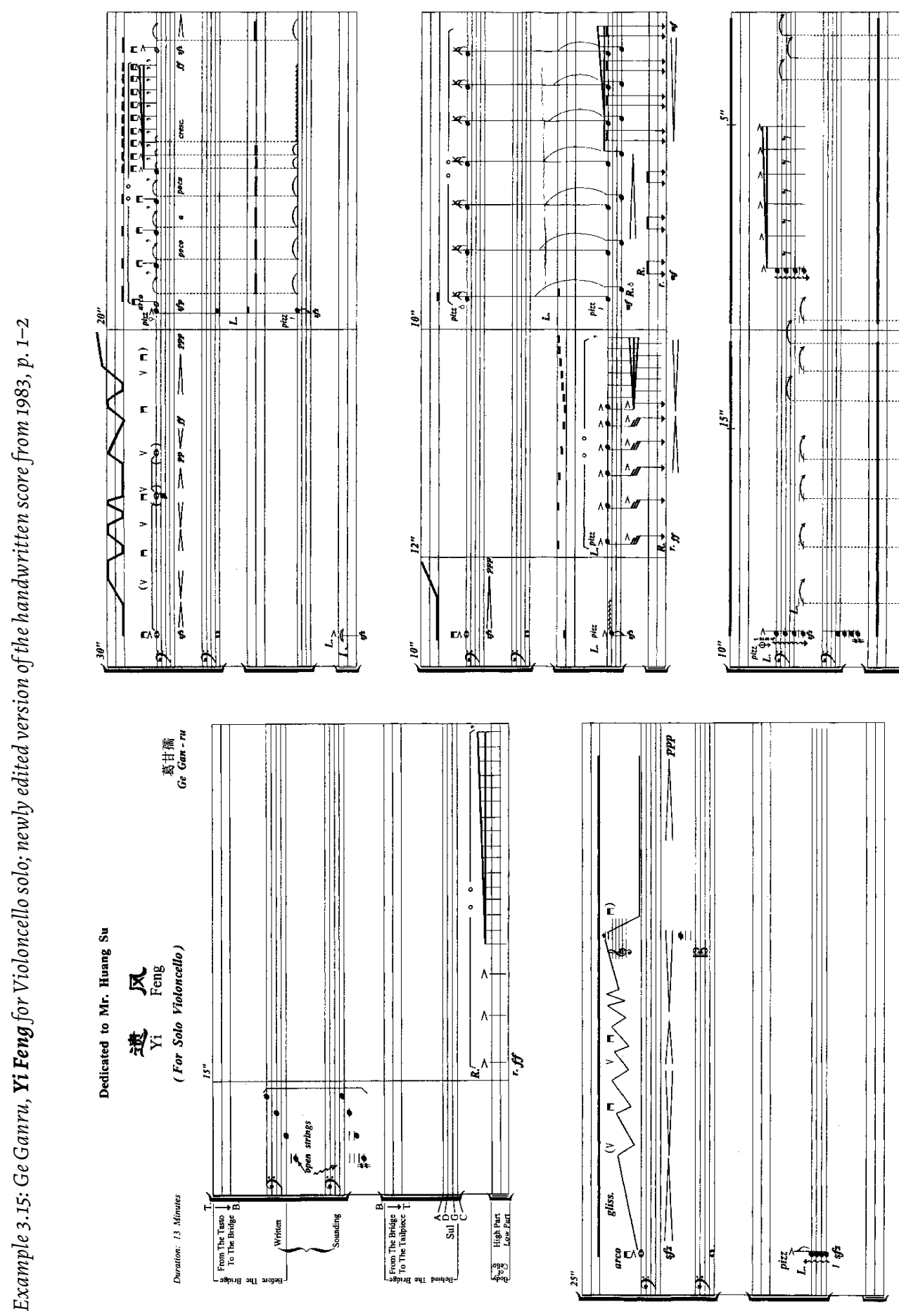

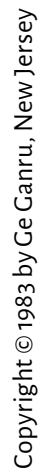


Takemitsu, and George Crumb. Though Ge's work may remind an "informed" listener of Lachenmann's Pression (1969), Ge remained unaware of Helmut Lachenmann's œuvre up to $2006 .^{223}$

Ultimately, in Ge's case, it was not so much a matter of "countering" a massive Western influence by a "culturally different" object as of preserving, or even gaining, a stable artistic position at all within China's extremely ambiguous discourses after the Cultural Revolution. The cultural opening up of the 1980s, following the extreme restrictions between 1966 and 1976, was accompanied by a continuity of repressive discourses around suspected over-individualism, culminating in two so-called "Anti-Spiritual Pollution Campaigns" (Qingchu jingshen wuran) in 1983 and $1987\left(\rightarrow\right.$ III.3). ${ }^{224}$ Yi Feng is, above all, a remarkable document of upheaval in recent Chinese music history, because it did not bow to those repressions. In the process, the characteristics of traditional instruments such as erhu, pipa, or qin (which were classified as deficient by the overwhelming majority of Chinese music makers) provided value. Their blurring and noise, and thus their cultural difference from the standardization of Western instruments, revealed great creative potential. Ultimately, this cultural difference in Ge's work served as one of several means of shaping an imaginary musical space beyond cultural and political categorization.

\section{Yūji Takahashi: Attentive Listening and Social Interaction}

To approach the compositional contexts of the Japanese composer and pianist Yüji Takahashi (b. 1938), the demand for attentive listening and hearing, which takes on a central position in Takahashi's conception, might be exemplified by reference to two idiosyncratic works: Koto nado asobi (2000) for koto and string quartet and Tori mo tsukai ka (1993) for shamisen and orchestra seem to design a music that knows no progression of time. Intersecting, presentist, rather than processual, sounds combine in an apparently free sequence, in varying character and density, not necessarily diverging, but moving as if in a free continuum in which they meet each other, seemingly incidentally. In his research on the music of Morton Feldman and John Cage, Martin Erdmann introduced the Beckettian concept of "lessness," 225 which seems to me to be very suitable for capturing a crucial quality of Takahashi's two works: "lessness" understood as the absence of clear, quasi-causal connections, conclusiveness, consequence, stringency - principles developed again and again in various ways in a range of new music during the twentieth century.

In fact, Takahashi's approach - similar to Maceda's - counters the concept of discursive musical logic that has had a lasting impact on European music since the medieval musica theorica. To hear his music exclusively as a counterdiscourse to Western aesthetic principles, however,

223 "I was not aware of any notations like what I did for Yi Feng when I composed that piece, as China was a closed society at that time. Prior to this piece, I focused all my energy on twelve-tone music. I had only heard John Cage's piano music once, saw George Crumb's score once. After completing Yi Feng, I heard Takemitsu's November Steps. These three were the only avant-garde composers I knew of when I was in China. Forgive my ignorance, up to today, I still don't know who Helmut Lachenmann is. The above Western contemporary music materials I had access to were left in China by some Westerners who came to visit. They [were] either just scores or tapes, never both. Our understanding of what was happening outside of China was very, very limited." (E-mail to the author, 10/10/2006.)

224 See, among others, Mittler, Dangerous Tunes, 99, 123-124.

225 See Erdmann, "Zusammenhang und Losigkeit" and Erdmann, "Webern und Cage: Zur Cenese der Cageschen Losigkeit." The German term “Losigkeit” comes from Elmar Tophoven's German translation of Samuel Beckett's experimental text sans (1969, English version: Lessness 1970). Beckett's text is based on chance procedures and was inspired, among others, by the music of John Cage. 
would be an ultimately ethnocentric and culturally essentialist understanding that fails to recognize how intensively Takahashi has been working since the late 1980 s on a conceptual liberation from the Western/non-Western cultural dualism. Relying on elementary phenomena of hearing, music-making, and practice, working directly from the organology of the instruments and corresponding performance methods or from models of interaction between the performers, he opens up not only transcultural, but often also wide historical, societal, and social spaces. His basic attitude is already clear from the instructions in the score of Koto nado asobi:

Stay out of tune as [sic] possible. Instruments don't tune together. Don't play self-assertively. Sounds are uncertain, ambiguous, faltering, transient, and a little out of control. Listen attentively but at ease to your own sound, how it begins, sustains and ends. ${ }^{226}$

\section{Example 3.16: Yüji Takahashi, Koto nado asobi; "koto," model A}

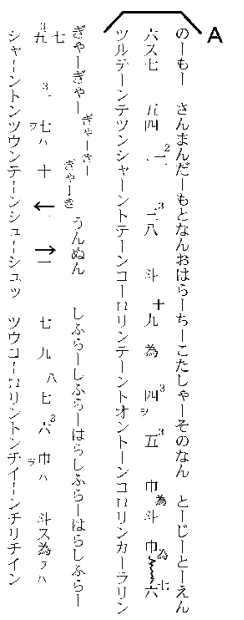

A

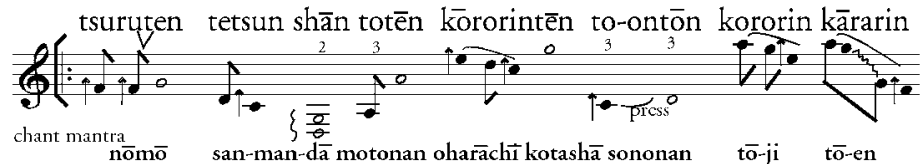

shān tontsu-untēn shū-shut tsu-u kōrorinton chi-in chiri chi-in

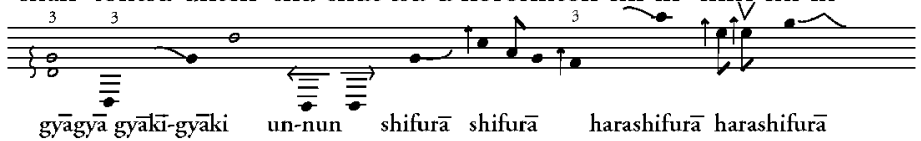

kārarin chirichin tōn tsuto-tsutsu shātsuren tsu-un tōn

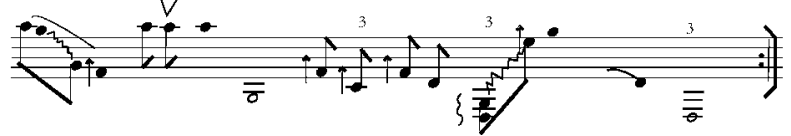

chishitta chishitta shicchiri shicchiri sohaja sohaja senchīgya shiriè tomok̄o

Copyright (c) 2000 by Yūji Takahashi, Tokyo

The music consists of two score pages for koto solo (koto) and a page with instructions for an ensemble of any instruments (nado asobi) (Ex. 3.16, 3.17). The koto score contains five different models, consisting of mnemonic syllables from koto practice, which date back to shamisen practice and are called kuchi-jamisen ("mouth shamisen"). In the Japanese version of the score (Ex. 3.16, left), model A appears in three columns: on the left are the kuchi-jamisen syllables in the katakana alphabet, in the middle the plucked string numbers in kanji, and on the right the Japanese transliteration of a Sanskrit Dhärani (mantra) which the performer recites. In the English version (Ex. 3.16, right), the kuchi-jamisen syllables are rendered in Romanized form and additionally transcribed onto five-line staff. Takahashi prescribes an irregular scale that deviates slightly from the traditional scales, and the performer is asked to decide "by ear" how large the microtonal deviations should be. The individual sounds or figures can either be fragmented, that is, framed by silence, or executed as repetitive loops. Similarly, the ensemble's instrumentalists respond very carefully to the sounds they hear, either adding slight microtonal alterations, playing in a distinct pitch register, or freely following the graphic symbols (Ex. 3.17).

226 Takahashi, Koto nado asobi, preliminary remarks. 
Example 3.17: Yüji Takahashi, Koto nado asobi; “-- nado asobi” for any instruments; models

Mclody instruments use the following threc modes of playing:

Mode 1. A long tone slightly off pitch from what you heard. No accent, no attack.

No tonguing and varying amount of breath and changing the mouth cavity for wind instruments.

Loose bow rolling between normal and col legno positions for strings with changing speed.

Mode 2. A different pitch than what you heard.

Short tone must be without intention like a child dropping an object in his hand.

Long tone must be prepared first by sounding faintly as if checking the pitch before playing.

Mode 3. Play one of the following fragments, different one from others are playing at the time.

Repeat any number of times. Change the fragment at will. Play unsteadily.

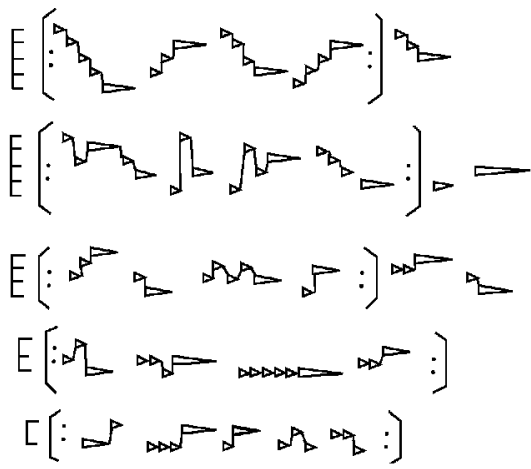

Copyright (c) 2000 by Yūji Takahashi, Tokyo

In Tori mo tsukai ka (1993), the anti-teleological conception of time is also achieved by superimposing fundamentally independent parts, with listening attention again playing a major role. The stanza-like traditional form of the shamisen part is superimposed on models for the orchestra (Ex. 3.18), which are freely developed by the musicians in individual groups following the signs of the conductor. Takahashi here refers to a dense, irregular canonic texture derived from gagaku: this structure is found in the concentration of lines at the end of the introductory netori section in some pieces from the komagaku repertoire ${ }^{227}$ and in the extended introduction to the bugaku repertoire called chōshi, in which the styles omeribuki and oibuki are known as forms of free or strict imitation. ${ }^{228}$ Due to the narrow, but not exactly fixed intervals between the voices, heterophonic structures arise in different density and arrangement. The desired blurring is reflected in the type of notation in which dashed lines indicate heterophony. The resulting sound is described by Takahashi as follows:

And so I am using a conventional ensemble with a conductor and a soloist but their functions are completely different. The music should be like a rolling wave. The sound comes up to the surface and then goes down. The players shouldn't try to be soloists, but contribute their sounds,

227 See Malm, Japanese Music and Musical Instruments, 103. In the chōshi introduction, the imitation is strict among the shō players who enter first, whereupon the hichiriki players imitate another musical figure. An extended version of the chōshi designs an A-B-A' form with kakebuki - netori (solo by the ryūteki flute) - oibuki, whereby in the oibuki the distances between the imitative entries are denser than in the kakebuki. Takahashi pointed out (correspondence with the author) that he understands kakebuki as glissando appoggiatura notes on the ryūteki, while he considers omeribuki and oibuki as free and strict forms of canonic imitation in gagaku.

228 See Carfias, Music of a Thousand Autumns, 76. 
listening to [the] whole ensemble, not competing, but allowing others to come up after their own sound has been heard. They must also resist the impulse to synchronise, because it is a natural tendency. 229

Example 3.18: Yüji Takahashi, Tori mo tsukaika, orchestra model 1

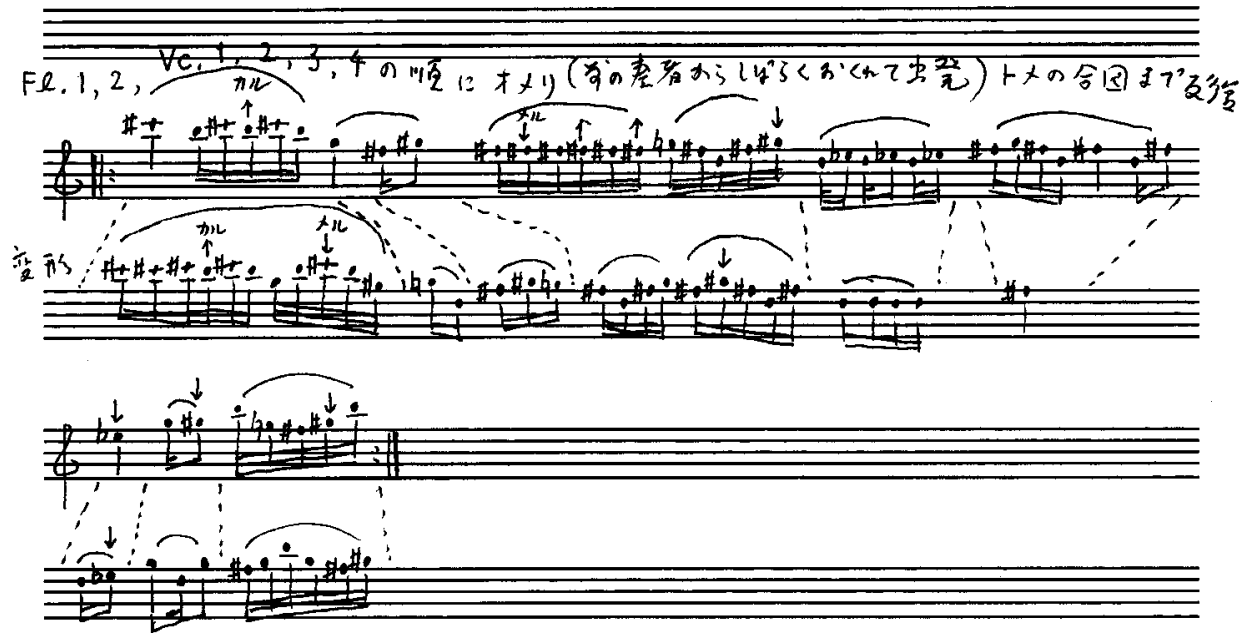

Copyright (c) 1993 by Yūji Takahashi, Tokyo

Since the late 1980s, Takahashi's finely calibrated compositions have been produced mainly for a small circle of musician friends, with whom the targeted social-communicative experiments could be achieved more easily than with institutionalized larger ensembles. Takahashi probably received lasting influences from related models and intellectual constellations in the musical concepts of Cornelius Cardew (1936-1981) and Christian Wolff (b. 1934) - with whom he also shared fundamental political convictions - but, to my knowledge, this influence is not yet sufficiently documented. To portray the background of Takahashi's approach more systematically, his rigorous critique of postcolonialism and political power struggles since the 1970s is fundamental. In 1976 Takahashi argued that "So long as colonialism exists politically, economically, and culturally, music cannot be a universal language. ${ }^{230}$ Despite some phases of sustained politicization, ${ }^{231}$ Takahashi has always responded to an affirmative politicizing musical tone with skeptical eyes and ears. He has firmly rejected a "music for the entire human race" or a "music for everyone," as dictated by populist politics and the mass media. ${ }^{232}$ Instead, he has demanded a skeptical attitude toward media abuse:

Music begins by doubting sounds. One tears oneself away from the charm of sounds, one cuts the stream by coming to depend upon musical elements that are not time-related. Eliminate all

229 Takahashi, "Between Cood and Evil," 10.

230 Takahashi, "From Words to Music," 65.

231 In 1978 Takahashi founded the group Suigyū (Water Buffalo), with which he sang East Asian political protest songs. See Galliano, Yōgaku, 234, and Takahashi, "The Resistance of the Asian Masses and Their Culture."

232 Takahashi, "From Words to Music," 66-67. 
unnecessary information and learn new techniques; repeat one thing again and again instead of indulging in the traditional dramas of time. ${ }^{233}$

Nonetheless, Takahashi's work in the 1970s and 1980s focused on projects with distinctly political themes. These themes contributed to the increasingly transparent texture of his scores. His well-known piano piece Kwangju, May 1980 (1980), for example, combines remembrance of the victims of the South Korean Kwangju uprising in May 1980 with echoes of various Korean folk songs, which, like the clearly referenced Saeya, saeya, have very specific coded meanings in the Korean context $\rightarrow$ III.5, VI.3). ${ }^{234}$ The Song of the Blue Sword (1980) also explicitly refers to a political theme; in this work, the political parable Forging the Sword (Zhu jian, 1926) by the Chinese writer Lu Xun (1881-1936) is performed by a choir of approximately two hundred students, implicitly referring to Maceda's mass settings. ${ }^{235}$ Freedom in the design of the individual parts of the score, which is determined only in its basic features and based largely on French-Chinese number notation (Ex. 3.19, $\rightarrow$ III.1), and the request for the participants' initiative, were part of Takahashi's conception as well as the spatial disposition in which a larger group of choir singers on stage was supplemented by a second group, which was placed at the corners of the hall.

There seems to be a clear distance between the political actions of these years and the introversion of the later works. Yet both periods are connected by a rigorous effort to find sensitive compositional solutions that avoid simplistic extremes. In addition, the later works can surely claim an implicit political dimension in a similar sense to what Luigi Nono claimed of his late works. ${ }^{236}$ This dimension is evident in the works of the 1990s, which show an intense engagement with traditional Japanese and other Asian genres, based on continued collaboration with soloists of Japanese instruments. ${ }^{237}$ In this context, Takahashi's critical approach received a precisely formulated ethnological and performative accent. Even in earlier reflections, aspects and paradoxes of instrumental practice - as pointed out in his article "Bach as a Failure" (1976) $(\rightarrow$ I.1) - had been an important starting point for compositional considerations, and now they assumed primary importance: learning and deepening through the repetition of models - especially in the mold of traditional Asian learning methods - and ultimately the liberation of such models in their free combination, crucially determine Takahashi's approach to Japanese genres and instruments. A close long-term cooperation with the instrumentalists is a fundamental prerequisite for such an approach and also has an effect on how the results of these working processes are laid down in musical notation. This approach also implies a tendency to reach beyond nationally defined traditions in a manner not dissimilar to Maceda's:

Instead of basing one's music on aesthetic or philosophical ideas or metaphors or a vague feeling of "Japaneseness," we can start directly from traditional techniques which are transmitted orally. You copy your teacher's playing, so it is a transmission from one body to another. And this is a very strong kind of memory, compared to intellectual understanding and transmission through

233 Ibid., 67.

234 Saeya, saeya was the signature song of the revolutionary Tonghak movement in the nineteenth century - the most important of many movements against authoritarian systems in modern Korean history ( $\rightarrow$ III.5).

235 See Reynolds, "A Jostled Silence: Contemporary Japanese Musical Thought (Part Two)."

236 See, for example, Metzger, "Wendepunkt Quartett?"

237 The musicians Takahashi has worked with regularly since the late 1980s include the shamisen soloists Kazuko Takada and Yumiko Tanaka, the shō soloist Kō Ishikawa, as well as Yoko Nishi (koto) and Keiko Kanda (percussion). 
Example 3.19: Yüji Takahashi, The Song of the Blue Sword, Section D1

\section{D1}

\begin{tabular}{|c|c|c|c|c|c|c|c|c|c|c|c|}
\hline $\begin{array}{c}1 \\
\text { उオ }\end{array}$ & • & $\begin{array}{l}\overline{71} \\
\stackrel{1}{1}\end{array}$ & $\begin{array}{l}\overline{\mathbf{4 3}} \\
\text { ケン }\end{array}$ & & • & $\begin{array}{l}\overline{45} \\
7\end{array}$ & $\begin{array}{r}\overline{75} \\
31\end{array}$ & $\cdot$ & $\begin{array}{c}\# 45 \\
\dot{y} \\
\end{array}$ & • & 0 \\
\hline $\begin{array}{l}5 \\
\text { H }\end{array}$ & $\begin{array}{l}7 \\
3 \\
\end{array}$ & $\begin{array}{l}1 \\
\neq\end{array}$ & $\begin{array}{l}\overline{72} \\
\text { 나 }\end{array}$ & $\begin{array}{l}1 \\
y\end{array}$ & & $\begin{array}{c}7 \\
\leqslant 7\end{array}$ & $\begin{array}{c}3 \\
\text { ステ }\end{array}$ & 5 & $\vec{b}$ & $\begin{array}{l}43 \\
\mathrm{I}\end{array}$ & • \\
\hline $\begin{array}{l}7 \\
+y \\
\end{array}$ & • & $\begin{array}{l}\overline{21} \\
+1\end{array}$ & $\longrightarrow$ & $\begin{array}{c}3 \\
\dot{y} p\end{array}$ & $\begin{array}{c}4 \\
t \pi ゙ \\
\end{array}$ & • & $\begin{array}{c}3 \\
カ \neq ゙\end{array}$ & $\begin{array}{c}\overline{45} \\
y\end{array}$ & $\begin{array}{l}\overrightarrow{\overrightarrow{75}} \\
+7\end{array}$ & • & • \\
\hline $\begin{array}{c}3 \\
\text { y }\end{array}$ & $\begin{array}{c}4 \\
y / 4\end{array}$ & $\begin{array}{l}5 \\
5 \\
\end{array}$ & - & $\overline{7}$ & $\begin{array}{l}4 \\
+\end{array}$ & $\begin{array}{l}3 \\
\mathbf{Z}\end{array}$ & • & • & 。 & 。 & 。 \\
\hline $\begin{array}{l}\overline{54} \\
\text { †y }\end{array}$ & $\begin{array}{l}5 \\
5\end{array}$ & $\begin{array}{c}1 \\
3 \pi\end{array}$ & & & $\begin{array}{l}\sqrt[43]{43} \\
\text { ケン }\end{array}$ & - & $\begin{array}{c}\overline{45} \\
7\end{array}$ & $\begin{array}{l}\overrightarrow{75} \\
31\end{array}$ & & $\begin{array}{c}\# \overline{45} \\
y\end{array}$ & 0 \\
\hline $\begin{array}{l}7 \\
3\end{array}$ & $\begin{array}{l}\mathbf{i} \\
3\end{array}$ & - & $\overline{7 \dot{2}}$ & & $\begin{array}{r}7 \\
\text { 나 } \\
\end{array}$ & $\begin{array}{l}3 \\
y \\
\end{array}$ & $\begin{array}{r}\mathbf{5} \\
+ \\
\end{array}$ & $\begin{array}{c}54 \\
5\end{array}$ & $\begin{array}{l}3 \\
\pi^{\prime \prime}\end{array}$ & • & 0 \\
\hline $\begin{array}{l}4 \\
7 \\
\end{array}$ & $\begin{array}{l}5 \\
\text { E゙ }\end{array}$ & - & $\begin{array}{l}7 \\
=\end{array}$ & $\begin{array}{l}\overrightarrow{b_{6}} 6 \\
11\end{array}$ & $\begin{array}{l}5 \\
7 \\
\end{array}$ & $\begin{array}{c}\sqrt[65]{ } \\
t\end{array}$ & $\begin{array}{l}4^{-} \\
7\end{array}$ & 5 & $\bullet$ & 0 & - \\
\hline $\begin{array}{l}5 \\
\text { H }\end{array}$ & $\begin{array}{l}7 \\
7\end{array}$ & i & $\bullet$ & $\begin{array}{l}7 \dot{2} \\
74\end{array}$ & $\begin{array}{l}\mathbf{i} \\
\text { y }\end{array}$ & $\begin{array}{c}7 \\
\leqslant 7\end{array}$ & $\begin{array}{c}3 \\
X \bar{T}\end{array}$ & 5 & - & $\begin{array}{l}\overline{43} \\
\text { IV }\end{array}$ & 0 \\
\hline $\begin{array}{l}7 \\
+77\end{array}$ & $\begin{array}{l}21 \\
\text { स1 }\end{array}$ & $\begin{array}{l}2 \\
\Sigma / p\end{array}$ & & & $\begin{array}{l}\overline{5^{4} 4} \\
\text { Tキ }\end{array}$ & $\begin{array}{c}2 \\
E^{\prime}\end{array}$ & $\begin{array}{c}5 \\
31\end{array}$ & $\bullet$ & $\begin{array}{c}\# \overline{45} \\
\text { 力 }\end{array}$ & $\begin{array}{l}\overline{75} \\
3 \overline{3}\end{array}$ & - \\
\hline
\end{tabular}

Copyright $\odot 1980$ by Yūji Takahashi, Tokyo

abstract means, such as notes on paper or a discussion of theory. There are certain aspects of using instruments which are broader than one tradition of music. In tracing these techniques back to the original concepts we can find something hidden in these apparently very different traditions of Asia and [the] Pacific region. [...]

I'm interested to start from how you produce the sound, instead of how you classify the sound. You make sound by contacting an instrument through your hand, finger or breath. Then there is a movement, a patterned movement, and you can start to combine those movements into larger units. [...]

Let's go back to the learning of music, the teacher and student, a one-to-one situation. The teacher plays a phrase, the student plays back a phrase. They play together. This is a copying, a synchronization of the movement of two different instruments. Another principle is response-you 
play that and I play this in response. This is also a learning process which can be developed into the next phase, as in gamelan, for example [...]..$^{238}$

usually my approach to the traditional instruments is not from the written materials about register, timbres, playing method, etc., but through the actual collaboration with performers studying the hand movements, traditional disciplines. [...] i am trying to go back to the origin by changing the habitual playing methods accumulated through traditions. you may call it [...] anti-training. this is difficult without the cooperation of the performers for some period. also you cannot notate this part of the training on paper and send it [...] to the performers wherever they live in the world. ${ }^{239}$

These quotations make it clear how much the observational and ethnological approach helped Takahashi break away from the precarious polarities of cultural nationalism and cultural Westernization (to some degree represented by the position of the gendai hogaku and preceding developments $\rightarrow$ III.1) as well as to liberate Japanese instruments from the widespread bias that assigns them a purely coloristic role: through careful observation and study of traditional performance practice, composer and performers reconstruct a kind of "physical archeology." The performative approach becomes more concrete in that standardized sequences of body movements (kata) in instrumental practice and the resulting sounds are considered complementary to each other. The confrontation with the most important musical instruments of bourgeois Edo culture (1600-1867), the arched zither koto and the long-necked lute shamisen, was the center of Takahashi's attention for many years. Especially for Kazuko Takada (who died in 2007), and later also for Yumiko Tanaka and Yoko Nishi, a large number of works, for both solo instruments and chamber music ensembles emerged. ${ }^{240}$ Takahashi wrote that the shamisen was his preferred model because it was least suited for "modernization." ${ }^{241}$ Through a tactile, sensualistic approach to sound production, Takahashi tried to overcome a fixed harmonic or tonal frame. His works, of course, do not spell out traditional forms. In Sangen sanju for shamisen solo (1992), for example, materials are eclectically combined from a variety of different genres to constitute the fictional genre "sanju" (the name refers to the well-known Korean semi-improvisational genre sanjo $\rightarrow$ III.5). With the help of a computer algorithm, Takahashi combined melodic variants of the koto repertoire, $j i$ melodies from the narrative genre jōruri $\rightarrow$ V.1), elements from the repertoires of gagaku and gamelan as well as rāga and taqsim models. ${ }^{242}$ The result does not sound eclectic at all, but suggests a close association of the traditional genres jiuta or nagauta with the shamisen's

238 Takahashi, "Between Cood and Evil," 7-9.

239 Correspondence with the author, 16/06/2001 (original orthography has been retained).

240 Takahashi's compositions for or with Takada include Kaze ga omote de yonde iru (The Wind is Calling Me Outside, 1986/94) for shamisen and voice, Sangen sanju for shamisen (1992), Nasuno ryōjō for shamisen and computer (1992), Nasuno kasane for shamisen, violin, and piano (1997) $\rightarrow$ III.5), and Tori mo tsukai ka for shamisen and chamber orchestra (1993, see above). Takahashi's other works with Japanese instruments include While I Am Crossing the Bridge (1984), Thread Cogwheels (1990), Bosatsu kangen dennōdate (1992), Yume, Tori mo tsukai ka II, Hiru wa moetsukita, Kagehime no michiyuki (1993), Mimi no ho (1994 $\rightarrow$ IV.1), Ongaku no Oshie (1995), Mono-Catari, Insomnia (1996), Samushiro, Ne monogatari, Kanashimi o sagasu ut, Sōjō rinzetsu (1997 $\rightarrow$ IV.1), Three Pieces for Ichigenkin, Ware wo tanomete konu wotoko, Momoka momoyo, Tsuginepu to itte mita, Oinaru shi no monogatari (1998), Aki no uta, Kotsu no utau (1999), Aomori gaeru, Sangen, Koto nado asobi (2000, see above), Palindrome (2001), To-i (2002), Sinubi (2007), Hanagatami 1 (2008), Ariake (2009), Tabibito ka herazu (2010), Yügao no ie, Kasuka ni (2013), and Bai gui yexing huijuan (2014).

241 Takahashi, "Two Statements on Music," 148.

242 See Takahashi, Tori no asobi. 
Example 3.20: Yüji Takahashi, Sangen sanju for shamisen, beginning

$$
\begin{aligned}
& \text { 睛高目和子 } \\
& \text { 三絃散手 }
\end{aligned}
$$
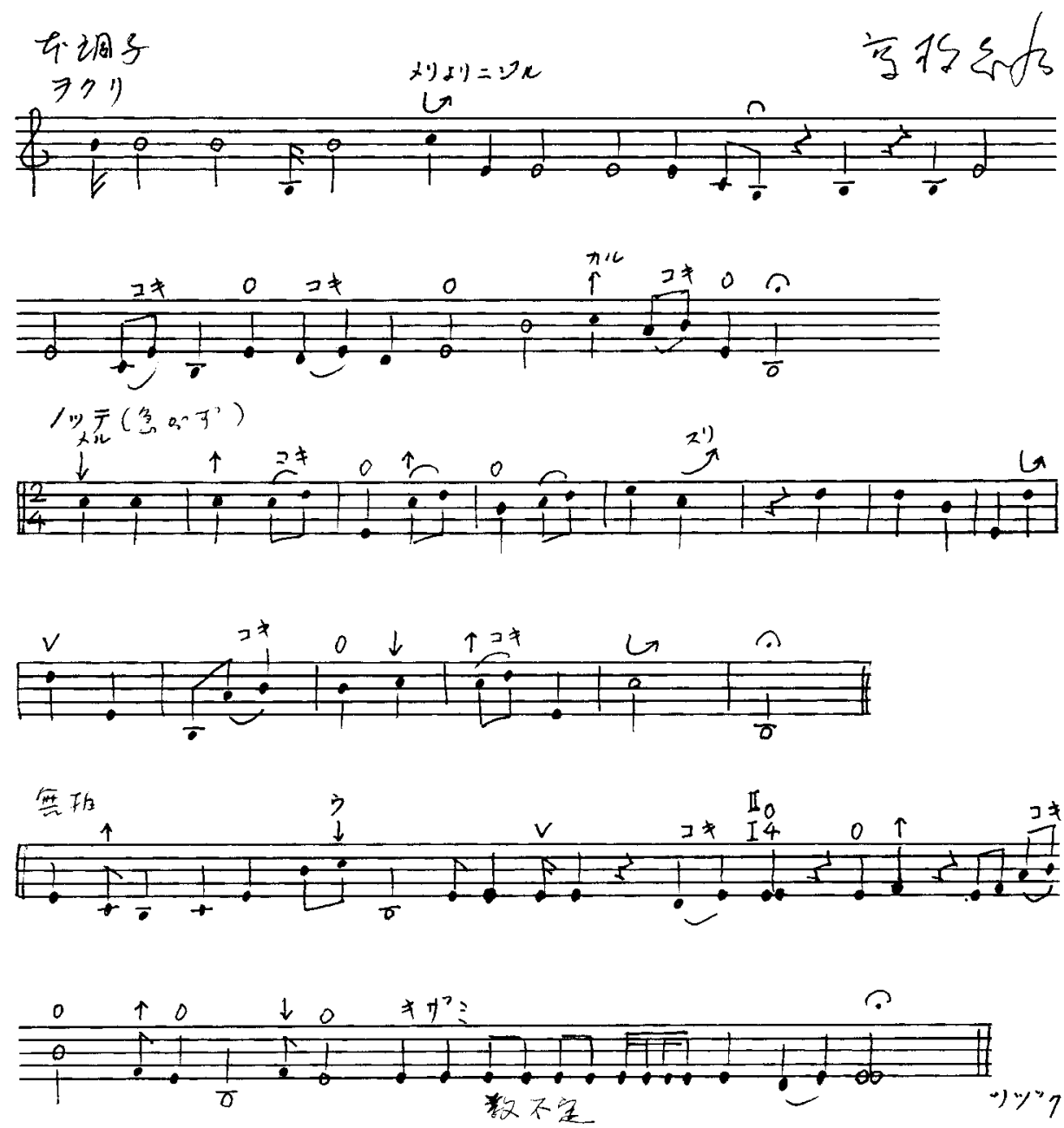

Copyright $\odot 1992$ by Yūji Takahashi, Tokyo

"incommensurable" timbre, which is hardly challenged by crosscultural melodic references (Ex. 3.20).

In addition, Takahashi has taken a radical "ethnological" approach to some instruments and their repertoire based on critical source study, as exemplified by his shō duo Sōjo rinzetsu (1997), in which he implicitly criticized nationalist tendencies in Japanese music research $(\rightarrow$ IV.1). The great potential of Takahashi's basic attitude unfolds in his five works for archaic instruments, which were reconstructed in the context of a project led by Toshirō Kido (National 
Theater Tokyo). ${ }^{243}$ The interest in archaic instruments is consistent with Takahashi's basic approach: it enables him to (re-)construct an instrumental idiom from instrumental movements for instruments whose playing practice has not been handed down to today through an unbroken tradition. ${ }^{244}$ In Unebiyama (1992) for five-string zither and incantation, for example, various stages of a "discovery" of the instrument by the musician are composed out $(\rightarrow$ V.1): starting from elementary movements of the hand and fingers - the individual strings are explored one after the other in a careful tactile manner - the arpeggio over all five strings is suddenly "discovered" as a combination of these individual sounds, and the player is led into a trance-like state - a reference to the shamanistic context of the original instrument.

For all his concentration on concrete aspects of performance practice, Takahashi's composition is, on the whole, rather pluralistic. This is evident not least in the variety of contexts invoked by his music: his cautious treatment of the re-composition of European and Asian music and text materials, his intense engagement with Buddhist philosophy and practice in the 1990s, as well as his identification with artists such as José Maceda, Ossip Mandelstam, Pier Paolo Pasolini, or Sofia Gubaidulina, with whom aesthetic affinities are visible and to whom Takahashi dedicated works.

The multifaceted relationship between aural tradition and writing in Takahashi's œuvre, the complexity and originality of his intercultural references, and his negation of the simplifications of cultural essentialism assign him a prominent role within an intercultural history of twentieth-century music. Not least, his procedures make it clear how complex the task can be to place non-written components or various juxtaposed forms of transcription in a balanced and appropriate relationship to one another in an intercultural context. His scores mix elements of traditional Japanese notation with five-line staff notation and various verbal and graphic instructions in hybrid score forms in which the prescriptive element of conventional notation takes a back seat in favor of a documentary, descriptive, or physical-haptic iconography. This implies an adequately "informed" interpretation with reference to the "aural practice" thematized by the composer.

\section{Discussion}

The examples discussed in this chapter point us to the insight that a break with an ethnocentric and one-sided historiographic model is inevitable in the analysis of social and music-historical developments in Asia - and has to be re-applied to the West as well, possibly following the model of entangled histories ( $\rightarrow$ II.1). Recourse to cultural difference, however, can be risky in this context, or even misleading for historiographical analysis, if based solely on stereotypes and an essentialist, post-nationalist concept of (music) culture. In contrast to Takemitsu's essentialization of musical sounds (to some degree characteristic of his generation), the construction of an imaginary archaic by Ge Ganru (in an entirely different context, less shaped by long-term entanglements with Western modernism) suggests a possible way of rejecting such stereotyping - along with other approaches to intercultural musical composition that we will

243 See Kido, Reconstructed Music Instruments of Ancient East Asia. Takahashi's works for reconstructed instruments include Zanshi no kyoku (Gauze-Silk-Chant, 1988) for the twenty-five-stringed Chinese zither se and recitation, Dream of Heaven (1989) for se, Unebiyama (Mount Unebi, 1992) for five-stringed zither and incantation, Tori no asobi (Birds' Play, 1993) for seven-stringed instrument, and Mangalasutta (1996) for an ensemble of archaic instruments and voices. See also Takahashi, Astray Among Decayed Strings.

244 For more detail, see Takahashi, "Two Statements on Music." 
encounter in the following chapters $(\rightarrow$ III.5-6, IV, V). To be sure, the compositional relevance of cultural difference cannot be denied. But we need to be aware that culturally coded idioms, instruments, or voices are subject to historical, political, and social change: they are unstable, and the form in which they confront us must always be open to discussion. For both Western and non-Western composers, the relevance of cultural difference is inseparably linked to a reflection on the inner historicity, ambiguity, and provisional nature of musical cultures.

Certainly, an intercultural music history cannot ignore actors like Takahashi or Maceda. Their concepts are characterized by complex interventions in theory and practice aiming at a reflection of performance situations in the compositional process. Further similarities in the approaches of the two composers may have become evident: the importance attached to fundamental ethnomusicological areas - although very differently accentuated - such as the practice of instrumental performance, the categorization of timbres, or the cultural encoding of sounds and instruments. This leads both composers to an intensive examination of the relationship between music and society, reflected in highly individual compositional projects and approaches, and to the rejection of simplistic compositional solutions such as references to folkloristic material.

Yet, differences in their procedures have become clear. The primary difference seems to be that Takahashi ultimately rejects the principle of cultural essentialism as a whole and directs his attention to very specific detail phenomena, whose particularity he leaves untouched. By contrast, Maceda certainly claims a supra-regional, if not universal substance in an attempt to counter the causal logic of Western music. This difference may be explained by a difference of age, but certainly also by the very different social situations in the Philippines and Japan: Maceda's postcolonial discourse is illuminated by Takahashi from a postmodern perspective, as it were - a "postmodernism" that began in Japanese cultural criticism during the 1960s, if not earlier. The diversity and particularism of Takahashi's œuvre may seem analogous to Masao Maruyama's analysis of Japanese intellectual history. In 1961, Maruyama analyzed the history of thought in Japan, in opposition to the widespread construction of essential Japanese peculiarities, as an extremely plural discourse that "failed to form a spiritual tradition serving as a point of crystallization or coordinate axis," and thus brought about a situation in which a variety of "ideas, modes of thought, and worldviews remain historically unstructured side by side."245 In contrast, the understanding of José Maceda as a "national" Filipino artist to this day shows that his attempt to construct such a coordinate axis, however open and complex, necessarily risks popularizing a leveling out of differences through cultural essentialism. ${ }^{246}$

It has become clear once again that an intercultural music history can no longer be satisfied with conventional methods of musical analysis if it is to deal with specific problems such as the relationship between aural and textual components of the compositional process. An exclusively "immanent analysis" of the works presented here must clearly remain insufficient,

245 Maruyama, Denken in Japan, 23, 24 ("In Japan hat sich keine als Kristallisationspunkt oder Koordinatenachse dienende geistige Tradition zu bilden vermocht"; "Ideen, Denkformen und Weltanschauungen historisch unstrukturiert nebeneinander bestehen bleiben”). See Janz, "Multiple Musical Modernities?” for a contextualization of Maruyama's thought with Eisenstadt's theory of "multiple modernities" ( $\rightarrow$ II.1).

246 See the accompanying text to the VCD Kuwadro-José Monserrat Maceda, National Artist for Music (Cultural Center of the Philippines, 2002), in which, after a short presentation of Maceda's compositional and ethnomusicological achievements, one can read: "In all these, fiercely nationalistic aesthetics pervades the spirit of this music visionary, forward-looking and confident, burning with a breath of life into an ideal springing forth from the soul of the Filipino." 
since, as we have seen, the musical text is often merely a documentary or mnemonic sketch, or represents an intermediate stage or plan (though sometimes quite precisely formulated) for execution. In addition, both composers very consciously and in a complex way manipulate cultural codes and meanings that can be deduced only through a correspondingly culturally "informed" hearing from the sounding result. For this music, new techniques of a "contextual analysis" must be found. There is no question that the works and conceptions of Takemitsu, Ge, Maceda, or Takahashi, and many other composers working on similar interfaces of cultural categorization, are decisive touchstones for alternative music historiographies.

\section{Intercultural Narrativity in East Asian Art Music since the 1990s}

Can art music actually create such a high degree of differentiation between questions of recognition, alterity, or hybridity, as outlined in the first chapter $(\rightarrow$ I.3)? Caution is generally advised when applying social, political, and literary concepts to musical contexts. The increasing difficulty for art music to claim social relevance was already mentioned at the beginning of this book $(\rightarrow$ I.2). In contrast to more semantically and semiotically constricted literature and the symbolic reception processes instigated by visual arts, the communication of multi-coded messages seems fundamental to the medium of music and sound. Lawrence Kramer once described this quality of music as a "semantic chameleon." ${ }^{247}$ Even more recent tendencies of topic theory or research into musical metaphoricism rarely posit unambiguous principles of musical communication. ${ }^{248}$ Such ambiguity initially seems an advantage in the field of interculturality. In the sense of a conception of music (prominently described by Kramer) as a "cultural practice" ( $\rightarrow$ I.2), it should be emphasized that this ambiguity is limited through reception history and other mechanisms by a wealth of "meta-musical" dimensions such as genre conventions, their topoi, and connotation. These contexts may allow a construction of musical narrativity, which of course is always to be weighed critically against alternative cognitive processes and cultures of hearing, since they are profoundly socioculturally and historically encoded.

Robert Samuels - following Jean-Jacques Nattiez - distinguished between two basic assumptions that allow, or even require, speaking of musical narrativity: on the one hand, a musical process must describe a continuous, irreversible change over time, and on the other hand, it must bring together identifiable musical characters to create an overarching meaning. This meaning cannot be reduced to individual components. ${ }^{249}$ In this chapter, I will present some striking case studies of works by East Asian composers since the 1990s for whom these criteria of musical narrativity undoubtedly apply. By focusing on works that combine Asian and European instruments, the following analyses to some degree reinforce associations of these instruments

247 Kramer, "Hercules' Hautboys," 149.

248 Zbikowski, Conceptualizing Music, Thorau, Vom Klang zur Metapher, and Mirka, The Oxford Handbook of Topic Theory.

249 Samuels, "When Must One Speak of Narrativity in Music?" with reference to Nattiez, "Can One Speak of Narrativity in Music?" and Abbate, Unsung Voices. Narratological concepts have received a great deal of attention in recent years, particularly in the interpretation of music from the nineteenth and twentieth centuries, though hardly ever in reference to newer music, with the exception of the remarkable dissertation Meelberg, New Sounds, New Stories. Foundational studies from the past years include Maus, "Narratology, Narrativity," Samuels, "Narrative Form and Mahler's Musical Thinking," Imberty, "Narrative, Splintered Temporalities and the Unconscious in 2oth Century Music," and Almén, A Theory OfMusical Narrative. 
with "characters." This should not be understood in the sense of a naive programmatic dramaturgy, but instead in such a way that the semantic connotations of the "acting" instruments or instrumental groups are not only accepted by the composers, but often also reinforced by compositional decisions. Most of these examples introduce the separation, rapprochement, or even indistinguishability of "Western" and "Asian" instruments or sounds in a more nuanced manner than the works discussed in the preceding chapters. This increasing differentiation of narrative threads probably has to do with how these works are less tied to specific genres in European or Asian music, such as the solo concerto or symphony. This work emerged from significant activities among the younger generation of Asian instrumental soloists from the 1980s onward, which aligned with a continuously pursued traditional practice. Their activities were aimed specifically at a collaboration with composers of contemporary music, not least with the intention of developing a new repertoire for their instruments and thus aiming to avoid falling into an overly small niche in the economically oriented East Asian societies. These soloists have a high degree of specialization in, and familiarity with, the techniques of contemporary music, yet the collaboration with composers, who are usually educated exclusively in Western music, comes into - more or less productive - conflict in the structure and sonority of the works produced. Although some of the following examples have been composed, performed, and discussed outside of Asia, and may thus only indirectly be relevant for analyzing processes of music history in the respective East Asian countries of the composers, ${ }^{250}$ the following discussion is organized around national music discourses, providing to some extent an opposing perspective on the transnational entanglements discussed in many other parts of this book.

\section{New Chinese Music Between Essentialism and Cultural Conflict}

The Tiananmen square massacre on 4 June 1989 and the already worsening political atmosphere before that proved a decisive turning point, following tentative signs of political liberalization in China during the post-Maoist period and the renewed efforts at an internationalization of Chinese music that this development implied. ${ }^{251}$ Although more attention has commonly been paid to expatriates such as Tan Dun (b. 1957) or Chen Yi (b. 1953), several composers deliberately chose to remain in or, from the late 1990s, return to China. Certainly, as elsewhere, there may be talk of increasing aesthetic pluralism among Chinese composers. The problems created by China's state-controlled capitalism, however, and the aggressive nature of the market economy in general certainly have not only been advantageous for independent Chinese art forms. Art music is considered a "luxury item," the composer's situation is largely one of isolation and often limited to activities within the academy. ${ }^{252}$ It may also be this partial isolation from international trends that, during the late 1990 s and early 2000 s, encouraged certain tendencies to-

250 It would surely be inadequate to continue claiming composers such as Tan Dun, Chen Yi, or Chen Qigang exclusively as "Chinese" composers, with their music considered in the framework of a (national) "Chinese music history" some thirty or more years after they have permanently left China for the United States or France. Rather, their unique contributions to North American or European music histories should be acknowledged. As they retain a prominent influence and exemplary function for both the more official cultural policies and the younger generations of composers in China, however, their cases evidently enforce a transnational approach as outlined in Chapter II.1.

251 A comprehensive historical overview of recent music history in China, Taiwan, and Hong Kong can be found in Utz, "China/Taiwan/Hongkong."

252 Guo Wenjing, e-mail to the author, 03/01/2002. See also Guo, "Traditional Music as Material." 
ward a radicalized emphasis on cultural difference. To be sure, in many of these newer Chinese works, there is a sharp distinction from the aesthetic requirements of the Western avant-garde, but without necessarily lapsing back into the Romanticism of the older generation, as Tan Dun did in his Symphony 1997 ( $\rightarrow$ III.3). Characteristic features in these more recent works include a replacement of polyphony with heterophony, a focused use of microtones and inflections, the deployment of Chinese texts and textures, structural references to Chinese or Asian genres, and, not least, the innovative use of Chinese instruments. This plurality of approaches is not synthesized into an affirmative unity of the music, but rather made audible as a coexistence of distinct qualities. Musical identities are self-reflexive here as a refracted experience, and not forced into the mold of violent cultural optimism.

\section{Polarizing Essentialism: Tan Dun}

The simplistic recourse to culturalist stereotypes of an imaginary China in Tan Dun's Symphony 1997 ( $\rightarrow$ III.3) seems particularly precarious and symptomatic of a broader societal tendency of a resurgence of nationalist currents in the People's Republic of China. As a result of targeted party politics, since the early 1990s, this nationalism has provided a welcome distraction from every kind of looming social conflict. ${ }^{253}$

Of course, not every turn toward issues of Chinese identity should be interpreted as the result of this neo-nationalism, especially since many composers began to engage with culturally coded idioms as early as the late 1970s. In the case of Tan Dun, however, in a work such as Ghost Opera (1994) for pipa and string quartet, one can clearly identify a "tamed" idiom compared to the enhanced modernist manifestations of localism in his works of the 1980 os $(\rightarrow$ II.3): here, both European and Chinese culture become a sort of soft souvenir. Quotations from Johann Sebastian Bach’s Prelude in C $\sharp$ minor BWV 849 (The Well-Tempered Clavier, vol. 1), reduced to a threepart skeleton, and from Shakespeare's The Tempest stand for European traditions, while the folk song Xiao bai cai (Little white cabbage, a xiaodiao folk song from the province of Hebei) and the ritualistic, folk-Daoist "ghost opera" stand for Chinese traditions. ${ }^{254}$ But the juxtaposition of Western complexity (polyphony, linguistic imagery) and Chinese simplicity (simple unanimity) or corporeality (ritual spirituality) seems to overly oblige culturalist stereotypes.

Even more problematically, the musical materials are deprived in their very first appearance of precisely those components that are undoubtedly crucial for the formation of their "cultural identity": owing to the three-part texture of the originally four-part Bach prelude, harmony notes are omitted several times, and the ornaments written out in the original, which give shape to the imitative polyphony, also disappear in Tan's rendering. ${ }^{255}$ The melody Xiao bai

253 Especially symptomatic of this is the publication of the book China Can Say NO! (Zhongguo keyi shuo bu! 1996); the more recent anti-Western nationalism goes back, among others, to the CCP's 1991 campaign of patriotic education (Aiguozhuyi Jiaoyu Yundong), which portrayed China's situation as a result of Western oppression: "The official Maoist 'victory narrative,' which was superseded by a new 'victimization narrative' that blames the West for China's suffering" (Wang, "National Humiliation, History Education, and the Politics of Historical Memory," 792). See also Barmé, "To Screw Foreigners Is Patriotic." In particular, this new nationalism had a significant impact on pop music in the form of waves of nostalgia and popularization of "revolutionary" songs ("Red Songs"), see Steen, "Voices of the Mainstream."

254 This example is also discussed in Utz, Neue Musik und Interkulturalität, 449-452. See also Young, "Reconsidering Cultural Politics in the Analysis of Contemporary Chinese Music" and the extensive analysis in Cooi, "Making an Identity," 115-139.

255 The Kronos Quartet plays the Bach passages on the CD recording (Nonesuch 7559-79445-2, 1997) and in live concerts with a Romantic emphasis that lacks any historical sensitivity. 
cai, in turn, loses the harmonic ambiguity of the pentatonic scale through the added drone in the viola; the characteristic inflections of the singing voice in Chinese vocal practice are hardly taken into account. Instead, string portamenti producing conventional sighing motifs are added in the instrumental repetition of the melody (third movement, rehearsal number $B$, first violin) that have nothing in common with traditional Chinese vocal or instrumental practice. Tan Dun's narrative of opposing materials, which enter into a dialogue in a supposedly "natural" manner, is therefore hindered from the very beginning by his failure to recognize precisely those delicate asymmetries between these materials on which his conception claims to rely.

\section{Pluralistic Essentialism: Qin Wenchen and Guo Wenjing}

Many other composers by no means discarded cultural essentialism, but the concept has become more nuanced and pluralized through the more diverse experiences of younger generations. An example of this extension of the idea can be found in Qin Wenchen's (b. 1966) He-Yi (Merging, 1999) for the Chinese arched zither zheng, six Western instruments, and percussion. Qin's "pluralistic essentialism" is characterized by an ethnographically consciously "imprecise" hybridity that merges source elements from different genres of Chinese traditional music with a sufficiently abstract atonal pitch structure. Like many other Chinese composers since the early 1990s, Qin draws on the mnemonic syllables of luogu dianzi, the "gong and drum patterns" of the Beijing Opera percussion music wuchang, ${ }^{256}$ but here combines the resulting evocation of Chinese opera with the withdrawn literary world of the zheng and the quasi-shamanistic singing of the zheng soloist (Ex. 3.21). This purposefully inaccurate form of intermingled reference to different Chinese genres and aesthetics seeks to find a general "Chinese tone":

The vocal lines [...] [at rehearsal number 14] all resemble the speech voice of Chinese opera. The different vocal parts all follow different lines, and every part is enhanced with different ornaments and slides that are characteristic of operatic singing style. The cellist here strikes a Chinese opera gong (jingluo) and changes between soft and hard strokes. All this conveys the atmosphere of Chinese opera without actually quoting or imitating a certain piece of music. ${ }^{257}$

Qin's work also places special emphasis on a feature that characterizes much of newer East Asian music, described by Barbara Mittler as "radicalization"258: certain aspects of traditional East Asian musical practice are driven to extremes with the intention of highlighting their specific characteristics (Tan Dun explained that Chinese folk music often appeared insufficiently harsh to him, not "folky" enough, so he must exaggerate it all the time ${ }^{259}$ ). In $\mathrm{He}-\mathrm{Yi}$, for example, the sound-syllables of the luogu dianzi are structurally condensed in a way that would never happen in traditional wuchang ensembles.

While Qin Wenchen takes a middle position between abstraction and concretion, Tan Dun (b. 1957) and Guo Wenjing (b. 1956) can certainly be considered the two Chinese composers most explicitly associated with traditional non-Western, not necessarily exclusively Chinese material, with Tan Dun producing a particularly broad variety of compositional techniques

256 See Rao, "The Tradition of Luogu Dianzi," Rao, "Chinese Opera Percussion from Model Opera to Tan Dun," and Utz, Neue Musik und Interkulturalität, 468-470 for further examples of the use of luogu dianzi in contemporary Chinese music.

257 Qin, “On Diversity," 145.

258 Mittler, Dangerous Tunes, 323-357.

259 See Tan and Utz, "Tan Dun's Art for a New Generation," 148-149, Utz, Neue Musik und Interkulturalität, 490. 


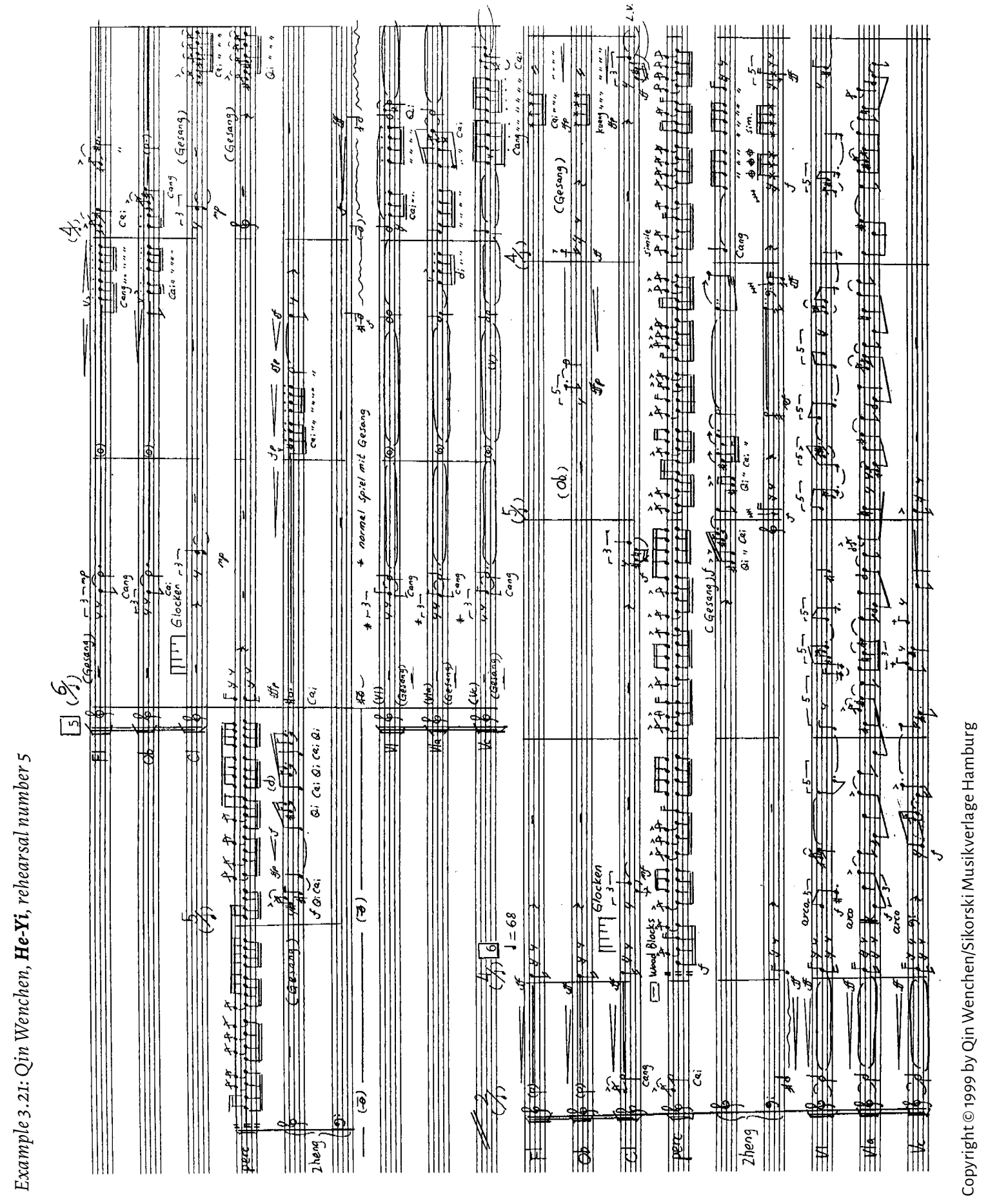


Example 3.22: Guo Wenjing, Ye Yan, Scene 1, entrance aria of Hong Zhu (soprano), accompanied by the pipa

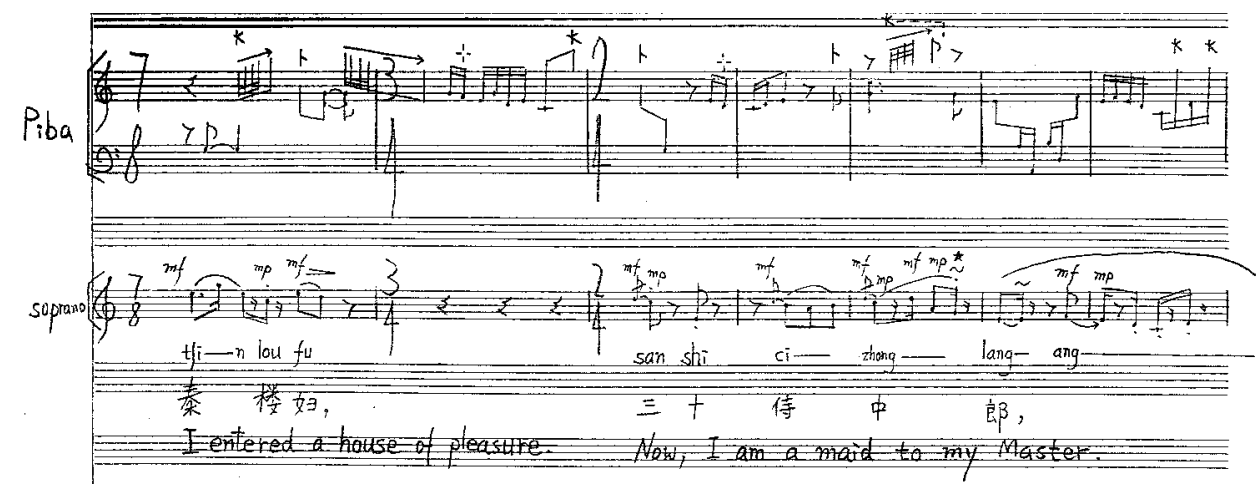

Copyright ( 1998 by Universal Music Publishing Ricordi - Milan, Italy

dedicated to such combinations until $1996 .{ }^{260}$ An important one is the aforementioned use of "non-original" material instead of quotations, where a quite deliberate effect is to lure the listener onto the "wrong track": the idea of the idiomatic is removed from an affirmative character to an ambiguous, sometimes ironic context.

Guo Wenjing, in his second opera Ye Yan (Night banquet, 1998), took the treatment of such "quasi-traditional" Chinese material to extremes. ${ }^{261} \mathrm{With}$ long stretches of only one unaccompanied musical line and the sound of the four-string lute pipa, the music is based on interlocking pentatonic modes. Thereby Guo creates an almost unbroken "Chineseness" idiomatically characterized by a special simplicity and economy (Ex. 3.22) and only temporarily broken up by sharply contrasting percussive tutti ensembles. This deliberately "Chinese" character is, of course, a construction that can only be justified with reference to a very restricted selection of Chinese musical forms, in particular the literary wenren aesthetic associated with the pipa, related to an idyllic concept of nature from which Guo has explicitly distanced himself. ${ }^{262}$ Yet, in addition to this strong identification with a Chinese musical language different from Western music, we can also see a degree of self-reflexive irony in the work, which at times seems to create a necessary distance from its apparent essentialism. This tendency can be identified, for example, in the slight, barely perceptible, shifts in pentatonic modes, or from a ubiquitous "grotesque" instrumentation that reminds us of Dmitri Shostakovich's writing for wind instruments. These piercing sounds aptly communicate with the constant presence of percussion ensembles that here, as in Qin's He-Yi and many earlier pieces by Guo $(\rightarrow$ II.3), emerge from the percussion patterns of jingju (Beijing Opera) and chuanju (Sichuan Opera).

260 See Utz, Neue Musik und Interkulturalität, 323-481.

261 See Guo, "Traditional Music as Material."

262 See ibid. 


\section{Interaction: Chen Xiaoyong}

For many East Asian composers whose music was originally more strongly based on the compositional techniques of European modernism, the encounter and longer-term cooperation with Chinese instrumentalists led to an intensive examination of the problems associated with culturally hybrid ensembles. Works such as The Prospect of Colored Desert (Mo motu, 2000) by Jia Daqun (b. 1956) for sheng (mouth organ), pipa, violin, violoncello, and percussion, written for Yo Yo Ma's Silk Road Ensemble, or Vacuité/Consistance (1996) by Xu Shuya (b. 1961) for zheng, pipa, and chamber ensemble prove that such works do not necessarily have to represent "traditional" or essentialist aesthetics, but that the East Asian instruments are at once more than merely unusual sound generators for otherwise "Western" structures. This polarity is broken up in particular by the considerable influence the performers usually exercise on the sounding result. For example, Chen Qigang's (b. 1951) famous Poème Lyrique II (1991) for baritone and chamber ensemble, ${ }^{263}$ an important work for the international recognition of the xinchao generation, would be difficult to imagine without Shi Kelong's "performative" realization of the highly precisely notated vocal part. Chen Xiaoyong's (b. 1955) zheng solo Circuit (1996), in turn, was developed in close collaboration with the soloist Xu Fengxia, who contributed not only a wide range of vocal colors but also experiences of free improvisation - qualities that are also clearly manifest in the zheng part of Qin Wenchen's He-Yi, which was also written for Xu.

This is all the more remarkable in the case of Chen Xiaoyong, who studied with György Ligeti after graduating in Beijing in 1989, as Chen originally distanced himself from explicit references to Chinese traditions. A tendency toward abstraction and play with abstracted "cultural" colors is certainly still recognizable in a later work such as Invisible Landscapes (1998): in the final caden$\mathrm{za}$, the three solo instruments zheng, piano, and percussion, facing a small chamber ensemble of six instruments, attempt almost systematically to continue the piano's line along with drumming and zheng harmonics. These parts are only partially synchronized at first, and the passage takes on the character of an experimental arrangement through the alternation of different types of Western and Chinese drums and ever-changing, "evasive" rhythmic figures. As in Chen's earlier works, the focus is less on culturally specific musical idioms than on a persistent attempt to fathom the closeness and distance between the various instrumental timbres (Ex. 3.23).

Chen's works from the turn of the millennium show an increasing "looseness," motivated not least, by an intensified collaboration with Chinese improvising musicians including, besides Xu Fengxia, the sheng soloist Wu Wei ( $\rightarrow$ II.6). In addition, there is an increased conceptual orientation toward the enigmatic and often paradoxical formulations of archaic Daoist traditions of Chinese thought. Yang Shen for soprano, zheng, sheng/xun (Chinese ocarina), and small chamber ensemble from 2002, for example, develops a reading of the poem Beifeng bo zhou from the Shijing (Book of Songs, c. 600 BCE). The poem's linguistic sounds are mixed with fragments of texts by the "classical" philosophers Laozi, Liezi, and Confucius in German translation, as well as instrumental sounds colored with unpitched noise. The Chinese and German speech sounds (all instrumentalists also act as vocalists) as well as Chinese and European instrumental sounds approach one another.

This concept continues to develop in Chen's Speechlessness, Clearness and Ease (Yin, xi, yi, 2004) for a larger ensemble of seven Chinese, eight European instruments, and percussion. The ensemble forms a multi-layered sound field that, by adjusting the positions, playing techniques, and articulations, minimizes the tonal, gestural, and cultural differences of the instruments; a dense 


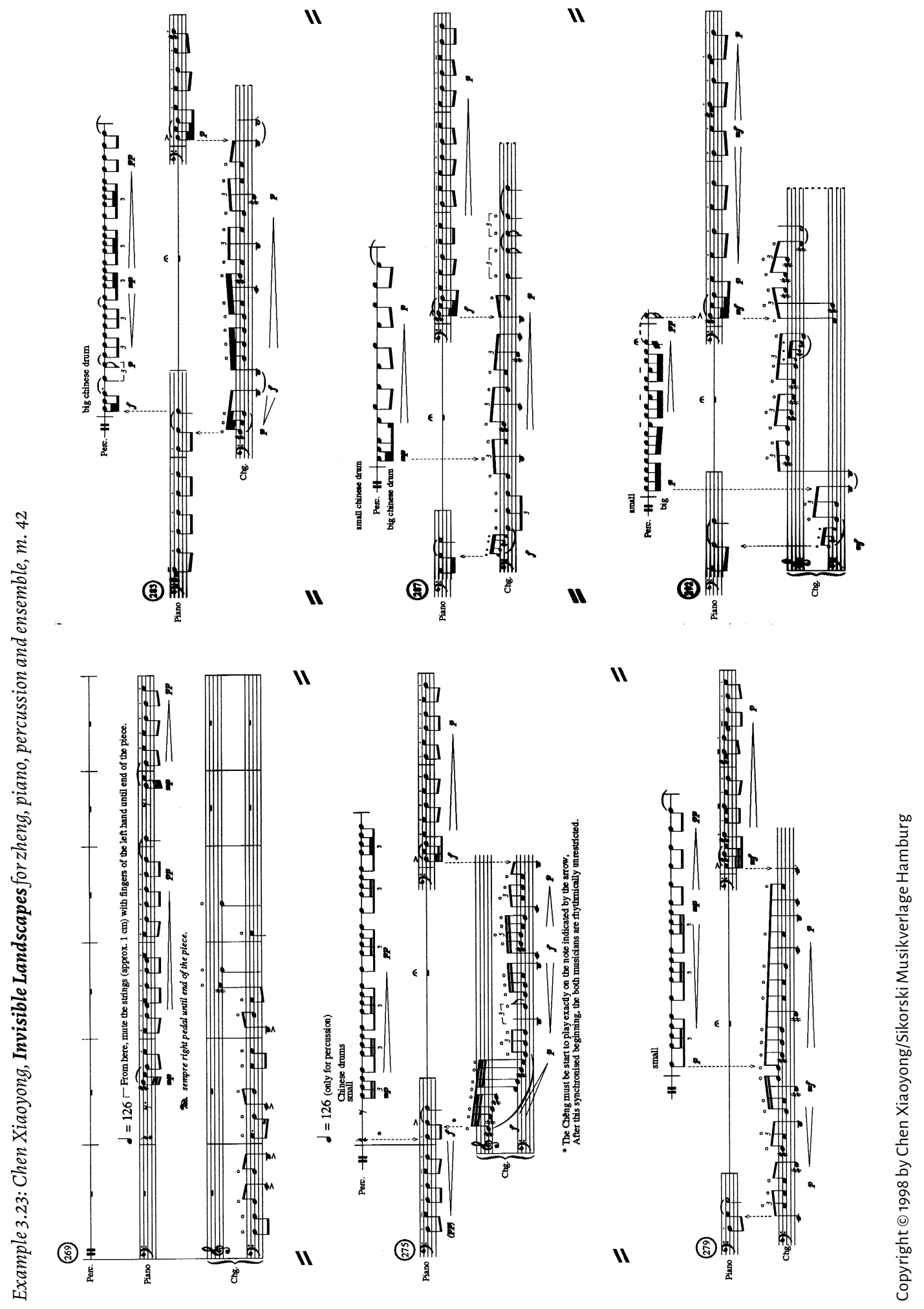


sequence of identifiable pitches and characteristic noise sonorities creates a complex overall system. Frequently, Chinese and Western instruments intermingle to form hybrid timbres (flute/ sheng $\mathrm{mm}$. 28/35, double bass/erhu $\mathrm{mm}$. 36-39, piano/yangqin $\mathrm{m} .36$, ruan/trombone/violin $\mathrm{m}$. 39, etc., see Ex. 3.24). Toward the end of the first section, the contours are increasingly resolved by the hissing noises already heard at the beginning (mm. 1-27); instrument-specific sound effects accelerate this process (collegno, rubbing of the zheng strings, jiaoxian: overlapping of three pipa strings with a metallic-sounding result, muted piano strings). In keeping with the quotation from the thirty-fifth chapter of Laozi's Daoist classic Daodejing: "One looks for it and does not see it" (shi zhi bu zu jian ${ }^{264}$ ), the composer wants to place the listener in a paradoxical situation "between delusion and reality, between sounds and noises, between real and artificial worlds of sound." 265 The "cultural identities" of instrumental sounds in this interactive area are reduced to a minimum, if not abandoned at all. To some degree, however, such a potential leveling of identities seems to diminish the intelligibility of Chen's narrative of a paradoxical world experience.

\section{Stratification and Conflict: Zhu Jian'er}

Zhu Jian'er impressive symphonic œuvre, introduced earlier ( $\rightarrow$ III.1), only corresponds to the xinchao generation's achievements in some ways, but retains a distinct position in which a more pronounced independence from Western modes of reception is apparent. While the claim was put forward in Chapter II.5 that composers since the 1950 s have increasingly addressed their work toward a potentially global public, the very real process of creating a particular work for a premiere at a specific location for a specific local audience surely has implications for many of the narratives addressed so far. Zhu's Sixth (1992-94) and Tenth (1998) Symphonies juxtapose field and studio recordings of traditional Chinese music with the symphony orchestra, played through loudspeakers. ${ }^{266}$ The Tenth Symphony features a free chant, recalling the stage styles of Beijing Opera, and recorded fragments of the literati zither qin, mostly in senza tempo sections that alternate with metrically stable orchestral sections. The three-movement Sixth Symphony, by contrast, creates a complex combination of orchestral sounds and a plethora of different regional styles played back as recordings, primarily of minorities from South-Western China. ${ }^{267}$ The third movement is initially dominated by a monophonic dance

264 The complete passage quoted from Chapter 35 reads: [道之出口, 淡乎其無味, ] 視之不足見, 聽之不足聞, 用之不足既 ([dao zhe chu kou, tan he qi wu wei,] shi zhi bu zu jian, ting zhi bu zu wen, yong zhi bu zu ji); “[But though the Dao as it comes from the mouth, seems insipid and has no flavour,] though it seems not worth being looked at or listened to, the use of it is inexhaustible." (Laozi, The Tao Te Ching; the bracketed part was not used in Chen's work). Chen also quotes the two basic concepts of the Daodejing ziran (nature) and wuwei (non-doing) as well as the first sentence of the sixteenth chapter: 致虛極, 守靜篤 (zhi xu ji, shou jing du), “The (state of) vacancy should be brought to the utmost degree, and that of stillness guarded with unwearying vigour." (Ibid.) Throughout the piece, only the initials of syllables without mid-vowels or final sounds are used.

265 Chen, "Speechlessness, Clearness and Ease," 285 ("zwischen Täuschung und Wirklichkeit, zwischen Klängen und Geräuschen, zwischen realen und künstlichen Klangwelten").

266 See Mao, "Jianxi Zhongguo xinan diqu minzu yinyue sucai" and Yi, "National Cultural Memory in Late-Twentieth-Century East Asian Composition."

267 A starting point similar to Zhu's symphony is found in Tan Dun's The Map (2002) for violoncello, orchestra and video playback. The work juxtaposes video field recordings of minority music in Hunan Province with the cello soloist and the Western symphony orchestra. In the fifth movement Feige, for example, a girl from the Miao minority appears on the video and the cellist imitates her singing. To be sure, Tan Dun's concept, unlike Zhu's symphony, strives for a conflict-free complementation and an effective, virtuosic interaction and integration of opposites, which places the composer in the paradoxical double role of both keeper of local tradition and 
Example 3.24: Chen Xiaoyong, Speechlessness, Clearness and Ease, mm. 32-39
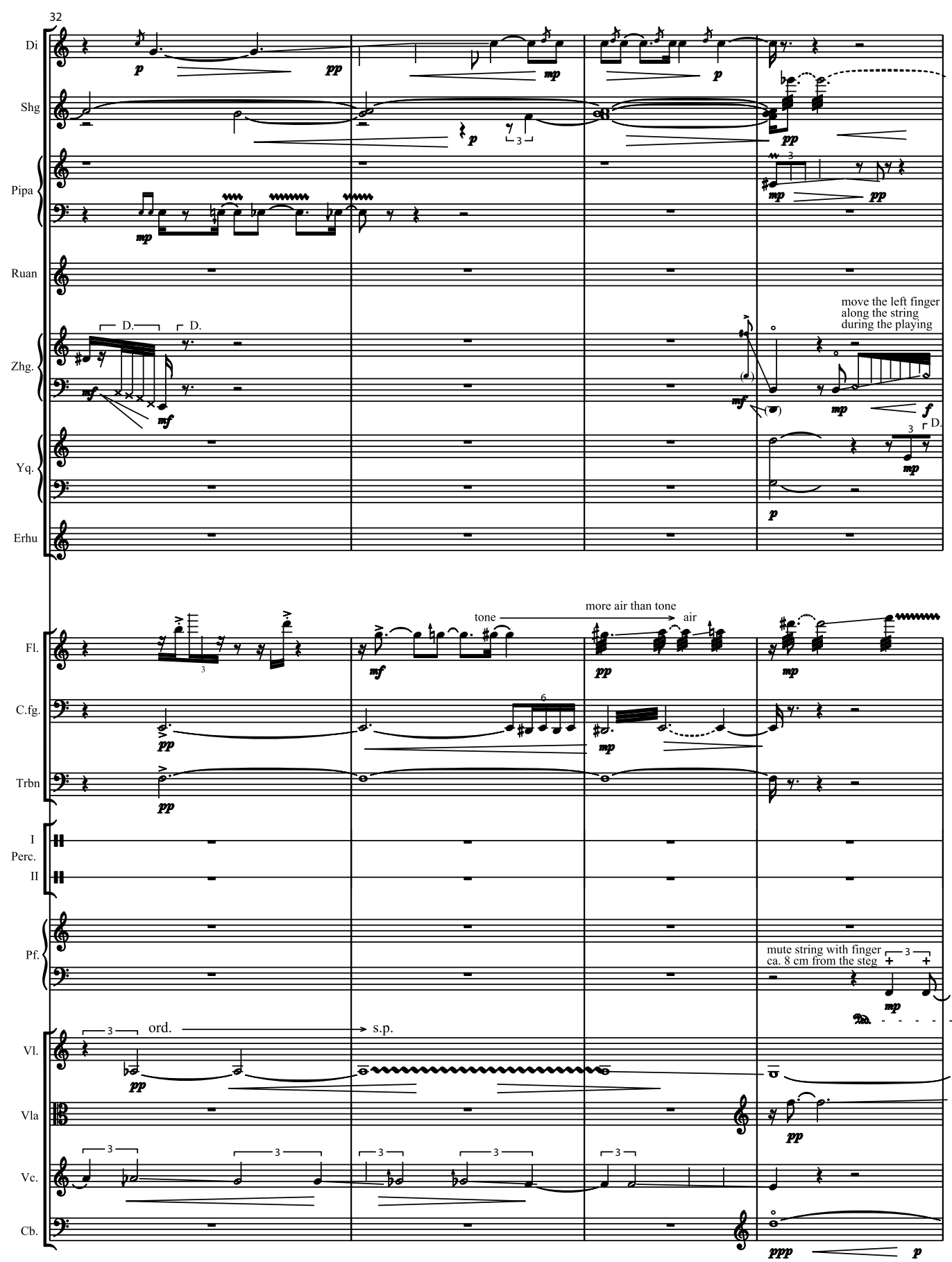

Copyright $\odot 2004$ by Sikorski Musikverlage Hamburg 
D
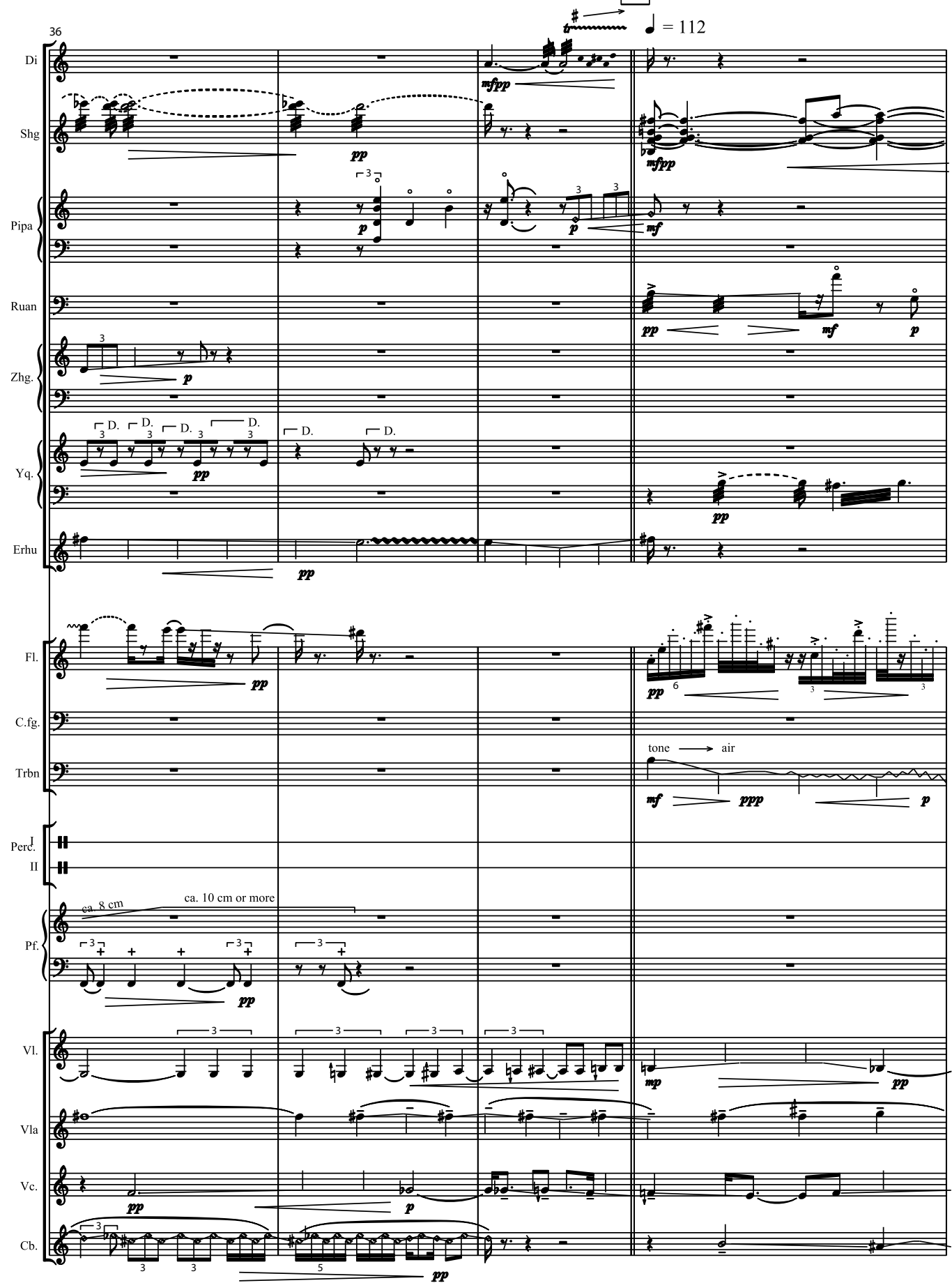
Example 3.25: Zhu Jian'er, Sixth Symphony, third movement, left: after rehearsal number 15; right: before rehearsal number 19; Tape I: upper system: song of the Yi girls; lower system: Naxi song (above: women, below: men)

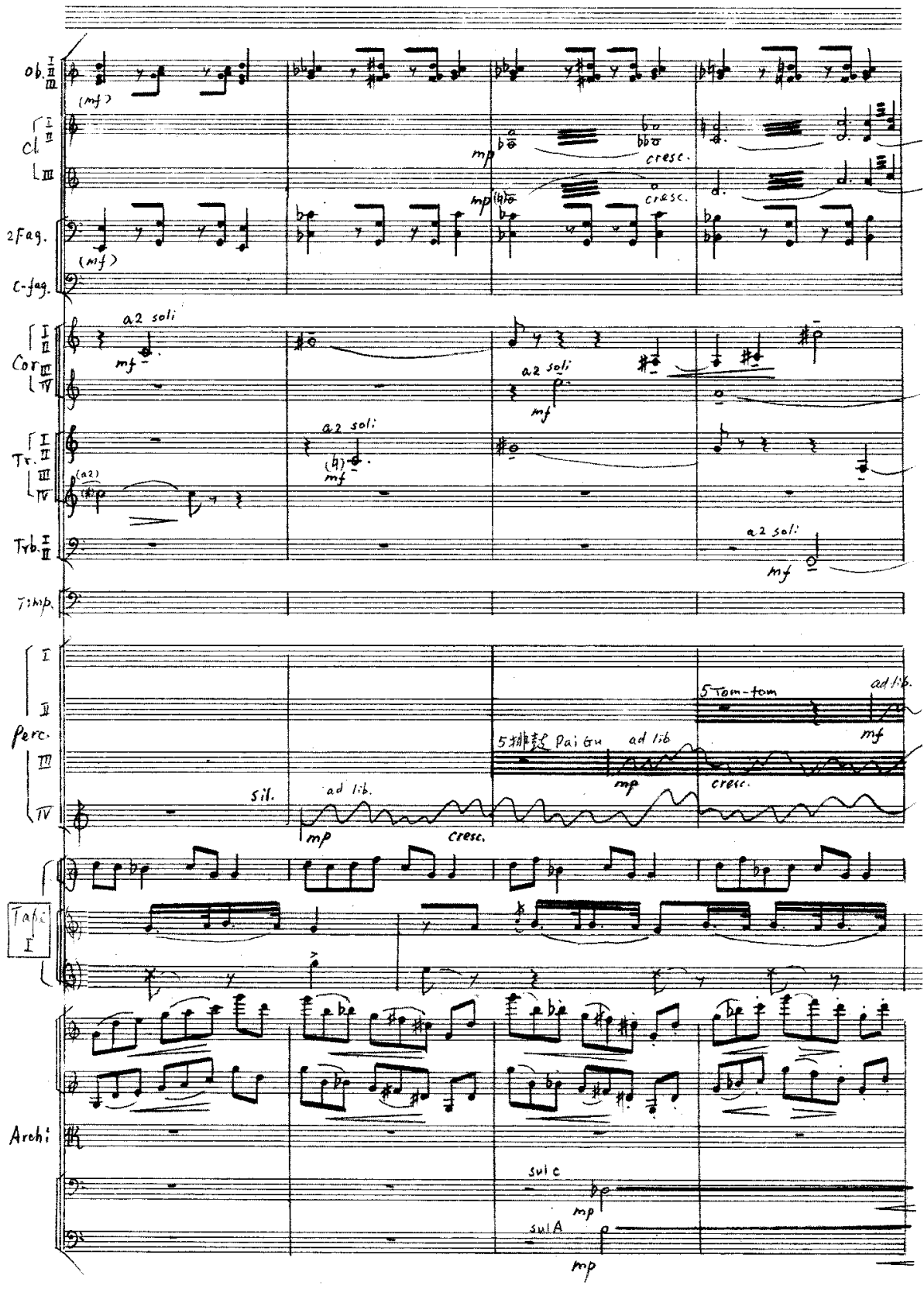




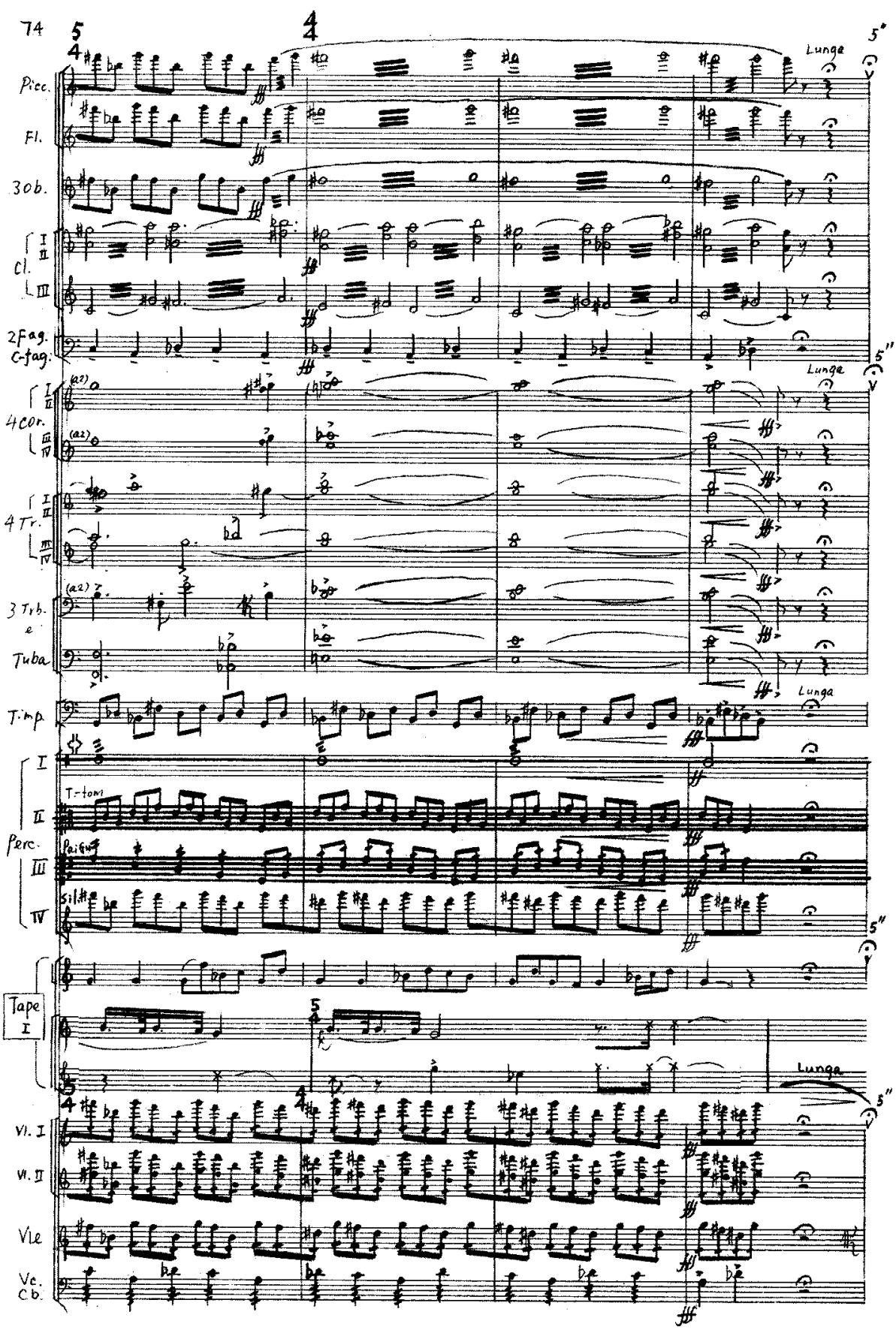


song of Yi minority girls ${ }^{268}$ whose simple 6/8-metered singing is accompanied or answered in an imitative manner by the orchestra. Toward the end of the movement, however, we experience a considerable compression and complication of the structure. At the movement's turning point, the layer of Yi vocals is complemented by a recording of the well-known Worere song of the Naxi minority (also from South-Western China). ${ }^{269}$ It is superimposed on the Yi girls' dance song, which has meanwhile been placed in $4 / 4$ meter, and triggers an orchestral texture that rapidly increases in dynamics and density (Ex. 3.25, left). These recorded Naxi songs are usually sung at funerals, with the female voices mimicking the bleating of sheep while the part of the male voices consists of loud, rhythmically free exclamations. ${ }^{270}$ The previously unambiguous metric structure collapses, and ultimately the recordings are crudely drowned out by a violent orchestral tutti (Ex. 3.25, right).

In the context of Zhu's symphonies, analogous to the Second and Fourth Symphonies $(\rightarrow$ III.1), an interpretation in the sense of an oppressive force of the collective toward the individual or the minority is indeed obvious in this "anti-finale." The overall sound is stratified from the beginning: despite attempts at a careful structural incorporation of tape recordings and orchestral writing, the different sound qualities of orchestra and field recordings never really merge (this stratification is not only due to the poor sound quality of the recordings), with these two layers breaking apart in a moment of final crisis. The idyllic glorification of the alleged closeness to nature in the music of China's minorities has long been idealized among Han Chinese (especially among composers ${ }^{271}$ ). The "nationalist" aspirations of bringing minority music into a symphonic work, as in Ding Shande's prototypical Long March Symphony ( $\rightarrow$ III.1), are counteracted not only by the "artificiality" of the recordings, but also by the failure of the synthesis with the orchestra. Characteristically, some Chinese researchers largely overlook this musical-narratological collapse, interpreting the symphony as a "search for roots" and as an affirmative adherence to the ethnic character of cultural identity:

The concepts in Zhu Jian'er's work are a necessary result of an awareness of the current deep crisis of people's culture. Precisely because Zhu senses the "loss" of traditional value systems and the metaphysical world, he wants all the more to seek the roots [xungen], to claim the identity of the traditional culture, and in doing so he especially emphasizes the national character [minzuxing] and the cultural heritage. As an outstanding representative of Chinese symphonism, he is fundamentally guided by the mission to heighten national self-esteem all the more, the greater this general crisis of people's culture becomes. ${ }^{272}$

Such a visualization or making audible of cultural conflict through the heterogeneity of sound layers is often viewed with suspicion as taking a superficial approach to musical phenomena, while conversely, coherent musical surfaces are presumed to contain an "internal struc-

symphonic innovator. See Young, "The Voicing of the Voiceless in Tan Dun's The Map" and Yang, "Musical Phantasmagoria in the Globalized Age."

268 Rees, "China, §IV: Living traditions 5 (i) (a).”

269 Rees, Echoes of History.

270 See ibid., 59. The dance song is called O ssei sseil in the Naxi language and is also known as Remeicuo.

271 See Utz, Neue Musikund Interkulturalität, 352. The highly politicized context of Chinese music between 1949 and 1989 may have sustained the idea of the "purity" and nativeness of minority musics.

272 Mao, "Jianxi Zhongguo xinan diqu minzu yinyue," 28 (translation by the author). 
ture" that should guide the reception process. ${ }^{273}$ It is obvious that this is an overly crude and, in many ways, questionable dichotomy. After all, there are probably two tendencies in almost every interculturally oriented musical concept: the desire for audible, comprehensible connecting threads, for elements that allow linking disparities as well as searching for the incompatible, incommensurable, different, for the residue that cannot be forced into synthesis. Perhaps Zhu's symphony is in some ways also a proof that - especially against the ambivalent background of nationalist tendencies in recent Chinese music - only a confrontation between heterogeneous, largely incommensurable elements can oppose the affirmative phrases of (national or artistic) unity, without having to abandon references to specific sounds from Chinese music.

\section{New Korean Music: New Exemptions}

In South Korea, in the late 1950s, after the turmoil of the Korean War and under the restrictions of an autocratic military government, the internationalization of musical life was only gradually beginning. In 1960 the western-trained composer Hoegap Chŏng (1923-2013) was commissioned by the Korean Air Force Orchestra to write a first concert for the Korean arched zither kayagŭm and orchestra. ${ }^{274}$ This "Theme and Variations" (Chujewa Pyŏnjugok) for kayagŭm and orchestra (1960-61) largely resulted from the impetus of the then 24-year-old kayagŭm player Byungki Hwang (b. 1936), who performed the solo part and subsequently became a key figure in Korean new music history. ${ }^{275}$ The following year, Hwang assisted the American composer Alan Hovhaness (1911-2000) in his remarkable Symphony no. 16 for kayagŭm, an ensemble of Korean instruments, and string orchestra (1962), as well as playing the solo part in the Seoul premiere. Hovhaness, who undertook extensive research trips to Asia from 1959 to 1963, had already encouraged young Japanese colleagues in Tokyo in 1960 to keep East Asian music away from the "violence and destruction" of Western music ${ }^{276}$ and was now celebrating traditional Korean music in Korea as "the most expressive, sublime and free in the world."277 In addition to Henry Cowell ( $\rightarrow$ II.4, II.5), the idealization of Asian music as an "antidote" to European influences was mainly spread by Dane Rudhyar (1895-1985) from France, who had lived in the USA since 1916 and had considerable influence on his composer colleagues. ${ }^{278}$ In any case, such impulses were decisive for the young kayagŭm innovator Hwang, and he subsequently emerged with increasingly confident pieces for Korean instruments, developing the movement of ch'angjak kugak in analogy to contemporary tendencies in Japan ("Traditional Korean Contemporary Music," see gendai hōgaku $\rightarrow$ III.1).

During the same period, Isang Yun's life situation as a migrant (since 1956 in Europe, since 1957 in the Federal Republic of Germany) meant that he was much more directly confronted with Western tendencies. Yun had already gained recognition as a composer in his adopted home $(\rightarrow$ III.4) when he was kidnapped by the South Korean secret service from Germany in 1967 and accused of acting as an agent, following a trip to North Korea in 1963 and his contacts with North Koreans in East Berlin. After torture and a life sentence, Yun was released under pres-

273 Utz, Neue Musikund Interkulturalität, 43-44, 58-62.

274 A detailed and updated historical overview on Korean new music can be found in Lee, "Korea."

275 See Killick, Hwang Byungki.

276 Quoted in Fukunaka, "Re-situating Japan's Post-War Musical Avant-Garde through Re-situating Cage," 192.

277 Hovhaness, "Korean Music is the Most Expressive, Sublime and Free in the World," 29.

278 See Ertan, Dane Rudhyar and Utz, "Klang als Energie in der Musik seit 1900." 
sure from the German and American public in 1969 and was able to return to Germany. ${ }^{279}$ From 1973, Yun was actively involved in Korean exile organizations for the democratization of South Korea and Korean reunification, which also had an effect on his music. While he had previously oriented his work toward traditional Korean music and the latest European trends such as serial music and sound composition, the search for political statements from the mid-1970s led to a clear realignment of models of (late) Romantic tonal language and the force of orchestral sound. One may observe these tendencies in works such as Exemplum in memoriam Kwangju for large orchestra (1981), a memorial composition to the victims of the massacre committed by government troops in South Korean Kwangju in May 1980, ${ }^{280}$ or in Naui dang, naui minjokiyo (My country, my people!) for soloists, choir, and large orchestra (1986-87), which Yun saw as an indictment of the persecution and oppression of South Korean dissidents. These two works in particular subsequently became welcome tools of propaganda against the South through multiple performances in North Korea from 1982 as part of the annual Isang Yun Music Festival, ${ }^{281}$ sometimes with Yun present. Even though Yun certainly did not follow "socialist realism" in the narrower sense in these works, his stylistic "willingness to compromise" and in some cases his highly illustrative idiom made such instrumentalization considerably easier: "Yun [...] under-estimated the veracity of state policy." ${ }^{282}$

The specifically strained political situation in divided Korea increased the profound skepticism toward (neo-)nationalist tendencies in some of the outstanding compositional positions of (South) Korean music from the 1990s onward. In particular, this skepticism opposed composers such as Lee Geon-Yong (b. 1947) and Yoo Byung-Eun (b. 1952), leading members of the "Third Generation" (Che Sam Sedae), a composers' group founded in 1981. This group newly discovered traditional Korean music as source material for their affirmative patriotic style but still committed to a Western Romantic idiom. Political-historical topics in this context were often explicitly taken up. Lee's cantata The Song of the Plain (1994), written for the hundredth anniversary of the Tonghak peasant rebellion (Joseon period, 1894-95), quotes the famous children's song Saeya, saeya, pahrang saeya ("Bird, bird, blue bird"), which served as a secret identifying signal within the Tonghak movement (see also the section on Koo below and the section on Takahashi in III.4). ${ }^{283}$ Similarly, Yoo Byung-Eun uses the "Song of May" in his orchestral work Shinawi no. 5 (1989) to commemorate the victims of the Kwangju massacre. In these works, the incorporation of traditional elements was not least a critique of the fact that the manifestations of Korea's traditional culture as a whole had been largely isolated from current social processes and considered museum artefacts from the 1960 s to the ' 80 s. This implied that traditional genres and idioms were not conceived as obvious or "natural" resources for composing, and had to be appropriated by composers on the basis of often inadequate secondary sources. ${ }^{284}$

279 See the extensive documentation in Sparrer, Ssi-ol. Almanach 2000/01 der Internationalen Isang Yun Cesellschaft, 139-248.

280 See Yi, "National Cultural Memory in Late-Twentieth-Century East Asian Composition" and Heister, "Kollektivität und Körperlichkeit." The massacre was committed under General Chun Doo-Hwan, who came to power through a military coup d'etat in December 1979 following the assassination of dictator Park Chung-Hee on 26 October 1979.

281 Choi, "Zur Rezeption des Fuvres von Isang Yun in der Republik Korea," 162.

282 Howard, “Korean Tradition in Isang Yun's Composition Style," 98.

283 Already in 1958, Isang Yun had incorporated this melody in a related sense in his FünfStücke für Klavier. See Lim, "Identity Performance and Performing Identity," 213-214.

284 See Lee, "Reconsidering Traditional Vocal Practices in Contemporary Korean Music,"136-137. 
As in other cultural contexts, it was above all "multiculturally" competent performers, such as the singer Sin-Cha Hong (b. 1940), who nonetheless enabled substantial forms of intercultural hybrid-ity at an early stage. ${ }^{285}$

\section{Sublation of Traditional Practice: Eun-Hye Kim, Jin-Hi Kim}

An explicit focus on the idioms of traditional Korean music since the 1990 s could refer to nuanced scholarly investigations and publications and, at the same time, increasingly rely on a circle of younger musicians of Korean instruments open to collaboration with composers. These musicians most notably came from the school of Byungki Hwang. ${ }^{286}$

Eun-Hye Kim's (b. 1956) composition Kayagum (2000) for soprano, 17-string kayagŭm and changgo (Korean hourglass drum) could hardly have been created without this context. Kim uses the vocal technique of the aristocratic genre kagok (sung by a soprano trained in European vocal technique) as well as two rhythmic models changdan from the well-known improvisation genre sanjo, where the patterns are further developed and varied in density and tempo as in the original sanjo, but in a complex way that is only possible through (Western) compositional and notational practice (Ex. 3.26).The composer, however, changes the rhythmic structure so much that only the basic character but not the shape of the changdan remains recognizable. For example, the strong accent at the beginning of a cycle (hap changdan) largely disappears in Kim's score, so that the sonic result has a high degree of idiomatic resemblance to sanjo and kagok, yet remains clearly recognizable as an independent compositional articulation. The precise and complex notation, which limits the dramatic emphasis of traditional kagok singing and draws more attention to structural detail compared to the improvised sanjo, also contributes to this feature of the music.

Kim's approach shows a focus on "fake traditions" that she shares with several composers of her generation. There is a demonstrative distancing from musical nationalism of any kind. At the same time, it remains unmistakable that we are dealing here with an intense examination of idioms that differ sharply from all facets of European music. Of course, it is only through compositional models from European modernism that one can reach a position from which the decades-old pitfalls of the discourse on "Koreanness" ${ }^{\text {"287 }}$ can be avoided.

Musicians such as the kayagŭm soloist Ji-Young $\mathrm{Yi}^{288}$ or the taegŭm (bamboo flute) soloist Jeong-Seung Kim have made a decisive contribution to shaping such a journey beyond polarizing extremes with the Contemporary Music Ensemble of Korea. The most renowned composer-performer in this field is the New York-based komun'go (six-string arched zither) player Jin-Hi Kim (b. 1957). In contrast to the aforementioned composers, Kim has undergone extensive training in traditional Korean music and has made a basic principle of East Asian music - albeit in a specifically Korean accentuation - a "trademark" of her playing and composing: "Living Tones," 289 the detailed design of melodic lines in traditional Korean/East Asian music through techniques summarized as ssigimsae:

285 See ibid., 143.

286 See especially Killick, Hwang Byungki and Han, Interkulturalität in der neuen Musik Koreas.

287 See, among others, Lee, "Korean Music Culture" and Howard, "Different Spheres: Perceptions of Traditional Music and Western Music in Korea."

$288 \mathrm{Yi}$ i-Young has proven her exceptional position not least through her systematic study Contemporary Gayageum Notation for Composers, Seoul 2011.

289 See above all Howard, Creating Korean Music, 143-147. 
Example 3.26: Eun-Hye Kim, Kayagum, III, mm. 14-19
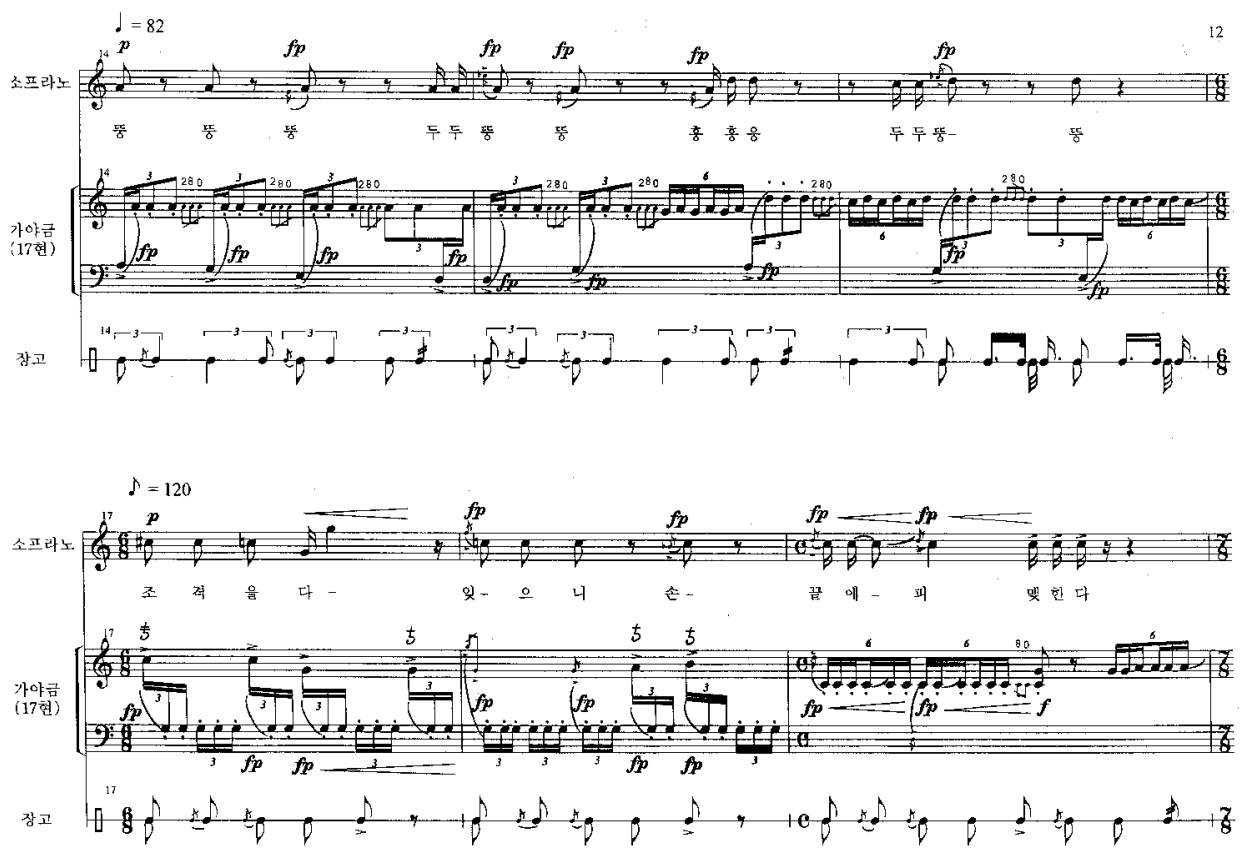

Copyright $\odot 2000$ by Eun-Hye Kim, Seoul

My bi-cultural compositional concept "Living Tones" is based on a sense of timing which is different from Western music. "Living Tones" function best in a slow tempo where enough space is available to shape notes, which does not work well in a strict time frame, such as in Western classical music. Therefore, I do not compose pieces with bars; rather, I finish the whole piece without counting the beats and then I add bars to facilitate performance. The ensemble sound flows horizontally within a heterophonic melody in which each individual instrument creates its own nuances and specific articulation. All this is happening slowly and within a calm space. "Living Tones" need time to take shape. During the rehearsals of my pieces I recommend that the performers use the score, not the parts. Every performer should listen carefully to the other parts. ${ }^{290}$

Although Kim's concept has many essentialist traits and is in some ways reminiscent of the musical conceptualization of Korea by Isang Yun three decades earlier $(\rightarrow$ III.4), and even though one of Kim's most important methods is the use of traditional Korean performance practice on European instruments - a concept explicitly criticized by other composers of the same generation such as Bonu Koo (see below) - her approach creates independent musical narratives that elude any form of stereotyping. The key work implementing Kim's "Living Tones" is her Nong Rock (1992) for kómun'go and string quartet, which was realized with the Kronos Quartet. The structures of the kagok genre in the first part (Nong, mm. 1-40) are transferred relatively precisely to the hybrid instrumentation (Ex. 3.27), where "Nong" refers to the characteristic vibrato nonghyŏn (vibrating or sliding by depressing the string with the left hand after plucking with the right hand). In the second section (Rock, mm. 41-129), this basic structure is developed 
Example 3.27: Jin-Hi Kim, Nong Rock for kŏmun'go and string quartet, I. Nong, mm. 1-5

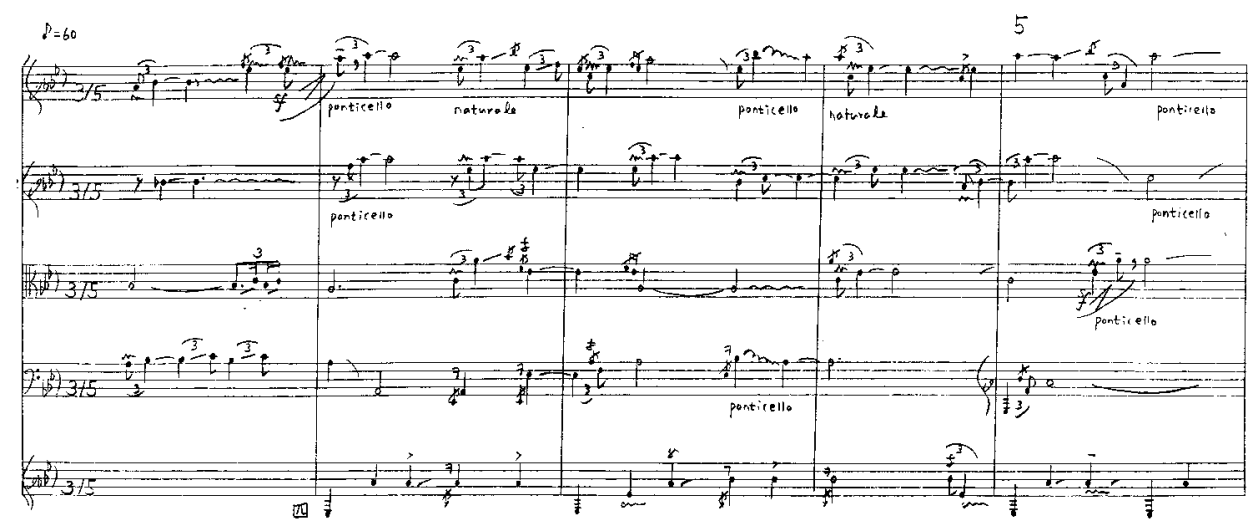

Copyright ( 1992 by Living Tones, ASCAP

into a more improvisational and energetic situation, with individual instruments, especially the kommun'go, now increasingly appearing as soloists. The starting point for the conception of this work were Kim's observations while she participated in a traditional kagok performance:

In a kagok song the kŏmun'go is a leading instrument and accompanies the vocal line together with other instruments, such as the se-piri (double-reed instrument), taegŭm (horizontal bamboo flute), tanso (vertical bamboo flute), haegŭm (fiddle) and changgo (hour-glass shaped drum). When I played a kagok suite, I had the feeling that the instrumental ensemble and the singer sounded separately. The instrumental parts have their own characteristic and function beyond accompanying the voice, and I thought that it would be wonderful to listen to the instrumental ensemble without the singer. Also, at first I had difficulties in counting the beats, because the kommungo somehow does not directly follow the singer's beats. However, once I had memorized both the rhythmic cycle and the vocal part, I was able to play with the singer. I also heard that the changgo drummer did not keep absolute tempo. He was following the singer, so that the overall time was very flexible. These experiences were an important motivation to compose Nong Rock. ${ }^{291}$

Not all types of ssigimsae are recorded in traditional music sources, and Kim's score can therefore be understood to some degree as the translation of an aural practice into a largely fixed form of notation. Naturally, a complementary aspect is even more significant: the performers are repeatedly called upon to listen to one another and to react in the course of the piece, and the imitation of the komun'go techniques regularly extends the conventional string sounds.

The tendency to idiomatically "imitate" a traditionalism reduced to the supposedly "essential" is certainly most evident in Kim's approach. It may also be the distance from the home culture and its politically charged discussions, as in the case of some Chinese immigrant composers, that fosters such fundamental cultural essentialism - at the risk of simplification and stereotyping. Kim's performance experience and practice, however, convincingly counters such skepticism on stage. In addition, the example of Eun-Hye Kim shows that even in today's 
Korea, with sufficient skill and nuance, a "Korean" idiomaticism can be sublated (in the Hegelian dialectical sense) in new music without evoking any form of nationalist pathos.

\section{Liberation from Culturalism: Bonu Koo, Kunsu Shim}

The incorporation of Korean traditions into works of the "Third Generation," which in part appears naïve when compared to later generations, was criticized in particular by Bonu Koo (b. 1958). Koo rejected a "cheap imitation" of Korean musical idioms and techniques, as he put it, and was equally skeptical of the (widespread) tendency toward timbral and technical imitation of Korean instruments by European instruments (or vice versa). ${ }^{292}$ Koo, who studied with Erhard Karkoschka at the Stuttgart Academy of Music from 1984 to 1990 and worked at the Institute for Psychoacoustics and Electronic Music (IPEM) in Ghent in 1990, opposes such tendencies with a psychoacoustically informed structuralism that avoids culturally encoded musical vocabulary by concentrating on the acoustic properties of the sounds employed and their compositionally structured convergence and/or divergence. A vivid example of this is offered by his work nah/fern for kayagŭm and string trio (1998):

What I then took as a point of departure for composing this work was sound. I tried to analyze and compare the quality of sound production by the kayagŭm and the Western strings. I found that a pizzicato of the strings and a plucked tone of the kayagŭm most differ in their release phase and therefore a muted tone (that has no or only a very short release) makes it possible to let them sound more alike. This was how I conceived the title "nah/fern" (close/far): it is possible to let the instruments come close to each other, but it is also possible for either side to retain its identity. Later in the piece this happens when the kayagŭm "emancipates" itself from the Western strings with the result of something like a "faked tradition."293

The difference in the decay phase between the two instrument types is explored by Koo in a systematic, almost deterministic, manner at the beginning of the work (Ex. 3.28): the kayagŭm and the pizzicato plucked strings perform dyads from which individual notes are gradually prolonged, first almost imperceptibly by the kayagŭm ( $\mathrm{mm} .3-5)$ and then by the kayagŭm (mm. 7-9) and strings (cello m. 10, other strings from m. 11). Koo's intention to erase the differences in the timbre of the two instrument types at the beginning is apparent, the "identities" of the instruments only gradually surfacing.

At a key point later in the work, as described by Koo, the kayagŭm abruptly falls into an idiomatic playing style, identifiable by the characteristic strong vibrato nonghyŏn, which evokes associations with the shinawi genre. At the same time, the three string instruments play an almost pitchless pizzicato, hinting at a percussion pattern in the style of the Korean hourglass drum changgo, so that a "fake tradition" can indeed be experienced for a few seconds (Ex. 3.29). Immediately after that, however, the kayagŭm reintroduces a kind of sonic "hideand-seek" with the three strings in which the instruments tend to mask one another.

One might argue that coherence and dissociation meet here on a micro-level. What dominates is a rationalized, "psychoacoustic" approach (sound production and acoustic envelope, plucked vs. bowed notes, focus on single notes and minimal frequency deviations, etc.) that aims to avoid any "cultural" association. With this approach, Koo resolves the dilemma of trying to explore a musical position relevant to contemporary Korean society without making

292 Koo, “Beyond 'Cheap Imitations," 134.

293 lbid. 
Example 3.28: Bonu Koo, nah/fern for kayagŭm (upper system) and string trio, $m m$. 1-14
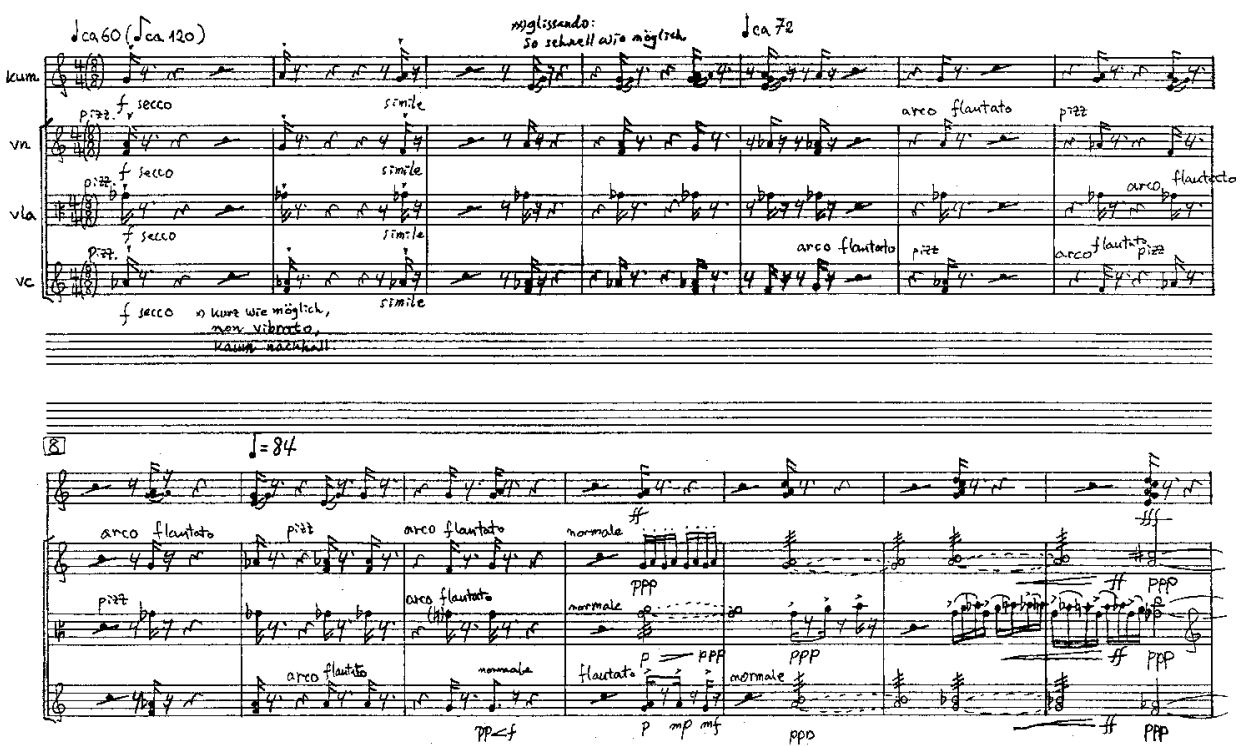

Copyright (c) 1998 by Bonu Koo, Seoul

Example 3.29: Bonu Koo, nah/fern for kayagŭm (upper system) and string trio, mm. 154-160

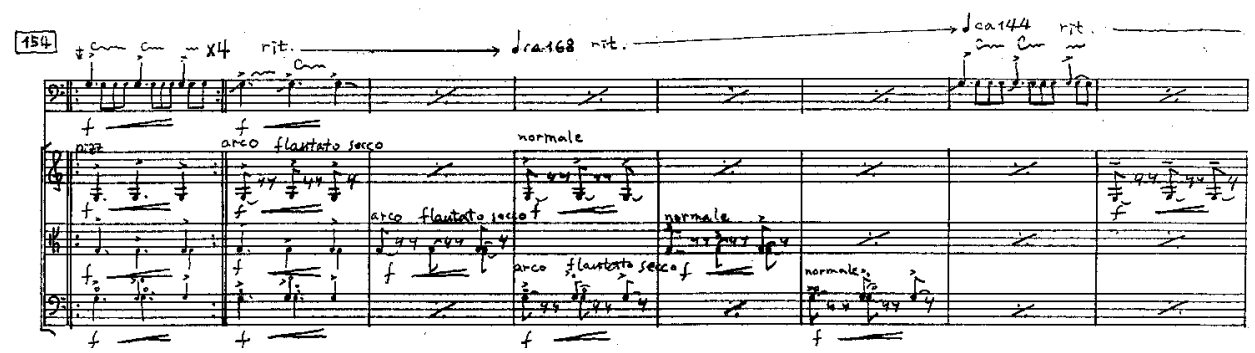

Copyright ( 1998 by Bonu Koo, Seoul

use of an affirmative "traditionalism." The "illumination" of the traditional idiom is perhaps comparable to the role played by marches or folk songs in Gustav Mahler's symphonies, or to the German national anthem in Helmut Lachenmann's Tanzsuite mit Deutschlandlied (1979-80): the presence of the traditional material is perceived, on the one hand, as "foreign matter," as incompatible with the basic tone of the work, but, on the other hand, appears as a result of a consistently developed structural-narrative gesture.

A radicalized variant of this structuralist strategy is the conception of "synthesis by nothing," which may be described as a basis of John Cage's concept of musical interculturality $\rightarrow$ II.6) ${ }^{294}$ On the basis of a sound-silence continuum, the attempt is made here to arrive at a hierarchy-free and "culture-free" form of music by turning to individual sounds and silences as basic elements - an attempt at liberation from conventional concepts of culture as a whole, 


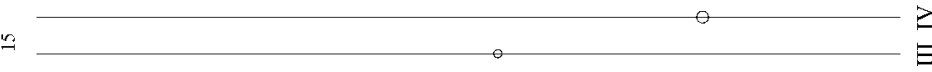

$\pm$

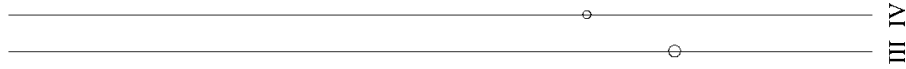

$\underline{-19}$

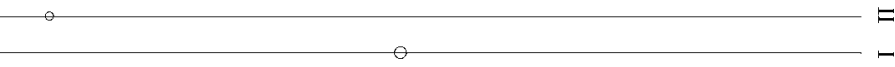

ร

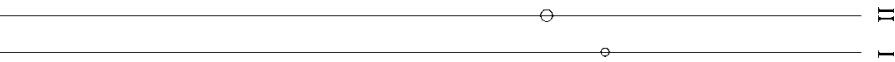

$=$

$\geq$

E

일 $\Xi$ E

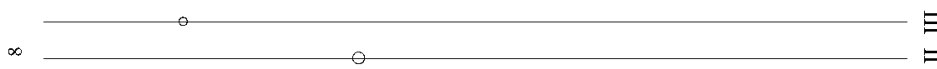
$\Xi$

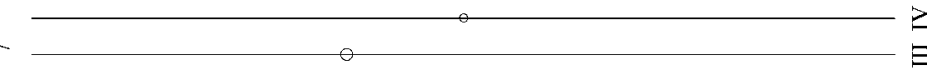

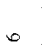
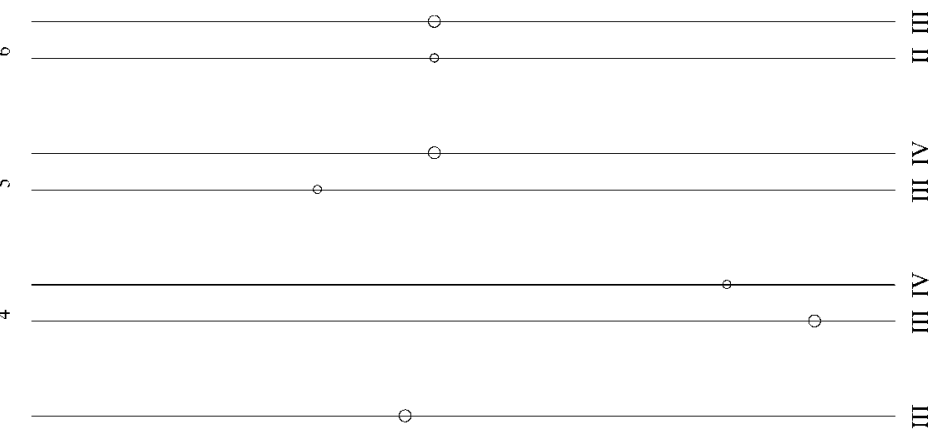

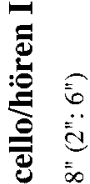

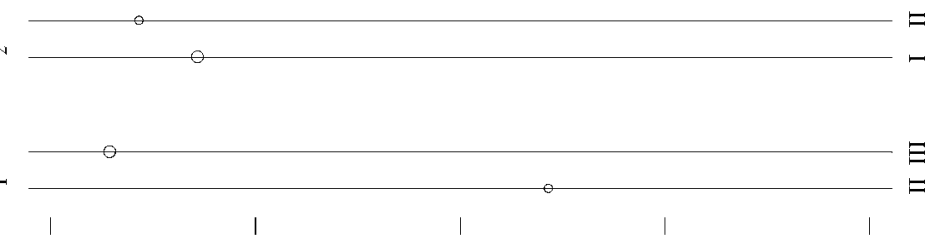


where "sounds are nothing but sounds." Undoubtedly, this project brings to the fore the paradoxes that are already apparent in structuralism, as they are only understandable in the light of specific tropes in North American cultural history of the twentieth century. ${ }^{295}$ The massive implied skepticism toward culturally encoded musical idiomatics, however, has been influential for a great diversity of artistic approaches beyond the immediate American context.

The scores of Kunsu Shim (b. 1958) surely endorse this principle most rigorously. Cello/hören for solo cello (1997), for example, consists of two sets of 45 minimal actions on two cello strings, each lasting two seconds, followed by six seconds of silence (Ex. 3.30). The player adopts the attitude of a listener; their movements are reduced to the bare essentials and follow an intuitively understandable action notation. In his essay "Richtungslosigkeit oder Denken der unbegrenzten Gegenwart," Shim meanders from Gilles Deleuze to Laozi, from Marina Abramović to the Korean poet Chi-Ha Kim, from Friedrich Nietzsche to John Cage, to outline this presence-focused sound perception. ${ }^{296}$

Shim's Luftrand (2000) for string trio (Ex. 3.31), which is to be played "placidly, with inner warmth and lightness," ${ }^{\text {297 }}$ consists, like most of the works of this period, of shorter sounds in both sections; sounds lasting three seconds each are followed by long silences (lasting for about six seconds in part A). After tuning down the strings by roughly an octave, part B introduces sound actions of flexible duration that the performers should carry out "with the idea that the sounds occur for themselves in a timeless space: one should hear them instead of playing them. ${ }^{298}$ Again, the sound events are indicated through action notation, which also specifies fine nuances in the performers' movements.

The strict temporal isolation of sound events stems from Shim's view of the perception of music as analogous to a non-intentional listening to the acoustic environment of the natural world and everyday life. Silence, as the basis of sonority, is particularly important in this respect: it sharpens the perception of the smallest details and can contribute to the experience of the "things of life" beginning to speak. Prerequisites for this are patience, a willingness to play with one's memory and expectation, as well as a curiosity about an "in-between" time-space beyond everyday goal-directed thinking. ${ }^{299}$

Shim repeatedly refers to the traditional Asian, especially Japanese, theory of art. Among other sources, he quotes an anonymous short poem that also plays a prominent role in a standard text of 1930s nationalist Japanese aestheticism, Jun'ichiro Tanizaki's essay In Praise of Shadows (In'ei Raisan, 1933); Tanizaki quotes the poem in order to illustrate the fascination of the continuous changing of the elements in nature:

\footnotetext{
295 See ibid., 112-116.

296 See Shim, "Richtungslosigkeit oder Denken der unbegrenzten Gegenwart."

297 Shim, Luftrand, score, Edition EarPort 2000, 2 ("gelassen, mit innerer wärme und leichtigkeit").

298 Ibid., 1 ("mit der vorstellung, daß die klänge für sich selbst in einem zeitlosen raum auftauchen: man höre sie, anstatt sie zu spielen").

299 See Leliwa and Stahl, leise, frei. der komponist kunsu shim.
} 
Example 3.31: Kunsu Shim, Luftrand for string trio, violin part, part A, no. 16-24
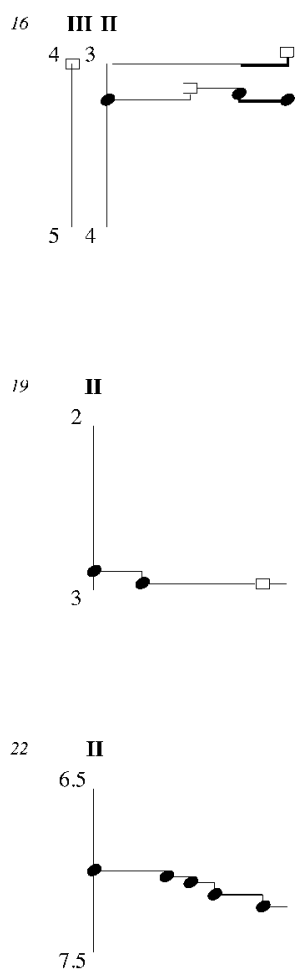

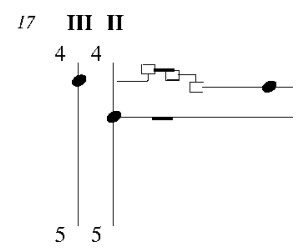

20
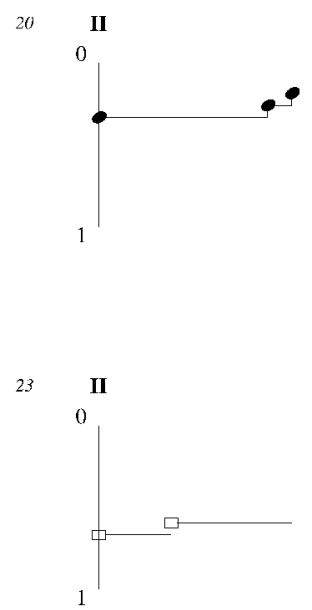

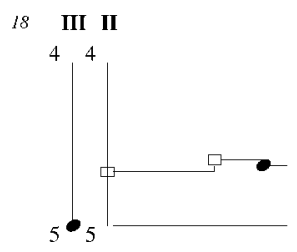

27

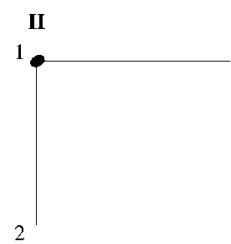

2

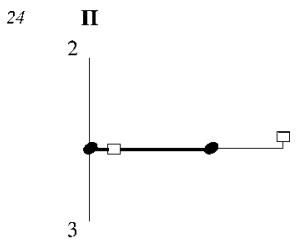

Copyright $\odot 2000$ by Kunsu Shim/Edition EarPort, Düsseldorf

the brushwood

we gather-stack it together,

it makes a hut;

pull it apart,

a field once more. ${ }^{300}$

To be sure, Shim does not stop at a naïve naturalism, but sees naturalness and artificiality as interdependent; even the idea of the "artificial" is to him, paradoxically, a basic precondition for imagining the natural.

Of course, such a continuum between sound and silence, derived from nature and sound ecology, is strongly oriented toward the legacy of the American avant-garde, as evidenced by Kunsu Shim's performances, which take up elements of Fluxus in a concentrated, ritualistic form. Shim's provocations of perception are constructively condensed with the utmost precision, and in their dramaturgy they pursue precisely conceived experimental arrangements. His works are aimed at a critical moment when the perceptual-narrative modes of hearing, waiting,

300 Tanizaki, In Praise of Shadows, 29-30. See Shim, "die kunst - verbunden und auflösen," 51 ("astwerk, / zusammengetragen und verbunden: / eine reisighütte. / aufgelöst: wie zuvor / wieder die wildnis." Shim quotes from the German edition Tanizaki, Lob des Schattens, 53-54). 
remembering, and forgetting all come into conflict with one another. His reference to Agnes Martin's structuralist constructivism, ${ }^{301}$ which is endowed with extremely subtle subversive elements, describes an essential aspect of Shim's own concept of form. An archetype of his composition, as clearly demonstrated in Sense of Measure for four percussionists (1999), is found in a critical moment when the continuum of sounds and silences is abruptly interrupted by a very long pause at a certain point. After this pause, the continuum returns as a reminiscence of earlier material, but now suddenly new sound qualities "come to light." A central theme in Shim's music becomes particularly evident here: waiting and remembering.

\section{Tendencies in Japanese Music Around the Millenium: Affirmation and Critique of the Essentialist Heritage}

In Japan, too, the construction of an essentialist Japanese aesthetic, prominently elaborated, for example, in Tōru Takemitsu's middle period, influenced many Japanese composers, sometimes lacking critical (self-) reflection on this essentialism and the associated culturalist polarization ( $\rightarrow$ III.4). Takemitsu himself thought deeply about this problem, but after a series of works with Japanese instruments between 1966 and 1973, finally became more and more involved in a tonally or modally oriented idiom, which suggested an institutional gravity of a Western-dominated international music business and discourse - the framework in which Takemitsu's works increasingly appeared (in and outside Japan). ${ }^{302}$

It is obvious that new Japanese music from the 1960 s to the 80 s cannot be reduced to a simplistic culturalist essentialism with national or nationalist resonances. Starting with Mayuzumi, a considerable number of Japanese composers have aimed at a transnational (or pan-) Asian idiom, with sources adopted from Southeast Asian musics (Akira Nishimura, Minoru Miki, Yüji Takahashi), while others have turned to particular variants of minimalism (Jō Kondō, Somei Satoh, Mamoru Fujieda). The internationalization of Japanese music was considerably promoted by transnational performance and ensemble activities that involved composers such as Maki Ishii (1936-2003) or Makoto Shinohara (b. 1931) from the 1960s and 70 s onwards. It is also evident that since the 1980 s and 90 , younger composers in particular increasingly no longer felt a need to face any issues of "Japaneseness" or employ material from traditional music - a kind of international "normalization" (if not standardization) that can be considered a broader characteristic of younger generations, and was discussed already in Chapter I $\rightarrow$ I.2).

Nevertheless, it should be noted that in Japan, since the beginning of the 1990s, a number of composers have still been very active in facing the challenges of the tension between European and Asian music cultures. The range of possibilities to act within this discourse cannot be addressed at adequate length here, and will instead be outlined in a brief comparison between the approaches of Toshio Hosokawa (b. 1955, $\rightarrow$ IV.1) and Yüji Takahashi (b. 1938, $\rightarrow$ III.4), whose work is discussed more comprehensively in other chapters of this book. The approaches of Hosokawa and Takahashi appear as two incompatible approaches to intercultural composition, yet in the sounding materiality of their works may not ultimately differ as dramatically as this conceptual divergence might suggest.

In a work representative of Hosokawa's music, such as Landscape $V$ (1993) for shō and string quartet $(\rightarrow I V .1)$, one can easily make out the essential characteristics of his composing that tend

301 See Shim, "die kunst-verbunden und auflösen."

302 Utz, Neue Musik und Interkulturalität, 282-306. 
Example 3.32: Toshio Hosokawa, Koto-Uta for singer and koto, rehearsal number 4

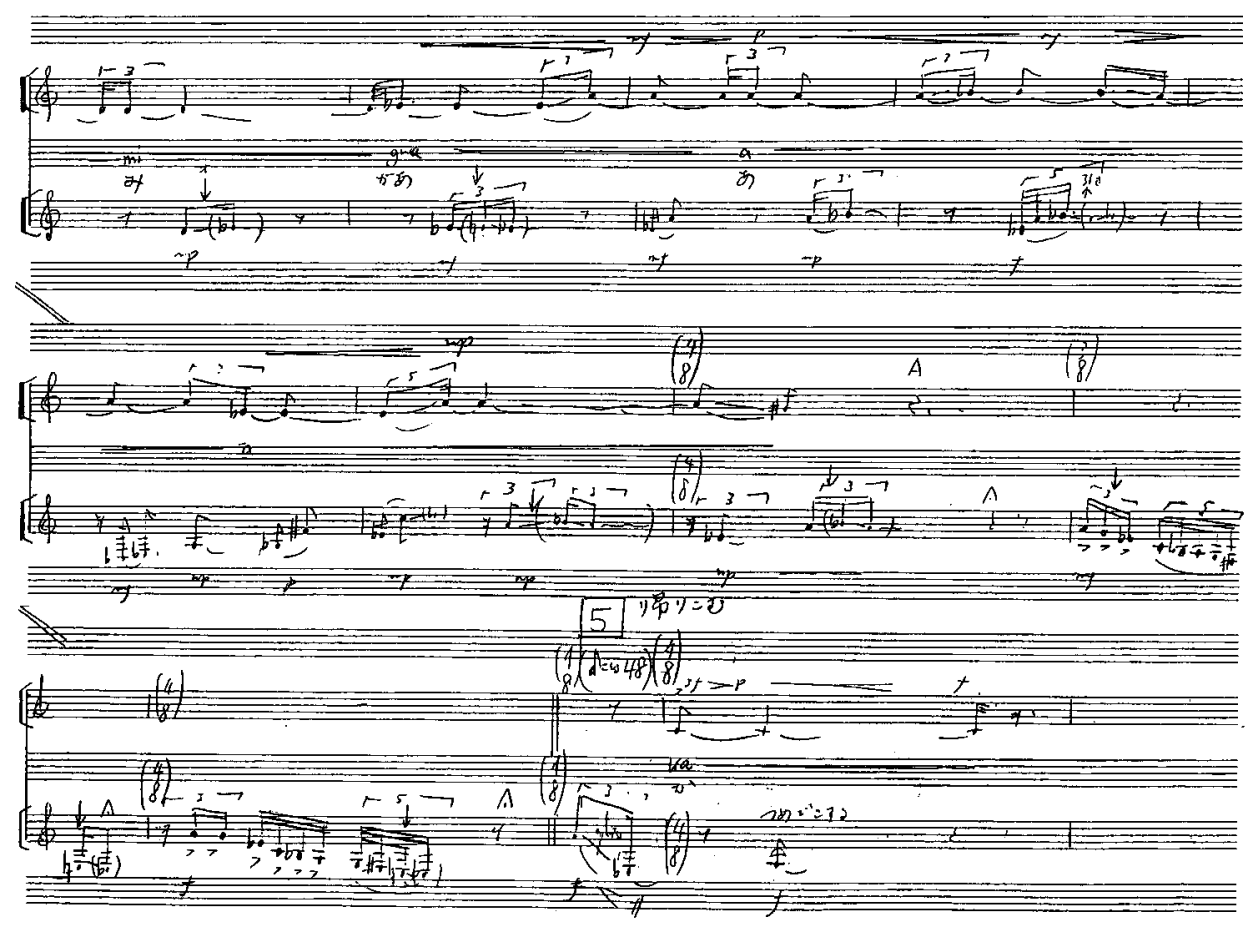

Copyright (c) 1999 by Schott Japan Company Ltd.

to solidify into a "style": the slightly roughened sound surface, for example, is composed with the concept of sawari in mind, which Takemitsu already singled out as a particularly cogent element of traditional Japanese music aesthetics, ${ }^{303}$ and which can be experienced in the buzzing sounds of the shamisen or biwa; at the same time, Hosokawa's sound fields recall the sustained aitake chords of the shō in gagaku $\rightarrow$ IV.1). Sharp "vertical" accents are cut into this smooth surface, analogously to the beats of the otsuzumi drum in no theater, in which the $m a$, that is, the gap between silence and sound, materializes clearly before the beat. ${ }^{304} \mathrm{Ma}$ exists, as it were, in the space between the hands and the drum surface. In short, therefore, Hosokawa aims to convey an abstraction of principles from different Japanese genres with the implicit claim of conveying a "core" of Japanese aesthetics.

In doing so, Hosokawa's works reveal a concept of time that is clearly derived from Japanese traditional music, involving much "blank" space between sound events, be they in the form of static textures, as in Landscape $V$, or complete silence. In his works for Japanese instruments in particular, this results partly in an overt idiomatic proximity to traditional Japanese genres, which is reinforced through collaboration with Japanese performers. In Koto-Uta (1999) for voice and koto, for example, Hosokawa explicitly refers to the traditional koto-kumiuta (vocal suites with koto accompaniment) and tries to imitate their gestures, such as a heterophony be-

303 Takemitsu, "My Perception of Time." See Miyamoto, Klang im Osten, 131-132, Burt, The Music of Tōru Takemitsu, 238-240, Utz, Neue Musik und Interkulturalität, 288-292, and Nuss, "Hearing 'Japanese,' hearing Takemitsu." 304 See Hosokawa's discussion of ma quoted in Utz, Neue Musik und Interkulturalität, 313-314. 
tween voice and instrument as well as a loosely bound musical form (Ex. 3.32) that the composer compares to a walk in a Japanese garden, picking up another metaphor favored by Takemitsu. ${ }^{305}$

It is striking in Hosokawa's conception how he synthesizes Japanese thinking and contemporary Western aesthetics of composition so easily and without conflict. By contrast, Yüji Takahashi's music, which, as shown in Chapter III.4, has also frequently featured Japanese instruments since the late 1980s, develops more critical and "unruly" methods in order to fundamentally oppose both the essentialist Japanese discourse and the standardizing Western discourse. In his works for reconstructed archaic instruments and for shamisen, for example, Takahashi has recreated an imaginary performance practice or imaginary genres by going back to elemental performance movements and instrumental practices $\left(\rightarrow\right.$ III.4; IV.1). ${ }^{306}$ In another concept, he has "overlaid" original traditional music, such as the shamisen and vocal parts of Yamada Kengyō's (1757-1817) classic Nasuno (written around 1800) in Nasuno kasane (Nasuno overlaid, 1997) for shamisen/voice, violin, and piano, which is based on Nasuno ryōjō (Nasuno surrounded, 1992) for shamisen/voice and computer. Takahashi adds extensions, irritations, and inserts around Yamada's original shamisen and vocal lines, and creates a dense simultaneity full of unexpected interrelations (Ex. 3.33). In the instrumental version, the computer part is transcribed for violin and piano. The piano and violin parts are sometimes connected to the original layer, but also proceed independently at times. Wave-like emergence and retreat create a wider perspective on the original, simultaneously expressing closeness and distance.

As discussed earlier, the conceptualization of one's own cultural difference and uniqueness, including gross exaggeration and self-exoticization, has a long tradition in Japan, ${ }^{307}$ and seems inextricably linked to the speed and perfection in the appropriation and consolidation of Western models of civilization in Japanese society since the Meiji restoration of $1868\left(\rightarrow\right.$ I.2, III.1).$^{308}$ Japanese composers were often receptive to these conceptualizations of Japanese culture, so much so that many developed a great interest in Tsunoda Tadanobu's abstruse pseudo-physiological theory of a supposedly "Japanese brain" that would be more receptive to noise-suffused sounds, as represented by the shamisen's or biwa's sawari timbre. ${ }^{309}$ In Japanese modernity, orthodox Japanese aesthetics, with the key concepts of $m a$, sawari, sabi, or yugen, were frequently employed by cultural figures (as in the case of Toshirō Mayuzumi, $\rightarrow$ II.5) for right-wing nationalist political purposes. Takahashi, in contrast, was strongly committed to the left during the 1970 s and 80 s. As a consequence, he increasingly made social communication the subject of his composing, and developed a fundamental compositional critique of this new Japanese culturalism $(\rightarrow$ III.4). Against this background, we can sense that the way in which Japanese composers contributed to the history and techniques of intercultural composition cannot be reduced to simplistic forms of appropriation, but is rather entangled in a web of cross-relations with political and cultural tropes within and beyond discourses on "Japaneseness."

305 Hosokawa, "Koto-uta." See particularly Takemitsu, "Dream and Number."

306 See Takahashi, "Two Statements on Music."

307 See, among others, Hijiya-Kirschnereit, Das Ende der Exotik, 13-16.

308 See Shimada, Grenzgänge-Fremdgänge.

309 Tsunoda, The Japanese Brain. See Nuss, "Hearing 'Japanese,' hearing Takemitsu." 
Example 3.33: Yüji Takahashi, Nasuno kasane, excerpt
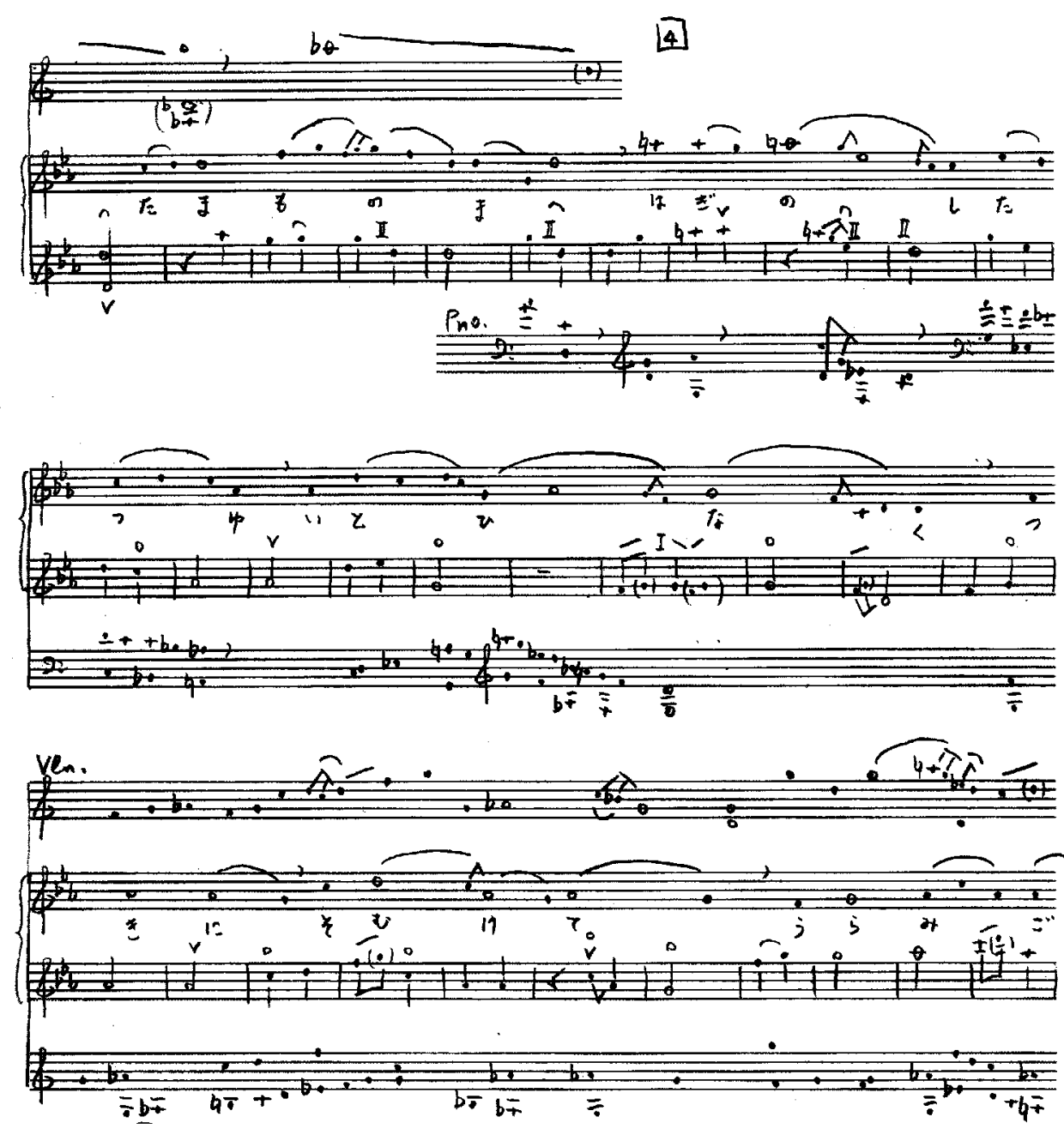

Copyright $\odot 1997$ by Yūji Takahashi, Tokyo

\section{Conclusion: The Limitations of Musical Narrative in an Intercultural Context}

The models of intercultural musical narrativity derived from the analytical snapshots discussed here seem generally plausible at the level of the musical "foreground": we hear "gestural types," 310 which are combined to form a chain of (pseudo-)causalities and thus narrative threads in an intercultural field of tension: tone color fusion or divergence, balanced dialogues or independent monologues, harmonization, conflict, or even aggression between the instrumental or sound groups are comprehensible, and are extrapolated to more general cultural dimensions, often due to a bi- or multi-cultural instrumentation. We derive these mean- 
ings above all from our "extra-opus" experiences with comparable gestural types in other works of Western or Asian music. The extent to which these meanings have to be conveyed or "translated" can hardly be answered in general terms. In our examples, the composers seem to want to ensure that the "gestural" narrative threads that are spun remain largely unequivocal. Yet the objection could be formulated that the semanticizations of musical material through structural abstraction and condensation (Qin Wenchen, Bonu Koo, Eun-Hye Kim), montage (Tan Dun, Zhu Jian'er, Yūji Takahashi), sound-silence enactment (Kunsu Shim, Toshio Hosokawa), or sound-noise boundaries (Chen Xiaoyong) cannot be called interculturally "narrative" to the same extent as purely gestural levels. This is countered by the cognitive principle that listening to music tends to correlate heterogeneous signals in an act of synthesis rather than recognizing a fundamental difference between them. This cognitive reasoning can also be extended to the question of aural-cultural hierarchies: a listening process without the formation of hierarchies between weaker and stronger "signals" is almost unthinkable, a phenomenon that the psychology of music classifies as "salience." While attempts to question cultural hierarchies in most of the works discussed here may be successful at first glance, this cannot prevent the new work, its key events, and its arrangement of sound elements from building new hierarchical environments that obscure the narrative threads of cultural identities to a considerable extent. This raises the question of whether harmonic, tonal, and rhythmic models, which refer to certain listening and intellectual traditions - such as contemporary, classical, traditional or popular Chinese/Korean/Japanese or Western music - do not, in turn, tend to establish new hierarchical discourses of power and exclusion $\rightarrow$ V.3, VI.4).

\section{The Impact of Traditional Music on Composition in Taiwan since the Postwar Period}

\section{The General Conditions of Contemporary Music in Taiwan and the Implications of its Historical Development since 1950}

During the frequently cited "Taiwan Miracle" of the 1970s (called "Ilha Formosa" by Portuguese seafarers in $1583^{311}$ and shaped by a changeable history since then) a huge wave of Westernization hit Taiwan. In light of the previous modernization during Japanese colonial rule (18951945) and under the Western-oriented Guomindang (Kuomintang; Chinese National Party; KMT) since 1945, this "miracle" is mostly described today as a simple consequence of a state-controlled economic infrastructure. ${ }^{312}$ Although there was serious conflict after 1945 between new "immigrants" from mainland China and "Taiwanese" (Han Chinese living in Taiwan before 1945 and their descendants) as well as the aboriginal peoples, the pro-Western attitude of the government was never seriously questioned in Taiwan, and was consolidated by Cold War politics in sharp contrast to the mainland's isolationism during the 1960 s and early 1970s. As a result, American (pop) culture has been especially influential since the beginning of the postwar pe-

311 Weggel, Die Geschichte Taiwans, 5.

312 General representations of Taiwan's history are provided by Weggel, Die Geschichte Taiwans and Rubinstein, Taiwan: A New History. 
riod, not least owing to the specific strained political situation in Taiwan during the Cold War period: its direct and irreconcilable confrontation with the political system of the mainland. ${ }^{313}$

The emphasis on a market economy, the utilitarian direction of government policies, and an all-encompassing business-like lifestyle have sometimes made it difficult for contemporary and traditional Taiwanese arts to prosper. Although a small number of Taiwanese artists - primarily film directors like Hou Hsiao-Hsien (Hou Xiaoxian) and Lee Ang (Li An) or choreographers such as Lin Hwai-Min, and to some extent also writers like Bo Yang and Li Ang - have found appreciation on the international scene, Taiwanese art music has been in a less privileged situation from the beginning. ${ }^{314}$ This is partly due to the difference between performance modes of contemporary music and traditional music in Taiwanese culture (genres of traditional music are mostly of Han Chinese origin), where music generally had a significant social, religious, or spiritual function in daily life. This gap appears to be more significant than the changes between traditional painting, poetry, or prose and their modern, Westernized successors.

Such considerations may shed light on why the visual arts and literature did not have the same problems attracting public interest as new Taiwanese music, despite a general public skepticism toward modernism in the arts during the postwar decades up to the 1990s. Of course, the "isolation" of new music is a social phenomenon that - partly in a targeted manner but partly also exaggerated in some research ${ }^{315}$ - has shaped the situation of advanced music worldwide since 1945, including in the West. And yet some specifics of the situation in Taiwan can be pinpointed, which will become evident in the course of the following discussion.

A first overview of twentieth-century Taiwanese music may be obtained here by listing key proponents of three generations of Taiwanese composers in Table 3.5, which simplifies a division into six generations as outlined in some historical studies. ${ }^{316}$ The composers of the first group (born between 1900 and 1939) brought Western music to Taiwan. In the 1960s and 1970s, some of them were involved in a new exploration of traditional Chinese and Taiwanese music as sources of musical composition and in the founding of basic music institutions. The second group of composers (born between 1940 and 1955) was able to build upon this basic infrastructure, undertaking more comprehensive studies in Europe or the USA, and therefore represented a new kind of "professionalism" that often also extended to traditional non-Western music genres. The composers of the third, and presently largest, group (composers born between 1955 and 1980) have had the most comprehensive formal education, mostly in Taiwan and abroad. Many composers of this generation are predominantly Western-oriented, and a significant incorporation of traditional Asian or other non-Western art forms can be observed only in rare individual cases.

313 A precise analysis of Taiwan's postwar cultural development and cultural influences on Taiwan can be found in Winckler, "Cultural Policy in Postwar Taiwan."

314 For modern Taiwanese literature and film, see Martin, The History of Taiwanese Literature, Martin, Taiwanesische Literatur and Widmer and Wang, From May Fourth to June Fourth: Fiction and Film in Twentieth Century China.

315 See Custodis, Die soziale Isolation der neuen Musik.

316 See Mittler, Dangerous Tunes, 126-268, Hsu, "Republic of China," and Liao, "Héritages culturels et pensée moderne," 307-320. 
Table 3.5: Three generation groups of Taiwanese composers

\begin{tabular}{|c|c|c|}
\hline $\begin{array}{l}\text { Xiao Erhua 蕭而化 (1906-1985) } \\
\text { Chen Sa-Zhi 陳酒治 (1911-1992) } \\
\text { Jiang Wenye 江文也 (1910-1983) } \\
\text { Lu Chuan-Sheng 呂泉生 (1916-2008) } \\
\text { Kuo Chi-Yuan 郭芝苑 (1921-2013) } \\
\text { Shen Bing-Kuang 沈炳光 (1921-2015) } \\
\text { Shi Wei-Liang 史惟亮 (1925-1977) } \\
\text { Hsu Tsang-Houei 許常惠 (1929-2001) } \\
\text { Liu Deyi 劉德義 (1929-1991) } \\
\text { Lu Yen 盧炎 (1930-2008) } \\
\text { Lin Tao-Sheng 林道生 (1934) } \\
\text { Chen Mao-Shuen 陳茂萱 (1936) } \\
\text { Chen Mau-Liang 陳禁良 (1937-1997) } \\
\text { Hou Chun-Ching 侯俊慶 (1938) } \\
\text { Ma Shui-Long 馬水龍 (1939-2015) }\end{array}$ & $\begin{array}{l}\text { Shen Chin-Tang 沈錦堂 (1940-2016) } \\
\text { Hsu Sung-Rung 徐松榮 (1941-2012) } \\
\text { Lee Tai-Hsiang 李泰祥 (1941-2014) } \\
\text { You Chang-Fa 游昌發 (1942) } \\
\text { Dai Hong-Hsuan 戴洪軒 (1942-1994) } \\
\text { Lai Deh-Ho 賴德和 (1943) } \\
\text { Wen Long-Hsin 溫隆信 (1944) } \\
\text { Hsu Po-Yun 許博允 (1944) } \\
\text { Pan Hwang-Long 潘皇龍 (1945) } \\
\text { Tzeng Shing-Kwei 曾興鬼 (1946) } \\
\text { Chien Nan-Chang 錢南章 (1948) } \\
\text { Wu Ting-Lien 吳丁連 (1950) } \\
\text { Wu Yuan-Fang 吳源鈁 (1952) } \\
\text { Yang Tsung-Hsien 楊聰賢 (1952) } \\
\text { Chien Shan-Hua 錢善華 (1954) }\end{array}$ & $\begin{array}{l}\text { Pan Shyh-Ji 潘世姬 (1957) } \\
\text { Chung Yiu-Kwong 鍾耀光 (1957) } \\
\text { Chin Shi-Wen 金希文(1957) } \\
\text { Lu Wen-Tze 呂文慈 (1962) } \\
\text { Wang Ming 王䓬 (1963) } \\
\text { Du Wen-Huei 杜文惠 (1964) } \\
\text { Wang Sue-Ya 王思雅 (1965) } \\
\text { Lee Tzyy-Sheng 李子聲 (1965) } \\
\text { Tung Chao-Ming 董眧民 (1969) } \\
\text { Chen Yu-Chou 陳俞州 (1970) } \\
\text { Lee Chih-Chun 李志純 (1970) } \\
\text { Chao Ching-Wen 趙菁文 (1973) } \\
\text { Shih Pei-Yu 石佩玉 (1973) } \\
\text { Liao Lin-Ni 廖琳妮 (1977) } \\
\text { Li Yuan-Chen 李元貞 (1980) }\end{array}$ \\
\hline
\end{tabular}

Although the history of Western-influenced Taiwanese music certainly began early in the twentieth century during Japanese colonization, one can probably only speak of "new music" in Taiwan from the late 1960 s onwards. ${ }^{317}$ Its early key figure is Hsu Tsang-Houei (1929-2001), who returned from his studies in Paris in 1959 and quickly became the defining personality of Taiwanese musical life. In Taiwan, the 1950s were long regarded as a "lost decade" in terms of cultural development which, of course, might also be said of developments in China and other Asian countries to some extent; the polemical term of the "cultural desert" (wenhua shamo) was only later included in the public discussion, ${ }^{318}$ but dates from this period.

The activities of Hsu Tsang-Houei, who had studied in Paris with André Jolivet and Olivier Messiaen (1954-59), were decisive for the establishment of a Taiwanese musical identity. Deux Poèmes for soprano and chamber ensemble op. 5, which Hsu wrote in 1958 while still studying in Paris, demonstrates this search for an identity between Japanese, Chinese, and French cultures through the use of texts by a Chinese and a Japanese poet (Chen Xiaoxi and Yumiko Takada). The polymodal structure in the second song "En revenant de la mer, hier" (Zuori haishang lai / Kinō umi kara) is, given the tabula rasa in Taiwan's modern music at that point, a daring experiment that can be traced back to Messiaen's polymodal techniques. The soloist is entwined with a fluctuating modal network in the string quartet.

That even such a "soft" modernism led to some small scandals in the early 1960 s (see below) demonstrates that Taiwan had, at that point, hardly been touched by modernist thought. Hsu subsequently gave decisive impulses for younger composers by organizing groups of compo-

317 For basic studies on the history of Taiwan's twentieth-century music, see Mittler, Dangerous Tunes, 187-229, Mittler, "Mirrors and Double Mirrors," Liu, A Critical History of New Music in China, 545-566, Lee, "Taiwan" ["IV. Musikpflege seit dem Ende des 19. Jahrhunderts"], Han, "4. Western art music," Chang, "Taiwan 'xiandai yinyue' 1945-1995," Hsu, Taiwan yinyueshi chugao, Lü, Taiwan yinyueshi, 149-207, 497-517, and especially Liao, "Héritages culturels et pensée moderne."

318 The writer Chen Ruoxi coined this polemical formulation in the 1960 s before she remigrated to China during the Cultural Revolution (Martin, Taiwanesische Literatur, 55). It was already widespread in the 1950s, however (Winckler, "Cultural Policy in Postwar Taiwan," 31). 
sers based on the Japanese model and establishing a Taiwanese ethnomusicology. The composers' groups were based on similar alliances of young Taiwanese painters such as Dongfang huahui (Eastern Painters) or Wu yue huahui (Painters of May). The most important composers' groups emerging in this period were Zhi yue xiao ji (Composers' Forum, 1961-72), Wu ren yueji (Five-Man Music Group, 1965-67), Xin yue chu zou (Music Premiere, 1961-62), Jianglan yueji (Jianglang Music Group, 1963-65), and Xiangrikui yuehui (Sunflower Group, 1968-71). Above all, the Composers' Forum enabled younger composers to present their works to a limited public in the 1960s and early 1970s. The music composed, however, was still largely defined by a Romantic orchestral and song style seasoned with pentatonicism, oriented toward the prewar styles of composers such as Xiao Youmei (1884-1940) and Huang Zi (1904-1938), which had been “imported" by mainland Chinese musicians in 1949. ${ }^{319}$

How sustainable the artistic and institutional development of the 1960s was can be measured by a comparison to works of the early 1970s. Efforts to forge links with local traditions played an increasingly important part during the 1960s. An important prerequisite for these new links was the fieldwork conducted by the composers Hsu Tsang-Houei and Shi WeiLiang (1925-1977) in 1966/67. Their work was part of the Minge caiji yundong ("Folk Song Collection Movement"), which placed a special focus on the music of indigenous peoples for the first time since Japanese colonial rule. Hsu's ongoing influence as a teacher at the National Taiwan Normal University (Guoli Shifan Daxue) and Shi's founding of the Xiandai yuefu (Modern Music Bureau) in 1973, which aimed to combine traditional and contemporary music, were crucial for promoting these activities further. ${ }^{320}$ The Xiandai yuefu - established while Shi was conductor of the Taiwan Provincial Symphony Orchestra (Taiwan sheng jiaoxiang yuetuan) and named after the famous music department at the Chinese imperial court of the Han Dynasty (206 BCE-220 CE) - explicitly encouraged Chinese and Taiwanese to incorporate musical traditions into the compositional process. Although the music performed by the Xiandai yuefu probably did not depart much from the more conservative style of the time, ${ }^{321}$ it had some impact on subsequent developments: it served as one of the starting points for the choreographer Lin Hwai-Min (b. 1947) to found his dance troupe Cloud Gate Theater (Yunmen wuji) at the end of $1973 .{ }^{322}$ In the following years, the dance productions of this group made it possible for a small avant-garde around composers such as Lee Tai-Hsiang (1941-2014) and Hsu Po-Yun (b. 1944) to perform larger-scale works at a time when such opportunities were still very limited.

The more experimental spirit of this period was supported not least by the rise of Xiangtu wenxue (Nativist Literature), ${ }^{323}$ which called for a reflection on a local Taiwanese identity follow-

319 Chang, "Taiwan 'xiandai yinyue' 1945-1995," 390. On Xiao Youmei and Huang Zi see Melvin and Cai, Rhapsody in Red, 92-115.

320 Shi Wei-Liang returned to Taiwan in 1966 from studies in Vienna and Stuttgart. Hsu's and Shi's efforts to document Taiwanese folk songs were initially supported privately by Fan Chi-Yun, as the government had refused to fund the project (Mittler, Dangerous Tunes, 192). Hsu and Shi founded the Society for Chinese Folk Music Research (Zhongguo minzu yinyue yanjiushe) in 1967 and subsequently collected more than 2,000 songs (Chang, "Taiwan 'xiandai yinyue' 1945-1995," 394-395). A course in ethnomusicology was first established at Donghai University in 1971.

321 Criticism of the Xiandai yuefu's first concert in July 1973 is mentioned in You, "Taiwan jin sanshi nian 'xiandai yinyue' fazhan," 94 and Mittler, Dangerous Tunes, 201-202. You also provides general information on the Xiandai yuefu ("Taiwan jin sanshi nian 'xiandai yinyue' fazhan," 91-102).

322 Chang, "Taiwan 'xiandai yinyue' 1945-1995," 395.

323 See Martin, Taiwanesische Literatur. 
ing the "Nixon Shock" in 1971 and the exclusion of Taiwan from the United Nations. For this reason, a distinction between Western and Chinese cultural models was increasingly sought. Writers such as Wang Tuoh (1944-2016) and Huang Chun-Ming (b. 1935) opposed the repression of the authoritarian KMT and developed an aesthetic alternative to the conservative "Cultural Renewal Movement" (Wenhua fuxing yundong) of the KMT government from 1966 and the restrictive cultural policy of the 1960s. Yet other groups, such as the Cloud Gate Dance Theater, tried to counteract polarization by highlighting similarities between archaic Chinese and contemporary Taiwanese culture.

In the realm of art music, however, it seems that the impact of the xiangtu movement was not as marked as is sometimes assumed. References to "indigenous" Taiwanese culture (as opposed to Mainland Chinese and Western culture) in compositions dating from the 1970s are very rare. Instead, there are frequent references to the legacy of (mainland) Chinese culture, most often to its much-revered archaic periods (for example, in Hsu Po-Yun's Han shi or in Lee Tai-Hsiang's Da shenji, see below). This tendency was partly due to the specific topics selected by Cloud Gate and other performance groups, which did, however, occasionally include more specific Taiwanese themes as well. ${ }^{324}$ On the threshold of songwriter and pop culture, by contrast, "root-seeking" led to a new wave of songs sung in the Taiwanese dialect that became very popular.

In any case, music in Taiwan was certainly a political matter during the 1970s. In particular, the use of folk songs from both China (suspected of communist sympathy) and Taiwan (interpretable as support for Taiwanese independence) was viewed with suspicion by the powerful. The Yayin opera group, which had set itself the goal of reforming Beijing Opera, was accused of imitating the model works of the Chinese Cultural Revolution. ${ }^{325}$ But the nervous energy that was set free at that time (peaking after the Formosa incident in $1979^{326}$ ) and the increasingly open criticism of authoritarian governmental rule had some effects on contemporary music. Among the results were the performance series New Environment of Asian Music (Yazhou yinyue de xin huanjing) by Hsu Po-Yun in 1977, and the Tradition and Prospect concert series (Chuantong yu zhanwang, 1978-90) organized by Lee Tai-Hsiang.

The establishment of state and private music institutions in the 1980 s was a sign of increasing cultural responsibility and prosperity, which, however, did not necessarily improve the situation of new music immediately. These included the State Council of Cultural Planning and Development (CCPD, 1982; today Council for Cultural Affairs; ${ }^{327}$ cultural agendas had previously been taken over by the Ministry of Education), the National Institute of the Arts (Guoli yishu xueyuan, 1982; today: Taibei yishu daxue/Taipei National University of the Arts), the National Cultural Center (1987), and the Taiwanese section of the ISCM (International Society for Contemporary Music), founded in 1989 by Pan Hwang-Long (b. 1945, see below). The National

324 Chang, "Taiwan 'xiandai yinyue' 1945-1995," 394-395.

325 Mittler, Dangerous Tunes, 191.

326 The "Formosa incident," also known as the "Kaohsiung incident," refers to events that occurred in 1979 as a result of a demonstration by the non-partisan political opposition (dangwai). Activists from the dangwai-founded Formosa magazine in May 1979 and demonstrated against martial law and human rights violations on International Human Rights Day (10/12/1979). Three days after this demonstration, 152 exponents of the dangwai movement were arrested, including many of the later leaders of the DPP (Democratic Progressive Party); see Weggel, Die Geschichte Taiwans 205-207 as well as Reinhardt, Politische Opposition in Taiwan 1947-1988.

327 The Council of Cultural Affairs consists of a number of foundations, of which the National Culture and Arts Foundation (Guojia wenhua yishu jijinhui) is the most important. 
Concert Hall and the National Theater, representative new buildings in traditional Chinese architecture in the center of the capital Taipei, were opened in 1987, although at first they did not provide sufficient programming or audience attractions. ${ }^{328}$ While new radio programs and a growing number of composition commissions were beginning to stabilize the situation of new art music in the late 1980s, it remained socially marginalized.

\section{Problems of Taiwanese Cultural Identity and the Two-Pronged Discourse of Traditional and Contemporary Music}

This brief historical survey shows that the question of cultural identity has played an important part for most Taiwanese artists from the beginning, and that it has done so in various distinct ways. This question is charged with tensions for a number of reasons. On the one hand, they result from the mingling of ethnic and social groups in Taiwan, including the aboriginal peoples of Austronesian origin (yuanzhumin), the "Taiwanese" (Han people who lived in Taiwan before 1945), the "Chinese" (Mainland Chinese who moved to Taiwan from 1945 on, a large number of them - around one million - in 1949, along with Chiang Kai-Chek's troops, who fled communist troops after their defeat in the civil war), and the Hakka (Kejia). While the specific identity and unique traits of the aboriginal and Hakka minorities (often more in theory than in fact) has become largely accepted, the conflict between "Taiwanese" and "Chinese" groups is unresolved, dating back to the "228-incident" of 1947, in which more than 10,000 native Taiwanese were killed by Chinese forces. ${ }^{329}$ Subsequently, there have been decades of authoritarian repression of a specific Taiwanese culture and language by the KMT government, which ruled solely by "martial law" for 38 years, from 18 May 1949 to 14 July 1987. Although there seem to be signs of reconciliation, this conflict still cuts across Taiwanese society today and considerably complicates the question of Taiwanese identity, primarily because of its instrumentalization by political parties, regularly fueled by the mainland's "One-China policy" and threats to occupy Taiwan by military force.

It is clear that against this background, anyone who seeks to define "traditional music" encounters difficulties. Overviews make it clear that, with the exception of the music of the indigenous groups, which has caused a stir in the field of ethnomusicology at least since the copyright lawsuit against the pop group Enigma, ${ }^{330}$ all music genres practiced in Taiwan have come from mainland China at some point over the centuries. Of course, genres such as beiguan, nanguan, gezaixi (Taiwanese Opera), or jingju (Beijing Opera) have developed quite differently from their mainland counterparts during the past 70 years; one could surely argue that the way they are performed now is "typically" Taiwanese. The above-mentioned problems of social marginalization, however, equally apply to most forms of traditional music: they do not fit into the economically dominated Taiwanese society, and their future as part of a Taiwanese identity therefore is not secure at all. It is also unclear whether the growing institutionalization of traditional music can counteract this or is rather part of this marginalization process.

Against this background, one might assume that new art music and traditional music in Taiwan, in their incommensurability and alterity in relation to processes in society and to in-

328 Mittler, Dangerous Tunes, 196.

329 Weggel, Die Geschichte Taiwans, 95-98. Under the government of the Democratic Progressive Party (DPP) and President Chen Shui-Bian (2000-2008), 28 February was declared a national holiday and a culture of remembrance began to establish a collective memory of this event.

330 See more detail in Utz, Neue Musik und Interkulturalität, 33-38. 
dustrially marketed music forms, perform the critical function of a counterdiscourse. It must be taken into account here, of course, that a "pure" or "authentic" form cannot be constructed in either area, but that both - together with their more popular variants - are involved in a process of continued recontextualization and reinterpretation of musical-cultural artifacts, and they inevitably, owing to their institutionalization, ${ }^{331}$ interact with societal processes as a whole. Mixed forms in particular are often under commercial pressure, and thus create a broad forum for, for example, aesthetically questionable arrangements of traditional music in a neo-Romantic guise, as evident from the tradition of the Chinese orchestra since its inception $(\rightarrow$ III.1).

Baldly "conservative" arguments from both areas of course fall short. One cannot "preserve" a local performance tradition or a self-referential avant-garde idiom, because neither ever existed in a pure form. The advice to return to one's "roots" and to study one's "own" traditions was thus only sporadic among the composers born in the 1950 s - a skepticism toward any form of instrumentalization of "tradition" prevailed as, in Taiwan, this term had been used too often as a nostalgic reminder of the Chinese "motherland" during the decades of the Cold War.

Against this background, it becomes clear that aesthetically independent art music can only be produced in this situation by a small avant-garde, which ultimately frees itself to some degree from local cultural-political and market-oriented needs without having to pay homage to an illusory concept of musical autonomy. Although the term "avant-garde" was dismissed in an earlier chapter of this book ( $\rightarrow$ II.1), it may have a certain relevance to the situation in Taiwan in the 1970s if one steps back to some degree from its transnational contexts: the term can be used to describe a form of musical creativity that self-confidently emancipates from dominant cultural discourses, a kind of creativity that - though often with limited international impact - eloquently challenges the global dominance of Western music as well as simplified forms of nationalist or folkloristic aesthetics.

\section{Taiwan's Small Avant-Garde During the 1970s and After - The Works of Lee Tai-Hsiang, Hsu Po-Yun, and Pan Hwang-Long}

Undoubtedly, some of the most remarkable connections between new and traditional music emerged in Taiwan during the 1970s, though this phase should certainly not be idealized, ${ }^{332}$ as the avant-garde achievements in this period faced massive social resistance, even among composer colleagues. I will examine the paradigmatic developments of Lee Tai-Hsiang, Hsu Po-Yun, and Pan Hwang-Long, who all began their careers in the 1970s. Despite their very different backgrounds, some of their works share the quality of exposing traces of the historical moment in a special way in their sound structures.

For Lee Tai-Hsiang, ${ }^{333}$ a member of the aboriginal Ami people, his relationship to the bentu culture, the local culture of Taiwan, has evidently been of great importance from the outset.

331 See ibid., 31-33.

332 Chang Chi-Jen's excellent investigation (Chang, "Taiwan 'xiandai yinyue' 1945-1995") sometimes tends to do this.

333 Basic information in this section comes from an in-depth personal conversation between the author and Lee Tai-Hsiang in Taipei (23/05/2000). An extensive biographical presentation in Chinese appeared in 2002 : Chiou, Li Taixiang. For Lee Tai-Hsiang see also Mittler, "Mirrors and Double Mirrors," 16-17, Mittler, Dangerous Tunes, 205-213, Mittler, "Li Taixiang," Ka, "Gaoshan liushui," and You, "Taiwan jin sanshi nian 'xiandai yinyue' fazhan," 48-49, 157-165. Extensive information and documents about Lee are available as part of the National 
Although his family moved from Taidong to Taipei when he was only four years old, he regularly met gezaixi and budaixi (puppet show) performers, and their sounds and language formed a natural part of his childhood's acoustic environment. Western music dominated his youth: he was a talented violin player and received early support from his teacher Chen Ching-Gang. After graduation he became concertmaster of the Taipei Symphony, and from 1969 to 1971 he was conductor of the Taiwan sheng jiaoxiang yuetuan (Taiwan Provincial Symphony Orchestra).

Only when he was 17 years old did he return to Taidong and consciously listen to Ami music. At that time, he also entered the National Academy of the Arts (Guoli yishu zhuanke xuexiao, today named Guoli Taiwan yishu daxue/National Taiwan University of the Arts) to study printmaking and, later, composition. His earliest compositions were stylistic copies of Corelli, Mozart, Schubert, and Brahms. In 1964 he had a crucial encounter with Hsu Tsang-Houei, who essentially told him two things: first, he should draw his music from his own origins; second, his music should be "much newer... even newer than Bartók."334 As a result, Lee's series of works Long $W u$ (1970-72) was written for various Chinese instruments, a first, still quite simple attempt to use these traditional "sound media." A more mature step to incorporate traditional elements can be found in the short piano trio Yunxing sanbian (Evolution: Three Chapters), composed in 1971 and later integrated into a performance at the Cloud Gate Theater. ${ }^{335}$ The work captivates the listener with the multitude of extended, "performative" playing techniques (playing inside the piano, beating and scratching the strings, "toneless" sounds, etc.), which were a novelty in the Taiwanese context. The fact that Lee tried to combine these techniques with an adaptation of the luogu dianzi patterns from the Beijing Opera drum ensemble (wuchang) $)^{336}(\rightarrow$ III.4) shows how consciously he was striving at the time for a synthesis of Western avant-garde and Chinese tradition. In the third part of the trio (Ex. 3.34), Lee develops a pattern based on the sequence of jingju percussive syllables cang (a firm beat on the daluo large gong, xiaoluo small gong, and ba cymbals) and qi (a firm clash of the cymbals), transformed into repeated chords (piano, later violin) and structured by irregular accents from the other instruments.

While Lee associated the scattered sounds produced by extended playing techniques with the calligraphic principle of liu bai (white space within and between the drawn lines is considered the essence of the calligraphic artwork), the melodic design in the first movement (Ex. 3.35) suggests the vocal inflections of Beijing Opera's spoken and frequently sliding vocal style yunbai $\rightarrow$ V.1).

Lee's trio can be described as a remarkable experiment considering the historical situation in which it appeared. The time from 1973 to 1975 was decisive for Lee's musical development. He developed his principal aesthetic ideas based on a unique combination of American-influenced experimental art and traditional Chinese philosophy. Supported by a grant from the Rockefeller Foundation in 1973/74, Lee delved into the experimental approach during a stay at the Center for Music Experiment (CME) at the University of California, San Diego, which was founded in 1972 and directed by Roger Reynolds from 1972 to $1975 .{ }^{337}$ Here, Lee took part in weekly rehear-

Digital Archives Program, Taiwan: http://lth.e-lib.nctu.edu.tw/en/bio-1.htm. See also http://musiciantw.ncfta. gov.tw/list.aspx?c=4\&p=Mo20 and http://baike.baidu.com/view/1107817.htm. 
Example 3.34: Lee Tai-Hsiang, Yunxing sanbian, III, staff systems 1-2

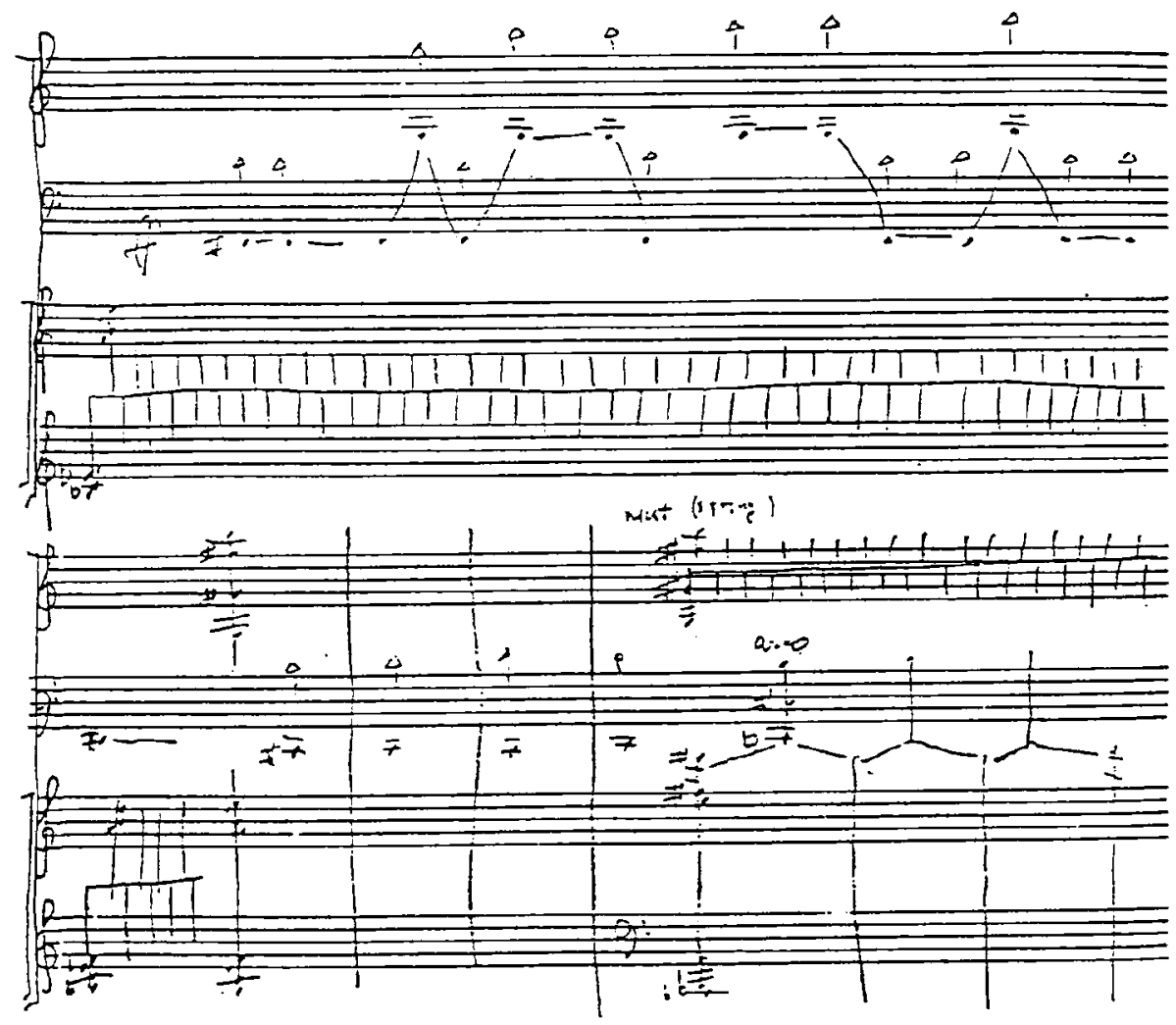

Example 3.35: Lee Tai-Hsiang, Yunxing sanbian, I, staff system 6

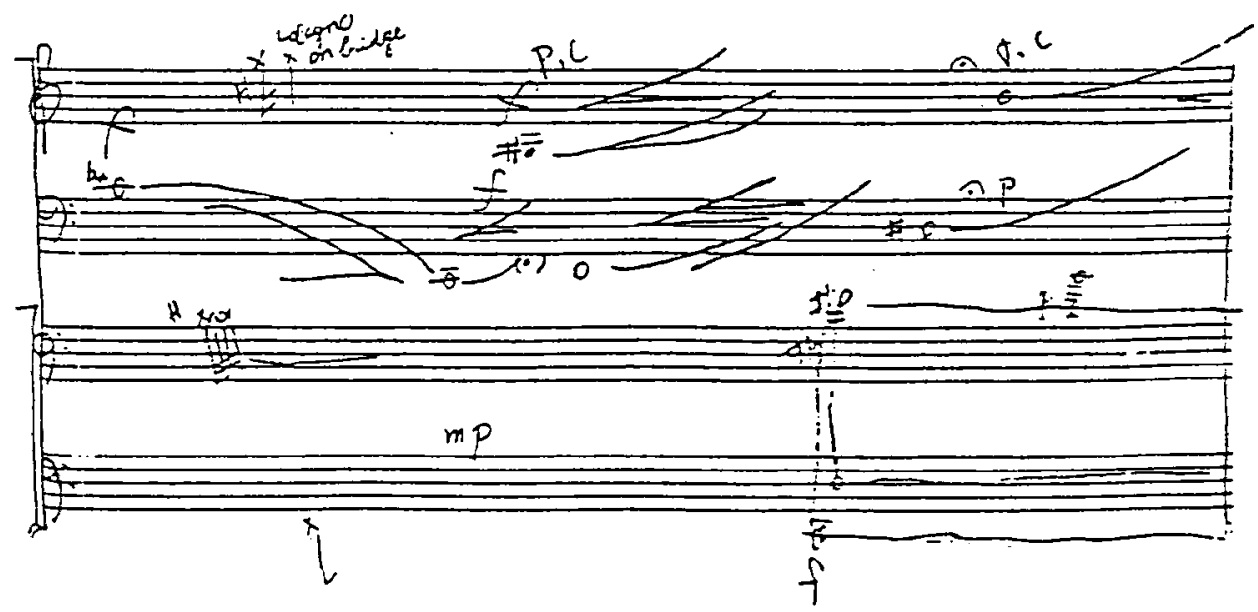

Copyright (c) 1973 by Lee Tai-Hsiang, Taipei 
sals and performances of new works, including his own, and, in line with the trend of the time, dealt with electronic music, Indian and Tibetan music, meditation, dance, photography, and multimedia performance concepts.

In linking these impressions back to the terminology of the Chinese philosophical tradition, he developed a compositional approach that he characterized with the terms kenengxing (potentiality), budingxing (indeterminacy), and kebianxing (variability). Another key experience was reading an article by the Japanese composer and pianist Yüji Takahashi $(\rightarrow$ III.4) that Lee said he read in Time in December $1974 .{ }^{338}$ Takahashi's article made him realize that he was looking for an "abstraction" of his own tradition, that the coloristic representation of tradition, criticized by Takahashi, also appeared to be unsatisfactory and insufficient to him. Lee believed that Chinese or Japanese instruments should not be used because of their special "color" or by simply transferring modern playing techniques originally developed for Western in-struments onto them; rather, he insisted that composers truly appreciate them and study their proper traditions. Lee saw the particularities of Chinese elements in the fact that they are able to express the aesthetic concepts of yun (rhyme, phrase, inflection) and kongjian (empty space), so that they ultimately lead to $x u$ yin (empty sound), to silence. Yun finds its most concrete manifestation in the ideal of a steadily changing pitch and tone color inherent in almost all genres of Chinese music. The "music of the void" meanwhile serves as the foundation on which all "real, continuous sounds" (shi yin) rest, and they must therefore be perceived as symbols of cosmic forces. The idea that all sounds, or basically all acoustic phenomena, are a representation of a natural cosmic principle according to Lee was a crucial key to understanding the Chinese perception of music, especially as transmitted in Daoist aesthetics.

Yu - Chan - Ximen ding (Rain - Zen - Ximen Market, 1975), Da Shenji (Great Ritual, 1975), and Taixuyin (Sound of the Great Void, 1979/97), Lee Tai-Hsiang's key works of the 1970s, probably represent his most successful and ambitious attempts to synthesize these two major starting points, the experimental avant-garde and Daoist thought. Yu-Chan-Ximen ding is a rare example of Taiwanese musique concrète, and accentuates dynamic and atmospheric contrasts by combining silence in the second movement ("Zen") with the noisy acoustic environment of Taipei's Ximen district in the third. The piece caused confusion in the audience at the eventful Taipei performance of 1975, shortly after Lee's return from the USA, featuring four tape machines, two vocalists, and also the illustration of rain (first movement) by throwing torn-up newspapers into the audience. ${ }^{339}$

The large-scale work Da Shenji was commissioned by the Cloud Gate Dance Theater for the production Wu Feng (1976). It clearly shows Lee's engagement with American minimalism: the "gamelan-like" instrumentation and structure overlaps ostinati of different lengths, which are based on different basic time values (Ex. 3.36).

While the dominance of the percussion ensemble and the mostly "shouting" voices establish a general "tribal" atmosphere, the interlocked dialogues of solo voices and choir, with their fre-

Extended Vocal Techniques Ensemble (EVTE), and the KIVA Improvisation Ensemble were founded. In 1977, a department for computer music was opened under the direction of Pauline Oliveros. See https://library.ucsd. edu/dc/collection/bb10936072.

338 Personal communication with the author, Taipei, 23/5/2000. Takahashi had returned to Japan from a nine-year stay in the USA, where he had contact with Roger Reynolds, among others, and Europe. During this period, Takahashi edited the magazine TransSonic (1974-76). I was unable to verify the article in Time. 
Example 3.36: Lee Tai-Hsiang, Da Shenji, II, Chengren li (Initiation Ritual), mm. 37-45

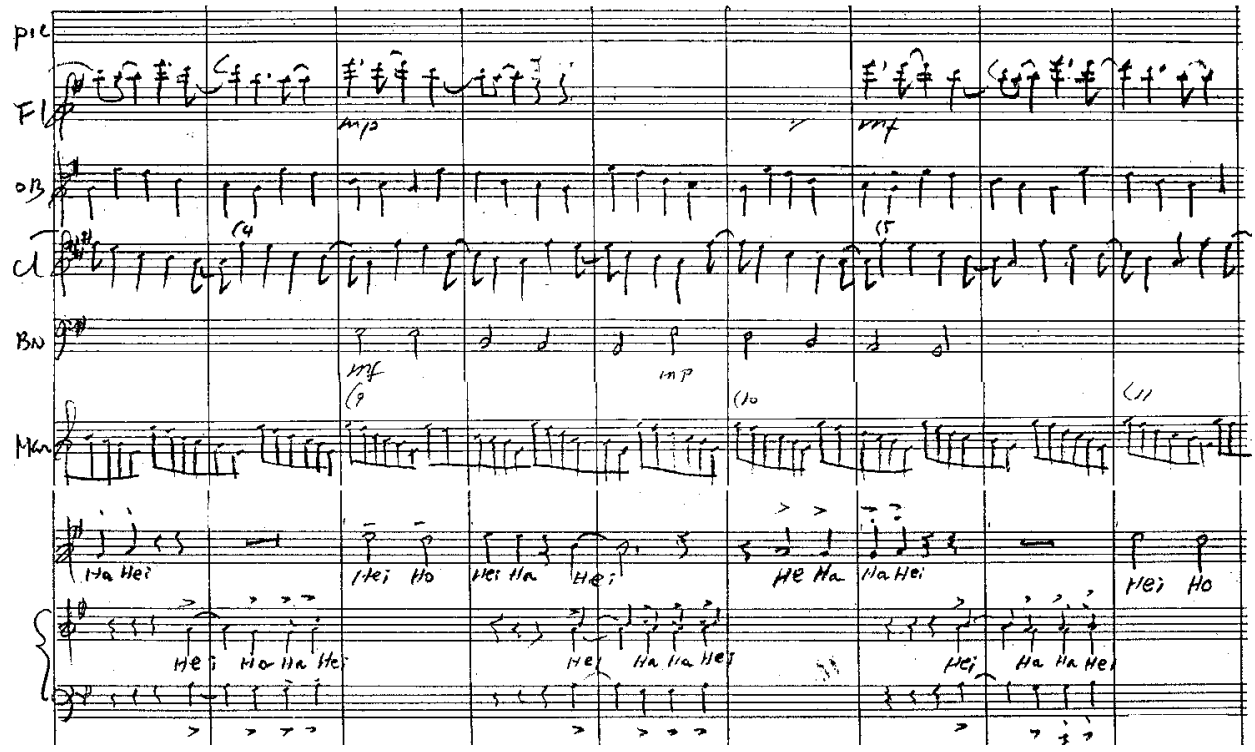

Copyright (c) 1986 by Lee Tai-Hsiang, Taipei

Example 3.37: Lee Tai-Hsiang, Da Shenji, III, Qi ge (Worship), voices, mm. 55-63

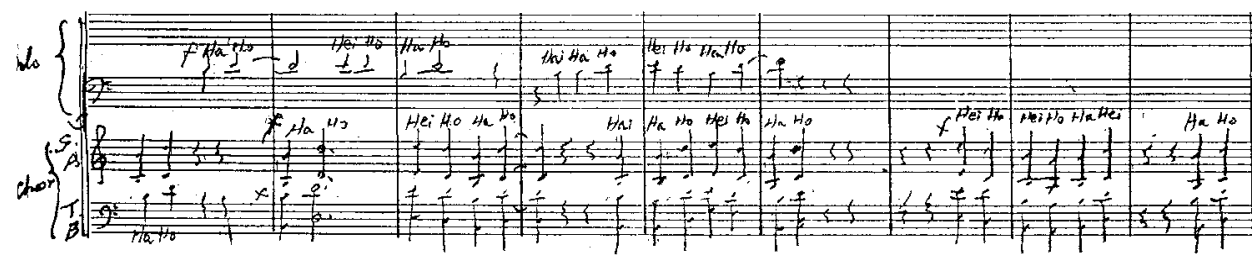

Copyright (c) 1986 by Lee Tai-Hsiang, Taipei

quently skipping and sliding qualities, demonstrate Lee's attempt to incorporate structures from Ami music in the third movement (Ex. 3.37).

Lee Tai-Hsiang's scores often resemble sketches; Taixuyin (1979) mainly consists of graphic notation and verbal instructions, which also relate to choreographic elements. The beginning of the work creates vocal sound from breath and buzzing noises. ${ }^{340}$ Performers of Lee Tai-Hsiang's music confirm that his works develop progressively during rehearsals, even when there is a more fixed score at the beginning.

The predominance of minimalist patterns in Da Shenji and Taixuyin can probably be linked to the choreography of the Cloud Gate Dance Theater. These influences make Barbara Mittler's claim that Lee "incorporated" ${ }^{\text {"34 }}$ Ami music in these works rather questionable. The music of the

340 See Mittler, "Mirrors and Double Mirrors," 17.

341 Ibid., 16. 
Ami actually contains few repetitive patterns and is characterized by its free and complex form of polyphony, which hardly allows for such minimalist music to be derived from it. ${ }^{342}$ Lee himself admitted that the Ami influence is not substantial in these works. He felt that it is much more difficult to synthesize Ami tradition and Western composition than to synthesize Chinese and Western aesthetics. There is no doubt, however, that something of the "atmosphere" of Ami music is preserved in Lee's thinking and musical writing, as the introductory text for the second part of Taixuyin (1997) puts it:

This composition is fundamentally an enormous song.

The expression of the song consists of linguistic linearity, aboriginal singing, and various expressions progressing in different patterns.

This work originates in Chinese literature and painting, with the music flowing endlessly like a landscape and the calligraphic strokes in a Chinese art masterpiece.

The composition is based on the structure of movement, and there are no architectural limits or frames of reference. It describes the continuous movement of airflow and the phenomena of self-preservation and self-destruction; the longer the performance, the larger the composition.

It describes relativity rather than absoluteness.

The audience is welcome to participate during the performance.

If more elements are added in each performance, the outcome... ${ }^{343}$

Lee also realized similar projects in cooperation with the American percussionist Michael Ranta (b. 1942), who had worked with Karlheinz Stockhausen, Jean-Claude Eloy, and Helmut Lachenmann, and lived in Taiwan for seven years (1973-79). ${ }^{344}$ Ranta subsequently invited Lee Tai-Hsiang to Germany, where Lee participated in a concert in Vlotho in October 1979 and realized Huanjing san zhang (Three Fantasy Landscapes, 1979) for voices, Chinese instruments, and percussion together with Ranta. ${ }^{345}$

Lee had already begun writing pop songs in the mid-1960s to "change the atmosphere in society," to "raise the level of popular music," and to "build a bridge to serious music." ${ }^{346}$ In these pop songs, which can be seen as part of a "songwriter movement" at Taiwanese universities, there is now a much more conscious construction of local Taiwanese identity. In the 1970s, some of these songs caused political controversy, for example because Lee used the image of the sun in Yi tiao riguang dadao (A Sunbeam Path into the Future), which was heavily loaded as a symbol of China's Mao Zedong propaganda. ${ }^{347}$ His most famous song Ganlanshu (Olive Tree,

342 Loh, "Tribal Music of Taiwan," offers a fundamental study of Ami music.

343 Lee Tai-Hsiang, program booklet, March 1998; Lee Tai-Hsiang Private Archives, translation by the author.

344 See Ranta, "Zeitgenössische Musik in Ostasien - vier Regionen," 38-39, 42-44.

345 A recording of the third movement was published on the LP Weltmusik - Resonanz (Feedback; Telefunken / Decca 1980).

$346 \mathrm{Ka}$, "Gaoshan liushui," 2-3. Translated by the author.

347 Mittler, "Mirrors and Double Mirrors," 16. 
1976) was criticized for its "nonaffirmative" language. ${ }^{348}$ Even if the boundaries between Lee's pop songs and his "serious" music seemed to be largely blurred, the shift toward songwriting led to a significant decline in Lee's avant-garde compositions. Lee, who never held an academic position, justified this change not least by economic necessity, which was also reflected in his activities as a film music composer. ${ }^{349}$

Hsu Po-Yun ${ }^{350}$ grew up in a cosmopolitan environment and was involved in internationally oriented cultural-political activities early on. He was active in the composers' groups of the 1960 s and founded a number of cultural organizations, in particular the New Aspect Cultural and Educational Foundation (Xin xiang wenjiao jijinhui, 1978); he was also involved in the founding of the Asian Composers League (ACL) in 1973 in Hong Kong together with Hsu TsangHouei and four other composers from Taiwan. He has traveled extensively within Asia since the early 1970s. Against this background, his tendency toward pan-Asian aesthetics takes on a clear autobiographical dimension.

Hsu Po-Yun's works, like those of Lee Tai-Hsiang, require a close form of collaboration between the composer and performer; in contrast to the precision of serial or postserial scores, the often sketch-like design usually leaves some room for interpretation, which should of course be "culturally informed." Against this background, Hsu inserted a variety of references to Asian vocal models, including details that are rendered in a precisely notated approximation, for example by molding the speech melody meticulously with graphic lines (see Ex. 3.39). It is characteristic that the identity conflict for Hsu, who was born in Japan and became acquainted with different musical traditions in Asia at an early age, resolves itself in a decidedly hybrid conception. As sources of inspiration for his vocal style - which he also transfers to the instrumental level - he names Beijing Opera (his father was in close contact with the legendary Beijing Opera actor Mei Lanfang), the local Taiwanese genres beiguan and nanguan, the Japanese $n \bar{o}$ theater, Korean p'ansori, Indonesian kecak, and Mongolian ritual chants:

For example, you will find the typical feature of a steadily sliding voice in nō as well as in p'ansori. The latter is distinguished by very sharp sfffz-attacks followed by a subito piano. As a composer, I feel free to play with these different elements, and while composing I think of myself being an actor on the stage. In the process of a composition however, I do not attempt to copy these elements, but to derive something new and original from them. ${ }^{351}$

Of course, Hsu also combines this thinking with compositional techniques of Western provenance. Partly self-taught, he took courses in music theory and analysis with Hsu Tsang-Houei for a time in 1960. Since the early 1970s, he has organized multimedia projects with Lee TaiHsiang and worked with the Cloud Gate Dance Theater and other performance groups. A remarkable series of works emerged in the mid-1970s (1973-75), after which he largely gave up composing in favor of his extensive work as a cultural manager.

The few works by Hsu from this period, however, are certainly among the most successful attempts to approach identity tensions productively in Taiwan. In Zhongguo xiqu mingxiang (Meditation on Chinese Theater, 1973) he transfers the vocal characteristics of the Asian genres

348 Ibid.

$349 \mathrm{Ka}$, "Gaoshan liushui," 4.

350 On Hsu Po-Yun see Mittler, "Mirrors and Double Mirrors," 28-29, Mittler, Dangerous Tunes, 206-207, 336-337, and Mittler, "Xu Boyun."

351 Personal communication with the author, Taipei, 18/3/1998. 
Example 3.38: Hsu Po-Yun, Zhongguo xiqu mingxiang, p. 27

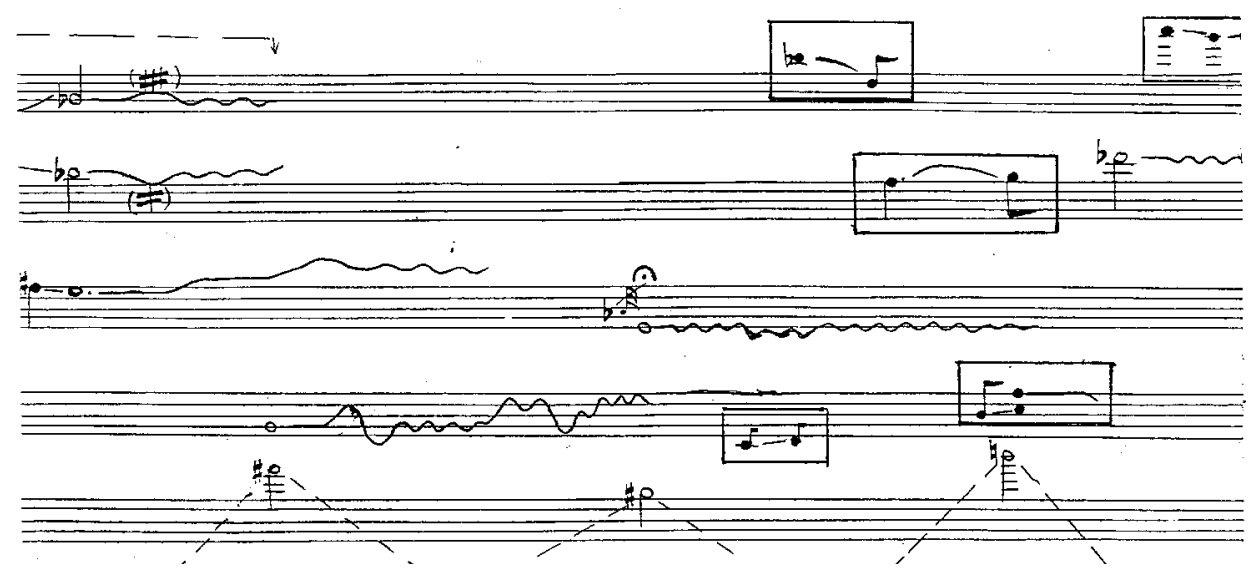

Copyright $\odot 1973$ by Hsu Po-Yun, Taipei

detailed in the above quotation to the "abstract" surface of a piano quintet. Similarly to what Lee Tai-Hsiang achieved at the same time in his piano trio, Hsu uses a wide range of advanced playing techniques but integrates them into a far more dramatic process of formal shaping. The vocal models lead to a large number of glissando variants, often combined with abrupt dynamic contrasts (Ex. 3.38).

Han shi (Cold Food, 1974) for male voice and chamber ensemble, based on a well-known legend from the Spring and Autumn Period (722-481 BCE), then applies these principles directly to the human voice, and the singer moves between toneless whispers and forceful calls within a highly dramatized instrumental environment (Ex. 3.39). The instruments are used sparingly but build up locally intensified textures. The resulting mood of ritual and the archaic, achieved by reducing the artistic means, prefigured the approach taken by Chinese composers of the xinchao (New Wave) in the 1980s (Tan Dun, Qu Xiaosong, $\rightarrow$ II.3; III.4-5) more than ten years in advance.

Hsu's Pipa suibi (Pipa Essay, 1975) for the Chinese pipa is based on the principle of an interrupted pulse, which is generated by guitar-like rather than traditional pipa playing techniques. ${ }^{352}$ This creates an atmosphere of restlessness comparable to the traditional repertoire of the $w u$ genre, ${ }^{353}$ whose most famous repertoire piece is Shimian maifu (Ambush from Ten Sides, 1818), but without quotations and based on a "reinvention" of the instrument. Although Hsu argues that he used the classical three-part form of the daqu ( $x u-p o-j i)$ from the ceremonial music yayue performed at the imperial court of the Tang Dynasty (618-907), it is possibly more

352 See Hu, "Zur Musik der Pipa im 20. Jahrhundert," 132-136 and Mittler, Dangerous Tunes, 347.

353 Traditional pipa compositions are mostly based on programmatic concepts and usually entitled with a timu (motto-like subject). An increasingly virtuosic performance practice developed in the nineteenth century. Particularly noticeable are onomatopoeic noise effects, which occur particularly in the pieces of the "war repertoire" (wu) (e.g., the clinking of weapons or the removal of armor), such as in Shimian maifu. The literary wen repertoire, on the other hand, developed gentler sonorities and is often associated with descriptions of nature and landscapes. 
Example 3.39: Hsu Po-Yun, Han Shi, p. 2

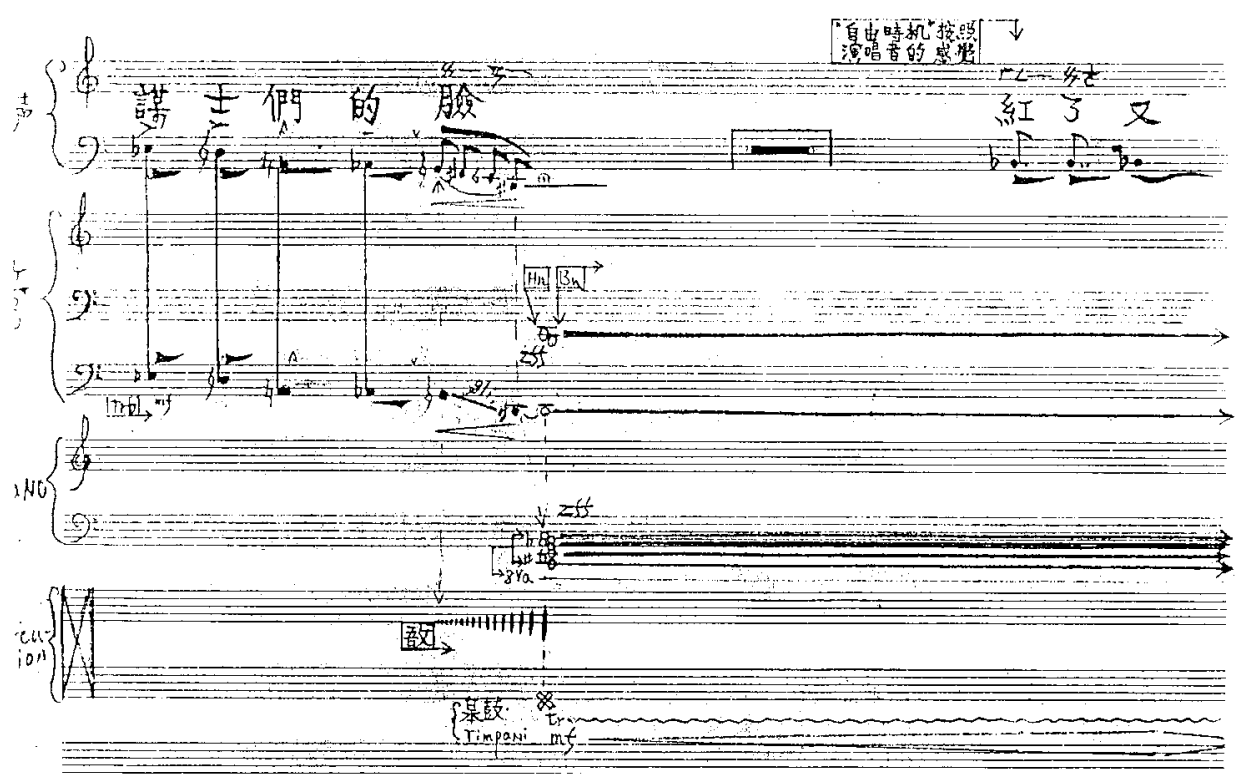

Copyright (c) 1974 by Hsu Po-Yun, Taipei

adequate, due to the mere nine-minute duration, to conceive the form of the piece as a single continuous process.

Finally, Sheng - si (Life - Death, 1974) can be described as Hsu's principal work. With a duration of over 30 minutes, the piece not only uses an variety of instrumental groups (including the Chinese instruments xiao, zheng, huqin, yangqin, sheng, and xun, as well as nine Western string instruments and four Western wind instruments), but also features an electronic soundtrack that can be considered advanced in the historical context. Even if Hsu claims that only simple technical means were available (including an echo unit and a wave oscillator), the development of the electronic part leads to spectacular sound situations, especially in the first part of the piece. Despite the large-scale setting, the structure is kept simple, with the last section focusing on an intensification of events. As in his other pieces, Hsu's international professionalism here takes priority over any form of localist identity construction.

Pan Hwang-Long, born in 1945 in Nantou County, is a significantly different case compared to Lee and Hsu. ${ }^{354} \mathrm{He}$ stayed in Europe from 1974 to 1982 and had apparently been little involved with the spirit of optimism during the early 1970s. This was probably due to the fact that he had not belonged to the "inner circle" around Hsu Tsang-Houei. He had studied at the National Taiwan Normal University with Liu Te-I ("Pietro," 1929-1991), who came from the Chinese province of Hebei and had studied in Germany with Paul Hindemith, Harald Genzmer, and Gün-

354 An extensive discussion of Pan's music is provided by Sung, Pan Hwang-long and Sung, "Interkulturelles Komponieren in der zeitgenössischen taiwanesischen Kunstmusik." Further basic information on Pan is provided in Liu, A Critical History of New Music in China, 554-556, Mittler, "Pan Huanglong," Lee, "Pan Hwang-Long," Zhao, "Renshi women de zuoqujia: Pan Huanglong," and Lo, Gu jin xiangsheng yinyue meng. 
ther Bialas. ${ }^{355}$ Pan was strongly influenced by his studies with Helmut Lachenmann in Hanover between 1976 and 1978. Intense personal sessions temporarily resulted in a close proximity to Lachenmann's musical conception. Pan's String Quartet no. 2 (1977), created in the spirit of Lachenmann, caused public protests at the premiere in Hanover on 26 January $1978 .{ }^{356}$ The young composer here followed the principle of musique concrète instrumentale, which Lachenmann had been developing since the late 1960s. The physical conditions of sound production are exposed compositionally, and thereby undermine established listening habits. The barren structure in Pan's string quartet is dominated by largely isolated noise sounds. In the later String Quartet no. 3 (1981-83), a gentler, more contemplative idiom is already hinted at, without disavowing the aesthetic of the earlier work. The fourth part develops a concentrated study in col legno techniques and harmonics, resulting in an exceptionally rich sound spectrum (Ex. 3.40).

Pan was aware that he had reached an extreme point with his second quartet, and subsequently turned, certainly encouraged by the far more moderate approach of his next teacher Isang Yun, with whom he studied at the Berlin University of the Arts (1978-80), toward the archaic Asian and Daoist thought to which Yun had repeatedly referred $(\rightarrow$ III.1). With Wandlungsphasen for eight performers (Wu xing sheng ke, 1979-80), Pan developed a compositional concept of tension and resolution that refers back to the archaic Chinese teaching of the five elements (wu xing: metal, water, wood, fire, earth) that continuously destroy and re-create one another. The design of musical tension and resolution places great emphasis on timbre. The basis for this is Pan's idea of a "sound cadence" (yinxiang zhongzhishi), probably linked to Lachenmann's sound typology, from which the principle of "sound content" (yinxiang yijing) later emerges as a central principle of composition. ${ }^{357}$ In Transformation for flute, clarinet, percussion, and two cellos (Hudie meng [Butterfly Dream], 1979), Pan applies similar principles to the famous butterfly parable of the Daoist philosopher Zhuangzi. Zhuangzi's philosophy subsequently gained special significance for Pan; it was fundamental to a whole series of works from the key year 1979, including Ursache und Wirkung (Yinguo sanzhongzou [Cause and Effect]), Kausalnexus (Yinguo muguan sichongzou [Causal Nexus]), and Erleuchtung (Qishilu [Illumination]), all scored for small chamber ensembles with three to five instruments.

Back in Taiwan, Pan became professor of composition at the newly founded National Institute of the Arts and was in charge of the Taiwanese section of the ISCM from 1985 to 1989. Although his wide-ranging international activities were now beginning, his compositional idiom, which he established around 1979/80, did not fundamentally change. He continued to adapt concepts from Chinese thought, such as in his yin-yang cycle (from 1992). From the middle of the 1970s on, Pan started organizing his works in cycles, one of the most extensive being the Migong daoyaoyou (Labyrinth - Promenade) cycle begun in 1988, which so far includes more than fifty different chamber music pieces. In this cycle, Pan pursues concepts of a mobile form, leaving the elaboration of the score to the performers, who can select from several predetermined sections.

Although Pan grew up in a very traditional environment and even played the xiao and dizi while still a child, he only started to write for Chinese instruments late on. He worked with the ensemble Caifeng Yuefang (China Found Music Workshop Taipei, today: Chai Found Music

355 Mittler, Dangerous Tunes, 199.

356 See Sung, Pan Hwang-Long, 44.

357 See Pan, "Yinxiang yijing yinyue chuangzuo de linian." 
Example 3.40: Pan Hwang-Long, String Quartet no. 3, IV, mm. 144-147

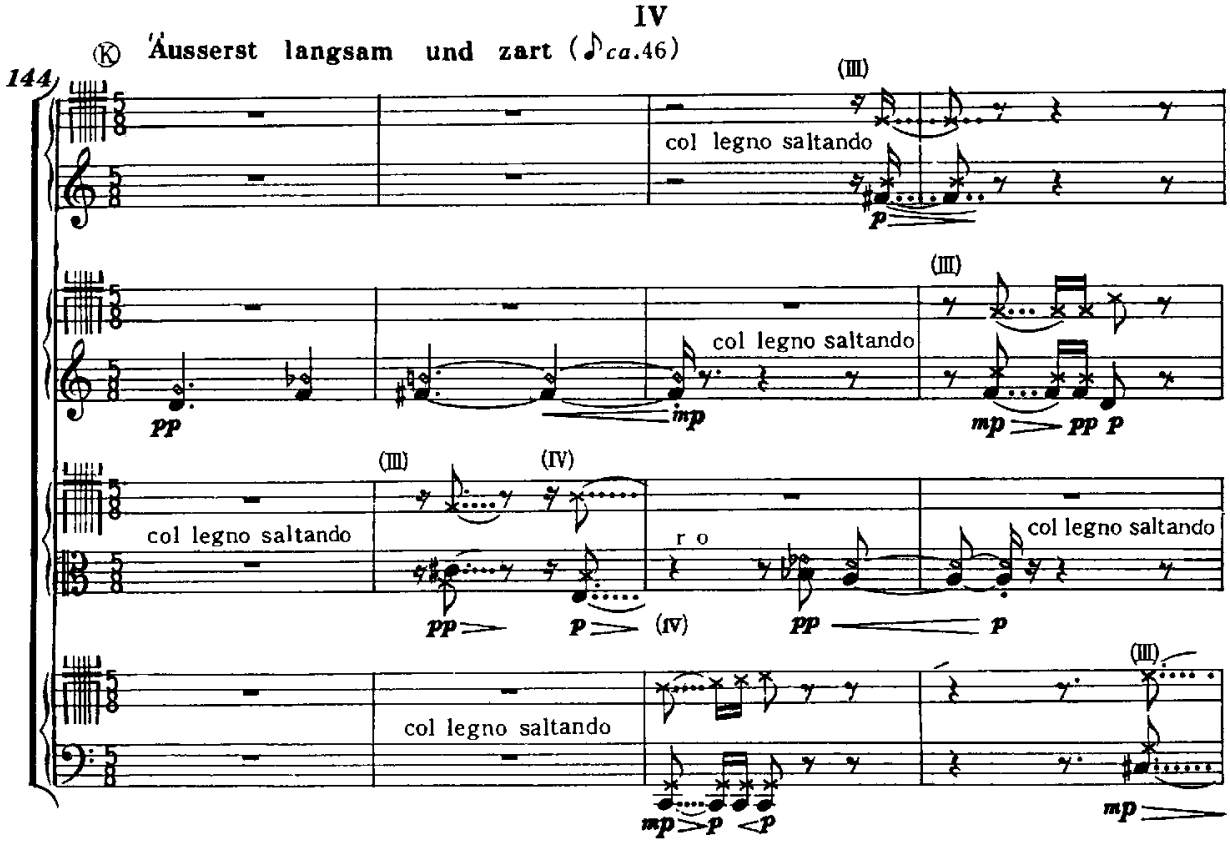

Copyright $\odot 1983$ by Pan Hwang-Long, Taipei

Workshop Taipei ${ }^{358}$ ). This ensemble specialized in new works for the Chinese sizhuyue ensemble $^{359}$ (silk and bamboo music). Of course, this also led to a more intensive examination of specific musical aspects of the Chinese-Taiwanese traditions in Pan's works. Previously, Pan had only employed highly indirect allusions, such as hints of nanguan melody in the two orchestral works Taiwan fengjing hua (Formosa Landscape, 1987-90, 1987-95). Pan states that the literary and musically refined genre nangua ${ }^{360}$ played a key role for him, not least because he was familiar with it since childhood. The first work for Caifeng Yuefang was the five-movement sextet Shi - Dao - Ru (Dialogue, 1991), in which Pan deals with the relationship between traditional and modern culture, alluding to the Confucian form of learned dialogue. What function should

358 Further information on this still active ensemble, which was frequently hosted in Europe, can be found at http://cfmw.com.tw.

359 Sizhu music is the predominant ensemble form of traditional music practice in southern China and is still cultivated in teahouses by amateur ensembles. Since the fourteenth century it has been irreplaceable for the accompaniment of opera music, musical dramas, chants, and dance theaters, but above all it has increasingly spread as an independent ensemble. The most common forms of sizhu music today are Jiangnan sizhu (in the area of Shanghai), Guangdong yinyue (Canton), and Fujian nanqu (Fujian, Taiwan). For a thorough study of Jiangnan sizhu, see Witzleben, "Silk and Bamboo" Music in Shanghai.

360 The genres nanguan and beiguan, which were brought to Taiwan with the Holo population from the southern Chinese province of Fujian about three hundred years ago, have received particular attention in Taiwan from the very beginning, also in ethnomusicological research. The Taiwan entries in Grove Music Online and MCC Online provide basic information: Lü and Lu, "3. Han Chinese traditional music" and Lee, "Taiwan" ["III. Volksmusik der Han-Chinesen"]. 
traditional instruments serve today? How could a music sound that brings out the qualities of traditional Taiwanese and Chinese music yet also participates in international developments? Pan lists several techniques he uses to find the answers to these questions: first, the use of single notes as an impulse for the entire musical development; second, the oppositions of emptiness and realism, movement and solidification, light and dark, etc. as a way to clarify the individuality and the similarities of the instruments; third, the contrast between fixed structures (movements 1, 3, 5) and mobile structures (movements 2, 4). The three Chinese characters of the title stand for the three great philosophical-religious traditions of Asia and the potential for their interpenetration: Buddhism (shi), Daoism (dao), and Confucianism ( $r u$ ).

In his quartet Wujing, qingjing, yijing (Matter, Expression, Substance, 1995-96) for dizi, pipa, erhu, and percussion instruments, the writing for the Chinese instruments seems more confident and idiomatic (Ex. 3.41). Pan again refers to a (in this case lesser-known) topos from classical Chinese aesthetics, the balance sought in Buddhism between matter (wujing), expression (qingjing), and substance (yijing), as conceived in a poem from the Tang Dynasty by Wang Changling (689-756). By alternating standard notation and variably notated sections (developing the mobile principles from the Migong daoyaoyou series), Pan aims at fluid, continuous transitions between "spiritual and real" and between "limited and limitless." Like Lee Tai-Hsiang, Pan also cites the aesthetic topos of qiyun, which he associates with a "light, introverted character, sometimes broken with a thundering strength." ${ }^{361}$

In the Concerto for Violoncello and Orchestra (1996-97), Pan tried to transfer the extremely sophisticated plucking techniques of the Chinese qin zither to the European solo instrument, while the binary rhythmic structure in East and West (Dong nan xi bei [East, South, West, North], 1998), Pan's first work for mixed Chinese-Western instrumentation, alludes to the ceremonial court music yayue of the Tang Dynasty as well as the European tonal musical tradition.

In all these approaches, it is always clear that Pan assumes an even stronger abstraction of tradition than Lee or Hsu. In addition, it becomes apparent that, much like these two colleagues, he never tries to construct a specific, local Taiwanese identity, but rather operates mainly on the - politically safe - terrain of ancient Chinese thought. Pan's approach is thus characteristic of an internationally oriented professionalism that was gradually established from the early 1990s among Taiwanese composers, who were well aware of the distinctness and qualities of Chinese and Taiwanese (music) traditions, but rarely gave them a prominent role in the musical structure.

The path of development taken by Lee, Hsu, and Pan since the 1970s also makes it clear that the "avant-garde" tendencies of their early work were not maintained, despite a changing and gradually liberalizing cultural and political climate. In this process, all three became personalities in Taiwanese cultural life in different ways and, not least, important cultural "ambassadors" and mediators for Taiwan on the international stage.

361 Pan, "Wujing, qingjing, yijing," 90 ("Die ungeradzahligen Abschnitte verwenden variable Notation und haben einen leichten, introvertierten Charakter, ab und zu durchbrochen von einer donnernden Stärke, erfüllt mit der Ästhetik des abstrahierten Reims (qiyun) [...]. Das ganze Stück vereint somit in sich das Geistige und das Reale, das Begrenzte und das Crenzenlose [...].) 
Example 3.41: Pan Hwang-Long, Wujing, qingjing, yijing, $m m .27-29$

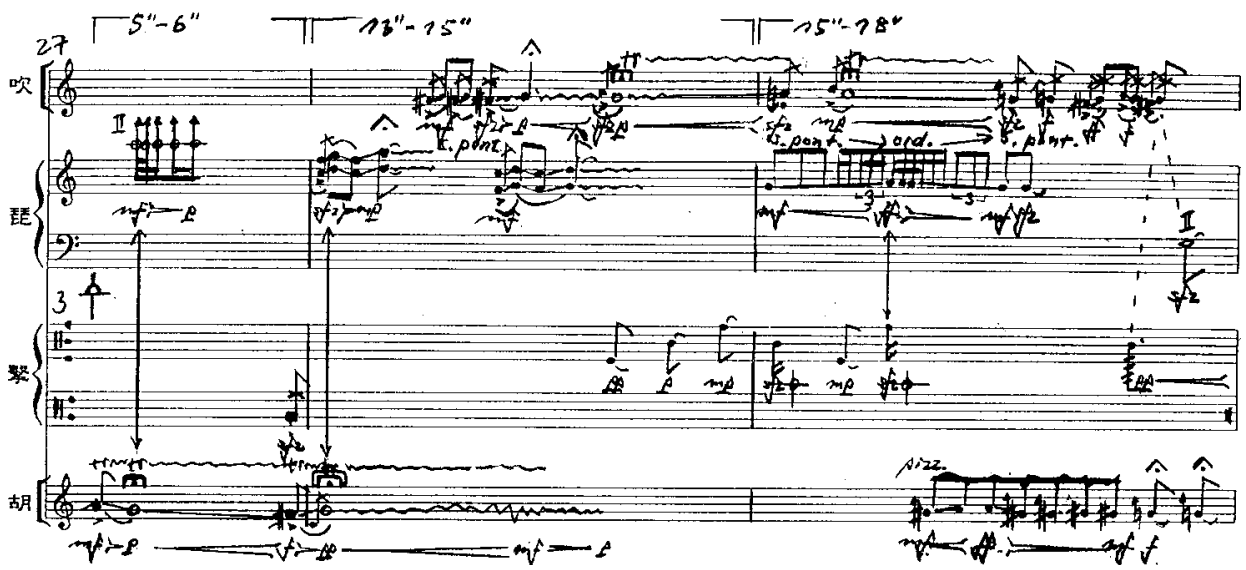

Copyright $(1996$ by Pan Hwang-Long, Taipei

\section{Conservatism and Reinvention of Traditions since the 1980s}

An avoidance of significant connections to "sounding" traditional music is unmistakable among the composers of the following generations, often accompanied by a conservatism brought back from academic education in the USA. Although traditional music was included as a compulsory subject in the training (also for composers) at several Taiwanese universities, ${ }^{362}$ it rarely seems to have had a far-reaching impact on the compositional work, not least because of the lack of informal, non-academic contact with traditional music genres and their performers. In the 1980s, a growing number of Taiwanese composers were trained in the USA, where an clear departure from the "experimental tradition" of Ives, Cowell, Cage, Partch, or Tenney had taken place since the late 1970s (anticipated early on by some of their representatives, for example in Henry Cowell's late work), involving increasing trends of popularization and commercialization. The institutionalization of compositional training at universities, the frequent isolation of academic composers from social, cultural, or political discourses, and the orientation toward the repertoire of early musical modernism, as evidenced by the success and spread of Allen Forte's set theory since the publication of The Structure of Atonal Music (1973), led most of the Taiwanese composers who were trained in the USA in the 1980s to return to Taiwan with an idiom that was technically advanced but lacked striking or visionary dimensions.

The slow political liberalization of Taiwan, which led to the abolition of martial law in 1987, seems to have been largely accompanied, at least temporarily, by a growing lack of interest in questions of cultural identity and an often uncritical adaptation to Western standards - in contrast, for example, to the filmmaking of Taiwanese directors. The issues of the Xiangtu movement were increasingly brought into the center of society by the political opposition, but seem to have influenced art music discourse only in few cases. The decline in personal, direct contact with traditional music practice, which was associated with the progressive urbanization and institutionalization of traditional music genres, had ramifications for Taiwan's mu- 
sical "landscape," as Lee Tzyy-Sheng (b. 1965), one of the leading Taiwanese composers of the current middle generation who studied with George Crumb, among others, argues:

The alienation of the young generation from Chinese or Taiwanese traditions is relatively strong. Our education is almost completely Western-oriented. During my studies at the National Institute of the Arts in Taipei we had some "antidote" in the form of classes in traditional music. But, except for a few composers, no one was interested in it. I found considerable inspiration in this preoccupation, however, and it was very inspiring to learn about these traditions [nanguan and beiguan] from the old masters. My music surely shows some traits of this fascination, but mostly only as a conceptual background and not in a very explicit way. ${ }^{363}$

Despite the last restriction, Lee Tzyy-Sheng's Wang guo shi I (Poem on the Country's Demise I, 1991) clearly shows how the heterophonic structure between soprano and instruments (Ex. 3.42) relates to the characteristic structures of traditional Chinese practice, for example the comparable adornment of the vocal parts by the knee fiddle (jinghu) that leads the instrumental ensemble in Beijing Opera (jingju).

Lee used a political reference rarely found among Taiwanese composers with a claustrophobically suggestive work for Chinese instruments entitled Mr. DE ---- ath (1990), composed in memory of the victims of the Tiananmen massacre of 4 June 1989. Together with composers such as Wu Ting-Lien (b. 1950) and Pan Shyh-Ji (b. 1957), Lee Tzyy-Sheng belongs to a group of outstanding composers with American training whose idioms shift between structuralist and dramatic-performative dimensions but clearly point beyond mere academicism. However, at the end of the 1990s, shifts toward a more pleasing idiom also seem unmistakable in this group, as becomes apparent when comparing Pan Shyh-Ji's complex and strictly atonal Quartet (1988) for guitar and string trio with her soft colored orchestral sketch Raining Night (1999).

For many representatives of the younger generations, "traditional music" may be an abstract concept from another era. Here too, exceptions confirm the rule, and this is especially true for those composers who have lived outside Taiwan for longer periods of time, sometimes permanently. Tung Chao-Ming (b. 1969) is undoubtedly one of the most original representatives of this generation. His personal "rediscovery" of native aboriginal music and Buddhist music at the end of the 1990s was accompanied by a light-footed synthesis somewhat indebted to the approaches of his teachers in Germany: the irony of Mauricio Kagel and Nicolaus A. Huber's "critical composition." In Formosa (1999), scored for two pianists who play "in and on" the instrument, Tung develops striking sonorities such as a "reinvention" of the jaw harp (lubung) of the Atayal and Bunun indigenous people and the wooden pestle of the Bunun and Tao groups in the second movement Wudao (Dance). An insistent rhythm and an increase in tempo and density lead to an ecstatic finale (Ex. 3.43).

The first movement, Fangwu luocheng ge (Song for Housewarming), refers on the one hand to the melodic structures of the song form mentioned in the title of the aboriginal Tao people (formerly known as Yami) who live on the island of Lanyu (Orchid Island) on the East coast of Taiwan; but the music here also reflects more generally the process of oral tradition, as Tung emphasizes in his introductory note:

After focusing for a long time on European music culture, I began to engage with the musical tradition of my mother's ancestors - the natives of Taiwan - and to learn and analyze their mu-

363 Personal communication with the author, Taipei, 16/3/1998. 
Example 3.42: Lee Tzyy-Sheng, Wang guo shi I, mm. 80-83

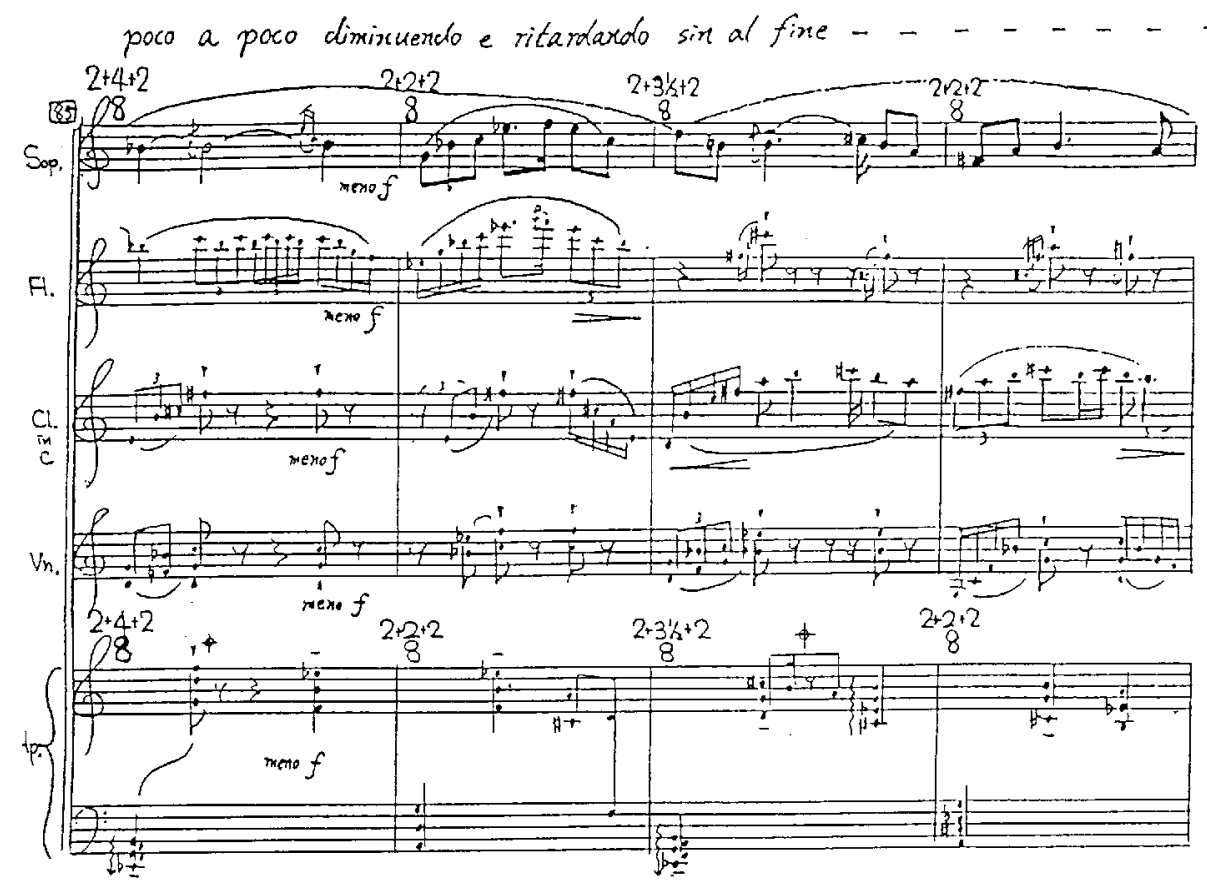

Copyright $\odot 1991$ by Lee Tzyy-Sheng, Taipei

Example 3.43: Tung Chao-Ming, Formosa, II. Wudao, m. 63

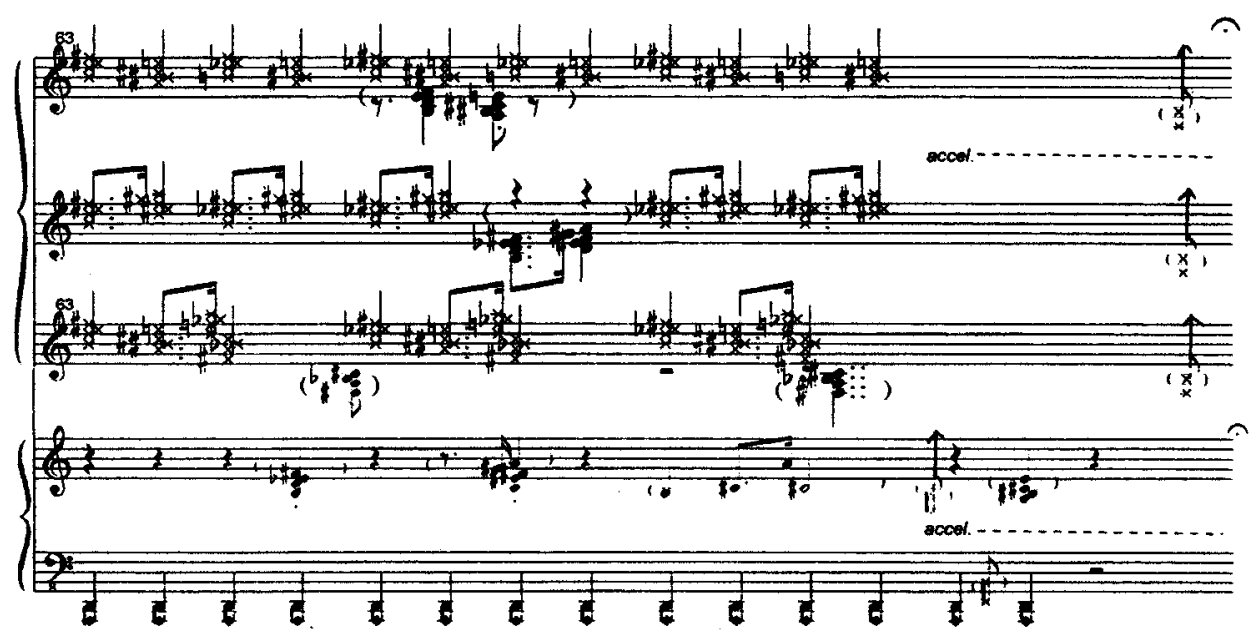

Copyright $\odot 1999$ by Tung Chao-Ming, Taipei

sical thinking in order to be able to combine this with my own music. [...] The four-handed piano piece Formosa [...] consists of three parts and deals with the music of Taiwan, which was once called "Formosa" by the Portuguese. The first part is a representation of the [orally transmitted] 
music-making of the aboriginal Taiwanese. The second pianist uses the duration of their breath to determine the duration of the individual phrases, so that the first pianist becomes familiar with the phrasing of the second pianist through repeated "practice," and thus the two of them make music together. ${ }^{364}$

This interactive and communication-based setting, comparable to Yūji Takahashi's approach to Asian instruments $(\rightarrow$ III.4) and not unrelated to Lee's or Hsu's semi-open forms of the 1970s, leads to a cautious, fragile texture that builds up tension through the process of mutual listening and imitation (Ex. 3.44). By integrating the oral transmission process and a specific tonality into the musical structures, Tung clearly points beyond the simplistic contrast between "coloristic" and "structuralist" appropriation.

Example 3.44: Tung Chao-Ming, Formosa, I. Fangwu luocheng ge, p. 6

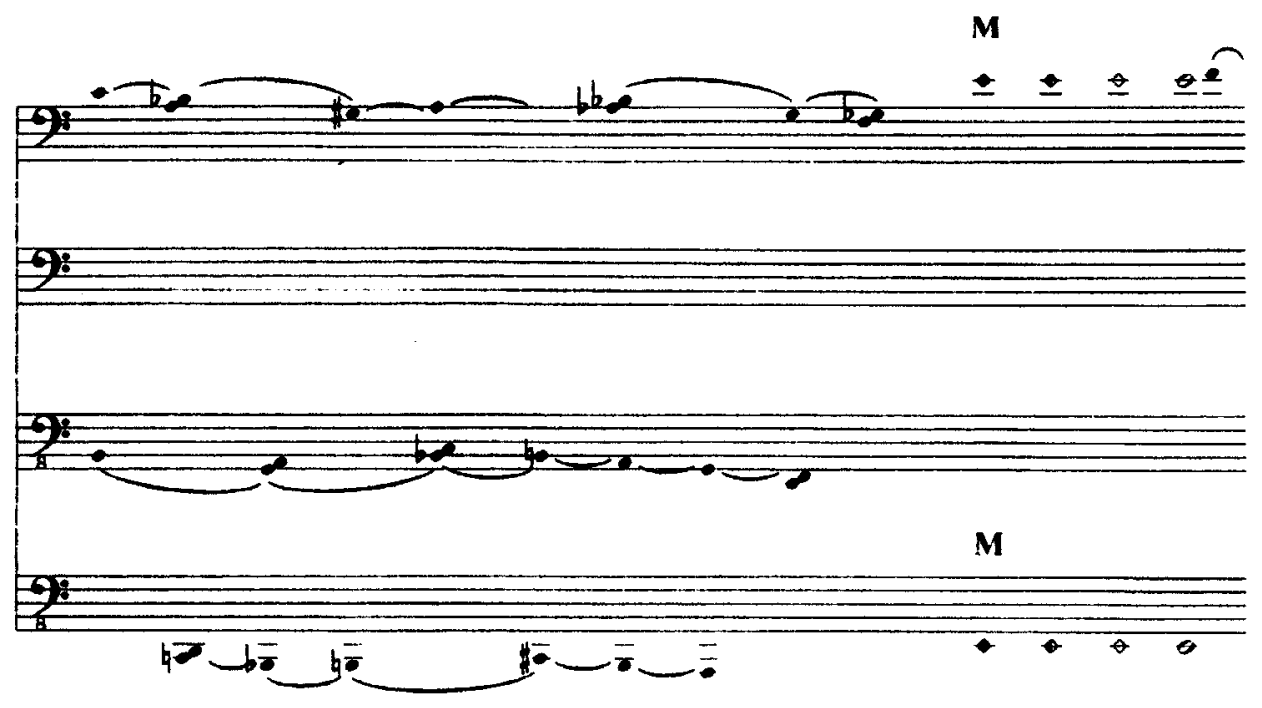

Copyright @ 1999 by Tung Chao-Ming, Taipei

364 Tung, "Formosa” ("Nach einer langen Phase der Beschäftigung mit der europäischen Musikkultur begann ich mich mit der Musiktradition der Vorfahren meiner Mutter-der Ureinwohner Taiwans-auseinanderzusetzen und ihr musikalisches Denken zu lernen und zu analysieren, um dieses mit meiner eigenen Musik zusammenbringen zu können. [...] Das vierhändige Klavierstück Formosa [...] besteht aus drei Teilen und beschäftigt sich mit der Musik Taiwans, das von den Portugiesen einst 'Formosa' genannt wurde. Der erste Teil ist eine Darstellung [des oral tradierten] Musizierens der taiwaner Ureinwohner. Der zweite Pianist bestimmt durch seine eigene Atemlänge die Dauer der einzelnen Phrasen, so dass der erste Pianist durch mehrmaliges 'Üben' die Phrasierung des zweiten Pianisten kennenlernt, und somit beide zusammen musizieren.") 
Example 3.45: Tung Chao-Ming, Die Gesichter des Buddha, p. 20

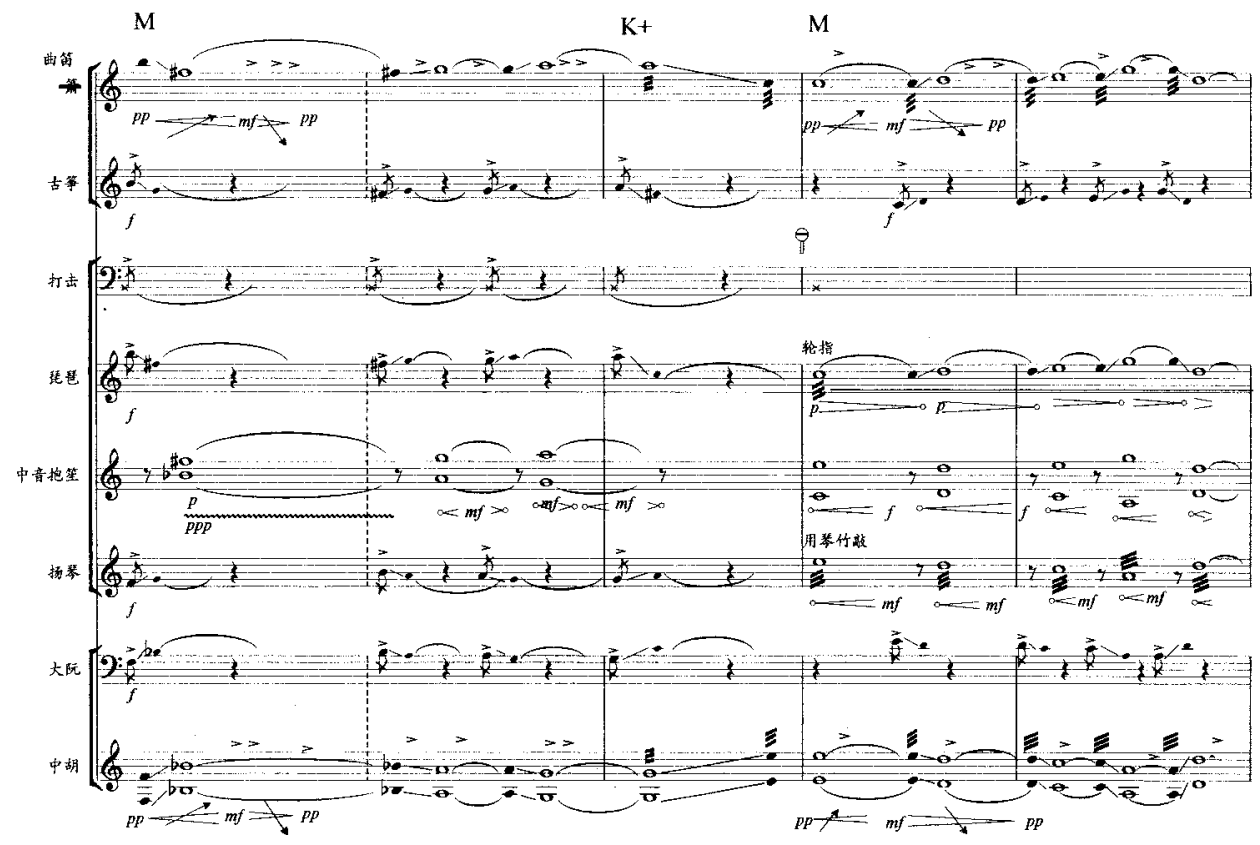

Copyright ( 2001 by Tung Chao-Ming, Taipei

In Die Gesichter des Buddha (The Faces of Buddha, 2001) for an ensemble of eight Chinese instruments, composed for Caifeng yuefang, Tung deepens this connection between structuralist and performative reception. The work is based on a structural treatment of the Daoist faqu melody Nishang yuyi qu (Song of the Rainbow Skirt and Plumage) from the Tang Dynasty. ${ }^{365}$ Whereas the melody notes in the first part are extremely drawn-out and colored by a dense network of noises inspired by the image of a "snoring Buddha," the melodic line in the second part (Ex. 3.45) gradually becomes more audible: Buddha awakes.

It is evident from the score and the sound result that the organization of this complex mixture of noise and pitched sound becomes an independent dimension in the first part, which develops its own dynamic from the underlying melodic and temporal organization. Culturally coded musical vocabulary is here secondary to concentrating on the acoustic properties of the instruments and sounds used, and increasingly gives way to a unique quality of sound.

The significantly growing number of female Taiwanese composers who are or were continuously active outside of Taiwan includes Wang Ming (b. 1963, based in Vienna), Wang Sue-Ya (b. 1965, temporarily based in Paris), Liao Lin-Ni (b. 1977, based in Paris), and Li Yuan-Chen (b. 1980, based in Chicago and Portland). They are often more respected on the international stage than in Taiwan, where patriarchal structures still shape many parts of academic life today. ${ }^{366}$ Wang Ming was trained as a performer of Chinese instruments (zheng, pipa) at the Chi-

365 The imperial music group Liyuan (Pear Carden) was founded under the Emperor Xuanzhong (reigned 713-755) and was under the direct command of the music-loving emperor, who primarily used it to study the "magical music" called faqu. The faqu was also part of the great court music called daqu.

366 See Liao, "Héritages culturels et pensée moderne," 140-141. 
nese Culture University, Taipei (Wenhua daxue) before studying composition and electroacoustics at the Vienna Academy of Music. From the beginning, she worked closely with her fellow students from Caifeng yuefang and often composed for Chinese instruments, for example in her remarkable work Ballade (1999). She searches for connections between the performance situation, natural elements, and autonomous musical structures, and combines these levels with a sensitive use of electronic media.

The composer-musicologist Liao Lin-Ni studied, among other teachers, with the Paris-based Japanese composer Yoshihisa Taira (1937-2005), who, since the 1960s, had developed a very individual synthesis of Japanese and French structures and sonorities. Liao has created a series of works emerging from synesthetic experiences which she has also discovered in poems by Emily Dickinson (1830-1886). The latter's late envelope poems provided a starting point for the trio one bird, one tree... (2017) for erhu, accordion, and piano, a set of five bagatelles to be played in any selection and order. As in earlier pieces, poetic language is transformed into spatialized sound, guided by impressions of light and shadow. Liao's Time of Trees II (2017) for finger gestures by two pianists, shadows, and sound installation, again consisting of five bagatelles, is based on a choreography of the pianists' hands emerging from Bach's "Goldberg Variations." Sound/silence and light/shadow are conceived as inseparable, the pianos' sound, intermingled with prerecorded "tree sounds," creates constantly changing audio-visual situations.

After completing a well-informed and well-researched dissertation on contemporary Taiwanese music at the Sorbonne in $2011,{ }^{367}$ Liao embarked on a remarkable international artsbased research project into the Chinese and Japanese mouth organs (sheng and shō) and their applicability in contemporary music, in cooperation with IRCAM and other prestigious French research institutions. ${ }^{368}$ Such transnational and interdisciplinary contexts provide increasingly powerful means for the younger generation to emancipate itself from Taiwanese cultural impasses and polarizations and to contribute substantially to an internationalized new music community.

A natural accentuation of cultural difference, as developed by Tung Chao-Ming, has meanwhile become increasingly rare in Taiwan itself. Although there is no shortage of cases in which, depending on the context, broadly Chinese or local Taiwanese concepts, languages, or musical idioms are incorporated into the works of composers of all generations, this incorporation is generally conceptualized and "hidden" to a far greater degree than with some mainland Chinese colleagues - though the situation has clearly changed and diversified in China too since the neo-traditionalist concepts of the xinchao during the 1990s $\rightarrow$ III.4).

\section{Outlook}

The relationship between brain drain and brain circulation is, in the complex intersection with migration, repression, and cultural criticism, key to understanding compositional work in twentieth-century China. With some modifications, this can also be said of the situation in Taiwan, which has become the model democracy of Asia alongside South Korea. The migration of the best minds among composers and musicians to (Western) foreign countries has long since become a brain circulation through which international experience is used effectively to establish a contemporary music life in their own country. Nevertheless, in some respects an "internal" brain drain remains, shaped by the danger of drying out independent creative 
forces in a somewhat utilitarian, economically oriented society - a tendency increasingly felt in many areas of the West as well. In addition to the need to support and champion new art in general, the preservation of aesthetic independence and the development of culture-critical compositional concepts seem to be decisive in this context. Despite all trends in society as a whole, the diversity of traditional musical forms in Taiwan continues to play an important part. The examples discussed here, often in a generation-based manner and sometimes with a certain hesitance and caution, show the great potential of a connection between specifically local Taiwanese, Chinese, Asian, and international ways of thinking, listening and composing, in the best case resulting in art music of the highest international standing, but with unmistakable individual qualities beyond cultural stereotypes. From this perspective, Taiwan's cultural and ethnic diversity appears as a unique opportunity, not just a source of never-ending social conflict.

Even if a difficult situation has continued to the present day owing to international political isolation and internal identity dispute, the idea of Taiwan as a "cultural desert" is definitely a thing of the past (leaving aside the fact that this was an ideologically charged phrase in the first place ${ }^{369}$ ). In the 1990s, Taiwan gradually discovered important ways to free itself from a long history of suffering through (cultural) imperialism, authoritarian state power, and decades of political censorship, economic commercialization, and nepotism, turning into a vibrant and largely well-functioning democracy. ${ }^{370}$ Against this background, it becomes clear that advanced art music must also function as an indicator of political liberalism and international connectivity. Thus the responsibility of cultural policymakers to continue supporting the representatives of Taiwan's vibrant musical life in building an infrastructure is obvious. Taiwan's music from the 1960s to the present must be seen as a small but valuable piece in the mosaic of cultural diversity in which global and local tendencies are constantly intertwined.

369 See footnote 318.

370 Winckler, "Cultural Policy in Postwar Taiwan," 41. 



\section{The shō Context}

\section{Transformation and Myth Criticism in Works for the Japanese Mouth Organ}

In Chapter 1, "intercultural composition" and related terms were understood as a reflection on the basic question of identity formation in the conflict zone of cultural "hypolepsis" $(\rightarrow$ I.3): how is a balanced reference to a globalized cultural memory possible when caught in the tension between diverse musical cultures, and to what extent do the incommensurable cultural idiomatics of those cultures allow for interchange among themselves or intermediate action spaces? Hypolepsis, in the ancient theory of rhetoric, is the connection of a statement to a previous speaker's words and their free development; transferred to intercultural contexts, it can signify the further development and (inter-)cultural transformation of texts and practices. We will use a concrete example to study this concept in practice, and we find an excellent case study in recent works for the Japanese mouth organ, the sho. The shō is a particularly apt example when debating these issues, because its sound is culturally coded like no other and it is therefore an excellent measure of the narrow gap between "culture-free" sound and simplistic culturalism, between incommensurability and the potential for hybridity. One might ask: where and how do composers continue to write about cultural memories while engaging with this instrument? What role is played by the construction of a "canonic" or "classical" tradition that is connected to this instrument (that Jan Assmann separates from the hypoleptic process $\rightarrow$ I.3)? How are the symbolic-connotative elements of the sho, what we could call the myth of the instrument, approached in newly written compositions? And what significance can be ascribed to a - possibly historicocritically-based - ethnomusicological expert knowledge in the compositional process?

\section{The Japanese Mouth Organ in the Traditional Context}

The multitude of new works with sho created since the 1980s is due in large part to the activities of soloist Mayumi Miyata, who, since 1983, has presented the shō as a solo instrument on the international concert stage. Her former student, Kō Ishikawa, has also helped to promote the instrument considerably since the early 2000s. All works discussed below were premiered either by Miyata or Ishikawa. Before I discuss individual compositional approaches, I will briefly outline the mythological content, history, and manner of playing of this instrument.

The shō consists of 17 bamboo pipes embedded in a circular wind chamber. Metal reeds vibrate when the finger holes are covered and produce 15 mostly diatonic pitches between $\mathrm{A} 4$ and $\mathrm{F} \# 6$ (the 13 pitches of the A major scale with G5 and C6added, Ex. 4.1) - two pipes remain mute 
and contain no reeds. ${ }^{1}$ Modern instruments - the majority of the instruments found in works after 1990 - have reeds added to both the muted pipes which produce the pitches $\mathrm{F}_{5}(m \overline{0})$ and $\mathrm{B} b 5(y a)$. The metal reeds inside the bamboo pipes vibrate during both exhalation and inhalation, so that it is characteristic for the shō to produce a continuous stream of sound.

Example 4.1: Pitches playable on the sho; the diamond noteheads indicate the pitches that are only available on the modern instrument and are not used in traditional music.

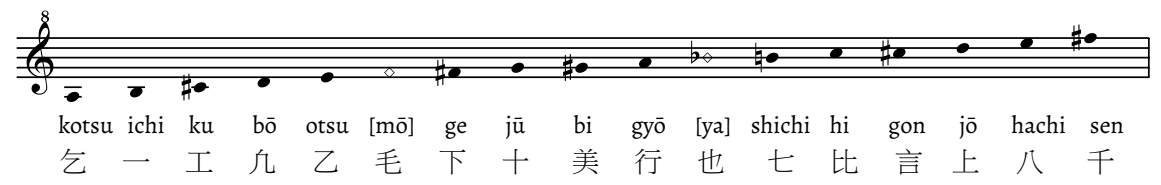

The sho came to Japan as a court music instrument in the eighth century during the Chinese Tang Dynasty (618-907 CE). Its Chinese precursor, the sheng, was an ancient instrument that can be traced as far back as the pictograms of the Shang Dynasty (1766-1122 BCE) $(\rightarrow$ II.6). The construction of the instrument is mythologically attributed to a goddess at the beginning of time, and it was supposedly played by an "immortal" at the foot of a mountain on a moonlit night. ${ }^{2}$ The character 笙 (Chin. sheng, Jap. shō) consists of the bamboo radical and the character for "to be born." Together they symbolize emergence, becoming, and passing away. It is associated with the mythological bird, the phoenix, which is reborn from its own ashes. Also, the character's shape and construction are modeled on the phoenix. In an archaic Chinese classification, the ordering of the eight sounds, ba yin, the sheng is likewise attributed to a process, namely the transition from winter to spring. ${ }^{3}$ The tuning of the shō is based on a cycle of pure fifths, which can be traced back to the ancient Chinese treatise Guanzi (Guan Zhong, died 645 $\mathrm{BC})$; the eleven aitake, the shō's basic chords in the tōgaku repertoire of the Japanese court music genre of gagaku, are constructed from superimposed fifths (Ex. 4.2). ${ }^{4}$

By the middle of the nineteenth century, in the early era of Meiji restoration, for political reasons, the current form of the tōgaku repertoire was unified and codified, making gagaku music - most often represented by the togaku repertoire - the principal representative of Japan's "traditional music." From the same period, gagaku was actively promoted to Western audiences (starting with presentations at the Paris world exhibitions in 1867 and 1878), its repertoire repeatedly being transcribed into Western notation. ${ }^{6} \mathrm{With}$ the exception of the free introductory sections, chōshi and netori, which resulted from tuning into the mode and partly contain canonic techniques ( $\rightarrow$ III.4), the sho part in this newly codified repertoire was limited

1 The mute pipes were originally (during the Nara period, 645-794 CE) also fitted with reeds and were interchangeable; they were able to produce up to four more pitches: ya $\left(\mathrm{G}_{4}\right), m \bar{o}(\mathrm{D} \sharp 5)$, as well as to $(\mathrm{B} b 4)$ and boku (F5), see Harich-Schneider, A History of]apanese Music, 126-128.

2 See, ibid., 131.

3 In the ba yin classification, the sheng is associated with the material pao (calabash) from which the wind chamber was originally made, as well as the direction northeast. Moreover, the sheng was considered a symbol of yin. See Liang, Music of the Billion, 64-70 and Schwörer-Kohl, "Mundorgel," 617.

4 See Garfias, Music of a Thousand Autumns, 65-66.

5 See, among others, Tsukahara, "Aspects of gagaku in the Late Nineteenth and Early Twentieth Centuries."

6 See Tsukahara, "State Ceremony and Music in Meiji-era Japan." 
exclusively to eleven different chords, known as aitake 合竹 (literally "united bamboo"). The aitake's "central pitches" (marked with black noteheads in the first row of Example 4.2; with the exception of the $j \bar{u}$ - and the $h i$-chords they are always the lowest note) follow the melodic scaffold of the togaku pieces which were heterophonically elaborated in on all other melody instruments, particularly the dominant reed oboe hichiriki and the bamboo flute ryüteki. In these pieces, the characteristic micro-glissandi embai were used extensively in the other wind instruments to connect the pitches of the basic melodic line. ${ }^{7}$

Example 4.2: Schematic presentation of the eleven aitake chords of the shō in traditional tōgaku repertoire; the black noteheads (row 1) represent the basic pitches of the chords; the numbers above the first row describe the interval structure of the chord in semitones; the second row breaks the chords up by the system of pitch-class set analysis; row 3 represents the (partly incomplete) underlying sequences offifths
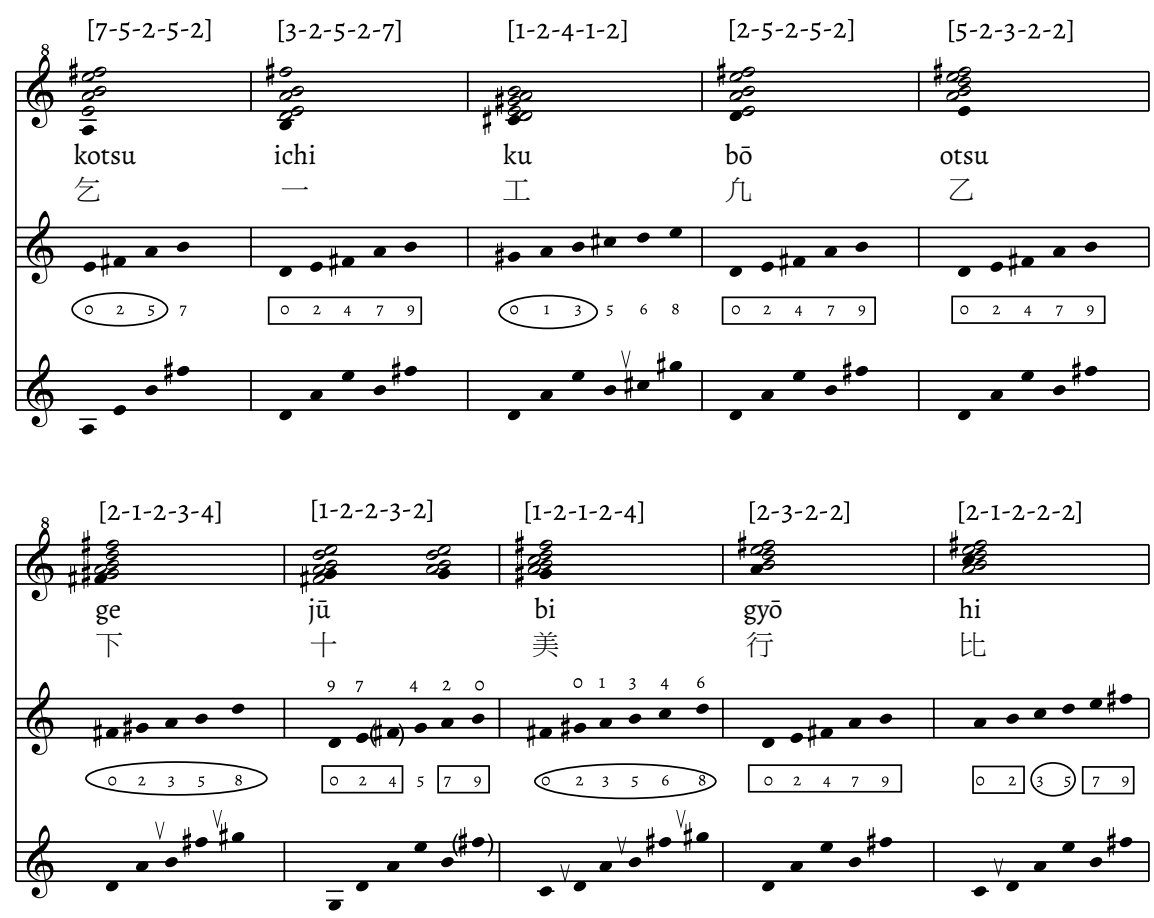

In the utterly characteristic manner in which the sho (usually three shō perform in a group) is used in the toggaku repertoire (which emerged from the court music of the Chinese Tang Dynasty), the mythological symbolism is aptly reflected. The swelling and receding of the aitake are strictly regulated (Ex. 4.3). Some 90 changes of position, as well as the corresponding changes of breath (ikigahe) must first be memorized by the sho pupil (as mentioned, the reeds vibrate during in- and exhalation, creating a continuous sound). 
Example 4.3: The beginning of the sho part in the famous piece Etenraku (in the mode hyōjo) from the tōgaku repertoire with the characteristic position changes known as te-utsuri (Miki, Nihon gakki hō, 79)

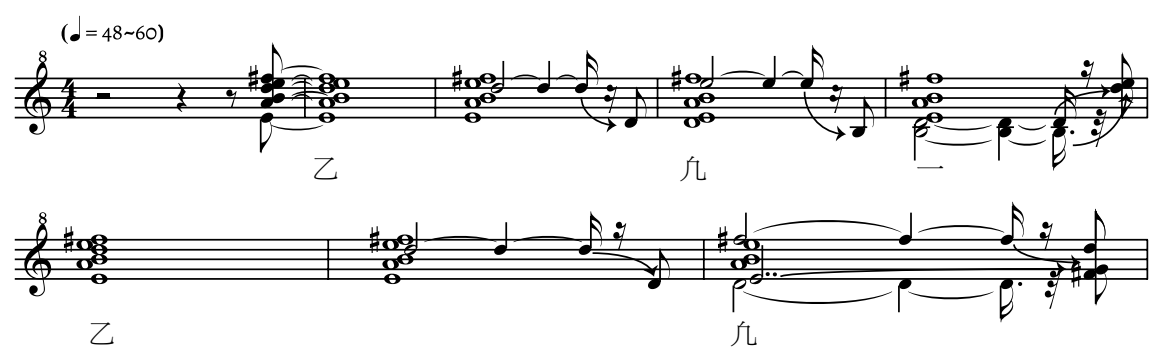

The character of gagaku, frequently described as "unmistakably Japanese," is significantly indebted to the slow swelling and receding curve of the sho part within the slow basic tempo, which is common today. Gagaku music thus appears particularly suitable to illustrate essential Japanese aesthetic principles, such as the sadness of transience (mono no aware) or the rusted austerity of old things (sabi). On the other hand, there is the objection that gagaku, as it was generally understood and conceptualized (in Japan and in the West) until recently, is thoroughly a result of Japanese nationalist sentiment since the nineteenth century and, as such, must be considered a product (rather than an a priori model) of such a culturalist aesthetic. In the Heian Period (794-1185 CE), not only was the basic tempo of gagaku music presumably substantially faster (arguably around eight to 16 times faster) than in most modern performance practice, but the shō was also a leading melodic instrument alongside the lute biwa and zither gakuso, and its character was not at all limited to today's "solemn" manner. Its performance practice was likely similar to today's chōshi sections with the enlargement of a basic melody through parallel fifths or fourths. ${ }^{8}$ Also during the Heian Period, the vocal genres saibara and roe i began to include the sho as the main melodic instrument playing in heterophony with the vocal line. The critical revision of the popular understanding of gagaku music as Japan's "cultural legacy," as a pivotal element in the authority of Japanese antiquity, and as evidence of an unbroken tradition of Japanese identity provides a central subject of debate for current gagaku research $\left(\rightarrow\right.$ II.6). ${ }^{9}$

8 Picken and Wolpert, "Mouth-Organ and Lute Parts of tōgaku and Their Interrelationships" as well as numerous other essays on the interpretation of old gagaku sources by Picken and his school, among others, in the series Music from the Tang-Court, ed. Laurence E. R. Picken and Noël ]. Nickson, vol. 1 (1981), vol. 2/3 (1985), vol. 4/5 (1990), vol. 6 (1997), vol. 7 (2000), Cambridge 1981-2000. Picken's Tang Music Project provided the basis for the reconstructions of Chinese court music of the Tang Dynasty under the direction of Chinese music scholar Chen Yingshi (published in 1989 on the CD Zhongguo tangyue).

9 See the contributions to the round table "Gagaku and Studies on Gagaku in the 2oth century" at the International Congress of the Musicological Society of Japan in Shizuoka 2002: Tsukahara, "Aspects of gagaku in the Late Nineteenth and Early Twentieth Centuries," Marett, "The Present State of Research on Early Notations," Endō, "The Revival of Lost Repertoire," and Terauchi, "Future Perspectives: New Possibilities in Research on gagaku." 


\section{The Reception of the shō in Contemporary Music}

Despite all historiographical criticism of essentialist discourses on identity, it is easy to understand why the shō (and, increasingly, the Chinese sheng $\rightarrow$ II.6) have become popular media for interculturally accentuated composition in the West and in Asia. It is hard to negate the aura of these instruments' sound and it seems to be the ideal embodiment of the auratic component of compositional material, to which Helmut Lachenmann attributed essential functions in new music as the "bearer of familiar experiences of existential reality"10 (it is no coincidence that one of the earliest new instruments, produced at the beginning of the nineteenth century on the model of the sheng - which was first sent to Europe by the Jesuit Joseph-Marie Amiot in 1777 - was called "Aura"11). Added to this are particular instrumental techniques that provoke compositional thinking: the limitation of available pitches on the instrument and the unorthodox finger positions based on a largely fixed assignment of the seven active fingers to individual holes/pitches (Ex. 4.4; $\rightarrow$ IV.2, Ex. 4.13). These limitations allow only a reduced number of sound combinations between one and six or seven pitches $(\rightarrow$ VI.2) and condition the peculiar changes of finger positions, te-utsuri. A further characteristic is the high degree of fusion between chord notes, due to the richness of overtones and the high register of the instrument. It is precisely these idiosyncratic properties of the sho that pose extraordinary compositional challenges: at first glance, they seem to leave little room for "interventions" by composers. Nevertheless, some fundamentally distinct approaches to these characteristics and the traditional contexts of the sho can be identified in the tension between myth reception and myth criticism.

\section{Example 4.4: Fingering table of the 17-pitched shō (Kō Ishikawa)}
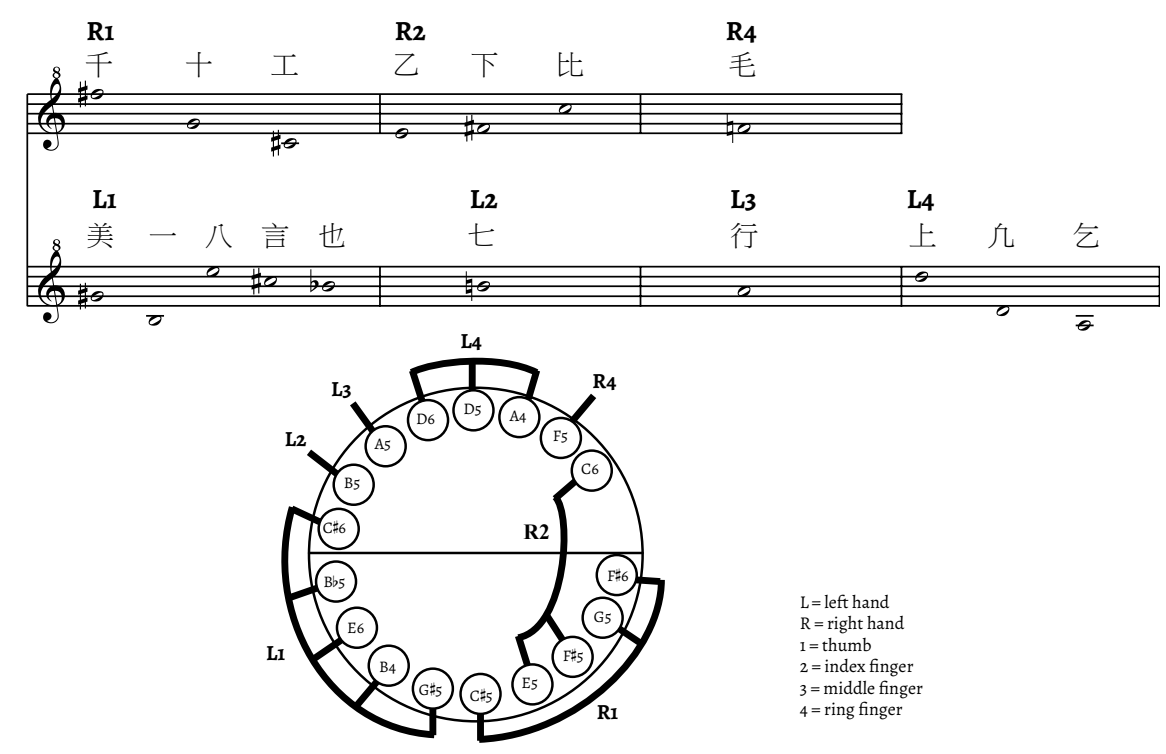

10 Lachenmann, "Vier Grundbestimmungen des Musikhörens," 61 ("Trägerin von vertrauten Erfahrungen der existentiellen Wirklichkeit").

11 The mouth-blown Aura (with 15 steel tongues) was designed by Christian Friedrich Ludwig Buschmann in Berlin in 1821 and was a direct forerunner of the accordion, which was patented in Vienna in 1829 by Cyril Demian (1772-1847), see Harrington and Kubik, "Accordion" and Schwörer-Kohl, “Mundorgel." 


\section{Myth and Aura}

Of course, the reception of gagaku music since the 1980 s is not without historical precedents; composers attracted by the shō before this period include Benjamin Britten, Olivier Messiaen, Karlheinz Stockhausen, Jean-Claude Eloy, and a group of Japanese composers who had begun to link current musical developments with structural and tonal aspects of the gagaku as early as the 1930s ( $\rightarrow$ II.4; III.1). Britten, who had brought a shō from his trip to Japan to England in 1956, uses a chamber organ in his church parable Curlew River (1964) to evoke, especially in the frame parts, the aura, structure, and function of sho chords in tōgaku, which are sometimes quoted verbatim. ${ }^{12}$ Olivier Messiaen, in the fourth movement of his Sept Haïkaï (1962), limits himself largely to a timbral reproduction of the sho sound (eight solo violins imitate the chords of the shō), while rhythm and pitch organization remain entirely within Messiaen's systematic approach. ${ }^{13}$ Stockhausen quoted the best-known gagaku piece Etenraku several times in an electronic piece written in Tokyo, the universalist Telemusik (1966, moments 3, 6, 20, 31) $(\rightarrow$ II.2) and attempted, by electronic glissando effects produced by a "gagaku circuit," a double ring modulation, to transform characteristic microtonal slides in gagaku melody by electronic means. ${ }^{14}$ Stockhausen also wrote Der Jahreslauf (1977) for a complete gagaku ensemble that was later included in Dienstag aus Licht and met with harsh criticism in Japan. ${ }^{15}$ Jean-Claude Eloy likewise composed an extensive work for gagaku orchestra, augmented by bugaku dancers and the Buddhist chanting style shōmyō (A l'approche du feu méditant, 1983, duration: 150 minutes). Eloy's central work is the four-hour Anāhata I-III (1986-90) for soloistic shō, hichiriki, ryūteki, two shōmyō singers, bonshō (Japanese temple bells), and electronics. Both works exude a pronounced ritualistic character and incorporate the "stretched" concept of time of gagaku. Eloy's methods are based on extensive knowledge of traditional music practice, and he developed special forms of notation in collaboration with the shomyō singers. ${ }^{16}$

The following part of this chapter focuses less on gagaku music in general than on concepts that place the shō as a solo instrument at the center of the compositional interest. ${ }^{17}$ Tōru Takemitsu's pioneering work Distance for oboe and shō (1972) acts as a starting point for a soloistic treatment of the $\operatorname{sho}(\rightarrow$ III.4). Similarly important are Takemitsu's works In an Autumn Garden (1973/79) for gagaku orchestra and Ceremonial (1991) for shō and (Western) orchestra. ${ }^{18}$ Toshio Hosokawa also provides a particular wealth of works for $\operatorname{sh} \overline{0},{ }^{19}$ which were performed

12 See Cooke, Britten and the Far East, 112-189, Utz, Neue Musik und Interkulturalität, 116-136, and Crilly, "There's No Theatre like Noh Theatre..."

13 See Utz, Neue Musik und Interkulturalität, 187-188 and Bispo, "Olivier Messian's Sept Haïkaï."

14 See Utz, Neue Musik und Interkulturalität, 153-165, Kohl, "Serial Composition, Serial Form, and Process in Karlheinz Stockhausen's Telemusik," and Erbe, "Karlheinz Stockhausens 'Telemusik."

15 See Utz, Neue Musik und Interkulturalität, 151-153 and Shimizu, "Stockhausen und Japan."

16 See Utz, Neue Musik und Interkulturalität, 195-200.

17 Also, new works for gagaku ensemble are not discussed below, since here the sho is strongly influenced from the outset by its context within the ensemble. The huge number of new compositions for gagaku ensemble could hardly be adequately dealt with in this chapter. For the compositional reception of the gagaku see especially Everett, "Mirrors of West and Mirrors of East" and Menzel, Hōgaku, 100-119, 181-194.

18 See Burt, The Music of Tōru Takemitsu, 139-141, 160-167, 224-225.

19 The following works by Hosokawa require a shō: the works for gagaku ensemble (partly with shōmyō vocals) Tokyo 1985 (1985), Seeds of Contemplation (Mandala) (1986), New Seeds of Contemplation (Mandala) (1995), and Garden at First Light (2002/03); Utsurohi (1986) for harp and shō, Utsurohi-Nagi (1995/96) for shō and string orchestra with harp, ce- 
by Mayumi Miyata throughout, and composed partly under the unmistakable influence of Takemitsu. ${ }^{20}$ Especially since the 1990s, Hosokawa has taken the reference to orthodox Japanese aesthetics, following Takemitsu, to an extreme, referring in almost every one of his works to the relationship between sound, breath, nature, and silence, as well as pointing to central culturalist concepts like $m a$, sawari, or principles of calligraphy, gardening, or landscape painting. ${ }^{21}$ His characterization of the sho remains firmly and seamlessly attached to the mythical aura of the instrument:

The mouth organ shō is a wonderful instrument. When it starts to play, its sound spreads out and fills the whole room, and one does not know where the sounds come from. The actual melody, as the pattern of this music, is immersed in the chords of the aitake, the background sounds, and is forgotten. This means that one does not clearly recognize its boundaries. These sounds make me think of the way cicada sounds penetrate the world. ${ }^{22}$

Hosokawa calls the shō chords in gagaku the "mother's womb" or the "mother's chord" from which the lines of the hichiriki and ryüteki develop. ${ }^{23}$ Hosokawa also transfers this relationship of chord and line to cosmology and compares it to the relationship between humans and nature. His works with shō are characterized by the constant flow of inhaling and exhaling and draw directly on the gagaku model sketched above. In particular, earlier pieces rely almost exclusively on this model of inhalation and exhalation. Particularly elementary in this regard, for example, is a work for shō solo "Wie ein Atem im Lichte" ("Like a Breath in the Light," 2002), whose title is borrowed from a poem by Rudolf Steiner. The religiously tempered natural mystique of the poem seems to find a logical equivalent in the harmonies based on quintal/quartal chords reminiscent of the chōshi introductory parts of tōgaku (Ex. 4.5). The aitake chords are quoted throughout, sometimes in complete form and sometimes fragmented: the sonority E5A5-B5-E6 at rehearsal number 1 contains the basic structure of the chords kotsu, $b \bar{o}$, and otsu; rehearsal number 2 , with $\mathrm{D}_{5}-\mathrm{E}_{5}-\mathrm{F}_{5}-\mathrm{A}_{5}-\mathrm{B}_{5}-\mathrm{E}_{6}$, features five of the six pitches of the $b_{\bar{o}}$ chord (with $F_{5}$ replacing the original $F \sharp 5$ ); rehearsal number 3 introduces $G \sharp 5-A 5-B 5-C 6-D 6-F \# 6$, an exact quotation of the $b i$ chord, and rehearsal number 4 quotes the ge chord with the pitches $\mathrm{F} 5-\mathrm{F} \# 5-\mathrm{G} \# 5-\mathrm{A} 5-\mathrm{B} 5-\mathrm{D} 6-\mathrm{F} \# 6$. At rehearsal number 7 , the quintal harmony is pointedly brought to the foreground and the fifth $\mathrm{F} \# 5-\mathrm{C} \sharp 6$ is twice repeated $f f$. Some more dissonant passages

lesta, and percussion; Birds Fragments II (1990) for shō with drums ad libitum, Birds Fragments III (1990) for shō and flute(s), Birds Fragments IV (1991) for violoncello, percussion, and shō; Landscape V (1993) for shō and string quartet; Cloudscapes - Moonlight (1998) for shō and accordion; "Wie ein Atem im Lichte" (2002) for shō solo; Cloud and Light for shō and orchestra (2008); Sakura für Otto Tomek for shō solo (2008); Two Japanese Folk Songs, arrangements for mixed chorus and percussion with/without shō (2008).

20 One can assume that all three of Takemitsu's works with shō had a great influence on Hosokawa; in particular, compare Distance with Utsurohi and the Birds Fragments, In an Autumn Garden with New Seeds of Contemplation (Mandala) and Garden at First Light, and Ceremonial with Utsurohi-Nagi. See also Hosokawa's notes on Takemitsu's Distance in Hosokawa, "Aus der Tiefe der Erde," 52.

21 See particularly Hosokawa and Sparrer, Stille und Klang, Schatten und Licht.

22 Hosokawa, "Aus der Tiefe der Erde," 51. ("Die Mundorgel shō ist ein wunderbares Instrument. Wenn sie zu spielen anfängt, breitet sich ihr Klang aus und füllt den ganzen Raum, und man weiß nicht, woher die Töne kommen. Die eigentliche Melodie als das Muster dieser Musik wird in die Klänge der aitake eingetaucht, in die Klänge als Hintergrund und gerät in Vergessenheit. So kommt es dazu, dass man ihre Grenzlinie nicht deutlich erkennt. Ich stelle mir bei diesen Klängen die Art und Weise vor, wie die Zikadenstimmen die Welt durchdringen.")

23 See ibid. ("Mutterschoß," "Mutterakkord.") 
eventually lead to the remaining highest pitch $\mathrm{F} \# 6$, before a reprise-like return at rehearsal number 12, where the fifth A4-E5 flows into the fifth A5-E6, an octave higher.

Example 4.5: Toshio Hosokawa, "Wie ein Atem im Lichte" for shō solo, opening
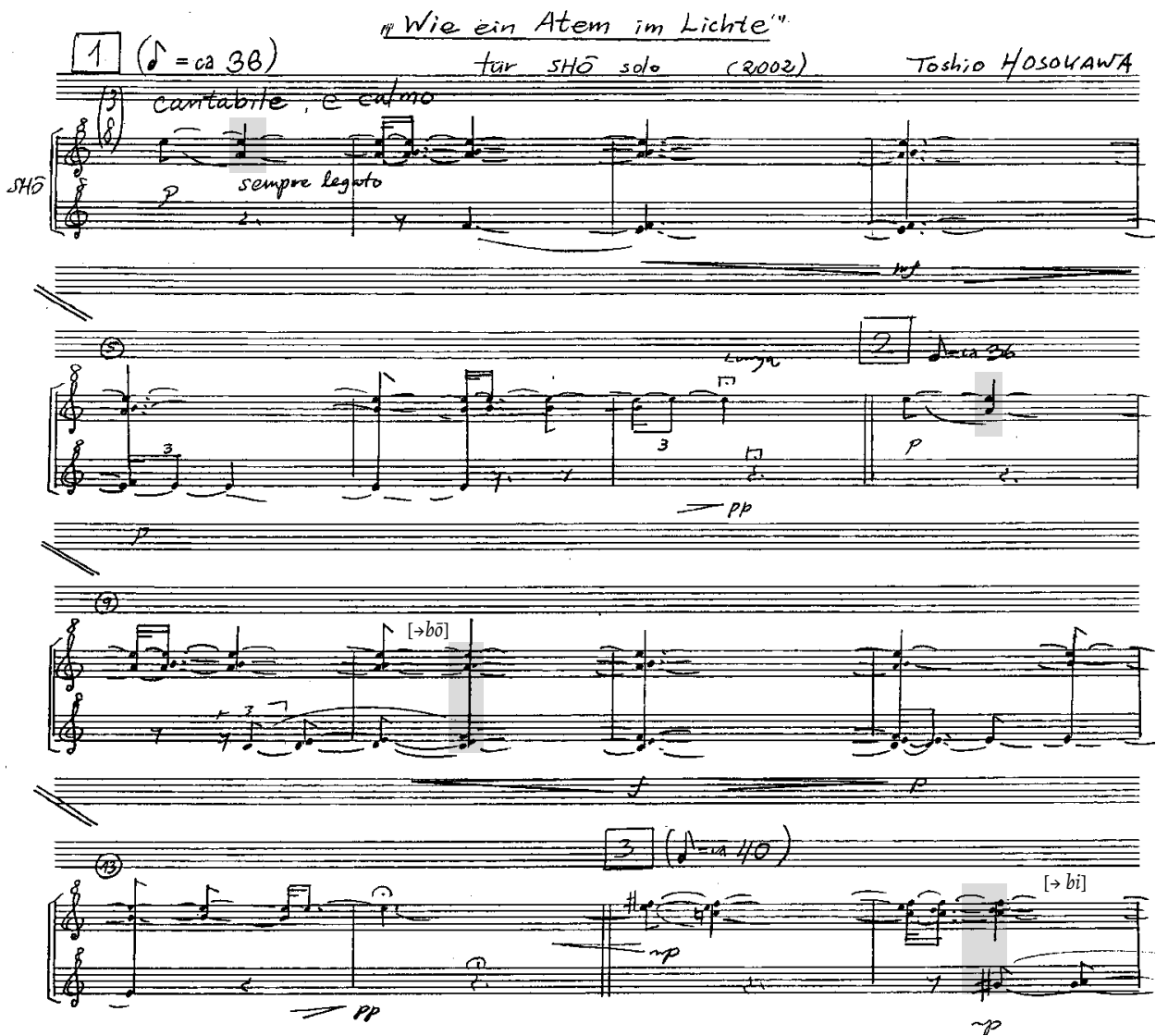

Copyright $\odot 2002$ by Schott Japan Company Ltd.

The sho myth here tends to turn into a regressive ideology of nature. The naïve devotion to the order of nature culminates in a fifth-octave harmony in which the few "wrong notes" appear as mere "decoration." Above all, this appears to be a development of the early 2000 , as an analysis of the harmony of Hosokawa's earlier shō works show. ${ }^{24}$ Landscape $V$ (1993) for shō and string quartet $(\rightarrow$ III.5) emanates from the microtonally colored tetrachord G $\# 5-\mathrm{A} 5-\mathrm{B} 5-\mathrm{D} 6$ (a subset of the ge and bi aitake chord), which, as a "mother chord," pervades most harmonic formations in the piece (Ex. 4.6). The "vertical" cuts (the principle of the "vertical" for Hosokawa is based, among others, on the energetic preparations of strokes of the drum òtsuzumi in $n \bar{o}$ theater ${ }^{25}$ ) at

24 Cloudscapes - Moonlight (1998) for shō and accordion occupies an intermediate position where the restriction of inhalation and exhalation is likewise unbroken and exclusive, but the harmony is more similar to Landscape $V$, in that it is much rougher and more dissonant.

25 See Utz, Neue Musik und Interkulturalität, 313-315. 
Example 4.6: Toshio Hosokawa, Landscape $\boldsymbol{V}$ for shō and string quartet, harmonic reduction and pitch-class set analysis

$\operatorname{sh} \bar{o}$

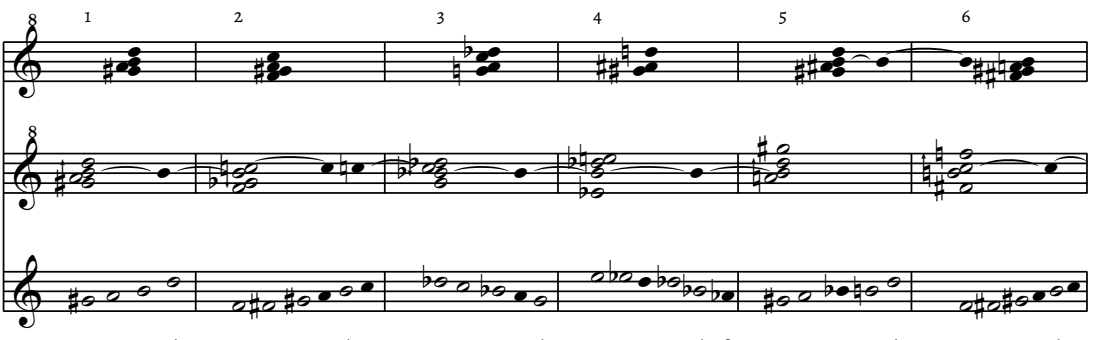

shö

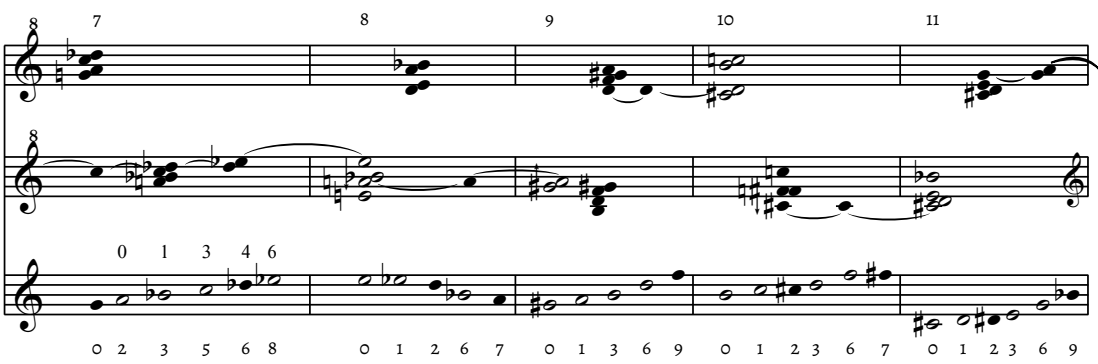

shö
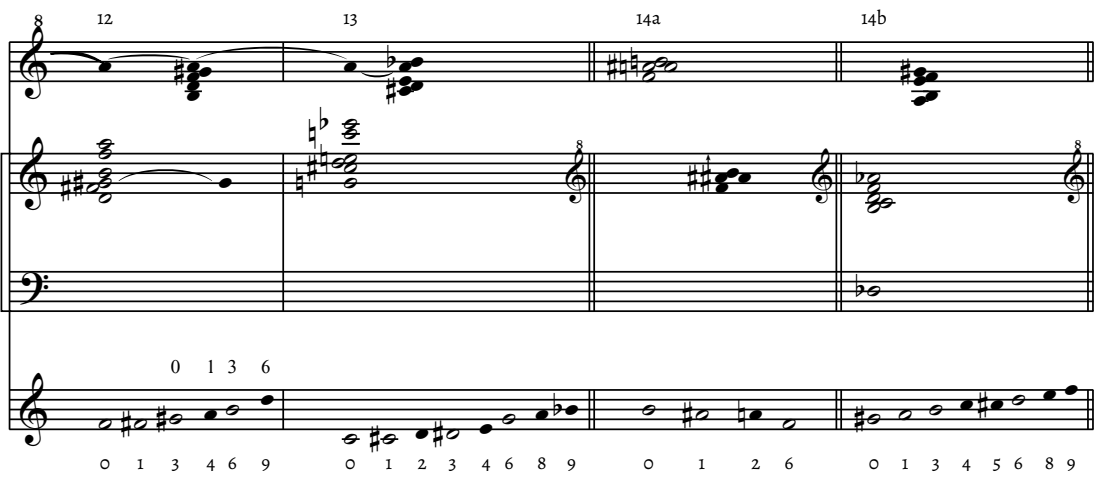

shō
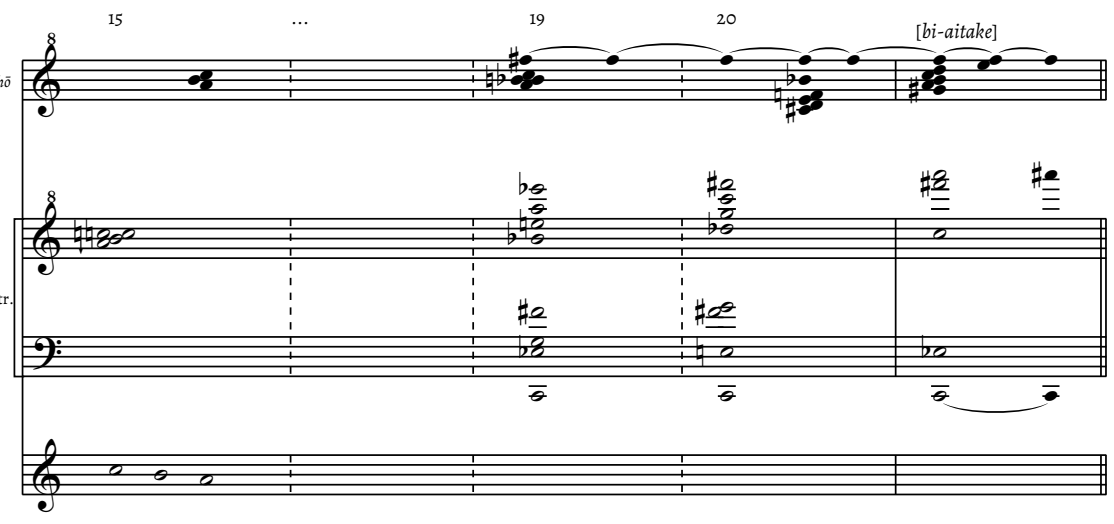
rehearsal numbers $14 \mathrm{a} / 14 \mathrm{~b}$, dividing the composition into two halves, spread the frame intervals from a narrow position of continuously increasing intervals (1-2-3 semitones, pitch-class set 0136) to extreme registers at the very end (rehearsal numbers 19/20). The complex structure of the intervening development can be consistently traced to the mother chord and reveals its potential in the extension of a semitone-whole-tone sequence to the modified octatonic scale (rehearsal numbers 13, 14b). Only in the very last sound field is there a complete aitake chord attained, embedded in a complex spectrum (and it hardly seems by chance that it is just that bi-aitake, as an excerpt from it had already appeared in the "mother chord").

Hosokawa's music thus shows that the world of the sho can develop considerable compositional density while also demonstrating the aesthetic pitfalls to which an unconditional surrender to the "shō myth" can lead. All in all, Hosokawa, to return to Lachenmann's words $(\rightarrow$ I.3), only communicates the "conjured magic" of shō music, but hardly its "broken magic." Yet Helmut Lachenmann himself seems to use the shō in the penultimate scene of his "music with images" Das Mädchen mit den Schwefelhölzern (The Little Match Girl, 1990-96) exclusively to evoke a state of mythical rapture, a dimension that the sonic structure of the two-hour music otherwise rarely approaches $(\rightarrow$ IV.2).

In this regard, a short comparison of Hosokawa's works for shō with a seemingly contradictory work of art like Matthew Barney's film Drawing Restraint 9 (2005-06), shot on the Japanese whaling ship Nisshin Maru, might be revealing. The music used in this film was produced by Björk, and the sho occupies a dominant role in three pieces (played by Mayumi Miyata, who also appears in the film). On the one hand, the film could easily appear as merely another example of the much-cited post-exotic Western fascination with Japan, but on the other hand, it may also achieve a hybrid in its sometimes abstruse mixture of shinto rituals, bathing culture, rebirth, $n \bar{o}$ theater, and shō music - a hybrid quality that Hosokawa's monistic sound blocks sometimes seem to lack. According to the film's press release, "the performance practice of the instrument itself reflects the organizing thematic of Drawing Restraint 9: the relationship between creativity and resistance."26

\section{From Myth to Myth Criticism}

Of course, there are also a number of compositional ways to deal with the myth and canon of the shō in a "critical" way, implicitly or explicitly. Klaus Huber's black plaint (1995) for shō and percussion may perhaps go the furthest in terms of an organological "reinvention" of the instrument: twelve of the 17 pipes are retuned to sixth- or third-tones, ${ }^{27}$ which is very difficult due to the fragile design of the instrument. Working with thirdtone and three-quartertone tunings has had a lasting impact on Huber's work since the 1990s, with an interest in old European tuning systems (especially 19-tone divisions of the octave from the sixteenth century) and the maqamāt in Arab music ( $\rightarrow$ II.6). ${ }^{28}$ Of course, in the traditionally Pythagorean-tuned shō, such a re-tuning has less of an archaizing, but rather a strongly alienating effect. In contrast to this break with a "traditionalist" approach (Huber states that he wanted to cut off the "tradition of Japanese music," as it were ${ }^{29}$ ), the gestalt and the atmospheric concentration on the inhalation and exhalation are strongly related to a tōgaku-oriented model. The five-note shō chords were

26 http://bjorknet.altervista.org/restored/dr9.

27 Huber and Mahnkopf, Von Zeit zu Zeit, 95.

28 See, among others, Knipper, "Tonsysteme im kompositorischen Schaffen von Klaus Huber."

29 Huber and Mahnkopf, Von Zeit zu Zeit, 95. 
created by a permutative principle and are blended into one another using te-utsuri-like techniques: Huber emphasizes the richness of detail of these transitions by a notation reminiscent of Robert Garfias' transcription of the te-utsuri on four staves ${ }^{30}$ (Ex. 4.7). An extremely slow basic tempo $(\downarrow=$ c. 32), continuous pianissimo, and the quasi-ritual conception of the drum part (the instruments include the shoko gong and the kakko coordinating drum from the tōgaku orchestra as well as the rin temple bell in addition to a stone slab and a roof tile) reinforce a quasi-ritualistic archaic atmosphere. This evocation of "shadows of millennia-old backdrops cast into the barbarism of our century"31 is further supported by the two performers' quiet recitation of two mourning poems from the oldest Japanese poetry anthology Man'yōsh $\bar{u}$ (Collection of 10,000 Leaves, Nara Period, c. 759), as well as fragments from the Hiroshima novel Black Rain (Kuroi ame, 1965) by Masuji Ibuse. In addition, characters from the texts are inscribed with mallets on the instruments and even carved into the stone slab. Clearly, the authority of the archaic is conceptualized as an "unspeakable" that is ideally opposed to the political and social conflicts of modernity. Especially in the alignment of the third-tone system (which refers to the history of European music) with the "Japanese" basic structure of sound composition, tempo, and color, Huber's work can be understood as an attempt to migrate into a global cultural memory beyond an explicit hybridization, but also with a clear recourse to mythologizing discourses.

Example 4.7: Klaus Huber, black plaint for shō and percussion, p. 8

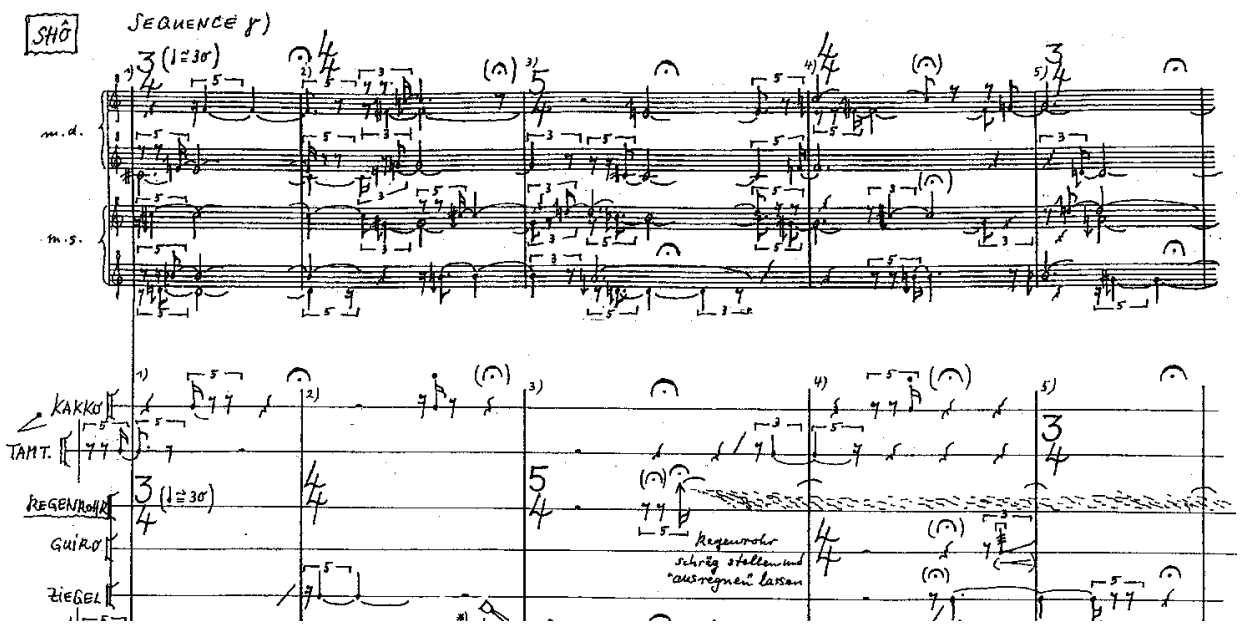

Copyright (c) 1995 by G. Ricordi \& Co, München

An atmospheric archaism was also a promising middle ground for many Asian composers, as shown in several examples in this book $(\rightarrow$ III.4, III.6, V.1). This middle ground helped to keep nationalist tendencies at arm's length while retaining a degree of cultural and personal independence from the European mainstream. Of course, as already discussed $(\rightarrow$ I.3, II.6), the archaic discourse can always turn into an uncritically mythologizing one. Gerhard Stäbler, who, like Huber, Lachenmann, and many others, strongly relied on the politically committed

30 See Garfias, Music of a Thousand Autumns, 48, 177-188.

31 Huber, "Black Plaint" ("Schatten jahrtausendealter Hintergründe, geworfen in die Barbarei unseres Jahrhunderts"). 
tradition of "critical composition" that had emerged since the late 1960s, clearly addressed this boundary when he introduced his 33-minute shō solo Palast des Schweigens (1992-93) by writing that the world of sho had remained "strangely alien" to him, "perhaps because in the traditional music of Japan it musically traces phases of becoming and decaying - as if following nature. This style of music does not seem to cope with impurities, external disturbances, 'worldly' interventions." ${ }^{32}$ Stäbler consequently sought "rough and chapped, sometimes even aggressively and intrusively charged" sounds in an attempt to "renounce" traditions. ${ }^{33}$ As a study for Stäbler's Christa Wolf opera CassandraComplex (1994), the isolated, harshly juxtaposed blocks of sound in Palast des Schweigens are also to be understood as a musical correspondence to Wolf's archaic language and a reflection on different forms of silence in the novel. ${ }^{34}$

Also, in more recent works by Stäbler for $s h \bar{o}$, an analogy between archaic Greek and Asian elements forms an important starting point for the conception. In ]LIFE[ (2004) for shō, hichiriki (the short doubled-reed oboe that leads the tōgaku orchestra), and glass chimes, the sho and hichiriki soloists alternately whisper fragments of Sappho, while the other instrument unfolds strictly monophonic lines. The underlying scale $\mathrm{B}-\mathrm{D}-\mathrm{E}-\mathrm{F} \#-\mathrm{A}$, to which later $\mathrm{C} \#$ and $\mathrm{G} \#$ are added, can be understood both in the context of togaku modality and as an allusion to archaic Greek scales. Especially in the third movement, analogously to the earlier solo work, extremes of dynamics are increasingly sought, culminating in a dense series of aitake chords at high volume. Example 4.8 shows the aitake $k u$, otsu, ge, $j \bar{u}, k o t s u$, and $j \bar{u}$ (second version without $F \sharp 5$ ) in the second system as well as the aitake $k u$ (the missing $\mathrm{D} 5$ is added by the hichiriki) and bi (with D6 instead of D5) in the fourth system. After a distant hichiriki line grows out of the last chord of the second system, the last Sappho fragment is whispered ("with a bright voice") along with bright glass sounds. For the two closing aitake sounds in the shō, the hichiriki is pushed "beyond its limits." In contrast to the uncompromising criticism of tradition in Palast des Schweigens, the peak of Stäbler's "anti-traditionalism" here translates into a quotation of traditional harmony, which, of course, extends almost "shamanistically" and thus appears in a refracted form.

The basic idea of an unbridgeable gap, which is related to this concept, is at the center of Chaya Czernowin's Die Kreuzung (1995). The composer starts from the paradox of constructing a "super instrument" ${ }^{\prime 35}$ out of an $\bar{u}$ mouth organ (a bass shō, pitched an octave lower), an alto saxophone, and a double bass, the instruments being related to one another only as opposites and by the curious attraction of the basically incompatible. As in Franz Kafka's short prose fragment "A Crossbreed" [Eine Kreuzung] (1917) about an animal that is half-cat and half-sheep, the mix-ture of repulsion and attraction results in a "net of impossible relationships between the micro and macro levels."36 Czernowin exacerbates these kinds of relationships through the extensive fragmentation of the structural building blocks of the piece $(\rightarrow \mathrm{V} .3)$ : the fragmented structures are layered and coupled in an unsystematic way. Especially in the first part of the work (sections A-C), this can easily

32 Stäbler, "Palast des Schweigens," 8 ("seltsam fremd"; "vielleicht weil sie mir zu eng mit der des kaiserlichen Hofes liiert schien, wahrscheinlich aber mehr, weil sie in der traditionellen Musik Japans - gleichsam der Natur folgend - Bögen des Werdens und Vergehens musikalisch nachzeichnet; ein Musizierstil, der Unreinheiten, äußere Störungen, 'weltliche' Eingriffe nicht zu verkraften scheint.")

33 Ibid., 8-9 ("rauh und rissig, manchmal sogar aggressiv und aufdringlich," "Traditionen zu kündigen").

34 Ibid., 9-10.

35 This is a very probably a conscious reference to Helmut Lachenmann, who has repeatedly spoken (especially with reference to his Second String Quartet) of producing a "super instrument" in the process of composing (Lachenmann, "Über mein Zweites Streichquartett," 232).

36 Czernowin, "Die Kreuzung." 
Example 4.8: Gerhard Stäbler, ]LIFE[ for shō, hichiriki and glass chimes, III, ending
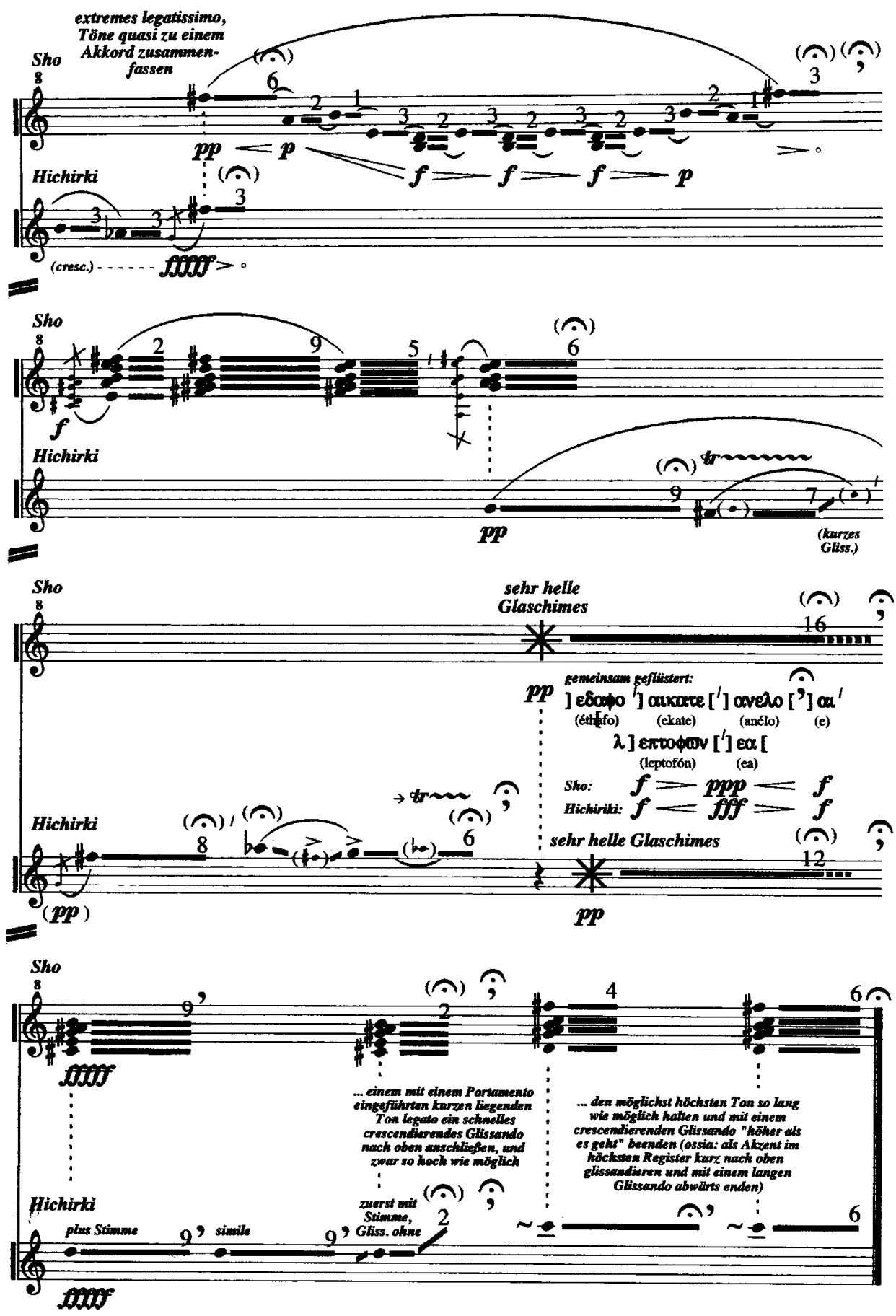


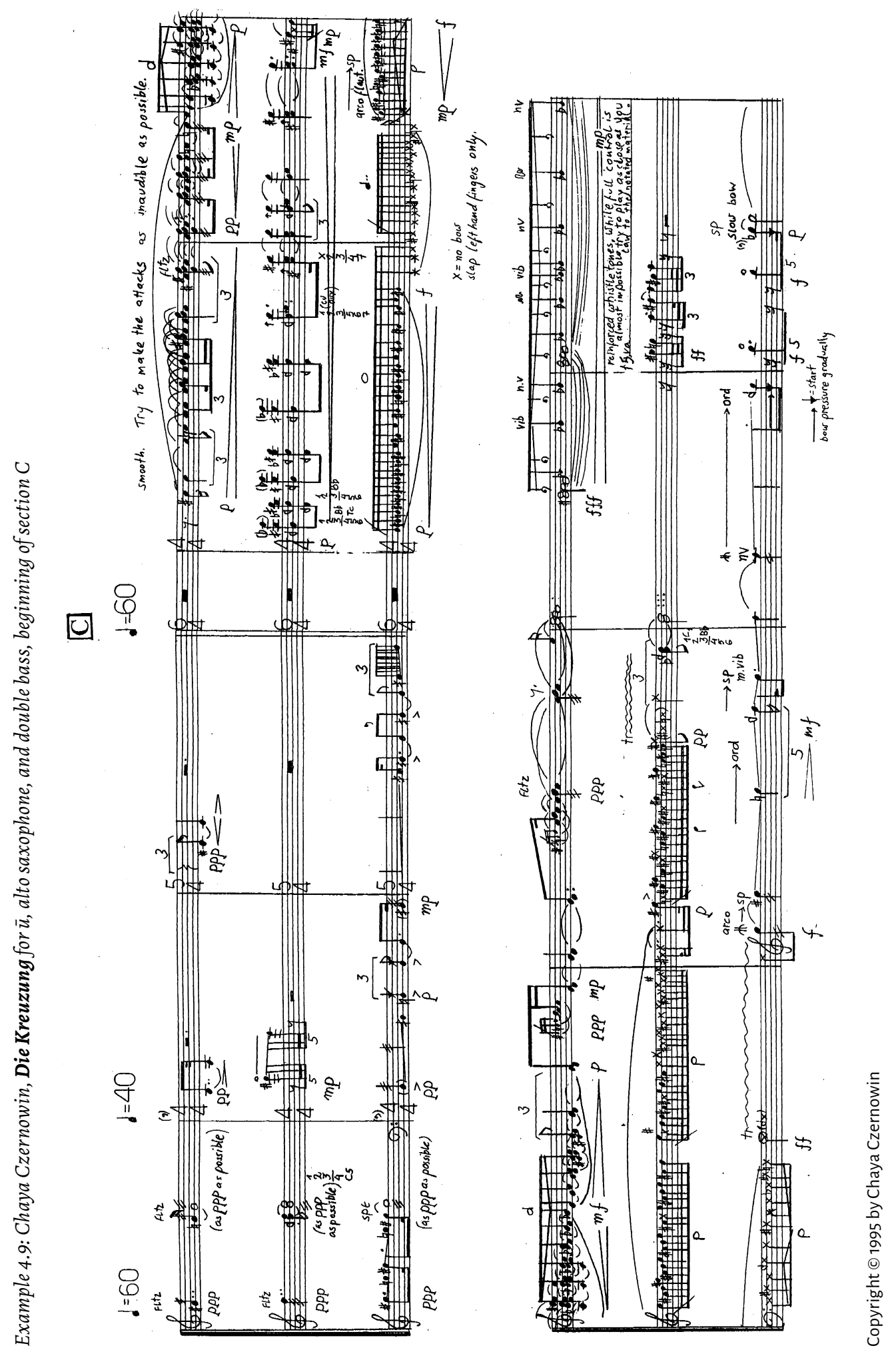


be recognized in the score: a constant alternation of homorhythmic and polyrhythmic passages, frequent changes in tempo, and continually changing figures express sameness through difference. Instrument-specific extremes of technical possibilities seem to be the object of the work, in dynamics $(\bar{u})$, registers (double bass), and timbre (alto saxophone). The density thus achieved in section $C$ (Ex. 4.9) and the virtuosity of the $\bar{u}$ part lack any reference to the mythical-canonical sho tradition. The cultural identity of all three instruments seems to be reduced to that minimum that ultimately does allow for a connection of their difference, counteracting on the "gap" between their contexts and, in this way, repeatedly tending toward leveling and neutralization.

The break with the myth of the sho is attainable here only at the expense of a complete "anti-idiomaticization" of the instrument. A different approach to myth criticism is found in John Cage's composition One (1991) for solo shō, one of the late "Number Pieces." ${ }^{37}$ In order to determine the selection of chords within the time windows, Cage started from a table of all possible chords and made a random selection (between one and seven notes), which can be repeated ${ }^{38}$ and may contain aitake chords as well as major or minor triads: ${ }^{39}$

Cage approached composition by determining a number of possibilities for an instrument and then using chance to select which of these possibilities would appear, and at what point in the composition. Among his musical sketches archived at the New York Public Library are copious notes indicating all individual notes and clusters (aitake) that the shō could play, both familiar and unfamiliar. Audiences and performers of his music who are intimately acquainted with the sho would surely recognize some of these combinations, but the unusual ones would defamiliarize the older chords and allow them to be experienced as fresh and novel sounds in their own right. ${ }^{40}$

Through pauses and caesuras, the flow of sounds is broken again and again - and thus the music maintains a clear distance from traditional shō performance practice. Sounds and silences are contained in an infinite continuum that Cage designed in the early 1950s, based on the maxim of "unimpededness and interpenetration" derived from Huayan Buddhism ( $\rightarrow$ II.6). Of course, this form of myth negation (to speak of myth criticism would arguably be inappropriate here) is characterized by a sharp paradox. By making instrumental technique, the playable sounds as delineated by traditional fingering, the sole basis, Cage replaces the canonical myth of the sho with the factual myth of playing technique: "The composer folds his hands in front of his sounds [...]" - "[...] the mythology that in play was expelled as semblance is more than ever reproduced [...]. ${ }^{, 41}$

37 Coupled with One ${ }^{9}$ is $T w o^{3}$ (1991), which combines the shō part of One ${ }^{9}$ with a part for conch shells; in Two ${ }^{4}$ (1991) for violin and shō, the shō part is newly composed (whereby the shō can also be replaced by a piano). In addition, One ${ }^{9}$ can be combined with 108 for large orchestra (1991). Some basic information about these pieces is provided by Haskins, "The Extraordinary Commonplace" and Drury, "Variation Pitch Structure Time." Toshio Hosokawa also mentions Cages Two ${ }^{4}$ in Hosokawa, "Aus der Tiefe der Erde," 53. For Cage's Number Pieces in general see Haskins, Anarchic Societies of Sounds.

38 Compare, for example, the seventh chord after 4:45 in no. 6 with the first chord after 2:00 in no. 1.

39 Examples of aitake chords are the first chord after 4:00 in no. 2 (ku) or the fourth chord after 7:45 in no. 2 (jū, second variant). The first major triad appears as the fourth chord after 0:00 in no. 3.

40 Haskins, "The Extraordinary Commonplace."

41 Adorno, "Anton von Webern," 122 (“Der Komponist faltet vor seinen Tönen [...] anbetend die Hände."); Adorno, Philosophy of New Music ("im Spiel reproduziert sich [...] erst recht jene Mythologie, die man als Schein vertrieben hat." Adorno, Philosophie der neuen Musik, 67n). These statements, in which one could see the essence of Adorno's critique of twelve-tone technique, especially in its application by late Webern, might make a fundamental aporia of Cage's aesthetics visible. 
Example 4.10: Yüji Takahashi, Mimi no ho, score pages shō (left) and viola (right); under the instructions for the viola player (section $C$ ) one finds the final sho glissandi with which the piece ends

Shō

\begin{tabular}{|c|c|c|c|c|c|c|c|c|}
\hline $\begin{array}{c}2 \\
t \\
t\end{array}$ & 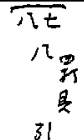 & $\begin{array}{c}t- \\
t \text { 罚 } \\
\end{array}$ & 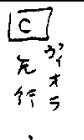 & $\begin{array}{l}2^{7} \\
+T^{\prime}\end{array}$ & $\begin{array}{l}\frac{1}{a} \\
\frac{1}{a}\end{array}$ & $\begin{array}{l}0^{7} \\
L^{7} \\
\end{array}$ & $\frac{\mid \vec{B}}{\frac{c}{2}}$ & 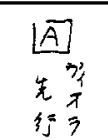 \\
\hline *言七 & 绝 & 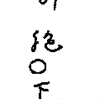 & $\begin{array}{l}2+8 \\
i+x \\
i\end{array}$ & 4 & $L^{1}$ & $\begin{array}{l}i \\
5\end{array}$ & $\stackrel{=7}{2}$ & 抑 \\
\hline & 此叫 & $\begin{array}{l}T_{18} \\
I^{\prime}\end{array}$ & $\dot{L}$ & $2_{45}$ & 个抑 & $L^{D^{7}}$ & $\stackrel{x}{a}$ & 行 \\
\hline 绝 & $r^{i} n$ & & 千 & $=7$ & & & & $t_{\text {洽 }}$ \\
\hline$\frac{2}{\mp F}$ & 比 & F & i & $\overline{2}_{1}$ & $f$ & $x_{\dagger} t_{i=1} P$ & & $\frac{10}{f^{7}}$ \\
\hline & $I$ & $t$ & 言 & $L_{n}$ & & & $L^{\circ}$ & 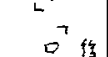 \\
\hline 闹 & is & 掕。 & $t$ & $L_{3 x}$ & 53 & 影 & 言 & \\
\hline 千 & $\tau$ & $t$ & 裳 & 八是 & $L^{a^{7}}$ & sz & $=7$ & -8 \\
\hline 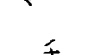 & 至七 & - & + & $\star^{n}$ & $\begin{array}{l}t^{2} \\
+\end{array}$ & & L & 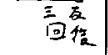 \\
\hline$t^{3}$ & $\dot{I}$ & 千 & 上 & F & $F$ & & $=$ & 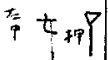 \\
\hline $\begin{array}{l}n_{2} \\
\end{array}$ & 亿 & $z$ & $\dot{F}$ & & $\dot{-x}^{x}$ & & $\stackrel{=}{\therefore}$ & \\
\hline$P_{2}$ & & 版 & 行招 & $t_{x}$ & & & & \\
\hline
\end{tabular}

Copyright ( 1994 by Yūji Takahashi, Tokyo

A probably more productive form of myth criticism via recourse to the physical-technical basics of shō performance practice is offered by Yūji Takahashi's Mimi no ho (Sails of the Ears, 1994) for $s h \bar{o}$, viola, and speaker. In many of his works, Takahashi "twists and turns" (Western and Asian) performance traditions back to their elementary beginnings through close observation and study of traditional performance practice $(\rightarrow$ III.4). To be sure, Takahashi's goal is neither a historical reconstruction of tradition nor its negation, but the almost playful discovery of a place beyond these extremes. These techniques, however, are by no means limited to Japanese instruments, but open up new possibilities of intercultural rapprochement, such as in the transfer of the kinaesthetic, haptic treatment of sho and viola in Mimi no ho. Just as the 15 or 17 sounding pipes of the sho, which are not arranged in a scale (see Ex. 4.4), require a specific haptic orientation from the player, the fretless fingerboard of the viola is predestined to connect pitches by sliding lines. This is particularly elaborated in Section $\mathrm{B}$, where the viola repeats a model several times, each time setting it a little higher, but maintaining the "physical" distance of the first played figure, creating slightly "stretched" intervals (Ex. 4.10, viola part). In Mimi no ho, as in many of Takahashi's other works, these two distinct performance modes, resulting in two fundamentally independent textures, are superimposed in a mode of attentive listening to one another. To this situation, the speaker adds a recitation of an early poem by Ossip Mandelstam that welcomes emptiness ("Sluh chutkij parus naprjagaet...," [Ears stretch sensitive sails...,] 1910). The final section is held together by a drone on A4 in the viola part, above which 


\section{耳の帆(1994)}

\section{Viola}

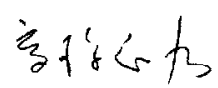

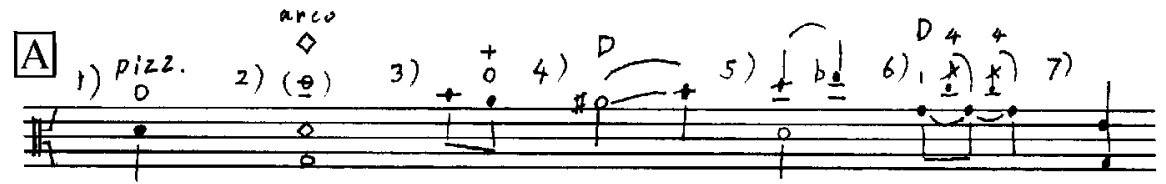

Violaからはじめる。1)〜7) で笙にあしらう。充分間をもって。
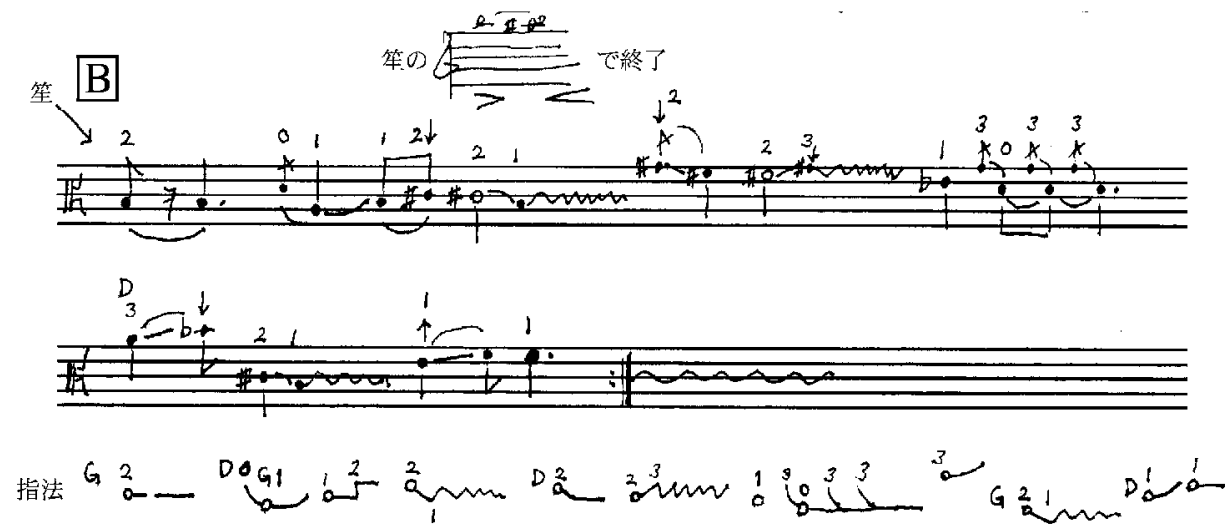
反復のたびに全体をすこしずつずり上げる。開放㹡だけは変光ない。

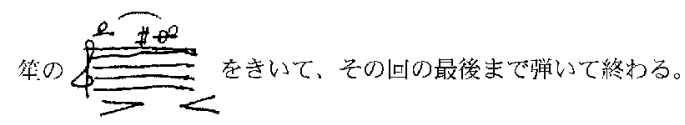

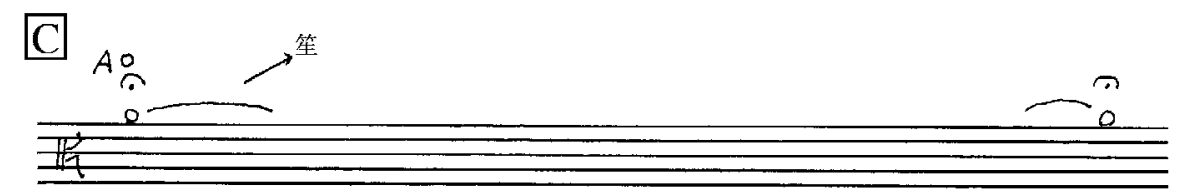

D弦で啭の音と同音（octave下）か上下に半音以内の守扎をもつpitchに ゆっくりgliss.で移る。そのあいだずっとAのdronc。

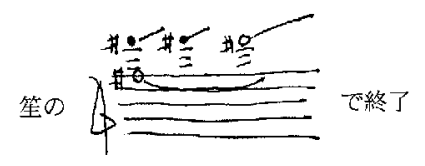

the viola follows the pitches of the shō in a free manner, connecting them with glissandi. The glissando gesture is in turn taken up by the shō in a concluding gesture, creating a model of subtle communication between the two soloists.

If in Mimi no ho the "organological" dimension of the instrument, its physical properties and their implied gestural performativity, is the starting point for overcoming its "canon," Takahashi, in Sōjo rinzetsu (1997) for one or two shō, takes the path of a more philologically accentuated myth criticism, not least against the background of an intensive study of old 
gagaku manuscripts. ${ }^{42}$ The composer uses elements of the archaic notation in this work (Ex. 4.11), which contained special signs for adding and removing individual fingers revealing a "haptic" playing logic increasingly lost in modern notation, ${ }^{43}$ and he also picks up on aspects of the archaic style that Laurence E. Picken and his colleagues have reconstructed. The thesis of the researchers, among others, was that, in the context of early tōgaku, the shō was not required to play those contemplative sound surfaces of the interlacing chords aitake for which it is known today. Rather, together with the biwa, it was used as a melodic instrument and integrated into a heterophonic structure. ${ }^{44}$ In addition, the melodies were supposedly played at a much faster tempo than today.

Example 4.11: Yüji Takahashi, Sōjō rinzetsu for one or two shō, part 2; right: transcription in Western notation by the composer
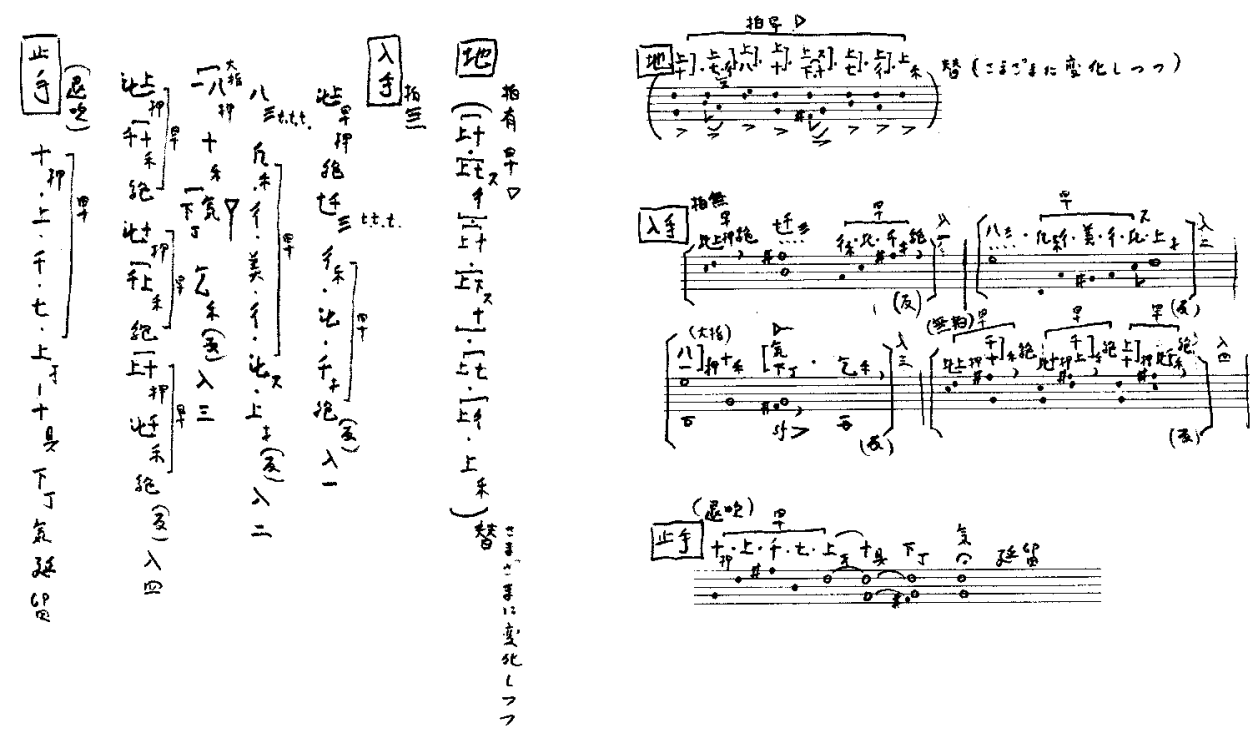

Copyright (c) 1997 by Yūji Takahashi, Tokyo

42 The sources used by Takahashi are, among others, Taigen shō (1512), ed. Toyohara no Muneaki, and Gaku ka roku, ed. Abe no Suehisa (1690), as well as a comparison of the three sources Shinsen shōteki fu (1302), Kofu ritsu ryokan (1201), ed. Toshiaki Toyohara, and Hōshō ryo ritsu kan (1345), ed. Tatsuaki Toyohara (1630?) by the shō soloist Kō Ishikawa. Takahashi also explicitly refers to the research tradition of the Laurence E. Picken school. He studied, among others, volumes 4 to 6 of the series Music from the Tang-Court and essays by Allan Marett and Steven Nelson, especially in connection with his composition Bosatsu kangen dennōdate (Computerized Music for a Bodhisattva) for gagaku ensemble und electronics (1992). Correspondence with the author 21/3/2006.

43 Takahashi calls this a "digital" notation method, in the double sense of the word, alluding to the Latin term for finger, "digitus." (Correspondence with the author 21/3/2006.)

44 See, for example, the transcription of Sendai-en in Wolpert, "The Mensural Notation," 128-129. 
Takahashi's Sōjō rinzetsu is surely more than a mere historical reconstruction of the tōgaku style during the Heian or Kamakura Periods. He also tries to include elements of oral tradition in his score (to which the second term of the title "rinzetsu" refers, ${ }^{45}$ while sōjō merely indicates the [G-] mode of the piece). In the second part of the piece, Takahashi extends the historico-geographical scope of his references to southwest China. Here he refers to a tradition of the Chinese Miao minority, ${ }^{46}$ possibly dating to an early historical period, in which the lusheng mouth organ is played by young men during courtship dances. It is no coincidence that this social practice stands in stark contrast to the solemnity of the courtly toggaku as we know it today.

The pseudo-archaic notation derived from the study of ancient shō manuscripts here helps to reconstruct a shō style in which the instrument shows a way of playing that has at best survived in the chōshi introductions of the tōgaku, but is here introduced in different tempi and enriched by ornamental gestures. The paradoxical effect of Sōjo rinzetsu lies in the fact that the authority of the archaic attributed to the sho, especially in the nineteenth and twentieth centuries, is overcome precisely by a meticulous, source-critical philological reconstruction of archaic shō music. Takahashi's composition is certainly more than mere archeology, as he refers above all to those improvisational parts of sho performance that do not appear in the written sources. Thus Takahashi also explicitly criticizes those nationalist currents of Japanese ethnomusicology that had negated such a view of the (early) history of the sho for a long time.

"Music begins by doubting sounds $\mathrm{s}^{\text {"47 }}$ : Takahashi's work aptly characterizes the far-reaching and complexly transformative approach that the composer has developed on the subject of cultural difference. Concentrating on specific case studies and historical sources, he refrains from any sort of pseudo-authentic historicism. Rather, his music permits the transformational and unpredictable on a large scale, which also manifests in the fact he gives much space to the personal responsibility of the performers. This approach can lead to individualized situations in which essentialist, political, or ideological definitions of culture become fluid.

New music for shō is more than a compositional confrontation or appropriation of a novel/ancient instrument with novel/archaic sounds; it is always especially a demonstration of a "world-

45 "I consider those old notations [a] personal memorandum by amateurs or students of oral transmissions devoid of extempore variations and ornaments, rather like some reconstructed performances of European Medieval dance tunes." (Correspondence with the author 7/6/2006.) According to Takahashi, rinzetsu refers to improvisational practices in the context of the historical gagaku. More commonly the term designates a freer composition style within the koto tradition, which dates back to the repertoire of Yatsuhashi-ryū of Yatuhasi (Yatsuhashi) Kengyō.

46 The lusheng (among the Miao in Cuizhou and Cuangxi) and hulusheng (among the Yi, Lahu, and other minorities in Yunnan) may be the descendants of one of the oldest demonstrable forms of the Chinese mouth organ sheng. This would support the theory that the mouth organ originated in the Southeast Asia region independently, or even before, central Chinese variants (this similarly applies to the mouth organ khaen in Laos and Thailand). For details of the history of the mouth organ, see Schwörer-Kohl, "Mundorgel."

47 "Music begins by doubting sounds. One tears oneself away from the charm of sounds, one cuts the stream by coming to depend upon musical elements that are not time-related. Eliminate all unnecessary information and learn new techniques; repeat one thing again and again instead of indulging in the traditional dramas of time." (Takahashi, "From Words to Music," 67.) 
view" - a word that appears repeatedly in Toshio Hosokawa's statements with good reason. ${ }^{48}$ But not only that extensive reference to the canon and myth of the sho, designed by Hosokawa's own music, produces a worldview, the term also applies to the myth-critical counter-positions described above, especially to those that implicitly pretend to have overcome the dimension of worldviews entirely, such as John Cage's Number Pieces, instead submitting to the facts of the sounds in the attempt to escape the myth.

A way out of this polarization between a reproduction of canonized repertoire or mythological aura on the one hand, and the mythology of a "pure sound" on the other, is suggested by those reflective positions outlined here, which critically take up the myth of the sho but neither negate its cultural historicity nor absolutize it aesthetically. Of course, it is inevitable that they, too, internalize the "myth" of the instrument, historically shaped in the unification of the gagaku repertoire since the mid-nineteenth century and its aestheticist essentialization. What is decisive, however, is that they allow this myth to be experienced in perspective, while deforming, perhaps distorting previous practice, continuing to rethink and transform the shō in a "hypoleptic" manner. Perhaps this is a measure of intercultural composition as a whole, which is certainly attained by the following, more thoroughly discussed example of shō reception.

\section{The shō as a Medium of Alterity and Self-Referentiality in Helmut Lachenmann's Music}

\section{Aura and Alterity}

When the chords of the Japanese shō sound in the penultimate scene of Helmut Lachenmann's Das Mädchen mit den Schwefelhölzern (The Little Match Girl, 1990-96), or when we hear the breathy wind chords in the final section of his large ensemble work Concertini (2004-05), these moments undoubtedly bring about what the composer has often described in his listening phenomenology: a conscious hearing-in ("Hin-Hören") takes place, a moment that makes the act of listening conscious and makes it possible, perhaps even inescapable, to listen sensuously for the sake of listening itself, to break out of the "listening grammar" that seemed unproblematic a few seconds earlier. When hearing-in, one questions the rules of this grammar, and with it the aesthetic and cultural agreements on which it is based $\left(\rightarrow\right.$ I.1).$^{49}$

Such an overt break with the directly preceding sound world refers in particular to that auratic component of the musical material, which Lachenmann accords a central position as the

48 "And to paint or sing this vivid line - I always need that mother chord and it can be like a very tight silence. And for me this is like a worldview: there must always be something in the background and there must be two different layers. That can be silence, that can be flowing sounds - and a line. Analogously, one can call these layers: universe and human, nature and human." "Und um diese lebendige Linie zu malen oder zu singen-dazu brauche ich immer diesen Mutterakkord und der kann auch wie ein sehr dichtes Schweigen sein. - Und das ist für mich wie eine Weltanschauung: Es muss auch im Hintergrund immer etwas da sein, und es müssen zwei verschiedene Schichten entstehen. Das kann Schweigen sein, das können fließende Klänge sein - und eine Linie. Analog kann man diese Schichten nennen: Universum und Mensch, Natur und Mensch." Hosokawa quoted in Sparrer, "Toshio Hosokawa," 8.)

49 A theory of "hearing-in" as an oscillation between metaphorical and non-metaphorical listening has been developed by Andy Hamilton in correspondence to Richard Wollheim's theory of "seeing-in" (see Hamilton, Aesthetics and Music, 95-111 and Hamilton, "The Sound of Music," 171). 
"bearer of familiar experiences in existential reality," ${ }^{\text {" }}$ whose significance for his work he emphasized early on ( $\rightarrow$ IV.1). In his studies on "event and aura," Dieter Mersch has shown that a perception of the auratic in the arts is closely linked to the principle of alterity $(\rightarrow$ I.3) as developed by Emmanuel Lévinas, among others. ${ }^{51}$ Mersch attempts to understand auratically qualifiable processes of perception by an "ek-static" basic principle, by "encountering an "outside of me,' which is part of the tendency to limit or confuse my concepts and signification schemata and to overthrow them. ${ }^{152}$ It is thus central to this understanding that, on the basis of the principle of alterity, this form of perception retains a fundamental riddle-character (in Lévinas: "enigma"), thereby "letting the form suspend itself in favor of the act of appearance."

This connection between breaking with an established and dominant state, the resulting discontinuity, and the categorial otherness of the newly emerging state can be experienced again and again in Lachenmann's music and serves the composer as a means of advancing to the concrete utopia of a "liberated perception." ${ }^{54}$ It quickly becomes audible and visible that, however this alterity is enacted (e.g., through musical structure, timbre, tempo, polyphony/density, sound-to-sound relationships, cultural and narrative contexts), polarities that initially seem "incompatible" emerge as "dialectical" in the further unfolding of events. Thus the aspect of the auratic and magical is successively captured by refractions and critique that Lachenmann considers key to an understanding of the European concept of art. ${ }^{55}$ Not least, these forms of mediation presuppose the awareness and the possibility of musical self-referentiality, in which musical language skills constantly question themselves rather than being simply "set." is hardly coincidental that, in The Little Match Girl's shō scene, the initially "solemnly" enacted unbroken sound field (stretched to 76 quarter notes) - at whose center is the perfect fourth B4-E5 - is contradicted in the second half of the scene by its "negative," a sound field that is only two quarters longer in length, in which the sho is completely silent and which is dominated exclusively by "perforated" string sounds created by increased bowing pressure. Similarly, it can be argued that the music of this scene from the beginning is subjected to a double (cultural and historical) coding, and therefore the musical material, in addition to a constant self-interrogation (on the "intra-opus" level), continuously refers to different con-texts (or "extra-opus" levels). ${ }^{57}$ Therefore, this music deliberately bypasses a simplistic construction of alterity.

50 Lachenmann, "Vier Crundbestimmungen des Musikhörens," 61 ("Trägerin von vertrauten Erfahrungen aus der existentiellen Wirklichkeit").

51 Mersch, Ereignis und Aura, 14-15, 50-52, as well as Lévinas, Alterity and Transcendence.

52 Mersch, Ereignis und Aura, 27 ('Begegnung mit einem 'Außer-mir', das in der Tendenz steht, meine Begriffe und Signifikationsschemata zu entgrenzen oder zu verwirren und umzustürzen").

53 Ibid., 50-51 ("wo sich die Form zugunsten des Erscheinens selbst suspendiert"). See Lévinas, "Phenomenon and Enigma."

54 Lachenmann, "Zum Problem des Strukturalismus," 90 ("befreite Wahrnehmung"). See also Lachenmann, Gadenstätter, and Utz, "Klang, Magie, Struktur," 19.

55 See Lachenmann, Gadenstätter, and Utz, "Klang, Magie, Struktur," 27-28 and Lachenmann, "East meets West?," 87-90.

56 This aesthetic demand can be traced in particular to Lachenmann's well-known debate with Hans Werner Henze, see Lachenmann, "Offener Brief an Hans Werner Henze."

57 The distinction between "intra-opus" and "extra-opus" knowledge was introduced, in particular, in the framework of cognitive-oriented currents of music theory, to describe different levels of reference formation that play a role in listening to and hearing music (see above all Narmour, "Hierarchical Expectation and Musical Style"). Of course, the distinction can easily be transferred to an "co-composing" "implicit listener," as it were, 
The "staging" of the Japanese instrument follows a general aural dramaturgy that Lachenmann has repeatedly implemented and developed in a wide variety of situations and with the most diverse sound resources. Thus the staging seems, at first, to have little to do with the fact that the instrument has a different cultural context (Japanese gagaku court music) than other instruments and voices (of European origin) "deconstructed" by Lachenmann. At first sight, this assessment is supported by several statements made by the composer in recent years, which demonstrated a sustained and fundamental skepticism about the possibilities of musical "interculturality" ( $\rightarrow$ I.3, II.6). ${ }^{58}$ Legitimate doubts, however, can be raised against the assumption that the treatment of the sho here is little more than a tried and tested means of extracting a new "effect" via Lachenmann's fundamental strategy of "refraction," supposedly merely serving as the negation of the negation of a sound ideal, which can be represented very aptly by the unbroken, "pure," fusing sound of the shō. In fact, Lachenmann himself hinted that he had resorted to the "scale" of the sho not only in his "opera" but also at the end of his ensemble work Concertini, ${ }^{59}$ implying that connections with traditional repertoire and the performance practice of the instrument $(\rightarrow$ IV.1) - and not just a celebration of its sounding aura - are intended.

Against this background, this chapter pursues the goal of analytically reconstructing structural and narrative contexts in which the principles of alterity and self-referentiality, as well as "extra-opus" and "intra-opus" references, materialize in the final stages of The Little Match Girl and the ending of Concertini. The discussion follows a series of short, loosely interconnected reflections on "sound organization," "split sound and structural sound," "temporal sections," "narrativity," and "interculturality."

\section{Sound Organization}

In the 1970s, Lachenmann critically remarked that the dialectic between consonance and dissonance was "infinitely expandable," and that it would be possible that

any musical experience, even if it is completely alien, can be attributed to the tonal principle as an experience of dissonance whose excitement increases as it moves away from the tonal middle toward whatever periphery. In other words, there is nothing that cannot be grasped with the categories of tonality and is correspondingly usable. ${ }^{60}$

In compositional terms, Lachenmann has addressed this "claim to totality" of the concept of tonality by entering the "lion's den" and constantly picking up, deconstructing, and reinventing genres, style characteristics, pitch structural models, and music-theoretical fundamentals of tonal music - analogously to the "traditionalism" in the institutional contexts of his composing (chamber music, orchestra, opera). In the same vein, Daniel Kötter has shown how, in The Little Match Girl, starting from a distanced, quasi-quotational treatment of the "debris field" of tonal

that is, to more or less conscious reference formations in the context of the compositional process. See Utz, "Das zweifelnde Gehör."

58 See particularly Lachenmann, "East meets West?"

59 Ibid., 84.

60 Lachenmann, "Vier Grundbestimmungen des Musikhörens," 55 ("jegliche Musikerfahrung, und sei sie noch so fremdartig, dem tonalen Prinzip zuzuordnen als Dissonanzerfahrung, deren Spannungsreiz in dem Maß noch zunimmt, wie sie sich von der tonalen Mitte weg in welche Peripherien auch immer entfernt. Anders gesagt: Es gibt nichts, was mit den Kategorien der Tonalität nicht erfaßbar und entsprechend nutzbar wäre.") 
Example 4.12: Above: beginning of the shō part of Etenraku (in the hyōjō mode; transcription after Miki, Nihon gakki hō, 79); below: Helmut Lachenmann, Das Mädchen mit den Schwefelhölzern, scene 23: Shō, shō part, $\mathrm{mm}$. 544-556

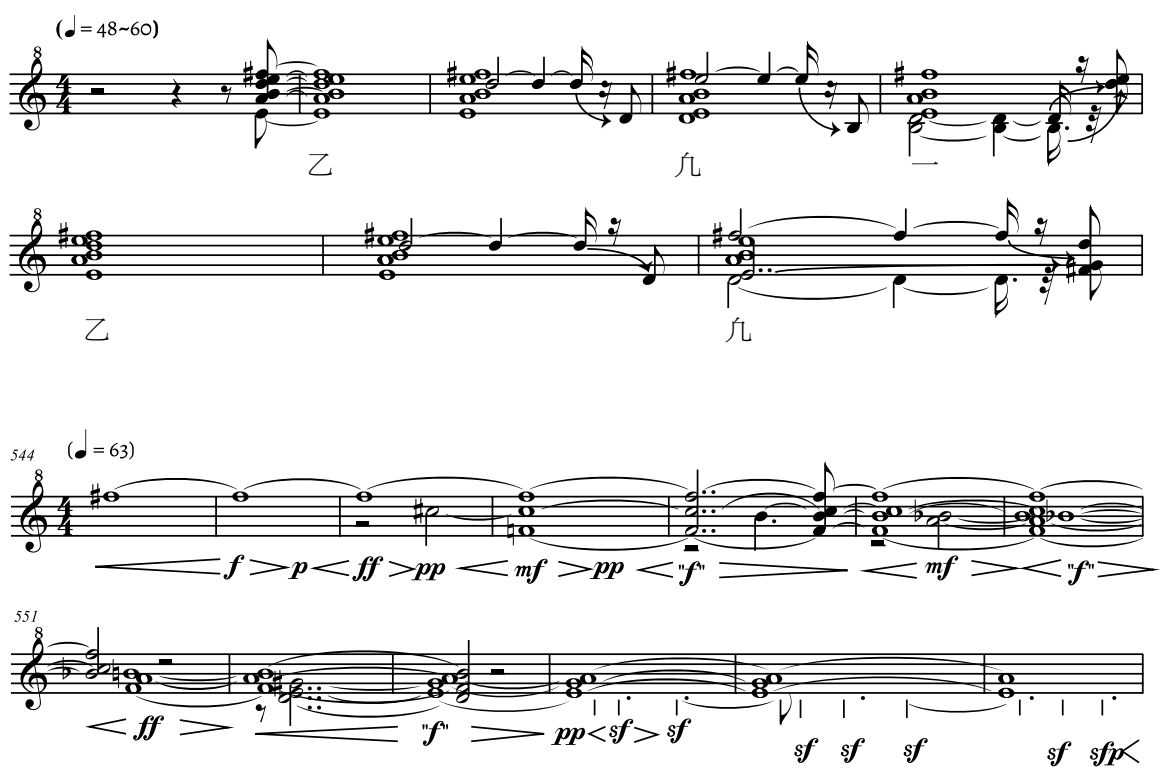

"flotsam," elements from the world of tonality become more and more "self-evident means of composition." ${ }^{\prime 61}$ Lachenmann has emphasized in this context that his basic compositional techniques of such a game of culturally familiar material layers, such as musical intervals ordered according to constant (equidistant), continuous (successively increasing), or cyclical (symmetrical) principles, were developed as early as the 1960s. ${ }^{62}$ With his "Kadenzklang" (cadential sound), Lachenmann bases his "sound types," conceived in 1963-66, on a musical archetype whose simple progression from calm to motion to calm, in addition to the acoustic transientdecay process, also associates common "primordial models" of tonality, as developed, among others, by Adolf Bernhard Marx or Ernst Kurth. ${ }^{63}$ In contrast to the monistic concept of tonality, Lachenmann's post-structural cosmos of music, of course, constantly changes the system of reference and thus the imaginary "middle ground" from which movement emerges, and to which it flows back.

61 Kötter, "Die Irreführung der Oper," 45 (“Trümmerfeld," “Hörreste," "selbstverständliche[] Mittel[] der Komposition").

62 Lachenmann, Gadenstätter, and Utz, "Klang, Magie, Struktur," 46.

63 See Lachenmann, "Klangtypen der Neuen Musik," 1-8; Marx, Die Lehre von der musikalischen Komposition, vol. 1, 23; Kurth, Grundlagen des linearen Kontrapunkts, 43. Both theorists start from the major scale to exemplify their model of motion. In Marx, the octave (e.g., $\mathrm{C}_{3}-\mathrm{C}_{4}$ ) represents the principle of calm, the intermediate stages (e.g., D-E-F-G-A-B) the principal of motion. For Kurth, who subdivides the octave into the tetrachords C-F and G-C, F represents a first target and resting point, anticipated by the intermediate leading tone $E$; with $G$, a new ascent begins. Overall, the upper tetrachord is more tense than the lower tetrachord for Kurth because of the leading tone $\mathrm{B}$. 
In the sho scene, one of these systems of reference is undoubtedly the instrument itself, whose uniqueness is underlined not least by the fact that it does not appear once in any of the preceding 22 scenes. It is unmistakable that Lachenmann starts from the traditional playing style of this instrument: the gentle rise and fall of the sound follows the rhythm of the breath, as in the toggaku repertoire of gagaku. Thus, Lachenmann brings a significant organological characteristic of the sho to the listener's awareness - its ability to create an uninterrupted sound field. At the same time, an "intra-opus" layer is emphasized, in that this continuous sound takes up the model of a "potentially infinite song" that was introduced in previous scenes, in particular by the soloistic vocal parts. ${ }^{64}$

The finger position changes (te-utsuri) between the chords and the changes between inhaling and exhaling (ikigahe) in traditional shō performance practice strictly follow codified rules, as shown above $(\rightarrow$ IV.1). A comparison of the shō part from the most famous tögaku piece - Etenraku - with a section of Lachenmann's shō part (mm. 544-556) clearly reveals as a common principle the successive addition or removal of individual tones during the swelling and decay process (Ex. 4.12). "Cadential sound" and traditional shō phrasing thus here form a double coding of Lachenmann's sound design.

While the changes of color - and thus the chords - in toggaku are intimately connected with the complicated arrangement of the 15 pitches on the instrument and the traditionally codified assignment of fingers to tones - every te-utsuri-change seems to emerge from this haptic performance feel $(\rightarrow$ IV.1) - , Lachenmann has obviously taken little account of the traditional fingering technique in constructing his sounds, as a conversation with soloist Mayumi Miyata confirmed. ${ }^{65}$ Example 4.13, top line, shows the sequence of the chords otsu-bo-ju-ge-otsu from Etenraku including a schematic representation of the underlying fingering, and the bottom line shows Lachenmann's shō chords in measures 516 to 518 and 540. ${ }^{66}$ To play these chords, Mayumi Miyata needed to replace the C6-tone bamboo tube to have what is normally an inside hole on the outside of the instrument, as well as developing many unconventional fingering techniques, including the non-standard covering of several holes with the same finger. Lachenmann calls for a similarly radical change in the playing habits of the Japanese instrument as he usually does for European instruments, but leaves its familiar traditional timbre intact.

The Pythagorean tuning of the sho is based on a cycle of perfect fifths, which also forms the structural basis for the aitake chords $(\rightarrow$ IV.1). A structural reduction of the sho sounds in Lachenmann's composition (Ex. 4.14) also reveals numerous quartal and quintal structures (shaded in gray), culminating in the aforementioned "celebrated" fourth B4-E5 (mm. 518-532), in which oboes, violas (later clarinets) and trumpets are added to the sho. This fourth acquires special meaning, since it is played for 57 quarter notes without any accompaniment. Later, the quintal-quartal structures even allow a purely pentatonic chord to emerge that can be regarded as a slightly "compressed" variant of the bo-aitake (m. 622, based on the pentatonic scale $E-F \#-G \sharp-B-C \sharp$; instead of $D 5-E 5-A 5-B 5-E 6-F \# 6$ [bō-aitake], Lachenmann uses $F \# 4-G \sharp 4-B 4-C \sharp 6-$ $\mathrm{E} 6-\mathrm{F} \# 6$ ). This pentatonic harmony, introduced after the aforementioned expanded field of "per-

64 See Kötter, "Die Irreführung der Oper," 41.

65 Personal conversation with Mayumi Miyata, Tokyo, 29/3/2008.

66 The fingerings are given by means of the usual abbreviations 11: left thumb, 12: left ring finger, etc. Small vertical arrows next to the finger symbols indicate raised finger holes. Arrows between finger symbols represent the finger movement from the preceding chord (Etenraku). Dashed framed finger symbols denote fingerings in which several holes must be covered by the same finger (Lachenmann). The bamboo tube for the tone C6, which is to be replaced due to the fingering structure in the chords of Lachenmann, is also shown in the diagram. 


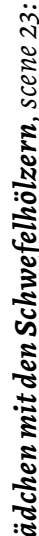

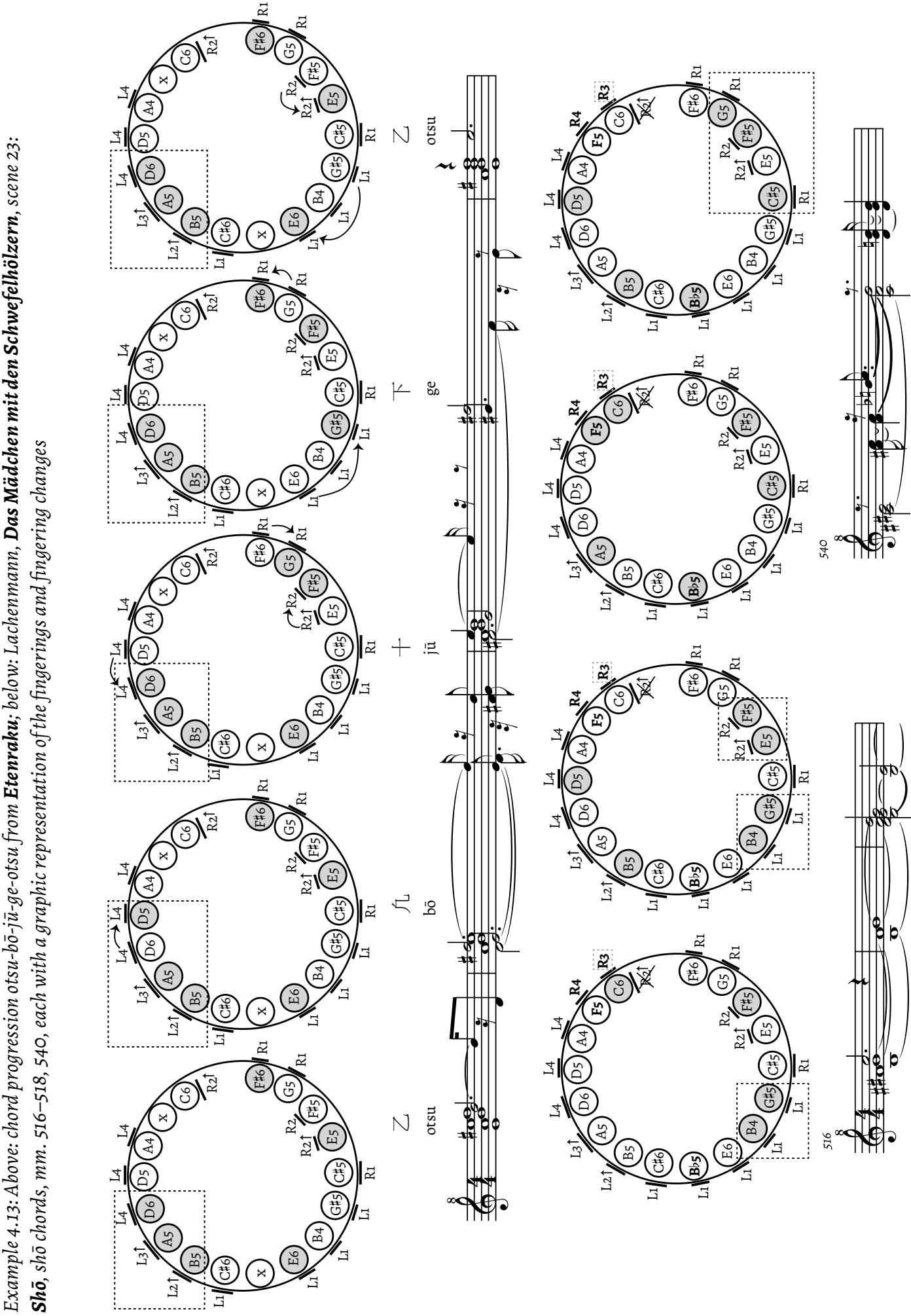


Example 4.14: Helmut Lachenmann, Das Mädchen mit den Schwefelhölzern, scene 23: Shō, analysis of the sho-sound fields; upper line: chord progression (gray highlights: quartal/quintal structures); lower line: analysis of the sounds according to pitch-class sets (white noteheads: whole tone segments)

forated sounds," which entirely dispenses with the sound of the shō over a total of 78 quarter notes, has a special auditory-psychological significance.

In addition, one can detect formations of interval structure in the shō chords and in the orchestra characteristic of Lachenmann's harmony during the 1980 s and $1990 s,{ }^{67}$ such as triadic stratifications at the interval of the (major or minor) second or tritone (indicated in brackets under the chords in Example 4.14), "continuants" (continuous 5-4-3-2 semitones in measure 532), "constants" (such as the numerous fragments of the whole-tone scale, marked in the score example by white noteheads), and cyclic interval arrangements (2-3-2-3-2 in measure 622). Such configurations can already be partially found in the aitake chords ( $\rightarrow$ IV.1, Ex. 4.2). For example, continuous interval sequences are found in the chord ge (2-1-2-3-4) and the chord $b i$ (1-2-[1-2]-4 [ $\rightarrow 1-2-3-4])$; the chords gyo (2-3-2-2) and hi (2-1-2-2-2) contain whole tone segments; triads superimposed by seconds are contained in the chords $j \bar{u}$ (D major/E minor) and $h i$ (A minor/B minor); and a cyclical structure in particular can be found in the chord $b \bar{o}(2-5-2-5-2) .{ }^{68}$ In the harmonic structures, therefore, one can equally speak of unmistakable double codes that permit two or more different interpretations.

This ambiguity of sound design is intensified if one includes the orchestral part in the analysis, which, according to Lachenmann, forms a "court' around the silvery removed sound of the 'Shō"'69 and is to be understood as complex, quasi-spectral extension of the sho sounds. The orchestra also establishes an echo-like sound processes continuing from the preceding scene (no. 22: Himmelfahrt [Ascension]) and, toward the end of the scene, where increasingly noisy structures are developed, transforms into the sparse sonority of the final scene (no. 24: Epilog ["Aber in der kalten Morgenstunde"] / Epilogue ["But in the cold dawn"]). In the interplay of sho and orchestra, in particular until around measure 608, there is an abundance of additional harmonic layers of meaning (Ex. 4.15-4.17).

By adding the orchestra, the first sound field of the $s h \bar{o}(\mathrm{~mm} .508-509)$ is interpreted in the sense of a D major cadenza ( $\left.\mathrm{A}^{(7)}-\mathrm{D}\right)$, while the second sound field (mm. 511-514) is characterized by an intertwined sequence of fifths $\mathrm{B}^{(7)}$-E-A (Ex. 4.15). At the same time, however, these orchestral additions are to be understood as deformed overtone spectra, in keeping with another basic harmonic technique frequently used by Lachenmann. The following enharmonically-mediated ( $G \sharp-A b, D \#-E b)$ echo of two quartal chords C-F-Bb / Eb-Ab-Db (mm. 513-516), stratified at a distance of a minor third, points to the large quartal field from measure 518 (the fourth is probably the most conspicuous interval from the beginning, since the second sho phrase enters on the fourth $\mathrm{F} 5-\mathrm{Bb} 5, \mathrm{~m}$. 511, anticipated by the piano in the same octave, $\mathrm{m}$. 509). The fourth $\mathrm{A} b 5-\mathrm{D} b 6$ in the $s h \bar{o}$, which marks the end of the quartal field in measure 532 , thus refers back to the echo of measures 513-515. The resonances of bowed cymbals (mm. 514-519), which appear for the first time with that echo, also return here and add a long decay to the quartal field (mm. 532-540).

67 See, among other, Zink, "Strukturen," 39-41 and Cavallotti, Differenzen, 114-124. See also footnote 62.

68 Interval data here and subsequently are provided in semitones.

69 Lachenmann, "A Musical Plot," 16 (see the section Narrativity below). 

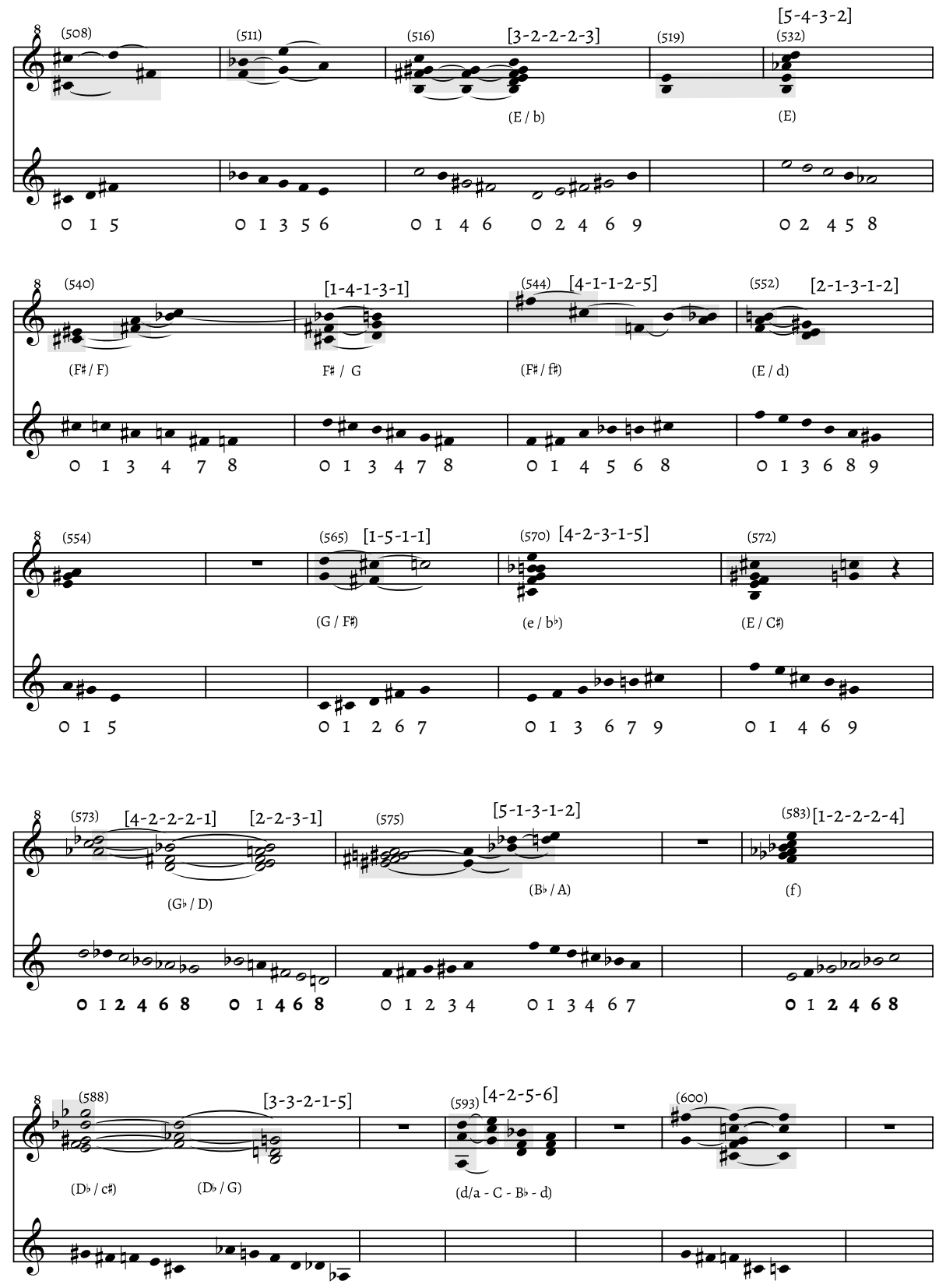
$02347 \quad 013679$

० 11267

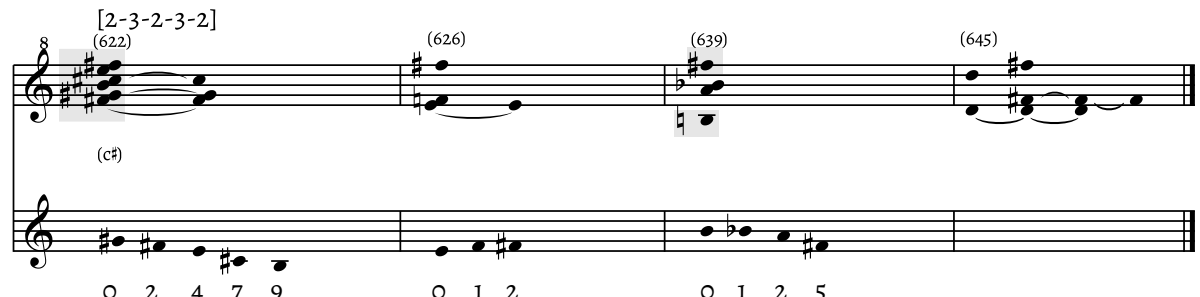


In measure 540 (Ex. 4.16) the cymbal resonances transform into a C8 in the violins, which remains as a reference pitch over 20 measures and frames a series of descending interval sequences, starting from the impulsive $\mathrm{F}$ major/F\# major/G major progression exposed in the sho. These descending interval chains in celesta, electric organ, and vibraphone are prefigured in the preceding scene 22, starting again from intervals of a fourth (first F7-B b7 in measure 544, a remote echo of the fourth F5-Bb5 in measures 509 and 511) and swirling downward in a cyclical sequence twice at the beginning, before the intervals gradually decrease, starting from the middle position, down to the harp's low-pitched noise-like second $B \sharp 1-C \sharp 2$. This second resonates in the reference tone lowered to $\mathrm{C}(5)$ (Viola) and then in the toneless strings. The entire progression is embedded in continuously narrowing interval sequences: ${ }^{70}$ $5[-1-] 4[-1-] 3[-1-] 4 / /$ [-1-]5[-1-]4[-1-]3[-1-]4 // [-1-]5[-1-]4[-1-]5[-1-]4[-1-]3[-1-]2[-1-]1; mm. 544-548 / $549-552$ / 556-561). The fifth sound field of the sho (mm. 544-556) sets up a highly complex harmonic relationship with the reference pitch $\mathrm{C} 8$, the air resonances of the brass (which according to the score are to be "exactly synchronized with the sho"), and the interval chains of the bell-like instrumental sounds. Thus, for example, the intervallic structure of the shō's six-note chord completed in measure 549 - 4-1-1-2-5 (or including the celesta's A5-D6 4-1-[1-2-]1-4) - may be interpreted as a variant of the symmetrical interval chain 4-1-3-1-4 of the celesta group; and the second six-note chord of the shō completed in measure 552 thus may appear as a compressed variant of this interval chain (2-1-3-1-2 vs. 4-1-3-1-4), with the celesta's third $\mathrm{E} 5-\mathrm{G} \sharp 5$ (m. 551) being implied in the shō's harmony.

Once again a pulsating, rapid sequence of triads in measure 565 ( $G$ major/F\# major, with the triad's thirds supplied by the flutes) ruptures the music, opening up into the glaring high fourth C6-F6, probably as an echo of the last phrases of the vocal solo parts from the previ-

Example 4.15: Helmut Lachenmann, Das Mädchen mit den Schwefelhölzern, scene 23:

Shō, simplified score reduction (without dynamics and articulations), mm. 508-539

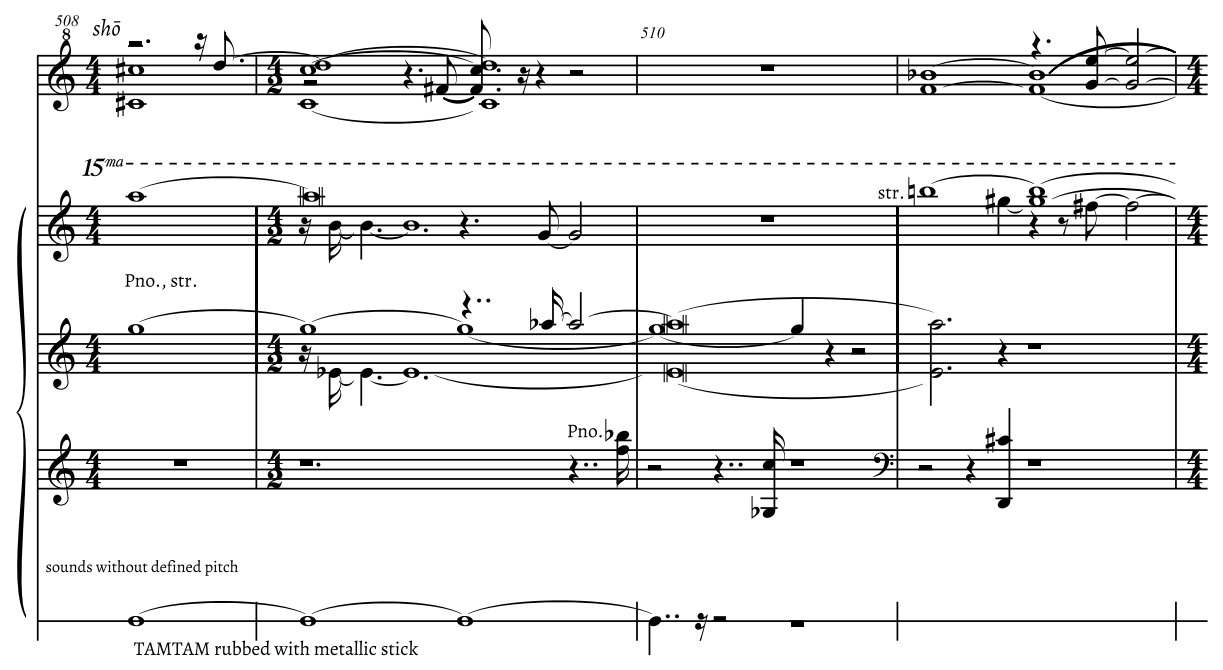

70 Bracketed intervals indicate the step to the next interval, 5[-1-]4 denotes a fourth followed by a major third, where the upper pitch of this major third is a minor second below the lower note of the preceding fourth. 

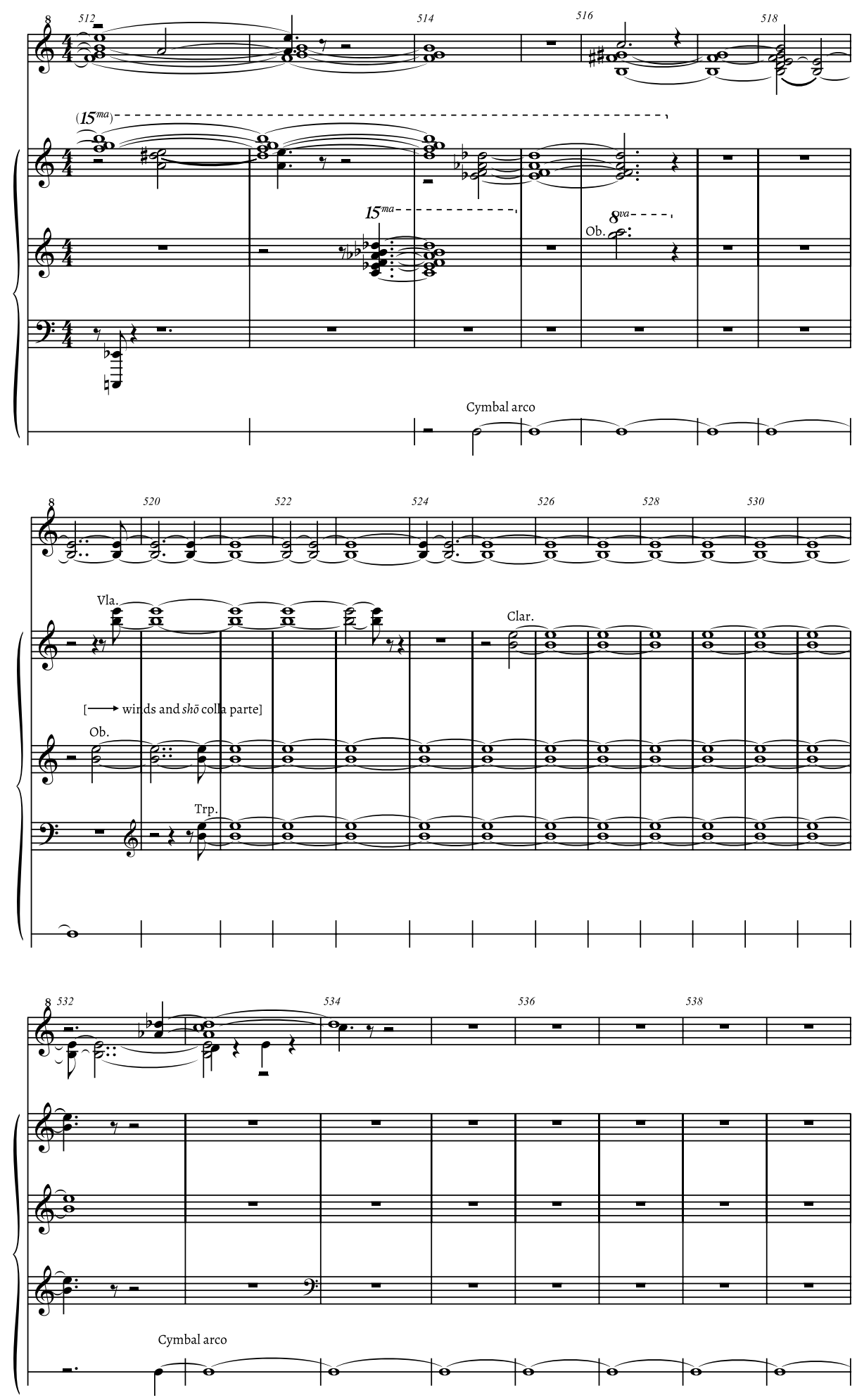

Copyright $\odot 2001$ by Breitkopf \& Härtel, Wiesbaden 
ous scene, in which a high F6 had been reached the first and only time (no. 22: Himmelfahrt, mm. 465-466: $B-D \sharp / E-G \sharp / A-C / D b-F$ or measure 477 unison F6 in fff). From this impulse, the fourth $\mathrm{B} b 4-\mathrm{E} b 5$ emerges, with the pitch $\mathrm{E} b 5$ (later $\mathrm{E} b 6$ ) remaining as a new reference pitch over the following 17 measures. The high $\mathrm{F}$ echo returns in the oboe a few measures later (m. 572), accompanied by rustling wind sounds played from the tape. The complex seventh sound field

Example 4.16: Helmut Lachenmann, Das Mädchen mit den Schwefelhölzern, scene 23: Shō, simplified score reduction, $m m$. 540-582
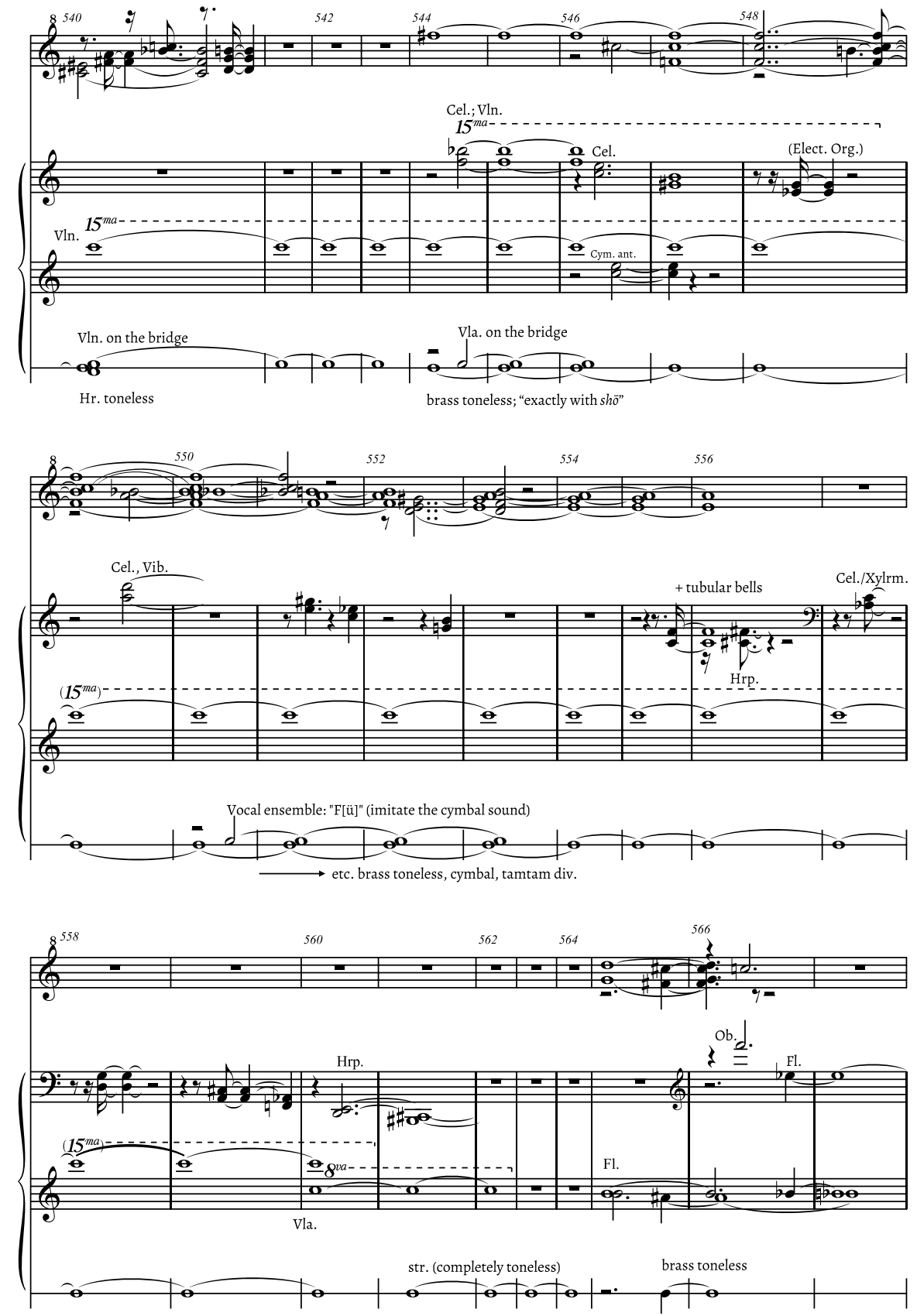

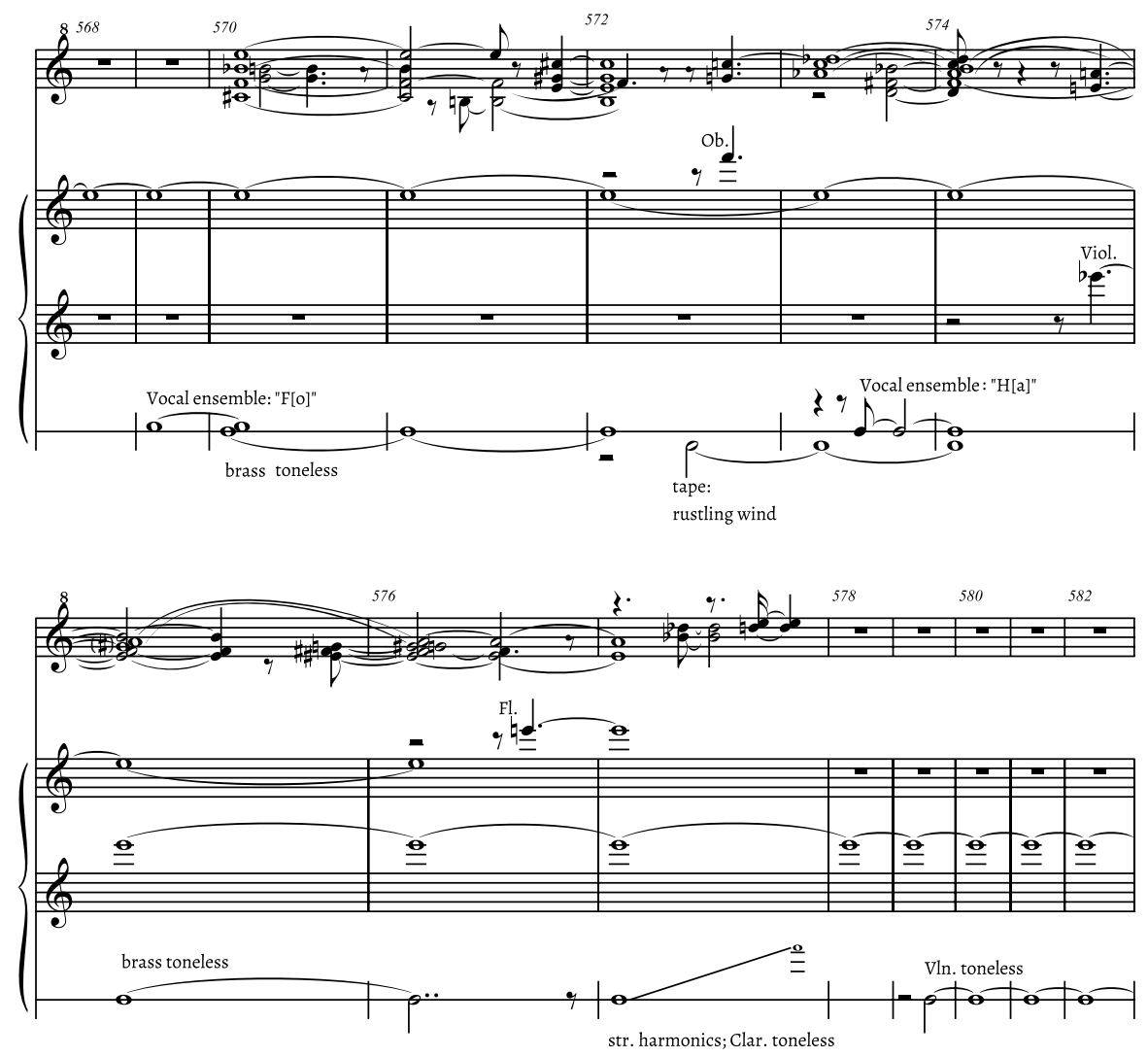

Copyright ( 2001 by Breitkopf \& Härtel, Wiesbaden

of the sho (mm. 570-577) again brings intertwined combinations of fourths ( $F 5-B b 5, G \sharp 5-C \sharp 6$, G5-C6, Ab5-Db6, E5-A5, see also Ex. 4.14).

In measure 583 (Ex. 4.17) we hear, for the first time, a long and sustained low pedal tone ( $\mathrm{B} b 2$ in contrabassoon and trombones), followed by more pedal tones in measures 600 to 603 ( $\mathrm{Bb2}$, double bass clarinet) and 606 to 608 (A2, piano and tuba), as if it were a signal of the overall pitched sound passing completely into noise. Consequently, the next triad impulse of the shō (mm. 588-589), this time with strings and piano added (shō: $\mathrm{D} b$ major/C\# minor; orchestra: $\mathrm{A} b$ major/D major, $\mathrm{G}$ major/D $b$ major), is followed only by resonances of the rubbed Japanese temple bells (rin) instead of further pitch processes, ${ }^{71}$ over which the plain fifths, fourths, and triads of the shō's tenth sound field are unfurled (mm. 593-597, C major/Bb major/D minor). This comes before, in measure 600, the "perforated" strings enter simultaneously with the eleventh sho sound field. The shō seems to react to this new sonority with sharper second- and tritone-dominated sounds (by means of the symmetric interval structure 6[4-2]-5-6).

71 The resonances through continuous circular rubbing of the rin bells were first used by Lachenmann in Air for a percussionist and orchestra (1968-69); see Lachenmann, “East meets West?," 84. 
The long decaying fourth $C \sharp 5-F \sharp 6$ after the end of the large perforation field (mm. 608-621), echoing the three large "Ritsch" aforementioned pentatonic twelfth sho sound field in the vocal ensemble and orchestra. Here the fourth $\mathrm{C} \sharp 4-\mathrm{F} \sharp 7$ is spread out even further (mm. 622-624), which unfolds a powerful resonating effect and markedly breaks with the perforation field. The $F \sharp 6$, which remains as a reference pitch, leads to a quasi-symmetrical shō harmony (mm. 626-630), whose second intervals, analogous to the eleventh sho sound field (m. 600 onwards), now initiate a fabric of "toneless" sounds with integrated Morse-code-like impulses of the two highest piano keys played ppp; until the end of the subsequent final scene (no. 24) this texture extends into a 77-measure permutative structure designed by mechanical means. ${ }^{73}$ The last two extremely short sho sound fields produce echo-like reminiscences, whereby the closing octave D5-D6 may have an "imaginary" resolution function in relation to the opening octave $C \sharp 5-C \sharp 6$.

Significant in terms of the pitch relations shown is therefore their multiple referentiality. The "intra-opus" dimension plays in particular with references to scenes 22 and 24 that frame the sho scene: from the beginning to the oboe's piercing F6 impulses, the sonority and downward direction of the Ascension resonate in many ways. As a result of the perforation field, especially from measure 626 , the "toneless" structure of the final scene and the permutation sequence on the two high piano keys begin. This "external framework" corresponds to the analogy between the two central sections within scene 23, the quartal field and the perforation field, which on the "intra-opus" level, however, have rather opposing functions: while, in the quartal field, the harmony established by the shō reaches its imaginary center and thus places

Example 4.17: Helmut Lachenmann, Das Mädchen mit den Schwefelhölzern, scene 23:

Shō, simplified score reduction, $m m$. 583-646

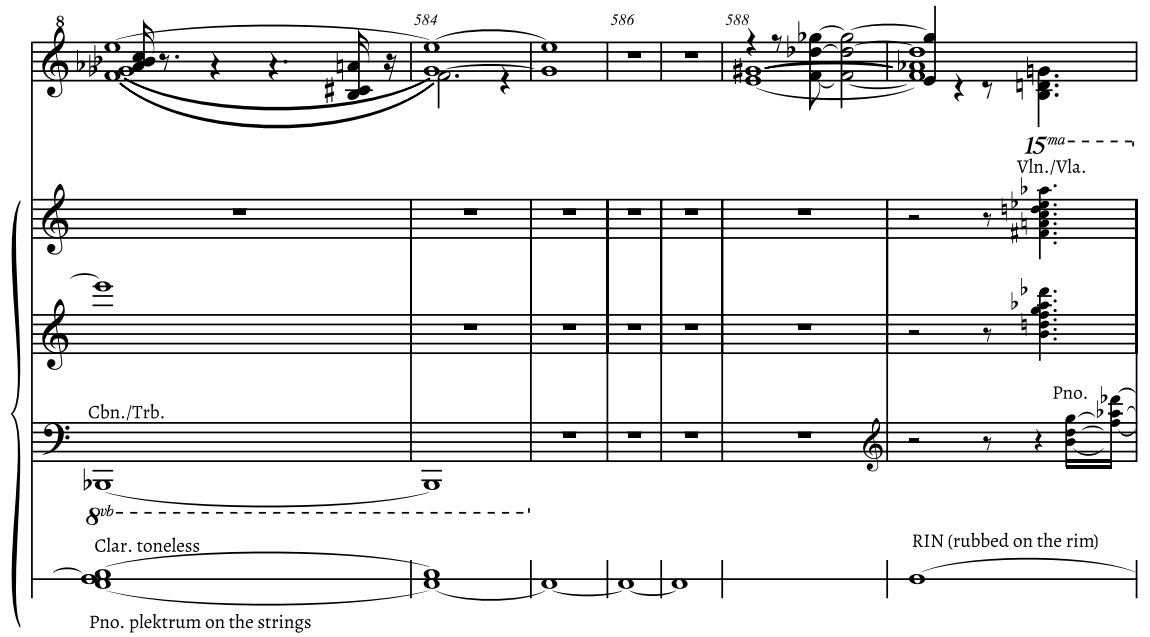

72 "Ritsch!" is the onomatopoetic word for the lighting of the matches used by Hans Christian Andersen in the fairy tale on which Lachenmann's work is based. This sound is explored through a particular abundance of orchestral-vocal constellations and timbres throughout the entire opera. Of the four scenes entitled Ritsch, no. 14: Ritsch 2 "gedeckter Tisch / Hauswand 3" [Ritsch 2 / Set Table / House Wall 3] eventually was not composed but kept in the order of the scenes (so that no. 15a immediately follows no. 13).

73 See Lachenmann, Gadenstätter, and Utz, "Klang, Magie, Struktur," 61-62, particularly note 63. 

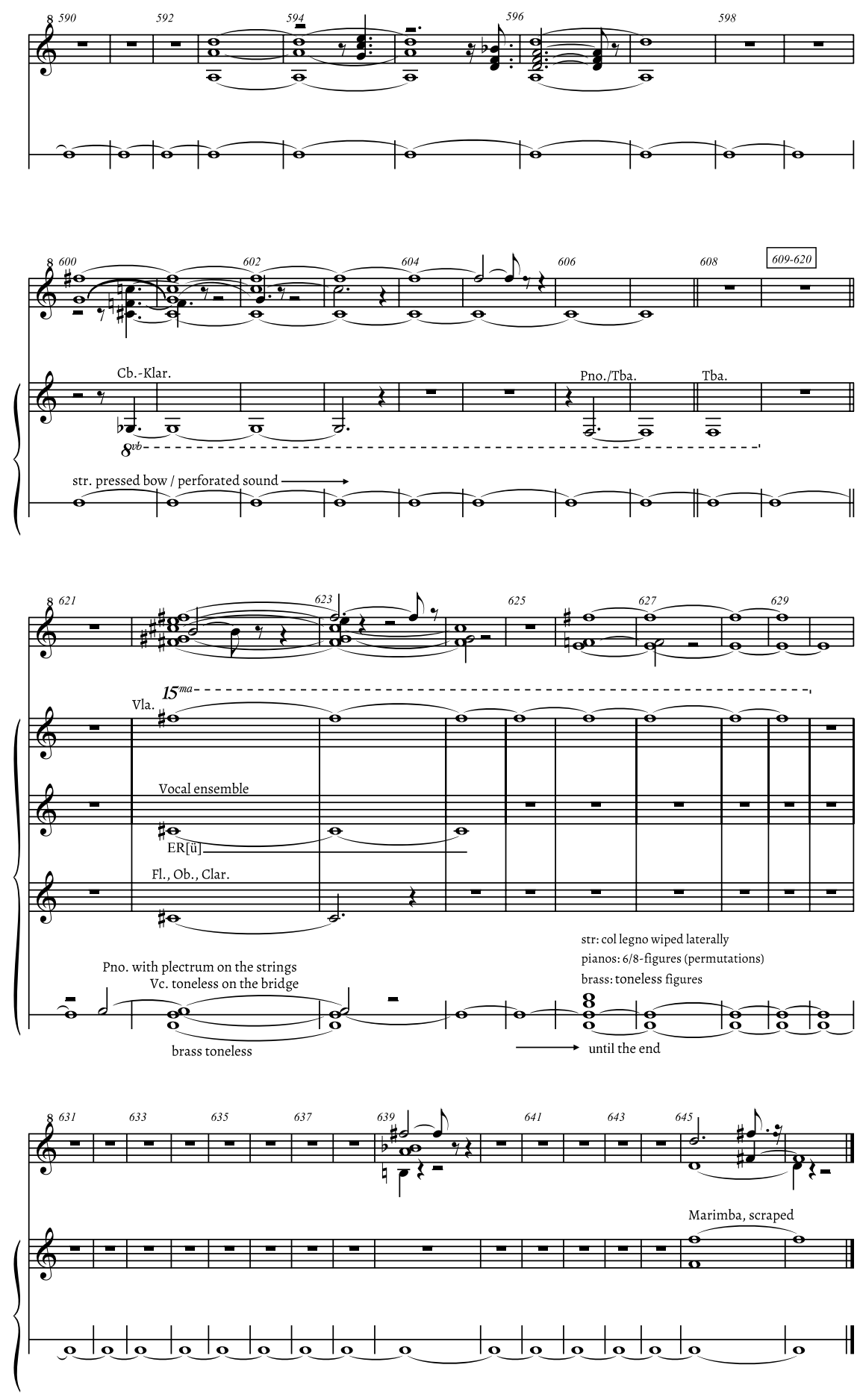
Example 4.18: Helmut Lachenmann, Concertini: analysis of the central sounds in the final section; first row: pitch sum with interval structure in semitones; second row: sequence of entries (below in brackets: included triads or four-note chords); third row: pitch content (pitch-class sets); fourth row: fifth/fourth structures

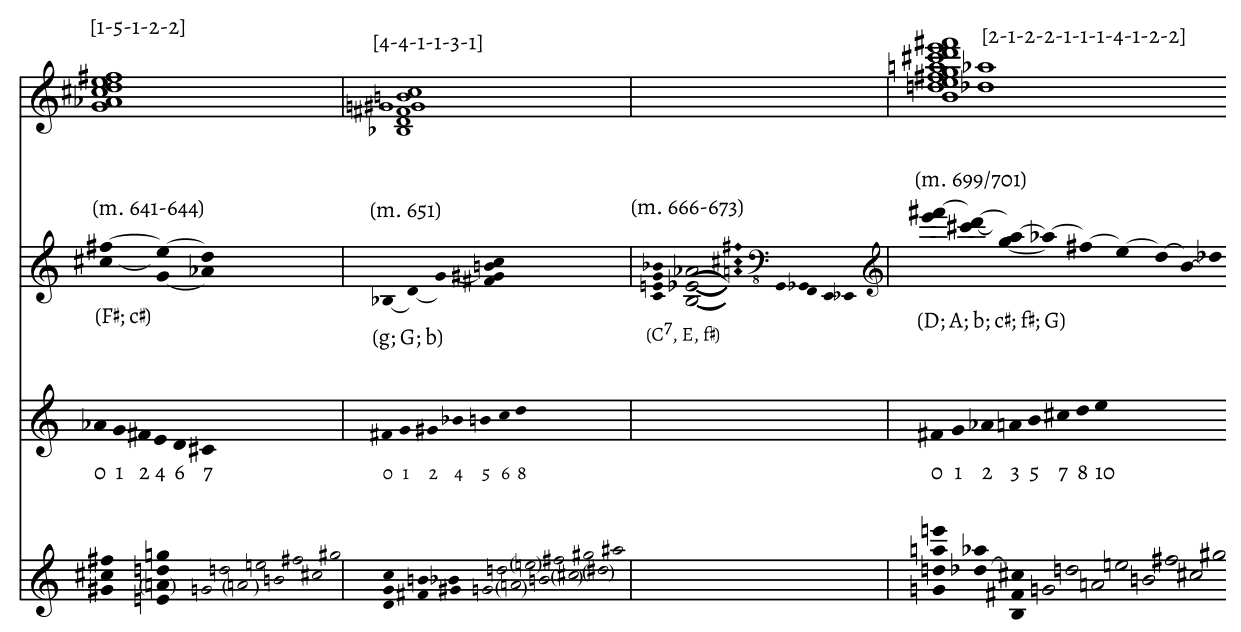

lasting emphasis on the principle of alterity, the perforation field goes far back to the three "Ritsch" scenes and thus adds a particularly lasting self-referential emphasis. These two basic referential gestures can also be clearly understood on the "extra-opus" level: while the manifold references to musical layers that form the traditional context of the shō introduce an element of categorial, cultural alterity, the music of this scene simultaneously remains understandable also as a phenomenon of "cultural self-referentiality," considering the deformations of European tonality traceable in the shö's sound processes, which are generally characteristic of Lachenmann's harmonic design.

Lachenmann suggests in his essay on sound types that (post-)tonal models such as the "cadential sound" can be decisive not only in the compositional microstructure, but also for largescale formal trajectories. ${ }^{74}$ This thought has been taken up variously in the exegesis of his works. Against this background, it is possible to derive factors from the close structural linkage of the last three scenes of The Little Match Girl, which allow us to interpret this series of scenes as a closing cadence - a cadential sound - of the entire two-hour "Music with Images." Evidence for this interpretation can be found, for example, in the fundamentally (self-)referential character of the pitch processes shown, but also in the extreme contrast between unbroken, seemingly "elevated" sound magic and an extremely barren "toneless" - or at least "pitchless" - environment on the threshold of silence. In "cadencing," after all, these properties present the entire diversity of sounds in this "opera" once again in condensed form.

Lachenmann's large ensemble work Concertini pursues a somewhat related formal model: broad exposition-like areas ( $\mathrm{mm}$. 1-275), in which both the ensemble as a collective and individual "concertante instruments" such as trombone (mm. 7-19), guitar (mm. 178-209), and harp

74 See Lachenmann, "Klangtypen der Neuen Musik," 20. 
(mm. 210-275) are acting in a "soloistic" manner. Three intensified zones follow, determined by an increasing urge to movement; repeatedly interrupted (mm. 276-417, 418-489, 490-610/614), these zones are characterized by ostinato figurations, changes of tempo, and general pauses that serve as structural markers. After this sequence of intensifying zones there is, analogously to the formal model of the Little Match Girl, a broad "cadencing" section (mm. 615-701), lasting about a quarter of the total duration, characterized by a distinctly slower tempo $(\cdot=38)$ than the basic tempo that initially dominated for a long time $(\downarrow=56)$. In this "cadential sound" a "verticalization" or calming of the musical texture is evident; only a few isolated virtuoso figures reminiscent of the preceding sections remain.

At the "harmonic" level, this final section fulfills its cadential function insofar as the pitch configurations scattered over the entire duration, usually fragmentarily distributed, building up on a pitch organization that basically grows out of beating seconds, are consolidated - if only temporarily - in two or three "cadential" sonorities, potentially verifying Lachenmann's statement that the "tone scale" of the sho had been important for this work (see above). Here, too, the principle of superimposed fifths is fundamental (Ex. 4.18, fourth line), along with triadic (Ex. 4.18, second line) as well as continuous and equidistant formations. The conceptual starting point could have been the eight-note final sonority that swells into a fortissimo ( $\mathrm{mm}$. 699-701, Ex. 4.19), creating a complete sequence of fifths with G-D-A-E/B-F\#-C\#-G\# and interleaving six different major and minor triads in close position. This "final cadence" is balanced out by the second central sound from the initial phase of the final section (mm. 641-644), in which only the A of a seven-part chain of fifths is missing, but which - in contrast to the final sound - is built around a quartal chord ( $G \#-C \#-F \#)$ (the fourth here also appears as a central interval in the piano part, which brings a virtuoso figuration of parallel fourths).

In other configurations in this section too, fourth and fifth harmonic layers reveal a hidden principle (Ex. 4.18). Of central importance is the fourth Eb4-Ab4 in measures 666 to 673, which is illuminated by various components in a constantly changing "crypto-tonally" shaded manner, for instance by a floating B (resulting from an $\mathrm{E}$ major second inversion chord), the initial dominant seventh chord on $\mathrm{C}$ (tubular bells, $\mathrm{m}$. 666), or the chromatically descending tuba line (G1-Eb1, mm. 669-670). In addition to these three pillar-like "cadential sounds," the other harmonic formations of the final section remain of secondary importance. They can be related either to Concertini's overall "beating microscopy" (for example, the beginning: mm. 615-635, or mm. 674-689), echo-like fragments of the long solo passages from the preceding sections (especially in the harp and piano from measures 646,659 , or 674 ), or are too fleeting to perform a truly structuring function (as in measures 651 and 661).

Of course, the quartal/quintal harmony continues to expand into these fragmentary formations, such that the "cadencing" sounds redeem something that the more complex processes between them suggest: the two framing harmonies, in particular, are also built after the transient decay model of the cadential sound or sho archetypes; the high wind ensemble unequivocally seeks a sonorous approach to the shō sound; and - most notably - all pitches in these sounds are indeed based on the "tone scale" of the Japanese instrument (although, of course, at least the final sonority - even with a highly unconventional fingering - would hardly be playable, such that a "utopian" sho becomes audible in it). It can therefore be concluded that the final section of Concertini has a similarly concentrating, "cadential" function as scene 23 in The Little Match Girl. Decisive for this function is the demonstrated simultaneity of alterity and selfreferentiality, which, in addition to an obvious "break" with what precedes it, also develops a synthesizing and "unbroken magical" magnetic effect in which heterogeneous "sound families" briefly come together in a fleeting "sonorous unity." 
Example 4.19: Helmut Lachenmann, Concertini, mm. 697-701
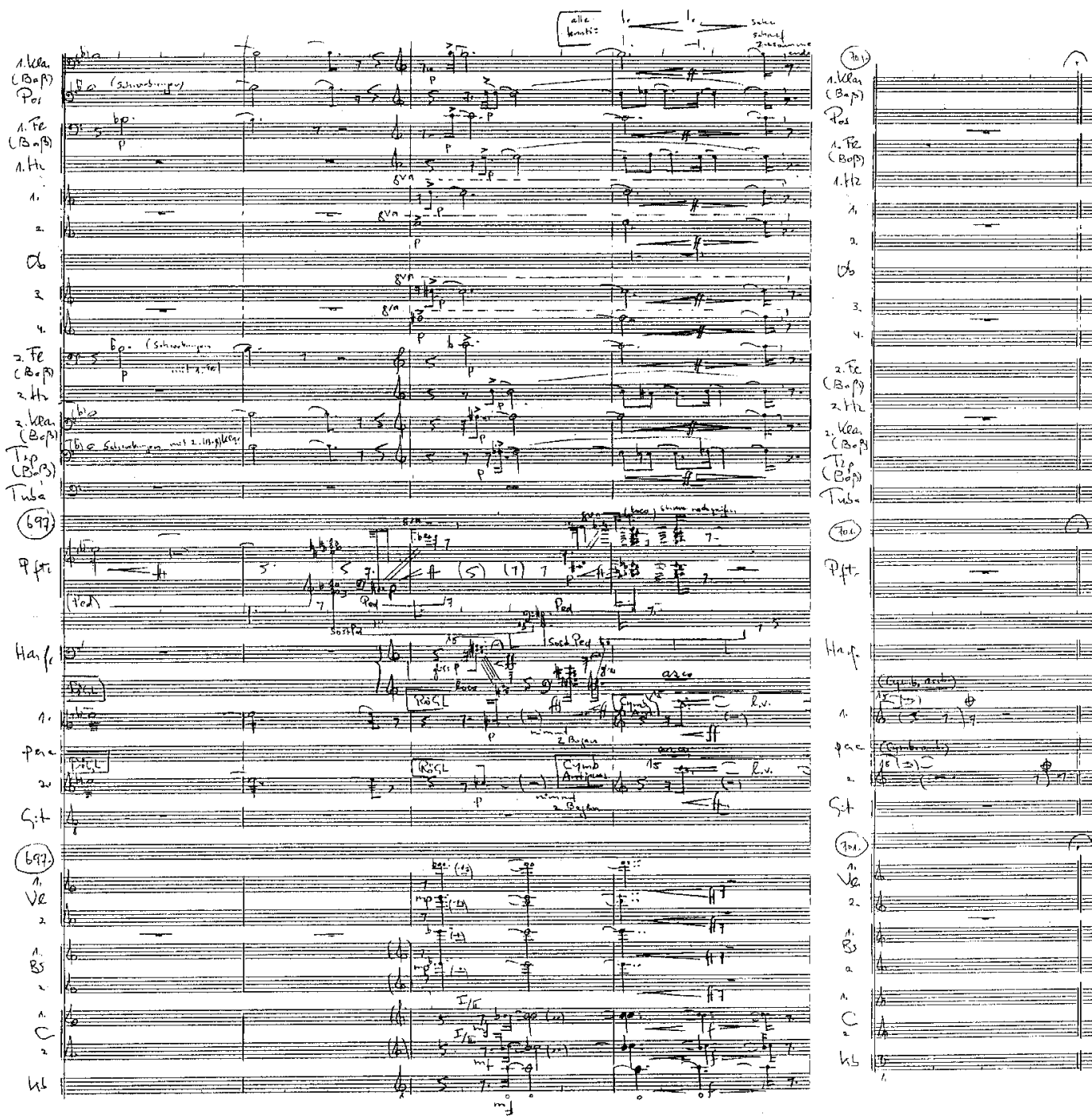

Copyright $\odot 2005$ by Breitkopf \& Härtel, Wiesbaden

\section{Split Sound and Structural Sound}

The "cadential" function of the extended final section of Concertini certainly appears most strongly in the last chord. In this twelve-voice sound played by wind instruments, consisting of eight different pitch-classes, an uninterrupted stratification of fifths is realized for the first time, which produces an interval structure of 2-1-2-2-1-1-1-4-1-2-2 semitones in close position (Ex. 4.20). Similar to the previous axial harmonies, this final chord is embedded in an extraordinarily complex sound spectrum composed of clusters of strings interleaved with the wind chord, resonances of the tubular bells, and a striking piano glissando. 
Example 4.20: Helmut Lachenmann, Concertini, mm. 697-701, reduction of instrumental groups

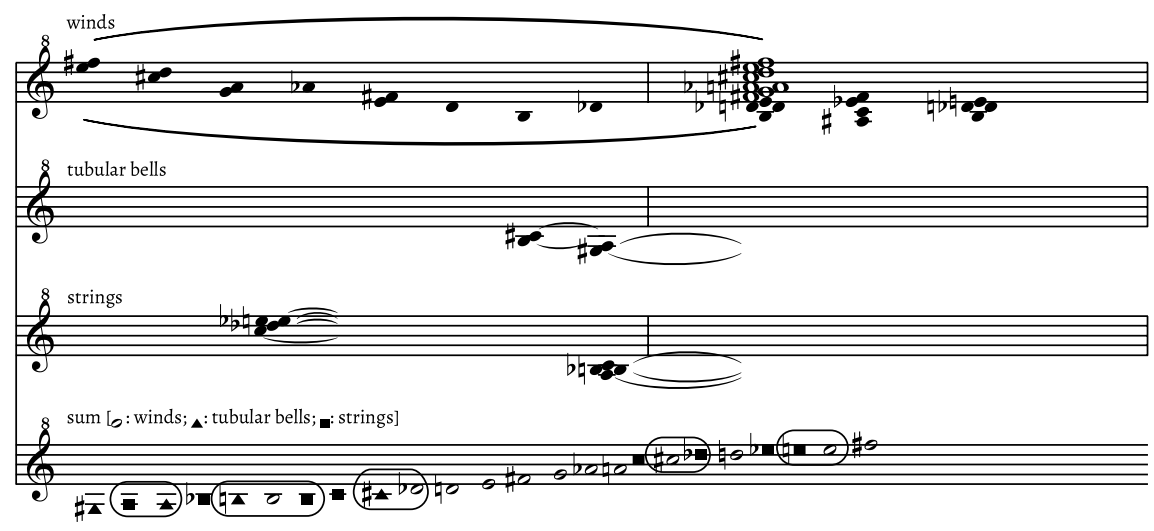

Here a sone-based spectral analysis ${ }^{75}$ will be used to gain a deeper insight into the relationship between the sound of the shō and the final sound of Lachenmann's Concertini. In the spectrum of the traditional sho chord $b \bar{o}$ with the basic pitches D5-E5-A5-B5-E6-F\#6 (Ex. 4.21), based on the fifth structure $D-A-E-B-F \#$, the impression is confirmed that the individual pitches tend to merge into a cluster-like sound: The fundamental tones recede into the background in contrast to dominating overtones such as the fifth partial of $\mathrm{E}_{5}(\mathrm{G} \# 7)$ or the seventh partial of $\mathrm{D}_{5}$ (a C8 lowered by 31 cents). The auditory impression is thus characterized not only by a high degree of blending, which can be partly explained by the tendency of the Pythagorean tuning of the instrument as well as the high position, but also by a diffuse "textural character" (in the sense of Lachenmann's definition of "textural sound"), in which it is difficult to isolate or identify individual sound components owing to the strong presence of partials in relation to the fundamental pitches.

Example 4.21: Spectral analysis of the traditional shō chord $b \bar{o}$, ordered according to loudness of the spectral components (duration of the sound: 5.532 seconds; source: CD of Miki, Nihon gakki hō); values above the notes denote the loudness in sone (average over the entire duration of the sound)
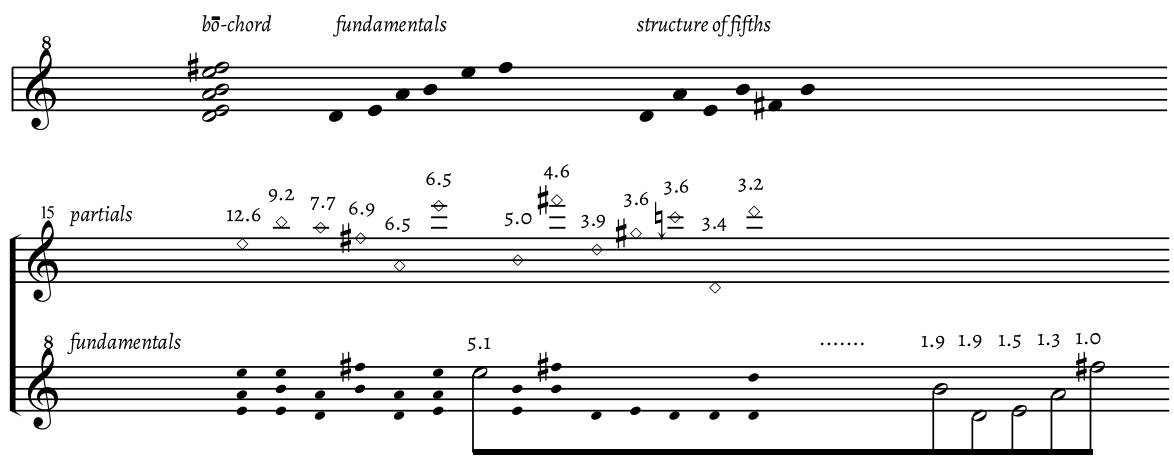

75 This analysis was realized with the software MUSE [later re-named CTPSO] by Dieter Kleinrath in 2009. For the functionality and programming aspects of the software, as well as for further analytical applications, see Utz and Kleinrath, "Klang und Wahrnehmung bei Varèse, Scelsi und Lachenmann," 84-89. 
Example 4.22: Spectral analysis of the final chord of Lachenmann's Concertini (m. 699), comparison of the recordings by Ensemble Modern (2006, above) and Klangforum Wien (2009, below); notation arranged according to loudness of spectral components (values in sone); the analyzed sections of the sound comprise the quasi-stationary part between the beats 2.3 and 3.4 of measure 699 (duration: Ensemble Modern: 1.609 seconds, Klangforum Wien: 3.890 seconds)

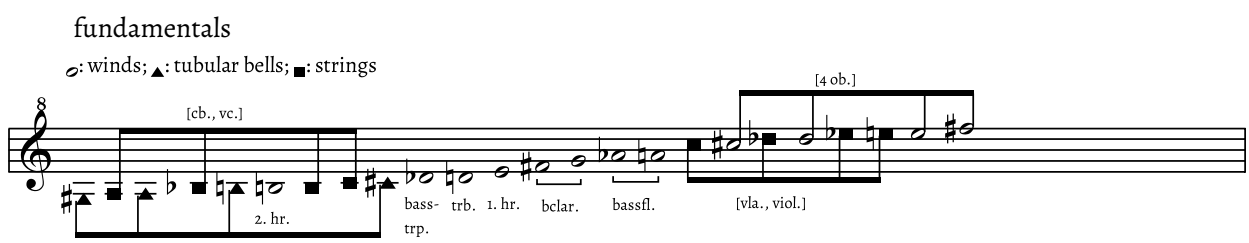

spectrum Ensemble Modern
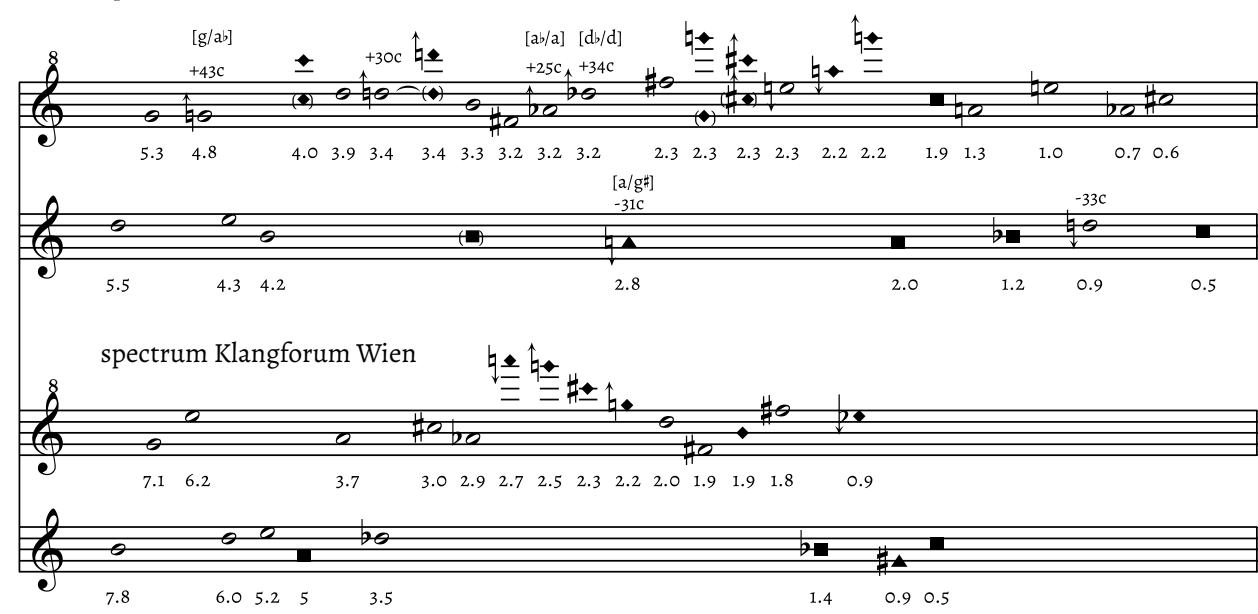

$o=$ fundamentals of the winds; $\bullet=$ spectral tones

The spectral analysis of Lachenmann's final chord is based on a comparison of two different recordings of the work by Ensemble Modern and Klangforum Wien ${ }^{76}$ (Ex. 4.22). Both recordings reveal - in contrast to the $b \bar{c}$ chord - a spectrum dominated by the lower fundamental pitches of the chords B4, D5, E5, G5, while the volume (and intonation) of the remaining notes in the two recordings varies widely. The presence of the other fundamental pitches is significantly greater in the Klangforum recording, which, together with significantly lower microtonal deviations in the individual spectral components, seems to indicate a more precise intonation. In addition, the stronger dynamic contrasts within the chord in the Klangforum recording are striking and also contribute to a more pronounced morphological profile: the perceived loudness of the seventh-loudest component (A5) is already only about half that of the loudest (B4); in the Ensemble Modern recording, the corresponding pitch is only in 14th place, so the overall dynamics of the pitches are more balanced here.

76 Helmut Lachenmann, Concertini: Ensemble Modern, Conductor: Brad Lubman, EMSACD o01 (2006); Klangforum Wien, Conductor: Johannes Kalitzke, Kairos 0012652KAI (2009). 
Lachenmann brings about this concentration on the fundamental pitches by having the lower eight notes of the chord played throughout on low wind instruments in (partly very) high position (two horns, two bass clarinets, two bass flutes, bass trumpet, trombone). Also, the oboes in the high position bring out the fundamental tones. As with the sho, masking effects occur; in both cases, the highest note ( $\mathrm{F} \# 6$ ) is largely obscured by the adjacent sine tone components (see Ex. 4.21 for the low loudness of the $F \sharp 6$ fundamental in the sho spectrum).

If we now try to evaluate the results of the spectral analysis with some caution from the perspective of the composer's aesthetics, we find, perhaps surprisingly, that despite the great spectral complexity, the individual (fundamental) pitches of the chord in the spectrum remain as distinct as possible, not least when Lachenmann's chord is set in contrast to the spectral characteristics of the traditional sho chord, in which the intensity of the partials contributes to a maximum sound fusion and a diffusion of the fundamental tones. It could thus be concluded that even where Lachenmann presents a seemingly "conventional" type of blended sound, its internal structure shows essential characteristics of a "split sound" or "structural sound."77 Even though the perception of Lachenmann's final sound undoubtedly "switches" perception into a "global" mode, an oscillation between such a global impression and the singling out of individual components seems to be a perfectly plausible description of the auditory process invoked. Lachenmann's important idea is that in certain situations, structural and textural sounds can easily merge into one another, "tilt" into the other state. ${ }^{78}$ This is supported by the highly differentiated instrumentation of the chord and its surroundings. In the terminology of Albert Bregman's Auditory Scene Analysis, one could argue that a "natural assignment," in which an unambiguous identification of the sound sources is possible, and a "chimeric assignment," in which such identification is impossible, fluctuate here in a micro-temporal process $(\rightarrow \mathrm{VI} .4){ }^{79}$ In one moment, individual instruments seem to emerge as identifiable, in the next they have disappeared in the global sound event, the "texture."

It should be pointed out that the technical method of rationalized analytical methodology, which has been "aggravated" here by spectral analysis, is insufficient for conveying the wealth of connotations or describing the implicit meanings of sounds that emerge. Lachenmann's conviction that musical sound to a considerable degree unfolds "magic" and leads to a high level of identification and a merging of listener and sound, but that magic can exist today only in the context of its negation as "broken magic," illuminates the inner connection between the "magic" of the diffuse textural character of the traditional bō chord and the "broken," "structuralist," fundamental-based character of Lachenmann's Concertini chord.

77 See Schering, "Nationale und historische Klangstile." Schering interpreted the history of music here as a constant change between the ideal of the "Verschmelzungsklang" (blended sound), dominant in vocal polyphony of the fifteenth and sixteenth centuries as well as in symphonic music from Haydn to Mahler, and the "Spaltklang" (split sound), dominant in the music of the Middle Ages, linear Baroque counterpoint, and modern music. Of course, Schering's "Spaltklang" (split sound) and Lachenmann's "Strukturklang" (structural sound) should not simply be equated here; a more nuanced discussion would have to weigh commonalities and differences in terms. One possibly significant aspect might be that both terms seem to be based on a consistently polyphonic model $(\rightarrow$ VI.4).

78 Lachenmann, "Klangtypen des Neuen Musik," 20.

79 Bregman, Auditory Scene Analysis, 459-460. 


\section{Temporal Sections}

In his pioneering work, Pietro Cavallotti argues that only meticulous sketch studies can actually trace and interpret those "muddled paths" that make up the substance of Lachenmann's and other composers' poststructural music:

The importance of sketch research for the analysis of "New Music" should no longer be in question today. [...] "New Music" increasingly defined itself, for the most part, through the composer's own rules, rules that differed in each work, meaning that source research is often an indispensable aid to understanding the most important structures and technical principles. ${ }^{80}$

In the case of Lachenmann, source studies reveal a rigorously anti-systematic, anarchic negation of regular, automated structures that are the exact opposite of a common concept of "structure." Lachenmann's structural grids are thus a medium that, on the one hand, enables an "almost complete pre-ordering of the material" and, on the other hand, includes the option of "freely editing all parts of a composition." ${ }^{\text {"I } 1}$ In Lachenmann's music, structure becomes a means of articulation only through conflict, friction, or synergy with an Other, with a principle of tonal, sensual, existential, or cultural alterity or through "imploding" conflicts with its selfcreated preconditions.

As most of the composer's works, The Little Match Girl and Concertini are based on structural grids and preformed material. Although the following considerations cannot document these preformations on the basis of the sketches, two tables clearly demonstrate the relevance of prearranged temporal sections for the perception of "cadence-like" effects, which are obviously very deliberately designed in the two sections of the works discussed here. In the case of the sho scene from The Little Match Girl, the table of temporal divisions (Table 4.1) initially shows proportions organized on the basis of the Fibonacci series or the Golden Section. ${ }^{82}$ For example, the distance from the beginning of the large quartal field to the end of its resonances (mm. 518.3-539) and the previous distance from the beginning of the scene to the beginning of the quartal field show the ratio of 21.5:13.5 (1.592). Significantly, the duration ratios of the sho sound fields to their echoes (indicated in Table 4.1 by " $x$ ") are also often subdivided by Fibonacci proportions: sound field \#1 3:2, sound field \#5 13:8; sound field \#6 2:3, sound field \#7 8:5, etc.). At least two distinct Fibonacci series (starting from different points), namely 1-2-3-5-8-13-21-34 and 2-5-7-12-19-31, appear to have been used.

The numerical relationship is also significantly related to the structuring of the large-scale form: the proportion 25 (equivalent to 100 quarters/pulses) frames the section from the shō's

80 Cavallotti, Differenzen, 12-13 ("Die Bedeutung der Skizzenforschung für die Analyse der "Neuen Musik" dürfte heute nicht mehr zur Debatte stehen. [...] 'Neue Musik' konstituierte sich zum großen Teil immer mehr über vom Komponisten selbst vorgegebene und in jedem Werk anders lautende Regeln, so daß die Quellenforschung oft eine unerläßliche Hilfe zum Verständnis der wichtigsten Strukturen und technischen Prinzipien darstellt.")

81 Ibid., 126 ("fast vollständige Vorordnung des Materials;" "alle Teile einer Komposition frei zu bearbeiten").

82 In other works by Lachenmann, selected rhythmic structures, possibly also pitch processes, have certainly been developed using the Fibonacci series. For example, the entry distances of the four sound families superimposed at the end of Mouvement (-vor der Erstarrung) for ensemble (1982-84) (from m. 483) follow the sequence 8-5-32-1-2-3-5 eighths. See also Piencikowski, "Fünf Beispiele," 109. The proportion of the Colden Section (Ф), known since ancient times, is rounded to 1.618033989 . The "Fibonacci series," named after the mathematician Leonardo of Pisa, called Fibonacci (c. 1170-c. 1250), is an integer approximation to this proportion. For the application of the proportion in musical contexts see among others Möller, "Coldener Schnitt" and Baltensperger, lannis Xenakis. 
Table 4.1: Helmut Lachenmann, Das Mädchen mit den Schwefelhölzern, scene 23: $\boldsymbol{S h} \overline{\mathbf{o}}$, analysis of temporal divisions

\begin{tabular}{|c|c|c|c|c|c|c|c|c|c|c|c|c|c|c|c|c|}
\hline measures & 508 & 510 & 511 & 515 & \multicolumn{3}{|l|}{516} & 535 & 540 & 541 & 544 & 557 & 565 & 567 & 570 & 578 \\
\hline $\begin{array}{l}\text { shō sound } \\
\text { fields/ } \\
\text { echoes (x) }\end{array}$ & 1 & $x$ & 2 & $x$ & $\begin{array}{l}3 a \\
(516)\end{array}$ & \begin{tabular}{|l}
$3 \mathrm{~b}$ \\
$(518.3)$
\end{tabular} & \begin{tabular}{|l}
$3 c$ \\
$(532.4)$
\end{tabular} & $x$ & 4 & $x$ & 5 & $x$ & 6 & $x$ & 7 & $x$ \\
\hline $\begin{array}{l}\text { durations } \\
\text { (quarters) }\end{array}$ & $12[8]$ & $8[4]$ & 20 [16] & 4 & \multicolumn{3}{|c|}{76 [10-57-9] } & 20 & 4 & 12 & 52 & 32 & 8 & 12 & 32 & 20 \\
\hline $\begin{array}{l}\text { durations } \\
\text { (quarters) }\end{array}$ & \multicolumn{2}{|l|}{$20[12]$} & \multicolumn{2}{|l|}{$24[20]$} & \multicolumn{4}{|l|}{96} & \multicolumn{2}{|l|}{16} & \multicolumn{2}{|l|}{84} & \multicolumn{2}{|l|}{20} & \multicolumn{2}{|l|}{52} \\
\hline \multirow{4}{*}{$\begin{array}{l}\text { micro- } \\
\text { formal } \\
\text { phases } \\
(=\text { dura- } \\
\text { tions/4) }\end{array}$} & $3[2]$ & $2[1]$ & $5[4]$ & 1 & $19[3-$ & 4-2] & & 5 & 1 & 3 & 13 & 8 & 2 & 3 & 8 & 5 \\
\hline & \multicolumn{2}{|l|}{$5[3]$} & \multicolumn{2}{|l|}{$6[5]$} & \multicolumn{4}{|l|}{24} & \multicolumn{2}{|l|}{4} & \multicolumn{2}{|l|}{21} & \multicolumn{2}{|l|}{5} & \multicolumn{2}{|l|}{13} \\
\hline & \multicolumn{2}{|l|}{5} & \multicolumn{5}{|l|}{25} & 5 & \multicolumn{4}{|l|}{25} & \multicolumn{4}{|l|}{18} \\
\hline & \multicolumn{3}{|c|}{$13.5\{5-8.5\}$} & \multicolumn{5}{|c|}{$21.5\{16.5-5\}$} & \multicolumn{4}{|l|}{25} & \multicolumn{4}{|l|}{18} \\
\hline
\end{tabular}

\begin{tabular}{|c|c|c|c|c|c|c|c|c|c|c|c|c|c|c|c|}
\hline measures & 583 & 586 & 588 & 590 & 593 & 598 & 600 & 608 & 622 & 625 & 626 & 631 & 639 & 640 & 645 \\
\hline $\begin{array}{l}\text { shō sound } \\
\text { fields/ } \\
\text { echoes }(x)\end{array}$ & 8 & $x$ & 9 & $x$ & 10 & $x$ & 11 & $x$ & 12 & $x$ & 13 & $x$ & 14 & $x$ & 15 \\
\hline $\begin{array}{l}\text { durations } \\
\text { (quarters) }\end{array}$ & 12 & 8 & 8 & 12 & 20 & 8 & 32 & $\begin{array}{l}\mathbf{7 8} \\
{[32-14-159-8]}\end{array}$ & 12 & 4 & 20 & 32 & 4 & 20 & 8 \\
\hline $\begin{array}{l}\text { durations } \\
\text { (quarters) }\end{array}$ & \multicolumn{2}{|l|}{20} & \multicolumn{2}{|l|}{20} & \multicolumn{2}{|l|}{28} & \multicolumn{2}{|l|}{110} & \multicolumn{2}{|l|}{16} & \multicolumn{2}{|l|}{52} & \multicolumn{2}{|l|}{24} & 8 \\
\hline \multirow{4}{*}{$\begin{array}{l}\text { microfor- } \\
\text { mal phases } \\
\text { (= dura- } \\
\text { tions/4) }\end{array}$} & 3 & 2 & 2 & 3 & 5 & 2 & 8 & 19.5 & 3 & 1 & 5 & 8 & 1 & 5 & 2 \\
\hline & 5 & & \multicolumn{2}{|l|}{5} & \multicolumn{2}{|l|}{7} & \multicolumn{2}{|l|}{27.5} & 4 & & \multicolumn{2}{|l|}{13} & \multicolumn{2}{|l|}{6} & 2 \\
\hline & \multicolumn{7}{|l|}{25} & 19.5 & \multicolumn{7}{|l|}{25} \\
\hline & \multicolumn{7}{|l|}{25} & 19.5 & \multicolumn{2}{|l|}{4} & \multicolumn{5}{|l|}{21} \\
\hline
\end{tabular}

sound field \#8 to the end of the scene symmetrically (17[5-5-7] + $8|\mathbf{1 9 . 5}| 17[4-13]+8[6-2])$, with the perforation field (19.5) forming the axis of symmetry. Also in the first part of the scene, the proportion 25 figures prominently and, in particular, links the shō sound fields \#2 and \#3, as well as \#4 and \#5. There are also multiplicative arrangements. For example, the duration of shō sound field \#3 (24) can be explained as a multiplication of the durations 6 (sound field \#2) and 4 (sound field \#4) surrounding it; equally, the duration of the shö's sound field \#11 and the following perforation field (27.5) might be approximated as a multiplication of the surrounding shō sound fields \#10 (7) and \#12 (4).

However consciously such time relationships may be constructed, they always create a clear distinction between the clearly marked shō sound fields \#4, \#6, \#9, \#11, \#13, and \#14, which open up wide-ranging "lingering" sound states of the orchestra (here, the length of these orchestral "echoes" clearly outweighs the sho's preceding sound field), and the remaining sho sound fields, in which the orchestra indeed acts primarily as a frame and/or resonance of the shō in the foreground. In addition, the time-span organization reveals an analogy between the quasi- 
Table 4.2: Helmut Lachenmann, Concertini, final section, analysis of temporal divisions

\begin{tabular}{|l|l|l|l|l|l|l|l|l|}
\hline sound fields & 1 & 2 & 3 & 4 & 5 & 6 & 7 & 8 \\
\hline measures & $\begin{array}{l}(611) 615-623 \\
624-628 \\
629-634 \\
635-640\end{array}$ & $641-644$ & $\begin{array}{l}645-650 \\
651-654\end{array}$ & $\begin{array}{l}655-657 \\
658-665\end{array}$ & $666-673$ & $674-689$ & $690-698$ & $699-701$ \\
\hline $\begin{array}{l}\text { number of } \\
\text { measures }\end{array}$ & $1(3 / 4)+25(4 / 4)$ & 4 & 10 & 11 & $\begin{array}{l}6+2 \\
(4 / 8)\end{array}$ & $\begin{array}{l}8(4 / 8)+8 \\
(4 / 4)\end{array}$ & 9 & 3 \\
\hline $\begin{array}{l}\text { durations } \\
\text { (quarters) }\end{array}$ & $35(46.5)-20-24-24(103)$ & 16 & $24-16(40)$ & $12-32(44)$ & 28 & 48 & 36 & 12 \\
\hline $\begin{array}{l}\text { microformal } \\
\text { phases } \\
(=\text { dura- } \\
\text { tions/4) }\end{array}$ & $25.75(8.75-5-6-6)$ & 4 & $10(6+4)$ & $11(3+8)$ & 7 & 12 & 9 & 3 \\
\cline { 2 - 9 } & $25.75[28.625]$ & 4 & 21 & & 7 & 21 & & 3 \\
\cline { 2 - 9 } & 25.75 & 25 & 4 & 49 & 7 & 24 & & 3 \\
\cline { 2 - 9 }
\end{tabular}

symmetrically arranged, perceptually highly significant large "fields of alterity" (quartal field and perforation field), whose special aural effect is underlined by the "disproportionality" of their durations. ${ }^{83}$ Undoubtedly, in both cases these are moments in which a "ripetere ad libitum" could be prescribed to designate the points of contemplation that the composer has described as essential formal pivots in his works. ${ }^{84}$ The analogy of these sound states corresponds to an analogy of the transformation fields at the beginning and at the end of the scene, which refer to the framing scenes (no. 22 and no. 24) in an "intra-opus" manner. The different length of the echoes from no. 22: Himmelfahrt in the first two sho sound fields of no. 23 (mm. 508-515, 5+6 = 11 proportion values) and the premature entry of the "toneless" epilogue structure at the end of no. 23 (mm. 626-645: $13+6+2=21$ proportion values) may be explained by a large-scale tendency within the scene toward the momentum of the echoes and their emancipation from the sho sound fields.

Undoubtedly, the deliberate design of the temporal proportions also represents a perceptually and psychologically relevant category, since the ever-reconfiguring relations between shō sound fields and echoes form a decisive criterion for the listening orientation. A relevant approach applicable to further interpret this scene in its larger context is the connection between a "saturated" listening situation, in which the expectation of change in the musical structure becomes increasingly "urgent" due to a permanently evaded closure, and the experience of musical coherence as developed in the music-theoretical discourse on expectancy and implication. ${ }^{85}$

83 Although the proportions of 19 and 19.5 could be regarded as parts of the "alternative" Fibonacci series 2-5-7-1219 , this does not explain the combination with the proportional number 8 in the case of the perforation field. Also, in the case of the quartal field, the proportion of 5:19 would have to be constructed with the less plausible omission of the numbers 7 and 12. Therefore, it seems more consistent to regard both fields as consciously stretched "sound states" that break out of the proportional structure.

84 Lachenmann, Gadenstätter, and Utz, "Klang, Magie, Struktur," 16.

85 Leonard B. Meyer introduces the concept of "saturation" in the context of his basic concepts of "completion" and "closure": "A figure which is repeated over and over again arouses a strong expectation of change both because continuation is inhibited and because the figure is not allowed to reach completion." (Meyer, Emotion and Meaning in Music, 135.) 
For the final section of Concertini one could probably develop a similar argument. Here, too, the overall proportions (Table 4.2) show a numerically very clear structure in which all three "cadential sounds" (sound fields \#2, \#5, and \#8) are preceded by longer sections of almost exactly the same duration (here the proportional number 25 or the duration of 100 quarters also form the mean value): $25.75-4-21-7-21-3$ (with the three cadential sounds in bold). Interpreted from a different angle, one can say that there are exactly the same distances between the three cadential sounds, and besides the sum of the two framing sounds' durations (\#2 and \#8) gives the duration of the central fourth Eb4-Ab4 (\#5): 4-21-7[4+3]-21-3. The ephemeral nature of the three cadential sounds, which seem to flash up instantaneously from a sea of differences, gives this final section a more fragmentary character when compared to the three final scenes of the "opera." One might argue that, in the long "coda" of Concertini, the same kind of disintegration that increases constantly in scenes 22 to 24 of The Little Match Girl up to the "toneless" barrenness of the epilogue prevents a stabilization of the musical structure from the outset.

\section{Narrativity}

Lachenmann's text "Eine musikalische Handlung" ("A Musical Plot"), which accompanies The Little Match Girl instead of a libretto or synopsis, inimitably links the technical-poetic description of musical processes, references to the underlying texts of Hans Christian Andersen, Gudrun Ensslin, and Leonardo da Vinci, and musical references to his own works and those of others. The discussion that has been going on for some time in musicology as to how music, especially instrumental music, might perform narrative functions or in which cases it is appropriate, or even necessary, to apply the concept of narrativity to music $(\rightarrow$ III.5), seems to be answered by this text in a strikingly straightforward manner:

She dares not return home. The cold gradually becomes more aggressive, reaching for her. $\mathrm{Mu}$ sic, as its image, becomes shrill, violent once again in a different manner, invoking torpor and trembling mortal fear of growing cold oneself. [...]

The girl comes to again in the held second and finally again the "Scratch!". Greatest sound perforation of all: rift across the vertebrae of the piano strings, just as the pattering pizzicato arpeggios, played with plectrums behind the bridge of the string instruments, transition through via a hammering wooden stick to the appearance of the Grand Mother, her giant contours sketched in one voice by the orchestra as quasi pedalled unisono line. ("Her grandmother had never appeared so large, so beautiful") ${ }^{86}$

Much has already been said about the specific pictorial character of Lachenmann's music, and differences from conventional concepts of musical narrativity have been identified in the fun-

86 Lachenmann, "A Musical Plot," 14-15 (translation adapted) ("Sie wagt nicht nach Hause zu gehen. Die Kälte wird zunehmend aggressiv, greift nach ihr. Musik, als ihr Abbild, gerät nochmals auf andere Weise ins Schrille, Gewaltsame, beschwört zugleich Erstarrung und zitternde Todesangst vor dem eigenen Erkalten. [...] Das Mädchen kommt wieder zu sich im gehaltenen Sekundklang und schließlich das erneute 'Ritsch!'. Größte Geräuschperforation: Riss über die Wirbel der Klaviersaiten, ebenso wie prasselnde pizzicato-Arpeggien, ausgeführt mit Plektren hinterm Steg der Streicher, Übergang durch hämmernden Holzstab zur Erscheinung der Croß Mutter, ihre Riesenkontur vom Orchester einstimmig gezeichnet als quasi pedalisierte Unisono-Linie. ('Die Großmutter war noch nie so schön, so großgewesen.')" (Lachenmann, "Eine musikalische Handlung," 4, 6). 
damental ambiguity of the "images" uncovered by his music. Even though Lachenmann's "listening guide" seems to suggest rather unambiguous assignments, this fundamental ambiguity results from the fact that any conventional semantics inherent in the sounds is first of all compositionally deconstructed by what the composer has called musique concrète instrumentale, which uncovers the physical conditions of sound production and makes it the topic of composition. ${ }^{87}$ Similarly, the semantic character of the music may be deconstructed by means of the "crypto-tonal" techniques of pitch organization discussed above. For Lachenmann, therefore, there is no contradiction between the demand for structurally oriented listening and the exposition of pictorial associations. This clarifies his statement that "precisely 'structurally' directed listening, that is, an observing perception of the immediate sounds and the connections acting in them, is connected to internal images and sensations that by no means distract from that observation process, but remain inseparably connected to it and even lend it a special characteristic intensity." ${ }^{88}$ In the context of such a "pictorial" narration as evoked by music, the tonal quality and symbolism of body gestures and movements, such as trembling or the igniting of a match, are of particular importance, since they converge with a repertoire of noise sounds that Lachenmann has continuously refined and expanded since the 1960 s.

Perhaps the contradiction between the unambiguousness of Lachenmann's musicalized prose in the "Musical Plot" and the demand for an openness to pictorial associations could be resolved by taking this "listening guide" as only one possible, by no means binding musicalnarrative structure. This can easily be understood from the final scenes discussed here. In Lachenmann's text (and score), the first use of the sho coincides with the arrival of the little girl in heaven, marked by Andersen's phrase "sie waren bei Gott" ("they were with God"). For Lachenmann, the "silvery removed sound of the "Shō' [...] in the happy-liberated sense" forms a "comfortless' medium of the transcendent," then "returning seamless[ly]" to the "cold morning hour" of the final scene $24 \cdot{ }^{89}$

In the context of Lachenmann's narrative structure, scene 23 thus essentially serves to concretize the celestial as a musica coelestis or musica mundana, which earlier music theory considered largely inaudible, but not actually sonically realizable. As outlined above, the shō, already in its earlier form as the Chinese sheng, was associated with the mythical phoenix owing to its shape since very early times ( $\rightarrow$ IV.1) and its sound is also closely linked to the best-known tōgaku repertoire piece Etenraku, literally "music of heaven." Moreover, due to its high position and overtone-rich, strongly fused sonority, it seems predestined for such a musical-narrative function. In Lachenmann's Das Mädchen, however, it is linked to the threads of the complete work via sound organization, timing, and also by the complex manner of its silencing. In its "structurality," it refutes the obvious assumption that it is only an easily accessible means of

87 See Nonnenmann, "Musik mit Bildern"; Kaltenecker, "Subtraktion und Inkarnation," and Kaltenecker, "Musique concrète instrumentale."

88 Lachenmann, “.... zwei Gefühle ...” (“[...] gerade das 'strukturell' gerichtete Hören, das heißt das beobachtende Wahrnehmen des unmittelbar Klingenden und der darin wirkenden Zusammenhänge, [ist] verbunden [...] mit inneren Bildern und Empfindungen, die von jenem Beobachtungsprozess keineswegs ablenken, sondern untrennbar mit ihm verbunden bleiben und ihm sogar eine besondere charakteristische Intensität verleihen.")

89 Lachenmann, "A Musical Plot," 16 (translation adapted) (see the section Sound Organization above) ("Der noch verbleibende Instrumentalapparat bildet einen Hof um den silbern-entrückten Klang des 'Shô' [...]: im glücklichbefreiten Sinne 'trostloses' Medium des Transzendenten, bruchlos hinüber- bzw. zurückführend in die 'kalte Morgenstunde' [...]." (Lachenmann, "Eine musikalische Handlung," 6.) 
generating aura; rather it seems, as the time span analysis showed, to be connected to a construction-based "celestial mechanics."

One might conclude from this constellation of ideas that there is a "harmonizing" fusion of shō and orchestra in scene 23 based on the hybrid combination of deconstructed "European" and "Japanese" harmonies. Analogously to the course of Andersen's narrative structure, this harmonization of opposites seems to appear only temporarily intact, designed as pure hallucination, an escapist fantasy inevitably followed by the "hard facts" of worldly reality. The image of the little girl's corpse, understood as an indictment not only of the society that shares responsibility for her death, but also of those who delight in the sentimentality of this image, appears to result in questions that cannot be answered by the hybrid sound formations of the shō scene; one might even argue that this scene completely fails in its futile attempt to conjure up an "idyll."

Largely independently of these questions, the extraterritorial character of the sho sound remains an important narrative basic figure in The Little Match Girl that updates the topos of spatial distance - a central aesthetic figure of nineteenth- and twentieth-century music featured perhaps most prominently in Gustav Mahler's music. In Concertini and its spatial disposition, in which the ensemble of soloists is placed around the audience in six heterogeneous groups, this topos becomes a basic element of the temporal-spatial narrative. Proximity and distance are here not only a question of individual listening position, but inscribed in extremely sharp dynamic and gestural contrasts on every page of the score. Only in the greater focus of the final section does the music seem to withdraw into the corners of the room through dynamic-gestural reassurance. Particularly in the fleeting yet sober "cadential sounds," that pick up the narrative thread of the sho from the Little Match Girl's ending, the topos of distance is formed into presence, an experienced moment. In its "utopian" harmony there is an inherent law which cannot be completely integrated into the harmonic matrix of the work and thus negates a conventional cadential function, as it does in the "opera." Lachenmann's musical narrativity reveals its ambiguity, especially in its open endings.

\section{Interculturality}

The analyses presented here have attempted, albeit in fragmentary fashion, to present different points of view on the question posed at the beginning, namely, how Lachenmann's music realizes the simultaneity of an "irrupting" auratic alterity and dialectical mediation in the overall context in terms of compositional technique and aesthetics. With regard to the cultural contextualization of the (real and imaginary) sho sounds, I have repeatedly referred to their "double coding," which evades simplistic culturalist assignments (in the sense, for example, that the shō would produce only "Japanese" sounds and the orchestra only "European" ones). The more complex picture emerging from this interpretive model ultimately also raises questions about the historicity of the soloistic instrument and its repertoire.

Pietro Cavallotti has shown how Lachenmann's "deconstruction" of cultural, social, selfcreated conventions, automatisms, and structural plans presupposes a comprehensive critique of the notion of structure, a substantial parallel to the philosophical poststructuralism of Jacques Derrida, Gilles Deleuze, and others. ${ }^{91}$ It is therefore not surprising that the term "interculturality" was similarly extensively "deconstructed" and problematized by Lachenmann in a lecture at the 2006 Darmstadt Summer Course published in 2008:

90 See Hiekel, “Interkulturalität als existentielle Erfahrung," 75.

91 Cavallotti, Differenzen. 
The term "intercultural" is, not without justification, suspected of disguising or cosmetically masking what could otherwise be described differently, namely as parasitic exploitation, reverential or unrepentant, loving or cleverly idyllic use of aesthetically "interesting" because untouched, "fresh," even "authentic" sources of fascination of "other," non-European or non-Central European, but internally - still - intact habitats, that is, cultures: fresh meat for a tired culture exhausted and drained by a gymnastics of reflection and perpetual horizon-crossing, and the compositional practice trapped in it in this part of the world. [...]

I am glad and it is important that there are seriously initiated "intercultural" encounters, not only in music and not only in the other arts: but even the very idea of "encounter" strikes me as a onesidedly Western proposition. [...] Thinking in European terms, the intellect, however it operates, must leap beyond its own horizon, both in intercultural discourse and in dealing with itself. It actually seems ready for this in lucid moments, for the aspect of transgression is a crucial part of its tradition. [...]

The mystery and the magic and the beauty of traditional ]apanese court music [...] may fascinate us aesthetically, interest us, or even touch something deep within us - nevertheless, it strikes me as problematic and misleading to speak of such an experience, however precious, in the same breath as a typically European artistic experience [...]. Perhaps it is infinitely superior in its authenticity and ritual integrity. But as an object of import in our Western reception practice, it soon becomes an exotic idyll, insofar as its aesthetic appearance, its perceived outer skin, so to speak, enters the mediating mechanisms of our bourgeois art-obsessed reception rituals: in the concert hall, or whatever replaces or supplements it today, stored on sound media and easily accessible artifacts, in the musical request program on the radio. ${ }^{92}$

The doubts about culturally encoded musical idiomatism as a whole, the legacy of the linguistic critique of the postwar avant-garde, is combined here with the offer to participate - through

92 Lachenmann, "East meets West?," 84, 87, 90. (“Der Begriff des Interkulturellen setzt sich, nicht zu Unrecht, dem Verdacht aus, etwas zu verschleiern bzw. kosmetisch zu maskieren, was auch anders bezeichnet werden könnte: nämlich als parasitäre Ausbeutung, ehrfurchtsvolle oder ehrfurchtslose, liebevolle oder schlau idyllisierende Nutzung von ästhetisch 'interessanten', weil unberührt 'frischen', gar 'authentischen' Faszinosa 'anderer', außereuropäischer bzw. außermitteleuropäischer, wie auch immer in sich - noch - intakter Lebensräume, sprich Kulturen: Frischfleisch für eine per Reflexions- und fortgesetzter Horizontüberschreitungsgymnastiken erschöpfte, müde, ausgelaugte Kultur und in ihr gefangenen [sic] Komponierpraxis hierzulande. [...] Ich bin froh darüber und es ist wichtig, dass es ernsthaft in die Wege geleitete 'interkulturelle' Begegnungen gibt, nicht nur in der Musik und nicht nur in den anderen Künsten: Aber schon die Idee der 'Begegnung' selbst scheint mir ein einseitig westlich geprägtes Ansinnen zu sein. [...] Das europäisch geprägte Denken, der wie auch immer denkend operierende Intellekt muss dabei im interkulturellen Diskurs und zugleich im Umgang mit sich selbst einen Sprung über den eigenen Horizont machen. Er scheint in lichten Momenten tatsächlich dazu bereit, denn gerade das Moment der Überschreitung gehört zu seiner Tradition. [...] Das Geheimnis und der Zauber und die Schönheit einer traditionellen japanischen Hofmusik [...] mag uns [...] ästhetisch faszinieren, interessieren oder auch tief in unserem Innern berühren - dennoch, es scheint mir problematisch und irreführend, ein solches, wie auch immer kostbares, Erlebnis in einem Atem zu nennen mit einem Kunst-Erlebnis europäischer Prägung [...]. Vielleicht ist jenes in seiner Authentizität und rituellen Ungebrochenheit diesem unendlich überlegen. Aber als Importgegenstand in unserer westlichen Rezeptionspraxis oxydiert es alsbald zur exotischen Idylle, insofern seine ästhetische Erscheinung, sozusagen seine wahrgenommene Außenhaut, in die Vermittlungsmechanismen unserer bürgerlichen kunstbeflissenen Rezeptionsrituale gerät: im Konzertsaal oder was immer ihn heute ersetzt oder ergänzt, auf Tonträgern gespeichert und bequem zugänglich macht, im Wunschkonzert einer Rundfunksendung.") 
a leap beyond one's own horizon - in a compositional-existential way in intercultural processes, though it is hardly specified where and how exactly the boundary between a (superficial) "exploitation" and a (substantial) "self-admitting" to an "Other" would be drawn $(\rightarrow$ I.2, I.3). By contrast, in his conceptualization of the shō, Lachenmann seems to take a less dualistic approach. Since the initially described first perception of the categorial alterity of the Japanese instrument in the course of scene 23 becomes an integral part of an expanded aesthetic horizon while maintaining an extremely complex networked mediation in the cosmos of Lachenmann's sound transformation, an irresolvable cultural difference is revealed, without degrading the shō to a mere "treasure." It seems essential that Lachenmann hardly touches the timbral peculiarities of the instrument. This becomes particularly clear when one compares Lachenmann's approach with other compositions in which far stronger interventions are made in the sho's peculiar sound space, for example in Chaya Czernowin's trio Die Kreuzung $(1995, \rightarrow$ IV.1), where the cultural identity of all instruments is reduced to a minimum through noise structures and great virtuosity in order to implicitly point at the "gap" between their traditional contexts, or in Gene Coleman's Yago for shō, hichiriki, ryüteki, saxophone quartet, live electronics and video (2003), in which the sho and the other gagaku instruments are integrated into semi-improvisatory noise structures. While both compositions - substantially influenced by Lachenmann's method of sonic alienation - try to shatter the myth of the instrument in almost didactic clarity, Lachenmann's own approach is characterized by much subtler intermediate stages.

Something similar may apply to Lachenmann's reception of the philosophy of the Kyoto school, which has already been treated in detail by Jörn Peter Hiekel: ${ }^{93}$ If the problematic historical-political context of this school's thought is not made explicit by Lachenmann ( $\rightarrow$ II.6), especially connections between philosophical rhetoric, nationalism, and militarism during the Second World War period, ${ }^{94}$ Lachenmann's sensitive "searching movements," which use the texts of Nishida, Nishitani, Ueda, and Teitaro Suzuki because they "try to illuminate the nonsensible, even the unthinkable with the help of discursively operating language," ${ }^{95}$ successfully avoid simple attributions without slipping into the arbitrary or mystifying. One significant element seems to be a hitherto seldom discussed connection between the Kyoto school's and Lachenmann's (in his later works) increasingly accentuated impulse toward a "liberated perception. ${ }^{96}$ In the words of Keiji Nishitani:

What the Japanese call mono no aware ("the pathos of things") indicates the point where lust and joy are one with a sadness over the feeling of impermanence. In other words, the phrase signifies that where the being of man, as something bound to things in time, rises to awareness "perfumed" with the feeling of world and time and under the Form of infinity, there also the essential impermanence of all things, or sheer being-in-the-world, is aesthetically felt to the quick-in the Kierkegaardian sense of "aesthetic existence." It means that all the things of the world and the self itself are realized together aesthetically, in the original countenance of their manifestation. ${ }^{97}$

93 See Hiekel, "Interkulturalität als existentielle Erfahrung."

94 See particularly Heisig and Maraldo, Rude Awakenings.

95 Lachenmann, "East meets West?," 86. ("Texte eines Nishida, eines Nishitani, Ueda, Teitaro Suzuki, [die] das Nichtsagbare, gar das Nichtdenkbare mit Hilfe der diskursiv operierenden Sprache anzuleuchten versuchen.")

96 For the broader historical and aesthetic context of Lachenmann's concept of "liberated perception" see Utz, "Auf der Suche nach einer befreiten Wahrnehmung," 39-40.

97 Nishitani, Religion and Nothingness, 247. 



\section{New Music and Beyond: Music-Historical and Cultural Entanglements}

This chapter focuses on three intercultural contexts in rather loose sequence (though arranged roughly chronologically) that may share some overarching themes and lines of development. Beside the inevitable confrontation with cultural essentialism, questions of political and social function and communicability of new music are foregrounded along with aspects that have not yet been discussed sufficiently or in detail, including the relevance of voice, body, and movement as well as questions of perception and metaphorical hearing. Deviating from the emphasis placed elsewhere on the East Asian space, problems of the conception and compositional reception of African rhythmic structures against the background of systematic and historical aspects of polymeter are outlined in part 2 of the chapter, proceeding from György Ligeti's much-discussed Piano Concerto. All three parts might also be understood as case studies for an entangled transnational music history as discussed in Chapter II.I.

\section{The Rediscovery of Presence: Intercultural Passages Through Vocal Spaces Between Speech and Song}

\section{The Voice in Twentieth- and Twenty-First Century Music}

Owing to its mythical and magical implications and its close relation to speech and language, the human voice has always been a crucial hinge between musical and social, spiritual, religious experience. It has also been a medium of sound that from the beginning was considered highly capable of communicating meanings, ideas, and ideologies. Researchers of evolutionary musicology and linguistic anthropologists have suggested that human language originated from symbolic patterns of vocalization and singing. A naive genealogy that attributes speech and singing to a common origin has become questionable at least since Jacques Derrida's deconstruction of Jean-Jacques Rousseau's Essai sur l'origine des langues, arguing that speaking and singing have always already deviated from each other. ${ }^{1}$

1 Derrida, Of Grammatology, 199. Rousseau's Essai (written in 1755, published posthumously in 1781) argues that speech and song would have been nothing more than language itself in a prehistoric era (see Rousseau, "Essay on the Origin of Languages"). Rousseau intended to prove that melody, not harmony, should claim priority in terms 
If one considers anthropological theses about the origin of language through the formation of semiotic patterns in archaic vocal music, however, ${ }^{2}$ it also becomes apparent that, on the one hand, a complete "desemanticization" of the human voice, as was sometimes rigorously sought in twentieth-century music, soon reaches its limits: speaking and singing, even non-verbal forms, generate meaning. On the other hand, it is also clear that the apparently "most neutral" forms of organization of language, such as the standardized voices of newsreaders, contain a subversive, sonically autonomous element that cannot be grasped using structural-syntactic language models. Nevertheless, in musical and linguistic environments - which often tend to stress this autonomy of vocal sonority - the voice is embedded in structural and cultural frameworks or codes that may both restrict and expand this sonorous presence and thus influence or multiply its connotations. These meanings are usually more ambiguous in performed language and vocal musical structures than in everyday language, and often intentionally so.

If the level of musical globalization comes into view regarding such ambiguity, understood as a constantly procedurally shifting constellation of homogenizing and differentiating movements $\rightarrow$ I.2-3), it becomes clear that the voice may reinforce both movements - cultural convergences or hybridizations as well as the articulation of local, regional, or national identities. ${ }^{3}$ Furthermore, it has become clear in the extensive studies on the aesthetics and cultural history of the voice in recent years ${ }^{4}$ that collective models of voice use and articulation are reflected in a highly complex manner in individual voices through personal appropriation or musical training, so that it seems impossible to separate or isolate them. Indeed, it is precisely the pluralistic variety of vocal characters and techniques that enables storytellers, singers of traditional narrative genres, opera singers, avant-garde vocalists, or theater actors to switch between different moods and characters in the shortest possible time. In contrast to such vocal "role play," deep psychological approaches aim at a "liberation" of the voice from the formalized "masks" and conventions of the daily use of voice, an approach pursued by the vocal pioneers Alfred Wolfsohn and Roy Hart ${ }^{5}$ as well as in the musical avant-garde since the 1960 s by Dieter Schnebel, Peter Maxwell Davies, or Jani Christou.

Maybe it was precisely this tendency toward more or less subconscious articulation of a not only culturally but also historically "charged" sonority of human singing voices that, in twentieth-century music, temporarily led to a widespread eschewal of the vocal element - a point Dieter Schnebel made rather clear:

of music and music theory, since it imitates the accents of language and, in its own linguistic similarity, would be superior to mere speech (see also Berger, "'Harmonie' und 'mélodie'”).

2 "Vocal music might have been the evolutionary laboratory in which early humans developed complex syntactic patterns and a system of multifaceted discrete contrasts that allowed them to attach to these patterns their preexisting symbolic abilities and thus to establish a stable speechlike system." (Richmann, "Did Human Speech Originate in Coordinated Vocal Music?," 244.) This argument has also been taken up in more recent research: "Performative functions associated with oral sound-making provided initial pressures for vocal communication by promoting rank and relationships. These benefits, I suggest, facilitated conflict avoidance and resolution, collaboration, and sharing of needed resources." (Locke, "Rank and Relationships in the Evolution of Spoken Language," 37, Abstract.)

3 See in particular Utz and Lau, Vocal Music and Contemporary Identities.

4 See among others Potter, Vocal Authority, Meyer-Kalkus, Stimme und Sprechkünste im 20. Jahrhundert, Kolesch and Krämer, Stimme, Kittler, Macho, and Weigel, Zwischen Rauschen und Offenbarung, Felderer, Phonorama, Dolar, A Voice and Nothing More, Cavarero, For More than One Voice, and Anhalt, Alternative Voices.

5 See Peters, Wege zur Stimme. 
Serial music was conceived as an abstract music, like abstract painting, nonrepresentational painting. We [the composers] also worked toward this. There were constructions and certain forms that we simply rejected. We didn't want to write symphonies. We didn't want to write operas. Vocal music also was almost taboo, because vocal music always has a text, and the text provides an emotional plan. The text has its own progression of sound, but we wanted to compose the sounds themselves. For this reason we turned to the phonetic script, because we had the possibility to notate minute differentiations within the [vocal] sounds. ${ }^{6}$

Where the voice did appear, it was sometimes approached radically in an instrumental idiom, perhaps oriented toward some of Anton Webern's vocal works. This did not preclude, in works such as Pierre Boulez's Le marteau sans maître (1953-57) or Luigi Nono's Il canto sospeso (1955-56), a specific expressivity resulting from an unresolved friction between the musical structure and the vocal-physical sonorities. On the subject of his magnum opus Das Mädchen mit den Schwefelhölzern (The Little Match Girl, 1990-96, $\rightarrow$ IV.2), Helmut Lachenmann (referring to his own œuvre, but also making a general point) (self-)critically discussed this tendency toward an "exclusion" of the voice:

I have always paid special attention to familiar musical genres - in a paradigmatically modified context, so to speak. Of course, this also applies to answering the question: "How do you feel about singing?" To this day, this question has remained traumatic for me. There is something wrong with a notion of music that avoids the voice, or even shuts out singing. [...] [My opera The Little Match Girl] can not least be attributed to an - unfinished - examination of the singing voice [...]. ${ }^{7}$

Lachenmann has explained further that his compositional practice, developed in the late 1950 s and early 1960s, by definition excluded the option of simply "recuperating" established modes of vocal and instrumental expression by employing "recognizable emotional gestures." For Lachenmann, compared to instrumental music, vocal music particularly relies on such gestures since "singing without preconceived emphasis is impossible;" a "singer cannot [...] deliver their tone from a distance, but must give themselves, identify themselves. That is why the sung tone today, like 500 years ago, is a magical event." In his few vocal works, Lachenmann consistently

6 Schnebel, personal communication, 25/05/2006, quoted in Cee, "The Notation and Use of the Voice in Non-semantic Contexts," 180 ("Die serielle Musik sollte eine abstrakte Musik sein, wie abstrakte Malerei, gegenstandslose Malerei. Und das haben wir auch angestrebt. Es gab Konstruktionen und bestimmte Formen, die wir einfach abgelehnt haben. Wir wollten keine Symphonien schreiben. Wir wollten keine Opern schreiben. Vokalmusik war auch fast verpönt. Weil Vokalmusik ist ja immer mit Text, und der Text liefert einen emotionalen Ablauf. Der Text hat auch selber einen Klangablauf, aber wir wollten die Klänge selber komponieren. Deswegen sind wir auch auf die phonetische Schrift gekommen, weil wir da die Möglichkeit hatten, die Klänge sehr differenziert zu notieren." Gee, "The Relationship of Non-Semantic Vocal Music to the International Phonetic Alphabet," 281.)

7 Lachenmann, "'Klänge sind Naturereignisse," 33 ("So ging es mir immer wieder um die Auseinandersetzung mit den vertrauten Werkgattungen - sozusagen in paradigmatisch verwandeltem Zusammenhang. Zum Beispiel natürlich auch um die Beantwortung der Frage: 'Wie hältst Du's mit dem Cesang?' Bis heute ist für mich diese Frage traumatisch geblieben. Ein Musikbegriff, der der Stimme ausweicht, gar den Cesang aussperrt, bei dem stimmt irgendetwas nicht. [...] [Das Mädchen mit den Schwefelhölzern verdankt] sich nicht zuletzt der noch nicht beendeten Auseinandersetzung mit der singenden Stimme [...].").

8 "Helmut Lachenmann im Gespräch," SFB 2005, 69, quoted in Meyer-Kalkus, "Stimme und Atemsyntax," 105. ("vorab eingeführte Ausdrucksregister der Vokal- und der Instrumentalmusik mit wiedererkennbaren emotionalen 
understood the voice as physical materiality that is made to sound on the basis of an anti-rhetorical "breathing syntax" whereby the instrumental approach of the musique concrète instrumentale is transferred to the vocal medium. ${ }^{10}$

Whether such developments are traced back to the music-aesthetic primacy of instrumental music in the nineteenth century or are thought of in combination with the radical criticism of conventional ideas of similarity between linguistic and musical elements in the period after the Second World War ( $\rightarrow$ I.2), it is clear that the voice in works such as Arnold Schoenberg's Erwartung (1909) or Dieter Schnebel's glossolalie (1959-60, a concept work for which the composer made a fully-notated performance score, Glossolalie 61, 1961-65) breaks into situations that threaten the credibility of the language-character of music, and with it the presence of the human voice with a kind of atavistic, eruptive force. Last but not least, the incommensurability of these works can be identified in the way the vocal protagonists assume a new responsibility that significantly encroaches on the monological authority of the composer. ${ }^{11}$ In Erwartung or glossolalie, neither the performer's nor the composer's voice communicates a stable identity any longer; rather, they articulate (deliberately) futile attempts at constructing coherence, which is clearly shown by their non-linear, anti-narrative formal design.

If the voice in European music after 1945 and until Lachenmann was deployed at all, it did not necessarily act as a medium for the articulation of linear and meaningful expressive content that had generally become questionable: an intact musical-vocal representation of texts seemed to be meaningless. Also in music composed outside of Western contexts, the vocal element was often used with great caution from the postwar period on - a turn surely indebted to Cold War aesthetics, in which the enthusiastic endorsement of vocal music during the prewar and wartime periods, for example in Japan ( $\rightarrow$ II.4), appeared problematic. ${ }^{12}$ Moreover, instrumental works seemed easier to convey to a global audience (an audience comprising a majority accustomed to Western music) than vocal music, not least because it allowed the composer to avoid primary language and phonetic problems. Against this background, it is again no coincidence that - contrary to this tendency - in what was perhaps the most important period of Asian music in the twentieth century - the emergence of young Chinese composers since the early 1980 s - the vocal element played a key role $\left(\rightarrow\right.$ II.3., III.5) ${ }^{13}$ In the space between the vocal

Gesten einfach abzurufen;" "Singen [ist] ohne [...] vorgelagerte Emphase unmöglich;" “Ein Sänger kann nicht [...] seinen Ton aus der Distanz abliefern, sondern er muß sich selbst dabei geben, muß sich identifizieren. Darum ist der gesungene Ton, heute wie vor 500 Jahren, ein magisches Ereignis.")

9 See ibid.

10 See Hiekel, "Escaped from Paradise?," 164-172.

11 See Abbate, Unsung Voices, 11-14.

12 This thesis only applies with certain qualifications, of course, and above all to the composers or works that have become known in the West. An indicator of this may be seen in the fact that the œuvres of the Asian composers best-known to Western audiences hardly include any vocal works at all (as with Tōru Takemitsu), or references to Asian vocal music have been largely suppressed (as in Isang Yun's operas). Yun's Asian-inspired vocal works Cagok for voice, guitar, and percussion (1972) and Memory for three voices and percussion (1974) are exceptions that prove the rule (see Eikemeier, "Zum Text von Yun Isangs Memory," Kabisch, "Klang, Ton, Geräusch, Exkurs," and Utz, Neue Musik und Interkulturalität, 243-244). A distance to the vocal medium can also more generally be found in new Korean music over longer periods of time (see Lee, "Reconsidering Traditional Vocal Practices in Contemporary Korean Music"). However, it must be emphasized that jōji Yuasa (b. 1929) worked at about the same time as Schnebel (1930-2018) on comparable body-oriented and sound-related forms of vocal music, for example in Voices Coming (1971), Toi (1971), and Utterance (1971). See Galliano, Yōgaku, 220-221.

13 See, for more detail, Utz, Neue Musik und Interkulturalität, 315-316. 
modernism represented by Schoenberg's Pierrot lunaire (1912) and the almost inexhaustible reservoir of Chinese local and national vocal genres, a "third space" with great potential opened up (see below).

A special characteristic of vocal music has always been the difficulty of notating it. The voice certainly reflects the tension between aural, performative and written, denotative layers of musical practice in a particularly fundamental manner. This tension is equally familiar from ethnomusicology ${ }^{14}$ and contemporary music. The minimal variations in pitch, vocal coloring, dynamics, and register changes that constitute an individual vocal sound can hardly ever be recorded in notation without omissions. In new music, this resulted on the one hand in overdetermined forms of notation, which, as in the aesthetics of Brian Ferneyhough, were sometimes linked to the idea of the vocal organ as a "resonator" to help filter out and individualize the notational complexity. ${ }^{15}$ This contrasts tendencies of works that have been created in close collaboration between composers and vocal soloists relying on their very specific vocal skills and colors - including vocal "composer-performers." In such collaborations, notation often has a merely supplementary role as a mnemonic device, establishing a kind of "oral tradition" comparable to many vocal genres in traditional music. Even though some of these developments can also be observed in the field of instrumental composition, the highly individual and peculiar vocal colors and possibilities of the singers led in many cases to particularly strongly performer-centered concepts. These include Peter Maxwell Davies's Eight Songs for a Mad King (1969), written for Roy Hart's "polyphonic" vocal artistry, a work reflecting the anti-psychiatric debate in the UK during the late 1960 s, $^{16}$ the large number of works created for, with, and by Cathy Berberian, including John Cage's Aria (1958), Luciano Berio's Sequenza III (1966), and Berberian's Stripsody (1966), ${ }^{17}$ as well as Giacinto Scelsi's works for solo voice, especially the Canti del Capricorno (1962-72); Michiko Hirayama played a crucial part in the creative process of the Canti, also adding connections to traditional Japanese vocal practices. ${ }^{18}$ In several cases, such collaborations touch on questions of authorship, since the performers often took on the role of a "co-composer." In the globalized context, such close collaborations between composer and vocal soloist reflect a growing importance of local contexts, which often involve new forms of global connectivity. ${ }^{20}$

14 See Nettl, The Study of Ethnomusicology, 74-91.

15 "[P]erformers are no longer expected to function solely as optimally efficient reproducers of imagined sounds; they are also themselves 'resonators' in and through which the initial impetus provided by the score is amplified and modulated in the most varied ways imaginable." (Ferneyhough, "Unity Capsule," 100.)

16 Williams, "Madness in the Music Theatre Works of Peter Maxwell Davies," 83-84.

17 See Herzfeld-Schild, "Studien zu Cathy Berberians 'New Vocality."

18 See, among others, Kirchert, "Between Worlds," Hirayama, "Mach's wie Du es fühlst," Tortora, Voce come soffio, Voce come gesto, and Hiekel, "Escaped from Paradise?," 161-164. Hirayama, however, emphasized that she had no sound knowledge of traditional ]apanese vocal music (Hirayama, "[Michiko Hirayama in Conversation with Jürgen Kanold],"16-17).

19 See especially Meehan, "Not Just a Pretty Voice."

20 This means, for example, that these collaborations often develop over a longer period of time at a certain location-often privately - but at the same time integrate the experiences of all those involved on the global "stage." See also Tomlinson, Clobalization and Culture, 1-31. 


\section{Articulation and Codification of the Voice: Thresholds and Interactions Between Speech and Song}

Analogously to the limitations of vocal notation, it was shown that even a tool designed as universalistically as the International Phonetic Alphabet (IPA), despite its high degree of differentiation, ultimately cannot capture many phonetic structures, for example, where a voice gradually changes between different phonetic types or categories. ${ }^{21}$ An interculturally accentuated historiography $\rightarrow$ II.1) that critically addresses the criterion of writing must see a central task precisely in the clarification of such tensions between notation and performance, writing and sound. Indeed, it is the transitional areas between established vocal categories and vocal styles, as reflected in the problem of adequate notation, that have repeatedly become a focal point of particular importance for vocal music of the most varied historical and cultural provenance, especially in the twentieth and twenty-first century. Such passages ${ }^{22}$ between speaking and singing voices are traced below using selected case examples from Japanese, Chinese, and European contexts. The exploration of the areas between speaking and singing seeks to question the relationship between voice and musical meaning, whereby structural and sociocultural dimensions of vocal music are interrelated. To this end, the interaction between "articulation" and "codification" is placed at the center of attention. "Articulation" is here understood not only in the technical or phonetic sense, but above all also metaphorically: the human voice "articulates" itself as an independent "agent" in a musical context where the vocal sound forms an autonomous psychophysical presence, while it might at the same time appear as one "voice" among several in the structure of the composition. Similarly, "codification" is understood not only in the obvious sense as a notation of sounding voice(s), but also as a term for those sound-immanent and language-discursive means for the constitution of cultural and historical "codes" in which a vocal sound is received and understood.

The passages between speaking and singing can be technically described in a variety of ways. Two culturally different "mappings" of this field will be discussed here, some parts of which will serve as a reference in the following analyses. As early as 1963, still somewhat indebted to the tradition of "Comparative Musicology," George List created a map conceived in an unambiguously universalist manner, based on a very wide number of traditional and new singing and speaking styles (Table 5.1). ${ }^{23}$ The examples include Western Australian Nyangumata wangka speech, Hopi Native American's laváyi (speech), táwi (song), and tí:ngava ("announcing," a chant on two reference pitches), and the New Zealand Maori's koorero (speech), karakia (ritual chant), waiata (song), and haka (narrative form with mixed styles). In addition, List discusses forms of heightened speech in advertising speakers, Western spoken drama, and jumping rope rhymes,

21 See Gee, "The Relationship of Non-Semantic Vocal Music to the International Phonetic Alphabet," 265.

22 In a wide-ranging essay, Martin Zenck presented the potential of the term "passage" as it is used here, historically prominently introduced by Walter Benjamin in The Arcades Project (Das Passagen-Werk). Zenck thematizes topographical-cultural fields (passages between geographic cultures or regions), intercultural fields (passages as interactions between cultures), philosophical fields (passages between physical and metaphysical levels and concepts), and aesthetic fields (passages as crossings and transgressions of boundaries). These fields are also associated with music-specific meanings of the passage concept (transitions as part of musical syntax and form, continuous transition as a principle in new music, etc.). According to Zenck, passages that "lead over thresholds" sometimes approximate transgressions in which borders are violently torn down "because this is the only way to cross them" (Zenck, "Zu einer kulturwissenschaftlichen Theorie der 'Passage," 30, "über Schwellen führen," "weil nur so ihre Überschreitung möglich erscheint").

23 List, "The Boundaries of Speech and Song," 9. 
Table 5.1: Gradation of the areas between spoken voice and singing by George List with placement of the examples discussed by List. 1: heightened speech (Western drama); 2: jump rope rhymes (USA); 3: Palau women song (Micronesia); 4: type of Thai Buddhist chant; 5: Schoenberg, Pierrot lunaire; Maori: haka; Chinese opera recitative (not specified); 6: tobacco "auctioneering" (USA); 7: Hopi Native Americans (Arizona): announcement; 8: aboriginal Australians (songs); 9: songs of black Americans; 10: bi-, tri-, tetratonic chants (Vedda: children's songs, folk songs)

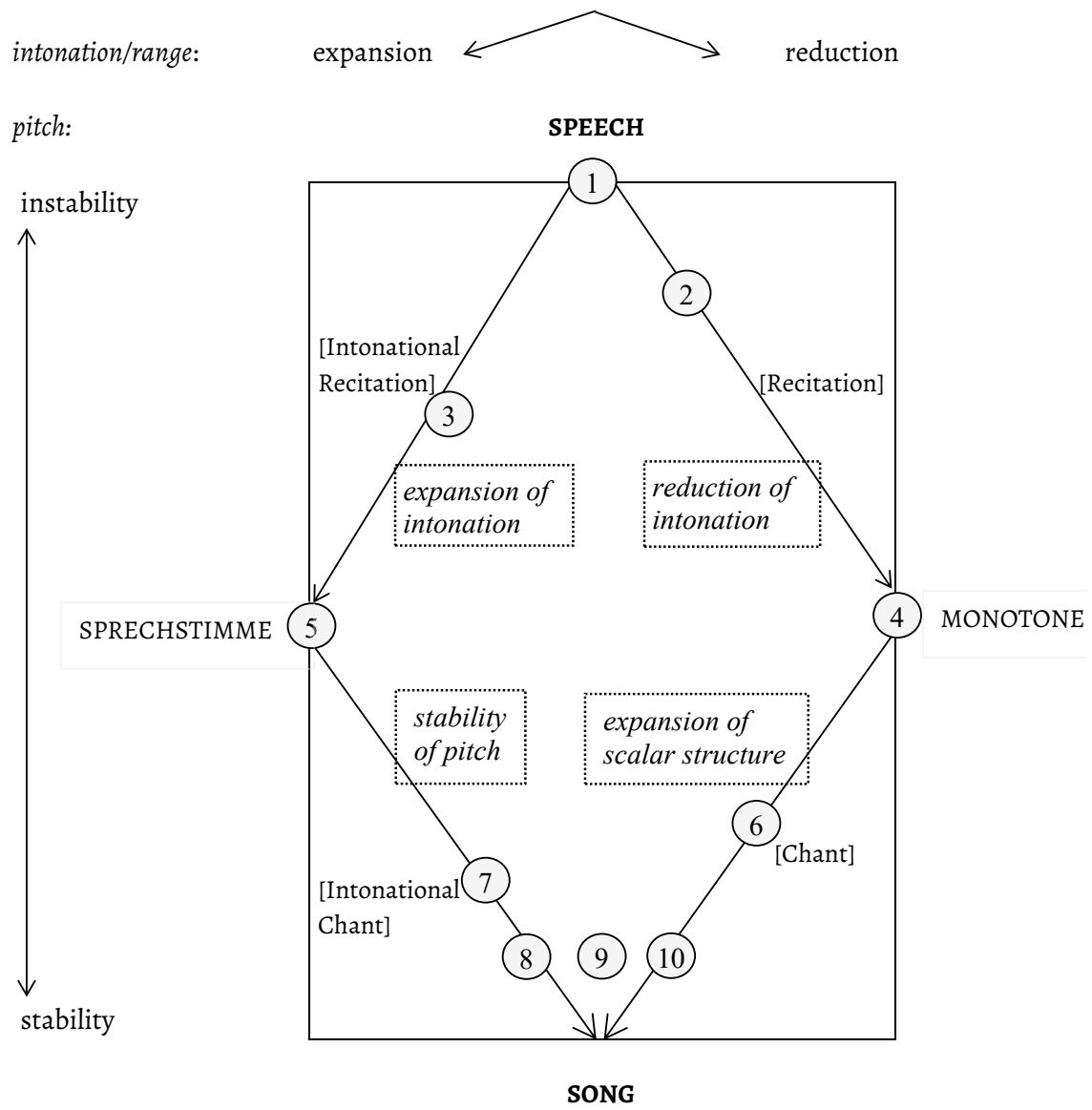

forms of recitation from Palau (Micronesia), Thailand, songs of black Americans, Schoenberg's Sprechstimme, and Chinese opera "recitative." The presupposed assumption of comparability within this sociologically and geographically exceptionally broad spectrum naturally leads to the question of how far the "technical" aspects of the voices gathered here can be isolated from the sociocultural conditions of their production and their emic concepts - a familiar argument from the broad criticism of comparative ethnomusicology since the 1960s. The meaningfulness of this map must certainly be limited to the "technical" dimension, which should not prevent us from using it as an aid to the following analyses. The pitches, which are less profiled in the everyday speaking voice than in the singing voice, gain clearer contours in more stylized declamation or in "half-sung" forms (List places Schoenberg's Sprechstimme in this area, center left). In contrast, pitch organization in the form of monotone recitation is increasingly narrowed 


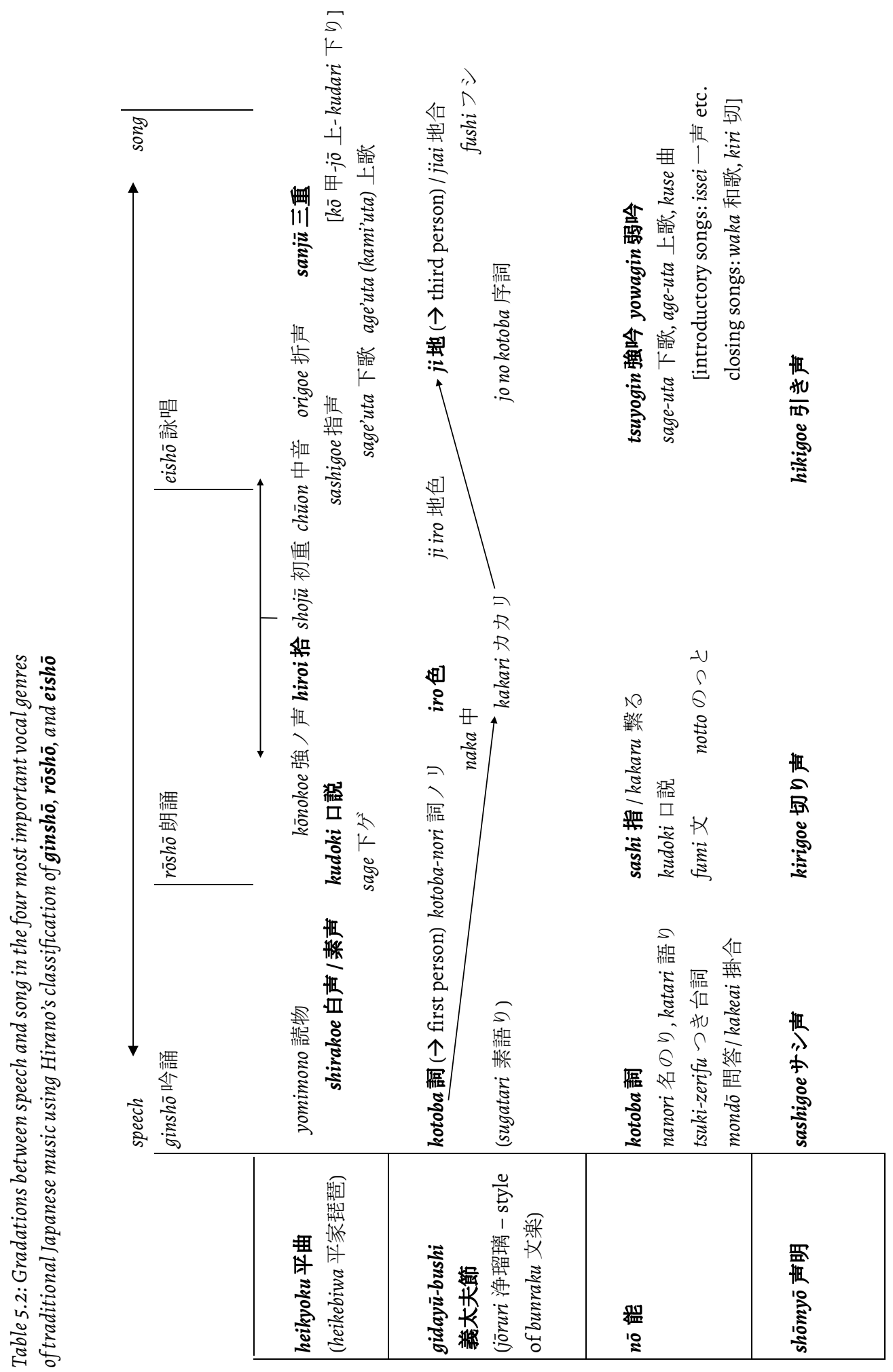


down to a single note (center right), often in ritual contexts. Recitative styles are often characterized by repetitions of sound, such as the parlando of opera buffa. An increasing stabilization of the pitch or an expansion of scalar structures then leads to forms that are generally referred to as "singing."

Even on a purely technical level, List's map obviously only provides a relatively rough grid. More detailed categories are required to describe specific forms of vocal delivery. In traditional Japanese vocal music, passages between speaking and singing have received special attention and have been differentiated into complex categories within the practice of the individual genres. Table 5.2 seeks to show these categories for the vocal styles from heikyoku (epic narrative singing accompanied by the lute biwa), gidayu-bushi (vocal style accompanying the puppet theater bunraku), $n \bar{o}$ (archaic music theater employing male voices exclusively in both solo and choir formats), and shōmyō (ritual Buddhist chant) in a representation using an overarching three-level typology based on research by Kenji Hirano on katarimono, an umbrella term for language-oriented traditional Japanese vocal genres. ${ }^{24}$ Hirano distinguishes between ginshō (declamation that moves close to the spoken language), rōshō (syllabic recitation at regular time intervals with pitch repetitions on one or a few pitch centers), and eishō (recitation tending toward singing, employing changing time intervals, with sustained notes alternating with faster notes of different pitches).

The vocal delivery techniques listed in Table 5.2 are by no means complete, however, and their assignment to the three categories is somewhat arbitrary, especially in heikyoku and giday $\bar{u}$-bushi, which have an extraordinarily large number of different gradations, although their exact relevance in practice often remains ambivalent and strongly dependent on additional factors such as the aural conventions of the respective schools. ${ }^{25}$ After all, in the three transcriptions shown in Example 5.1 (shirakoe, kudoki, sanjū) from the heikyoku piece Suzuki, one can recognize the three categories ginsh $\bar{o}, r \bar{o} s h \bar{o}$, and eishō in a relatively pure form.

The vocal delivery techniques in heikyoku are generally referred to as kyokusetsu ${ }^{26}$ (alteration, change, melodic formula), and in giday $\bar{u}$-bushi as senritsuke ${ }^{27}$ (melody type). Depending on the context, these terms may designate vocal techniques in the narrower sense but also melodic contours, lines, or even certain individual pitches. ${ }^{28}$ Giday $\bar{u}$-bushi includes particularly numerous transitory styles that are used to switch between the main styles kotoba (speech), iro (recitation), and $j i$ (chant), such as kotoba-nori, ji iro, or kakari. Cadential figures, melodic patterns, and quotations of specific melodies are juxtaposed to these main styles, resulting in a layered complexity that is inwardly connected to the process of oral transmission. ${ }^{29}$

24 See Hirano, "Beziehungen zwischen Sprache und Musik im katarimono."

25 Updated introductions into the two genres can be found in Komoda, "The Musical Narrative of The Tale of the Heike" and Yamada, "Cidayu-bushi: Music of the bunraku Puppet Theatre."

26 Komoda, "The Musical Narrative of The Tale of the Heike," 84. Sometimes the term onsetsu (syllable) is used instead of kyokusetsu (see Mayeda, "Über die sanjū-Abschnitte im heikyoku," 174).

27 Yamada, "Gidayu-bushi: Music of the bunraku Puppet Theatre," 205.

28 The use of these terms is not uniform in research and is not limited to the two genres: "[kyokusetsu] tends to indicate longer passages of section length, while [senritsukei] [...] refers to shorter phrases" (Tokita and Hughes, "Context and Change in Japanese Music," 24).

29 "All katarimono of pre-modern provenance stem from oral practices in which text and music were produced by techniques of oral composition. Evidence for oral composition in such traditions is demonstrable through analyses developed from the principles of oral-formulaic theory." (Ferranti, "Transmission and Textuality in the Narrative Traditions of Blind Biwa Players," 141, note 22.) 
Example 5.1: The three vocal delivery techniques shirakoe, kudoki, and sanjü in transcriptions of the heikyoku piece Suzuki (performer: Tsutomu Imai; transcription: Komoda, Heike no ongaku, 404-417)

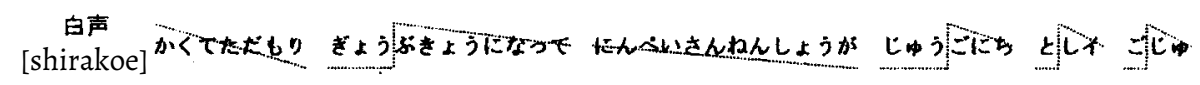
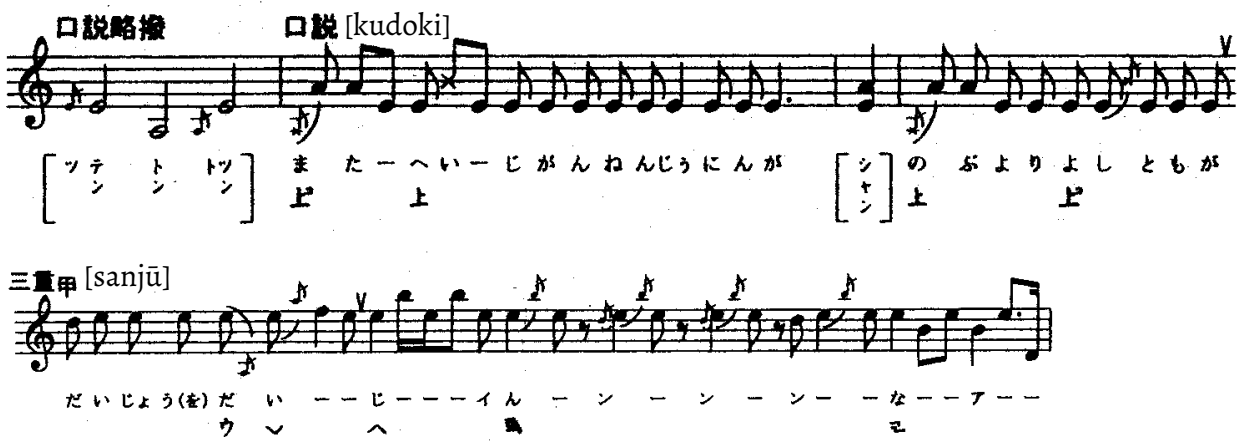

Copyright $\odot 2003$ by Haruko Komoda/Daiichi Shobō Tokyo

Hirano particularly highlights the intersections and transitions between the three main categories, which show a tendency toward hybrid formation. For example, a kotoba recitation in giday $\bar{u}$-bushi can tend to stabilize pitches in the manner of rōshō practice, motivated by dramatic, phonetic, or symbolic contexts. The hiroi technique in heikyoku, in turn, can be extended both to the regions of eishō and ginshō. Furthermore, as both traditions are transmitted orally, performance styles specific to a certain school and/or individual performers may lead to substantially different interpretations of the same technical terms. We can thus infer that even the most refined typologies do not provide sufficient tools to grasp the specific manner and criteria of transformation between speech and song inherent to many elaborate vocal styles. This obvious shortcoming implies that the interaction and transformation between speech and song must be analyzed comparatively in a variety of specific contexts.

\section{Fragmentation and Montage (gidayū-bushi, Tan Dun, Schoenberg)}

A detailed analysis of a section from giday $\bar{u}$-bushi will initially show how its "hybrid formation" of vocalizations is achieved practically. Giday $\bar{u}-b u s h i$ is a specific vocal style of the narrative genre jōruri used in Japanese bunraku puppet theater and developed by Gidayū Takemoto (16511714) in Osaka around 1684. The ambivalences and complexity of this style seem to me to allow particularly vivid passages to other types of vocal articulation. Gidayu-bushi is performed by a reciter (tay $\bar{u}$, narrator) and a player of the three-string long-necked futozao shamisen (a bass shamisen, usually tuned in honchōshi with the [relative] pitches B3-E4-B4). The tay $\bar{u}$ acts as the narrator of the story and simultaneously lends his voice to all puppet characters acting on the stage. His vocal timbre is based on a strong chest voice and diaphragmatic breathing and is of a rough and throaty quality, which is guided by the aesthetic ideal ibushi (oxidation) ${ }^{30}$ and closely linked to the buzzing sawari timbre of the futozao shamisen. The shamisen contributes to the 
expression of the text by playing finely spun heterophonic lines around the reciter's part and bridging gaps between sections with solo melodies (meriyasu). The continuing changes in the reciter's vocal character can only inadequately be inferred from the sparse original notation, which merely consists of a few instructions noted down in the tayü's book to the right of the column with the lyrics. ${ }^{31}$

Example 5.2 shows the transcription of a section from the scene Yama no dan (Mountain Scene) from Imoseyama onna teikin (Mount Imo and Mount Se: A Parable of Female Virtue, 1771) a bunraku drama written by Hanji Chikamatsu (1725-1783). This section gives a good understanding of the mosaic-like microstructure that is so characteristic of giday $\bar{u}$-bushi, in that the vocal delivery changes with every line of text, or often even within the same line. ${ }^{32}$ The lyrical pas-

Example 5.2: Hanji Chikamatsu, Imoseyama onna teikin (Mount Imo and Mount Se. A Parable of Female Virtue). Section from the scene Yama no dan (Mountain Scene), based on a performance by Sumitayū Takemoto, recitation, and Kizaemon Nozawa, futozao shamisen (transcription: Malm, "A Musical Analysis of 'The Mountains Scene," 78-79; the transcription follows the convention of notating the open strings of the futozao shamisen with the pitches B3-E4-B4; in the recording of the scene attached to Malm's analysis, the pitches are about a minor third lower, so the open strings of the futozao shamisen are at $G \# 3-C \# 4-G \# 4$
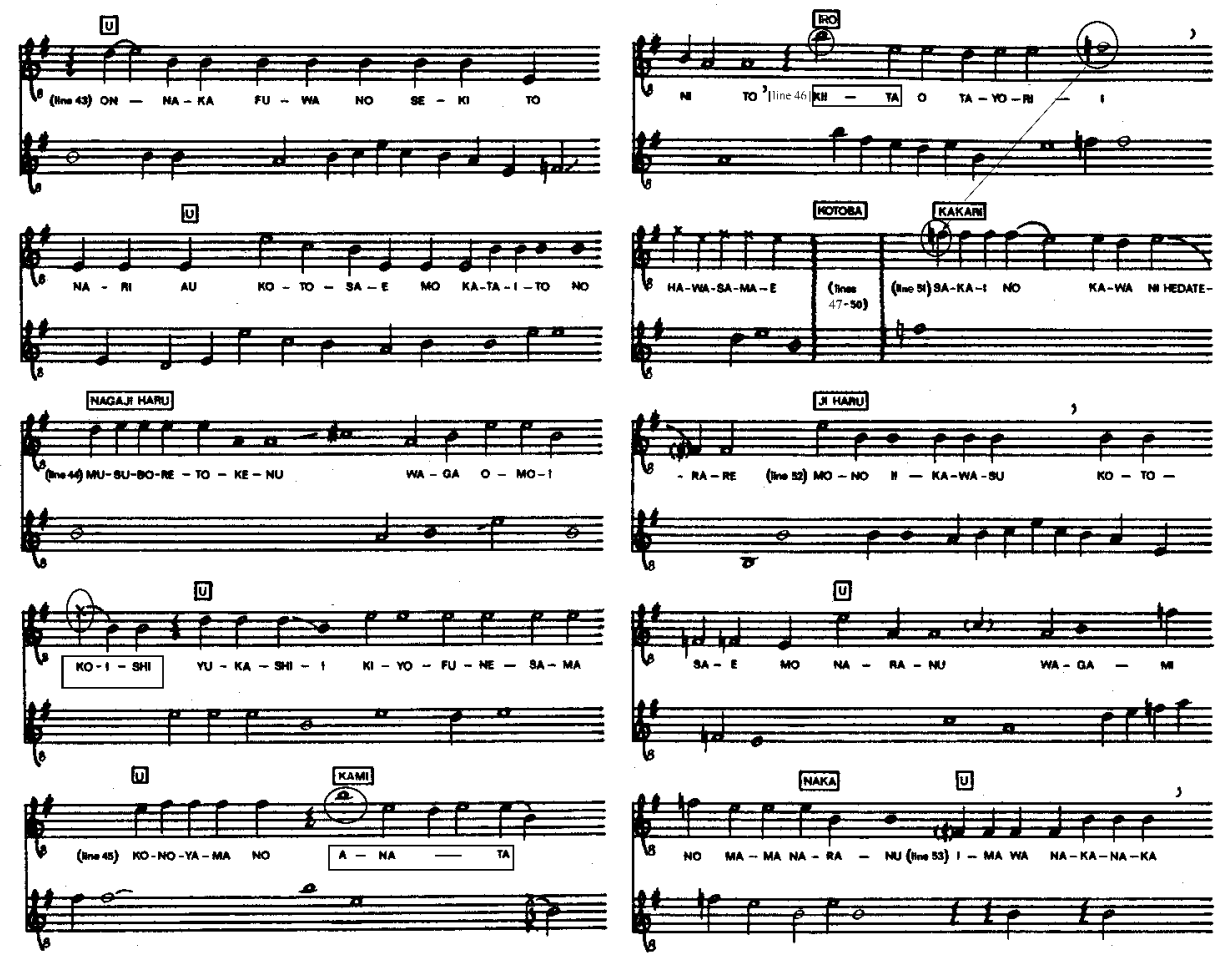

Copyright @ 1990 by Center for Japanese Studies, The University of Michigan

31 See Yamada, “Cidayū-bushi: Music of the bunraku Puppet Theatre," 204-205.

32 See Malm, "A Musical Analysis of 'The Mountains Scene'" and Inobe, "Reading 'The Mountains Scene' as Music." 
sage belonging to the overarching category $j i$ at the beginning of text line 44 (third system on the left) is designated with the term nagaji, which symbolizes elegance, and is subdivided by the beginning of the direct speech of the young Hinadori, marked by the word "koishi" ("dearest [missed Koganosuke]"), which is clearly distinguished from the previous song by speaking. The melody then reaches a melodic and emotional climax with the B4 (kami) on the word "anata" ("you"). The top note, B4, returns at the beginning of the following line on the word "kiita" ("I asked [my mother to let me go]"), but with slightly less intensity and in a semi-spoken voice, marked by the vocal delivery technique iro. The "open end" of the sung phrase on F4, the upper secondary note of the pitch center $\mathrm{E} 4$, facilitates the transition to an initially half-spoken, then purely spoken passage (category: kotoba); another transitional passage employing the recitation technique kakari, in which the $\mathrm{F}_{4}$ is taken up again, finally leads back to the singing type $j i$. Hinadori's direct speech continues during all these changes in the vocal articulation; the forms of vocal delivery are thus not synchronized with the narrative-dramatic sectional structure of the text.

The transitions between sung and spoken passages are organized down to the last detail and at the same time with great variability, whereby pitch, timbre, and the interaction between voice and instrument continuously influence one another, "blurring" the vocal techniques. Owing to a high number of repeated pitches, most lyrical passages (ji) contain references to stylized speech (in Hirano's terms, it is a mixture of rōsho and eishō), while conversely spoken passages (kotoba) retain clearly present melodic forms (i.e., they mediate between ginshō and rōsho); references to gender, class, or age of the characters, or to the dramatic situation are encoded in these gradations. We therefore cannot reduce the complex relationships between melodic form, melodic patterns, the meaning of the words, and the phonetic structure to simple schemata or rules. The resulting high level of fragmentation is analogous to the flexibility with which the performers translate the traditional performance instructions into sound; the information in the notation is formed by the reciter and the singular timbre of his voice into a strong vocal presence whose fragmentary microstructure is shaped into an ever-changing continuum.

Comparable forms of vocalization that continually change between different articulation types can be found in numerous Asian dramatic and narrative genres, though only a few show a degree of fragmentation in the microstructure similar to giday $\bar{u}$-bushi. The vocal articulation in Beijing Opera (jingju), which is usually summarized with the overarching categories of sangzi (voice) or changbai (singing and speaking), encompasses a large number of formalized gradations, even if these often vary imperceptibly in practice: "Because the same basic techniques of vocal production are used for all types of vocal performance, there is no feeling that a character suddenly stops talking and starts singing, or stops singing and begins talking; 'a very smooth transition from speech to song and vice versa [is achieved], contributing to the unity of a whole play."'33

In addition to the Chinese folk song type shan'ge ("mountain songs"), Daoist ritual music, and Schoenberg's "speech voice," the singing styles of Beijing Opera constitute a key element of the vocal style developed by the Chinese American composer Tan Dun. Comparable to many other Chinese composers of his generation such as Qu Xiaosong (b. 1952), Wen Deqing (b. 1958), or Mo Wuping (1958-1993), Tan Dun created this distinctive style primarily on the basis of his own voice and during the 1980 s consequently often acted as a vocal soloist of his own works. Starting with the early Fu, Fu, Fu (1982) to On Taoism (1985) and Nine Songs (1989), the metaphorical saying of "finding one's own voice" can be understood literally in Tan's case. Establishing

33 Wichmann, Listening to Theatre, 177, quoting Hwang, "Peking Opera," 220. 
Example 5.3: Tan Dun, Silk Road for soprano and percussion, 3, systems 1+2

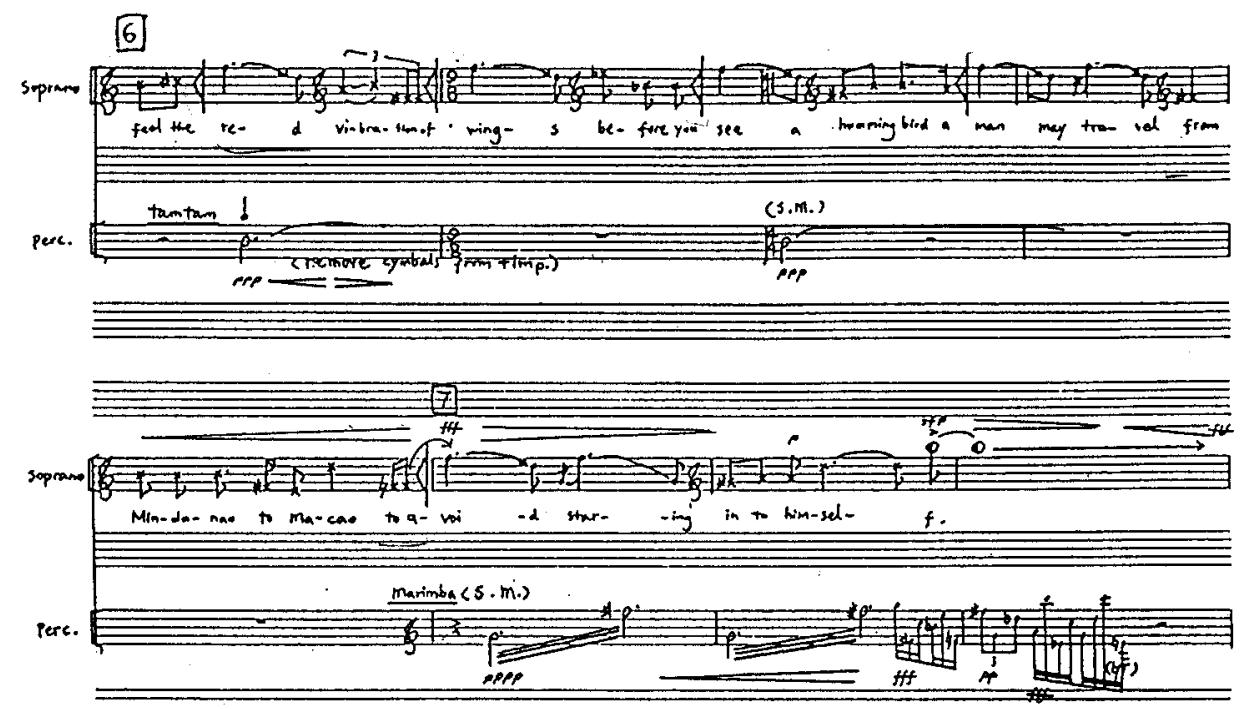

Copyright (c) 1989 by C. Schirmer, Inc. [ASCAP]

an "oral tradition" of its own, Tan subsequently passed on this style to other singers who (with the exception of Beijing Opera singer and director Chen Shi-Zheng) were usually trained in European vocal technique. The American soprano Susan Botti (b. 1962), for example, worked with Tan Dun on a number of projects in the 1980s and 90s. An important step in this cooperation was Silk Road for soprano and percussion (1989). ${ }^{34}$ Example 5.3 shows a section of this work in which the voice alternates regularly on almost every beat between Tan's "register notation," marked by a "register key," which distinguishes five registers, and a speech voice, marked by cross-shaped noteheads and notated in chromatic pitch degrees.

The sections in register notation connect the individual syllables by means of sliding lines whose shapes are precisely prescribed, the falsetto and breast voice constantly merging into one another, as is characteristic of the yunbai style of declamation in Beijing Opera, in which stylized Chinese speech tones are connected to a melodic contour through glissandi. The relative pitches in yunbai follow the conventions of Zhongzhou yun (Zhongzhou rhyme, based on a dialect of the district of Zhongzhou, Henan province in the tenth to fourteenth centuries), a style distinct from "Beijing dialect" (Mandarin) which is also used in Beijing Opera. ${ }^{35}$ In Tan Dun's adoption, both types of vocal articulation, the "chromatic" chanting in the Schoenbergian speech voice style and the glissando-laden yunbai style, which is only roughly designed melodically according to registers, are combined in a way that minimizes their conceptual difference, not least by assigning them to the same performer and thus by linking them through a constant timbre.

34 A first version of Silk Road was presented by Joan La Barbara on 01/04/1989, but subsequently the work was performed by Susan Botti and recorded on CD by her. See Utz, Neue Musikund Interkulturalität, 397-398 and 423-429 (a detailed description of Tan Dun's compositions with voice up to the years 1996 to 1998).

35 Wichmann, Listening to Theatre, 204-211. 
In his opera Marco Polo (1991-95), Tan Dun then referred to the yunbai style much more extensively and, in this context, expanded the concept of stylistically hybrid voices suggested in Silk Road. The type of voice treatment for the role Water, for example (Ex. 5.4), which emerged from the long-standing cooperation with Susan Botti (the soloist of the premiere), shows such a hybrid character in a particularly sustainable manner. The vocal structure aptly mirrors the symbolism of the Water-role in the opera as a mediator between geographical areas (water as a transport medium) and between the opera's spiritual and physical layers (water as a transformative medium). Although Tan Dun's elaboration for all voices in Marco Polo refers to the traditional singing technique of the Beijing Opera, differentiating between three phases of sound production - head (tou), belly ( $f u$ ), and tail (wei) - according to the initial, middle, and final sounds of the Chinese syllable, ${ }^{36}$ this characteristic and the resulting inflection techniques summarized in Tan's term "vocal calligraphy" are particularly formative for the Water-part. ${ }^{37}$ In addition, this part is characterized by a montage-like, paratactic structure that constantly changes between allusions to Beijing Opera vocal qualities, including the hightened speech (yunbai) and colloquial speech (nianbai), as well as to the singing style of Chinese mountain songs (shan'ge) and a (Western music based) lyrical high soprano register with controlled vibrato. Here too, the timbre of the vocal performer lends this fragmented mosaic-like structure a certain timbral unity. In fact, Susan Botti's performance as recorded on CD does not seem to be essentially informed by Asian singing traditions, ${ }^{38}$ so that the structural analytical impression of hybridity to some degree appears questionable in the result.

Example 5.4: Tan Dun, Marco Polo. An Opera within an Opera, Scene Sea; Part “Water," $m m .35-70$

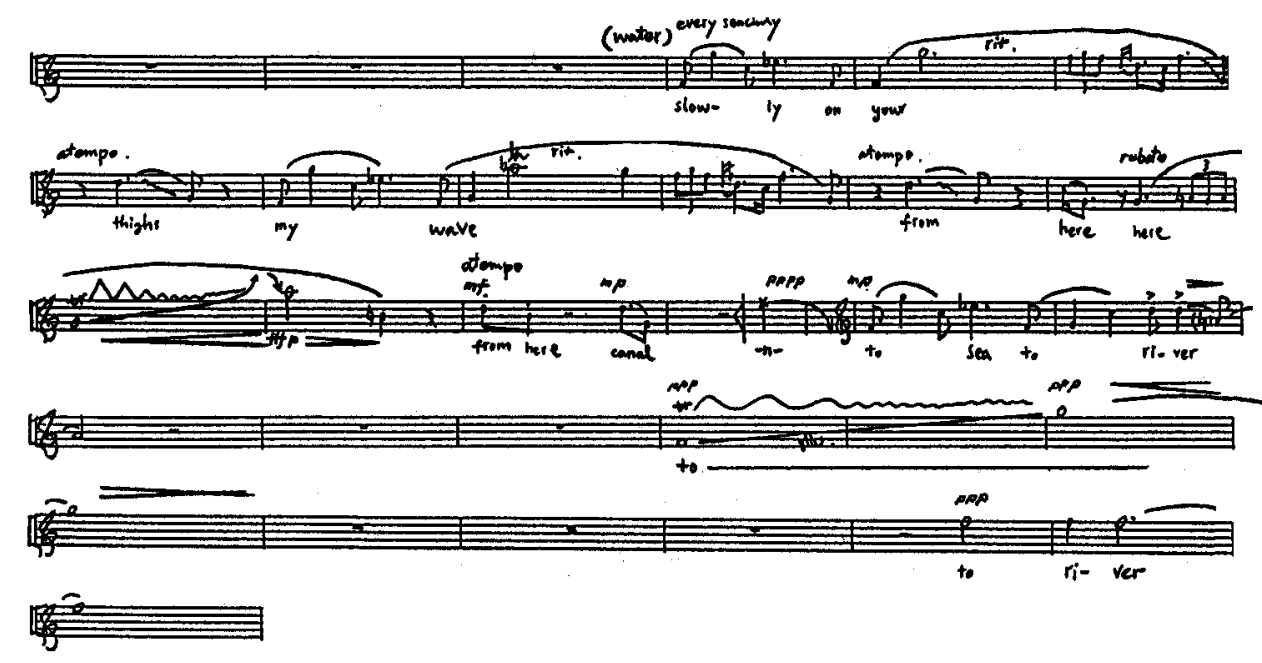

Copyright (c) 1997 by G. Schirmer, Inc. [ASCAP]

36 For more details see ibid., 194-199.

37 See Utz, Neue Musik und Interkulturalität, 423-427.

38 Vgl. Tan Dun, Marco Polo: An Opera within an Opera, Sony Classical S2K 62912 (1997), CD 1, Track 11. 
It becomes clear from the examples discussed so far that "vocal styles" that are linked in such hybrid contexts are almost infinitely differentiable and "fragmentable" in themselves. And this perspective can be further condensed if one includes a historical dimension that, for example in the case of the Beijing Opera, would have to take into account all those local and national singing styles from which a specific singing style emerged. ${ }^{39}$ The same applies, of course, to what is probably the best known form of vocal hybridization in the twentieth century - Arnold Schoenberg's Sprechstimme, as introduced by the composer in Pierrot lunaire op. 21 (1912). An interpretation of Schoenberg's Sprechstimme as hybrid, as a montage from fragments of different voice concepts, could initially point to the wealth of its actual and potential sources, ${ }^{40}$ including post-Wagnerian styles of vocal declamation, for example in Hugo Wolf's songs ${ }^{41}$ or in Engelbert Humperdinck's short experiment with Sprechgesang, as well as contemporary forms of heightened speech in theater and literature, prominently embodied in Karl Kraus's readings or in the speech art of the legendary Burgtheater actor Josef Kainz, in which the melodic ambitus was stretched far beyond what is common today. ${ }^{42}$ Last but not least, the Sprechstimme concept in Pierrot lunaire is linked to the aesthetics of a "tonal freedom" of vocal articulation, as demanded in a 1920 treatise by Albertine Zehme, ${ }^{43}$ the soloist in the premiere of Pierrot lunaire in 1912 and the commissioner of the work - even if one has to assume that there was ultimately no consensus between Schoenberg and Zehme regarding the degree of this "freedom." It is clear, however, that Schoenberg wanted to go beyond a simple imitation of the fin-de-siècle trend of "pathetic speaking" when, in his foreword written in 1914, he stated that the vocal performer "must always be on guard against falling into a 'singing' manner of speech, ${ }^{, 44}$ and that he disagreed with Zehme's increasing "tonal freedom" in the performances following the premiere. ${ }^{45}$

The microstructural fragmentation of the vocal part in Pierrot can be traced not only in terms of cultural history, but also in terms of the compositional structure. The peculiarity was pointed out in the literature several times that in no. 3 of Pierrot (Der Dandy) in addition to the general Sprechstimme as employed in all movements of the cycle, no less than six other different types of vocal articulation are explicitly distinguished (Ex. 5.5): tonlos geflüstert (whispered tonelessly), tonlos (toneless), gesprochen (spoken), mit Ton gesprochen (spoken with tone), halb gesungen (half sung), and gesungen (sung). One can find comparable instructions for the

39 The main styles converging in the Beijing Opera are xipi and erhuang, the styles of local operas in the Chinese provinces of Anhui and Hubei. See Li, The Soul of Beijing Opera, 18-24, Schönfelder, Die Musikder Peking-Oper, and Mackerras, The Rise of the Peking Opera 1770-1870.

40 See, in addition to countless other contributions, Brinkmann, "Kritischer Bericht," Stephan, "Sprechgesang," Meyer-Kalkus, Stimme und Sprechkünste im 20. Jahrhundert, 299-318, Cerha, "Zur Interpretation der Sprechstimme in Schönbergs Pierrot lunaire," and Byron, "The Test Pressings of Schoenberg Conducting Pierrot lunaire."

41 See Kravitt, "The Influence of Theatrical Declamation upon Composers of the Late Romantic Lied."

42 See Cerha, "Zur Interpretation der Sprechstimme in Schönbergs Pierrot lunaire" and Nöther, Als Bürger leben, als Halbgott sprechen.

43 See Zehme, Die Grundlagen künstlerischen Sprechens und Singens.

44 Schönberg, "Vorwort" ("sich sehr davor hüten [muss], in eine 'singende' Sprechweise zu verfallen"), translation after Byron, "The Test Pressings of Schoenberg Conducting Pierrot lunaire," 2.6; see Nöther, Als Bürger leben, als Halbgott sprechen, 131.

45 Meyer-Kalkus, Stimme und Sprechkünste im 20. Jahrhundert, 308-309. 
Example 5.5: Different instructions for voice articulation in Arnold Schoenberg's Pierrot lunaire op. 21, no. 3: Der Dandy, mm. 6-11, 15-20, 30-31
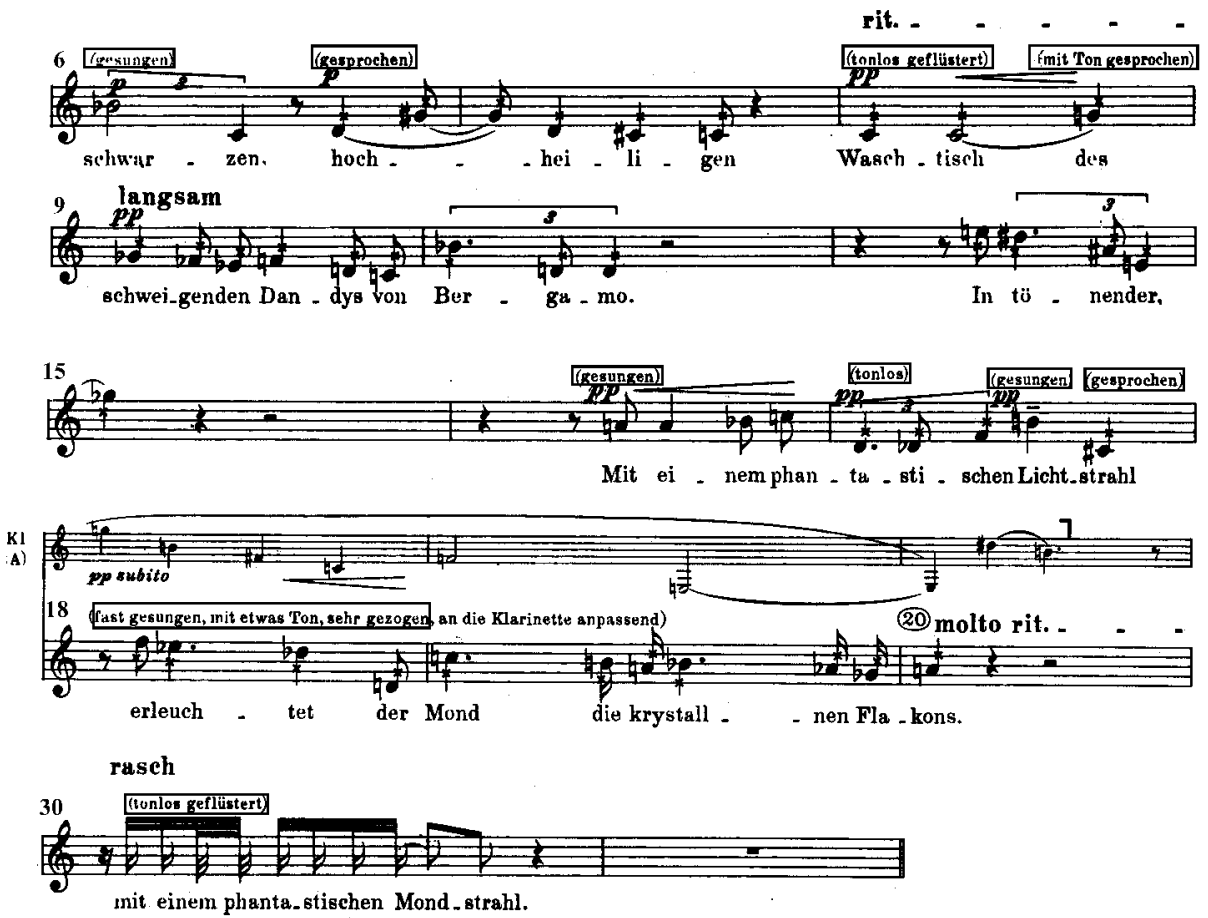

Copyright $\odot$ 1914, 1941 by Universal Edition A. G., Wien/UE 5336

voice only in five other movements of the cycle, only in one place each. ${ }^{46}$ While this on the one hand surely proves that the fanciness of this movement (and the portrayed character) was of particular importance to Schoenberg, I would suggest that the continuous change between different nuances of Sprechstimme here only prescribes a performance practice in particular detail that can (cautiously) be transferred to the other movements as well.

This viewpoint perhaps provides a new perspective on the much-discussed problem of the interpretation of the Sprechstimme in Pierrot lunaire: Schoenberg's ambiguous information on the performance of the vocal part in the score, to which he added further, no less contradictory, restrictions and clarifications, unintentionally opened a space, a passage for the collaboration between the composer and the vocal soloist. He consistently notated clear chromatic levels for the Sprechstimme but at the same time - also in performances he directed himself - apparently allowed interpretations (or even preferred ones) in which the sung-spoken pitches differed sig-

46 Four times it is a short "sung" phrase (gesungen), the end of which is marked by the instruction gesprochen (spoken), see no. 4 (Eine blasse Wäscherin), mm. 14/15, no. 8 (Die Nacht), mm. 10/11, no. 9 (Gebet an Pierrot), mm. 13/14, no. 11 (Rote Messe), mm. 24/25. In no. 10 (Raub), mm. 9/10, the voice alternates between tonlos (toneless), here indicated by special noteheads that occasionally appear without comment in later movements, and ton ([with] tone). 
nificantly from those specified in the score. ${ }^{47}$ The artistic process initiated by Schoenberg can therefore neither be described as a license for "self-assumed musical reciters" nor as an unambiguous product of a "radical aesthetic of the work."48 With this passage between speaking and singing Schoenberg also opened one between writing and orality. His concept of Sprechstimme "resists the view of music as solely the composer's sound which needs to be reproduced by passive performers ${ }^{\prime 49}$ and thus opens a space of negotiation between notation and orality, between compositional intentionality and performative presence.

There are key moments in Pierrot lunaire in which the voice moves to extreme registers, such as in some phrases of Nacht (no. 8), where an extremely low register symbolizes blackness, darkness, or in Die Kreuze (no. 14), where ascending leaps of over two octaves are contained within a structural cross symbolism. In these moments, the ecstatic potential of the voice can be experienced abruptly, it transcends the meaning of the word just as it goes beyond a simple illustration of rhythmized text declamation..$^{50}$ Indeed, it is probably these moments when the fragmentary microstructure is most sustainably absorbed in the presence of the voice and can be filtered by the performer into a new unity - similarly to what has been described above for the voice in giday $\bar{u}-b u s h i$. In all the examples discussed so far, there is this tension between fragmentation, particularity, a tendency to disintegrate into individual articulations and their connection in the act of an overarching vocal representation by the performer.

\section{Incantation, Prosody, Ritual (Shimoyama, Takahashi, Peri, Sciarrino)}

Such moments of vocal presence, immediacy, even ecstasy, were exploited most extensively in the twentieth century as a key subject of vocal composition. Some Western composers such as Dieter Schnebel, Giacinto Scelsi, or Jani Christou, encountered this field mainly through "psychoanalytic" and ritualistic approaches, and it is hardly coincidental that the attraction of the voice's presence resulted from the extreme fragmentation or parameterization in serial and postserial music.

47 See Byron, "The Test Pressings of Schoenberg Conducting Pierrot lunaire," 4.1-4.12. On the problems of whether the vocal part in Pierrot should respect the notated pitches or not, a broad discussion has continued for decades. Recently, Lukas Dorfegger made detailed transcriptions of the vocal part in three recordings (Erika Stiedry-Wagner/Arnold Schoenberg 1940, Anne-Lise Berntsen/Christian Eggen 1994, Christine Schäfer/Pierre Boulez 1998) and summarized that while the more recent recordings surely respected the pitches more than the earlier ones, "the demand to sing each pitch exactly is basically hardly feasible and thus is cannot become the most important criterion for a good performance of Pierrot lunaire." (Dorfegger, "Praktische und theoretische Überlegungen zur Ausführung der Sprechstimme in Pierrot lunaire op. 21 von Arnold Schönberg," 32; "die Forderung [...], jeden einzelnen Ton genau anzusingen, [ist] praktisch kaum ausführbar ist und [kann] daher auch nicht zum wichtigsten Kriterium für eine gute Aufführung von Pierrot lunaire werden [...].")

48 Meyer-Kalkus, Stimme und Sprechkünste im 20. Jahrhundert, 309 ("musikalisch sich dünkende Rezitatoren," "radikale[] Werkästhetik").

49 Byron, "The Test Pressings of Schoenberg Conducting Pierrot lunaire," 4.6.

50 Some research (e.g., Rapoport, "On the Origins of Schoenberg's Sprechgesang") argues that the melodic contours of Schoenberg's Sprechstimme basically follow the model of intonation in spoken language in an almost literal manner, and the musical result is "alienated" through structural procedures such as reversal or octave transposition. Even though I doubt that the "melody" in Pierrot actually came about in such an analogical way, it is by no means unreasonable to assume that spoken intonation could have been essential for the melodic and rhythmic design of the vocal part. 
Against a comparable background, vocal works by Hifumi Shimoyama (b. 1930) ) $^{51}$ and Yūji Takahashi can be cited from the Japanese context, in which a countercurrent to the cases discussed so far becomes apparent: the starting point is less a variety of fragmented vocal techniques than a single reference articulation that is eroded in several ways. Since the 1970s, Japanese composers have responded to the simplistic combinations of "Western" structure and "Japanese" color, as sought in some parts of Japanese postwar music, by turning to ritualistic simplicity $\rightarrow$ III.1).

Shimoyama's vocal works generally use text material from Buddhist ritual music as it can be found in shōmyō or $n \bar{o}$, specifically relying on the Japanese transliteration of archaic Sanskrit, in which the textual meaning dissolves into auratically conceptualized sequences of sounds. ${ }^{52}$ Shimoyama explains that the meaning of these texts, if they can be reconstructed at all, has no relevance for his compositions. ${ }^{53}$ Rather, he focuses on the magical implications of individual words or phrases. This attitude is also reflected in his approach to archaic Japanese words, which are no longer part of everyday language today but can still be found in the local Tsugaru dialect of his home prefecture Aomori and also in the vocal aesthetics of the narrative genre tsugaru-jamisen, ${ }^{54}$ which is little known in or outside of Japan. Shimoyama hears these magical dimensions of words and phonemes in this genre and in the ancient Tsugaru language, in giday $\bar{u}$-bushi, as well as in nō singing.

His Monolog (1991) for shamisen-playing vocalist, written for Kazuko Takada, and Breath for three voices, two drummers, and piano (1971/77), written for Michiko Hirayama (who, as mentioned above, is noted for her performance and co-creation of Scelsi's Canti del Capricorno), vividly illustrate the type of vocal presence in Shimoyama's vocal works. The reference technique in both works is an almost pure variant of the rōshō type, which suggests Buddhist recitation; it consists of rapid repetitions of a single, not precisely defined pitch. In Monolog (Ex. 5.6) fragments are arranged around this reference model, which deepen into the auratic qualities of individual phonemes and describe interrelations between voice and instrument as familiar from numerous traditional genres. The Buddhist text is taken from the nō play Funa Benkei (Benkei on the Ship), where it is presented as a prayer to guardian deities.

Breath introduces a "multiplication" of Hirayama's voice into three parts, two of which were pre-recorded by the soloist. ${ }^{55}$ The text material is compiled from the three different $n \bar{o}$ pieces Okina, Aoi no ue [The Court Lady Aoi], and Atumori (from which a prayer of the Nenbutsu sect is used). All vocal textures are based on the same rōshō model, which occurs in at least five different forms of articulation (Ex. 5.7), including a microtonally layered recitation tone with

51 Shimoyama belongs to the large group of Japanese composers who are hardly known in the West. He was born in the same year as Tōru Takemitsu and, after graduating from Hirosaki University (Aomori Prefecture), studied with Yoritsune Matsudaira in Tokyo from 1955. In an international context, his works were presented primarily at the festivals of the International Society for Contemporary Music (ISCM).

52 This transliteration tries to imitate the pronunciation of Sanskrit using the syllables or morphemes available in Japanese, but without linguistic meaning; it is a purely onomatopoetic procedure. See Nelson, "Court and Religious Music (2),"67-68.

53 Personal communication with the author, Tokyo, 26/2/2008.

54 See Groemer, The Spirit of Tsugaru.

55 Breath was premiered by Hirayama in Rome in 1974 and revised by the composer in summer 1977. In 1978 the revised version was premiered at the ISCM festival in Helsinki. The live recording of this performance is published on $\mathrm{CD}$. In addition to a performance by a live vocal soloist and two pre-recorded vocal parts, which are played on tape, a performance by three live soloists is also possible. 
Example 5.6: Hifumi Shimoyama, Monolog for shamisen and vocal soloist, p. 4, systems 1-3
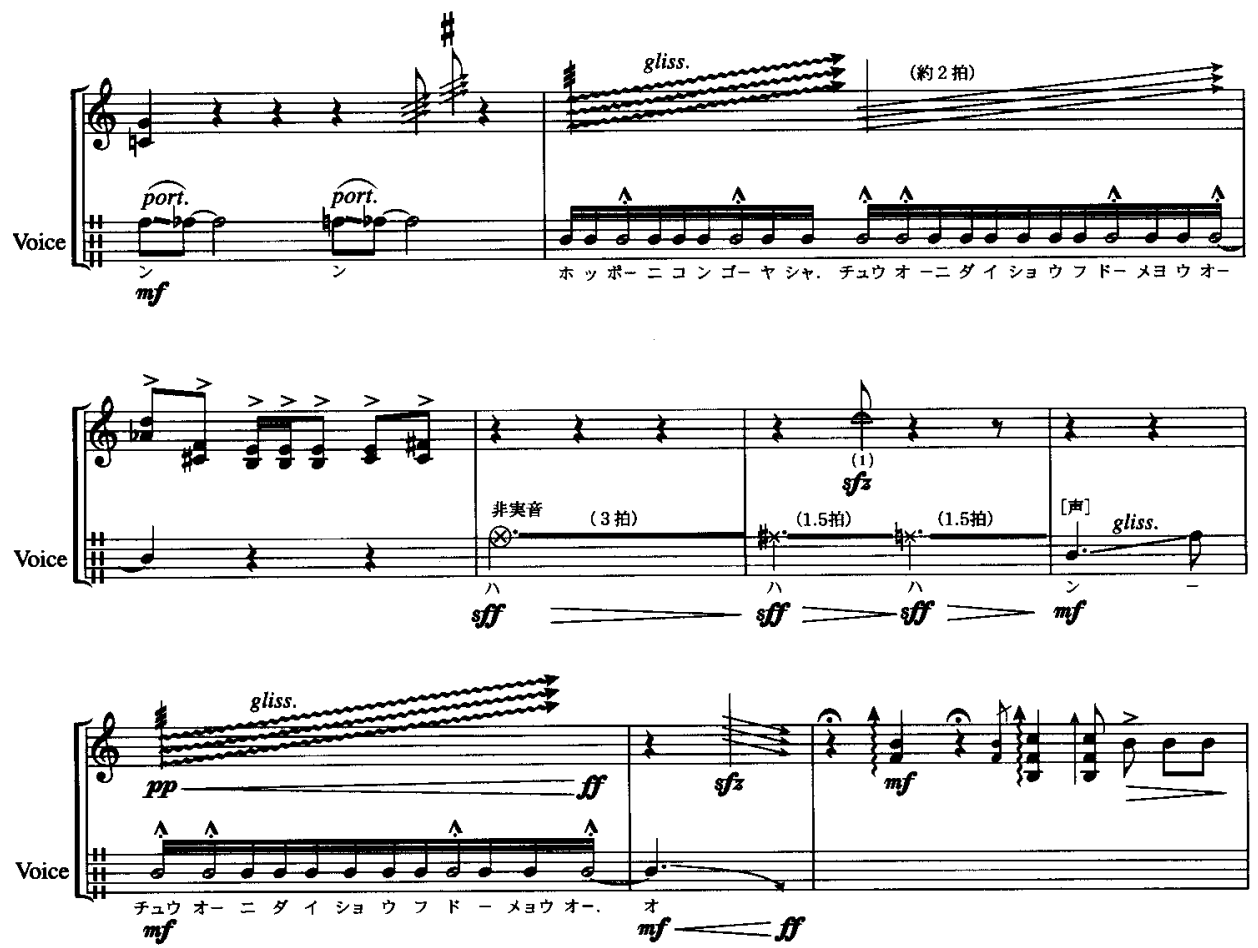

Copyright $\odot 2003$ by Mother Earth Company Ltd. Tokyo, Japan

crescendo [a], also occurring in a whispered variant [b] and in a variant with "pressed" voice [c], which Shimoyama associates with giday $\bar{u}-b u s h i^{56}$ but in the score refers to with the (original German) word "sprech-stimme." In addition, there is a texture of sustained notes performed with "larynx articulation" [d], which can be seen as a much slower variant of the rōshō model, as well as mixed polyphonic textures [e] that also contain vocal inserts by the instrumentalists, comparable to the kakegoe-calls of the drummers in $n \bar{o}$ theater. ${ }^{57}$

Yūji Takahashi's works since the late 1980s were introduced in Chapter III as remarkable examples of an anti-essentialist approach to traditional Asian musical practices, informed by long-term composer-performer collaborations ( $\rightarrow$ III.4). The vocal style in Takahashi's Unebiyama (1992) for a reconstructed archaic five-string zither and chant is mainly derived from vocal practices in shamanistic genres. Although there are still a few female shamans (fujo) practicing in Japan's northern Aomori Prefecture, Takahashi's work primarily refers to shamanistic music from Southeast Asian regions, particularly to "hidden traditions" that are hardly documented and which Takahashi encountered through field recordings. More specifically, the

56 Personal communication with the author, Tokyo, 26/2/2008.

57 A detailed description of the function and content of these calls, which can be associated with the cries (katsu) of masters of Zen Buddhism during meditation, is provided in Tamba, The Musical Structure of Nō, 228-229. 
Example 5.7: Hifumi Shimoyama, Breath for three voices, two percussionists, and piano, five vocal articulations (a-e) from pages 3, 13, 11, 2, 7 of the score
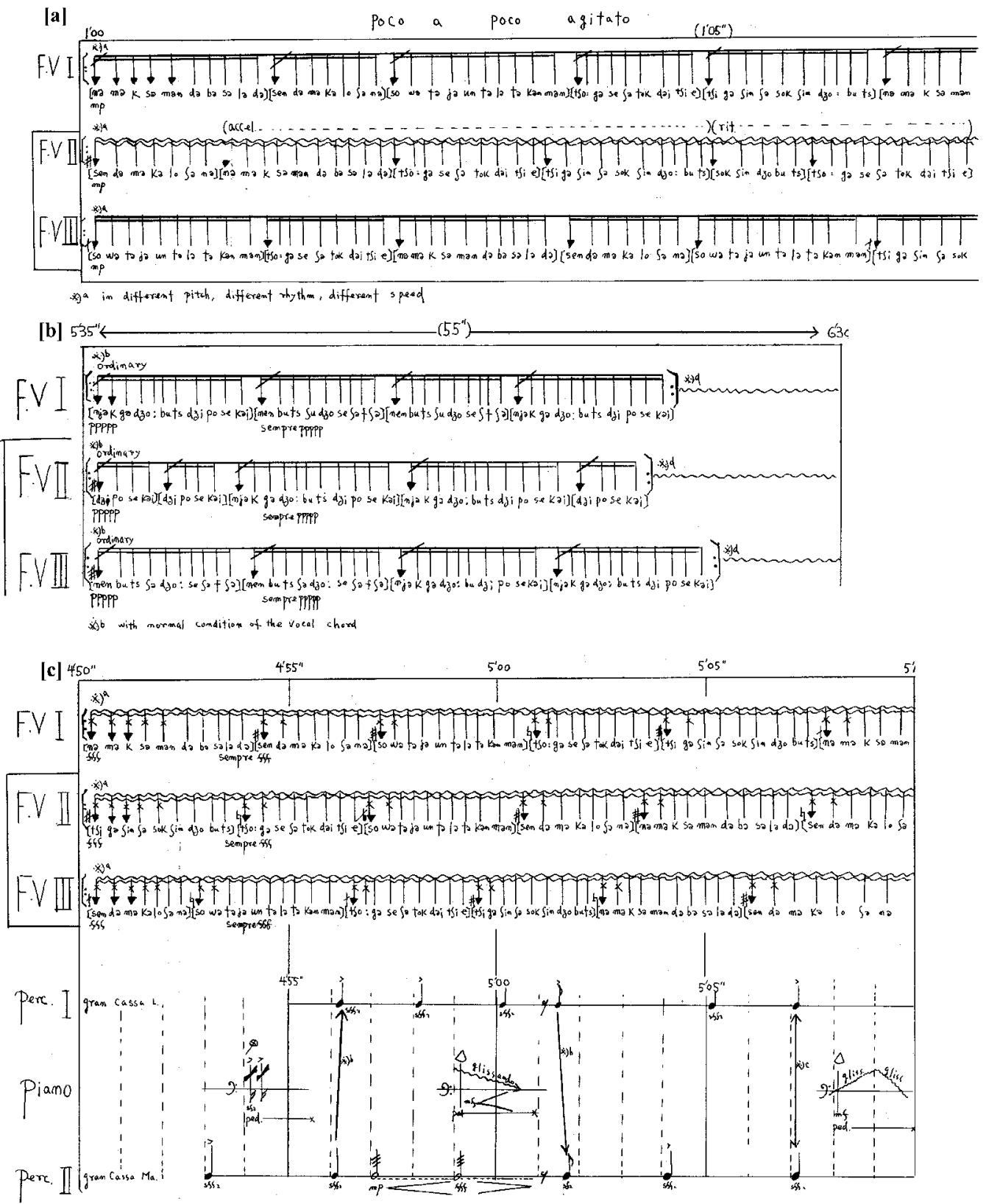

$\dot{x})^{a}$ speak(sprech-stimme) by the extremely pressed rocal chord

$x)^{6}$ immediatily

$x)^{c}$ at the same time 

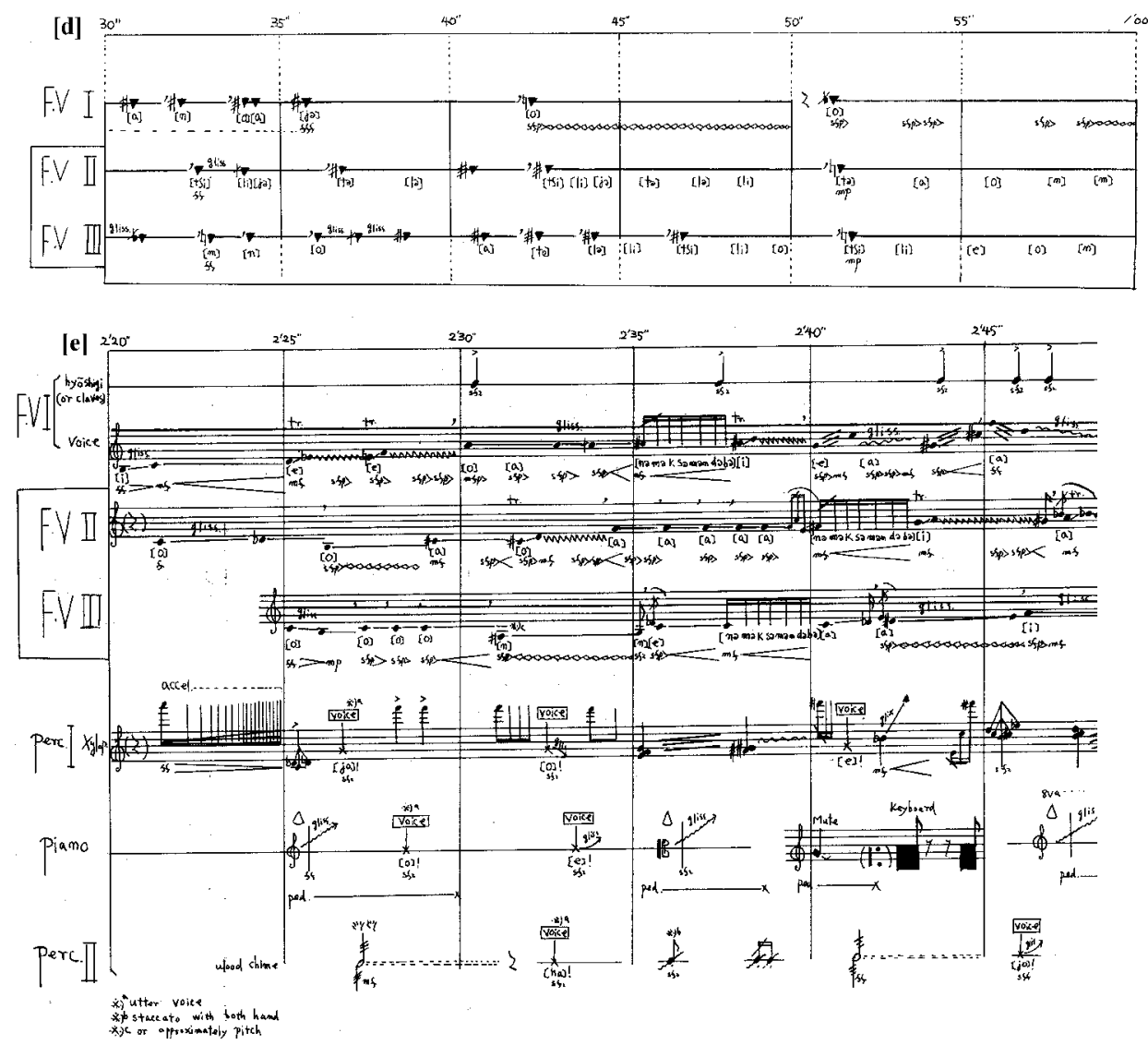

Copyright (C) 1982 by Hifumi Shimoyama, Tokyo

composer identified music by shamans from the Temiar ethnic group in Western Malaysia as one of his main sources. ${ }^{58}$

The organology and construction of the five-stringed zither (length: $115 \mathrm{~cm}$ ) and ethnological evidence form another important background of this work. The instrument dating from the fifth century BC was discovered 1978 in a tomb of the Marquis Yi of Zeng in Hubei Province, China. ${ }^{59}$ Not much is known about the original name or usage of this instrument. Takahashi argues that, based on iconographic evidence, it may have been used in shamanistic rituals. ${ }^{60}$ He tunes the instrument in a modified, "oblique" pentatonic system (D2, lowered E2, A2, D3, raised $\mathrm{C}_{3}$ ) that bears some resemblance to the popular Japanese mode miyakobushi $\rightarrow$ II.4). The strings are plucked with a long pick made from the horn of a water buffalo. Since it is almost impossible to depress the strings, Takahashi's composition consists almost exclusively of open strings, with the repeated patterns enhancing the impression of ritual music.

58 Personal communication with the author, Tokyo, 22/2/2008. The Temiar belong to the Senoi group of the indigenous orang asli people. See Roseman et al., "The Indigenous Peoples (Orang Asli) of the Malay Peninsula."

59 Kido, Reconstructed Music Instruments of Ancient East Asia, 126-133.

60 Takahashi, Astray Among Decayed Strings, 9. 
Example 5.8: Yüji Takahashi, Unebiyama for five-string zither and incantation, p. 1

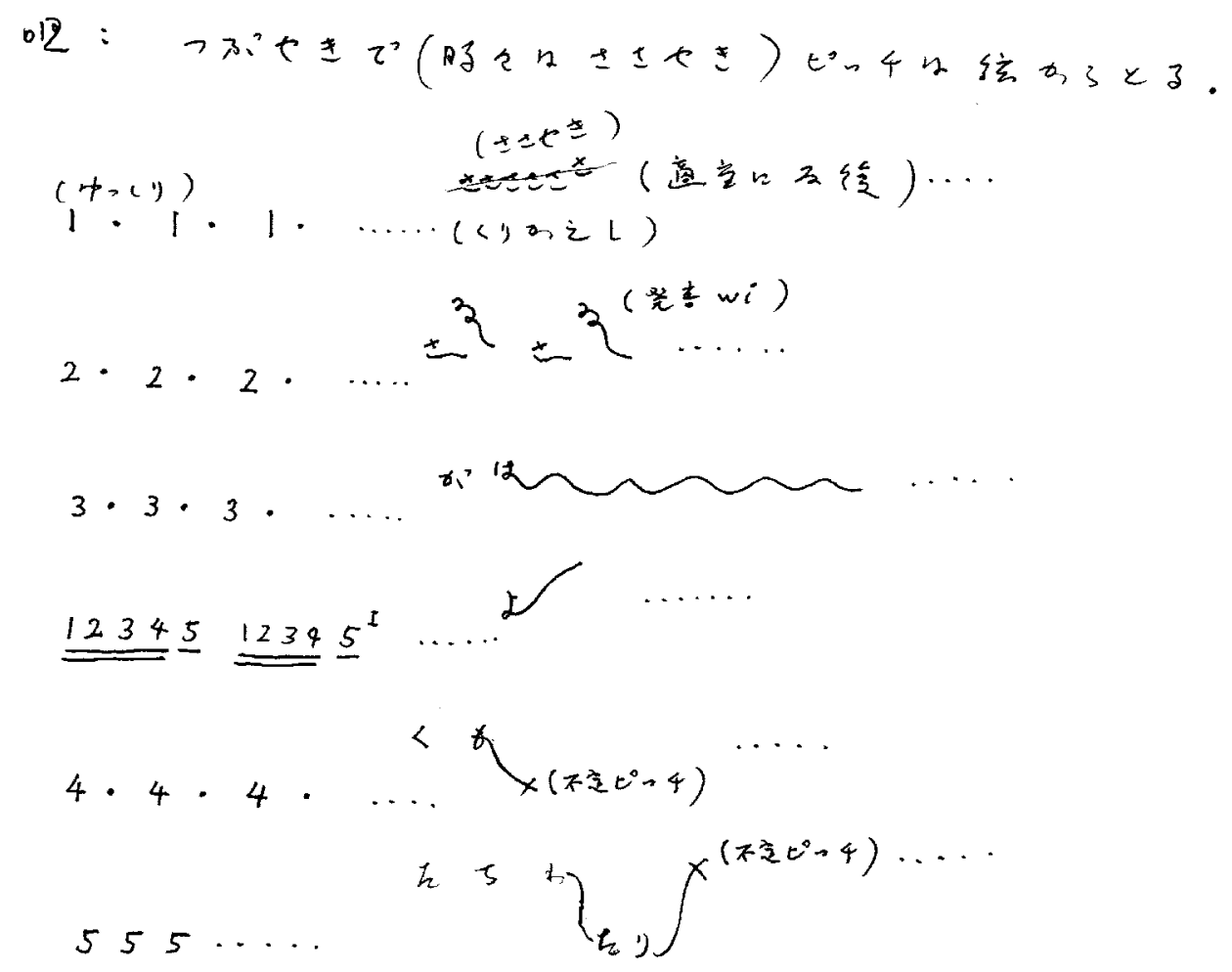

Copyright $\odot 1992$ by Yūji Takahashi, Tokyo

The voice takes up the pitches of the five open strings (Ex. 5.8). The instructions in the score call for a voice that combines "muttering" (tsubuyaki) and "whispering" (sasayaki). The text is based on the Japanese creation story Kojiki (compiled around 712 CE by Ō no Yasumaro) and can be linked to the dragon iconography of the original instrument via the symbolism of water and clouds. The selected poem belongs to the category of wakauta, songs that handed down oracles sung by young virgins who warned of political crises. ${ }^{61}$ It is attributed to Isukeyorihime, the wife of the mythical emperor Jinmu. ${ }^{62}$

61 lbid., 11.

62 There is, however, notably no explicit reference in Takahashi's work to the archaic recitation style that is usually associated with the Kojiki. This style was practiced by singers called kataribe and is considered the origin of the Japanese katarimono (dramatic narrative chants, see above). Hirano connects this style to genres practiced by the Ainu and Okinawa peoples (yükara, omoro; see Hirano, "Beziehungen zwischen Sprache und Musik im katarimono," 57.) 


$\begin{array}{lll}\text { 佐韋河 } & \text { Saigawa yo } & \text { From Sai river } \\ \text { 雲立ち渡り } & \text { kumo tachiwatari } & \text { Clouds rise and spread across the sky; } \\ \text { 畧傍山 } & \text { Unebiyama } & \text { Unebi Mountain } \\ \text { 木の葉さやぎぬ } & \text { konoha sayaginu } & \text { Rustles with the leaves of trees; } \\ \text { 風吹かむとす } & \text { kaze fukamutosu } & \text { A wind is about to blow. }{ }^{63}\end{array}$

The notation developed here is based on the composer's reflections on the difference between the notation methods for vocal and instrumental music in the traditional music of Japan: while music for instruments is usually recorded in a form of tablature that indicates the position of the fingers, the string, etc., and is permeated with instrumental patterns learned by mnemonics, the notation of vocal music is based on gestural analogies between writing and sound as in the notation forms hakase (e.g., in the Buddhist chant shōmȳ̄) or gomaten (in $n \bar{o}$ theater) ${ }^{64}$ For Takahashi, these different paradigms convey the more temporal quality of vocal music, in which the sounds are continuously "stretched" over time, compared to the more spatial, punctuating characteristics of the (often plucked or struck) instrumental impulses.

One method by which Shimoyama and Takahashi circumvent the tendency toward fragmentation is to consciously refrain from specifying pitches or their constant inflection and fluctuation in an often vague (registral) area. As shown, this method can be closely related to linguistic articulation or corresponding forms of notation in traditional Japanese music.

In a completely different historical-cultural context, related methods for deriving different degrees of vocal pitch determination from linguistic particularities can be observed. In his preface to Le musiche, sopra l'Euridice (1601), Jacopo Peri (1561-1633), singer, composer and a key figure in the nuove musiche around 1600, refers to the ancient distinction between "diastematic" and "continuous" vocal articulation. This distinction can be traced back to around $500 \mathrm{CE}$, when Boethius adopted it from Aristoxenus's Elementa Harmonica, while describing a mixed type of vocal articulation for the presentation of "heroic poems. ${ }^{165}$ Peri developed a theory of Italian speech and intonation patterns from these categories, conveyed by Girolamo Mei and Vincenzo Galilei, whereby clearly intoned speech sounds were assigned to a consonance or a change of harmony, whereas the syllables in between could be free and independent of the bass part.

An intercultural passage can therefore by opened in relating to the spatial characteristic of the instrumental sounds accentuated by Takahashi (Peri's "diastematic" vocal style coupled to change of harmony) and temporal vocal articulation (Peri's harmony-independent "continuous" vocal style). Peri, who, like his rival Giulio Caccini, was trained in strict counterpoint, must have been aware of the provocative effect of such a musical structure. The notable dissonant passages from Daphne's speech in Peri's Euridice are not merely constructed according to the text's prosody, of course, but driven primarily by the (negative) affect of the words ("Angue crudo e spietato," "con si maligno dente"). ${ }^{66}$ The freedom in the articulation of the unstressed syllables prompts a novel musical form: the recitative.

A flexible articulation of unstressed syllables was also fundamental to Giulio Caccini's theory of vocal style, as documented in the dedication of his L'Euridice (1600) and his collection

63 After Takahashi, Astray Among Decayed Strings, 11 (English translation based on A Waka Anthology, vol. 1: The GemGlistening Cup. Translated by Edwin A. Cranston. Stanford: Stanford University Press, 1993).

64 Personal communication with the author 22/2/2008. For a good introduction to the notation forms of traditional Japanese music see Malm, Traditional Japanese Music.

65 See Palisca, Studies in the History of Italian Music and Music Theory, 456-457.

66 See ibid., 460. 
Nuove musiche (1602). Caccini used a key concept of the high Renaissance to describe the lightness of these phrases, sprezzatura ([noble] negligence): "In this manner of song, I used a certain negligence that I valued as having a noble quality, for it seemed to me that with it I approached natural speech that much more." ${ }^{167}$

In the years after 1600, there was a paradoxical development. The reference to spoken language helped to free song from the rhythmic rigor of speech-based declamation. Thus virtuoso "fioraturi" and "passagi" increasingly replaced the ascetic early syllabic style, so that in 1614 Caccini consistently applied the term "sprezzatura" to the execution of these "passagi" and no longer primarily to a vocal style close to speech:

Sprezzatura is that gracefulness conferred upon singing by passing through a number of eighth notes and sixteenths over various notes [of the bass], through which, when done in time, removing from the singing a certain bare poverty and dryness, it is rendered pleasing, unhindered, and airy... ${ }^{68}$

The Italian composer Salvatore Sciarrino (b. 1947) has described his vocal style using the term "sillabazione scivolata" ("sliding syllabic articulation"), and one can recognize in it something akin to a shadow of Peri's recitative, interspersed with some elements of Caccini's "passagi." Sciarrino refers to spoken language in a way closely related to Peri's theory, emphasizing the "scioltezza" ("lightness") of everyday language as a model for the vocal performers. And by combining sustained, "diastematic," stressed syllables/notes with several extremely short, "continuous," unstressed ones, Sciarrino's works also use a musical approach analogous to Peri's (Ex. 5.9). Sciarrino notes that the intonation of the closing figures, consisting of short notes, should not be rendered precisely and need not be equally tempered, meaning that "the nuancing of non-tempered intervals, as is customary when speaking," is possible. ${ }^{69}$

Example 5.9 shows variants of the "sillabazione scivolata" from Sciarrino's opera Luci mie traditrici (1996-98) in which the stylization and variation of the interval structure $[a, b]$, the breaking-up of the lines with rests (symbols for hesitation [b], fainting [c], death [e]), and their dissolution into descending micro-glissandi $[b, c, e]$ or monotonously spoken phrases [d] are clearly recognizable. In fact, the formal process of the entire opera can be seen as an increasing reduction of intonation, culminating in the dark final scene, in which all articulation types extending to extreme interval jumps [d] recur in a (nightmarish) reminiscence. ${ }^{70}$

\section{Articulation - Codification - Presence - Passage}

The discussion presented here attempted to show how different forms of articulation and codification between speaking and singing voices - in situations with strongly divergent historical and cultural conditions - are organized in a related manner and performatively transformed into a presence of the voice. Finally, three main threads of this discussion will now be highlighted and linked:

67 Giulio Caccini, L'Euridice composta in musica in stile rappresentativo [1600], dedication to Giovanni Bardi, quoted from ibid., 463.

68 Giulio Caccini, Nuove musiche e nuova maniera di scribere [1614], preface, quoted from ibid., 464-465.

69 Sciarrino and Petazzi, "Salvatore Sciarrino im Cespräch," 37 ("die Nuancierung nicht temperierter Intervalle, wie dies beim Sprechen üblich ist").

70 See, for more detail, Utz, "Statische Allegorie und 'Sog der Zeit." 
Example 5.9: Salvatore Sciarrino, Luci mie traditrici, variants of the "sillabazione scivolata": [a]-[c] scene 1, Il Malaspina (baritone), mm. 15, 17, 29-30; [d], [e] scene 8, La Malaspina (soprano)/Il Malaspina (baritone), $m m$. 67-69, 83

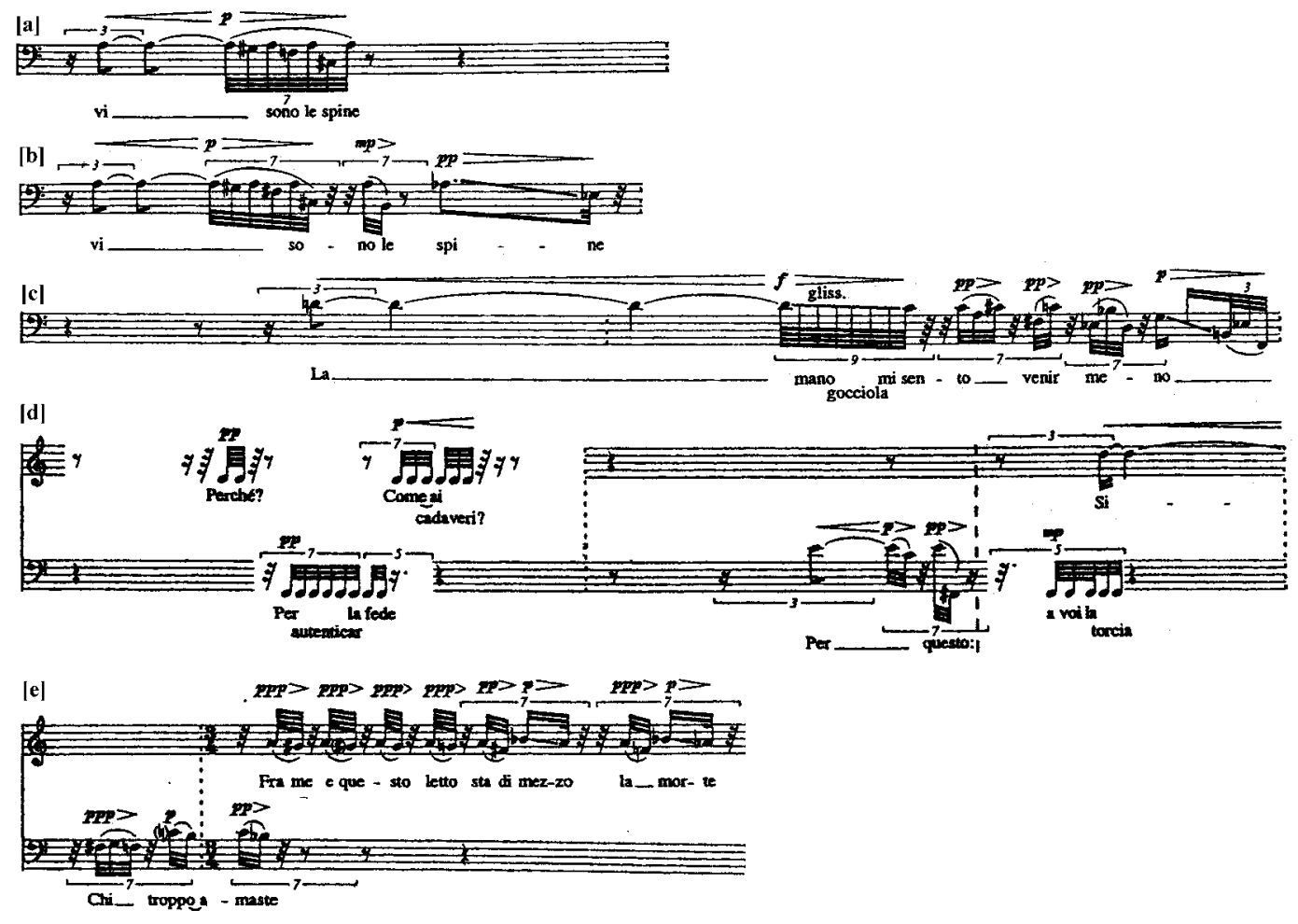

Copyright (c) 1998 by Universal Music Publishing Ricordi - Milan, Italy [NR 138034]

1. In a wide variety of contexts, types of vocal music can be found that tend to hybridize an abundance of fragmentary individual articulations. It is therefore logical that the role of the performer becomes central, for it is only in the act of vocal execution that it becomes possible to form an overarching musical meaning from this fragmented material. If one compares the field of possibilities of a tay $\bar{u}$ reciter in giday $\bar{u}-b u s h i$, a vocal performer of Pierrot lunaire, or a singer of Sciarrino's "sillabazine scivolata," it becomes evident that, despite the clearly different degrees of prescriptive notation and performance traditions involved (that is, the codifications on which these articulations are based), the performers face only gradually different tasks: in all cases they are required to consider a wide range of secondary information in addition to the notation, and to make essential intuitive decisions where the notational or oral codification does not provide sufficiently binding instructions. In this regard, there is an obvious convergence of "traditional," mostly orally transmitted, non-Western practices and vocal music of the twentieth and twenty-first centuries.

2. Such a form of vocal articulation operates in a particularly close relationship with language in which its semantic dimension is often put aside. In this sense, all the examples discussed here can be understood with reference to Roland Barthes as representatives of the "geno song," as "the space where significations germinate "from within language and its very 
materiality'; [...] where the melody really works at the language, [...] explores how the language works" ${ }^{\prime 1}$ - to the point, of course, that they obscure or even destroy the language. And by ultimately provoking - for all the inspiration they derive from the spoken language - conflicts with conventional forms of prosody, linguistic intonation and declamation instead of following these structures, they probably represent far more suitable examples of the "grain of the voice" than those Barthes himself tried to grasp (which tend toward a culturalist stereotyping of French and German song traditions that has become increasingly dubious $^{72}$ ).

3. Carolyn Abbate's narratological expansion of the concept of the voice as part of an "aural vision of music animated by multiple, decentered voices localized in several invisible bodies," but can also counteract them and thus destabilize the composer's monological authority, can be assumed for all the examples presented here. Yet the "codification" of the vocal articulation can neither be reduced to the type of written notation nor to the gestural-performative presence of its actual rendering but arises from the interaction of these two "voices" with those of cultural memory and reception history. The passages between speech and song explored here seem to exhibit a particular, obvious tendency toward the divergence of written and performed voices, resulting in an unfolding of composition, terminology, and categorization on the one hand and vocal practice on the other. The nature of this divergence, as is equally evident in giday $\bar{u}$-bushi, in Schoenberg's Pierrot, Peri's Euridice, or Sciarrino's "sillabazione scivolata," allows a specification of the vocal medium, and thus a differentiation from Abbate's metaphor of "multiple voices" applicable to both instrumental and vocal music alike.

Seen in this way, an intercultural history of the voice could appear as a process of condensation in which such contradictions, divergences between individual voices in the conception, written codification, sounding event, and perception are made visible, and physical and metaphorical levels of the phenomenon are envisaged. The outline undertaken here can at best be understood as a first attempt in this direction.

71 Barthes, "The Grain of the Voice," 269.

72 See Meyer-Kalkus, Stimme und Sprechkünste im 20. Jahrhundert, 427-444.

73 Abbate, Unsung Voices, 13. 


\section{Space-Time Movements in György Ligeti's Piano Concerto: Polymeter and Conflicting Meter in Historical and Intercultural Perspective}

\section{György Ligeti's "Space-Time" and the "Generalized Hemiola"}

The polyglot, boundary-defying conceptions of György Ligeti, driven by artistic curiosity, have been widely praised, and his collected writings published in German posthumously in 2007 impressively demonstrate the rhizome-like ramifications of his thinking in and about music, as also aptly demonstrated by the polymorphic vividness of the structures in his music since Apparitions (1958-59). From the very beginning, Ligeti, in his own energetic manner, absorbed impulses from often heterogeneous areas of the arts and sciences, and idiosyncratically interwove them into an asymmetrical, open maze of sounds and thoughts. Still, it should be emphasized how intensively, but also "art-typically" Ligeti engaged with scientific thinking, especially since the beginning of the 1980s, for example in the areas of chaos theory, fractal geometry, and artificial intelligence. At the beginning of his essay "Paradigmenwechsel der achtziger Jahre" (1988), Ligeti emphasizes that he does not write "'scientific' music, do[es] not use calculations, nor algorithms [...], realize[s] only [his] own ideas, but deal[s] with analogous ideas from other areas. Complexity or complex patterns have always attracted [him]. ${ }^{\text {"74 }}$ Not least, Ligeti's view of European or indeed "global" music history was given new impetus by these search movements (for example, through the discovery of the ars subtilior) and a no less consequential turn toward music genres from Africa, Java, Bali, Melanesia, China, and Korea, with their specific structures and underlying ways of thinking. ${ }^{75}$

The reception of sub-Saharan African genres, which include the ensembles of ongo horns of the Central African Banda Linda, songs of the Aka pygmies, the kiganda music of the amadinda xylophones in Uganda as well as the mbira lamellophone music of the Shona in Zimbabwe, form just one layer in an eclectic chain of associations in Ligeti's thinking and compositions in the 1980s. As outlined earlier in this book, intercultural reception processes in European music of the twentieth and twenty-first centuries have often been (and still are) integrated into comparably universalist aesthetic-conceptual designs, reaching out in a self-reflexive and complex manner in the most diverse directions and determining a reception model that I have attempted to characterize with the term "interpenetration" $(\rightarrow$ II.6). Such reception strategies proceed structurally, associatively, and transformatively and are based on analogous formations and cross-connections between different contexts and discourses - something that is particularly characteristic of Ligeti's approach.

In the case of sub-Saharan music, Ligeti's particular interest was in gestalt paradoxes and illusionary effects, which are also reflected in fractal geometry or M. C. Escher's visual paradoxes, such as the waterfall or staircase, which seem to be constantly falling or rising but in

74 Ligeti, "Paradigmenwechsel der achtziger Jahre," 116 ("keine 'wissenschaftliche' Musik, verwende keine Kalküle, keine Algorithmen [...], verwirkliche nur [seine] eigenen Vorstellungen, doch beschäftige [er sich] mit analogen Vorstellungen in anderen Bereichen. Komplexität beziehungsweise komplexe Muster [hätten ihn] immer angezogen").

75 On Ligeti's reception of African music see especially Ligeti and Bouliane, "Stilisierte Emotion," Taylor, "Ligeti, Africa and Polyrhythm," Scherzinger, "György Ligeti and the Aka Pygmies Project," Scherzinger, "Remarks on a Sketch of György Ligeti," and Taylor, "Hemiola Maximal Evenness and Metric Ambiguity in Late Ligeti." Ligeti's relation to mensural organization in works by ars subtilior composers is mentioned in Cünther, "Die Ars subtilior" and explored in Schütz, "Wiedergeburt der Ars subtilior?" 
fact always return to their starting points. Comparable musical phenomena include above all "inherent patterns," as described in detail in amadinda music by Gerhard Kubik: ${ }^{76}$ phenomena emerging in aural perception in a kind of relief from interlinked rhythmic-melodic lines. Starting from other African contexts, Steve Reich's music had already been crucial to exploring such patterns (labeled "resulting patterns" by Reich) over ten years earlier ( $\rightarrow$ II.6). ${ }^{77}$ Gerhard Kubik's and Simha Arom's structuralist and cognitive ethnomusicological approaches had a significant impact on Ligeti. Both researchers assume a fundamental alterity between African and European music, rhythm, and the underlying ways of thinking - an a priori assumption of ethnomusicology as a whole that had remained unquestioned for decades but has been harshly criticized for some twenty years from postcolonial perspectives. The central argument in Kofi Agawu's criticism, for instance, is that research committed to Western knowledge discourse has construed "African rhythm" as extraordinarily complex in order to categorize it as something categorically different from European rhythmic phenomena. Inevitably, however, this almost completely obscures the rhythmic complexity of Western music in the twentieth century. ${ }^{78}$ Agawu concludes:

A determined researcher could easily show that the sum of isolated experiments in rhythmic organization found in so-called Western music produces a picture of far greater complexity than anything that Africans have produced so far either singly or collectively. One could, in short, quite easily invent "European rhythm."

Ligeti points out Kubik's interpretation of sub-Saharan musical practices as particularly significant for his reorientation in the 1980s, saying that it led him to develop an analogous conception of musical spatiality in his own work:

Gerhard Kubik has shown that, in another culture, categories of our European ways of thinking are not valid, that there is a completely different way of experiencing time, space, and form. This is a way of thinking in certain patterns that arise from movements, a culture in which movement, language, dance, and also spatial configurations are conceived differently than in European culture.

What this way of thinking shares with my work is the idea of a unity of time and space. [...] I think in musical structures and forms in which the temporal is actually conceived spatially - as if everything were present at the same time. In the second movement of my Requiem, in the Piano Concerto, and also in the Cello Concerto, there are formations that cannot be compared with

76 See, among others, Kubik's essays "The Phenomenon of Inherent Rhythms in East and Central African Instrumental Music," "Die Amadinda-Musik von Buganda," "Kognitive Grundlagen afrikanischer Musik," and "Theorie, Aufführungspraxis und Kompositionstechniken der Hofmusik von Buganda." Kubik refers in detail to Ligeti's compositional techniques in conversation with the author in Kubik and Utz, "Auf Entdeckungsreise durchs Universum." See also Arom, Duchesneau, and Marx, "A Kinship Foreseen."

77 For more detail, see Reich's essays "Gahu-A Dance of the Ewe Tribe in Chana" and "Non-Western Music and the Western Composer."

78 See especially Agawu, "The Invention of 'African Rhythm," and Agawu, Representing African Music. An updated and concise historical account on art music in Africa that is multiply indebted to forms of rhythmic complexity, can be found in Scherzinger, "Art Music in a Cross-Cultural Context" and Scherzinger, "Afrika."

79 Agawu, "The Invention of 'African Rhythm," 386. 
the traditional concepts of melody, harmony, and rhythm. They are very differently conceived, static forms. They seem to stand in front of us as if they were objects and did not unfold in time. ${ }^{80}$

This "frozen turbulence" ${ }^{\text {"11 }}$ can actually be experienced again and again in Ligeti's music, though the aforementioned characterization of an "annihilation" of the temporal dimension could easily be refuted by a formal analysis of specific works, since the often "spiral-like" processes in Ligeti's works, including the famous Kyrie of the Requiem (1963-65) referred to by Ligeti, and even more clearly the paradigmatic works of the 1980 s such as the first or sixth Piano Etudes (1985), formally point toward central moments of conflict, which does indeed imply a decisive temporal, sometimes almost deterministic, strategy. ${ }^{82}$ So perhaps it would be more accurate to say that Ligeti's music plays out in a musical "space-time" in which spatial and temporal characteristics - state and process - are formative for our reception of the music, constantly re-orienting ourselves in the ever-changing mixtures of not exclusively present-oriented or goal-oriented states.

Works in which these characteristics appear in a particularly mature and varied manner are the three volumes of Ligeti's Piano Etudes (1984-97) ${ }^{83}$ and his Concerto for Piano and Orchestra (1985-88). ${ }^{84}$ Following on from some passages of the Piano Concerto, Ligeti's connection of historical-European and African formations of polyrhythm, polymeter, conflicting meter, and their different dimensions will be addressed and expanded upon with the aim of showing areas of friction in Ligeti's original forms of intercultural and historical reception.

The relationship between Ligeti's spatial metaphoricism and the compositional significance of conflicting meters is clearly demonstrated by some passages from the third movement of the Piano Concerto, which Ligeti described as "the most succinct example of illusionary rhythm and illusionary melody so far." 85 This is easy to see at the beginning of the movement (Ex. 5.10) and, thanks to a clear difference in color, it is not difficult to grasp perceptually how successive

80 Ligeti, “Paradigmenwechsel der achtziger Jahre," 117-118 (“Cerhard Kubik hat gezeigt, daß in einer anderen Kultur Kategorien unserer europäischen Denkweise keine Gültigkeit haben, daß es eine ganz andere Weise gibt, Zeit, Raum und Form zu erleben. Dies ist ein Denken in bestimmten Mustern, die aus Bewegungen entstehen, eine Kultur, in der Bewegung, Sprache, Tanz und auch Raumkonfigurationen anders aufgefaßt werden als in der europäischen Kultur. Gemeinsam mit meiner Arbeit ist darin die Vorstellung einer Einheit von Zeit und Raum. [...] Ich denke in musikalischen Strukturen und Formen, in denen das Zeitliche eigentlich räumlich konzipiert ist - so als ob alles gleichzeitig anwesend wäre. Im zweiten Satz meines Requiems, im Klavierkonzert, auch im Cellokonzert gibt es Formationen, denen man mit den herkömmlichen Begriffen Melodie, Harmonie, Rhythmus nicht beikommt. Es sind ganz anders gedachte, statische Formen. Sie scheinen vor uns zu stehen, als ob sie Objekte wären und sich nicht in der Zeit entfalten würden.")

81 Ligeti and Bouliane, "Stilisierte Emotion," 61 ("gefrorene Turbulenz").

82 See, for example, Haapamaki, "Order in Désordre," 40-44.

83 Analytical examinations of the piano etudes can be found in Bouliane, "Imaginäre Bewegung," Wilson, "Interkulturelle Fantasien," Rothkamm, "Ordnung in der Unordnung," Scherzinger, "György Ligeti and the Aka Pygmies Project," Haapamaki, "Order in Désordre," and Polth, "nicht tonal und nicht atonal." See also the composer's notes in Ligeti, "Études pour piano," "Études pour piano - Premier livre," and "Études pour piano - Deuxième livre."

84 Analytical studies of the Piano Concerto are provided by Willmann, "Cebannte Zeit," Steinitz, "A qui un hommage?," and Huber, Das zeitgenössische Klavierkonzert, 85-134. See also the composer's notes in Ligeti, "Zu meinem Klavierkonzert" and "Zum Klavierkonzert."

85 Ligeti, "Zu meinem Klavierkonzert," 298 (“das bislang prägnanteste Beispiel für Illusionsrhythmik und Illusionsmelodik"). 
pulse layers enter. First the sixteenth-notes in the piano are established, indicating the smallest basic rhythmic value on which the other pulses are built. In measure 2 the left hand adds dotted eighths, which are in turn adopted by the flute in measure 5. In measure 6 , a descending melodic movement appears in the right hand in values of seven sixteenths, and in measure 9 the viola joins in with straight quarter-notes, resulting in a ratio of 1:3:4:7.

The special nature of the space-time structures in Ligeti's works since the early 1980s may well be seen in his attempt to create a sense of levitation or "lift-off" by superimposing various pulsations and accents:

If this music is played correctly, at the right speed and with the right accentuation within the individual layers, after a certain time it will "lift off" like a plane after take-off: the rhythmic event, too complex to be followed in detail, hovers above us. ${ }^{86}$

Such a situation undoubtedly occurs at the moment of greatest density in the same movement. Example 5.11 shows a schematic representation of this passage, in which the ratio 1:4:5:6:7:9:11 is formed. All seven layers appear in the piano part (the orchestra merely doubles the 9/16 layer), indicating related techniques in the works for solo piano, the Piano Etudes, whose first book was written immediately prior to (and partly probably in parallel with) the concerto.

Ligeti summarized these compositional procedures with the term "generalized hemiola" and described their historical and cultural reference points most extensively in 1987, in a conversation with Denys Bouliane published in $1989 .{ }^{87}$ Ligeti traces a wide arc from the basic definition of the "hemiola," that is, the rhythmic ratio of three against two, to its extension from Chopin to Debussy, the discontinuous superimposition of different "pulses" in his own sixth Piano Etude, examples from Mozart, Scriabin, Ives, Messiaen, and Stockhausen, to the African Banda Linda and the music of the Aka Pygmies. Ligeti (as emerges from Arom's investigations) sees the peculiarity of the rhythmic organization in the African genres, in comparison to the explicit simultaneity of different meters in Mozart's "Imbroglio" (the famous superimposition of three dances with different meter in Don Giovanni), Charles Ives's The Fourth of July, or Karlheinz Stockhausen's Gruppen, in the fact that they do not describe polymeter, but rather a polyrhythm in which "different rhythmic patterns can be accommodated [...] in the same basic pulse," ${ }^{88}$ whereas "there is no simultaneity of different meters." ${ }^{199}$ Ligeti uses Alfons Dauer's term Nennwert ${ }^{90}$ (nominal value; today's more common terms for this phenomenon are "Ele-

86 Ligeti, quoted in Dibelius, György Ligeti, 234 ("Wenn diese Musik richtig gespielt wird, also in richtiger Ceschwindigkeit und mit richtiger Akzentuierung innerhalb der einzelnen Schichten, wird sie nach einer gewissen Zeit 'abheben' wie ein Flugzeug nach dem Start: Das rhythmische Geschehen, da zu komplex, um im Einzelnen verfolgt zu werden, geht in ein Schweben über.").

87 Ligeti and Boulaine, "Stilisierte Emotion" (conversation from 08/07/1987). Unfortunately, this highly informative and rich conversation was not included in the edition of Ligeti's Cesammelte Schriften.

88 Ibid., 52 ("verschiedene rhythmische Patterns [...] im selben Grundpuls unterbringen").

89 Ibid., 53 ("weil es [...] keine Gleichzeitigkeit von verschiedenen Metren gibt"). This rejection of the concept of polymeter can possibly credited to Ligeti's exchange with Simha Arom whom Ligeti met for the first time around 1985 when the original French edition of Arom's book on Central African music appeared (see Arom, Duchesneau, and Marx, "A Kinship Foreseen"). Arom denies the concept of polymeter for African music, in opposition to earlier ethnomusicological approaches such as that of Arthur Morris Jones (Studies in African Music) and dedicates an entire chapter to this question (Arom, African Polyphony and Polyrhythm, 179-212).

90 See Dauer, "Musiklandschaften in Afrika." 


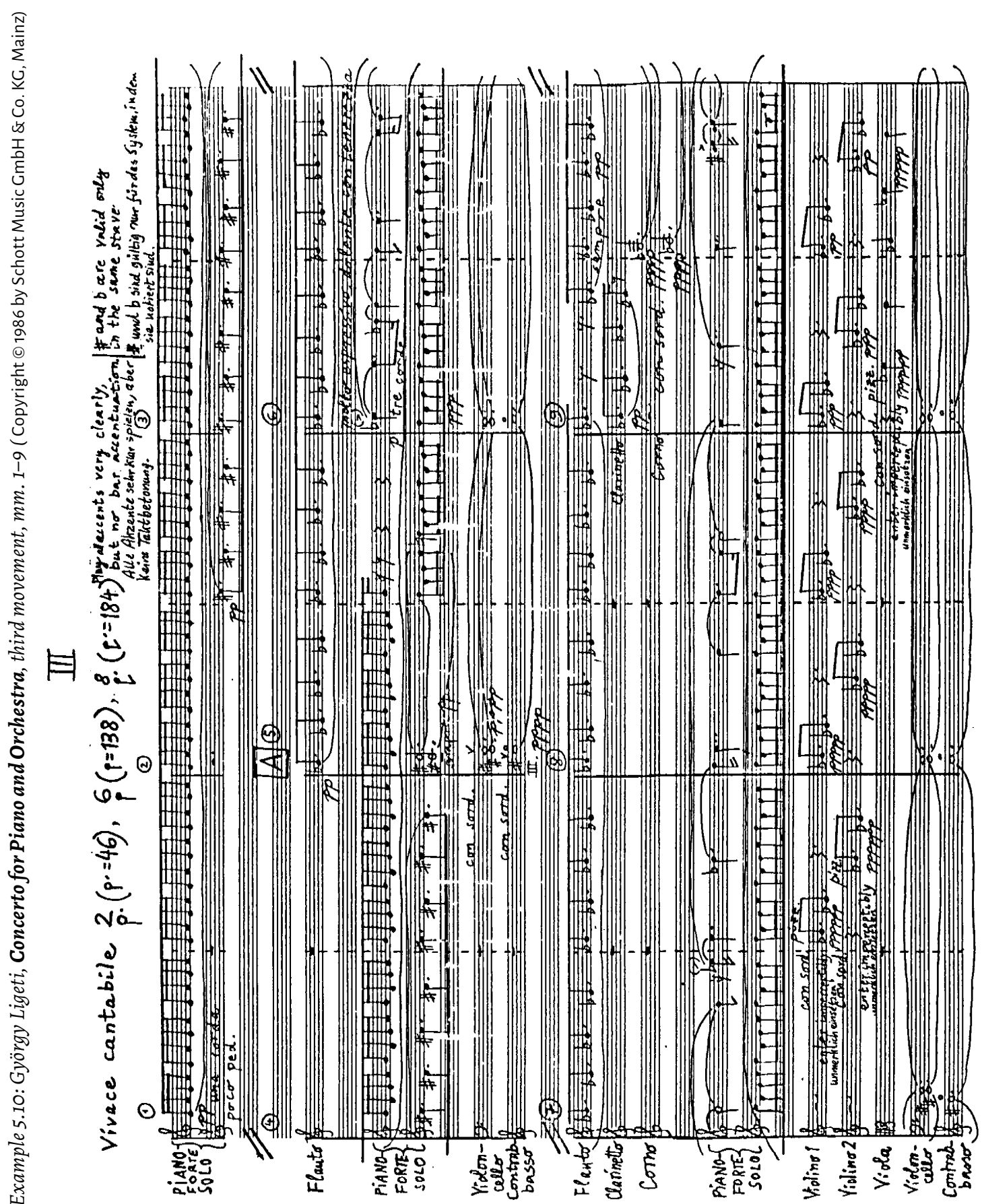


Example 5.11: György Ligeti, Concerto for Piano and Orchestra, third movement, mm. 83-85, layers

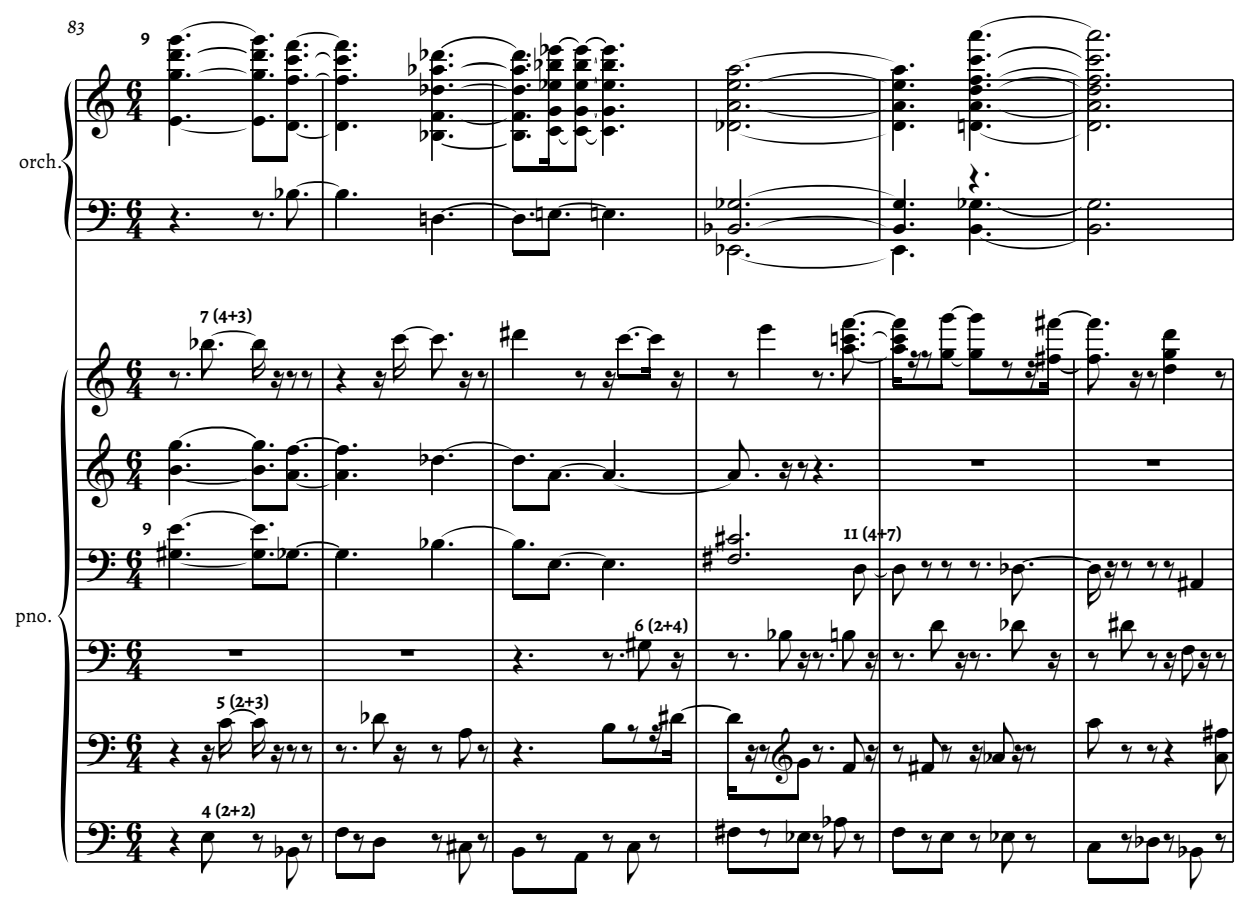

mentarpulsation"91 [elementary pulsation] or "density referent" ${ }^{\text {"92 }}$ ) and describes this crucial aspect of African music in detail in his foreword to Simha Arom's seminal study African Polyphony and Polyrhythm:

For composition, [Simha Arom's fundamental work] opens the door leading to a new way of thinking about polyphony, one which is completely different from the European metric structures, but equally rich, or maybe, considering the possibility of using a quick pulse as a "common denominator" upon which various patterns can be polyrhythmically superimposed, even richer than the European tradition. ${ }^{93}$

Various metric figures that can be related to a very rapid basic pulse are clearly audible in the third movement of the Piano Concerto, as shown above. All rhythmic processes here are based on a very fast basic pulse as a "common denominator": the sixteenths of the piano (at the stated rate, a sixteenth-note should be played at a tempo of $552 \mathrm{bpm}$, which corresponds to 9.2 attacks

91 Vgl. Kubik, "Einige Grundbegriffe und -konzepte der afrikanischen Musikforschung," 72-74.

92 See Nketia, The Music of Africa, 127-139. The problem of incoherent terminology has been noted and debated also in recent research on African rhythm, see Polak, Jacoby, and London, "Kulturelle Diversität in der empirischen Rhythmusforschung," 206, note 32.

93 Ligeti, "Foreword," xviii. 
Example 5.12: György Ligeti, Concerto for Piano and Orchestra, third movement, mm. 71-76, piano solo/xylophone

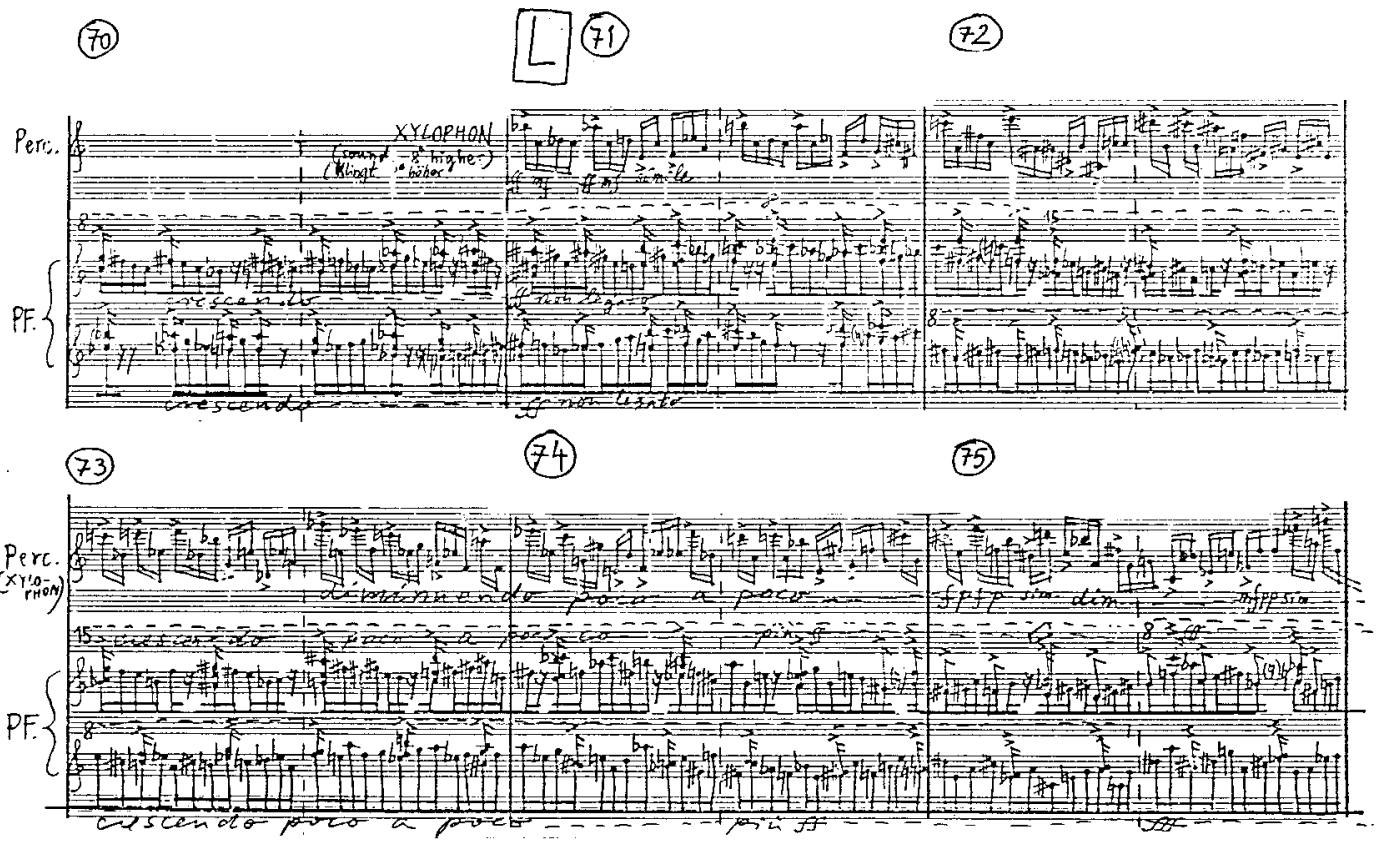

(76)

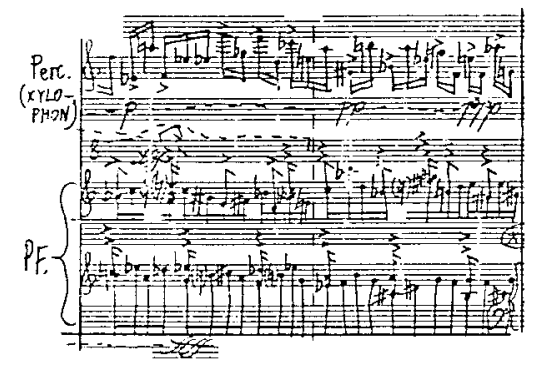

Copyright $\odot 1986$ by Schott Music CmbH \& Co. KG, Mainz

per second and a pulse duration of about $10.86 \mathrm{~ms}^{94}$ ). Of course, the different periodicities that sound at the same time might also be perceived as a superimposition of tempo layers and less as an overlaying of different rhythms or meters - an aspect that Ligeti himself has reflected

94 Here too, one can see a reference to the African genres. Ligeti describes in detail that the basic pulse can here be even faster than ten attacks per second: "The fastest piano-tremolo that we can perform consists of 13, 14 attacks per second, that is a bit faster, but the Central Africans are building incredibly complex polyphony on such frantically fast pulses." (Ligeti and Boulaine, "Stilisierte Emotion," 53; "Das schnellste Klaviertremolo, das wir ausführen können, besteht aus 13, 14 Anschlägen pro Sekunde, das ist zwar etwas schneller, doch die Zentralafrikaner bauen eine unglaublich komplexe Polyphonie auf solch rasend schnellen Pulsen."). 
Table 5.3: György Ligeti, Concerto for Piano and Orchestra, third movement, mm. 71-76: pulse layers, data in sixteenth note values ( $"=$ offset), ostinato pulses marked in bold

\begin{tabular}{|c|c|c|c|c|}
\hline measure & xylophone & piano (r. h.) & piano (I. h.) & piano (r. h.) \\
\hline 71a & $4-3-2-3(12)$ & $3-4-2-3(12)$ & $\{93\}^{*}$ & $3-4-2-3(12)$ \\
\hline $71 \mathrm{~b}$ & $4-3-2-3(12)$ & $3-4-2-4(73)$ & & $3-4-2-4(73)$ \\
\hline $72 a$ & $4-3-2-3(12)$ & $3-2-6(11)$ & & $3-2-5(10)$ \\
\hline $72 b$ & $2-2-3-2-3(12)$ & 6-6 (12) & & 5-5-5 (15) \\
\hline 73a & $2-2-3-2-3(12)$ & 6-6 (12) & & 5-5 (10) \\
\hline 73b & $2-2-3-3-2(12)$ & 7-7 (14) & & 5-5-5 (15) \\
\hline $74 a$ & $2-3-2-3-2(12)$ & 7-7 (14) & & 5-5 (10) \\
\hline $74 b$ & $2-3-2-3-2(12)$ & 7-7 (14) & 3- & $\mathbf{5 - 5 - 5}(15)$ \\
\hline $75 a$ & 2-3-2-3-3-(73) & $\mathbf{7}(7)$ & $3-3-3-3(12)$ & 5-5 (10) \\
\hline $75 b$ & $2-2-3-2-3-(12)$ & 7-7 (14) & $3-3-3-3(12)$ & 5-5-5 (15) \\
\hline $76 a$ & $2-3-2-2-3-(12)$ & 7-7 (14) & $3-3-3-3(12)$ & 4-4-4 (12) \\
\hline $76 \mathrm{~b}$ & $2-3-2-2-2(71)$ & $7(7)$ & $3-3-3-3(12)$ & $4-4-4(12)$ \\
\hline
\end{tabular}

with the term "polytempo." 95 The orientation of the listener is deflected away from the basic musical framework, the sixteenth pulse, to different pulse rates or periodicities, which are at first clearly distinguishable from one another, but later increasingly blur into texture and thus produce a "destabilization" of cognitive interpretation. It remains to be noted, then, that the distinction between "polyrhythm," "polymeter" and "polytempo" is by no means trivial and requires a more detailed discussion.

The relation of such layering to the aspect of the illusionary can be discussed in reference to another passage from the same movement in which, over six measures, a xylophone part joins the solo piano and interlocks with it, no doubt following the model of amadinda music (Ex. 5.12; this setting and reference are taken up again at the end of the fifth movement ${ }^{96}$ ). By auditory streaming, notes in the same registers in the listener's interpretation are connected to form common patterns, ${ }^{97}$ so that rhythmic-melodic shapes - "inherent patterns" - arise that none of

95 Ibid., 52 ("Polytempik." - The term is here suggested by Bouliane). Ligeti developed this concept of "polytempo" already in 1974, using the example of Ives's music: "Ives needed the exact tonal definition of his quoted materials in order to set them apart clearly from the context, which of ten described a different tonality. The polytonality is joined by polyrhythm, polymeter and - one would actually have to introduce this term - polytempo. Polymeter already existed in Mozart's Don Giovanni. In Ives, however, different metric processes sometimes also have different tempi." (Ligeti, "Zur Collagetechnik bei Mahler und Ives," 289; "Ives brauchte die exakte tonale Bestimmung seiner zitierten Materialien, um sie deutlich gegen den Kontext, der oft eine andere Tonalität beschrieb, absetzen zu können. Zur Polytonalität gesellen sich Polyrhythmik, Polymetrik und - man müßte eigentlich diesen Begriff einführen - Polytempik. Polymetrik gab es ja schon in Mozarts Don Giovanni. Bei Ives jedoch haben die metrisch verschiedenen Abläufe mitunter auch verschiedene Tempi.")

96 Ligeti, Piano Concerto, fifth movement, mm. 79-84; see Jena, "Raum und Zeit in der Neuen Musik," 52-76.

97 Phenomena of auditory streaming or stream segregation have received broad attention in music psychology, and are most prominently described in Bregman, Auditory Scene Analysis, 47-212. 
the two soloists alone plays (Ligeti has repeatedly used formulations by Gerhard Kubik almost verbatim to describe this effect $\left.{ }^{98}\right)$.

How do the levels of rhythm, meter, tempo, and melody relate to each other in this situation? In order to answer this question, it is advisable first to consider the individual strata in isolation; one quickly sees that there are essentially four pulse layers, all of which have different characteristics, or "tempos." Ligeti notates the passage in 6/4 time, with each measure divided in the middle by dashed lines in $2 \times 3$ quarters (these half-measures are indicated by adding a and $b$ to the measure numbers below). The 24 sixteenths of a measure can be divided into the hemiolic ratio $3: 2$ at four levels $-24: 16 \downarrow / \downarrow, 12: 8 \downarrow / \downarrow, 6: 4 \downarrow / \downarrow$, and $3: 2 / / \phi$.

Already in the transition from measures 71 to 72 , both hands of the piano add a sixteenth note to the regular $12+12$ sixteenth pattern, thus creating a friction with the regular meter of the xylophone, which retains the 4-3-2-3 division from measure 71 (Table 5.3). On sixteenth beat $72 a .7$, ostinato pulses begin in the piano at 6 , then 7 sixteenths (right hand) as well as 5 sixteenths (left hand), which from the end of measure 74 are supplemented by another layer in the right hand ( 3 sixteenths). By measure $73 \mathrm{~b}$ at the latest, one would have to speak of a continued "generalized" hemiola with the accents only realigning at the beginning of measure 77 . This moment of synchronization is prepared, in particular, by the regular isochronous 3 and 4 divisions from measures 75 and 76 , consolidating the given meter; this regularity, however, continues to be disturbed by an accent shift of one sixteenth in the xylophone layer.

So far, I have consciously restricted the description to the terms "pulses" and "accents." The extent to which these also constitute meter can only be clarified by discussing whether these pulses in themselves or in their interaction have superior salient properties that give rise to metric periodicities. For this purpose, I extracted all accented notes from the musical text and wrote them on three staves (A, B, C) separated by register (Ex. 5.13). This reduction makes clear that registers $\mathrm{A}$ and $\mathrm{C}$ describe an upward movement to the highest piano key $\mathrm{C} 8$ in measures 73 and 74, and then a downward movement which can also be observed in registral layer B entering shortly before measure 75 .

The xylophone part, marked in Example 5.13 by wedges (accents together with piano) or circles (xylophone accents without piano), jumps between all three registers, transforming the largely periodic layers of the piano into changing "inherent patterns." It can be assumed that the shared accents (wedges) are particularly emphatic markers, so that the first pulses of the measures $71 a, 71 b, 72 b, 73 a, 73 b$ are clear indications of marking the given meter (6/4, subdivided in $2 \times 3$ fourths or $2 \times 12$ sixteenths), which is also supported by highlighted register peaks (this results in an overarching aural stream of Bb6-B6/C7-[D7-E7-]F\#7-G7-[G\#7-]Bb7 in layer A; thereafter almost no common accents occur. The alternative presentation in Table 5.4 vividly demonstrates the compression process leading to metric leveling and destabilization: whereas measures 71 to 73 contain between five and seven accents on twelve fundamental pulses in each half-measure, this number rises between measures 74 and 76 to eight and ten accents per half-measure.

The relative metric stability of measures 71 to 73 is also demonstrated by another illustration in which the resulting rhythmic figures of layers $A$ and $B+C$ are placed one below the other in a simplified manner (Ex. 5.14). Here it is obvious how, from measure 74 onward, the initially clear periodicity of the resulting patterns seriously disintegrates. This becomes apparent relatively late in layer $A$, in which the accents within the first three eighths of each half-measure are shifted only in measure 75b. Here, as well as in measure 76a, new (off-meter) periodicities are formed by the shared accents of piano and xylophone. In registers $C$ and $B$, the processual shift

98 Compare, for example Ligeti, "Zum Klavierkonzert," 301, with Kubik, “Musikgestaltung in Afrika," 39. 
Example 5.13: György Ligeti, Concerto for Piano and Orchestra, third movement, mm. 71-76, accent layers in three registers $A, B$ and $C$; wedges: common accents piano and xylophone; circles: accents xylophone (without piano)
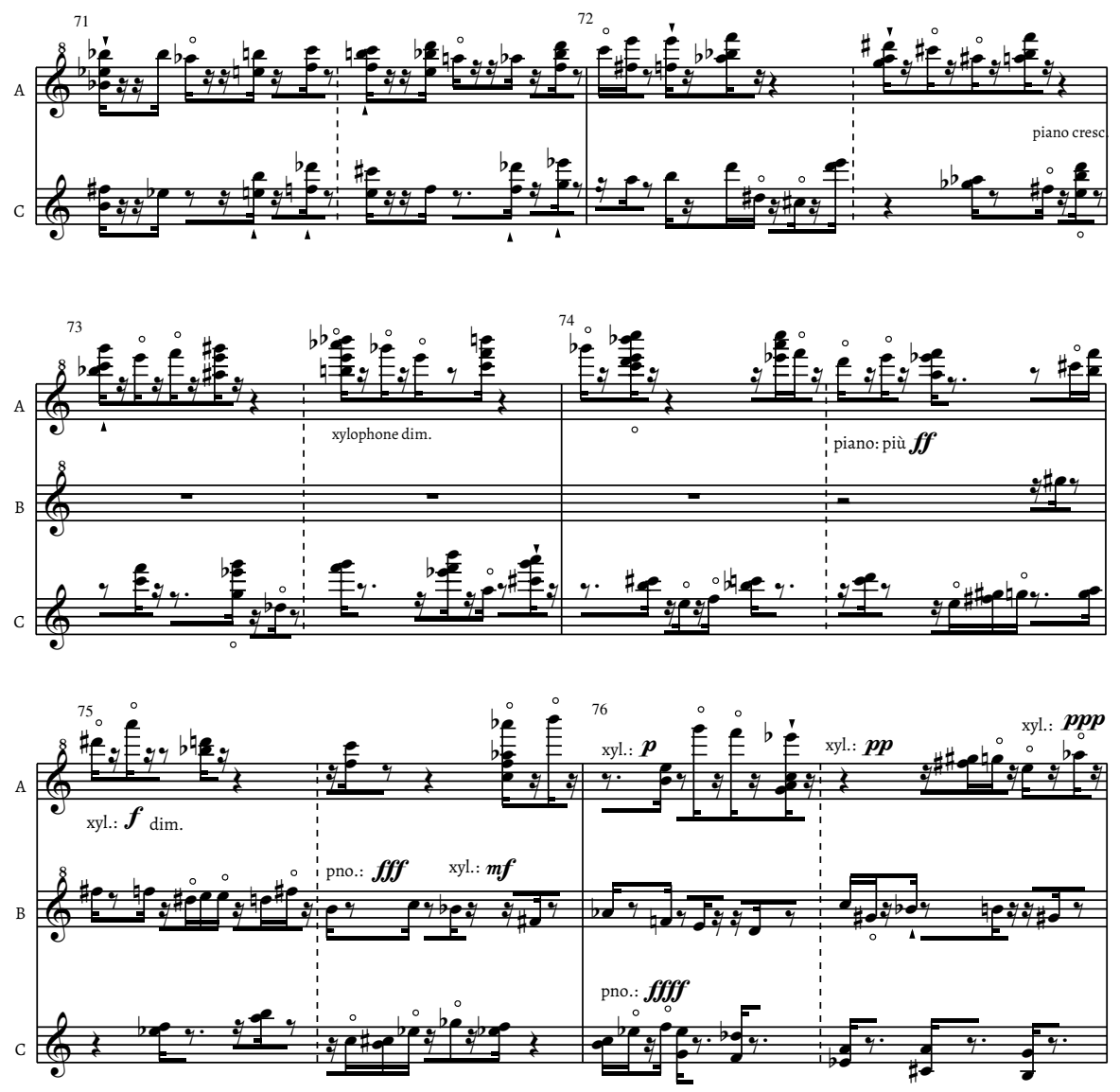

begins earlier, with particular emphasis on the development of the figure, which at first seems to be clearly syncopated at positions $71 a .8$ and 71a.10. These positions remain stable until measure 73a, thus contributing significantly to an "intact" metric periodicity, while afterward they move more and more "to the left," switching between layers $\mathrm{C}$ and $\mathrm{B}$ - a process of convergence is completed that simultaneously blends the pitch registers of these two layers (see Ex. 5.13).

While measures 71 to 73 can still be perceived as metric despite their complexity, and within this basic meter, the deviation of the piano accents' shape in measure $72 \mathrm{a}$ can clearly be identified as a conflicting metric layer, the following three measures, with the seven-sixteenths ostinato pulses of the upper piano register, the addition of a third register, and a shift in the resulting salient patterns, eliminate almost any sense of meter, although new stabilizing factors counteract this process (such as the 3-sixteenth and 4-sixteenth pulses). Owing to the overall compression, these pulses also tend toward a dissociation of meter - ten accents on twelve basic pulses, such as in measure 74b, hardly allow us to speak of a reference metric layer anymore. Time becomes space, structure becomes texture - a paradigmatic process in Ligeti's later works that can be equally observed in Piano Etudes 1, 6, 12, or 13, as well as in the first, fourth, and fifth movements of the Piano Concerto. 
Table 5.4: György Ligeti, Concerto for Piano and Orchestra, third movement, mm. 71-76, accent layers in three registers $A, B$ and $C$, represented on the basis of an adapted Time-Unit Box System (TUBS), developed by Philip Harland

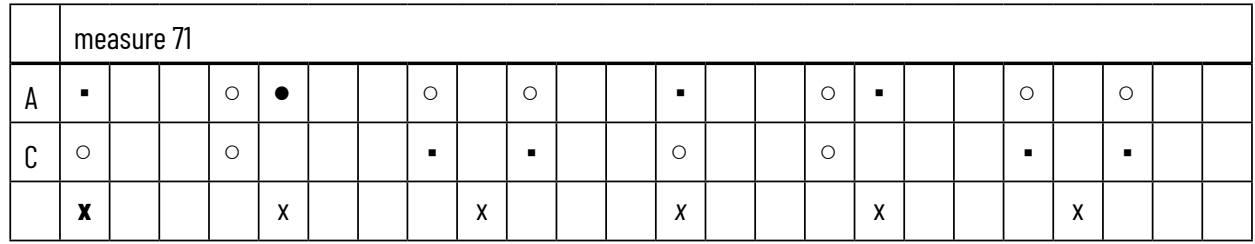

\begin{tabular}{|c|c|c|c|c|c|c|c|c|c|c|c|c|c|c|c|c|}
\hline & \multicolumn{16}{|c|}{ measure 72} \\
\hline A & $\bullet$ & ○ & $\cdot$ & o & & & & & $\cdot$ & $\bullet$ & $\bullet$ & o & & & & \\
\hline C & & o & ○ & o & $\bullet$ & & $\bullet$ & o & & & ○ & & $\bullet$ & & $\cdot$ & \\
\hline & $\mathbf{x}$ & & $x$ & & & $x$ & & & $x$ & & $x$ & & & $x$ & & \\
\hline
\end{tabular}
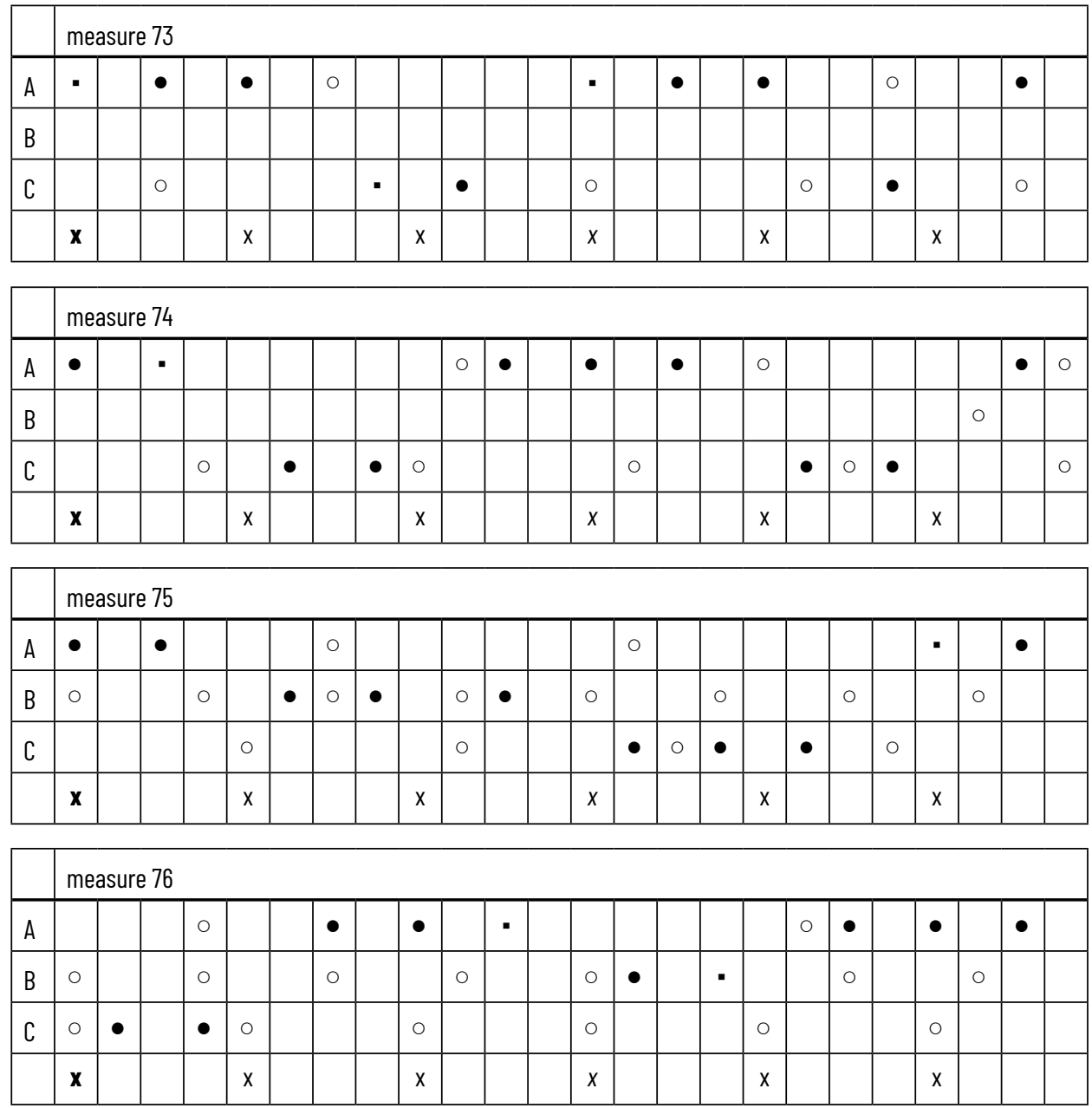
Example 5.14: György Ligeti, Concerto for Piano and Orchestra, third movement, $m m$. 71-76, resulting rhythms of layers $A$ (left) and C/B (right); accents: common accents piano/xylophone; circles: impulses xylophone
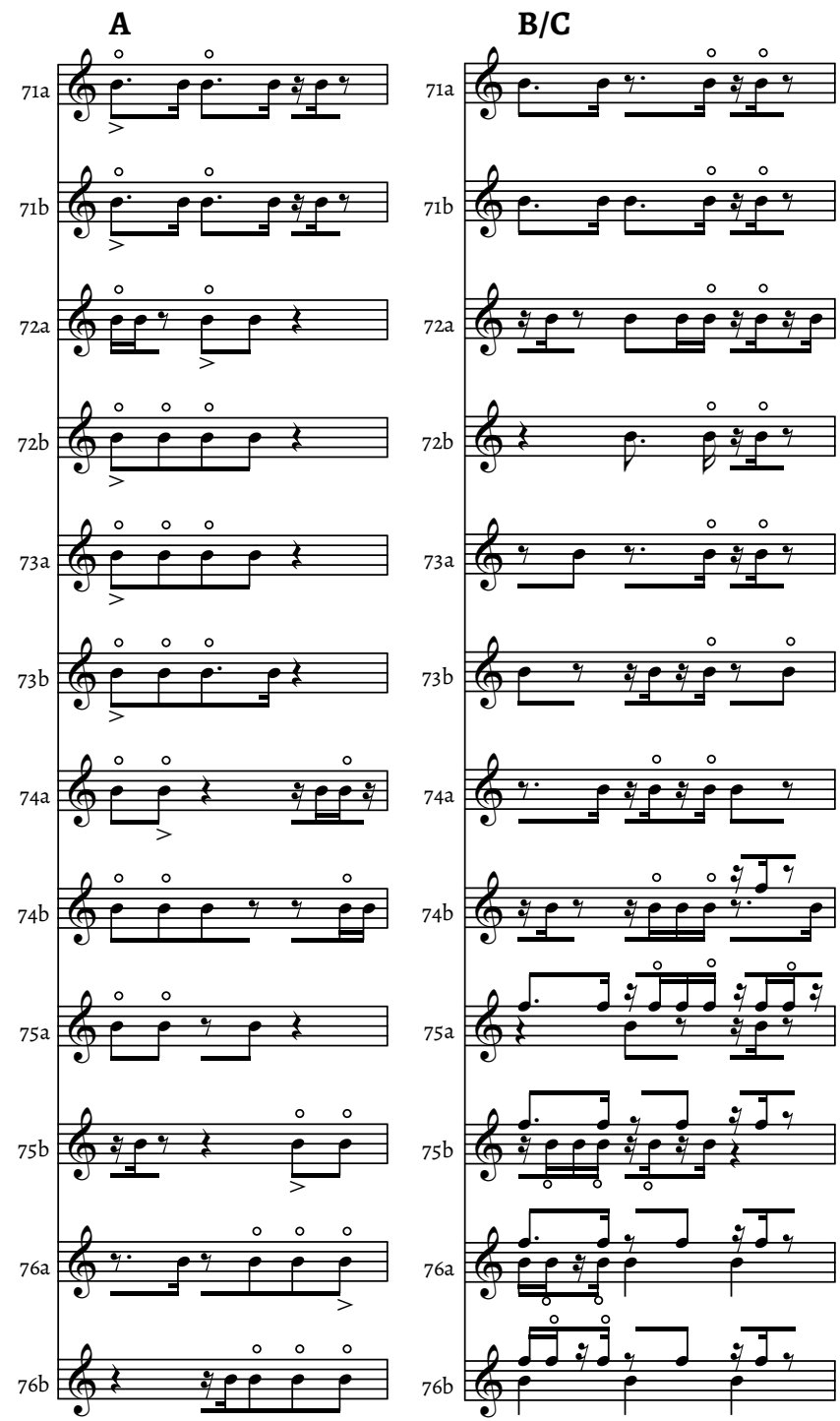


\section{Summation Meter and Metric Dissonance}

Let us now try to expand this analytical approach to Ligeti's "generalized hemiola" somewhat more systematically. It seems necessary to problematize the arguably inadequate distinction between polyrhythm and polymeter in Ligeti's theoretical perspective, which corresponds to a similar lack of distinction in some approaches in music theory, music psychology, and ethnomusicology.

The phenomenon of meter can, as already shown in the above analysis, usually be explained as periodically recurring salient signals within regular pulse sequences, that is, dynamic or register-based emphases, accents, patterns, or events, which can be eliminated when the meter is established, so that meter cannot be generally defined on the basis of "accents," as has long been the norm. On the contrary, a distinction must be made between "commetric" and "contrametric" accents, a necessity which becomes very clear, for example, from measures 71 to 73 of the example discussed above. ${ }^{99}$

In research, there has been a tendency only to recognize those musical contexts as "metric," where meter can also be identified by an "experienced listener." Meter has thus been described as an essentially cognitive phenomenon, often in explicit contrast to rhythm. ${ }^{100}$ In this context, the existence of polymeter was repeatedly questioned, since it was only possible to perceive different metric shapes simultaneously to a limited extent. ${ }^{101}$ On the contrary, it has been stated that the term "rhythm" today says "much and yet almost nothing anymore."102 One could justifiably assert that the term "polyrhythmic" is, on closer examination, tautological and therefore unusable, since countless types and forms of music are composed of different simultaneous "rhythms," while the simultaneity of different metric periodicities constitutes a far more specific form of superposition. ${ }^{103}$

At any rate, it seems problematic to make a (narrowly empirically defined) cognitive level the sole prerequisite for a definition of meter. For there are - not only in the twentieth and twenty-first centuries - musical contexts and compositional processes in which the conflicts between a metric base layer and the actual formations in musical groupings, or conflicts between such units, are crucial factors of the structure which are not aimed at a clear identification of one or more meters, but are still essential for complex and often ambiguous manners

99 Kolinsky, "A Cross-Cultural Approach to Metro-Rhythmic Patterns," 497.

100 See London, "Rhythm," I.1. The Distinction Between Rhythm and Metre. This distinction essentially goes back to the rhythm and meter theories of Lerdahl and Jackendoff, A Cenerative Theory of Tonal Music. See also London, Hearing in Time, 65-76.

101 See Drake and Parncutt, "Psychology of Music," II. Perception and Cognition, 2. Rhythm; London, Hearing in Time, 67.

102 Seidel, "Rhythmus, Metrum, Takt," I. Zur Definition des Prinzips (“Heute bezeichnet Rhythmus alles, was irgendwie mit der Struktur oder dem Ablauf der musikalischen Zeit, oft auch, was mit Bild- und Raumbewegungen zu tun hat. Das Wort sagt vieles und doch fast nichts mehr.")

103 Arom tries to circumvent this problem by defining polyrhythm as "different patterns of accent [...] superposed in the same work" (Arom, African Polyphony and Polyrhythm, 205). To associate rhythm (rather than meter) with "patterns of accent" might, of course, appear quite problematic. Arom's rejection of the concept of polymeter for African music is consequently based on a very narrow definition of "meter": "If we take 'metre' in its primary sense of metrum (the metre being the temporal reference unit), 'polymetric' would describe the simultaneous unfolding of several parts in a single work at different tempos so as not to be reducible to a single metrum. This happens in some modern music, such as some of Charles Ives's works, Elliott Carter's Symphony, B. A. Zimmermann's opera Die Soldaten, and Pierre Boulez's Rituel." (ibid.) 
Example 5.15: E Juba - beginning of a popular song from South Sudan (transcription: Gerhard Kubik; Kubik, "Musikgestaltung in Afrika," 36)

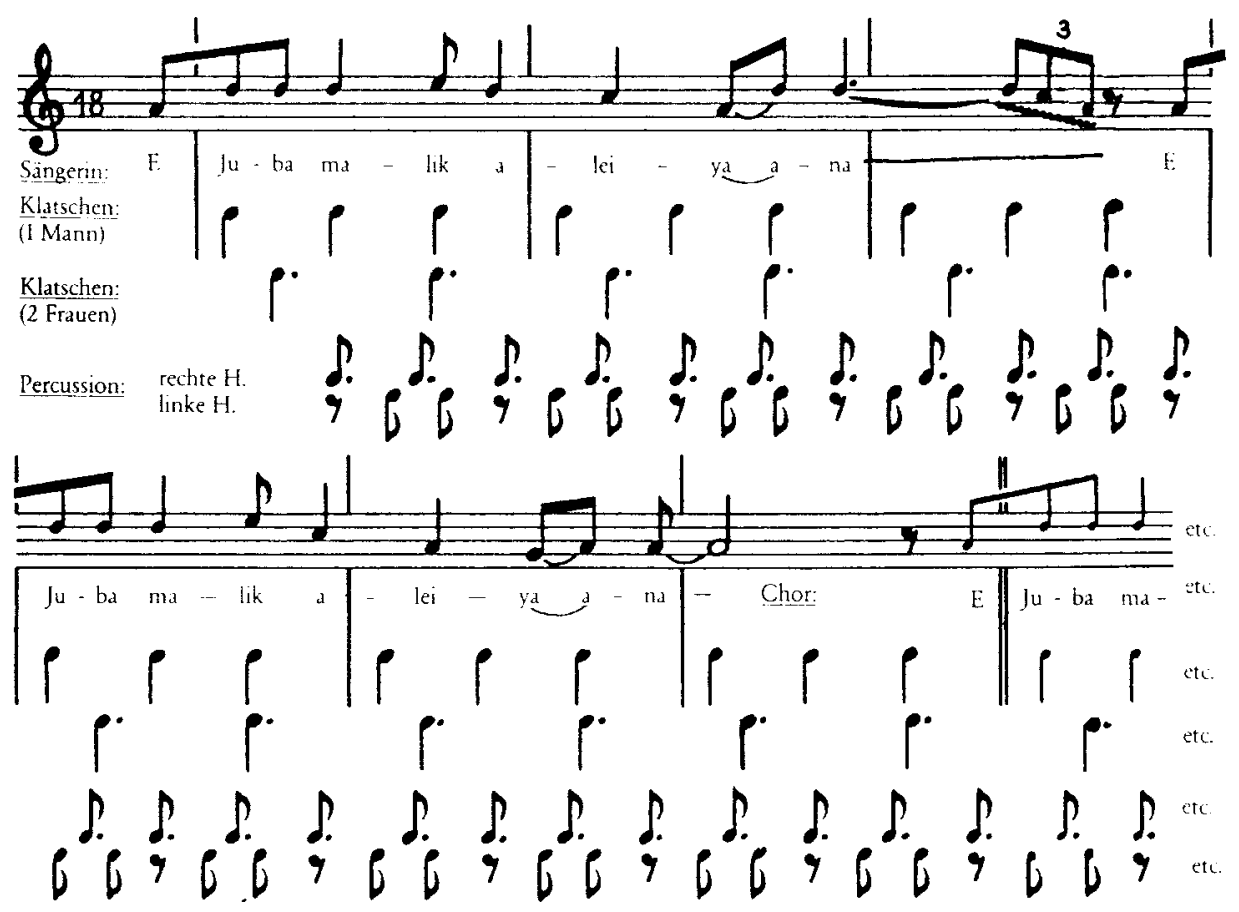

Copyright $\odot 1983$ by Gerhard Kubik/Staatliche Museen Preußischer Kulturbesitz Berlin

of gestalt perception. Ligeti's music is a prominent example of this. Of course, the problem (or indeed the impossibility) of providing a succinct definition of "rhythm" and "meter" accommodating not only different periods of Western music history but also musical time structures on a global scale is far beyond what can be achieved here and would require a monograph on its own (as presented for the Western context, most notably, by Christopher Hasty ${ }^{104}$ ). Especially when we turn to the richly imaginative and thorough treatment that the relationships between rhythm, meter, and tempo have received in twentieth- and twenty-first-century music, it seems inevitable to conceive of a complex model in which the interrelation of these concepts or areas is maintained and highlighted. ${ }^{105}$

Examples 5.15 and 5.16 and Tables 5.5 to 5.8 show polymetric situations in African contexts based on the studies of Kubik, which Ligeti knew, and without taking into account the extensive more recent research on African rhythm, which has undergone much further development. ${ }^{106}$ Although to what extent a concept such as "meter" can be appropriate for African designs of

104 Hasty, Meteras Rhythm. The concepts of polyrhythm or polymeter are not discussed in Hasty's book which otherwise offers an unsurpassedly nuanced discussion of the relation between rhythm and meter.

105 See Utz and Nonnenmann, "Rhythmus, Metrum, Tempo" for a comprehensive overview of definitions and compositional approaches in twentieth- and twenty-first-century music. See also Delaere, "Tempo, Metre, Rhythm."

106 Polak, Jacoby, and London, "Kulturelle Diversität in der empirischen Rhythmusforschung" provides an excellent example. 
Example 5.16: Tan'b'oloko se? - song from a fairy tale of the Yoruba, West Africa

(transcription: Gerhard Kubik; Kubik, "Musikgestaltung in Afrika," 37)

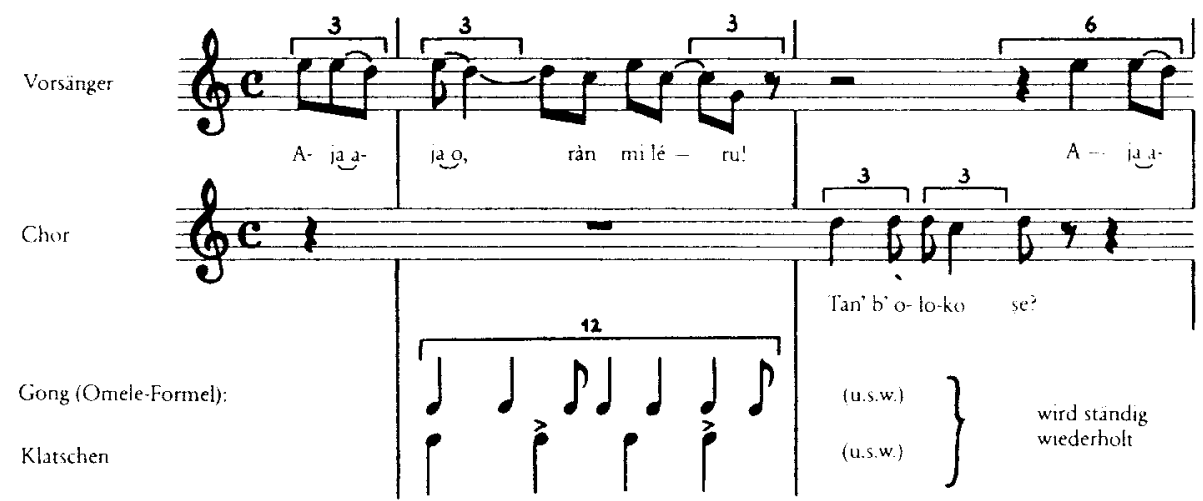

$12 \underline{3} 1 \underline{2} \underline{3} \underline{1} \underline{2} \underline{1} 2 \underline{3}$

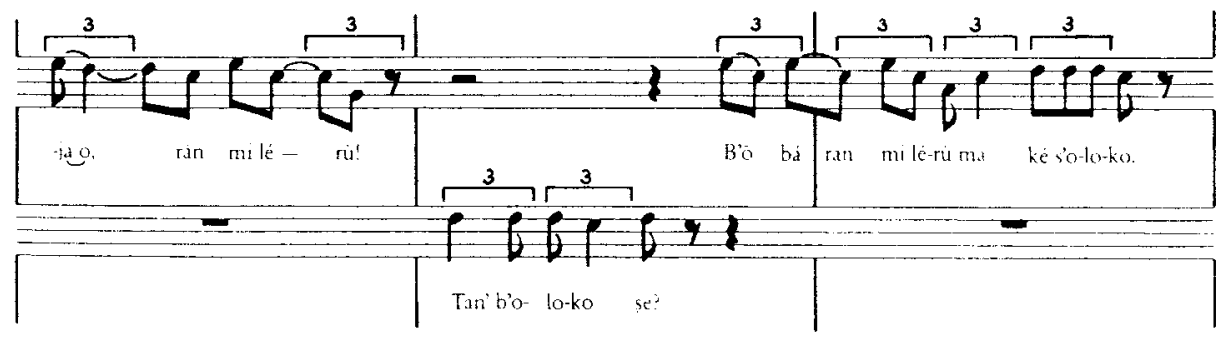

Copyright (c) 1983 by Gerhard Kubik/Staatliche Museen Preußischer Kulturbesitz Berlin

music at all remains controversial in ethnomusicology, there is broad agreement that most African musicians think in larger, frequently recurring, rhythmic-melodic formulas, and thus in periodicities whose relationship to European concepts of meter has possibly not yet been fully explored. ${ }^{107}$ In Example 5.15, Kubik uses a popular song from southern Sudan to show how four different periodicities are superimposed. ${ }^{108}$ They comprise $6,9,12$, and 18 pulses per "summation meter" of 36 basic pulses read from top to bottom (schematic representations in Tables 5.5 and 5.6). The numbers 6,12 , and 18 are divisible by both 2 and 3, thus allowing constantly changing metric references. In addition, a periodically recurring vocal melody comprising 36 basic pulses, which is shifted by two basic pulses with respect to the rhythmic group generates an additional quasi-canonic metric displacement.

107 Polak, Jacoby, and London, for example, argue: "We concur with authors who support an application of the concept of meter in African music research; however, we emphasize the necessity to keep the theoretical definition of the concept of 'meter' open." (Ibid., 198; "Wir folgen Autor*innen, die eine Anwendung des Metrumsbegriffs in der afrikanistischen Musikforschung befürworten, betonen jedoch gleichzeitig die Notwendigkeit, die theoretische Bestimmung des Konzepts 'Metrum' offen zu halten.")

108 Kubik, "Musikgestaltung in Afrika," 36. 
Table 5.5: Representation of Example 5.15 in the Time-Unit Box System (TUBS); metric periodicities of the patterns are marked by changing gray levels

\begin{tabular}{|c|c|c|c|c|c|c|c|c|c|c|c|c|c|c|c|c|c|}
\hline & 1 & 2 & 3 & 4 & 5 & 6 & 7 & 8 & 9 & 10 & 11 & 12 & 13 & 14 & 15 & 16 & 17 \\
\hline \multirow[t]{6}{*}{$\bullet$} & $\bullet$ & & $\bullet$ & & • & & & & • & & $\bullet$ & & & & • & & \\
\hline & & & & & & & & & & & & & & & & & \\
\hline & $\bullet$ & & & & $\bullet$ & & & & $\bullet$ & & & & $\bullet$ & & & & $\bullet$ \\
\hline & & & • & & & & & & • & & & & & & • & & \\
\hline & & $\circ$ & & & • & & & • & & & • & & & • & & & • \\
\hline & 0 & & 0 & & - & & • & & $\bullet$ & & - & & • & & $\bullet$ & & - \\
\hline
\end{tabular}

\begin{tabular}{|l|l|l|l|l|l|l|l|l|l|l|l|l|l|l|l|l|l|l|}
\hline 18 & 19 & 20 & 21 & 22 & 23 & 24 & 25 & 26 & 27 & 28 & 29 & 30 & 31 & 32 & 33 & 34 & 35 & 36 \\
\hline & $\bullet$ & & $\bullet$ & & $\bullet$ & & & & & & & & $\bullet$ & & $\bullet$ & - & & 0 \\
\hline \multicolumn{10}{|c|}{} \\
\hline & & & $\bullet$ & & & & $\bullet$ & & & & $\bullet$ & & & & $\bullet$ & & & \\
\hline & & & $\bullet$ & & & & & & $\bullet$ & & & & & & $\bullet$ & & & \\
\hline & & $\bullet$ & & & $\bullet$ & & & $\bullet$ & & & $\bullet$ & & & $\bullet$ & & & $\bullet$ & \\
\hline & $\bullet$ & & $\bullet$ & & - & & $\bullet$ & & $\bullet$ & & - & & $\bullet$ & & $\bullet$ & & - & \\
\hline
\end{tabular}

Table 5.6: Pulse speeds and metric patterns in Example 5.15

\begin{tabular}{|c|c|}
\hline \multicolumn{2}{|l|}{ pulse speeds } \\
\hline clapping (one man) & $4-4-4-4-4-4-4-4-4(9 \times 4)$ \\
\hline clapping (two women) & $6-6-6-6-6-6[4+2](6 \times 6)$ \\
\hline percussion $r . h$. & $3-3-3-3-3-3-3-3-3-3-3-(3)(12 \times 3)$ \\
\hline percussion I. h. & $2-4[2-2]-2-4-2-4-2-4-2-4-(2-4)(6 \times 6[2+4] ; 18 \times 2)$ \\
\hline \multicolumn{2}{|l|}{ meter/pattern } \\
\hline voice & -2 6-6-4-4-4-12 [12-12-12] \\
\hline clapping & $12-12-12 \ldots$ \\
\hline percussion & $4-6-6-6-6-6-6 \ldots$ \\
\hline
\end{tabular}

The different pulse speeds, on the one hand, and the meter within the three sound layers (voice, clapping, percussion), on the other hand, should be differentiated here. The representation in Table 5.5 shows clearly that only with the completion of a full 36-valued unit can all periodicities be synchronized again. It also becomes clear that the meter of the percussion layers follows that of the voice (with a hemiolic dissonance between the 11th and 22nd pulse), while the meter of clapping is canonically displaced by two fundamental pulses. Hemiolic overlays occur even within the metric periods in clapping and percussion layers (3:2 and 6:4 pulses).

The values transcribed as triplets by Kubik between the 29th and the 32nd pulse of Example 5.15 seem to be a rhythmically free "phrasing" provoked by a speech-oriented vocal intonation, 
Table 5.7: Representation of Example 5.16 in the Time-Unit Box System (TUBS);

metric periodicities of the patterns are marked by changing gray levels

\begin{tabular}{|l|l|l|l|l|l|l|l|l|l|l|l|l|l|l|l|}
\hline & & & & & & & 1 & 2 & 3 & 4 & 5 & 6 & 7 & 8 & 9 \\
\hline lead singer & $\bullet$ & & $\bullet$ & & $\bullet$ & & $\bullet$ & & $\bullet$ & & & & & & \\
\hline choir & & & & & & & 0 & & & & 0 & & 0 & & 0 \\
\hline gong & & & & & & & $\bullet$ & & & & $\bullet$ & & & & $\bullet$ \\
\hline clapping & & & & & & & $\bullet$ & & & & & & $\bullet$ & & \\
\hline
\end{tabular}

\begin{tabular}{|l|c|c|c|c|c|c|c|c|c|c|c|c|c|c|c|}
\hline & 10 & 11 & 12 & 13 & 14 & 15 & 16 & 17 & 18 & 19 & 20 & 21 & 22 & 23 & 24 \\
\hline lead singer & $\bullet$ & & & $\bullet$ & & & $\bullet$ & & & & & $\bullet$ & & - & \\
\hline choir & & & & 0 & & & & $\bullet$ & & & & $\bullet$ & & $\bullet$ & \\
\hline gong & & $\bullet$ & & & & $\bullet$ & & & & $\bullet$ & & & & $\bullet$ & \\
\hline clapping & & & & $\bullet$ & & & & & & $\bullet$ & & & & & \\
\hline
\end{tabular}

Table 5.8: Pulse speeds and metric patterns in Example 5.16

\begin{tabular}{|l|l|}
\hline \multicolumn{2}{|l|}{ pulse speeds } \\
\hline lead singer & $(2-2-2) 2-7-33-5-4$ \\
\hline choir & $4-2-2-4-4-(4-2-2)[6 \times 4]$ \\
\hline gong & $4-4-2-4-4-4-2[12 \times 2]$ \\
\hline clapping & $6-6-6-6[4 \times 6]$ \\
\hline meter/pattern & \multicolumn{2}{|l}{} \\
\hline lead singer/ choir & $(2-2-2) 2-7-33-5-4[12-12]$ \\
\hline gong & $10-14$ \\
\hline clapping & $12-12$ \\
\hline
\end{tabular}

while the continued triplet values in Example $5.16^{109}$ produce additional rhythmic-metric complexity. Based on Kubik's note values, one must assume that triplet sixteenths act as a common fundamental pulse, so that a "summation meter" of 24 values is obtained (Table 5.7). Continuing in the gong, the omele formula is one of Africa's best-known structural elements, commonly also referred to as "time-line pattern," and has been widely deployed by Ligeti and others. ${ }^{110}$ Due to its irregular division according to the proportion $n-1 / n+1$ ( $5+7$ triplet-eighths - here cor-

109 Ibid., 37.

110 See Scherzinger, "György Ligeti and the Aka Pygmies Project," 240-244. The omele formula has also been related to Steve Reich's paradigmatic works Drumming (1970-71) and Clapping Music (1972), see Klein, Alexander Zemlinsky-Steve Reich: Alternative Moderne(n), 139-147 and Colannino, Gómez, and Toussaint, "Analysis of Emergent Beat-Class Sets in Steve Reich's 'Clapping Music.' 
Table 5.9: Categories of metric dissonance in Classical-Romantic music

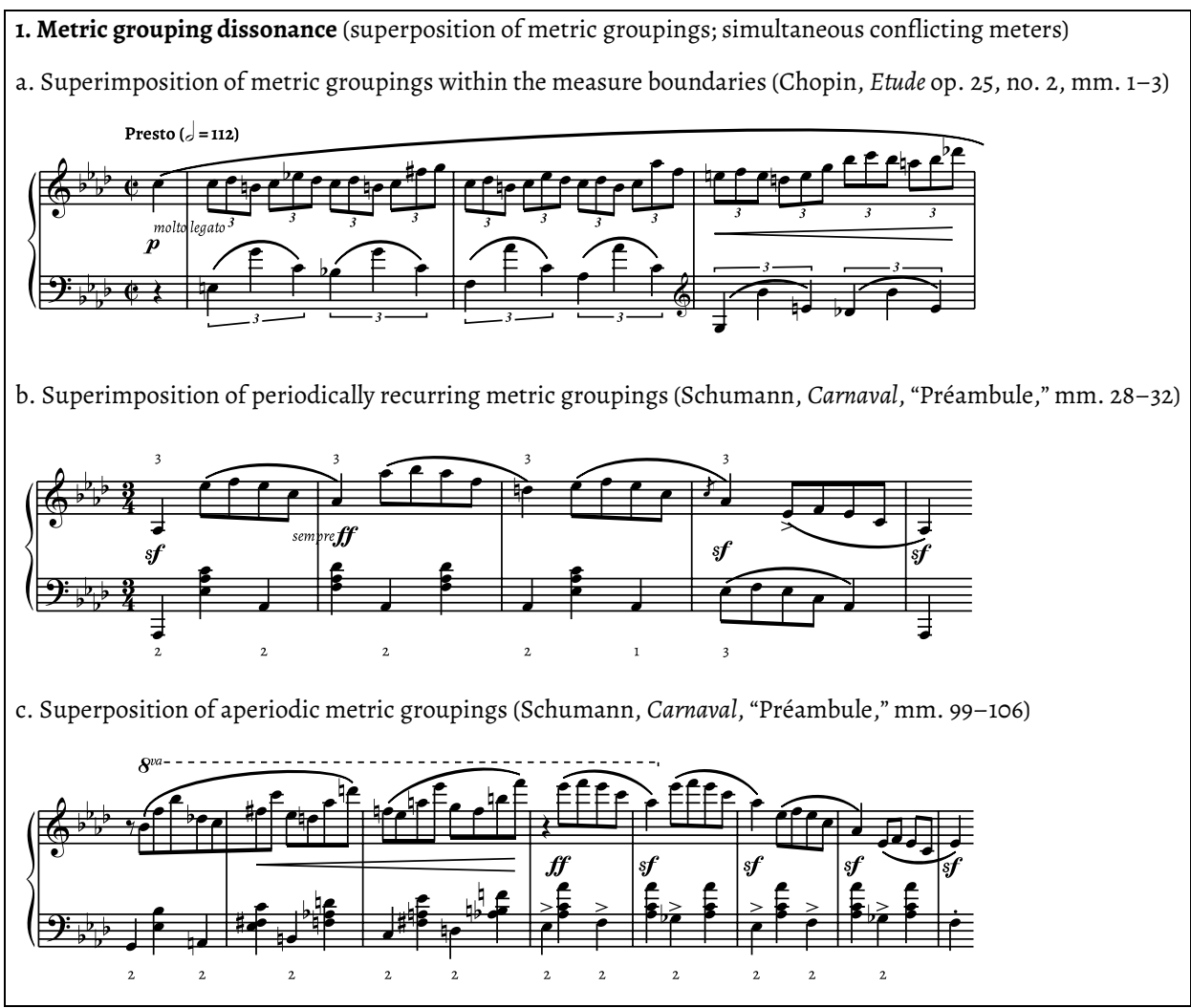

responding to $10+14$ fundamental pulses) and the additional constant change between threeand two-division in the singing voice (lead singer), metric tension is created on a simultaneous and successive dimension (Table 5.8). ${ }^{11}$

The function of such overlays in the African context varies. In some genres - as is often the case, for example, with the Aka pygmies in Central Africa - the strata are gradually built up, and the increasing "polymeter" thus serves to increase the density of sounding events and is often coupled with an intensification of dance movement. In other genres, the metric layers are established from the beginning, so that the complex mesh over time appears static and basically only the inherent patterns within a summation meter are perceived, as in the examples discussed above. In general, the superposition of different periodicities in numerous genres of African music can be understood as the basic constant.

In contrast, the simultaneity of different meters in European music, at least within the framework of the common-practice tonality of about 1600 to 1900, most often fulfills a very specific formal function, namely that of a metric dissonance. This dissonance deliberately distinguishes itself from the metric consonance of (established or imagined) rhythmic constellations supporting the prescribed meter, so that one can meaningfully speak of "conflicting meters" in 
2. Displacement dissonance (shift of focus by syncopation/accentuation, successive conflicting meters)

a. without changing the group length (Beethoven, Symphony no. 3, i, mm. 46-52, melody instruments)

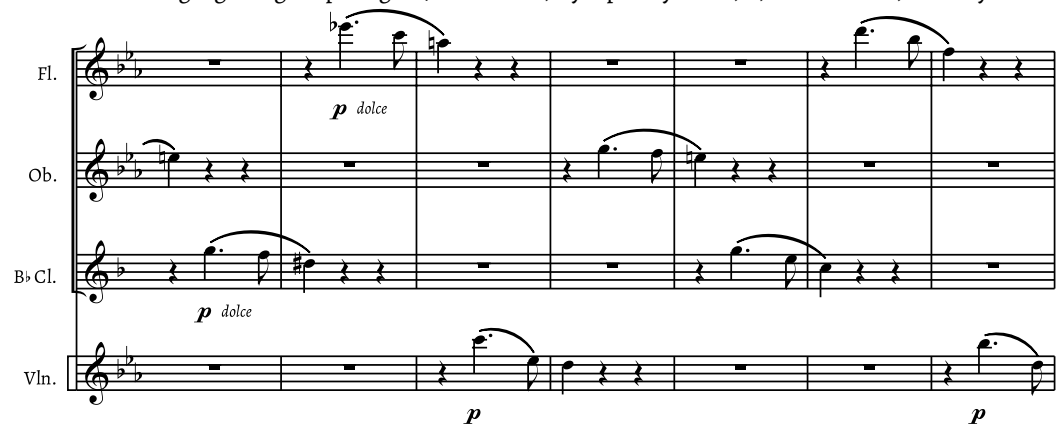

b. with change of group length (Beethoven, Symphony no. 3, i, mm. 250-257, strings)

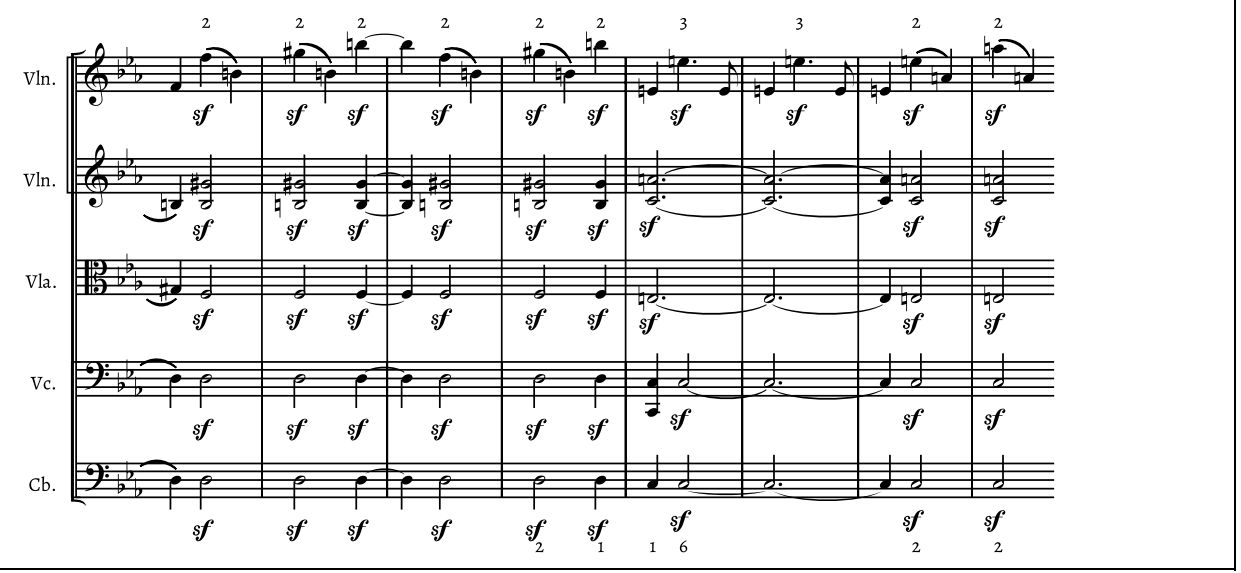

this context. Yet, numerous examples can be found in music history, particularly before 1600 and after 1900, in which certain affinities with the African models become visible.

Following on from Harald Krebs, one can distinguish two basic types of metric dissonance (Table 5.9). ${ }^{112}$ In a metric grouping dissonance (or simultaneous conflicting meters) a continuous shift in emphasis is brought about by ongoing and possibly irregular syncopation or accentuation, while in a displacement dissonance (or successive conflicting meters) different metric groupings or accents are superimposed, leading to a continuous shift of metric emphasis. ${ }^{113}$ In each case, subcategories of increasing complexity are to be differentiated, with hybrids occurring frequently. Each displacement dissonance is at the same time a metric grouping dissonance relative to the (possibly inaudible) periodicity of the prescribed meter.

112 See Yeston, The Stratification of Musical Rhythm, Krebs, "Rhythmische Konsonanz und Dissonanz," Krebs, "Some Extensions of the Concepts of Metrical Consonance and Dissonance" and Krebs, Fantasy Pieces. London, "Rhythm in Twentieth-Century Theory," 708 provides a useful summary.

113 This distinction is particularly linked to the terminology first developed by Krebs in "Rhythmische Konsonanz und Dissonanz" and further developed in Fantasy Pieces, 31-45. Krebs acknowledges the origin of these terms in Kaminsky, "Aspects of Harmony, Rhythm and Form in Schumann's Papillons, Carnaval and Davidsbündlertanze," 27. 
Of the categories and examples provided in Table 5.9, the basic meter remains intact in category 1a, but is subdivided by the dissonant combination of quarter and eighth triplets, which creates a floating character that the mathematically equivalent notation of eighths and quarters in a 6/4 meter could surely not generate. This points to the important fact that metric dissonance can have profound implications for performance and is crucial for a particular aspect of virtuosity and the impression of "levitation" in Romantic piano music. In category $\mathrm{lb}$, the $2 / 4$ grouping in the left hand faces a $3 / 4$ grouping in the right and both groupings return periodically and therefore realign after two measures, that is, they sound together again after $2 \times 3 / 3 \times 2$ pulses. ${ }^{114}$ We find a more complex case in category $1 \mathrm{c}$, where the periodic $2 / 4$ grouping of the left hand is overlaid with an aperiodic sequence in the right hand. The grouping dissonance becomes so intense here that Schumann inserts a $4 / 4$ measure (not indicated) in the third measure of the specified section in order to re-synchronize the layers with the prescribed meter - a moment that actually aptly exemplifies an interaction of grouping and displacement dissonance.

The second basic form of metric dissonance, displacement dissonance, is illustrated here by two widely cited examples from the first movement of Beethoven's Eroica. In category 2a, the group length of the basic meter $3 / 4$ is retained, but shifted by one beat to create a syncopation that turns into a continuing displacement of the metric grid, while in category $2 b$ - analogously to the right hand in ic - the grouping lengths change constantly, which increases the metric destabilization or the degree of metric dissonance. As frequently observed, harmonic and metric dissonances here reinforce one another, marking a crucial moment in the movement's formal process.

\section{Toward an Intercultural Theory of Musical Time and Its Historiographic Implications}

I will refrain here from further exploring the history of polymeter in Western music, as I have done in earlier versions of this chapter. ${ }^{115}$ Much of this is familiar from a variety of studies and does not need to be repeated here at length. ${ }^{116}$ The implications of hemiolic or sesquialtera proportions to provoke metric ambiguities might be traced back to ancient Greek theory, where the term hemiólion is found in Pythagorean tuning theory and already transferred to five-beat rhythmic patterns by Aristoxenus. ${ }^{117}$ The ambiguity is made explicit in mensural notation where especially the coloring of notes can be associated with hemiolic re-

114 See Krebs, Fantasy Pieces, 33.

115 Compare this part in the Cerman edition of the present book (Utz, Komponieren im Kontext der Globalisierung, 300-316) which is, as the entire chapter, based on an earlier 2009 publication $(\rightarrow$ Appendix).

116 Grove Music Online offers articles on hemiola and proportio sesquialtera (see Rushton, "Hemiola," Hiley, Stanford and Laird, "Sesquialtera"). A systematic study of hemiolysis and polymeter in European music has so far taken place mainly on the basis of isolated case studies. See among others Ham, "A Sense of Proportion: The Performance of Sesquialtera ca. 1515-ca. 1565," Willner, "Metrical Displacement and Metrically Dissonant Hemiolas," Willner, "The Two-Length Bar Revisited: Handel and the Hemiola," Lewin, "On Harmony and Meter in Brahms's Op. 76, No. 8," Cohn, "Complex Hemiolas, Ski-Hill Graphs and Metric Spaces," Cohn, "Metric and Hypermetric Dissonance in the Menuetto of Mozart's Symphony in G minor, K. 550," Cohn, "The Dramatization of Hypermetric Conflicts in the Scherzo of Beethoven's Ninth Symphony," Berktold, "Zur Satztechnik der Hemiolenbildung in Klaviersonaten Mozarts," and Plyn, Die Hemiole in der Instrumentalmusik von Johannes Brahms. More general studies relevant in this area include the classic Apel, The Notation of Polyphonic Music, 900-1600 as well as Schachter, "Rhythm and Linear Analysis," Kramer, The Time of Music, Hasty, Meter as Rhythm, Maurer Zenck, Vom Takt, and particularly Mirka, Metric Manipulations in Haydn and Mozart.

117 Aristoxenos, "Elementa Rhythmica, Book II," 189. 
lationships, eventually resulting in prolonged phases of polymensural structures in music by Johannes Ciconia and his contemporaries. For Baroque music Channan Willner distinguishes between "cadential hemiolas," "contraction hemiolas," "expansion hemiolas," and "overlapping hemiolas" in Handel and Bach, thus making it clear how diverse and sometimes formative hemiolic structures could be in the eighteenth century. ${ }^{118}$ Further elaborations of hemiolas in the classical style and the nineteenth century arise from "dance" movements, particularly the courante and minuet, and eventually result in famous examples of metric dissonance in the Minuet from Mozart's Symphony G minor K. 550, the first and third movements of Beethoven's Eroica, Schumann's piano cycles, Chopin's Fourth Ballade, as well as Brahms's late Klavierstücke and the first movement of his Third Symphony. ${ }^{119}$

In the most complex of these examples, such as the Chopin, more than two metric layers are established, anticipating the subsequent practice of superimposing structures in differing meters in the twentieth century. More generally, one can distinguish two main tendencies in the unprecedented wealth of rhythmic-metric dimensions since 1900 that are conjoined in the late music of Ligeti. On the one hand, the metric organization might tend to increase in complexity by means of multiple superimpositions, up to the point at which they transform into a texture that we can no longer conceive of metrically in any specific sense. On the other hand, metric structures can be somewhat overemphasized, be it through clear tonal or registral structuring, that allows their friction, interaction, and internal dynamics to be perceived. ${ }^{120}$ In works such as Charles Ives's Fourth Symphony (1910-16) ${ }^{121}$ and Universe Symphony (1911-28), Karlheinz Stockhausen's Gruppen (1955-56), or Bernd Alois Zimmermann's Die Soldaten (1958-64), we can witness both tendencies in permanent interaction with the polyphony of meter and/or tempo exposed and concealed at irregular intervals. In the Universe Symphony, Ives conceived of a "basic unit," a macro-metric period symbolizing the "pulse of the universe," that is cyclically overlaid with ever new metric layers until a structure of twenty different layers is reached. The arrangement for percussion orchestra entitled Life Pulse Prelude by Larry Austin (1984) uses different tempo layers to realize this polymeter for practical reasons. ${ }^{122}$ The pulses are sent to the players via click track. In his Memos, Ives worked intensively on questions of the feasibility and perceptibility of such stratifications:

The listener, if he tries enough, will get the composite effect that's wanted, while each player concentrates on his particular meter, hearing the others as secondary sounds, at least while practising [sic] them. [...] if the different meters are each played by groups of different sounding units, the effect is valuable, and I believe will be gradually found an important element in deepening and enriching all of the depths of music, including the emotional and spiritual. ${ }^{123}$

118 Willner, "The Two-Length Bar Revisited: Handel and the Hemiola."

119 See Ligeti and Boulaine, "Stilisierte Emotion," 54. The passage from Chopin's Fourth Ballad (mm. 175-178) referred to by Ligeti is also dealt with in an essay by Douglas R. Hofstadter that obviously pointed Ligeti to the respective passage: Hofstadter, Metamagical Themas, 179 (the article first appeared in 1982 in Scientific American).

120 See Utz and Nonnenmann, "Rhythmus, Metrum, Tempo" for an overview.

121 See, among others, Gail, Charles E. Ives' Fourth Symphony, 308-434 and Gail, "Die 4. Symphonie von Charles Ives," 73-87, and Utz, "Bernd Alois Zimmermann und Charles Ives," 126-129.

122 See Austin, "The Realization and First Complete Performances of Ives' Universe Symphony."

123 Ives, Memos, 125. 
Both the systematic considerations of summation meter and metric dissonance as well as the historical examples of conflicting metric formations in Western music make it clear that a complex reflection of the simple hemiolic principle of juxtaposed or superimposed metric periodicities is found in various eras and cultural contexts. These properties thus can by no means be considered a specific aspect of recent music, although twentieth-century composers, often inspired by Stravinsky and Bartók, offer an extraordinary variety of examples. Many genres of African music seem to imply comparable types of superimposition of meter-like periodicities as a fundamental prerequisite for music making, even though both the conceptualization of the performer and the perception of the listener may be more focused on the patterns resulting in the summation meter than on the superimposition itself. At this point, it seems important to stress that, in contrast to a strong focus on "emic" approaches, that is, on the musical structures as imagined and conceived by the performing musicians (and local audiences) in ethnomusicology, an intercultural approach aiming at global historical and theoretical perspectives must go beyond these restrictive premises, as Michael Tenzer has most notably done in his essays exploring musical temporality by systematically referring to repertoire of different cultures and historical periods. ${ }^{124}$ While it is clear that some of Tenzer's arguments risk overgeneralization, his typology of musical temporalities (though it conspicuously lacks a type that could apply to polymeter or polytempo) would surely make a good starting point for rethinking musical time in broader terms than has been done until now.

A dimension of polymeter that may be further explored in the intercultural universe is the idea of musical spatiality as it emerges particularly strongly in polymetric music of the twentieth century with Ives, Mahler, Zimmermann, or Ligeti, but which also resonates with African genres, as they are often characterized by an anti-teleological, quasi-spatial basic principle ${ }^{125}$ with which Ligeti's "frozen turbulence" has close affinities. Even in most of the other examples discussed here, metric confusion produces a temporal delay, a congestion of energy, and sometimes a momentary stasis, which, however, is not always to be understood as a tension that requires resolution. Thus the concept of "metric dissonance" should reasonably be limited to the three or so centuries of common-practice tonal music.

In any case, one can take the history of polymeter as proof of the thesis resulting from the considerations in Chapter II.I that music history, especially from an intercultural perspective, is not a linear progression from simple to more complex forms. On the contrary, it becomes clear from the examples discussed here that - as in many other areas of music - the different concepts and musical contexts of metric conflict and overlays describe a network of references that embody the most diverse, sometimes unexpected and surprising connections as they were drawn again and again by composers such as Ligeti in the twentieth and twenty-first centuries. It is more than a mere bon mot to say that polymeter constitutes a kind of "metric dissonance" in the structure of music history.

124 See Tenzer, "A Cross-Cultural Topology of Musical Time" as well as the earlier "Temporal Transformations in Cross-Cultural Perspective."

125 See Arom, African Polyphony and Polyrhythm, 17. 


\section{Intercultural Tension in Music by Chaya Czernowin and Isabel Mundry: Variations on Identity and Musical Meaning}

A phenomenon crucial for the perception of new music, and which is featured prominently in Helmut Lachenmann's sound typology, is the transition between structure and texture: the more information is conveyed at once in a musical context, the more it is perceived in terms of "global" characteristics - that is, structure (conceived as an interaction of individual sound elements or "families") morphs into texture (in which one global characteristic dominates) - and the reverse process is, of course, equally relevant. Although this principle was particularly wellknown and much explored in "sound composition" during the 1960s, it plays a certain role in listening to almost any polyphonic or multi-layered music. Complex and dazzling musical stratification was derived by many composers in the twentieth century from the legacy of Romantic orchestral magic $(\rightarrow$ VI.1). Such a "dialogue" between layers can give rise to a morphological vividness that communicates itself directly, even without the framework of tonal harmony.

In the music that emerged from the fault lines of cultural globalization from the end of the nineteenth century, it was, as we have seen, a much-used procedure to conceptualize the differences between cultural idioms in the form of such a layered structure: groups of instruments and/or musical timbres were often arranged "culturally" (and usually differing compositional techniques applied to such groups mirrored this cultural segregation). In Tan Dun's Ghost Opera (1994), the string quartet was culturally "identified" by the $\mathrm{C} \#$ minor prelude from volume 1 of Bach's Well-Tempered Clavier, the Chinese pipa by the Chinese folk song Xiao bai cai. The more such musically "cultural" layers are combined, the more they become "anonymized" in a global sound and dissolve into a "metacultural" texture, or else, if necessary, a "secondary" texture might develop out of hierarchies in which certain strata follow others or are clearly subordinate to them $(\rightarrow$ III.5). A fundamental criticism of such processes could be made based on the argument that every stratification ultimately reflects a "politics of polarity" that Homi K. Bhabha sees overcome only by a "third space of articulations" in which cultural hybridity can arise $\left(\rightarrow\right.$ I.3). ${ }^{126}$ Is it possible to create such a "third space" in music?

\section{Chaya Czernowin's Excavated Dialogues - Fragments: Is Cultural Hybridity Musically Representable?}

In Chaya Czernowin's Excavated Dialogues - Fragments (2003-04) for seven Chinese and nine Western instruments, cultural hybridity as a potential is presupposed, but at the same time deliberately limited. Using the compositional principle of fragmentation, the composer intends from the outset to leave no space for cultural idiomatics, even where it should appear unintentionally. The original cultural codes of the instruments can at best flash up as vague intuitions, characterized by instrument-specific performance gestures, for example. Czernowin's antiessentialist approach first appears in the division of the ensemble into three groups - wind instruments, plucked instruments, strings - each containing both Chinese and European instruments. Indeed, the instruments are not subject to any polarized categorial separation. The four movements of different lengths, with a total duration of about ten minutes, are based on various "dialogues" within these groups: in the first movement - hardly perceptible - between the mouth organ sheng and the bass trombone, in the second, the most complex and longest movement, initially between the high bamboo transverse flute bangdi and the oboe as well as 
between the knee fiddle erhu and the violin, later between the dulcimer-zither yangqin and the piano, in the third movement between the bamboo flute dizi and the (Western) flute, later the trombone, and in the fourth movement again between erhu and violin.

It is obvious that Czernowin does not trust the concept of a balanced dialogue between equal partners and, consequently, cut and rearranged the dialogue sections during the compositional process. Against this background, one can hear an increasing "talking at cross purposes" in the second movement: a self-contained, elegantly complementary opening cadenza of Chinese and European string instruments (erhu, zheng, string trio, Ex. 5.17a) in the first three measures is soon followed by a wind instrument section (mm. 11-29, Ex. 5.17b) in which the bangdi and oboe try to drown each other out like "angry speech" and with "aggression" (instructions in the score, m. 13), but in the end synchronize in a "cadence-like" phrase. The dialogue layer between the yangqin and the piano, starting ppp at measure 20, finally disappears in a field of pure unpitched string noise before resuming from measure 38 (Ex. 5.17c), where the instruments now "aggressively" interrupt one another (note in the score, m. 38), surrounded by a "deafening" tutti chord that eventually silences everything.

In this way, Czernowin explicitly tries to disrupt the identity discourse: "The different dialogues between alternating instruments merge into one another and decompose one another - as though they had been buried in the ground for a long time where they had lost their original separate identities." 127 The composer explained that in this process, she deliberately ignored the East-West conflict temporarily in order to emphasize the "abyss" between East and West in the collision of the fragmented material. ${ }^{128}$ She seems to want to make it audible in the music that hybridization - in the sense of Peter Burke's critique of this term $\rightarrow \mathrm{I} .3)^{129}$ - contains an element of violence, and intends to let the seemingly neutral-objective observer position collapse, from which the opposites appear to flow into each other naturally.

The perceived sonic experiences, not least based on "gestural types" in Robert Hatten's $\operatorname{sense}^{130}(\rightarrow$ III.5), appear to be connected in a causal chain, with syntactic consequences: timbral blending, balanced dialogues, or independent monologues, divergence, conflicts, or even aggression between the instrumental or sound groups are detectable spontaneously and intuitively. Czernowin's archaeological idea of unearthing remnants of a former dialogic practice can be associated with the pre-linguistic character that Hatten presupposes for musical gestures as a whole and on which their immediacy rests. ${ }^{131}$

One may object that semanticizations of musical organization through fragmentation and montage are not directly comprehensible to the same extent as the gestural levels. They represent a conceptual sphere of abstraction, at least limited in its effectiveness by the cognitive relevance of hierarchically salient events. Although the attempt made by Czernowin to question cultural hierarchies may be successful at first sight, it cannot prevent the resulting work, its key events, and its arrangement of sound elements building a new hierarchical environment that overlays the culturally hybrid space of identities. This raises the question of whether harmonic, tonal, and rhythmic models, which refer to certain listening and intellectual traditions (such as contemporary, classical, Chinese, or popular music) do not again produce a new hierarchical

127 Czernowin, "Excavated Dialogues - Fragments."

128 Czernowin, "Der Dialog als ein kompositorisches Modell," 168-170.

129 Burke, Cultural Hybridity, 54-55.

130 See Hatten, Interpreting Musical Cestures.

131 Ibid., 108-110. 
Example 5.17: Chaya Czernowin, Excavated Dialogues-Fragments, second movement, a. mm. 1-3 (string instruments); b. mm. 7-19 (bangdi/oboe); c. mm. 37-42 (tutti)
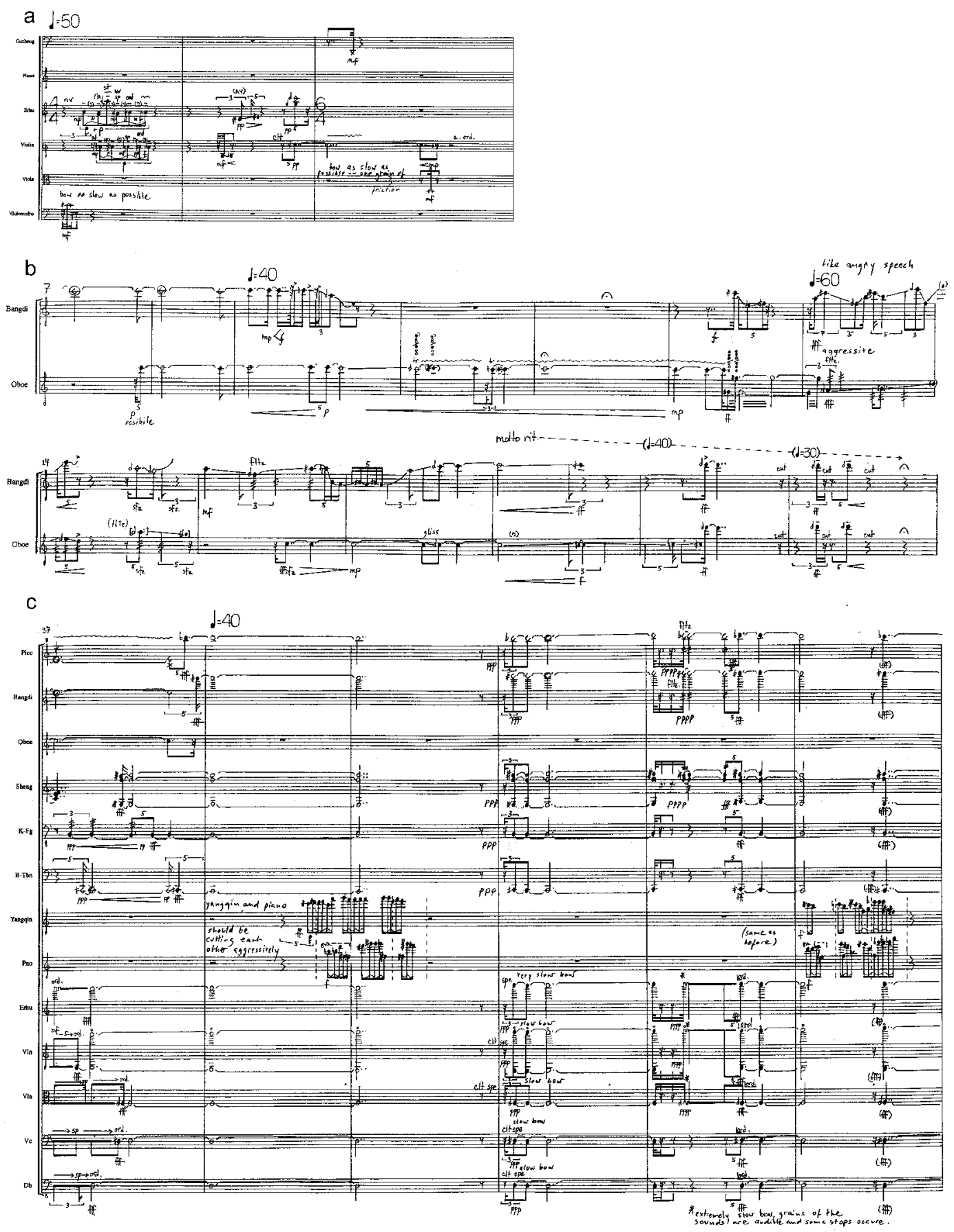
discussion of power and exclusion. Without them, however, musical articulation is hardly possible - a productive paradox that also applies to the following example.

\section{Isabel Mundry's Ich und Du: Identity Riddle}

Isabel Mundry sees her music as permeated by intangible layers of meaning characterized by blurriness, ambivalence, doubt, and suspension of time. ${ }^{132}$ In Mundry's music, meaning arises from fleeting, passing, and unfinished states of sound, time, and space. If this aesthetic stance seems to resist any signification of music in a sociopolitical sense, a tendency in twentieth-century music criticized by Susan McClary and many other scholars, ${ }^{133}$ it nevertheless goes far beyond a simplistic ideal of autonomy. Mundry evokes Nelson Goodman's concept of metaphorical exemplification ${ }^{134}$ as a link to the desire in her music to open a horizon beyond "pure listening," to create musical situations that can be related to experiences, recollections, or emotions from everyday life. She quotes the piano accompaniment of the song Die Krähe from Schubert's Winterreise to illustrate this principle: the piano figure creates "an experiential correspondence between our sensory perception of the music and what we experience during a walk when birds circle above our heads. ${ }^{135}$ More formally than Mundry, Christian Thorau describes the transfer of Goodman's concept to musical contexts as a "mode of reference that is linked to the exhibited sensual properties of the sign, i.e., implanted in the music [Mundry's reference to Schubert's piano accompaniment], while at the same time transcending it in the manner of a metaphor [the correspondence between musical structure and the experience of circulating birds]."136 However, Mundry's intention is to relate to experiences of daily life without resorting to conventional musical gestures, figures, or topics such as Schubert's. Her attitude thus blends in with the image of numerous compositional approaches since the 1970s that combine a demand for their social relevance with the insistence on a certain degree of auto-referentiality $\rightarrow$ I.2).

The title of Mundry's 2008 composition Ich und $\mathrm{Du}$ for piano and orchestra clearly indicates her intention of referentiality. It stands for the construction and deconstruction of identity, the theme of the essay Watashi to nanji (I and You) by the Japanese philosopher Kitarō Nishida (1870-1945), first published in 1932, which Mundry references. ${ }^{137}$ In his texts, Nishida, a princi-

132 See Hiekel, "Über Isabel Mundry."

133 See McClary, "Terminal Prestige" and Born and Hesmondhalgh, "Introduction: On Difference, Representation, and Appropriation in Music."

134 See Goodman, Languages of Art.

135 Mundry, Resonanzverhältnis zwischen kompositorischem Ich und Cesellschaft, 21 ("erzeugt [...] eine Erfahrungskorrespondenz zwischen dem, was wir in der Musik sinnlich wahrnehmen, und dem, was wir von einem Spaziergang kennen, nämlich daß über unseren Köpfen Vögel kreisen.").

136 Thorau, "Interagierende Systeme," 77 ("Referenzmodus, der an die gezeigten sinnlichen Eigenschaften des Zeichens gebunden, also in der Musik verankert ist, und diese zugleich nach Art einer Metapher übersteigt."). In this text and other publications Thorau has connected Goodman's theory of symbols with a coherent theory of musical analysis. See above all Thorau, Vom Klang zur Metapher, 85-116.

137 Nishida's philosophy has received considerable attention in recent contemporary music $(\rightarrow$ II.6). It exerted a major influence on Hans Zender (one of Mundry's teachers), who in turn acquainted Helmut Lachenmann with Nishida. The latter referred to Nishida's philosophical positions ( $\rightarrow$ IV.2) and quoted text fragments in NUN for flute, trombone and orchestra (1999/2002) (see Hiekel, "Interkulturalität als existentielle Erfahrung," 77). Independently of Zender and Lachenmann, I realized a 40-minute composition based on Nishida's essay Place [bashō] (1926) termed Site (2001) for gagaku ensemble and live electronics during a two-month residency at the Akiyoshidai International Art Village. 
pal exponent of the Kyoto school, explores classical topics of Western philosophy such as logic, subject-object dichotomy, knowledge, and identity, with his later texts (after I and You) increasingly reflecting on cross-cultural thought figures in these fields. The key ideas of I and You are succinctly summarized by Rolf Elberfeld:

The question of the relationship between I and You is dealt with at different levels. [...] Since we encounter the absolute negation at the bottom of our self-determination, we encounter in ourselves the absolute other, where a You or an absolute Other is already given within myself, so that the absolute Other in myself opens up access to the You of the other person. That is, the absolute difference between I and You becomes animated, as we both realize within ourselves the absolute Other, and thus I become I and You become You. ${ }^{138}$

Thus, as in Czernowin's work, complex philosophical-aesthetic premises are juxtaposed with a purely instrumental work, which, in contrast to Excavated Dialogues - Fragments, is based on an ensemble and genre - the piano concerto - with a long and influential historical background. Mundry's introductory text plays in a characteristic way with this interlocking of philosophical-semantic and music-immanent levels:

The composition is not about a biographical I and You, but rather addresses the I as a place of centered perception and You as a place of projection. [...] The frame suggests thinking of the solo instrument as the I and the orchestra as the You, but the music is about shifts and reinterpretations, about demarcations, encroachments, attributions, or self-determination. In this respect, the piano can become You while the orchestra stands out in front of it as an I, or it can become alien to itself by mutating from intimate sound to an externally determined machinery. ${ }^{139}$

To approach such musical processes, a morphosyntactic approach ${ }^{140}$ seems particularly appropriate: the contrast between the concentration of the overall sound on a single point in time and space, as well as the "drifting out" of the sound through the three almost identical orchestral groups, take on the force and precision of physical gestures. The connection between these two basic events, which already clearly emerge on the first page of the score (Ex. 5.18), is completed by a third, which can be added to the other two events as an echo. Point, proliferation, and echo form an equally simple and productive material that almost forms the sole basis for the nearly 15-minute work.

138 Elberfeld, "Einleitung," 11 ("Die Frage nach dem Verhältnis von Ich und Du wird auf verschiedenen Ebenen bearbeitet. [...] Da wir im Grunde unserer Selbstbestimmung auf die absolute Negation stoßen, treffen wir in uns selbst auf das absolut Andere, wodurch in mir selber bereits ein Du bzw. ein absolut Anderes gegeben ist, so daß sich durch den absolut Anderen in mir selbst ein Zugang zum Du der anderen Person eröffnet. Das heißt, die absolute Differenz zwischen Ich und Du wird lebendig, indem wir beide in uns selber den absolut anderen realisieren und so Ich Ich werde und Du Du wirst.").

139 Mundry, "Ich und Du" ("In der Komposition geht es nicht um ein biografisches Ich und Du, sie thematisiert vielmehr das Ich als einen Ort zentrierter Wahrnehmung und das Du als einen Ort der Projektion. [...] Die Disposition legt nahe, das Soloinstrument als das Ich und das Orchester als das Du zu denken, doch die Musik handelt von Umschichtungen und Umdeutungen, von Grenzziehungen, Übergriffen, Zuschreibungen oder Selbstbestimmungen. Insofern kann das Klavier zum Du werden, vor dem das Orchester sich als ein Ich abhebt, oder es kann sich selber fremd werden, indem es vom intimen Klang zur fremdbestimmten Maschinerie mutiert.").

140 For the foundations of the morphosyntactic analytical method, see especially Utz, "'Liberating' Sound and Perception" and "Time-Space Experience in Works for Solo Cello by Lachenmann, Xenakis and Ferneyhough." 
The composer distinguishes five sections that pass through "Ich" and "Du" in five modes: intersection, self-interrogation, landscape, attribution/loss of self, and permeability. ${ }^{141}$ Is this narrative thread plausible? From a morphosyntactic point of view, three phases in particular can be distinguished. Several times in the course of Ich und $\mathrm{Du}$, a pizzicato impulse appears, a symbol of coherence, synchronicity, and identification, which can be assigned an energetic "trigger" function. The opening piano pizzicato (G4, m. 1, Ex. 5.18) first triggers a sequence of four further pizzicato points of increasing intensity (m. 2/III, m. 3/I: vla., vc., Bartók pizzicato, m. 4/I, left: Bartók pizzicato behind the bridge, m. 5/I-III: pizzicato in high position ${ }^{142}$ ), the latter of which finally causes a first cascade-like proliferation (m. 5). In the first phase, the sound cascades derived from the proliferation in measure 5 become increasingly dense (after an initially hesitant release from measure 10) and from measure 51 blend into a continuous virtuoso figuration in the solo instrument, shaded by the orchestral groups in an extremely fragmented instrumentation. This impression is often reversed, and the piano appears as the shading of a dominant orchestral sound - a complex, field-like sound transformation in which no sharp delimitation of individual "sound events" can be identified.

After this figuration is slowed down by quarter-note pulses marked by chords, the second phase begins in measure 140, again marked by a piano pizzicato in measure 142 (now F4). It is characterized by long, resonant single tones (and thus by clearly marked sound events) over a noise-saturated background, has a reflexive character, and transfers the echo principle from the micro- to the macroformal level. The third phase begins in measure 167 again with the piano pizzicato (now A4) and is characterized by the attempt of the piano to pick up the cascading figurations from the first phase again. It seems essential that, in the now more chamber-musical environment, the colors of the cimbalom and the vibraphone, which are "competing" with the piano (m. 174), are more pronounced than in the tutti constellations of the first phase, and the energetic gestures of the piano are increasingly deformed. With the expansions in measures 243 to 244 and 249 to 250 the music ends in a long composed-out echo (mm. 253-269), thus again transferring this central morphological principle to the macroformal level.

In conjunction with the title of the work, it is undoubtedly appealing to play with the identities given by Mundry and Nishida's text in relation to this musical unfolding. One aspect in particular seems to stand out: that of ambiguity. For whether the interlocking proliferations of piano and orchestra in the first phase are now seen as mutually reinforcing their respective identities (in one case "Ich"/piano, in another case "Du"/orchestra - or vice versa) or their doubts in the sense of a "permeability," as Mundry puts it only for the end of the work, can certainly not be decided unequivocally. In any case, Mundry's identity discourse has found a suitable area for the concept of metaphorical exemplification, in which referentiality can be held sufficiently in limbo and an overly clear symbolic assignment of the material is avoided.

It does not seem coincidental that Thorau also explains the "referential complexification" of metaphors in art through the interlinking of reference levels between a work's title and the musical structure. ${ }^{143}$ An interpretation of Mundry's "piano concerto" - and concertante in the sense of "competing" is what the solo instrument and orchestra are all about in this work would certainly lead in different directions without the title. The rather ephemeral character of Mundry's referentiality is thus fundamentally different from Czernowin's attempt to convey

141 Mundry, "Ich und Du."

142 Roman numerals designate the three orchestral groups.

143 Thorau, Vom Klang zur Metapher, 201-205. Thorau here discusses Robert Schumann's piano piece Vogel als Prophet from Waldszenen op. 82. 
Example 5.18: Isabel Mundry, Ich und Du, mm. 1-5

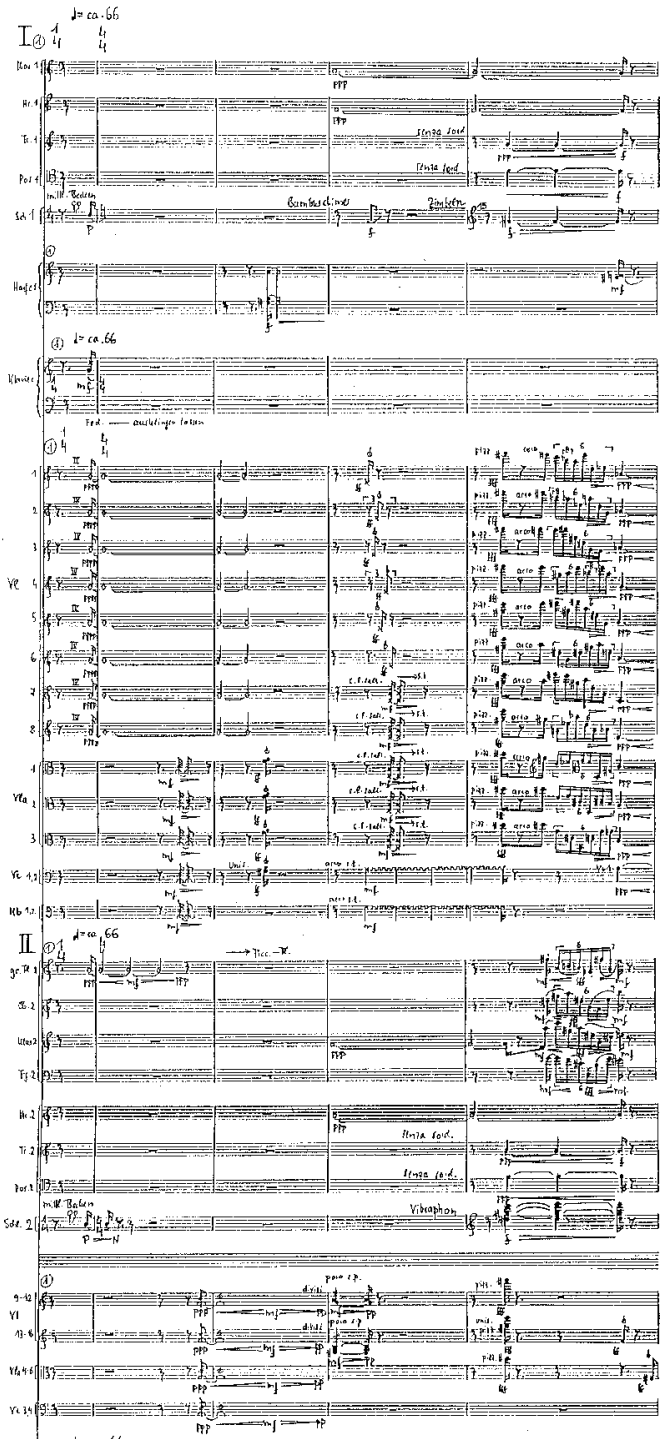

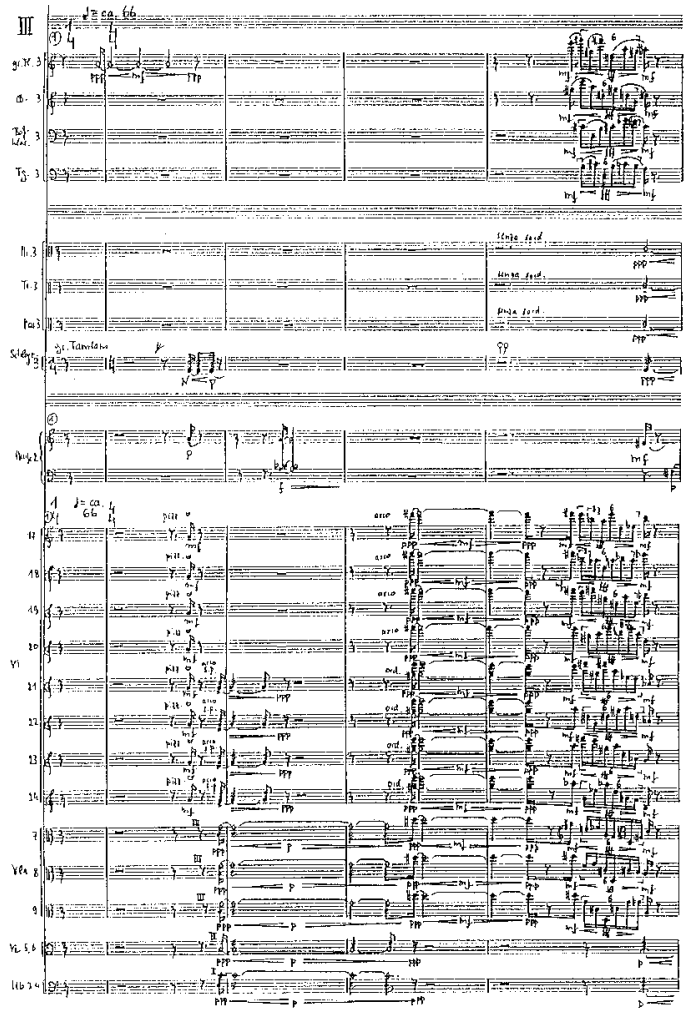

Copyright $(2008$ by Breitkopf \& Härtel, Wiesbaden

cultural conflict through a gesturally effective vocabulary. What is common to both compositional designs, however, is the effort to prioritize the emergence of musical meanings from an interplay between referential and transcendental levels, and with the help of morphosyntactically tangible musical elements. 


\section{The Limits of Musical Signification}

The contradictions arising between the musical contexts that emerge from Czernowin's and Mundry's sound events and the possibilities of signification, of "worldliness,"144 demanded and approached by the composers, can generally become productive for a theory of intercultural composition in the twentieth and twenty-first centuries. These conflicting lines should not be surprising, as they point to a fundamental music-specific ambiguity and a persistent riddle character of the musical work of art, which no cleverly equipped theory should try to dissolve. The context of reflexive globalization ( $\rightarrow$ I.2) and the references to metaphor theory and semiotics also show that such a theory faces quite different challenges than, for example, a theory of common practice tonal harmony. The intensified concern of many composers for perception and meaning since the 1980s, as well as an insistence on the (much-debated and doubted) social relevance of contemporary music, pushes the necessity of interdisciplinary networking into the foreground. It also becomes obvious that there can be no more "historically informed" analytical practice or theory, in the sense that recently emerged for music of the fourteenth to nineteenth centuries based on source criticism and period theory. For apart from a problematic reduction to authorial perspectives ( $\rightarrow$ II.1), the "sources" of the composers, the traces of the compositional process, however minutely they might be reconstructed, can always elucidate only a small portion of the processes that take place in the intermediate domain of structure, perception, and meaning - domains increasingly emphasized as essential also by the composers themselves. Nevertheless, structural analysis will continue to form an essential component in the theory of post-tonal music. Linking it to music psychology, ethnomusicology, and related fields appears to be a deciding factor, enabling an expanded, contextual understanding of new music in a global context. 


\section{Reflections on My Own Composing as a Search for Traces in the In-Between}

In turning my attention toward my own attempts at composition, I in no way intend to hold them up as any form of "model," nor do I intend to ascribe any "historical" value to my work. It has been a long-standing fact for me that the musicological and compositional examination of questions of intercultural fluctuation, the problems of the different culturally coded idioms, languages, listening styles, and sound producers, continue to run parallel to one another. It is difficult from my perspective to judge whether, and how, artistic and scholarly activities may have influenced one another. In any case, it was always clear (and many composers can confirm this from their own experience) that theoretical and historical knowledge - even in the form of the quasi-ethnomusicological "competence" sometimes demanded in the previous chapters - are ultimately of little help at the moment of composing, and often take a back seat. Rather, my compositional thinking has grown from encounters with performers, fellow composers, and listeners, in discussions about crossing borders, drawing boundaries, possibilities, and dead ends of dialogue. If there is a basic feature of my compositional work that resulted from these continuous interactions, then perhaps it is the principle of a "polyphony of meanings" outlined in the third and especially fourth sections of this chapter, which can be found in the mostly multilayered, "multitextual" works to be discussed. At this point, it is particularly important for me to offer the possibility of perceptual exploration: recordings of all seven of my own works discussed below are available online. ${ }^{1}$

\section{Layered Fabric, Intertextuality, and Cultural Context: From Striated to Open Space}

It may be surprising that, despite the omnipresence of a shift toward stratified thinking in new music from its beginnings around 1900 until today, there have been only tentative attempts to approach a theory of musical stratification. While this may be because stratification methods in music theory and analysis are often subsumed under more conventional terms such as structure or polyphony, it may also be due to the fact that they are usually difficult to generalize owing to some inherent breaches of rules and limits. A distinction between stratification methods and polyphonic methods would be established, for example, in the fact that a

1 https://soundcloud.com/chr_utz; https://www.youtube.com/watch?v=3JVDCA3tmds. Weblinks to individual pieces are provided below in the respective sections of this chapter. 
higher-level rule or reference system (such as the different types of tonality or counterpoint), which is always unspoken in the latter, can very easily be undermined by the former. In other words, one could speak of layered phenomena in music when individual levels emerge from the structure of the music simultaneously as autonomous, individualized "personae," their heterogeneity can be heard, and their cross-relationship is not trivial, self-evident, or inherent in the system. The constant oscillation between such processes of contouring individual elements and the change in the textural impression of an overall sound is characteristic of many compositional layering processes and can be linked to Helmut Lachenmann's distinction between structural and textural sound; Lachenmann's emphasis on the interlocking of different sound types is especially relevant in this context. ${ }^{2}$ In the structural sound, the relationship between detail and the whole is non-linear and oversummative, the overall character is not a blanket quality, but something "virtually new" that "requires formal projection in a temporal space that allows a listener to feel their way through it." It is precisely this processual nature, allowing sonic and formal conceptions to coincide in the structural sound, that must also be assumed for the stratification processes envisaged here. What is aimed at are not some automated schemes but networks that enable novel, surprising, and non-linear connections - a dimension that Lachenmann's well-known formulation of structure as a "polyphony of orderings" captures only insufficiently, since it tends to mark a territorialized, "striated" musical space, ${ }^{5}$ namely the (potential) control systems of the "orderings" organized by means of "polyphony." The aforementioned autonomy of the figures or "personae" linked by means of complex layering techniques, on the other hand, can sometimes turn them into independent musical texts, or - viewed in reverse - the intention to put different musical texts or contexts in nonlinear relationships with one another can lead to complex stratification procedures, eventually resulting in a far-reaching deterritorialization, an open musical space. The intertextuality that arises in this space stands out significantly from more conventional assemblage or collage processes but can temporarily adopt its vividness and alienation processes.

In this context, it is no coincidence that composers whose music developed "proliferating" tendencies, and was thus determined by increasingly complex stratification processes, attempted to sharpen the contours of tempo, metric, or timbral strata, which are usually difficult for listeners to grasp, with extraterritorial quotations or related intertextual reference techni-

2 Lachenmann, "Klangtypen der Neuen Musik," 20.

3 Ibid., 17-18 ("virtuell Neues"; [bedarf einer] "formalen Projektion in einen abzutastenden Zeit-Raum").

4 Ibid., 18 ("Polyphonie von Anordnungen"); see also Lachenmann, "Vier Grundbestimmungen des Musikhörens," 62.

5 The distinction between "striated" and "smooth" spaces goes back to Pierre Boulez's Darmstadt lecture Musikalische Technik (1960), which was published in 1963 (see Boulez, Musikdenken heute I, 58-61, 72-83). The two terms were taken up in Cilles Deleuze's and Félix Guattari's "nomadology" and extended to the analysis of the history of technology and power in the twentieth century (Deleuze and Cuattari, A Thousand Plateaus, 474-500, with explicit reference to Boulez 477-478). Boulez's position is paraphrased succinctly by Deleuze and Guattari: "In the simplest terms, Boulez says that in a smooth space-time one occupies without counting, whereas in a striated space-time one counts in order to occupy. He makes palpable or perceptible the difference between nonmetric and metric multiplicities, directional and dimensional spaces. He renders them sonorous or musical. Undoubtedly, his personal work is composed of these relations, created or recreated musically." (ibid., 477). In the following, instead of the "smooth" I speak of the "open" space, since the metaphor of the "smooth" - apart from general aesthetic-pejorative connotations - would contradict the "points of friction" in the layer structure that are aimed for here. 
ques. ${ }^{6}$ The background to this decision was the strong tendency toward texture that can be observed as a consequence of complex layering, for example in Bernd Alois Zimmermann's music. One problem with Zimmermann's quotation process could perhaps be seen in the deliberately decontextualized references to melodies and idioms that are forced into a rigorous structure and thus territorialized - their function is an affirmation, not a critique of the stratification structure. While their extraterritorial character becomes palpable within the basic idiom of Zimmermann's musical language, their system-disrupting potential is rarely fully established.

The relationship between stratification technique and intertextuality in the work of Charles Ives is even more ambiguous. Ives's witty musical puns create a paratactic, conflict-laden formal tension in which self-quotation, outside quotation, and pseudo-quotation become indistinguishable. The ambiguity of the references or fragments of quotes is primarily determined by the interlocking of symbolism and structure and thus leads to a unique proliferation, a constant tactile shifting of the musical space. The montage in the second movement of the Fourth Symphony (1910-16) at rehearsal number 8, consisting of a total of six hymn citations or allusions and a self-quotation, overlays the adagio material that started at rehearsal number 7 in 3/2 time, which symbolizes the march of pilgrims, with an allegro layer in $4 / 4$ time, from which we hear the heavily altered Beulah Land anthem in the trumpets (mm. 43-45, G major), then in the trombones (mm. 47-50, F major). After eight measures, the allegro layer suddenly disappears by means of a sudden fade-out and the adagio layer of the pilgrims, who have had soot blown in their faces by the passing allegro railway (an orchestral rendering of real-world sounds that Ives labeled "take-off"), can continue: a multidimensional layering with connecting lines between and within the tempo layers, from which contoured figures emerge again and again with a programmatic context that can also be related to basic philosophical concepts (the flat, continuous adagio layer corresponds to the string layer in The Unanswered Question [1906] and stands for a transcendent, timeless principle; the rushing allegro layer stands for the fleeting frenzy of the world). Ives's unique form of intertextual stratification can only be grasped by acknowledging how all these factors, which lead to an "overdetermination" of the musical structure, work together.

As indicated, the transcendentalist symbolism presents itself as the decisive motivation for Ives's multipolar stratification processes, but at the same time tends to dissolve this multipolarity in the affirmative, emphatic transformation of heterogeneity into a hierarchical structure - turning an open space into a striated space - as in the finale of the Fourth Symphony, or at the end of many other works, when the archetypical, primordial, "transcendental" ground of music remains as the only layer of music symbolizing "purity." This indicates that the complexity of a layered fabric and intertextual cross-references alone do not guarantee an analogous polyphony of meaning. Rather, what is decisive are the formal processes, however symbolically connoted, that are triggered by them.

With Zimmermann and even more with Ives, one can also observe how the musical texts linked in the layering process often turn into musical-cultural contexts. This process of association is often deliberately provoked by the composers, in some cases even relying on the rather clumsy effect of blatantly obvious references. While a quotation can thus impose itself on the listener in such a way that it flattens the layered fabric as a whole, and consequently

\footnotetext{
6 See on this and the following Utz, "Bernd Alois Zimmermann und Charles Ives."

7 See Giebisch, Take-off als Kompositionsprinzip bei Charles Ives.

8 Rathert, Charles Ives, 98 ("Überdetermination").

9 See Kramer, "Cultural Politics and Musical Form," 192-195.
} 
undermines it, the links to a broader context, intelligently articulated, might offer the advantage of basic ambiguity. This becomes particularly relevant where different musical-cultural contexts are to be related, for example in works for Western and non-Western instruments. Such a process raises the question of whether cultural difference - that is, heterogeneity - or the linking of what is different is emphasized by the stratification process, or in what way the cultural texts and contexts are made the subject at all $\rightarrow$ III.4).

As explored in detail in this book, East Asian composers have been observing this urgent cultural-historical tendency at least since Takemitsu's November Steps, seeking to counteract the gravitational effect and acceptance of Western music discourse with a special emphasis on the cultural non-commensurable. Meanwhile, one has clearly gone beyond the paradox of Takemitsu's work outlined earlier ( $\rightarrow$ III.4), with the composer striving for coexistence, a layering of Japanese solo instruments and Western orchestra, but ultimately composing a delicate web of soft transitions between these supposedly separate worlds. Takemitsu's transitions are linear, modulative, transformative, and thus remain in the "striated" space. They lack a "second reality," a polylinear layered fabric that points beyond such simple connecting lines between polarized entities.

This is not to say that the arrangement of such a fabric alone guarantees the desired openness of musical space. On the contrary, the high density of the suggested model seems to contradict the xieyi and liu bai principles in Chinese calligraphy, the idea - broadly developed beyond classical East Asian aesthetics - that the center of artistic meaning is where there is no script, no materiality. ${ }^{10}$ Here, one should not only look for density or multipolarity as manifest in the complexity of a score; concentration can also be found in the spaces between types of notation, oral instrumental traditions, and precise communication models, in a conceptual rather than a compositional layered fabric, as shown by the social-communicative experiments of Yūji Takahashi or José Maceda ( $\rightarrow$ III.4). In addition, there are also successful materialized intercontextual and intercultural stratifications, for example in the best works by Tan Dun like Orchestral Theatre I: Xun (1990) or some scenes from Marco Polo (1991-95), ${ }^{11}$ or in Qin Wenchen's $\mathrm{He}-\mathrm{Yi}$ (1999) for zheng and chamber ensemble $\rightarrow$ III.5). The common denominator of these works could perhaps be found in the fact that different, mutually heterogeneous idioms are constantly present through their "tone," without ever being directly quoted, whereby constant transformations of a newly heard Chinese musical tradition into formally constitutive approaches developed in the area of Western new music - and vice versa - take place. Tan Dun's works, of course, also show how fine the boundary is between such compactions and the moments already outlined above, in which the directness of the heterogeneous texts makes striated and open spaces collapse like a house of cards $(\rightarrow$ III.3).

This problem always comes to the fore when the quoted idioms appear in an unmediated and affirmative form - which is why the danger of slipping toward cultural essentialism (which might also have a nationalist accent) is never far away in the intercultural context. Within European music, such an unquestioning turn toward an apparently "secured" repertoire of

10 See Utz, Neue Musik und Interkulturalität, 235-237, 268-270 for a summary of traditional East Asian aesthetics relating to calligraphy. Elements of calligraphic practice and aesthetics have been taken up by a large group of both East Asian and Western composers including Isang Yun, Chou Wen-Chung, Tōru Takemitsu, Tan Dun, Toshio Hosokawa, and Hans Zender. For Chou Wen-Chung's calligraphy-informed compositional aesthetics see especially Everett, "Cesture and Calligraphy in the Music of Chou Wen-Chung" and Lai, "Calligraphy and Texture in Chou Wen-Chung's Music."

11 See Utz, Neue Musik und Interkulturalität, 460-474. 
musical signs or gestural types was already rejected in Brian Ferneyhough's criticism of the neotonal and neo-Romantic tendencies in European music during the early 1980 s. $^{12}$ Ferneyhough polemically referred to the faith in such a limited repertoire, aimed specifically at certain perceptual abilities of the listener, as "Pavlovian' semanticism." ${ }^{13}$ The authenticity of a musical dialect, according to Ferneyhough, cannot be reconstructed through references to such surface features, but rather requires a re-establishment of the connection between surface characteristics, subcutaneous driving forces, and a compositional attitude that becomes aware of the energetic potential of gestures.

Though we can certainly question whether Ferneyhough's own music always lives up to this standard in a convincing way, his picture of the musical surface and its inherent energetic potential points in a direction that now can lead to brief descriptions of my own works. My instrumental works for East Asian-European instrumentation, as discussed in parts 1, 2, and 4 of this chapter, focus on the sonic concept of a large-scale, relief-like sound mass that - similarly to a kaleidoscope or computer animation - constantly dynamically changes its surface structure, its foreground and background, height, depth and "breadth." In all cases, the intention to create such three-dimensional situations necessitated a more intensive examination of the possibilities of interlocking layers, which ultimately also led to the inclusion of simple algorithmic formalizations.

\section{Interference: Contradictory Self-Identity}

The challenge of finding music for piano and Chinese instruments initially drew my attention to cultural difference as outlined above: the contrast between the European and East Asian musical traditions embodied in the instruments and the "states of friction" this created were of primary interest. It would have been an obvious move to implement these in the form of a dichotomic layer structure, in which this difference between the piano as one layer and the Chinese ensemble as another is preserved or carefully reduced. Instead of building the music around such a polarization, however, I tried to create a musical situation where closeness and distance dissolve in a constantly oscillating energy state, influenced by the two concepts of "contradictory self-identity" (mujunteki jikodoitsu) and "discontinuous continuity" (hirenzoku no renzoku) formulated by Kitarō Nishida ( $\rightarrow$ V.3), which Rolf Elberfeld explains as follows:

Neither identity nor the general take priority over difference or the individual, nor does the reverse relationship take precedence. Both are equally original and mutually determined. [...]

Time is neither mere continuity nor a random series of moments. Rather, time is the dialectical simultaneity of continuity and discontinuity. At the same time, I and You are neither simply identical nor absolutely separate. Discontinuous continuity thus denotes an intermediate area that rejects extremes as false one-sidedness. ${ }^{14}$

12 Ferneyhough, "Form-Figure-Style."

13 Ibid., 23.

14 Elberfeld, "Begriffserklärung," 308, 290 ("Weder hat die Identität bzw. das Allgemeine einen Vorrang über die Differenz bzw. das Einzelne noch besitzt das umgekehrte Verhältnis einen Vorrang. Beides ist gleichursprünglich und bestimmt sich gegenseitig. [...] Zeit ist weder eine bloße Kontinuität noch eine zufällige Reihe von Augenblicken. Zeit ist vielmehr das dialektische Zugleich von Kontinuität und Diskontinuität. Zugleich sind Ich 
The three-movement formal design of Interference (2001) ${ }^{15}$ builds on Anton Webern's Variations for piano op. 27 (1935-36), which also form the main source of the musical material in the piano part. In the first movement, this material is incorporated into a process of accumulation and reduction in the instrumentation, based on a sizhuyue ensemble with dizi/xiao (bamboo flutes), sheng (mouth organ, $\rightarrow$ II.6), huqin (knee fiddle, alternating between gaohu, gezaixian, and zhonghu), pipa (lute), daruan/zhongruan (mandolin), zheng (arched zither), and yangqin (hammered dulcimer). Based on the well-known melody Xing jie (Street Procession) from the Jiangnan sizhu repertoire, the Chinese instruments are carefully approximated to the piano, which initially remains strangely indifferent. Although it is supposedly in dialogue with the zheng, it nevertheless sustains an independent level and, like the sheng and the percussion, forms a selfcontained structure. The sheng, which forms a constantly present sound band, analogous to the tōgaku repertoire of gagaku ( $\rightarrow$ IV.1), follows a progression from twelve-note to pentatonic chords and back (Ex. 6.1). The drum part is based on basic rhythmic patterns (changdan) from the Korean genre p'ansori during all three movements of the work, and the same genre also provided a model for the shifting and entangling of simultaneous processes, which becomes particularly evident in the second and third movements.

Example 6.1: Christian Utz, Interference, first movement: chord structure of the sheng

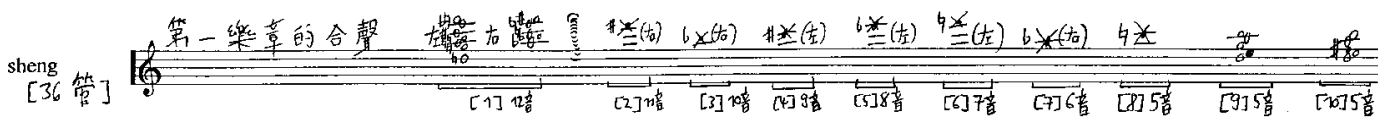

Copyright $\Subset 2001$ by UtzMusicPrints, Vienna

In the second movement, as in the second movement of Webern's Variations, a game of illusions with "self-similar aggregates" is provoked, forcing the piano and the Chinese instruments, repeatedly driven into noise-saturated sonorities here, into a shared gestural sequence. The third movement, on the other hand, which uses successively increasing tempos in a highly abstracted analogy to the Chinese suite form (liuban, baban), ultimately forces the simultaneity of piano and Chinese instruments, already suggested in the first movement, into an extreme form of unrelated superposition. The eleven aitake chords that form the basic structure of the tōgaku repertoire $(\rightarrow$ IV.1) can now be heard in the sheng. The Chinese title of the work Jiao die sheng luan (roughly translated as "Crossed Layers - Sound of the Phoenix") refers to the energetic processes at the node of the work shortly before the end (Ex. 6.2), which in the score is marked metaphorically by three Chinese characters with similar pronunciation - luàn (chaos), luán (spasm), luán (phoenix) - a moment in which the conflicts that have built up in the course of the music dissolve in an ecstatic, cathartic booming and screaming. Finally, the sheng mouth organ (symbolizing the phoenix, $\rightarrow$ IV.1) becomes audible, underlaying a succinct conclusion (an analogue to the end of the third movement of Webern's Variations).

und Du weder einfach identisch noch bloß absolut voneinander getrennt. Die diskontinuierliche Kontinuität bezeichnet somit einen Zwischenbereich, der die Extreme als falsche Vereinseitigungen zurückweist.")

15 At the world premiere of Interference on 12 April 2001, I conducted the Taiwanese ensemble China (Chai) Found Music Workshop ( $\rightarrow$ III.6) at Deutschlandfunk Cologne; Wen-Tsien Hong played the piano part. The edited recording of this world premiere appeared on the CD Christian Utz: Site (Composers Art Label, cal 13012, 2002) and can be accessed at https://soundcloud.com/chr_utz/christian-utz-interference. 
Example 6.2: Christian Utz, Interference, third movement, p. 26

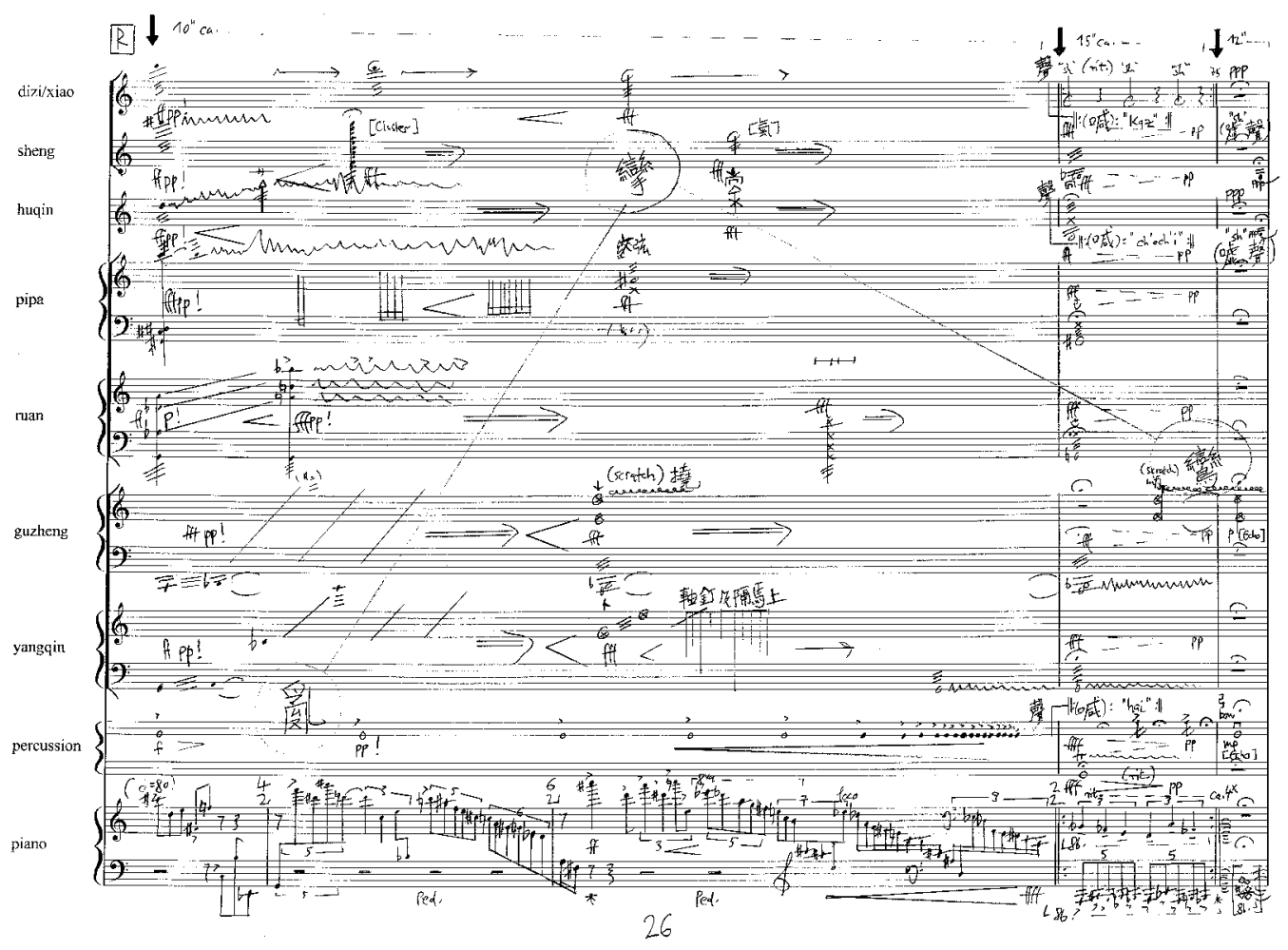

Copyright ( 2001 by UtzMusicPrints, Vienna

The layering principle aims for a dynamically changing, open sound space that alternates between different stages and levels of cultural coding, between repulsion and attraction. The English title Interference describes how the constant fluctuation of "contradictory self-identity" is transformed into music, but also contains the meaning "to interfere," suggesting an unwillingness to hold on to established categories.

\section{the wasteland of minds: Sound Layer Relief and Disintegration}

This relief-like sonic concept first used in Interference became the central starting point for the wasteland of minds (2003-04) for two Chinese and four European instruments (sheng/xun [a Chinese ocarina], zheng, clarinet in A, accordion, violin, cello) and live electronics. ${ }^{16}$ An intricately

16 The premiere of the wasteland of minds was given on 24 January 2004 at the Wiener Konzerthaus by Wu Wei (sheng), Yeh Jiuan-Reng (zheng) and the ensemble on_line (today PHACE) under Simeon Pironkoff. A studio recording appeared on CD with the same performers: Christian Utz: transformed. music for asian and western instruments 2001-2006, Spektral Records SRL4-08028, 2008; the recording can also be accessed at https://soundcloud.com/chr_utz/the-wasteland-of-minds-2003. 
Figure 6.1: Structural grid of rhythmic periods for Christian Utz, the wasteland of minds, $m m$. 1-20

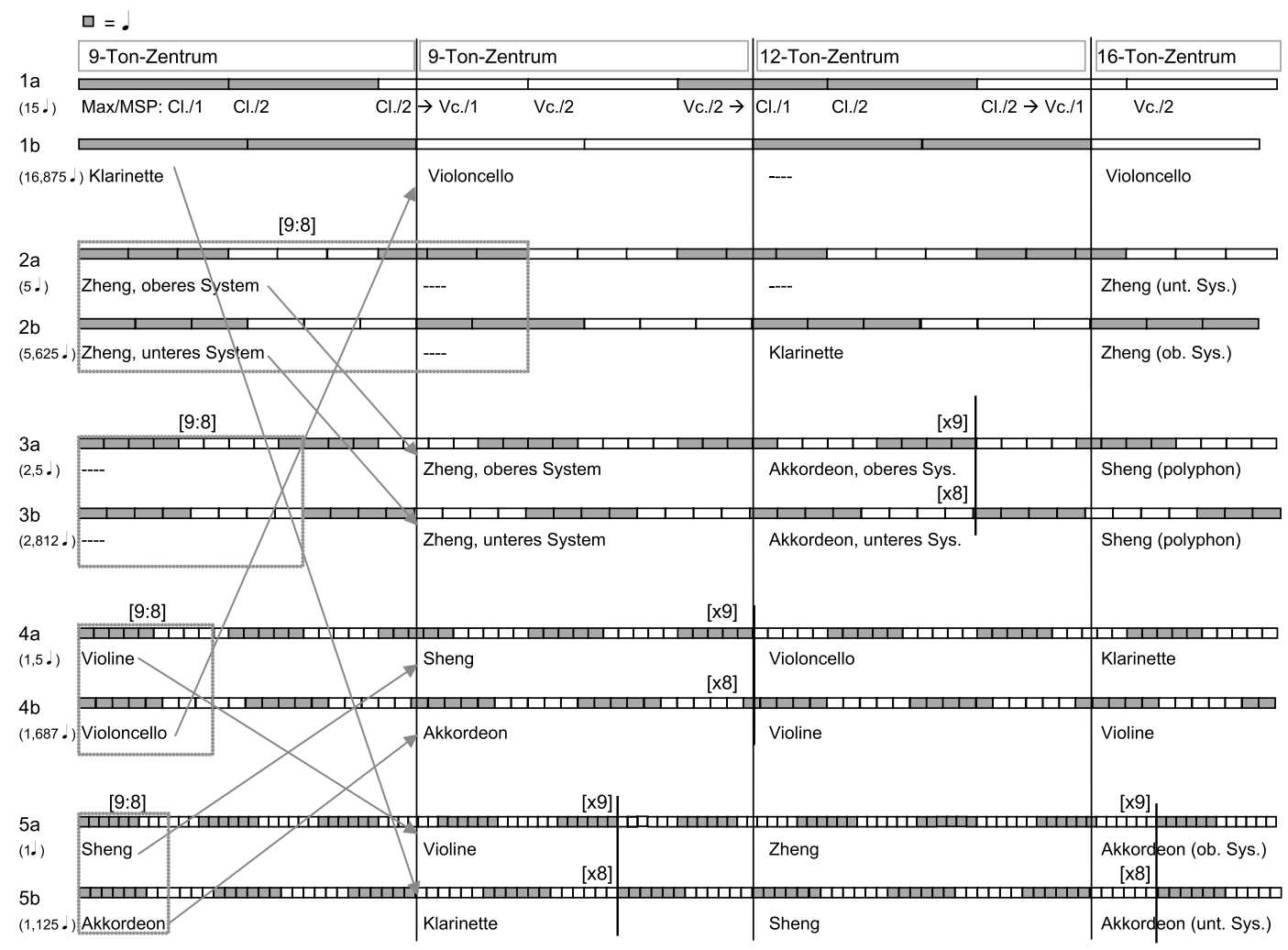

layered structural grid of rhythmic periods (Fig. 6.1), woven by means of a freely managed formalization, serves as a canvas in this work on which colors are constantly highlighted, scratched off, or painted over. The binding of layers results in an extremely compact, highly energetic overall sound whose surface structure is constantly changing. The foreground and background alternate continuously and create mergings, dissociations, or splits of instrumental colors.

Of the five different rhythmic layers, each has two sublayers in the ratio 9:8, with the five main layers shifted by the ratio 6:5:4:3:2. This sets in motion a process that only returns to its starting point after $486 / 4$-measures (the first c. five-minute phase in a total duration of around 16 minutes); in this first phase there is a constant inner tension, a frictional energy, an inner dynamic that is explored compositionally. This can be seen, for example, in the constant variation of musical details, which can be traced back to eight basic models. There is never any mechanical repetition of such a model; even in the substructure, there are continuous "changes of illumination." The live electronics are also involved in this interplay; it colors those instruments that follow the slowest layer, creating a musical background that is always slightly roughened.

The cultural intercontextuality here is limited primarily to the harmonic organization derived from the organology of the two Chinese instruments. The nine-note center at the beginning requires a special microtonal tuning of the zheng, which is pentatonic in the traditional context; as often in contemporary music, the bridges are moved to achieve a new form of pitch systematization, reflecting the sometimes very different regional tuning conventions in China. The axial pitches of this tuning are $\mathrm{D} 2, \mathrm{C} \sharp 3, \mathrm{E} b 4, \mathrm{C} 5$, and $\mathrm{B} 5$, on which five microtonally 
spread variants of the traditional pentachord are built (all pentachords have the same sequence of microtonally modified intervals: lowered whole tone, raised fourth, semitone, raise whole tone, lowered semitone), and below that, F\#1 appears as a further axial pitch (Ex. 6.3). In addition to these six pivot pitches, the three highest pitches of the A clarinet (F6), violin (A\#6), and accordion (G7) accumulate to form a nine-note chord (covering the full chromatic aggregate without the pitch-classes E, G\#, and A) (Ex. 6.4).

Example 6.3: Christian Utz, the wasteland of minds, tuning of the zheng. The accidentals marked with an arrow indicate a retuning of the pitch by 30 cents (higher/lower). In the score (see Ex. 6.5), the other parts with the same notation show a quartertone offset (+/- 50 cents).

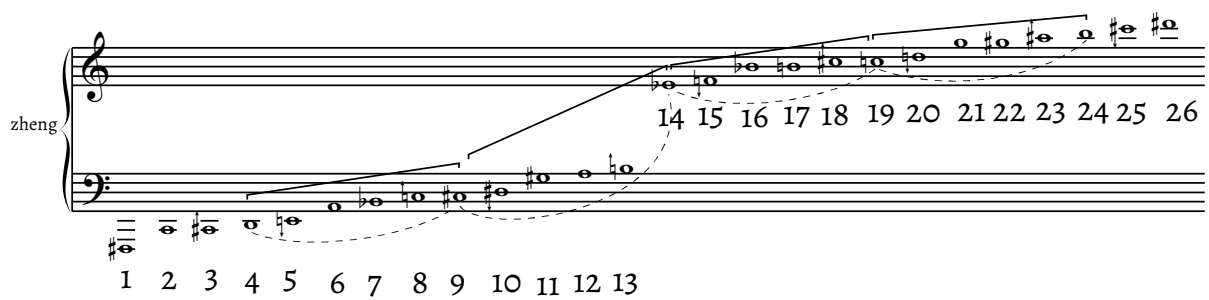

Example 6.4: Christian Utz, the wasteland of minds, compositional sketches of the harmony

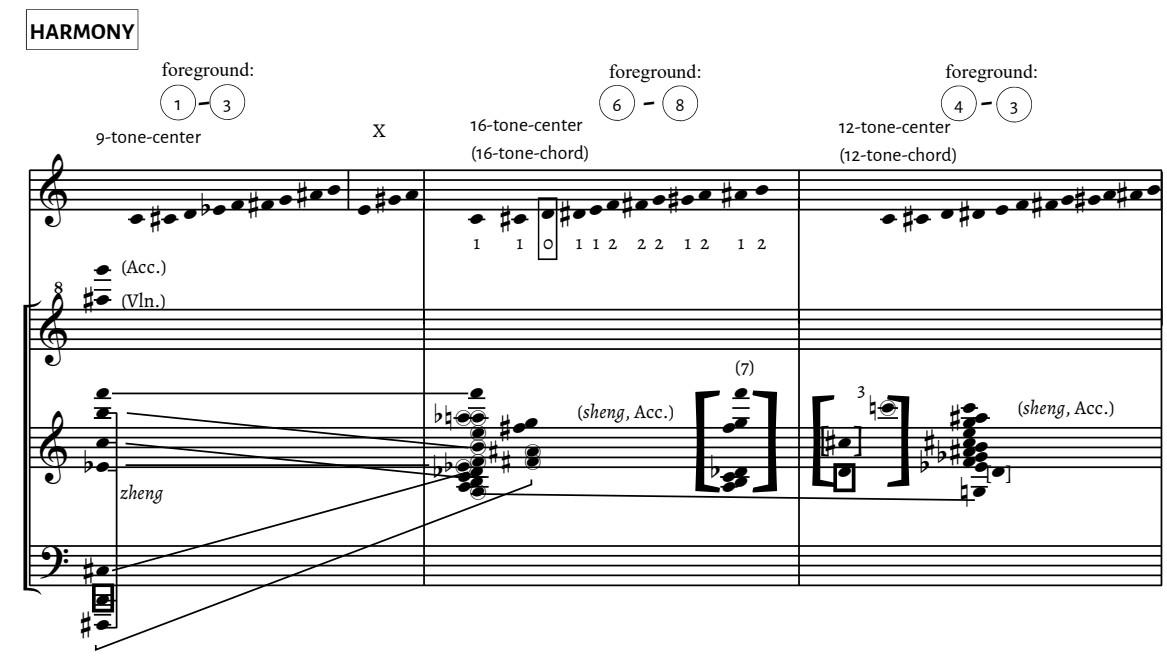

The other two pitch centers (see Ex. 6.4) were obtained from "maximum-pitched" chords of the sheng mouth organ, a 16-note chord (with eleven different pitch-classes, where only the pitch $\mathrm{D}$ is missing to complete the aggregate) and a twelve-note sound (containing all twelve pitchclasses). Pitches common to two out of the three chords (9-tone, 16-tone, 12-tone) are used for "modulation," with the principle of the (complementary) "negative" also playing an important role; for example, the pitch $\mathrm{D}$ can appear as a negative of the 16-note chord. Within the four large sections of the work, especially from the third section onward, increasing "decay processes" occur, which prompt an emancipation from the "striated" layer structure, especially in the "extraterritorial" solo of the Chinese ocarina xun at the beginning of the last section 
(mm. 126-138) ${ }^{17}$ But there is already a kind of "implosion" of layers in the dense first section, followed by an abrupt breakdown (Ex. 6.5). The formal dramaturgy is loosely related to the four short poems MISHIMA Skizzen by petschinka (Eberhard Petschinka, b. 1953) based on the novel Thirst for Love (Ai no kawaki, 1950) by Yukio Mishima (1925-1970). Mishima's novel was one of the starting points for the (unrealized) music theater project wüst.land, which was conceived by petschinka and myself in 2003 and sporadically developed until 2006. The project, based on such global political conflicts as the Iraq War, reflected on questions of intercultural encounter from the perspective of deep psychological dimensions of dissent, violence, and war (my work Glasakkord emerged from the same context, $\rightarrow$ VI.2). There is a certain trail leading from scenes in Mishima's novel (including sudden shock effects such as the gruesome murder committed by the main character Etsuko toward the end of the plot) and petschinka's adaptation of the text to dramatic turns in the music, although there is no linear program or storyline running through the musical narrative.

In the wasteland of minds, the multi-contextual layered fabric creates a tension between construction and realization in sound that seeks to constantly renew the energetic potential of the musical process. Spontaneous compositional decisions are not hindered by the layered construction, but rather made possible, and here the oscillation between structure and texture, between soft connectivity and formalized simultaneity takes on a key position. Nishida's terms "contradictory self-identity" and "discontinuous continuity," of course, describe a vision that music can only tentatively approach. The same applies to the aesthetics of the open musical space laid out at the beginning. In contrast to the "striated," territorialized, hierarchized space of the city, Deleuze and Guattari design the "smooth" vectoral space of the sea, which is difficult to occupy. ${ }^{18}$ Perhaps my instrumental work in this phase may be described as diving into this marine space with no certain destination.

\section{Stratification and Analysis}

The aesthetic and quasi-political impulse to preserve identity, perhaps even the incommensurability of individual idioms, vocabulary, structures, and to avoid subjecting them to an imposed hierarchical order through a layered musical situation, appears to be a necessity in intercultural thinking. Of course, as hinted at above and explored in further detail below $\rightarrow$ III.5, V.3, VI.4), it is hardly conceivable to compose in a way that completely dissolves hierarchies (and, as has been shown on various occasions, they are usually very clearly preserved, even in John Cage's attempts at musical "anarchy"). At least, the utopia of a hierarchy-free space may still be a good starting point for approaching intercultural situations musically. Complementary to stratification is the analytical insight into specific forms of music. Analysis aims for something distinctive: it can try - as utopian as it may seem - to "subtract" culturalist attributions from the analyzed object by conceiving of it as something that cannot be subsumed, but at the same time is also provisional and changeable. In this way it approaches the "hypoleptic" discourse $(\rightarrow$ I.3), denying musical objects a "mythical" or "canonical" status. A link between stratification and analysis is obvious; in fact, the two strategies seem to be mutually dependent.

17 A similar formal function is served by the concluding xun and zheng soli in my work walls for ensemble and electronics (2018) $\rightarrow$ VI.4).

18 Deleuze and Guattari, $A$ Tausend Plateaus, 478-481. 


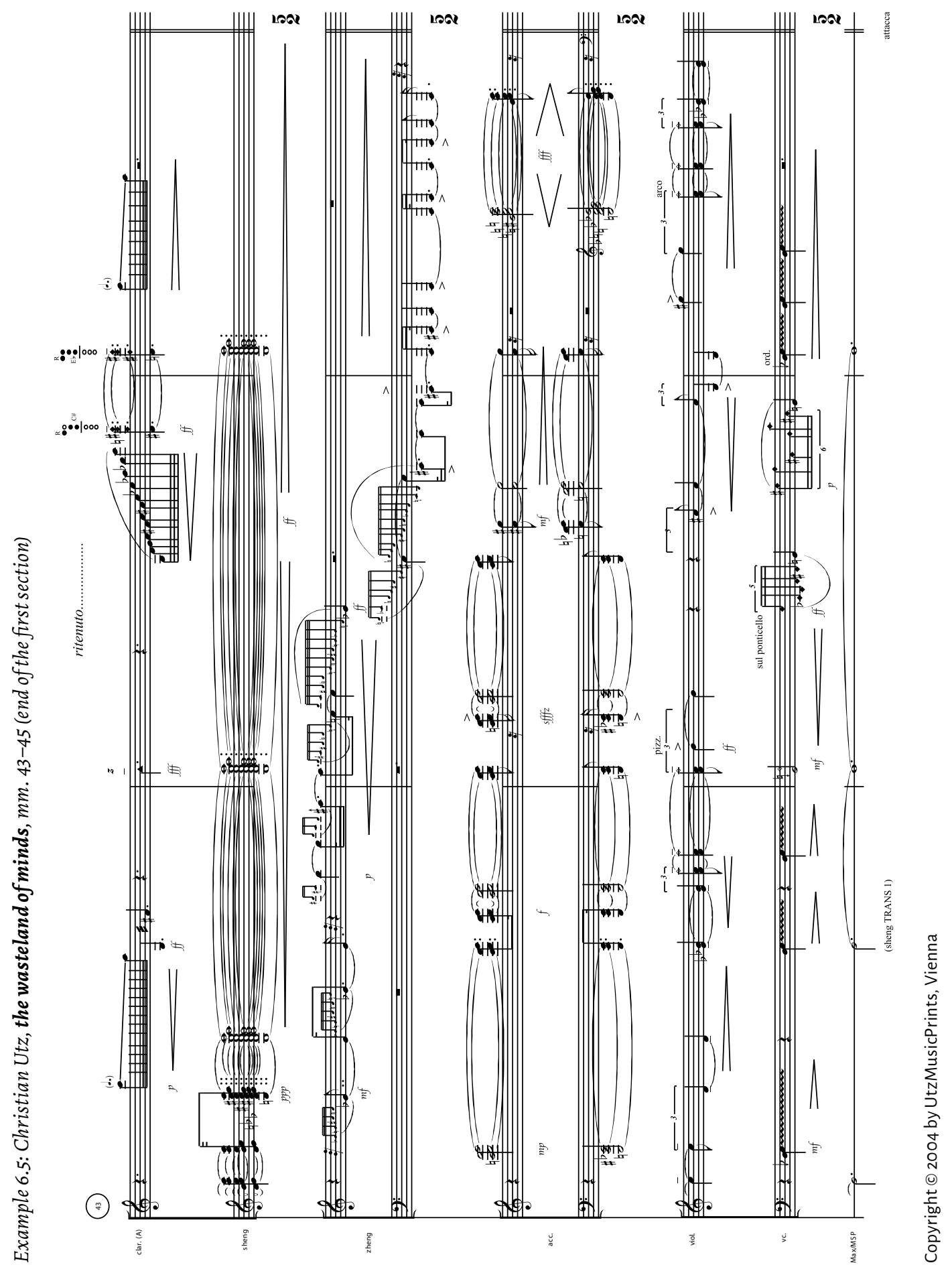




\section{Symbolism and Implosion in Glasakkord}

In Glasakkord for shō, shakuhachi, bass clarinet, tubular bells and string trio (2006), ${ }^{19}$ I started developing the music from two almost hermetically opposed structures in the sho and strings. This formation of layers was not based on cultural paradigms, however, and is moreover exposed to a process of decay, which from the outset establishes an undeniable internal tension. This differentiation between layers unfolds by means of the analysis of an instrumental-haptic "internal logic" in the case of the sho and the analysis of glass sound spectra in the case of the strings.

The sho part is defined by a series of seven-note chords, which are connected to each other by means of two dyads and shared pitches (Ex. 6.6). The basic structure includes all 135 possible seven-note chords on the modern 17-note $\operatorname{sho}(\rightarrow$ IV.1) and all 117 possible dyads, and no chord is repeated. ${ }^{20}$ These limitations of harmony result from the specific fingering layout of the instrument $(\rightarrow$ IV.1, Ex. 4.4). At the same time, the string trio follows a completely independent sound process derived from spectral analyses of eight different glass sounds (Ex. 6.7), which merge into one another continually to create new sequences. In this context, the glass symbolism is of particular importance: the sounds of the "glass strings" are fragile, fragmented, untempered, intangible - just like tentative (and sometimes unsuccessful) forms of intercultural encounter, which may lead to conflicts and even violence. ${ }^{21}$

Both processes are contained within a polyphonic network of rhythmic layers, based on the layered structure of the wasteland of minds $(\rightarrow$ VI.1). The scheme was freely reworked in Glasakkord: some of the five layers were not considered at all, but new microperiods were introduced (especially in the shō and strings), related to the peculiarities of the respective material, with shakuhachi, bass clarinet, and tubular bells fluctuating in their coordination with the sho layer or the string layer. At the beginning, the period of a layer period lasts 33.75 quarter notes, so the

19 The world premiere of Clasakkord took place on 23 March 2006 at the MaerzMusik Festival (Berliner Festspiele); it was performed by Kō Ishikawa (shō), Tony Clark (shakuhachi), and ensemble on_line (today PHACE), directed by Simeon Pironkoff. A studio recording of the work with the same performers has been released on the CD Christian Utz: transformed. music for asian and western instruments 2001-2006, Spektral Records SRL4-08028, 2008 (https://soundcloud.com/chr_utz/glasakkord-2006-for-sh). Aside from Glasakkord, I have only composed one more work for Japanese instruments so far, namely Site (2001) for gagaku ensemble and live electronics, produced in collaboration with the Wakatake Gagaku Society Yamaguchi/Japan and premiered (10 March 2001) at the concert hall of Akiyoshidai International Art Village. Since these were not professional musicians, the compositional concept was mainly limited to the electronic transformation of traditional sound material into natural sounds and the connection with text fragments from Kitarō Nishida's essay bashō (Place, 1926), which was the source of the title. The edited recording of the premiere appeared on the CD Christian Utz: Site (Composers Art Label, cal 13012, 2002).

20 Owing to the arrangement of the fingers ( $\rightarrow$ IV.1, Ex. 4.4), the pitches A5, B5, and F5 are included in all seven-note chords, since three of the seven fingers used (R4, L2, L3) are each assigned exclusively to one of these three notes. Based on my information, Wolfgang Suppan has developed an algorithm that calculated the exact number of possible chords (assuming that the assignment of the fingers to the individual pipes is defined as in Example 4.4 from Chapter 4 ; in some cases, there might be changes in these assignments [ $\rightarrow$ IV.2] that would result in further possible combinations). Accordingly, the following pitch combinations are possible: 117 dyads; 421 three-note chords; 851 four-note chords; 963 five-note chords; 567 six-note chords; and 135 seven-note chords.

21 In similar semantic contexts, glass sounds were used in the following works of mine: Zersplitterung for baritone, piano, and glass percussion (2002) $\rightarrow$ VI.3), specula for percussion and live electronics (2005), and vier epigramme for percussion and live electronics (2005-06). The eight glass sounds (Ex. 6.7) spectrally analyzed for Glasakkord were taken from a concert recording of specula. 
Example 6.6: Christian Utz, Glasakkord, mm. 1-17, shō part; chord progression: 7-2-2 pitches
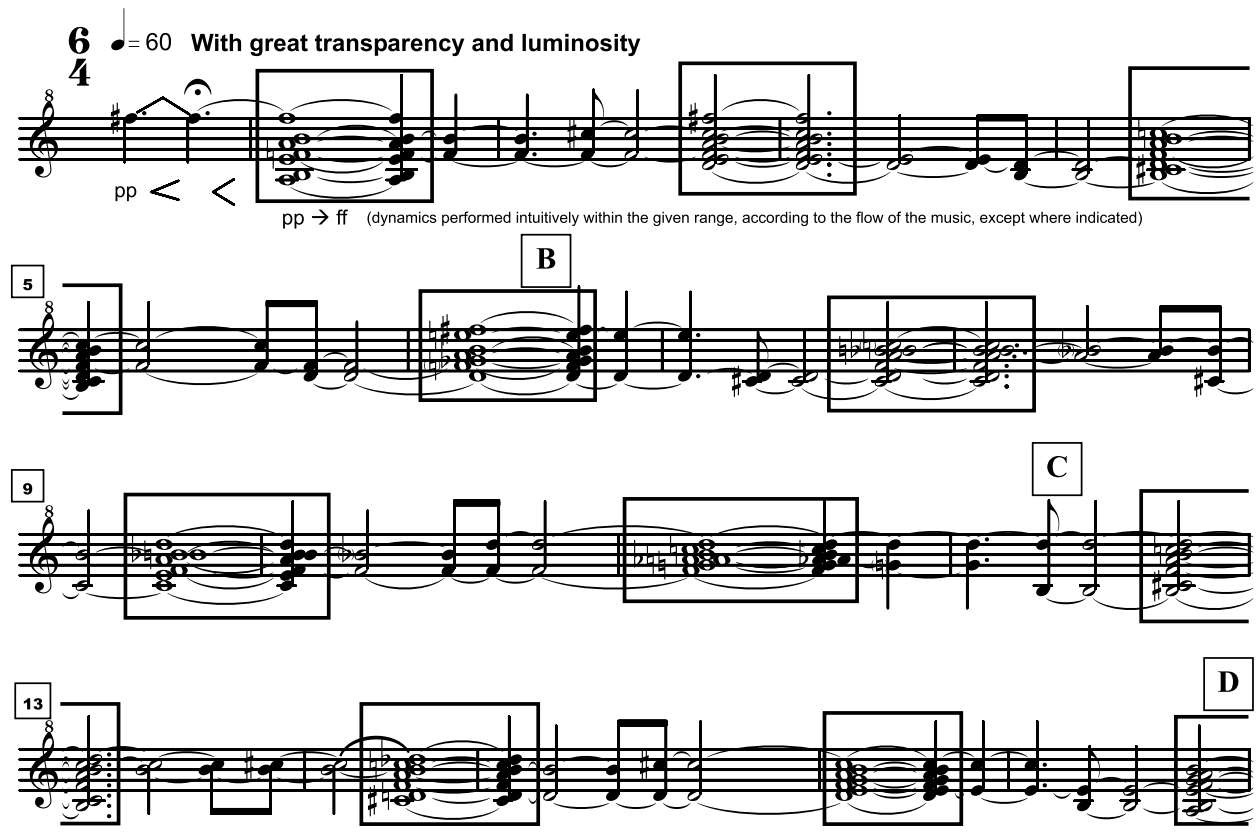

Copyright $\odot 2006$ by UtzMusicPrints, Vienna

Example 6.7: Christian Utz, Glasakkord; "glass chords" of the strings obtained by spectral analysis of glass sounds
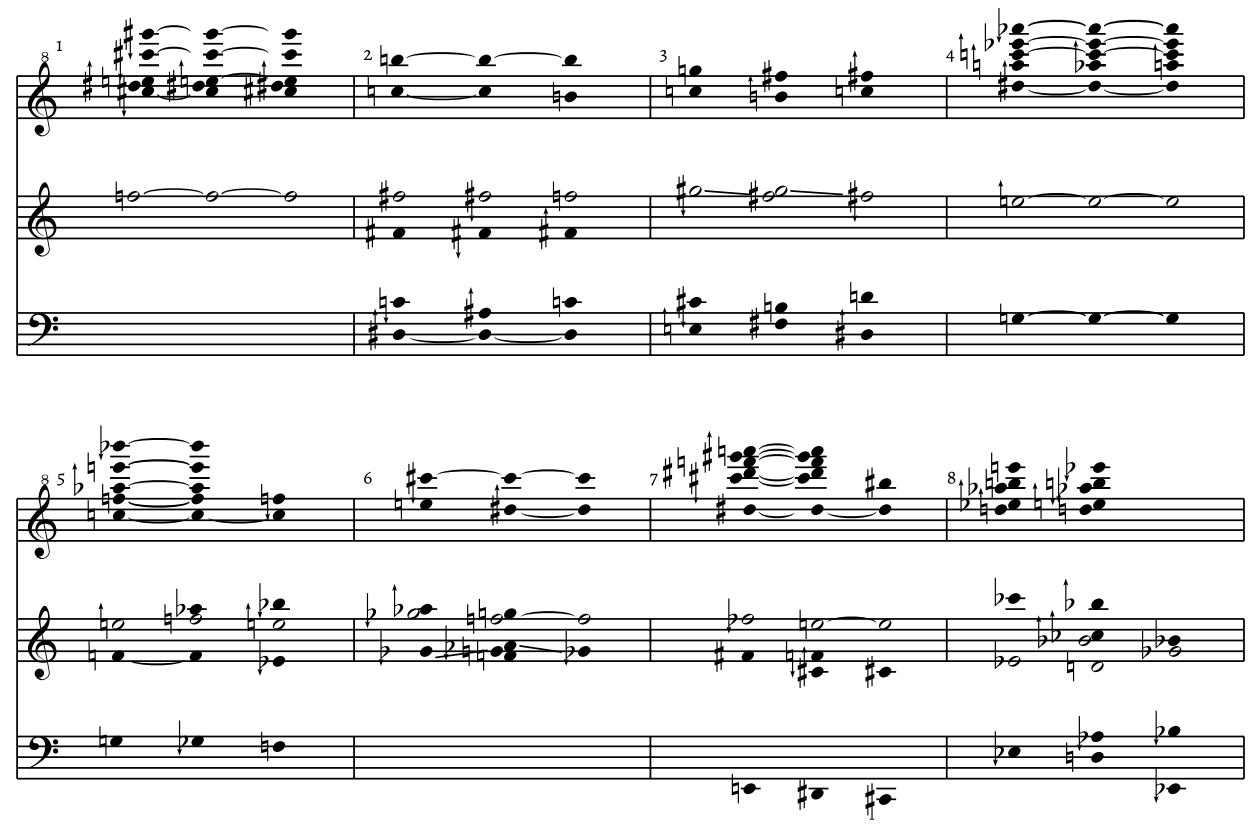
change from the first glass chord (Ex. 6.8: no. 6) to the second (no. $5^{22}$ ) takes place after five 6/4 measures and 3.75 quarters. The three chordal phases (related to the acoustic phases of attack, sustain, a decay in the respective spectral analyses) are here reproduced with the same duration at 11.25 quarters each (see Ex. 6.7 and 6.8).

Example 6.8: Christian Utz, Glasakkord; "glass chords" of the strings: realization in the score, mm. 1-7

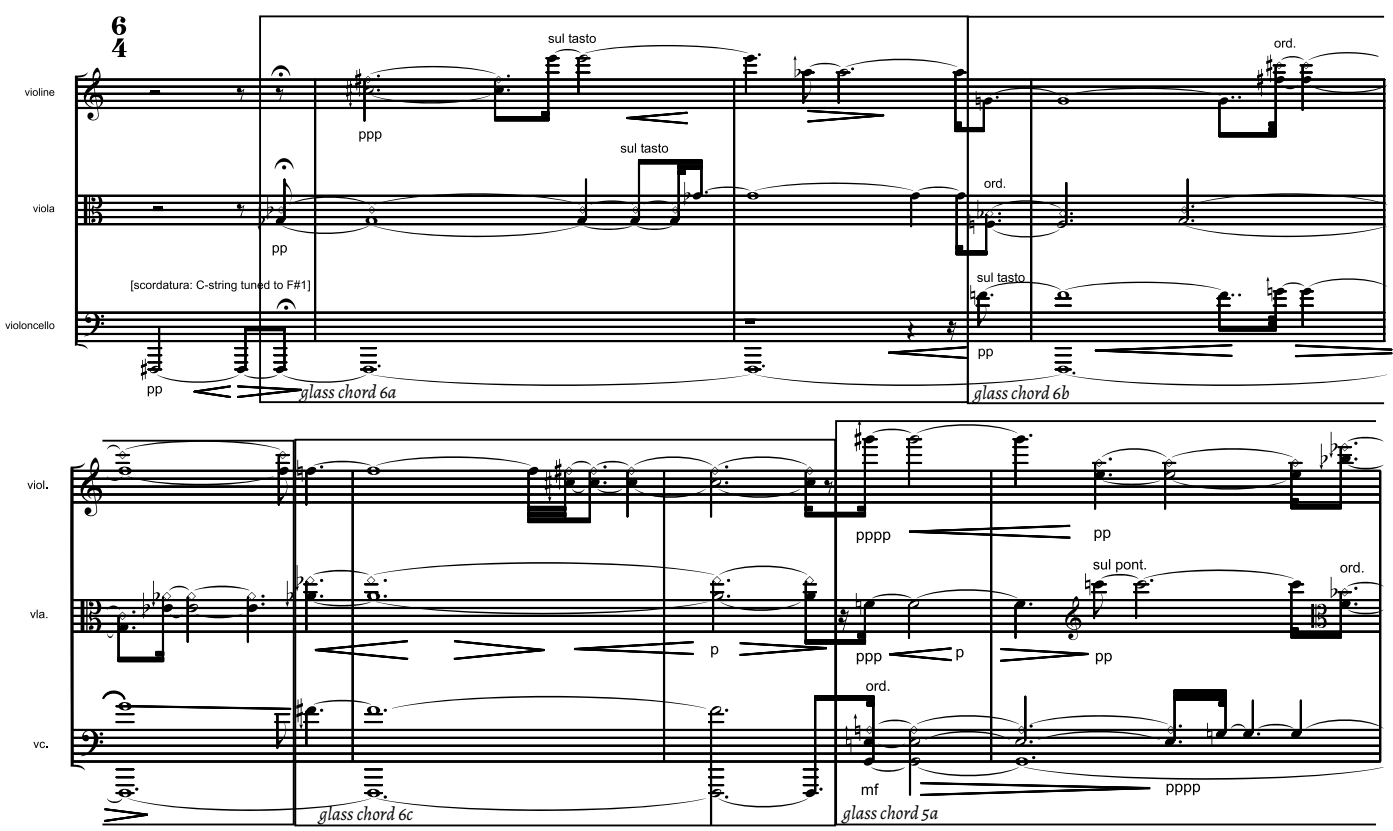

Copyright $(2006$ by UtzMusicPrints, Vienna

The crucial point here is that this layered structure by no means remains intact, but is completely "thrown off track" by interpolated solos from the sho and shakuhachi, and later by vocal passages performed by these two soloists. ${ }^{23}$ The lack of connection between sho and strings becomes increasingly problematic; the intricate structure is, as it were, "decomposed" from the inside - even more clearly than in the wasteland of minds. The dramatic texts by petschinka ${ }^{24}$

22 The numbering of the chords was conceived at a precompositional stage and is not related to the order in which the chords appear in the finished work.

23 In contrast to the invariable pulse of the layered structure, the two instrumental soli are characterized by a "recomposition" of the free-floating temporality of the chōshi and netori introductory parts in gagaku (in the case of the shō solo, mm. 28-29) and the similarly freely timed traditional honkyoku solo repertoire of the shakuhachi (shakuhachi solo, m. 64). The style of the first vocal passage ( $\mathrm{mm}$. 117-120), sung by the shakuhachi soloist, is a free transformation of low-pitched Buddhist shōmyō vocalization. In the second passage (mm. 137-140), sung by the shō soloist, a transcription of the song Kashin from the repertoire of the archaic vocal genre rōei (recitation of Chinese poetry with instrumental accompaniment, Heian period, 794-1185) is slightly microtonally distorted and placed under petschinka's text (see footnote 24). The position of these four solo inserts within the overall form is determined by the proportions of the golden ratio.

24 The texts specially written by petschinka for Glasakkord are: 1. (Originally in English, sung by the shakuhachi soloist): 'they entered the mosque in boots. / they heard a silent voice. / 'look over there! what the hell is that?!' / they 
relating to the Iraq War, which can be heard in the two vocal passages, reveal the insistence on cultural difference, on which the musical strata are indirectly based, as an impasse. The system of layers collapses, imploding the tension generated by the solidified structure (Ex. 6.9).

Example 6.9: Christian Utz, Glasakkord, $m m$. 151-155

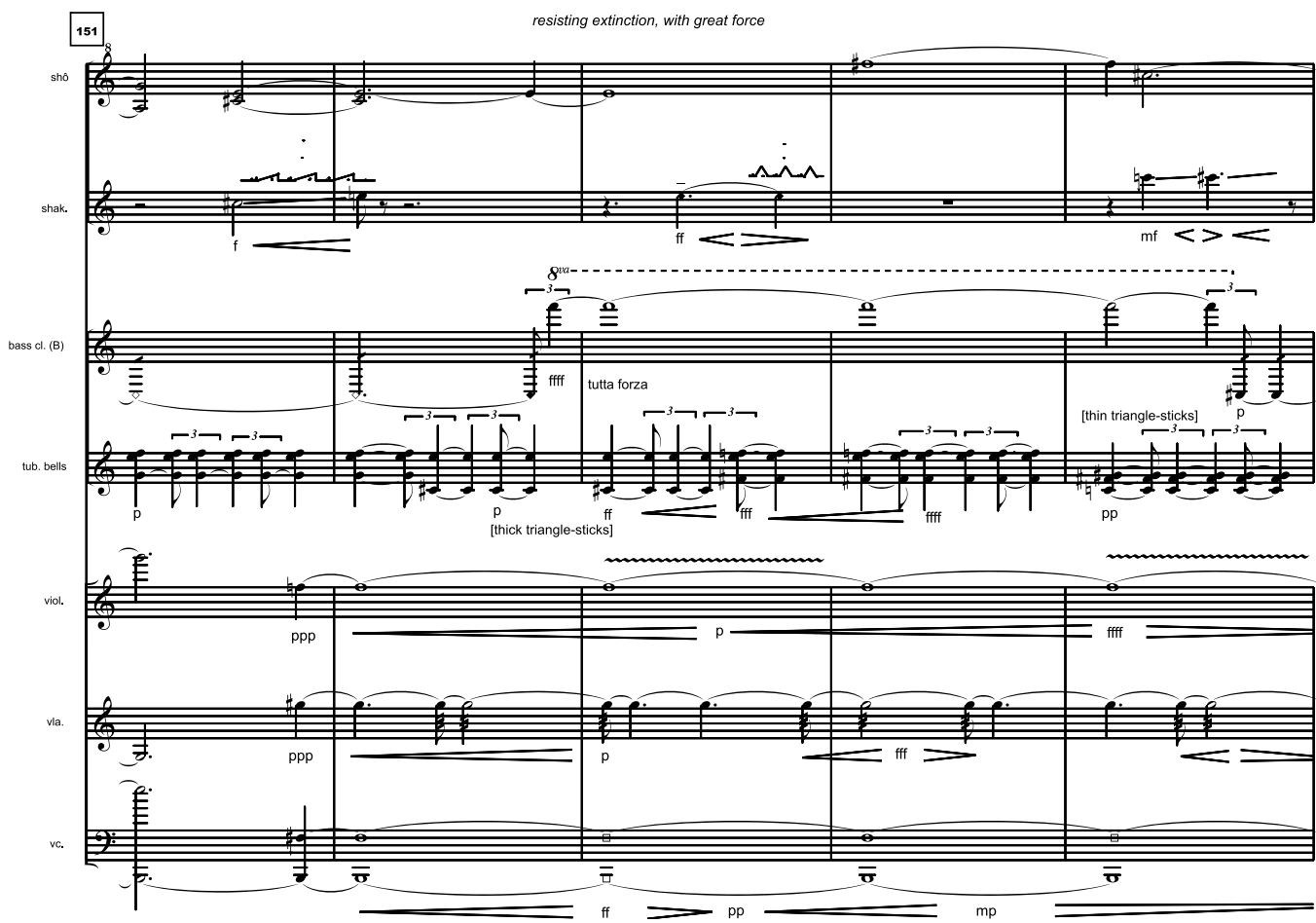

Copyright (๐) 2006 by UtzMusicPrints, Vienna

To what extent can we actually hear and comprehend the process described here? Is the initial assemblage of two independent layers perceptible at all, or does the ear not listen out immediately for relationships, connections, for the synthesis of the different? A problematization of hidden hierarchies has already been addressed when challenging the compositional relevance of cultural difference $(\rightarrow$ III.4, V.3). The question of which factors contribute to an actually perceptible difference between musical layers, or whether a layered fabric does not merely result in a flat sound texture, can hardly be understood through generalization. The dialectical relationship between structural and textural sound, as Lachenmann's sound types essay states, is self-evident $(\rightarrow$ VI.1). In connection with the cultural coding of the material, however, it becomes even clearer that in fluctuations between structure and texture, second-order hierarchies as well as the leveling of difference can indeed occur more quickly than expected $\rightarrow$ III.5, VI.4). 


\section{together//apart: Reconstruction, Recomposition, and Irritation}

In my preparatory work for together//apart (hamkke//ttŏrŏjyŏ) for the Korean instruments kayagŭm (arched zither), taegŭm (bamboo flute), saenghwang (mouth organ), as well as violoncello, piano, and live electronics (2001), ${ }^{25}$ I analyzed in some detail the structure and sound effects of a well-known piece from the repertoire of Korean court music: Sangnyŏngsan from the Yorngsan hoesang suite. In addition, an extraction of the pitch organization from the second movement of Isang Yun's duo together (1989) for violin and double bass, to which the title also refers, plays a part in the musical structure. The arched zithers kayagŭm and kómun'go perform the main melody of Sangnyongsan, which is elaborated heterophonically by the other instruments, whereby the lines become very independent from the start and combine to form a fabric-like texture (Ex. 6.10). The melody comprises four stanzas of three, four, four, and six phrases $(k \bar{a} k)$.

A decisive compositional thought was now directed toward rethinking this varied, rhythmically very flexible, and therefore also unpredictable type of heterophony using a type of temporal stratification that avoids exact rhythmic synchronization. The basis for this is a metertempo scheme based on the metric structure of the Korean template 6-4-4-6; the ensemble is divided into three groups (taegŭm + saenghwang, kayagŭm + violoncello, and piano + electronics). While the wind group always maintains the 6/4 meter and changes the tempo every two measures in a ratio $2: 3$ or 3:2, kayagŭm and violoncello alternate at the same distance at a constant tempo between a $9 / 4$ and a 6/4 measure. The piano in turn maintains a 2:3 ratio to the pattern in the wind instruments (Ex. 6.11). Through the very free use of the given pitch material and a radicalization of the heterophonic principle, there is an extremely high notational and tonal density from the beginning. It is important to realize the notation as precisely as possible, yet it is never a matter of mechanical or mathematical precision, but rather a constant oscillation between the concentration on one's own part and a common "breathing," which is also provoked by the limited flexibility within the prescribed tempo ranges. This breathing is particularly important at the beginning of each measure and should be carried out very deliberately by the entire ensemble (but without creating a clearly noticeable break or caesura). The percussive accents adopted from the Korean model contribute to this underlying pseudoregularity. The electronics transform the pitches of the piano by means of a pitch-shifting effect approximating the piano's sound to the constantly sliding, deliberately unstable pitch design of the other instruments.

The decisive factor - and this is an analogy to Glasakkord - is not the "strutting" of these layers as such, but rather the molding process resulting from the internal tension thus generated. While the layered fabric initially eliminates the feeling of linear temporality, targeted and "pinpoint" processes are gradually introduced. On the one hand, four ensemble sections are interrupted by three solos (piano, violoncello, kayagŭm) that are increasingly theatrical and gestural, but the ensemble sections also develop within themselves. On the other hand, from the second ensemble section, there are more and more synchronized actions, such as a spiral-

25 The premiere of this work took place almost six years after its creation on 10 February 2007, thanks to an invitation from Jack Body to participate in the Asia Pacific Festival of the Asian Composers League in Wellington/ New Zealand. The Contemporary Music Ensemble Korea (CMEK, $\rightarrow$ III.5) and Stroma (New Zealand), directed by Hamish McKeich, performed. A remixed live recording of this premiere was released on the CD Christian Utz: transformed. music for asian and western instruments 2001-2006, Spektral Records SRL4-08028, 2008 (https:// soundcloud.com/chr_utz/together-apart-for-kayag-m). 

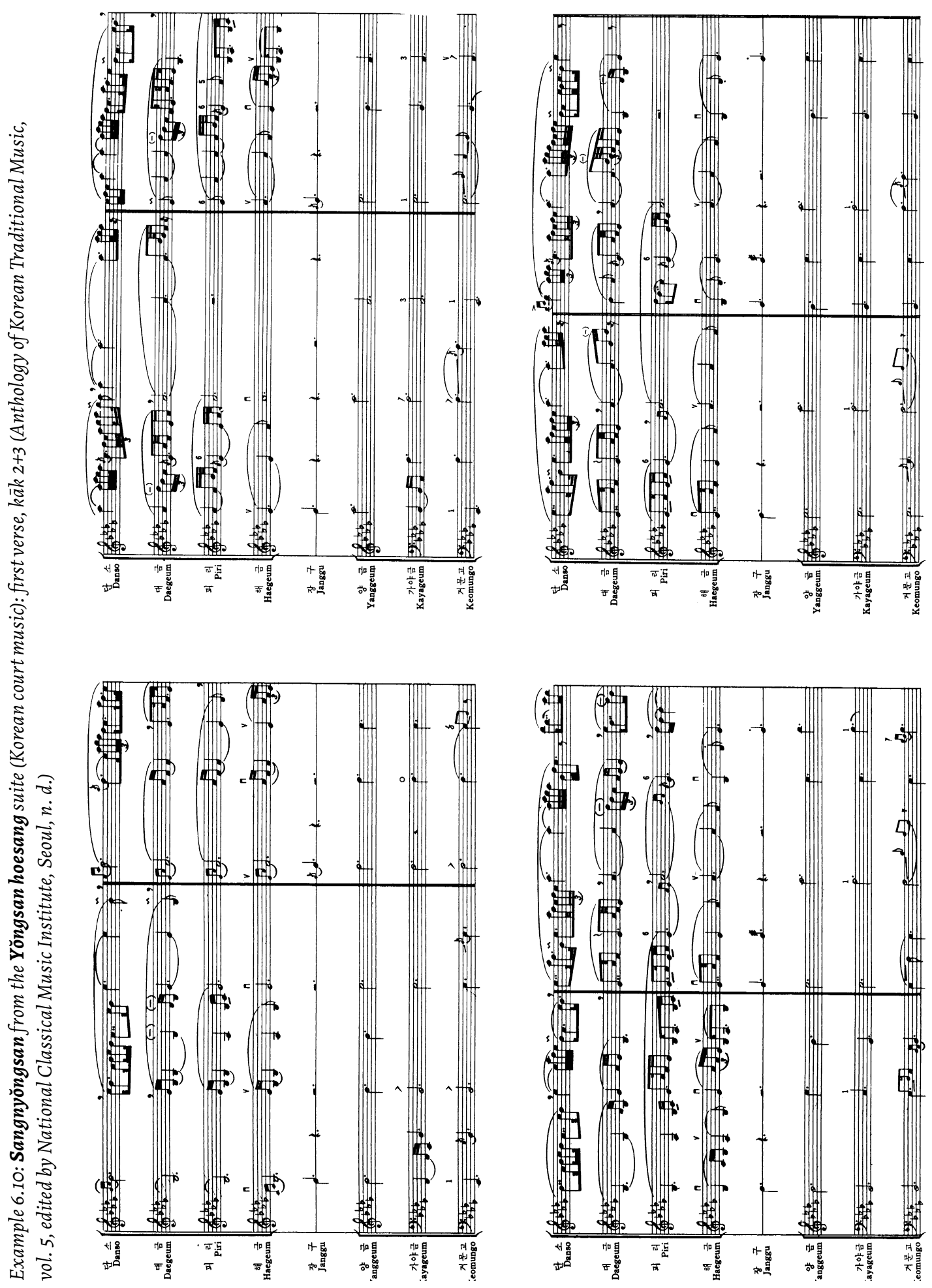
Example 6.11: Christian Utz, together//apart, $m m$. 4-6

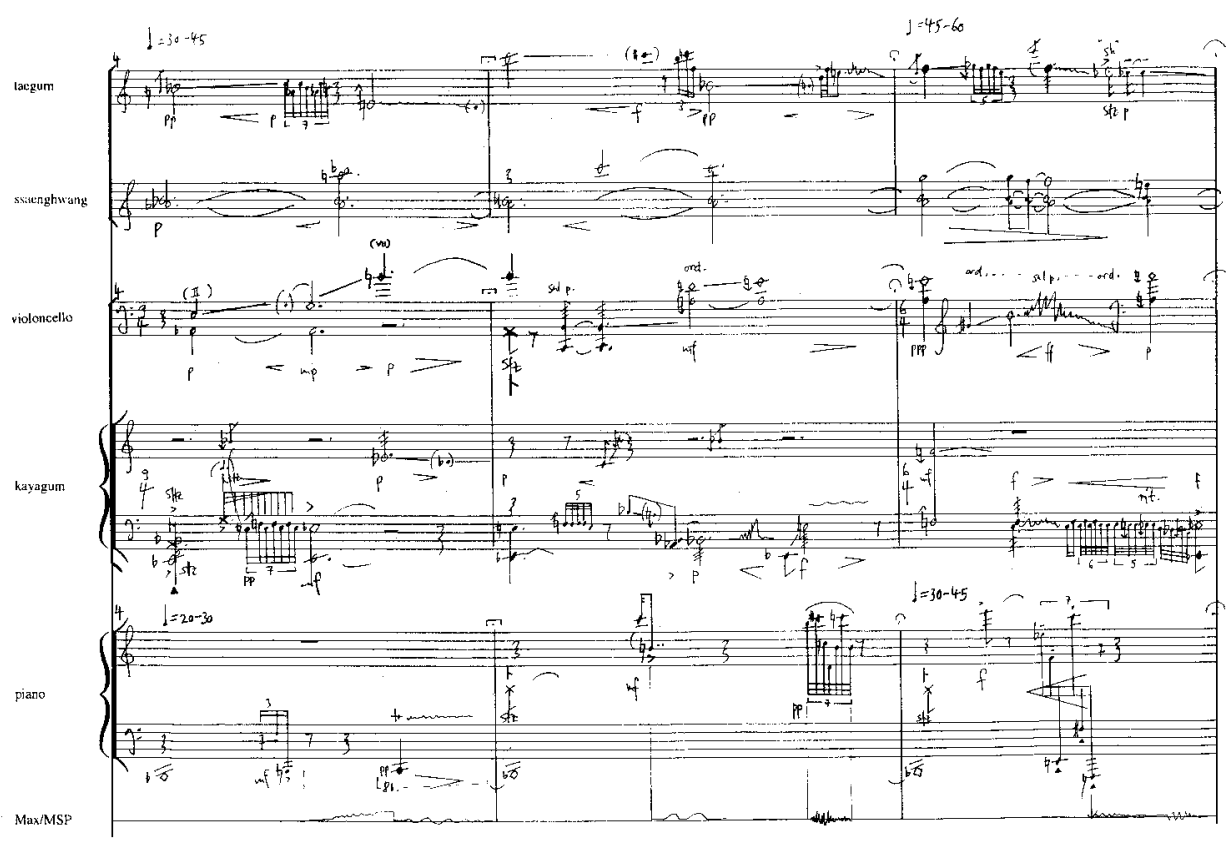

Copyright $\odot 2001$ by UtzMusicPrints, Vienna

ing ascending figure in the taegŭm or tone repetitions, which give the sound more pronounced contours. This process of contouring is intensified in the third ensemble section, where increasingly block-like agglomerations and synchronicities appear. In the last section, apart from a short insert, the polymetric grouping is completely removed, the music "tears itself free," and the previously largely "invisible" theatrical parts of the music forcefully push through the calls and bodily actions of the musicians to the surface, comparable to the cathartic moment in Interference $\rightarrow$ VI.1) (Ex. 6.12). ${ }^{26}$

The complexity of the layering technique and the interwoven intertextual references are thus not ends in themselves, but trigger concise formal processes. At the same time, the cultural context of Korean music can be placed in an open musical space without a direct quotation but is very close to an "original text." Here, "analysis" contributes to a transformative and abstract rewriting of a reference model while maintaining an idiomatic reference based on meticulous rewriting. It is precisely this insistence on (audibly) demonstrable idiomatic difference that can disorient the listener in the resulting music, pointing beyond the limits of purely conceptual integration.

26 Together//apart has a "recomposed" version for seven (European) instruments and live electronics entitled Unsichtbares Theater (2001), which was premiered on 21 November 2001 by Klangforum Wien (director: Ed Spanjaard) as part of the European Music Month in Basel. 
Example 6.12: Christian Utz, together//apart, $\mathrm{mm} .84-87$

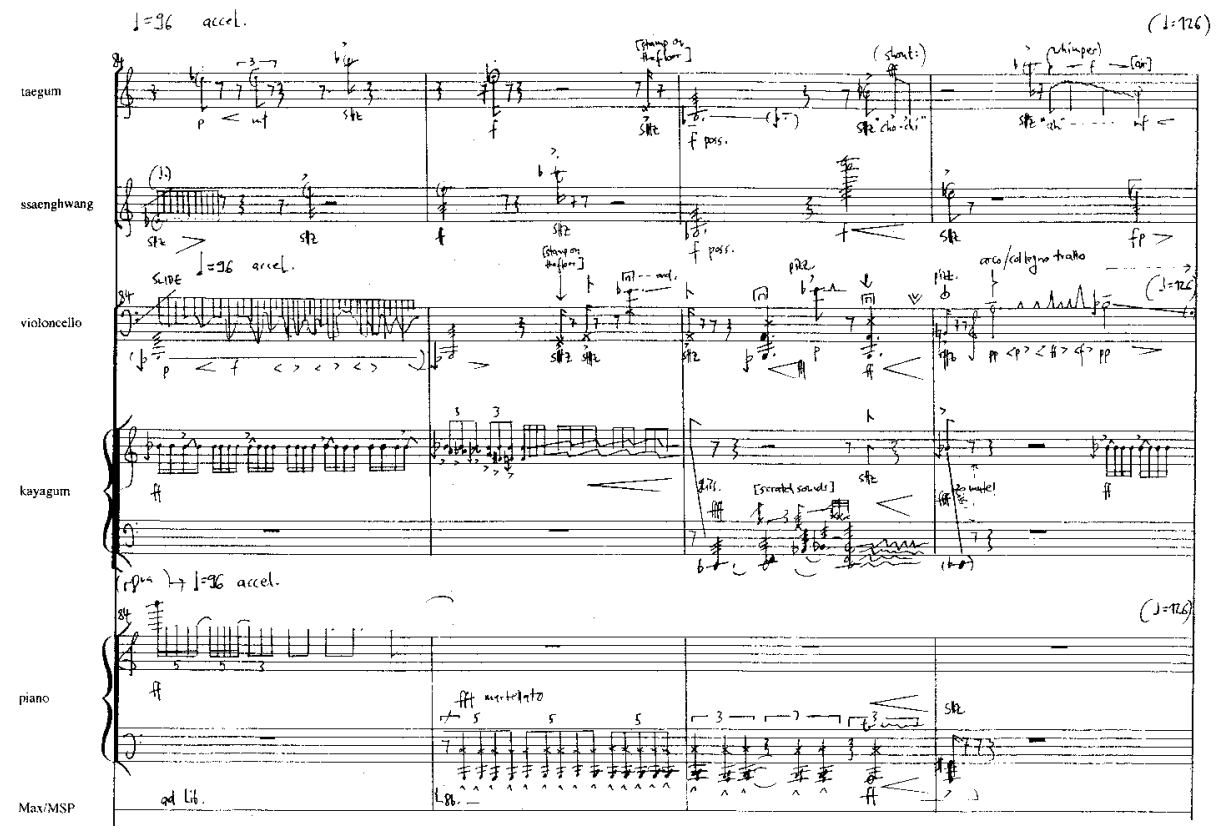

Copyright @ 2001 by UtzMusicPrints, Vienna

\section{Intercultural and Multilingual Trajectories of the Human Voice}

It makes sense to present my two vocal works Zersplitterung (2002) and telinga - mulut (2009) after the analyses of the four instrumental works with crosscultural instrumentation, since they demonstrate fully an aspect that was a factor in many of the previous arguments but hardly became explicit: the (inherent) coherence and ambiguity of the sounds creates a productive tension in relation to the singular, presumably "authentic" voice from which these sounds emanate. Already at the beginning of this book, it was suggested that the demand for a simple model of identity, in which one is expected "to speak with one's own voice" ( $\rightarrow$ I.2), poses almost insoluble problems in today's floating and evolving societies as well as in many musical discourses. It was also highlighted, however, that in a musical context, the voice always gains a communicative potential from the ambiguity of identities located in the sound structures, a potential that may directly "touch" the other, the listener, as explored with reference to the boundary between speaking and singing in the preceding chapter $\rightarrow$ V.1). Both works discussed below reveal this potential in the ways they address idiomatic-phonetic alterity (Zersplitterung) or hybridity (telinga - mulut) against the background of multilingual conceptions (Korean/German/English and Indonesian/German/English). In particular, these two works seek to convey meaning on a multitude of levels and through different "channels," all of which are eventually transported through a single vocal persona (in both cases a baritone part, performed by Martin Lindsay). Political and historical problems in contemporary Korean and Indonesian societies also resonate in the often-conflicting lines of fracture of the text-music structures. 


\section{Zersplitterung - Splintering of Voices}

In Zersplitterung (pusŏjin chogak, Splintering) for baritone, piano, and glass percussion, I tried to approach the tension between contemporary and traditional Korean culture as I had experienced it both during my short visit to South Korea in 2001 and during my study of contemporary and traditional Korean music since $1998\left(\rightarrow\right.$ III.4, III.5) ${ }^{27}$ After researching music in the Korean context for a few years, I had written together//apart in 2001 for the Contemporary Music Ensemble Korea (CMEK). As explained above, this work emerged from the Korean court music piece Sangnyŏngsan from the suite Yŏngsan hoesang and from Isang Yun's Together (1989) for violin and double bass. My compositional method in this piece was based on detailed analyses of both works, and developed a "stratified" structure, in which these two materials coincided and were substantially transformed and contextualized $(\rightarrow$ VI.2). This approach resulted, among other factors, from my research on Isang Yun's music and my criticism of simplified tendencies in his Asia-West dualism ( $\rightarrow$ III.4), but more importantly from a detailed study of Yūji Takahashi's non-essentialist reinvention of Asian instrumental practices $(\rightarrow$ III.4) as well as conversations with Korean composers of a younger generation, mainly Bonu Koo $\rightarrow$ III.5). In our conversation, Koo referred to Takahashi's concepts, a connection that Koo documented in his own works by quoting the Korean children's song Saeya, saeya, pahrang saeya (Bird, bird, blue bird), also mentioning the role of this melody in Takahashi's piano work Kwangju, May 1980 (1980):

Supporters of the late nineteenth-century Tonghak movement used this song as a key melody. Since the Tonghak movement was brutally suppressed, it soon became very dangerous to sing this song. Only children were allowed to sing it without repercussions. Meanwhile, it became a symbol of hope. The way Takahashi quoted this song was very moving and I felt that he had a deep understanding of Korean politics, for he connected the Tonghak movement and the Kwangju protests. ${ }^{28}$

As a tribute to Takahashi and Koo and a reference to politically charged Korean music and art discourses, a quotation from this song also appears in Zersplitterung, in the first interlude, whistled by the pianist (Ex. 6.13).

In Zersplitterung, Takahashi's tendency toward "radical traditionalism" ${ }^{29}$ is reflected above all in the musical elaboration of the vocal part, which follows the principle of the traditional Korean vocal genre sijo and is closely modeled on the speech melody and rhythm of the spoken text. As in together//apart, the approach was rather "philological" in the beginning, guided by the idea that only a close understanding of and compositional intervention into the microstructure of a model would make it possible to bring its incommensurability to light during the compositional process. Furthermore, it was exactly such a method that I missed in a famous

27 Zersplitterung was commissioned by the Rice \& Bread music festival in 2002, whose focus was Korean-European musical cross-relations, organized by earPORT Duisburg/Germany (Gerhard Stäbler, Kunsu Shim). It was first performed by Martin Lindsay (baritone), Jong-Ah Yoon (piano), and Dirk Rothbrust (glass percussion) in Essen and Duisburg (two performances) on 22 June 2002. A more recent performance took place at the Salihara Festival in Jakarta, Indonesia on 14 July 2009 with Martin Lindsay (baritone), Hsin-Huei Huang (piano), and Berndt Thurner (glass-percussion). A recording of the 2009 performance can be accessed online: https://soundcloud. com/chr_utz/zersplitterung-2002.

28 Koo, "Beyond 'Cheap Imitations," 133-134.

29 See Miller, "Radical Traditionalism." 
Example 6.13: Christian Utz, Zersplitterung, first interlude (p. 5),

reference of Saeya, saeya (whistled by the pianist)

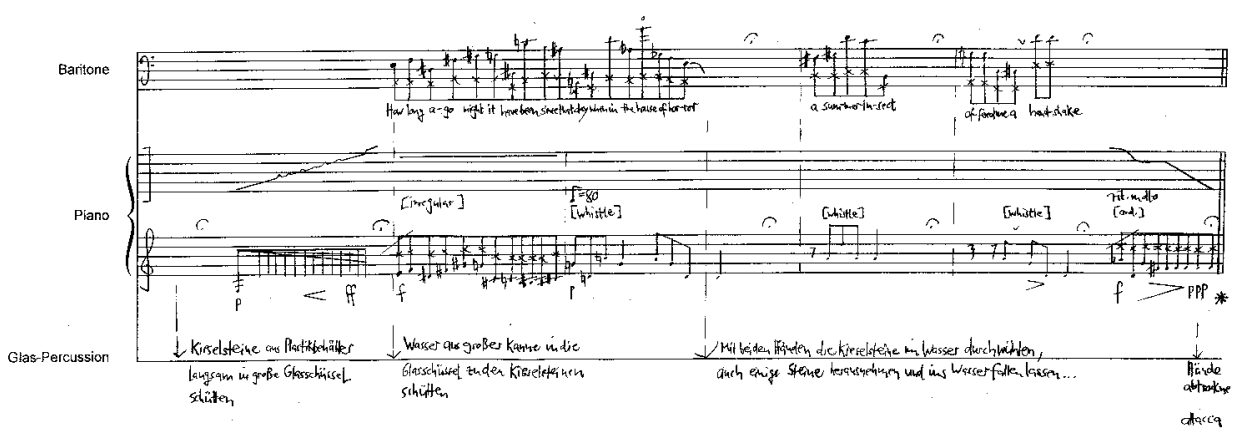

Copyright $\odot 2002$ by UtzMusicPrints, Vienna

appropriation of sijo, Isang Yun's Fourth Symphony "Im Dunkeln singen" (1986), ${ }^{30}$ to which I was seeking a kind of countermodel. My main sources for the study of sijo were a transcription ${ }^{31}$ (Ex. 6.14) and a recording of a pyŏng sijo song. ${ }^{32}$ In preparation for the premiere, I played this recording to the vocal performer, Martin Lindsay, and together we developed vocal timbres and techniques in Zersplitterung based on a rather intuitive graphic vocal notation (Ex. 6.15).

Although the basic orientation of the vocal line around central pitches is derived from a similar structure in sijo, where only three main pitches, constantly inflected and varied, form a drone-like pitch space, the highly expressive and contemplative sijo vocal style is not imitated, but rather expanded into extreme registers and experimental timbres that transcend stylistic limitations. This vocal line merges with irregular repetitive structures in the (extended) piano and glass percussion into "hybrid" sonic constellations (see Ex. 6.15). The tension created by the vocal-instrumental interaction and the dense structure set up by the superimposition of three interrelated ostinato cycles (in a much simpler way than in the wasteland of minds, $\rightarrow$ VI.1) is released in two interludes and a postlude that are written in unmetered time and include "spectacular" gestures, most prominently the breaking of a glass plate in the second interlude that marks the climax of the piece (Ex. 6.16). I had already developed this type of simple ritornello-like large-scale form plan in my earliest pieces with intercultural content, such as sheng$y u e-l \ddot{u}$ (1997) for vocal quartet and, more importantly, in Abstract Voyage (2000) for soprano and string quartet. These simple formal models enhance the ritualistic character of the music and guide the listener through altered and ambiguous musico-lingual territories while ensuring a basic orientation in the formal architecture.

The fragility of glass material as a sound source has been further explored in many of my subsequent works such as specula (2005) and vier epigramme (2005-06) for percussion solo and live electronics. The symbolic connection between this fragility and the conflict-laden atmosphere of particular cultural-political contexts established in Zersplitterung is further explored in Glasakkord, where spectral analyses of glass sounds serve as one of the main materials in a stratified structure with a strong tendency toward collapse $(\rightarrow$ VI.2).

30 See Stephan, Isang Yun: Die fünfSymphonien, 95-128 and Choi, Einheit und Mannigfaltigkeit, 175-207.

31 Reese, "Gattungen des Kunstliedes," 105-107.

32 Korean Traditional Music Vol. 1 (Court Music Highlights), The National Classical Music Institute, SKC Limited, 1987 , Track 8. 
Example 6.14: Transcription of pyŏng sijo by Chang Sa-hun, "Art Song." In Survey of Korean Arts Traditional Music, Seoul 1973, 194 (quoted in Reese, “Gattungen des Kunstliedes," 106)
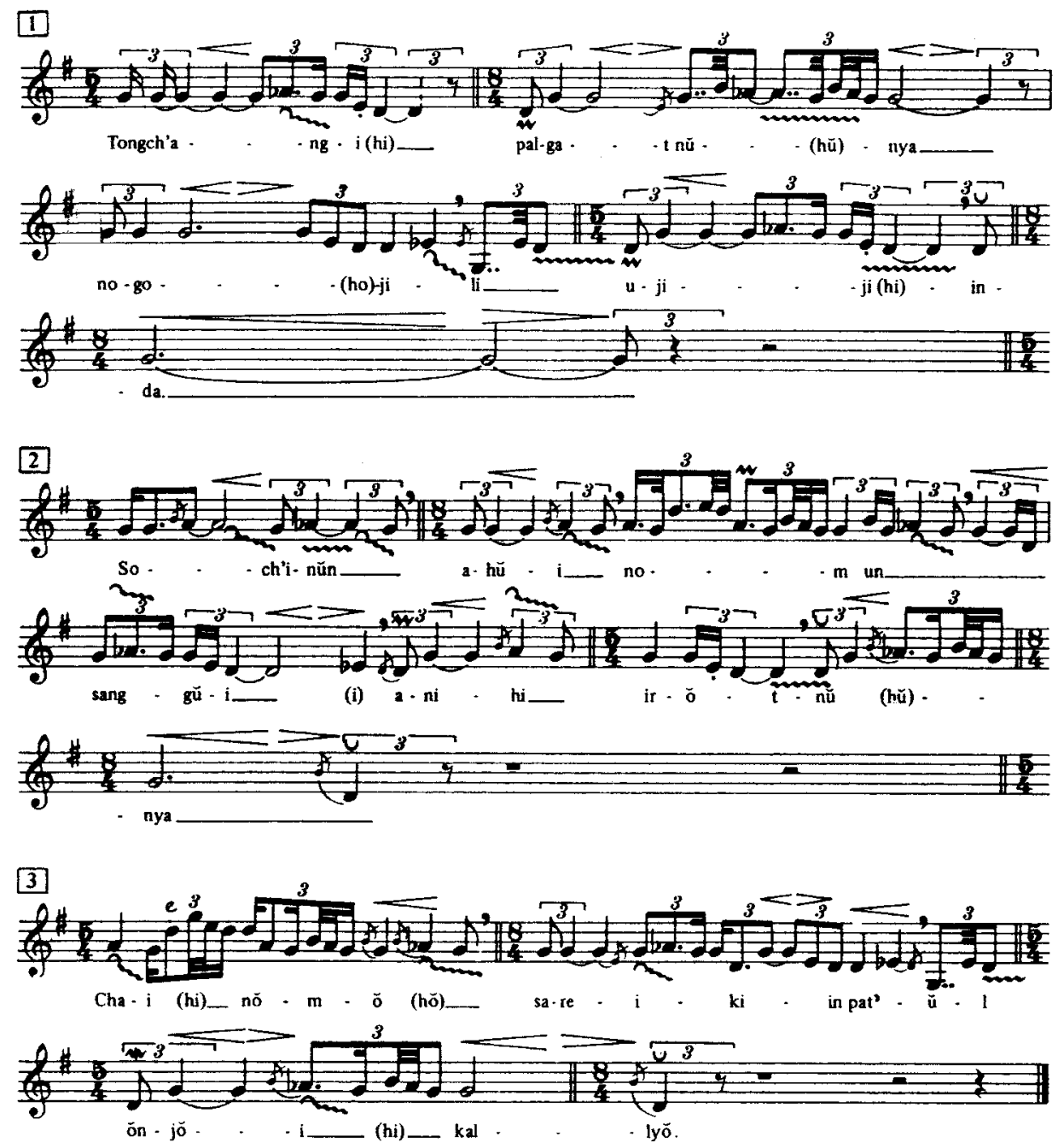

In the center of the text arrangement of Zersplitterung is the poem Ch'immuge taehayo (Silence) by Ko Ŭn (b. 1933), set in the original Korean (Table 6.1). The structure of this poem is juxtaposed with two further Korean poems, Kŭ nalŭn [This Day] by Sangbyŏng Ch’ŏn (1930-1993) in the two interludes and a traditional sijo short poem by Kim Inhu (1510-1560) in the postlude. The "splintering," the fragmentation of traditional and modern culture in Korea, is analogous to the gap between silence and speech, political commitment and interiorization, as documented in the two contemporary poems. They make the suffering and suppression of Korean intellectuals (both in South and North Korea) another facet of this piece.

In addition to dealing with the sijo vocal style, dealing with the sound and rhythm of the Korean language and the poetic style of the poems played a key part in the compositional process. The Koreanist Marion Eggert sent me the original Korean versions of the poems that I had found in 
Example 6.15: Christian Utz, Zersplitterung, beginning of the second part (p. 6)

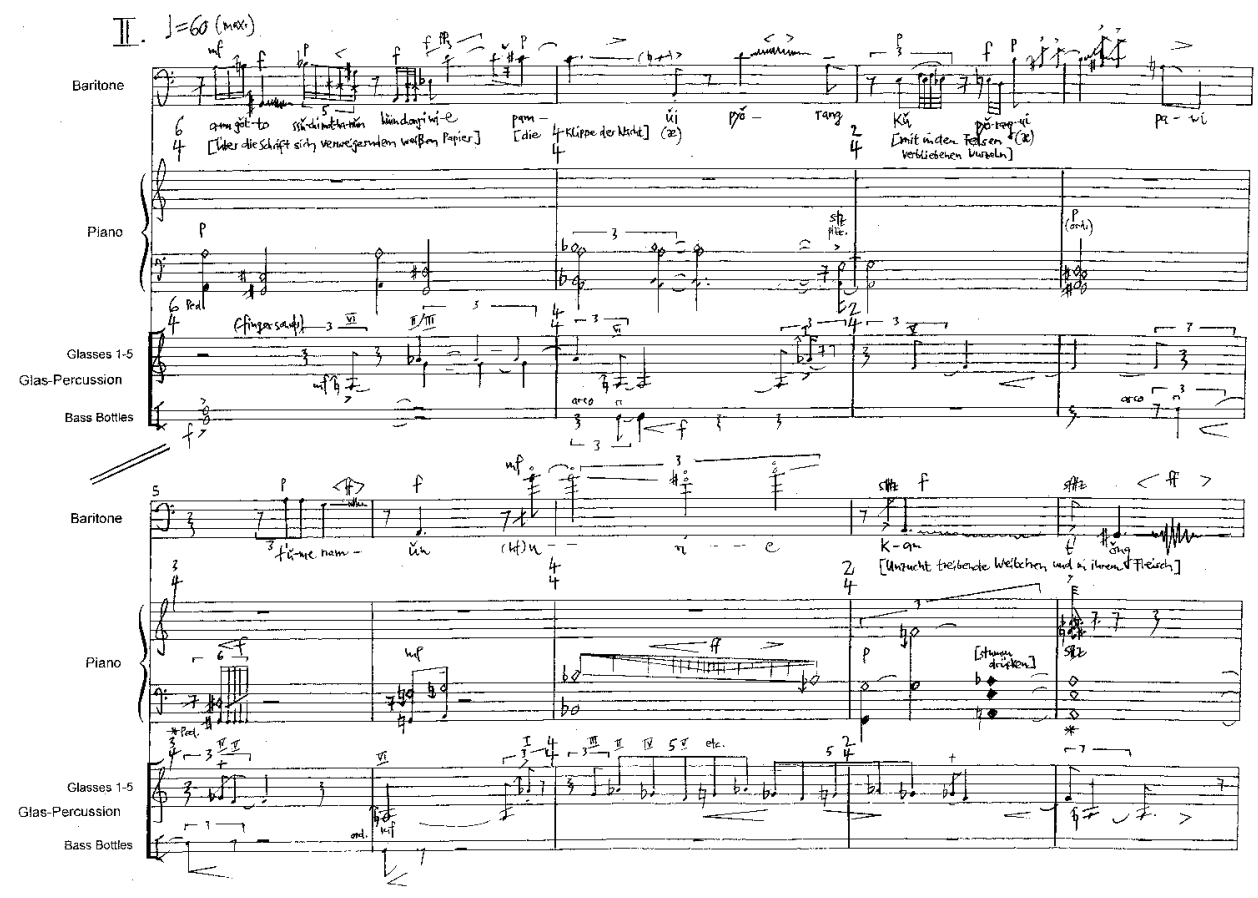

Copyright $\odot 2002$ by UtzMusicPrints, Vienna

Example 6.16: Christian Utz, Zersplitterung, second interlude; breakage of the glass plate (p. 11)

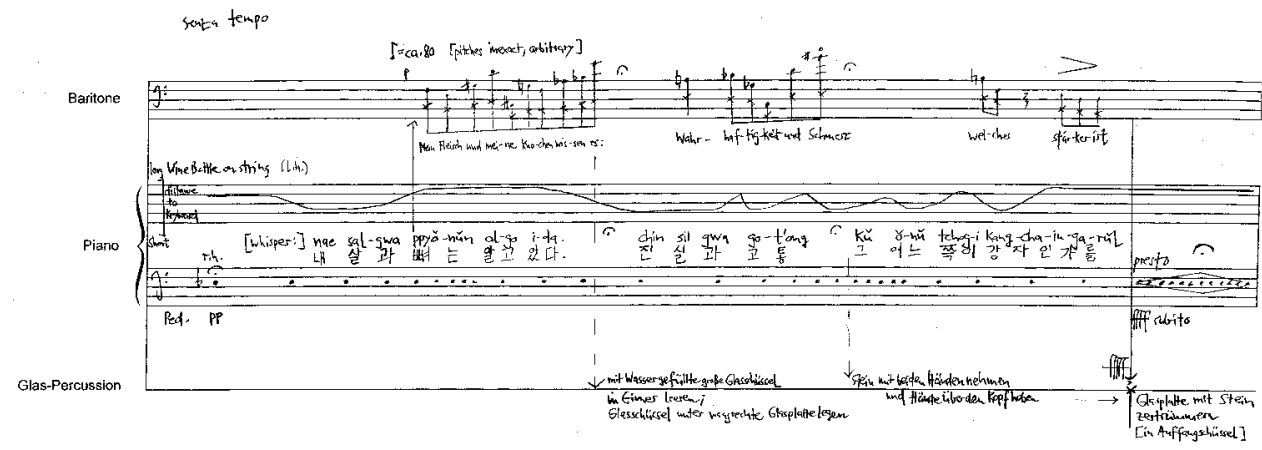

Copyright $\odot 2002$ by UtzMusicPrints, Vienna

her compilation Wind und Gras, ${ }^{33}$ and the pianist at the premiere, Jong-Ah Yoon, recited the poems for me in the original Korean. The rhythm and design of the vocal part are derived directly from the speech rhythm and intonation of this reading; again, I was not aiming for an imitation, but in some places, blatant exaggerations of, or "counter-designs" to, Yoon's reading were included.

33 Eggert, Wind und Gras, 95 and 96-97. The original poem by Kim Inhu and the English translation were taken from the collection Kim, Classical Korean Poetry, 55 (no. 2055). 
Table 6.1: Christian Utz, Zersplitterung, (2002), Libretto, based on poems by Ko Ǔn (b. 1933), Ch'immuge taehayŏ (Silence); Sangbyŏng Ch'ŏn (1930-1993), Kŭ nalŭn (This Day); Inhu Kim (1510-1560), Ch'ŏngsanto (The Blue Hills) (words or verses in italics are not sung/spoken)

\author{
baritone \\ modŭn ch'immuktŭra \\ hanpantoe hŭt'ǒchin ch'immuktŭra \\ toraora \\ oksusŭstae sakyŏinŭn paramsori sairo \\ kangmuri hŭrŭun kosŭl kŏsŭllŏsŏ \\ ŏcheoa talli irŭk'inŭn mulkyŏlsairo \\ ssŏgŭn tuiŏm soke pakheinŭn kich'i sori sairo \\ toraora \\ \{Ko Ǔn, Ch'immuge taehayŏ\} \\ How long ago might it have been \\ since that day when it hit me \\ like the shirt under the iron ... \\ How long ago might it have been \\ since that day when in the house of horror \\ a summer insect offered me a handshake... \\ amu kŏtto ssŭchi mothanŭn hŭin chongi wie \\ pamŭi pyŏrang \\ kŭ pyŏrangŭi pawi t'ŭme namŭn ppurie \\ kant'ŏnghanŭn amk'ŏttŭrŭi sal soge \\ ani soriran sorirŭl ta ijŏbŏrin saramtŭrŭi \\ cham soke inŭn ch'immuktŭra \\ toraora \\ toraoasŏ k’ŏdaran ch'immugŭro \\ ch'immugŭi ausŏngŭl tŭllyŏdao \\ ŏttŏn ausŏngpodado musŏpke \\ modŭn ch'immuktŭra toraora \\ \{Ko Ŭn, Ch'immuge taehayŏ
}

Mein Fleisch und meine Knochen wissen es:

Wahrhaftigkeit und Schmerz

welches stärker ist ...

An einem Rand

des Himmels in mir

reitet ein Vogel in jähem Schrecken die Flügel*
All you silences,

Silences scattered on this island,

come back.

To the crackling of the wind in the blade of corn

Among those waves rebelling against the river,

erected today differently from yesterday,

to the cough that got stuck in the dung heap,

come back.

i jen myŏ nyŏn i ŏ nŭn ga,

a i ron mi wa i sya ŭ gat'i

tang han kŭ narŭn ...

i jen myŏ nyŏn i ŏ nŭn ga,

mu sŏ un chip ti ch'ang sa e yŏ rŭm kon ch'ung han ma ri ttam hul li nŭn na e ge ak su rŭl ch'ong han kŭ nar ŭn ...

\{Sangbyŏng Ch'ŏn, Kŭ nalŭn\}

Over white paper refusing the writing

the cliffof the night-

with roots left in the rocks,

fornicating females and in their flesh

the silences in the sleep of people who forgot

the voiceless voice,

come back.

Returned to a tremendous silence

let the cry of silence be heard

more terrible than any other outcry.

All you silences, come back,

pianist (whispered)

nae sal gwa ppyŏ nŭn al go i ta.

chin sil gwa ko t'ong

kŭ ŏ nŭ tchog i kang cha in ga rŭl ...

nae ma ŭm ha nŭl

han p'yŏn sa e sŏ

sae nŭn so sŭ ra chi ge nal gae p'yŏn ta.

\{Sangbyŏng Ch'ŏn, Kŭ nalŭn\}

* My flesh and my bones know: / Truthfulness and pain / which is stronger ... / On one edge / of heaven in me / a bird spreads its wings in sudden terror 


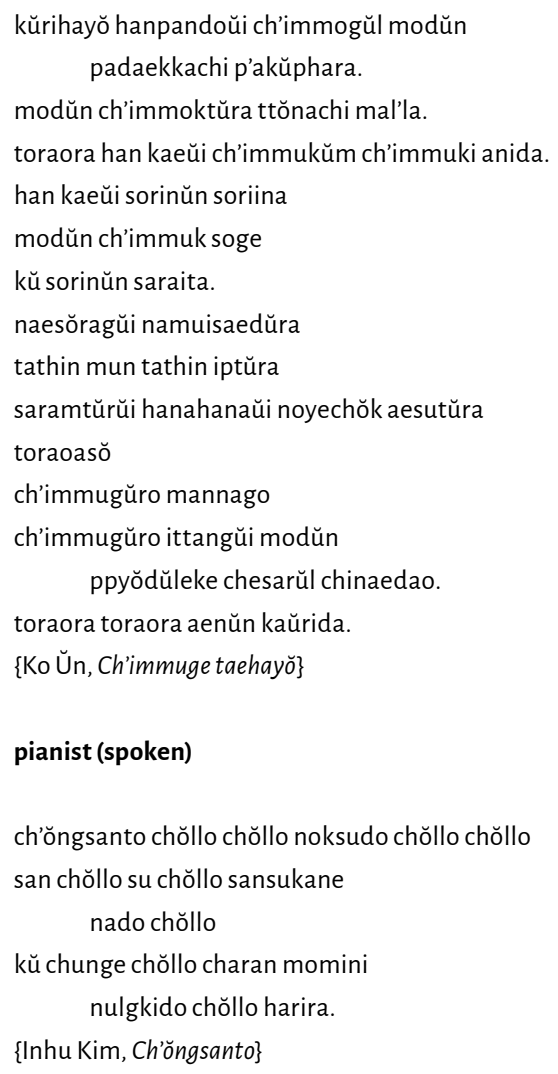

\author{
and carry the silence of Korea to \\ the ends of the seas. \\ All ofyou, don't go \\ turn back. A single silence is not a silence. \\ A single sound is a sound, \\ in every silence \\ lives this sound \\ You leaves of the mountain forest, \\ locked doors, locked mouths you, \\ slavish melancholy from person to person, \\ come back \\ and meet as silence. \\ In silence, bow to every skeleton \\ in this country. \\ Come back, it is autumn.
}

The instrumental writing acknowledges the tensions inherent in the vocal part's "orality" by aiming at a balance between the unstable, sensitive fragility of sounds that are hard to control (overtones produced by bowing glasses or piano strings) and explosive violence charged with maximum energy (booming and piercing effects produced by bottles in the piano, breaking of the glass plate, crushing glass splinters with a mortar, etc.). These sound events, however, are not used as naïve illustrations of the poetic meanings. Instead, they can be understood as a consequence of the music's structural tendency toward fragments or "splinters." A tension between concentration, self-control, and the eruption of withheld energies is a key aspect in the interaction of words and music in Zersplitterung.

\section{Exploration of Tone Spaces and Political Narrativity in telinga - mulut}

Zersplitterung is possibly the last work in which I pursued an explicitly "philological" approach aimed at an intensification of cultural and structural incompatibilities. In a series of ensemble works written between 2001 and 2006, I combined Asian and Western instruments, often with the addition of live electronics, ${ }^{34}$ in varying forms and situations. In these works, I replaced the

34 In addition to the works dealt with in Chapters VI.1 and VI.2 (Interference, together/lapart, the wasteland of minds, and Glasakkord) this series of works includes Kreise - Yuan (1998-2001) for soprano, shakuhachi, flute, string trio, and live electronics and repercussion.camouflage.report (2003) for flute, trombone, sheng/xun, percussion, and live electronics. In 1999, I composed my first work for East Asian instruments, Koinzidenzen (ouran yizhi) for six Chinese instruments (xiao, sheng, erhu, pipa, zhongruan, zheng). 
evocation and transformation of traditional pieces or genres with a more structuralist contextualization in which pitch and timbre constellations were, for instance, derived from the organology, the fingerings, or the string layouts of instruments, common registers, peak pitches, or hybrid timbres. A key aspect of Zersplitterung, the idea of a musical structure that is highly loaded with sometimes narrative, sometimes vaguely metaphorical, but usually ambiguous meaning, however, has been pursued further in my subsequent work, as already demonstrated in Glasakkord, and has become an important link between the structural design and the exploration of cultural conflict and encounter in subsequent works of mine $(\rightarrow$ VI.4).

This principle of structural semantics (or semanticized structure) was taken to a new level in telinga - mulut [ears - mouths] for baritone, recorded female speaker, and four instruments (flute/bass flute, clarinet/bass clarinet, violin, violoncello) (2009), a work exploring the boundaries between concert and stage music. Commissioned by the Salihara Festival in Jakarta, telinga - mulut approaches the poem Suatu Cerita dari Negeri Angin [A Story from the Country of Hot Air, 1998] by the Indonesian poet Agus R. Sarjono. ${ }^{35}$ Sarjono's poem develops highly disturbing images of a village society dominated by suspicion, spying, and open violence, all triggered by the breaking of a dam (presumably linked to corruption among local officials). This is a dimension to which the title of the piece - ears - mouths - refers (Table 6.2): the villagers were once "required to become ears" $\left(76^{36}\right)$ - which I read as a metaphor for spying and mistrust -, but after they had unlearned listening "they are delighted to have become mouths" (78-79) - and they repeat the same, "long-winded and repetitive" story (92-93), possibly propaganda slogans of an authoritarian political regime. Telinga - mulut is thus loosely connected to Zersplitterung, as both pieces focus on highly political questions arising from cultural and social conflicts evident in the selected poetry, and these also leave their marks on the musical settings. Furthermore, both works pursue a multilingual conception in which Indonesian/ Korean, English, and German textual elements are crossrelated.

The setting of telinga - mulut, however, confronts this political impact of the words with a strict, conceptual musical organization that contrasts with the more explicitly expressive writing of the main vocal part in Zersplitterung. In telinga - mulut, music and words remain far more isolated, each leaving the other largely "without comment." No attempt was made to "musicalize" the text according to general musical principles or to shape musical gestures according to the language structure. This stems from my intention to give Sarjono's words, which are fraught with collective traumas from more recent Indonesian history, their own space. They are interspersed with enigmatic prose fragments by Franz Kafka which tell of a bridge equipped with human sensitivity that eventually collapses. Despite the obvious analogy between a breaking dam and a collapsing bridge, this insertion might be understood as a polyvalent comment on the musical structure, rather than Sarjono's words: it is not following the pitch organization in most other sections, which is based on two non-chromatic equidistant

35 Telinga - mulut was premiered in Jakarta at Teater Salihara on 15 July 2009 by Martin Lindsay and ensemble on_line (now PHACE), conducted by Simeon Pironkoff. An edited recording of this performance can be accessed online: https://soundcloud.com/chr_utz/telinga-mulut-2009. I first encountered Sarjono's poems through a collection in German translation (Agus R. Sarjono. Frische Knochen aus Banyuwangi. Berlin: Edition Galrev, 2002), that is opened by Suatu Cerita dari Negeri Angin ("Eine Geschichte aus dem Land der heißen Luft," pp. 5-7). With the kind assistance of the translator Berthold Damshäuser, I contacted Sarjono personally and he provided me with the Indonesian original and an English translation by Toenggoel Siagian, which was slightly adapted for my setting.

36 Numbers refer to the lines in the libretto provided in Table 6.2. 
Table 6.2: Christian Utz, telinga - mulut (ears - mouth) (2009), Libretto, based on texts by Agus $R$. Sarjono (b. 1962), Suatu Cerita dari Negeri Angin (A Story From the Land of Hot Air, 1998; English version after Toenggoel Siagian - slightly modified by the composer) and Franz Kafka (1883-1924),

Die Brücke (1917, fragments from a short prose sketch) (words or verses in italics are not sung/spoken)

\section{baritone}

Airmata yang berpuluh

One morning the dam in my village

built by a thousand hours of indoctrinations,

a hundred ceremonies and ten bayonets

started to rumble and collapsed.

One morning the dam in my village

2 built by a thousand hours of indoctrinations,

a hundred ceremonies and ten bayonets

started to rumble and collapsed. Tears

held back for decades

burst out sweeping the street clean

and changed into a pool of blood.

People hurried to ritually wash their hair

and their memories in it.

they wandered around

with heads looking like cool melons

slinking through all corners of the village

some were even disguised

as assasins for hire.

My uncle and my cousins pounced on them

and then they went berserk. They bashed

those heads with rocks and cutlasses,

maybe there was a sliver of memories

hidden, they said, a kind

of mysterious data useful as topic of conversation

while doing the night rounds.

But there was nothing in those heads

except for soapsuds, remnants of a laundry

too carefully rinsed. Some immediately

went to parade the severed heads around

as if they were parading tattered memories

about a time about a season

in an overcrowded country

filled with hot air.

\section{tape (female speaker)}

Tears held back for decades

Bendungan di kampungku yang dibangun

oleh seribu jam penataran, seratus upacara

dan sepuluh sangkur, pada sebuah subuh

berderak-derak dan runtuh.

Bendungan di kampungku yang dibangun

oleh seribu jam penataran, seratus upacara

dan sepuluh sangkur, pada sebuah subuh

berderak-derak dan runtuh. Airmata

yang berpuluh tahun tertahan

pecah menderas menyapu jalanan

lalu berobah menjadi genangan darah.

Orang-orang bergegas mengeramasi rambut

dan ingatannya di sana. Mereka pun berkeliaran

dengan kepala serupa labu dingin

menyusuri pelosok-pelosok pedesaan

sebagian bahkan menyamar

sebagai pembunuh bayaran.

Paman dan sepupuku yang memergokinya

jadi penasaran. Mereka pecahkan

kepala-kepala itu dengan batu

atau parang, siapa tahu ada sebersit saja ingatan

atau kenangan, ucapnya, semacam data misterius

sebagai bahan gunjingan dikala ronda malam.

Tapi tak ada apa-apa dalam kepala-kepala itu kecuali gelembung sabun, seperti sisa pencucian yang tak dibilas dengan teliti. Sebagian mereka segera mengarak potongan kepala itu seperti mengarak ingatan yang compang-camping tentang sebuah saat sebuah musim

di sebuah negeri yang padat

berisi angin. 
30 My neighbor who loves to tell stories

31 once caught a magician who

32 was slinking stealthily through the bedrooms

33 of his village. When he was strangled

34 and his head cut off, not one story

35 flowed from his throat. His slashed veins

36 just spouted gas accompanied by the shrieking

37 of a siren, a kind of emergency alarm

38 from a sinking ship.

Ich war steif und kalt, ich war eine Brücke, über einem Abgrund lag ich. Diesseits waren die Fußspitzen, jenseits die Hände eingebohrt, in bröckelndem Lehm habe ich mich festgebissen. [...] Gegen Abend im Sommer, dunkler rauschte der Bach, da hörte ich einen Mannesschritt! [...]

Er kam, [...] In mein buschiges Haar fuhr er mit der Spitze und ließ sie [...] lange drin liegen. Dann aber [...] sprang er mit beiden Füßen mir mitten auf den Leib. Ich erschauerte in wildem Schmerz, [...] da stürzte ich schon, ich stürzte, und schon war ich zerrissen und aufgespießt von den zugespitzten Kieseln, die mich immer so friedlich aus dem rasenden Wasser angestarrt hatten.

Since then

56 One morning, I do not know in what month,

57 what year, our village

58 was forced to rebuild the dam.
Tetanggaku yang gemar cerita, pernah menangkap seorang pesulap yang entah mengapa sibuk mengendap-endap di ruang tidur kampungnya.

Setelah dicekik dan ditebas lehernya, ternyata tak sebuah ceritapun mengalir dari kerongkongannya. Dari potongan urat lehernya, hanya gas yang memancar keluar diiringi denging sirine, semacam isyarat darurat dari sebuah kapal yang tengah karam.

Sejak itu

penduduk kampungku ramai-ramai melepas

kepala mereka dan menggantinya

dengan buah kelapa: keras dan berair.

Buat persiapan, ucap mereka, jika seluruh

kampung hangus terbakar, kepala kami

masih bisa basah menyimpan ingatan

tentang anak-anak tersayang yang mengembara

ke kota-kota, bersekolah atau bergelandangan

mengais hari depan. Tiba-tiba

di suatu malam anak-anak mereka bermunculan

dari balik gumpalan asap dan gas airmata

dengan tengkuk penuh peluru hingga semua bapak

tersedak dan ibu tersedu. Akhirnya, selepas musim panen yang gagal karena hama dan cuaca busuk dengan sabar mereka tanam kembali anak-anak mereka di tengah sawah dan ladang.

Di sebuah pagi, entah bulan apa entah tahun berapa, seluruh kampung kami diwajibkan bergotong-royong membangun 


\section{For quite some time}

Now they are delighted

9 to have become mouths.

When they began

80 to be able to construct stories,

81 they were disappointed, for no one

82 was willing anymore to be ears

83 including members of the village board.

84 So all the new stories that they had composed

85 no longer had an audience.

Patienly, they took them quietly in the rice fields and gardens imagining that during the coming harvest time the grown trees would bear fruit to thousands of stories. But one of the trees grew too fast and bore as fruit the same story: long-winded and repetitive.

bendungan itu kembali. Segera mereka curahkan habis-habisan seluruh airmata mereka di sana sambil berharap-harap barangkali saja suatu hari kelak bisa mereka lepaskan kelapa, semangka atau labu dari atas leher mereka.

Di bawah gerimis di sebuah sore entah bulan apa entah tahun berapa, penduduk kampung itu ramai-ramai memenuhi tepian bendungan untuk mengail dan mencari kembali kepala mereka.

\section{Sungguh}

lama mereka rindukan kepala yang biasa saja lengkap dengan ingatan atau kenangan tentu izin untuk memakainya kembali sudah mereka urus bersama di kantor kepala desa yang entah mengapa kini tampak tersipu dan agak malu dengan kepala buaya yang selama ini terpasang elok di atas lehernya.

Dulu, di kampung kami seluruh penduduk diwajibkan menjadi telinga.

Mereka terbiasa menerima gelembung-gelembung sabun dari mulut licin para pengurus desa.

Kini mereka bersukaria bisa menjadi mulut.

Tatkala mereka mulai pandai membikin cerita, merekapun kecewa tak ada lagi yang bersedia menjadi telinga juga segala aparat desa hingga segala cerita baru yang mereka susun itu tak lagi ada yang mendengarnya.

Dengan sabar, segala cerita yang mereka susun mereka tanam diam-diam di sawah dan ladang sambil membayang-bayangkan tibanya musim panen ketika semua pohon tumbuh dan berbuah ribuan kisah. Tapi salah satunya tumbuh kelewat cepat dan berbuah cerita-cerita yang sama: panjang dan berulang. 
scale systems (Ex. 6.17). In system A the octave is divided into ten equal steps (i.e., 120-cent steps), and in system B the minor ninth is divided into seven equal steps (i.e., c. 186-cent steps). The confines of these rigid pitch structures are challenged by inflections in sections where pitches are consistently destabilized, creating fields of varying noise content, especially during the insertion of the Kafka fragment in Section C (see Table 6.3). The rigidity of the pitch structure exhibits a tendency to "collapse" at a very sudden, unpredictable moment toward the end of the piece in part B4 (see Table 6.3).

Neither pitch system makes any reference to the lower parts of the harmonic series or its proportions, and they are therefore not intended (in contrast to some proponents of spectral approaches in contemporary music) to imply "pure" intervals as an implicit criticism of the equidistant chromatic system. Instead, they are representative (just like the chromatic scale commonly used) of a highly artificial rationalization of note relationships and might be understood as tongue-in-cheek musings on the phenomenon of tempered pitch systems (- why could history not also have produced systems with ten, instead of twelve, notes per octave?). The performers are, however, encouraged to stretch and narrow the intervals intuitively, though without resorting to the habitual twelve-tone scale. Thus, I give each system an individual sound space (in a similar way, intonation is always adjusted in more conventional pitch systems according to style, composer, or work). This idea of a deliberate stretching and narrowing of intervals also refers to the practice in some Indonesian gamelan ensembles of consciously detuning identical paired instruments in relation to each other in order to create beating and interference patterns.

Again, the overall formal design of telinga - mulut follows a very simple alternating scheme with slight "interruptions" (Table 6.3). In all A sections, Sarjono's poem is rendered by the baritone in English translation, while in the B sections it is heard from tape recited by the female Indonesian speaker Palupi Warananingtyas. ${ }^{37}$ In the beginning and toward the end, English and Indonesian layers overlap.

In the A sections, the baritone is conceived as part of a basic five-part structure in which the voice and instruments act on the same hierarchical level, molded into "homophonic fields" that gradually explore the scale and intervals of system $A$. These fields are interrupted by three recitative-like vocal narratives in Section $\mathrm{A} 1$ in which the baritone takes the role of a storyteller - a function that is further explored in dramatic scenes in Sections $\mathrm{C}$ and $\mathrm{A} 3$ and taken to surreal and ecstatic levels. In $\mathrm{A}_{2}$ and $\mathrm{A} 4$, the homophonic fields tend to disperse into fragmented and, especially in A4, into heterophonic structures. All A sections have been developed from the same basic model introduced at the beginning of A1, resulting in a large-scale variation structure. Example 6.18 gives a sense of the transformation process taking place during these four "variations" by comparing a few measures from the beginning of each A section.

The $B$ sections take the speech rhythm of the prerecorded Indonesian text as a structural model for six complementary duos (including, as two variants, a solo in B3 and a tutti in B4). "Complementary" here means that the live instruments punctuate the speech rhythm heard from tape. Similarly to the A sections, the pitch constellations are derived from a cautious exploration of pitch system B in its scale and intervals (Ex. 6.19).

37 Palupi Warananingtyas is a singer and academic teaching at the Universitas Sebelas Maret, Surakarta/Java; her recitation of Sarjono's poem was recorded in at the University of Music in Graz, Austria on 6 May 2009, where Ms. Warananingtyas presented a guest lecture on vocal music genres in Indonesia. 
Example 6.17: Christian Utz, telinga-mulut, tone systems: scale A divides the octave into ten equal steps (one step = 120 cent) from Bb1 (the lowest instrumental pitch used in this piece); scale B divides the minor ninth into seven equal steps (one step $=185.71$ cent) from $\mathrm{C} 2$

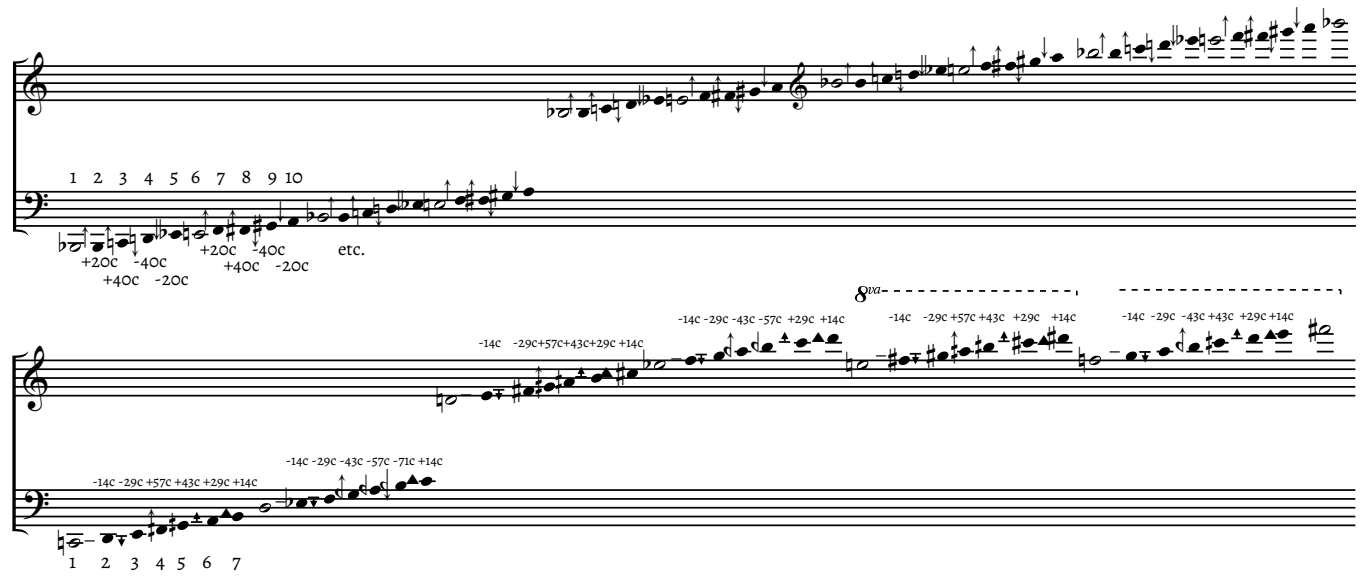

The multiplicity of perspectives involved in the compositional process (pitch systems, scalar, intervallic, and timbral principles, phonetic, semantic, and rhythmic dimensions of the text, and text-music interaction) mirrors the confusing effect of the multilingual setting. The deformation and destabilization of all layers is considerably enhanced after the sudden collapse in the ephemeral Section B4: the final crisis is reached in the breathless alternation between heterophonic fragments between baritone and instrumental ensemble and isolated snatches of the prerecorded Indonesian recitation in Section A4.2 (Ex. 6.20). The rigid musical structure is turned completely on its head by these ruptures and develops into a strange figural field, with the high bass clarinet taking up the falsetto timbre of the baritone, who in turn whistles a melodic fragment that has emerged over the course of the piece as a fixed idea within pitch system A (mm. 289-294). The atmosphere has turned into a field of memory, a remembrance that gets stuck toward the end in a sequence of abruptly rhythmicized, pressed bow impulses (mm. 294-296). In the end, the singer appears to have lost his ability to articulate (soundless movements of the mouth in the baritone part mark the end of the piece).

\section{Toward a Polyphony of Meanings}

As mentioned at the beginning of this chapter $(\rightarrow$ VI.1), the compositional approaches I have described should not be seen as exemplifications of a theory of interculturality. My music, however, definitely aims to encompass concepts of composed alterity - musical processes which are rigorously separated from one another, and hypolepsis - musical processes that connect to one another both by negation and transformation. However, the music never really "succeeds" in keeping the layers or sections "pure" and separate; rather, processes of convergence or dissolution remind the listener that these layers constantly refer to one another and have a common destiny. There is no harmonious reconciliation of the realms and dimensions of the music, but neither is there any insistence on negativity as the only way.

In Zersplitterung and telinga - mulut, the highly versatile nature of the human voice as a messenger between musical structure and meaning, in conjunction with the multilingual text settings and the specific qualities of the languages involved, is of particular significance for the 
Table 6.3: Christian Utz, telinga - mulut, synopsis. Line numbers for the poem refer to the English translation (see Table 6.2), although the verse structure differs from that of the Indonesian original in some instances.

\begin{tabular}{|c|c|c|c|c|c|}
\hline section & measures & formal function & tempo/character & $\begin{array}{l}\text { text }(S=\text { Sarjono; } \\
\mathrm{K}=\text { Kafka) }\end{array}$ & $\begin{array}{l}\text { tone } \\
\text { system }\end{array}$ \\
\hline \multirow[t]{2}{*}{ A1.1 } & 1 & echo & & -- & \multirow[t]{8}{*}{ A } \\
\hline & $2-13$ & $\begin{array}{l}\text { introduction } \\
\text { (homophonic field 1) }\end{array}$ & $\begin{array}{l}d=30 \text {, tentative } \\
\text { and fragile }\end{array}$ & $\begin{array}{l}\text { S.1-4 Indonesian (tape) } \\
\text { S.4-5 Indonesian (baritone) }\end{array}$ & \\
\hline \multirow[t]{6}{*}{ A1.2 } & $14-16$ & vocal narrative 1 & slow, in time & S.1-4 English (bar.) & \\
\hline & $17-28$ & homophonic field 2 & $\begin{array}{l}d=40 \text {, pressing } \\
\text { forward imperceptibly }\end{array}$ & S.4.2-8.1 English (bar.) & \\
\hline & $29-35$ & vocal narrative 2 & & S.8.2-14 English (bar.) & \\
\hline & $36-47$ & homophonic field 3 & $d=50$, restless & S.15-18.1 English (bar.) & \\
\hline & $48-51$ & vocal narrative 3 & $\begin{array}{l}\text { slower, but in } \\
\text { steady time }\end{array}$ & S.18.2-21 English (bar.) & \\
\hline & $52-54$ & echoes & $d=40$ & -- & \\
\hline \multirow{2}{*}{$\begin{array}{l}\text { B1 } \\
\text { (vl. + vc.) }\end{array}$} & $55-64$ & duo: introduction & $d=40 ; \cdot d=40$ & -- & \multirow[t]{2}{*}{ B } \\
\hline & $65-71$ & complementary duo 1 & $\cdot=60$ & S.22-29 Indonesian (tape) & \\
\hline \multirow[t]{3}{*}{ A2 } & $72-83$ & \multirow[t]{3}{*}{$\begin{array}{l}\text { homophonic field } 4 \\
\text { (dispersed) }\end{array}$} & $\begin{array}{l}d=40 \text {, continuously } \\
\text { pressing forward, } \\
\text { but not actually } \\
\text { accelerating }\end{array}$ & S.30-31 English (bar.) & \multirow[t]{3}{*}{ A } \\
\hline & $84-97$ & & & S.32-35.1 English (bar.) & \\
\hline & 98-1111 & & & S.35.2-38 English (bar.) & \\
\hline \multirow[t]{4}{*}{ C } & 112 & \multirow{4}{*}{$\begin{array}{l}\text { noise field + } \\
\text { dramatic scene }\end{array}$} & senza tempo & & \multirow[t]{2}{*}{--} \\
\hline & $113-126$ & & $d=132$ & K & \\
\hline & $127-133$ & & & & B \\
\hline & $134-157$ & & & & -- \\
\hline \multirow[t]{5}{*}{$\begin{array}{l}\text { B2 (bcl. + } \\
\text { vc.) }\end{array}$} & $158-161$ & $\begin{array}{l}\text { complementary } \\
\text { duo } 2\end{array}$ & $\downarrow=40-. d=60$ & S.39-41 Indonesian (tape) & \multirow[t]{5}{*}{ B } \\
\hline & $162-166$ & duo: interlude & & & \\
\hline & $167-172$ & $\begin{array}{l}\text { complementary } \\
\text { duo } 3\end{array}$ & & S.42-47.1 Indonesian (tape) & \\
\hline & $173-176$ & duo: interlude & $d=40$ & & \\
\hline & $177-185$ & $\begin{array}{l}\text { complementary } \\
\text { duo } 4\end{array}$ & $\cdot=60$ & S.47.2-55 Indonesian (tape) & \\
\hline
\end{tabular}




\begin{tabular}{|c|c|c|c|c|c|}
\hline \multirow[t]{3}{*}{ A3 } & 186-203 & $\begin{array}{l}\text { homophonic field } 5 \\
\text { (interrupted) }\end{array}$ & $d=60$, sleepwalking & S.56-61 English (bar.) & \multirow[t]{3}{*}{$A$} \\
\hline & 204-212 & breakout & $d=90$, precipitato & S.62-63 English (bar.) & \\
\hline & $213-220$ & madness scene & $d=60$, semplice & S.64-67 English (bar.) & \\
\hline B3 (vl.) & $221-237$ & $\begin{array}{l}\text { complementary } \\
\text { "duo" } 5\end{array}$ & $d=40$ & S.68-74 Indonesian (tape) & B \\
\hline \multirow[t]{2}{*}{ A4 } & $238-245$ & $\begin{array}{l}\text { homophonic field 6: } \\
\text { introduction }\end{array}$ & $\begin{array}{l}d=60, \text { gentle and } \\
\text { serene }\end{array}$ & -- & \\
\hline & $246-263$ & homophonic field 6 & & S.75-79 English (bar.) & \\
\hline B4 (tutti) & $264-269$ & $\begin{array}{l}\text { complementary } \\
\text { "duo" } 6 \text { / } \\
\text { dramatic scene }\end{array}$ & $d=60$, collapsing & $\begin{array}{l}\text { S.80-85.1 English (bar.; } \\
\text { mouth shut) + Indonesian } \\
\text { (tape) }\end{array}$ & \\
\hline \multirow[t]{3}{*}{ A4.2 } & $270-300$ & $\begin{array}{l}\text { homophonic field } 7 \\
\text { (dispersing) }\end{array}$ & $\begin{array}{l}d=60, \text { sempre } \\
\text { ritardando à } d=40 \\
\text { (m. 296) }\end{array}$ & $\begin{array}{l}\text { S.85.2-93 English (Bar.)+ } \\
\text { Indonesian (tape) }\end{array}$ & \multirow[t]{3}{*}{ A } \\
\hline & $301-303$ & echoes & $d=30$ & & \\
\hline & 304 & $\begin{array}{l}\text { silent mouth } \\
\text { movements }\end{array}$ & & & \\
\hline
\end{tabular}

Example 6.18: Christian Utz, telinga - mulut, beginnings of sections A1 (mm. 1-6), A2 (mm. 72-79), A3 (mm. 186-192), A4 (mm. 238-243)

A1

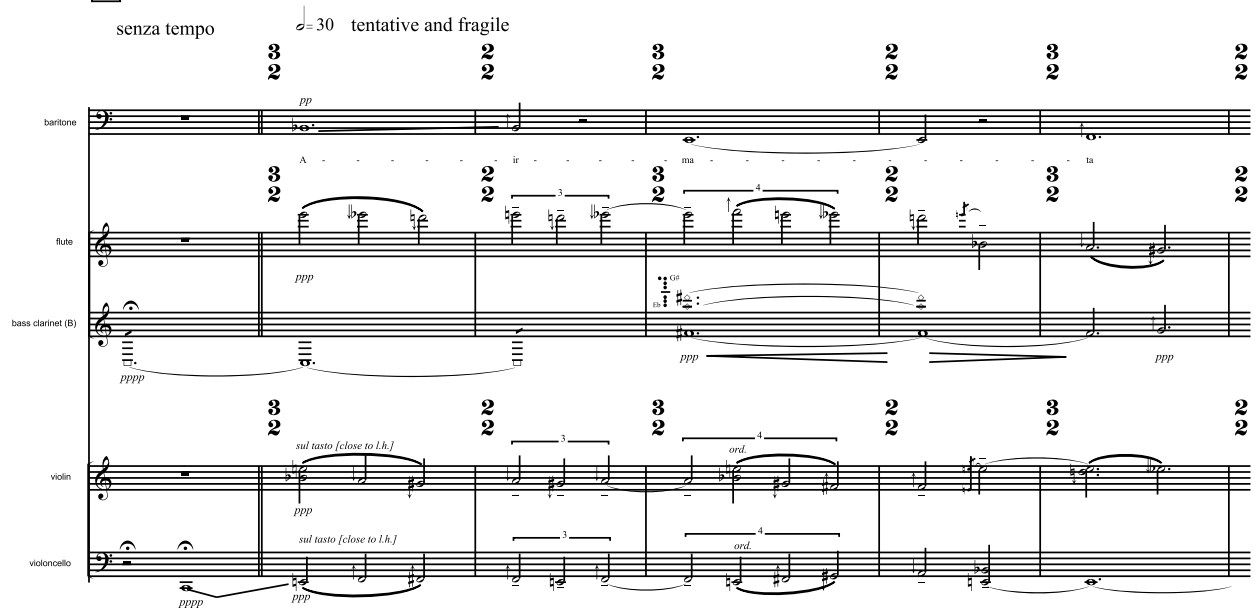


A2 $d=40$ continuously pressing, but not actually accelerating

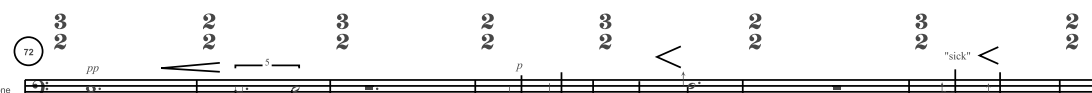

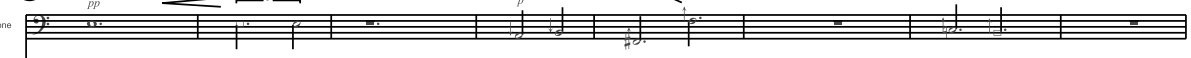

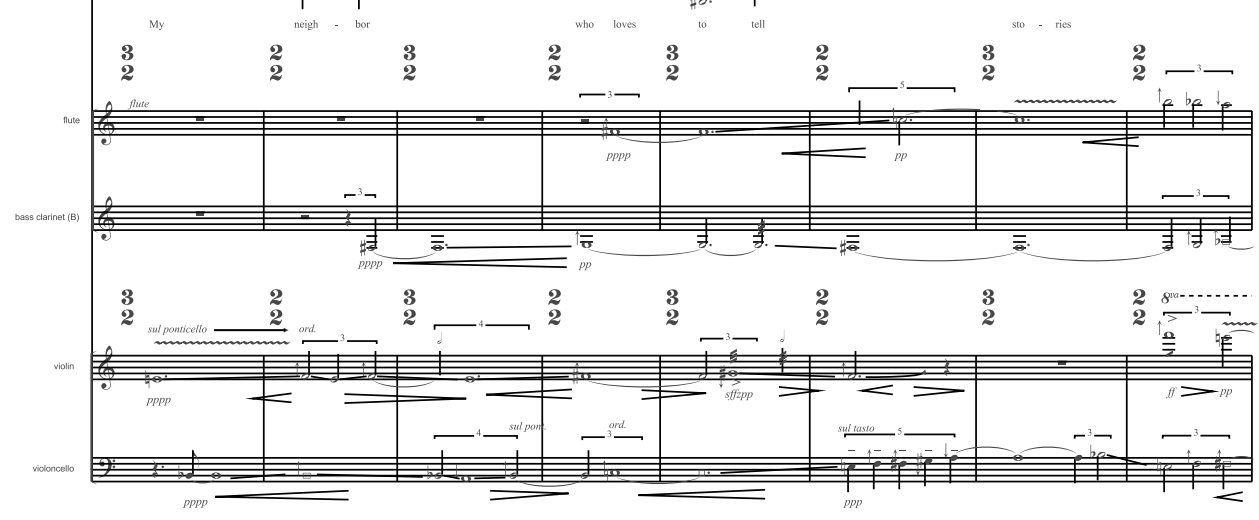

A3 $d=60$ sleepwalking

(13) $\stackrel{3}{2}$

$\stackrel{2}{2}$

$\mathbf{2}_{\mathbf{2}}^{+}+\frac{\mathbf{1}}{4}$

$\mathfrak{2}^{+}+\frac{1}{4}$

$\stackrel{2}{2}$

$\mathbf{5}$
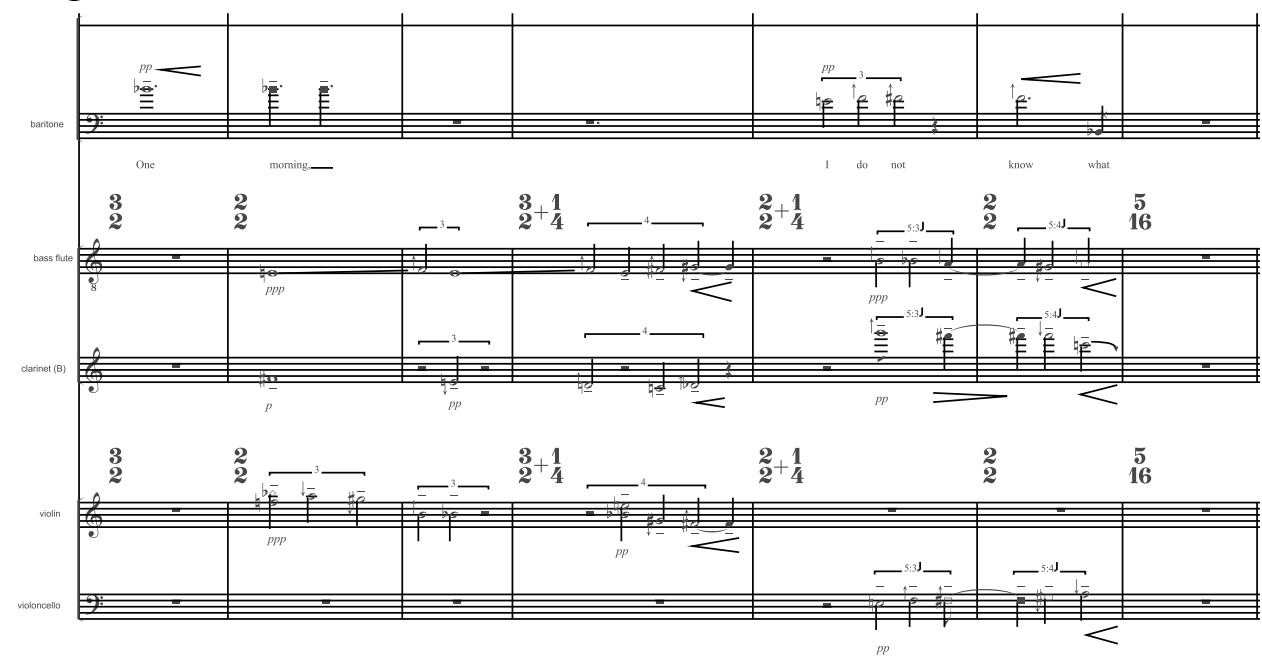

A4 $\delta=60$ gentle and serene

(2003) $3_{2}^{3}$

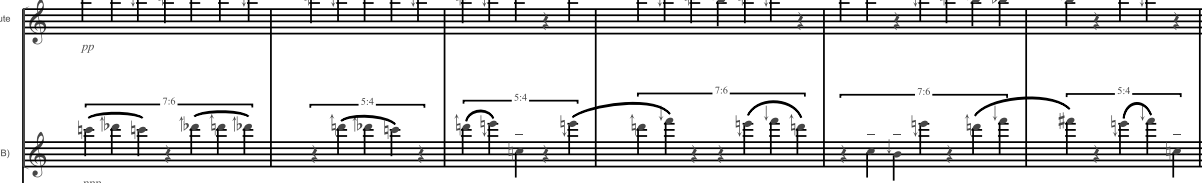

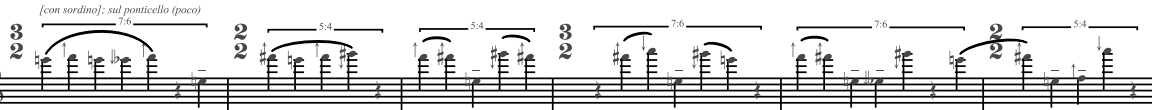

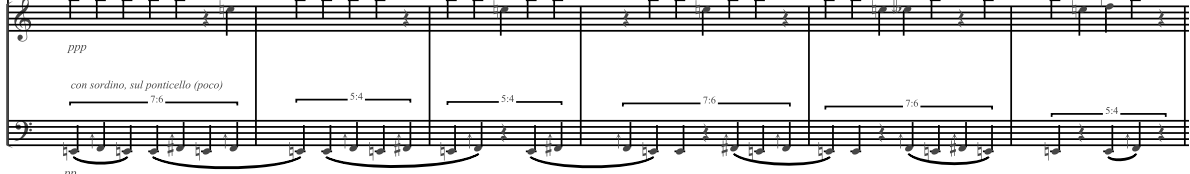


Example 6.19: Christian Utz, telinga-mulut, section B2, mm. 177-185
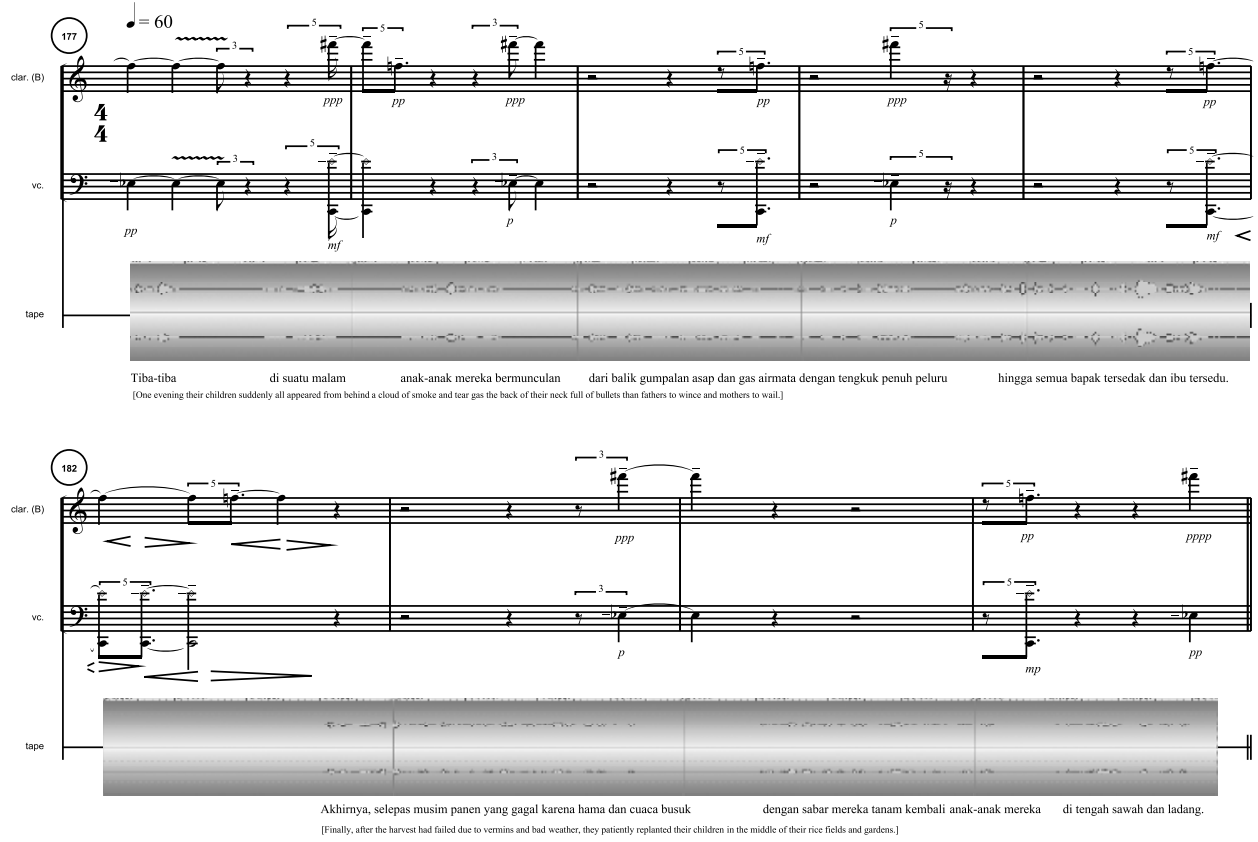

Copyright $\odot 2009$ by UtzMusicPrints, Vienna

Example 6.20: Christian Utz, telinga - mulut, section A4.2, mm. 275-282

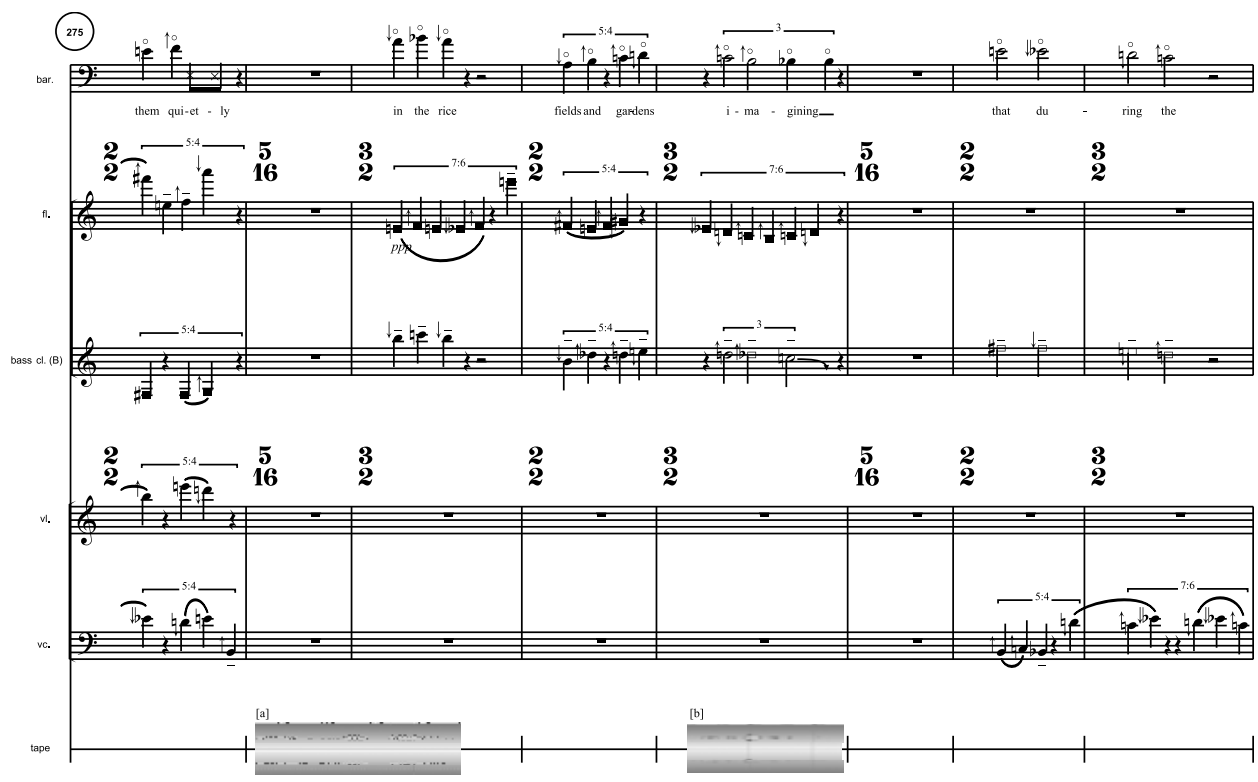

Copyright $\odot 2009$ by UtzMusicPrints, Vienna 
overall effect of the music on the listener. Its chameleon-like interaction with the sound world of the instrumental layers - acting as subject, object, and an almost imperceptible element among equal voices in a global texture or structure - brings together dramatic, narrative, and purely structural dimensions.

Despite the politically loaded references and symbolism of the texts, both works refrain from making any authoritative statement about musical or political meaning. The polyphony of the compositional methods employed can be understood as an affinity for the metaphors of "polyphony" or "plurality of voices" in literary criticism as developed by Mikhail Bakhtin and Jacques Derrida, among others. Bakhtin describes the polyphonic novel as a situation in which an author or narrator no longer has control over the characters, but acts with them on the same hierarchical level: ${ }^{38}$ "There is no third person to bring unity to the confrontation between the two; they do not culminate in a stable ' $I$ ' which would be the ' $\mathrm{I}$ ' of the monologic author." ${ }^{39}$ In my compositions, however, "polyphony" is not limited to the hierarchical balance of different musical and textual layers, but might also be connected to Derrida's idea of an inner polyphony within voices and single words:

Voice can betray the body to which it is lent, it can make it ventriloquize as if the body were no longer anything more than the actor or the double of another voice, of the voice of the other, even of an innumerable, incalculable polyphony. A voice may give birth [...] to another body. ${ }^{40}$

Already when a word has several meanings - and this plurality is irreducible -you can hear in it, or it lets you hear even if you don't take the initiative, several meanings and thus several voices. There are several voices already in the word. One can give this plurality of voices in the word itself its freedom, more or less freedom. ${ }^{41}$

\section{Composition as Polyphony: Creating, Performing, and Perceiving Music Non-Hierarchically}

When we speak of "polyphony" in the context of this book, this naturally implies the idea of an "(inter)cultural polyphony," the idea of an "encounter" or "confrontation" between two (or more) different systems or understandings of sound and listening that may or may not have common features, common ground. Bhaktin's and Derrida's decentering of the subject as condensed into the metaphor of polyphony, outlined above, has profound musical implications. In contemporary music, however, the term "polyphony" has rarely been used after 1945, probably because of its close association with past musical epochs such as Renaissance or Baroque (not to mention "counterpoint," which, owing to its image as a narrowly rule-based and outdated method, has temporarily disappeared almost entirely from compositional discourse). ${ }^{42} \mathrm{~A}$ "radicalized" polyphony, a simultaneous occurrence of different musical layers or personae, however, is at the core of many new music poetics, as demonstrated in preceding chapters $(\rightarrow$ V.3, VI.1).

38 See Bakhtin, Problems of Dostoevsky's Poetics, 5-46.

39 Kristeva, "The Ruin of a Poetics," 111.

40 Derrida, Points... Interviews 1974-1994, 161.

41 Ibid., 392-393.

42 See the detailed discussion of these terms and their applicability to new music in Kleinrath and Utz, "Harmonik / Polyphonie." 
John Cage is an obvious example: from the early 1950s, he created many pieces or collections of pieces that can be performed simultaneously in any combination, often without any specified restrictions. In 1991, experiencing a complete simultaneous performance of Cage's Ten Thousand Things, a collection of solo pieces for piano, violin, percussion, and speaker completed between 1953 and 1956, ${ }^{43}$ was a revelation for me as a young composer. It motivated me to engage more self-consciously with the idea of simultaneous musical structures that would not be coordinated precisely by a score, but rather allow for different versions and interconnections in each performance.

It seems that some recent developments in contemporary art music tend to give up the kind of pleasantly disorienting complexity that I associate with such an experience of musical simultaneity, and I feel that this leads to a certain dependence on "designed" but one-dimensional musical surfaces. (This may seem an overly generalized criticism, but it will suffice here to point to common experiences I might share with many colleagues in daily encounters with "academic" new music, however broadly defined.) That is why I feel a certain necessity to insist on "polyphony" as a fruitful component of a critical music of our time. In approaching this dynamic, I will proceed by discussing a number of my own works from perceptual perspectives, leading into a theoretical-psychological excursus and closing with analytical remarks on my recent work walls for ensemble (2018), premiered in Beijing in July 2018.

Several years after my 1991 "Cage experience," the problem of simultaneous layers reoccurred in my music when I tried to find compositional solutions to the challenge of musical interculturality. Simultaneity in a narrower sense, explored repeatedly in this book, seemed to be a valid option for combining East Asian and Western instruments in the same ensemble, as suggested most prominently by Tōru Takemitsu's well-known (and Cage-influenced) work November Steps from 1967 ( $\rightarrow$ III.4, VI.I). As elaborated earlier, the cultural essentialism inherent in such a conception appeared increasingly problematic to me. How, then, was it possible to put "Asian" and "Western" parts of an ensemble on the same footing without reducing them to a static image of associated local, national, or "cultural" traditions - but also without subsuming them under an authoritative compositional concept that does not allow any kind of idiomatics to emerge?

The preceding analyses aimed to demonstrate the answers to this intricate compositional problem that I have attempted to provide in a series of chamber music pieces composed between 2001 and 2006, in which Western instruments mix with Korean, Chinese, and Japanese instruments. The principal idea on which these works are based may be understood as evoking the image of a broad three-dimensional sonic and temporal space subjected to constant kaleidoscopic transformation during the listening process. These works aim at a sonic situation in which foreground and background are permanently reconfigured; culturally defined idioms may be incorporated as inseparable parts of this sonorous environment, partly preserved, partly dissolved.

As we have seen, Interference and together//apart from 2001 employ culturally defined structural layers as key materials: Webern's piano variations op. 27, Xing jie from the South Chinese Silk-and-Bamboo repertoire (sizhuyue), the Korean court music piece Sangnyŏngsan, and Isang Yun's duo Together. In many parts of Interference, the different materials are still recognizable, remaining broadly indebted to Takemitsu's idea of enhanced cultural difference preserved in a montage-like simultaneity, especially in the first part, where the mosaic-like surface consists of easily distinguishable layers ( $\rightarrow$ VI.1). Although there are multiple processes of interaction between these layers, most notably in a transformation of the zheng zither in the direction of the piano's Webernian idiom, the idea of enhanced cultural difference is expressed in a rather

43 See Pritchett, The Music ofJohn Cage, 95-103. 
crude montage-like simultaneity. Similar processes operate in the background of together// apart, though here the original materials largely "disappear" in a dense polymetric and polytemporal structure. The layering of meter and tempo in this work serves to communicate a refined form of heterophony or slight "asynchronicity" in response to traditional Korean ensemble playing, resulting in a mode of performance that "collapses" toward the end and gives way to a more propulsive ensemble structure $(\rightarrow$ VI.2).

Three to five years later, I further radicalized the idea of simultaneous layering in the wasteland of minds and Glasakkord. Here, I increasingly associated the idea of simultaneity with conflict and "incompatibility," resulting from a more "pessimistic" perspective on interculturality in the wake of $9 / 11$ and the Iraq War. The dense layering of proportional structures of asynchronous and cyclical rhythmic layers is continuously transformed by live electronics in the wasteland of minds and destroyed by increasingly contrasting interruptions in Glasakkord.

In turning to my more recent research on the phenomenological and performative aspects of musical listening, ${ }^{44}$ I would like to convey a somewhat more precise idea of the experience of hearing sound structures as resulting from layered structures, as in the wasteland of minds $\rightarrow$ VI.I, Ex. 6.3-6.6). What is the auditory consequence of this kind of enhanced layering? One might emphasize the diversity of perceptual approaches that this layered structure affords, something that might be described as "performative listening": the option to fluctuate or switch constantly (or selectively) between different "listening attitudes." If we take the beginning of the wasteland of minds (mm. 1-8), it is intended to allow for - at least - four different attitudes of listening. Needless to say, these attitudes are not mutually exclusive, but rather overlap or can be considered complementary to some degree (Fig. 6.2):

1. An "isolationist" or analytical mode would carefully distinguish between the different sound strata or streams: the sustained clarinet, the nervous gestures of the accordion, the plucked impulses of the zheng, etc. Heard in this way, the music seems literally to place ("-pose") together ("com-") different characteristic and superimposed elements in an almost montagelike manner that can be related to one another by multiple cross-connections (dotted lines).

2. Listening to this section "holistically" would imply considering the different elements as "sub-streams" of an overall transformative sound process; this attitude is suggested by the rudimentary transcription of the sonographic analysis to score notation, demonstrating several layers of sonic continuity; in consequence, one might perceive this opening as a single constantly transforming and evolving sound.

3. In yet another listening attitude, we might focus on cues in the overall musical process, salient, outstanding events that organize the temporal flow of the sound, marked by vertical lines on the sonogram. These are most notably the plucked impulses of the zheng but may also include entries of new registers or timbres.

4. Finally, one can practice an attitude of presentist listening, focusing on the sound events as they occur in real time, without analytical distinctions between streams or segments. This mode would largely relate to what Stockhausen has described as "moment form,"

44 See, among other publications, Utz, "Liberating' Sound and Perception" and Utz, "Time-Space Experience in Works for Solo Cello." My research on performative listening and performative analysis has been conducted since 2009, documented in around twenty articles, and is set to appear in a monograph in 2021.

45 Stockhausen, "Momentform." 
Figure 6.2: Christian Utz, the wasteland of minds, $m m$. 1-8, sonagram and rudimentary transcription; the graphic elements suggest four different modes of listening: "analytical" (small gray boxes and dotted lines), "holistic" (large black box around the entire sonagram excerpt), "cue-oriented" (arrows and vertical lines), and "presentist" (mid-size gray boxes)

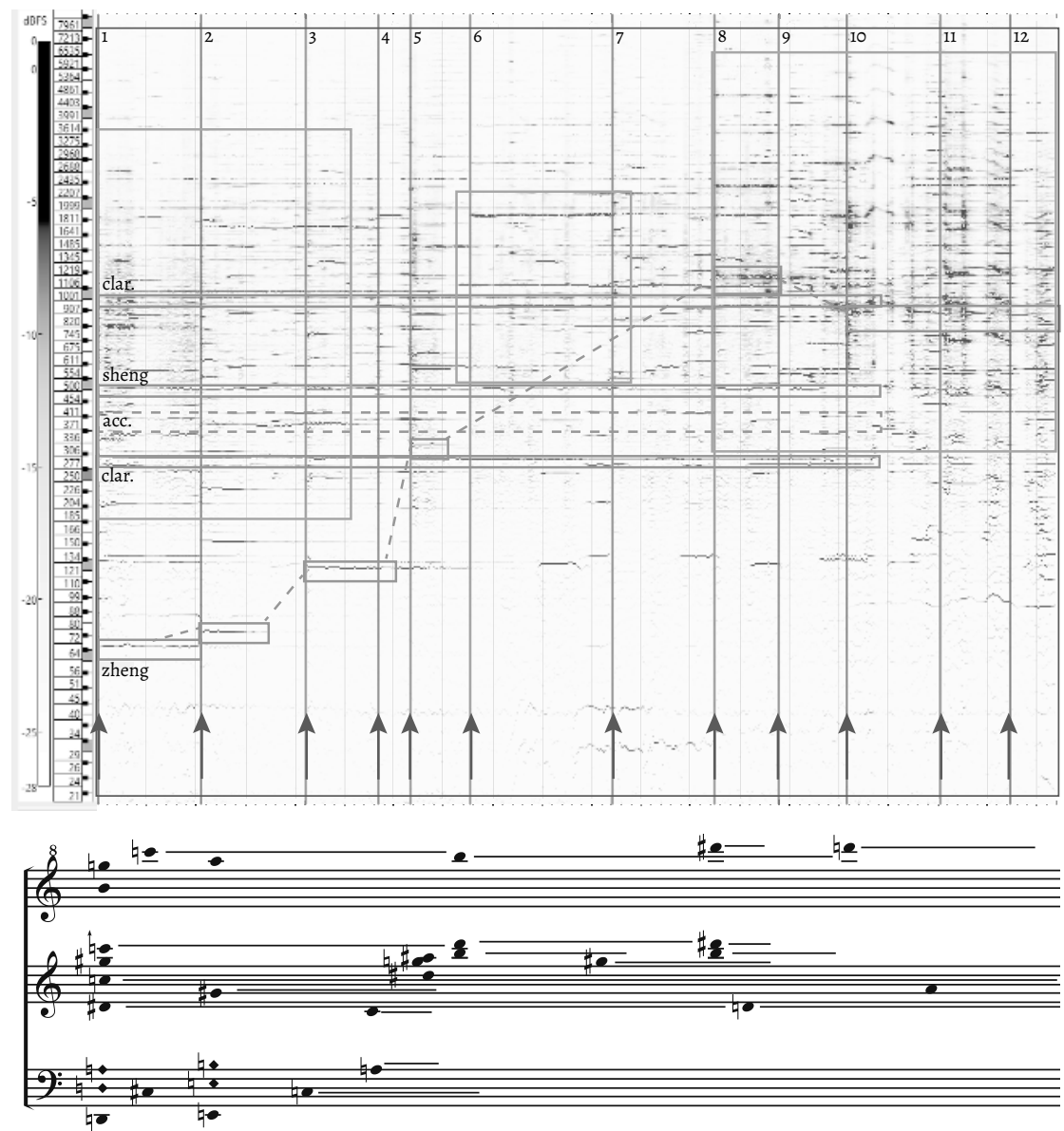

by Jonathan Kramer as "moment time" expectation than on a contemplation of the present moment.

The plausibility of these listening attitudes surely changes as the piece progresses; toward the end of the first phase of the piece, after about five minutes, a "collapse" of the layered structure occurs, resulting in a high density of cue-based fragmentation that disrupts the temporal flow and can already be inferred from the scattered impression of the score $\rightarrow$ VI.1, Ex. 6.6).

Another type of listening experience can be triggered if we jump to a later stage: roughly six minutes into the piece, in the middle of its second phase, a more rigid and repetitive, less gestural version of the layered structure evolves, so here the transformative, "holistic" and/or presentist listening attitudes surely gain importance. In later stages of the piece, the dense and tightly layered model continuously disintegrates, giving way to more prominent soloistic articulations such as a solo by the Chinese ocarina xun performed by the sheng soloist, which is 
singled out in the listening act because of its unfamiliar and unique timbre as a prominent cue in the large-scale formal process.

\section{A Map of Musical Simultaneities}

Some of the terminology I have used here is taken from psychological and psychoacoustic theories of perception, such as those summarized in Albert Bregman's major book Auditory Scene Analysis from 1990. ${ }^{47} \mathrm{I}$ will now expand these categories as basic parameters of a "map of musical simultaneities" (Fig. 6.3) and explain different categories and examples with reference to this map.

Musical perception might be described as building spatiotemporal relationships between sounds. This process involves many preconditions, not least an implicit and explicit knowledge of everyday and musical sounds, most of them acquired during our experience as lifelong listeners. Establishing spatiotemporal relationships during musical perception means that we organize sound in a twofold manner: sounds occupy an imaginary spatial "map" on which we locate sound events and processes simultaneously and sequentially or linearly. The simultaneous dimension might be described as a continuous space between segregation and fusion of sound layers or streams, while the linear dimension lets sound events appear either in isolation, prompting the model of a large-scale architectural form of different events in time, or as part of an ongoing process or continuity without clear-cut segmentation. ${ }^{48}$

Placing concepts of musical simultaneity in music on this map first requires looking at the most common concept established for this phenomenon in music theory: polyphony. Western polyphonic music might be grasped as an ensemble of independent voices, intertwined in a sonorous space, subject to a hierarchical system of note relations but appearing free and unique in their melodic contour and registral space. Ernst Kurth's 1918 definition of polyphony captures some of these features while notably emphasizing the priority of overall coherence over an independence of parts:

The highest law of polyphonic structure is that the complex of voices must always appear as a unity; the multiplicity of voices never suppresses the sense of a totality into which the lines are woven, and at the same time, omitting a single voice would not only lead to a reduction of the complex of lines but would mean its organic distortion. ${ }^{49}$

Established notions of polyphony had been challenged as early as 1911 (six years before Kurth's monograph Grundlagen des linearen Kontrapunkts) in Arnold Schoenberg's Theory of Harmony, where harmony in modern music is described as a result of musical lines that are pursued with

47 Bregman, Auditory Scene Analysis. See also Deutsch, "Grouping Mechanisms in Music" and Deliège and Mélen, "Cue Abstraction in the Representation of Musical Form."

48 There is a huge number of studies on these two conflicting conceptions of musical listening and musical form, which I have summarized and transformed into analytical perspectives on music from Dufay to Varèse in the extended article Utz, "Räumliche Vorstellungen als 'Grundfunktionen des Hörens."

49 Kurth, Grundlagen des linearen Kontrapunkts, 351 ("Das oberste Gesetz polyphoner Struktur besteht darin, daß der Stimmenkomplex stets als eine Einheit erscheint; nie verdrängt die Häufung der Stimmen den Eindruck einer Gesamtheit, zu der die Linien ineinandergeflochten sind und andrerseits würde das Weglassen einer einzigen Stimme nicht eine bloße Verdünnung des Linienkomplexes darstellen, sondern seine organische Zerstörung.") 
Figure 6.3: A map of musical simultaneities

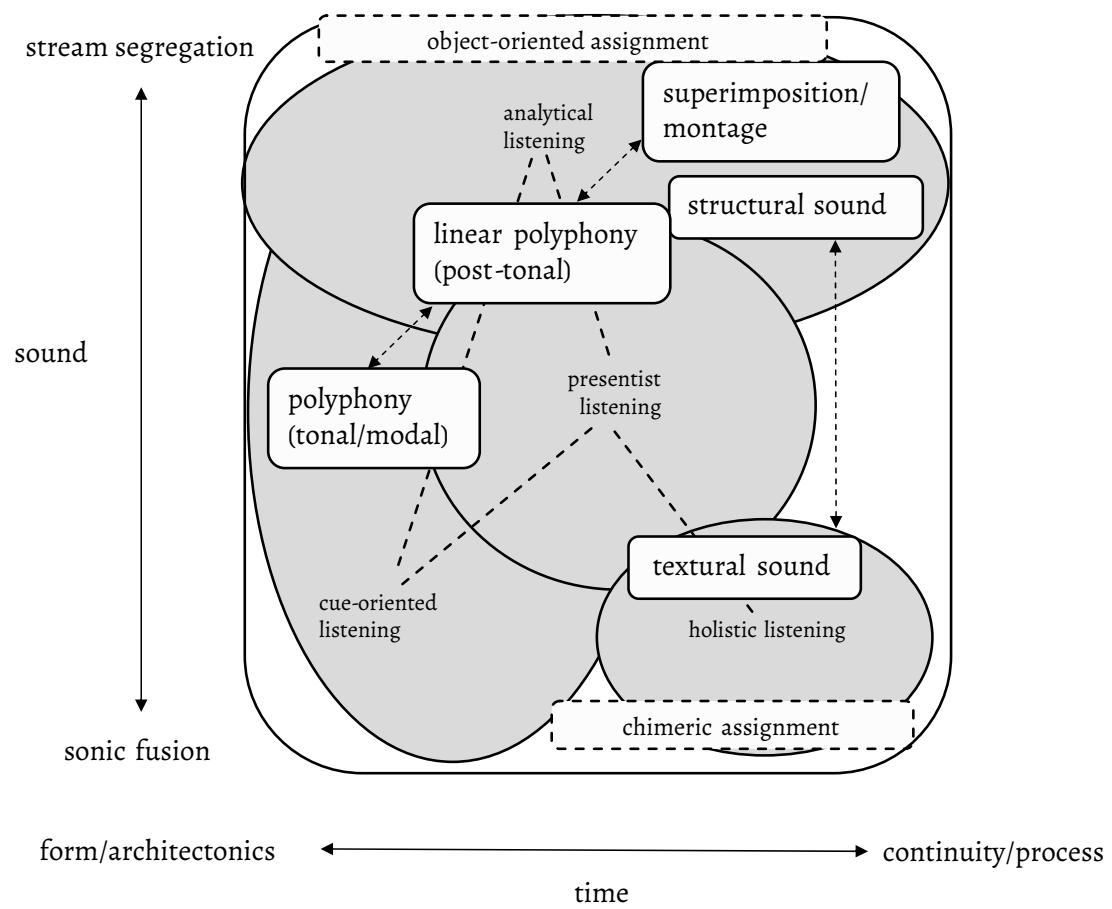

a particular degree of independence. ${ }^{50}$ Schoenberg elaborated on this point in the 1931 manuscript "Der lineare Kontrapunkt." ${ }^{51}$ Here, he insisted on the "carelessness" (Unbekümmertheit) of simultaneous lines and suggested avoiding all progressions that might remind one of tonal cadences or fundamental chord relationships. ${ }^{52}$

This perspective had far-reaching consequences: in dodecaphony and (proto-)serial music, note rows and aggregates are superimposed in a rigorous manner, as did, even earlier, the tunes of military bands, Protestant hymns, folk songs, and quotations of art music in the works of Charles Ives, testifying to a simultaneity of independent events or "personae" as a key experience of modernity $(\rightarrow$ V.3, VI.1). Many serialist approaches to musical structure were derived from radical interpretations of polyphony akin to Schoenberg's. In a 1955 radio program,

50 "For it is apparent [...] that we are turning to a new epoch of polyphonic style, and as in the earlier epochs, harmonies will be a product of the voice leading: justified solely by the melodic lines!" (Schoenberg, Theory of Harmony, 389; "[...] anscheinend [...] wenden wir uns einer neuen Epoche des polyphonen Stils zu, und wie in den früheren Epochen werden die Zusammenklänge Ergebnis der Stimmführung sein: Rechtfertigung durchs Melodische allein!" (Schönberg, Harmonielehre, 466.) In the preface to the third edition of his monograph from 1927, Kurth insisted that a "harmony-free patching together of pitch lines" ("harmoniefreie[s] [...] Zusammenflicken von Tonlinien," Grundlagen des linearen Kontrapunkts, third edition, XVI) had in no way been implied in his use of the concept of linearity. He thus rejected the idea that his title "linear counterpoint" suggested a radicalization of linear independence to the point of making the resulting harmonies a byproduct of the complex of lines.

51 Schoenberg, "Linear Counterpoint."

52 Ibid., 291-292. 
Stockhausen was particularly explicit about the consequences of (post-)serial composition for a non-hierarchical musical perception:

We listen to the whole, retaining an overall impression in which the details are distinguished from one another sufficiently strongly to prevent any interconnections that might become more important than others. [...] As far as possible, everything composed should be part of the formal process, nothing should dominate [...]. [...] the music is in a state of constant flux [...], without lingering on the instantaneous, on the beautiful moments [.....$^{53}$

Following Kurth's, Schoenberg's, and Stockhausen's definitions, we might place the three concepts of (tonal) polyphony, linear (post-tonal) polyphony, and superimposition on a diagonal line on our map. Of course, these areas on the diagonal are to some degree arbitrary and should be regarded as movable, at least in the horizontal; in general, the relationship between polyphony and superimposition appears not as a categorial distinction but as a permeable relationship indicated by the dotted arrows on the map.

In John Cage's 45' for a Speaker from 1954, a component of the Ten Thousand Things, a radicalized form of superimposition is interpreted as a logical consequence of the decision to "give up counterpoint": "Giving up counterpoint one gets superimposition and, of course, a little counterpoint comes in of its own accord. How I wouldn't know. ${ }^{154}$ For Cage, non-hierarchical simultaneity is closely connected to the abandonment of "form" and leads to the model of presentist listening.

The term "polyphony" is also used in another key concept of musical simultaneity that must complement our map: in 1963, nine years after Cage's 45' for a Speaker, Helmut Lachenmann first developed his much-cited sound typology in a series of lectures $(\rightarrow$ VI.1). As outlined above $(\rightarrow$ VI.I), this typology insists on the key model of "structural sound" (Strukturklang) as a "polyphony of orderings." ${ }^{55}$ Lachenmann's idea of structural sonority suggests that the "development of each element is traceable by the listener" resulting in "a sort of montage of different structures [that] actively dispels any sense of hierarchy or priority."

The most efficient compositional tool Lachenmann invented in order to realize such "structures" is the idea of "sound families." The key feature of this idea is that, similar to Ludwig Wittgenstein's idea of family resemblance, family affiliations are not exclusive. ${ }^{57}$ This means that, for example, the flutter tongue of a flute in the middle register might be part of three families at once: the family of flute sounds, the family of middle-register pitched sounds, and the family of "perforated" tremolo sounds. A work like Lachenmann's orchestral piece Kontrakadenz (1970)

53 Stockhausen, "Gruppenkomposition: Klavierstück I," 65, 67 (“Wir hören vielmehr auf das Ganze hin, behalten einen zusammenfassenden Eindruck, in dem die Einzelheiten so gleich stark auseinandergehalten werden, daß keine Verbindungen auftauchen, die wichtiger als andere werden [...]. Möglichst alles Komponierte soll gleich stark am Formprozeß beteiligt sein, und nichts soll dominieren [...]. [...] die Musik [befindet] sich ständig im Fluß [...], ohne das Verweilenwollen beim Augenblicklichen, bei den schönen Stellen [...].")

54 Cage, "45' for a Speaker," 164.

55 Lachenmann, "Klangtypen der Neuen Musik," 18 (“Polyphonie von Anordnungen;" emphasis is mine).

56 Heathcote, "Liberating Sounds," 28.

57 See Neuwirth, "Strukturell vermittelte Magie," 79-82. Wittgenstein's concept has been thoroughly explored and adopted for musical analysis by Dora A. Hanninen ("Associative Sets, Categories, and Music Analysis," 160163). 
exemplifies how Lachenmann creates a universe of interacting and superimposed sounds from this framework. ${ }^{58}$

Albert Bregman's distinction between "natural" and "chimeric" assignment is equally relevant to a further analysis of such situations, and is an important addition to our map: $:^{59}$ in the case of "natural assignment" (which I prefer to label "object-oriented assignment"), the identification of the sound source is a vital part of musical experience, connecting it with everyday audition where we are used to identifying sound sources. In many other musical cases, which Bregman labels "chimeric assignment," several sound sources create a composite timbre, or the originating sound object is obscured for other reasons. In Lachenmann's Kontrakadenz, both types of assignment are clearly contributing to the listening experience; at the beginning, rotating metal discs and table tennis balls are identified as "non-musical" sounds unexpected in an orchestral piece, but they soon merge with other members of the sound family "accelerating impulses" into a chimeric situation. Ultimately, it becomes clear that many composers (including myself) were or are seeking musical situations that enable perception to fluctuate continuously between the whole and individual streams or segments, between "chimeric" and "object-oriented" listening situations.

\section{walls: Ongoing Processes of De- and Restabilization}

In order to contextualize these attempts to systematize polyphony and simultaneity in music in a broader research context, one might refer to the question of hierarchies in music. These may be configured in two different ways, along the two axes of our map in Figure 6.3:

1. events in time may be singled out as particularly important, suggesting a large-scale formal architecture with the most salient events building the foundation of a hierarchical temporal-architectonic structure; this is a common description of formal perception in music psychology;

2. concurrently experienced events may be brought into a hierarchical relationship with louder, higher, more clearly "pronounced" or "articulated" sounds dominating a hierarchy of streams or voices.

While it is clear that both kinds of hierarchy can be reduced to a minimum, musical experience is never entirely hierarchy-free. A valuable artistic aim may thus be defined as developing compositional ideas that result in spatiotemporal constellations that are sufficiently multivalent to allow for both increasing and decreasing simultaneous and sequential hierarchies during the act of listening.

These ideas were triggers for my most recent work to be discussed here, walls for chamber ensemble and electronics (2018), which is predominantly a piece for Western ensemble, interrupted three times by electronic ritornellos accompanied by the instruments on stage - but eventually extending into the audience space, where two Chinese instruments (zheng and $x u n$ ) act as surprising and unfamiliar "sounds from afar." The metaphor of "walls" not unintentionally invokes cultural and political references (the Great Wall of China, the Berlin wall, the wall built recently between the United States and Mexico, the firewall censoring the Chinese internet, etc.) but it

58 See the analyses of this work in Nonnenmann, Angebot durch Verweigerung, 80-137 and Utz, "Auf der Suche nach einer befreiten Wahrnehmung," 48-49.

59 See Bregman, Auditory Scene Analysis, 459-460. 
Example 6.21: Anton Webern, Symphonie op. 21, second movement, variation V; the structural model explored in Utz, walls for ensemble and electronics
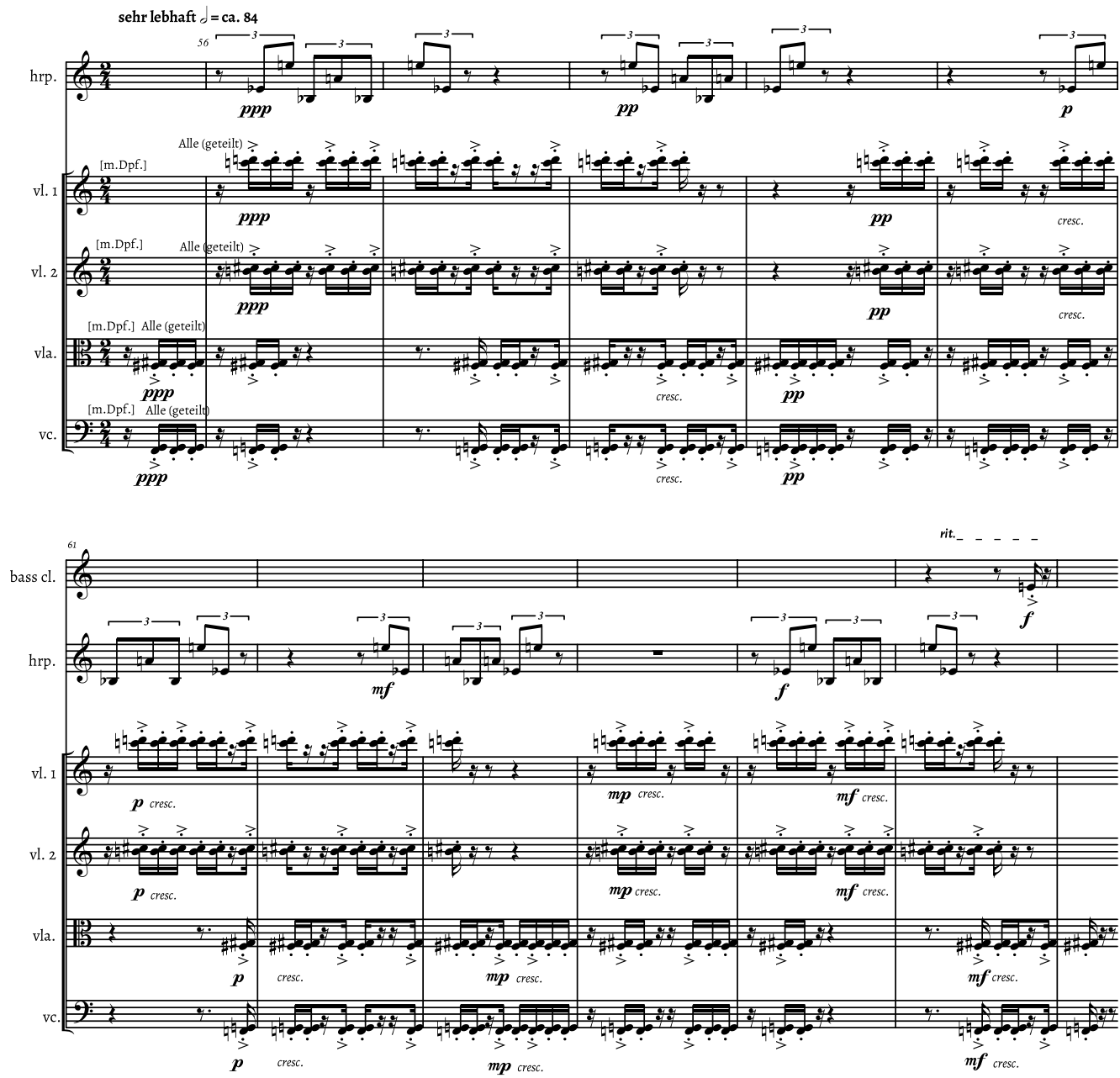

Copyright $\odot 1929$ by Universal Edition

is also used and deconstructed in the compositional process. Imaginary "walls" are necessary in order to construct the two hierarchical concepts during listening, as explained above: simultaneous and sequential "walls" may help to distinguish formal sections or polyphonic layers.

In composing this piece, I once again used a preconceived structure, serving here as a representation of a "stable" system of walls: Variation 5 from the second movement of Anton Webern's Symphonie op. 21 (1928) (Ex. 6.21). In a complex conceptual transformation, this rhythmic canon was expanded to a duration of twenty minutes. Although I originally intended to preserve and continue this expanded canon until the end of the piece, it soon occurred to me that this would have resulted in an overly deterministic, overly even formal process. Thus, the stability of the "Webern wall" is continuously challenged and eroded by all sorts of "distur- 
bances," most prominently by three loop-saturated sequences of electronic sound, using excerpts from one of my early electronic pieces (time freeze, 1996), which resonate with Webern's ostinato structures. The musicians initially attempt to "integrate" the electronic sounds, but the situation gets increasingly "out of control." The Chinese instruments zheng and xun enter from afar, completely denying the "controlled time" of the Western ensemble and introducing, among other things, allusions to the qin classic Guang ling san (Shen Qi Mi Pu, 1425). Thus, the music in walls moves from a clear and probably somewhat overemphasized focusing of perceptual attention (a single dodecaphonic sonority, repeatedly introduced, opens the piece, Ex. 6.22) to situations of changing, movable, transforming centers of perceptual attention. The "walls" in the music lose their stability, and an open space of conflicting layers gains prominence (Ex. 6.23).

The idea of simultaneity and non-hierarchy also has consequences for performance - indeed, the question of musical hierarchies is not least a question of performance in general. In the more recent performance practice of contemporary music, a brilliant, virtuosic, "philharmonic" sound has prevailed which tends to hierarchically separate foreground and background, and to accentuate formal segmentation even in cases where the musical score might be ambiguous in these respects. ${ }^{60}$ Thus, the idea of rediscovering ambiguity and polyphony might also provide inspiration for performers who seek to go beyond the harsh "synchronizing" effects of formal contrast. This is a point that cannot be elaborated upon here, as it has been explored quite extensively in recent studies on musical performance that aim to draw conclusions from both quantitative measurements of recorded performances and the aesthetic ideas guiding individual interpretations. ${ }^{61}$

Ultimately, the metaphor of fabric, in French "agencement," a key term in Gilles Deleuze's and Félix Guattari's Thousand Plateaus, seems an adequate model for the interaction between the different types of simultaneities, non-simultaneities, hierarchies, and non-hierarchies in music and elsewhere. In the rhizomatic "agencement" of Deleuze and Guattari, hierarchies are not resolved by compromise or consensus, but by a non-localization of things; this invokes a "perpendicular direction, a transversal movement that sweeps one and the other away, a stream without beginning or end that undermines its banks and picks up speed in the middle."

\footnotetext{
60 I have critically described this tendency especially in the example of performance practice of Ciacinto Scelsi's music; see Utz, "Scelsi hören,"166-169.

61 See especially Cook, Beyond the Score.

62 Deleuze and Guattari, $A$ Thousand Plateaus, 25.
} 


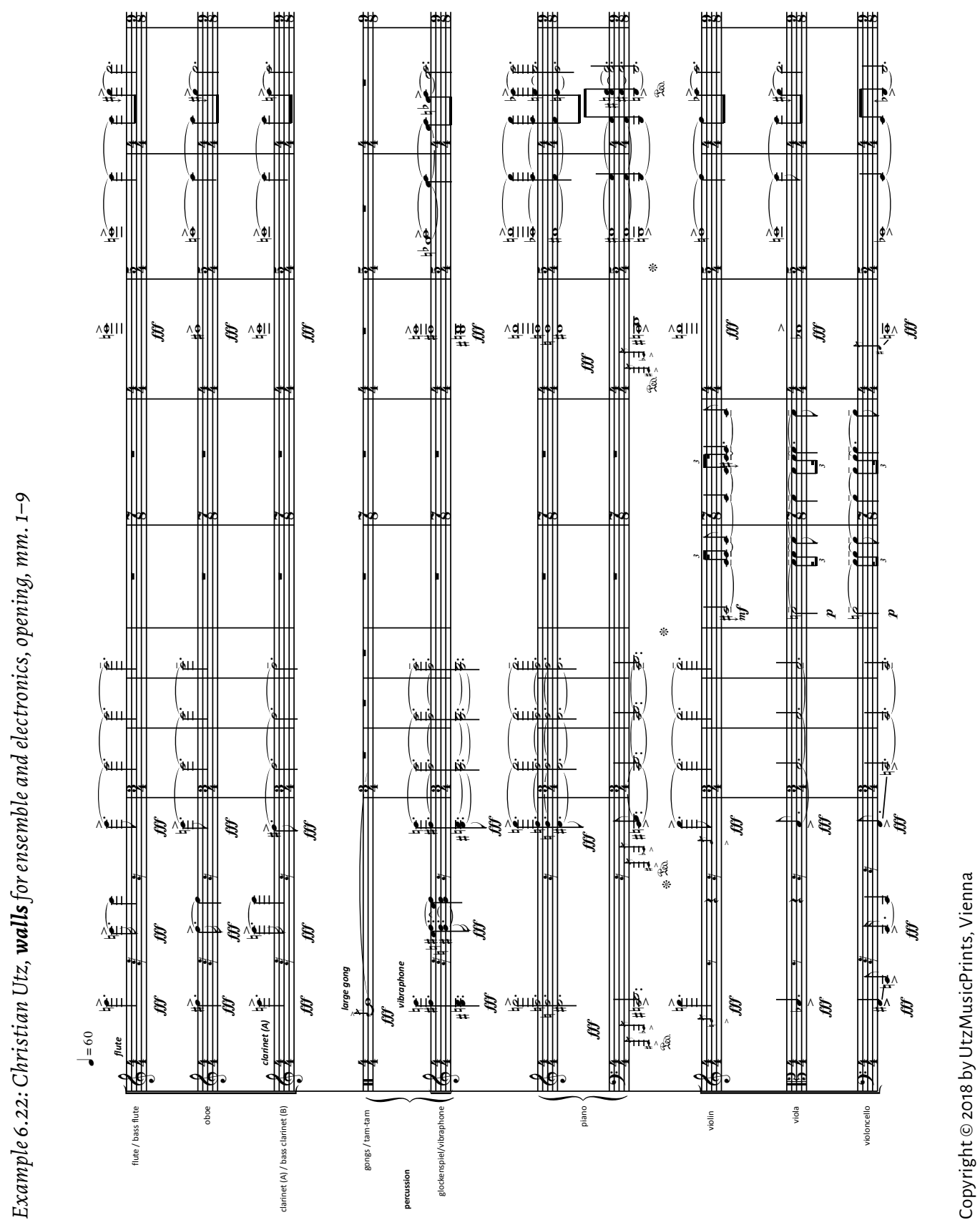




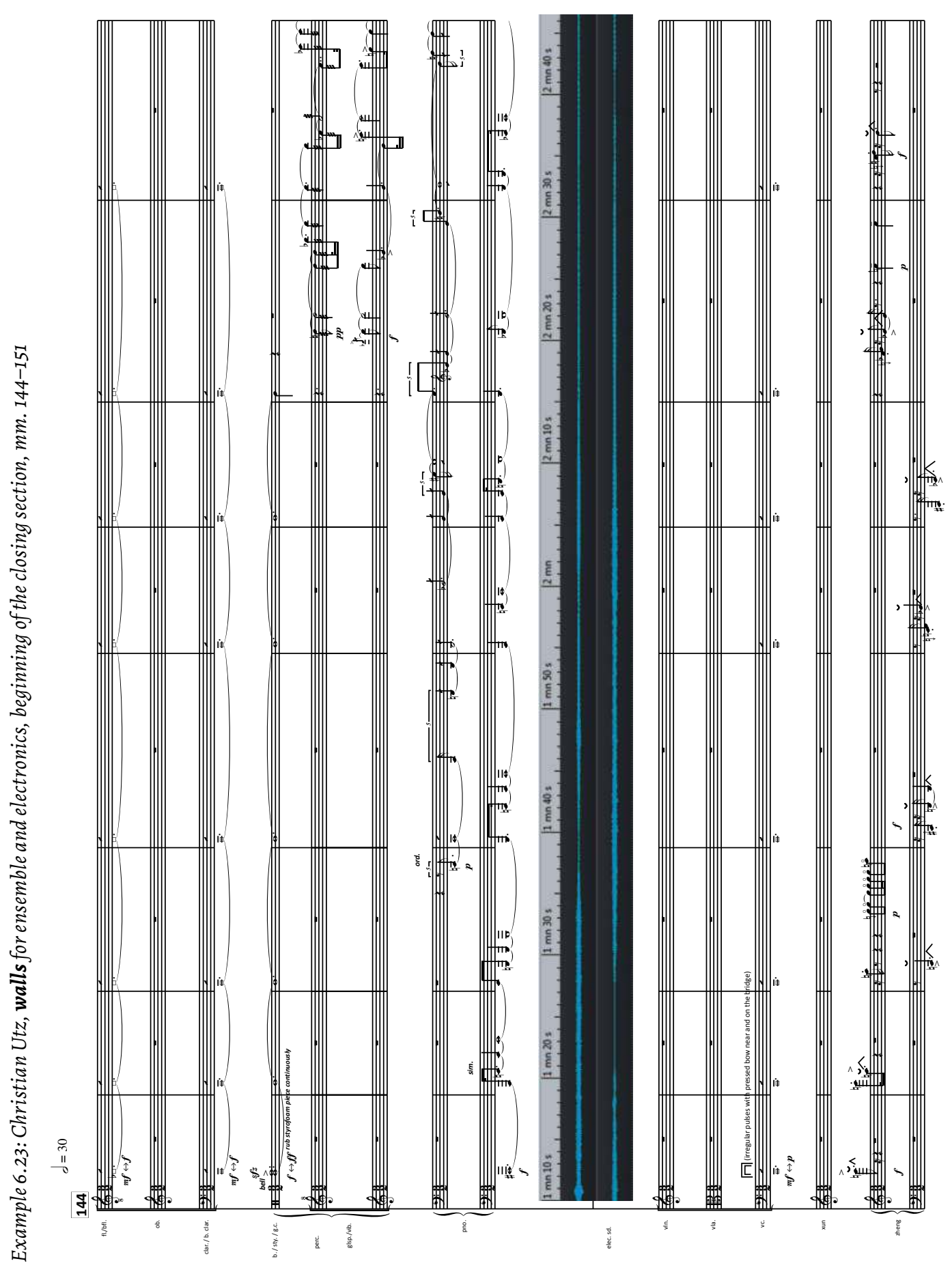

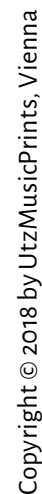





\section{Bibliography}

Aalst, Jules A. van. Chinese Music. Shanghai: Inspectorate General of Customs, 1884.

Abbate, Carolyn. Unsung Voices: Opera and Musical Narrative in the Nineteenth Century. Princeton: Princeton University Press, 1991.

Abbate, Carolyn. "Music - Drastic or Gnostic?" Critical Inquiry 30, no. 3 (2004): 505-536.

Abitor, Daniel. "Metapher als Antwort auf Inkommensurabilität." PhD dissertation, Ludwig Maximilian University, Munich, 2010. https://edoc.ub.uni-muenchen.de/11466

Ackermann, Peter. “Japan." In Außereuropäische Musik, Vol. 1, edited by Hans Oesch, 110-145. Laaber: Laaber, 1984.

Adami, Giuseppe. Puccini. [1935] Second edition. Milan: Treves, 1938.

Adler-Rudel, Salomon. Jüdische Selbsthilfe unter dem Naziregime 1933-1939: Im Spiegel der Reichsvertretung der Juden in Deutschland. Tübingen: Mohr, 1974.

Adorno, Theodor W. "Zur gesellschaftlichen Lage der Musik." [1932] In Musikalische Schriften V (Gesammelte Schriften, Vol. 18, edited by Rolf Tiedemann), 729-777. Frankfurt: Suhrkamp, 1984.

Adorno, Theodor W. "Über den Fetischcharakter in der Musik und die Regression des Hörens." [1938] In Dissonanzen (Gesammelte Schriften, Vol. 14, edited by Rolf Tiedemann, 7-167), 14-50. Frankfurt: Suhrkamp, 1973.

Adorno, Theodor W. "On the Fetish-Character in Music and the Regression of Listening." [1938] In Essays on Music, edited by Richard Leppert, translated by Susan H. Gillespie, 288-317. Berkeley: University of California Press, 2002.

Adorno, Theodor W. Philosophie der neuen Musik. [1949] In Gesammelte Schriften, Vol. 12, edited by Rolf Tiedemann. Frankfurt: Suhrkamp, 1975.

Adorno, Theodor W. Philosophy of New Music. [1949] Translated by Robert Hullot-Kentor. Minneapolis: University of Minnesota Press, 2006.

Adorno, Theodor W. "Die gegängelte Musik." [1953] In Dissonanzen (Gesammelte Schriften, Vol. 14, edited by Rolf Tiedemann, 7-167), 51-66. Frankfurt: Suhrkamp, 1973.

Adorno, Theodor W. "Anton von Webern." [1959] In Klangfiguren (Gesammelte Schriften, Vol. 16, edited by Rolf Tiedemann, 7-247), 110-125. Frankfurt: Suhrkamp, 1978.

Adorno, Theodor W. "Einleitung in die Musiksoziologie: Zwölf theoretische Vorlesungen." [1962/1968] In Gesammelte Schriften, Vol. 14, edited by Rolf Tiedemann, 169-433. Frankfurt: Suhrkamp, 1978.

Agawu, Kofi. "The Invention of 'African Rhythm." Journal of the American Musicological Society 48, no. 3 (1995): 380-395. 
Agawu, Kofi. Representing African Music: Postcolonial Notes, Queries, Positions. New York: Routledge, 2003.

Almén, Byron. A Theory of Musical Narrative. Bloomington: Indiana University Press, 2008.

Altmann, Peter. Sinfonia von Luciano Berio: Eine analytische Studie. Vienna: Universal Edition, 1977.

Ambros, August Wilhelm. Geschichte der Musik, Vol. 1. Third edition. Leipzig: Leuckart, 1887.

Anderson, Benedict. Imagined Communities: Reflections on the Origin and Spread of Nationalism. [1983] Second edition. London: Verso, 1991. (Revised, third edition, London: Verso, 2006; tenth edition, London: Verso, 2016.)

Anhalt, Istvan. Alternative Voices: Essays on Contemporary Vocal and Choral Composition. Toronto: University of Toronto Press, 1984.

Apel, Willi. The Notation of Polyphonic Music, 900-1600. [1942] Fourth edition. Cambridge: Medieval Academy of America, 1949.

Appadurai, Arjun. "Grassroots Globalization and the Research Imagination." In Globalization, edited by Arjun Appadurai, 1-21. Durham: Duke University Press, 2001.

Aristoxenos. "Elementa Rhythmica, Book II." In Greek Musical Writings, Vol. 2: Harmonic and Acoustic Theory, edited by Andrew Barker, 185-189. Cambridge: Cambridge University Press, 1989.

Armbrüster, Georg, Michael Kohlstruck, and Sonja Mühlberger, editors. Exil Shanghai 19381947: Jüdisches Leben in der Emigration. Teetz: Hentrich \& Hentrich, 2000.

Arom, Simha. African Polyphony and Polyrhythm: Music Structure and Methodology. Cambridge: Cambridge University Press, 1991.

Arom, Simha, Louise Duchesneau, and Wolfgang Marx. "A Kinship Foreseen: Ligeti and African Music - Simha Arom In Conversation." [19 November 2008] In György Ligeti: Of Foreign Lands and Strange Sounds, edited by Louise Duchesneau and Wolfgang Marx, 107-122. Woodbridge: Boydell, 2011.

Asad, Talal. "The Concept of Cultural Translation in British Social Anthropology." In Writing Culture: The Poetics and Politics of Ethnography, edited by James Clifford and George E. Marcus, 141-164. Berkeley: University of California Press, 1986.

Ashbrook, William, and Harold Powers. Puccini's Turandot: The End of the Great Tradition. Princeton: Princeton University Press, 1992.

Assmann, Aleida. Cultural Memory and Western Civilization: Functions, Media, Archives. Cambridge: Cambridge University Press, 2011.

Assmann, Jan. Das kulturelle Gedächtnis: Schrift, Erinnerung und politische Identität in frühen Hochkulturen. Fifth edition. Munich: Beck, 2005.

Assmann, Jan. Cultural Memory and Early Civilization: Writing, Remembrance, and Political Imagination. Cambridge: Cambridge University Press, 2011.

Austin, Larry. "The Realization and First Complete Performances of Ives' Universe Symphony." In Ives Studies, edited by Philip Lambert, 179-232. Cambridge: Cambridge University Press, 1997.

Avshalomov, Jacob, and Aaron Avshalomov. Avshalomovs' Winding Way: Composers Out of China -A Chronicle. Bloomington: Xlibris, 2001.

Azadovskii, Konstantin, and Boris Egorov. "From Anti-Westernism to Anti-Semitism: Stalin and the Impact of the 'Anti-Cosmopolitan' Campaigns on Soviet Culture." Journal of Cold War Studies 4, no. 1 (2002): 66-80. 
Baatz, Ursula. "Resonanz des 'weißen Unbewegten:' Die Asien-Rezeption Scelsis.” In Klang und Quelle: Ästhetische Dimension und kompositorischer Prozess bei Giacinto Scelsi, edited by Federico Celestini and Elfriede Reissig, 31-48. Vienna: LIT, 2014.

Badrinathan, Vasumathi. "Interplay of the devadasi and the Composer." The Asian Age, 14 December 2015. https://www.asianage.com/music/interplay-devadasi-and-composer-890

Baier, Christian. "50 Jahre danach: Julius Schloss, Karl Steiner, Jenö Takács." Österreichische Musikzeitschrift 43, no. 12 (1988): 677-681.

Baier, Karl. "Offenes Kunstwerk versus Kunst der Offenheit: Umberto Ecos abendländische Werk-Ästhetik und John Cages buddhistische Alternative." Polylog: Zeitschrift für interkulturelles Philosophieren no. 9 (2003):38-56.

Bakhtin, Mikhail M. Problems of Dostoevsky's Poetics. [1929] Minneapolis: University of Minnesota Press, 1984.

Bakhtin, Mikhail M. The Dialogic Imagination: Four Essays. [1934-38] Austin: University of Texas Press, 1981.

Baltensperger, André. Iannis Xenakis und die stochastische Musik: Komposition im Spannungsfeld von Architektur und Mathematik. Bern: Peter Lang, 1996.

Bandur, Markus. "Composition/Komposition." In Handwörterbuch der musikalischen Terminologie, edited by Albrecht Riethmüller. Stuttgart: Steiner, 1996. https://www.musiconn.de/ Vta2/bsbo0070510f49t82/hmt:hmt2bsbo0070510f 49t82?page $=49$

Bandur, Markus. "I prefer a wake.' Berios Sinfonia, Joyces Finnegans Wake und Ecos Poetik des 'offenen Kunstwerks." In Luciano Berio, edited by Ulrich Tadday, 95-110. Munich: edition text + kritik, 2005.

Barmé, Geremy. “To Screw Foreigners Is Patriotic: China's Avantgarde Nationalists.” The China Journal 34 (1995): 209-234.

Barrow, John. Travels in China, Containing Descriptions, Observations, and Comparisons, Made and Collected in the Course of a Short Residence at the Imperial Palace of Yuen-Min-Yuen, and on a Subsequent Journey Through the Country From Pekin To Canton. London: Strahan, 1804.

Barrow, John. Johann Barrow's Reise durch China von Peking nach Canton im Gefolge der Großbrittannischen Gesandtschaft in den Jahren 1793 und 1794. Translated by Johann Christian Hüttner. Weimar: Industrie-Comptoir, 1804.

Barthes, Roland. "The Grain of the Voice." [1972] In The Responsibility of Forms: Critical Essays on Music, Art, and Representation, 267-277. Berkeley: University of California Press, 1991.

Bartók, Béla. "Gypsy Music or Hungarian Music?" [1931] In Essays, edited by Benjamin Suchoff, 206-223. Lincoln: University of Nebraska Press, 1976.

Bartók, Béla. "The Influence of Peasant Music on Modern Music." [1931] In Essays, edited by Benjamin Suchoff, 340-344. Lincoln: University of Nebraska Press, 1976.

Bartók, Béla. "Race Purity in Music." [1942] In Essays, edited by Benjamin Suchoff, 29-32. Lincoln: University of Nebraska Press, 1976.

Bartók, Béla. "Harvard Lectures." [1943] In Essays, edited by Benjamin Suchoff, 354-392. Lincoln: University of Nebraska Press, 1976.

Bartók, Béla. Weg und Werk: Schriften und Briefe, edited by Bence Szabolcsi. Kassel: Bärenreiter, 1972.

Beal, Amy. "Negotiating Cultural Allies: American Music in Darmstadt, 1946-1956." Journal of the American Musicological Society 53, no. 1 (2000): 105-139.

Beal, Amy C. New Music, New Allies: American Experimental Music in West Germany from the Zero Hour to Reunification. Berkeley: University of California Press, 2006. 
Beck, Ulrich. Die Erfindung des Politischen: Zu einer Theorie reflexiver Modernisierung. Frankfurt: Suhrkamp, 1993.

Beck, Ulrich. "Das Zeitalter der Nebenfolgen und die Politisierung der Moderne." In Reflexive Modernisierung: Eine Kontroverse, edited by Ulrich Beck, Anthony Giddens and Scott Lash, 19-112. Frankfurt: Suhrkamp, 1996.

Beck, Ulrich, and Danilo Zolo. "What Is Globalization? Some Radical Questions." [1999] Jura Gentium: Rivista di filosofia del diritto internazionale e della politica globale (2005). http://www. juragentium.org/topics/wlgo/en/beck.htm

Bekker, Paul. Musikgeschichte als Geschichte der musikalischen Formwandlungen. Stuttgart: Deutsche Verlags-Anstalt, 1926.

Benhabib, Seyla. The Claims of Culture: Equality and Diversity in the Global Era. Princeton: Princeton University Press, 2002.

Benítez, Joaquim M., and Jō Kondō, editors. Gagaku and Serialism: A Portrait of Matsudaira Yoritsune. Contemporary Music Review 17, no. 4 (1998).

Benjamin, Walter. Das Passagen-Werk. Frankfurt: Suhrkamp, 2000.

Berger, Christian. 'Harmonie' und 'mélodie:' Eine musikästhetische Kontroverse im Frankreich des 18. Jahrhunderts und ihre Auswirkungen auf das Komponieren im 19. Jahrhundert." In Festschrift Klaus Hortschansky zum 60. Geburtstag, edited by Axel Beer and Laurenz Lütteken, 275-288. Tutzing: Schneider, 1995.

Bergeron, Katherine, and Philip V. Bohlman. Disciplining Music: Musicology and Its Canons. Chicago: University of Chicago Press, 1992.

Berio, Luciano. "The Composer on His Work: Meditation on a Twelve-tone Horse." Christian Science Monitor, 15 July 1968, 8.

Berio, Luciano. Sinfonia for Eight Voices and Orchestra (score). London: Universal Edition, 1969.

Berio, Luciano. Two Interviews with Rossana Dalmonte and Balint András Varga. New York: Boyars, 1985.

Berktold, Christian. "Zur Satztechnik der Hemiolenbildung in Klaviersonaten Mozarts." In Compositionswissenschaft: Festschrift Reinhold und Roswitha Schlötterer zum 70. Geburtstag, edited by Bernd Edelmann and Sabine Kurth, 163-173. Augsburg: Wißner, 1999.

Bernstein, Thomas P. Up to the Mountains and Down to the Villages: The Transfer of Youth from Urban to Rural China. New Haven: Yale University Press, 1977.

Bhabha, Homi K. The Location of Culture. London: Routledge, 1994.

Bhagwati, Sandeep. "Meistern, Warten, Vergessen, Finden. Zwölf Bedingungen für intermusikalische Zusammenarbeit: Ein Vademecum." In Soukous, Kathak und Bachata: Musik und Tanz aus Afrika, Asien und Lateinamerika in der Schweiz, edited by Mauro Abbühl, Chudi Bürgi and Dagmar Kopše. Zurich: Limmat, 2004.

Bhagwati, Sandeep. "Sein Zuhause komponieren... Illusionen aus Lärm und aus Stille." Neue Zeitschrift für Musik 167, no. 3 (2006): 24-25.

Bhagwati, Sandeep. “Imagining the Other's Voice: On Composing across Vocal Traditions." In Vocal Music and Contemporary Identities: Unlimited Voices in East Asia and the West, edited by Christian Utz and Frederick Lau, 76-95. New York: Routledge, 2013.

Bickers, Robert. "The Greatest Cultural Asset East of Suez: The History and Politics of the Shanghai Municipal Orchestra and Public Band, 1881-1946." In Ershi shiji de Zhongguo yu shijie (China and the World in the Twentieth Century), Vol. 2, edited by Chi-Hsiung Chang, 835-875. Taipei: Institute of Modern History, Academia Sinica, 2001. 
Bispo, Ieda. “Olivier Messian's Sept Haïkaï: Beyond Japonisme.” In Musicology and Globalization: Proceedings of the International Congress in Shizuoka 2002, edited by the Musicological Society of Japan, 242-246. Tokyo: Musicological Society of Japan, 2004.

Blacking, John. How Musical is Man? [1973] Seattle: University of Washington Press, 2000.

Bloch, Ernst. Erbschaft dieser Zeit. [1935] Frankfurt: Suhrkamp, 1985.

Blum, Stephen. "Composition." Grove Music Online, 2001. https://doi.org/10.1093/gmo/ 9781561592630.article.06216

Blumröder, Christoph von. Die Grundlegung der Musik Karlheinz Stockhausens. Stuttgart: Steiner, 1993.

Boas, Franz. The Mind of Primitive Man. New York: Macmillan, 1911.

Boehmer, Konrad. "Globalisierung als heimischer Fetisch." Neue Zeitschrift für Musik 167, no. 3 (2006): 43-44.

Bohlman, Philip V. Focus: Music, Nationalism, and the Making of the New Europe. Second edition. New York: Routledge, 2011.

Borio, Gianmario. Musikalische Avantgarde um 1960: Entwurf einer Theorie der informellen Musik. Laaber: Laaber, 1993.

Borio, Gianmario. "Convergence Between West and East in 2oth-Century Music: Reflections on Some Crucial Aspects." In Music Facing Up to Silence: Writings on Tōru Takemitsu, edited by Gianmario Borio and Luciana Galliano, 107-115. Milan: Pavia University Press, 2010.

Borio, Gianmario. "Vom Ende des Exotismus, oder: Der Einbruch des Anderen in die westliche Musik des 20. Jahrhunderts." In Was bleibt? 100 Jahre Neue Musik, edited by Andreas Meyer, 114-134. Mainz: Schott, 2011.

Bork, Camilla. "Text versus Performance - zu einem Dualismus der Musikgeschichtsschreibung." In Historische Musikwissenschaft: Grundlagen und Perspektiven, edited by Michele Calella and Nikolaus Urbanek, 383-401. Stuttgart: Metzler, 2013.

Born, Georgina. Rationalizing Culture: IRCAM, Boulez and the Institutionalization of the Musical Avant-garde. Berkeley: University of California Press, 1995.

Born, Georgina. "For a Relational Musicology: Music and Interdisciplinarity, Beyond the Practice Turn." Journal of the Royal Musical Association 135, no. 2 (2010): 205-243.

Born, Georgina, and David Hesmondhalgh, editors. Western Music and Its Others: Difference, Representation, and Appropriation in Music. Berkeley: University of California Press, 2000.

Born, Georgina, and David Hesmondhalgh. "Introduction: On Difference, Representation, and Appropriation in Music." In Western Music and Its Others: Difference, Representation, and Appropriation in Music, edited by Georgina Born and David Hesmondhalgh, 1-58. Berkeley: University of California Press, 2000.

Boulez, Pierre. Musikdenken heute 1. Mainz: Schott, 1963.

Bouliane, Denys. "Imaginäre Bewegung: György Ligetis 'Etudes pour piano." MusikTexte no. 28/29 (1989): 73-84.

Bregman, Albert S. Auditory Scene Analysis: The Perceptual Organization of Sound. Cambridge: MIT Press, 1990.

Brinkmann, Reinhold. "Kritischer Bericht, Studien zur Genesis, Skizzen, Dokumente." In Pierrot lunaire, Op. 21 (Arnold Schönberg: Sämtliche Werke, Vol. 24.B.1, edited by Reinhold Brinkmann), edited by Rudolf Stephan. Mainz: Schott, 1995.

Brown, Julie. "Bartók, the Gypsies, and Hybridity in Music." In Western Music and Its Others: Difference, Representation, and Appropriation in Music, edited by Georgina Born and David Hesmondhalgh, 119-142. Berkeley: University of California Press, 2000. 
Bruhn, Siglind. Messiaens musikalische Sprache des Glaubens: Theologische Symbolik in den Klavierzyklen Visions de l'Amen und Vingt Regards sur l'Enfant-Jésus. Waldkirch: Edition Gorz, 2006.

Bühler, Joachim, and Kyong-Sun Chu. “Korea: B. Koreas Musikleben in der Neuzeit.” [1996] MGG Online. Last updated 2016. https://www.mgg-online.com/mgg/stable/14938

Bürger, Peter. Theory of the Avant-Garde. [1974] Translated by Michael Shaw. Minneapolis: University of Minnesota Press, 1984.

Burke, Peter. Cultural Hybridity. Cambridge: Polity Press, 2009.

Burney, Charles. "Chinese Music." In The Cyclopedia; or, Universal Dictionary of Arts, Sciences and Literature, edited by Abraham Rees. London: Strahan, 1819-1820.

Burt, Peter. The Music of Tōru Takemitsu. Cambridge: Cambridge University Press, 2001.

Byron, Avior. "The Test Pressings of Schoenberg Conducting Pierrot lunaire: Sprechstimme Reconsidered." Music Theory Online 12, no. 1 (2006). https://mtosmt.org/issues/mto.06.12.1/ mto.06.12.1.byron_frames.html

Cage, John. "45' for a Speaker." [1954] In Silence: Lectures and Writings [1961], 146-193. Hanover, NH: Weslyan University Press, 1973.

Cahn, Peter. 'Zur Vorgeschichte des 'Opus perfectum et absolutum' in der Musikauffassung um 1500." In Zeichen und Struktur in der Musik der Renaissance, edited by Klaus Hortschansky, 11-26. Kassel: Bärenreiter, 1989.

Caitano, Joevan de Mattos. "Intercultural Perspectives in the International Summer Courses for New Music: The Internationales Musikinstitut Darmstadt in the context of exchanges with Latin America, Africa, USSR, Oceania and Asia." PhD dissertation, Hochschule für Musik Carl Maria von Weber Dresden, 2019.

Calella, Michele. "Migration, Transfer und Gattungswandel: Einige Überlegungen zur Oper des 18. Jahrhunderts." In Migration und Identität: Wanderbewegungen und Kulturkontakte in der Musikgeschichte, edited by Sabine Ehrmann-Herfort and Silke Leopold, 171-181. Kassel: Bärenreiter, 2013.

Calico, Joy H. Arnold Schoenberg's A Survivor from Warsaw in Postwar Europe. Berkeley: University of California Press, 2014.

Capellen, Georg. Ein neuer exotischer Musikstil an Notenbeispielen nachgewiesen. Stuttgart: Grüninger, 1905.

Capellen, Georg. "Exotische Rhythmik, Melodik und Tonalität als Wegweiser zu einer neuen Kunstentwicklung." Die Musik 13 (1906/07): 216-227.

Capellen, Georg. “Was können uns exotische Melodien lehren?" Die Musik 17 (1907/08): 301-306.

Carroll, Mark. Music and Ideology in Cold War Europe. Cambridge: Cambridge University Press, 2003.

Cavallotti, Pietro. Differenzen. Poststrukturalistische Aspekte in der Musik der 1980er Jahre am Beispiel von Helmut Lachenmann, Brian Ferneyhough und Gérard Grisey. Schliengen: Argus, 2006.

Cavallotti, Pietro. "Avantgarde." In Lexikon Neue Musik, edited by Jörn Peter Hiekel and Christian Utz, 194-196. Stuttgart: Metzler/Kassel: Bärenreiter, 2016.

Cavarero, Adriana. For More than One Voice: Toward a Philosophy of Vocal Expression. Stanford: Stanford University Press, 2005.

Celestini, Federico. "Busoni und Scelsi, oder: von den klingenden Hinterwelten." Archiv für Musikwissenschaft 69, no. 3 (2012): 218-228.

Cerha, Friedrich. "Zur Interpretation der Sprechstimme in Schönbergs Pierrot lunaire." [1978] In Schönberg und der Sprechgesang, edited by Heinz-Klaus Metzger and Rainer Riehn, 62-72. Munich: edition text + kritik, 2001. 
Chan, Amy and Alistair Noble, editors. Sounds in Translation: Intersections of Music, Technology and Society. Canberra: Australian National University, 2009.

Chang, Chi-Jen. "Alexander Tcherepnin, his Influence on Modern Chinese Music." PhD dissertation, Columbia University, 1983.

Chang, Chi-Jen. “Taiwan 'xiandai yinyue' 1945-1995” (Taiwan's 'Modern Music' 1945-1995). In Yinyue Taiwan yi bai nian lunwenji (Studies on One Hundred Years Music in Taiwan), 388404. Taipei: Egret Foundation, 1997.

Chang, Chi-Kuang. Minge "Molihua" yanjiu (Research on the Folk Song "Jasmin Flower"). Taipei: Wenshizhi chubanshe, 2000.

Chao, Mei-Pa. "The Trend of Modern Chinese Music." T'ien Hsia Monthly no. 4 (1937): 269-286.

Chapuis, Alfred. History of the Musical Box and of Mechanical Music. [1955] Translated by Joseph E. Roesch. Summit: The Musical Box Society International, 1980.

Charle, Christophe. "Debussy in Fin-de-Siècle Paris." In Debussy and His World, edited by Jane Fulcher, 271-296. Princeton: Princeton University Press, 2001.

Chen, Xiaoyong. "Speechlessness, Clearness and Ease." In MaerzMusik 2004 Program, edited by Berliner Festspiele, 285-286. Berlin, 2004.

Cheong, Wai-Ling. "Reading Schoenberg, Hindemith, and Kurth in Sang Tong: Modernist Harmonic Approaches in China." Acta Musicologica 88, no. 2 (2016): 87-108.

Cheong, Wai Ling, and Ding Hong. "Sposobin Remains: A Soviet Harmony Textbook's Twisted Fate in China." Zeitschrift der Gesellschaft für Musiktheorie 15, no. 2 (2018): 45-77. https://doi. org/10.31751/974

Cheung, Joys H.Y. "Divide and Connections in Chinese Musical Modernity: Cases of Musical Networks Emerging in Colonial Shanghai, 1919-1937." Twentieth-Century China 37, no. 1 (2012): 30-49.

Chiou, Joyce (Qiu Yuan). Li Taixiang: Meili de cuowu (Lee Tai-Hsiang: The Beautiful Mistake). Taipei: Shibao wenhua, 2002.

Chipot, Dominique. "Musique \& haiku." 2012. http://www.dominiquechipot.fr/haikus/fiches/ musique\%2oet\%2ohaiku.pdf

Choi, Ae-Kyung. "Zur Rezeption des Cuvres von Isang Yun in der Republik Korea." In Ssi-ol: Almanach 1998/99, edited by Walter-Wolfgang Sparrer, 156-170. Munich: edition text + kritik, 1999.

Choi, Ae-Kyung. Einheit und Mannigfaltigkeit: Eine Studie zu den fünf Symphonien von Isang Yun. Sinzig: Studio, 2002.

Choi, Ae-Kyung. "Réak (1966): Eine Analyse von Isang Yuns 'Hauptklangtechnik' vor dem Hintergrund der ostasiatischen Musiktradition." In Ssi-ol: Almanach 2000/01, edited by Walter-Wolfgang Sparrer, 101-137. Munich: edition text + kritik, 2002.

Chou, Oliver. "From Nation's Favourite to Populist Poison." South China Morning Post, 6 March 2011. http://www.scmp.com/article/740037/nations-favourite-populist-poison

Chou, Wen-Chung. "Asian Esthetics and World Music." In New Music in the Orient. Essays on Composition in Asia since World War II, edited by Harrison Ryker, 179-195. Buren: Knuf, 1991.

Christensen, Thomas. "Dahlhaus in Amerika." Musik \&Ästhetik no. 47 (2008): 133-139.

Citron, Marcia J. Gender and the Musical Canon. Cambridge: Cambridge University Press, 1993.

Clark, Paul. "Model Theatrical Works and the Remodelling of the Cultural Revolution." In Art in Turmoil: The Chinese Cultural Revolution, 1966-76, edited by Richard King, 167-187. Vancouver: University of British Columbia Press, 2010.

Cohn, Richard. "Metric and Hypermetric Dissonance in the Menuetto of Mozart's Symphony in G minor, K. 550." Intégral 6 (1992): 1-33. 
Cohn, Richard. "The Dramatization of Hypermetric Conflicts in the Scherzo of Beethoven's Ninth Symphony." 19th-Century Music 15, no. 3 (1992): 188-206.

Cohn, Richard. "Complex Hemiolas, Ski-Hill Graphs and Metric Spaces." Music Analysis 20, no. 3 (2001): 295-325.

Colannino, Justin, Francisco Gómez, and Godfried T. Toussaint. "Analysis of Emergent BeatClass Sets in Steve Reich's 'Clapping Music' and the Yoruba Bell Timeline." Perspectives of New Music 47, no. 1 (2009): 111-134.

Coleman, Peter. The Liberal Conspiracy: The Congress for Cultural Freedom and the Struggle for the Mind of Postwar Europe. New York: Free Press, 1989.

Conrad, Sebastian, and Andreas Eckert. "Globalgeschichte, Globalisierung, multiple Modernen. Zur Geschichtsschreibung der modernen Welt." In Globalgeschichte. Theorien, Ansätze, Themen, edited by Sebastian Conrad, Andreas Eckert, and Ulrike Freitag, 7-52. Frankfurt: Campus, 2007.

Conrad, Sebastian. What Is Global History? Princeton: Princeton University Press, 2016.

Cook, Lisa M. "Venerable Traditions, Modern Manifestations: Understanding Mayuzumi's Bunraku for Cello." Asian Music 45, no. 1 (2014): 98-131. https://doi.org/10.1353/amu.2013.0029

Cook, Nicholas. “'One Size Fits All?' Musicology, Performance, and Globalization.” In Musicology and Globalization: Proceedings of the International Congress in Shizuoka 2002, edited by the Musicological Society of Japan, 13-22. Tokyo: Musicological Society of Japan, 2004.

Cook, Nicholas. "Alternative Realities: A Reply to Richard Taruskin." 19th-Century Music 30, no. 2 (2006): 205-208.

Cook, Nicholas. "We Are All (Ethno)musicologists Now." In The New (Ethno)musicologies, edited by Henry Stobart, 48-70. Lanham: Rowman \& Littlefield, 2008.

Cook, Nicholas. "Intercultural Analysis as Relational Musicology." Paper presented at the First Conference on Analytical Approaches to World Music, University of Massachusetts Amherst, 19-21 February 2010.

Cook, Nicholas. "Anatomy of the Encounter: Intercultural Analysis as Relational Musicology." In Critical Musicological Reflections: Essays in Honour of Derek B. Scott, edited by Stan Hawkins, 193-208. Aldershot: Ashgate, 2012.

Cook, Nicholas. Beyond the Score: Music as Performance. New York: Oxford University Press, 2013.

Cook, Nicholas, and Anthony Pople, editors. The Cambridge History of Twentieth-Century Music. Cambridge: Cambridge University Press, 2004.

Cook, Nicholas, and Anthony Pople. "Introduction: Trajectories of Twentieth-Century Music." In The Cambridge History of Twentieth-Century Music, edited by Nicholas Cook and Anthony Pople, 1-17. Cambridge: Cambridge University Press, 2004.

Cooke, Mervyn. Britten and the Far East: Asian Influences in the Music of Benjamin Britten. Woodbridge: Boydell \& Brewer, 1998.

Cott, Jonathan. Stockhausen: Conversations with the Composer. London: Pan, 1974.

Covell, Jon Carter, and Sōbin Yamada. Unraveling Zen's Red Thread: Ikkyū's Controversial Way. Elizabeth, NJ: Hollym, 1980.

Cowell, Henry. "How Young Hungary Expresses Individuality." Musical America 46, no. 7 (1927): 11.

Cowell, Henry. "Moravian Music." Pro-Musica Quarterly 5, no. 2 (1927): 25-29.

Cowell, Henry. "Vocal Innovators of Europe." Modern Music 7, no. 2 (1930): 34-38.

Cowell, Henry. "Towards Neo-Primitivism." Modern Music 10, no. 3 (1933): 149-153.

Cowell, Henry. "Introduction." In United Quartet (String Quartet no. 4). San Francisco: New Music Edition, 1937. 
Cowell, Henry. "Shaping Music for Total War." Modern Music 22, no. 4 (1945): 223-226.

Cowell, Henry. "Oriental Influence on Western Music." In Music - East and West: Report on 1961 Tokyo East-West Music Encounter Conference, edited by the Executive Committee for 1961 Tokyo East-West Music Encounter, 71-76. Tokyo 1961.

Cox, Franklin. "Richard Taruskins The Oxford History of Western Music." Musik \& Ästhetik no. 61 (2012): 95-106.

Crilly, David. “'There's No Theatre like Noh Theatre...:' Cultural Montage in Britten's Curlew River." In Musicology and Globalization: Proceedings of the International Congress in Shizuoka 2002, edited by the Musicological Society of Japan, 247-251. Tokyo: Musicological Society of Japan, 2004.

Cui, Xiaohuo. "Classical Piece Will Ring in Ears of Winners." China Daily, 8 June 2008. http:// www.chinadaily.com.cn/olympics/2008-08/06/content_6912001.htm

Custodis, Michael. Die soziale Isolation der neuen Musik: Zum Kölner Musikleben nach 1945. Stuttgart: Steiner, 2004.

Custodis, Michael. Klassische Musik heute: Eine Spurensuche in der Rockmusik. Bielefeld: transcript 2009.

Czernowin, Chaya. "Die Kreuzung." Program note, 1995. https://en.schott-music.com/shop/ die-kreuzung-no140095.html

Czernowin, Chaya. "Excavated Dialogues - Fragments." Program note, 2003. https:// en.schottmusic.com/shop/excavated-dialogues-no175067.html

Czernowin, Chaya. "Der Dialog als ein kompositorisches Modell." In Freiräume und Spannungsfelder: Reflexionen zur Musik heute, edited by Jörn Peter Hiekel and Marion Demuth, 165-170. Mainz: Schott, 2009.

Dahlhaus, Carl. "Zur Problemgeschichte des Komponierens." [1974] In Carl Dahlhaus, Gesammelte Schriften in 10 Bänden, Vol. 6, edited by Hermann Danuser, 447-473. Laaber: Laaber, 2003.

Dahlhaus, Carl. Grundlagen der Musikgeschichte. Cologne: Gerig, 1977.

Dahlhaus, Carl. "Historisches Bewußtsein und Ethnologie." [1977] In Carl Dahlhaus, Gesammelte Schriften in 10 Bänden, Vol. 1, edited by Hermann Danuser, 216-220. Laaber: Laaber, 2000.

Dahlhaus, Carl. "Der Werkbegriff als Paradigma." In Systematische Musikwissenschaft, edited by Carl Dahlhaus and Helga de la Motte-Haber, 90-100. Laaber: Laaber, 1982.

Dai, Penghai. Ding Shande yinyue nianpu chang bian (Chronology for the Music of Ding Shande). Manuscript. Shanghai, 1991.

Danielczyk, Sandra, Christoph Dennerlein, Sylvia Freydank, Ina Knoth, Matthias Maschat, Lilly Mittner, Karina Seefeldt, and Lisbeth Suhrcke, editors. Konstruktivität von Musikgeschichtsschreibung: Zur Formation musikbezogenen Wissens. Hildesheim: Olms, 2012.

Danuser, Hermann. Die Musik des 20. Jahrhunderts. [1984] Laaber: Laaber, 1992.

Danuser, Hermann editor. Musikalische Lyrik, Vol. 2: Vom 19. Jahrhundert bis zur Gegenwartaußereuropäische Perspektiven. Laaber: Laaber, 2004.

Dauer, Alfons M. "Musiklandschaften in Afrika." In Musik in Afrika: 20 Beiträge zur Kenntnis traditioneller afrikanischer Musikkulturen, edited by Artur Simon, 41-48. Berlin: Museum für Völkerkunde, 1983.

Debussy, Claude. Monsieur Croche et autres écrits [1971], edited by François Lesure. Paris: Gallimard, 1987.

Delaere, Mark. “Tempo, Metre, Rhythm: Time in Twentieth-Century Music.” In Unfolding Time: Studies in Temporality in Twentieth-Century Music, edited by Darla Crispin and Kathleen Snyers, 13-43. Leuven: Leuven University Press, 2009. 
Delage, Maurice. "Lettre de l'Inde, 4 March 1912, Kandy." Revue musicale S.I.M., 15 June 1912, $72-74$.

Deleuze, Gilles, and Félix Guattari. A Thousand Plateaus: Capitalism and Schizophrenia. [1980] Translation and Foreword by Brian Massumi. Minneapolis: University of Minnesota Press, 2011.

Deliège, Irène, and Marc Mélen. "Cue Abstraction in the Representation of Musical Form." In Perception and Cognition of Music, edited by Irène Deliège and John Sloboda, 387-412. Hove: Psychology Press, 1997.

Derrida, Jacques. Of Grammatology. [1967] Baltimore: Johns Hopkins University Press, 1976.

Derrida, Jacques. Points... Interviews 1974-1994, edited by Elisabeth Weber. Stanford: Stanford University Press, 1995.

Deutsch, Diana. "Grouping Mechanisms in Music." In The Psychology of Music [1982], edited by Diana Deutsch, 299-348. San Diego: Academic Press 2012.

Dibelius, Ulrich. György Ligeti: Eine Monographie in Essays. Mainz: Schott, 1994.

Dirlik, Arif. "Transnationalism in Theory and Practice: Uses, Mis-Uses, Abuses." ALAI: América Latina en Movimiento, 17 November 2010. https://www.alainet.org/es/node/145569

Dolar, Mladen. A Voice and Nothing More. Cambridge: MIT Press, 2006.

Dorfegger, Lukas. "Praktische und theoretische Überlegungen zur Ausführung der Sprechstimme in Pierrot lunaire op. 21 von Arnold Schönberg." Bachelor's thesis, University of Music and Performing Arts Graz, 2019.

Dorschel, Andreas. "Über Kanonisierung." Musiktheorie 21, no. I (2006): 6-12.

Dorschel, Andreas. "Interkulturelle Begegnung als existentielles Risiko. Ästhetische, historische und gesellschaftliche Aspekte musikalischer Globalisierung" (Panel discussion with Gerd Grupe, Jörn Peter Hiekel, Peter Revers, Christian Utz, and Hans Zender, held on 17 October 2006). In Musik und Globalisierung: Zwischen kultureller Homogenisierung und kultureller Differenz, edited by Christian Utz, 103-115. Saarbrücken: Pfau, 2007.

Drake, Carolyn, and Richard Parncutt. "Psychology of Music: II. Perception and Cognition." Grove Music Online, 2001. https://doi.org/10.1093/gmo/9781561592630.article.42574

Dreyer, Hubertus. 2015. "Theorie aus der Ferne." In Musiktheorie und Komposition: XII. Jahreskongress der Gesellschaft für Musiktheorie Essen 2012, edited by Markus Roth and Matthias Schlothfeldt, 53-63. Hildesheim: Olms.

Drury, Stephen. "Variation Pitch Structure Time: Two for Violin and Piano or Shō (2000)." In $\mathrm{Two}^{4}$, mode 88, 2000. Supplemental booklet. http://www.stephendrury.com/writings/ cagetwo4.html

Dubal, David. The Essential Canon of Classical Music. New York: North Point Press, 2003.

Duchesneau, Michel. "Maurice Ravel et la Société Musicale Indépendante: 'Projet mirifique de concerts scandaleux." Revue de Musicologie 80, no. 2 (1994): 251-281.

Eco, Umberto. Das offene Kunstwerk. Frankfurt: Suhrkamp, 1990.

Eggert, Marion, editor. Wind und Gras. Moderne koreanische Lyrik. Munich: Rohr, 1991.

Ehrmann-Herfort, Sabine. "Teatro per gli orecchi. Luciano Berios Experimente zum musikalischen Theater." In Luciano Berio, edited by Ulrich Tadday, 67-93. Munich: edition text + kritik, 2005.

Eikemeier, Dieter. “Ist Yun Isangs Musik koreanisch?" In Der Komponist Isang Yun, edited by Hanns-Werner Heister and Walter-Wolfgang Sparrer, 29-39. Munich: edition text + kritik, 1997. 
Eikemeier, Dieter. "Zum Text von Yun Isangs Memory für drei Stimmen mit Schlagwerk (1974)." In Ssi-ol: Almanach 2000/01, edited by Walter-Wolfgang Sparrer, 79-100. Munich: edition text + kritik, 2002 .

Eisenstadt, Shmuel N. Multiple Modernities. New Brunswick: Transaction, 2002.

Elberfeld, Rolf. "Einleitung." In Kitarō Nishida, Logik des Orts: Der Anfang der modernen Philosophie in Japan, edited by Rolf Elberfeld, 1-19. Darmstadt: Wissenschaftliche Buchgesellschaft, 1999.

Elberfeld, Rolf. "Begriffserklärung." In Kitarō Nishida, Logik des Orts: Der Anfang der modernen Philosophie in Japan, edited by Rolf Elberfeld, 285-310. Darmstadt: Wissenschaftliche Buchgesellschaft, 1999.

Elberfeld, Rolf. Phänomenologie der Zeit im Buddhismus: Methoden interkulturellen Philosophierens. Stuttgart: Frommann-Holzboog, 2004.

Elberfeld, Rolf. "Moderne interkulturell. Tradition und Traditionsbruch im Horizont der europäischen Expansion." In Tradition und Traditionsbruch zwischen Skepsis und Dogmatik: Interkulturelle philosophische Perspektiven, edited by Claudia Bickmann, Hermann-Josef Scheidgen, Tobias Voßhenrich, and Markus Wirtz, 383-392. Amsterdam: Rodopi, 2006.

Elberfeld, Rolf. “'Das Ich ist kein Ding, sondern ein Ort:' Identität im Zwischen.” In Kulturelle Identität(en) in der Musik der Gegenwart: Kolloquium des Europäischen Zentrums der Künste Hellerau im Rahmen der 18. Dresdner Tage der zeitgenössischen Musik in Kooperation mit der Hochschule für Musik Carl Maria von Weber Dresden, edited by Marion Demuth and Jörn Peter Hiekel, 43-52. Saarbrücken: Pfau, 2010.

Ellis, Alexander J. "On the Musical Scales of Various Nations." The Journal of the Society of Arts 33, no. 1688 (1885): 485-527.

Emigranten Adressbuch für Shanghai: Mit einem Anhang: Branchen-Register (Facsimile reprint of the original edition). [1939] Hong Kong, 1995.

Endō, Tōru. "The Revival of Lost Repertoire and the Composition of New Works for the gagaku Ensemble." In Musicology and Globalization: Proceedings of the International Congress in Shizuoka 2002, edited by the Musicological Society of Japan, 78-81. Tokyo: Musicological Society of Japan, 2004.

Eory, Martina. "Zur Rolle der Musik für zentraleuropäische jüdische Flüchtlinge in der Diaspora Shanghai, 1939-1949." Master's thesis, University of Vienna, 2009. http://othes.univie. ac.at $/ 6022$

Erbe, Marcus. "Karlheinz Stockhausens ‘Telemusik' (1966)." In Kompositorische Stationen des 20. Jahrhunderts: Debussy, Webern, Messiaen, Boulez, Cage, Ligeti, Stockhausen, Höller, edited by Christoph von Blumröder, 129-171. Münster: LIT, 2004.

Erdmann, Martin. "Zusammenhang und Losigkeit: Zu Morton Feldmans Kompositionen zwischen 1950 und 1956." In Morton Feldman, edited by Heinz-Klaus Metzger and Rainer Riehn, 67-94. Munich: edition text + kritik, 1986.

Erdmann, Martin. "Webern und Cage: Zur Genese der Cageschen Losigkeit." In John Cage II, edited by Heinz-Klaus Metzger and Rainer Riehn, 237-259. Munich: edition text + kritik, 1990.

Ertan, Deniz. Dane Rudhyar: His Music, Thought, and Art. Rochester: University of Rochester Press, 2009.

Everett, Yayoi Uno. "Mirrors of West and Mirrors of East: Elements of Gagaku in Postwar Art Music." In Translating Asia's Traditions: Diasporas and Interculturalism in Asian Performing Arts, edited by Hae-kyung Um, 176-203. New York: Routledge, 2005. 
Everett, Yayoi Uno. "Gesture and Calligraphy in the Music of Chou Wen-Chung." Contemporary Music Review 26, no. 5-6 (2007): 569-584.

Everett, Yayoi U. "From Exoticism to Interculturalism: Counterframing the East-West Binary." Music Theory Spectrum, forthcoming.

Ewell, Philip A. "Music Theory and the White Racial Frame." Music Theory Online 26, no. 2 (2020). https://doi.org/10.30535/mto.26.2.4

Executive Committee for 1961 Tokyo East-West Music Encounter, editors. Music-East and West: Report on 1961 Tokyo East-West Music Encounter Conference, Tokyo. Tokyo, 1961.

Fauser, Annegret. Musical Encounters at the 1889 Paris World's Fair. Rochester: University of Rochester Press, 2010.

Felderer, Barbara, editor. Phonorama: Eine Kulturgeschichte der Stimme als Medium. Berlin: 2004 .

Feng, Guangyu. Zhongguo tongzong minge (Chinese Folk Songs of Self-Same Origin). Beijing, 1988.

Ferneyhough, Brian. "Unity Capsule: An Instant Diary." [1980] In Collected Writings, edited by James Boros and Richard Toop, 98-106. Second edition. Amsterdam: Harwood, 1998.

Ferneyhough, Brian. "Form - Figure - Style: An Intermediate Assessment." [1982] In Collected Writings, edited by James Boros and Richard Toop, 21-28. Second edition. Amsterdam: Harwood, 1998.

Ferranti, Hugh de. "Transmission and Textuality in the Narrative Traditions of Blind Biwa Players." Yearbook for Traditional Music 35 (2003): 131-152.

Fetthauer, Sophie. "Alfred Dreifuß." In Lexikon verfolgter Musiker und Musikerinnen der NS-Zeit, edited by Claudia Maurer Zenck, Peter Petersen, and Sophie Fetthauer. Hamburg: University of Hamburg, 2017. Last updated 31 January 2020. https://www.lexm.uni-hamburg.de/ object/lexm_lexmperson_00005276

Fetthauer, Sophie. "Das Far Eastern Jewish Central Information Bureau in Harbin und Shanghai: Nachrichtensteuerung und individuelle Beratung für NS-verfolgte Musiker und $\mathrm{Mu}$ sikerinnen mit dem Fluchtziel Shanghai bzw. Ostasien." In Musik und Migration, edited by Wolfgang Gratzer and Nils Grosch, 51-65. Münster: Waxmann, 2018.

Fetthauer, Sophie. "Fritz A. Kuttner." In Lexikon verfolgter Musiker und Musikerinnen der NS-Zeit, edited by Claudia Maurer Zenck, Peter Petersen, and Sophie Fetthauer. Hamburg: University of Hamburg, 2018. Last updated 7 February 2018. https://www.lexm.uni-hamburg.de/ object/lexm_lexmperson_00003563

Fetthauer, Sophie. "Ferdinand Adler." In Lexikon verfolgter Musiker und Musikerinnen der NS-Zeit, edited by Claudia Maurer Zenck, Peter Petersen, and Sophie Fetthauer. Hamburg: University of Hamburg, 2019. Last updated 15 January 2020. https://www.lexm.uni-hamburg.de/ object/lexm_lexmperson_00003254

Feyerabend, Paul. "Explanation, Reduction and Empiricism." In Scientific Explanation, Space, and Time, edited by Herbert Feigl and Grover Maxwell, 28-97. Minneapolis: University of Minnesota Press, 1962.

Fillitz, Thomas. "Anthropology and Discourses on Global Art." Social Anthropology 23, no. 3 (2015): 299-313.

Finchum-Sung, Hilary Vanessa. "Foreword: Aesthetics of Interculturality in East Asian Contemporary Music." the world of music [new series] 6, no. 1 (2017): 7-20.

Flavin, Philip. "Meiji shinkyoku: The Beginnings of Modern Music for the Koto." Japan Review 22 (2010): 103-123.

Flotzinger, Rudolf. "Glossen zum frühen abendländischen 'Kompositions'-Begriff." In Musik des Mittelalters und der Renaissance: Festschrift Klaus-Jürgen Sachs zum 80. Geburtstag, edited 
by Rainer Kleinertz, Christoph Flamm, and Wolf Frobenius, 197-203. Hildesheim: Olms, 2010.

Foucault, Michel. The Order of Things: An Archaeology of the Human Sciences. [1966] London: Routledge, 2002.

Fraenkel, Wolfgang. Afunktionelle Musik: Versuch einer Erforschung und systematischen Darstellung neuer Musik, edited and with commentary by Markus Köhler. Licensing thesis, Munich, 1989.

Freud, Sigmund. Das Unbehagen in der Kultur. [1930] In Das Unbehagen in der Kultur und andere kulturtheoretische Schriften, 29-108. Frankfurt: Fischer, 1994.

Freud, Sigmund. Civilization and Its Discontents. [1930] Edited by Todd Dufresne. Translated by Gregory C. Richter. Peterborough: Broadview Press, 2016.

Fricke, Stefan. "Ein saarländischer Vertreter der Zweiten Wiener Schule: Der Komponist Julius Schloß." In Musik in Saarbrücken: Nachklänge einer wechselvollen Geschichte, edited by Nike Keisinger and Ricarda Wackers, 171-178. Saarbrücken: Staden, 2000.

Fricke, Stefan. "Julius Schloß (1902-1973)." mr-Mitteilungen 35 (2000): 1-5.

Fritsch, Ingrid. "Zur Idee der Weltmusik." Die Musikforschung 34, no. 3 (1981): 259-273.

Fukunaka, Fuyuko. "Chinmoku suru 'seijin,' chūshō ka sareta 'aika:' 'bunka teki jiyū no tame no kaigi' ni miru, niju seiki ongaku ni okeru reisen poritikkusu no shatei (Politicizing Music: Saints, Lamentations, and the Congress for Cultural Freedom). Keiōgijuku daigaku hiyoshi kiyō jinbun kagaku (The Hiyoshi Review of the Humanities) 23 (2008): 243-274.

Fukunaka, Fuyuko. "Re-situating Japan's Post-War Musical Avant-Garde through Re-situating Cage: The Sōgetsu Art Center and the Aesthetics of Spontaneity." In Contemporary Music in East Asia, edited by Hee Sook Oh, 181-208. Seoul: Seoul National University Press, 2014.

Fukunaka, Fuyuko. "World Music History and Interculturality: Toward Recontextualizing Post-War Japanese Avant-Garde Music." the world of music [new series] 6, no. 1 (2017): 59-71.

Funayama, Takashi. "Three Japanese Lyrics and Japonisme." In Confronting Stravinsky: Man, Musician, and Modernist, edited by Jann Pasler, 273-283. Berkeley: University of California Press, 1986.

Gail, Dorothea. "Die 4. Symphonie von Charles Ives: Hermeneutik zwischen Programmmusik und absoluter Musik." In Charles Ives, edited by Ulrich Tadday, 73-87. Munich: edition text + kritik, 2004.

Gail, Dorothea. Charles E. Ives' Fourth Symphony: Quellen-Analyse-Deutung. Hof heim: Wolke, 2009.

Galliano, Luciana. Yōgaku: Japanese Music in the Twentieth Century. Lanham: Scarecrow Press, 2002.

Gaonkar, Dilip Parameshwar, editor. Alternative Modernities. Durham: Duke University Press, 2001.

Garfias, Robert. Music of a Thousand Autumns: The Tögaku Style of Japanese Court Music. Berkeley: University of California Press, 1975.

Gaub, Albrecht. "Karl Steiner." In Lexikon verfolgter Musiker und Musikerinnen der NS-Zeit, edited by Claudia Maurer Zenck, Peter Petersen, and Sophie Fetthauer. Hamburg: University of Hamburg, 2006. Last updated 29 March 2017. https://www.lexm.uni-hamburg.de/ object/lexm_lexmperson_00001389

Gee, Erin. "The Relationship of Non-Semantic Vocal Music to the International Phonetic Alphabet and Research in the Phonetic Sciences: Brian Ferneyhough, Georges Aperghis and Dieter Schnebel." PhD dissertation, University of Music and Performing Arts Graz, 2007. 
Gee, Erin. "The Notation and Use of the Voice in Non-Semantic Contexts: Phonetic Organization in the Vocal Music of Dieter Schnebel, Brian Ferneyhough, and Georges Aperghis." In Vocal Music and Contemporary Identities: Unlimited Voices in East Asia and the West, edited by Christian Utz and Frederick Lau, 175-199. New York: Routledge, 2013.

Geisel, Eike, and Henryk M. Broder. Der Jüdische Kulturbund 1933-1941: Texte und Bilder. Berlin: Siedler, 1992.

Geist, Beate. Die Modernisierung der chinesischen Kultur: Kulturdebatte und kultureller Wandel im China der 8oer Jahre. Hamburg: Institut für Asienkunde, 1996.

Gellner, Ernest. Nations and Nationalism. [1983] Second edition. Oxford: Blackwell, 2006.

Gerhardt, Frank. "'Gegenstrebige Harmonik:' Über Hans Zenders harmonisches Ordnungssystem." In Orientierungen: Wege im Pluralismus der Gegenwartsmusik, edited by Jörn Peter Hiekel, 138-150. Mainz: Schott, 2007.

Gertich, Frank, and Martin Greve. "Neue Musik im postkolonialen Zeitalter." In Geschichte der Musik im 20. Jahrhundert, Vol. 4: 1975-2000, edited by Helga de la Motte-Haber, 51-64. Laaber: Laaber, 2000.

Giebisch, Thomas. Take-offals Kompositionsprinzip bei Charles Ives. Regensburg: Bosse, 1993.

Gild, Gerlinde. "Early 2oth Century 'Reforms' in Chinese Music: Dreams of Renewal Inspired by Japan and the West." CHIME no. 12/13 (1999): 116-123.

Giroud, Vincent. Nicolas Nabokov: A Life in Freedom and Music. New York: Oxford University Press, 2015.

Glaser, Thomas. "René Leibowitz und die Idee einer 'musique engagée.” Jahrbuch des Zentrums für Populäre Kultur und Musik 60/61 (2016): 99-116.

Goebbels, Heiner. Komposition als Inszenierung, edited by Wolfgang Sandner. Munich: edition text + kritik, 2002 .

Goehr, Lydia. The Imaginary Museum of Musical Works: An Essay in the Philosophy of Music. [1992] Revised edition. New York: Oxford University Press, 2007.

Goehr, Lydia. "'On the Problems of Dating' or 'Looking Backward and Forward with Strohm." In The Musical Work: Reality or Invention, edited by Michael Talbot, 231-246. Liverpool: Liverpool University Press, 2000.

Goodman, Nelson. Languages of Art: An Approach to a Theory of Symbols. Indianapolis: Hackett, 1976.

Goody, Jack. The East in the West. Cambridge: Cambridge University Press, 1996.

Gooi, Tah-Choe. "Making an Identity: A Study of Three Compositional Strategies in the Music of Tan Dun." PhD Dissertation, Nanyang Technological University Singapore, 2002.

Gordon, Barbara N. “Discovering Maurice Delage.” Journal of Singing 65, no. 3 (2009): 297-313.

Gottschewski, Hermann. "Eine Musikkultur auf dem Scheidewege. Die Hoiku Shōka ('Erziehungslieder,' 1877-1883) als restaurativer Gegenentwurf zur Einführung der westlichen Musik in Japan." Habilitation thesis (manuscript), Humboldt University of Berlin, 2000.

Gottschewski, Hermann. "Poesie und Musik:' Das japanische Klavierlied um 1920." In Musikalische Lyrik, Teil 2: vom 19. Jahrhundert bis zur Gegenwart: Außereuropäische Perspektiven, edited by Hermann Danuser, 364-384. Laaber: Laaber, 2004.

Gottschewski, Hermann. "Zur Rezeption chinesischer Musik in Japan um 1900." In Musik und kulturelle Identität: Bericht über den XIII. Internationalen Kongress der Gesellschaft für Musikforschung, Vol. 2, edited by Detlef Altenburg and Rainer Bayreuther, 607-616. Kassel: Bärenreiter, 2012.

Gratzer, Wolfgang, and Nils Grosch, editors. Musik und Migration. Münster: Waxmann, 2018. Gritten, Anthony, and Elaine King. Music and Gesture. Aldershot: Ashgate, 2008. 
Groemer, Gerald. The Spirit of Tsugaru: Blind Musicians, Tsugaru-jamisen, and the Folk Music of Northern Japan. Warren: Harmonie Park Press, 1999.

Groß, Thomas. "Aus dem Schrein." Die Zeit 2008, no. 6. https://www.zeit.de/2008/06/ D-Klassiker-6

Gruhn, Wilfried. "Das andere Denken der Ohren: Der Einfluss fernöstlichen Denkens auf die Zeitvorstellung in Kompositionen Hans Zenders." In Philosophischer Gedanke und musikalischer Klang: Zum Wechselverhältnis von Musik und Philosophie, edited by Christoph Asmuth, Gunter Scholtz and Franz-Bernhard Stammkötter, 193-204. Frankfurt: Campus, 1999.

Grupe, Gerd. "Wachswalzen und CDs, Synthies und Sampler: Musikethnologie und 'neue' Medien." In "Alte" Musik und "neue" Medien, edited by Jürgen Arndt and Werner Keil, 195-216. Hildesheim: Olms, 2003.

Grupe, Gerd. "Notating African Music: Issues and Concepts." the world of music 47, no. 2 (2005): 87-103.

Günther, Ursula. "Die Ars subtilior." In Für György Ligeti: Die Referate des Ligeti-Kongresses Hamburg 1988, edited by Constantin Floros, Hans Joachim Marx, and Peter Petersen, 277-288. Laaber: Laaber, 1991.

Guo, Wenjing. “Traditional Music as Material.” the world of music 45, no. 2 (2003): 125-126.

Gut, Serge. Le Groupe Jeune France: Yves Baudrier, Daniel Lesur, André Jolivet, Olivier Messiaen. Paris: Honoré Champion, 1977.

Gutknecht, Dieter. "Stockhausen und Japan." In Lux oriente: Begegnungen der Kulturen in der Musikforschung: Festschrift Robert Günther zum 65. Geburtstag, edited by Uwe U. Pätzold, Kyochul Chung, Klaus Wolfgang Niemöller, and Oliver Seibt, 271-284. Kassel: Bosse, 1995.

Gutknecht, Dieter. "Das Geistliche im realen Kompositionsprozeß Stockhausens: Tradition und neuer Ansatz." In Internationales Stockhausen-Symposion 1998, edited by Imke Misch and Christoph von Blumröder, 9-18. Saarbrücken: Pfau, 1999.

Haapamaki, Sampo Elias. "Order in Désordre: Rhythmic and Melodic Structure in György Ligeti's Piano Etude No. 1.” DMA dissertation, Columbia University, 2012.

Haddad, Saed. "The Abstraction of Arabic Musical Vocabulary, Spiritual and Cultural Values into Contemporary Western Music." PhD dissertation, King's College London, 2005.

Haefeli, Anton. IGNM: Die Internationale Gesellschaft für Neue Musik: Ihre Geschichte von 1922 bis zur Gegenwart. Zurich: Atlantis, 1982.

Hall, Stuart. "The Question of Cultural Identity." In Modernity and Its Futures, edited by Stuart Hall, David Held, and Anthony McGrew, 273-316. Cambridge: Polity Press, 1992.

Ham, Martin. "A Sense of Proportion: The Performance of Sesquialtera ca. 1515-ca. 1565." In Musica Disciplina: A Yearbook of the History of Music, edited by Stanley Boorman. American Institute of Musicology, 2012.

Hamilton, Andy. Aesthetics and Music. London: Bloomsbury, 2007.

Hamilton, Andy. "The Sound of Music." In Sounds and Perception: New Philosophical Essays, edited by Matthew Nudds \& Casey O'Callaghan, 146-182. New York: Oxford University Press, 2009.

Han, Byung-Chul. Hyperkulturalität: Kultur und Globalisierung. Berlin: Merve, 2005.

Han, Insook. Interkulturalität in der neuen Musik Koreas: Integration und Hybridität in der Musik von Isang Yun und Byungki Hwang. Hamburg: Kovac, 2011.

Han, Kuo-Huang. "4. Western art music." In Tsang-Houei Hsu, Yu-Hsiu Lu, Chuikuan Lü, KuoHuang Han, and Joanna C. Lee, "Taiwan," Grove Music Online, 2001. https://doi.org/10.1093/ gmo/9781561592630.article.49502 
Handschin, Jacques. "Réflexions dangereuses sur le renouveau de la musique ancienne." [1938] In Über reine Harmonie und temperierte Tonleitern: Ausgewählte Schriften, edited by Michael Maier, 263-275. Schliengen: Argus, 2000.

Hanninen, Dora A. "Associative Sets, Categories, and Music Analysis." Journal of Music Theory 48 , no. 2 (2004): 147-218.

Harich-Schneider, Eta. A History of Japanese Music. Oxford: Oxford University Press, 1973.

Harrington, Helmi Strahl, and Gerhard Kubik. "Accordion." Grove Music Online, 2001. https:// doi.org/10.1093/gmo/9781561592630.article.46180

Harrison, Frank L. Time, Place and Music: An Anthology of Ethnomusicological Observation c. $1550-$ c. 1800. Amsterdam: Knuf, 1973.

Harvey, David. The Condition of Postmodernity: An Enquiry into the Origin of Cultural Changes. Oxford: Wiley-Blackwell, 1989.

Hasegawa, Robert. "Gegenstrebige Harmonik in the Music of Hans Zender." Perspectives of New Music 49, no. 1 (2011): 207-234.

Haselböck, Lukas. "Debussy und die Wiener Schule." Musiktheorie 28, no. 1 (2013): 76-94.

Hashimoto, Kunihiko. "Nagauta shinkyoku 'Akebono' no henkyoku ni tsuite" (On the Orchestration of the nagauta-shinkyoku "Akebono"). Ongaku sekai 3, no. 12 (1931): 44-47.

Haskins, Rob. Anarchic Societies of Sounds: The Number Pieces of John Cage. [2004] Saarbrücken: VDM, 2009.

Haskins, Rob. "The Extraordinary Commonplace: Cage's Music for Shō, Violin, Conch Shells (2004)." Archived 9 February 2012. https://web.archive.org/web/20120209143208/http:// robhaskins.net/writings/sho_notes.htm

Hasty, Christopher F. Meter as Rhythm. Oxford: Oxford University Press, 1997.

Hatten, Robert. Interpreting Musical Gestures, Topics, and Tropes: Mozart, Beethoven, Schubert. Bloomington: Indiana University Press, 2004.

Häusler, Josef. "Begegnungswege. Über Motivationen europäischer Komponisten im Kontakt mit fremden Welten." In Fremde Welten (Program Wien Modern 1996), edited by the Wiener Konzerthaus, 35-39. Vienna, 1996.

Havens, Thomas R. H. Radicals and Realists in the Japanese Nonverbal Arts: The Avant-garde Rejection of Modernism. Honolulu: University of Hawai'i Press, 2006.

Hayasaka, Fumio. "Tanaka hakushi no Nihon wasei no kiso ni oite no shiken" (My View on Dr. Tanaka's Foundations of Japanese Harmony). Gekkan gakufu 4 (1941).

Hayasaka, Fumio. Nihonteki ongakuron (Treatise on Japanese Music). Tokyo: Shinkō Ongaku Shuppansha, 1942.

Hayashi, Hikaru. “Two Opinions Over the Tokyo World Music Festival: II." Ongaku geijutsu 19, no. 4 (1961): 44-46.

$\mathrm{He}$, Chengzhou. "The Ambiguities of Chineseness and the Dispute Over the 'Homecoming' of Turandot." Comparative Literature Studies 49, no. 4 (2012): 547-564.

Heathcote, Abigail. "Liberating Sounds: Philosophical Perspectives on the Music and Writings of Helmut Lachenmann.” PhD dissertation, Durham University, 2003.

Heile, Björn. "Weltmusik and the Globalization of New Music." In The Modernist Legacy: Essays on New Music, edited by Björn Heile, 101-119. Farnham: Ashgate, 2009.

Heisig, James W., and John C. Maraldo, editors. Rude Awakenings: Zen, the Kyoto School, \& the Question of Nationalism. Honolulu: University of Hawai'i Press, 1995.

Heister, Hanns-Werner. "Kollektivität und Körperlichkeit: 'Exemplum in memoriam Kwangju' (1981)." In Der Komponist Isang Yun, edited by Hanns-Werner Heister and Walter-Wolfgang Sparrer, 234-259. Second edition. Munich: edition text+kritik, 1997. 
Herd, Judith Ann. "The Cultural Politics of Japan's Modern Music: Nostalgia, Nationalism, and Identity in the Interwar Years." In Locating East Asia in Western Art Music, edited by Yayoi Uno Everett and Frederick Lau, 40-56. Middletown: Wesleyan University Press, 2004.

Herzfeld, Gregor. Zeit als Prozess und Epiphanie in der experimentellen amerikanischen Musik: Charles Ives bis La Monte Young. Stuttgart: Steiner, 2007.

Herzfeld-Schild, Marie Louise. "Studien zu Cathy Berberians 'New Vocality." Archiv für Musikwissenschaft 68, no. 2 (2011): 121-156.

Hiekel, Jörn Peter. Bernd Alois Zimmermanns Requiem für eine jungen Dichter. Stuttgart: Steiner, 1995.

Hiekel, Jörn Peter. "Über Isabel Mundry." Komponistenprospekt: Isabel Mundry. Wiesbaden: Breitkopf \& Härtel, 2000.

Hiekel, Jörn Peter. "Interkulturalität als existentielle Erfahrung: Asiatische Perspektiven in Helmut Lachenmanns Ästhetik." In Nachgedachte Musik: Studien zum Werk von Helmut Lachenmann, edited by Jörn Peter Hiekel and Siegfried Mauser, 62-84. Saarbrücken: Pfau, 2005.

Hiekel, Jörn Peter. "Erstaunen und Widersprüchlichkeit: Tendenzen kultureller Entgrenzung in der Musik von Hans Zender." In Musik und Globalisierung: Zwischen kultureller Homogenisierung und kultureller Differenz, edited by Christian Utz, 79-94. Saarbrücken: Pfau, 2007.

Hiekel, Jörn Peter. "Vielstimmig in sich: Zu einigen Kernaspekten von Hans Zenders Schaffen." In Vielstimmig in sich, edited by Werner Grünzweig, Jörn Peter Hiekel, and Anouk Jeschke, 13-28. Hof heim: Wolke, 2008.

Hiekel, Jörn Peter. "Escaped from Paradise? Construction of Identity and Elements of Ritual in Vocal Works by Helmut Lachenmann and Giacinto Scelsi." In Vocal Music and Contemporary Identities: Unlimited Voices in East Asia and the West, edited by Christian Utz and Frederick Lau, 158-174. New York: Routledge, 2013.

Hiekel, Jörn Peter. "Angekommen im Hier und Jetzt? Aspekte des Weltbezogenen in der Neuen Musik." In Lexikon Neue Musik, edited by Jörn Peter Hiekel and Christian Utz, 54-76. Stuttgart: Metzler/Kassel: Bärenreiter, 2016.

Hijiya-Kirschnereit, Irmela. Das Ende der Exotik: Zur japanischen Kultur und Gesellschaft der Gegenwart. Frankfurt: Suhrkamp, 1988.

Hijiya-Kirschnereit, Irmela. "Leuchtet Japan? Einführende Gedanken zu einer proklamierten Zeitenwende." In Überwindung der Moderne? Japan am Ende des zwanzigsten Jahrhunderts, edited by Irmela Hijiya-Kirschnereit, 7-24. Frankfurt: Suhrkamp, 1996.

Hiley, David, E. Thomas Stanford, and Paul R. Laird. "Sesquialtera." Grove Music Online, 2001. https://doi.org/10.1093/gmo/9781561592630.article.40114

Hijleh, Mark. Towards a Global Music Theory: Practical Concepts and Methods for the Analysis of Music Across Human Cultures, Farnham: Ashgate, 2012 (New York: Routledge, 2016).

Hirano, Kenji. "Beziehungen zwischen Sprache und Musik im katarimono." In Japans traditionelle Musik aus der Sicht japanischer Musikologen, edited by Robert Günther and Heinz-Dieter Reese, 57-72. Wilhelmshaven: Noetzel, 2004.

Hirayama, Michiko. 'Mach's wie Du es fühlst.' Michiko Hirayama im Gespräch über Giacinto Scelsi (mit Berno Odo Polzer)." In Wien Modern 2005, edited by Berno Odo Polzer and Thomas Schäfer, 235-239. Saarbrücken: Pfau, 2005.

Hirayama, Michiko. "[Michiko Hirayama in Conversation with Jürgen Kanold]." In Giacinto Scelsi: Canti del Capricorno, Wergo 6686-2, compact disc, 2007. Supplemental booklet, 16-21. Hobsbawm, Eric. "Introduction: Inventing Traditions." In The Invention of Tradition, edited by Eric Hobsbawm and Terence Ranger, 1-14. Cambridge: Cambridge University Press, 1983. 
Hobsbawm, Eric, and Terence Ranger, editors. The Invention of Tradition. Cambridge: Cambridge University Press, 1983.

Hochgeschwender, Michael. Freiheit in der Offensive? Der Kongreß für kulturelle Freiheit und die Deutschen. Berlin: De Gruyter, 1998.

Hofstadter, Douglas R. Metamagical Themas: Questing for the Essence of Mind and Pattern. [1982] New York: Basic Books, 1985.

Homenick, Erik C. "Biography." In akiraifukube.org. Last updated 2020. https://www. akiraifukube.org/biography

Hornbostel, Erich M. von. "Die Probleme der vergleichenden Musikwissenschaft." Zeitschrift der Internationalen Musikgesellschaft 7, no. 3 (1905): 85-97.

Hornbostel, Erich M. von. "U.S.A. National Music." Zeitschrift der Internationalen Musikgesellschaft 12, no. 3 (1910): 64-68.

Hosokawa Toshio. "Aus der Tiefe der Erde: Musik und Natur." MusikTexte no. 60 (1995): 49-54.

Hosokawa Toshio. "Koto-uta für Gesang und koto." In Biennale neue Musik Hannover 1999, edited by the Hannoversche Gesellschaft für Neue Musik, 125-126. Hannover: Col Legno, 1999.

Hosokawa Toshio, and Walter-Wolfgang Sparrer. Stille und Klang, Schatten und Licht: Gespräche mit Walter-Wolfgang Sparrer. Hof heim: Wolke, 2012.

Hovhaness, Alan. "Korean Music is the Most Expressive, Sublime and Free in the World." Korea Journal 3 (1963): 29-32.

Howard, Keith. "Different Spheres: Perceptions of Traditional Music and Western Music in Korea." the world of music 39, no. 2 (1997): 61-67.

Howard, Keith. "Korean Tradition in Isang Yun's Composition Style." In Ssi-ol:Almanach 1998/99, edited by Walter-Wolfgang Sparrer, 67-106. Munich: edition text + kritik, 1999.

Howard, Keith. Creating Korean Music: Tradition, Innovation and the Discourse of Identity. Aldershot: Ashgate, 2006.

Howard, Keith. "P'iri: Isang Yun's composition and the Korean oboe." In Ssi-ol: Almanach 2004/09, edited by Walter-Wolfgang Sparrer, 109-129. Munich: edition text + kritik, 2009.

Hsu, Tsang-Houei. "Republic of China." In New Music in the Orient: Essays on Composition in Asia since World War II, edited by Harrison Ryker, 217-224. Buren: Knuf, 1991.

$\mathrm{Hsu}$, Tsang-Houei. Taiwan yinyueshi chugao (First Sketch for a History of Taiwanese Music). Third edition. Taipei: Quan yinyuepu chubanshe, 1996.

$\mathrm{Hu}$, Xien-Yue. "Zur Musik der Pipa im 20. Jahrhundert. Historische Voraussetzungen, Entwicklung und die Situation in Taiwan." Master's thesis, University of Vienna, 2002

Huang, Yi-Long. "Zhongguo minge 'Molihua' de xizhuang yu donggui" (The Journey to the West and Return to the East of the Chinese Folk Song "Jasmine Flower"). Wen yu zhe (Literature and Philosophy) 9 (2006): 1-16.

Huang, Yu. "Constellating World Literature." Neohelicon 40, no. 2 (2013): 561-580.

Huber, Klaus. "Black Plaint.” 1995. http://klaushuber.com/dsp_wk.php?lg=de\&op=107

Huber, Klaus, and Claus-Steffen Mahnkopf. Von Zeit zu Zeit: Das Gesamtschaffen-Gespräche mit Claus-Steffen Mahnkopf. Hof heim: Wolke, 2009.

Huber, Sonja. Das zeitgenössische Klavierkonzert: Analysen zu M. Feldman, M. Jarrell, G. Kühr, H. Lachenmann, G. Ligeti und W. Lutosławski. Vienna: Böhlau, 2014.

Hünermann, Tobias. "Transkription und Intermodulation. Integrative kompositorische Verfahren bei Luciano Berio und Karlheinz Stockhausen." Die Musikforschung 68, no. 1 (2015): 53-67.

Hüttner, Johann Christian. Nachricht von der Britischen Gesandtschaftsreise nach China 1792-94, edited by Sabine Dabringhaus. Sigmaringen: Thorbecke, 1996. 
Hwang, Mei-Shu. "Peking Opera: A Study of the Art of Translating the Scripts with Special Reference to Structure and Conventions." PhD dissertation, Florida State University, 1976.

Ichikawa, Hakugen, Yoshitaka Iriya, and Seizan Yanagida, editors. Chūsei Zenka no shisō (The Thought of Medieval Zen Figures). Tokyo: Iwanami Shoten, 1972.

Imberty, Michel. "Narrative, Splintered Temporalities and the Unconscious in 2oth Century Music." Musicae Scientiae, Special Issue: Narrative in Music and Interaction (2008): 129-146.

Inobe Kiyoshi. "Reading 'The Mountains Scene' as Music: The Chanter's Notation." In Theater as Music: The Bunraku Play "Mt. Imo and Mt. Se: An Exemplary Tale of Womanly Virtue," edited by C. Andrew Gerstle, Kiyoshi Inobe, and William P. Malm, 39-64. Ann Arbor: University of Michigan Press, 1990.

Irwin, Eyles. "Chinese Musick." In The Oriental Collections, Vol. 1, edited by William Ouseley, 343. London: Cadell and Davies, 1797.

Ives, Charles. Memos, edited by John Kirkpatrick. London: Norton, 1973.

Janz, Tobias. Klangdramaturgie. Studien zur theatralen Orchesterkomposition in Wagners "Ring des Nibelungen." Würzburg: Königshausen \& Neumann, 2006.

Janz, Tobias. "Musikhistoriographie und Moderne." Musiktheorie 24, no. 4 (2009): 312-330.

Janz, Tobias. "Gibt es eine Weltgeschichte der Musik?' Mit Carl Dahlhaus auf dem Weg zu einer komparativen Historiographie der musikalischen Moderne." In Musikhistoriographie(n), edited by Michele Calella and Nikolaus Urbanek, 129-155. Vienna: Hollitzer, 2015.

Janz, Tobias. "Multiple Musical Modernities? Dahlhaus, Eisenstadt, and the Case of Japan." In Decentering Musical Modernity: Perspectives on East Asian and European Music History, edited by Tobias Janz and Chien-Chang Yang, 279-312. Bielefeld: transcript, 2019.

Janz, Tobias, and Chien-Chang Yang, editors. Decentering Musical Modernity: Perspectives on East Asian and European Music History. Bielefeld: transcript, 2019.

Jedeck, Hannes. "Different Interpretations of Musical Modernity? Xiao Youmei's Studies in Leipzig and the Foundation of the Modern Chinese Folk Orchestra." In Decentering Musical Modernity: Perspectives on East Asian and European Music History, edited by Tobias Janz and Chien-Chang Yang, 123-143. Bielefeld: transcript, 2019.

Jena, Stefan. "Raum und Zeit in der Neuen Musik: Mit besonderer Berücksichtigung melodisch-rhythmischer Strukturen im Klavierkonzert György Ligetis.” Diploma thesis, University of Vienna, 1989.

Jiang, Mingdun. Hanzu minge gailun (Introduction to the Folk Songs of the Han People). Shanghai: Yinyue chubanshe, 1982.

Johnson, Steven. "Henry Cowell, John Varian, and Halcyon." American Music 11, no. 1 (1993): 1-27.

Jones, Andrew F. Yellow Music: Media Culture and Colonial Modernity in the Chinese Jazz Age. Durham: Duke University Press, 2001.

Jones, Arthur Morris. Studies in African Music. 2 Vols. Oxford: Oxford University Press, 1959.

Jones, Stephen. Folk Music of China: Living Instrumental Traditions. Oxford: Clarendon Press, 1995.

Jones, Stephen. "China, Peoples Republic of: IV. Living Traditions." Grove Music Online, 2001. https://doi.org/10.1093/gmo/9781561592630.article.43141

Josephson, Jason Ānanda. The Invention of Religion in Japan. Chicago: Chicago University Press, 2012.

Jost, Christofer. "Der 'performative turn' in der Musikforschung: Zwischen Desiderat und (teil) disziplinarem Paradigma." Musiktheorie 28 (2013): 291-309.

Jungmann, Irmgard. Kalter Krieg in der Musik: Eine Geschichte deutsch-deutscher Musikideologien. Vienna: Böhlau, 2011. 
Jungmann, Irmgard. Sozialgeschichte der klassischen Musik: Bildungsbürgerliche Musikanschauung im 19. und 20. Jahrhundert. Stuttgart: Springer, 2008.

Ka, Zushan. "Gaoshan liushui, konggu huixiang” (High Mountain, Flowing Water, Echoing Sounds in the Valley). Renmin Yinyue 1989, no. 9: 2-7.

Kabisch, Thomas. "Klang, Ton, Geräusch, Exkurs: Kategorien musikalischen Zusammenhangs in Yuns Gagok für Stimme, Gitarre und Schlagzeug (1972).” In Ssi-ol. Almanach (1998/99), edited by Walter-Wolfgang Sparrer, 146-155. Munich: edition text + kritik, 1999.

Kabisch, Thomas. “Verschwindendes Erscheinen' als Prinzip einer Musik der Moderne: Vladimir Jankélévitch über Debussy, Fauré und Ravel.” Musik \& Ästhetik no. 72 (2014): 38-64.

Kaden, Christian. Des Lebens wilder Kreis: Musik im Zivilisationsprozess. Kassel: Bärenreiter, 1993. Kaltenecker, Martin. "Subtraktion und Inkarnation: Hören und Sehen in der Klangkunst und der 'musique concrète instrumentale." In Musikals Wahrnehmungskunst: Untersuchungen zu Kompositionsmethodik und Hörästhetik bei Helmut Lachenmann, edited by Christian Utz and Clemens Gadenstätter, 101-126. Saarbrücken: Pfau, 2008.

Kaltenecker, Martin. “Musique concrète instrumentale.” In Lexikon Neue Musik, edited by Jörn Peter Hiekel and Christian Utz, 425-426. Stuttgart: Metzler/Kassel: Bärenreiter, 2016.

Kaminsky, Peter M. "Aspects of Harmony, Rhythm and Form in Schumann's Papillons, Carnaval and Davidsbündlertanze." PhD dissertation, University of Rochester, 1989.

Kartomi, Margret. "Maceda, José.” MGG Online. 2019. https://www.mgg-online.com/mgg/ stable/55194

Kassebaum, Gayathri R. "Karnatak Raga." In The Garland Encyclopedia of World Music. Vol. 5: South Asia: The Indian Subcontinent, edited by Alison Arnold, 89-109. New York: Routledge, 2000.

Katayama, Morihide. "Toshiro Mayuzumi." Symphony Mood, Bugaku, Mandala Symphony, Rumba Rhapsody. Naxos 8.557693J, 2005, compact disc. Supplemental booklet, 14-25.

Kellermann, Josef. “Kellermann-Verzeichnis der Werke von Wolfgang Fraenkel: 1897-1983." Licensing thesis, Munich, 1989.

Kelly, Barbara L. French Music, Culture, and National Identity, 1870-1939. Rochester: University of Rochester Press, 2008.

Kido, Toshirō. Reconstructed Music Instruments of Ancient East Asia, edited by the National Theatre of Japan. Tokyo: Japan Arts Council, 1994.

Kikkawa, Eishi. Vom Charakter der japanischen Musik. Kassel: Bärenreiter, 1984.

Killick, Andrew. Hwang Byungki: Traditional Music and the Contemporary Composer in the Republic of Korea. Aldershot: Ashgate, 2013.

Kim, Jaihiun Joyce, editor. Classical Korean Poetry: More Than 600 Verses Since the 12th Century. Seoul: Hanshin, 1990.

Kim, Jeongmee. "The Diasporic Composer: The Fusion of Korean and German Musical Cultures in the Works of Isang Yun." PhD dissertation, University of California at Los Angeles, 1999.

Kim, Jeongmee. "Musical Syncretism in Isang Yun's Gasa." In Locating East Asia in Western Art Music, edited by Yayoi Uno Everett and Frederick Lau, 168-192. Middletown: Wesleyan University Press, 2004.

Kim, Jin-Ah. "European Music' Outside Europe? Musical Entangling and Intercrossing in the Case of Korea's Modern History." In Studies on a Global History of Music: A Balzan Musicology Project, edited by Reinhard Strohm, 177-197. New York: Routledge, 2018.

Kim, Jin-Ah. "Migration im Wandel. Isang Yun, Younghi Pagh-Paan und Unsuk Chin." Neue Zeitschrift für Musik no. 6 (2018): 12-15. 
Kim, Jin-Hi. "Living Tones: On My Cross-Cultural Dance-Music Drama Dragon Bond Rite." the world of music 45, no. 2 (2003): 127-131.

Kimmerle, Heinz. Interkulturelle Philosophie zur Einführung. Hamburg: Junius, 2002.

Kinderman, William. "Das Institut für Musikwissenschaft in der NS-Zeit: Der Fall des Wagner-Forschers Alfred Lorenz." 2010. https://lmuwi.hypotheses.org/alfred-lorenz-2

King, Betty Nygaard, and Hiram Silk. "Barban, Andreas." In The Canadian Encyclopedia. 2007. Last updated 16 December 2013. https:/www.thecanadianencyclopedia.ca/en/article/andreas-barban-emc

Kirchert, Kay-Uwe. "Between Worlds: Reflections on Ritual in the Music of Giacinto Scelsi." the world of music 40, no. 1 (1998): 79-100.

Kittler, Friedrich, Thomas Macho, and Sigrid Weigel, editors. Zwischen Rauschen und Offenbarung: zur Kultur-und Mediengeschichte der Stimme. [2002] Berlin: Akademie, 2008.

Klein, Hans Michael. "Gegenseitige Durchdringung und Nicht-Behinderung." In John Cage, Anarchic Harmony, edited by Stefan Schädler and Walter Zimmermann, 97-101. Mainz: Schott, 1992.

Klein, Tobias Robert. Alexander Zemlinsky - Steve Reich: Alternative Moderne(n): "Afrika" in der Kompositionskultur des 20. Jahrhunderts. Cologne: Dohr, 2014.

Kleinen, Günter. "Ausweitung harmonischer Räume durch arabische Tonarten: Lösung aus historischer Umklammerung oder neue Zumutungen?" In Klaus Huber, edited by Ulrich Tadday, 135-152. Munich: edition text + kritik, 2007.

Kleinrath, Dieter. "Minimalismus/Minimal Music.” In Lexikon Neue Musik, edited by Jörn Peter Hiekel and Christian Utz, 373-380. Stuttgart: Metzler/Kassel: Bärenreiter, 2016.

Kleinrath, Dieter, and Christian Utz. "Harmonik/Polyphonie.” In Lexikon Neue Musik, edited by Jörn Peter Hiekel and Christian Utz, 257-269. Stuttgart: Metzler/Kassel: Bärenreiter, 2016.

Klüppelholz, Werner. Sprache als Musik: Studien zur Vokalkomposition bei Karlheinz Stockhausen, Hans G. Helms, Mauricio Kagel, Dieter Schnebel und György Ligeti. Saarbrücken: Pfau, 1995.

Knipper, Till. "Tonsysteme im kompositorischen Schaffen von Klaus Huber." In Transformationen: Zum Werk von Klaus Huber, edited by Jörn Peter Hiekel and Patrick Müller, 167-199. Mainz: Schott, 2013.

Koechlin, Charles. Écrits, Vol. 1: Esthétique et langage musicale. Edited by Michel Duchesneau. Sprimont: Mardaga, 2006.

Koetting, James. "Analysis and Notation of West African Drum Ensemble Music." Selected Reports: Publication of the Institute of Ethnomusicology of the University of California at Los Angeles 30, no. 1 (1970): 115-146.

Kogler, Susanne. "Von der großen Erzählung zur Mikrologie? Musikhistoriographische Methodik zwischen Moderne und Postmoderne." In Passagen: Theorien des Übergangs in Musik und anderen Kunstformen, edited by Christian Utz and Martin Zenck, 71-86. Saarbrücken: Pfau, 2009.

Kohl, Jerome. "Serial Composition, Serial Form, and Process in Karlheinz Stockhausen's Telemusik." In Electroacoustic Music: Analytical Perspectives, edited by Thomas Licata, 91-118. Westport: Greenwood Press, 2002.

Kohn, Margaret. "Colonialism." In The Stanford Encyclopedia of Philosophy, edited by Edward N. Zalta. Last updated 10 April 2012. http://plato.stanford.edu/archives/spr2014/entries/colonialism

Kolesch, Doris, and Sybille Krämer, editors. Stimme: Annäherung an ein Phänomen. Frankfurt: Suhrkamp, 2006. 
Kolinsky, Mieczyslaw. "A Cross-Cultural Approach to Metro-Rhythmic Patterns." Ethnomusico$\log y$ 17, no. 3 (1973): 494-506.

Komoda, Haruko, and Mihoko Nogawa. "Theory and Notation in Japan." In The Garland Encyclopedia of World Music, Vol. 7: East Asia: China, Japan, and Korea, edited by Robert Provine, Yoshihiko Tokumaru and Lawrence Witzleben, 601-620. New York: Routledge, 2001.

Komoda, Haruko. Heike no ongaku. Tōdō no dentō (Music of the Heike. The Tradition of the Tōdō Gild), Tokyo 2003.

Komoda, Haruko. "The Musical Narrative of The Tale of the Heike." In The Ashgate Research Companion to Japanese Music, edited by Alison McQueen Tokita and David W. Hughes, 77-104. Aldershot: Ashgate, 2008.

Koo, Bonu. "Beyond 'Cheap Imitations." the world of music 45, no. 2 (2003): 133-135.

Kooijman, Jaap. Fabricating the Absolute Fake: America in Contemporary Pop Culture. Amsterdam: Amsterdam University Press, 2008.

Kötter, Daniel. "Die Irreführung der Oper: Sprachlosigkeit und -fertigkeit in Helmut Lachenmanns Das Mädchen mit den Schwefelhölzern." MusikTexte no. 105 (2005): 37-48.

Kouwenhoven, Frank. "Mainland China's New Music (I) - Out of the Desert." CHIME no. 2 (1990): 58-93.

Kouwenhoven, Frank. "Mainland China's New Music (II) - Madly Singing in the Mountains." CHIME no. 3 (1991): 42-75.

Kouwenhoven, Frank. "Mainland China's New Music (III) - The Age of Pluralism." CHIME no. 5 (1992): 76-134.

Kovács, Inge. "Die Institution - Entstehung und Struktur." In Im Zenit der Moderne: Die Internationalen Ferienkurse für Neue Musik in Darmstadt 1946-1966, Vol. 1, edited by Gianmario Borio and Hermann Danuser, 59-139. Freiburg: Rombach, 1997.

Kramer, Jonathan D. The Time of Music. New York: Schirmer, 1988.

Kramer, Lawrence. Music as Cultural Practice, 1800-1900. Berkeley: University of California Press, 1990.

Kramer, Lawrence. "From the Other to the Abject: Music as Cultural Trope." In Classical Music and Postmodern Knowledge, 33-66. Berkeley: University of California Press, 1995.

Kramer, Lawrence. "Cultural Politics and Musical Form: The Case of Charles Ives." In Classical Music and Postmodern Knowledge, 174-200. Berkeley: University of California Press, 1995.

Kramer, Lawrence. "Hercules' Hautboys: Mixed Media and Musical Meaning." In Musical Meaning: Toward a Critical History, 145-172. Berkeley: University of California Press, 2002.

Kramer, Lawrence. Why Classical Music Still Matters. Berkeley: University of California Press, 2007.

Kraus, Richard Curt. Pianos \& Politics in China: Middle-Class Ambitions and the Struggle over Western Music. Oxford: Oxford University Press, 1989.

Kravitt, Edward F. "The Influence of Theatrical Declamation upon Composers of the Late Romantic Lied." Acta Musicologica 34, no. 1-2 (1962): 18-28.

Krebs, Harald. "Some Extensions of the Concepts of Metrical Consonance and Dissonance." Journal of Music Theory 31, no. 1 (1987): 99-120.

Krebs, Harald. "Rhythmische Konsonanz und Dissonanz." Musiktheorie 9, no. 1 (1994): 27-37.

Krebs, Harald. Fantasy Pieces: Metrical Dissonance in the Music of Robert Schumann. Oxford: Oxford University Press, 1999.

Kristeva, Julia. "The Ruin of a Poetics." In Russian Formalism, edited by Stephen Bann and John E. Bowlt, 102-119. Edinburgh: Scottish Academic Press, 1973. 
Krones, Hartmut. "Es waere die Erfuellung eines meiner ernstesten Wuensche und Pflichten, die LULU zu vollenden:' Der Alban-Berg-Schüler Julius Schloß. Von Saarlouis über Wien und Shanghai nach Belleville." In Musik-Transfer-Kultur: Festschrift für Horst Weber, edited by Stefan Drees, Andreas Jacob, and Stefan Orgass, 269-292. Hildesheim: Olms, 2009.

Krones, Hartmut. "Karl Steiner - ein später Pianist der 'Wiener Schule." In An: Karl Steiner, Shanghai: Briefe ins Exil an einen Pianisten der Wiener Schule, edited by Hartmut Krones, 1384. Vienna: Böhlau, 2013.

Krones, Harmut. "Julius Schloß." In Lexikon verfolgter Musiker und Musikerinnen der NS-Zeit, edited by Claudia Maurer Zenck, Peter Petersen, and Sophie Fetthauer. Hamburg: University of Hamburg, 2014. Last updated 18 March 2019. https://www.lexm.uni-hamburg.de/ object/lexm_lexmperson_00003503

Kubik, Gerhard. "The Phenomenon of Inherent Rhythms in East and Central African Instrumental Music." African Music 3, no. 1 (1962): 33-42.

Kubik, Gerhard. "Musikgestaltung in Afrika." In Musik in Afrika: 20 Beiträge zur Kenntnis traditioneller afrikanischer Musikkulturen, edited by Artur Simon, 27-40. Berlin: Museum für Völkerkunde, 1983.

Kubik, Gerhard. "Die Amadinda-Musik von Buganda." In Musik in Afrika: 20 Beiträge zur Kenntnis traditioneller afrikanischer Musikkulturen, edited by Artur Simon, 139-165. Berlin: Museum für Völkerkunde, 1983.

Kubik, Gerhard. "Kognitive Grundlagen afrikanischer Musik." In Musik in Afrika: 20 Beiträge zur Kenntnis traditioneller afrikanischer Musikkulturen, edited by Artur Simon, 327-400. Berlin: Museum für Völkerkunde, 1983.

Kubik, Gerhard. "Einige Grundbegriffe und -konzepte der afrikanischen Musikforschung." In Zum Verstehen afrikanischer Musik, 52-113. Leipzig: Reclam, 1988.

Kubik, Gerhard. "Theorie, Aufführungspraxis und Kompositionstechniken der Hofmusik von Buganda: Ein Leitfaden zur Komposition in einer ostafrikanischen Musikkultur.” In Für György Ligeti: Die Referate des Ligeti-Kongresses Hamburg 1988, 23-162. Laaber: Laaber, 1991.

Kubik, Gerhard, and Christian Utz. "Auf Entdeckungsreise durchs Universum: Der Musikethnologe Gerhard Kubik über György Ligeti, inhärente Patterns in der Musik Bugandas und das Illusionäre." Neue Zeitschrift für Musik 164, no. 3 (2003): 44-45.

Kuhn, Thomas S. The Structure of Scientific Revolutions. [1962] Chicago: University of Chicago Press, 1970.

Kuo, Tiffany M. "Composing American Individualism: Luciano Berio in the United States, 1960-1971." PhD dissertation, New York University, 2011.

Kurth, Ernst. Grundlagen des linearen Kontrapunkts: Bachs melodische Polyphonie. [1917] Second edition. Berlin: Hesse, 1922; Third edition. Berlin: Hesse, 1927.

Kutschke, Beate. Neue Linke - neue Musik: Kulturtheorien und künstlerische Avantgarde in den $1960 e r$ und 70er Jahren. Cologne: Böhlau, 2007.

Kuttner, Fritz. The Archaeology of Music in Ancient China: 2000 Years of Acoustical Experimentation, 1400 B.C.-A.D. 750 . New York: Paragon House, 1990.

La Motte-Haber, Helga de, editor. Nationaler Stil und europäische Dimension in der Musik der Jahrhundertwende. Darmstadt: Wissenschaftliche Buchgesellschaft, 1991.

Lachenmann, Helmut. "Klangtypen der Neuen Musik." [1966/93] In Musik als existentielle Erfahrung. Schriften 1966-1995, edited by Josef Häusler, Wiesbaden: Breitkopf \& Härtel, 1996, $1-20$.

Lachenmann, Helmut. "Vier Grundbestimmungen des Musikhörens." [1979] In Musik als existentielle Erfahrung, edited by Josef Häusler, 54-62. Wiesbaden: Breitkopf \& Härtel, 1996. 
Lachenmann, Helmut. "Accanto." [1982] In Musik als existentielle Erfahrung, edited by Josef Häusler, 168-176. Wiesbaden: Breitkopf \& Härtel, 1996.

Lachenmann, Helmut. "Offener Brief an Hans Werner Henze." [1983] In Helmut Lachenmann, edited by Heinz-Klaus Metzger and Rainer Riehn, 12-18. Munich: edition text + kritik, 1988.

Lachenmann, Helmut. "Zum Problem des Strukturalismus." [1990] In Musik als existentielle Erfahrung, edited by Josef Häusler, 83-92. Wiesbaden: Breitkopf \& Härtel, 1996.

Lachenmann, Helmut. “.... zwei Gefühle ...,' Musik mit Leonardo (1991/92).” [1994] In Musik als existentielle Erfahrung, edited by Josef Häusler, 401. Wiesbaden: Breitkopf \& Härtel, 1996.

Lachenmann, Helmut. "Über mein Zweites Streichquartett." [1995/2002] In Musik als existentielle Erfahrung, edited by Josef Häusler, 227-245. Wiesbaden: Breitkopf \& Härtel, 1996.

Lachenmann, Helmut. "Eine musikalische Handlung." In Das Mädchen mit den Schwefelhölzern, Kairos $0012282 \mathrm{KAI}$, compact disc, 2002. Supplemental booklet, 5-7.

Lachenmann, Helmut. "A Musical Plot." In Das Mädchen mit den Schwefelhölzern, Kairos 0012282 KAI, compact disc, 2002. Supplemental booklet, 14-16.

Lachenmann, Helmut. “Klänge sind Naturereignisse:' Auszüge aus einem Gespräch mit Klaus Zehelein und Hans Thomalla." In Das Mädchen mit den Schwefelhölzern, Kairos CD 0012282 KAI, compact disc, 2002. Supplemental booklet, 31-34.

Lachenmann, Helmut. "East meets West? - West eats Meat ... oder das Crescendo des Bolero: Materialien, Notizen und Gedankenspiele." In Musik-Kulturen: Texte der 43. Internationalen Ferienkurse für Neue Musik 2006, edited by Jörn Peter Hiekel, 84-98. Saarbrücken: Pfau, 2008.

Lachenmann, Helmut, Clemens Gadenstätter, and Christian Utz. "Klang, Magie, Struktur: Ästhetische und strukturelle Dimensionen in der Musik Helmut Lachenmanns. Podiumsdiskussion mit Helmut Lachenmann an der Kunstuniversität Graz (21.11.2005)." In Musik als Wahrnehmungskunst: Untersuchungen zu Kompositionsmethodik und Hörästhetik bei Helmut Lachenmann, edited by Christian Utz and Clemens Gadenstätter, 13-66. Saarbrücken: Pfau, 2008.

Lai, Eric. "Calligraphy and Texture in Chou Wen-Chung's Music." In Polycultural Synthesis in the Music of Chou Wen-chung, edited by Mary Arlin and Mark Radice, 86-117. New York: Routledge, 2018.

Lam, Joseph S. C. "Writing Music Biographies of Historical East Asian Musicians: The Case of Jiang Kui (A.D. 1155-1221).” the world of music 43, no. 1 (2001): 69-95.

Langenkamp, Harm. "Close Encounters of Another Kind: Strategies of Intercultural Composition, 1960s-2000s." Dutch Journal of Music Theory 16, no.3 (2011): 180-201.

Langenkamp, Harm. "(Dis)Connecting Cultures, Creating Dreamworlds: Musical 'East-West' Diplomacy in the Cold War and the War on Terror." In Divided Dreamworlds? The Cultural Cold War in East and West, edited by Joes Segal, Giles Scott-Smith, and Peter Romijn, 217234. Amsterdam: Amsterdam University Press, 2012.

[Laozi.] The Tao Te Ching. Translated by James Legge. Oxford: Oxford University Press, 1891. https://ctext.org/dao-de-jing

Lau, Frederick. "Forever Red: The Invention of Solo dizi Music in Post-1949 China." British Journal of Ethnomusicology 5, no. 1 (1996): 113-131.

Lau, Frederick. "Fusion or Fission: The Paradox and Politics of Contemporary Chinese Avantgarde Music." In Locating East Asia in Western Art Music, edited by Yayoi Uno Everett and Frederick Lau, 22-39. Middletown: Wesleyan University Press, 2004. 
Lechner, Ethan. "Composers as Ethnographers: Difference in the Imaginations of Colin McPhee, Henry Cowell, and Lou Harrison." PhD dissertation, University of North Carolina at Chapel Hill, 2008.

Lee, Gavin. "Postcolonial Affect: Ambiguous Relationality in Robert Casteels's L'(Autre) Fille Aux Cheveux de Bali." Journal of the Royal Musical Association 140, no. 2 (2015): 417-443. https:// doi.org/10.1080/02690403.2015.1075812

Lee, Gavin. "Introduction: From Difference to Ambiguity." In Rethinking Difference in Gender, Sexuality, and Popular Music: Theory and Politics of Ambiguity, edited by Gavin Lee, 1-11. New York: Routledge, 2018.

Lee, Heekyung. "Korea." In Lexikon Neue Musik, edited by Jörn Peter Hiekel and Christian Utz, 350-352. Stuttgart: Metzler/Kassel: Bärenreiter, 2016.

Lee, Heekyung. "Reconsidering Traditional Vocal Practices in Contemporary Korean Music." In Vocal Music and Contemporary Identities: Unlimited Voices in East Asia and the West, edited by Christian Utz and Frederick Lau, 133-157. New York: Routledge, 2013.

Lee, Kang-Sook. “Korean Music Culture: Genuine and Quasi-Korean Music.” Korea Journal 8 (1977): 70-77.

Lee, Schu-Chi. "Pan Hwang-Long." In Komponisten der Gegenwart, edited by Hanns-Werner Heister and Walter-Wolfgang Sparrer. 12th Dispatch. Munich: edition text + kritik, 1997.

Lee, Schu-Chi. “Taiwan.” [2008] MGG Online. Last updated November 2016. https://www.mggonline.com/mgg/stable/47282

Lehmann, Harry. "Entfremdung - Verfremdung. Identitätsprobleme in Kunst und Gesellschaft." Neue Zeitschrift für Musik 167, no. 3 (2006): 13-15.

Lehtonen, Lasse. "March from the Age of Imitation to the Age of Creation:' Musical Representations of Japan in the Work and Thought of Shinkō sakkyokuka renmei, 1930-1940." PhD dissertation, University of Helsinki, 2018.

Leliwa, Elisabeth von, and Enno Stahl, editors. leise, frei: Der Komponist Kunsu Shim. Düsseldorf: Edition Virgines, 2018.

Lerdahl, Fred, and Ray Jackendoff. A Generative Theory of Tonal Music. [1983] Cambridge: MIT Press, 1996.

Leßmann, Benedikt. “Übersetzung - ein Thema der Musikforschung?” In Zwischen Transfer und Transformation: Horizonte der Rezeption von Musik, edited by Michele Calella and Benedikt Leßmann, 147-174. Vienna: Hollitzer, 2020.

Lévinas, Emmanuel. "Phenomenon and Enigma." In Collected Philosophical Papers. Dordrecht: Nijhoff, 1986, 61-73.

Lévinas, Emmanuel. Alterity and Transcendence. New York: Columbia University Press, 1999.

Levinson, Jerrold. Music in the Moment. Ithaca: Cornell University Press, 1997.

Lewin, David. “On Harmony and Meter in Brahms's Op. 76, No. 8." 19th-Century Music 4, no. 3 (1981): 261-265. https://doi.org/10.2307/746699

Lewis, George E. “Improvised Music after 1950: Afrological and Eurological Perspectives." Black Music Research Journal 16, no. 1 (1996): 91-122.

Li, Ruru. The Soul of Beijing Opera: Theatrical Creativity and Continuity in the Changing World. Hong Kong: Hong Kong University Press, 2010.

Li, Yinghai. Hanzu diaoshi ji qi hesheng (Han Modality and Its Harmony). Shanghai: Shanghai Wenyi chubanshe, 1959.

Liang, Mingyue. Music of the Billion: An Introduction to Chinese Musical Culture. New York: Heinrichshofen, 1985. 
Liang, Yongsheng. "Western Influence on Chinese Music in the Early Twentieth Century." PhD dissertation, Stanford University, 1994.

Liao, Lin-Ni. "Héritages culturels et pensée moderne: Les compositeurs taiwanais de musique contemporaine formés à l'étranger." PhD dissertation, Université de Paris-Sorbonne (Paris IV), 2011.

Ligeti, György. "Zur Collagetechnik bei Mahler und Ives." [1974] In Gesammelte Schriften, Vol. 1, edited by Monika Lichtenfeld, 285-290. Mainz: Schott, 2007

Ligeti, György. “Études pour piano - Premier livre." [1987] In Gesammelte Schriften, Vol. 2, edited by Monika Lichtenfeld, 290-293. Mainz: Schott, 2007.

Ligeti, György. "Paradigmenwechsel der achtziger Jahre." [1988] In Gesammelte Schriften, Vol. 2, edited by Monika Lichtenfeld, 116-118. Mainz: Schott, 2007.

Ligeti, György. "Zu meinem Klavierkonzert." [1988] In Gesammelte Schriften, Vol. 2, edited by Monika Lichtenfeld, 296-300. Mainz: Schott, 2007

Ligeti, György. "Foreword." In Simha Arom, African Polyphony and Polyrhythm: Music Structure and Methodology, xvii-xviii. Cambridge: Cambridge University Press, 1991.

Ligeti, György. "Études pour piano - Deuxième livre: Notizen zu einzelnen Etüden." [19891996] In Gesammelte Schriften, Vol. 2, edited by Monika Lichtenfeld, 293-295. Mainz: Schott, 2007.

Ligeti, György. "Études pour piano." [1996] In Gesammelte Schriften, Vol. 2, edited by Monika Lichtenfeld, 288-289. Mainz: Schott, 2007.

Ligeti, György. "Zum Klavierkonzert." [2001] In Gesammelte Schriften, Vol. 2, edited by Monika Lichtenfeld, 300-301. Mainz: Schott, 2007

Ligeti, György, and Denys Bouliane. "Stilisierte Emotion: György Ligeti im Gespräch." MusikTexte no. 28/29 (1989): 52-62.

Lim, Jin Hyung. "Identity Performance and Performing Identity: Performing Isang Yun's Fünf Stücke für Klavier (1958)." In Performance, Subjectivity, and Experimentation, edited by Catherine Laws, 197-228. Leuven: Leuven University Press, 2020.

Lindhorst, Elke. "Gedanken, Bilder und Schlüsselbegriffe des Renouveau catholique in den Texten von Olivier Messiaen - eine kritische Betrachtung." In Olivier Messiaen und die "französische Tradition", edited by Stefan Keym and Peter Jost, 71-81. Cologne: Dohr, 2013.

Lissa, Zofia. "Vom Wesen des Universalismus in der Musik." In Weltkulturen und moderne Kunst, Ausstellungskatalog für die Spiele der XX. Olympiade, 22-26. Munich: Bruckmann, 1972.

List, George. "The Boundaries of Speech and Song." Ethnomusicology 7, no. I (1963): 1-16.

Liu, Ching-Chih. A Critical History of New Music in China. Hong Kong: Chinese University of Hong Kong Press, 2010.

Lo, Kii-Ming. Turandot aufder Opernbühne. Bern: Peter Lang, 1996.

Lo, Kii-Ming. Gu jin xiangsheng yinyue meng: Shu xie Pan Hwang-Long (Musical Dream of Past and Present: Writing on Pan Hwang-Long). Taipei: Shibao wenhua, 2005.

Löchte, Anne. Johann Gottfried Herder: Kulturtheorie und Humanitätsidee der "Ideen," "Humanitätsbriefe" und "Adrastea." Würzburg: Königshausen \& Neumann, 2005.

Locke, John L. "Rank and Relationships in the Evolution of Spoken Language." The Journal of the Royal Anthropological Institute 7, no. 1 (2001): 37-50.

Locke, Ralph P. Musical Exoticism: Images and Reflections. New York: Cambridge University Press, 2009.

Loesch, Heinz von. Der Werkbegriff in der protestantischen Musiktheorie des 16. und 17. Jahrhunderts: Ein Missverständnis. Hildesheim: Olms, 2001.

Loesch, Heinz von, and Claus Raab, editors. Beethoven-Lexikon. Laaber: Laaber 2008. 
Loh, I-To. "Tribal Music of Taiwan: with Special Reference to the Ami and Puyuma Styles." PhD dissertation, University of California, Los Angeles, 1982.

London, Justin. "Rhythm: I.1. The Distinction Between Rhythm and Metre." Grove Music Online, 2001. https://doi.org/10.1093/gmo/9781561592630.article.45963

London, Justin. "Rhythm in Twentieth-Century Theory." In The Cambridge History of Western Music Theory, edited by Thomas Christensen, 695-725. Cambridge: Cambridge University Press, 2002.

London, Justin. Hearing in Time: Psychological Aspects of Musical Meter. New York: Oxford University Press, 2012.

Lorenz, Alfred. Abendländische Musikgeschichte im Rhythmus der Generationen: Eine Anregung. Berlin: Hesse, 1928.

Lu, Sheng. “Ting Tan Dun xianyue sichongzou Feng - Ya - Song” (Hearing Tan Dun's String Quartet Feng-Ya-Song). Renmin Yinyue 1984, no. 7: 7-9.

Lü, Chuikuan, and Yu-Hsiu Lu. "3. Han Chinese traditional music." In Tsang-Houei Hsu, YuHsiu Lu, Chuikuan Lü, Kuo-Huang Han, and Joanna C. Lee, "Taiwan," Grove Music Online, 2001. https://doi.org/10.1093/gmo/9781561592630.article.49502

Lü, Yuxiu. Taiwan yinyueshi (Taiwan's Music History). Taipei: Wunan tushu, 2003.

Lyotard, Jean-François. La condition postmoderne: Rapport sur le savoir. Paris: Les éditions de minuit, 1979.

Lyotard, Jean-François. “Answering the Question: What is Postmodernism?" [1982] In The Lyotard Reader and Guide, edited by Keith Crome and James Williams, 123-132. New York: Columbia University Press, 2006.

Lyotard, Jean-François. The Differend: Phrases in Dispute. [1983] Translated by Georges van den Abbeele. Minneapolis: University of Minnesota Press, 1988.

Maceda, José. "Chants from Sagada Mountain Province, Philippines." Ethnomusicology 2, no. 2 (1958): 45-55; no. 3 (1958): 96-107.

Maceda, José. "Drone and Melody in Philippine Musical Instruments." In Traditional Drama and Music of Southeast Asia, edited by Mohammad Taib Osman, 246-273. Kuala Lumpur: Dwan Bahasa Dan Pustaka (Institute of Language and Literature), 1974.

Maceda, José. "A Search for an Old and a New Music in Southeast Asia." Acta Musicologica 51, no. 1 (1979): 160-168.

Maceda, José. "A Concept of Time in a Music of Southeast Asia (A Preliminary Account)." Ethnomusicology 30, no. 1 (1986): 11-53.

Maceda, José. Dorōn to merodī: Tōnan Ajia no ongaku shisō / Drone and Melody: Musical Thought in Southeast Asia. Edited and translated by Yūji Takahashi. Tokyo: Shinjuku shobō, 1989.

Maceda, José. "In Search of a Source of Pentatonic Hemitonic and Anhemitonic Scales in Southeast Asia." Acta Musicologica 62, no. 2-3 (1990): 192-223.

Maceda, José. "Acculturation and Internationalization: The Philippine Situation." In World Music - Musics of the World: Aspects of Documentation, Mass Media and Acculturation, edited by Ulrich Wegner and Max Peter Baumann, 295-306. Wilhelmshaven: Noetzel, 1992.

Maceda, José. "A Logic in Court Music of the Tang Dynasty." Acta Musicologica 67, no. 2 (1995): 109-141.

Maceda, José. "Bipolarity and the Fifth Interval in Gamelan and Medieval European Music." In The Medieval West Meets the Rest of the World, edited by Nancy Van Deusen, 91-107. Ottawa: Institute of Mediaeval Music, 1995.

Maceda, José. "Counts of Four and the Fifth Interval." World New Music Magazine no. 6 (1996): 46-57. 
Maceda, José. Gongs and Bamboo: A Panorama of Philippine Musical Instruments. Quezon City: University of the Philippines Press, 1998.

Maceda, José. "Upland Peoples of the Philippines." In The Garland Encyclopedia of World Music, Vol. 4: Southeast Asia, edited by Terry E. Miller and Sean Williams, 913-928. New York: Garland, 1998.

Maceda, José, Ramón Santos, Lucrecia R. Kasilag, Della G. Besa, and Leonor Orosa Goquingco. "Philippines." Grove Music Online, 2001. https://doi.org/10.1093/gmo/9781561592630.article. 48467

Mackerras, Colin P. The Rise of the Peking Opera 1770-1870: Social Aspects of the Theatre in Manchu China. Oxford: Clarendon, 1972.

Maconie, Robin. The Works of Karlheinz Stockhausen. Oxford: Oxford University Press, 1976.

Mahnkopf, Claus-Steffen. "Polykulturalität als Polyphonietypus: Zum Alterswerk Klaus Hubers." In Klaus Huber, edited by Ulrich Tadday, 155-169. Munich: edition text + kritik, 2007.

Maier, Michael. Jacques Handschins "Toncharakter:" Über die Bedingungen seiner Entstehung. Stuttgart: Steiner, 1991.

Malm, William P. Japanese Music and Musical Instruments. Rutland: Tuttle, 1959.

Malm, William P. "A Musical Analysis of "The Mountains Scene." In Theater as Music: The bunraku Play "Mt. Imo and Mt. Se: An Exemplary Tale of Womanly Virtue," edited by C. Andrew Gerstle, Kiyoshi Inobe, and William P. Malm, 65-96. Ann Arbor: University of Michigan Press, 1990.

Malm, William P. Traditional Japanese Music and Musical Instruments. Tokyo: Kodansha, 2000.

Mao, Yungang. "Jianxi Zhongguo xinan diqu minzu yinyue sucai zai Zhu Jian'er 'di liu jiaoxiangqu' zhong de zhuyao yunyong" (Analytical Remarks on the Use of Material of Folk Music from the Southwestern Areas of China in Zhu Jian'er's "Sixth Symphony"). Yinyue tansuo [25], no. 4 (2008): 26-29.

Maraqa, Salah Eddin. "Auf der Suche nach den Anfängen der 'modernen' arabischen Musiktheorie." Die Musikforschung 68, no. 4 (2015): 341-352.

Marcuse, Herbert. "Repressive Tolerance." In A Critique of Pure Tolerance, 81-123. Boston: Beacon Press, 1965.

Marcuse, Herbert. "The Individual in the Great Society." Alternatives 1 no. 1 (1966): 14-16, 20; no. 2 (1966): 29-35.

Marett, Allan. "The Present State of Research on Early Notations and Points of Scholarly Contention in Their Interpretation." In Musicology and Globalization: Proceedings of the International Congress in Shizuoka 2002, edited by the Musicological Society of Japan, 76-78. Tokyo: Musicological Society of Japan, 2004.

Martin, Helmut. The History of Taiwanese Literature: Towards Cultural-Political Identity: Views from Taiwan, China, Japan and the West. Bochum: Ruhr University, 1995.

Martin, Helmut. Taiwanesische Literatur: Postkoloniale Auswege. Dortmund: Projekt, 1996.

Maruyama, Masao. Studies in Intellectual History of Tokugawa Japan. Princeton: Princeton University Press, 1974.

Maruyama, Masao. Denken in Japan. [1957] Edited and translated by Wolfgang Schamoni and Wolfgang Seifert. Frankfurt: Suhrkamp, 1995.

Marx, Adolf Bernhard. Die Lehre von der musikalischen Komposition, praktisch theoretisch, Vol. 1. Leipzig: Breitkopf \& Härtel, 1837.

Maurer Zenck, Claudia. Vom Takt: Untersuchungen zur Theorie und kompositorischen Praxis im ausgehenden 18. und beginnenden 19. Jahrhundert. Vienna: Böhlau, 2001. 
Maus, Fred Everett. "Narratology, Narrativity." Grove Music Online, 2001. https://doi.org/ 10.1093/gmo/9781561592630.article.40607

Mayeda, Akio. “Über die sanjū-Abschnitte im heikyoku." In Japans traditionelle Musik aus der Sicht japanischer Musikologen, edited by Robert Günther and Heinz-Dieter Reese, 171-191. Wilhelmshaven: Noetzel, 2004.

Mayuzumi, Toshirō. "Baranshin to barē 'Bugaku' - Sakkyokka no tachiba kara" (Balanchine and the Ballet "Bugaku" from the Composer's Perspective). Ongaku-geijutsu 21, no. 6 (1963): 47, 68-69.

Mayuzumi, Toshirō. "Traditional Elements as a Creative Source for Composition." Journal of the International Folk Music Council 16 (1964): 38-39.

McClary, Susan. "Terminal Prestige: The Case of Avant-Garde Music Composition." [1989] In Susan McClary, Reading Music: Selected Essays, 85-109. Aldershot: Ashgate, 2007.

McCredie, Andrew. "Komponisten, die in den westpazifischen Raum und nach Ozeanien emigrierten: Ein einleitender Bericht." In Musik, Macht, Missbrauch, edited by Frank Geißler and Marion Demuth, 120-127. Altenburg: E. Reinhold, 1999.

McCredie, Andrew. "Die emigrierten euro-jüdischen Komponisten im ostasiatischen Raum: Ihre Theorien und Rezeptionen der örtlichen Musiktraditionen." In Musikkonzepte - Konzepte der Musikwissenschaft, Bericht über den Internationalen Kongress der Gesellschaft für Musikforschung Halle 1998, Vol. 2: Freie Referate, edited by Kathrin Eberl and Wolfgang Ruf, 72-79. Kassel: Bärenreiter, 2000.

McQueen Tokita, Alison, and David W. Hughes. "Context and Change in Japanese Music." In The Ashgate Research Companion to Japanese Music, edited by Alison McQueen Tokita and David W. Hughes, 1-33. Aldershot: Ashgate, 2008.

Mead, Rita H. "Henry Cowell's New Music Society." The Journal of Musicology 1, no. 4 (1982): 449463.

Meehan, Kate. "Not Just a Pretty Voice: Cathy Berberian as Collaborator, Composer and Creator." PhD dissertation, Washington University in St. Louis, 2011. https://openscholarship. wustl.edu/etd/239

Meelberg, Vincent. New Sounds, New Stories: Narrativity in Contemporary Music. Leiden: Leiden University Press, 2006.

Melvin, Sheila, and Cai Jindong. Rhapsody in Red: How Western Classical Music Became Chinese. New York: Algora, 2004.

Menzel, Stefan. Hōgaku: Traditionelle japanische Musik im 20. Jahrhundert. Hildesheim: Olms, 2015.

Mersch, Dieter. Ereignis und Aura: Untersuchungen zu einer Ästhetik des Performativen. Frankfurt: Suhrkamp, 2002.

Mersch, Dieter. "Das Entgegenkommende und das Verspätete. Zwei Weisen, das Ereignis zu denken: Derrida und Lyotard." In: Im Widerstreit der Diskurse, edited by Dietmar Köveker, 69-108. Berlin: Berliner Wissenschafts-Verlag, 2004.

Messmer, Matthias. Jewish Wayfarers in Modern China: Tragedy and Splendor. Plymouth: Lexington Books, 2012.

Metzger, Heinz-Klaus. “Wendepunkt Quartett?” In Luigi Nono, edited by Heinz-Klaus Metzger and Rainer Riehn, 93-112. Munich: edition text + kritik, 1981.

Meyer, Andreas. Ensemblelieder in der frühen Nachfolge (1912-17) von Arnold Schönbergs Pierrot lunaire op. 21: Eine Studie über Einfluß und “misreading." Munich: Fink, 2000. 
Meyer, Andreas. "Volkstümlich - primitiv - populär: Neue Musik als musikalische Anthropologie." In Was bleibt? 100 Jahre Neue Musik, edited by Andreas Meyer, 11-40. Mainz: Schott, 2011.

Meyer, Leonard B. Emotion and Meaning in Music. [1956] Chicago: University of Chicago Press, 2004.

Meyer-Kalkus, Reinhart. Stimme und Sprechkünste im 20. Jahrhundert. Berlin: De Gruyter, 2001. Meyer-Kalkus, Reinhart. "Stimme und Atemsyntax in Vortragskunst, Prosa und Musik." Musik $\&$ Ästhetikno. 51 (2009): 73-106.

Miki, Minoru. Nihon gakki hō (Japanese Musical Instruments). Tokyo: Ongaku no tomo sha, 1996. Miller, Chris. "'Radical Traditionalism:' Reconfigured Connections Between the Experimental and the Traditional in East Asian Music." Paper delivered at the Northeast Chapter of the Society for Ethnomusicology, 17 April 2004.

Minamoto, Ryōen. "The Symposium on 'Overcoming Modernity." In Rude Awakenings: Zen, the Kyoto School, \& the Question of Nationalism, edited by James W. Heisig and John C. Maraldo, 197-229. Honolulu: University of Hawai'i Press, 1995.

Mirka, Danuta. Metric Manipulations in Haydn and Mozart: Chamber Music for Strings, 1787-1791. New York: Oxford University Press, 2009.

Mirka, Danuta, editor. The Oxford Handbook of Topic Theory. New York: Oxford University Press, 2013.

Mishra, Pankaj. From the Ruins of the Empire: The Intellectuals who Remade Asia. New York: Farrar, Straus and Giroux, 2012.

Mitsukuri, Shūkichi. "Über japanische Harmonie / De l'harmonie japonaise / Nihon wasei ni tsuite." Ongaku hyōron 2, no. 4 (1934): 1-20.

Mittler, Barbara. Neue Musik aus China (program book). Berlin: House of World Cultures, 1993.

Mittler, Barbara. "Mirrors and Double Mirrors: The Politics of Identity in New Music from Hong Kong and Taiwan." CHIME no. 9 (1996): 4-44.

Mittler, Barbara. Dangerous Tunes: The Politics of Chinese Music in Hong Kong, Taiwan, and the People's Republic of China since 1949. Wiesbaden: Harrassowitz, 1997.

Mittler, Barbara. "Li Taixiang [Lee Tai-hsiung]." Grove Music Online, 2001. https://doi. org/10.1093/gmo/9781561592630.article.51528

Mittler, Barbara. "Pan Huanglong [Pan Hwang-Long]." Grove Music Online, 2001. https://doi.org/10.1093/gmo/9781561592630.article.51530

Mittler, Barbara. "Xu Boyun [Hsu Po-Yun]." Grove Music Online, 2001. https://doi.org/10.1093/ gmo/9781561592630.article.51531

Mittler, Barbara. "Cultural Revolution Model Works and the Politics of Modernization in China: An Analysis of Taking Tiger Mountain by Strategy." the world of music 45, no. 2 (2003): 53-81.

Mittler, Barbara. "Against National Style: Individualism and Internationalism in New Chinese Music (Revisiting Lam Bun-Ching and Others)." In Proceedings of the Symposium at the 2003 Chinese Composers' Festival, edited by Daniel Law and Ming-chi Chan, 2-26. Hong Kong: Hong Kong Composers' Guild, 2004.

Mittler, Barbara. "Sound Patterns of Cultural Memory: 'Wound/Scar Music' and its Making in Contemporary China." World New Music Magazine no. 17 (2007): 33-54.

Mittler, Barbara. "Wider den 'nationalen Stil.' Individuelles und Internationales in Chinas Neuer Musik." In Musik und kulturelle Identität: Bericht über den XIII. Internationalen Kongress der Gesellschaft für Musikforschung, Weimar 2004, Vol. 2, edited by Detlef Altenburg and Rainer Bayreuther, 603-607. Kassel: Bärenreiter, 2012. 
Miyamoto, Kenjiro. Klang im Osten, Klang im Westen: Der Komponist Tōru Takemitsu und die Rezeption europäischer Musik in Japan. Saarbrücken: Pfau, 1996

Miyuki, Dohi. "Basho kikoshu to Mitsukuri Shūkichi" (Basho kikoshu and Mitsukuri Shūkichi). Studies (Kobe College) 35, no. 1 (1988): 57-94.

Moise, Edwin E. Modern China: A History. London: Longman, 1994.

Möller, Hartmut. "Goldener Schnitt.” [1995] MGG Online. Last updated November 2016. https:// www.mgg-online.com/mgg/stable/12884

Möller, Hartmut. "Komposition." In Lexikon der Systematischen Musikwissenschaft, edited by Helga de la Motte, Heinz von Loesch, Günther Rötter, and Christian Utz, 221-224. Laaber: Laaber, 2010.

Monod, David. Settling Scores: German Music, Denazification, and the Americans, 1945-1953. Chapel Hill: University of North Carolina Press, 2005.

Mosch, Ulrich. "'Freiheit war es immer, die er meinte.' Karl Amadeus Hartmann und die 'Stunde Null." In "Stunde Null" - zur Musik um 1945: Bericht über das Symposion der Gesellschaft für Musikforschung an der Musikhochschule Lübeck 24-27 September 2003, edited by Volker Scherliess, 111-126. Kassel: Bärenreiter, 2014.

Mundry, Isabel. Resonanzverhältnis zwischen kompositorischem Ich und Gesellschaft. Munich: Thinkers' Corner, 2005.

Mundry, Isabel. "Ich und Du." In Donaueschinger Musiktage 2008 Program, edited by Armin Köhler, 28-29. Saarbrücken: Pfau, 2008.

Nabokov, Nicholas. “Introduction à L'Cuvre du XXe siècle.” La Revue musicale 212 (1952): 5-8.

Nagami, Isamu. "The Ontological Foundation in Tetsuro Watsuji's Philosophy: Ku and Human Existence." Philosophy East \&West 31, no. 3 (1981): 279-296.

Narmour, Eugene. "Hierarchical Expectation and Musical Style." In The Psychology of Music, edited by Diana Deutsch, 441-472. San Diego: Academic Press, 1999.

Nattiez, Jean-Jaques. "Can One Speak of Narrativity in Music?” Journal of the Royal Musical Association 115, no. 2 (1990): 240-257.

Nattiez, Jean-Jacques, and Robert Piencikowski, editors. Pierre Boulez-John Cage: Correspondance et documents. Mainz: Schott, 2002.

Nelson, Steven G. "Court and Religious Music (2): Music of gagaku and shōmyō." In The Ashgate Research Companion to Japanese Music, edited by Alison McQueen Tokita and David W. Hughes, 49-76. Aldershot: Ashgate, 2008.

Nettl, Bruno. The Study of Ethnomusicology: Thirty-One Issues and Concepts. Urbana: University of Illinois Press, 2005.

Nettl, Bruno. "On World Music as a Concept in the History of Music Scholarship." In The Cambridge History of World Music, edited by Philip V. Bohlman, 23-54. Cambridge: Cambridge University Press, 2013.

Neuwirth, Markus. "Strukturell vermittelte Magie: Kognitionswissenschaftliche Annäherungen an Helmut Lachenmanns Pression und Allegro Sostenuto." In Musik als Wahrnehmungskunst: Untersuchungen zu Kompositionsmethodik und Hörästhetik bei Helmut Lachenmann, edited by Christian Utz and Clemens Gadenstätter, 73-100. Saarbrücken: Pfau, 2008.

Nicholls, David. "Henry Cowell's United Quartet." American Music 13, no. 2 (1995): 195-217.

Nicholls, David. "Transethnicism and the American Experimental Tradition." Musical Quarterly 80 (1996): 569-594.

Nishitani, Keiji. Religion and Nothingness. Translated by Jan Van Bragt. Berkeley: University of California Press, 1982.

Nketia, Joseph H. Kwabena. The Music of Africa. London: Gollancz, 1975. 
Noeske, Nina. Musikalische Dekonstruktion: Neue Instrumentalmusik in der DDR. Weimar: Böhlau, 2007.

Nonnenmann, Rainer. Angebot durch Verweigerung: Die Ästhetik instrumentalkonkreten Klangkomponierens in Helmut Lachenmanns Orchesterwerken. Mainz: Schott, 2000.

Nonnenmann, Rainer. “'Musik mit Bildern:' Die Entwicklung von Helmut Lachenmanns Klangkomponieren zwischen Konkretion und Transzendenz." In Nachgedachte Musik: Studien zum Werk von Helmut Lachenmann, edited by Jörn Peter Hiekel and Siegfried Mauser, 17-43. Saarbrücken: Pfau, 2006.

Nonnenmann, Rainer. "Institutionen/Organisationen." In Lexikon Neue Musik, edited by Jörn Peter Hiekel and Christian Utz, 284-289. Stuttgart: Metzler/Kassel: Bärenreiter, 2016.

Nöther, Matthias. Als Bürger leben, als Halbgott sprechen: Melodram, Deklamation und Sprechgesang im wilhelminischen Reich. Cologne: Böhlau, 2008.

Nuss, Steven. "Hearing 'Japanese,' hearing Takemitsu." Contemporary Music Review 21, no. 4 (2002): 35-71.

Nuss, Steven. "Music from the Right: The Politics of Toshiro Mayuzumi's Essay for String Orchestra." In Locating East Asia in Western Art Music, edited by Yayoi Uno Everett and Frederick Lau, 85-118. Middletown: Wesleyan University Press, 2004.

Nyffeler, Max. "Der Reiz des Fremdgehens: Europäische Komponisten und außereuropäische Kulturen." In Freiräume und Spannungsfelder: Reflexionen zur Musik heute, edited by Jörn Peter Hiekel and Marion Demuth, 153-163. Mainz: Schott, 2009.

Oberheim, Eric. "On the Historical Origins of the Contemporary Notion of Incommensurability: Paul Feyerabend's Assault on Conceptual Conservativism." Studies in History and Philosophy of Science 36, no. 2 (2005): 363-390.

Obert, Simon. Musikalische Kürze zu Beginn des 20. Jahrhunderts. Stuttgart: Steiner, 2008.

Ōhashi, Ryōsuke. Kire: Das "Schöne" in Japan: Philosophisch-ästhetische Reflexionen zu Geschichte und Moderne. Cologne: DuMont-Schauberg, 1994.

Oja, Carol J. Making Music Modern: New York in the 1920s. New York: Oxford University Press, 2000.

Orledge, Robert. Charles Koechlin (1867-1950): His Life and Works. London: Harwood, 1989.

Osmond-Smith, David. Playing on Words: A Guide to Luciano Berio's Sinfonia. London: Royal Musical Association, 1985.

Osterhammel, Jürgen. Die Verwandlung der Welt: Eine Geschichte des 19. Jahrhunderts. Munich: Beck, 2009.

Paci Zaharoff, Flora. The Daughter of the Maestro: Life in Surabaya, Shanghai, and Florence. Lincoln: iUniverse, 2005.

Pacun, David. "Nationalism and Musical Style in Interwar Yōgaku: A Reappraisal." Asian Music 43, no. 2 (2012): 3-46.

Palisca, Claude V. Studies in the History of Italian Music and Music Theory. Oxford: Clarendon, 2001.

Pan, Hwang-Long. "Yinxiang yijing yinyue chuangzuo de linian" (A Theory of Sonic Content in Musical Creation). Yishu pinglun (Arts Review) 6 (1995): 117-136.

Pan, Hwang-Long. "Wujing, qingjing, yijing. Quartett für dizi, pipa, Schlaginstrumente und erhu." In MaerzMusik 2002 Program, edited by Berliner Festspiele, 89-90. Berlin, 2002.

Parsons, Ben. "Sets and the City: Serial Analysis, Parisian Reception, and Pierre Boulez's Structures 1a." Current Musicology 76 (2003): 53-79.

Pasler, Jann. "Stravinsky and the Apaches." Musical Times 123, no. 1672 (1982): 403-407. 
Pasler, Jann. "Reinterpreting Indian Music: Maurice Delage and Albert Roussel." In Music-Cultures in Contact, Convergences and Collisions, edited by Margaret Kartomi and Stephen Blum, 122-157. Sydney: Routledge, 1994.

Pasler, Jann. "Race, Orientalism, and Distinction in the Wake of the Yellow Peril." In Western Music and Its Others: Difference, Representation, and Appropriation in Music, edited by Georgina Born and Dave Hesmondhalgh, 86-118. Berkeley: University of California Press, 2000.

Patterson, David W. "Cage and Asia: History and Sources." In The Cambridge Companion to John Cage, edited by David Nicholls, 41-59. Cambridge: Cambridge University Press, 2002.

Pelinski, Ramón. "Oriental Colouring in the Music of the Nineteenth Century." In World Cultures and Modern Art: The Encounter of 19th-and 2oth-Century European Art and Music with Asia, Africa, Oceania, Afro- and Indo-America, edited by Siegfried Wichmann, 80-82. Munich: Bruckmann, 1972.

Pelinski, Ramón. "Musical Exoticism Around the Year 1900: Claude Debussy." In World Cultures and Modern Art: The Encounter of 19th-and 2oth-Century European Art and Music with Asia, Africa, Oceania, Afro- and Indo-America, edited by Siegfried Wichmann, 234-235. Munich: Bruckmann, 1972.

Pepper, Ian. "From the 'Aesthetics of Indifference' to 'Negative Aesthetics:' John Cage and Germany 1958-1972." October 82 (1997): 30-47.

Pepper, Ian. "John Cage und der Jargon des Nichts." In Mythos Cage, edited by Claus-Steffen Mahnkopf, 9-34. Hof heim: Wolke, 1999.

Peters, Ralf. Wege zur Stimme: Reisen ins menschliche Stimmfeld. Cologne: Unverzagt, 2008.

Picard, François. "Oralité et notations, de Chine en Europe." Cahiers d'ethnomusicologie 12 (1999): 35-53.

Picken, Laurence E. R., and Rembrandt Wolpert. "Mouth-Organ and Lute Parts of Tōgaku and Their Interrelationships.” Musica Asiatica 3 (1981): 79-90.

Picken, Laurence E. R., and Noël J. Nickson, editors. Music from the Tang Court. 7 Vols. Cambridge: Cambridge University Press, 1981-2000.

Piencikowski, Robert. "Fünf Beispiele." In Helmut Lachenmann, edited by Heinz-Klaus Metzger and Rainer Riehn, 109-115. Munich: edition text + kritik, 1988.

Pietschmann, Klaus, and Melanie Wald-Fuhrmann, editors. Der Kanon der Musik: Theorie und Geschichte. Ein Handbuch. Munich: edition text + kritik, 2013.

Pinder, Wilhelm. Das Problem der Generation in der Kunstgeschichte Europas. Berlin: Frankfurter Verlags-Anstalt, 1926.

Plyn, Franz Hermann Wolfgang. "Die Hemiole in der Instrumentalmusik von Johannes Brahms." PhD dissertation, University of Bonn, 1984.

Polak, Rainer, Nori Jacoby, and Justin London. "Kulturelle Diversität in der empirischen Rhythmusforschung: Drei Analysen eines Audio-Korpus von Percussion-Ensemblemusik aus Mali." Zeitschrift der Gesellschaft für Musiktheorie 13, no. 2 (2016): 195-235. https://doi. org/10.31751/908

Polth, Michael. '"nicht tonal und nicht atonal.' Zur Bedeutung der Quinten in Ligetis Etüde Nr. 8 'Fém.'” Studia Musicologica 57, no. 1-2 (2016): 121-138.

Pörtner, Peter, and Jens Heise. Die Philosophie Japans. Stuttgart: Kröner, 1995.

Potter, John. Vocal Authority: Singing Style and Ideology. Cambridge: Cambridge University Press, 1998.

Potter, Pamela M. Most German of the Arts: Musicology and Society from the Weimar Republic to the End of Hitler's Reich. New Haven: Yale University Press, 2000.

Pritchett, James. The Music of John Cage. Cambridge: Cambridge University Press, 1993. 
Proescholdt, Catherine W. "Johann Christian Hüttner (1766-1847). A Link Between Weimar and London." In Goethe and the English-Speaking World, edited by Nicholas Boyle and John Guthrie, 99-110. Rochester: University of Rochester Press, 2002.

Pym, Anthony. Exploring Translation Theories. New York: Routledge, 2010.

Qiao, Jianzhong, editor. Zhongguo jingdian minge jianshang zhinan (Guide to Appreciating Chinese Classical Folk Songs). 2 Vols. Shanghai: Yinyue chubanshe, 2002.

Qin, Wenchen. "On Diversity.” the world of music 45, no. 2 (2003): 143-146.

Qin, Xixuan. "Huiyi Woerfugang Fulanke'er" (Wolfgang Fraenkel In Memoriam). Yinyue yishu (The Art of Music) 23, no. 1 (2001): 18-19.

Qureshi, Regula Burckhardt. "Other Musicologies: Exploring Issues and Confronting Practice in India." In Rethinking Music, edited by Nicholas Cook and Mark Everist, 311-335. Oxford: Oxford University Press, 1999.

Raab, Claus. "Difficulties in the Fusion of Jazz and Symphonic Music." In World Cultures and Modern Art: The Encounter of 19th-and 2oth-Century European Art and Music with Asia, Africa, Oceania, Afro- and Indo-America, edited by Siegfried Wichmann, 322-329. Munich: Bruckmann, 1972.

Raab, Claus. "Negro Music in Latin America." In World Cultures and Modern Art: The Encounter of 19th-and 2oth-Century European Art and Music with Asia, Africa, Oceania, Afro-and Indo-America, edited by Siegfried Wichmann, 329. Munich: Bruckmann, 1972.

Ranta, Michael. "Zeitgenössische Musik in Ostasien - vier Regionen." In Weltmusik, edited by Peter Ausländer and Johannes Fritsch, 29-65. Cologne: Feedback Studio, 1981.

Rao, Nancy Yunwha. "The Role of Language in Music Integration in Chen Qigang's Poème Lyrique II." Journal of Music in China 2, no. 2 (2000): 270-291.

Rao, Nancy Yunhwa. "American Compositional Theory in the 1930s: Scale and Exoticism in "The Nature of Melody' by Henry Cowell.” The Musical Quarterly 85, no. 4 (2001): 595-640.

Rao, Nancy Yunwha. "Hearing Pentatonicism Through Serialism: Integrating Different Traditions in Chinese Contemporary Music." Perspectives of New Music 40, no. 2 (2002): 190-231.

Rao, Nancy Yunhwa. "Henry Cowell and His Chinese Music Heritage: Theory of Sliding Tone and His Orchestral Work of 1953-1965." In Locating East Asia in Western Art Music, edited by Yayoi Uno Everett and Frederick Lau, 119-145; 241-246. Middletown: Wesleyan University Press, 2004.

Rao, Nancy Yunwha. "The Tradition of Luogu Dianzi (Percussion Classics) and Its Signification in Contemporary Music." Contemporary Music Review 26, no. 5 (2007): 511-527.

Rao, Nancy Yunhwa. "Chinese Opera Percussion from Model Opera to Tan Dun." In China and the West: Music, Representation, and Reception, edited by Hon-Lun Yang and Michael Saffle, 163-185. Ann Arbor: University of Michigan Press, 2017.

Rapoport, Eliezer. "On the Origins of Schoenberg's Sprechgesang in Pierrot Lunaire." Min-Ad: Israel Studies in Musicology Online 2006, no. 1. https:/www2.biu.ac.il/hu/mu/min-ad/06/ Sprchgsng.pdf

Rathert, Wolfgang. Charles Ives. Second edition. Darmstadt: Wissenschaftliche Buchgesellschaft, 1996.

Reber, Heinz. "Music for Sheng." In MaerzMusik 2004 Program, edited by Berliner Festspiele, 280. Berlin, 2004.

Rees, Helen. Echoes of History: Naxi Music in Modern China. Oxford: Oxford University Press, 2000. 
Rees, Helen. "China, Peoples Republic of: IV. Living Traditions: 5.1.a Traditional Musics and Their Context." Grove Music Online, 2001. https://doi.org/10.1093/gmo/9781561592630.article. 43141

Reese, Heinz-Dieter. “Bunraku: Puppenspiel als dramatisches Musiktheater in Japan.” In Der Fremde Klang: Tradition und Avantgarde in der Musik Ostasiens, edited by Hinrich Bergmeier, 135-154. Berlin: Bote \& Bock, 1999.

Reese, Heinz-Dieter. “Gattungen des Kunstliedes.” In Weltmusik Korea: Einführung in die Musiktradition Koreas, edited by Wolfgang Burde, 81-111. Mainz: Schott, 1985.

Reich, Steve. "Some Optimistic Predictions (1970) About the Future of Music." [1970] In Writings on Music 1965-2000, edited by Paul Hillier, 51-52. Oxford: Oxford University Press, 2002.

Reich, Steve. "Drumming." [1971] In Writings on Music, 1965-2000, edited by Paul Hillier, 63-67. Oxford: Oxford University Press, 2002.

Reich, Steve. "Gahu - A Dance of the Ewe Tribe in Ghana." [1971] In Writings on Music 1965-2000, edited by Paul Hillier, 56-63. New York: Oxford University Press, 2002.

Reich, Steve. "Postscript to a Brief Study of Balinese and African Music." [1973] In Writings on Music 1965-2000, edited by Paul Hillier, 69-71. Oxford: Oxford University Press, 2002.

Reich, Steve. "Non-Western Music and the Western Composer." [1988] In Writings on Music 1965-2000, edited by Paul Hillier, 147-151. Oxford: Oxford University Press, 2002.

Reinhardt, Monika. Politische Opposition in Taiwan 1947-1988. Bochum: Brockmeyer, 1989.

Reish, Gregory N. Reish. "The Transformation of Giacinto Scelsi's Musical Style and Aesthetic, 1929-1959." PhD dissertation, University of Georgia, Athens, 2001.

Revers, Peter. "Hans Zender: Furin no kyo." In Nähe und Distanz: Nachgedachte Musik der Gegenwart, Vol. 1, edited by Wolfgang Gratzer, 213-222. Hof heim: Wolke, 1996.

Revers, Peter. Das Fremde und das Vertraute: Studien zur musiktheoretischen und musikdramatischen Ostasienrezeption. Stuttgart: Steiner, 1997.

Revers, Peter. "Europäische Treibhausblüten (Hugo Riemann) versus 'Exotische Zukunftsmusik' (Georg Capellen): Zur enttäuschten Perspektive einer Weltmusik.” In Das gebrochene Glücksversprechen: Zur Dialektik des Harmonischen in der Musik, edited by Otto Kolleritsch, 189-199. Vienna: Universal Edition, 1998.

Reynolds, Roger. “A Jostled Silence: Contemporary Japanese Musical Thought (Part Two)." Perspectives of New Music 30, no. 2 (1992): 60-63.

Richmann, Bruce. "Did Human Speech Originate in Coordinated Vocal Music?” Semiotica 32, no. 3-4 (1980): 233-244.

Ricœur, Paul. The Course of Recognition. Translated by David Pellauer. Cambridge, MA: Harvard University Press, 2005.

Riemann, Hugo. Handbuch der Musikgeschichte, Vol. 1. First edition. Leipzig: Breitkopf \& Härtel, 1904.

Rienäcker, Gerd and Helmut Rösing. "Epochendefinition und Geschichtsschreibung." In $\mathrm{Mu}$ sikwissenschaft: Ein Grundkurs, edited by Herbert Bruhn and Helmut Rösing, 409-429. Reinbek: Rohwolt, 1998.

Ristiano, Marcia Reynders. Port of Last Resort: Diaspora Communities of Shanghai. Stanford: Stanford University Press, 2001.

Ritzer, George. The McDonaldization of Society. [1993] Los Angeles: Pine Forge Press, 2008.

Robertson, Roland. "Glocalization: Time-Space and Homogeneity-Heterogeneity." In Global Modernities, edited by Mike Featherstone, Scott Lash, and Roland Robertson, 25-44. London: SAGE, 1995.

Rodriguez, Philippe. Maurice Delage ou La solitude de l'artisan. Geneva: Editions Papillon, 2001. 
Roseman, Marina, Hans Oesch, and John O'Connell. "The Indigenous Peoples (Orang Asli) of the Malay Peninsula." In Garland Encyclopedia of World Music, Vol. 4: Southeast Asia, edited by Terry E. Miller and Sean Williams, 560-589. New York: Garland, 1998.

Rosenson, Harriet P. "Jewish Musicians in Shanghai: Bridging Two Cultures." In The Jews of China, Vol. 1: Historical and Comparative Perspectives, edited by Jonathan Goldstein, 239-250. Armonk: Sharpe, 1999.

Rothkamm, Jörg. "Ordnung in der Unordnung: Neues zur Polyrhythmik in György Ligetis Klavieretüde Désordre." Musiktheorie 19, no. 1 (2004): 63-68.

Rousseau, Jean-Jacques. "Essay on the Origin of Languages." In Essay on the Origin of Languages and Writings Related to Music, edited by John T. Scott, 289-332. Dartmouth: Dartmouth College Press, 2009.

Rubinstein, Murray A., editor. Taiwan: A New History. Armonk: Sharpe, 1999.

Rudhayr, Dane. "Edgard Varèse and the New Music of America." [1923] https://khaldea.com/ rudhyar/vareseamerica.html

Rudhyar, Dane. "A Call to Indian Musicians." Hindustan Review 49 (1926): 359-362.

Rushton, Julian. "Hemiola." Grove Music Online, 2001. https://doi.org/10.1093/gmo/978156 1592630.article.12768

Sabbe, Hermann. Karlheinz Stockhausen: ... wie die Zeit verging ... Munich: edition text+kritik, 1981.

Sachs, Harvey. Music in Fascist Italy. London: Weidenfeld and Nicolson, 1987.

Sachs, Joel. Henry Cowell: A Man Made of Music. New York: Oxford University Press, 2015.

Sachs, Klaus-Jürgen, Peter Cahn, Rudolf Kelterborn, and Helmut Rösing. "Komposition." [1996] MGG Online. Last updated 2016. https://www.mgg-online.com/mgg/stable/14891

Said, Edward. Culture and Imperialism. New York: Knopf, 1993.

Sampath, Vikram. "Coimbatore Thayi, the Carnatic singer who struck a chord in Paris but is unknown in India." The Print, 9 June 2019. https://theprint.in/opinion/treasured-tunes/coimbatore-thayi-the-carnatic-singer-who-struck-a-chord-in-paris-but-is-unknown-in-in$\mathrm{dia} / 247641$

Samson, Helen F. Die zeitgenössische Kunstmusik der Philippinen im Spannungsfeld zwischen nationalem Erbe und europäischem Einfluss. Regensburg: Bosse, 1989.

Samson, Jim. “Canon (iii).” Grove Music Online, 2001. https://doi.org/10.1093/gmo/9781561592630. article. 40598

Samuels, Robert. "When Must One Speak of Narrativity in Music?" Paper presented at the Cardiff Music Analysis Conference, 6 September 2008.

Samuels, Robert. "Narrative Form and Mahler's Musical Thinking." Nineteenth-Century Music Review 8, no. 2 (2011): 237-254.

Sánchez-Chiong, Jorge. "Teatro Shanghai - Bühnenmusik." In Spiegel: Komponieren in Österreich 2000 Program, edited by the Wiener Konzerthaus, 117. Vienna, 2000.

Sang, Tong. “Jinian Fulanke'er yu Xu Luoshi” (Reminiscences of my Teachers Wolfgang Fraenkel and Julius Schloß). Yinyue yishu (The Art of Music) 12, no. 1 (1990): 10-12.

Sang, Tong. "Yejing zhong de wudiaoxing shoufa ji qita" (Atonal and Other Techniques in Night Scenery). Yinyue yishu (The Art of Music) 13, no. 3 (1991): 56-63.

Santos, Ramón. "Art Music of the Philippines in the Twentieth Century." In The Garland Encyclopedia of World Music, Vol. 4: Southeast Asia, edited by Terry E. Miller and Sean Williams, 868-882. New York: Garland, 1998.

Sarjono, Agus R. Frische Knochen aus Banyuwangi. Berlin: Edition Galrev, 2002. 
Sawabe, Yukiko. Neue Musik in Japan von 1950 bis 1960: Stilrichtungen und Komponisten. Regensburg: Bosse, 1992.

Sawabe, Yukiko. "Der lange Weg zur 'Geschichte vom Prinzen Genji." In Poetik: Gastvorträge Portraitkonzerte - Unterricht - Lesungen. Yoritsune Mastudaira 6.-17. Mai 1996, edited by the Academy of Music and Performing Arts Mozarteum Salzburg, 11-23. Salzburg, 1996.

Schachter, Carl. "Rhythm and Linear Analysis: Aspects of Meter." Music Forum 6, no. I (1987): $1-59$.

Schaffrath, Helmut. Einhundert chinesische Volkslieder: Eine Anthologie. Bern: Lang, 1993.

Schering, Arnold. "Nationale und historische Klangstile." Jahrbuch Peters 34 (1927): 31-43.

Scherzinger, Martin. "Art Music in a Cross-Cultural Context: The Case of Africa." In The Cambridge History of Twentieth-Century Music, edited by Nicholas Cook and Anthony Pople, 584613. Cambridge: Cambridge University Press, 2004.

Scherzinger, Martin. "György Ligeti and the Aka Pygmies Project." Contemporary Music Review 25, no. 3 (2006): 227-262.

Scherzinger, Martin. "Remarks on a Sketch of György Ligeti: A Case of African Pianism." Mitteilungen der Paul Sacher Stiftung 20 (2007): 32-37.

Scherzinger, Martin. 'Luciano Berio's 'Coro:' Nexus between African Music and Political Multitude." In Luciano Berio: Nuove prospettive/New Perspectives, edited by Angela DeBenedictis, 401-432. Firenze: Olschki, 2012.

Scherzinger, Martin. "Afrika." In Lexikon Neue Musik, edited by Jörn Peter Hiekel and Christian Utz, 157-165. Stuttgart: Metzler/Kassel: Bärenreiter, 2016.

Schimmelpenninck, Antoinet, and Frank Kouwenhoven. "The Shanghai Conservatory of Music: History \& Foreign Students Experiences.” CHIME no. 6 (1993): 56-91.

Schmelz, Peter J. "Introduction: Music in the Cold War." The Journal of Musicology 26, no. 1 (2009): 3-16.

Schmidt, Dörte. 'WWegkarte für Orpheus?' Historische und kulturelle Fremdheit in ChiefJoseph von Hans Zender." In Orientierungen: Wege im Pluralismus der Gegenwartsmusik, edited by Jörn Peter Hiekel, 151-160. Mainz: Schott, 2007.

Schnebel, Dieter. "New World Music." In World Cultures and Modern Art: The Encounter of 19thand 2oth-Century European Art and Music with Asia, Africa, Oceania, Afro- and Indo-America, edited by Siegfried Wichmann, 338-342. Munich: Bruckmann, 1972.

Schönberg, Arnold. Harmonielehre. [1911] Third edition. Vienna: Universal-Edition, 1922.

Schönberg, Arnold. "Vorwort." In Pierrot lunaire, Op. 21. Vienna: Universal-Edition, 1914.

Schoenberg, Arnold. "Linear Counterpoint." [1931] Translated by Leo Black. In Style and Idea: Selected Writings by Arnold Schoenberg, edited by Leonard Stein, 289-293. Berkeley: University of California Press, 1975.

Schoenberg, Arnold. Theory of Harmony. Translated by Ray E. Carter. Berkeley: University of California Press, 1978.

Schönfelder, Gerd. Die Musik der Peking-Oper. Leipzig: Deutscher Verlag für Musik, 1972.

Schütz, Hannes. "Wiedergeburt der Ars subtilior? Eine Analyse von György Ligetis Klavieretüde Nr. 2 “Cordes Vides.” Die Musikforschung 50, no. 2 (1997): 205-214.

Schwanitz, Dietrich. Bildung: Alles, was man wissen muß. Frankfurt: Eichborn, 1999.

Schwartz, Frederic J. "Ernst Bloch and Wilhelm Pinder: Out of Sync." Grey Room 3 (2001):54-89.

Schwörer-Kohl, Gretel. "Mundorgel." [1997] MGG Online. https://www.mgg-online.com/mgg/ stable/16188 
Sciarrino, Salvatore, and Paolo Petazzi. "Salvatore Sciarrino im Gespräch mit Paolo Petazzi." In Die tödliche Blume, Program, Schwetzinger Festspiele/Wiener Festwochen, 36-40. Vienna, 1998.

Scott-Smith, Giles. The Politics of Apolitical Culture: The Congress for Cultural Freedom, the CIA and Post-war American Hegemony. London: Routledge, 2002.

Seidel, Wilhelm. "Rhythmus, Metrum, Takt." [1998] MGG Online. Last updated November 2016. https://www.mgg-online.com/mgg/stable/11614

Senghaas, Dieter. "Moderne und Antimoderne angesichts kultureller Globalisierung: Plädoyer für einen zeitgemäßen, jedoch geschichtsbewußten Diskurs." In Tradition und Traditionsbruch zwischen Skepsis und Dogmatik: Interkulturelle philosophische Perspektiven, edited by Claudia Bickmann, Hermann-Josef Scheidgen, Tobias Voßhenrich, and Markus Wirtz, 325-342. Amsterdam: Rodopi, 2006.

Service, Jonathan. "Harmony Outside the Iron Cage: Tanaka Shōhei's Strategic Deconstruction of the Music-Theoretical Edifice." History of Humanities 22 (2017): 375-387.

Sharif, Malik. Speech about Music: Charles Seeger's Meta-Musicology. Vienna: Hollitzer, 2019.

Shen, Qia. "Ethnomusicology in China." Journal of Music in China 1, no. 1 (1999): 7-36.

Sheppard, W. Anthony. "Continuity in Composing the American Cross-Cultural. Eichheim, Cowell, and Japan." Journal of the American Musicological Society 61, no. 3 (2008): 465-540.

Sheppard, W. Anthony. "Puccini and the Music Boxes." Journal of the Royal Musical Association 140, no. 1 (2015): 41-92.

Sheppard, W. Anthony. Extreme Exoticism: Japan in the American Musical Imagination. New York: Oxford University Press, 2019.

Shi sheng tongxun lu (Record of Teachers and Students), National Conservatory of Music Shanghai, July 1947.

Shim, Kunsu. "Richtungslosigkeit oder Denken der unbegrenzten Gegenwart - ein Konzept für die Kunst." [1997] Translated by Cho Wonkyu. https://kunsu-shim.de/pages/texte/richtungslosigkeit-oder-denken-der-unbegrenzten-gegenwart.php

Shim, Kunsu. "die kunst - verbunden und auflösen (künstliches und natürliches) - die gegenwart." KunstMusik: Schriften zur Musik als Kunst 4 (2005): 51-53.

Shimada, Shingo. Grenzgänge - Fremdgänge: Japan und Europa im Kulturvergleich. Frankfurt: Campus, 1994.

Shimizu, Minoru. "Stockhausen und Japan: Licht und Schatten." In Internationales Stockhausen-Symposion 1998, edited by Imke Misch and Christoph von Blumröder, 87-94. Saarbrücken: Pfau, 1999.

Shimizu, Minoru. "Was ist PluraMonismus?" In Internationales Stockhausen-Symposion 1998, edited by Imke Misch and Christoph von Blumröder, 112-125. Saarbrücken: Pfau, 1999.

Shimizu, Yoshihiku. "Mayuzumi Toshirō no kanpanoloji efekuto niokeru onretsu gihō" (Serial Technique in Toshiro Mayuzumi's Campanology Effect). Ongakugaku 56, no. 1 (2010): 26-37.

Shreffler, Anne C. "Ideologies of Serialism: Stravinsky's Threni and the Congress of Cultural Freedom." In Music and the Aesthetics of Modernity. Festschrift Reinhold Brinkmann, edited by Karol Berger and Anthony Newcomb, 217-245. Cambridge, MA: Harvard University Press, 2005.

Shreffler, Anne C. "Dahlhaus und die 'höhere Kritik.' Schriften über Neue Musik und Politik." In Carl Dahlhaus und die Musikwissenschaft: Werk, Wirkung, Aktualität, edited by Hermann Danuser, Peter Gülke, and Norbert Miller, 249-264. Schliengen: Argus, 2011. 
Shreffler, Anne C. "Cold War Dissonance: Dahlhaus, Taruskin, and the Critique of the Politically Engaged Avant-garde." In Kultur und Musik nach 1945: Ästhetik im Zeichen des Kalten Kriegs, edited by Ulrich J. Blomann, 46-59. Saarbrücken: Pfau, 2015.

Siebert, Daniel. Musik im Zeitalter der Globalisierung: Prozesse - Perspektiven - Stile. Bielefeld: transcript, 2014.

Slonimsky, Nicolas, editor. "Fraenkel, Wolfgang." In Baker's Biographical Dictionary of Musicians, 1164-1165. New York: Schirmer, 2001.

Small, Christopher. Musicking: The Meanings of Performing and Listening. Middletown: Wesleyan University Press, 1998.

Spahn, Claus. "Gegen die Vormacht der Oberflächlichkeit: Interview mit Helmut Lachenmann." Die Zeit 2004, no. 19.

Spahn, Claus. "Der lange Marsch zu Beethoven: Liegt die Zukunft der klassischen Musik in China? Auf Asientournee mit Simon Rattle und den Berliner Philharmonikern." Die Zeit 2005 , no. 47.

Sparrer, Walter-Wolfgang. "Isang Yun und koreanische Tradition." In Ssi-ol. Almanach 1998/99, edited by Walter-Wolfgang Sparrer, 107-144. Munich: edition text + kritik, 1999.

Sparrer, Walter-Wolfgang. "Toshio Hosokawa." In Komponisten der Gegenwart, 18th Dispatch. Munich: edition text + kritik, 1999.

Sparrer, Walter-Wolfgang, editor. Ssi-ol. Almanach 2000/01 der Internationalen Isang Yun Gesellschafte.V. Munich: edition text + kritik, 2002.

Sparrer, Walter-Wolfgang. Isang Yun: Leben und Werk im Bild 윤이상. 사진으로 보는 인생과 예 술 Isang Yun: His Life and Work in Pictures. Hof heim: Wolke, 2020.

Spengler, Oswald. Der Untergang des Abendlandes. 2 Vols. Munich: Beck, 1922.

Sprout, Leslie A. "The 1945 Stravinsky Debates: Nigg, Messiaen, and the Early Cold War in France." The Journal of Musicology 26, no. 1 (2009): 85-131.

Stäbler, Gerhard. "Palast des Schweigens." In Gerhard Stäbler, Karas. Krähen und Palast des Schweigens. Mayumi Miyata spielt Gagaku. Wergo 282056-2, edition zkm 6, 1999. Supplementary booklet: 8-10.

Steen, Andreas. "'Voices of the Mainstream:' Red Songs and Revolutionary Identities in the People's Republic of China." In Vocal Music and Contemporary Identities: Unlimited Voices in East Asia and the West, edited by Christian Utz and Frederick Lau, 225-247. New York: Routledge, 2013.

Steiner, Karl (Ka'er Shitaina). "50 nian zhi hou” (50 Years Afterwards). Yinyue yishu (The Art of Music) 12, no. 1 (1990): 13.

Steiner, Karl. "Report about my Years in Shanghai, 1939-1949." In Karl Steiner Collection, Leo Baeck Institute Archives, New York.

Stenzl, Jürg. Von Giacomo Puccini zu Luigi Nono: Italienische Musik 1922-1952: Faschismus - Resistenza-Republik. Laaber: Laaber, 1998.

Stephan, Ilja. Isang Yun: Die fünf Symphonien. Munich: edition text + kritik, 2000.

Stephan, Rudolf. "Sprechgesang." [1998] MGG Online. Last updated November 2016. https://www.mgg-online.com/mgg/stable/17211

Stock, Jonathan. "An Ethnomusicological Perspective on Musical Style, with Reference to Music for Chinese Two-stringed Fiddles." Journal of the Royal Musical Association 118 (2003): 276-299.

Stock, Jonathan. "Contemporary Recital Solos for the Chinese Two-Stringed Fiddle erhu." British Journal of Ethnomusicology 1 (1992): 55-88. 
Stockhausen, Karlheinz. "Zur Situation des Metiers (Klangkomposition)." [1953] In Texte zur Musik, Vol. 1, edited by Dieter Schnebel, 45-61. Cologne: DuMont-Schauberg, 1963.

Stockhausen, Karlheinz. "Gruppenkomposition: Klavierstück I." [1955] In Texte zur Musik, Vol. 1, edited by Dieter Schnebel, 63-74. Cologne: DuMont-Schauberg, 1963.

Stockhausen, Karlheinz. "Momentform. Neue Beziehungen zwischen Aufführungsdauer, Werkdauer und Moment." [1960] In Texte zur Musik, Vol. 1, edited by Dieter Schnebel, 189210. Cologne: DuMont-Schauberg, 1963.

Stockhausen, Karlheinz. "Nr. 13: Momente für Sopran, 4 Chorgruppen und 13 Instrumentalisten (1961/62).” [1962] In Texte zur Musik, Vol. 2, edited by Dieter Schnebel, 130-133. Cologne: DuMont-Schauberg, 1964.

Stockhausen, Karlheinz. "Telemusik." [1966/1969] In Texte zur Musik, Vol. 3, edited by Dieter Schnebel, 75-77. Cologne: DuMont-Schauberg, 1971.

Stockhausen, Karlheinz. "Interview über Telemusik." [1968] In Texte zur Musik, Vol. 3, edited by Dieter Schnebel, 79-84. Cologne: DuMont-Schauberg, 1971.

Stockhausen, Karlheinz. "Ein Mundstück." [1969] In Texte zur Musik, Vol. 3, edited by Dieter Schnebel, 300-302. Cologne: DuMont-Schauberg, 1971.

Stockhausen, Karlheinz. "Weltmusik." [1973] In Texte zur Musik, Vol. 4, edited by Christoph von Blumröder, 468-476. Cologne: DuMont-Schauberg, 1978.

Stockhausen, Karlheinz. "World Music." [1973] the world of music 21, no. 1 (1979): 3-16.

Stokes, Martin. "Music and the Global Order." Annual Review of Anthropology 33 (2004): 47-72.

Stollberg, Arne. Ohr und Auge - Klang und Form: Facetten einer musikästhetischen Dichotomie bei Johann Gottfried Herder, Richard Wagner und Franz Schreker. Stuttgart: Steiner, 2006.

Stonor Saunders, Frances. The Cultural Cold War: The CIA and the World of Arts and Letters. [1999] New York: The New Press, 2013.

Straus, Joseph N. The Remaking of the Past. Musical Modernism and the Influence of the Tonal Tradition. Cambridge, MA: Harvard University Press, 1990.

Stravinsky, Igor. An Autobiography. London: Norton, 1962.

Strohm, Reinhard. "Looking Back at Ourselves: The Problem with the Musical Work-Concept." In The Musical Work: Reality or Invention, edited by Michael Talbot, Liverpool: Liverpool University Press, 2000, 128-152.

Strohm, Reinhard. "Opus: An Aspect of the Early History of the Musical Work-Concept." In Musik des Mittelalters und der Renaissance: Festschrift Klaus-Jürgen Sachs zum 80. Geburtstag, edited by Rainer Kleinertz, Christoph Flamm, and Wolf Frobenius, 205-217. Hildesheim: Olms, 2010.

Strohm, Reinhard. "Der musikalische Werkbegriff: Dahlhaus und die Nachwelt (Versuch einer Historisierung in drei Phasen)." In Carl Dahlhaus und die Musikwissenschaft: Werk, Wirkung, Aktualität, edited by Hermann Danuser, Peter Gülke, and Norbert Miller, 265-278. Schliengen: Argus, 2011.

Stumpf, Carl. Die Anfänge der Musik. Leipzig: Barth, 1911.

Suchy, Irene. "Deutschsprachige Musiker in Japan vor 1945: Eine Fallstudie eines Kulturtransfers am Beispiel der Rezeption abendländischer Kunstmusik." PhD dissertation, University of Vienna, 1992.

Sun, Guozhong. “Zhu Jian'er's Symphonies: Context, Style, Significance.” PhD dissertation, University of California, Los Angeles, 1997.

Sung, Yu-Jen. "Interkulturelles Komponieren in der zeitgenössischen taiwanesischen Kunstmusik: Eine exemplarische Untersuchung zur Komposition 'Wandlungsphasen für acht Spieler' (1979/80) von Pan Hwang-long." In weltmusik - Musik interkulturell, Schlaglichter, 
Aufbruch - Umbruch, Zeiten - Räume, Modelle, Nähe - Ferne, edited by the Institut für Neue Musik und Musikerziehung Darmstadt, 189-207. Mainz: Schott, 2004.

Sung, Yu-Jen. Pan Hwang-long - Leben und Werk: Studien zur zeitgenössischen Kunstmusik in Taiwan. Aachen: Shaker, 2005.

Takahashi, Yūji. "From Words to Music." Perspectives of New Music 30, no. 2 (1992): 64-71.

Takahashi, Yūji. "Bach as a Failure." Perspectives of New Music 30, no. 2 (1992): 72-75.

Takahashi, Yüji. "The Resistance of the Asian Masses and Their Culture." Perspectives of New Music 30, no. 2 (1992): 90-100.

Takahashi, Yūji. Tori no asobi: Works for Japanese Instruments. Real Time 6, Fontec FOCD3191, compact disc, 1994. Supplemental Booklet.

Takahashi, Yūji. "Between Good and Evil: Yūji Takahashi in Conversation with Jack Body." World New Music Magazine no. 5 (1995): 6-11.

Takahashi, Yūji. Astray Among Decayed Strings: Looking Back on My Pieces for Reconstructed Instruments. Tokyo: Shunjūsha, 2000.

Takahashi, Yūji. Koto nado asobi (score). Tokyo, 2000. http://www.suigyu.com/yuji/score-pdf/ kna_e.pdf

Takahashi, Yūji. “Two Statements on Music.” the world of music 45, no. 2 (2003): 147-152.

Takemitsu, Tōru. "Notes on November Steps." [1971] In Confronting Silence: Selected Writings, 83-90. Berkeley: Fallen Leaf Press, 1995.

Takemitsu, Tōru. "Dream and Number." [1984] In Confronting Silence: Selected Writings, 97-126. Berkeley: Fallen Leaf Press, 1995.

Takemitsu, Tōru. "My Perception of Time in Traditional Japanese Music." Contemporary Music Review 1, no. 2 (1987): 9-13.

Takemitsu, Tōru. "Music and Culture." In Toki no Entei (The Gardener of Time). Tokyo: Shinchosha 1996; excerpts translated by Ashida Naoyuki. http://www.child-dream.net/ashida/ tt/essays.html

Tamagawa, Kiyoshi. Echoes from the East: The Javanese Gamelan and Its Influence on the Music of Claude Debussy. Lanham: Lexington Books, 2019.

Tamba, Akira. The Musical Structure of Nō. Tokyo: Tokai University Press, 1981.

Tan, Dun. Heaven Earth Mankind - Symphony 1997 (score). New York: Schirmer, 1997.

Tan, Dun, and Christian Utz. "Tan Dun's Art for a New Generation: 'Extreme Cross-over, Extremely Personal Music." CHIME no. 12/13 (1998): 142-150.

Tanaka, Shōhei. Nihon wasei no kiso (Foundations of Japanese Harmony). Tokyo: Sōgensha, 1940.

Tang, Yating. "Musical Life in the Jewish Refugee Community in Shanghai: Popular and Art Music." Journal of Music in China 4, no. 1-2 (2002): 167-186.

Tang, Yating. "Reconstructing the Vanished Musical Life of the Shanghai Jewish Diaspora: A Report." Ethnomusicology Forum 13, no. 1 (2004): 101-118.

Tang, Yating. Shanghai Youtai shequ de yinyue shenghuo (1850 1950, 1998 2005) (The Musical Lives of the Jewish Community in Shangai, 1850-1950, 1998-2005). Shanghai: Shanghai yinyuexueyuan chubanshe 2007.

Tang, Yating. "Japanese Musicians and the Shanghai Municipal Orchestra (1942-45)." the world of music [new series] 1 (2012) special issue: Colonial Modernity and East Asian Musics: 47-80.

Tang, Yating. Diguo feishan bianzouqu: Shanghai gongbuju yuedui shi (Variations on Imperial Diasporas: A History of the Shanghai Municipal Orchestra). Shanghai: Shanghai yinyuexueyuan chubanshe, 2014.

Tanizaki, Jun'ichirō. In Praise of Shadows. [1933] Translated by Thomas J. Harper and Edward G. Seidensticker. Stony Creek: Leete's Island Books, 1977. 
Tanizaki, Jun'ichirō. Lob des Schattens. Entwurfeinerjapanischen Ästhetik. [1933] Zürich: Manesse, 1996.

Taruskin, Richard. "Russian Folk Melodies in The Rite of Spring." Journal of the American Musicological Society 33, no. 3 (1980): 501-543.

Taruskin, Richard. "The Dark Side of the Moon" (Review: Harvey Sachs, Music in Fascist Italy, 1987). [1988] In The Danger of Music and Other Anti-Utopian Essays, 202-216. Berkeley: University of California Press, 2009.

Taruskin, Richard. Stravinsky and the Russian Traditions: A Biography of the Works through Mavra. 2 Vols. Berkeley: University of California Press, 1996.

Taruskin, Richard. "Notes on Svadebka." In Defining Russia Musically. Historical and Hermeneutical Essays, 389-467. Princeton: Princeton University Press, 1997.

Taruskin, Richard. "Introduction: The History of What?" In Music from the Earliest Notations to the Sixteenth Century (The Oxford History of Western Music, Vol. 1), XXI-XXX. New York: Oxford University Press, 2005.

Taruskin, Richard. "Speed Bumps." 19th-Century Music 29, no. 2 (2005): 185-207.

Taruskin, Richard. "Why You Cannot Leave Bartók Out." Studia Musicologica Academiae Scientiarum Hungaricae 47, no. 3/4 (2006): 265-277.

Taruskin, Richard. "Afterword: Nicht blutbefleckt?" The Journal of Musicology 26, no. 2 (2009): 274-284.

Taruskin, Richard. The Oxford History of Western Music. 5 Vols. New York: Oxford University Press, 2010.

Taruskin, Richard. Music in the Late Twentieth Century (The Oxford History of Western Music, Vol. 5). New York: Oxford University Press, 2010.

Taruskin, Richard. "Preface." In Music in the Late Twentieth Century (The Oxford History of Western Music, Vol. 5), XIX-XX. New York: Oxford University Press, 2010.

Taylor, Charles. Sources of the Self: The Making of the Modern Identity. Cambridge, MA: Harvard University Press, 1989.

Taylor, Charles. The Malaise of Modernity. Concord: Anansi, 1991.

Taylor, Charles. "The Politics of Recognition." In Charles Taylor, Anthony Appiah, Jürgen Habermas, Stephen C. Rockefeller, Michael Walzer, and Susan Wolf, Multiculturalism and the Politics of Recognition: An Essay. Expanded paperback edition. Edited and introduced by Amy Gutmann, 25-74. Princeton: Princeton University Press, 1994.

Taylor, Stephen Andrew. "Ligeti, Africa and Polyrhythm." the world of music 45, no. 2 (2003): 83-94.

Taylor, Stephen Andrew. "Hemiola, Maximal Evenness, and Metric Ambiguity in Late Ligeti." Contemporary Music Review 31 no. 2-3 (2012): 203-220.

Taylor, Timothy D. Beyond Exoticism. Western Music and the World. Durham: Duke University Press, 2007.

Tcherepnine, Alexander. "Music in Modern China." Musical Quarterly 21, no. 4 (1935): 391-400.

Tenzer, Michael. "José Maceda and the Paradoxes of Modern Composition in Southeast Asia." Ethnomusicology 47 no. 1 (2003): 93-120.

Tenzer, Michael. "Introduction: Analysis, Categorization, and Theory of Musics of the World." In Analytical Studies in World Music, edited by Michael Tenzer, 3-38. New York: Oxford University Press, 2006.

Tenzer, Michael. "Temporal Transformations in Cross-Cultural Perspective: Augmentation in Baroque, Carnatic and Balinese Music." In Music Theory and Interdisciplinarity: 8th Congress of the Gesellschaft für Musiktheorie Graz 2008, edited by Christian Utz, 517-530. Saarbrücken: 
Pfau, 2010. Also published in Analytical Approaches to World Music 1, no. I (2011): 152-175. http://aawmjournal.com/articles/2011a/Tenzer_AAWM_Vol_1_1.pdf

Tenzer, Michael. "A Cross-Cultural Topology of Musical Time: Afterword to the Present Book and to Analytical Studies in World Music (2006)." In Analytical and Cross-Cultural Studies in World Music, edited by Michael Tenzer and John Roeder, 415-439. New York: Oxford University Press, 2011.

Terauchi, Naoko. "Future Perspectives: New Possibilities in Research on gagaku." In Musicology and Globalization: Proceedings of the International Congress in Shizuoka 2002, edited by the Musicological Society of Japan, 82-84. Tokyo: Musicological Society of Japan, 2004.

Theobald, Werner. "Spuren des Mythos in der Aristotelischen Theorie der Erkenntnis: 'Hypolepsis' bei Aristoteles, De anima und Anal. post." Archiv für Begriffsgeschichte 44 (2002): 25-37.

Thorau, Christian. "Interagierende Systeme: Überlegungen zu einem zeichentheoretischen Rahmen musikalischer Analyse." In Systeme der Musiktheorie, edited by Clemens Kühn and John Leigh, 70-84. Dresden: Sandstein, 2009.

Thorau, Christian. Vom Klang zur Metapher: Perspektiven der musikalischen Analyse. Hildesheim: Olms, 2012.

Thrasher, Alan. "Bianzou - Performance Variation in Jiangnan sizhu." CHIME no. 6 (1993): 4-20.

Thrasher, Alan. "The Chinese Sheng: Emblem of the Phoenix." ACMR Report 9, no. I (1996): 1-20.

Thrasher, Alan. "Sheng." Grove Music Online, 2001. https://doi.org/10.1093/gmo/9781561592630. article. 25623

Tischer, Matthias. "Musik in der Ära des kalten Krieges." In Was bleibt? 100 Jahre Neue Musik, edited by Andreas Meyer, 135-161. Mainz: Schott, 2011.

Tomlinson, Gary. Music in Renaissance Magic: Toward a Historiography of Others. Chicago: University of Chicago Press, 1993.

Tomlinson, John. Globalization and Culture. [1999] Cambridge: Cambridge University Press, 2006.

Tortora, Daniela, editor. Voce come soffio, Voce come gesto: Omaggio a Michiko Hirayama: Atti delle due giornate internazionali di studio Roma, 9-10 giugno 2003. Rome: Aracne, 2008.

Treitler, Leo. Music and the Historical Imagination. Cambridge, MA: Harvard University Press, 1989.

Tsui, Yingfai. “The Modern Chinese Folk Orchestra: A Brief History." Musical Performance: An International Journal 2, no. 2 (1998): 19-32.

Tsui, Yingfai. "Ensembles: The Modern Chinese Orchestra." In The Garland Encyclopedia of World Music, Vol. 7: East Asia: China, Japan, and Korea, edited by Robert Provine, Yosihiko Tokumaru, and Lawrence Witzleben, 227-232. New York: Garland, 2001.

Tsukahara, Yasuko. "Aspects of gagaku in the Late Nineteenth and Early Twentieth Centuries." In Musicology and Globalization: Proceedings of the International Congress in Shizuoka 2002, edited by the Musicological Society of Japan, 72-75. Tokyo: Musicological Society of Japan, 2004.

Tsukahara, Yasuko. "State Ceremony and Music in Meiji-era Japan." Nineteenth-Century Music Review 10, no. 2 (2013): 223-238.

Tsunoda, Tadanobu. The Japanese Brain: Uniqueness and Universality. [1978] Tokyo: Taishūkan, 1985.

Tsuyuki, Tsugio. "Nihon ongaku to yōgaku to no kōryū" (Exchange between Japanese and Western Music - Exemplified by Recent Radio Broadcasts). Ongaku sekai 11, no. 5 (1939): 35-37.

Tully, James. Strange Multiplicity: Constitutionalism in an Age of Diversity. Cambridge: Cambridge University Press, 1995. 
Tung, Chao-Ming. "Formosa" (Program note). In cross//roads 4 Program, edited by Christian Utz, 12. Vienna: AsianCultureLink, 2002.

Turner, John W. "Performing Cultural Hybridity in Isang Yun's Glissées pour violoncelle seul (1970)." Music Theory Online 25, no. 2 (2019). https://doi.org/10.30535/mto.25.2.6

Ulrich, Thomas. 'Spirituelle All-Einheit und das Subjekt des Komponisten: Zum 'Katholischen' bei Stockhausen.” In Internationales Stockhausen-Symposion 1998, edited by Imke Misch and Christoph von Blumröder, 18-25. Saarbrücken: Pfau, 1999.

Utz, Christian. Neue Musik und Interkulturalität: Von John Cage bis Tan Dun. Stuttgart: Steiner, 2002.

Utz, Christian. "Interkulturalität in der neuen Musik: Kulturelle Differenz als kompositorische Herausforderung." In MaerzMusik 2004 Program, edited by Berliner Festspiele, 28-32. Berlin, 2004.

Utz, Christian. "Bernd Alois Zimmermann und Charles Ives: Schichtungsverfahren, Intertextualität, kulturelle Verortung." In Bernd Alois Zimmermann, edited by Ulrich Tadday, 121141. Munich: edition text + kritik, 2005.

Utz, Christian. "Zwischen Mythos und Kooperation. Transkulturelle Rezeption westlicher Komponisten in historischer Perspektive." In Neue Zeitschrift für Musik 167, no. 3 (2006): 27-31.

Utz, Christian. "Musik von einem fremden Planeten? Variationen über Struktur, Wahrnehmung und Bedeutung in der Musik des 20. und 21. Jahrhunderts." In Musiktheorie als interdisziplinäres Fach. 8. Kongress der Gesellschaft für Musiktheorie Graz 2008, edited by Christian Utz, 377-399. Saarbrücken: Pfau, 2010.

Utz, Christian. "Statische Allegorie und 'Sog der Zeit:' Zur strukturalistischen Semantik in Salvatore Sciarrinos Oper Luci mie traditrici." Musik \& Ästhetik no. 53 (2010):37-60.

Utz, Christian. "Liberating' Sound and Perception: Historical and Methodological Preconditions of a Morphosyntactic Approach to Post-tonal Music." In Organized Sound: Klang und Wahrnehmung in der Musik des 20. und 21. Jahrhunderts, edited by Christian Utz, 13-48. Saarbrücken: Pfau, 2013.

Utz, Christian. "Das zweifelnde Gehör: Erwartungssituationen als Module im Rahmen einer performativen Analyse tonaler und posttonaler Musik." Zeitschrift der Gesellschaft für Musiktheorie 10, no. 2 (2013): 225-257. https://doi.org/10.31751/720

Utz, Christian. "Morphologie und Bedeutung der Klänge in Klaus Hubers Miserere Hominibus." In Transformationen: Zum Werk von Klaus Huber, edited by Jörn Peter Hiekel and Patrick Müller, 129-165. Mainz: Schott, 2013.

Utz, Christian. Komponieren im Kontext der Globalisierung: Perspektiven für eine Musikgeschichte des 20. und 21. Jahrhunderts. Bielefeld: transcript, 2014.

Utz, Christian. "Scelsi hören: Morphosyntaktische Zusammenhänge zwischen Echtzeitwahrnehmung und Formimagination der Musik Giacinto Scelsis." In Klang und Quelle: Ästhetische Dimension und kompositorischer Prozess bei Giacinto Scelsi, edited by Federico Celestini and Elfriede Reissig, 143-175. Vienna: LIT, 2014.

Utz, Christian. "Vom adäquaten zum performativen Hören: Diskurse zur musikalischen Wahrnehmung als Präsenzerfahrung im 19. und 20. Jahrhundert und Konsequenzen für die musikalische Analyse." Acta Musicologica 86, no. 1 (2014): 101-123.

Utz, Christian. "Paradoxien musikalischer Temporalität in der neueren Musikgeschichte. Die Konstruktion von Klanggegenwart im Spätwerk Bernd Alois Zimmermanns im Kontext der Präsenzästhetik bei Giacinto Scelsi, György Ligeti, Morton Feldman und Helmut Lachenmann." Die Musikforschung 68, no. 1 (2015): 22-52. 
Utz, Christian. "Auf der Suche nach einer befreiten Wahrnehmung. Neue Musik als Klangorganisation." In Lexikon Neue Musik, edited by Jörn Peter Hiekel and Christian Utz, 35-53. Stuttgart: Metzler/Kassel: Bärenreiter, 2016.

Utz, Christian. “China, Taiwan, Hong Kong.” In Lexikon Neue Musik, edited by Jörn Peter Hiekel and Christian Utz, 200-209. Stuttgart: Metzler/Kassel: Bärenreiter, 2016.

Utz, Christian. "Räumliche Vorstellungen als 'Grundfunktionen des Hörens:' Historische Dimensionen und formanalytische Potenziale musikbezogener Architektur- und Raummetaphern - Eine Diskussion anhand von Werken Guillaume Dufays, Joseph Haydns und Edgard Varèses." Acta Musicologica 88, no. 2 (2016): 193-222.

Utz, Christian. "Time-Space Experience in Works for Solo Cello by Lachenmann, Xenakis and Ferneyhough: A Performance-Sensitive Approach to Morphosyntactic Musical Analysis." Music Analysis 36, no. 2 (2017): 216-256. https://doi.org/10.1111/musa.12076

Utz, Christian. "Zum performativem Hören serieller Musik: Analyse und Aufführung von Pierre Boulez' Structures Ia (1951) und Polyphonie X (1951)." In Beitragsarchiv des Internationalen Kongresses der Gesellschaft für Musikforschung, Mainz 2016 - "Wege der Musikwissenschaft," edited by Gabriele Buschmeier and Klaus Pietschmann. Mainz: Schott, 2017. http://schott-campus.com/zum-performativen-hoeren

Utz, Christian. "Klang als Energie in der Musik seit 1900: Erfahrungsorientiertes Zeit-RaumKomponieren bei Edgard Varèse, Dane Rudhyar und Giacinto Scelsi." In Energie! Kräftespiele in den Künsten, edited by Arne Stollberg and Kathrin Eggers, 247-276. Würzburg: Königshausen \& Neumann 2021.

Utz, Christian. "Carolyn Abbate: Music - Drastic or Gnostic?” In Lexikon Schriften über Musik, Vol. 2: Musikästhetik, edited by Hartmut Grimm, Melanie Wald-Fuhrmann, and Felix Wörner. Kassel: Bärenreiter, forthcoming.

Utz, Christian. "Musikalische 'Treibhausblüten'? Universalismus und Kulturpessimismus bei Hugo Riemann (1849-1919) und Georg Capellen (1869-1934): Musiktheorie und Musikhistorik im Spannungsfeld globaler Moderne." In Hugo Riemann: Musikforschung zwischen Universalität, Nationalismus und internationaler Ausstrahlung, edited by Stefan Keym and Christoph Hust. Hildesheim: Olms, forthcoming.

Utz, Christian and Dieter Kleinrath. "Klang und Wahrnehmung bei Varèse, Scelsi und Lachenmann: Zur Wechselwirkung von Tonhöhen- und Klangfarbenstrukturen in der Klangorganisation post-tonaler Musik." In Klangperspektiven, edited by Lukas Haselböck, 73-102. Hof heim: Wolke, 2011.

Utz, Christian, and Frederick Lau, editors. Vocal Music and Contemporary Identities: Unlimited Voices in East Asia and the West. New York: Routledge, 2013.

Utz, Christian, and Rainer Nonnenmann. "Rhythmus, Metrum, Tempo." In Lexikon Neue Musik, edited by Jörn Peter Hiekel and Christian Utz, 526-541. Stuttgart: Metzler/Kassel: Bärenreiter, 2016.

Vertovec, Stephen. "Super-Diversity and Its Implications." Ethnic and Racial Studies 30, no. 6 (2007): 1024-1054.

Vlad, Roman. "Reihenstrukturen im Sacre du Printemps." In Igor Strawinsky, edited by HeinzKlaus Metzger and Rainer Riehn, 4-64. Munich: edition text + kritik, 1984.

Vuillermoz, Emile. "La musique au concert." Comodia, 19 January 1914, 2.

Wade, Bonnie C. Composing Japanese Musical Modernity. Chicago: University of Chicago Press, 2014.

Wagnleitner, Reinhold. Coca-Colonisation und Kalter Krieg: Die Kulturmission der USA in Österreich nach dem Zweiten Weltkrieg. Vienna: Verlag für Gesellschaftskritik, 1991. 
Walravens, Hartmut. Vincenz Hundhausen (1878-1955): Leben und Werk des Dichters, Druckers, Verlegers, Professors, Regisseurs und Anwalts in Peking. Wiesbaden: Harrassowitz, 1999.

Wang, Ningyi. "Farenshensi de tansuo: Ping Luo Zhongrong de 'Shejiang cai furong" (A Thought-Provoking Experiment: A Critique of Luo Zhongrong's Picking Lotus Flowers at the Riverside). Yinyue yanjiu (Music Research) 4 (1981): 41-45.

Wang, Zheng. "National Humiliation, History Education, and the Politics of Historical Memory: Patriotic Education Campaigns in China.” International Studies Quarterly 52 (2008): 783-806.

Wang, Zhenya. Wusheng yinjie ji qi hesheng (The Pentatonic Scale and Its Harmony). Shanghai: Wenguang Shudian, 1949.

Weber, William. "The History of Musical Canon." In Rethinking Music, edited by Nicholas Cook and Mark Everist, 336-355. Oxford: Oxford University Press, 2001.

Weggel, Oskar. Die Geschichte Taiwans. Cologne: Böhlau, 1991.

Welch, Allison. "Meeting Along the Edge: 'Svara' and 'Tala' in American Minimal Music." American Music 17, no. 2 (1999): 179-199.

Wellens, Ian. Music on the Frontline: Nicolas Nabokov's Struggle Against Communism and Middlebrow Culture. Aldershot: Ashgate, 2002.

Wellmer, Albrecht. Versuch über Musik und Sprache. Munich: Hanser, 2009.

Wellmer, Albrecht. "Über Musik und Sprache: Variationen und Ergänzungen." In Musik-Sprachen: Beiträge zur Sprachnähe und Sprachferne von Musik im Dialog mit Albrecht Wellmer, edited by Christian Utz, Dieter Kleinrath, and Clemens Gadenstätter, 9-39. Saarbrücken: Pfau, 2013.

Welsch, Wolfgang. "Transculturality: The Puzzling Form of Cultures Today." In Spaces of Culture: City, Nation, World, edited by Mike Featherstone and Scott Lash, 195-213. London: SAGE, 1999.

Werner, Michael, and Bénédicte Zimmermann. "Beyond Comparison: Histoire Croisée and the Challenge of Reflexivity." History and Theory 45, no. I (2006): 30-50.

Werner, Michael, and Bénédicte Zimmermann. "Vergleich, Transfer, Verflechtung: Der Ansatz der Histoire croisée und die Herausforderung des Transnationalen." Geschichte und Gesellschaft 28, no. 4 (2006): 607-636.

Wichmann, Elizabeth. Listening to Theatre: The Aural Dimension of Beijing Opera. Honolulu: University of Hawai'i Press, 1991.

Widmer, Ellen, and David Dewei Wang, editors. From May Fourth to June Fourth: Fiction and Film in Twentieth Century China. Cambridge, MA: Harvard University Press, 1993.

Williams, Alan E. "Madness in the Music Theatre Works of Peter Maxwell Davies." Perspectives of New Music 38, no. 1 (2000): 77-100.

Williams, Christopher. "Of Canons and Context: Toward a Historiography of Twentieth-Century Music." Repercussions 2, no. 1 (1993): 31-74.

Willmann, Roland. Gebannte Zeit: Studien zum Klavierkonzert György Ligetis. Anif: Mueller-Speiser, 2006.

Willner, Channan. "The Two-Length Bar Revisited: Handel and the Hemiola." Göttinger HändelBeiträge 4 (1991): 208-231.

Willner, Channan. "Metrical Displacement and Metrically Dissonant Hemiolas." Journal of Music Theory 57, no. 1 (2013): 87-118. https://doi.org/10.1215/00222909-2017115

Wilson, Alexandra. "Modernism and the Machine Woman in Puccini's Turandot." Music and Letters 86, no.3 (2005): 432-451. 
Wilson, Peter Niklas. "Interkulturelle Fantasien: György Ligetis Klavieretüden Nr. 7 und 8." Melos: Jahrbuch für zeitgenössische Musik 51 (1992): 63-84.

Wilson, Peter Niklas. "Sakrale Sehnsüchte: Der Scelsi-Feldman-Nono-Kult." MusikTexte no. 44 (1992): 2-4.

Wilson, Peter Niklas. "Die Ahnen des Kolumbus: Notizen zum Umgang mit dem musikalisch Fremden." In Fremde Welten (Program Wien Modern 1996), edited by the Wiener Konzerthaus, 13-19. Vienna, 1996.

Wimmer, Franz Martin. Interkulturelle Philosophie: Eine Einführung. Vienna: WUV, 2004.

Wimmer, Franz Martin. "Vom Umgang mit kulturellen Differenzen in der Philosophie." In Musik und Globalisierung: Zwischen kultureller Homogenisierung und kultureller Differenz, edited by Christian Utz, 59-78. Saarbrücken: Pfau, 2007.

Winckler, Edwin A. "Cultural Policy in Postwar Taiwan." In Cultural Change in Postwar Taiwan, edited by Stevan Harrell and Chün-chieh Huang, 22-46. Boulder: Westview, 1994.

Winzenburg, John. "Aaron Avshalomov and New Chinese Music in Shanghai, 1931-1947." Twentieth-Century China 37, no. I (2012): 50-72.

Winzenburg, John. "Heteroglossia and Traditional Vocal Genres in Chinese-Western Fusion Concertos." Perspectives of New Music 51 no. 2 (2013): 101-140.

Winzenburg, John. "Musical-Dramatic Experimentation in the Yangbanxi: A Case for Precedence in The Great Wall." In Listening to China's Cultural Revolution: Music, Politics, and Cultural Continuities, edited by Paul Clark, Laikwan Pang, and Tsan-Huang Tsai, 189-212. London: Palgrave MacMillan, 2015.

Winzenburg, John. "Spanning the Timbral Divide: Tradition, Multiplicity, and Novelty in Chinese-Western Fusion Concerto Instrumentation." In China and the West: Representation, Reception, and Reception, edited by Hon-Lun Yang and Michael Saffle, 186-204. Ann Arbor: University of Michigan Press, 2017.

Winzenburg, John. "A New Multivoiced World: Bakhtinian Polyphony and the First ChineseWestern Fusion Concerto." Journal of Musicological Research 37, no. 3 (2018): 209-238.

Winzenburg, John. "From 'Folk Cure' to Catharsis: Alexander Tcherepnin and New Chinese Piano Music." In Hon-Lun Yang, Simo Mikkonen, and John Winzenburg, Networking the Russian Musical Diaspora in Inter-War Shanghai, 148-172. Honolulu: University of Hawai'i Press, 2020.

Winzenburg, John. "Partnering with the Shanghai Arts Community: Aaron Avshalomov and Symphonic-Theatrical Experimentation." In Hon-Lun Yang, Simo Mikkonen, and John Winzenburg, Networking the Russian Musical Diaspora in Inter-War Shangha, 173-202. Honolulu: University of Hawai'i Press, 2020.

Wiora, Walter. "Die Tonarten im deutschen Volkslied." Deutsche Musikkultur 3 (1938/39): 428440.

Wiora, Walter. Die vier Weltalter der Musik: Ein universalhistorischer Entwurf. [1961] Kassel: dtv, 1988.

Wirtz, Markus. Licht: Die szenische Musik von Karlheinz Stockhausen - eine Einführung. Saarbrücken: Pfau, 2000.

Wißmann, Friederike. Hanns Eisler: Komponist, Weltbürger, Revolutionär. Munich: Edition Elke Heidenreich bei C. Bertelsmann, 2012.

Witzleben, John Lawrence. "Silk and Bamboo" Music in Shanghai: The Jiangnan Sizhu Instrumental Ensemble Tradition. Kent: Kent State University Press, 1995.

Wolpert, Remprandt. "The Mensural Notation of Rhythmic Modes, in String and Wind Parts of Tögaku, in the Twelfth, Thirteenth, and Fourteenth Centuries." In Music from the Tang Court, 
Vol. 4, edited by Laurence E. R. Picken and Noël J. Nickson, 117-133. Cambridge: Cambridge University Press, 1990.

Wong, Hoi-Yan. "Bartók's Influence on Chinese New Music in the Post-Cultural Revolution Era." Studia Musicologica 48, no. 1/2 (2007): 237-243.

Wong, Isabel K. F. "Geming gequ: Songs for the Education of the Masses." In Popular Chinese Literature and Performing Arts 1949-1979, edited by Bonnie McDougall, 112-143. Berkeley: University of California Press, 1984.

$\mathrm{Xu}$, Buzeng. "Nacui tudao xia de toushengzhe: Ji dierci dazhan zhong binan lai Hu de youtairen" (Survivors of the Nazi Holocaust: On the Jewish Refugees Who Came to Shanghai during World War II). Shanghai dang'an (Shanghai Archive) 1 (1989): 37-43.

$\mathrm{Xu}$, Buzeng. "The Influence of Jewish Refugees on the Musical and Intellectual Life of Shanghai, Part 1." Points East 5 (1990): 10-12; Part 2, Points East 9 (1994): 8-10.

$\mathrm{Xu}$, Buzeng. "Youtai yinyuejia zai Shanghai" (Jewish Musicians in Shanghai). Yinyue yishu (The Art of Music) 13, no. 3 (1991): 36-43; no. 4 (1991): 1-7.

$\mathrm{Xu}$, Buzeng. "Jews and the Musical Life of Shanghai." In The Jews of China, Vol. 1: Historical and Comparative Perspectives, edited by Jonathan Goldstein, 230-238. Armonk: Sharpe, 1999.

$\mathrm{Xu}$, Buzeng. Xunfang Youtairen: Youtai wenhua jingying zai Shanghai (Research on the Jews: The Elite of Jewish Culture in Shanghai). Shanghai: Shanghai shehuike xueyuan chubanshe, 2007.

Yamada, Chieko. "Gidayü-bushi: Music of the bunraku Puppet Theatre." In The Ashgate Research Companion to Japanese Music, edited by Alison McQueen Tokita and David W. Hughes, 197228. Aldershot: Ashgate, 2008.

Yang, Chien-Chang. "Musical Phantasmagoria in the Globalized Age: Tan Dun's The Map and the Environmental Politics of Musical Materials." In Contemporary Music in East Asia, edited by Hee-Sook Oh, 241-265. Seoul: Seoul National University Press, 2014.

Yang, Chien-Chang. "Technologies of Tradition in Post-War Musical Avant-Gardism: A Theoretical Reflection." the world of music [new series] 6, no. 1 (2017): 41-58.

Yang, Hon-Lun. "The Shanghai Conservatory, Chinese Musical Life, and the Russian Diaspora, 1927-1949." Twentieth-Century China 37, no. 1 (2012): 73-95.

Yang, Hon-Lun. "From Colonial Modernity to Global Identity: The Shanghai Municipal Orchestra." In China and the West: Music, Representation, and Reception, edited by Hon-Lun Yang and Michael Saffle, 49-64. Ann Arbor: University of Michigan Press, 2017.

Yang, Yinliu. "Guoyue qiantu jiqi yanjiu" (The Future of National Music and Its Study). Yuefeng 2, no. 4 (1942): 17-19; 3, no. 1 (1943): 16-19; 3, no. 2 (1945): 22-25; reprinted in Zhongguo yinyuexue (Musicology in China) (1989), no. 4:4-15.

Yeston, Maury. The Stratification of Musical Rhythm. New Haven: Yale University Press, 1976.

Yi, Ji-Young. Contemporary Gayageum Notation for Composers. Seoul: Korean Traditional Performing Arts Foundation, 2011.

Yi, Hyejin. "National Cultural Memory in Late-Twentieth-Century East Asian Composition: Isang Yun, Hosokawa Toshio and Zhu Jian'er." the world of music [new series] 6, no. 1 (2017): 73-101.

You, Sufeng. “Taiwan jin sanshi nian 'xiandai yinyue' fazhan zhi tansuo 1945-1975” (Studies on the Development of 'Modern Music' in Taiwan over the Past 30 Years, 1945-1975). Master's thesis, National Taiwan Normal University, Taipei, 1990.

Young, Robert J. C. Colonial Desire: Hybridity in Theory, Culture and Race. New York: Routledge, 1994. 
Young, Samson. "Reconsidering Cultural Politics in the Analysis of Contemporary Chinese Music: The Case of Ghost Opera." Contemporary Music Review 26, no. 5 (2007): 605-618.

Young, Samson. "The Voicing of the Voiceless in Tan Dun's The Map: Horizon of Expectation and the Rhetoric of National Style." Asian Music 40, no. 1 (2009): 83-99.

Young, Samson. "Reading Contemporary Chinese Music: Reconsidering Identity and Cultural Politics in Analysis." PhD dissertation, Princeton University, 2013.

Yu, Siu Wah. "Two Practices Confused in One Composition: Tan Dun's Symphony 1997: Heaven, Earth, Man." In Locating East Asia in Western Art Music, edited by Yayoi Uno Everett and Frederick Lau, 57-71. Middletown: Wesleyan University Press, 2004.

Yun, Isang. "Musik und Instrumente des alten Korea (1963)." In Ssi-ol. Almanach 2002/03, edited by Walter-Wolfgang Sparrer, Munich: edition text + kritik, 2004, 13-24.

Yun, Isang. "Über meine Musik: Vorlesungen an der Salzburger Hochschule für Musik und darstellende Kunst 'Mozarteum." [1993] In Der Komponist Isang Yun, edited by Hanns-Werner Heister and Walter-Wolfgang Sparrer, 297-313. Second edition. Munich: edition text + kritik, 1997.

Yun, Shin-Hyang. Zwischen zwei Musikwelten: Studien zum musikalischen Denken Isang Yuns. Würzburg: Königshausen \& Neumann, 2002.

Zbikowski, Lawrence M. Conceptualizing Music: Cognitive Structure, Theory, and Analysis. New York: Oxford University Press, 2002.

Zehentreiter, Ferdinand. "Anatomie des Bildungsbürgertums oder musiksoziologische Halbbildung?" Musik \& Ästhetik no. 52 (2009): 85-90.

Zehme, Albertine. Die Grundlagen künstlerischen Sprechens und Singens mit völliger Entlastung des Kehlkopfes, für den Selbstunterricht. Leipzig: Merseburger, 1920.

Zenck, Martin. "Ritual or Imaginary Ethnography in Stravinsky's Le Sacre du Printemps?" the world of music 40, no. 1 (1998): 61-78.

Zenck, Martin. "Artaud - Boulez - Rihm: Zur Re- und Trans-Ritualität im europäischen Musiktheater des 20. Jahrhunderts." In Musiktheater heute: Internationales Symposion der Paul Sacher Stiftung Basel 2001, edited by Hermann Danuser and Matthias Kassel, 235-264. Mainz: Schott, 2003.

Zenck, Martin. "Zu einer kulturwissenschaftlichen Theorie der 'Passage." In Passagen: Theorien des Übergangs in Musik und anderen Kunstformen, edited by Christian Utz and Martin Zenck, 9-30. Saarbrücken: Pfau, 2009.

Zenck, Martin. Pierre Boulez: Die Partitur der Geste und das Theater der Avantgarde. Paderborn: Fink, 2017.

Zender, Hans. "Muji no kyō." [1975] In Die Sinne denken: Texte zur Musik 1975-2003, edited by Jörn Peter Hiekel, 314. Wiesbaden: Breitkopf \& Härtel, 2004.

Zender, Hans. "Was kann Musik heute sein? Musik in der von Medien und Kommerzialisierung bestimmten Welt." [1988] In Die Sinne denken: Texte zur Musik 1975-2003, edited by Jörn Peter Hiekel, 145-156. Wiesbaden: Breitkopf \& Härtel, 2004.

Zender, Hans. "Über das Hören.” [1991] In Die Sinne denken: Texte zur Musik 1975-2003, edited by Jörn Peter Hiekel, 177-182. Wiesbaden: Breitkopf \& Härtel, 2004.

Zender, Hans. "Weltmusik." [1992] In Die Sinne denken: Texte zur Musik 1975-2003, edited by Jörn Peter Hiekel, 234-237. Wiesbaden: Breitkopf \& Härtel, 2004.

Zender, Hans. "Gegenstrebige Harmonik." [2000/2002] In Die Sinne denken: Texte zur Musik 1975-2003, edited by Jörn Peter Hiekel, 95-135. Wiesbaden: Breitkopf \& Härtel, 2004. 
Zender, Hans. "Das Eigene und das Fremde: Gedanken zu meiner Oper ChiefJoseph." In Musik und Globalisierung: Zwischen kultureller Homogenisierung und kultureller Differenz, edited by Christian Utz, 95-102. Saarbrücken: Pfau, 2007.

Zhang, Que. Akkulturationsphänomene in der gegenwärtigen Musikkultur Chinas: Die musikalische Avantgarde der achtziger Jahre. Hamburg: Wagner, 1992.

Zhao, Ronglin. "Renshi women de zuoqujia: Pan Huanglong" (Meeting with our Composers: Pan Hwang-Long). Yinyue yu yinxiang 169 (1987): 90-93.

Zheng, Yinglie. "Sang Tong de Yejing shishi” (A Preliminary Analysis of Sang Tong's Night Scenery). Yinyue yishu (The Art of Music) 5, no. 2 (1983): 54-59.

Zheng, Yinglie. "Letter from China: The Use of Twelve-Tone Technique in Chinese Musical Composition." Musical Quarterly 74, no. 3 (1990): 473-488.

Zhongguo minjian gequ jicheng (Anthology of Chinese Folk Songs). Beijing: Renmin yinyue chubanshe, 1981-2005.

Zhou, Grace. "Essentialist Legacies and Shifting Identities: Language in Central Asian NationBuilding." The Journal of Politics and Society 21 (2010): 147-166.

[Zhuangzi.] The Writings of Chuang Tzu. Translated by James Legge. Oxford: Oxford University Press, 1891. https://ctext.org/zhuangzi

Zidarić Györek, Petra. "Transformation und Polyphonie in Klaus Hubers Die Seele muss vom Reittier steigen." In Musik im Zusammenhang: Festschrift Peter Revers zum 65. Geburtstag, edited by Klaus Aringer, Christian Utz, and Thomas Wozonig, 629-640. Vienna: Hollitzer, 2019.

Zimmermann, Christian von. "Globale Entwürfe. China in der Kulturgeschichtsschreibung und in Weltreiseberichten zwischen 1850 und 1920." In Herausforderung China: Referate einer Vorlesungsreihe des Collegium Generale der Universität Bern im Sommersemester 2007, edited by Thomas Borgard, Christian von Zimmermann and Sara Margarita Zwahlen, 215-251. Bern: Haupt, 2009.

Zink, Michael. "Strukturen: Analytischer Versuch über Helmut Lachenmanns 'Ausklang." MusikTexte no. 96 (2002): 27-41.

Žižek, Slavoj. Ein Plädoyer für die Intoleranz. Vienna: Passagen, 2003. 


\section{Appendix}

\section{Text Sources}

Large parts of the text material presented in this volume have been published since 2002 in a total of 41 different publications, which are listed in chronological order below. These texts have appeared in journals and anthologies or been presented at symposia. None of the texts, however, return verbatim in this book. In most cases, extensive reworking processes have taken place. Analyses and sections from different texts were often placed in a new, overarching argumentative context within a chapter, material from different research on the same topic was compared and linked together, texts or text components were newly transferred from German into English, etc. In the following, the most important basic material of each chapter is identified using the list of publications given below.

I.1 main source: $2010 b$, first section

I. 2 main sources: 2013a, 2013c, 2014a (first section), 2014b; expanded and revised. 2014a first arose as the opening lecture in the context of the roundtable "Identity Construction and Deconstruction in East Asian Music since the 1960s" chaired by the author at the congress of the International Musicological Society, Rome, 2012.

I. 3 main sources: $2007 \mathrm{~b}, 2009 \mathrm{~d}, 2010 \mathrm{a}, 2010 \mathrm{~b}, 2014 \mathrm{~b}$

II.1 main sources: music-historically focused sections in 2002c, 2003d, 2005b, 2010a, and particularly 2016a, 2018, and 2019; the first section was first written for the 2014 German edition of this book based on a music history lecture by the author at the University of Vienna.

II.2 main source: 2019 , first part

II.3 main source: $2006 \mathrm{~b}$; supplemented by material from $2010 \mathrm{a}$

II.4 main source: 2020 . The version presented here considerably expands the short 2020 article based on a presentation at the international symposium "The Musical Fabric of Globalization: Hegemony, Creativity, and Change in Transcultural Settings, 1880s to 1930s," Bauhaus-Universität Weimar, 2019.

II.5 main sources: 2018,2019 , second part

II.6 main source: $2006 \mathrm{a}$; supplemented by material from $2008 \mathrm{~b}$ (Zender) and $2005 \mathrm{~b}$ (works for sheng)

III.1 main sources: $2010 \mathrm{a}, 2010 \mathrm{~b}, 2012 \mathrm{~b}$

III.2 main sources: 2003a, 2004a, 2004c. The text is based on archival research in the Moldenhauer archives of the Bavarian State Library in Munich in 2002 and a short research stay in Shanghai and Beijing in November and December 2002, which was funded by the Austrian 
Research Association. The material was first presented in a lecture on 29 November 2002 on the occasion of the 75th anniversary of the Shanghai Conservatory.

III.3 main sources: $2002 \mathrm{a}, 2002 \mathrm{c}, 2003 \mathrm{~d}, 2003 \mathrm{e}, 2004 \mathrm{~b}$

III. 4 main sources: $2003 \mathrm{~d}, 2005 \mathrm{c}, 2007 \mathrm{~d}, 2008 \mathrm{a}, 2009 \mathrm{~b}, 2012 \mathrm{~b}$

III. 5 main sources: $2002 \mathrm{c}, 2003 \mathrm{c}, 2003 \mathrm{~d}, 2004 \mathrm{~b}, 2004 \mathrm{~d}, 2007 \mathrm{~b}, 2007 \mathrm{c}, 2010 \mathrm{a}, 2010 \mathrm{~b}, 2012 \mathrm{~b}$. The methodological thread of intercultural musical narrativity developed especially in $2010 \mathrm{~b}$ was expanded here as an overarching aspect to which, accordingly, newly focused analyses from older texts also referred.

III.6 main source: $2002 \mathrm{~b}$; updated. This chapter is the product of a research project that the author carried out in 2000 with the support of the Fondation sino-française pour l'éducation et la culture Taipei at the National Institute of the Arts Taipei (now Taipei National University of the Arts, TNUA). Additional material had already been collected during two previous research trips to Taipei in February and March 1998 and August 1999.

IV.1 main sources: $2007 \mathrm{a}, 2005 \mathrm{~b}, 2008 \mathrm{~b}$

IV.2 main source: $2008 \mathrm{~b}$; this most extensive treatment of Lachenmann's shō reception was developed in several other essays, including 2005b, 2007a, 2016c.

V.1 main source: 2009c; supplemented by the English version (2013b). The chapter originated in the research project "Comparative Study of Conceptualizations of Vocal Music in East Asian and Western Music Traditions and their Relevance for Contemporary Composers" carried out in 2007 to 2008 at the University of Tokyo, Graduate School of Arts and Sciences, and the National Chiao-Tung University Hsinchu, Taiwan. The research project was supported by the two host universities as well as by a scholarship from Eurasia Pacific Uninet, Salzburg. The first results of this research were presented at the international conference "Unlimited Voices: Contemporary Vocal Music in the Era of Globalization" (University of Tokyo, 8-9 March 2008), which was initiated and coordinated by the author. Some additional aspects dealt with in $2013 \mathrm{a}$ were also incorporated.

V.2 main source: 2009 a. This text goes back to $2003 \mathrm{~b}$, as well as to the manuscript of my first lecture at the University of Music and Performing Arts Graz in June 2003, which was extensively revised for publication. The final part of the version presented here considerably revises and shortens the German edition of 2014.

V.3 main sources: 2010b (Czernowin), 2010c (Czernowin/Mundry), 2012a (Mundry)

VI.1 main source: 2005a; supplemented by material from 2005b (analysis of Interference)

VI.2 main source: $2009 \mathrm{~d}$ (analytical section)

VI.3 main source: $2014 \mathrm{~b}$ (analytical section)

VI.4 first publication, with parts presented at keynote lectures at three conferences and workshops (European Platform for Artistic Research in Music 2015, Graz, 2015; "Integrative Approaches to Contemporary Cross-Cultural Music Making: Turkey, Italy, Germany,” Deutsches Historisches Institut Rome, 2016; Beijing International Composition Workshop, Central Conservatory of Music, Beijing, 2018) 


\section{Publications}

2002a. "A Marco Polo (Re)Constructed by the West. Intercultural Aspects in Tan Dun's Compositional Approach." World New Music Magazine no. 12: 51-57.

2002b. "The Potential of Cultural Diversity. The Impact of Traditional Music on Musical Composition in Taiwan Since the 1970s." Journal of Music in China 4, no. 1-2:129-165.

2003a. "Auslöser der musikalischen Moderne in China. Das Wirken Wolfgang Fraenkels im Exil Shanghai." $m r$ [musica reanimata]-Mitteilungen 49: 1-16.

2003b. "Gefrorene Turbulenz. Die Rezeption afrikanischer Musik in György Ligetis Klavierkonzert." Neue Zeitschrift für Musik 164, no. 3:36-43.

2003c. "Entortete Identitäten. Fragmentarische Gedanken über ostasiatische Musik in Europa." Österreichische Musikzeitschrift 58, no. 6, 30-34. Also published in Positionen no. 63 (2005), 27-30; in Swedish: "Utlokaliserade identiteter - tankar kring östasiatisk musik i Europa." Nutida Musik 2006 (no. 1): 36-40; in English: "Dislocated Identities. Fragmentary Thoughts on East Asian Music in Europe." World New Music Magazine no. 17 (2007), 55-61.

2003d. "Listening Attentively to Cultural Fragmentation. Tradition and Composition in Works by East Asian Composers." the world of music 45, no. 2: 7-38.

2003e. "Ein Feld 'entorteter' Identitäten. Essentialismus und Differenz in der neuen Musik Chinas und Japans." In Reflexionen der kulturellen Globalisierung - Interkulturelle Begegnungen und ihre Folgen (Discussion Paper SP III 2003-110), edited by Ute Hoffmann, 105-125. Berlin. Also published in Musik-Wissenschaft an ihren Grenzen. Festschrift Manfred Angerer, edited by Dominik Schweiger, Nikolaus Urbanek and Michael Staudinger, 187-205. Vienna: Lang, 2004.

2004a. "Cultural Accommodation and Exchange in the Refugee Experience: A German Jewish Musician in Shanghai." Ethnomusicology Forum 13, no. 1:119-151.

2004b. "Gravitation und Differenz? Die interkulturelle Dimension in neuer ostasiatischer Musik seit den 1990er Jahren.” In welt@musik. Musik interkulturell (Veröffentlichungen des Instituts für Neue Musik und Musikerziehung Darmstadt, Vol. 43), 72-86. Mainz: Schott. 2004c. "Zhongguo shi'er yin yinyue zai Shanghai de dansheng. Woerfugang Fulanke'er - zuoqujia, yinyuejia, jioashi." [The Birth of Twelve-Tone Music in Shanghai. Wolfgang Fraenkel - Composer, Musician, Teacher] Yinyue Yishu (The Art of Music) 98, no. 3: 56-63; no. 4: 28-32. 2005a. "Vom gekerbten zum offenen Raum. Gedanken zum Verhältnis von Schichtengewebe, Intertextualität und kulturellem Kontext in der Musik." KunstMusik no. 4: 54-62.

2005b. "Beyond Cultural Representation. Recent Works for the Asian Mouth Organs sho and sheng by Western Composers." the world of music 47, no. 3: 149-171.

2005c. "Aurale Überlieferung und Verschriftlichung in der Musik von Yūji Takahashi und José Maceda. Zur Methodik einer interkulturellen Kompositionsgeschichte." In Oralität, klingende Überlieferung und mediale Fixierung: Eine Herausforderung für die Musikwissenschaft (Musicologica Austriaca, Vol. 24), edited by Andrea Lindmayr-Brandl, 39-66. Vienna: Präsens. 2006a. "Zwischen Mythos und Kooperation. Transkulturelle Rezeption westlicher Komponisten in historischer Perspektive." In Neue Zeitschrift für Musik 167, no. 3: 27-31.

2006b. "Lambivalenza del localismo nella musica colta/The Ambivalence of Localism in Art Music." Rassegna no. 83:128-133.

2007a. "Interkulturelles Komponieren als Herausforderung. Transformation, Bruch und Mythoskritik in Werken für die japanische Mundorgel shō." In Orientierungen. Wege im Pluralismus der Gegenwartsmusik (Veröffentlichungen des Instituts für Neue Musik und Musikerziehung Darmstadt, Vol. 47), edited by Jörn Peter Hiekel, 63-84. Mainz: Schott. 
2007b. "Zur kompositorischen Relevanz kultureller Differenz. Historische und ästhetische Perspektiven." In Musik und Globalisierung. Zwischen kultureller Homogenisierung und kultureller Differenz (musik.theorien der gegenwart 1), edited by Christian Utz, 29-49. Saarbrücken: Pfau.

2007c. "Warten und Erinnern. Zu Kunsu Shims Klavierstücken trace, elements (II) und 54 things." In Kunsu Shim, trace, elements (II) | 54 things, Composers ArtLabel, cal-13022. Supplementary booklet: $2-6$.

2008a. "On the Compositional Relevance of Cultural Difference. Historical and Aesthetical Perspectives." In Musik-Kulturen. Texte der 43. Internationalen Ferienkurse für Neue Musik 2006 (Darmstädter Diskurse, Vol. 2), edited by Jörn Peter Hiekel, 23-41. Saarbrücken: Pfau. 2008b. "Klangkadenz und Himmelsmechanik. Alterität und Selbstreferentialität in Helmut Lachenmanns Das Mädchen mit den Schwefelhölzern und Concertini." In Musik als Wahrnehmungskunst. Untersuchungen zu Kompositionsmethodik und Hörästhetik bei Helmut Lachenmann (musik.theorien der gegenwart, Vol. 2), edited by Christian Utz and Clemens Gadenstätter, 125-152. Saarbrücken: Pfau.

2009a. "Bewegungen in der 'Raum-Zeit' des Ligeti-Kosmos. Modelle von Polymetrik und Konfliktmetrik in historischen und kulturellen Perspektiven." In Kunst und Wissen in der Moderne. Festschrift Otto Kolleritsch zum 75. Geburtstag, edited by Andreas Dorschel, 187-233. Vienna: Böhlau.

2009b. "Interkulturelle Rezeption am Beispiel Isang Yuns." In Ssi-ol Almanach 2004-09, edited by Walter-Wolfgang Sparrer, 246-254. Berlin: Internationale Isang Yun Gesellschaft. 2009c. "Die Wiederentdeckung der Präsenz. Interkulturelle Passagen durch die vokalen Räume zwischen Sprechstimme und Gesang." In Passagen: Theorien des Übergangs in Musik und anderen Kunstformen (musik.theorien der gegenwart, Vol. 3), edited by Christian Utz and Martin Zenck, 31-69. Saarbrücken: Pfau.

2009d. "Stratifizierung und Analyse. Methoden und Diskurse interkulturellen Komponierens." In Freiräume und Spannungsfelder. Positionen der zeitgenössischen Musik heute, edited by Marion Demuth and Jörn Peter Hiekel, 131-151. Mainz: Schott.

2010a. "Neue Musik in Ostasien als Kritik essentialistischer Kulturmodelle. Wege zu einer interkulturellen Kompositionsgeschichte." In Kulturelle Identität(en) in der Musik der Gegenwart. Kolloquium des Europäischen Zentrums der Künste Hellerau im Rahmen der 18. Dresdner Tage der zeitgenössischen Musik in Kooperation mit der Hochschule für Musik Carl Maria von Weber Dresden, edited by Marion Demuth and Jörn Peter Hiekel, 173-195. Saarbrücken: Pfau.

2010b. "Kunstmusik und reflexive Globalisierung. Alterität und Narrativität in chinesischer Musik des 20. und 21. Jahrhunderts." Archiv für Musikwissenschaft 67, no. 2: 81-103.

2010c. "Musik von einem fremden Planeten? Variationen über Struktur, Wahrnehmung und Bedeutung in der Musik des 20. und 21. Jahrhunderts." In Musiktheorie als interdisziplinäres Fach. 8. Kongress der Gesellschaft für Musiktheorie Graz 2008 (musik.theorien der gegenwart, Vol. 4), edited by Christian Utz, 377-399. Saarbrücken: Pfau.

2012a. "Isabel Mundry's Ich und Du and the Elusiveness of Musical Meaning. Variations on Music, Body, Structure, Perception." In Bodily Expression in Electronic Music, edited by Andreas Dorschel, Gerhard Eckel, and Deniz Peters, 97-113. New York: Routledge.

2012b. "Musikästhetische Voraussetzungen kultureller Differenz in der neuen Musik Chinas und Japans." In Musik und kulturelle Identität. Bericht über den XIII. Internationalen Kongress der Gesellschaft für Musikforschung Weimar 2004, Vol. 2, edited by Detlef Altenburg and Rainer Bayreuther, 629-640. Kassel: Bärenreiter. 
2013a. (together with Frederick Lau) "Introduction: Vocal Music and Reflexive Globalisation in Contemporary Music Practices." In Vocal Music and Contemporary Identities. Unlimited Voices in East Asia and the West, edited by Christian Utz and Frederick Lau, 1-22. New York: Routledge.

2013b. "The Rediscovery of Presence. Intercultural Passages through Vocal Spaces between Speech and Song." In Vocal Music and Contemporary Identities. Unlimited Voices in East Asia and the West, edited by Christian Utz and Frederick Lau, 45-75. New York: Routledge.

2013c. "Erfundene Traditionen und multiple Identitäten. Tendenzen reflexiver Globalisierung in der neuen Kunstmusik." Österreichische Musikzeitschrift 68, no. 4: 51-60. Also published in English as: "Identity Criticism and Reflexive Globalisation in New Art Music." World New Music Magazine no. 23 (2013): 26-34.

2014a. "Neo-Nationalism and Anti-Essentialism in East Asian Art Music since the 1960s and the Role of Musicology." In Contemporary Music in East Asia, edited by Hee-Sook Oh, 3-29. Seoul: Seoul National University Press.

2014b. "Polyphonies of Musical Meaning. Multiple Voices in My Works Zersplitterung (2002) and telinga - mulut (2009) in the Context of a Globally Informed Compositional Practice." Unpublished manuscript.

2015. "Paradoxa, Sackgassen und die 'geschichtliche Wirklichkeit' interkultureller Rezeption. Hugo Riemanns Auseinandersetzung mit der ostasiatischen Musik im Kontext der Diskussionen über eine 'japanische Harmonik' im Zeitraum 1900-1945.” Archiv für Musikwissenschaft 72, no. 3: 188-212.

2016a. "Verflechtungen und Reflexionen. Transnationale Tendenzen neuer Musik seit 1945." In Lexikon Neue Musik, edited by Jörn Peter Hiekel and Christian Utz, 135-154. Stuttgart: Metzler/Kassel: Bärenreiter.

2016b. "China, Taiwan, Hong Kong." In Lexikon Neue Musik, edited by Jörn Peter Hiekel and Christian Utz, 200-209. Stuttgart: Metzler/Kassel: Bärenreiter.

2016c. "Kompositorische Konstruktion kultureller Alterität als Kritik von 'Kanonizität'. Eine vergleichende Studie von Tan Duns Marco Polo und Helmut Lachenmanns Das Mädchen mit den Schwefelhölzern." In Ein Ort für das Wagnis. Die Hellerauer Akademien für experimentelles Musiktheater, edited by Marion Demuth, 66-75. Saarbrücken: Pfau.

2018. "Transnationale Verflechtungen in der Musik der 1950er und 1960er Jahre. Henry Cowell, Toshirō Mayuzumi und Luciano Berio im Kontext des 'Cultural Cold War'." Archiv für Musikwissenschaft 75, no. 2: 135-162.

2019. "Nonsimultaneity of the Simultaneous. Internationalism and Universalism in Postwar Music until the 1970s." In Decentering Musical Modernity. Perspectives on East Asian and European Music History, edited by Tobias Janz and Chien-Chang Yang, 207-245. Bielefeld: transcript.

2020. "The Beginnings of Transnational Musical Modernity. Early Twentieth-Century Reception of Traditional Japanese Music in Works by Maurice Delage and Shukichi Mitsukuri." In Understanding Musics: Festschrift on the Occasion of Gerd Grupe's 65th Birthday (Graz Studies in Ethnomusicology), edited by Malik Sharif and Kendra Stepputat, 103-124. Düren: Shaker. 



\section{Index}

Aalst, Jules A. van; Chinese Music 195, 198, 200

Abbate, Carolyn 235, 362; "Music - Drastic or Gnostic?" 55-56

Abe no Suehisa; Gaku ka roku 306

Abramović, Marina 257

Academy of Arts (Akademie der Künste Berlin) 170

action notation 257

Adami, Giuseppe 198

Adler, Ferdinand 169, 173, 177, 187

Adorno, Theodor W. 25, 29, 57, 66, 118; Philosophy of New Music 82

aesthetics $26-27,38,40,44,47,59,61-66,69$, $71-72,75,77,83,94,112,114,134,136-137$, $143,156-157,167,170,206,210,212-213$, $215,217,234,238,241,269,303,327,333$, $338,340-341,351,354,402$; aesthetics of genius 29; Chinese 280; Daoist 272; East Asian 396; Japanese 137, 260-261, 295; pan-Asian 127, 275; Western 35, 261, 274

Africa 26, 28, 34, 49-50, 53, 55, 70-72, 96, $121,130,134,137-138,206,337,363-366$, $368-369,375-377,379-381,384$

Agawu, Kofi 364

agencement (fabric) 437

agung (Philippine nipple gong) 217, 219

Aid Association of German Jews (Hilfsverein der Juden in Deutschland) 169, 173

Ainu (northern Japanese indigenous people) 358

aitake (chords of $\rightarrow$ shō in $\rightarrow$ gagaku) 125, 164, 260, 290-291, 295-298, 300, 303, 306, 312, 314,398 ajaeng (Korean arched zither) 139, 206

Aka Pygmies (Central African ethnic group) $138,363,365-366,379-380$

Akutagawa Yasushi 127

alap (unmeasured introduction in Indian rāga music) 88

Albeniz, Isaac 83

Albertson, Dan 217

aleatoricism 114, 128, 163

alienation 62, 149, 282, 335, 394

Alliance to Promote the New Order in the Musical World (Gakudan shintaisei sokushin dōmei) 103

alterity $34,36,42-44,46,67,139,152-153$, $160,166,185,206-207,212-213,235,268$, $308-310,322-323,328,330,333,335,364$, 411,423

alternative modernities $\rightarrow$ modernity amadinda 138, 363-364, 370

ambiguity 12, 134-135, 159, 221, 234-235, 238, $314,332-333,338,382,390,392,395-396$, 411, 437

ambivalence 55, 75, 92, 206, 346, 388

Ambros, August Wilhelm 58, 195, 197-198

American Musicological Society (AMS) 95

Ami (Taiwanese indigenous people) 269-270, 273-274

Amiot, Joseph-Marie 293

Ampo Pact (Treaty of Mutual Cooperation and Security between the United States and Japan, 1960) 120, 129

Andersen, Hans Christian 319, 331-333

Ansermet, Ernest 92

anthropology 59, 61, 75, 126, 221, 337-338 
anti-Semitism 77

Anti-Spiritual Pollution Campaigns (Qingchu jingshen wuran) 201, 225

Aoi no ue (Japanese nō play) 354

Aomori (Japanese prefecture) 354-355

Apaches (Paris composers' group) 83, 85-86

Aperghis, Georges 75

Arab music 77, 96, 125, 143, 298

archaism 27, 40, 45, 77, 80, 126, 136, 139, 147, 149, 204, 210, 223, 232-233, 241, 261, 267,

$276,278,290,298-300,306-307,338,345$, 354-355, 358, 406

Arezzo, Guido of; Micrologus de musica 54

Aristoxenos; Elementa Harmonica 359

Arom, Simha 134, 364; African Polyphony and

Polyrhythm 366, 368, 375, 380

ars subtilior 54, 138, 363

art music 12, 25-29, 31-35, 37-41, 43, 45, 49, $51,58-59,61,63,65,73,77-78,82,116,135$, $138,146,206,235-236,264-265,267-269$, 281, 287, 364, 429, 433

Artaud, Antonin 33 artificial intelligence 363

Asia 12, 26-28, 34-36, 49-50, 67-68, 72, 75, $78,82-83,86,96,116,119,121,123,137$, 139-140, 153, 158, 161, 163, 166-167, 179, 182-183, 189, 194, 198, 206-207, 209-213, 219-221, 229-230, 233, 235-238, 249, 259, 263-265, 267, 275, 278, 280, 284, 286-287, 293, 299-300, 304, 340, 348, 350, 399, 412, 417, 429; East Asia 25, 39-40, 49, 53, 60, $116-118,137,139,142,146-147,153,155-157$, 159, 166-167, 172, 186, 206-207, 209-212, 228, 235-236, 238, 241, 249, 251, 259, 337, 396-397, 418, 429; Southeast Asia 215, 220-221, 259, 307, 355

Asia Pacific Festival 408

Asian Art Ensemble 146

Asian Composers League (ACL) 12, 275, 408

AsianCultureLink 146

assimilation 52-53, 77

Assmann, Aleida 29

Assmann, Jan 29, 38, 41-42, 289

Association for Japanese Music Culture

(Nihon ongaku bunka kyōkai) 103 Atayal (Taiwanese indigenous people) 282 Atlas Ensemble 146 atonality $65,161,170,182,188,238,281-282$,

365

Atumori (Japanese nō play) 354

auditory streaming / stream segregation

370-371, 430-433, 435

aura 139, 293-295, 308-310, 333, 354

aurality (see also orality) 54, 56, 76, 137, 139,

$215,233-234,253,263,310,330,341,345$,

$362,364,371$

Austin, Larry 383

authenticity $34,43,57,77-78,81-82,149,159$,

$196,198,200,210,215,269,307,334,397$,

411

auzān (rhythmic cycles in $\rightarrow$ Arab music) 143 avant-garde 12, 45, 60-62, 102, 115-116, 123,

$127,129,135,161,209,225,237,258,266$, $269-270,272,275,280,334,338$

Avshalomov, Aaron 165, 167, 177, 185-187, 192;

Piano Concerto 161; The Great Wall (Meng Jiang Nü) 161

Avshalomov, Jacob 186

ba yin (ancient Chinese classification of sounds) 290

baban (Chinese suite type) 398

Babbitt, Milton 116

Bach, Johann Sebastian 25, 180, 187, 189, 208, 221, 229, 383; Brandenburg Concerto no. 5 BWV 1050 177; Chromatic Fantasy and Fugue BWV 903 177; English Suite in $\mathrm{G}$ minor BWV 808 172; Prelude in $\mathrm{C} \sharp$ minor BWV 849 (The Well-Tempered Clavier, vol. 1) 237, 385; "Goldberg Variations" BWV 988 27, 286

Bakhtin, Mikhail 428

Balanchine, George 127

Bali 69, 71, 97, 120, 138, 219, 363

balingbing $\rightarrow$ pakkung / balingbing

Banda Linda (Central African ethnic

group) 134, 138, 363, 366

bangdi (Chinese horizontal flute) 385-387

bangibang (Philippine wooden stick) 219

Barmas, Issay 168

Barney, Matthew; Drawing Restraint 9298

Barrow, John 195-198; Travels in China 195-

197, 202

Barthes, Roland 361-362 
Bartók, Béla 27, 30, 32-33, 59-61, 65, 67, $75-78,80,82,96,112,159,182,270,384$, 390

Bashō Matsuo 91-92, 105

basic pulse 366, 368-369, 372, 377

Bathorie, Jane 92

Beck, Ulrich 35

Beckett, Samuel; sans (Lessness) 225; The Unnamable 132

Beethoven, Ludwig van $28,40,66,78$, $175-178,180,187,204,208,380-383$;

Romance no. 2 F major op. 50 177; Symphony no. 1 178; Symphony no. 3 "Eroica" 381-383; Symphony no. 5 175; Symphony no. 6 "Pastorale" 175; Symphony no. 9205

Beifeng bo zhou (poem from the $\rightarrow$ Shijing) 241

beiguan (Chinese traditional musical genre) $268,275,279,282$

Beijing 34, 49, 158-159, 161, 169, 175, 184, 190, 195-196, 205, 223, 238, 240-241, 243, 267-268, 270, 275, 282, 348-351, 429

Beijing Opera $\rightarrow$ jingju

Bekker, Paul 56; Musikgeschichte als Geschichte der musikalischen Formwandlungen 51

Bellman, Jonathan 37

Bénarès (Varanasi) 86

Berberian, Cathy 129; Stripsody 341

Berg, Alban 97, 167

Berio, Luciano 74, 114, 117-118, 120, 122; Coro 132, 134; Folk Songs 130; "Meditation on a Twelve-tone Horse" 132; Passaggio 130; Sequenza III 341; Sequenza XIV 134; Sinfonia 129, 131-134; Traces 130, 133

Berlin Philharmonic Orchestra 168

Berliner Festspiele 121, 404

Berlioz, Hector 178, 208

Bernstein, Leonard 120, 127

Berntsen, Anne-Lise 353

Bertelsmann Foundation 28

Beulah Land 395

Bhabha, Homi K. 43, 385

Bhagwati, Sandeep 146, 153; Illusies van harder en zacht 149-150; Traces and Shadows 149; Wörterbuch der Winde 149

Bhatia, Vanraj 120

Bialas, Günther 278 bianzhong (archaic Chinese bronze bell set) 204

Birman, Meir (Meyer Eliash) 172

biwa (Japanese lute) 166, 213, 260-261, 292, 306, 345; satsuma-biwa 206, 212

Björk; Drawing Restraint 9 (see also Barney, Matthew) 298

Blacher, Boris 118, 120

Blacking, John 52-53; How Musical Is Man? 52

Bloch, Ernst 58, 60, 62, 82

Blum, Stephen 53, 56

Bo Yang 264

Boas, Franz 59, 100

Body, Jack 408

Boethius, Anicius Manlius Severinus 359

Bons, Joël 146

bonshō (Japanese temple bells) 127, 294

Borio, Gianmario 62

Botti, Susan 349-350

Boulez, Pierre 62, 74-76, 114-115, 135, 170, 353; Le marteau sans maître 339; Musikalische Technik 394; Rituel 375; Second Piano Sonata 33

Bouliane, Denys 366, 370

Bovet, Frederic 'Fritz' 200

Brahms, Johannes 177, 180, 270; Klavierstücke 383, Symphony no. 3383

Brandt, Willy 121

Brecht, Bertold 130

Bregman, Albert 435; Auditory Scene Analysis $327,370,432$

Britten, Benjamin 53, 75, 125; Curlew River 294 Brown, Julie 77

Bruch, Max 162

budaixi (Taiwanese puppet theater) 270

budingxing (indeterminacy) 272

bugaku (Japanese traditional dance) 127-128, 134, 227, 294

bunmei (civilization) 102

bunraku (Japanese puppet theater) 127, 345-347

Bunun (Taiwanese indigenous people) 282

Bürger, Peter 62

Burian, Emil František 98

Burke, Peter 43, 386

Burney, Charles 196

Buschmann, Christian Friedrich Ludwig 293 
Caccini, Giulio; L'Euridice 359; Le nuove musiche 359-360

cadential sound (Kadenzklang) 139, 311-312, $322-323,331,333$

Cage, John 32, 60, 74, 122, 124, 135-137, 140, 148, 213, 223, 225, 255, 257, 281, 402; Aria 129, 341; 4'33" 212; 45' for a Speaker 434; Fontana Mix 129; One 303; "Number Pieces" 303, 308; The Ten Thousand Things 429, 434; $\mathrm{Two}^{3}$ 303; Two 303; 108303

Cai Yuanpei 179

Caifeng Yuefang (Chai Found Music Workshop) 146, 278-279, 285-286, 398

calligraphy 191, 270, 274, 295, 350, 396

canon 11, 25-26, 41, 203, 298, 305, 308, 436

canonicity 26,45

canonization 26-27, 63

Canton 96, 177, 196-197, 202, 279

Cantonese Opera 96

Cardew, Cornelius 228

Carnatic music 89

Carnegie Hall 28, 94, 127

Carter, Elliott 118, 120; Symphony 375

Cavallotti, Pietro 62, 328, 333

censorship 205, 287

Central Africa 134, 138, 363-364, 366, 369, 380 ch'angjak kugak (Traditional Korean Contemporary Music) 249

Ch'ŏn Sangbyŏng; Kŭ nalŭn (This Day) 414, 416

Chang Sa-hun 414

Chang, Lynn 205

changbai (Beijing Opera voice) 348

changdan (rhythmic cycles in Korean traditional music) 251, 398

changgo (Korean hourglass drum) 251, 253-254

chant $139,215,233,243,275,279,342-343$, $345,355,358-359$

Chao Ching-Wen 265

Chao Mei-Pa (Zhao Meibo) 187

chaos theory 138, 363

Cheetham, Edgard 95

Chen Ching-Gang 270

Chen Duxin 156

Chen Gexin 180-181

Chen Mao-Shuen 265
Chen Mau-Liang 265

Chen Mingzhi 166

Chen Qigang 236; Poème Lyrique II 241

Chen Sa-Zhi 265

Chen Shi-Zheng 349

Chen Xiaoxi 265

Chen Xiaoyong 263; Circuit 241; Invisible Landscapes 241-242; Speechlessness, Clearness and Ease (Yin, xi, yi) 241, 244; Yang Shen 241

Chen Xujing 156

Chen Yi 236

Chen Yingshi 292

Chen Yu-Chou 265

Chengdu 169

Chiang Kai-Shek 194

Chien Nan-Chang 265

Chien Shan-Hua 265

Chikamatsu Hanji; Imoseyama onna teikin (Mount Imo and Mount Se: A Parable of Female Virtue) $\mathbf{3 4 7}$

chimeric assignment $327,433,435$

Chin Unsuk 36

China Can Say NO! (Zhongguo keyi shuo bu!) 237

China Symphonic Orchestra (Zhongguo Jiaoxiang Yuetuan) 175-176, 178

China 25, 27, 33, 35, 37, 40, 68, 71, 78, 80-82, $96,103,124,146,155-156,159-161,164-$ 169, 175-188, 194-205, 225, 236-237, 243, $248,263,265,267-268,274,277-279,286$, $307,357,363,398,400,435$

Chinese Civil War 157, 170

Chinese opera 96, 223, 238, 343

Chinese Symphony Orchestra 157-158, 166

Chinese Youth Orchestra (Zhongguo Qingnian Yuetuan) 177-178

Chineseness 36, 240

Chŏng Hoegap; Theme and Variations (Chujewa Pyŏnjugok) 249

Chongming (Chinese island) 223

Chopin, Frédéric 58, 180, 366, 380-381; Ballade no. 4 in f minor op. 52383 chōshi (introductory parts in $\rightarrow$ gagaku) 128 , 227, 290, 292, 295, 307, 406

Chou Wen-Chung 35, 78, 206, 211, 396; The Willows are New 36; Yü Ko 36 
Christou, Jani 338, 353

$\mathrm{Chu}$ (ancient Chinese kingdom, c. 800-223 BCE) 80

chuanju (Sichuan Opera) 80, 240

Chuantong yu zhanwang (Tradition and Prospect) 267

Chun Doo-Hwan 250

Chung Il-Ryun 146

Chung Yiu-Kwong 265

CIA (Central Intelligence Agency) 115-117, 120-122

Clark, Tony 404

classical music 25-29, 192, 252

cliché 27,113

close reading 138, 211

closure 330

Cloud Gate Dance Theater (Yunmen Wuji) 266-267, 270, 273, 275; Wu Feng 272

Club of Poets, Essayists, Novelists (PEN) 64 cluster 38, 94-95, 98, 164, 303, 324-325

Coca-Colonization 34

codification $342,360-362$

coexistence 38, 155, 163, 166, 213, 237, 396

Cold War 12, 60, 63, 66-67, 101, 114-118, 121, $123-124,129,133-134,263-264,269,340$

Coleman, Gene 117; Yago 335

collage 70, 72, 129, 132-133, 370, 394

colonialism 31, 50, 52-53, 55, 58, 66, 127, 139, $156,167,173-175,197,205,207,215,219$, $228,263,266$

Commission for International Exchange Concerts 95

Committee for Assistance of European Refugees in Shanghai $\rightarrow$ Speelman committee) 169

comparative musicology 59, 67, 74, 97, 342-343

complexity (musical) 48, 54-55, 88, 100, $133,147,149,165,208,221,237,327,341$, $345-346,363-364,372,379,381,383$, 395-396, 410, 429

composition $38,45,48,51,53-58,61,71,88$, 116-117, 125, 187, 362, 368; critical composition 300; intercultural composition 38$46,56,82,134-137,142-143,149,211,259$, 261, 289, 308, 392; sound composition 93 , $98,250,299,385$
Confucian ritual music (see also Jikong dianli) 147

Confucianism 147, 155, 279-280

Confucius 241

Congress for Cultural Freedom (CCF) 115-118, 120-121, 123, 133

Conklin, Harold C. 217

connective structure 29

connectivity $287,341,402$

conservatory style 147, 153, 165

constants (pitch collections of even-sized intervals) 314

container model 35

Conte Rosso 169

Contemporary Music Ensemble Korea

(CMEK) 408, 412

contemporary Xchange 146

contextual analysis 53, 235

continuants (pitch collections of steadily increasing interval sizes) 314

Convention of Geneva 63

Convention of The Hague 63

convergence $46,73,101,113,118,254,338,361$, 372,423

Cook, Nicholas 47, 127; Cambridge History of Twentieth-Century Music (see also Pople, Anthony) 49

Corelli, Arcangelo 270

corporeality 237

cosmopolitanism 49, 64, 169, 275

Couchoud, Paul-Louis; Au fil de l'eau 91

Council for Cultural Affairs 267

Council of Cultural Planning and Development (CCPD) 267

counterculture 30,210

counterpoint 30, 55, 100, 137, 169, 180, 185, $187-189,311,327,359,394,428,433-434$

Cowell, Henry 74, 82-83, 93-101, 112-114, 117-118, 120-127, 249, 281; American Melting Pot 98; Amiable Conversation 96; Atlantis 97-99; Celtic Set 98; Concerto for Harmonica 123; Concerto [no. 1] for koto and Orchestra; Concerto no. 2 for koto and Orchestra 123; Four Assorted Movements 98; Mosaic Quartet 98; New Musical Resources 95; Ongaku 123-126, 127, 134; Ostinato Pianissimo 98; Persian Set 98; 
Pulse 98; Rest 98; Some Music 98; Symphonies no. 11 to 15 98; Symphony no. 1398 ; The Nature of Melody 97; The Universal Flute 123; United Quartet (String Quartet no. 4) 98,113

Crawford-Seeger, Ruth; Chinaman Laundryman 96

Crossley-Holland, Peter 120

Crumb, George 62, 74, 225, 282

cultural difference $\rightarrow$ difference

cultural globalization $\rightarrow$ globalization

cultural history 59, 63, 257, 338, 351

cultural memory 29, 41-42, 250, 289, 299, 362

cultural pessimism $30,50-51,64,73$

cultural practice 29,35

cultural racism 38

Cultural Revolution 78, 155, 158, 161, 165-166, $175,185,200,223,225,267$

cultural self $38,40,207,322$

cultural studies 29

culturalism 43, 254, 261, 289

Curran, Alvin 74

Cvetko, Dragotin 120

Czernowin, Chaya 385-387, 389-390, 392;

Die Kreuzung 300, 302-303, 335; Excavated Dialogues-Fragments 385, 387, 389

D'Indy, Vincent 83, 158

Dahlhaus, Carl 51, 115-116

Dai Hong-Hsuan 265

Dainihon sakkyokuka kyōkai (Great Japanese Association of Composers) 102

daluo (large Chinese opera gong) 270

Damshäuser, Berthold 418

Dan Ikuma 127

Daniélou, Alain 120-121

Daoism 204, 280

Daoist ritual music 348

daqu (Chinese Tang-Dynasty court music) 276

Darmstadt Summer Course 33, 45, 60, 65, $115-116,163,333$

daruan $\rightarrow$ ruan

Dauer, Alfons 284, 366

Davies, Peter Maxwell 338; Eight Songs for a Mad King 341
Debussy, Claude 29-30, 33, 55, 69, 86-87, 102, 113, 138, 160, 177, 182, 187, 208, 366; La mer 132; Pagodes 86; Pelléas et Mélisande 83

declamation 159, 343, 345, 349, 351, 353, 360, 362

deconstruction $26,43,57,136,149,310$, $332-333,337,388,436$

Delage, Maurice 69, 83-94, 112-113; Conté par la mer 85; Quatre poèmes hindous 85-86, 88; Ragamalika 86, 88-90, 92-93; Sept Haï-kaïs 86, 89, 91-93

Deleuze, Gilles 257, 333, 402; A Thousand Plateaus (see also Guattari, Félix) 394, 437

Délibes, Léo; Lakmé 88

Demian, Cyril 293

Deng Erjing 181

density referent 368

dentō / denshō 27

Derrida, Jacques 333, 337, 428

descriptive notation 48,233

devadasi (Indian temple prostitutes) 88-89

Devi, Indira 177, 192

dhārani (mantra) 226

dialogue 38-39, 41-42, 146, 163, 238, 272, 279, 385-386, 393, 398

diaoshi ("mode") 157

Dickinson, Emily 286

difference $37,41-44,46-47,53,67,88,94$, $114,139-140,166,254,263,303,331,349$, $359,365,385,410$; cultural difference 12 , $33-34,38,67,71,78,80,113,142,206-235$, 237, 241, 261, 286, 307, 335, 396-397, 407, 429

digitalization 29, 34, 45

Ding Shande 180; Long March Symphony (Changzheng jiaoxiangqu) 159, 248

Dirlik, Arif 31, 35

discursivity 208

displacement dissonance $377,381-382$

dissonance $65,114-115,125,310,375,378$, 380-384

diversification $26,33,57$

dizi (Chinese horizontal bamboo flute) 149, $157,165,278,280,386,398$

dodecaphony 102, 161, 163, 165-166, 170, 189, 191, 433, 437 
Dongfang huahui (Eastern Painters) 266

double coding 312, 333

Draeger, Hans H. 120

Dreifuß, Alfred 175, 178

drone 88-89, 92, 100, 113, 215, 219-221, 238, 304, 413

Du Wen-Huei 265

Duan Pingtai 181, 184

dudka (Russian shawm) 76

Dufay, Guillaume 432

duikou chang (Chinese antiphonal singing) 159

Dukas, Paul 158

E Juba (popular song from South Sudan) 376

East Asia $\rightarrow$ Asia

East India Company 86, 197

East-West Music Encounter Conference and Festival (Tokyo 1961) 117-122, 124, 127, 129

Eco, Umberto 136

Edo Culture 231

Eggen, Christian 353

Eggert, Marion 414; Wind und Gras 415

Eichheim, Henry 74

Eimert, Herbert 114

Einem, Gottfried von 120

eishō (category of vocal delivery in traditional Japanese music) 345-346, 348

Elberfeld, Rolf 32, 137, 389, 397

electroacoustic music 286

electronic music / live-electronics 70-71, 119, $127,135,152,254,272,277,286,294,306$, $335,388,399-400,404,408,410,413,417$, 430, 435, 437

Elementarpulsation (elementary pulsation) 368

Elision Ensemble 147

Ellis, Alexander; "On the Musical Scales of Various Nations" 59

Eloy, Jean-Claude 74, 125, 143, 274; A l'approche du feu méditant 294; Anāhata I-III 294

embai (sliding tones in $\rightarrow$ gagaku) 291

embodiment 28, 293, 351, 384, 397

emic 343,384

Enigma (pop group) 268, 309

Enlightenment 29, 58, 66, 68, 221

ennui 30
Ensemble Modern 146, 326

ensemble on_line / PHACE 399, 404, 418

Ensslin, Gudrun 331

entangled history / histories $11,13,43,46,51$,

$57,60-62,82,113,117,135,233,337$

Erdmann, Martin 225

erhu (Chinese knee-fiddle) 27, 147, 149,

156-157, 225, 243, 280, 286, 386, 418

Escher, Mauritz Cornelis 363

essentialism $35-37,42-43,48,67,75,205$, 207, 220, 236-238, 240, 259; cultural essentialism 29-30, 35, 37, 39, 46, 61, 78, $128-129,135,213,233-234,238,253,337$, 396, 429; pluralistic essentialism 238; polarizing essentialism 237

Etenraku 101, 164, 192, 292, 294, 311-312, 332

ethnicity 31, 34, 37

ethnicization 30-31

ethnocentrism 46

ethnomusicology $34,50-51,60,215,266,268$, $307,341,343,364,375,377,384,392$

Eto Kimio 125-126

Eurocentrism 52, 59

Eurological discourse 38

Everett, Yayoi Uno 11, 294, 396

evolutionary musicology 337

Ewell, Philip A. 11

exile 59, 160, 167-168, 170, 182, 189, 194, 250

exoticism 27, 30, 36-37, 39, 43, 51, 61-62, 69,

$74,82-83,86-88,96,98,128,136-137,158$,

191, 198, 200-201, 205, 261, 298, 334

experimental music 130

expressionism 33

extended vocal technique(s) 98, 272

Falla, Manuel de 83, 112; El amor brujo 104

falsetto 349,423

fanshen ("subversion") 157

faqu (Chinese Tang-dynasty court music) 285

Far Eastern Jewish Central Information

Bureau (DALJEWCIB) 168-169, 172-173

Farfield Foundation 117

fascism 51, 58, 73, 75, 77

Fassini-Camossi, Edoardo 195, 198, 200

Fauser, Annegret 29-30

Felber, Erwin 177-178

Feldman, Morton 60, 223, 225 
feminism 31

Feng Zicun 157

Ferneyhough, Brian 54-55, 341, 397

Ferroud, Pierre-Octave 104

Fétis, François-Joseph 58

Feyerabend, Paul 44

Fibonacci series / proportions 328, 330

Finchum-Sung, Hilary Vanessa 12

Findlay, E. J. 124

fioraturi 360

Fish Leong (Liang Jingru); Wings of Love 195, 202

Foa, Arrigo 173, 177

folk song / folk tune $27,52,76,78,80,102$, 130, 139, 159, 182, 194-196, 198, 202-203, $229,237,255,266-267,295,343,348,385$, 433

folklorism 59, 61, 65, 103-104, 159, 182, 234, 269

Ford Foundation 117-118, 121, 127, 129-130

Forkel, Johann Nikolaus 58

Formosa incident 267

Forte, Allen 197; The Structure of Atonal Music 281

Fou Tsung ( $\mathrm{Fu}$ Cong) 178

Foucault, Michel 29, 31, 44

fractal geometry 138, 363

Fraenkel, Agnes 168

Fraenkel, Philipp 168

Fraenkel, Rosa 168, 170

Fraenkel, Wolfgang 160, 167-194; 3 Impromptus 171; Afunktionelle Musik 167, 170, 181, 188; Chinese Song 192, 195, 197; Der brennende Dornbusch 170; Der Wegweiser 170; Die 82. Sure des Koran 170-171; Drei Orchesterlieder 189-191, 192-193; Drei zweistimmige Praeludien 182, 189-190; "Grundprobleme der Neuen Musik" 188; Hölle-Weg-Erde 189; Music for String Quartet 170; "Music-Development?" 184-185, 188; Musik für großes Orchester 170, 189; Musik mit konzertanter Flöte 170; Musik mit obligater Oboe 170; Ombacha 177, 192; Sonata for Violin 170; Sonata for Violoncello 170; Symphonische Aphorismen 170; Symphony no. 3 189; Symphony no. 4 189; Three Masks (Im- provisation on a Japanese Theme) 177, 192;

Variationen und Fantasien über ein Thema von Arnold Schönberg 171

fragment / fragmentation 13, 26, 31, 35, 41, $50,68,71,80,137,189,207,211,213,215$, 223, 226, 241, 243, 295, 299-300, 314, $323,331,333,346,348,350-351,353-354$, 359, 361, 385-390, 395, 404, 414, 417-419, $422-423,431$

France $65,68,75,83,87,95,112,114,198,236$, 249

Franco-Flemish school 54

Frescobaldi, Girolamo 180-181

Freud, Sigmund 31, 43; Totem and Taboo 76 fu ("belly," phase of vocal sound production in Beijing Opera) 350

Fujian (Chinese Province) 195-196, 279

Fujieda Mamoru 259

Fujii Kiyomi 102

Fujikura Dai 36

fujo (Japanese female shamans) 355

Funa Benkei (Japanese nō play) 354

gagaku (Japanese court music) 68, 101, 103, $105,110,120,123-125,128-129,163-164$, $192,213,227,231,260,290,292,294-295$, $306-308,310,312,335,388,398,404,406$ Galilei, Vincenzo 359 gamelan saléndro 29 gamelan 29-30, 34, 55, 68, 86, 120, 128, 138, $146,215,231,272,422$

gandingan (Philippine nipple gong) 219

Ganges 86-87

gangsa (Philippine flat gong) 222

Gansu (Chinese Province) 195-196

gaohu (Chinese knee-fiddle) 398

Ge Ganru 233; Yi Feng 223, 225

gegenstrebige Harmonik 139

gendai hōgaku (Traditional Japanese Music of

the Present) 146, 164, 231, 249

gender 11, 26, 348

Genet, Jean; Les nègres 130

geno song 361

Genzmer, Harald 277

Germany 32, 64, 67, 74, 116, 146, 149, 167, 187, 211, 249-250, 274, 277, 282, 412

gestalt perception 376 
gestural types 262-263, 386, 397

gesture 49, 142, 147, 149, 165, 241, 255, 260,

$262-263,286,305,307,322,332-333,339$,

$359,362,385-386,388-391,396-398,408$,

$413,418,430-431$

gezaixi (Taiwanese Opera) 268, 270

gezaixian (Taiwanese knee fiddle) 398

giday $\bar{u}$-bushi (musical style of Japanese pup-

pet theater $\rightarrow$ bunraku) 345-348, 353-355,

361-362

Gil-Marchex, Henri 92, 104

ginsho (category of vocal delivery in traditional Japanese music) 345-346, 348

gitgit (Philippine three-string fiddle) 217

Glash, Joe 173

Glass, Philip 138

globalization 26, 29, 32-38, 42, 44, 49, 53, 56, $63,67,69,73,112-113,135,206,289,338$, 341; cultural globalization $12,33,57,211$, 385; grassroots globalization 31; reflexive globalization $28,35,38,45-46,392$

glocalization 34,75

Glock, William 120, 141

Goebbels, Heiner 143

Goebbels, Joseph 114

Goehr, Alexander 223

Goethe, Johann Wolfgang von 138, 196

gomaten (Japanese traditional vocal music notation) 359

gongche (Chinese traditional character notation) 195-196, 198, 202

Goodman, Nelson 388

Gostuški, Dragutin 120

Gottwald, Clytus 138

Gould, Glenn 27

grain of the voice 362

Grainger, Percy 55, 74

gravitation 46, 396

Great Depression 83, 95, 112

Grey, Madeleine 92

Grieg, Edvard; Piano Concerto 179

Grisey, Gérard; Les Espaces Acoustiques 33

grouping dissonance 380-382

Grupe, Gerd 34

gu wei jin yong, yang wei Zhong yong (Making

the past useful to the present and the

foreign useful for China) 203
Guan Yinshen 181

Guan Zhong; Guanzi 290

Guang ling san 437

Guangxi (Chinese Autonomous Region) 195$196,200,307$

Guattari, Félix 402; A Thousand Plateaus (see also Deleuze, Gilles) 394, 437

Gubaidulina, Sofia 233

Guggenheim Foundation 97

Guizhou (Chinese province) 307

Gulf War 143

Guo Nai'an 181

Guo Wenjing 82, 238; She Huo 79-81; Ye Yan

(Night banquet) 240

guocui $\rightarrow$ national essence

Guoyue gaijinshe (Society for the Improve-

ment of National Music) 156

gusli (Russian psaltery) 76

Guttmann, Oscar 168

gypsy music 77

haegŭm (Korean fiddle) 253

Hagiwara Sakutarō 112

haikai (Japanese poetic genre) 91, 113

haiku (Japanese poetic genre) 91-92, 105-106, 113

haka (Maori narrative form with mixed styles) $342-343$

hakase (Japanese traditional vocal music notation) 359

Hakka (Kejia) 268

Hall, Stuart 31

Hamel, Peter Michael 74

Hammelmann, Hans 198

Han (Chinese dynasty) 266

Han Byung-Chul 38-39, 61

Han Chinese 157, 248, 263-264, 268

Han Shaogong 80

Handel, George Frideric 187, 383; Passacaglia in G minor HWV 432/6 172

Handschin, Jacques 51

haozi (Chinese work songs) 159

Harbin Symphony Orchestra 172

Harewood, The Earl of 120

Harland, Philip 373

harmony / theory of harmony (see also gegenstrebige Harmonik, Japanese har- 
mony) 40, 88, 92-93, 102-106, 110-113, $125,127,139,143,147,157-159,162-164$, 169, 180-182, 187-189, 197, 200, 204, 237, 295-296, 300, 312, 314, 316, 320, 323-324, $333,337,359,365,381-382,385,392,400$, 404, 432-433

Harmondie 70

Harrison, Lou 74, 118, 120, 197

Harsányi, Tibor 104

Hart, Roy 338, 341

Hashimoto Kunihiko 166, 173; Akebono 162-163

Hasty, Christopher 376

hát bội (Vietnamese music theater) 29

Hatten, Robert 339, 386, 420

Havana Society for Contemporary Music 95

Hayasaka Fumio 83, 101; Ancient Dance (Kodai no bukyoku) 104, 164; Four Unaccompanied Songs to Poems by Haruo (Haruo no shi ni yoru yottsu no mubansō kakyoku) 110-111; Nihonteki ongakuron (Treatise of Japanese Music) 110; Piano shōhin shü (Piano Pieces) 109-110

He Fang 195, 203

He Luting 186; Buffalo Boy's Flute (Mutong duandi) 104, 159-160

Hebei (Chinese Province) 195-196, 237, 277

Hegel, Georg Wilhelm Friedrich 43, 50, 208 hegemony $38,61,75,134$

Heian Period (Japan, 794-1185 CE) 91, 155, 292, 307, 406

heightened speech 342-343, 351

heikyoku (Japanese traditional narrative genre) 345-346

Heile, Björn 49

Heilongjiang (Chinese Province) 195-196

Heinecke, Max 168

hemiola $363,366,371,375,382-383$

hemiólion 382

Henan (Chinese Province) 349

Herder, Johann Gottfried 38, 77

hermeneutics 29, 53

Herzfeld, Gregor 95

heterogeneity 50, 103, 185, 206, 248, 263, 323, $333,363,395-396$

heteroglossia 138 heterophony $88,100,103,149,157,196$, 208-209, 227, 237, 252, 260, 282, 291-292, $306,347,408,422-423,430$

Hezarfen Ensemble 146

hichiriki (Japanese double-reed wind instrument) 125, 163, 227, 291, 294-295, 300-301, 335

hierarchy 43, 54, 67, 112, 208, 213, 221, 255 , $263,309,385-386,395,402,407,422,428$, 432-437

Higho, high-hau (Chinese rowing song) 197 Hilfsverein der Juden in Deutschland $\rightarrow$ Aid Association of German Jews

Hindemith, Paul 60, 65, 161, 170, 180, 182, 187-189, 277

Hindu music 87

Hinkel, Hans 168

Hirano Kenji 345

Hirashima Masao 120

Hirayama Michiko 341, 354

hiroi (vocal delivery technique in Japanese $\rightarrow$ heikyoku) 346

historicism 50, 307

historicity 234, 308, 333

historiography $46-48,50-51,57-59,62,67$, $82,115,156,194,211,235,342$

Hobsbawm, Eric 31, 157

Hofstadter, Douglas R. 383

Hōgaku yonin no kai (Group of four for traditional Japanese music) 164

Holliger, Heinz 213

homogenization $33-34,38,57,78,81,208$, $212,215,338$

Honegger, Arthur 104, 112

Hong Kong 123, 169, 200, 275

Hong Sin-Cha 251

Hong Wen-Tsien 398

Hong Zhu 240

Hongkou (Jewish ghetto in Shanghai) 169170

Hood, Mantle 120-121, 215

Hopi (Native American group) 342-343

Hornbostel, Erich Moritz von 59, 74, 95, 97

Horthy-regime (Hungary) 77

Hosokawa Toshio 32, 125, 137, 206, 263, 303, 308, 396; Birds Fragments II 213, 295; Birds Fragments III 213, 295; Birds Fragments 
IV 295; Cloudscapes Moonlight 295; Garden at First Light 294-295; Koto-Uta 260-261; Landscape V 259-260, 295-297, 298; New Seeds of Contemplation (Mandala) 294-295; Seeds of Contemplation (Mandala) 294-295; Tokyo 1985 294; Utsurohi-Nagi 294-295; Utsurohi 294-295; "Wie ein Atem im Lichte" 295-296

Hou Chun-Ching 265

Hou Hsiao-Hsien 264

Hou Xiaoxian 264

Hovhaness, Alan 74, 118; Symphony no. 16 for kayagŭm, Korean instruments, and string orchestra 249

Howard, Keith 210

Hsu Po-Yun 265-267, 269; Han shi 267, 276-277; Pipa suibi 276; Sheng-si 277; Zhongguo xiqu mingxiang 275-276

Hsu Sung-Rung 265

Hsu Tsang-Houei 266, 270, 275, 277; Deux Poèmes 265

Hsu, William 178

Hu Shi 156

Huang Chun-Ming 267

Huang Hsin-Huei 412

Huang Lung-Yi 147-148

Huang Zi 186, 266; In Memoriam 175, 250

Huayan Buddhism 135, 137, 212, 303

Hubei (Chinese Province) 195-196, 204, 357

Huber, Klaus 282; Black Plaint 298-299; Die Erde bewegt sich aufden Hörnern eines Stiers [Ochsen] (The Earth Moves on the Horns of a Bull [Ox]) 143, 146; Miserere Hominibus 143

Huber, Nicolaus A. 282

hulusheng (mouth organ in $\rightarrow$ Yunnan / China) 307

Humperdinck, Engelbert 351

Humphrey, Doris 97

Hunan (Chinese Province) 80, 243

Hundhausen, Vinzenz 189-190; Chinesische Dichter in deutscher Sprache, mit 2 Bildern nach Originalen des Wang Ting-Dsche 190 huqin (Chinese knee fiddle) 277, 398 Hüttner, Johann Christian 195-198, 202; Nachricht von der Britischen Gesandtschaftsreise nach China 1792-94197
Hwang Byungki 249, 251

hybridity 13, 31-32, 36, 38, 40-41, 43-44, 61, $77,80,93,95,97,122,127,129,134,140$, $142,149,153,206,211,233,235,238,241$, 243, 251-252, 275, 289, 298, 333, 346, $350-351,381,385-386,411,413,418$

hybridization $26,42,49,80,122,124-126$, $299,338,351,361,386$

hyperculturality 39,44

hypolepsis $38,41-42,46,289,308,402,423$

\section{Ibert, Jacques 104}

Ibuse Masuji; Black Rain (Kuroi ame) 299 ibushi (vocal timbre in Japanese $\rightarrow$ giday $\bar{u}$ bushi) 142, 346

Ichiyanagi Toshi 206

identity $12,25,27,29-39,41-43,45,53,64$, $67,80,82,94,134,155,159,161-162,167$, 173, 175, 189, 194, 203-205, 207, 209, 211, 223, 254, 265-266, 274-275, 277, 280-281, 287, 289, 292-293, 338, 340, 385-386, 388-390, 397, 399, 402, 411; cluster identities 38; cultural identity 31, 36-37, 39, 117, 204-205, 237, 243, 248, 263, 268, 281, 303, 335; mixed identities 29, 39; multiple identities 38; patchwork identities 38

Ifukube Akira 103; Japanese Rhapsody (Nihon kyōshi kyoku) 104

Ikenouchi Tomojirō 207

ikigahe (changes of breath in Japanese $\rightarrow s h \bar{o}$ performance) 291, 312

Ikkyū Sōjun 140-141

Imai Tsutomu 346

imbroglio 366

immediacy 51, 148, 353, 386

imperialism 53, 58, 64, 66, 124, 173, 287

improvisation 54, 88-89, 143, 177, 192, 241, 251,272

in-between 43, 46, 217, 257

incommensurability $34,42,44-46,56,61,113$, $153,206,232,249,268,289,340,402,412$

India $27,34,40,51,68,82-83,86-89,95-98$, $113,119-120,123,137-138,146,149,177$, 197, 272

Indonesia 83, 98, 119, 123, 137, 146, 275, $411-412,418,422-425$ inherent pattern $364,370-371,380$ 
integration 35, 38-39, 49-50, 55, 57, 61, 67, 70, $73,77,80,97,101,124,127,138-139,159$, 163-166, 204, 206, 209, 213, 243, 270, 276, $284,306,320,333-335,363,410,437$

interconnectedness $12,66,73,117$ intercultural dialogue $\rightarrow$ dialogue intercultural composition $\rightarrow$ composition intercultural reception 135-138, 146, 209-211, 363

interculturality $11-13,26-27,32,34,36$, $38-40,42,44-48,51,53,56-57,62,75,82$, 95, 129, 134-139, 143, 146, 149, 153, 167, 194, 196, 203, 207, 209-213, 233-235, 249, 251, 255, 259, 261-263, 289, 293, 304, 308, 310, $333-335,337,342,359,362-363,365,382$, $384-385,392-393,396,402,404,411,413$, $423,429-430$

intermodulation 136

International (First, Second) 63-64

International Association for Cultural Freedom (IACF) 117

International Congress of Composers and Music Critics, Second (Prague 1948) 64, 116

International Council of Women 63

International Institute of Comparative Music Studies and Documentation (iicmsd) 121 International Institute for Traditional Music 121

International Phonetic Alphabet (IPA) 339, 342

International Society for Contemporary $\mathrm{Mu}$ sic (ISCM) 64, 92, 103, 112, 127, 164, 267, 278, 354

Internationale Isang Yun Gesellschaft (Isang Yun Society) 146, 211

internationalism 63-66, 83, 93-94, 104, 112, 117-118

internet 69, 205, 435

interpenetration $135,137-138,142,188,212$, $280,303,363$

intertextuality $45,393-395,410$

invented tradition 31, 75, 157

Iran 98,123

Iraq War 402, 407, 430

Irino Yoshirō; Music for Two Kotos 165 iro (vocal delivery technique in Japanese $\rightarrow$ gidayü-bushi) 345, 348

Irwin, Eyles 195, 197-198

Ishii Gorō 102

Ishii Maki 259

Ishikawa Kō 289, 293, 306, 404

isolationism $33,59,66,263$

Israel 49

Isukeyorihime 358

Italy $74-75,79,81,117-118,127,198,361$

Ito Noboru 102

Ives, Charles 223, 281, 370, 375, 383-384, 433; Life Pulse Prelude 383; Memos 383; Symphony no. 4 383, 395; The Fourth of July 366; The Unanswered Question 395; Universe Symphony 383

Jankélévitch, Vladimir 56

Japan Philharmonic Symphony Orches-

tra 120

Japan Society for Contemporary Music (JSCM; Nihon gendai ongaku kyōkai) 103

Japan $25,27,35,68,71,74,83,86,89$, 91-92, $96,98,101-106,112-113,117,119-120$, $123-127,129,136-137,140,146,155-156$, 159, 162-164, 172-174, 179, 182, 207, 212, 234, 249, 259, 261, 272, 275, 290, 292, 294, $296,298,300,340,354-355,359,404$

Japanese harmony (Nihonteki waseiron; see also harmony) 102, 104, 106, 110, 164 Japanese Symphony Orchestra 101 Japaneseness 229, 259, 261 Jasmine Revolution (molihua geming) 205 Java 29-30, 34, 55, 86, 97, 219, 363, 422 Jewish Club (Shanghai) 177 Jewish Cultural League (Kulturbund Deutscher Juden) 168, 173

Jeypore (Jaipur) 86 $j i$ (vocal delivery technique in Japanese $\rightarrow$ gidayu-bushi) 344-345, 348 ji iro (vocal delivery technique in Japanese $\rightarrow$ giday $\bar{u}$-bushi) 345

Jia Daqun; The Prospect of Colored Desert (Mo motu) 241

Jiang Kui 56

Jiang Wenye 159, 265

Jiang Zemin 200 
Jianglan yueji (Jianglang Music Group) 266

Jiangnan sizhu (South Chinese musical genre) 279, 398

Jiangsu (Chinese Province) 195-196, 198, 202-203

Jiangwan (district of Shanghai) 179-180

Jiangxi (Chinese Province) 159

jianzipu (Chinese cipher notation) 156, 196

jiaoxian (performance technique in Chinese pipa music) 243

Jikong dianli (Confucian shrine music) 147

jinghu (knee fiddle in Beijing Opera) 282

jingju (Beijing Opera) 49, 158, 161, 238, 240,

$243,267-268,270,275,282,348-351$

Jinmu 358

jiuta (Japanese traditional music genre) 103, 231

Joachim, Joseph 173

Joachim, Otto 173

Joachim, Walter 173

Jodjana, Raden Mas 97

Johnson, Lyndon B. 96, 130, 133

Jolivet, André 62, 68, 265

jōruri (Japanese traditional music genre) 231, 346

Joseon Period (Korea, 1392-1910) 250

jumping rope rhymes 342

Juszkiewicz, Anton; Melodje ludowe litewskie 76

kabuki (Japanese traditional music drama) 163

Kafka, Franz 424; Die Brücke 419-420; Eine Kreuzung 300

Kagel, Mauricio 74, 282; Anagrama 135; Exotica 136

kagok (Korean traditional music genre) 251253

Kainz, Josef 351

Kaiser, Georg 189

$k \bar{a} k$ (musical phrase in Korean court music) 408

kakari (vocal delivery technique in Japanese $\rightarrow$ $\rightarrow$ gidayu-bushi) 345, 348

kakebuki (introductory section in Japanese $\rightarrow$ gagaku) 227 kakegoe (calls of the drummers in Japanese $\rightarrow n \bar{o}$ theater) 355

$k a k k o$ (coordinating drum in Japanese $\rightarrow$ tōgaku) 299

Kalinnikov, Vasily 176

Kalipay (festival of the Philippine Hanunóo) 217

Kamakura Period (Japan, 1185-1333 CE) 307

Kambra, Karl 195, 197-198; Higho high-hau 197

kami (high pitch in Japanese $\rightarrow$ giday $\bar{u}-$ bushi) 348

Kandy (Ceylon / Sri Lanka) 86

Karajan, Herbert von 164

karakia (Maori ritual chant) 342

karawitan (Javanese gamelan composition) 34

Karkoschka, Erhard 254

Kashin (song from Japanese $\rightarrow$ rōei repertoire) 406

kata (sequence of body movements) 231

kataribe (archaic Japanese reciters) 358

katarimono (group of Japanese narrative musical genres) 345,358

Kathakali Dance Group Kerala (India) 120

kayagüm (Korean arched zither) 249, 251, 254, 408

kebianxing (variability) 272

kecak (Indonesian dance drama) 275

Kelemen, Milko 120

Kelly, Barbara L. 30

kenengxing (potentiality) 272

Kennan, George F. 133

Kennedy, John F. 130

Khan, Imdad; Jaunpuri Todika Alap 87-88

Khrennikov, Tikhon 64

Kido Toshirō 232

kiganda ( $\rightarrow$ amadinda xylophone music in Uganda) 363

Kim Chi-Ha 257

Kim Eun-Hye 253, 263; Kayagum 251-252

Kim Inhu 414; Ch'óngsanto (The Blue

$$
\text { Hills) 416-417 }
$$

Kim Jeong-Seung 251

Kim Jin-Hi 251; Nong Rock 252-253

Kindai Nippon sakkyokuka renmei (Modern

Composers' Federation of Japan) 103

Kineya Rokeshiro 162

Kineya Sakichi IV 92 
King, Martin Luther 133

Kipling, Rudyard; Jungle Book 55

Kitazawa Masakuni 120

Kiyose Yasuji 102-103

Kiyoshi Komatsu 102-103

Klangfarbenmelodie 213

Klangforum Wien 146, 326, 410

Kleinen, Günter 143

Klemperer, Otto 172-173

Klindworth-Scharwenka Conservatory 168

Klingsor, Tristan 86

Ko Ŭn; Ch'immuge taehayŏ (Silence) 414, 416-417

Kodály, Zoltán 182

Koechlin, Charles; Deux pièces javanaises 86; Etudes antiques 85; Suite Javanaise 86

Kokoschka, Oskar 170

kokosui $\rightarrow$ national essence

kokumin-shikyoku (Japanese national tone poems) 104

kokumin shugi (Japanese nationalist political ideology) 129

kokyū (Japanese knee fiddle) 124

komagaku (Japanese court music genre) 128, 227

Komatsu Heigorō 102-103

Komatsu Kiyoshi 102-103

Komatsu Kōsuke 103

kŏmun'go (Korean arched zither) 251-253, 408

Kondō Hakujirō 102

Kondō Jō 259

kongjian (Chinese aesthetic concept) 272

Konoe Hidemaro 101, 172-173

Konoe Naomaro 101

Kontarsky, Alfons 120

Kontarsky, Aloys 120

Koo Bonu 252, 263, 412; nah/fern 254-255

koorero (Maori speech) 342

Korea 25, 68, 116, 123-124, 146, 207-209, 211, $249-252,254,286,363,408,412,414,417$

Korean court music (a-ak) 36, 208, 408-409, 412,429

Korean War 116, 123, 249

Koreanness 251

koto (Japanese arched zither) 96, 123-125, $163-165,210,225-226,231,260,307$ kotoba (vocal delivery technique in $\rightarrow$ gidayu bushi) 345-346, 348

kotoba-nori (vocal delivery technique in $\rightarrow$ giday $\bar{u}$-bushi) 345

koto-kumiuta (vocal suites with koto accompaniment) 260

Kötter, Daniel 310

Koussevitzky Foundation 130

Kramer, Jonathan 432

Kramer, Lawrence 235

Kraus, John 177

Kraus, Karl 351

Krebs, Harald 381

Kronos Quartet 252

Kubik, Gerhard 364-365, 371, 376-379

kubing (jaw harp of the $\rightarrow$ Hanunóo-

Mangyan) 215

kuchi-jamisen (mnemonic syllables from koto practice) 226

kudoki (vocal delivery technique in Japanese $\rightarrow$ heikyoku) 345

kudyapi (guitar-like Philippine instrument) 217

Kuhn, Thomas; The Structure of Scientific Revolutions 44

Kulturbund Deutscher Juden $\rightarrow$ Jewish Cultural League

kundiman (Philippine vocal music genre) 215

kunqu (Chinese traditional opera) 147, 162

Künstlerhilfe der Jüdischen Gemeinde Berlin

(Association for the Support of Artists of the Jewish Community) 172-173

Kuo Chi-Yuan 265

Kuo, Tiffany M. 129, 133

Kuomintang (KMT, Chinese National Par-

ty) $263,267-268$

Kurth, Ernst 161, 170, 182, 188-189, 434; Bruckner 188; Grundlagen des linearen Kontrapunkts 180, 188, 311, 432-433; Musikpsychologie 188; Romantische Harmonik und ihre Krise in Wagners Tristan 188

Kutschke, Beate 138

Kuttner, Fritz A. 188

kyokusetsu (vocal delivery techniques in $\rightarrow$ heikyoku) 345

Kyoto school 136-137, 335, 389 
La Jeune France 68

La Scala (Milan) 130, 170

Lacan, Jacques 31

Lachenmann, Helmut 26, 32, 40-41, 45, 74, 136-137, 274, 278, 293, 298-299, 308-312, $322-335,339-340,385,388,394,407,434-$ 435; Air 152, 219, 249, 316, 318, 418-419; Concertini 308, 310, 322-328, 330-331, 333; Das Mädchen mit den Schwefelhölzern (The Little Match Girl) 139, 206, 298, 308-322, 328-335; "Eine musikalische Handlung" 331-332; Kontrakadenz 434-435; Mouvement (-vor der Erstarrung) 328; Pression 225; Tanzsuite mit Deutschlandlied 255

Lahiri, Sarat 96

Lahore 86-89, 93

Lahu (Chinese minority) 307

Lai Deh-Ho 265

Lam Doming; Insect World 158

Lang Lang 27

Laozi 241, 257; Daodejing 243

Latin America 26, 28, 34, 49-50, 53, 65, 94, 121, 206

Lau, Frederick 37

laváyi (speech of $\rightarrow$ Hopi Native Americans) 342

Lavoie-Herz, Djane 95

Le festival de musique contemporaine (Sapporo) 104

League of Composers 94

League of Nations 64

Lechner, Ethan 100

Lee Ang (Li An) 264

Lee Chih-Chun 265

Lee Geon-Yong; The Song of the Plain 250 Lee Tai-Hsiang 265-267, 269, 271-276, 280; Da Shenji 267, 272-273; Ganlanshu (Olive Tree) 274; Huanjing san zhang 274; Long Wu 270; Taixuyin 272-274; Yi tiao riguang dadao (A Sunbeam Path into the Future) 274; Yu-Chan-Ximen ding 272; Yunxing sanbian 270-271

Lee Tzyy-Sheng 265; Mr. DE--ath 282; Wang guo shi I 282-283

Lehmann, Harry 32

Lehtonen, Lasse 105-106

Leibowitz, René; L'artiste et sa conscience 65
Leonardo da Vinci 328, 331

Lerner, Murray; From Mao to Mozart 175

Lévinas, Emmanuel 309

Levinson, Jerrold 50

Li Ang 264

Li Delun 175, 181

Li Jue 175

Li Naicong 181

Li Tai-Bo; "Ein Flötenlied in Lau-Yang" (Chunye Luoyang xin di) 190

Li Weining 175, 177, 180

Li Yinghai 181; Hanzu diaoshi hesheng (Han Chinese Musical Modes and Harmonies) (see also Wang Zhenya) 157

Li Yuan-Chen 265, 285

Li Zhengfan 202

Liao Lin-Ni 265, 285-286; one bird, one tree... 286; Time of Trees II 286

Liaoning (Chinese Province) 195-196

Liezi 241

Ligeti, György 55, 138, 223, 241, 337, 363-367, 369-376, 379, 383-384; Apparitions 363; Aventures 135; Concerto for Piano and Orchestra 365-374; Études pour piano 365366, 372; "Paradigmenwechsel der achtziger Jahre” 363, 365; Requiem 364-365

Lin Hwai-Min 264, 266

Lin Tao-Sheng 265

Lindberg, Paula 170

Lindsay, Martin 411-413, 418

linguistic anthropology 337

linguistics 31, 45, 71, 140-141, 160, 237, 241, $274,334,337-338,340,359,362,386$

líra (Russian hurdy-gurdy) 76

List, George 342-343

listening $13,25-26,37,50,56,82-83,86,133$, $146,225,227-228,257,263,278,284,287$, $304,308-309,330,332-333,385-386,388$, 393, 418, 428-435; attitudes / modes of listening 430-431

Listenius, Nikolaus; Musica 54, 88, 225, 332

Liszt, Franz 27, 58

liu bai (white space within and between lines in calligraphy) 270,396

Liu Te-I 277

Liu Tianhua 156-158, 166, 186, 192; studies for $\rightarrow$ erhu 156 
Liu Xiaobo 156, 205

Liu Xiaozu; Ci Luan (woodcut print, 1655) 195

liuban (Chinese suite form) 398

live-electronics $\rightarrow$ electronic music

Living Tones 251-252

Liyuan (Pear Garden, Chinese Tang-Dynasty imperial music group) 285

Lloyd-Triestino 169

localism 78, 80-82, 220, 237

logic 32, 87, 135-136, 215, 220-221, 225, 234, 306, 389, 404

London Symphony Orchestra 28

Lorenz, Alfred; Abendländische Musikgeschichte im Rhythmus der Generationen 51

Los Angeles 93, 121, 162, 168, 170, 215

Lu Chuan-Sheng 265

Lu Chunling 157

Lu Qingshuang 196

Lu Wen-Tze 265

Lu Xun; Forging the Sword (Zhu jian) 229

Lu Yen 265

lubung (jaw harp of Taiwanese $\rightarrow$ Atayal and $\rightarrow$ Bunun indigenous peoples) 282

Luo Zhongrong 80; She jiang cai furong 161 luogu dianzi ("gong and drum patterns" in Beijing Opera percussion music) 238, 270 lusheng (mouth organ of the $\rightarrow$ Miao minority in southern China) 307

Lyceum Theatre (Lanxin daxi yuan, Shanghai) $173,176-178$

Lyotard, Jean-François 44-45, 47

$m a$ (Japanese aesthetic concept) 260-261, 295

Ma Shui-Long 265

Ma Sicong 178, 186

Ma Si-Hon (Ma Sihong) 178

$\mathrm{Ma}$, Yo Yo 241

Macartney, George 196-197

Maceda, José 35, 56, 75, 78, 120, 206, 211, 217-223, 225, 229, 233-235, 396; Ading 217; Cassettes 100 217; Kubing 215; Pagsamba 217, 218; Suling, Suling 222-223; UdlotUdlot 220-221; Ugnayan 217

Mack, Dieter 146

Maderna, Bruno 118, 120, 170

Madras (Chennai) 86, 88, 97-98, 121
Maehder, Jürgen 198

Magellan, Ferdinand 215

Mahabalipuram 88

Mahler, Gustav 25, 53, 58, 84, 173, 182, 235, 255, 327, 333, 370, 384; Das Lied von der Erde 200; Symphony no. 2132

mainstream 47, 49, 78, 136, 185, 237, 299

Malaysia 357

Manchuria 101, 162, 172, 196

Mandarin (putonghua) 161, 349

Mandelstam, Ossip 233; "Sluh chutkij parus naprjagaet" (Ears stretch sensitive sails) 304

Man'yōshü ("Collection of 10,000 Leaves") 110, 299

Mao Zedong 81, 203, 274

Maoism 116, 157, 182, 236-237

Maori 342-343

maqām (Arab mode) 143, 298

Marcuse, Herbert 32; "The Individual in the Great Society" 130

Marett, Allan 292, 306

marginalization 13, 29, 61, 63, 268

Margolinski, Henry 173, 176-177

Martin, Agnes 259

Maruyama Masao 113, 234

Marx, Adolf Bernhard 311

Marx, Karl 63

Marxism 31, 58, 68

mat (Korean aesthetic concept) 209

Matsudaira Yoritsune 92, 102, 129, 354; Bugaku 127; Drei Arien nach Gedichten aus der "Geschichte vom Prinzen Genji" 163; Genji Monogatari 163; Pastorale 104; Saibara ni yoru Metamorfōzu 164; Sonatine for Flute and Piano 164; Theme and Variations for Piano and Orchestra 163; U-Mai 163

May Fourth Movement (Xin wenhua yundong [New Culture Movement]) 156, 186

Mayer, Hans 65

Mayuzumi Toshirō 75, 117-118, 122, 261; Bacchanale 118, 127; Bugaku 127-128, 134; Bunraku 127; Geka (Pratidesana) (Public Confession) 127; Mandala Symphony 127; Nirvana Symphony (Nehan kokyokyoku) 126-127; Ochitaru tennyo 101; 
Samsara (Reincarnation) 127; Sange

(Scattering) 127; Showa tenpyōraku 129

mbira (African lamellophone) 363

McClary, Susan 388

McDonaldization 34

McKeich, Hamish 408

McLuhan, Marshall 69-70; The Gutenberg Galaxy 69; The Medium Is the Message 69;

Understanding Media 69; War and Peace in the Global Village 69

McPhee, Colin 74, 118, 120

medieval music 91, 134, 215, 225, 307

meditation 104, 132, 272, 275, 355

Mei Lanfang 275

Mei, Girolamo 359

Meiji era / Period / restauration (Japan, 1868-1911) 101, 113, 125-126, 163-164, 212, 261, 290

Melanesia 363

Mendelssohn Bartholdy, Felix; Violin Concerto 175,178

Meng Haoran; "Am frühen Frühlingstage" (Chun xiao) 190-191, 193

Menuhin, Yehudi 121

Menzel, Stefan 101, 104

Mersch, Dieter 309

Messiaen, Olivier 69, 71, 76, 125, 265, 366; Sept Haïkaï 68, 294; Turangalîla Symphony 68

metaphor theory 392

metaphorical exemplification 388,390

metric dissonance 375, 380-384

Meyer, Andreas 61, 86, 126

Meyer, Leonard B. 330

Meyer-Eppler, Werner 71

Miao (Chinese minority) 243, 307

micrology 47

microtonality $80,95,204,221,223,226,294$, $296,326,354,400,406$

migration $12,31,36,40-41,58,67,135,172$, 207, 211, 249, 286

Miki Minoru 75, 259

militarism 58, 126, 335

military music 155

Mills College 118

Minge caiji yundong (Folk Song Collection

Movement) 266 minimalism 129, 138, 259, 272-274

minzoku shugi ("cultural tradition") 129

minzuxing (national character) 248

Mishima Yukio 129; Ai no kawaki (Thirst for

Love) 402

Mitsubishi corporation 101

Mitsukuri Shūkichi 83-84, 101-102, 110, 112-113, 164; Bashō kikōshū 103, 105-108;

Sinfonietta [Shōkōkyōkyoku] 104; Sonata

for Violin and Piano 106

Mittler, Barbara 40, 165, 273

Miura Atsushi 84, 104

Miyagi Mamoru 120

Miyagi Michio 125, 164, 166; Etenraku Variations 101

miyakobushi (Japanese scale / mode) 92, 102, 105-106, 110, 124-125, 357

Miyata Mayumi 146, 289, 295, 298, 312

Mo Wuping 348

model works (yangbanxi) 158, 161, 175, 223, 267

modernism (see also postmodernism) 46, 49, $55,58,61,63,65,83,89,110,129,138,156$, $159-161,167,182-183,186-187,189,194$, 200, 206, 223, 233, 237, 241, 251, 264-265, 281, 341; anti-modernism 55, 61; capitalist modernism 116; ultramodernism 93, 122 modernity $11,30-31,35-36,51,55-57,61-62$, $64-65,67,69,74,80,92,101,112-113$, $126-127,129,155-156,159,166,168,173$, 175, 182-184, 194, 206, 219, 234, 261, 299, 433; alternative modernities 35,57 ; multiple modernities $11,51,57,62$, 113, 156, 234; reflexive modernity 35; Second Modernity 35

modernization 61, 101, 121, 147, 156, 158, 163, 207, 231, 263

modality 59, 61, 88, 92, 100, 102, 105-106, 110, $113,125,127,143,157,161,163-164,240$, 259, 300; polymodality 92-93, 265

Moffat, Julie 140

Moldenhauer, Hans 168

Molihua (Jasmine Flower) (see also Xianhua) 194-198, 200, 202-205

mono no aware (Japanese aesthetic concept) 292,335

monotonous recitation 343 
Moroi Makoto 120

Moroi Saburō 35, 84, 103, 121, 155

mŏt (Korean aesthetic concept) 209

mother chord 296, 298, 308

Mozart, Wolfgang Amadeus 175, 177-178, 270, 382-383; Don Giovanni 366, 370; Eine kleine Nachtmusik (Serenade for Strings in G major K. 525) 210; Symphony in G minor K. 550210

multiculturalism 37-38, 43, 98, 130, 251

multiple modernities $\rightarrow$ modernity

Mundry, Isabel 385, 388-392; Ich und Du 388-391

Murata Takeo 120

music historiography $47-48,50-51,57-59$, $62,67,82,115,156,194,211$

music history $11,13,34,39,51,53-54,57-58$, $60,62,67-68,78,112-114,117-118,122$, $135-136,167,188,203,225,234,236,249$, $337,363,376,381,384$

music journalism 12, 33, 206

music psychology 370, 375, 392, 435 music theory 11, 48, 67, 95, 97, 116, 124, 139, 143, 168-169, 174, 180, 188, 208, 275, $309-310,330,332,338,375,393,432$

musica coelestis 332

musica mundana 332

musica theorica 225

musical meaning 195, 342, 361, 385, 391

musicking 55

musicology 11-12, 29, 49-51, 56, 59-61, 67, 74,

97, 114, 331, 337, 342

musique concrète 127, 217, 272

musique concrète instrumentale $278,332,340$

myth criticism 289, 293, 298, 303-305

myth negation 303

myth reception 40,293

mythologization 40, 137, 139, 299

Nabokov, Nicholas 118, 121

nagaji (vocal delivery technique in Japanese

$\rightarrow$ giday $\bar{u}$-bushi) 348

nagauta (Japanese musical genre) 162-163, 231

Nakayama Shinpei 103

nanguan (South Chinese and Taiwanese

musical genre) 268, 275, 279, 282
Nanjing guoli yinyue yuan (National Music

School Nanjing) 180

Nantou (Taiwanese district) 277

Nara Period (Japan, 645-794 CE) 299

narrativity $13,39,47-48,50,57-60$, 114, $142,165,231,235-238,243,252,255,258$, $262-263,309-310,314,331-333,338,340$, $342,345-346,348,354,358,390,402$, $417-418,422,424,428$

National Academy of the Arts (Guoli yishu zhuanke xuexiao) (Taipei) 270

national character $32,77,248$

National Concert Hall (Taipei) 112, 268, 334, 404

National Cultural Center (Taipei) 267

national essence (Chin. guocui, Jap. kokosui) 157

National Institute of the Arts (Guoli yishu xueyuan) (Taipei) 267, 278, 282

national schools 156, 201

National Socialism 51-52, 75, 112, 114-115, $160,167,169,187$

National Taiwan Normal University (Guoli Shifan Daxue) 266, 277

National Taiwan University of the Arts (Guoli Taiwan yishu daxue) 270

National Theater (Taipei) 129, 268

National Theater Tokyo 129

National Vocational School for Music (Guoli yinyue zhuanke xuexiao) 179 nationalism (see also neo-nationalism) 30$32,35,38-40,52,58-59,63-68,75,77$, $81-83,86,94,101-102,105,110,112,116$, $124,126-129,134,137,155-156,158,162-$ $163,186-187,205,219-220,223,231-234$ 237, 248-251, 254, 257, 259, 261, 269, 292, $299,307,335,396$

Nattiez, Jean-Jacques 235 natural assignment 327, 435

Naxi (Chinese minority) 246, 248

Nelson, Steven 306

Nennwert (nominal value) 366 neoclassicism $32,65,75,78,100,102,118,127$, $163-164,170$

neo-nationalism (see also nationalism) 31, 38, $59,67,77,127,129,134,237$ neotonality 59, 397 
netori (introductory section in Japanese

$\rightarrow$ gagaku) 227, 290, 406

Neue Musikgesellschaft (Berlin) 94

New Age 136

New Aspect Cultural and Educational Foundation (Xin xiang wenjiao jijinhui) 275

New Complexity 54

New Culture Movement $\rightarrow$ May Fourth Movement

New Delhi 86

New Environment of Asian Music (Yazhou yinyue de xin huanjing) 267

New Life Movement (Xin shenghuo yundong) 187

New Music Society of California 93-94

New Musicology 51

New Symphony Orchestra (Shin kōkyō gakudan) 101, 173

New York Musicological Society 95

New York Philharmonic 118, 120, 127

New York Times 117

NHK (Nippon Hōsō Kyōkai) Orchestra 173

nianbai (Beijing Opera vocal delivery technique) 350

Nietzsche, Friedrich 257

Nigg, Serge 65

Nihon gendai sakkyokuka renmei (Federation of Contemporary Japanese Composers) 103

Nihon wo mamoru kokumin kaigi (National

Conference for the Defense of Japan) 129

nihonjinron (Japanese discourses) 128

Ningxia (Chinese Autonomous Region) 195196

Nippon kaigi (Japan Conference) 129

Nishang yuyi qu (Song of the Rainbow Skirt and Plumage) 285

Nishi Yoko 231

Nishida Kitarō 335, 389-390, 397, 402; Bashō (Place) 388, 404; Watashi to nanji (I and You) 388

Nishimura Akira 75, 259

Nishitani Keiji 137, 335

$n \bar{o}$ theater (Japanese traditional drama) 139, $142,163,260,275,296,298,354-355,359$

Nobel Peace Prize 205

noble savage 30,77 noise 140, 149, 223, 225, 241, 243, 261, 263, $273,276,278,285,316,319,332,335,386$, $390,398,422,424$

Nomura Koichi 120

Nomura Yoshio 120

nonghyŏn (vibrato technique in Korean traditional music) 252,254

Nono, Luigi; Il canto sospeso 339; Intolleranza 1960134

Nooteboom, Cees 149

North Korea 249-250, 414

notation $28,48,54-56,76,149,156-157,166$, $196,198,200,215,221-223,225,227,229$, 231, 233, 241, 251, 253, 257, 273, 275, 280, 290, 292, 294, 299, 306-307, 326, 339-342, $347-349,352-353,359,361-362,371,382$, $396,401,408,413,430$

Nozawa Kizaemon 347

Nuss, Stephen 127

Nyangumata (aboriginal Australians) 342

Ō no Yasumaro; Kojiki 358

O ssei sseil (Remeicuo; dance song of the $\rightarrow$ Naxi minority in China, see also Worere) 248

object-oriented assignment 433, 435

Oceania 28, 72

October Revolution 76, 172

oibuki (canonic introductory section in Japanese $\rightarrow$ gagaku) 227

Oida Kōkichi 102

Oki Masao 103; Yoru no meisō (Evening Meditation) 104

Okina 354

Okinawa (southern Japanese island) 358

Oliveros, Pauline 272

omele (rhythmic formula in African music) 379

omeribuki (canonic structures in $\rightarrow g a g a-$ ku) 227

omoro (traditional musical-poetic genre of $\rightarrow$ Okinawa) 358

Ongaku hyōron (Music Review) 103

Ongaku konkuuru (Music Competition) 104

ongiyong (Philippine duct flute) 219

ongo (horns of Central African $\rightarrow$ Banda

Linda) 138,363 
opera (see also Chinese opera, chuanju, gezaixi, jingju, kunqu) 25, 28, 33, 55, 58, 72, 80, $83,86,88,158,163,168,170,185,189,194$, 197-198, 200, 203, 238, 300, 310, 320, 331, $333,338-340,345,350,360,375$

Olympic Games 64, 71 (Munich 1972), 205

(Beijing 2008)

oral tradition 203, 282, 307, 341, 349

orality (see also aurality) 54, 56, 136, 156,

194, 203, 211, 229, 282-284, 307, 338, 341,

$345-346,349,353,361,396,417$

organology 147, 149, 153, 226, 298, 305, 312,

$357,400,418$

orientalism 30, 37, 61, 77, 86, 88-89, 93, 113,

$198,200,208$

Ormandy, Eugene 175

Osterhammel, Jürgen 48

Other / otherness 32, 55, 61-62, 75, 136-137,

139, 206-207, 309, 328, 335, 389

òtsuzumi (drum in Japanese $n \bar{o}$ theater) 260 , 296

Oyama, Susan 130

Ozawa Seiji 118

p'ansori (Korean traditional narrative genre) 275,398

Paci, Mario 173, 176, 178-179, 186

Pacific War 126, 162, 172-173

Pacun, David 110

pakkung / balingbing (Philippine buzzers) 219, 222

palakpak (Philippine rattle) 219

Palau (Micronesia) 343

Palestrina, Giovanni Pierluigi di 30, 55, 180

Pan American Association of Composers

(PAAC) 94-95

Pan Hwang-Long 265, 267, 269, 277;

Concerto for Violoncello and Orchest-

ra 280; East and West (Dong nan xi bei) 121, 123-124, 280, 386; Erleuchtung (Qishilu [Illumination]) 278; Kausalnexus (Yinguo muguan sichongzou [Causal Nexus]) 278; Migong daoyaoyou 278, 280; Shi-DaoRu 279; String Quartet no. 2 278; String Quartet no. 3278-279; Taiwan fengjing hua 279; Transformation (Hudie meng [Butterfly Dream]) 278; Ursache und
Wirkung (Yinguo sanzhongzou [Cause and Effect]) 278; Wandlungsphasen (Wu xing sheng ke) 278; Wuqing, qingjing, yijing 137, 278, 280; yin-yang cycle 278

Pan Shyh-Ji; Quartet 282; Raining Night 282

Pang Xianpin 181

Paolini, Luigi Gualtiero 198

parallel cultures 38-39

Parish of the Holy Sacrifice 219

Park Chung-Hee 250

parlando 345

Partch, Harry 74, 281

Pasler, Jann 86-88

Pasolini, Pier Paolo 233

passagi 360

pentatonic Romanticism (see also Romanticism) 40, 186, 200-201

pentatonicism 40, 92, 96, 102, 127, 157-159, $161,164,175,186-187,200,215,238,240$, $266,312,320,357,398,400$

performance practice $125,203,231,233-234$, 252-253, 261, 264, 269, 276, 292, 298, $303-304,307,310,312,342,351-353,361$, $382,385,430,437$

performative listening 56,430 performativity $48,56,153,229,231,241,270$, $282,285,305,338,341,353,360,362,430$ Peri, Jacopo 359-360, 362; Le musiche, sopra l'Euridice 359

periodicity 369-372, 375, 377-381, 384

Peru 134

pétit récits (Lyotard) 47

petschinka (Petschinka, Eberhard) 406;

MISHIMA-Skizzen 402

Philadelphia Orchestra 175

Philharmonic Society Tokyo 101

Philippines 119, 123, 215, 217, 219, 221, 234

phoenix 290, 332, 398

Phonogramm-Archiv (Berlin) 97, 100

phonograph 87

Picard, François 156

Picken, Laurence E. 292, 306

Pinder, Wilhelm 58

pipa (Chinese lute) 149, 186, 196, 206, 225, 237, 240-241, 243, 276, 280, 285, 385, 398, 418

Pironkoff, Simeon 153, 399, 404, 418; Fall/

Wende 149, 151-152 
Pisa, Leonardo of 328

pluralism 58, 71, 236

poeticus musicus 54

polyculturality 32

polymeter $337,363,365-366,370,375-376$,

$380,382-384,410,430$

polyphonic novel 428

polyphony $30,48,58,70,100,142-143,152$,

$157,180,198,237,274,309,327,341,355$,

$366,368-369,375,380,382-383,385$,

$393-395,404,423,428-429,432-437$

polyrhythm 95, 100, 303, 363, 365-366, 368,

$370,375,380$

Pople, Anthony; Cambridge History of

Twentieth-Century Music (see also Cook,

Nicholas) 49

popular music / pop music $28,32,34,37,43$,

$45,49,52,58-60,62-63,65,67,77,92$,

$102,130,133,157,160,172,180,202-203$,

$228,234,237,252-253,263,267-269$,

274-275, 279, 281, 292-293, 357, 376-377,

$386,416,419$

popular music studies 12

popularization 237,281

postcolonialism $31,38-39,51,53,55,57-58$,

$61,67,72,137,139,167,204,208,220,228$,

234,364

postmodernism (see also modernism) 44, 47,

140, 206, 234

post-tonality 188, 221, 392, 434

postwar period / history $32,35,57,60,64-66$, $68,71-72,82,112,114,116-117,122,126$, 129, 135-136, 162-164, 217, 221, 263-264, $334,340,354$

Pousseur, Henri 75

pragmatism 137-138, 174

Prague manifesto 64-65, 116, 118

prescriptive notation $222,233,361$

presence $56,257,333,338,340,342,348$,

$353-354,360,362$

Prey, Hermann 120

Princeton University 116

Pringsheim, Klaus 106, 164

Prometeo (Japanese composers' group) 102

Prunières, Henri 104, 112

Prüwer, Julius 168

psychoanalysis 31, 353
Puccini, Giacomo 75, 203-204; Turandot 194195, 197-198, 200

pulse $98,217,276,328,366,368-372,375$, $377-380,382-383,390,406$

Punjab (Indian state) 86

qawwali (Indian and Pakistani vocal music genre) 34

Qian Decang; Zhui bai qiu (see also Wang Xieru) 195, 202

Qianlong (Chinese emperor) 195

qin (Chinese zither) 36, 225, 243, 280, 437

Qin Wenchen 263; He-Yi 238, 240-241, 396

Qin Xixuan 169-170, 180-181

Qing (Chinese dynasty) 195

Qinghai (Chinese Province) 182

qiyun (Chinese aesthetic concept) 280

Qu Qiubai 156

Qu Xiaosong 82, 276, 348; Mong Dong 80

$\mathrm{Qu}$ Xixian 181

Qu Yuan 45; Jiu ge (Nine Songs) 80

Quezon City 215, 219

Qureshi, Regula Burckhardt 49

race $11,37,64,67,69,77-78,88,94-95,130$, 228

rāga (Indian mode) 88-89, 96, 231

Rāgamālika, Ramalinga swamis arulpa 89

Rajasthan (Indian state) 86

Rákóczi March 77

Rameau, Jean-Philippe; Les Indes galantes 86

Ranta, Michael 274

Rao, Nancy Yunhwa 97

Rapp, Sabine 177

Rasalîla 146

Rattle, Simon 25, 27, 219

Ratz, Erwin 208

Ravel, Maurice; Histoires naturelles 92; Shéhérazade (song cycle) 86; Trois poèmes de Mallarmé 85

Reber, Heinz 153; Music for Sheng 147-148

recitation $27,47,94,96,104,127,159,170,177$, $226,233,299,304,343,345-348,353-354$, $358-361,406,415,422-423$

recitative $159,343,345,359-360,422$

recognition 42-43, 46, 235; struggle for recognition 43,46 
reflexivity $25,27,29,31,33,35,37,39,41,43$, 45

Reich, Steve 52, 129, 137-138, 364; Drumming 379

Reichskristallnacht pogrom 169

relational musicology 49-50

relativism 48, 59, 61, 67, 100, 121

Renaissance 360

Renouveau catholique 68

res facta 54-55

Reynolds, Roger 270, 272

Ricœur, Paul 42-43

Riemann, Hugo 58-59, 105, 188, 208, 221;

Folkloristische Tonalitätstudien 59; Hand-

buch der Musikgeschichte 59

Rihm, Wolfgang; Jakob Lenz 33

Riley, Terry 129, 138

Rimski-Korsakov, Nikolai 76

rin (Japanese temple bell) 141, 232, 299, 318-319, 438

ring modulation 294

ritual $29,34,40,45,53,77,80,125,129,137$, $147,217,219,221,237,258,272,275-276$, 294, 298-299, 334, 342, 345, 348, 353-354, 357, 413, 419

Robertson, Roland 34, 75

Rockefeller Foundation 118, 123, 132, 270

rōei (Japanese traditional vocal genre) 110, 292, 406

Roemahlaiselan, A. F. 97

Roerich, Nicholas 77

Romanticism (see also pentatonic Romanticism) 237

Rose, Michael 85, 198

rōshō (category of vocal delivery in traditional Japanese music) 345-346, 348, 354-355

Rothbrust, Dirk 412

Rousseau, Jean-Jacques 156; Essai sur l'origine des langues 337

Roussel, Albert 69, 104, 112

rowing song 158,197

Roy, R.L. 120

Royal Ballet (UK) 120

Royal Dancers of Thailand 120

rozhók (Russian shawm) 76 ruan (daruan, zhongruan) (Chinese mando-

lins) $149,243,398,418$

Rudhyar, Dane 68, 73-74, 87, 93-95, 249

Ruppel, Karl H. 120

ryüteki (Japanese transverse bamboo

flute) 227, 291, 294-295, 335

Saager, P. 168

sabi (Japanese aesthetic concept) 261, 292

Sabiron, Georges 91

Sachsenhausen (concentration camp) 169, 194

saenghwang (Korean mouth organ) 408

Saeya, saeya, pahrang saeya (Bird, bird, blue bird) 229, 250, 412

saibara (Japanese traditional vocal genre) 164, 292

Said, Edward 39

Saitō Hideo 102

Sakka Keisei 120

Sakuma Shōzan 155

Salihara Festival Jakarta 412, 418

Sambamoorthy, Pichu 97

Samson, Jim 26, 37

Samuels, Robert 235

San'nin no kai (Group of Three) 126-127

Sánchez-Chiong, Jorge 153; Teatro ShanghaiBühnenmusik 148-149

Sang Tong 180-184, 187; Yejing (Night Scenery) 161, 182-183; Zai na yaoyuan de difang

(In the Land, Far, Far Away) 161, 182, 184

Sangnyongsan (piece from the $\rightarrow$ Yŏngsan hoesang suite of the $\rightarrow$ Korean court music

repertoire) 408-409, 412, 429

Sanguineti, Edoardo 130

sangzi (Beijing Opera voice) 348

sanjo (Korean musical genre) 139, 231, 251

sanjo ajaeng (Korean arched zither) 139

sanjü (vocal delivery technique in Japanese $\rightarrow$ heikyoku) 231-232, 345

sankyoku (Japanese musical genre) 103, 123-125

Sanskrit 89, 226, 354

Santos, Ramon P. 217

Saram, Rohan de 134

Sarduy, Severo; De donde son los cantantes?

(Where do the singers come from?) 149 
Sarjono, Agus R. 422, 424; Suatu Cerita dari Negeri Angin (A Story from the Country of Hot Air) 418-419

Sartre, Jean-Paul 115

Satō Haruo 110

Satoh Somei 259

Satsuma Jirohachi 92

sawari (timbre / aesthetic concept in Japanese traditional music) 260-261, 295, 346

Scelsi, Giacinto 68, 74, 143, 223, 325, 353; Canti del Capricorno 341, 354, 437

Schaeffner, André 75

Schäfer, Christine 353

Scherchen, Hermann 65, 94

Schering, Arnold 327

Schiller, Friedrich; An die Freude (Ode To Joy) 204

Schlegel, Friedrich 50

Schloß, Julius 167, 182, 194

Schnabel, Artur 178

Schnebel, Dieter 71, 338-340, 353; Glossolalie 61 135, 340; glossolalie 135, 340

Schnittke, Alfred; Symphony no. 1134

Schoenberg, Arnold 33, 36, 59-60, 84, 93, 97, 160, 162, 167, 182, 187-188, 208, 223, 346, 348, 362, 434; A Survivor from Warsaw op. 46 65; Erwartung op. 17340 ; Five Orchestral Pieces op. 16 132; Harmonielehre (Theory of Harmony) 180, 432-433; Ode to Napoleon Buonaparte op. 41 170; Pierrot lunaire op. 21 85, 94, 341, 343, 351-352, 353, 361; Six Little Piano Pieces op. 19 85, 171; Three Piano Pieces op. 1185

Schola Cantorum (Paris) 83

school songs (Jap. shōka, Chin. xuetangge) $155-156$

Schubert, Franz 177, 180, 208, 270; Die Krähe 388; Winterreise 388

Schuh, Willi 120

Schumann, Robert 208, 380-383

Schütz, Alfred 56

Schwanitz, Dietrich; Alles, was man wissen muß 26

Sciarrino, Salvatore 353, 362; Luci mie traditrici 360-361

scioltezza 360

Scriabin, Alexander 68, 95, 176, 182, 366 scripturality 48, 50, 53-55

se (Chinese ancient arched zither) 233

Second World War 32, 35, 72, 155, 157, 164, 335,340

Seefehlner, Egon 120

Segall, Fritz 172-173

Seidel-Margolinski, Irene 176

self-referentiality 135, 309-310, 322

semantics 29, 114, 135, 235-236, 263, 332, 339, $361,386,389,397,404,418,423$

semiotics 134, 138, 235, 338, 392

Senghaas, Dieter 32

senritsukei (vocal delivery techniques in

Japanese $\rightarrow$ giday $\bar{u}$-bushi) 345

Seoul 249, 414

se-piri (Korean double-reed instrument) 253

serial music 32-33, 49, 60-61, 66, 71-72,

75-76, 114-118, 120-121, 123, 127-128, 133,

135-136, 161, 163-164, 211, 217, 221, 250,

$275,339,353,433-434$

Shaanxi (Chinese Province) 158, 195-196

Shade, Nancy 97, 140

Shakespeare, William; The Tempest 237

shakuhachi (Japanese vertical flute) 96,

122-124, 142, 166, 206, 210, 212, 404, 406,

417

shamanism 139, 210, 221, 233, 238, 300, 355, 357

shamisen (Japanese long-necked lute) 92, $96,124,162-163,210,225-227,231-232$, 260-261, 346-347, 354-355; futozao shamisen 346-347; sero shamisen 92; teion shamisen 92

shan'ge (Chinese mountain songs) 80,348 , 350

Shandong (Chinese Province) 195-196

Shang (Chinese dynasty) 147, 290

Shanghai Conservatory 160, 166, 175, 179, 223

Shanghai Municipal (Symphony) Orchestra

(SMO) 172-180, 186-187

Shanghai Opera House 203

Shanghai Philharmonic Society 173

Shanghai Public Band 173

Shanghai Symphony Orchestra (SSO) 173

Shanghai 104, 147-149, 159-162, 166-170,

172-184, 186-189, 191-192, 194-196, 203,

$223,246,279$ 
Shankar, Ravi 45

Shanxi (Chinese Province) 195-196

Shen Bing-Kuang 265

Shen Chin-Tang 265

Shen Qi Mi Pu 437

Shen Zhibai 185

sheng (Chinese mouth organ) 135, 141, 147-

153, 195, 241, 243, 265-266, 270, 277-278, $282-283,286-287,290,293,307,332,385$, 398-401, 413, 417, 431

Shi Kelong 241

Shi Wei-Liang 265-266

shi yin (real, continuous sounds) 272

Shi Yongkang 166; Huanghe de gushi (The

Story of the Yellow Crane) 165

Shiba Sukehiro 120

shidiao (Chinese folk song type) 196

shifan luogu (patterns in Chinese percussion music) 80

Shih Pei-Yu 265

Shijing (Book of Songs) 241

Shim Kunsu 254, 263, 412; cello/hören 256257; Luftrand 257-258; "Richtungslosigkeit oder Denken der unbegrenzten Gegenwart" 257; Sense of Measure 259 Shimian maifu (Ambush from Ten Sides; piece of the $\rightarrow$ pipa repertoire) 276 Shimoyama Hifumi; Breath 354, 356-357; Monolog 354-355

Shin Nihon ongaku (New Japanese Music) 164 Shin ongaku ha (New Music Group) 102 Shin ongaku renmei (New Music Federation) 101, 104

shinawi (Korean musical genre) 250, 254 shinkō (Japanese cultural movement / period) 101-104, 163-164

Shinkō sakkyokuka renmei (Federation of Innovative Composers) 101-102, 104, 163-164

shinkyoku (pieces of the $\rightarrow$ koto repertoire) 163-164

Shinohara Makoto 259

Shinsen shōteki fu 306

Shioiri Kamesuke 102

shirakoe (vocal delivery technique in Japanese $\rightarrow$ heikyoku) 345 shō (Japanese mouth organ) 40, 103, 123, 125, $139,146-147,153,163-164,206,213,227$, $232,259-260,286,289-301,303-320$, $322-323,325,327-333,335,404-407$

shōka $\rightarrow$ school songs

shoko (gong in Japanese $\rightarrow$ gagaku) 299

shōmyō (Japanese traditional Buddhist chant) 294, 345, 354, 359, 406

Shona (Zimbabwe native ethnic group) 363 Shostakovich, Dmitri 114, 240; Symphonies 9 to 1365

Shreffler, Anne C. 114-116, 118

Shuang die cui (Chinese melody) 195

Siagian, Toenggoel 418-419

Sibelius, Jean 30

Sichuan (Chinese Province) 80, 195-196, 240

Sichuan Opera $\rightarrow$ chuanju

signification 309, 361, 388, 392

sijo (Korean traditional vocal music genre) 412-414

silence $78,135,137,147,212,226,255$, 257-260, 263, 272, 286, 295, 300, 303, 308-309, 322, 332, 386, 414, 416-417, 425

Sili Shanghai yinyue yuan (Shanghai Private Music School) 180

silk and bamboo music (sizhuyue) 147, 158, 196, 279, 398, 429

Silk Road Ensemble 241

sillabazione scivolata 360-362

simplicity 147, 237, 240, 354

Singer, Gregory (Grisha) 187

Singh, Thakur J. 120

singing 59,80 , 110, 158-159, 238, 243, 248, $251,274,337-339,342-343,345,348$,

$350-351,353-354,360,380,411$

Sino-Japanese War, Second 172 sitar (Indian plucked long-necked lute) 96 sixte ajoutée 200

Slavina-Brown 177, 192

Sloutsky, Alexander 173

social history 47,51

socialist realism $65,116,250$

Société Musicale Indépendante 83, 86, 93

Société National de Musique 83

Society for Chinese Folk Music Research

(Zhongguo minzu yinyue yanjiushe) 266

Society for Ethnomusicology 219 
Society for Music Theory (SMT) 11

Society for the Improvement of National

Music $\rightarrow$ Guoyue gaijinshe

solmisation 198

Song (Chinese dynasty) 56, 189

songwriter / songwriting 180, 267, 274-275

sound cadence $\rightarrow$ yinxiang zhongzhishi

sound families $323,328,434-435$

sound structure 139, 221, 269, 411, 430

sound types $311,322,394,407$

sound typology $278,385,434$

Southeast Asia $\rightarrow$ Asia

Soviet Union 95, 116

Spahlinger, Mathias; passage/paysage 149

Spanjaard, Ed 410

Sparrer, Walter-Wolfgang 207-208, 211, 308

spectral analysis 325-327, 405

Speelman, Michel 169

Spengler, Oswald; Der Untergang des Abend-

landes (The Decline of the West) 51, 73

spirituality 40-41, 68, 86, 94, 137, 143, 201,

$225,234,237,264,280,337,350,383$

Spittel, Helmut 173

Spivacke, Harold 130

split sound (Spaltklang) 310, 324, 327

Spoliansky, Alexander 173

Sprachkomposition 133, 135, 343, 351-353

Sprechgesang 141, 351, 353

Sprechstimme 343, 351-353

sprezzatura 360

Spring and Autumn Period (China, 722-481

BCE) 276

ssigimsae (melodic variation in Korean traditional music) 251, 253

St. John's University (Shanghai) 188

Stäbler, Gerhard 299-301, 412; CassandraComplex 300; ]LIFE[ 300-301; Palast des Schweigens 300

standardization 12, 33-34, 63, 75, 141, $156-158,225,259,261,338$

Staunton, George Leonhard 196

Steiner, Adolf 173

Steiner, Karl 167, 182, 194, 295

Steiner, Rudolf 295

stereotype $13,27,34,37,39-40,46,58,75,88$, $100,200,208,233,237,252-253,287,362$

Sterev, Krassimir 152
Stern, Isaac 120, 175

Stiedry-Wagner, Erika 353

Stockhausen, Karlheinz 36, 68-75, 125, 129, 134-136, 140, 170, 274, 430, 434; Der Jahreslauf 125, 294; Dienstag aus Licht 294; Gruppen 366, 383; Hymnen 33, 70, 135; Kreuzspiel 33; Licht 125; Telemusik 33, 70-71, 135, 294

Stokes, Martin 43

strange multiplicity 39

stratification $243,248,314,324,383,385$, 393-396, 402, 408, 412-413

Straus, Joseph N. 62

Strauß, Johann 178

Strauss, Richard 101, 163, 176, 180

Stravinsky, Igor 30, 32, 59-61, 65-67, 75-78, $80,82-83,87,92-93,104,114-115,160$, 182, 187, 384; An Autobiography 76; Danse Sacrale 77; L'Histoire du Soldat 168; Petrushka 76; Symphony in Three Movements 65-66; The Firebird 76; The Rite of Spring (Le Sacre du Printemps) 76, 78; Trois poésies de la lyrique japonaise (Three Japanese Lyrics) 85, 89, 92

streaming / stream segregation $\rightarrow$ auditory streaming

structural semantics 418

structural sound (Strukturklang) 310, 324, 327, 394, 433-434

Stuckenschmidt, Hans Heinz 120-121

Stuttgart Academy of Music 254

Su Dong-Bo (Su Shi) 190-191; "Frühlings-

nacht" (Chun xiao) 190

Subotnick, Morton 133

Sudan 376-377

Sugawara Meirō 102

Sugawara no Michizane 155

Suigȳu (Water Buffalo; Japanese music group) 357

Sujech'ön 208

suling (Southeast Asian bamboo flute) 222223

super instrument 300

SuperCollider 152

superstar syndrome 37

Suppan, Wolfgang 153, 404; Studie II 152 
surbahār (Indian plucked long-necked

$$
\text { lute) } 87-88
$$

Suzuki Daisetz Teitaro 136, 335

Suzuki Fumio 102

Suzuki Kayoko 165

Suzuki Shigetaka 35

Suzuki (piece of the Japanese $\rightarrow$ heikyoku repertoire) 345-346

Swamigal, Ramalinga (Swamy) 89

synthesis $46,67,70,74,126,129,142,159,163$, 185-187, 213, 248-249, 263, 270, 282, 286, 407; synthesis by nothing 255

tabla (Indian twin hand drums) 89

taegŭm (Korean transverse flute) 251, 253 , 408, 410

Tagalog 217, 219

tagutok (Philippine bamboo scrapers) 219, 222

Taipei National University of the Arts (Taibei yishu daxue) 267

Taipei Symphony 270

Taipei 146-147, 267-272, 276-279, 282-284, 286

Taira Yoshihisa 286

Taiwan Provincial Symphony Orchestra

(Taiwan sheng jiaoxiang yuetuan) 266, 270

Taiwan 116, 147, 263-270, 274-275, 277-287

Taiwanese Opera $\rightarrow$ gezaixi

Takada Kazuko 231, 354

Takada Yumiko 265

Takahashi Yūji 56, 215, 230, 259, 263, 272, 284, 354-355, 396; Aki no uta 231; Aomori gaeru 231; Ariake 231; "Bach as a Failure" 229; Bai gui yexing huijuan 231; Bosatsu kangen dennōdate 231, 306; Dream of Heaven 233; Hanagatami 1 231; Hiru wa moetsukita 231; Insomnia 231; Kagehime no michiyuki 231; Kanashimi o sagasu ut 231; Kasuka ni 231; Kaze ga omote de yonde iru 231; Koto nado asobi 225, 226-227, 231; Kotsu no utau 231; Kwangju, May 1980 229, 250, 412; Mangalasutta 233; Mimi no ho 213, 231, 304-305; Momoka momoyo 231; MonoGatari 231; Nasuno kasane 231, 261-262; Nasuno ryōjō 231, 261; Ne monogatari 231; Oinaru shi no monogatari 231; Ongaku no
Oshie 231; Palindrome 231; Samushiro 231;

Sangen sanju 231-232; Sinubi 231; Sōjō rinzetsu 231, 305, 306-307; Tabibito ka herazu 231; The Song of the Blue Sword 229-230; Thread Cogwheels 231; Three Pieces for Ichigenkin 231; To-i 231; Tori mo tsukai ka 225, 227-228; Tori mo tsukai ka II 231; Tori no asobi 233; Tsuginepu to itte mita 231; Unebiyama 233, 355, 357, 358-359; Ware wo tanomete konu wotoko 231; While I Am Crossing the Bridge 231; Yügao no ie 231; Yume 231; Zanshi no kyoku 233

Takano Tatsuyuki 162

Takemitsu Tōru 26, 35, 78, 110, 129, 211-212, 259, 354; Ceremonial 213, 294-295; Distance 213-214, 294-295; Eclipse 165, 212; In an Autumn Garden 213, 294-295; November Steps 134, 165-166, 206, 212-213, 225, 396, 429

Takemoto Gidayū 346

Takemoto Sumitayū 347

tāla (rhythmic-metric structures in traditional Indian music) 96, 98

Tamada Kitaro 122

Tamil 86, 89

Tan Dun 59, 200-206, 236-238, 263, 276, 346, 348-350; Fu, Fu, Fu 348; Ghost Opera 206, 237, 385; Internet Symphony "Eroica" 28; Marco Polo 350, 396; Nine Songs 80-82, 348; On Taoism 80, 348; Silk Road 241, 349-350; Symphony 1997. Heaven - EarthMankind 194-195, 198-201, 202-205, 237; The Fire 27; The Map 73, 243, 248

Tan Shuzhen 175

Tan Xiaolin 187

Tanaka Shōhei 164; Nihon wasei no kiso (Foundations of Japanese Harmony) 106

Tanaka Yumiko 231

Tan'b'oloko se? (song from a fairy tale of the $\rightarrow$ Yoruba) 377

Tang (Chinese dynasty) 189, 215, 276, 280, 285, 290-292

Tang Zhengfang 181

Tanizaki Jun'ichiro; In Praise of Shadows (In'ei Raisan) 257-258

tanpura (Indian plucked long-necked lute) 89 Tansman, Alexandre 103-104 
tanso (Korean vertical flute) 253

Tao [Yami] (Taiwanese indigenous peop-

le) $243,265,282$

taqsīm (maqām-improvisation in Arab and

Turkish music) 231

Taruskin, Richard 47-48, 50, 59-60, 75-76, $78,89,114$

Tateyama Noboru 164

táwi (singing of Hopi Native Americans) 342

Taylor, Charles 41, 55

Taylor, Timothy 100

tay $\bar{u}$ (reciter in Japanese $\rightarrow$ bunraku) 346-347, 361

Tcherepnin composition prize 104, 163

Tcherepnin, Alexander 103-104, 160, 163, 167, 182, 185, 187; "Music in Modern China" 159

techno-essentialism 37,48

Temiar (Western Malaysian ethnic group) 357

Tenney, James 281

Tenzer, Michael 48, 217, 384

te-utsuri (changes of finger position of the $\rightarrow$ shō in $\rightarrow$ gagaku) 292-293, 299, 312

Thailand 120, 123, 307, 343

Thayi, Coimbatore 88

Theater of the Absurd 45

Third Generation (Che Sam Sedae; Korean composers' group) 250, 254

Thomson, Virgil 120

Thorau, Christian 388, 390

Thurner, Berndt 412

Tiananmen square massacre 81, 236, 282

Tibet 69, 196, 272

timbre 87-88, 162-163, 200, 212, 220-221, 231-232, 234, 241, 243, 254, 261, 278, 303, $309,312,319,346,348-350,385,413,418$, $423,430,432,435$

Time-Unit Box System 373, 378-379

Tinctoris, Johannes; Terminorum Musicae Diffinitorium 54

tí:ngava (chant of Hopi Native Americans) 342-343

tōgaku (Japanese court music genre) 104, 124-125, 128, 139, 213, 290-292, 294-295, 298-300, 306-307, 312, 332, 398

Tokyo Music School 106 tonality $26,52,59,102,156-157,159-160$, 163-164, 175, 188, 197, 200, 221, 231, 241, $250,259,263,280,284,294,310-311$, $322-323,328,332,351,365,370,380$, $383-386,392,394,433-434$

Tonghak movement / rebellion (Korea) 250, 412

total Westernization (quanpaixifanghua) 80, 156

tou - fu - wei (phases of vocal sound production in Beijing Opera) 350

Toyama, Kazuyuki 120

tōyō dōtoku, seiyō gakugei (Eastern ethics, Western technical learning) 155

Toyohara no Muneaki; Taigen shō 306

Toyohara Tatsuaki; Hōshō ryo ritsu kan 306 Toyohara Toshiaki; Kofu ritsu ryo kan 306 traditionalism 128, 253, 255, 310; anti-traditionalism 300; radical traditionalism 412 Tran Van Khe 120

trance 233

transcription $76,86-88,134,170,192$, 195-198, 200, 233, 299, 306, 311, 345, 347, $353,376,406,413-414,430-431$

transculturality 38,61

transethnicism 74, 123, 129, 134

transfer $27,36-37,58,60,135,148,275,280$, $295,304,388,390$

transformation $12,48,61,63,76,82,143,167$, 204, 217, 223, 278, 289, 307, 330, 335, 346, $390,395-396,404,406,418,422-423,429$, 436

translation 43-44, 69, 87, 89, 140, 157, 190$191,197,208,210,225,241,253,331-332$, $418,422,424$

Tsugaru 354

tsugaru-jamisen (Japanese narrative genre) 354

Tsunoda Tadanobu 261

Tsurukame (Japanese nō / kabuki play) 163 Tudor, David 212

Tung Chao-Ming 265, 282-284, 286; Die Gesichter des Buddha 285; Formosa 263, 267, 279, 282, 283-284

Tung Kwong-Kwong (Dong Guang-Guang) 178 
twelve-tone technique 132, 161, 166, 170, 182, 189, 191-192, 223, 225, 303, 422

twentieth-century music 58, 62-63, 68, 210, $233,265,333,338,388$

Tzeng Shing-Kwei 265

$\overline{\boldsymbol{u}}$ (Japanese mouth organ) 12, 29, 39, 54-55, 62, 70, 74, 84, 104, 107-108, 111, 116, 123-125, 131-132, 150, 163, 187, 194, 198, 205, 214, 233-234, 239-240, 242, 300, $302-303,313,322,334,343-344,354$, $365-367,372,375,403,409,416,438-439$

Ueda Shizuteru 335

Union of Soviet Composers 64

United States 11, 37, 60, 74, 82-83, 94-96, 112, $114-118,120-124,129-130,132,138,146$, 168-169, 172, 178-179, 182, 187-188, 191, $215,236,249,264,272,281,343,435$

universal history 50, 58 universal language 67, 136, 228 Universal Peace Congress (Paris 1889) 63 universalism $32-33,46,48,50-52,58-59$, $61,63,66-75,77,79,81,98,100-101,117$, $120-124,129,134-136,140,171,228,234$, $294,342,352,361,363$

University of California Los Angeles 215 utilitarianism 138, 156, 203, 264, 287 utopia 40, 74, 309, 402

Uttar Pradesh (Indian state) 86 Utz, Christian; Abstract Voyage 413; Glasakkord 402, 404-407, 408, 413, 417-418, 430; Interference 397-399, 410, 417, 429; repercussion.camouflage.report 63, 412, 417; sheng-yue - lü 413; Site 404; specula 404, 413; telinga - mulut 411, 417-427; the wasteland of minds 399-403, 404, 406, 413, 417, 430-431; time freeze 437; together/lapart (hamkke//ttŏrŏjyŏ) 408-411, 412, 417, 429430; vier epigramme 404, 413; walls 85 , 429, 435-439; Zersplitterung (pusǒjin chogak) 404, 411, 412-417, 418, 423

Valenti-Ferro, Enzo 120

Valéry, Paul; "La cimitière marin" 132 Valesby, Leonora 178

Varèse, Edgard 36, 59-60, 62, 65, 94-95, 217, $219,223,432$
Varian, John 95-96; The Harp of Life 95

Varian, Russel 95

Vatsyayan, Kapila 120

Vaughan Williams, Ralph 182

Venda (South African ethnic group) 53

Vertovec, Stephen 31, 35

Vienna Academy of Music 286

Vietnam War 27, 121

Vieuxtemps, Henri; Ballade et Polonaise G major op. 38177

Vinci, Leonardo da 331

Viswanathan, T. 120

Vlad, Roman 120

vocal music $87-88,97,110,187,338-342,345$,

$359,361-362,422$

vocalization $337,346,348,406$

voice / voices 12, 29, 48, 51, 80, 89-90, 92, 97, 100, 105-106, 110, 141, 161, 166, 171, 196-197, 200, 215, 219, 227, 231, 233-235, 237-238, 248, 253, 260-261, 272, 274-276, $300,310,324,331,337-343,345-346$, $348-356,358,360,362,378,380,411-412$, $416,422-423,428,432,435$

voice leading 433

Vuillermoz, Émile 85

Wagner, Richard 58, 68; Parsifal 55 waiata (Maori song) 342 waka (Japanese poetic genre) 91 Wakasugi Hiroshi 162 Wakatake Gagaku Society Yamaguchi 404 wakauta (Japanese song / poetic genre) 358 wakon kansai (Japanese spirit, Chinese technique) 155

wakon yōsai (Japanese Spirit and Western

Technology) 155

Waldemar Meyer String Quartet 168

Waldmann, Guido; Zur Tonalität des deutschen

Volksliedes 52

Wang Changling 280

Wang Guangqi 186

Wang Hesheng 205

Wang Kang Hou 96

Wang Ming 265, 285; Ballade 286

Wang Ningyi 161

Wang Shifu; The West Chamber (Xi Xiang

Ji) 195-196 
Wang Sue-Ya 265, 285

Wang Tuoh 267

Wang Xieru; Zhui bai qiu (see also Qian Decang) 195, 202

Wang Ying 36

Wang Zhengya 181, 184

Wang Zhenya; Hanzu diaoshi hesheng (Han Chinese Musical Modes and Harmonies) (see also Li Yinghai) 157; Wusheng yinjie ji qi hesheng (The Pentatonic Scale and Its Harmonies) 157

wangka (speech of Australian $\rightarrow$ Nyangumata) 342

Warananingtyas, Palupi 422

Warschauer, Max 176

Watsuji Tetsurō 43

Weaver, William 198, 200

Weber, Carl Maria von 178

Webern, Anton 97, 112, 166, 170, 225, 303, 339; Symphonie op. 21 436; Variations for piano op. 27398,429

Wei Zhongle 186

Weingartner, Felix 104

Wellesz, Egon 162

Welsch, Wolfgang 38-39, 41, 61

Wen Deqing 348

Wen Long-Hsin 265

Wen Yan 181

Wenhua fuxing yundong (Cultural Renewal Movement) 267

wenhua shamo (cultural desert) 265

wenren (Chinese literary aesthetics) 240

West German Radio (Westdeutscher Rundfunk, WDR) 207

Western exceptionalism 136

Western music 25, 49-50, 52, 54, 59, 61, 63, $72,83,86,96-97,101,113,119,122-124$, 135, 137-138, 143, 155-156, 160, 163-164, $185-187,200,208-209,234,236,240,249$, $252,263-264,269-270,340,350,364,376$, $382,384,396$

Westernization 33-35, 78, 80, 101, 156, 206, 220, 231

Westernization and Self-Strengthening Movement $\rightarrow$ Yangwu ziqiang yundong

Willner, Channan 382-383

Winkler, Eugen 173
Wiora, Walter; Die vier Weltalter der Musik 52,

67

Wittenberg, Alfred 54, 173

Wittgenstein, Ludwig 44, 434

Wolf, Christa 300, 351

Wolf, Hugo 177

Wolf, Karl 162

Wolff, Christian 228

Wolfsohn, Alfred 338

Worere (dance song of the $\rightarrow$ Naxi minority in China, see also O ssei sseil) 248

work concept 47, 54-55, 263, 309-310, 312, $320,322,330,339$

work history 47

world exhibitions 64, 290

World Festival of Youth and Students 203 world literature 66, 138

world music 13, 33, 43, 48, 60, 66-67, 71-74, $96,118,134,136$

worldliness 392

wu ai yuan rong (unimpededness and interpenetration) 135

Wu ren yueji (Five Man Music Group) 266

Wu Ting-Lien 265, 282

Wu Wei 147, 152, 241, 243, 399

wu xing (five elements) 27, 278

Wu Yuan-Fang 265

Wu yue huahui (Painters of May) 266

wuchang (Beijing Opera percussion music) 238,270

Xenakis, Iannis 36, 98, 118, 120, 125, 219, 223, 328; Pithoprakta 217

xi ti zhong yong (Western as substance, Chinese as means of use) 155

Xian Xinghai 186; Huanghe dahechang (Yellow River Cantata) 158

Xiandai yuefu (Modern Music Bureau) 266

Xiangrikui yuehui (Sunflower Group) 266

Xiangtu wenxue (Nativist Literature) 266-267, 281

Xianhua (Fresh Flower) (see also Molihua) 194-195, 197-198, 202

xiao (Chinese vertical flute) 156, 179-180, 190-191, 195, 202, 237, 265-266, 277-278, $385,398,418$

Xiao bai cai (Little white cabbage) 237, 385 
Xiao Erhua 265

Xiao Liu; Xiao hui ji 195, 202

Xiao Youmei 156, 179-180, 266

xiaodiao (Chinese folk song type) 196, 237

xiaoluo (small Chinese opera gong) 270

Xin wenhua yundong (New Culture Movement) $\rightarrow$ May Fourth Movement

Xin yue chu zou (Music Premiere) 266

xinchao (new wave) 37, 80, 182, 201, 223, 241, 243, 267, 276, 286

Xing jie 398, 429

$x u-p o-j i$ (three-part form in Chinese $\rightarrow$ daqu) 276

$\mathrm{Xu}$ Fengxia 147, 241

$\mathrm{Xu}$ Shuya; Vacuité/Consistance 241

xu yin (empty sound) 272

Xue Yan 181

xuetangge $\rightarrow$ school songs

xun (Chinese ocarina) 241, 277, 396, 399,

401-402, 417, 431, 435, 437

xungen (root) 80, 248

Yamada Kengyō; Nasuno 261

Yamada Kōsaku 84, 102-103, 166; Kurai to 101; Nagauta Symphony "Tsurukame" 162-163; Ochitaru tennyo 101; Symphony in F major "Peace and War" 101; Yoake - Kuro Fune 158, 163

Yamamoto Naotada 102-103

Yamata Kikou; Sur les lèvres japonaises 89

Yang Chien-Chang 11-12

Yang Liqing 166

Yang Tsung-Hsien 265

Yang Yinliu; Zhongguo gudai yinyue shi gang

(A Draft History of Ancient Chinese

Music) 186; "Guoyue qiantu jiqi yanjiu"

(The Future of National Music and Its

Study) 186

Yang Yong 181

Yang Yushi 181-182

yangbanxi $\rightarrow$ model works

yangqin (Chinese hammered dulcimer-zit-

her) 149, 243, 277, 386, 398

Yangwu ziqiang yundong (Westernization and

Self-Strengthening Movement) 156

Yao (Chinese minority) 159, 200, 202

Yao Ruolong 202
Yasser, Joseph 188

Yayin opera group 267

yayue (Chinese Tang-dynasty ceremonial court music) 276,280

Yeh Jiuan-Reng 399

Yi (Chinese minority) 248

Yi Ji-Young 251

yi zhong bu xi (using the Chinese to comple-

ment the Western) 156

Yijing (Book of Changes) 137, 278, 280

yinxiang yijing (sound content) 278

yinxiang zhongzhishi (sound cadence) 278

Yŏngsan hoesang $(\rightarrow$ Korean court music suite) 408, 412

Yoo Byung-Eun; Shinawi no. 5250

Yoon Jong-Ah 412, 415

Yoruba (West African ethnic group) 377

Yoshi 96

Yoshica 96

Yoshida Hidekazu 120

Yoshikawa Tadayasu; Kaika sakuron 155

Yoshizumi Kosaburo 162

You Chang-Fa 265

Young Women's Christian Association

(YWCA) 176

Young, La Monte 138

Young, Samson 37

YouTube Symphony Orchestra 28

Yu Siu Wah 204

Yuan (Chinese dynasty) 196

yuanzhumin (Taiwanese indigenous peoples) 268

Yuasa Jōji; Toi 340; Utterance 340; Voices

Coming 340

yugen (Japanese aesthetic concept) 261

Yuize Shinichi 120

yūkara ( $\rightarrow$ Ainu epic singing) 358

yun (Chinese aesthetic concept) 272

Yun Isang 35-36, 59, 75, 78, 206-211, 249, 252, 278, 396; Exemplum in memoriam Kwangju 250; Gagok 211, 340; Glissées 211; "Musik und Instrumente des alten Korea" 207208; Memory 340; Naui dang, naui minjokiyo (My country, my people!) 250; Piri 211; Réak 36, 211; Symphony no. 4 "Im Dunkeln singen" 413; Together 408, 412, 429 
yunbai (Beijing Opera vocal delivery techni-

que) $270,349-350$

Yunnan (Chinese province) 307

Yuzuru Ike 102

Zakharoff, Boris 177

Zehme, Albertine 351

Zen Buddhism 102, 107-109, 136-137, 140, 202, 272, 355

Zenck, Martin 76, 114-115, 342, 382

Zender, Hans 41, 74, 137-142, 388, 396; Chief Joseph 139, 206; Fürin no kyō 140-141, 142, 144-145, 213

Zeng (Chinese State) 204, 357

Zhang Guoling 182

Zhang Hao 180-181

Zhang Ninghe 181

Zhang Zhidong 155, 203

Zhdanov, Andrej 65, 116

zheng (Chinese arched zither) 147, 149, 161, 238, 241, 243, 277, 285, 349, 386, 396, 398-402, 418, 429-430, 435, 437

Zheng Yinglie 161

Zhi yue xiao ji (Composers' Forum) 266

zhonghu (Chinese knee fiddle) 398

zhongruan $\rightarrow$ ruan

zhongxue weiti, xixue wei yong (Chinese thinking as substance, Western thinking as means of use) 155, 203

Zhongzhou yun 349

Zhou (Chinese dynasty) 204

Zhou Guangren 170, 179, 181, 184

Zhu Jian 184

Zhu Jian'er; Sinfonietta 165; Symphony no. 1 165; Symphony no. 2 165-166;

Symphony no. 4 165; Symphony no. 6243 , 246-247, 248-249; Symphony no. 10243

Zhuangzi 204, 278; Qi wu lun 205

Zidarić Györek, Petra 143

Zimmermann, Bernd Alois 60, 223, 384, 395;

Die Soldaten 375, 383; Requiem für einen jungen Dichter 134

Žižek, Slavoj 31-32, 41, 43 


\section{Musikwissenschaft}

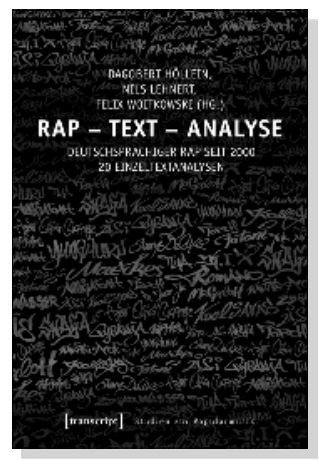

Dagobert Höllein, Nils Lehnert, Felix Woitkowski (Hg.)

Rap - Text - Analyse

Deutschsprachiger Rap seit 2000.

20 Einzeltextanalysen

Februar 2020, 282 S., kart., 24 SW-Abbildungen

$34,99 €(D E), 978-3-8376-4628-3$

E-Book: 34,99 € (DE), ISBN 978-3-8394-4628-7

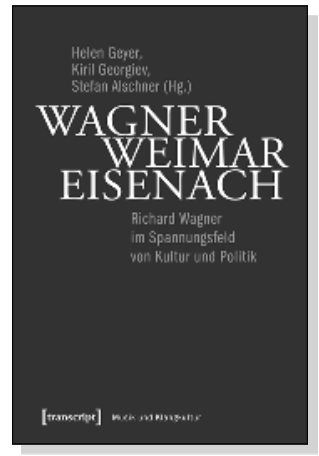

Helen Geyer, Kiril Georgiev, Stefan Alschner (Hg.)

Wagner - Weimar - Eisenach

Richard Wagner im Spannungsfeld von Kultur und Politik

Januar 2020, 220 S., kart.,

6 SW-Abbildungen, 5 Farbabbildungen

$34,99 €(D E), 978-3-8376-4865-2$

E-Book: kostenlos erhältlich als Open-Access-Publikation, ISBN 978-3-8394-4865-6

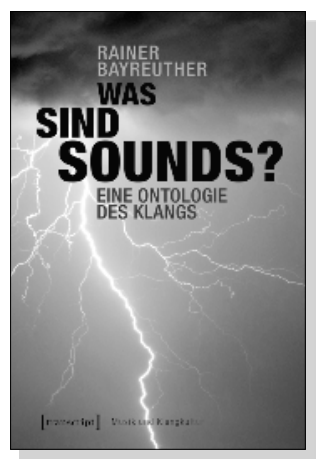

Rainer Bayreuther

Was sind Sounds?

Eine Ontologie des Klangs

2019, 250 S., kart., 5 SW-Abbildungen

$27,99 €(D E), 978-3-8376-4707-5$

E-Book: $24,99 €$ (DE), ISBN 978-3-8394-4707-9 


\section{Musikwissenschaft}

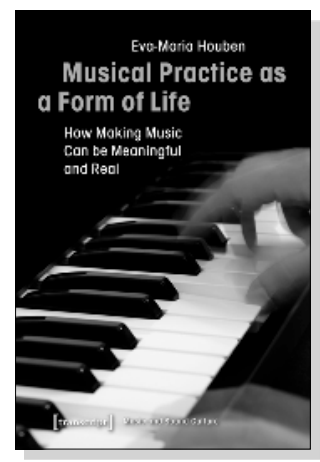

Eva-Maria Houben

Musical Practice as a Form of Life

How Making Music Can be Meaningful and Real

2019, 240 p., pb., ill.

$44,99 €(D E), 978-3-8376-4573-6$

E-Book: 44,99€ (DE), ISBN 978-3-8394-4573-0

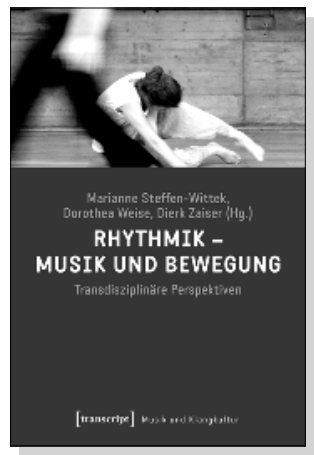

Marianne Steffen-Wittek, Dorothea Weise, Dierk Zaiser (Hg.)

Rhythmik - Musik und Bewegung

Transdisziplinäre Perspektiven

2019, 446 S., kart., 13 Farbabbildungen, 37 SW-Abbildungen 39,99€ (DE), 978-3-8376-4371-8

E-Book: 39,99 € (DE), ISBN 978-3-8394-4371-2

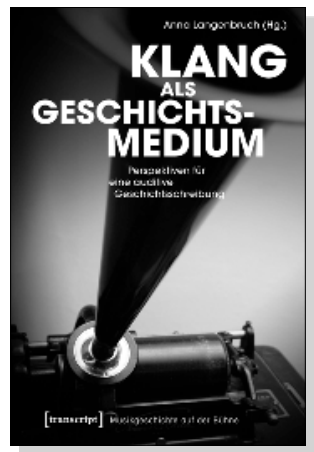

Anna Langenbruch (Hg.)

Klang als Geschichtsmedium

Perspektiven für eine auditive Geschichtsschreibung

2019, 282 S., kart., 19 SW-Abbildungen

$34,99 €(D E), 978-3-8376-4498-2$

E-Book:

PDF: $34,99 €$ (DE), ISBN 978-3-8394-4498-6 
